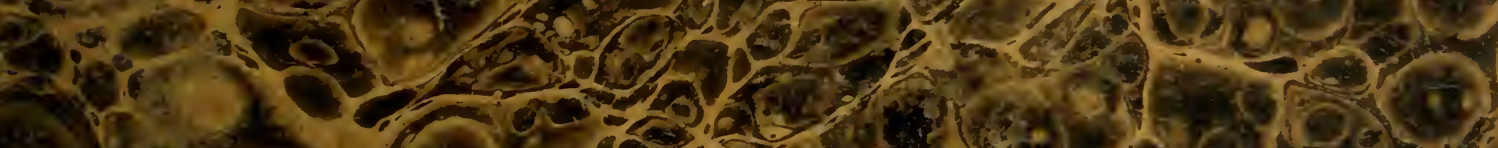

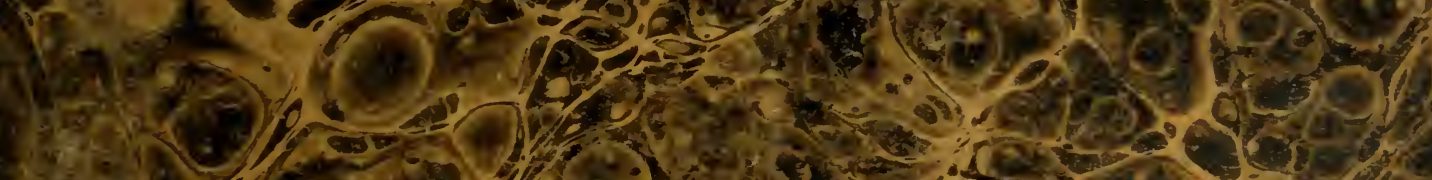
exi?

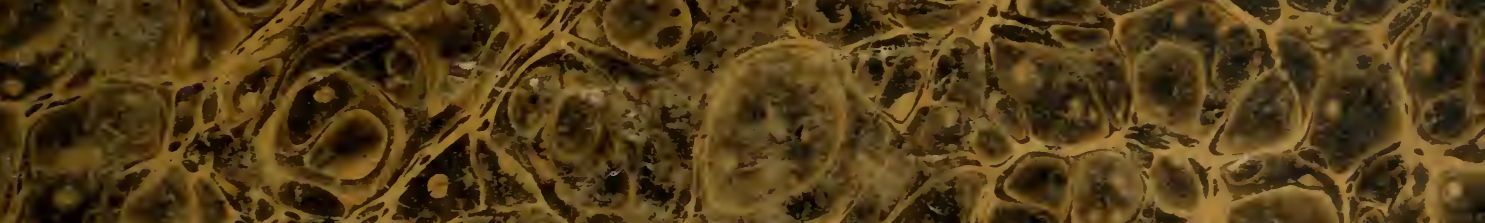

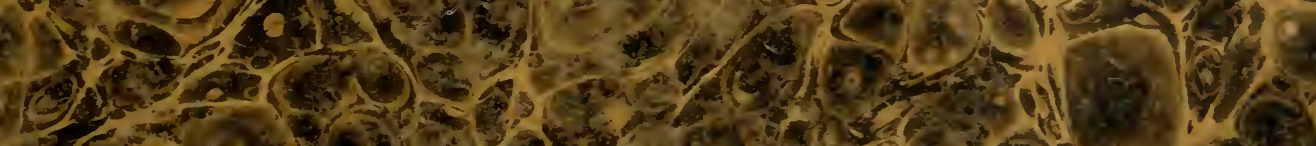

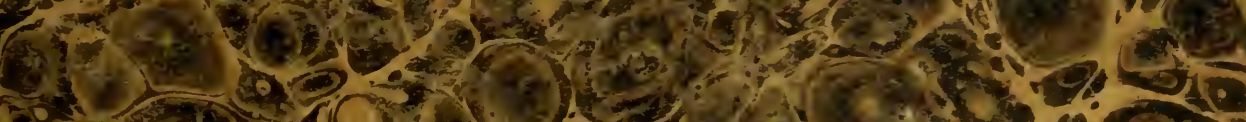

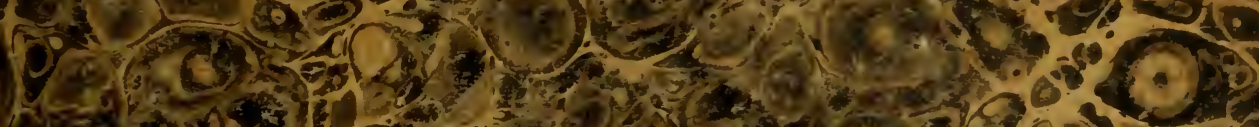

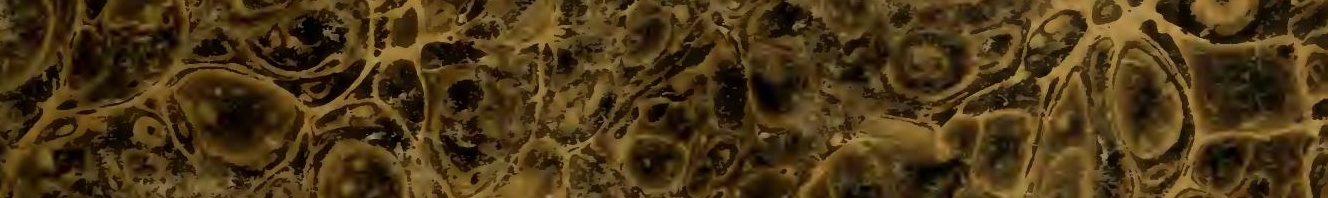
a)

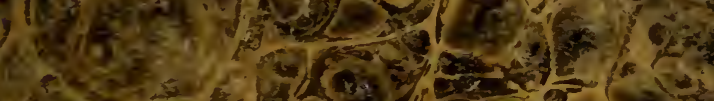

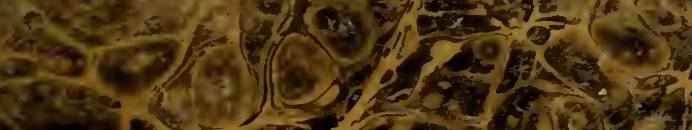

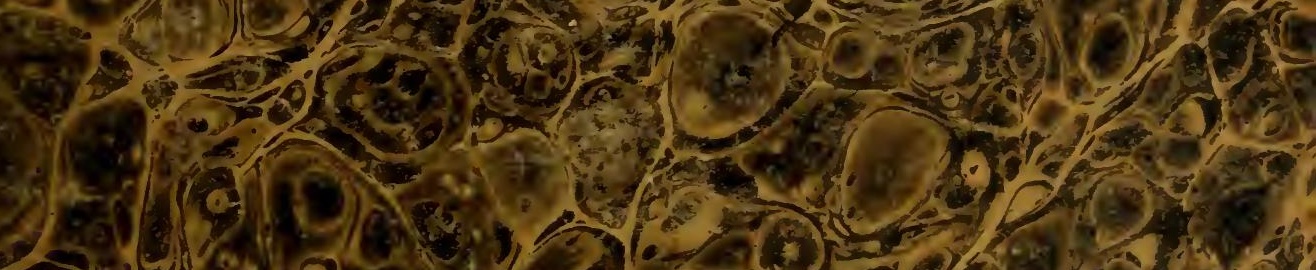

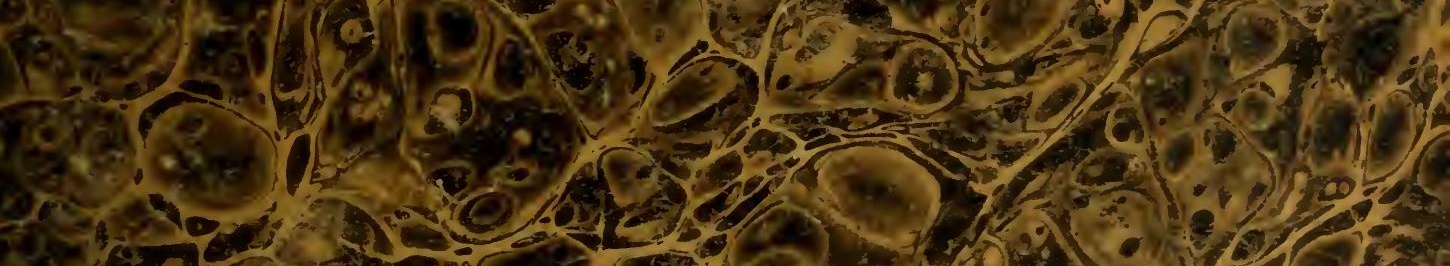

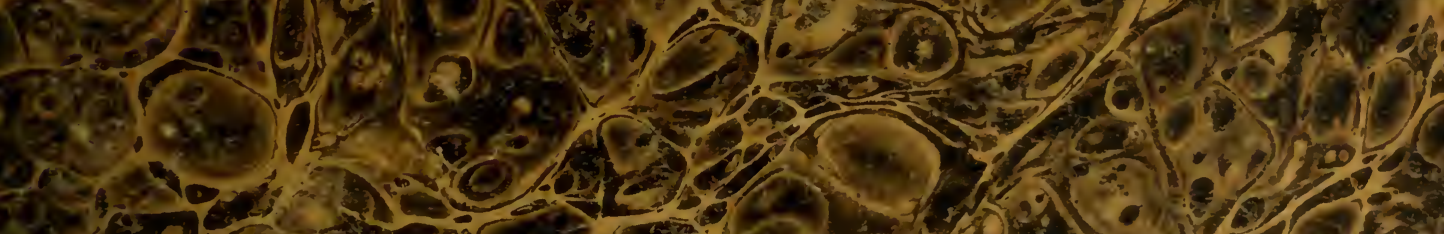

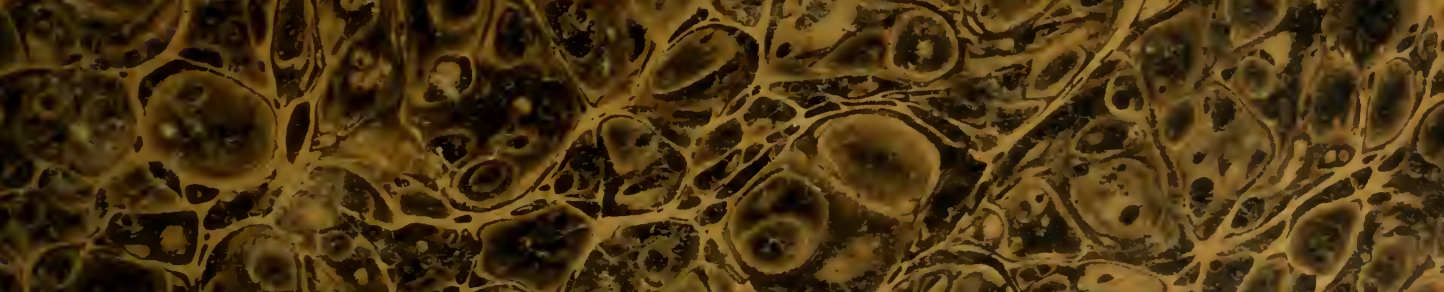

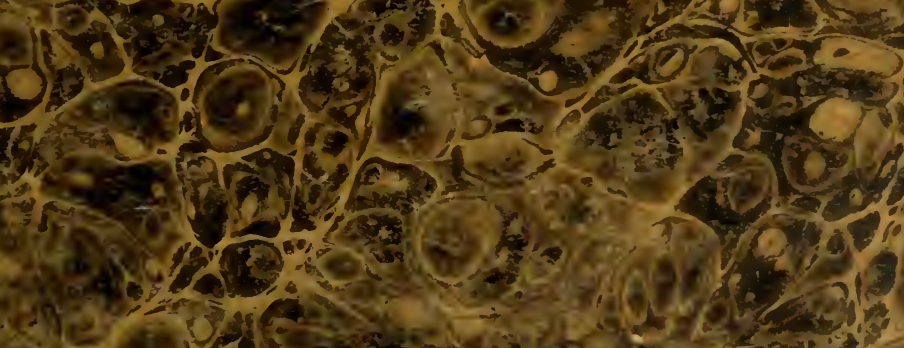

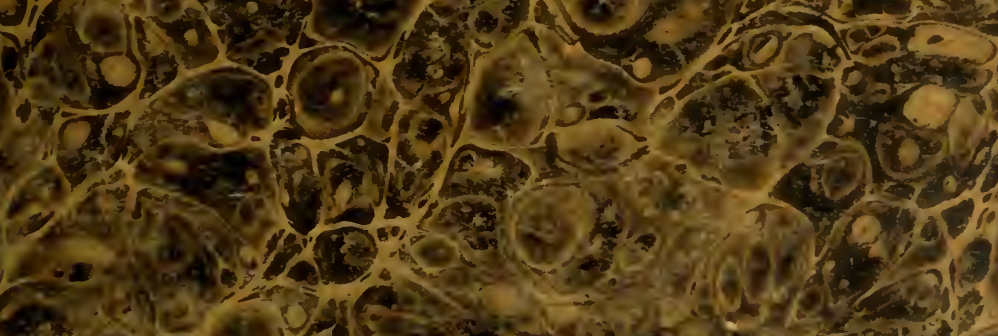

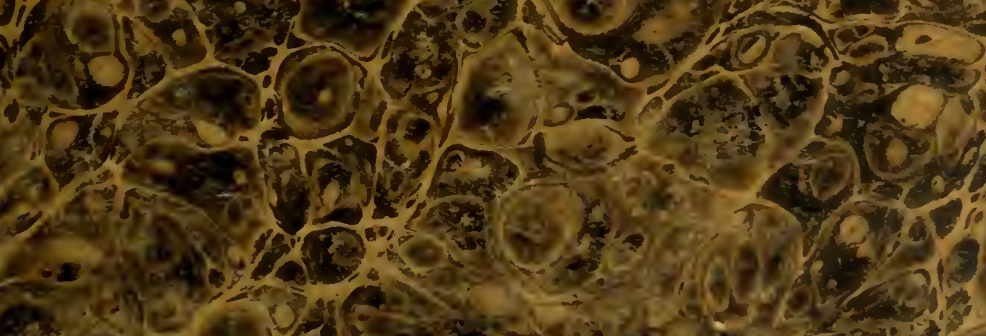

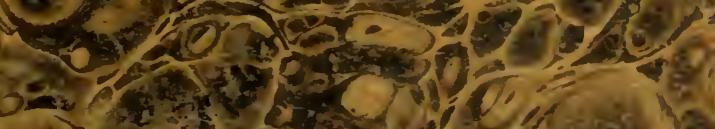

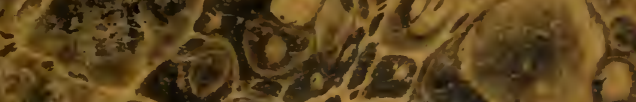

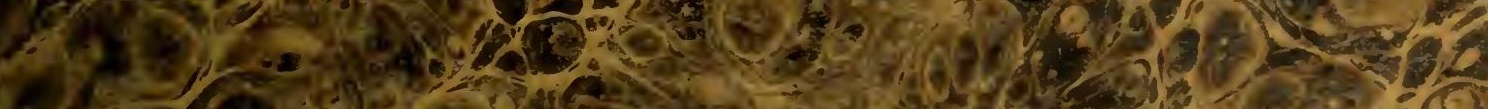

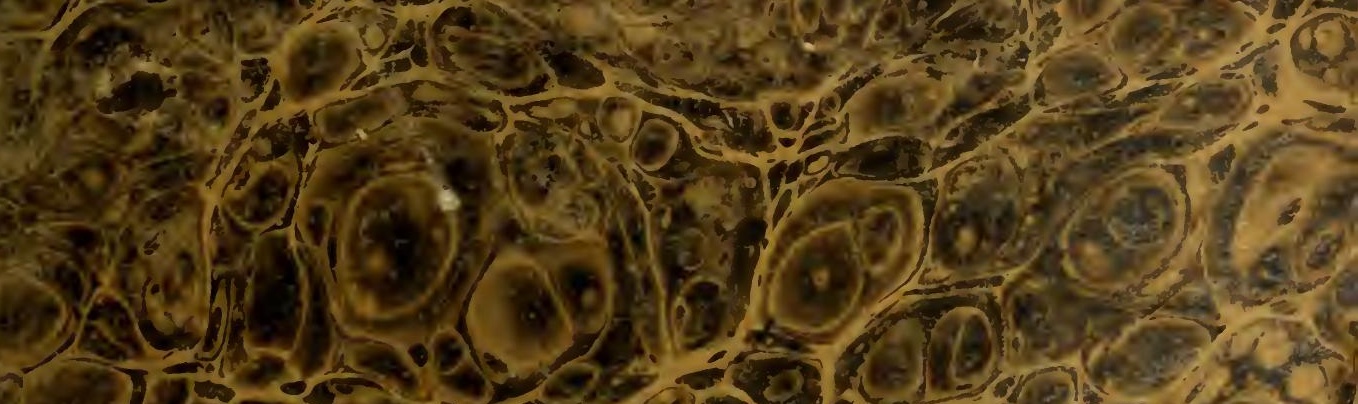

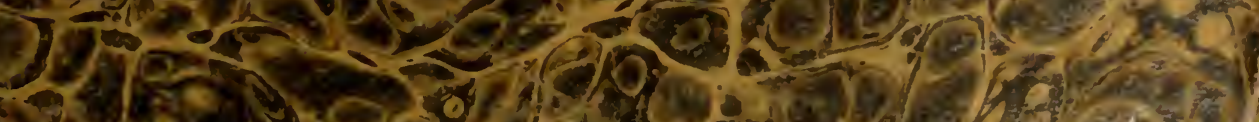

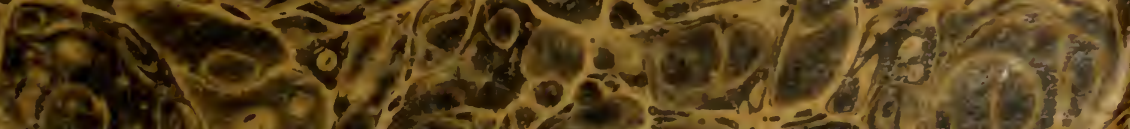




\section{$G j-\mathrm{N}$}

WHITNEY LIBRARY,

HARVARD UNIVERSITY.

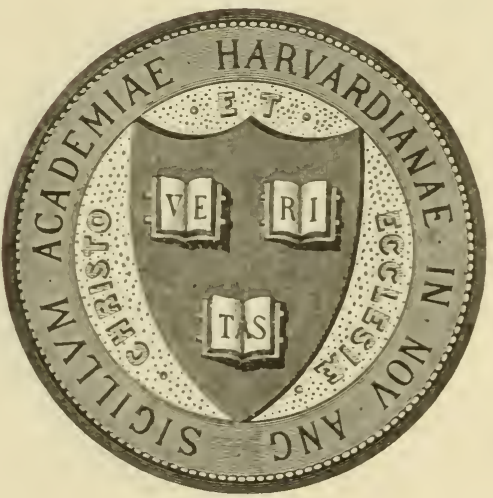

THE GIFT OF

J. I. W H I T N E Y, Sturgis Hooper Professor

IN THE

MUSEUM OF COMPARATIVE ZOÖLOGY 1485

Guly 2.1903. 



\title{
Neues Jahrbuch
}

für

\section{Mineralogie, Geognosie, Geologie}

\author{
und

\section{Petrefaktenkunde,}

\author{
h e ra us g g e b e n
}

von

Dr. K. C. von Leonhard und Dr. H. G. Bronn,

Professoren an der Universität zu Heidelberg.

Jahrgang 1836.

M i t 8 T a f e I $n$.

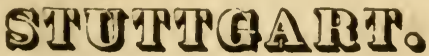

E. Scluweizerbarl's Verlagshandlung.

c 1836 . 
$N \leq v \leq 230.6$

$$
\begin{aligned}
& \text { जानिधाग }
\end{aligned}
$$

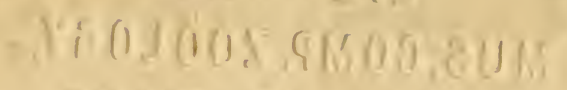

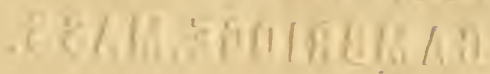




\title{
Einige Bemerkungen
}

zu

Herrn T. E. Gumprecht's Schrift:

\section{Beiträge zur geognostischen Kennt- niss einiger Theile Suchsens und}

\section{Böhmens,}

\author{
von \\ Herrn Professor Karl Naumann.
}

Caedimus, inque vicem praebemus crura sagittis.

Herr Gumprecht hat in dieser Schrift gelegentlich meine, vor mehreren Jahren bei einer flüchtigen Bereisung der Teplitzer Gegend und bei einer Tour längs der GranitGrenze von Oberau bis Hohenstein niedergeschriebenen Bemerkungen einer Kritik unterworfen. Ich selbst habe anf diese Bemerkungen keinesweges den Werth gelegt, welcher ihnen von Andern beigelegt worden zu seyn scheint; es waren Notizen und Gedanken bei der ersten Wahrnehmung der Erscheinungen aufgezeichnet, die mir nur in sofern eine Veröffentlichung zu verdienen schienen, als sie die Aufmerksamkeit späterer Beobachter' auf dieselben Erscheinungen lenken konnten.

Dieses ist auch geschehen, und einige Beobachter hahen jene Erscheinungen in :ihnlicher $W$ eise aufgefasst und eben so ansgelegt, als ich sie damals bei der ersten Ansicht auf- 
fasste und ansznlegen versuchte, während wiederum andere Beobachter sie ander's ansahen und deuteten; wie diess bei so eigenthümlichen und seltsamen Phänomenen zu erwarten war. Dass spätere Beobachter iiberhaupt, und insbesondere solche, denen Zeit und Verhältnisse ein wiederholtes und detaillirtes Studium dieser Erscheinungen gestatteten, den früheren Beobachter in manchen Punkten berichtigen würden, war gleichfalls zu erwarten; wenn auch nicht gerade zu vermuthen stand, dass diese Berichtigung in einer Weise ausgesprochen werden wïrde, die so ziemlich darauf berechnet zu seyn scheint, den ersten Beobachter förmlich in Misskredit zu bringen. *)

Ich will nicht glauben, dass Herr Gumprecut gerade diese Absicht hatte; allein die Worte und Wendunge $n$, deren er sich zum Theil bedient, und die unbedingte Abläuguung fast aller meiner Angaben, weil er einige derselben berichtigen konnte, scheinen wenigstens anzudeuten, dass ihn der kritische Eifer etwas über die, in jeder wissenschaftlichen Controverse zu respectirenden Schranken hinwegreissen mochte.

Herr Gumprecur hat nicht nur Berichtigungen gegeben, wo er sie zu geben berechtigt war; er hat sich auch verleiten lassen, Angaben abzuläugnen, die sich auf unwiderlegte

- Auch mir hat Heri Grinerecht, so höre ich, die Ehre erwiesen, mich hinsichtlich der Phänomene von Zscheila, wie ich solche im Jahrbuch für 1834 S. 127 ff. geschildert, eines Bessern belehren zu wollen. Noch gestattete es meine, viclscitig in An. spruch genommene Zejit nicht, die Gumprechт'sche Schrift zu durchlesen; allein nach dem, was sachkundige Mämner darüber ge. äussert, darf ich mir.wohl erlauben, vorläufig zu bemerken, dass meine und meiner Freunde an Ort und Stelle crlangte Überzen. gungen durch die Grimprecht'sche Kritik nicht in mindesten geschwächt worden sind. Nach mir waren die Herren vos Bren und vox Hunbozox in zscheila. Von solchen Koryphäen würde ich gerne Belehrung angenomnen haben. Wie Herr vox Buch geur. theilt, ist in crwähut’n Bande des Jahrbuches S. 532 zu lesen. - Es gibt mancherlei Mittel, zu einem Namen zu gelangen; aber sicht alle Wege fülnen nach Jerusalem!

LEONHARD. 
Thatsachen beziehen. Ich werde mir daher erlauben, erst zu den Berichtigungen einige Erläuterungen zu geben, und dann mehrere Thatsachen aufzuzählen, welche ich Herrn Gumprecht bei einem nochmals wiederholten Besuche der fiaglichen Gegenden aufzusuchen bitte, um sich von ihrem wirklichen Vorhandenseyn zu überzeugen, und daraus die gute Lehre zu abstrahiren, dass man die Geissel der Kritik nicht schwingen darf, ohne die Wage der Gerechtigkeit im Auge zu behalten.

Allerdings geht besonders ein Fehler durch meine friiheren Beobachtungen hindurch; der Fehler nämlich, dass ich nach einer. Seite freie, aber sonst eingeschlossene Partie'n für ursprünglich rings u m eingeschlossene Partie'n des Pläners hielt, und sonach Infiltrate für Fragmente, rückstïindige Gesteinsrippen für ursprüngliche Gesteinsadern ansprach. Dieser Fehler ist es, welcher sich in meine Beobachtungen bei Zschcila, eben so wie in jene bei Teplitz eindrängte. Obwohl nun die Veranlassung zum Irrthume hier sehr nahe liegen muss, weil $\mathrm{n}$ a ch mir, der ich zufälliger Weise zuerst auf diese Er'scheinungen aufmerksan machte, gar manche achtungswerthe Männer dieselben Erscheinungen in "̈hnlicher Weise gesehen und gedentet haben, so will ich doch, da Hr. Gumprecht daran ein psychologisches Räthsel (wenigstens in mir) gefunden zu haben scheint, zur Lösung desselben die Erklärung abgeben, wie mir danals die sehr ähnlichen Erscheinungen*) vori (Tufle und Gjällebïck noch in so frischem Andenken vorsch webten, während mir die ÜberlagerungsVerhältnisse bei Weinböhla und Hohenstein so unberingt für die spätere Emportreibung der dortigen Granite und Syenite

*) Dass sie aber ganz anderartig sind, davou habe ich mich, was $Z$ scheila betrifft, bei einem. im verflossenen Frühjahre vorgenommenen Besuche überzeugt, noch ehe ich die Gumprecur'sche Schrift kannte. Durch die mehrmals stattgefundenen Sprengarbeiten waren diessmal die Verhältnisse so evident blossgelegt, dass man sie unmöglich verkennen kohnte. Ganz anders verhielt sich diess bei neiner ersten Anvesenheit. 
im flüssigen Zustande zu sprechen schienen, dass ich die Pläner-Partie'n für Einschlüsse und die Granit - oder respective Porphyr-Partie'n für Eindringlinge nehmen zu müssen glaubte, um so mehr, weil die Formen und Konturen sowohl jener als dieser so sondexbar und auffallend waren, dass ich die ersteren eben so wenig für ausgefüllte Klufträume, als die letzteren für rückständige Rippen oder Schalen halten konnte.

Bei Besprechung der Teplitzer Verhältnisse hebt es Herr Gumprecht besonders hervor, dass ich für das sonderbare Conglutinat von Pläner und Porphyr bei Schönau den Vergleich mit einer $\mathbf{S}$ chlack e $\mathbf{k} \mathbf{r}$ u s te gebraucht habe, und er bemüht sich, das Publikum glauben zu machen, ich habe dieses Conglutinat für wirkliche Schlacke erklärt. Wer meine Bemerkungen unbefangen durchliest, sieht sogleich, dass dieser Ausdruck offenbar im tropische n $S$ in ne gebraucht wurde, un das bunte Gewirr und DurcheinanderVorkommen der beiderseitigen Massen dem Leser zu versinnlichen. Ich sagte ja nur: ,dass ich die Schale mit nichts besser zu vergleichen wisse, als mit einer Schlackenkruste, und dass ihr Gestein ein sehr buntscheckiges, Schlacken-artiges Anseh en habe."

Man muss sich aber um so mehr wundern, wie Herr Gumprecht an diesem Vergleiche so grossen Anstoss nehmen konnte, da er selbst S. 95 die „Ähnlichkeit mit poröser Schlacke" zugibt. Wenn er aber ebendaselbst in der Anmerkung 2) diesen, hier nur in tropischem Sinne zu nehmenden Ausdruck mit dem von mir späterhin sensu proprio gebrauchten Ausdrucke einer Schlacken-artigen (d. h. feurigen) Flüssigkeit des Porphyr's absichtlich in Verbindung bringt, wenn er zugleich da, wo ich nur vermuthungswe is e sage, dass, ,des Porphyrs Flüssigkeit eine Schlakken-artige gewesen seyn k o n nte, " den Sinn meiner Worte willkührlich erweiternd, mich, ,ausdrüeklich von einer Schlacken-artigen $\mathbf{N}$ atur" des Porphyrs sprechen lässt, da sieht man, wie wenig ängstlich Herr GuMprecht in der 
Wahl seiner Mittel ist, wo es ihm darauf ankommt, seine Kritik zu motiviren.

Überhaupt ist mein ganzer damaliger Erklärungsversuch der Teplitzer Verhältnișe in so hypothetischer Weise ausgesprochen worden, dass ich wahrscheinlich Herrn GumPRECHT's ausführliche Widerlegung vorzüglich dem Umstande zu danken habe, dass nach mir auch Andere die dortigen Erscheinungen in derselben Weise auffassen und deuten konnten, woraus wenigstens zu folgen scheint, dass bei der ersten Ansicht eine Täuschung über die wahre Natur dieser Erscheinungen nicht so gar unbegreiflich seyn müsse.

So weit über Herm Gumpreche's Berichtigungen.

Was nun aber die ohne allen Grund von ihm abgeläugneten oder verdächtigten Angaben betrifft, so glaube ich besonders folgende ausheben zu müssen. S. 44, Anmerkung 1, wo der von mir beobachteten Aufrichtung der Plänerschichten bei Niederwarta erwähnt wird, sagt Herr Gumprecht :

„Das Vorkommen ist aber höchst unbedeutend und das 200 Schritt davon hochaufsteigende Niveau des granitischen Elb-Randes . . . . beweist, dass hier eine ähnliche Influenzirung auf den Absatz des Pläner's wie bei Jüdendorf und Hundorf stattgefunden haben mag. Von einer auffallenden Zertrümmerung der Schichten, die Naumans erwähnt, ist gar nichts zu sehen; der Pläner ist nur zerklüftet."

lch weiss zuvörder'st nicht, warum dieses Vorkommen unbedeutend genanut wird. *) Etwa um meine erste Beobachtung desselben bedeutungslos erscheinen zu lassen! Ich habe mir nie etwas darauf eingebildet, wemu mir der Zufall die Priorität einer Beobachtung gönnte. Oder liat der Verfasser die Erscheinung nur so weit verfolgt, dass

*) Die Aufrichtung der Plänerschichten bis zu $45^{\circ}$, verbunden mit vielfältiger Zerklüftung, ist auch in der von Weisstropp lierabkommenden Schlucht unmittelbar vor dem Granit zu beobachten; auch fiuden sich deutliche Spuren einer gleichen Aufrichtung in der zwischen Niederuarta und Costebaude liegenden Schlucht. 
ihm die Anfrichtung der Schichten noch unbedeutend vorkommen konnte, wie ich fast daraus schliessen möchte, dass er den granitischen Abhang noch 200 Schritte davon entfernt angibt und von einer Zertrümmerung des Schichtenbaues auch gar nichts wissen will.

Ich ersuche Herrn Gumprecht, sich noch einmal an Ort und Stelle zu verfügen und sich zu überzeugen, dass die Schichten, welche allerdings $\mathrm{da}$, wo dêr Feldweg in das Thal hineinbiegt, nur $30^{\circ}$ einfallen, unterhalb der Brücke an Wasser $55^{\circ}$, und weiter oben, ganz nahe vor dem granitischen Abhange, 70 bis $90^{\circ}$ vom Granite wegfallen, sich hierauf überstürzen, und zuletzt $75^{0}$ dem Granite zufallen. Dieser ganze Wechsel der Schichtenstellung von $30^{\circ}$ nordöstlicher bis $75^{\circ}$ südwestlicher Neigung ist in nerhal b 100 Schritt zu verfolgen. Wenn dergleichen Erscheinungen nicht als Zerrüttungen und auffallende Zertrümmerungen des ursprünglichen Schichtenbaues bezeichnet werden dürfen, so weiss ich nicht, was solchen Namen noch verdient. Aber die Schichten sind auch im Detail sehr zerklüftet und zerrüttet. *)

S. 134 heisst es in der Anmerkung, wo von dem Sandsteine ain Hutenberge die Rede ist: "Der Sandstein in den Brüchen ist sehr eisenschüssig, im Übrigen aber der gewöhnliche. Wenigstens fand ich nicht die mindeste Spur einer Härtung oder einer sonstigen pyrischen Einwirkung vor, wie dergleichen Herr Professor Naumann angibt."

Der Verfasser citirt hiebei Poggendorff's Annalen XIX, S. 439; weil aber dort mit keiner Sylbe einer Härtung des Sandsteins gedacht wird, so mag ihm irgend eine andere Reminiscenz vorgeschwebt haben, und man sieht wenigstens hieraus, wie leicht sich Herr Gumprecut seiner Urtheile entschüttet. Wahrscheinlich hat er die in v. Leonhard's Basaltgebilden II, S. 453 auf meine Autorität mitgetheilten

3) Und früher sah man, was gegenwärtig. durch herabgerollten Schutt verdeckt ist, jenseits der $75^{\circ}$ südwestlich einfallenden Schichten grosse Pläner-Fragmente in verschiedeneu Lagen. 
Angaben von einer harten und dichten Beschaffenheit des Quadersandsteins unmittelbar an der Granitgränze bei Dobra und am Hutenberge im Sinne. Dass er nun diese meine Angabe, so weit sie den Hutenberg betrifft, in die dasigen $\mathbf{S}$ teinbr ü ch e verlegt, die freilich noch weit vom Granite liegen, dafür mag er mich nicht verantwortlich machen; denn von dort habe ich sie nirgends und niemals behauptet. Wohl aber ist mir diese härtere und kompaktere Beschaffenheit des Sandsteines aufgefallen an dem in einem Fahrwege auf der Höhe des Hutenberges anstehenden Sandsteine, an dem Sandsteine am Kulminationspunkte der Strasse zwischen Lohmen und Dobra und an dem Sandstein bei Hohenstein, da wo der Fusssteig vom Falarwege in das Polenzthal abgeht. Alle diese Punkte liegen aber nur einige Schritte vom Granite entfernt.

S. 151 und 152, wo über den Verlauf der Grenze von Hohenstein nach dem Polenzthale gesprochen wird, heisst es: „Geht man den Abhang in das Polenzthal hinab, so findet sich von da an, wo der nähere Fusssteig den Fahrweg verlässt, eine Schlucht, die, auf der Scheide selbst eingeschnitten, in gerader und steiler Linie nach dem Grunde hinabführt. - - Auf der rechten Seite der Schlucht für den Hinabgehenden sieht man nur Gra nit, links nur Sandstein, beide oft nur wenige Fuss von einander abstehend. Diese Angaben, die ich vérbürge, zeigen, wie wenig genau des Herrn P's. NauMANN Bestimmungen sind, wenn derselbe ausdrücklich einer Auflagerung des Granites in - einem grossen Massstabe auf dem Sandsteine von dem Polenzthale bis nach der Stadt hinauf erwähnt. Von einer solchen ist keine Spur vorhanden; vielmehr ergibt eine genaue Beobachtung, dass der Granit und Sandstein an dieser Stelle gegen einander senkwechte Grenzen bilden.6

Nun wahrlich, Herr GuMrRecur publizirt hier sein Verdammungsurtheil in einem so zuverlässigen Tone, dass 
man glauben möchte, er habe vor Fassung des Urtheils sowohl den Statum causae, als auch seine richterliche Kompetenz auf das Sorgfültigste geprüft. Aber dennoch muss ich sein Urtheil für höchst ungerecht, seine Ansicht für ganz falsch erklären.

Die beiden Grenzpunkte in Hohenstein und im Anfange des Kohlicht liegen schon anf der Höhe; und anf der Höhe läuft die Grenze zunächst von Hohenstein südöstlich nach dem Kalkofen, vom Kohlicht westlich nach der Zeschniger Ziegelscheune. Trägst man nun diese Grenzlinien zugleich mit den Grenzpunkten am rechten und linken Gehänge und in der Tiefe des Polenzthales in eine gute Charte ein, so stellt sich ganz unzweifelhaft das Resultat heraus, dass der Sandstein im Polenzthale mit einem fast spitzen Winkel bedeutend weit in das Gebiet des Granites hineinreicht; zugleich fallen seine, ausserdem horizontalen, Schichten an der Spitze dieses Vorsprunges bis $20^{\circ}$ dem Granitgebiete entgegen. Dieses Resultat ist so in die Augen springend, dass sich mir sofort die Überzeugung aufdrängte, hier müsse die Überlagerung auf mehrere hundert Schritt weit Statt finden, obgleich natiirlich der innerhalb des eigentlichen Thalraumes überlagernde Granit in Fólge der Thalbildung verschwunden ist. ${ }^{*}$ )

Jeder Unbefangene, der mit den einfachen geometrischen Regeln, nach welchen Auflagerungs - Verhältnisse zu beurtheilen sind, bekannt ist, wird diese Überzeugung mit mir theilen.

Herr Gumprecht aber glaubt meine Angabe durch folgenden Syllogismus zu widerlegen: die am linken Gehänge herabkommende Grenzschrunde läuft in gerader und ganz steiler Linie herunter; folglich muss die Grenzfläche senk-

*) Eine Linie von der Zeschniger Ziegelscheune nach dem Kalkofen dürfte den Verlauf der Granitgränze vor der Bildung des PulevisThales bezeichnen. Auf der trefflichen Militärcharte von Sachsen gemessen, beträgt die Weite, um welche der Sandstein in das Granitgebiet hineiuspringt, über 1000 Fuss. 
recht seyn. Wir wollen diesen Syllogismus. etwas näher prüfen. Da nicht anzunehmen ist, Herr Gumprecht habe sich eingebildet, in der (uns wohlbekannten) Grenzschrunde senkrech therabgestiegen zu seyn, so müssen wir zu seinem Enthymem als proposilio major den Satz suppliren: wo das Streichen der flachen Grenzlinie (an Thalgehänge) mit dem Streichen der horizontalen Grenzlinie (auf der Höhe) zusammenfällt, da ist die Gränzfläche vertikal. Herr Gumy'RECHT führt nun offenbar die Assumtion ein, dass die erwähnte Grenzschrunde in das dortige Hauptstreichen der Granitgrenze falle. Dieses ist aber durchaus nicht der Fall, :) daher die minor seines Syllogismus völlig unrichtig, und der ganze Schluss ein Fehlschluss. Mit dem atqui fällt auch das ergo, und der gegen mich geführte Streich war ein Hieb in die Luft.

S. 156. Indem hier der Verfasser vom Sandsteine bei Dillersbach spricht, sagt er:

„Ein Einfallen der Schichten in den Dittersbacher Sandsteinbrüchen auf der Kuppe der Schünhühe, wie ein solches vom Herrn Professor Naumann angegeben wird, und zwar gegen den Granit, habe ich nicht bemerkt, vielmehr ganz deutliche horizontale Schichtung."

Meine Worte sind aber folgende:

,In den Dittersbacher Sandsteinbrüichen fällt der Sandstein etwa $15^{\circ}$; der Berg selbst bildet einen der höchsten Punkte und fällt nach dem in der Tiefe liegenden Granit hin ziemlich steil ab: an seincm Fusse sieht man denselben Sandstein nahe vor dem Granite unter $30^{0}$ einschiessen."

*) Vielmehr weicht sie von der Strcichungslinie der Granitgrenze auf der Höhe des Pulenz-Thales, von der Kirche nach dem Kalkbruche, um $30^{\circ} \mathrm{ab}$, wie schon aus der ODELEBes'schen Charte zu ersehen ist, die ja Hrn. Gumprecht bekannt war; auf derselben Cliarte konnte er sich überzeugen, dass die am rechten Gehänge ausstreichende Grenzlinie wenigstens um $45^{\circ}$ vorspringt; die Spitze liegt etwa bei der Brücke über der Polenz. 
Der Verfasser erlaubt sich also, tneine Angaben in zwei Punkten ganz nach seinem Belieben zu interpretiren:

1) Verlegt er meine Angabe in den Sandsteinbruch auf der K uppe der Schönhöhe*) und

2) behauptet er, ich spreche von einem Einfallen g ege n den Granit.

Indem ich mich gegen dergleichen willkürliche Auslegungen meiner Angaben verwahre, bemerke ich, dass die unter 12 bis $15^{\circ}$ einfallenden Schichten in einem Steinbruche an demjenigen Abhange der Schönhö̈he zu beobachten sind, welcher dem nach Eschdorf aufsteigenden Thale zugewendet ist. Die unter $30^{\circ}$ einfallenden Schichten aber trifft man in einem alten Steinbruche, unten am linken Gehänge dieses Thales, so wie in einer kleinen, am Wasser entblösten Felswand, nicht weit vor dem Granite. ${ }^{* *}$ ) An allen diesen Punkten jedoch fällt der Sandstein vom Granite weg.

Dass Hr. Gumprecht bei seinen wiederholten und gründlichen Untersuchungen diese Punkte nicht bemerkte, welche mich ein günstiger Zufall bei der ersten flüchtigen Tour auffinden liess, ist freilich nicht meine Schuld.

Wenn wir Herrn Gumprecut, welchem Zeit and Verhältnisse ein wiederholtes und sehr genaues Studium der von ihm besuchten Gegenden gestatteten, einerseits für die Berichtigung der geschehenen Missgriffe zum Dank verpflichtet sind, so müssen wir ihn andererseits freundlichst erinnern, bei künftigen kritischen Versuchen etwas vorsichtiger zu Werke zu gehen. Übrigens will ich recht gerne glanben, dass wie Herr Gumprecht's Kritik überhaupt nur aus

-) Selbst in dem ganz oben auf der Kuppe liegenden alten Steinbruche ist noch ein Fallen von $5-8^{\circ} \mathrm{zu}$ beobachten.

**) An diesen letzteren Punkte ist der Sandstein sogar 45 bis $50^{\circ}$ aufgerichtet, sehr eisenschüssig und mit spiegelblanken Friktionsflächen versehen; die Richtung der Friktionsstriemen weicht etwas von der Fallinie der Schichten ab. Dr. Cotra, dem beide Punkte bekannt sind, bestätigte diese Beobachtungen. 


\section{$-13-$}

einer Liebe zur Wissenschaft und Wahrheit hervorging, 60 auch die dabei unterlaufenen Irregularitäten im Eifer für die gute Sache entschlüpft sind. Denn darin stimmen wir wohl beide überein, dass das Bewusstseyn, etwas Besseres sagen zu können, als unsre Vorgänger, uns niemals verleiten dürfe, die etwaigen Missgriffe deiselben mit Schroffheit hervorzuheben, oder wohl gar durch entstellende Combinationen und verfälschende Interpretationen zu steigern. 


\section{A ufforderung}

an das

\section{geognostische Publikum,}

\section{die Erforschung der Alters-Beziehungen} zwischen Granit und Kreide in Sachsen

betreffend,

VOD

Herrn Dr. B. CotTa.

I.

Sendschreiben an Hrn. Oberbergrath Nögerata in Bonn.

Seit einigen Jahren hatte ich Gelegenheit, die merkwürdigen Grenzverhältnisse zwischen dem Granit und der Kreide-Formation in Sachsen immer näher kennen zu lernen, die sich aber, wie Sie aus der Beilage ersehen werden, bei genauerer Bekanntschaft nur immer verwickelter zeigten. Auf zwei kleinen Reisen, die ich diesen Sommer zuerst mit Herrn Professor Gustav Rose, und dann mit Hrn. Alexander von Humboldt nach der Gegend von Hohnstein zu machen die Freude hatte, kam desshalb der Plan zur Reife, den ich Ihnen hiebei vorlege, mit der Bitte, ihn 


\section{$-15-$}

bei den diessjährigen Versammlungen der Naturforscher in Bonn vorzutragen.

Es ist zwar neu, dass man die Geognosten zu einem gemeinsamen Unternehmen dieser Art auffordert, scheint mir jedoch nicht unpassend, und vielleicht auf mehrere Fälle von besonderer Wichtigkeit anwendbar. Denn Thatsachen zu sammeln und verworrene Verhältnisse der Beobachtung so viel als möglich zugänglich zu machen, muss noch immer ein Hauptbestreben in der Geognosie seyn.

Ich habe der Aufforderung zum gemeinsamen Wirken eine kurze Darstellung der gegenwärtigen Lage der Sache vorausgeschickt, damit einem Jeden die Phänomene selbst, so wie dio bisherigen Deutungen ins Gedächtniss zurückgerufen werden; dabei konnte es aber natürlich weder der Zweck seyn, die Erscheinungen genau zu schildern, noch auch die Erklärungen kritisch zu prüfen: Beides soll ja durch diese Aufforderung erst vorbereitet werden.

Die Ausführung der vorgeschlagenen Untersuchangsarbeiten kann, wenn keine besondere Hindernissen in den Weg treten, vielleicht im Lanfe des nächsten Sommers beendiget werden; wor diese Arbeiten während des Betriebes besuehen will, ist freundlichst dazu eingeladen.

Sie sehen aus den Unterschriften, dass mehrere ausgezeichnete Geognosten sich für Ausführung dieser Untersuchungen besonders interessiren, auch von Ihnen wage ich diess zu hoffen. Es könnte Ihnen aber vielleicht auffallen, nur e in en Freiberger Namen darunter zu finden: diess rührt jedoch keineswegs von einem Mangel an Interesse an dieser Sache her, sondern beruht lediglich auf dem Umstande, dass unser hochverehrter Herr Oberberg-Hauptmann Freiherr von Herder, wie Ihnen bekannt seyn wird, auf einer Reise in Serbien begriffen ist, um den Bergbau des Fürsten $M_{1-}$ Loscu zu organisiren. Man hat mir Hoffunng gemacht, dass unsre Regierung, die durch Besorgung der petrographischen Karten von Sachsen ohnediess verhältnissmässig mehr für die Ausbildung der Geognosie thut, als jeder andere Staat, das 


\section{$-16$}

Unternehmen wesentlich unterstützen werde; und es steht tiberhaupt nach der Rückkehr des Herrn vos Herder, der sich wie Herr Bergrath Freiesleben für alle wissenschaftliche Unternehmungen so thätig interessirt, von Freiberg aus eine sehr erfolgreiche Theilnahme zu erwarten.

Ausser der Subscriptionsliste, welche ich Sie ersuche in Bonn vorzulegen, werden Unterschriften und Beiträge von dem Mineralien-Comptoir in Heidelberg, sowie von mir in Tharand angenommen.

Tharand, am 8. Sept. 1835.

Bernhard Cotta, Dr. ph.

II.

Nach8chriff von NögGEнатн.

Das vorstehende Schreiben und die nachfolgende Aufforderung meines werthen Freundes, des Herrn Dr. BersHARD CotTa in Tharand, wurde von mir in einer. Sitzung der mineralogisch-geognostischen Sektion der Naturforscher-Versamnlung vom Jahr 1835 hier in Bonn verlesen. Es war voraussichtlich, dass der Plan, durch welchen eine so bedeutende geognostische Frage zur völligen anschaulichen Lösung gebracht werden soll, bei den zahlreich anwesenden Geognosten, worunter viele in der Wissenschaft hochgeachtete Namen des In - und Auslandes sich befanden, lebendigen Beifall erhalten musste, und in der That war dieses auch der Fall, wie die am Schlusse mit abgedruckten Subscriptionen beweisen. Noch grössere Verbreitung und noch grössere Aufnahme verdient und erfordert aber die lobenswerthe Absicht des Herrn Dr. СоттA. Er hat daher auch gerne in meinen Vorschlag eingewilligt, unsern gemeinschaftlichen hochverehrten Freund, den G. R. von Leonhard, wie hiermit geschieht, zu bitten, den sämmtlichen Verhandlungen durch das allgemein verbreitete Jahrbuch eine noch grössere Publizität in der geognostischen Weit verleihen zu wollen. 
Möchten also die Freunde unserer Wissenschaft, denen der Plan hierdurch erst bekannt wird, sich noch mit zahlreichen Subscriptionen anschliessen, und so es möglich machen, dass die Unternehmung in einer Weise durchgeführt werden könne, welche ihrer wissenschaftlichen Bedeutung entspricht. Von dem regen Eifer des Herrn Dr. Corta darf es mit Recht erwartet werden, dass die Ausführung der Schurfarbeiten unter seiner Umsichts - und Kenntnissvollen Leitung so bewirlkt werde, um ein erschöpfendes Resultat nach Möglichkeit zu erzielen.

Bonn, im November 1835.

NögGerath.

\section{III.}

Aufforderung zur Entscheidung der Frage, ob der Granit des rechten Elbufers in Sachsen jünger oder älter sey, als die Kreide.

Die Grénze der Kreideformation gegen den Granit zwischen Meissen und Zittau in Sachsen ist seit mehreren Jahren der Gegenstand vielseitiger geognostischer Untersuchungen und Spekulationen gewesen, und hat mit Recht ein sehr allgemeines Interresse erregt. Es ist unverkennbar: die Meinungen, welche man darüber aussprach, wurden nicht allein durch die lokalen Umstände, welche eben vorlagen, sondern auch durch die Verschiedenheit der Ansichten über Entstehung der Gebirge und Gebirgsarten überhaupt bedingt.

Nachdem Herr Professor Weiss auf die wichtigen Verhältnisse bei Weinböhla und Hohnstein zuerst öffentlich aufmerksam gemacht hatte, folgten ihm nach einander die Herren: Graf Münster, Klipstein, Naumaxn, Elle de Beaumont, Kühn, vox Lennhard und Leopold von Buch in der Untersuchung und Prüfung dieser Phänomene, und noch neuerlichst lieferte Herr Gumprecht eine sehr ausführliche Arbeit über diesen Gegenstand. Viele Andere sahen und urtheilten, ohne ihre Meinungen darüber dem grösseren Publikum vorzulegen. 
Über die Hauptthatsachen wurde man bald einig; nur Herr Gumprecht erhob mancherlei $Z_{w e i f e l}$ über einzelne Erscheinungen, die früher von ausgezeichneten Beobachter'n (von Buch, von Leonhard, Naumann u. s.w.) ziemlich übereinstimmend gesehen worden waren.

Der Granit liegt an dieser ganzen Grenze in der Regel -, der Syenit an einer Stelle schräg über den Gliedern der Kreideformation; zwischen beiden findet man zuweilen kalkige, mergelige und sandigeSchichten mit Versteinerungen der Juraformation. Ob man den Granit und Syenit für älter oder jünger als Pläner und Quader-Sandstein halten sollte war die wichtigste Frage, welche sich hier erhob. Auf welche Weise er im ersteren, und in welchem Zustande er im letzteren Falle über die Kreide zu liegen gekommen, und wie die Jurakalk-Zwischenlagerung zu erklären sey§ das waren die speciellen Probleme.

Werss hielt dafuir, Granit und Syenit seyen als feste Gesteine zugleich mit den Hohnsteiner Kalkschichten durch plutonische Kräfte über die Glieder der Kreideformation hinweggeschoben worden. (Karstens Arehiv f. Bergb. XVI, S. 3 und Karsten's Archiv f. Min. I, S. 155). Graf MúnSTER erkannte die Hohnsteiner Zwisehenlagerung zuerst als zur Juraformation gehörig (Kefersteivs Geogn. Deutschl. VII, H. 1, S. 2), wo ihr Leopord von Buch eine bestimmtere Stellung anwies, indem er sie mit dem $\mathbf{O}$ x ford, clay und Coral rag parallelisirt. (Jahrb. f. Mineralogie u.s.w. 1S34, S. 532).

Kuipstein neigte sich zu der Idee, der Granit sey ältes und der Quadersandstein untergelagert, eine Idee, welche wohl ursprünglich von Freiberg ansging und besonder's durch Küun sehr scharfsinnig entwickelt worden ist (Handbuch der Geognosie \$. 461). Dabei sah man sich jedoch genöthigt, mit Iintenansetzung des Werthes der Versteinerungen jene Hohnsteiner Schichten für Plïner zu halten. Naumans sprach sich zuerst dahin aus, der Granit und Syenit müssten 


\section{$-19-$}

in heissflüssigem Zustande nach der Kreideablagerung emporgequollen seyn (Poggendorf's Annalen XIX). ELIE de Braumont, der die Verhältnisse jedoch nicht aus eigener Anschauung kannte, hielt den Granit und Syenit des linken Elbufers für älter, den des recliten hingegen für jünger als die Kreide, weil allerdings viele Umstände beweisen, dass der Syenit des Plauischen Grundes vor der Grünsandablagerung vorhanden war. (Annal. des sc. nat. 1829). Herr GuMprecht bildete dieselbe Haupt-Idee auf eine andere Weise aus, indem er die Grenzen dieser Altersverschiedenheit modificirte*), Granit, Syenit und Porphyr unbedingt zu einer den Sandstein gleichzeitigen Formation rechnete (S. 27 und 183), und diese Gesteine - im Fall sie plutonischen Ursprunges seyen - aus Öffnungen emporquellen liess, welche von der jetzigen Kreidegrenze - einem ehemaligen steilen Abhange - ziemlich er:tfernt lagen (S. 169). Bei einer solchen ruhigen Ausfüllung eines vorhandenen Raumes konnte or natürlich die Hohnsteiner Zwischenlagerungen ebenfalls nicht als gehobenen Jurakalk anerkennen; er hält ihn vielmehr für Pläner (S. 143).

Der meisten Theilnahme hatte sich nun zwar bisher die von Leonirad ausgesprochene Ansicht zu erfreuen, nach welcher der Granit die Kreideformation ain rechten Elbufer durchbrochen und überlagert, und vorhandene ältere Gesteine - den Syenit bei Weinböhla und den Jurakalk bei Hohnstein - darüber geschoben hat ${ }^{* * *}$ ); demungeachtet ist diese Ansicht keineswegs als vollikommen begründet anzusehen: sie bedarf vielmehr einer sorgfältigen Prüfung, zumal

*) Bciträge zur geogn. Kenntniss einiger Theile Sachsens und Böhmens. Berlin 1835. S. 182.

Jalırb. für Mineralogio u. s. w. 1834, Heft II. - Dass der Syenit älter sey als die Kreideformation, ergab sich aus mehreren Verhältnissen mit Bestimmtheit, besonders auf der linken Elbseite; cben so sicher ist es aber auch, dass der meiste Granit des rechten Elbufers jünger ist als der Syenit, den er an virlen Orten, besonders deutlich am Bocksberg bei Meissen - gangförmig durchsetzt; noch jünger sind die dasigen Porphyre. 


\section{... $20-$}

da wiederholte Untersuchungen *) zu den alten Bedenklichkeiten, welche dagegen sprachen, noch einige neue gehäuft haben.

Die Hauptmomente, welche bei Vielen die Überzeugung hervorbrachten, dass der Granit die Kreideformation durchbrochen habe, sind folgende:

Der Überhang, welchen der Granit fast überall an der Grenze über den Quader-Sandstein bildet, beträgt bei Holnstein, wie sich im Thaleinschnitt der Polenz zu erkennen gibt, bei einer Höhe von mehr als 600 Fuss, gewiss über 1000 Euss. Bei Hinterhermsdorf, Saupsdorf und Hohnstein ist er durch vielartige Grubenbaue und Versuchsarbeiten auf eine Tiefe von 30 bis 100 Fuss genau ermittelt und bei 20 bis So Grad Neigung häufig von einer Art befunden worden, dass man nicht füglich glauben kann, vorhandene Granitfelsen hätten solche bedeutende Überhänge gebildet, um von erst später darunter gelagerten Gebirgsarten unterstützt zu werden.

Auch bei Oberau unweit Meissen sieht man den Granit 30 Schritt weit unter einem Winkel von 20 bis $30^{\circ}$ deutlich auf den Pläner auflagern, und sehr bekannt ist das ahnliche Verhalten des von Graniten durchsetzten Syenits, welches durch die Weinböhlaer Kalkbrüche zu Tage gelegt worden ist.

Die Juraglieder $\left.{ }^{*}\right)$, welche bei Hohnstein, Saupsdorf, Hinterhermsdorf und Daubitz unter dem Granit, aber a uf dem Quader-Sandstein liegen, sprechen sehr unzweideutig für eine Umkehrung der ursprünglichen Lagerungsverhältnisse; denn an was Anderes als an eine solche Umwälzung

*) Untersuchungen der Herren Gustav Rose, Ferdinand Reich, von Warnsdorf und Bernhard Cotta im J. 1835 und Herrn GumPRECrT's in den Jahren 1833 und 1834.

**) Dass es bei Hohnstein solche sird, kann von keinem Geognosten bezweifelt werden, der den Werth der Versteinerungen nur irgend anerkennt. An den übrigen Orten ergibt es sicls durch Analogie. 


\section{$-21-$}

soll man da glauben, wo man eine ganze Reihenfolge von Gebirgsarten in verkehrter Ordnung vorfindet?

Manche andere Umstände, so die unzähligen, oft glatt polirten Reibungsflächen, welche den Quadersandstein in der Nähe der Granitgrenze auszeichnen, seine dichtere, kieseligere (vielleicht durch Hitze hervorgebrachte) Beschaffenheit daselbst:), so wie der Mangel an Granitfragmenten in demselben treten jenen, bei weitem gewichtigeren Gründen noch zur Seite. Auch das jedenfalls jüngere Alter dieses Granites im Vergleich zum hiesigen Syenit, die aufgerichtete Schichtenstellung des Pläners und Quader-Sandsteins an den Gebirgsscheiden bei Oberau, am Heller (bei Dresden) und bei Dittersbach unweit Lohmen kommen hinzu, um die Wahrscheinlichkeit dieser Hypothese zu vermehren.

Diese Verhältnisse mussten, so lange man gewisse entgegengesetzte Thatsachen nicht gehörig kannte, zu der Überzeugung führen, dass der Granit jünger sey als Jurakalk und Kreide, und dass er bei Hohnstein, Saupsdorf, Hinterhermsdorf und Daubits den ersteren über den Quader-Sandstein herausgeschoben habe. Sorgfältigere Prüfungen machten diese Annahme jedoch wieder bedenklich, und noch jetzt karn man die Sache nicht als entschieden erachten.

Es sey nun hier erlaubt, auch auf diejenigen Punkto aufmerksam zu machen, welche sich gegen das jüngere Alter des Granites, im Vergleich zur Kreideformation, erheben.

1) Man ist nicht gewohnt, die jüngsten Flötzgebirge von Granit durchbrochen zu sehen.

2) Die Schichtung des Quader - Sandsteins in der sogenannten Süchsischen Schweitz ist bis nahe an den Granit heran fast überall ungestört und ziemlich söhlig. Diese ganze Sandstein-Ablagerung erscheint als eine ungeheure

*) Sie wurde, wie die Reibungsflächen, vou Vielen, uur vois Herru GuJPRECHT nicht beobachtet. 
fast horizontal liegende Platte, in welche unzählige Thäler und Schluchten tief eingefurcht sind.

3) Man hat noch an keinem Punkte eine scharfe Grenze zwischen den Gebirgsschichten mit Juraversteinerungen und dem Quader - Sandsteine aufgefunden; mineralogisch s ch e i$\mathrm{n}$ en dieselben vielmehr in einander überzugehen, nach einigen Angaben sogar zu wechsellagern. Sie unterscheiden sich im Allgemeinen von den Kreidegliedern durch die Hohnsteiner Ver'steinerungen, sowie durch stets aufgerichtete Schichtenstellung.

4) Bei Weissig und Zscheila (unweit Dresden und Meissen) und bei Hinterhermsdorf liegen einzelne Parzellen des Quadersandsteins und Pläners mit ziemlich horizontaler Schichtung auf Granit. Ähnlich sieht man den Pläner bei Nieder-Fehre ungestört auf Syenitfelsen ruhen, die von jüngeren Granitgängen und von noch jüngeren Porphyrgängen durchsetzt sind.

5) Nirgends findet man im Sandstein oder Pläner gangartige Verzweigungen oder vereinzelte, ihn durchsetzende Kuppen des Granits (im Syenit sind beide Erscheinungen sehr häufig). Eben so wenig bemerkt man irgendwo mit Bestimmtheit Bruchstücke jener Gesteine in der Granitmasse. (Über Zscheila vergl. 7).

6) Ein ähnlicher Granit, wie er am rechten Elbufer den Quader-Sandstein überlagert, findet sich auf der linken Elbseite wieder, ohne hier gleiche auffallende Kontalkt - Erscheinungen hervorzurufen, da bei Dohna der Pläner vielmehr ungestört, wenn auch nur in geringer Ausdehnung, darauf liegt und nach Herrn von Weissenbach's Beobachtungen sogar Granitfragmente enthält. Ein Zusammenhang der Granite beider Elbufer lässt sich zwar nicht unmittelbar nachweisen, ist aber dureh das Hervorstehen des Granits unter dem Sandstein im Elbthale bei Tetschen hinreichend angedeutet.

7) Gang-artige Verzweigungen, welche, wie es neuerlich sichtbar wurde, die vermeintlichen Plänerbruchstücke 


\section{$-23-$}

im Granit bei Zscheila unter einander verbinden, machen es nebst andern Umständen wahrscheinlich, dass dieselben keine eingebacknen Stücke, sondern Ausfüllungen von unregelmässigen Spalten oder Löchern sind. Ob nun zwar zu gleicher Zeit der Zscheilaer Granit sich petrographisch mehr zur Syenit - als zur jüngeren Granit-Formation gehörig ergab, so wurde doch durch jene Beobachtungen eines der wichtigen Momente, welche man früher zum Beweis der Erhebung des Granites nach der Kreide anführte, vernichtet oder wenigstens schwankend gemacht.

Dafür, dass es Ausfüllungen im Granit vorhanden gewesener Räume seyen, spricht allerdings auch die ungewöhnliche Häufigkeit von Versteinerungen (von denen man glauben kann, dass sie entweder darin gelebt haben, oder hineingespühlt wurden), so wie das Vorkommen von Granitfragmenten in denselben. Eine ungewöhnliche Festigkeit und krystallinische Natur des Gesteins dieser Einschlüsse hingegen, so wie die innige Verwachsung mit dem Granit, leiten mehr zu der Idee von Bruchstücken. Auch fragt man sich, warum wurden diese Räume nicht schon von dem früher abgelagerten Quader - Sandstein erfüllt ؟

Dieser, wie alle die vorigen Punkte, enthalten jedoch nur indirekte Gegenbeweise; sie gründen sich auf den Mangel gewisser Erscheinnngen, die man zu erwarten sich berechtigt glaubt. Schwieriger zu beseitigen und weit bedenklicher für die Haltbarkeit der Hypothese ist der Unstand, dass man:

S) in dem, wahrscheinlich der Juraformation zugehörigen Konglomerat-artigen Sandsteine des Forstgrabens bei Hohnstein, der mit geneigter Schichtung zwischen Granit und Sandstein ruht, kleine Granitfragmente gefunden hat*), die dem Gesteine nach von demselben Granit herzurühren scheinen, der zunächst darüber liegt. Hierlurch wird der ganze Fall erst recht ins Unbegreifliche gezogen;

") G. Rode und B. Сотта zu Pfingsten 1835. 
denn wie man auf der einen Seite sich unwiderstehlich genöthigt sieht, den Granit für jünger zu halten, so kann man doch auf der andern Seite nicht begreifen, wie Bruchstücke dieses Granites in den darunter liegenden Sandstein gekommen sej̧n können, wenn jener wirklich jünger ist als dieser. Die Fragen: gehören diese Granitstücke vielleicht doch einer andern, älteren Formation an § oder ist jener Konglomerat-artige Sandstein, der sie enthält, ein Produlkt der Reibung und erst durch die Emporhebung gebildet@ scheinen hier die einzigen, obwohl sehr gesuchten Auswege zu enthalten; denn der von Weiss vorgeschlagenen Annahme einer trocknen Hebung des bereits fertigen und festen Granites, 'welche sich mit diesem Phänomen wohl vereinigen liesse, stellen sich, - so sinnreich und genügend sie auch Anfangs erschien - manche andere gewichtige Umstände in den Weg, welche hier einzeln aufzuzählen der Zweck dieser Zeilen nicht gestattet, die überhaupt eine genauere Prüfung der Phänomene und Hypothesen nur vorbereiten, nicht liefern sollen.

Wo die Natur so viele scheinbare Widersprüche gehäuft hat, die den gewöhnlichen Deutungen widerstreben, da verdient sie gewiss mit vereinten Kräften erforscht zu werden. Der vorliegende Fall aber ist einer gründlichen Untersuchung um so mehr werth, da er nicht nur über sehr bedeutende geologische Fragen zu entscheiden geeignet ist, sondern auch in einer der schönsten und besuchtesten Gegenden Deutschlands sich findet, wo jährlich zahlreiche Naturforscher beobachten und urtheilen, unzählige Naturfreunde und Anfänger Belehrung schöpfen liönnen. In der Sächsischen Schweitz, in einer Gegend, die noch jüngst durch voN Odelebens vortreffliche Karte*) um so lehrreicher und zugänglicher geworden ist, als sie nun bei den verwickeltsten Terrain-Verhältnissen dennoch die genaueste Orientirung gestattet.

\footnotetext{
") Topographische Karte der Gegend von Hohnstein und Schandau.
} 


\section{$-25-$}

Ob Granit noch nach der Kreide-Ablagerung emporgelioben worden sey

In welchem Zustande und mit welchen Kraftäusserungen er im gegenwärtigen Falle hervortrat?

Wie er auf die vorhandenen Gesteine einwirkte@ Oder im anderen Falle:

Welches mächtige Ereigniss diese totale Umkehrung der gewohnten Lagerungsverhältnisse bedingen lionnte?

Diese und viele andere gewichtige Fragen sind es, die durch genauere Untersuchung hier zur Entscheidung kommen können, während sie jetzt nur durch individuelle Beurtheilung gewisser problematischer Verhältnisse fast von jedem Beobachter auf andere Weise beantwortet worden sind.

Das von tiefen Schluchten zerrissene Terrain ist gerade in der Gegend von Hohnstein sehr geeignet, genaue Untersuchungen zu gestatten und in sehr verschiedenen $\mathrm{Hö}_{0}$ hen, nahe beisammen gelegene Punkte darzubieten. Nur an einigen leicht herzustellenden Entblössungen und an ein paar tiefer gehenden Bohrversuchen oder Grubenbauen fehlt es noch, um diese wichtigen Grenzverhältnisse Jedem klar vor Augen zu legen. Diese, jedem Forscher wünschenswertho Offenlegung der vorhandenen Thatsachen ist der Hauptzweck gegenwärtiger Zeilen.

Die Sächsische Regierung hat auf Bevorwortung des Oberbergamtes, welche durch Hrn. B.C. R. KüHN veranlasst wurde, mit wahrhaft gemeinnützigem und wissenschaftlichem Sinne schon viel gethan, um durch Untersuchung dieser Grenze bestimmte Resultate herbei zu führen. Da man aber hierbei, als bei einem Unternehmen des Staates, das Interessante stets mit dem Nützlichen zu verbinden suchen musste, so konnte man nur an der Oberfläche bleiben und war auf diejenigen Lokalitäten beschränkt, wo auf fiskalischem Grund und Boden eine Zwischenlagerung von Kalkstein gehofft werden konnte. Die Resultate dieser jedenfalls dankenswerthen Untersuchungen, welche zum Theil in Küus's Handbuch der Geognosie mitgetheilt wurden, sind. 
daher zwar von hohem Interesse, aber in Beziehung auf den vorliegenden wissenschaftlichen $Z_{\text {weck }}$ doch keineswegs erschöpfend.

Es ergeht desshalb an alle Geognosten Deutschlands, so wie an alle Freunde der Geologie die Aufforderung, durch gemeinschaftliche Beiträge eine mässige Geldsumme zusammen zu bringen, mittelst welcher die Grenz - Verhältnisse des Granites zur Kreideformation in Sachsen bis zur Evidenz aufgeschlossen werden können. Einige hundert Thaler würden dazu hinreichen. Diese zusammen zu bringen, dürfte bei allgemeiner Theilnahme den Einzelnen nicht schwer fallen. Nachstehend folgt hier der Plan zur Ausführung.

\section{A. A r t d er B e it räg e.}

Es erscheint am zweckmässigsten, zu Erreichung des

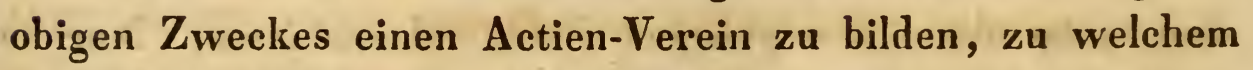
sämntliche Geognosten und Freunde der Naturkunde hierdurch eingeladen sind. Jede Actie ist mit einem Thaler zu bezahlen und wird ausser dem Verdienst ein wichtiges Phänomen allen nachfolgenden Beobachtern offen zu Tage gelegt und somit etwas Wesentliches zur Entscheidung einer wissenschaftlichen Streitfrage beigetragen zu haben, mit je einem Exemplar der auf Kosten der Actiengesellschaft zu druckenden Resultate der Untersuchung vergütet werden.

B. Untersuchungsarbeiten.

1) Im Polenz-Thale bei Hohnstein ist genau zu ermitteln, und vielleicht durch Bohr - Versuche zu bestätigen, um wie viel der Granit über den Sandstein überhängt.

2) An der Strasse von Rathewalde nach Hohnstein, am rechten Gehänge des Polenz-Thales, ist die Grenze zwischen Granit und Sandstein durch Abräumung an zwei Punkten vollständig zu entblösen, so dass man über das Einschiessen derselben so wie über etwaige Kontakt-Erscheinungen sichere Beobachtungen anstellen könne. 


\section{$-27-$}

3) An einem noch aufzusuchenden passenden Orte ist das Grenzverhältniss und besonders das Verhalten der Juraschichten gegen den Quader-Sandstein durch einen Stollen oder durch ein Fallort genau zu ermitteln.

Alle diese Punkte sind in einen Zustand zu bringen, dass sie von Reisenden leicht aufgefunden und beobachtet werden können.

\section{B erichterstat $t$ ung.}

Über die Art der Ausführung, wie über die unmittelbaren Resultate dieser Untersuchungen ist ein gedruckter Bericht zu erstatten und mit genauen Zeichnungen zu versehen, von welchem Berichte, wie erwähnt, alle Theilnehmer für jede Actie ein Exemplar erhalten. Ein gedrucktes Verzeichniss der Theilnehmer so wie eine genaue Berechnung des verwendeten Geldes ist beizufügen. .

$$
\text { D. Kostenanse h } 1 \text { a g. }
$$

Die unter B. genannten Untersuchungsarbeiten dürften ung e fähr zu veranschlagen seyn:

$$
\begin{aligned}
& \text { Nr. } 1 \text { zu } 50 \text { bis } 150 \text { Rthlr. } \\
& \text { Nr. } 2 \text { zu } 20 \text { bis } 30 \text { - } \\
& \text { Nr. } 3 \text { zu } 100 \text { bis } 140 \text { - }
\end{aligned}
$$

Die Besorgung des Druckes und der Abbildungen

$$
\text { zu } 70 \text { bis So Rthlr. }
$$

\section{Summa: 240 bis 400 Rthlr.}

Sollte, wie sehr zu hoffen ist, eine noch grössere Summe zusammengebracht werden, so lassen sich alle obengenannte Untersuchungsarbeiten weiter ausdehnen und neue können dazu kommen.

B. C. 
Unterzeichnete sind bereit, im Falle das Unternehmen hinlängliche Theilnahme findet, für Ausführung der besprochenen Arbeiten Sorge zu tragen.

\author{
Alexander von Humboldt. \\ Chr. Samuel Weiss. \\ K. Cäsar von Leonitard. \\ Carl Naumanis. \\ Gustav Rose. \\ JACOB Nöggerath.
}

In Auftrag unterschrieben von

Bernhard Cotta.

\title{
IV.
}

Subscribenten-Verzeichniss.

Herr Alexander von Huarboldt

Zahl der

Actien.

- Graf Kaspar Sterkiberg

- Professor Werss in Berlin

- Prof. Reich in Freiberg.

- Wolfgang v. Herder in Freiberg. . . . . 3

- Oberforstrath Coтta in Tharand . . . . . 5

- Oberberghauptmann Freih. v. HERDER in Freiberg . 10

- Bergrath Freiesleben in Freiberg. • . . . 3

- Berg - Kommissionsrath KüHN in Freiberg . . . 3

- Dr. R. Blum in Heidelberg • • . . . . 2

- Geheimerath v. LeoNhard daselbst . . . . . 5

- Prof. Bronn daselbst . . . . . . . 2

(Bei der Zusammikunft in Bonn subscribirten:).

Herr Leopold v. Buch • • . . . • . . 10

- Berghauptmann Graf Beust in Bonn . . . . 5

- Berginspector Gubner in Mechernich . . . . 1

- Berghauptmann v. Charpentier in Dortmund . . 5

- General v. Pfure in Cöln . . . . . . 3

- Bergrath Selco in Saarbrücken . . . . . 1

- Oberbergrath v. Oeynhausen in Bonn . . . . 1

- Prof. Charlés Lyele in London . . . . . 5

- Gumprecht in Berlin . . . . . . . 1

- Oberbergrath FuldA in Bonn . . . . . . 1

- Dr. Roberton in Paris (20 Fr.) . . . . . 5

- L. HORNer in Edinburg . . . . . . . 5 
Zahl der
Actien.

Herr Prof. W. Buckland in Oxford (20 Fr.) . • , . 5

- Elif de Beaumont, Ing. en chef des mines (20 Fr.) . 5

- Oralius D'Hallax in Halloy (20 Fr.) . . . . 5

- Prof. Walchiner in Carlsruh . . . . . 3

- Präsident Hönsighaus in Crefeld . . . . . 5

- Prof. Sidvey Smith in London . . . . . 3

- Amtsassessor Röner in Hildesheim . . . .

- Oberbergrath Nöggeratr in Bonn . . . . . 1

$\frac{153}{153}$

307

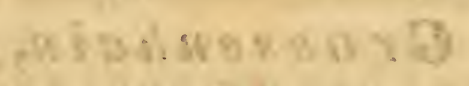

31: 15

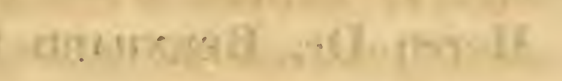

-

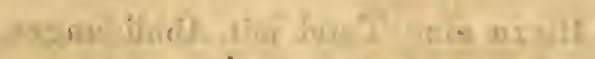

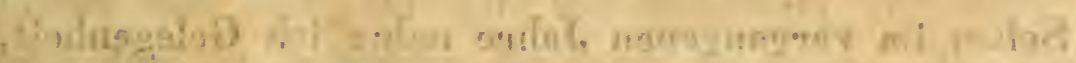

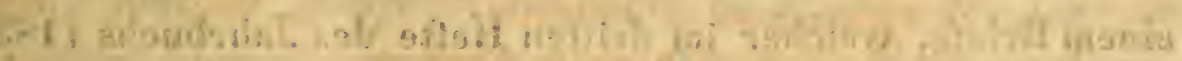

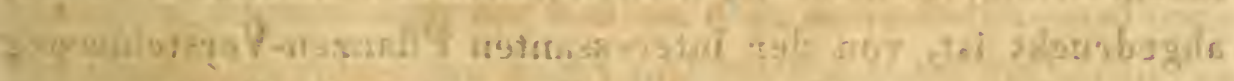

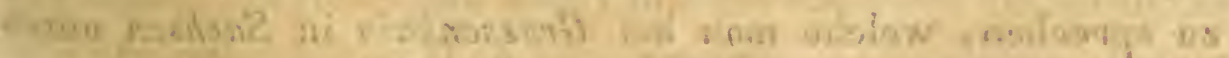

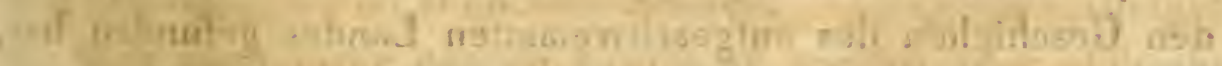

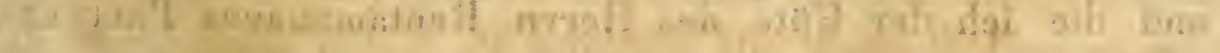

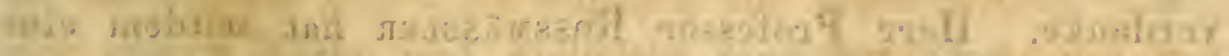

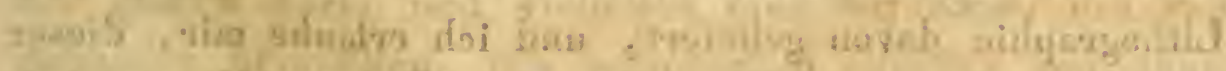

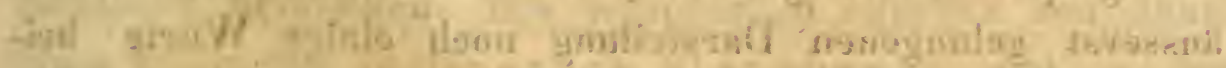

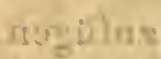

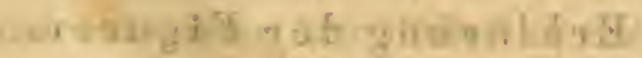

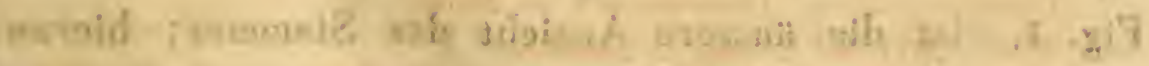




\section{$\ddot{U}$ b e $r$ \\ Lepidodendron punctatum von}

\section{Grossenhain,}

von

Herrn Dr. Bernhard Cotta.

Hiezu eine Tafel mit Abbildungen.

Schon im vergangenen Jahre nahm ich Gelegenheit, in einem Briefe, welcher im dritten Hefte des Jahrbuchs (1834) abgedruckt ist, von der interessanten Pflanzen-Versteinerurg zu sprechen, welche man bei Grossenhain in Sachsen unter den Geschieben des aufgeschwemmten Landes gefunden hat, und die ich der Güte des Herrn Rentamtmanns Preusker verdanke. Herr Professor Rossmässler hat seitdem eine Lithographie davon geliefert, und ich erlaube mir, dieser äusserst gelungenen Darstellung noch einige Worte beizufügen.

$$
\text { Erklärung der Figuren. }
$$

Fig. 1. ist die äussere Ansicht des Stammes; hierzu gehören :

Fig. 3. eine vergrösserte Wedel-Narbe mit den für L. pun cta t u m charakteristischen Abzeichnungen, und 
Fig. 5. ein einzelnes, noch mehr vergrössertes, vollständiger als gewöhnlich erhaltenes Grübchen, deren $6-7$ unterhalb jeder Narbe stehen.

Fig. 2. ist die Ansicht der unteren angeschliffenen Querschnittfläche, welche der Einförmigkeit wegen nur an einer Stelle ausgeführt worden ist. Hiervon gibt

Fig. 4. einen vergrösserten Theil (Gefässbündel), wie deren mit unbewaffnetem Auge einige 70 als kleine doppelto Kreise auf der Schnittläche gesehen werden. Die Steinmasse in den $Z$ wischenräumen dieser Gefäss: bündel zeigt die Struktur eines gleichförmigen, markigen Zellgewebes (Parenchym's).

Vergleichung derinnerenundäusserenStraktur.

Die Umwandlung des Ganzen ist inf Chalzedon-artigen Hornstein erfolgt. Innere und äussere Struktur sind deutlich erhalten und zeigen eine grosse Übereinstimmung der einzelnen Theile. Die bandartigen Streifen, welche auf dem Querschnitte gegen die zunächstliegenden und einige entferntere Wedel-Narben ausgebuchtet sind, bestehen aus Gefässen und sind, wie alle Gefässbündel, von einer dichteren, dunl:ler gefärbten Basthaut umgeben. Sie sind es, die an der Aussenfläche der Narben (Fg. 3) in Hufeisen-förmiger Gestalt hervortreten, and von hier aus wohl friher in den nun davon abgelösten Wedel fortsetzten. Vorher aber scheinen sie sich nach ihrer ganzen Breite zu spalten oder vielmehr zu verdoppeln, indem sie zugleich eine äussere Umgrenzung der ganzen Narbe und vielleicht eine Art Rinde des Wedelstieles herstellten. Sio entsprechen offenbar den ähnlichen Bildungen in $C_{y}$ athea Sternbergii und in dem von MEYen aus Amerika mitgehrachten Polypodium spec i o s $\mathrm{m},{ }^{*}$ ) und erinneren, wie diese, an die Band-förmigen

*) Auch die äusseren Abzeichnungen von Polyp. speciosum haben viel Analogie mit denen von Lep. punctatum. In Innern sind beide so ähnlich gebaut, dass man ohne weiteres geneigt wird, diese Baumfabren in ein Grschlecht zu recbnen. Der Hauptunter- 
Gebilde - der sogenannten Madensteine - im Innern von Psaronius helmintholithus.

Die kleineren runden Gefässbündel, welche im ganzen Stamme unregelmässig vertheilt liegen, bestehen aus zwei konzentrischen Gefässkörpern, die durch eine dazwischen liegende Bast-Scheide getrennt sind. Die sie zunächst umgebende dunkle Wand besteht gleichfalls aus dichten Bastzellen, sowie auch der innerste Kern, der häufig durch eine Lücke des inneren Gefässringes mit dem mittleren Bastringe in unmittelbarer Verbindung steht (Fig. 4). Diese Gefässbündel sind es wahrscheinlich, welche den an der Oberfläche des Stammes erscheinenden, in Fig. 5 vergrössert abgebildeten, kleinen Grübchen entsprechen, deren Gestalt und Grösse vollkommen mit dieser Vermuthung übereinstimmt, obgleich sich ein unmittelbarer Zusammenhang, wie bei den vorigen Gefässkörpern, zufällig an diesem Exemplare nicht nachweisen lässt. Es gleichen diese Gefüssbündel wieder ganz den ähnlichen in Polypodium speciosum, welche mit den Röhren-artigen Körpern des sogenannten Staarsteins im Äussern von Psaronius helmintholithus eine sehr analoge Erscheinung sind.

Noch gibt sich eine dritte Art von Gefässvereinigung, ganz wie bei Polypodium speciosum, an den Stellen zu erkennen, wo die Ausmündungen nach den Wedel - Narben durchschnitten sind (Fig. 2 im ausgeführten Theile). Hier nämlich scheint der ganze Raum zwischen den Bandartigen Streifen aus einer Vereinigung von Bast und Gefässen zu bestehen in der Art, dass innerhalb der Hauptmasse sich wieder einzelne Gefässe zu dünnen zylindrischen Körpern vereinigen und wahrscheinlich mit feinen BastMembranen umgeben, in Querschnitt dem Auge als Punkte -

schied beschränkt sich darauf, dass bei ersterem die kleinen Gefässbündel mehr an der Peripherie, bei letzterem mehr in der Mitte verlaufen, we!che hier dicht crfüllt, dort aber - wenigstens bei dem getrockneten Exemplare, welches ich Herin Prof. Merex vordanke - hohl ist. 


\section{$-33-$}

an der Oberfläche der Narben aber (Fig. 1 und 3) als kleine Vertiefungen erscheinen.

Aus diesem Allem, besonders aber aus der grossen Åhnlichkeit mit Polypodium speciosum, dürfte mit Sicherheit hervorgehen, dass Lepidodendron punctatum, wie Graf von Sternabrg, der berühmte Gründer dieses Geschlechtes und Entdecker dieser Art, zuerst aussprach, ein F ahren-Stamm ist. Ob es aber noch ferner mit den übrigen Lepidodendron-Arten zusammengestellt werden könne, wird dadurch un so mehr fraglich. Schliesst man aus der inneren Struktur von Lepidodendron Harc o u rti (Wrtham, Fossil Vegetabl.1833, Pl. XII) auf die der übrigen ähnlichen Arten, so 'wird diess sehr "wahrscheinlich, und es wäre vielleicht besser, Lep. punctatum ohne weiteres dem lebenden Geschlechte Polypodium beizuzählen.

Geologische Bemerkungen.

Ich gehe nun zu einigen geologischen Betrachtungen über, welche sich an die Auffindung dieser Versteinerung im aufgeschwemmten Lande eng anschliessen.

Es kann wohl keinem $Z$ weifel unterliegen, dass dieses Lep. punctatum aus dem Steinkohlen-Gebirge abstamme und somit bei Grossenhain auf sekundärer Lagerstätte gefunden worden seye. In denselben Kiesgruben findet man als Geschiebe : ver'steinerte Dikotyledonen-Hölzer, Feuersteine mit Kreide - Versteinerungen, Quarz, Bergkrystall, Hornstein, Kieselschiefer, Amethyst, Achat, Granit, Grünstein, Porphyr, Basalt, Grauwacke u. s. w. Ein Theil dieser Gesteine lässt sich in der Umgegend von Grossentuin anstehend nachweisen; einige aber sind hier eben so fremd, als unser Lepidodendron. Der nächste Basalt-Berg ist der von Stolpen; das nächste Achat- und Amethyst-Vorkommen ist das bei Schlottwitz, 5 Meilen von hier. Feuersteine mit Kreide-Versteinerungen fundet man in ganz Sach. sen nicht auf ursprünglicher Lagarstätte, und deutliches ver- 


\section{- 31}

steinertes Holz enthält das Rothliegende des 4 bis 5 Meilen entfernten Plauischen Grundes so selten, dass man die grosse Menge des im aufgeschwemmten Lande vorkommenden wohl noch aus anderen Gegenden ableiten muss.

Es ist bekannt, dass das anfgeschwemmte Land der norddeutschen Ebene, dessen höchste Spuren man am Erzgebirge (z. B. bei Tharand) ungefähr $1000^{\prime}$ über dem Meeres-Spiegel findet, viele fernländische Geschiebe und Petrefakten enthält; bisher waren es jedoch meist Fremdlinge aus dem Norden, die man darin fand, und Versteinerungen solcher Formationen, die wahrscheinlich bedeckt darunter liegen, oder die an Ort und Stelle zerstört worden sind. Auf letztere Art wird man die unendlich vielen Feuersteine der Kreide erklären müssen, die sich selbst an den südlichen Gränzen des aufgeschwemmten Landes finden, wo weit' und breit keine andere Spur der oberen Kreide-Abtheilung - welche jene Feuersteine vorzugsweise einschliesst - zu finden ist. In ganz Sachsen und Bölmen, wo die unteren Glieder der Kreicie-Formation so schör entwickelt sind, findet sich nichts von dem "upper chall"; aber Feuerstein-Geschiebe in so ungeheurer Menge, dass man nicht wohl annehmen kann, sie seyen aus grosser Entfernung, aus nördlichen Gegenden herbeigeschwemmt; zumal da die übrigen nordischen Gesehiebe hier schon mehr zu den Seltenheiten gehören.

Einen anderen Urspruing scheint nun aber ein Theil der Pflanzen-Versteinerungen zu haben, welche der Steinkohlen-Fornation und dem Rothliegenden angehören; denn sie stimmen, wie es scheint, weit mehr mit der Flora der Böhmischen Kohlengebirge, als mit der der Süchsischen überein. Lepidodendron punetatumz. B., ist in unsern Kohlen-Formationen nie gefunden worden, wohl aber in der von Kainitz in Böhmen, und jene dem aufgeschwemmten Lande ganz charakteristischen Holzsteine (Dikotyledonen-Ḧ̈lzer mit undeutlichen Jahresringen), welche durch die Art der. Umwandlung ein fleckiges Staarstein - artiges Ansehen erlangt haben (vulyo Punktsteine, vergl. neine Den- 
drolithen S. 55), sind mir ebenfalls in keinen Sächsischen Gebirgsschichten bekannt; ich vermuthe vielmehr, dass sie ursprünglich den Gebirgen von Neu Paka in Böhmen angehörten, wo versteinerte Hölzer und Staarsteine in grosser Menge gefunden werden.

Demnach dürfte also ein Theil der eigentlichen Fremdlinge in unserem aufgeschwemmten Lande durch die $E l b-$ Strömung aus Böhmen herbeigeführt worden seyn, während ein anderer, sehr geringer Theil durch Meeres - Fluthen aus dem Norden heran gebracht wurde. Auch hieraus bestätiget es sich, dass hierher die Küstenlinie des Ozeans der Diluvialperiode gedacht werden müsse, und dass Sachsen und Böhmen in jenen Zeiten, nur theilweise aus dem Wasser hervorragend, durch eine Meeresströmung - im jetzigen Elb-Thale - mit einander in Verbindung standen. 


\section{B e m e r k u n g e n uiber \\ das Genus Belemnosepia}

und über

\section{den fossilen Dinten - Sack in dem vorderen Kegel der Belemniten,}

von

\section{Herrn Professor WM. Buckland}

in Oxford.

Die grosse Familie der Belenıniten findet sich nur im fossilen Zustande. Diese sonderbaren Körper nähern sich den andern Familien der gekammerten Konchylien, unterscheider sich aber dadurch von ihnen, dass ihre Scheidewände eingeschlossen sind in einer faserigen, mehr oder weniger Kegel-förmigen Scheide, deren Form oft einer Pfeilspitze gleicht, worauf ihr Name Bezıg hat.*)

*) Vox Buarvile hat in seiner Abhandlung über die Belenmiten, mit Theophisas beginnend, 81 Autoren über Belemniten aufgeführt, worunter die gelehrtesten in der Ansicht übereinstimmen, dass diese. Körper von Cephalopoden, den noch lebenden Sepien verwandt, gebildet worden seyen. Voltz, v. Zieten, Raspail und Graf v. MÜNster haben später noch wichtige Abhancilungen über diesclben geliefert. Die wichtigsten in England erschienenen Aufsätze darüber sind jene von Milzer (Geolug. Transact. N. S. Lundon 1826) und von Sowerisy (Miser. Conchol. V1. 169 ff.) 


\section{$-37$}

Die Belemniten waren innerliche Konchylien, aus drei wesentlichen Theilen zusammengesetzt, welche sich nur selten noch in einem Zustande vollkommener Erhaltung beisammen finden.

Zunächist findet man eine Kegel-förmige faserig - kalkige Schaale, deren dickeres Ende wieder eine Kegel-förmige Höhle enthält. Dieser Theil des Belemniten wird gewöhnlich dessen Scheide genannt: sie besteht aus ineinander steckenden hohlen Kegeln, die eine gemeinschaftliche Achse haben und deren grösster alle übrigen einschliesst. Diese Kegel bestehen aus Fasern von Kohlen-saurem Kalke, welche von einer excentrischen Achse ausstrahlen und bis zur Oberfläche des Belemniten fortsetzen. Der dichte und krystallinische Zustand der fossilen Scheide scheint von Kalk - Infiltrationen herzurühren, welche nach deren Einschliessung in den Gebirgsschichten in die Zwischenräume zwischen die ursprünglichen [nicht dicht aneinander gelegenen] Kalkfasern Statt gefunden haben.

Die Ansicht, dass der Belemnit sclon ein dichter, Steinartiger Körper gewesen, als er noch einen Theil der lebenden und schwimmenden Sepie ausmachte, würde allen durch die imneren Organe der lebenden Cephalopoden gebotenen Analogieen entgegen seyn. Der Geruch nach gebranntem Horn, welchen diese Körper geben, wenn man sie denı Feuer яussetzt, rührt von den Überresten der Horn-artigen Häute zwischen den einzelnen Faser-kalkigen Kegeln der Scheide her. - Zu Gunsten der Meinung, dass die Belemniten innere Organe gewesen, spricht die Thatsache, dass ihre Obertläche oft mit Eindrücken von den Gefässen des Mantels bedeckt ist, von dem sie eingeschlossen gewesen. Bei einigen Arten ist ihre Rückenfläche gekörnelt, wie derselbe Theil bei der imeren Schale der Sepia officinalis es ist.

Zweitens hatten die Belemniten eine vordere, Keyelfürmige, dünne und Horn-artige Höhle, welche von der Basis des hohlen Kegels der kalkigen Scheide begain, sich rasch erweiterte und susserhalb der Scheide noch auf eine 
ansehnliche Strecke fortsetzte. Diese Hornscheide ist selten noch an die kalkig - faserige Scheide befestiget; doch findet man sie ziemlich häufig ohne dieselbe im Lias von Lyme Regis. An einer und derselben solchen Scheide findet man oft einige Theile Perlmutter-artig, während die andern ihre Horn-artige Beschaffenheit behalten haben.

Drittens besassen die Belemniten eine innere gekammerte Kegel-förmige Schaale, Alveole genannt, welche in dem kalkigen Kegel stack und nach ihrer Bildung viele Ähnlichkeit mit den Nautilen und 0 rthoceratiten zeigt. Sie ist durch dünne Queer-Wände von gleicher Beschaffenheit mit ihr selbst in eine Reihe von Kammern getheilt, wie wenn ein Stoss von unten nach oben an Grösse abnehmender Uhrgläser aufeinander läge. Die Queer-Wände sind Aussen konkav und von einem zusammenhängenden Siphon auf der unteren oder Bauch-Seite durchbohrt.

Seit einigen Jahren hat man im Lias von Lyme Regis Horn-artige, dünne Konchylien (Sepioteuthis) in Verbindung mit den Dintensäcken eines fossilen Loligo gefunden, - so wie analoge Dintensäcke in Verbindung mit den dortigen Belemniten. Einige dieser Dintensäcke sind fast 1 Fuss lang und zeigen, dass das Thier, von dem sie stammen, zu einer sehr ansehnlichen Grösse gelangt seyn musste.

Im Jahr 1829 theilte ich der geologischen Sozietät in London eine Notiz über die wahrscheinliche Verbindung der Belemniten mit gewissen fossilen Dintensäcken mit, welche, von einem glinzenden Perlmutter ungeben, im Lias von Lyme Regis vorkommen (Philos. Magaz. N. S. 1829, p. 388), und liess zu gleicher Zeit Zeichnungen einiger fossilen Stücke fertigen, die mich veranlasst, diese Dintensäcke von den Cephalopoden herzuleiten, welche auch die Belemniten gebildet haben. Ich habe sie damals nicht weiter bekannt gemacht, in der Hoffnung, den gewissen Beleg dafür hald in irgend einem Handstücke zu funden, worauf der DintenSack noch mit den Belemniten verbunden wäre, und diesen 
Beleg habe ich endlich durch Herrn Prof. Agassiz*) erhnlten, welcher im Oktober 1834 im Kabinete der Miss Phicpors zu Lyme Regis zwei wichtige und die Frage entscheidende Exemplare entdeckte, an welchen beiden der Dintensack noch in der vorderen Hornscheide eines vollkommenen Belemniten steckt; und von nun an kömnen wir mit Zuverlässigkeit alle Belemniten-Arten in ein Geschlecht in der Klasse der Cephalopoden verweisen, für welehes ich mit Agassiz den Namen Belemnosepia vorschlagen möchte.

Von Blainvilue hatte zwar nie einen Belemniten mit vorderer Kegel-förmiger Hornscheide gesehen, aber gleichwohl aus der Analogie anderer gekammerten Konchylien auf einen ähnlichen Theil bei den Belemniten geschlossen. Die Gediegenheit seines Urtheils ist daher durch die Entdeckung der erwähnten Exemplare bestätigt worden.

Graf Münster hat sehr vollständige Belemniten von Solenkofen abgebildet (A. BouÉ Mémoir. géolog. 1832, I, pl. IV, Fig. I, 2, 3, 15, 16) - an deren einigen die Form der vorderen Horn-Scheide in einer Länge, welche der der Kalkscheide des Belemniten gleich kommt, erhalten ist, aber in keinem von ihnen sieht man eine Spur von Dintenbeuteln. H. v. Mever hat jedoch in seinen $\mathrm{Pal}$ a e ologica eine Notiz über einen solchen Dintensack mitgetheilt, der einem Belemniten aus dem Lias von Banz angehörte. **)

Die Thatsache, dass die Belemniten mit einem so grossen Dinten-Behälter versehen gewesen, macht es a priori wahrseheinlich, dass diese Thiere keine äussere Schaale besassen; denn die nackten Cephalopoden allein (so viel wir bis jezt wissen) sind mit einem solchen Organe versehen; d:s ihnen in gewisser Weise die Schaale ersetzen, sie gegen

*) Vergl. Jahrì. 1835, S. 168.

***) Verirl. auch über Loligo-Arten mit Dintenbeuteln Rüprer. Solenho/: Versteinerungen; - vos ZreTen, Verstein. Wïrtembergs S. 34, Taf. XXV, Fg. 4-10, Tf. XXXVII, Fg. 1; v. Müssтne u. A. 
ihre Feinde schützen muss. *) Nie aber hat man Dinte in einer Ammoniten- oder Nautilen - Schaale gefunden; hätte dieso Substanz je bei Thieren existirt, welche die letzte Kanmer dieser Schaalen bewohnten, so würde man in den Lins - Schichten von Lyme Regis die so ganz mit den letzteren angefüllt sind, sicher schon Spuren davon entdeckt haben, wie man dort die Dintensäcke der nackten Cephalopoden so schön erhalten gefunden hat.

Die junge, noch in ihrem Eye eingeschlossene Sepia officinalis führt schon einen mit Dinte angefüllten Sack mit sich für die Zeit, wo sie das Ey verlassen wird, und dieser Sack ist mit einer Perlmutter-glänzenden Hülle umgeben, ähnlich demjenigen, was man an einigen inneren Hüuten vieler Fische sieht.

Die gekammerte Schaale des Belemniten zeigt uns, wenn wir sie mit der des Nautilus und anderen Geschlechtern vielkammeriger Konchylien vergleichen, eine fast vollstindige Übereinstimmung zwischen ihren wichtigern Theilen.

Man kennt bereits Ss Belemniten-Arten, und die ungeheure Menge ihrer Reste fast in allen Schichten von dem Anfange des Lias an bis zum Ende der Kreide beweiset, dass dieselben einst in grosser Verbreitung und IndividuenZahl vorgekommen seyn müssen.

Bedenkt man, dass in diesen zwei grossen geologischen Formationen die noch zahlreichere Familie der Ammoniten, mit den Belemniten von gleicher geologischer Ausdehnung, zusammengesetztere und vollkommenere Organe als die Arten der geringen Anzahl von Cephalopoden-Geschlechtern besassen, welche heut zu Tage noch existiren, so muss man zugeben, dass diese untergegangenen Familien eine grössere Verbreitung besessen und wichtigere Verrichtungen unter den Bewohnern der ehemaligen Meere hatten, als jetzt die kleine Anzahl ihrer noch lebenden Repräsentanten.

*) Bekanntlich findet man auch fossile Sepie mit den Rhyucholithe $n$ in Muschelkalk, die ebenfalls von nackten Thieren herstam. men dürften.

Br. 


$$
\text { Uे b e } r
$$

die geognostischen Verhältnisse

\section{G e g e n d u m Rod $n a$ in}

$$
\text { Siebenbürgen, }
$$

von

$$
\begin{gathered}
\text { Herrn Fr. Taminau jun. } \\
\text { in Berlin. }
\end{gathered}
$$

Als ich mich im Jahr 1524 längere Zeit in Siebenbürgen aufhielt, um die Goldbergwerke in der Umgegend von Zalathna in Augenschein zu nehmen, wollte ich auch die interessanten Bleibergwerke von Kirlibaba in der Bukowina und von Rodna an den Grenzen der Marmaròs besuchen, weil dieselben bis dahin wohl wegen ihrer sehr grossen Entfernung äusserst wenig bekannt waren. Ich ging demnach von Zalathine nach Karlsburg, und von hier aus immer an dem Ufer der Maròs hinauf über Enged, Pel Vinez und Maros Vasurhely nach Regen. Hier verliess ich die Maròs, die, bei Karlsburgy ein mächtiger Strom, hier nur noch ein unbedeutender Fluss ist, und ging über Batós nach Bistritz. Die Gegend um Maròs Vasarhely und Regen ist flach und eben, füngt jedoch hinter diesem Ort an sich zu erheben, und man findet bei

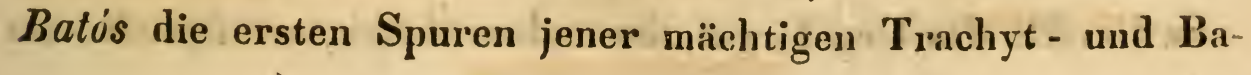


salt - Erhebung, die sich längs der Grenze der Moldau und Siebenbürgens fortzieht. Diese Formation bildet weiter nördlich das Grenzgebirge zwischen der Bukowina und Siebenbürgen, und hängt weiter sülllich ohne $Z_{w}$ eifel mit den Basalten und mit dem beruihmten Schwefelberge der Umgegend von Kronstadt zusammen. Wie man mich versicherte, sollen sich östlich und südöstlich von Batós und Regen, an der Grenze der Moldau, mehrere Punkte befinden, an denen Schwefel, - wahrscheinlich auf dieselbe Art wie bei Kronstadt - in so grosser Menge vorkommt, dass die Bauer'n ihn einsammeln, um ihn als Handelsartikel zu benutzen. In wie fern sich ein Zusammenhang nachweisen liesse zwischen dieser Formation und den Gold - und Silber-haltenden Porphyren der Gegend von Zalathna, Offenbanya, Vóróspatack und Abrndbanya, und den Basaltkuppen derselben Gegend, - das muss dahingestellt bleiben, bis genauere Untersuchungen mehr Licht über die Verhältnisse beider Erhebungen verbreiten werden. - Leider erlaubte mir meine Zeit damals nur eine sehr flüchtige Durchreise durch diese Gegenden, und wie schwer es unter solchen Uinständen ist, sich eine auch nur einigermassen klare und sichere Einsicht in die geognostischen Verhältnisse eines noch gar nicht oder noch wenig bekannten Landes zu verschaffeir, das wird jeder zu würdigen wissen, der sici in einer ahnlichen Lage befand.

Von Bistritz führt eine schöne Strasse über das Gebirge nach Tschernowicz in der Bukowina. Ich folgte dieser Strasse über Jad, Borge, durch den Tajo Borgo, über Jehara und Pojana Stampi bis Jacobeni durch wilde, unfruchtbare Gegenden, über nackte Berggipfel und durch unübersehbare Fichtenwälder. In dem Passe Borgo ist die Wasserscheide zwischen der westlichen Bistritz, die bei Bethlen in die Szamos und mit dieser in die Theiss fälit, und der östlichen goldenen Bistritz, die ihre Gewässer der Moldawa und später dem Pruth zuführt. Die westliche Bistritz enthält fast nur Geröllo des Urgebirges, besonders Quarz, weniger Gneiss 
und Glimmerschiefer, aber fast kène Gerölle der vulkanischen Formation. Die östliche golòne Bistritz enthält im Gegentheil in ihren Geröllen sehr viłe vulkanische Massen und verhältnissmässig viel weniger Kiesel und Glimmerschiefer. Wenn man sich von Bistrts aus dem Gebirge nähert, so trifft man zuerst in der Umgegend von Jad einen rothen, schiefrigen, thonigen, viel Eiseroxyd enthaltenden Sundstein, durch die spätere vulkanische Irhebung zu einem Winkel von etwa $45^{\circ}$ geschichtet. Weiterhin gegen Borgo 2u erscheint in grossen Erstreckungen jeres thonige, viel Eisenoxyd enthaltende und davon rothgefäıłbte Bindemittel, in dem kleine Augit-Krystalle in grosser $\mathbf{A}_{\text {izahl }}$ zerstreut liegen. Diese Masse gleicht vollkommen den bekannten bei Bovislaw im böhmischen Mittelgehirge unweit Töplitz vorkommenden, nur dass an letzterem Orte die Aucit-Krystalle ungleich grösser sind als bei Borgo. Von Borgo bis Jehuะa trifft man. mit Ausnahme des wirklichen Basalt die eigentlichen vulkanischen Felsarten, namentlich einen bräunlichgrünen Trachyt mit sehr vielen deutlichen Augit-Krystallen. Diese Augit-Krystalle zeigen das sonderbare Phänomen, welches G. Rose an ähnlichen Krystallen im Ural beobachtet hat; sie haben nämlich die Krystallform des Augits und die Blätterdurchgänge der Hornblende. - In der Umgegend von Jehuza hören die vulkanischen Massen auf; es erscheint Thonschiefer und weiterhin, bei Dorna Kandreni, das eigentliche Urgebirge dieser Gegend, der Glimmerschiefer und Gneiss, der sich nach Jacobeni und Kirlibaba hin erstreckt.

Ich habe nicht Gelegenheit gehabs, auf diesem Wege die Grenze zwischen dem Trachyt und dem Thonschiefer oder dem Glinmerschiefer zu sehen, und mithin nicht die Veränderungen beobachten können, die de: durchbrechende Körper auf den durchbrochenen olne Zweifel ausgeübt hat. Wie man mich indessen versichert, hat man im lnnern des Gebirges häufig Gelegenheit, die Grenze des Trachyts entblöst zu sehen. Doch will man ihn nianals in Berührung mit dem Thonschiefer oder mit dem Gimmerschiefer gese- 
hen, sondern immer zw'schen beiden ein mehr oder minder mächtiges Lager von Kalk bemerkt haben. Ich habe diess nicht gesehen, sondern erzähle es nach Hörensagen, wie es mir von del Bergbeamten jener Gegend mitgetheilt worden ist, die übrigens bei den häufigen Schürfungen wohl Gelegınheit hatten, diese Verhältnisse zu beobachten.

Um Jacobeni herum liegen die verschiedenen Bergwerke dieser Gegend, ramentlich die Kupfergruben von Posahonita, das Bleibergwerk von Kirlibaba und die Eisengruben von Tundi Moldoux, Valestina, Corna u. s. w. Die Gebirge dieser Gegenren bestehen gänzlich aus Glimmerschiefer, der zuweilen von Kalk bedeckt wird. Jene Erz-Lagerstätten bilden jede:zeit Lager im Glimmerschiefer selbst, niemals auf den Grenzen, auf der Scheidung zwischen dem Glimmerschiefor und dem Kalk, wie diess in anderen Gegenden, namentlich im Bannat der Fall ist. - In Posahonita bebaut man ein mächtiges Lager von Kupferkies mit wenigem beigemengcem Buntkupfererz. Das Blei von Kirlibaba wird aus einem mächtigen Stockwerk von Bleiglanz, der mit sehr vielem Spatheisenstein vermischt ist, gewonnen; in den oberen Teufen dieses Bergwerkes kommen sehr niedliche kleine Krystalle von Weissbleierz und von Vitriolbleierz vor. Die Eisengruben liefern theils Spatheisenstein, theils einen rothen mulmigen Thoneisenstein. Das Gebirge verflächt sich von hier aus immer mehr und mehr gegen Südosten nach den Grenzen der Moldar zu, bis es sich endlich in den grossen Ebenen dieser Provinz verliert. - Der Glimmerschiefer der Gegend von Jacobeni soll nach der Richtung des schwarzen Meeres zu bald einem bituninösen Mergelschiefer Platz machen und dieser endlich von einer ganz jungen SandsteinFormation bedeckt werden, die hier das üusserste Vurgebirge ausmacht. - Die Ablagerungen von Eisenstein, die grösstentheils selr mächtig sind, soll man in einer ununterbrochenen Kette von den Ufern des schwarzen Meeres, durch die Moldan die Bukowina und durch Gallizion bis 
nach Schlesien verfolgen können in einer Richtung, die fast vollkommen dem Hauptstamm der Karpathen parallel läuft.

Es war meine Absicht, von Jacobeni aus entweder durch den Pass Rodna oder durch den Pass Kukuraza nach dem berühmten Bergwerk Rodna zu gelangen. Beide Wego wurden von meiner Karte angegeben, waren aber dort gänzlich unbekannt, und ich musste demnach auf derselben Strasse, die ich gekommen war, bis nach Jad zurück gehen. Von hier überschritt ich einen nicht ganz unbedeutenden Gebirgsrücken und gelangte so bei dem kleinen Dorfe Havamika in das weite Thal der Nagi Szamos, welches sich von hier nach Rodna uud noch weiter hinauf zieht. Der Bergrücken besteht ganz aus dem eben angeführten rothen schiefrigen Sandstein. Der kleine Bach, der sich bei Havamika mit der Nagy Szamos vereinigt, enthält ausser Geröllen des ebengenannten Sandsteins ungeheure Blöcke eines grauen Porphyrs mit sehr deutlichen kleinen Feldspath - Krystallen und wenigem Quarz.

Auch im Thal der Nagy Szamos, deren Gerölle aus Quarz, Gneiss und wenigem Porphyr bestehen, herrscht der rothe Sandstein vor, verliert sich indessen schon vor $S t$. Georgii, wo der Glimmerschiefer das Daseyn des Urgebirges bekundet.

Bevor man Rodna erreicht hat, wird man durch einen höehst ungewöhnlichen und sonderbaren Anblick überrascht. Mitten in dem weiten Thal der Nagy Szamos entspringt nämlich eine eigenthünliche Mineralquelle, in der dortigen Gegend weit und breit unter dem Namen des Rodnaer Sauerbrunnens bekannt. Diese Quelle setzt in sehr bedeutender Menge kohlensauren Kalk ab, und es hat sich durch den regelmässigen und gleichförmigen Abfluss der Quelle ein ganz bedeutender, kegelförmiger Berg rund um diese Quelle gebildet, der aus dem reinsten Kalksinter besteht. Die Quelle entspringt mithin nicht mehr in der Ebene, sondern auf der Spitze dieses Kegels, und letzterer wird fortdanernd durch das immerwährende Absetzen von Kalksinter ver- 
grössert. Ob diese Quelle ihren Ursprung in irgend einem bedeutenden Kalklager hat, das vielleicht dem Urgebirge aufgelagert wäre, welches die Wand des Thales ausmacht, oder ob, wie der Carlsbader Sprudel, diese Quelle aus den tieferen Orten unseres Erdkörpers entspringen mag, - muss ich dahingestellt seyn lassen. Jedenfalls erscheint sie als ein höchst interressantes und sehr zu beachtendes Phänomen, und nur die eben erwähnte Carlsbader Quelle dürfte in Betreff der Quantität des abgesetzten Kalkes mit ihr zu vergleichen seyn. - 


\section{$\ddot{U}$ b e r}

\section{einen als Hüttenprodukt entdeckten Felsit, \\ von}

\section{Herrn Professor Breithaupt. ${ }^{*}$ )}

Hiezu Taf. II. Fg. 7.

Das mir von dem Hrn. Bergrath Ritter Freiesleben zur Untersuchung gegebene Mineral-ähnliche Hüttenprodukt ist ganz richtig von Herrn Gewerke-Probirer Heine für einen Orthoklas angesprochen worden, wenn man mit diesem NaInen einen Körper bezeichnet, der, in das Genus der Felsite (Feldspäthe) gehörend, die zwei wichtigsten Spaltungsrichtungen ( $P$ und $M$ ) unter $90^{\circ}$ sich schneidend zeigt. Wir kennen aber von dieser Beschaffenheit bereits vier verschiedene Species, 1) den pegmatischen Felsit oder Pegmatolith (gemeiner Feldspath), 2) den adularen Felsit oder Alular, beide von mir näher bestimmt, 3) den ryakonen Felsit orler Ryakolith (ein Theil des sogenannten glasigen Feldspaths) und 4) einen andern noch nicht näher benannten Theil des glasigen Feldspaths, diese beide rom Herm Professor G: Rose näher bestinmt. An diese vier Körper

") Aus einem von Herm Prof. Bramthaupt an Herm Berg-Probirer Heine unter dem 30. Oktober 1834 erlassenen Schreiben durch letz. teren zum Abdrucke im Jahrbuche mitgetheilt. 'Das, was sonst viber die so interessante als wichtige Entdeckung zu Sangerhau. sen verlaucicht worden, ist unsern Lesern bekannt.

D. $\mathrm{R}$. 
schliesst sich das Hüttenprodukt, welches ich hier beschreiben werde, an.

Glasglanz, auf der vollkommenen Spaltungsrichtung zuweilon in Perlmutterglanz übergehend.

Farbe, blassviolblan.

Durchsichtig bis durchscheinend.

Nur krystallisirt als hemidomatisches Diploprisma, in die normal tetartoëdrische Abtheilung des rhombischen Systems gehörend. Die Kombinazion zeigt (Fig. 7 auf Taf. II):

$\mathbf{P}=-\mathbf{P} \bar{\infty}$, d. i. das hintere primäre Doma zur Makrodigonale.

$\mathbf{M}=\infty \mathbf{P} \nsim$, d. i. das brachydiagonale Flächenpaar, $\mathbf{T}=\bigvee \cdot+\infty \mathbf{P}, \mathrm{d} . \mathbf{i}$. das rechte vordere (linke hintere) Hemiprisma,

$1=+\infty \mathbf{P}<$, d. i. das linke vordere (rechte hintere) Hemiprisma.

Der Leser sieht den Krystall von hinten, und es waren die hier zu sehenden Flächen, deren Neigung ich vor dem Reflexions - Goniometer gemessen habe :

1) $P$ auf $M=90^{\circ}$

2) $\mathrm{P}-\mathrm{l}=111^{\circ} \mathrm{5 \%}$

3) $\mathrm{P}-\mathrm{T}=111^{\circ} 34^{\prime}$

4) $M-1=119^{\circ} 22^{\prime}$

5) $\mathrm{T}-\mathrm{l}=120^{\circ} 23^{\prime}$

6) $\mathrm{T}-\mathrm{M}=120^{\circ} \quad 5^{\prime}$ :

Von diesen Winkeln ist nur der sechste * berechnet, die übrigen sämmtlich gemessen. Der erste, zweite und vierte Winkel sind gut, die zwei andern approximativ bestimmt. Von sieben Krystallen, die ich ummessen habe, konnte ich nur den einen gebrauchen, weil die Flächen gar zu wenig reine Ebenen zeigten, zarte Rundungen auf del terminalen Fläche und Streifungen auf den lateralen Flächen gaben schlechte Resultate. Indessen liess sich $\mathbf{P}$ auf $\mathbf{M}$ in vollkommener Spaltungsgestalt unter $\mathbf{9 0}^{\circ}$ gleichmässig mit 
dem guten Krystalle, finden. Das Prisma zeigte sich in jedem Krystalle unsymmetrisch.

Die hemidomatische $S$ paltungsrichtung $\mathbf{P}$ ist höchst vollkommen, die brachydiagonale $M$ fast eben so deutlich, die hemiprismatische nach $\mathbf{T}$ undeutlich bis Spuren. Es kommt auch muschliger Bruch vor.

Die Härte $=7 \frac{1}{2}$ bis 8 meiner Skale.

Das spezifische Gewicht $=2,541$ von einer freilich sehr kleinen Quantität.

Dieser gewiss recht interessante Körper nähert sich den Winkeln nach am meisten dem Ryakolith, der Härte und dem Gewichte nach aber dem Pegmatolith. Wenn man auch in der Wissenschaft noch nicht dahin vorgerückt ist: dergleichen Produlte in das Mineral-System aufzunehmen, so halte ich doch für gut, sie wenigstens, wo sie etwas Besonderes sind, zu benennen, und für diesen Mineral -ähnlichen Körper des Ofenschachtes schlage ich den Namen $\mathrm{K}$ a minolith, zu deutsch Ofenstein, vor. 


\section{Briefwechsel.}

\section{Mittheilungen, an den Geheimenrath v. LEONHARD gerichtet.}

München, 25. November 1835.

Im vierten Hefte des Neuen Jahrbuches der Mineralogie für 1835 las ich den von Herrn Russegger in Böckstein ausgesprochenen Wunsch, über die sogenaunten Rinner etwas Näheres zu erfahren, welche ein besonderes Vorkommen in dem Fahlerz-führenden Kalkstein Tyrols darbieten sollen.

Da die Grubengebäude um Schwatz, in welchen dieses - allerdings merkwürdige - Erz-Vorkommen allein getroffen wurde, bereits gänzlich aufgelassen sind, sohin neue Beobachtungen nicht mehr angestellt wcrden können, so dürften Herrn Russegarn viclleicht die wenigen Nachrichten nicht unwillkommen seyn, die ich in meinen Notizen über den Tyroler Bergbau aufgezeichnet finde. Ich sage, die wenigen Nachrichten, - denn vor 28 Jahren, wo ich in Tyrol war, stund kein sogenannter $\mathrm{R}$ inner nehr in Abbau, und ich konute ihre Eigenschaften nur mehr aus ihren leeren Räumen, aus einzelnen zurückgelassenen Spuren ihrer Erzführung, und aus Fragen, an alte Steiger und Bergleute gestellt und von ihmen so gut als möglich beantwortet, beurtheilen.

So manchfaltig die Abänderungen des Kalksteines sind, in welchem - im. Innthal, von Schu:atz in östlicher Richtung bis unterhalb Rattenberg - die vormals so ausgedehnten, und sich so lohnenden Bergbaue getrieben wurden: so manchfaltig sind auch die Kupfererze, die dieses mächtige Lager einschloss, und eben so verschieden ist auch die Art des Erz-Vorkommens.

Ohne hier ins Specielle einzugehen, was dieser brieflichen Mittheilung eine zu grosse Ausdehnung geben wïrde, will ich hier gleich dic. sogenannten $R$ inner behandeln. 
In den Gruben des Kalksteines, meist in der mittlen Höhe des Berges über der Ebensohle des Thales, und zwar in jener Abänderung des Kalksteines, die sich durch dunkelgraue Farbe, splittrigen Bruch, grosse Festigkeit und dadurch auszeichnet, dass sie keine Schichtung, sondern nur Klüfte nach allen Richtungen dem Beobachter darbietet, zogen sich prismatische Räume, nach keiner horizontalen Richtung über 1 Lachter messend, 50 bis 100 und mehr Lachter seiger oder fast seiger in die Teufe. Nur Fahlerz - führend waren diese Räume, und die Erze kamen eingesprengt, in Schnürchen und in mehr und minder grossen Nestern vor; stets aber war die Reichlaltigkeit der Erzführung so gross, dass das Treffen einer solchen Lagerstätte - eines Rinners - stets als ein ausgezeichneter Bergsegen betrachtet wurde. Um so erfreulicher wurde ein solches Auffinden, als keine Spur im Gebirge einen Wegweiser dahin gab, sondern reiner Zufall sie - diese überhaupt sehr seltenen Erscheinungen - treffen liess.

Ausserhalb der kleinen Grenzen der Erzführung verloren sich auch schnell wieder alle Spuren von Erzen, ohne dass im Gesteine selbst irgend eine Veränderung eingetreten wäre. Diese Rinner boten keine andere Erscheinung dar, als dass in einem kleinen Raume die Erze sich anhäuften, während in dem zunächst angrenzenden Gesteine kaum schwache Spuren von Erzen sich zeigten. Diese waren auch nic von anderen Erz-oder Gesteins-Arten begleitet, bildeten keine Drusen, und bewirkten auch nicht die mindeste Veränderung des sie unmittelbar berührenden Kalksteins, mit welchem sie durchaus vollständig verwachsen waren.

\section{Freiherr von Gumppenberg.}

\section{Bern, 4. Oktober 1835.}

Ich glaube auf Ihren, kurz vor meiner Abreise erhaltenen, Brief noch nicht geantwortet zu haben, jedenfalls will ich Ihnen meine glück. liche Püickkehr und Einiges über die Resultate meiner Reise berichten, die leider nicht so glücklich gewesen ist, als ich mir versprochen hatte. In Zürich schloss Escher sich mir an und blieb während der ganzen Zeit ein sehr werther und thätiger Peisegefährte. Gleich am dritten Tage aber nahm die bisher so konstant herrliche Witterung einen entgegengesetzten Charakter an. Der Regen hinderte uns am Vorrücken, zwang zu mehrtägigem Aufenthalt an den einsamsten Orten; dann kam Schnee, der ersehnte Vorbote besserer Tage, that aber des Guten so im Übermaase, dass alle höheren Punkte, die gerade die wichtigsten Aufschlüsse geben sollten, tief bedeckt wurden. Wir rückten über den Berninu bis ins Velllin vor; aber die Untersuchung der Bergamasker Gebirge musste aufgegeben werden. In dem Malenker-Thal, nördlich von Sundrio, hatte ich beim Besuch der Lavez-Steinbrüche überdiess das Unglück, 


\section{2}

mir ein Schienbein zu quetschen, und, obgleich ich noch etwa acht Tage damit herumlief, so wurde die Wunde doch zuletzt so schlimm, dass mir in Cliurenna nichts übrig blieb, als mich in den Wagen zu setzen und, nach einer Reise von vier Wochen, zurückzukehren. Ganz fruchtlos ist indess die Untersuchung nicht geblieben. Ich zweifle zwar, dass ich es wagen dürfte, jetzt schon an eine Monographie der BündtnerGebirge zu gehen, vielleicht aber bcschränke ich mich auf die kleinere Partie von Dar:os, und von diesen sind wir nun in Stande, sowohl die Topographie, als das Geologische ziemlich vollständig zu liefern. Was das übrige Bündten darbietet, ist meist Wiederholung jener Verhältnisse, die, wenn schon anderwärts, wie in Ural, in Schottland, bei Christiania beobachtet, doch für die Alpen ganz neu sind, und Bündten als eine Ausuahme von dem übrigen alpinischen Charakter erscheinen lassen. Was man sich etwa in unseren Berner-A/pen abstrahirt haben möchte, ist in jenen Gegenden rein verloren: man muss von Vorn anfangen und sich nach ganz anderen Analogie'n umsehen; doch meine ich desswegen nicht, dass mit der Zeit nicht auch von da aus ein helleres Licht sich über das grosse Ganze verbreiten könne. Einstweilen aber überzeuge ich mich immer mehr, dass wir noch lange nicht an eine Theorie der Alpenkette und ähnlicher Gebirge denken durfen, und dass alle diese Versuche, wenn auch noch so geistvoll durchgeführt und von grossen Namen unterstützt, unsern Nachfolgern nicht anders vorkommen werden, als uns nun die Systeme von Bufron, De Luc u. s. w., und das wichtigste Ergebniss unserer Reise ist wohl, dass wir nun (Escher's besonders komnt diess Verdienst zu) in dem Kalk der Bündtner-Gebirge, der an vielen Stellen zu Dolomit oder weissem Marmor wird, an vielen auch von Glimmerschiefer, Gineiss, Amphibolith etc. bedeckt erscheint, untrügliche organische Überreste gefunden haben, besonders Pentacriniten; dass ferner der Bündtner. Schiefer, der sich bald als Glimmerschiefer, Talk -, Chloritschiefer, bald wieder als Thou- und Mergelschiefer zeigt, und in allen diesen Abänderungen unter sich wechselt, fast überall, wo er in letzterer Gestalt auftritt, Fucoiden, dem Fuc. intricatus nahe stehend, wenn nicht damit identisch, enthält, und sich hiedurch als derselbe Schiefer erweist, der in Glarus und der mittleren Schweitz in genauester Verbindung mit Nummulitenkalk und Grünsandbildungen steht. Es scheint hieraus hervorzugehen, dass wir alle Gesteine zwischen Appenzell und dem Engadin, wenn nicht bis ins Veltlin hinein, als ein umgewandeltes Kreidegebirge zu betrachten haben, so unverdaulich auch die Anlagerung von Gneiss, Hornblende-Gestein, Granit u. s. w. uns erscheinen mag. - Über die hicher gehörende Frage von Freunc Brons, ob das Vorkommen von Kreidepetrefaliten in den Sentis-Gebirge: etwas Neues sey, glaube ich Ihnen schon geschrieben zu hahen, wenig. stens meine ich mich einer Mittheilung zu erinnern über Turrilites Bergeri und Ostrea carinat a oder nahestchende Petrefakten, die wir vor einiger Zcit von daher erhalten hatten. Im Jahre 1830 hatte ich diese Gegenden ebenfalls besucht, und in einer Notiz, die Bous inas 
Bulletin, wenn ich nicht irre, einrücken liess, auch in einem Briefe an Sie, der in dem Jahrbuche.1831 steht, bekannt gemacht, dass der grössere Theil der St. Galler- und Appenzeller-Gebirge der Kreide angehöre. Dasselbe Resultat habe ich in meinem Buche wiederholt. Genaue Petrefakten-Bcstimmungen fehlen indess noch und Brovr wird durch Bekauntmachung der seinigen uns jedenfalls einen Dienst leisten; dies e Bestimmungen werden neu seyn, nicht aber die Nachweisung der Kreide selbst. Grobkalk, d. h. eine ältere Tertiärformation als die Molasse, kömmt in den Alpen, wenigstens in unseren schweitzer-Alpen, wohl nicht vor, und alle die Bildungen, die, wie diejenigen der Diablerets, Grobkalk - Petrefakten zu enthalten scheinen, müssen nach meiner Ansicht noch zur Kreide gerechnet werden, indem der Fucoiden-Sandstein mit Belemniten und Fucus intricatus dieselben bedeckt, wie z. B. im Habkerenthale zu sehen ist, wo unter einer sehr mächtigen Decke von Fucoiden-Sandstein oder Macigno theils Nummulitenkalk, theils Steinkohlenlager mit calcinirten Petrefakten vorkonmen, die mit denjenigen der Dinblerets gewiss in die nämliche Formation gehören und wie diese den tertiären Charakter tragen. Ich habe dieselben, so weit ich sie bestimmen konnte, in meinem Buche aufgezählt. - Vor Kurzem haben wir eine sehr interessante Sendung von Petrefakten aus unserem Oberlande erhalten: aus der Gegend des Jochs zwischen Meiringen und Engelberg, Ammoniten, die mir, nach oberflächlicher Ansicht, Li asAmmoniten zu seyn scheinen; von Meiringen selbst vorzüglich schön und wohl erhaltene In oceramen oder Catillen von etwa $2 \frac{1}{2}$ Zoll Länge und $1 \frac{1}{2} Z_{\text {lll }}$ Breite, leider nur aus einem Stück, das in einer Mauer steckte; aus der Gegend von Gadmen endlich mehrere Stücke, die identisch sind mit Diablerets-Sachen, u a. die grosse Ampullaria, das grosse Cardium und ein Cerithinm, das, so viel sich erkennen lăsst, von $\mathrm{C}$. Diaboli nieht verschieden scheint. Vou ebendaher besitze ich ferner Ammoniten, die mit denjenigen dés Raththules übereinstimmen, d. h. dem unteren Oolith angehören. Sobald im nächsten Jahre die Witterung es gestattet, werde ich jene Gebirge bereisen und die verschiedenen Fundorte besuchen. Vielleicht lassen sich an dieser Stelle meine bisherigen Untersuchungen im Berner Oberland nit denjenigen von Lusser in Verbindung setzen, vielleicht auch gewinne ich bestimntere Aufschlüsse über die Fornationsfolge gerade desjenigen Theiles unserer Gehirge, der mir bis jetzt, wegen Mangel an Petrefakten, am dunkelsten geblieben ist.

Lyelr ist auf seiner Durchreise wohl bei Ihnen gewesen. Ich habe seither zwei Briefe an ihm aus Bonn gehabt. Wie er mir schreibt, hat er sich vorzüglich mit den Gegenden an Thunersee beschäfiigt, ist aber nicht ganz ins Klare gekommen. Bei Unterseen will er Hippuriten gefunden haben an einer Stelle, wo ich gewiss oft vorbei gegangen. Es ist nicht unmöglich; da man oft am wenigsten genau sieht, was immer vor der Thüre liegt; doch ist der dortige Kalk ganz verschieden, wenn auch derselben Formation angehörend, von demjenigen, 
der sonst bei uns Hippuriten einschliesst. Übrigens scheint er, wie so viele andere, in den Alpen nichts sehen zu wollen, als Analogie mit der bereits bekannten Sedimentfolge und mit dieser einseitigen Richtung kann ich mich nimmermehr befreunden, so wichtig mir selbst auch die Formationsbestimmungen sind, doch will ich nicht nach Briefen urtheilen, in denen er mir nur dasjenige mittheilte, worüber er Aufschluss wïnscht.

\section{B. Studer.}

Freiberg, 20. November 1835.

Bei einer Untersuchung der Porphyre des Tharandter Waldes fand ich einen reclıt auffallenden Beweis für die enorme Kraftäusserung, welche die Porplıyre bisweilen bei ihrem Hervorbrechen ausüben mochten. Am südlichen Rande des Tharandter Waldes bei Klein-Dorfhain tritt nämlich von dem Hauptdepot des Porphyrs eine gangartige Porphyr-Partie aus, die sich bei einer mittlen Mächtigkeit von etwa $800^{\prime}$ an $9000^{\prime}$ weit verfolgen lässt; sie läuft in gekrümmter Linie der dortigen Grenze des Haupt-Depots ungefähr parallel, so dass zwischen ihr und der grossen Porphyrmasse ein Streifen des Gneissgebirges eingeschlossen ist, der bei etwa 8000 Fuss Länge eine anfängliche Breite von 1300 F. hat, und sich zuletzt zwischen beiden Porphyr.Partie'n auskeilt. Diese Gneiss - Partie ist jedoch grösstentheils durch und durch zertrümmert, so dass ihr Gestein als eine Breccie erscheint, in welcher grössere Gneiss-Fragmente durch feineren Gneiss-Schutt verbunden sind. Im Thale des Serrenbaches, am dasigen Floss-Teiche und weiter abwärts, ist diese Breccie sehr schön entblöst; aber in der ganzen Ausdehnung der Gneiss-Partie vom Steinberge (zwischen Klingenberg und Durflain) bis zu ihrer Auskeilung, alṣo in einer Länge von wenigstens 6000 Fuss bei einer mittlen Breite von 800 bis 900 Fuss, traf ich dieselbe Breccie, so dass sich ein Gueisskörper von fast 5 Millionen Quadratfuss Oberflächen - Ausdehnung im Zustande solcher Zermalmung befindet.

Bei Gelegenheit einer geognostischen Revisions-Reise in Obergebirge beobachtete ich am Schiebenberger Basaltberge einige Verhältnisse, die man früher zum Theil übersehen zu haben scheint. Dieser Berg besteht nämlich aus zwei Theilen, man könnte sagen aus zwei Bergen, die, obwohl miteinander zusammenhängend, dennoch in ihren Lagerungsund Struktur-Verhältnissen eine sehr auffallende Verschiedenheit zeigen. Der südliche Berg ist niedriger, liegt unmittelbar auf Gliminerschiefer und zeigt kleine, meist nur Fuss-, selten bis Ellen-dicke Basaltsäulen, die nach sehr verschiedenen Richtungen liegen und bisweilen nur wenig gegen den Horizont geneigt sind. Der nördliche, durch eine flache kleine Stelle abgesonderte Berg ist höher, liegt in seiner ganzen Ausdehnung auf den so viel besprochenen horizontalen Grus., Sand- und Thon-Massen, und besteht aus sehr 
gros se $\pi, 2$ bis 4 Ellen starken Basaltsäulen, welche durchgängig vertikal stehen. Die Sand - und Grus-Ablagerung keilt sich am südlichen Ende dieses Berges aus, während sie an seinem nördlichen Ende unter den Thurm-hohen Basaltsäulen an 50 Ellen mächtig seyn dürfte. Hier ist eine grosse Sandgrube angelegt, in welcher man eine, durch eine kaum sichtbare von 0 . nach $W$. laufende Kluft hervorgebrachte Verwerfung heobachten kann, in deren Folge sich das Hangende um 3 Fuss herabgezogen hat. Älınliche Niederziehungen mögen auch früher Statt gefunden haben, als die Sand- und Basalt-Massen noch weiter nacl Norden fortsetzten, und daher dürfte vielleicht eine kleine BasaltTerrasse zu erklären seyn, welche sich am nördlichen Fusse der Sand'Terrasse hinzieht und ein System von nah an einander schliessenden Basaltsäulen darstellt, daher man sie nicht mit den aus Blöcken und Kurzgeröll bestehenden Basalt-Terrassen verwechseln darf. Die Säulen dieser kleinen Terrasse sind jedoch nicht mehr vertikal, sondern sie lehnen sich mit $70^{\circ}$ Neigung an den Fuss der oberen Sand-Terrasse; auch muss unter ihnen noch etwas Sand und Grus liegen, wie dieses die Spuren einiger alten Versuche am Fusse der Basalt-Terrasse beweisen; doch ist der Glimmerschiefer überall sehr nahe. Wahrschein. lich wurde der, einstmals weiter nach Norden reichende. Sand-und Basalt-Berg bei der Thalbildung unterwaschen; der ganze vordere Rand des Berges rutschte herab, und da diess ziemlich gleichmässig erfolgte, so blieben die Basaltsäulen noch ziemlich in ihrem Zusammenhange; doch musste sich das ganze System an die Dossirung des stelien gebliebenen Theiles der Sand-Terrasse anlehnen. Wir erkennen hierin augenscheinlich die Art und Weise, wie die Zerstörung der Basaltströme auf dem ehemaligen Plateau des Erzgebirges erfolgt seyi mag.

Carl Naumann.

\section{Mittheilungen, an Professor Brons gerichtet.}

\section{Frankfurt, 20. Oktober 1835.}

Bei der wichtigen Entdeckung des Herrn Prof. Agassiz an einer Versteinerung aus dem Lias von Lyme Regis in der Sammlung der Miss Philpot, wonach Onychoteuthis prisca nichts anderes, als die vordere Verlängerung des Belemnites ovalis ist, und derselbe in Innern einen Dintenbeutel besitzt, dem der $S$ e pia ähulich, glaube ich in Erinnerung bringen zu dürfen, dass ich bereits in Sommer 1830 an dem untern Ende eines Belemniten aus dem Lias der Gegend vou Banz diese dem Dintensack der Sepie ähnliche Substanz beobachtete. (Vergl. meine Palaeologica S. 322 , auch das Register verweiset auf diese Erscheinung). 
Nach Zeichnungen, welche Professor Buckrand zur Versammlung in Bonn mitbrachte, finden sich in dem Lias von Lyme Regis in Enyland Überreste ähnlicher innerer Schaalen Sepien-artiger Thiere von bedeutender Grösse, wie die, von denen ich eine Verwandte unter der Benenuung Leptoteuthis (L. Gigas) aus dem Solenhofer Kalkschiefer beschrieb, und die sicherlich von Sepia oder Loligo generisch zu trennen ist. (Vergl. Museum Senkenbergianum I, S. 292).

Ein würdiges Gegenstück zu dem fossilen vierstrahligen Cidarite n, von welchem ich Ihnen früher (Jahrb. 1835, S. 68) schrieb, ist mir seitden in einem fossilen sechsstrahligen Gal e rite n bekannt geworden. Wie ersterer in Übrigen mit Cidarites coronatus übereinstimmt, so ist letzterer, abgesehen von seiner Sechsstrahligkeit, nach der mir über denselben von Herrn Steiv in Rostock, dem Besitzer dieser Seltenheit, und von Professor Helmontir von Buẗcher zugekommenen Abbildung und Beschreibung, dem Galerites albo-galerus zu vergleichen.

Über meine Species fossiler Krebse kann ich Ihnen eine nachträgliche und zugleich berichtigende Mittheilung machen. Der Krebs Pemphix Sueuri (vorher P. spinosa) herrscht nun nicht mehr allein in der oberen Abtheilung des Muschelkalkes, dem sogenannten Kalkstein von Friedrichshall, wie es anfangs schien, sondern ist jetzt-auch, nach einem kürzlich bei Bergrath WaLchNer in Karlsruhe gesehenen schönen Exemplar, in dem Dolomitmergel bei Durlach gefunden, der die untere Abtheilung des Muschelkalkes bildet, und hier unmittelbar auf buntem Sandstein ruht. Aus diesem Dolomitmergel war mir bisher nur Pemphix Albertii von Horgen in Schwarzwald bekannt, der noch nicht in Schichten darüber gefunden ist.

Mein Makrouren-Genus Glyphea bcsteht nun aus folgenden fünf Species: Glyphea ventrosa, G. Regleyani (vorher Grovulgaris), G. Münsteri (vorher G. speciosa), G. Dressieri und G. pustulosa. Von diesen kommen G. Regleyani, G. ventrosa und G. Münsteri im Terrain à Chailles des Departements der Haute Saone, erstere am häufigsten, vor; G. Dressieri im Terrain $\dot{a}$ Chailles bei Besancon, G. pustulosa dugegen im Bradfordthon von Bouxweiler (Bas-Rhin). Es ist bemerkenswerth, dass letztere Form aus dem Bradfordthon weniger von den Species aus dem späteren Terrain à Chailles abweicht, als mehrere von diesen aus einer und derselben Zeit unter sich; hierin liegt wieder ein Beweis, wie wenig das relative Alter zum Maasstab des Grades von Abweichungen der fossilen Formen zu gebrauchen ist.

Von dem Krebse Pros op on hebes bin ich nun im Stande, Ihnen den Fundort anzugeben; er rührt aus dem Unteroolith von Crune, Departement de la Moselle her, während Prosopon tuberosum im cretajurassischen Gebilde zu Boucherans in Jura-Departement gefunden wurde, was zu bemerken nicht ohne Interesse seyn dürfte.

Unser verehrter Freund Voutz in Strasburg hat mir einen Crinoiden zur Untersuchung mitgetheilt, in welehem ich ein neues Genus er- 
kannte. Ich gab ihm den Namen Isocrinite s, und nanute die Species I. pendulus. Die Versteinerung besteht in dem Kelche mit etwas vom Stiel. Die Stielglieder sind Pentacriniten-artig, und auch mit quirlförmig gestellten Hülfsarmen versehen. Der Kelch lässt sich zunächst mit Pentacrinites und Encrinites vergleichen. Beckenglieder, die in Pentacrinites sich so deutlich vorfinden, und die in Encrinites in einem zerlegten letzten Säulenglied bestehen, dessen Stücke grosse Ausdehnung erlangt haben, konnte ich keine wahrnehmen. Es besteht dagegen ein ungetheiltes Glied von der Form der Säulenglieder, nur auffallend grösser und etwas aufwärts gebogen, das man als den Repräsentanten des letzten Säulengliedes und des Beckens zusammen betrachten könnte; das letzte Säulenglied ist bekanntlich in Pentacrinites auffallend klein. Während Pentacrinites und Encrinites zwei Reihen Rippenglieder besitzen, so enthält die neue Form nur eine Reihe, und diese Rippenglieder ragen nicht, wie in Pentacrinites, spitz über die Säule herunter. Die Einreihigkeit der Rippenglieder erinnert an Comatula, die indess sonst einem ganz andern Typus folgt. In unEerer Form waren die Rippenglieder nicht, wie die der ersten Reihe in Encrinites, zu einem Ringe verbunden, sondern getrennt, und konnten sich auseinander begeben, wie in Pentacrinites. Bei mehr geschlossenem Kelche berührten sich die Rippen-, Schulter - und ersten Arm-Glie: der an den Seiten, was Pentacrinites ganz zuwider läuft, und sich mehr Encrinites nähern würde, wo indess in diesem Fall nicht nur alle Armglieder, sondern sämmtliche Glieder des Kelches sich an den Seiten berühren. Auch das Schulterglied ist abweichend geformt; die 10 Arme sind paarig. Es besteht nicht der Übergang der Glieder eines Armes in eine paarige Hand, der Encrinite:3 so merkwürdig macht, sondern es lenkt, wie bei Pentacrinites, in jeden Arm eine paarige Hand ein; in Pentacrinites gehen diese Hände bis zum Ende des Kelches, und an ihnen sitzen in gewissen Abständen sogenannte Finger, wogegeu hier keine solche Finger vorhanden sind, dafür aber auf jeder Hand, nach einer gewissen Länge, wieder eine paarige Hand, so dass statt einer Reihe Hände mit Fingern, bloss paarige Hände, jedoch mehrere Peihen anzunehmen sind; man bemerkt hier wenigstens drei Reihen solcher paarigen Hände. An allen diesen Händen sind die vię ersten Glieder von den übrigen Gliedern verschieden, und so beschaffen, dass sie den Händen an diesen Stellen eine grössere Beweglichkeit gestattet haben werden. Im Sinne der einmal üblichen Nomenklatur habe ich diese Glieder Handwurzelglieder genannt; an Pentacrinites bemerkte ich nichts Ähnliches. Übrigens tragen Arme und Hände, wie Arme, Hände und Finger in Pentacrinites, Tentakeln. In Form und Zahl der Glieder, der Arme und Hände, so wie in andern Stücken bestelıen $A b-$ weichungen von Pentacrinites und Encrinites, neben Eigenthümlichkeiten, wie aus der Beschreibung und Abbildung zu ersehen seyu wird, die von mir in den Mémoires de la soc. d'histoire naturelle de Stras. bourg erscheint. Diese schöne Versteinerung rührt aus dem Calcaire 
corallien der Gegend von Besançon, und befindet sich mit der oben erwähnten Glyphea Dressieri in der Sammlung des Grafen Dressirr in Besançon.

Über die fossilen Nage $\mathrm{r}$ der Tertiärablagerung von Öningen kann ich Ihnen vorläufig eine Mittheilung machen, aus der wieder deutlich hervorgehen wird, wie leicht Irrthümer sich zu befestigen suchen, und wie begründet dás Misstrauen ist, dessen ich mich gegen manche frühere Untersuchungen nicht erwehren kann. Hauptsächlich auf KARG beruht die Annahme vom Vorkonmen dreier verschiedener Nager-Gattungen in der Ablagerung des Schiefers von Öningen, wozu die Sammlungen Lavater's, Zieglen's in Winterthur und des Meersburger Kabinets die Exemplare enthielten. Diese Nager sind die Hausmaus (Mus musculus), eine Haselmaus (Myoxus) in der Meersburger Sammlung, und ein Thier, das Gessner für ein Meerschweinchen hält, Blumeniacu für Scalpris, Karg für einen Iltiss; von mehreren Exemplaren dieser Species existirt nach Curien das vollständigste in der Karlsruher Naturaliensammlung. Die Hausmaus hat sich bereits als eine versteinerte Pflanzenwurzel herausgestellt; die Exemplare, vom zweiten und dritten Thier sind mit andern beträchtlichen Schätzen an Pflanzen und Insekten der Öninger Ablagerung aus der alten Meersburger Samnlung in die Sammlung in Carlsrule gekommen und durch die Güte des Professor Alex. Braun ward ich in den Stand gesetzt, diese Stücke genauer Untersuchung zu unterwerfen. Hiebei fand ich, dass die Versteinerung, welche der Errichtung des zweiten Nagers oder der Haselmaus zum Grund liegt, eine künstliche Zusammensetzung aus nicht weniger als drei verschiedenen Stücken ist, von denen nur das mittle Stïck einige Aufmerksamkeit verdient, das aber ein Stück aus des Rumpfes Mitte von den gleich $z u$ erwähnenden dritten Nager ist; die beiden andern Stücke rühren von Fischen her. Auf diese Weise löst sich also auch der zweite Nager von Öningen, die vermeintliche $\mathrm{H}$ as el$m a u s$, auf. Der dritte Nagcr endlich ist kein Iltiss, wofür ibn KARG nahm, sondern ein wirklicher Nager, wie Andere mit Cuvịer behaupteten, aber weder 0 ndatra, noch Anoema, wofür ihn zuletzt König in London erklärte. Beim Entblüssen der Füsse und Schneidezähne fand ich die Hinterfüsse vierzehig und alle Anzeigen für die Fünfzehigkeit der Vorderfüsse, während in Anoema die Füsse hinten nur drei und vorn nur vier Zehen besitzen. Das fossile Thier wird hiedurch den Hasen-artigen Thieren verwandt, wofür eine Bestätigungr in dem kleinen Schneidezälinchen liegt, das mir im Oberkiefer hinter dem grossen Schneidezahn zu entblössen gelang. Das übrige Skelett widerspricht so sehr der Struktur des eigentlichen $\mathrm{Hasen}$, als es sich für Lago mys (H a s enmaus) entscheidet. Da das aus der Lavater:schen Sammlung ins Brittische Museum gekommene Exemplar derselbeu Species seyn soll, der das Carlsruher Exemplar angehört, so wird jenes wohl auch nicht Anoema, sondern Lagomys seyn, was zu entscheiden ich Agassz bei seiner Anwesenheit in London gebeten habo. 
Hiedurch würden sich die drei Nager von Öningen theils wieder auflüsen, theils zu einem Lagomys vereinigen, die ich Lagomys 0 enin. gensis nenne, der auch die Reste angehören werden, welche letztlicb SEDGwick von Öningen nach England brachte, und in denen schon Latriclard in Paris gleichfalls Lagomys vernuthete. Die genaue Untersuchung und Abbildung des schönen Carlsruher Exemplars werde ich anderwärts bekannt macheu.

Bei der Zusammensetzung von Versteinerungen ist man früher mit dem Öninger Schiefer nicht weniger künstlich verfahren, als mit dem von Bulca. Die Carlsruher Sammlung hat von ersterem bemerkenswerthe Stücke aufgewiesen. In einer Platte ist der Mahlzahn eines Pferdes aus dem Diluvium, oder nicht einmal fossil, täuschend eingekittet, und dazu ist sogar eine Gegenplatte mit dem Abdrucke des Zahnes gemacht. Auf verschiedenen Platten sieht man andere Knochen, welche zum Theil fossil seyn können; aber gewiss nicht in dem Öninger Gestein sich vorfanden, zum Theil aber auch Säugethierknochen aus ganz neuer Zeit sind. Dass Fische aus mehreren und verschiedenen Species zusammengesetzt sind, und Schwanzstücken der S a la mandra giga ntea Köpfe von Fischen angekittet sind, um fossile Schlangen zu schaffen, ist gar nicht selten.

Es beschäftigen mich gegenwärtig auch die fossilen Knochen des fürstlich Fürsteneerg'schen Naturalien-Kabinets zu Donau-Eschingen, deren Mittheilung ich der Güte des Herrn Hofrath Dr. Remmans verdanke. Ich kann darüber Folgendes berichten. Die meisten Stücke rühren aus dem Bohnerzgebirge der Altstätter Grube bei Mösskirch im Baden'schen her. Darunter erkannte ich an Landsäugethieren Backeuzähne und Knochen von Rhinoceros, das ich einstweilen noch mit dem Namen $R h$. incisivus zu belegen mich genöthigt sehe, da ich es für unmöglich halte, aus diesen einzelnen Theilen mit Bestimm theit zu ersehen, ob sie dem Rhinoceros Schleiermacheri oder dern Aceratheri um incisivum angehören: es sind Reste derselben Art, wie in den meisten Rhinoceros-führenden Tertiärgebilden; 2) Mahlzahn - und Knoclien-Fragmente von Mastodon angustidens: diese Benennung gebrauche ich in demselben Sinn wie die von $R$ hinoceros incisivus, indem es mir nämlich nicht möglich ist, mit Bestimmt. heit zu entscheiden, ob sie von dem eigentlichen Mast od o n angustidens oder dem Tetracaulodon longirostris herrühren, icls aber die sichere Bestimmung der Species für zu wichtig erachte, als dass sie einem blossen Errathen anheim gegeben werden dürfte; es sind Reste derselben Art, wie sie sich in den meisten Mastodonoder Tetracaulodon - führenden Tertiärschichten auch anderwärts vorfinden und gewöhnlich unter der Benennung M a stodon angustidens begriffen werden, und darunter auch wohl noch länger zu stellen sind, weil es nach meinen Bekenntniss bis jetzt nicht möglich ist, aus solchen Theilen das Mastodon oder den Tetracaulodon zu ersehen; - 3) Ein Mahlzahn-Fragment von Dinotherium Bavari- 


\section{$-60$}

c um; - 4) Mahlzahnfragmente von einem oder zweien Schweins-artigen Thieren; - 5) ein Mahlzahn-Fragment eines $\mathbf{T}$ a pir-artigen Thieres; - 6) ein Mahlzahn-Fragment von $P$ al a e o the riu m ; - 7) der grosse Mahlzahn aus dem Oberkiefer eines Fleischfressers, einer der stärksten unter den bis jetzt bekannten, der einen neuen Fleischfresser anzeigen würde, zwischen $\mathrm{Felis}$ und $\mathrm{Hyae} \mathrm{na}$; ein Eckzahn in Warchner's Sammlung aus deniselben Gebilde scheint auch von dieser Species herzurühren; - 8) Ein Eckzahn-Fragment, eigent!ümlich geformt, das ich noch keinem Thier zuweisen kounte; 9) wenigstens zwei Wiederkäuer, von denen der eine die Zahn-Struktur der lebenden, der andere, ein kleinerer, solche Zahnstruktur,besitzt, wie ich sie bis jetzt nur an Wiederkäuern erloschener Genera vorgefunden. Von Meeres-Säugethieren sind 10) Rippenfragmente des Cetaceen vorhanden, das so häufig im tertiären Sande bei Flonheim gefunden wird. Von Reptilie u kenne ich 11) Zähnc eines grossen $S$ a urus, der vielleicht dem Krokodil am nächsten steht; und 12) in WaLchNer's Sammlung aus derselben Ablagerung ein Fragment aus dem Panzer einer Schildkröte, von dem es schwer halten wird, $z u$ entscheiden, ob es von einer $\mathrm{E}$ m y s oder von Testudo herrührt. 13) Von Fischen ist ein Gaumenstück mit Pflasterstein -förmigen Zähnen, wie ich ein ähnliches in dem tertiären Sande bei Uffhofen unfern Flonheim fand, und 14) Zähne von Lamna denticulat a vorhanden, die auch bei Uffhofen und Flonheim häufig vorkommen, und überdiess den Muschelsandstein der Molasse charakterisiren. Ich möchte daher auch dieses Knochen-führende Bolınerz-Gebilde von Mösskirch, oder vielmehr den Knochenreichthum desselben in jene OberTertiärzeit bringen, zu der der Muschelsandstein der Molasse gehört. In dieser Sammlung liegt auch ein oberer Mahlzahn von $R$ hinoceros tichorhinus von Mösskirch, im Aussehen denen aus dem Diluvium oder den Höhlen ganz ähnlich.

Aus den fossilen Kuochen der Fürstenrerg'schen Sammlung ergibt sich ferner, dass in der Gegend von Klosterwald im Sigmaringischen eine ähnliche Ablagerung liegt mit abgerundeten Fragmenten von Backenzähnen des Mastodon angustidens. Von Walpertsweiler bei Klosteruald rühren Knochen von Landsäggethieren her, eine Rippe des Flonheimer Cetacee's und Reste von F is chen; auch diese Ablagerung wird tertiär seyn; das Gebilde ist ein feiner mergeliger Sand von grünlich-weisser Farbe. Ein dem Sandgebilde bei Walpertsweiler ähnliches Gebilde liegt bei Pfullendorf, von wo mehrere Reste herrühren, Mahlzähne von Rhinoceros incisivus, Zahn-Fragmente von Mastodon angustidens, ein Zahn von Flonheimer Cetaceen, ein Zahn von einem Saurus, der verschieden ist von dem aus der Altställter Grube bei Mösskirch; Wirbel von einer Fisch von mittler Grösse und, wie es scheint, von einer ähnlichen Species, wie die, welcher die bei Walpertsweiler gefundenen Reste angehören.

Unter den fossilen Knochen der Fürstenberg'schen Sammlung sind auch Landsäugethier-Knochen aus dem Gypsgcbilde bei Holienhöven, 
woraus Sic Ihre Testudo antiqua beschrieben, die in diesem Gebilde so zahlreich ist. Ich werde diese Reste von Landsäugethieren, mit denen, welche aus derselben Ablagerung Baron Acthaus in Dürrheim und Bergrath Walchner in Carlsruhe besitzen, somit wohl Alles, was bis jetzt dort gefunden wurde, näher untersuchen. Unter diesen Knochen aus der Fürstenberg'schen Sammlung befinden sich welche von grösseren uud kleineren Thieren, namentlich aber ein Phalanx von einem sehr grossen $\mathbf{P}$ achyder men.

Meine Arbeit üler die Knochen aus den Torfmooren von Enkheim bei Frankfurt und von Dürrheim im Baden'schen, deren letztere mir von Baron Azthaus gütigst mitgetheilt wurden, ist nächstens beendigt. Sie wird sich hauptsächlich über die an den. beiden genannten Orten vorgefundenen Reste von Emys verbreiten, und an denselben wohl die merkwürdigsten individuellen Abweichungen nacliweisen, sowohl in Betreff der Knochenplatten als auch der Schuppenbedeckung. Von Enkheim kenne ich bis jetzt Reste von Emys, Ochs, Pferd, Hirsch, 2 Vögel, Mensch, Sumpfkonchylien, Töpferwaren etc.; von Dürrheim: Emys, Frösche, 2 Maus - artige Nager, Reh, Hirsch, Bos primigenius, Pferd, Canis, Meles, 2 Vögel, Mensch, Sumpfkonchylien, Töpferwaaren, andere Artefakten etc.

\section{Herm. v. Meyer.}

\section{Strassburg, 8. November 1835.}

Sie erhalten hiebei einige interessante Gypsabgüsse von Jura-Versteinerungen, welche Ihnen hoffentlich angenehm seyn werden: sie sind so instruktiv als die Originalien selbst. In Kurzem hoffe ich Ilınen eine kleine Arbeit über Nerineen nachzusenden, welche so wichtig für die mittle und obere Jura-Abtheilung sind. Die Angabe AD. Brongnrart's, dass Mantellia eylindrica in Muschelkalk vorkomme, ist irrig, und durch eine Verwechslung veranlasst worden: sie stammt aus dem Gryphitenkalke. Im Keuper haben wir kürzlich eine kleine Ophiura gefunden.

Voltz. 


\section{Neueste Literatur.}

\section{A. Bücher.}

\section{4.}

Gr. Fr. v. Mandelsloh: geognostische Profile der Württembergischen Alp, durch einen Vortrag erläutert bei derVersammlung der Deutschen Naturforscher in Stuttgart, 36 SS. $4^{\circ}$. mit 3 lith. illum. Tafeln, [nicht in Buchhandel; Pg. 3 und 4 wurden später umgedruckt, und das Ganze erschien verbessert in unten folgender Übersetzung.]

L. Prlla: osservazioni geognostiche, che possonsi fare lungo la strada da Napoli a Vienna. Napoli, $91 \mathrm{pp} . \mathrm{s}^{\circ}$.

\section{5.}

DE LA BÊche: How to observe. Tome 1. Geology. London, $8^{6}$. with 138 woodcuts [10 sh. 6 d.]

Alex. Bertrand: the revolutions of the globe, familiarly described, Edinburgh.

F. C. von Beust : Geognostische Skizze der wichtigsten Porphyr-Gebilde zwischen Freiberg, Fraucistein, Tharandt 4. Nossen. 112 SS. $8^{\circ}$. mit einer petrogr. Übersichts - Karte und 7 Blättern geognostischer Zeichnungen. [3 fl. $18 \mathrm{kr}$.]

Le Blanc et Watter: Métalluryie pratique du fer, ou Atlas des machines, appareils et outils actuellement employés à la fabrication de la fonte du fer; - avec un texte méthodique etc. in $4^{\circ}$. Paris Livrais. I. avec $6 \mathrm{pl}$. in Fol. $[12 \mathrm{Fr}$. Erscheint in Quartal-Lieferungen und gibt 1 Band Text.]

F. Dreves: und A. Wiggers: die Mineralquellen bei Wildungen. Göttingen, 112 SS. $8^{\circ}$. [Äusseres der Gegend; Geognosie derselben; Analyse der Quellen.] 
ÉLIE DE BEAvmont: Extrait d'une série de recherches sur quelquesunes des révolutions de la surface du globe. Paris $8^{\circ}$ [ $3 \frac{1}{2} \mathrm{Fr}$.]

Founner: Études sur les dépôts metallifères. Paris $8^{\circ}$.

S. Grus: statistique minéralogique du departement de la Drôme, 300 pp. $8^{\circ}$. a Grenoble.

T. E. GuMpprecht: Beiträge zur geognostischen Kenntniss einiger Theile Sachsens und Böhmens. 238 SS. mit 9 Kupfer [?]-Tafeln. Berlin $8^{\circ}$. [3 fl. $36 \mathrm{kr}$.]

G. F. JÄGER: über die fossilen Säugethiere, welche in Württemberg aufgefunden worden sind. - Erste Abtheilung, die in der Molasse, den Bohnerz - Ablagerungen des Jurakalks und in dem Süsswasserkalke von Steinheim aufgefundenen Überreste enthaltend. Stuttgart, 70 SS. und 9 lithogr. Taf. in Fol. [5 fl. $24 \mathrm{kr}$.]

J. Lindery and W. Hutton: The fossil Flora of Great Britain, London 1835, Aprilheft [5 sh. 6 d.g] enthält: $S$ phaenopteris polyphylla, Sph. serrata, Sigillaria Murchisoni, Otopteris dubia, Sph. macilenta, Lepidophyllum trinerve, Pecopteris lonchitica, P. dentata, Otopteris cuneata, Sphaenopteris latifolia.

Lindeey and Hutton: t'le fossil Flora of Great Britain, Juli 1835 [5 sh. 6 d.g] enthält: Pecopteris acutifolia, P. obtusifolia; Sphaereda paradoxa; Sphaenopteriscrassa; Lepidoden. dron longifolium; Lepidostrobus comosus; L. ornatus; Pinus anthracina; Zamia gigas; Stigmaria ficoides.

Fr. de Mandelsloh: Mémoire sur la constitution géologique de l'Albe du Württemberg avec des profiles de cette chaine, $42 \mathrm{pp} .4^{\circ}$ et 3 pl. lithogr. Strassburg (s. o. 1834).

De Montrosier: du Cantal, du Basalte et des anciennes rérolutions ds la terre, en réponse à un nouvel écrit de Mr. ELIK DE BEAUMOXT. Clermont Ferrand, 80. (Extrait des Annal. de l'Auvergne).

H. Nyst : Recherches sur les coquilles fossiles de la province d'Anvers. Bruxelles $8^{\circ}$.

Fr. A. Römer: die Versteinerungen des norddeutschen Oolithengebirges, mit 12 lithographirten Tafeln. Erste Abtheilung, Text p. 1-74 und alle Tafeln enthalteud. Hannover $4^{\circ}$.

Rozet: Traité élémentaire de géologie, $8^{\circ}$, avec Atlas in $4^{\circ}$. de 13 planches, Paris [18 Fr.]

A n $\mathrm{g}$ e k ü n d i g t :

C. Hartapion: Lehrbuch der Mineralogie und Geologie, II, $8^{\circ}$ mit $\mathrm{X}$ Queerfolio - Kupfertafeln. Nürmberg [8 fl.] 


\section{4 \\ B. Zeitschriften.}

F. Cassola e L. Pilla: 10 spettature del Vesuvio e de'Campi Flegrei. $\left(\right.$ Napoli $\left.\boldsymbol{8}^{\circ}\right)$.

\section{2 : Fascicolo I*), Num. 1. Juli - August.}

Einleitung. Seite 1.

Erste Exkursion nach dem Vesuv an 5. Juli. S. 6.

Chemische Untersuchung der dabei gesammelten Erzeugnisse: der

Strom - und Massen - Lava, der Auswürflinge, der Salze und der Gase. S. 20-36.

$1 S 32$ : Fascicolo I, Num, 2, Septbr. - Oktober.

Zweite, dritte und vierte Exkursion, an 1., 9., 16. August, durch die Ausbrüche in dieser Zeit veranlasst. S. 1-19.

Übersicht der meteorologischen Erscheinungen während derselben, nach den Beobachtungen auf der Sternwarte. S. 20-21.

1S32: Fascicolo I, Num. 3, Novbr. - Dezember.

Fortsetzung der Beschreibung obiger Exkursionen und der meteoro-

logischen Beobachtungen. S. 1-12.

Fünfter Ausflug nach dem Vesuv am 17 Oktober, S. 12-16.

Beschreibung und analytische Untersuchung der Erzeugnisse des. letzten Ausbruches, der Strom - und Massen-Laven, der Auswürflinge, der Sublimationen, umgewandelter Materien und Gasstoffe, - Meteorologische Beobachtungen. S. 16-31.

1833 : Fascicolo II, **) Num. 1, 2, Jänner - April.

Sechster Besuch des Vesuvs am 9. Dezember 1832. S. 1-8.

Siebenter Ausflug am 23. Dezember nach dem Ausbruche, und atmosphärischer Zustand, S. 8-23.

Achte Exkursion am 12. Jänner 1833 und Bèsteigung des innern Kegels. S. $23-43$.

Beschreibung und chemische Untersuchung der Erzeugnisse des letzten Ausbruches, S. 43-57.

Messung des innern Kegels; meteorische Erscheinungen. S. 57-59.

1833 : Fascicolo II, Num. 3, Mai - Juni.

Neunter Besuch am 4. Juni, bei dem Ansbruche und meteorische Erscheinungen dabei. S. $59-74$.

Beschreibung und chemische Untersuchung der Erzeugnisse dabei. S. $74-80$.

Übersicht der wichtigsten Beobachtungen, welche im bisherigen ersten Jahrgang dieses Journales berichtet worden. S. 80 .

*) Der erste Faszikel kostet für den Fremden 16 Franes Pränumeration.

*) Dieser Faszikel mit 3 Nummern kostet 10 Yrancs Vorausbezahlung. 
Über einen Springquell und einen $\$ 0$ Palmen tief in Tuff aufrecht stehenden Zypressen - Stamm bei Torre dell'Annunzicita, nach AuLdjo, S. 84-89.

Meteorologische Beobachtungen. S. 90 .

L. Pruta: Bulletino geologico del Vesuvio e de' Campi Flegrei. (Napoli, $\left.8^{\circ}\right)$.

1534: Num. 1.

\section{- Einleitung.}

Beschreibung einiger im Krater des jetzigen inneren Kegels des

Vesurs bei seinen Ausbrüchen beobachteten Phänomene. S. 8-15.

Zehnter Besuch des Vesuvs, am 14. und 15. August 1833, nach neuem Ausbruche. S. 16-23.

Eilfter Ausflug am 28. und 29. November nach neuen Ausbrüchen in diesen Monate. S. 24-33.

Zwölfte Exkursion am 31. Dezember 1833. S. 34-35.

\section{4 : Num. 2.}

Dreizehnter Ausflug am 21. Jänner 1834. S. 1-6.

Vierzehnter Ausflug am 24. Jänner. S. 6-11.

Fünfzehnter Ausflug am 2. März. S. 11-16.

Sechzehnter Besuch am 21. März. S. 16-24.

Siebenzehnte Exkursion vom 25. April. S. 24-30.

\section{S34: Num 3.}

Beschreibung und analytische Untersuchung der Erzeugnisse des

Vulkanes vom Dezember 1833 bis April 1834. S. 1-8.

Achtzehnter Besuch am 31. Mai. S. 8-11.

Neunzehnter Besuch am 7. und 8. Juni. S. 11-23.

Beschreibung eines Granit-führenden Trachytes der Insel Ischia.

S. 23-28.

Kapsten's Archiv für Mineralogie, Geognosie, Bergbau und

H üttenkunde. Berlin $8^{\circ}$, (vergl. Jahrb. 1835, S. 461) enthält ausser rein Berg - und Hütten - männ'schen Abhandlungen in

\section{5: VIII, II, S. 273-416, Tf. IV-X.}

BескS: geognostische Bemerkungen über einige Theile des Münster-

Landes, mit besonderer Rücksicht auf das Steinsalzlager, welchẹs

die Westphälischen Soolen erzeugt. S. 275-389.

Вескs: über das Vorkommen fossiler Knochen in dem aufgeschwemmten Boden des Mïnster-Landes, S. 390-417, Tf. Iv, v.

Löw : über das Zusammenvorkonmen fossiler Thierknochen mit KunstProdukten in den Sandgruben des Kreutzberges bei Berlin. S. 479 bis 487 .

*) Drei Nummern kosten für den Fremden 5 Franes Pränumeration; - beim Verf. 
Tıntscher: Bemerkungen über den Fränkischen Jura-Dolomit S. 488-496. Krug voi NidDa: über das Vorkommen des Anthracit's auf einen Gange in Granit im Erzgebirge. S. 497-499.

Journal of the Geological Society of Dublin. Dublin, $8^{\circ}$. (vergl. Jahrb. 1835, \%3).

\section{$1 S 34:$ I, II.}

Anrede des Präsidenten bei der 2ten Jahrs-Versammlung am 13. Febr. 1833. S. 53.

J. Рetherick: über die Geologie der Ungebung der Alten-Minen in Finnmark. S. 66-68.

R. J. Graves: über einen Granit-Gang im Glimmerschiefer der Graf. schaft Wicklow, S. 69-71, mit Abbildungen.

Pontlock: Bemerkungen über den Basalt-Distrikt in Nord-Irland. S. $71-74$.

Portwock: über die Schwierigkeit, die Identität der Schichten herauszustellen. S. $75-79$.

Bericht über fossile Equiseten bei Carrickfergus. S. 79-82.

H. Lxoxd: Notitz über einige bemerkenswerthe Erscheinungen in Graniten südlich von Dublin. S. $83-85$.

J. Hodgson Holdsworth : über die Geologie des Bezirkes der Knockmahon-Gruben in der Grafschaft Waterford. S. 85-99, mit 1 Karte.

J. M'Aрsм: Bericht über den Erdfall, der kürzlich zu Larne in der Grafschaft Antrim Statt hatte. S. 100-103.

J. Арјону über die neulich zwischen Caher und Mitchelstown entdeckte Höhle. S. 103-111 mit 2 Grundrissen.

W. Aisswortн: fernerer Bericht über die Trappfelsen von Limerick. S. 112-128, mit 1 Karte.

J. M'Adar: über die Geologie des Bezirkes von Famet in der Grafschaft Donegal. Erste Mittheilung. S. 128-139. 


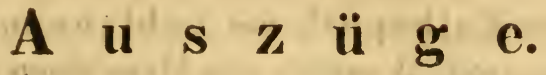

\section{Mineralogie, Krystallographie, Mineralchemie.}

Fuchs: Analyse der schwarzen Kreide (Zeichn'-Schiefer) von Luidwigstadt im Bayreuthischen. (ERdmanin und Schweigcer-Sridex, Journ, für Ch. V, 322).

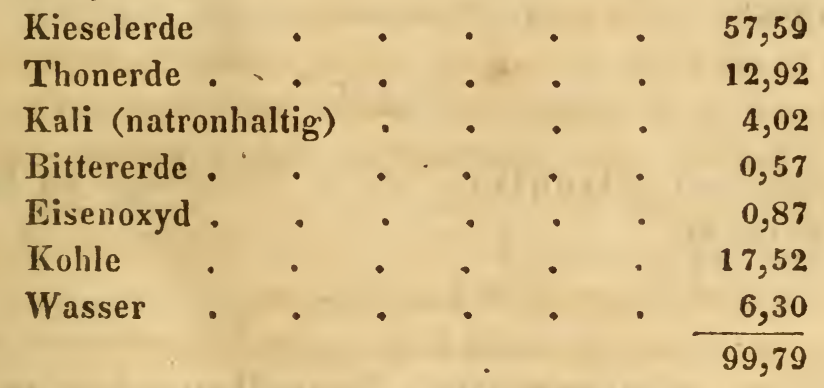

C. U. Shepand: der Microlith, eine neuo Mineral-Gattung (Silliman, Amer. Journ. of Sc. 1835, XXVII, 361 etc.). Kernform: regelmässiges Oktacder; abgeleitete Gestalten: enteckt; vierfach enteckt in der Richtung der Flächen. Unvollkommene Durchgänge parallel den Kernflächen. Bruch muschelig ins Unebenc. Harzglänzend. Farbe: gelb ins Röthlich-Braune. Durchscheinend bis durchsichtig. Strichpulver weiss; nur wemn das Mineral braun ist, zeigte er sich eben so gefürbt. Härte 5.5. Eigenschwere $=4.75$ bis 5.00. Bleibt fïr sich vor dem Löthrohr unverändert; lösbar in Boraxglas und dieses gelb färbend. - Fundort: Chesterfield in Massachusetts; Vorkommen auf Albit, seltener in Turmalin eingewachsen.

O. Linné Erdnañ: Analyse des sogenannten Chloritspathes (Ernmann u. Scuwhigen-Smider, Journ. f. Chem. 1835, VI, 89). 
Unter dem Namen Chloritspath hat Fradsa ein neues Mineral beschrieben, welches in Begleitung des Diaspor bei Kosoibrod in Ural vorkommt. Resultat der Analyso:

$\begin{array}{lllllll}\text { Kieselerde } & \cdot & \cdot & \cdot & \cdot & \cdot & \mathbf{2 4 , 9 3 1} \\ \text { Eisenoxydul } & \cdot & \cdot & \cdot & \cdot & \cdot & \mathbf{3 0 , 0 4 7} \\ \text { Thonerde } & \cdot & \cdot & \cdot & \cdot & \cdot & 45,016 \\ & & & & & & 99,994\end{array}$

Berzenius: über Kalkspath mit kohlensaurem Kupfer-Oxydul (XIVr Jahresber. 195). B. erhielt von Hess einen strahligen Kalkspath, der fast weiss, kaum merkbar gelblich ist, und die Eigenschaft besitzt, beim Erhitzen bis zum anfangenden Glühen, cine dunkle Farbe anzunehmen und nach dem Erkalten blutroth zu werden. Siberien ist das Vaterland dieses Kalkspaths. HEss hat gefunden, dass das färbende Prinzip Kupfer-Oxydul ist, und da das Mineral erst nach dem Glühen roth wird, so zeigt diess, dass es das Kupfer-Oxydul mit Kohlensäure verbunden enthält, eine Verbindung, die zum ersten Male in der Mineralogie auftritt.

Kohlensaurer Strontian wurde neuerdings zu Schoharie in New-York entdeckt.

L. Fr. BLey: Analyse einer Porzellanerde vom Gute Gutenberg unweit Halle an der Saale. (Erdmar und SchwaggerSeidвr, Jour. d. Chemie V, 313 ff.).

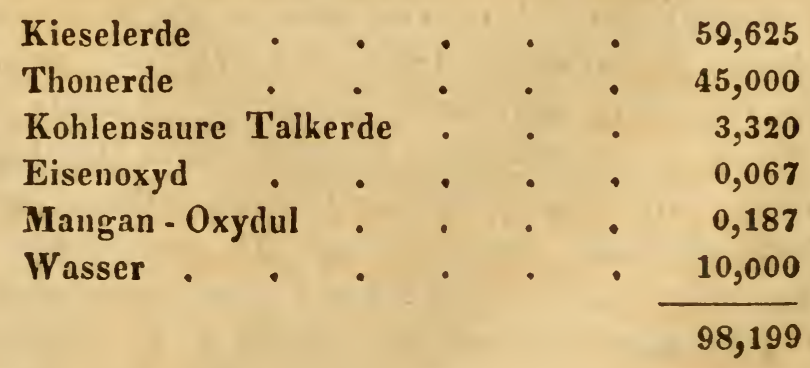

Fucrs: überTriphyllin (A. a. O. S. 319). Vgl.Jahrb.183.5, 198. Das Mineral kommt auch bei Rabenstein am BryerischenWalde in dem nämlichen Bruche yor, wo der rosenrothe Quarz, der Beryll, Tantalit u. s. w. sich finden : scine Begleiter sind: Feldspath, Glinmer und Quarz. Der vermeint 
liche Triplit, welcher dort getroffen wird, ist nichts als verwitterter Triphyllin, der keine Spur von Lithion melır enthält. Die Analyse ergab:

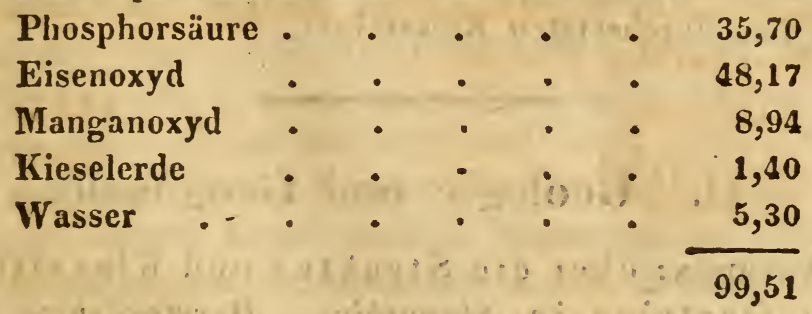

Forchinmare: Zerlegung des Ocrstedits. Behzishus, JahrsBericht 209). Vergl. Jahrb. 1835, 342. Dieses neue Mineral findet sich zu Arendal vom Augit begleitet, auf dessen Krystallen es aufgewachsen ist. Seine Farbe ist braun, es hat Glasglanz und zeigt eine schr zusammengesetzte, dem Pyramidal-Systeme angehürige, Form, welche etwas Ähnlichkeit mit der des Zirkones hat. Spezifische Schwere $=$ 3,629. Härte zwischen Feldspath und Apatit. Die Analyse ergab:

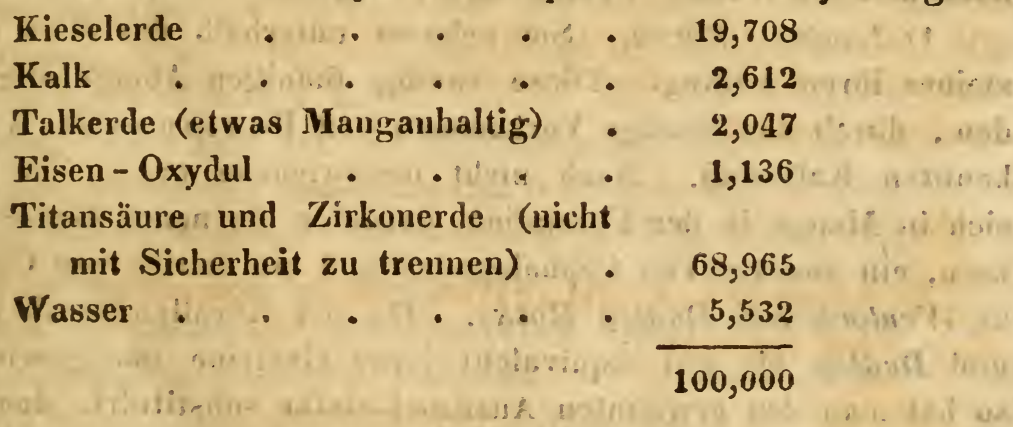

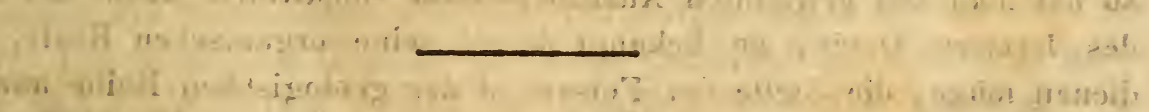

IM. LApps: Analyse eines Asbestes von Koruk, einein Arme des Pissiksarbik-Fiords in Grönland. (Poggendorfy's Ann. d. Phys. XXXV, 486).

Kieselerde

Eisenoxydul . • . • . .

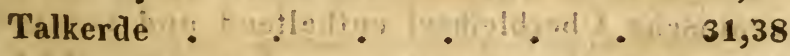

Kalkerde (mit etwas Eisen-Oxydul) 0,04

Mangan - Oxydul, äusserst geringe

Spuren

Kupferoxyd

Thonerde

Phosphorsäure?

Verlust$$
\begin{array}{cc}
\because & \ddots \\
- & \ddots \\
. & \ddots \\
. & .
\end{array}
$$ 


\section{$-70-$}

G. B. Grabrovgr entdeckte 1dokras auf dem Eilande Skye. Das Mineral kommt unfern Broadfurd vor, an der Grenze eines Trápp-Dykes und des von ihm durchsetzten Kalksteines.

\section{Geologic und Geognosie.}

R. J. Murchison: über die Struktur und Klassifikation der Ubergangs-Gesteine in shropshire, Herefordshire und in einem Theilevon Wales, so wie über die Merkmale erlittenex Störungen, welche jene, das Erhebungs-Thal umschliessende, Ablagerungen tragen (Lond. and Edinb. philos. Hag. and Journ. of Scienc. IV, $3 \mathbf{Z} 0 \mathrm{etc}$.). Der Verfasser beschäftigte : sich neuerdings mit Untersuchung der Transitions -Gesteine, namentlich der Versteinerungen - fübrenden Grauwacke, im östlichen Theile von Herefordshire, in einigen Gegenden von Monmouth, Gloucester, Worcester und Staffordshire. Er stellt, nach vorhandenen fossilen Resten, so iwie nach den Lagerungs - Beziehungen, folgende Klassifikation auf:

1) Ludlow Rocks. Sie nehmen unterhalb des alten rothen Sandsteines ihren Anfang. Diese sandig thonigen Ablagerungen enthalten den, durch das häufige Vorkommen von Pentamerus Knightii bekannten Kalkstein. Noch nicht-beschriebene organische Reste finden sich in Menge in der Formation, darunter ein neues Genus von Krustazeen, ein anderes von Cephalopoden und ein drittes von Conchiferen. 2) Wenlock und Dudley Rocks. Da der Korallen-Kalk von Wenlock und Dudley als ein Äquivalent jener Gesteine nachgewiesen worden, so hat man den erwähnten Ausdruck dafür substituirt, damit der Name des letz.tern Ortes, so bekannt durch seine organischen Reste, dazu dienen möge, die Stelle der Felsart in der geologischen Reile anzudeuten. Den untern Theil der Formation bezeichnet der. Verfasser. mit dem Ansdrucke Wenlock-S chiefer, die frülere Benennung "Earth" führte zu Missverständnissen. - 3) Horderley und May Hill Rocks. Die Formation, as Muscheln-führendem Sandstein, aus unreinem Kalkstein u., s. w. bestehend, ergab sich bei genauterer, Untersuchung als noch mehr organische Üherbleibsel enthaltend und von grösserer Mächtigkeit, als frïher vernuthet worden. - A) Builth und Llandeilo Flags. Vorzïglich bezeichnet durch grosse Exemplare von Asaphus Buchii. Man kannte die Gebilde, ais besonders schön entwickelt in den Grafschaften Crermarthen und Brecknock bekannt; sie wurden neuerdings zu Rorington in Westen von Shropshire nachgewiesen. - 5) Longmynd und Gwastaden Rocks. Bilden den ausigedehuten Hügelzug von Longmynd, Linley u. s. w. Versteinerungen führen sie nicht. - Jede der vier erwähnten, Petrefakten enthaltenden Formationen ist leicht unterscheidbar durch die Eigenthüılichkeit des Charakters derselben, durch petrographische Merkmale und geographische Grenzen, während das unterliegende System von Schiefern und Konglomeraten vollkommen 
davon abweicht. - In elnem andern Kapitel schildert der Verf. diejenigen, der erwähnten Fels-Gebilde, welche in den Aberrley-Bergen, an den Seiten der Malvern. Berge u. S. w. vorkommen. Die Ludlow- und Wenlock-Rocks zeigen sich am mäclitigsten und beharrlichsten entwickelt. - Erhebungs-Thal von Woolhope. Es soll das am meisten symmetrische in Britannien seyn und findet sich im S.O. von Hereford, wo die zwei oberen Formationen der Grauwacke-Reile in der Runde um eine mittlere Kuppel-förmige Masse gelegen sind, welche aus dem Muscheln - führenden Sandstein der dritten Formation besteht; die Schichten fallen stets nacli allen Seiten unter Winkeln von 15 bis $70^{\circ}$. Die festen Schichten widerstanden der Zerstörung, während die Schiefer weggeführt worden, und so machen jene die höhern umkreisenden Züge aus, letztere aber lassen tiefe Einschnitte wahrnehmen. Die äussere Zone hat alle fossile Reste aufzuweisen, welche die Ludlow Rockis charakterisiren, und zieht sich unter dem Old red Sandstone hin; die innere Zone enthält die Petrefakten des Koralleu-Gebildes von Wenlock und Dudley, und beide umbüllten gewissermaasen einen Kern der dritten Formution. Die äusserste Zone blieb undurclibrochen auf zwei Drittheilen ihres Umfanges, allein bei Mordifurd sieht man dieselbe gewaltsam verschoben, und das Resultat ist eine Kluft, durch welche, so wie durch einige kleine Spalten, das Thal gäuzlich trocken gelegt worden. Das Thal ist ein Entblössungs - Thal, frei von allen Fels-Trümmern, selbst von denen des Old red Sandstone, obwohl die emporgehcbenen tiefern Schichten durch dieses Gebilde hindurch getrieben worden seyn müssen. Die Erhebungs-Linie streicht aus N.W. nach S.O. und solil sich bis Gloucestershire erstrecken, woselbst die drei oberen Grauwacke-Formationen wieder auftreter. - - Das vorherrschende Streichen der sämmtlichen geschilderten Ablagerungen ist von NO. nach S.W. Die westlichen Grenzen der Grafschaften Salop, Hereford, Brechnock und Caermarthen zeigen die nämliche Schichten-Richtung. Die Länge d’es Landstrichs beträgt ungefähr 100 Meilen, die Breite 30 bis 40 M. Innerhalb dieses Raunes sind zahlreiche kleine ElevationsAxen, welche sich nur auf kurze Entfernungen, auf der Hauptstreichungs-linie verfolgen lassen, aber alle sind vollkommen parallel unter einander und der grossen Erhehungs - Linie untergeordnet. Meist findet man sie bezeichnet durch hervortretende Trapp-Pücken, an ihren Seiten senken sich die Schichten gegen N.W. und S.O.; und wo solche parallele Ausbrüche gehäuft sind, wie z. B. zwischen Wenlock elge und dem Viemiew-Flusse, veranlassten sie Überstürzungen der Schichten, während da, wo jener Parallelismus vermisst wird, die jüngere Formation, die von Ludlow und Wenlock, in wenig gestörten Lagerungs-Verhältnissen die senkrechten und manchfaltig verrückten ältern Felsschichten bedecken. - Dic Erhebungs-Linie, deren Mittelpunkt die TrappGesteine von Old Radnor bezeichnen, endigt gegen N.O. im ErhebungsThale von Wigmore, das Vorgebirge von Lullow bildet den erhabensten Punkt. - Lie allgremeine Streichungr-Linic wird der Queere nach 
durchbrochen von manchen Rissen und Klüften, die mitunter grosse Verrückungen veranlassten. - An der üstlichen Seite des old red Sand. stone von Herefordshire senken sich die Schichten, bestimmt durch Trapp- und Syenit-Züge von Abberley und Malvern, aus N. nach S.; allein zahllose Ausnahmen, Krümmungen und Biegungen, Rücken und Wechsel finden Statt. - - Der Bergkalk und die Steinkohlen - Formation von Wellington und in den Titterstone und Clee Hills, sind, wo sie von Basalten durchdrungen werden, in derselben nordöstlichen und südwestlichen Richtung emporgetrieben, wie die Grauwacke-Reihe von Salop und Wales, während in den Abberley Hills und um Dudley in Staffordshire eine südliche Bewegung sowohl auf die Transitions. Gesteine, als auf die Kohlen-Gebilde eingewirkt hat. - Eine besonders denkwürdige Verrückung ist die gänzliche Umdrehung der beiden jüngern Formationen der Grauwacke-Reihe auf eine Erstreckung von mehreren Meilen von den Seiten der Abberley-Berge. In diesem Zuge ruben die untern Ludlow Rocks, auf den obern unter Winkeln, die von 70 bis $z u 5^{\circ}$ wechseln, und der angrenzende parallele Rücken des Wenlock-Kalkes erscheint darüber hingestürzt. Muthmaaslich wurde die Erscheinung bedingt durch das Ausbrechen der anstossenden Trapp. Berge von Abberley und Woodbury.

J. Rofe: Geologie der Gegend von Reading (Lond. and Edint. Mag. Vol. V, p. 212). Der obere Theil der Kreide erscheint, bis zur Tiefe eines Fusses, von Röhren - artigen Kavitäten durchbohrt, älnnlich jenen, welche Folgen des Nagens von Holzwürmern sind. Die AusteruSchicht, über der Kreide ihre Stelle einnebmend, besteht theils aus braunem Thon, theils aus Sand mit Grünerde-artigen Partikeln; ,jede dicser Ablagerungen hat ungefähr $1 \mathrm{~F}$. Stärke. Über derselben kommt Thon etwa vor, $1 \frac{1}{3}$ F. mächtig, und quarziger Sand mit Ocker-Nieren.

Tantscher: Vorkommen der Kobalterze in den Kamsdorfer und angrenzenden Revieren (Karst., Arch.f. Min. B. VII, is.606 ff.). Mit Ausnahme des Glanz-Kobaltes kommen alle bekannte A.rten vor, aber nicht alle brechen zusammen, sondern sie sind an gewisse relative Teufen und Gebirgsschichten gebunden, theils allgemeiner in letzteren verbreitet, theils von besondern Lagerstätten, den sogenannten Gängen abhängig. Der Vf. unterscheidet ein Gang-und ein Flötz-artiges Vorkommen, und ausserdem noch drei Teufen, in deren jeder besondere Kobaltarten aufsetzen. Das gangartige Vorkummen hängt von den Rücken ab, welche auf manchfaltige Weise im Kalk-Gebirge sich einstellen und für dasselbe charakteristisch sind. Mitunter sieht man wirkliche Verschiebungen und Rutschungen von Gebirgstheilen; die gangartigen Vorkommnisse der untersten und oberen Teufen mögen 
melır Folge gewaltsamer Verrückungen der meist horizontalen Flützlagen seyn, als Absetzungen auf vorhandene Unebenheiten des Grund-Gebirges. Dergleichen gangartige Lagerstätten sind bei Kamsdorf die häufigeren. Mit den gangartigen ist ein flötzartiges Vorkommen bei den Kobalten in der Ârt verbunden, als gewisse Schichten im Hangenden oder Liegenden, auf grössere oder geringere Erstreckung von der Rücken-Fläche mit Kobalt, oft in Gesellschaft anderer Erze durchzogen sind; das Haupt-Yorkommen der Art findet jedoch auf weitere Verbreitung nur im Kupferschiefer und in der obersten Schicht des Weiss-Liegenden, unmittelbar unter dem Kalkflötz - Dache, mitunter auch in einigen Kalkstein-Schichten und in sogenannten Glimmerflötz statt. Auf der Lagerstätte selbst selten und schwer erkennbar, ergibt sich der KobaltGehalt erst durch Beschlag nach langem Liegen der Gebirgstheile in den Gruben oder an der Luft. Die Kobalte und die Fahlerze haben Arsenik- und Antimon-Gehalt. - Das flötzartige Vorkommen des Koba!tes ist im Kamsdorfer Reviere weit verbreitet; fast nirgends fehlt der Kobalt - Gehalt in Kupferschiefer ganz. - Was die drei Teufen beim gangartigen Auftreten des Kobaltes betrifft, so bemerkt der Vf. darüber Folgendes: Die unterste Kobalt-Teufe ist am sogenannten weissen Gebirg e (einer aufgelösten Thonschiefer-Schicht, dem verbindenden Glied zwischen Sandstein und Thonschiefer) und an Weiss - Liegenden. Hier ist der Sitz der Speiskobalte, begleitet von Fahlerzen, nicht selten auch von Kupfernickel und von Kupferkies. Nieren und Nester mehrerer Erze - auch nachdem das Gang-Verhältniss gegen die Teufe längst aufgehört hat - in das Grundgebirge niedersetzend, sind am häufigsten; selten ist das Vorkommen in langgedehnten Platten der Rücken-Fläche parallel. Kobalt - Blüthe und Kobalt - Beschlag fehlen nicht. $Z$ w eit e Kobalt-Teufe: Zwischen dem Kupferschiefer und dem Weiss-Liegenden nimmt zumal im Kobalt - Revier ein, höchstens ein Lachter mächtiges Kalkstein-Flötz seine Stelle ein. Am Kupferschiefer, und zunächst darunter, ist die zweite oder mittle Kobalt-Teufe. Hier findet man die braunen, gelben und grünen Erdkobalte, von Fahlerzen und KobaltBlüthe begleitet. Schwarzer Erdkobalt wird nie getroffen, Speiskobalt selten. Das eigenthümliche Auftreten der verschiedenen Kobalte in verschiedenen Teufen ist mit der eigenthümlichen Beschaffenheit der Rückenoder Gang-Verhältnisse, oder beider zugleich genaucr verbunden (der Verf. theilt zur Erläuterung einige besonders belehrende Profile mit). Schwarze Erdkobalte bilden die dritte oder oberste Kobalt-Teufe, von Kupferschiefer aufwärts bis in die oberste Abtheilung des FlötzkalkGebirges, den Dolomit-artigen Kalkstein. Der Kobalt sitzt $\frac{1}{8}$ bis 2 bis 3 Zoll mächtig in den Kalkstein-Klüften, wie Russ, hie und da auch auf Neben- und Schichtungs - Klüften sich hinausziehend. Mitunter ist das Nebengestein (Rauchwacke) mit schwarzem Erdkobalte fein, wie von Dampf durchzogen; auch in den Drusen und Poren siizt der Kobalt wie angehaucht. Sehr wahrscheinlich hat sich diese oberste Kobalt - Niederlage durch Sublimation abgesetzt. Dazu kommen gewaltsame, Schich- 
ten-Umstürzungen und der Unstand, dass von den Klüften aus eine Veränderung des Zechsteines in Dolomit vorgegangen zu seyn scheint.

MrLle : tertiäre Ablagerung der Gegend von Pointe-à-pêtre a u f Guadeloupe. (Ann. des Sc. et de l'industr. du midi de la France. III, Nro. 9. p. $1>$ Bullet. géol. $V, 414$ et 415.) Die Formation hat Ähnlichkeit mit der Muscheln-führenden Molasse in Süd-Frankreich und enthält in grösster Häufigkeit Pectiniten, Bukarditen, Pektunkuliten, Lithophagen, Echinodermen u. s. w.; es sind theils Steinkerne, theils Muscheln mit noch erhaltener Schale. Diese Versteinerungen verhalten sich zu den lebenden Wesen im Meere der Antillen etwa so, wie die fossilen Körper der Tertiär-Gebilde in Languedoc zu den Thieren im Mittellïndischen Meere. Wenn folglich unter den Versteinerungen auf Guadeloupe sich nur sehr wenige finden, die auch in Frankreich vorkommen (Echinoueus semilunaris LaM.), so müssen dennoch beide Gebilde in einer und derselben geologischen Zeitscheide entstanden seyn; ferner beweisen diese Differenzen, dass einst zwischen den Antillen und dem nürdlichen Frankreich Temperatur-Verschiedenheiten Statt fanden, wie diess noch heutigen Tags der Fall ist.

J. B. Boussingaurt: Versuch einer Ersteigung des Chimborazo, un ternommen am 16 . Dezember 1831 (Poggendonff, Ann. d. Phys. XXXIV, 193). Der Bericht enthält viele interessante physikalische Thatsachen; wir müssen uns auf Mitteilung der geologischen Wahrnehmungen beschränken. "Alle Beobachtungen", sagt B., "welche ich während dieses Ausflugs zu sammeln vermochte, neigen alle dahin, die Idee'n zu bestätigen, welche ich anderswo über die Natur der den Kamm der Andes bildenden Trachytberge ausgesprochen habe; denn auf dem Chimborazo zeigten sich alle Thatsachen wieder, welche ich bei $\mathrm{Be}-$ schreibung der Äquatorial - Vulkane angeführt habe. Offenbar ist dieser ein ausgebrannter Vulkan, wie der Cotopaxi, der Antisana, der Tunyuragua, und überhaupt alle auf den Plateaus der Andes stehenden Berge. Die Masse des Chimborazo besteht aus einem Haufwerk ganz ohne alle Ordnung über einander gethürmter Trachyt-Trümmer. Diese oft ungeheuern Trachytstücke eines Vulkans sird im starren Zustand gehoben; ihre Ränder sind scharf; nichts deutet darauf, dass sie in Schmelzung oder nur einmal im Zustande der Erweichung gewesen wären. Nirgends beobachtet man an irgend einem Vulkane Etwas, was auf einen Lavastrom schliessen lassen könnte. Niemals ist aus diesen Kratern etwas anderes ausgeworfun als Schlamm-Massen, elastische Flüssigkeiten und glühende, mehr orler weniger verschlackte Trachytblücke, welche oft in beträchtliche Entfernungen geschlendert wurden. - Den Fuss des Chimburazo bildet ein Plateau, welches man an den Bächen in der Nähe der Meierei im Detail studiren kann. Hier konnte ich auch er- 
kenuen, dass der Trachyt durchaus nicht geschichtet ist, wohl aber nach allen Richtungen zerklüftet. Dieses Gestein ist der Hauptmasse nach feldspathig, gewöhnlich von grauer Farbe, und schliesst Augit, so wie Krystalle von glasigem Feldspath ein. Der Trachyt erhebt sich gegen den Chimborazo und zeigt oft beträchtliche Spalten, die desto breiter und tiefer werden, je mehr sie sich dem Berge nähern. Man könnte sagen, der.Chimborazo habe, als er sich hob, das Plateau zersprengt, welches ihm zur Basis dient. Das Trachyt - Gestein, welches beinahe den grössten Theil des Bodens der.Provinz Quito ausmacht, bietet wenig Abweichung dar. Die vorworren aufgehäuften Blöcke, welche die vulkanischen Kegel bilden, sind mit dem Gesteine, aus welchem ihre Grundlage besteht, von ähnlicher mineralogischer Beschaffenheit. Diese Kegel und steilen Berge sind oline Zweifel gehoben durch elastische Flüssigkeiten, welche sich an den Punkten des kleinsten Widerstandes Luft gemacht haben. Der in eine Unzahl von Bruchstïcken zertrümmerte Trachyt ist, wie er war, an die Oberfläche gebracht, gehoben durch Dämpfe, die sich entwickelten. Nach der Eruption musste der zertrümmerte Fels ein grösseres Volumen einnehmen, da alle Stïcke nicht wieder dahin gelangen konnten, von woher sie gekommen waren; sie häuften sich also oberhalb der Öffnung an, durch welche die Entwicklung der Gase Statt gefunden hatte. Es ist genau, was geschehen würde, wenn man in einem harten und kompakten Felsen einen tiefen Brunnen ausgehauen hätte, und nun die dabei erhaltenen Steinstücke wieder hineinschütten wollte; bald würde der Brunnen gefüllt seyn, und wenn man fortführe: die Steinstücke längs -seiner Axe aufzuhäufen, so würde man über seiner Mündung einen Kegel bilden, der desto hüher seyn würde, als der Brunnen tiefer wäre. So sind, wie ich mir denke, der Cotopaxi, der Tunguragua, der Chimborazo u. s. w. gebildet. Die elastischen Flüssigkeiten, welche, nachdem sie die Trachytkruste zerrissen, sich einen Ausgang durch dieselbe bahnten, mochten die Oberfläche des Bodens mit bedeutenden, in mehr oder wenigen grossen Tiefen vorhandenen Höhlungen in Gemeinschaft setzen, und man begreift alsdann, dass die Anfangs gehobenen Felsstücke sich später senken und in diese Höhlungen begeben mochten. So musste sich dann, statt eines über der Eruptionsstelle erhobenen Kegels, eine Vertiefung auf der Oberfläche des Bodens bilden. So begreife ich die so merkwürdigen Senkungen, welche der Krater des Rucupichincha darbietet, so wie den grünen See der Solfatara des Tuqueres. Ich halte demnach die Bildung der Trachytkegel der Kordilleren für später, als die Hebung der Masse der Audes. Es sind diess indess nicht die jüngsten Hebungen, welche in diesen Bergen Statt gefunden haben. In der Nachbarschaft der höehsten Pies, namentlich des Cayambé, des Antisana und des Chimburazo beobachtet man kleine Berge, zwar noch aus Felsstücken bestehend, aber aus neuerem Gestein, welches merklich vom gewöhnlichen Trachyt abweicht. Es ist schwarz, porphyrartig, und seine Masse welche Krystalle von glasigem Feldspath einschliesst, ist durch Augit 
gefärbt ; die Feldspath - Krystalle sind ziemlich selten, und oft glaubt man Basalt zu sehen. Ich habe jedoch nie Olivin darin angetroffen. $\mathrm{Zu}$ weilen ist dieses Gestein kompakt und in Prismen angeordnet, zuweilen auch Schlacken-artig, erfüllt mit Löchern. Dann würde man es für Lava nehmen, wenn es etwas beträchtliche Strecken bedeckte; allein nun zeigt es sich immer in Stücken, welche selten Faustgrösse crreichen. Dieses Gestein ist offenbar in sehr neuer Zeit herausgetreten. $\mathrm{Zu}$ Chorrera de Pisque bei Iburra sieht man eine schöne Colonnade auf Alluvium ruhend. Bei dem Pachtgute Iysco hat sich dieses Gestein im Zustande von Bruchstücken eineu Ausgang durch den von ihm gehobenen Traclyyt gebahnt. Es ist da, wo Humbond geglaubt hat, einen Lavastrom aus dem Antisana hervorgetreten zu sehen. In einer andern Abhandlung habe ich die Gründe entwickelt, welche mich bewogen, dieser Meinung nicht beizutreten. Der am Fusse des Chimbora $\approx$ o liegende, erloschene Vulkan von Calpï besteht ebenfalls aus dieser Art von Basalt; wir haben ihn auf unserer Rückkelır nach RioBamba besucht. Mitten in dem Sande, welcher die ganze Ebene von Rio Bamba bedeckt, gewahrt man beim Dorfe Calpi einen Hügel von dunkler Farbe; es ist der Jana-urcu (schwarze Berg). Am unteren Theile dieses kleinen Berges sieht man Trachyt aus dem Sande hervortreten; er ist von gleicher Natur mit dem, welcher in einiger Entfernung den Chimborazo trägt. Dieser Trachyt scheint stark durchgerüttelt worden zu seyn; er ist voller Spalten und Risse in allen Richtungen. Der Abhang des Jana-urcu, nach Calpi hin, besteht aus kleinen Brocken des schwarzen Gesteins, deren Anhäufung ganz an die Stein - Eruption von Lysco erinnert. Es scheint sogar, dass diese Eruption am Jana-urcu erst nach der Ablagerung des die Ebene bedeckenden Sandes geschah; demn in der Nachbarschaft des Vulkans ist der Bodeu mit schwarzen schlackigen Steinen bestreut.

Heine: über künstliche Feldspath-Bildung (Poggendonfr's Ann. d. Phys. XXXIV, 531 ff.). Zu Ende des Mai-Monats 1834 wurden die beiden Hochöfen zu Sangershausen ausgeblasen. In einem derselben fand man, beim Ausräumen der Ofenbrüche, blass violblaue Krystalle, welche an der Formenwand, etwa 12-16" über der Form, also gleich über dem Schmelzpunkt des Ofens sassen. Sic wurden gefunden, nachdem man eine halbgeschlossene, schweelartige Kruste z.erschlagen und weggeräunt hatte. Theils fanden sich dergleichen in den Rissen in den geborstenen Ofensteinen, theils in kleinen; durch Ausspringen von Quarz-Körnern gebildeten hohlen Räume, theils und hauptsächlich sassen sie auf einer Lage dichter, dem Graphit vicht uuäbnlicher, doch mehr abfärbender Kohle, die aus mehreren dünnen Schalen bestand und an den Gestellsteine des Ofens festsass. Nacls den Ergebnissen zweier Analysen ist die Zusammensetzung der bezeichucten Krystalle folgende: 


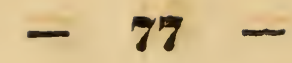

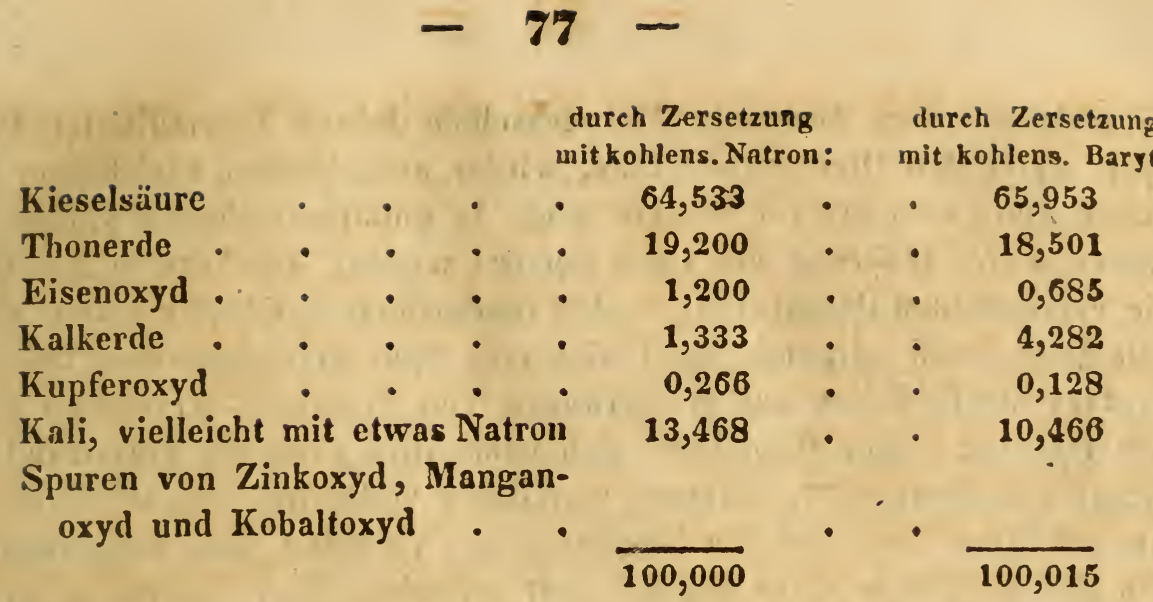

Hiernach ergibt sich unzweideutig, dass die Krystalle, welche ausser einigen zufälligen Bestandtheilen, wodurch die Färbung entstanden ist, eine ganz ähnliche Zusammensetzung haben, wie der Adular Werner's, nur mit dem Unterschiede, dass bei ihnen etwas Kali durch Kalkerde ersetzt wird, daher sie als Feldspath betrachtet werden müssen, und dass diesem Kunstprodukte die Formel:

$$
\begin{gathered}
\dot{K} \\
\dot{C} a
\end{gathered} \mid \ddot{S} i+\ddot{A l} \dddot{S}^{3}
$$

zukommt. - Obgleich die zur Feldspath-Bildung erforderliche Kieselsäure und Thonerde stets in der Beschickung enthalten ist, so bleibt diese Bildung doch darum merkwürdig, weil die nöthige, nicht unbeträchtliche Menge Kali löchst wahrscheinlich aus der Asche der Holz. kohlen hinzutrat. Dass das Kali nicht im Überschuss vorhanden gewe. sen, zeigt die Gegenwart der Kalkerde, deren Quantität nicht in allen Krystallen gleich seyn dürfte, und der Umstand, dass mit der Zunahme des Kalk-Gehaltes eine Abnahme des Kali Statt findet. Wahrscheinlich hat auch die verschiedene Mischung Einfluss auf die Krystall-Bildung gehabt, da die Krystalle mehrfache Kombinationen zeigen *). Erwägt man, wie viele Versuche, künstliche Feldspath-Krystalle zu bilden, namentlich durch MitscherLich gemacht worden sind, von welcheın keiner $\mathrm{zu}$ erwünschten Resultaten führte, so müssen $\mathrm{zu}$ einer solchen Bildung viele Bedingungen nöthig und viele Schwierigkeiten zu beseitigen seyn. Zwar ist nun die Möglichkeit dargethan, keineswegs aber haben Art und Weise und die Bedingungen der Bildung erforscht werden können. Nur so viel ergibt sich aus dem Vorkommen, dass ein Drusen - artiger Raum, der durch eine feste Lage Schweel vor dem Eindringen der schmelzenden Beschickung geschützt und dem Drucke derselben nicht ausgesetzt war, dic Krystallbildung begünstigt hat. Auch scheint eine sehr langsanse Abkühlung nicht ohne Einfluss gewesen zu seyn. Ende 1831 wurde der obere Hohofen auf der Kupferhütte bei Sangerhausen,

*) Zu bedauern ist, dass nicht Material genug vorhanden war, um eine Analyse mit regelmässig ausgebildeten einfachen, und eine andere mit Krystallen von abweichender Form vorzunehmen. 
in welchem man Ausgangs Mai desselben Jahres krystallisirten Feldspath unter den Ofenbrüchen fand, wieder ausgeblasen, nachdem er seit dieser Zeit, also etwa 7 Monate lang, in ununterbrochenem Gange gewesen war. Während der Ofen reparirt wurde, durchsuchte der Verf. die entstandenen $O$ fenbrüche. - Die Innenwände des Ofens waren ziem. lich glatt, und nirgends fand sich eine Spur krystallinischer Bildung, so dass die Hoffunng auf Wiederfinden von Feldspath - Krystallen ziemlich fern lag. Der Ofen hatte sich namentlich nach der Formwand hin ziemlich ausgearbeitet, letztere war daher völlig frei von Ofenbrüchen. Am stärksten hatte sich die Blende an der Vorwand und namentlich in den Ecken, welche diese mit den Seitenwänden bildet, angesetzt, indessen fanden sich auch an letztern nicht unbedeutende Schalen von Blende. Zuerst liess der Vf. an der Vorwand die blendigen und kohligen Scha. len bis auf die Gestellsteine des Ofens durchbrechen. Die jüngste Bildung, welche von der letzten Campagne herrührte, löste sich sehr gut von der ältern Blende-Lage, die der vorigen Campagne angehörte, ab. Nicht selten wurden die Ofenbrüche 2, ja mitunter 4 Zoll stark gefunden, aber weder in denselben, noch auf der Ablösungsfiäche, welche die jüngere Bildung von der älteren trennte, war eine Spur von Feldspath zu entdecken. Als jedoch die zweite Blendelage, die der jüngern an Stärke nur mitunter fast gleich kam, durchbrochen wurde, stiess man wieder auf die Feldspathkrystalle. In zwei Fuss Höhe über der Form fand sich der erste Ansatz von Blende und Feldspath, und in $4-4 \frac{1}{2}$ Fuss Höhe über der Form hörten beide Bildungen auf, so dass also die ganze Ausdehnung der Höhe nach 2 bis $2 \frac{1}{2}$ Fuss betrug. Die Feldspathkrystalle fanden sich meist weiss; die blassviolblauen waren weniger häufig, noch seltener die dunkelviolblauen, und sehr selten ganz schwarze von Kohlen gefärbte. Bei der ersten Auffindung suchte man hauptsächlich nach den gefärbten und liess die weissen wahrscheinlich unbeachtet, so dass die hübsche violette Farbe als Leiter beim Aussuchen gedient haben mag. Die Krystalle fanden sich auch jetzt wieder entweder auf Lagen einer dichten Kohle, oder in Klüften und Höhlungén der Ofensteine, welche aus Rothliegendem vom Kyffhäuser bestehen. Dic meisten und grössten Krystalle fanden sich an derjenigen Fläche, welche die Ofensteine von der ältesten Blende-Lage trennte, und zwar sassen sie entweder an dieser oder an den Ofensteinen fest. Mitunter traf man hier Krystalle, deren Endfächen eine Ausdehnung von 1, ja sogar bis 2 Linien hatten. - Dass die neuerdings gefundenen Krystalle nicht von der jüngsten, sondern von einer ältern Schmelz-Campagne herrühren, beweist schon der Umstand, dass weder in den neuesten Ofenbrüchen, nocli auf der Grenze mit den älteren eiue Spur davon wahrgenommen wurde. Noch mehr wird diese Behauptung durch das Vorkommen von Krystallen, deren Kanten und Ecken durch Abschmelzung gerundet erscheinen, unterstiutzt. Die einfache Erklärung des Vorkommens von angeschmolzenen Krystallen möchte folgende seyn: bei der Reparatur des Ofens zu Ende Mai wurden die Ofenbrüche stellenweise bis auf die Ofensteine 
durchbrochen, also die Klüfte und Ablösungsflãchen, wo sich die Feldspath-Krystalle fanden, theilweise geöffnet. $\mathrm{Da}$ wo die $\mathrm{Ofenbrüche} \mathrm{rubig}$ hängen geblieben waren, blieben die darunter befindlichen Feldspath-Krystalle geschützt, wo hingegen Partie'n von letzteren frei standen, erlitten sie beim Wiederanblasen des 0 fens eine Sclimelzung, welche sich jedoch nicht fïglich auf die ganze Krystallmasse, sondern nur auf die dünnern Stellen der Krystalle erstrecken kounte, weil sonst bei der, zur Schmelzung der ganzen Krystalle nöthigen, grösseren Hitze die zinkischen Ofenbrüche zunächst geschmolzen seyn und sich an höhere Stellen des Ofeus angesetzt haben würảen.

C. Reicher: Analyse des Mineral-Wassers von Hohenstein im Schönburgischen. (Erdman und Schweigger-Seider, Journ. für prakt. Chemie IV, 324 ff.). In 138,240 Gran sind enthalten:

\begin{tabular}{|c|c|c|c|}
\hline Salzsäure & . $\quad$ & . & 1,336 \\
\hline Kohlensaurer & Kalk & . & 1,211 \\
\hline Talkerde & - $\quad$. & . & 1,200 \\
\hline Thonerde & & - & 0,100 \\
\hline Kieselerde & & . & 1,200 \\
\hline Kali • & & . & 2,000 \\
\hline Natron & . & . & 1,240 \\
\hline Lithion . & - & . & 0,089 \\
\hline Eisenoxydul & - & - & 7,002 \\
\hline Harzige Materi & & . & 1,900 \\
\hline Quellsäure & & - & $?$ \\
\hline $\begin{array}{l}\text { Phosphorsaurer } \\
\text { Manganoxydul }\end{array}$ & r Kalk & & Spuren \\
\hline Schwefelwasse & ffgas & 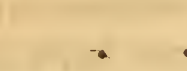 & $7,712 \mid$ Rh. D. I \\
\hline Kohlensaure & & & $11,520\}$ Kub. $Z_{0 l}$ \\
\hline
\end{tabular}

W. STockes: über kugelige Bildungen mineralischer Substanzen. (Journal of the geological Soc. of Dublin, Vol. I, S. 1, 1.15 etc.). Viele Mineralien erscheinen in kugeliger oder in Röhren - förmigen Gestalten, deren Entstehen auf verschiedene Weise zu erklären ist. Peibung, Zersetzung, Krystallisirung sind die bedingenden Ursachen, und im letztern Falle haben Einseihungen in kugelichten Höhlungen Statt, wobei sich die Krystalle divergirend an einander reihen. Auch bei Sublimationen können Formen, wic die erwähnten, entstehen, indem mit der Cohäsiv - Attraktion sich die Rotation verbindet. Welche von diesen Ursachen in einzelnen Fällen gewirkt, ist nicht immer leicht auszu. mitteln. Man wili zuweilen'Tropfen Vesuvischer Laven von vollkommener Ku. gelform gefunden haben : im Allgemeinen erscheinen sio jedoch mehr flachgedrückt und in die Lünge gezogen, dabei zeigen sie sich ungeben durch 
eine hervorragende Zone, die mit kleinen Knötchen besetzt ist. Solche Verschiedenheiten hängen vom Grade der Flüssigkeit ab; welcher der herabfallenden Mlasse verbleibt, und von dem Boden, auf den sie niederfällt. Tassen - ähnliche Gestalten werden dadurch hervorgebracht, dass der Rand zuerst erkaltet. Ungleiche Flïssigkeits - Grade können sehr manchfaltige Phänomene bedingen. Berrlesy sah im Vesuvischen Kra. ter zwei Höhlungen an Krater-Boden sich bilden; in einer siedete Lava und floss zuweilen über aus der Mündung eines inneren Kegels; in der andern wurden rothglühende Kugeln ausgeworfen, die ganz oder zerbrochen in die ergossene Lava fielen; so entstanden Obsidian-artige Kugeln, zusammengehalten durch ein Lava-Zäment. Es ist wohl annehmbar, dass im Innern des Vulkans, selbst auf dem Krater-Boden, rothglühende Lava - Kugeln sich mit einer Decke bekleideten; diess fand nämlich statt, indem sich dieselben um ihren Mittelpunkt in einer Atmosphäre verschiedener Dämpfe drehten, in welcher Staub und kleine Steinstücke gefallen seyn kounten, wodurrh sich Kugeln bildeten, deren Kerne und konzentrische Schaalen auf verschiedene Art zusammengesetzt sind. HAMILTon besass kugelige Stücke weissen Kalksteins, vom Vesuv ausgeworfen, die Lava-Kerne hatten. Sodalit-Massen trifft man als Einschlüsse im Eudyalit, und diese wieder im Basalt [wo?]. Im Sodalit sind 23,5 Natron enthalten*), im Eudyalit nur 13,82, und der Eudyälit enthält 11,1 Zirkonerde, der Basalt sehr wahrscheinlich nicht eine Spur; darum ist nicht wohl anzunehmen, dass der Sodalit aus dem Eudyalit ausgeschieden worden, und eben so wenig der Eudyalit aus dem Basalt. Hyazinth kommt in sehr kleinen Theilchen im Basalt vor; diess Mineral enthält 70,0 Zirkonerde ${ }^{* *}$ ), der Basalt nicht eine Spur. Darum scheint es glaubhaft, dass solche Substanzen, während sie noch flüssig waren, in geschmolzene Iava fielen. - Lava zeigt die unmerklichen Übergänge in Obsidian.

Obsidian aber scheint von Lava und von Basalt dadurch verschieden zu seyn, dass er mehr Kieselerde enthält, und dass er glasiger ist, in Folge schnellerer Abkühlung. Basalt wird bäufig in kugeligen Massen getroffen, sphärisch, oder diesen nahe stehend, welche wieder von minder festem Basalt unschlossen werden. Theils rührt das Phänomen von der Zersetzung her, allein oft ist noch eine Form der ur. sprünglichen Struktur wahrzunehmen. Angeblich sollen, in der Mitte solcher Kugeln, mitunter verschiedenartige Stein-Kerne, besonders eckige Kalk. Stücke gefunden worden seyn; der Perlstein Ungarns der in Obsidian allmälliche Übergänge zeigt - besteht aus einer $\mathrm{Zu}$ sammenhäufung von Kügelchen, deren Grösse von jener einer Nuss bis zu der eines Sandkorns wechselt; kein fremdartiges Bindemittel hält diese Kügelchen zusammen : ein Schmelz-Teig, der viclartige Wendungen

\footnotetext{
*) Der Natron - Gehalt des Sodalits beträgt 26,55.

**) 66,0 .

D, R.

D. $R$.
} 
wahrnehmen lässt, verbindet sie. - Obsidian geht in Pechstein taber; auch die Analyse und die Zersetzungs - Phänomene zeigen Analogie'n. Pechstein kommt auf Lipari in kugeligen Massen vor. Obsidian und Bimsstein verlaufen sich in einander; verglaste Schlacken stehen in der Mitte zwischen beiden. Die kleinen Höhlungen und Räume im Bimsstein, in der Schlacke, so wie jene im Mandelstein, scheinen durch elastische Dämpfe gebildet worden zu seyn. Wären sie Folgen der Zersetzung durch Ausspühlung von Wasser, so könnten dieselben nicht so regellos sich darstellen. -- Feuerstein und Hornstein sind beinahe identisch; das Bruch - Ansehen bedingt unbedeutende Verschiedenheiten. Manche ihrer Massen stellen sich fast als Kugeln dar; einige zeigen eine Rinde, an der zuweilen noch eine kleine Erhöhung walhrzunehmen, scheinbar die Folge frủherer Erhärtung. - Menilit nähert sich dem Obsidian und dem Pechstein. Er kommt in knolligen Massen vor, die ursprünglich so gebildet seyn dürften. - Quarz-Kugeln von der Grösse einer Erbse finden sich in Mulattoe-S tone (einer Art Greensand) in der Grafschaft Antrim, so wie, in beträchtlicherer Grösse, in Kalkstein von Sliwe Gallion. In Corkshire werden in einem Talkschiefer - ähnlichen Gesteine glänzende HornblendeKugeln getroffen. Im Sandstein von Skreen, in der Grafschaft Sligo, findet sich ein Lager fest verwachsener Quarz-Kugeln. Der rothe Sandstein besteht aus ahgerundeten Stücken und aus eckigen Fragmenten verschiedenartiger Gesteine von sehr ungleicher Grösse. Er trägt ganz das Ansehen vulkanischer Breccien, die dureh Hitze gebunden worden. Von $Z$ wischenräumen ist wenig oder nichts wahrzunehmen. - Quarzgesteine zeigen sich in der Regel frei von allen eingeschlossenen Theilen älterer Gebilde. - Im Glimmerschiefer trifft man Quarz-Massen, grösser als ein Menschen-Kopf. Die GlimmerschieferLagen scheinen sich um dieselben herum gebildet zu haben. - Im Kohlenschiefer sieht man rundliche, zum Theil flach gedrückte Massen. Der roth- und -weiss-gefärbte Marmor Italiens hat eingeschlossene Massen aufzuweisen, die erlittenen Druck verrathen. - Gold kommt in Massen vor, welche geschmolzen scheinen; zuwcilen stellen sich Tropfen [?] dar, die unvollkommen mit einander vereinigt sind. - Eisenkiese und kohlensaures Kupfer bilden durch Krystallisirung rundliche Massen. - - Kugelige Bildungen hat die Natur demnach häufig aufzuweisen. Als ursprünglich so entstanden sind jene zu betrachten, die ihrer Oberfläche parallele Lagen haben, in denen man Kerne findet, deren Äusseres etwas verschieden von der Masse des Ganzen ist; ferner sprechen für ursprüngliche Bildung: eine beim Festwerden etwas zusammengeschrumpfte Pinde, und Eindrücke, von äusseren Krifften herriührend. 
L. Hor ier: ïber die Menge des im Rheine enthaltenen $\mathrm{Schl}$ am me s. (London and Edinburg phil. Mag. 183t, Nr.27, p. 211 etc.). Die Versuche, auf welche sich der Verfasser bezieht, wurden in den Monaten August und November 1833 angestellt. Der Apparat, dessen er sich bediente, bestand aus einer Steinflasche, die ungefähr eine Gallone enthielt, versehen mit einem Kork, bedeckt mit eingeschmiertem Leder, und daran eine lange Schnur befestigt. Vermittelst eines Gewichts, konnte die Flasche bis auf beliebige Entfernung von Boden des Stromes versenkt werden, und durch die Schnur liess sich der Kork wegnehmen, so dass das Gefäss augenblicklich gefüllt und sodann heraufgezogen wurde. Die ersten Versuche hatten in 165 Fuss Entfernung vom linken Ufer, $7 \mathrm{~F}$. von der Oberfläche und $6 \mathrm{~F}$. vom Boden statt. Der Rhein hatte einen ungewöhnlich niedrigen Staud; das Wasser war tiübe ynd von gellhicher Farbe. Die lienge des Materials, welches ein. Kubikfuss Wasser lieferte, nachdem allmähliche Abtrocknung vorgenommen worden, betrug $21,10 \mathrm{Gr}$, oder ungefähr den $\frac{1}{20} \frac{1}{37}$, Theil des Wassers. Das Residuum brauste mit verdünnter Salzsäure schnell auf, hatte eine licht gelbbraune Farbe, füblte sich weich an und ähnelte am meisten dem Lösse des Rheinthales. Spätere Experimente, wobei man das Wasser aus der Mitte des Flusses nahm, und ungefälir 1 F. unterhalb der Oberfläche, nach und während heftigen Regengüssen, lieferte noch dunkler gelb gefärbtes Wasser. Der Rückstand von eitiem Kubikfuss Wasser wog $35 \mathrm{Gr}$, oder $\frac{1}{2 \frac{1}{50}}$ Theil. - Der Verfasser stellt Berechnungen an über die durchschnittliche Mergre des vom Rhein in 24 Stunden weggeführten erdigen Materials. Er nimmt die mittle Breite des Flusses, Bonn gegenüber, zu 1,200 F. an, die mittle Tiefe zu 15 F., die mittle Geschwindigkeit $=2 \frac{1}{2}$ Engl. Meil. in eiver Stunde, und den ungefährem Betrag festen Materials, vom Wasser getragen, zu 28 Gran auf den Kubikfuss. Als Resultat ergibt sich, dass 145,981 Kubikfuss soliłden Materials in je 24 Stunden bei Bonn vorbeigeführt werden,

A. Schneider: geognostische Bemerkungen a uf einer Reise von Warschau durch eiuen Theil Litthauens und Wolhyniens nach Podulien: (Karstes's Archiv für Min. VII, S. $311 \mathrm{ff}$.). Die Resultate sümmtlicher Beobachtungen ergaben nachstehende Lagerungs - Verhältnisse der Gebirgs - Bildungen in untersten Theile PodoTiens. Die Ubergangs-Formation, Thon- und GrauwackeSchiefer, welche theilweise Kalkstein-Straten aufuehmen, erscheinen iiberlagert durch einen Grauwacke-Sandstein mit Productus II. s. W. Wahrscheinlich ruhen sie auf dem nördlich und westlich am Buy vorkommenden Granit. Der Übergangs-Kalkstein, Spirifer, Productus u. s. w. führend, wechselt mit Thou- und Kalk-Schiefer. Als Flïtzgebilde treten auf: Grünsand und Feuerstein. Das Grün- 
sand-Gebilde zeigt sich zusammengesetzt aus weissem Kiesel-Sandstein und aus Grünsand mit Hornstein-Lagen; häufig kommt Gry$p$ ha ea colu mba darin vor. Mächtigkeit $=50-100$ F. Der Feuer. stein vertritt die Stelle der an andern Orten mächtig verbreiteten Krcide und erlangt mitunter eine Mächtigkeit von 20 bis $80 \mathrm{~F}$. In den obern Lagen des Grünsand-Gebildes finden sich zuweilen statt des Hornsteins Blöcke von Feuerstein ein, welche stellenweise ganz vorherrschend werden und den grünen Sand völlig verdrängen. Dieser Feuerstein kommt in Stücken und Blöcken von sehr manchfaltiger Grösse vor, zwischen denen gewöhnlich ein gelber oder grünlich-weisser Letten liegt, durch welchen die Feuerstein-Stücke lose mit einander verburiden sind; ebenso findet sich derselbe in den manchfaltigsten Farben-Nüanzen. Die tertiären Gebilde haben eine Gesammt - Mäch. tigkeit von 150 bis 240 Fuss. Sie bestehen aus folgenden einzelnen Gliedern:
1. Töpferthon
2 bis 8 F. mächtig.

2. Meeressand, mit schwarzen FeuersteinGeșchieben

3. Mergelkalk nit untergeordneten Kalkstein - Straten

4. Dichter Kalkstein

5. Oolith . . . . . .

6. Mergelkalk mit Cardium lith opodo-

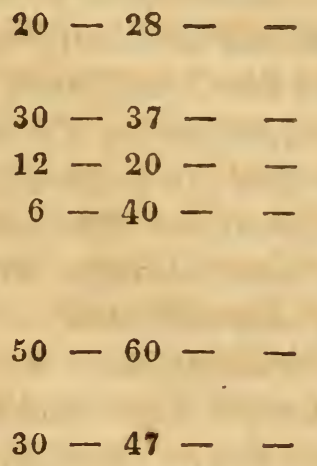
licu m, und mit untergeordneten Schichten ron Kalkstein, Gyps und Walkererde

7. Oberer Felsenkalk mit Serpulen (DU Bors' qu a'tärer Kalkstein. . .

Die Meeressand-Schichte (Nr, 2) enthält eine Menge von Konchylien und kleinen Knochen. Die Konchylien sind meist sehr schön erhalten. Auf der Holozubincer Höhe wurden, durch Abteufung eines Schachtes, folgende Arten getroffen: Marginclla eburnea; Buccinum sem icostatum, Brocc.; B. baccat um, Bast.: B. dis it um, Erchw.; Nassa Zberszewsci, Andrych.; N. laevigata; N. asperula, Bast.; Pleurotoma costellata, Bast.; Fusus intortus, Lam.; F. subulatus; F. harpula, Brocc.; Cancellaria macrostoma, Du Bors; Cerithium pictum; C. plicatum, Brug.; C. corrugatum; C. baccatum, Derr.; C. lima, Bruc.; Turritella Archimedis, Brongr.; Trochus patulus; T. turgidulus; Monodonta Araonis; Natica glaucina, LrN.; N. epiglottina, LAu.; N. helicina, Brocc.; Neritina picta, Erchw.; Melania Ropii, du Bors; Melania la evigata, Desh.; Melania pupa, du Bors; M. spiralissima, id.; M. reticulata, id.; Cyclostoma planatum, id.; C. Bialozurkense, id; Bulla ovulata, Brocc.; B. spirata, id.; Panopaea Faujasii; Tellina pellucida; Brocc. vel Erycina apellina, Puscr; Lucin a columbella, Bast.; Squama?; Cytherea unidens; Arca diluvii, LAm.; A. antiquata; Pectunculus variabilis: P. pulvinatus, Lan.; P. nummiformis, Lan.; 
Pecten pulchellinus, du Bors; Calyptraea, du Bors; Ostren digitalina, Ercuw.; Ostrea la noch gegenwärtig sich erzeugende Bildung ist $\mathrm{K}$ a l k tuff, welcher überziehend die untern tertiären Schichten, den Feuerstein, Grünsand und selbst die Übergangs - Gebirgsarten bedeckt, oder auch nur angelagert erscheint.

W. Ch. H. Staring: Beiträge zur Geologie des Königreiches der Niederlande. (Specimen academicum inaugurale de Geolo. gia gatrias. Lugd. 1833). Frühere Literatur. Schilderung der Kreide und des Grün-Sandsteines, und Andcutung der älteren Gebilde, von denen die neuen Ablagerungen der Niederlande begrenzt werden. Beschreibung der tertiären Fornationen mit einer Übersicht der ihnen zu. stehenden Petrefakten, nach den einzelnen Örtlichkeiten. Alte Alluvion: lose Blöcke und Sand. Fossile Geboine findet man nie in grösserer Tiefe als 20 Meter; der Zustand ihres Erhaltenseyus beweist, dass sie nicht aus beträchtlicher Weite herbeigeführt worden. Neue Alluvio. nen: Torf, und darin vorkommende fossile Überreste (Cervus megaceros, Castor, Emys), und ein thonig Torf-artiger Schlamm (D ar g oder Derrie genannt). Fluss-Alluviouen (Schlamm in Menge, von den verschiedenen Flüssen abgesetzt u. s. w.). Meeres-Alluvionen. Sie sind sehr mäcistig. Beim Graben eines artesischen Brunnens in Amster. dam erreichte nian erst in 27 Meter Tiefe ein Thon-Lager. Der Alluvial-Meeresboden, Sand und thoniger Schlamm, überragt das gewöhnliche Meeres-Niveau nur sehr wenig, oder erreicht dasselbe mitunter selbst nicht. Gebeiue, Waffen, Theile vou Schiffen u. s. w. finden sich darin. Am Schlusse schildert der Verfasser die Dünen.

Brennender Berg in den Dazischen Fürstenthümern (v. Meyer: über Fortschritte der Kultur in W'allachei und Moldau, vorgetragen bei der Versamnl. der Naturf. in Bınn am 18. Sept. 1835. Bonn, 16 SS. $8^{\circ}$.). Nordöstlich vou der Stadt Tschernetz beim Dorfe Malowiza, 4 Stunden von der Donau, befindet sich ein Berg, der seit 20 Jahren gebrannt und Rauch und Feuer aus seinen Spalten entwickelt hat. Vor sechs Jahren in der Nacht stürzte er mit furchtbaren Getöse zusammen und verschüttete 16 an seinem Fusse gelegene Häuser mit ihren Bewohnern. Die nach dem Thal herabgedrängte Masse bildet eine gencigte Ebene, welche sich jährlich, durch Regen und Schnecschmelzen veranlasst, un $\sigma^{\prime}$.voranschiebt. An der Nordseite des Berges ist ein kleiner, seir tiefer See entstanden, dessen Wasser deutliche Spuren von Hydrothiongas, Kohlensäure und Eisen verräth. Der Bergfall selbst ist $5 \$ 60$ Schritte lang, bis 3200 Schritte breit und $245^{\prime}$ hoch. Die Schuttmasse ist mit Tausenden vou schwar 
zeu Hugeln bedeckt, welche aus gebranntem Sandstein, rothgeglühetem Schieferthon, verkohlter Braunkohle, Erdschlacken und Schwefel bestebeu. Der Kegel-förmige Berg ist durch einen senkrechten Spalt genau in zwei Hälften getheilt, in welchem man Schichten von verwittertem Sandstein, Erdschlacke, Quarz und Kalkstein erkennt. Im Innern jener Hügel findet man Baumstämme, horizontal wie Blätter übereinanderliegend, selten aufrecht, zuweilen zerquetscht, und mitunter so dick, dass zwei Männer sie nicht umspannen können. Es sind zweifelsohne die Überbleibsel eines Eichenwaldes, der vor dem Einsturze auf dem Gipfel des Berges gestandeı. In einigen Hügeln fand man auch Braunkohle, woruuter sich Reste von Palmrinden erkennen liessen.

J. Pournet: Abhandlung über die Zersetrung der Mineralien feurigen Ursprungs und ihre Verwandlung in Kaolin (Awn. chim. phys. 183t, Mars, LV, 225-256).

1. Auseinandersetzung und Widerlegung der vorzüglichsten Theorie'n über die Entstehung des Kaolins. Aus den Mischungs- und Lagerumgs-Verhältnissen ergibt sich, dass der Kaolin ein zerfallener, vou Kali befreiter und noch weiter umgeänderter Feldspath sey, und dass der Galvanismus diese Umänderung bewirkt habe, welcher aus dem Kontakte später aufgelagerter Felsarten entspringt, noch mehr aber jener, welcher in der Heterogeneität der Gemengtheile der Gesteine selbst begründet ist. - II. Folgende Erscheinungen sind mit dieser Umwandlung verbunden: In der harten Steinmasse der Basalte, Phonolithe und Trachyte entstehen zerstreute crdige Punkte, welche scharf begrenzt an Grösse und Zahl zunehmen; eine kuboidische Zerklüftung mit abgerundeten Kanten gesellt sich hinzu, die Felsart schwillt au, und es entsteht eine konzentrische Abblätterung kugeliger Massen von Erbsen - bis zu Kopf-Grösse, und das Gestein wird so erdig, dass chemische Agentien ein leichtes Spiel haben: nun erst oxydirt sich das Eisen hölıer, die anfangs dunkle Farbe wird hiedurch röthlich oder sehr intens gelb (zumal in Auvergne). Zu Poullaouenn in Bretagne gelit man weit über Aphanite weg, welche ganz in $3^{\prime \prime}-4^{\prime \prime}$ dicke Kugeln zerfallen sind (D'Aubusson). Ähnlich ver!nalten sich die prismatischen Granite. Aber an geschichteten Graniten, welche in Zersetzung begriffen sind, kann man folgende drei Zonen unterscheiden: zu oberst gelber oder rother Thun, gefärbt durch Eisen-Peroxyd-Hydrat, welcher beim Truchuen oft salzige Ausblühungen gibt, inden bei der Oxydation les Eisens das Alkali frei geworden ist; - eine mittle grüue Zone, wo die Oxydation des Eisens noch unvollkommen ist; - eine untere Zone aus anscheinend unverändertem Granit, welcher abev durch einen Hammerschlag gä̈zlich zerfällt, und worin ein Theil der Feldspith. Kiystalle woch seine Form besitzt; - er liegt auf wirklich noch unverändertem Granite. In jenen oberen Schichten liegen dic andern 


\section{$-86$}

Gemengtheile des Granites, Quarz und Glimmer, noch in anfïnglicher Weise zwischen den Feldspath, so lange nicht Regenwasser, welche das Alkali wegspühlen, und andere Ursachen diese mürben Massen einstürzen machen, sie durchwaschen und schlämmen; - sie geben guten Mörtel. Aus gleicher Ursache zerfallen auch manche Granite alsbald zu Gruus, wenn man sie aus dem Bruche nimmt, wo sie durch den Seitendruck zusammengehalten worden waren. - III. Diese Erscheinungen des mechanischen Zerfallens lassen sich nicht erklären aus dem Wechsel der atmosphärischen Temperatur, indem dieser nicht so tief einzudringen vermag, als jenes Zerfullen in pyroxenischen wie in Feldspathigen Gesteinen Statt findet. Es ist vielmehr begründet theils in der Neigung pyrogener Felsarten bei dem Erkalten sich in prismatische, Tafel-artige und andere Formen zu zerspalten, theils und hauptsächlich aber in dem Dimorphismus ihrer Bestandtheile, welche das Bestreben haben, die eine Form mit der anderen zu vertauschen. Wie frisch sublimirte arsenige Säure glasartig ist, aber mit der Zeit opak, lockerer und in Wasser löslicher wird, ohne eine chemische Veränderung zu erleiden, so scheint es, nach Berzelius, auch bei vielen anderen Verbindungen zweierlei Grade der Innigkeit der Verbinduntr zu geben, deren einer, schwächerer, auf nassem Wege bei niedriger Temperatur, der andere auf trockenem Wege in hoher Hitze entstelit, und auf die letztere Art scheinen alle Mineral-Arten entstanden zu seyn, welche ihrer Mischung nach von Säuren leicht angreifbar seyn müssten, aber deren Wirkung widerstehen (Feldspath, Spinell, Zinn-Oxyd). So ist nach G. Rose die Hornblende nur ein langsamer erkalteter Augit. Aber er zerfällt weniger leicht, als der im nämlichen Gesteine mit-vorkommende Feldspath; doch ist er reicher an Eisen und ärmer an Kieselerde. Andere Belege verschiedener Aggregat - Zustinde bei gleicher Mischung geben uns die langsam oder schuell abgekühlten Metalle, die ungeglüheten und die geglüheten Gläser, welche letztere jedoch mit der Zeit, selbst wenn sie ticf vergraben siud, sich ebenfalls absplittern, irisiren u. s. w.; ja es scheint, dass diese Stoffe in jenem Aggregat-Zustande, welchen man als den stärkeren betrachten muss, mit der Zeit durch unmerkbare Einfiüsse mehr angegriffen werden, als im schwächeren. - IV. Aus der Zersetzung des Feldspathes entstehen zwei neue Verbindungen, jedoch in zweifachen Proportionen, im einen Falle nämlich, wie schon BERTHIEn gezeight, tremnt sich der Feldspath $\mathrm{K} \mathrm{A}^{3} \mathrm{Si}^{12}$ in $\mathrm{A}^{3} \mathrm{Si}^{3}$, $=48 \mathrm{~A}$ $+52 \mathrm{Si}$, welches mit etwas unzersetzten und fremden Theilen als Kaolin zurückbleibt, und in K $\mathrm{S}^{9}$, welches verschwindet (?Aue in Sachsen und St. Yrieix); im anderen Falle scheidet er sich in $\mathrm{A}^{3} \mathrm{Si}^{4}=44,70$ $\mathrm{A}+55,30 \mathrm{Si}$, und $\mathrm{K} \mathrm{Si}^{8}$ (Passuu, Meissen, St. Tropez, England) mit einigen kleinen Variationen, welche von dem bercits stattgefundenen Zersetzungsgrade und dem Verhalten der zufällig beigremengt gewesenen Bestandtheile (Eisenhydrat etc.) abhängig seyn mügen. Rechnet man das Wasser mit hinzu, so würde der Kaolin von S. Yrieix enthalten: 


\section{$-87-$}

11 Kieselerde $=22,73$

9 Alaunerde $=19,09$ was sich wicht auf einfache Furmeh zu-

6 Wasser $=13,66$ rückführen lässt, -

die Kaoline der 2ten Abtheilung aber

$\left.\begin{array}{l}4 \text { Kieselerde }=24,22 \\ 3 \text { Alannerde }=18,00 \\ 2 \text { Wasser }=13,19\end{array}\right\} \mathrm{Si}^{4} \mathrm{~A}^{3} \mathrm{aq}^{2}$ oder $\mathrm{Si}^{4} \mathrm{~A}^{2}+\mathrm{A} \mathrm{aq}^{2}$

was der Zusammensetzung des Halloisites ganz nahe steht; doch ist inmer ciniges fest adhärirende Wasser vorhanden, das nicht chemisch gebunden, und seiner Menge nach schwer zu bestimmen ist. Einige Kaoline, welche in der Erde weich und halb duktil gewesen, werden durch Austrocknen sehr hart und bleiben es, wenn sie gleich lange Zeit wieder unter Wasser kommen, was sie eben zur Mörtel-Bereitung sehr geeignet machen mag. Ähnlicbe Erscheinumgen nimmt man au Feuersteinen, manchen Specksteinen, dem Andalusit von Herzogau und manchen Molassen und Arkosen wahr. -- Basaltische Gesteine zeigen ein analoges Verhalten; wie denn in Basalt-Strome von Churuet in Alveryne vicle Äderchen reinen Lenzinites, der den Halloisiten ebenfills rahe steht, nitten in den ockrigen Hydrosilikat-Bänderu vorkommt, - und wie ferner die Hornblende-haltigen Diabasen (Sachsens und Schlesiens) sich in Walkerde, die Serpentine ebenfalls in Hydrosilikat-artige Erden zcrsetzen. - V. Um jene Zersetzung zu bewirken, möchte das reine Wasser nicht, wohl aber die Kohlensäure der Atmosphäre liunreichend seyn, welche nämlich mit stärkerer Affinität als die Kiese!(rrle versehen, diese ausscheidet, und sich ihrer Basen bemächtiget, der stärkeren und auflöslicheren vorzüglich, wesshalb die Kalk - tind 'TalkFeldsputhe ihrer Einwirkung mehr als die Kali-Feldspathe widerstehen. Die so ausgeschiedne Kieselerde ist Gallert-artig und mit Wasser, wässeriger Kohlensïure, reinen und kohlensauren Alkalien verbindbar, wo sie daun die Materien zur Bildung neuerer Quarze, Fioritn, Achate, Opale, Kalzedone und selbst Mesotype und Stilbite liefern mag. Jene Zersetzung wird besonders noch durch die häufige Anwesenheit von Eisen - und Mangan - Protoxyd begünstigt, durch dessen hölere Oxydation und Umwandlung in Peroxyd-Hydrat die Neutralität der Verbindung atifgehoben, deren Festigkeit zerstört und weitere Veränderung der Kiesel-Thonerde in Kiesel-Alaunerde-Hydrat mit den Verhältnissen A Si oder $\mathrm{A}^{3} \mathrm{Si}^{+}$herbeigeführt wird, während nemlich jedes etwa entstehende saure Silikat tei niedriger Temperatur sich abscheiden würde. In der That lıaben die häufigen kohlensäuerlichen Quellen von Castelg"yyn in Auvergne alle Spalten des Granites, aus denen sieliervortieten, erweitert und wieder mit Eisen-Hydrat überzogen; an piner andern Stelle, bei Pont Gibaud, haben sie schwefelsauren Baryt ganz zerfressen und die darin eingeschlossenen Talkschiefer-Stücke in hohen Grade angegriffen. Durch die Einwirkung solcher Sauerquellen und der in ihnen enthaltenen Bicarbonat-Salze auf verscliedene Felsarten mag die Bildung der Allophane, Collyrite, Pholerite, Meerschaume, Fettbole, Cero- 
lithe, Scarbroite u. s. w. erklärlich seyn. Dazu gesellt sich daun endlich noch die Wirkung andrer, in den Quellen aufgelöster Salze, der Sulfate u. s. w.

Auch andre, durch ihren Dimorphismus bekannte Mineral - Verbindungen haben ähnliche Erscheinungen zur Folge, wie die Feldspathe. So ist die prismatische Form der Pyrite weniger dauerhaft als die kubische, und zu Effloreszenzen geneigt. So zersetzen sich die prismatischen Gestalten des kohlensauren Kalkes (Arragonite) in Auvergne in Masse, wälırend die rhomboidischen dauerhaft sind. So scheint der Granat nur die weniger dauerhafte, der Idokras die stärkere Form einer und derselben Substanz zu seyn; die Neigung des ersteren, zerreiblich zu werden, ist bei Framont auffallend und bekannt. Ein ähnliches Verhältniss mag zwischen Laumontit, Amphigen und Peridot seyn.

T. A. CATur.Lo: memoria geognostico-zoologica sopra alcune conchiglie fossili del calcare jurese, che si eleva presso il lago di Sta. Croce nel territorio di Belluno. Padova 1834 ( $>$ Bibl. Ital. 1834, $L X X V, 272-273)$. Östlich von Belluno erheben sich die Alpugeser Berge zum Joche, Pine genannt, dessen Gestein milchweiss und vollkommen krystallinisch, voll undeutlicher Bivalven-Versteinerungen ist, deren Schaalentrümmer eben jene krystallinische Struktur herbeizufüh. ren scheinen. Es geht nach unten nicht in Oolith über, und ruht auf dichten, graulichem Kalke voll Terebratel-Schaalen. Die fossilen Reste des erstern aber sind von der Art, wie sie sich nur selten im Venetianischen, um Romagnano, im Veronesischen und im Fenera. Berge unfern Asolo finden: nämlich $\mathrm{Sph}$ aeruliten und Hippuriten [mithin nicht Jurakalk, sondern Kreide!], welche letzten eine grössere und eine klcincre Art darbieten, mit einigen Plagiostomen und Gryphäen. Die Versteinerungen des Jurakalkes von Alpago gehören lauter neuen Arten an, welche am Schlusse der. Abhandlung einzeln beschrieben und lithographirt sind.

J. Pubrips: über unterirdische Temperatur, am 15. Nov. 1834 beobachtet in einer Tiefe von 500 Yards unter dem Meeresspiegel, im $54^{\circ} 55^{\prime} \mathrm{N}$.' Br. (Lond. a. Edinb. phil. mag. 1834, $V, 446$-451). Die Herren Prmberton und Thompson liessen einen $12^{\prime}$ weiten Schacht zu Monk-Wearmouth abteufen, um durch den Durltam'schen Magnesian-Kalk zum Kohlengebirgc zu gelangen, in welchem, noch ehe die Werke in den Kohlen selhst eine grössere Ausdehnung gewonnen, ehe Fferde u. s. w. da hinab gebracht worden, der Verf. in Verbindung mit mehreren andern Gelehrten eine Reihe von Versuchen über die Wärme-Zunahme anstellte. Die Sohle des èrsten Kohlenlagers Von 6'Mächtigkeit erreichte man mit 1584' mittelst eines Schachtes, dessen 
Mundluch $87^{\prime}$ über dem Hochwasserstand des Meeres sich befindet, und welcher bis $z$ 1497' unter dem Meeresspiegel reicht. Setzt man die mittle Temperatur dieser Oberfläche in jener Gegend $=\mathbf{4 7 ^ { \circ }}, 6 \mathrm{~F}$, die höchste auf der Sohle des Kohlenlagers den Beobachtungen zufolge $=72^{\circ} 6$, so entspricht diese Differenz von $25^{\circ}$ einer Tiefe von 1484' unter dem Meeresspiegel, oder je $1^{0}$ auf $59^{\prime} 36$ Tiefe, oder etwa $1^{\circ} \mathrm{F} \therefore$ auf 20 Engl. Yards.

Der Schacht ist zwar verzimmert, doch so, dass noch immer etwas Wasser hindurchdringt, und auf dessen Sohle hinabträufelt, welche sich einige Yards unter dem ersten Kohlenlager 'befindet und noch bis zu einem folgenden fortgetrieben werden soll. Kohlenwasserstoffgas dringt aus der durch 4 Strecken angebrochenen Kohle überall mit Geräusch hervor, wird aber durch den hergestellten raschen Wetterwechsel so schnell in die Höhe geführt, dass man dessen Brennbarkeit nicht zu gewahren vermag. Das Kohlenlager fällt etwas von W. nach 0 ., auf welch' letzter Seite sich Salzwasser in einer $2^{\prime}$ tiefen Lache im Liegenden des Lagers gesammelt hatte, 22 Yards vom Schachte entfernt. Die Luft in dieser und der südlichen Strecke hatte $62^{\circ}$ bis in die Nähe des Schachtes, die des Salzwassers war $70^{\circ} 1$, die der Luft vor Ort $64^{\circ}$, und da, wo das Gas summend hervordrang, ohne jedoch entzïndbar zu seyn, $68^{\circ}$. Ein Minimum-Thermometer zeigte in $19^{\prime \prime}$ tiefen Löchern auf dem Boden der östlichen Strecke, nachdem sie zuerst mit wärmerem Wasser gefüllt worden waren und dieses dann erkaltet war, $62^{\circ}-63^{\circ}$, in Kohleńklein an der Oberfäche $64^{\circ}-67^{\circ}$, und $2-3$ Yards vor Ort in Salzwasser steckend, $71^{\circ}, 4$. Senkt man das Thermometer in ein frisch gemachtes Loch in die Kohlenwand zwischen das hiebei sich ergebene Kohlenklein, so zcigt es anfänglich $69^{\circ}$ und nach kurzer Zeit $71^{0 \frac{1}{4}}$. Im Salzwasser der Lörher am Boden der Strecke wechselte der Thermometerstand jedoch um einen ganzen Grad und stund um so höher, je reichlichere Gas-Bläschen durch das Wasser in die Höhe stiegen: in einem derselben von $69^{\circ} 1$ bis $69^{\circ} 7$, im andern von $71^{\circ} 6$ bis $72^{\circ} 6$. Im Wasser eines $2 \frac{1}{2}^{\prime}$ tiefen Loches der westlichen Strecke stellte sich das Thermometer auf $71^{\circ}$. Das auf dem Boden des Schachtes angesammelte Wasser besass $67^{\circ}$. Es ist offenbar, dass der starke Wetterwechsel in den noch wenig ausgedehnten Werken eine fortdauernde Abkühlung bewirkt, dass die Oberfläche des Gesteines wärmer als die Luft (frisch entblösste Flächen um $9^{\circ} 6^{d}$ wärmer), das aus der Tiefe kommende und mit jener in Berührung. bleibende Wasser wärner als die Oberfläche, und das noch viel schneller emporsteigende Kohlenwasserstoffgas noch wärmer als dieses Wasser ist. Eine chemische Ursache von WärmeEntbindung ist hiebei wohl nicht mit in Anschlag zu bringen, dia Lisenkiese u. dgl., die sich zersetzen könuten, noch nicht in dieser Kulle nachigewiesen worden sind. 


\section{$-90$}

Arago: über Quellen, Bohr-Brunnen und Springbrunneu (Annuaire pour l'an $1835>$ Jaubs. Edinb. $n$. plitus. Journ. 1835, XVIII, 205-2t7). OnYmpiodor erzählt bereits in der Mitte des VI. Jahrhunderts, dass Landbauer in der Oase, wenn sie $200^{\prime}-500^{\prime}$ tief graben, reichliches Wasser finden, welches übersteigt und Bäche zur Bewässerung der Felder bildet. - Der älteste bekannte artesische Brunnen in Frankreich soll der im Karthäuser-Kloster zu Lillers in Artois (woher der Nane) seyn, welcher von J. 1126 herrührt. - Auch zu Stuttyardt sollen sich sehr alte Brunnen der Art finden. - SHaw berichtet in seinen Reisen, dass, wenn dic Bewohner des Wal reag, einer Gruppe von Dörfern tief in der Sahara, 100'-200' tief graben, sie auf einen Schieferthon stossen und nach dessen Durchbrechung den Bahar tâht el Erd (d. i. See unter der Erde) erreichen: eine Sclichte, woraus das Wasser mit grosser Heftigkeit emporsteigt. - Dic Kunst, tiefe Brunnen mittelst an Seilen aufgehängten Bohrern zu bilden, ist bei den Chinesen sehr alt, doch scheint es nicht, dass dort das Wasser je übersprudele*). - Donivicus CAssini bohrte in der Mitte des XVII. Jahrhunderts, ehe er nach Frankreich ging, zu Fort Urbino in Kirchenstaate einen Brunnen, dessen Wasser 15' über die Obcrfläche sprang, und in aufgesetzten Röhren bis zur Spitze der höchsten Häuser geleitet werden konnte.

1. Woher rührt das Wasser dieser Quellen? Am einfachsten und natürlichsten ist es anzunehmen, dass es das durch Regen, Thau und Schnee aus der Luft anf die Erdoberfläche niedergeschlagene Wasser seye, welches durch Sandlager und Felsen-Spalten in das Innere eindringe, sich dort sammle und durch die tiefste sich ihm darbietende $\mathrm{Ab}$ fluss-Öffnung wieder zum Vorschein komme. Darum wachsen die Quellen in der Tiefe der Englischen Grubenwerke jederzeit schon wenige Stunden nach starkem Regenfalle an; - darum sind alle zu Tage gehende Quellen voll Wasser zur Regenzeit und versiegen oft nach kurzer 'Trockuiss. Man hat zwar die Quellen, welche unter dom See-Spiegel liegen, von den aus dem Meere unter ganzen Kontinenten hin eindringenden Wasser ableiten wollen: aber längs der Wolga sind unermessliche Länderstrecken, welche weit unter dem Spiegel des benachbarten Schumzen Meeres liegen und dennoch weder von diesem durchdringenden Wasser überschwemmt werden, noch versumpfen. Umgekehrt liessen Aristoteles, Seneca, Cakdan, Descartes die Quellen aus einer Destillation des Wassers im Innern der Erde durch Zentralwärme und durch Abkühlung der so entstandenen Dünste an den kältcrn Schichcen der Oberfläche entstehen, weil auch der stärkste Regen nicht über $3^{\prime}-4^{\prime}-6^{\prime}$ in gebaute Ackererde cindringeu könne und auch nicht selten Quellen in der Nähe der Berggipfel hervorkommen. Aber solche Ackererd-Schichten bedecken weder uberall die durchlassenden Sandlager und Felsklüfte der Erde, noch kann man eine Quelle aufweisen, die nicht noch ansehnliche Erstreckungen höherer Gebirgstheile über sich hätte.

*) Jahrb. 1831, S. 69, Note. 
Ja: es lässt sich gerade bei den, neuerlich zum Gegenbeweisse angefïhrten Quellen, wie am Montmartre zu Paris, an einer Quelle bei Dijon und an dem Font Feyole am Mont Ventoux im Vaucluse-Depart. nachweisen, dass der Regenfall in den noch über diese Quellen liegenden Gebirgstheilen ansehnlicher ist, als die Wassermenge, welche diese, Quellen liefern. [Doch scheinen durch diese Berechnungen die Schwierigkeiten noch nicht alle beseitigt, welche sich aus der ungleichen Vertheilung des Regenfalles im Verhältniss zum Ergebnisse der Quellen an Wasser erheben. Br.] Ja: nich MAriotte's Versuchen und Berechnungen fülırt die Seine jährlich nur $\frac{1}{6}$ des Wassers zum Meere, welches als Regen in ihr Becken niederfällt; $\frac{5}{6}$ müssen daher als Dunst in die Atmosphäre aufsteigen, von Pflanzen und Thieren zu ihrer Ernährung konsumirt werden, oder durch Felsspalten zu den innerlichen Becken geleitet werden, aus denen die Quellen entspringen; [dieser letzte Abgang muss sich jedoch im Verlauf des Jahres immer wieder mit Denjenigen kompensiren, was die Quellen und die sich auflösenden Pflanzen und Thicre zurückgeben. . Es ist daher wohl richtiger, wenn der Verf. a. e. a. O. sagt:] ein Theil geht auch durch unterirdische Kanäle dem Meere $\mathrm{zu}^{*}$ ). Der Ingenieur Dausse hat (in einem noch ungedruckten Werk) berechnet, dass das Seine-Becken oberhalb Pavis 10,307,000 Acres misst und jährlich 20 " Wasser empfängt, was 677,000,000,000 Kubikfuss beträgt, während nur 234,585,140,000 Kubikfuss ( $\frac{1}{3}$ des Ganzen) durch den Pont de la Revolution alsfliesst ${ }^{*}$ ). Diese Zahlen zeigen das Grundlose der Meinung, dass durch die Quellen allmählich innere Wasserbecken sich ganz entleeren müssten.

2. Wie das Oberflächen-Wasser in den verschiedenen Formationen in der Erdrinde vorkommen und zirkuliren könne.

a) Urgesteine sind nicht oder kaum geschichtet, von kleinen nur wenig miteinander in Verbindung stehenden Spalten und Ablosungen durchsetzt und geben daher häufige aber schwache Quellen ganz nahe dem Orte, wo die Erde das Regenwasser aufgenommen. - b) Die se-

*) Den eigentlichen Regen kaun man überall unmittelbar sammeln und bemessen ; auch die Menge des in auf ähnliche Weise gesanmeltem Schnee enthaltenen Wassers, wenn man ihn nur vor seiner theilweisen V'erdünstung schmilzt. In grossen Flocken gefallener Schnee liefert eike Wassermenge, die dẹn Boden nur 0,1 so hoch bedeckt, als er selbst; - in kleinern Theilen gefallen gibt er 0,2 - und hatte er sich sehr dicht zusammengesetzt, bis 0,66 jener Höhe. - Hagel fällt sel. ten olıne Rugen und schmilzt dann ait diesenı in Regenwasser aufgefangen. Der Betrag des Thaues ist nach Ort und Zeit zu veränderlich, un eine allgemeine Proportion dafür angebel zu können; denu Datrox's Angabe, dass er im Verlaufe eines ganzen Jahres eine 3" holıe Wasserschichte auf der ganzen Erdoberfläche bilden wïrde, berulte auf falschen Voraussetzungen. Fine grosse Wasserfläche mag jahrlich so viel Wasser verdunsten, als sie durch Regen wieder erhïlt.

*4) Das Mittel ist 7537' Kub. in der Sekunde, das bekannte Maximun (im Jahr 1615) 40,838' Kub., das Minimum (1767 und 1803 während grosser Trockue) 2187 Kubikfuss. 
kundären und tertiären Formationen bestehen aus übereinander liegenden manchfaltigen, durchlassenden und undurchlassenden Schichten, welche gewöhnlich ursprünglich in grossen Ebenen abgesetzt, später aber durch Emporhebung nach gewissen Linien zu Becken umgestaltet worden sind, wodurch also diese Schichten, die sonst untereinander horizontal liegen, an den Rändcrn der Becken mit ihrem Ausgehenden nebeneinander zu liegen kommen und in den Stand geseizt sind, in ihren permeabeln Gliedern die Tagewasser aufzunehmen, welche sich dann darin, zwischen zwei undurchgänglichen Gliedern eingeschlossen, oft auch an tieferen Stellen im Innern der Erde fortbewegen, wenn die sie leitenden Schichten daselbst noch irgend ein geringes Gefälle besitzeu, oder wenn die vom Tage her nachdringenden Wasser darauf irrücken. Tertiäre Bildungen bieten kleinere Becken: sie sind theils in den früleren Becken der sekundären abgesetzt, theils selbst erst später durch Hebungen zu Becken umgestaltet; sie sind loser, reicher an völlig durchlassenden Sandschichten, daher reicher an Klüften, veränderlicher in Schichtenfalle und bieten daher nicht wie die sekundären die Erscheinung dar, dass sie auf grosse Strecken hin gar keine Quellen liefern, an andern sehr reich daran sind (J. BURAT). - Die Schichtgesteine enthalten auch grosse Höhlen und Spalten in ihrem Innern, welche das Wasser fortleiten. So ist der berühmte Fels bei Torghat in Norwegen durch einen geradlinigen natürlichen Stollen von $150^{\prime}$ Höhe und $3000^{\prime}$ Länge von einem Ende zum andern durchbohrt. Die Guacharo-Höhle in Jurakalke des Caripe-Thals in Südamerika ist nach Humbonds $80^{\prime}$ breit, und auf eine Erstreckung von $1455^{\prime}$ bei gleichbleibender Richtung $72^{\prime}$.hoch; sie geht aber viel weiter, obschon die Eingebornen durch Aberglauben abgehalten werden, weiter als $2400^{\prime}$ vom Eingange vorzudringen; ein $30^{\prime}$ breiter Bach durchströmt sie der Länge nach. Die Adelsberger Höhle in Krain, welche den Poick-Fluss aufnimmt, ist 6 Meilen [Englisch, und die Angabe doch wohl noch un die Häfte zu gross] lang und enthält einen See, über den man nur in Boote kommen kann. Nach Pantopyidan ist zu Frederikshal in Norwegen ein senkrechter Felsschacht, in welchem ein Stein wenigstens 2 Minuten braucht, um zu Boden zu fallen, was, sofern dieser Fall nicht etwa gebrochen ist, eine Tiefe von 12,000' (1200' mehr als die Spitze der Pyrenäen hoch ist) andeutet. - Die Schichtgesteine enthalten unermessliche Wasser-Schichten zwischen sich. So gibt die Quclle von Vauchuse, welche gleich an ihrem Ursprung die Sorgue bildet, nach GuÉrn's Messung in jeder Minute mindestens $13,000^{\prime}$ Kub., wenn sie aber stark ist, $39,000^{\prime}$ Wasser von sich, wovon $28,000^{\prime}$ als Mittel jährlich über 13,650,000,000 Kub. Fusse betragen würden, was fast dem ganzen Regenfalle auf 96 Quadrat-Meilen in diesem Theile von Frankreich entsprechend wäre. Dic: grossartigen verwandten Erscheinungen am Zirknitzer. See in Krain sind bekannt. Ähnliche Erscheinungen biete! aber F'rankreich noch viele, nur in kleinerem Maasstabe dar. So ist zu Sáblé in Anjou mitten in einem Moore ein natürlicher Schacht von $25^{\prime}$ Durchmesser und 


\section{$-93$}

unbekannter Tiefe, dessen Wasser zur Regenzeit überfliesst und eine bewundernswürdige Menge von Fischen, insbesondere Forellen von besonderer Art mit sich führt (Mém. de l'Acad. scienc. Paris 17\$1, p. 37). Eben so strümt nach 3-4 Tage lang anhaltendem Regen der Frais Puits bei Vessoul an der obern Saone and überschwemmt die ganze Nachbargegend, in der man, wenn sein Wasser wieder verlaufen ist, zuweilen Fische umherliegen sieht. - Auch in flachen Gegenden gibt es Höhlungen, in welchen ganze Flüsse verschwinden. Plisius sagt dieses vom Alpheus im Peloponnes, vom Tigris in Mesopotamien, vom Timavus im Gebiete von Aquilia, vom Nil bei seinem Eintritt in das Cäsareische Mauritanien (auf einer Strecke von 3) und an der Grenze Äthiopiens (auf einer Strecke von 20 Tagereisen). Es ist der Fall mit der Guadiana in Estremadura, mit der Mans bei Bazoilles, wo man ihr altes Bett zu Tage über dem jetzigen unterirdischen erblickt, mit der Drôme, Rille, Iton und Aure in Normandie, wo diese Flüsse in mehreren aufeinanderfolgenden Schlünden immer mehr und mehr verschwinden. - Oft findet man in der Erde mehrere übereinanderliegende Wechselschichten, welche Wasser führen: man hat sie beim Bohren artesischer Brunnen entdeckt, und bei allen sogleich anzufübrenden einc aufsteigende Bewegung des Wassers im Bohrloch gefunden.

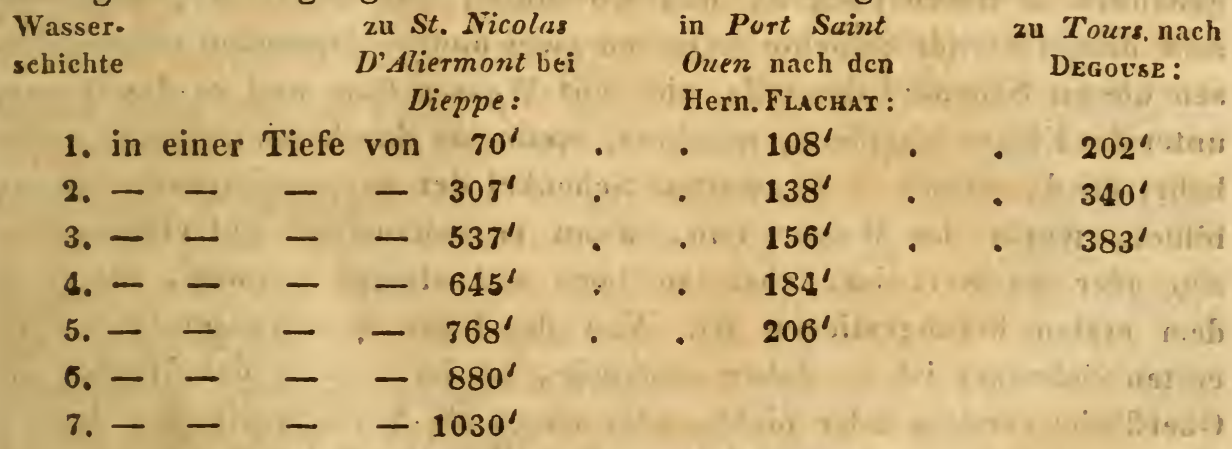

Vier von den bei Port' St. Ouen gefundenen Wasserschichten haben die Herrn Fuchat zu St. Denis wieder gefunden, wo sie 200! tief bohrten. - Manche so erreichte unterirdische Wasserschichten sind in einer starken Strömung begriffen: als man zu Paris in der Brauerei der Maison blanche nächst der Barriere von Fontainebleau bohrte, stürzte der Bohrer plötzlich $20^{\prime}$ tief hinab, wo dann der am oberen Ende an. gebrachte Griff sein wciteres Einstürzen hinderte; bei dem Wiederherausziehen desselben fühlte man, dass sein unteres Ende frei in einem starken Wasserstrome hing und von demselben in Schwingung versetzt wurde. Ähnliche Anzeigen erhielt man von der dritten Wasserschichte zu Port St. Ouen, welche den aus tieferen Schichten heraufgezogenen Bohrlöffel regrelmässig auswusch, so dass man ihn nicht bis zu Tag zu bringen brauchte; - zu Stains bei Saint Denis: hier sank der Bohrer mit 197' Tiefe plützlich um cin Yard ein; - zu Cormailles im Seine- und Oise-Dept., wo der Bohrer mit 220 Tiefe wie ein Pendel in Schwingung gericth. Endlich als man am 30. Jänner 1831 zu Tours die Röhre im Bohrioche auf dem Kathedral-Platze um $20^{\prime}$ abkürzte, vernehrte sich 


\section{$-94$}

das aufsteigende Wasser um $\frac{1}{3}$, wurde trübe, und brachte binnen einigen Stunden aus 335' Tiefe $1^{\prime \prime}-2^{\prime \prime}$ lange Dorn - Zweige, die durch Liegen im Wasser schwarz geworden, weisse Stengel und Wurzeln von SumpfPflanzen, verschiedene wohlerbaltene Samenkörner, unter andern von einem im Sumpfe wachsenden Galium, welche im Herbst reifen, nebst Land- und Süsswasser-Schnecken zum Vorschein, welche alle das Wasser kürzlich erst von der Oberfläche mit sich in die Tiefe gefülurt haben musste. Die berühnte Quelle von Nisme's wächst binnen wenigen Stunden beträchtlich an, wenn es 6-7 Engl. Meilen von da in N.W.Richtung stark reguet, so dass dann ihr Wasserergebniss von 145 Gallonen in der Minute auf 1100 steigt, was auf einen sehr raschen Lauf in unterirdischen Kanälen schliessen lässt, welche, da sich dabei die Temperatur der Quelle nicht beträchtlich ändert, ziemlich tief liegen müssen.

3. Welche Kraft ist es, welche die unterirdischen Wasser in die Höhe treibt und selbst bis über die Oberfläche des Bodens hebt? Es ist der Wasserdruck selbst in kommunizirenden Röhren, deren einer Schenkel in einer gewissen Höhe beginnt, z. B. auf den Bergen, wo die aufgerichteten Gebirgsschichten ihr Ausgehendes zu haben pflegen, und wo mithin nur nöthig ist, dass cine sehr durchlassende Schichte zwischen zwei undurchlassenden eingeschlossen diesen Schenkel darstelie, sich mit Wasser fülle und so das Wasser unter die Ebene hinableite, wo dann, wenn sie durch ein Bohrluch angebohrt wird, dieses den zweiten Schenkel der kommunizirenden Röhre bildet, worin das Wasser nun, wenn es vollkommen gut eingeschlossen oder gesperrt ist, eben so hoch anzusteigen vermag, als es in dem ersten herabgestiegen ist. Von der Höhe des Wasserstandes im ersten Schenkel ist es daher abhängig, ob im zweiten das Wasser die Oberfliche erreiche oder nicht, oder ob es als Springquell über denselben. emportreibe und endlich in auf die Mündung des Bohrloches anfgesetzten Röhren noch höher geleitet werden könne. So muss das Wasser, welches aus dem Bohrbrunnen CAssivi's zu Modena [Urbino?] aufstieg, den anderen Schenkel der es leitenden kommunizirenden Röhre in den 10 Engl. Meil. entferuten Apenninen gehabt haben. Der oben erwähnte Bohrbrunneu in Artvis liegt mitten in einer unermesslichen Ebene: iu diesen und älnnlichen Fällèn muss der erste Schenkel der kommunizirenden Röhre in $40,80,180$ und, wenn es Noth thut, 300 Meil.. Entfernung gesucht werden, gegen welche Zumuthung sich nichts einwenden lässt, wenn nachgewiesen werden kann, dass die Gebirgsschichten auf diese Erstreckung hin beständig bleiben. Nur so ist u. A. das Erscheinen von Süsswasserquellen mitten im Ozean erkläıbar, welche manchmal ihre Wassersäule, nit dem Salzwasser d’s Meeres unvermischt, bis an dessen Oberfläche emportreiben; - Bicinsis hat vor wenigen Jahren als Passagyier auf der Englischen Flotte im Indischen Meere dergleichen beobachtet: 125 Engl. Meil. von Chittayony und 100 Meil. von dem nächsten Küsten junkte der Junderbunds befindlich. Bei Orléans ist die Quelle Bouillon oder Source du Loiret merkwürdig, da sie auch 


\section{5}

in der grössten Trockenheit von 1801 noch 733 Gallonen Wasser in der Miuute gab. Aber sie steht mit der Loire in Verbindung und steigt, ohne sich sogleich zu trüben, wenn diese durch das Schneeschmelzen auf dem Hochgebirge in der Mitte von Frankreich anschwillt. - In eivigen Fällen steht zwar das Wasserergebniss der Spring-Quellen mit der Ebbe und Fluth in Beziehung, wie nach Barlest zu Noyelle sur Mer in Somme-Dept. und wahrscheinlich in allen un Abbeville gebohrten Brunnen, so wie auch ferne bei einem $300^{\prime}$ tief gebohrten artesischen Brunnen zu Fulham an der Themse, welcher zur Ebbezeit 60, zur Fluthzeit 80 Gallonen Wasser in der Minute liefert. Man wird aber diese Erscheinung begreifen, wenn man annimmt, dass das in geschlossenem Kanale erbohrte Wasser früher seinen alleinigen Abfluss in der Nähe des Mleeresspiegels hatte, wo dann dessen Abfluss in dieser früheren Öffnung durch den Gegendruck der steigenden Fluth auf dieselbe jedeswal geschwächt werden muss. - Aus einer grossen Anzahl von ihm gresammelter Beobachtungen theilt A. nur wenige mit, um zu zeiģen, dass die Temperatur der artesischen Brunnen um etwa $1^{\circ} \mathrm{C}$. aut jede $20^{\text {n }}-30^{\mathrm{m}}$ ihrer Tiefe böher seye, als die mittle Jahrestemperatur in derselben Gegend. Bald hofft er die oben erwähnten Beobachtungen vollständig bekannt machen zu könneu. - Hier eine Übersicht der Tijefe einiger Bohrbrunnen zu

$$
10 \mathrm{rt} \text {. }
$$

Tiefe.

$$
\text { Bemerkungen. }
$$

Prov. Kia-ting-fou in China

St. Niculas NAliermont $1800^{\prime}$ : viele Brunnen, woraus Salzwas. ser geschöpft wird.

Genta - $682^{\prime}$ : gab kein übersteigendes. Wasser. Suresne bei Paris .. . - 663': 537' tief in Kreide, ohne Wasser. Cheswick in Northumberland - 582': Wasser steint 1 Yard hoch über. bétlune u. Aive im $P$ as de Calais, $461^{\prime}$ : W. steigt $7^{\prime}$ hoch über., Tours, 1834 . . . . .

$259^{\prime}$

a. $13 \times 1$

Wasserergebuiss einirer Quellen: BÉlbon erwähnt in seiner Scienc. de l'Lngénieur bcreits einer Quelle in Kloster St. Andvé, 2 Meilen von fire im Artois, welche $11^{\prime}$ über den Boden steigt und in der Mlinute fast 2 Tonnen Wasser gibt. - Hrn. Devands Bohr-Brunnen zu Bages bei Perpignan liefert 333 Gallonen. - Die bei den Kavallerie-Baracken zu Tours gibt, 6' über dem Boden, 237 Gallonen, - In England: ist pin Buhr-Brunnen in dex Kupfer-Manufaktur zu Merton in Surrey, welcher 200 Gall, erriesst. - Der z.4 Rivesaltes liefort 176 Gall. - Der zu Jillers im plis de Calcris endlich. 155 Gall, - $\mathrm{Zu}$ Guéhem bei Béthune vereinigen 4 Bobrbrunneu ihr Wasser um eine Mahl-Mühle treiben $\mathrm{zu}$ helfen und zu anderi landwirthschaftlichen Zwecken; - zu Saint Pol thun 5 Bohr-Brunnen dasselbe Brunnen die Stcine cince grossen Mühle und die Gebläse und die Hämmer einer Nagelfabrik. Der Brunnen zn Tours bewegt mittelbar die 
Webstühle einer Seidenfabrik und einer zu Tooting bei London setzt ein Rad und hiedurch ein Pumpenwerk in Bewegung, welches Wasser bis zur Spitze einer 3 Stock hohen. Apotheke hinauftreibt. Wegen der unveränderlichen Klarheit des Wassers empfehlen sich die Bohrbrunnen in Papiermühlen; wegen ihrer gleichbleibenden Temperatur zur mässigen Erwärmung von Arbeits - Räumen, Gewächs- und Treib - Häusern. In Heilbronn erhalten die verschiedenen Wasser mehrerer Quellen von $12^{\circ}$ C., die Temperatur in einigen Manufakturen auf $8^{\circ}$, wenn sie auch ausserhalb auf $0^{\circ}$ herabsinkt. Im Dorfe Chandes Aigues gebraucht man das Wasser zu Treibereien, und zu Erfurt gibt es auf ähnliche Weise (bei Kressenbeeten?, cress plots) angewendet, einen jälırlichen Ertrag von 12,000 Pf. [?]. In den Fischteichen von St. Gratian bei Montmorency endlich gebraucht man solches Wasser ebenfalls zur Unterhaltung einer passenden Tenperatur in Sommer und Winter. Auch legt man umgekehrte oder negative Brunnen an, um Ländereien trocken zu legen. So hat sie König RenE zur Abtrocknung der Paluils bei Marseille gebraucht: sie nähren auf diese Weise die Springquellen im Hafen von Mion bei Cassis. Die Orbe führt aus dem See des Rousses im Jura mehr Wasser in den Jonx-See, als dieser verdunsten kann, und doch hat er zu Tage keinen Abfluss. Verstopft sich aber einer seiner inneren Abflüsse, so teufen die Landlente, um ihr Gut vor Aus? tritt und Überschwemmung zu sichern, Schächte von $10^{\prime}$ Breite und 15-20' Tiefe $a b$, die sein Wasser versenken, das sodaun 2 Meil. unterhalb dem südlichen Ende des See's wieder aus dem Boden hervordringt. Zu Villetaneiuse bei st. Denis grub ein Kartoffelstärke-Fabrikant in Winter 1832 auf 33 ènen Schacht bis auf Wasser-absorbirende Sandschichten hinab, worin er dann täglich 16,000 Gallonen unreines Wasser versenkte, wegen dessen Nichtbeseitigung seine Nachbarn ihn zum Aufgeben seiner Manufaktur zu nötligen im Begriffe waren. Nach 6 Monaten fand man in Gruide des Schachtes noch immer reinen Sand. Eben so beseitigten die Aufseher der Gemein-Kloakèn 'zu'Bondy täglich 3000 Kubikfuss Wasser. Das Wasser von dem artésischen Brunnen zu St. Denis war, weil es seinen Ablauf durch die Strasse hatte und diese in 'Winter mit Eis überzog, sehr lästig' geworden. Da senkte Mứcor drei metallne Röhren, eine die andere mit je einem Zwischenraume ungeteind, in das Bolirloch, die innerste und engste geht $200^{\gamma}$ tief und fülirt das beste Trinkwasser zu Tage; zwischen ihr und der zweiten steigt Wasser von geringerer Güte aus einer Tiefe von $170 \mathrm{~F}$. herauf; zwischen der zweiten und dritten sinkt im Winter das Wasser der zwei vorigen aus dem Brunnenbecken wieder bis zu einer Wasser einsaugenden Schichte hinab und macht mithin die Strassen nicht melir unbrauchbar, noch bringt es, da es von reiner Bescliaffenheit, andere nahe Brunnen in Gefahr. - Leicht erklärliche Anomalien zeigen sich nicht selten, in so ferne als ein Bohrloch reichliches Wasser liefert, während ein unmittelbar darneben niedergetriebenes trocken bleibt; oder wenn in einer Gegend nach und nacb viele Bohrlöcher ohne Nachtheil für den 
Wasserreichthum der früheren niedergetrieben werden können, während in der anderen derselbe durch jedes neue Bohrloch vermindert wird. Auch hat der 584' tiefe Bohrbrunnen von Larockelle, welcher $215^{\prime}$ von der Seeküste entfernt ist, in Herbste 1833 eine merkwürdige Undulation in der Höhe seines vorher $21^{\prime}$ unter der Oberfiäche gebliebenen Wasserstandes dargeboten, indem mehrmals derselbe binnen je 1-2 Tagen um $200^{\prime}-300^{\prime}$ fiel und dann langsamer wieder stieg. Man hat öfters gefragt, ob die Bohrbrunnen sich nicht erschöpfen würden; jedoch gibt der vos Lillers seit mehr als 700, und jener vom Kloster Saint Audré schon über 100 Jahre täglich eine gleiche Menge und Qualität von Wasser. Zuweilen erbohrt man unterirdische Gas- státt Wasser-Behälter, und meist unbrennbares Gas, zuweilen reines oder auch KohlenWasserstoffgas strömt aus dem Bohrloche hervor, bald nur vorübergehend bis zu Erschöpfung des Behälters, bald auf eine andauernde Weise. Letzteres ist oft der Fall in China, wo das so erbohrte Gas zur Abdunstung der Salzsoole und zur Beleuchtung dient; - auch in einigen Nurlamerikanischen Dörfern dient das erbohrte Gas seit Jahren zur Haus - und Strassen - Beleuchtung, und Prisius berichtet, dass auf dem Berge Chimera bei Phaselis eine Flamme Tag und Nacht brenne, welche Kapitïn BesufonT im Jahr 1811 noch wiedergefunden bat.

VAx Breds hat bei Zutphen in Geldern eine tertiäre thonige For. mation unter dem Diluvium cutdeckt, welche den yrössten Theil des Bodens dieser und der benachbarten Provinzen bildet. Sie enthält: Ple urotoma colon, P. I a evigata?, Dentalium elephantinum, Corbula rugosa, C. elegans, Venus dysera, Venericardia orbicularis, Isocardia ventricosa, Pectunculus a uritus, P. granulatus, Nucula striata, Turbinolia cuneata var, anceps, T. appendiculata. Die Abhandlung darüber steht im Harlemer Kunst en Letter Bode und in Neederland'schen Staats Courent. (B̈ull. géol. 1834, IV, $3+\boldsymbol{l}$ ).

C. Matefcci: über die Bildung von Schwefel-und Gyps-Schichten. (Ann. chim. phys. 1834, Mars, LV, 313-317). Diese Schichten finden sich vorzüglich in der Näle thätiger und ausgebrannter Vulkane, und entstehen durch Sublimation von Schwefel a:ts denselben, welcher sich theils als solcher in Krystallen absetzt, theils zu schwefeliger und Schwefel-Säure verbrennt, vorhandene Kalksteine zersetzt und so wieder zu Entwickelung von kohlensaurem Gase Veranlassung gibt. Von der Decke einer vulkauischen Höhle Airsst die Schwefel-Süure Tropfen-weise, und Doconiec has gie in den Girtten des Ätna gesammelt. 
Jameon: liber die Ablagerung von Konchylion noch lebender Arten in den Friths von dem Forth und derClyde über der jatzigen Wasserhöhe dipser Buchten (vorgelesen bei der Wensen'schen Soc. in Edint. am 7. Febr. $1835>$ l'Instit. 1835, III, 2.52 - 253). Solvhe Ablagerungen 'aben Jimeson und seinc Schüler. schon seit langer Zeit beobachtet. So hat der verstorbene Macknegos vor der Gesellschaft 1811 pine Vorlesung über eine solche $4 \frac{1}{2}$ Engl. Meilen von Glrsgow beobachtete Lagerung gehalten. - Kapt. Laskey beobachtete 1814 eine andre $40^{\prime}$ iibcr dem Spiegel der Clyde in der Linic des Kanals von Ardrossan einige Meilen von Glasgow (vergl. den IV. Bd. der Verhandlungen der Gesellsch.), worunter Schaalen von Turbo littoreus, T. rudis, T. terelira, Nucula minuta, N. nuclea; Patella vulgaris, P. pellucida, Buccinum lapillus, B. Indatum, Mytilus odulis, Veuus Islandica, V. striata, V.literata, Pecten opercularis (P. subrufus Dovov.), Balanus communis, Anomia ephippium, Tellina plana, Neritalitto. ralis, N. glauciua, Mya truncata, Trochus crassus, Cardium echinatum waren, welche noch jetzt alle den Frith der Clyde, aber erst unterhalb Dumbarton bewohnen, wo sein Wasser beständig salzig bleibt. - Eine andre Ablagerung hat derselbe bei Dunbarton selbst, doch ebenfalls über der Wasserhöhe der Clyde beobachtet, in welcher sich Venus sulcata, Pecten IsIandica und Ostrea Islandica Terr. befanden. - Später hat Fuming der Sozietät über ein solches Muschel-Lager berichtet, das sich an der Küste des Forth, westlich vou Borrou'stomess, $33^{\prime}$ über dem Hochwasserstande befindet, $3^{\prime}$ Mächtigkeit besitzt, auf einer Kiesschichte über dem herrschenden Sandsteine der Gegend ruht, sich auf den Gestade des Forth in gerader Linie von W. nach 0 . 3 Meilen weit crstreckt und die Gehäuse der in der Gegend häufig lebenden Mollusken, insbesondere Austern, dann Mytilus edulis, Venus rhomboidea, Mactratruncata, Buccinum undatum, Turbo littureus, Patellavulgaris u. s. W., nur mit etwas Sand enthält. - BacD hat in den Verhandlungen der Sozietät eine Beschreibung der Seckonchylien gegeben, die man zu Allon, $20^{\prime}$ ïber dem jetzigen Spiegel des Furth findet, - und anderer ähulicher erwïhnt, dic einige Meilen westlich von Stirling Castle vor. kommen, und worunter sich besonders A ust ern-Schaalen auszeichuen von ciner Grösse, wie sic jetzt nicht mehr vorkommen, wie man uberhaupt keine Austern mehr oberhalb Queensferry sieht; - auch lindet sich nach ilm eine solche $A$ ustern- und -Sand-Schichte am Fusse des Clackmannim-Berges. - Avamson hat im IV. Bande der Verhandlungen eiue Secmuscliel-Bank auf der Insel Lonach des Loch Lomund, $20^{\prime}$ ïber dem Meeres. Spiegel bei Dumbarton, beschrieben, wo sich jedoch einige neue Arten, wio es scheint, nebst mehreren Echiniden finden. - In einei in Jahr 1821 vorgelesenon Abhandlung über dic ossilen Elephanten-Reste von Kilmarnock hat man erwähnt, dasa sich in deren Gesellschaft Konchylien von noch in den benachbarten 
Meereu lebenden Arten finden. - Im J. 1824 sandte Brackadden an die Gesellschaft eine Abhandlung über die oberflächlichen Erdschichten, wovon ein Auszug im V. Ba:sde ihrer Verhandlungen mitgetheilt worden, und wornach die im Forth gemeinen Seekonchylien sich auch zu Polmaise unterhalb Stirling, zı Grangemouth und anderwärts an den Ufern des Furth, zuweilen weit entfernt von uud hoch über ihrem jetzigen Wohnorte, abgelagert finden. - Derselbe hat später in einer der Gesellschaft überreichten Abhandlung die Seekoncliylien-Lager beschrieben, welche sich hoch über dem jetzigen Spiegel des Frith zu Wardie und Newharen befinden. - Vor wenigen Monaten noch hat Macharen in der Zeitschrift "the Scotsman" einen Theil der Muschel-Schichte bescliricben, welche zwischen Leith und Portobello beobachtet wird. Endiich hat Dr. R. Tномsоs in seinem neuen Jouruale "Records of General Science" viele neue Beobachtungen über die Nuschel-Ablagerungeu an den Ufern der Clyde mitgetheilt.

\section{Petrefaktenkunde.}

R. Hartan: kritische Bemerkungen über einige bisher in Nord-Amerika gefundene organische Uherbleibsel (nach den Aushïugebogen der Transactions of the geological Society of Pliladelphin, vol. I, in Janes. Edinit. n. philos. Journ. 183t, XVII, 342-362; I. (i).

\section{Mammalia.}

$$
\text { (A. P a c h y d e r m a t a.) }
$$

1. Mastodon Cuv. (Tetracaulodon Gobri.).

1) M. gigante um Cuv, oss. foss $I$; MrtchecL's Ausgabe von dessen Lid-Theorie; Hafian Fanna Americana; Cooper im Amer. Journ. of Geology; Prare's Abhandiung, $4^{0}$; Transaci. of the Aner. Philos. Soc.; Grodman ib. new series III; Amnals of the Lyc. of New-York; Mí a muthoth der Anglo-Amerikaner; Büffel-Vater der Indier; OhioThier der Franzosen. - Ist bekannt in Nord-Amerika voraüglich in dem Ohio-Thal, zu Big-bone-lick, Kentucky, findet sich aber auch in jodem Staate der Union. Zahu- und Knochen-Reste liegen in den meisten Sammlungen; zwei fast vollständige Skelette stehen in den Museen von Philadelplica und Baltimore. Sein geologisches Alter ist nach Dr LA Brone nicht ganz genau ermittelt; inzwischen liegen seine Reste hiinfig in und über Diluvial-Schutt; zuweilen finden sich noch vollstiudiwr Skelette, stehend wie sie versunken sind, wie jenes des Great OsageFlusses (Cuv. I, 222), das von Deray erwähnte (Ann. Lyc. N.-Y.) u. a.; nuch scheint der Magen mit scinem Inhalt cinmal mit vorgekommen zu 
seyn (Cuv. 1, 219). Lovg grub 1824 am Big-bone-lick viele (neuc und lossile) Elenn- und Bison-Knochen mit denen des Mastodon aus. Darnach glaubt der Verf., dass diese Thierart, wie das Irische Elk, erst nach dem Erscheinen des Menschen, Jedoch lange vor den historischen Eriunerungen aus der Reihe der Lebenwesen verschwunden seye. Un. erfahrene Schriftsteller haben Manches von diesem Thiere gefabelt. Als man den Kanal um die Ohio-Fälle ausgrub, fand man Reste verschiede. ner Mastodon-Individuen einige Fuss tief im Boden und dabei einige Stosszahn-Paare um die Ùberbleibsel eines Heerdes und Indianischer Werkzeuge absichtlich im Kreise geordnet; andere Knochen aber darum hergestreut: diess veranlasste Jemanden zur Bekanntmachung in den Blät. tern von Kentucliy, dass man so viele Überreste eines einzigen Individuums einer ausgestorbenen Thierart gefunden habe, dessen ungeheures Maul mit so vielen und furchtbaren Zähnen erfüllt gewesen seye, dass es ciнen ganzen Wald auf cimmal zu zermalmen und zu verschlingen vermocht hahe. Eine andere Zeitungs-Nachricht gedachte eines $60^{\prime}$ langen und 25' hohen Riesen-Thieres [vergl. neues Jahrb. 1832, S. 484]. Nicht viei besser war Godmax's Bericht über den Unterkiefer eines jun. gen Individuums mit Stosszähnen, worauf er sein Genus Tetracaulodon grüudete, dessen Benennung zudem auf manche andere Pachydermen-Genera aucl passen würde; auch ist das Vorkommen oder der Mangel von Eckzïhnen in einer Kinnlade oft nur ein sexueller Unterschied: und als ein solcher ergaben sich eben diese Eckzähne auch in Folge der Untersuc!ung einer grösseren Anzahl junger und alter Unterkiefer: nie war mit ihrem Vorhandenseyn ein weitrer Unterschied in der Bil. dung des Kicfers oder der Backenzähne verbunden. Dazu kam noch neuerlich ein Neophyte, welcher in den Transactions of the Americ. Society $I V$, $317 \mathrm{ff}$. einen 23 SS. langen Aufsatz mit 10 Tafeln mittheilte, dessen Resultat noch 3 neue Mastodon- und $2-3$ neue Tetracaulodon-Arten sind; aber alle angebliche Verschiedenheiten dieser Arten sind nur solche des Geschlechtes (die Stosszähne), des Alters (Form, Zacken, Zahl der Backenzähne selbst, die von 8 auf 4 herabgeht und dabei natürlich auch die Gestalt der Kinnlade etwas mit modifizirt), oder des Individuuns, wie sic Cuner in seinem Werke (I, 226, 227) schon lïngst als solche bezeichnet hat. Das ist auch W. Cooper's letzte Ansicht als Resultat vieler Untersuchungen über Zahn. Wechsel und - Bildung beim Mastorlon, dass es in Nord-Anerilia nur eine Art desselben gebe, und dass Tetracaulodon nur junge Individuen in sich begreife, die aber ihre unteren Stosszähne zuweilen, in Folge sexueller oder individueller Eigenthümlichkeit, längere Zeit behalten (FEAтнEкsт. IMonth. Amer. Journ. of Geology, I, 1.58). Auch scheint jener Monograph von Tetraca! lodon sclbst einige Zweifel in die Selbststindigkeit der einen oder der andern seiner Arten gresetzt zu haben [vergl. HiYs, im .Jahrb. 183.5, 735].

2) M. angustidens Cuv. und II. tapiroides Cur. - Die cinzige weitere Nachricht gibt HALLAN in sciner Fauna Americ. p. 212, 213. 


\section{$-101$}

2. Elephas.

3) E. primigenius Eungerb., Cuv. oss. I, 75; Hangan Fuuna Amer., und Journ. of the Plitad. Acad. of natural Scienc., III; MrTchels's Ausgabe von Curier's Erd-Theorie. Weit verbreitet in N. und süd-Amerika, und eingefrorene Körper kommen auch an der N.W.Küste Amerikas (Kotzenue), wie in Sibirien, vor. Diese 80 verbreiteten Reste scheinen aber verschiedeuen Arten angehörig, deren zwei der Vf. bereits a. 0. a. O. (Philac.. Journ.) seit mehrereu Jahren in Anerika nach den Zälınen unterschieden hat. Zähne und Skelett-Trümmer sind häufig in dortigen Sammlungen, zumal in denen der Akademie von Philadelphia, der P'ilosophical Society u. s. w., und die Geological Society ron Pennsylvania besitzt ein ungeheures Schenkelbein dieses Thicres von Moorestou'n, N.-J. Der Verf. bewahrt selbst eineu Zahn und hat zwei im Museum zu Liverpool gesehen, welche deneu der Afrikrmischen Art ähnlich und anscheinend fossil sind, aber aller Fundorte sind unbekannt.

3. Tapirus.

4) T. mastodontoides Haru. Fumm. Amer. 22t. Ein Mahlzahn von Big-bone-lick in Kentucky, dem von Cuviks's kleiner 'Tapir-Art sehr ähnlich, nur sind scine Queerhügel schiefer und geben etwas anders gestaltete Abnutzungsfächen: Abweichungen, wie sie nach Ansich der Pariser Sammlungen sich dem Verf. selbst bei verschiedenen Zälnnen des nämlichen Individuums ergeben haben, so dass sic kaum eine spezifische Differenz begründen. Er ist nur halb so gross als der lileinste Milchzahn eines Mastodon, den H. noch gesehen hat, besitzt aurh eine andere Form und Struktur der Wurzeln, so dass derselbe niclit begreift, wie Cooper (a. a. O. in Feitruerst. Journ.) ihn dem M astodon zuschreiben kann. Nach in Paris angestellten Vergleichungen geliört er in die vordere Lücke (?Alveole, „sochet") des Oberkiefers. Vorkommen mit Mastodon.

4. Equus.

5) E. caballus. Seine Reste sind in Amerika selton. Nitcinth. (in der Ausgube vou Cuvier's Erd-Theorie) gedenkt fossiler P fe y deZähne und - Koochen, wèlche bei Neversink Hills, N.J. gefunden worden: das Museum der Akademic von Philadelplica enthält andre aus dem Ohio- oder Mississippi-Thale, und Colonel Anent zu Hashingtun hat welche aus dem Chesapeake- und - Ohio-Kanal bei Georgrturun, $\boldsymbol{D}$. C. unfern dem Potomac erhalten.

5. Thinoceros.

6) Rhinoceroides Alleghaniensis (Fentuenst's.Juls'n. > Juhrl. 1832, 478). Ein Londoner Geolog hat nach Ansicht des Originals erklärt, diss es zu zweifelbafter Art seye, um es als einen Fussil-Rest zuzulassen. Anch HarLan wïnscht erst wcitere Eutdeckungeu abzuwarten, elie er es als eincu solchen erklärt: es ist ein Stein, welcher mit der kü̈chcruen Schuautze eines Rhinozeros viele Ähulichkeit besitzt, aber vielleicht doch nur vin Lusus uaturae ist. Der gränzliche Maugrel aller Knoclsen-Substanz darin 
würde allein den Verf. woch nicht bestinmen, seine organische Abstammung geradezu zu läugnen, obschon sie solche zweifelhaft macht.

$$
\text { (B. E d e n t a t a). }
$$

6) Megatherium Cur.

7) M. Cuvieri cuctt. - Cuv. oss. V, $1,17 t$; MrснецL in Ann. Lyc. N.-York, I. 58, $\mu l .6$; Cooper ib. I, 11t. $\nu l .7, I I, 267$; HaRL. Faun. Amer. 200. Das Paraguay-Thier ist - ausser in Süd-Amerika - seit 1823 auch in N. - Amerika gefunden worden. Von skidaway Island in Georgia sind Exemplare nach dem New-York Lyceum gebracht worden, welche Cooper und Mrtchels beschrieben haben. Ihr geologisches Vorkommen in letzterer Gegend kennt mau nicht genau; doch müssen sie zur Hälfte aus dem Boden hervorgeragt haben und vom Meere bespühlt worden seyn, da sie auf einer Seite mit Flustren u. a. Zoophyten, mit Balanen und Austeru bedeckt sind. Sie sind schwer, hart, schwarz, ohne organische Materie, jedoch nicht durch Fortrollen noch durch eine sehr lange Einwirkung der Meereswellen abgerundet. Mit einigen Kosten köunte man deren noch eine grosse Menge erhalten, theils am nämlichen Orte, theils an zwei Stellen: White Bluff an der Küste Georgia's und etwas davon entfernt am Savannah.

7) Megal on yx JefFers.

8) M. Jeffersonii Harl. Faun. Amer. 201 und Desmar. Mammalogie 336 ; - Jefrerson in Transact. of the Amer. philus. Suc., old series, IV, 2屯6; Wistak ib. 526, pl. I, II; Cuv. uss. $\mathrm{F}, \mathrm{I}, 160$. Cuvier kannte nur einen Backenzahn davon. In Nord-Amerika hat man Reste dieses Thieres nur an drci Stellen entdeckt, nämlich in der Greenbriar Co., Firg. (Jefrerson); am Big-bone-lick und in der White Cave, Kentucky (PaLisot DE Beavvors). In den westlichen Theilen Virginiens, Kentucliy's, Tennessee's u. a. Gegenden des MississippiThales enthält der weit erstreckte Kalkstein eine Menge oft Meilenlanger Höhlen, durch welche einst unterirdische Flüsse sich bewegt zu haben scheinen, wesshalb sie vielleicht eben nicht mels fossile Kuochen enthalten: in vielen derselben wird Salpeter gewonnen.

9) M. I aqueatus Harc. Juurn. of the Acarl. Philad. VI, 269, pl. 12, 13, 14 und Featherst's. Jolırn. 1831 u. 1832, $I, 7 t, p l$. 3. Vorkoumen in White Cave, Edmondsun Co., Kentucky, an südlichen Ufer des Green-Flusses, 50 Meil. gerade nòrdlich vom Ohio und $\frac{1}{2}$ Meile vom Eingange der Mammoth Cave. Die hicr erhaltenen Peste gehören Jour Price Wetuenill, der sie im Muscum der Akademie zu Philadelphia niedergelegt hat. Sie bestehen in 2 Klauenbeinen des Vorderfusses, 1 Radius, 1 Humerus, 1 Scapula, 1 Fcmur-Stück, 1 Rippe, 1 Tibia, 4 Brust-und 1 Lenden-Wirbel, 1 Backenzalın-Stück, mehreren kleinen Trümmern und einigen Epiphysen, Alles Überbleibsel eines jungen Individuums, noch viele animalische Materie enthaltend, und die Langknochen an ibren Endeu noch mit Knorpel bedeckt. Eiuer der Klauen-Phalangen ist noch mit einem hornartigen Überzug (Klaue) von gelber ockriger Farbe 
versehen. Neuere Kuochen von Bison, Hirsch, Bär, cin mensehlicher Mittelhandknochen, welche aufbewaht werden, sollen in derselben Höhle mit vorgekommen seyn. Die Megalonyx-Knochen sollen unbedeckt an der Oberfläche des Bodens gelegen seyn. Der Zahn sowohl, als die übrigen Theile geben spezifische Merkmale zur Unterscheidung von voriger Art an Handen. Diesclbe Sammlung enthält einen 19" langen fast vollstïndigen Humerus gleicher Art von Big-bone-lick, jedoch von schwarzer Farbe, dichter Struktur, hart, gleich den besterhaltenen Mastodon-Knochen: und später hat mau von diesem letzteru Fundorte eine grosse Sammlung fossiler Knochen nach New.Yurk gebracht, worunter sich die Kinnlade, Zülnne, Schlïssclbeine und eine vechte Tibia des M. laqueatus befinden, welche in Fratherst's. Journal beschrieben worden. Im Alter stehen sie auf ciner Seite den Thieren des Big-bune-lick und der Europäisclien Knochen-Höhlen gleich, das 'Thier scheint aber, nach dem Vorkommen in Big bone-lick zu schliessen, linger als irgend ein ausgestorbenes Thier, mit Ausuahme des Irischen Elkes, forthestanden zu haben [vergl. Jahrb. 1833, S. 624].

$$
\text { (C. P u m i a n t i a). }
$$

\section{Cervus.}

10) C. Americanus Harr. Funn. Amer. 245; Wrstar Transact. Amer. philus. Suc. N.S. I, 375, pl. $x$, fig. 4. Das fossile Elk der Vereinigten Staaten. Diese Art ist auf einen unvollständig erhaltenen Schädel, welcho die Amerikanische Sozietät von Jefrersun erhalten, gegründet und dem Cervus Canadensis zunächst verwandt, docls der Schädel grösser und die Art von allen übrigen lebenden und fossilen Hirschen verschieden. Dic übrigen Knochen sind im Big-bone-lick nicht selten. Einige andere hat BigsBy in Canada gefunden, welche nach seinen davon genommene: Zeichnungen derselben Art angehört haben mögen.

9. Bos.

11) B. bombifrons Hanc. F. A. 271; Wistar l.c. I, 379, pl. xr, fig. 11, 13. Die davon bekannten Reste sind den entsprechenden Theilen des Bos American us oder Buffalo sehr ähnlich, doch weicht die Form des Schädels und die Stellung der Hörner spezifisch ab. Von Biy-bone-lick; die Zähne auch sonst häufig.

12) B. Iatifrons HarL. F. A. 273; Cuv. uss. 1me édit. Ir, pl. Irr, fig. 3. Ein beschädigter. Schädel in der Sammlung der Akademie von Philadelphia, in mancher Riucksicht dem des Bos Urus Cuv. ähnlich. Das Horn hat 28" Umfang an der Basis, In Kentucky. Staate. Nach Cuvikr wären ähnliche Schädel am Rheine, bei Krakan etc. gefunden worden.

18) B. Palla si i Dekay Ann. Lyc, N. - Y., II. 280, pl. vr. Mrt. cHeLL hat der Gesellschaft in New-York eine Sammlung fossiler Knochen überlassen, worunter sich der von Dкках beschriebene Schädel fin. det, welchen er dem des Bos mosebatus vergleicht, dem er auch 


\section{$\sin$

sehr ähnlich ist. Zu New Madrid am Mississippi, durch das Erdbeben von 1812 ausgestossen. Entsprechende Schädel sind in Sibirien vorgekommen.

$$
\text { (D. C a } r n i \text { y }
$$

10. Trichechus.

14) T. rosmarus Cur. V, Cooper Ann. Lyc. N..Y. IT, 271. Aus. ser einigen Backenzähnen u. a. in Frunkreich gefundenen KnochenTrümmern scheint man von diesem Genus bisher nur den von Cooper beschriebenen Schädel in fossilem Zustande gefunden zu haben, der, ctwas beschädigt, in Museum zu Neu-York vorhanden ist. Er ist hart und schwer, die Stosszähne siud fast ganz in Achat verwandelt, und scine Ubereinstimmung mit dem des lebenden Trichechus rosmarus scheint vollkommen. Aus Virginien, mit Cetaceen-Resten; tertiär.

15) Capitän BeEchex brachte von der N.W. - Küste Amerikas den fossilen Wirbel eines unbekannten Säugethieres mit, der nach der Vergleichung im Pflanzengarten zu Paris angestellt, einem Amphibien - artigen Säugethier anzugehören scheint.

\section{(E. C e t a c e a.)}

\section{Manatus.}

16) Rippen und Wirbel einer grossen Manatus-Art, welche an der Ostküste der Vereinigten Staaten (in Georgia, New.Jersey) und an der Westküste von Maryland in tertiären Bildungen vorkommen, liegen in den Sammlungen der Akademie zu Philadelphia (HARLAN im Journ. Acud. Philad. IV, 32).

12. Eigentliche Cetaceen haben fossile Rippen und Wirbel in den tertiären Schichten zunächst dem Ozean hinterlassen, dergleichen In der eben genannten Sammlung so wie in der des Lyceums von NewYork aufbewahrt werden. Aber täglich entdeckt man auch an der Mündung des Mississippi Reste verschiedener Wal-Arten von neuerem Ursprung, welche dort ausgewaschen werden. So erhielt man vor einigen Jahren den Schädel, die Kinnladen und Zühne eines sehr grossen Physeter, welche dann als Reste eines unbekannten Monstrums nach New-Orleans gebracht, bewundert, in allen Zeitungen ausgeschrieen, um hohen Preiss für die Vereinigten Staaten erworben und endlich von Godrax als ein alle bekannte an Grösse übertreffender S a u rier, dem er den Namen Megistosaurus beilegt, in einer eigenen Ablandlung an die Amerikanische philosophische Sozietät angekündigt, in deren Annalen or noch als solcher bezeichnet ist. Das Thier sollte ein grosses mehrere Fuss langes Horn an der Seite des Schädels haben, das aber nichts anderes als das herausgesägte und an das rechte Jochbein angepasste Intermaxillar-Bein war. Diese Reste sollten eben macb England eingeschifft werden, als man den Irrthum entdeckte.

Die „articulirenden Platten der Oberfläche oder Epiphysen der Wirbel" des Physeters werden frisch und fossil nicht selten einzeln gefun- 


\section{$-105$}

den: Rafpiresqub hat eine derselben für eine Schädel-Platte eines fossilen Sauriers angesehen und (Atlantic Jourmal) dessen Genus $\mathrm{N}$ cp h r o s t e on genannt.

\section{I. Ave 8.}

Von dieser Klasse ist dem Verf. nur ein Femur bekannt geworden, welcher an seinem oberen Ende beschädigt ist und von einer zu Scolopax gehürigen Art abstammen mag. Er ist ganz mineralisirt, befindet sich in Museum der Akademie von Pliladelphia und rülurt aus einer Mergelgrube in New-Jersey her.

\section{Reptilia.}

\section{(A. Che 1 o n i i.)}

1. Fossile Ínochen und Brust-Platten von Schildkröten sind in deu sekundären Mergeln New-Jerseys nicht selten, aber zu unvollkommen erhalten, um sie in Arten und Genera zusammenzuordnen. Stücke davon befinden sich in den Sammlungen zu Philadelphia und New-York.

Fortsetzung (a. B. 0. 1834, XVIII, 28-40).

\section{(B. $S$ a u $r$ i i.)}

2) Erocodilus macrorhynchus Harl. (Journ. Acad. nat. Sc. Philad., IV, 15, pl. I). Schöne Kinnladen, Zähne, Wirbel u. s. w. aus den Mergel-Gruben *) von New-Jersey sind im Museum von Plitadelphia aufbewahrt, und das wichtigste Stück davon, das Zahn-Bein der rechten Seite mit den Alveolen von 11 Zähnen auf $12^{\prime \prime}$ Länge, woh! erhalten nud mit Eisen imprägnirt, ist a. a. O. beschrieben. Es ist im Verhältnisse zu dem der lebenden Krokodile hauptsächlich ausgezeichnet durch seine Dicke gegen die Länge genommen, wo dann auch die Zähnc ausserordentlich dick und kurz sind; da sie auf $2^{\prime \prime}$ Länge $1^{\prime \prime}$ Dicke an der Basis besitzen und nur $\frac{1}{2} "$ aus der Alveole hervorstehen. - Dr. DF. кАY besitzt

3) die Kinnlade einer selır verschiedenen Art, dem C. Gangeticus Cuv. sehr analog, aus den Sekundär-Gebilden New-Jerseys, die er in den Amals of the Museum of New-Jersey beschreiben will.

4) ? Plesiosaurus. Ein Wirbel mit den allgemeinen Merkmalen wie bei Plesios a urus, aber durch seine grosse Achsen-Länge von denen aller bekannten Geschlechter abweichend, stammt aus dem Mergel vou New-Jersey, findet sich im Pliladelphia Museum und ist im Journalc der Akademic IV, 232, pl. xIv vom Verf. beschrieben und abgebildet.

*) Mergelgruben kommen owohl in den sekundören als tertiären Bildungen der $A t$ lantischen Kriste vor. 
5) Basilosaurus hat Hartar ein riesenmässiges, von ihen in den Transact. Amer. philus. Suc. 183t, N. S. IV, 297, pl. xx beschiebenes und abgebildetes Reptil aus den ältern Tertiär-Gebilden (mit Corbula wie zu Alabama) an den Ufern des Washita-oder Ollıchita-Flusse's im Luisiana-Stuate genaunt. Es gehört zu Conybeare's Enaliosa uriern. Sein wichtigstes Überbleibsel ist ein Wirbel, der mit denen der Plesiosauren noch am meisten Ähnlichkeit hat. Er ist $14^{\prime \prime}$ lang und 8" breit, und 44 Pf. schwer. Hat das Thier wie Plesiosaurus 66 Wirbel (ohue die des Schwanzes) besessen, so nüsste das ganze Skelett $80^{\prime}-100^{\prime}$ lang gewesen seyn und, jeden Wirbel zu $30 \mathrm{Pf}$. und die übrigen Knochen einschliesslich des Scliwanzes zu etwas mehr als die Wirbelsäure angeschlagen, wohl über 2 Tonnen gewogen haben. Die [vorderen und hinteren?] Seiten des Wirbels sind in der Mitte etwas konkav. Nach der schief nach unten gehenden Richtung der Qucerfortsätze und der geringen Weite des Rückenmark-Kanals zu urtheilen, war dieser Wirbel aus der Lendengegend. Wie an dem linteren Theile der Wirbelsäure von Plesiosaurus, genau so sind auch die hier vorkommenden zwei Grübchen an der unteren Fläche des Wirbels miteinander verschmolzen, und wie bei jenem ist die Gelenkflïche des Wirbelkörpers gestaltet; aber bei jenen sind die Wirbel bekanutlich breiter als lang, und die Dornenfortsätze durch Nähte mit dem Körper verbunden, von welch' letzteren man hier keine Spur findet. Dem Berichte des Richters BRY'zufolge, dem die Gesellschaft die Überbleibsel dieser ThierArt verdankt, lagen solche auf eine Erstreckung von $400^{\prime}$ Länge nach einer krummen Linie zerstreut, und scheinen melireren Individuen angehört zu haben.

6) Ichthyosaurus Missouriensis HarL. (ut supra, 9. 405) hat den vorderen Theil des Ober- und des Unter-Kiefers mit den noch in den Alveolen steckenden Zälnen im sekundären Kalk der subcretaciousGruppe bei dem Yellow stone- und dem Missouri-Flusse in MissouriGebiet hinterlassen. Die ausserordentliche Länge und Breite des Zwischenkieferbeines, welches über das Ende des Oberkieferbeines vorsteht, unterscheidet diesen " langen Theil von dem analogen der übrigen bekanuten Arten. Die daran noch fest gewachsenen Kieferbeine enthalten jederseits drei Zähne, die über der Wurzel abgebrochen siud. Das Zwischenkieferbein enthält deren jederseits zwei, eben so abgebrochen. Rücksichtlich des Wachsthums und des Wechsels der Zähne stimmt die Art mit andern Ichthyosauren überein. Am a. O. hat H. weitere Derails angegeben. Ein Pelzhändler hatte diese Reste an Major WArE zu St. Loris überlassen. Auf dem Heimwege von den Rucky Mountains liatte er in einem Felsen das Skelett eines Alligator-artigen Thieres, etwa $70^{\prime}$ lang stecken sehen und davou jene vorragende Spitze des Kopfes abgebrochen, dessen Länge er zu $3^{\prime}-4^{\prime}$ angab [Jahrb. 183.5, 368].

Prinz Max voN Nưwied hatte während seiner letzten Reise ein fossiles Saurier. Skclett $15^{\prime}$ lang von der grossen Krïmmung des 


\section{$-107-$}

Missouri-Flusses nuitgebracht, das vou der nănlichen Art zu, seyn scheint. [Vergl. Jalirb. 1835, S. 625.]

7) I os a saurus Conyb. (Cuv. oss. foss. V, $I I, 310 ;-\mathrm{H}_{\Delta \mathrm{HL}}$. in Journ. Acad. Philad. IV, Deray in Ann. Lyc. New-York III, 13t, gl. XIII). Man hat Zähne und wahrscheinlich auch einen Femur desselben Thicres im Kabinete der mehr erwähnten Akadenio und Backenzähne in naturhistorischen Lyceum zu New-York, dunkelschwarz, mit Eisen imprägnirt, hart und schwer, aus einer (sckundären) Mergelgrube von Woodbury, in der Monmouth County in New. Jersey. Einige Zähne sitzen noch in den Alveolen eines Knochen fest und haben einen sägeförmigen Rand.

8) Geosaurus Mitchilli Dexay (in Ann. Lyc. New-Yor\% III, 138, pl. III, Fig. 3, 4). Ein Zahn mit einem daran hängenden Kiefer-Stücke, wohl aus dem Vordertheile des Unterkiefers. Seine hochvorragende Stellung auf dem Knochen hat er mit denen von Mosasaurus und Geosaurus gemein; seine zusammengedrückte Gestalt entfernt ihn von ersteren und nähert ihn abermals denen des letzteren. Seiner Grösse nach muss das Individuum, dem er angehört, noch ansehnlicher gewesen seyn, als der G. Soemmeringii Dекат von Munheim. Er stamnt aus den Sekundär - Gebilden von Monmouth in New. Jersey. - [Vergl. Jahrb. 1835, S. 235.]

9) Saurocephalus lanciformis Harz. (Journ. Acad. Philud. 1824, III, 331, pl. XII). Das Genus wurde zuerst auf ein fossiles Zahnbein und Zähne gegründet, welche Lswis und Clark auf ihrer Reise an Columbia-Flusse 1804 entdeckten und dem Kabinete der Ame. rik. philosophischen Sozietät schenkten. Es scheint aus ? sckundärem Kalkstein (der subcretaceuns - Gruppe) im Missouri - Staate herzurühren. LEA hat später eine andere Art dieses Geschlechts in einer Mergelgrube bei Moorestown in New-Jersey gefunden, und Dr. HAxs sie als $\mathrm{S}$ a urodon Leaae (p. 476), S. Le anus (p. 477, Transact. Amer. philos. Suc. N. S. 1830, III, 471 ff.,,$l$. xtx $)$, und endlich als

10) Saurocephalus Leanus beschrieben. Dic Reste beider Arten haben miteinander gemein, dass die Zähne geschlossen nebeneinander liegen, doch getrennte Alveolen habeu, dass die des Ober- und Unter-Kiefers wie Schneidezähne auf einander stehen; - dass die ZahnNerven und Gefässe auf der innern Seite der Alveolar-Fortsätze verlaufen, woselbst für den Unterkicfernerven eine Grube auf der MesialFläche des Kieferbeines, gerade unter dem Alveolar-Rande (doch schwächer in dem nur halb so grossen S. Leanus) vorhanden ist. (Etwas unklar ist der Theil der Beschreibung in Originale, worin gesagt wird, dass "die untere [Ersatz?.] Zahnreihe in die Höhlen der oberen gerade in Zentrum, im ,"srocess of shedding" eindringe, dass dic untere Reilie vollständig geworden - completed - ist, ehe sie in die obere ein. dringt; und die Zahn-Sägeliaien - dental serrature - des Ober- und des Unterkiefers wie Sclmeidezälne aneinauderschliessen.") Durch ebeu diese Alerkmale unterscheidet sich aber das Genus zugleich vou I ch. 


\section{$-108$}

thyosaurus, von Plesíosaurus und von der Ordnung der Saurier überhaupt. Die zwei Arten aber werden durch folgende Merkmale von einander getrennt: bei S. lanciformis : der vorragende Theil der Zühne glatt und stunpf lanzettförmig; - bei S. Leanus: die Zühne spitzer, schlanker, etwas zusammengedrückt und getrümmert. [Vgl. Jahrb.183.5, S. 593.]

11) Koprolithen finden sich im Sekundär-Gebirge von New-Jersey; Dekax hat einen Saurocopros beschrieben und abgebildet (Ann. Lyc. N.-York. III. 140, pl. III, Fig. 6, > Jahrb. 183.5, S. 235).

12) Noch hat Dr. Blandivg einen sonderbaren fossilen Zahn aus Süd-Carolina mitgebracht, dessen Wurzel eine ganz eigene Art von Gliederung besitzt und dadurch ein neues fossiles Thiergeschlecht anzuzeigen scheint.

13) Aus New-Jersey's Sekundär-Gebilden hat H. noch viele Wirbel. beine, welche in ihrer Bildung von allen anderen bis jetzt beschriebenen abweichen.

14) DEKAY besitzt von ebendaher noch den Unterkiefer eines unbeschriebenen Thieres, der einige Ähnlichkeit nit denı "Jaw of a Regtile" auf S. 153 in Martere's Geologie von Südost-England zeigt: Dr. PickeRIv sieht ihu jedoch als einen Fisch. Kiefer vom Geschlechte $S \mathrm{p}$ h $\mathrm{y}$ raena an.

$$
\text { IV. } P \text { i s c e s. }
$$

Fossile Fische sind nicht selten, aber ihre Untersuchung war bisher unvollkommen. Die meisten Überreste rühren von

A. Knorpel-Fischen her. C a rcharias-Zähne von bis $40^{\prime}$ langen Thieren sind an mehreren Stellen vorgekommen. Nach MrTchics's Note in Cuvier's théory of the Earth, p. 400 , hat man an Ufer des Meerrin. Flusses bei Murfreesborough, 60 Meilen vom Ozean ein Riesenthier gefunden, dessen von den Negern zerstreute Wirbel Capt. Neville und Dr. Fowler sammelten und in eine Reihe legten, welche $36^{\prime}$ Länge hatte, so dass das Thier mit Kopf und Schwanz über 50' lang gewesen seyn muss. Ersterer brachte MrtchiL's zwei trianguläre Zähne mit, deren jeder 16 Unzen wog, welche mit Ausnahme des Wurzelendes mit aschgrauen Schmelz bedeckt waren, und deren Basis $4{ }^{\prime \prime} "$, die zwei andern Seiten 6 " jede mass. Ein einzeluer Wirbel hatte $12 \frac{1}{2}$ Pfund Schwere. Haruan hat diese Reste, die sich jetzt in Lyzeum von New-York befinden, für die eines Riesen-Haies erkannt, ohne jedoch sie nach den Zähnen näher bestimmen zu können. - Das Museum der Akademic besitzt andre Hai - Zähue aus den Mergel-Gruben in New Jersey, welche mit denen von Squalus Zygaena, Sq. $m$ ustelus, Sq. Squatina und Sq. Carcharias ganz übercinstimmen; zwei Exemplare der letztern sind 5" lang und unten 4 "breit, was bei einem lebenden Carch arias auf ein $40^{\prime}$ langes Thier schliessen lassen würde. Bei Pafkinson (org. rem. III) und Mantelz (Geol.s. L'. Engl. p. 133) findet mau gute Abbildungen von den meisten eben ge- 
nannten Arten. Weitere Nachrichten über solehe Zühne stehen im Journ. Acad. mat. sc. Philad. IV, 232, pl. xIV, und in Hincav's Notice on the Plesiosaurus and other fossil reliquiae from the state of New Jersey, 1821. -

Hrтcncok (Report on the Geology of Massaschus., p. 1.93, pl. xI und $x I t$ ) theilt Abbildungen von fossilen Zühnen und Wirbeln aus der von ihm sg. Plastisch-Thon-Formation zu Gay Head in Martha's Vineyard mit, wovon die ersteren offenbar den Hai-Zähnen im Green. sand von New-Jersey gleichen, die letzten, schlecht abgebildeten, nicht nïher zu bestimmende Hai-Zähne seyn mögen. -

Auch Raia- und Acipenser-Reste finden sich hin und wieder mit vorigen.

B. Weich flossen-Fische. Dr. Dekay hat am 24. Jänner 1825 bein Lyzeum von New-York einc, wie es scheint, noch nicht gedruckte Vorlesung über die fossilen Fische der Vereinten Staaten gehalten, wornach alle von ihm daselbst untersuchten fossile Fische nach dem Muster dis Esox osseus im Mississippi gebildet sind, was Cuvira später bestätigt hat.

C. St acheIflossen-Fische.

Der fossilen Kinulade von New-Jersey in Dekay's Sammlung ist oben Erwähumg geschehen.

Vor mehreren Jahren hat H. durch seinen Freund JEssup eine Sammlung fossiler Fische aus den Schiefern von Westfield in Con. necticut erhalten. Professor Нгтснсок theilt in seiner vorhin angeführten Schrift (p. 236, pl. xıv, fg. 44, 45, 46, 48) ausführlichere Nachricht unit über das Vorkommen der Fische im bituminösen Schiefer und Mergel zu Niddleton, Connect., $\approx$ Sunderland, Massachus., so wie zu I Hest-Springfield und Deerfield. Nur zu Sunderland ist es leicht, sich solche zu verschaffen. Selten sind hier die Abdrücke ganz erhalten, immer ist der Kopf sehr undeutlich. Öfter liegen zwei Abdrücke z̧anz unmittelbar aufeinander. Häufigliegen die Ichthyolithen schon zerstücktim Gestein, welches sich zu langsam gebildet haben mag, um die zu Boden gesunkenen Fische alle gleichmässig gegen Zerstörung durch das Wasser und durch Raubthiere zu schitzen. Sie sind den Mansfelder Fischen schr ähnlich und scheinen vier verschiedenen Arten. des Paliiothrissen-Geschlechtes anzugehören (Hrtchc.).

Ein verstiindiger Freund H's. besitzt einen Marmor-Bruch im Oval rimestone Valley oder Nipnose Vulley in Pennsylvanien, an westlichen Arme des Susquehanna. Der Marmor ist ein grüulich gefärbtes Konglomerat, fast dem Verd antique ähnlich, sehr politurfähig, feinkürnig, und hart, und an manchen Stellen ganz mit Resten von Fischen angrefüllt, welche die Grösse der Häringe und Karpfen besitzen. Einige haben noch ihre Sithuppen, andere nur noch Knochen; vollständige Exemplare jedoch daraus zu gewinnen, gestattet die Sprödigkeit des cresteins niclıt. 
LA Joye: über den Portunus Hericartil (Bull. géol. 1834, IV, 427-428). Im oberen Sande des Pariser Grobkalkes über dem Weiler Gue bei Tresnes, 3 Stunden von Meaux gegen Ferté-Milon findet sich eine Menge $\mathrm{K} r$ ustazeen-Reste, von welchen Desmarest in seinem Werk über fossile Krustazeen bereits den Cephalothorax als Portunus Hericartii abgebildet hatte. Der Verf. legt nun alle Theile des Thieres einzeln vor und bestätigt die Richtigkeit der Bestimmung des Geschlechtes. Derselbe Krebs ist es aber auch, der im Paguren-Kalke von Lisy so häufig ist, welcher daher Portunen-Kalk genannt werden muss. Diese Thiere scheinen sich in solcher Menge zusammengefunden zu habell, wie man jetzt noch oft Portunus puber des Eyerlegens wegen versammelt findet.

T1!. Evars: über die Koprolithen Buckzand's (Bull. soc. d. $l$. imperr. nat. de Moscou, 1833, VI . . ).

S. C. WAGERR: der Sonne Kinder, eine Hypothese (111 SS. Potsdam 1835, $8^{\circ}$ ).

"Das Menschengeschlecht reicht sehr weit über ADam hinauf, denn der Ewige rief uranfänglich das All ins Daseyn". Von diesem Argumente ausgehend ist der Verf. bemüht, die Entstehung des Menschen um etwa ein paar Myriaden Jahre weiter gegen den "Uranfang" hinauf $2 \mathrm{u}$ rücken, muss es aber alsdann doch noch inmer e u t$\mathrm{s}$ t e h e n lassen. Die Weltkörper sind belebt, die Doppelsterne begatten sich, die Sonne gebährt, so oft ihre dunkeln Flecken verschwinden, Planeten, die Anfangs Kometen scyn mögen; sie schleudert sie aus, diese aber werden erst sichtbar, wemn sie so weit von ihr entfernt sind, dass sic nach dem Untergang der Sonne am dunkeln Ho. rizont bleiben; die Erde ist auf diese Art aus ihr geboren worden; die auf ihr Anfangs befindlichen Lebenwesen kamen bei diesem heftigen Akt theils um und hinterliessen ihre Reste im Gestein, theils erstarrten sie vor Schrecken u. s. w., wurden in diesem Erstarrungs-Zustande oder Scheintod von Schlanm umhüllt, gegen Verderben geschützt, bis sie endlich durch irgend einen Zufall von dieser Fessel befreit wieder zu einem thätigeren Leben zurückkehren konnten, wie z. B. Venus Anadyonens aus dem Meerschaume erstund und sich, da ihr Sonnen-Kleid inzwischen vermodert war, unter dem Myrten-Baume gegen die Sonne schuitzte oder sich dort woht gar, in der Sonne bereits bis zur Entwiekelung des Sittlichkeitsgefühles vervollkommnet, aus Scham über ilre Nacktheit verbarg. Diess ist ungefïhr der licen-Gang des Vf., der seine Hypothese unbefangener Beurtheilung, empfiehlt. Er stellt insbesondere, um jene Ansicht von tansendjährigem Scheintod zu begründen, die Beobachtungen über in Gestein eingeschlossene lebende 
Kröten ziemlich vollständig zusammen und legt besonderen Werth darauf, ob ein Thier in voller Lebensthütigkeit, oder bereits in Winterschlaf 11. dgl. von jener Katastrophe betroffen worden, und somit in diesen Falle mehr geneigt gewesen, sich in allmählich erhärtendem Schlamm lange zu Lonserviren.

A. Wiegmans: über die Thier-Fährten im Sandsteine von Hillburghrusen (WIEGM. Arch. für Naturgeschichte, 1835, I, 129-131 und 395-397). Wir theilen hier noch eines andern Zoologen Urtheil über die Entstehung jener Thierfihten nit. Er entschied sich nach Ansicht der Zeichnung von der Führte des grösseren Thieres „wegen der Gestalt der fleischigen Sohle der Hinterfüsse und dem stark abgesctzten Daume derselben" für Annahme eines Didelphys, olıne über den Unterschied dieser Führten vơn denen der Affen im Allgemeinen und über das Abstehen des Daumens an den Vorderfüssen insbesondere Rechenschalt zu geben; in dem kleinen Thiere aber vernuthete er einen vierzehigen Krokodil-ähnlichen Saurier, ohne der S. 234 von uns erwähnten Eiuwürfe zu gedenken. Nachdem der Verf, aber zwei nach Berlin gekomenene Sindstein. Platten seibst zu untersuchen Gelegenheit gefunden, so beharrte or rücksichtlich der grösseren Thierart zwar bei seiner frühıern Ansicht, el wähnt jedoch dabei, dass Kaup das Thier we. gen des deutlichern Abstaudes des Daumens der Vorderhände von D idelphys generisch verschieden geglaubt und Chirotherium genannt habe. - Rüicksichtlich des kleineren Thieres dagegen bestätigt er die von uis und BERThold, der aber Amphibien vermuthet, (Gütting. Anzeig. 1835, St. 52) schon gemachte Benierkung, dass auf SickLER's Steinplatte sich Fährtenzüge zweier Individuen neben einander befinden, welche nach W. mit erstrem wo nicht zur näılichen Art, doch zum nämlichen Geschlechte gehörten, indem ihre Vorderfüsse, wie auch die des vorigen viel schwereren Thieres an einer Stelle, gar keine Eindrücke hinterlassen, weil sie damit leise (nach Benthond gar nicht, nach unserer Ansicht vielleicht in der Hinterfährte) auftraten; der seitliche Anhang ihrer Hinterfiisse aber, wie wir ebenfalls vermuthet, scheint ihm von einem wirklichen Daumen herzurühren. Der Verfasser fügt hinzu, dass nach einer Nachricht des Herrn T. Brǘcкner man an Ort und Stelle schon Fuss - Eindrücke von wenigstens 10 verscbiedenen Thier - Arten unterscheide. - Ref. kann sich, rücksichtlich der grossen Art, noch immer nicht für Beutelthicre erklären, da er an den Vorderfüssen der lebenden den Daumen stets entweder in gleicher Höhe mit den andern Fingern sich abtrennen und mit ihnen parallel und dicht anliegen, oder gau\% verkümmert sieht. Doch scheint die Kürze des auftretenden Theilis der Hand den Beutelthicren melir als den Affen zu entsprechen. 
F. A. Conrad: Fossii Shells of the Tertiary Formutions of NordAmerika, illustrated by Figieres drawn on Stone from nature. Vol. I, Nr. $1-I 1,28 \mathrm{p}$. with $14 \mathrm{pll}$. Philadelphia 1832, $8^{\circ}$.

Vorrede (S. I-vir). Der Verfasser beabsichtigt in dieser Schrift die Bekanntmachung tertiärer Konchylien Nord-Amerika's. Мовтож wird seine Arbeiten über die fossile Reste der Eisensand-Formation New-Jersey's als selbststïndiges Werk, ergänzt und mit schönen litho• graphirten Abbildungen versehen, aufs Neue herausgeben. Endlich nach Vollendung der gegenwärtigen Arbeit gedenkt der Verf, auch die älte. ren Amerikanischen Sekundär-Testazeen in dieser Weise bekannt zu machen.

Das tertiäre Gebiet erstreckt sich in Nord-Amerika von NewJersey einschliesslich bis zum Golfe vor Mexiko, mit einem grossen Reichthum an fossilen Überbleibseln. Jedoch kann man darin dreierlei Ablagerungen unterscheiden, welche sich auch auf der westlichen Halbinsel von Maryland beisammenfinden, rü̈mlich solche mit lauter ausgestorbenen, solche mit gemischten und solcle mit lauter an dortigen Küsten noch lebenden Arten, so dass ein allmählicher Übergang in der tertiä. ren Schöpfung Statt gefunden zu haben scheint. Die erstern und zugleich ältesten dieser Ablugerungen bilden die westliche Grenze des tertiären Gebietes, die letztern kommen längs dessen östlicher Grenze vor, und unter den gemischten Arten sind selbst einige vorhanden, von wel. chen es zweifelhaft ist, ob sie als Zeit- und Orts - Varietäten noch le. bender, oder als eigene ausgestorbene Arten anzusehen seyen. Namentlich sind die senkrecht eingeschnittenen und beständig nachfallenden Sand- und Lehm - Ufer der grösseren Flüsse durch das Tertiär - Gebiet hin sehr reiche Fundortc jener Reste, wie z. B. die Rocks bei Smithfield an James River. Die obere Meeres-Formation ist durch eine grosse Nanchfaltigkeit von Arten - insbesondere von Bivalven mehr als von Univalven, und durch eine grosse Abwechselung derselben in der Weise ausgezcichnet, dass schon auf wenige Stunden Entfernung hin ganz andere Arten erscheinen und verschwinden, wie solches, nach der Jahreszeit und nach Lokal-Verhäitnissen der Küste, eben auch noch im Leben beobachtet wird. Wenn den fossilen analoge lebende Arten oft wärmeren Klimaten angehören, als jene sind, wo erstere begraben worden, so findet man dagegen in Virginien und Nord-Carolina mit ausgestorbenen Arten welche, deren Analogen an den Küsten von Rhode Island und Massachussetts $5^{\circ}-8^{\circ}$ nördlicher wohnen, wie Mactra tellinoides, M. Iateralis, Nucula limatula, N. proxima, Lucina contracta, L. divaricata u. e. a.

Einleitung, S. 9-14.' Die Glieder der 'Tertiär-Formationen und ihre Verbreitung ergeben sich für Nord-Amerika aus folgender $\mathrm{Zu}$ sammeustellung: 


\begin{tabular}{|c|c|c|}
\hline B en ennung. & Possil. Reste. & Vorkommen. \\
\hline Alluvium. & & in Newo-Jersey mächtig. \\
\hline Diluvium. & \begin{tabular}{|c|} 
Landthier- \\
Knochen
\end{tabular}$\left\{\begin{array}{l}\text { Mastodon. } \\
\text { Elephas. } \\
\text { Megatherium. }\end{array}\right.$ & $\begin{array}{l}\text { Pemberton in N.J-. u. südlicher } \\
\text { New-Jersey, Nord-Carolina, } \\
\text { Georgien. }\end{array}$ \\
\hline Duschelkies, Crug & Lebende Konchyl-Arten . & Mündung des Potomac. \\
\hline
\end{tabular}

Obre Tertiăr-Formation $\left\{\begin{array}{l}\text { Konchylien, meist Mu- } \\ \text { scheln. Alle Genera und } \\ \text { meiste Arten lebend. }\end{array} \quad \begin{array}{l}\text { Halbinsel von Maryland, Ost-Vir- } \\ \text { ginien, N. u. S.-Curolina, Geor- } \\ \text { gien. }\end{array}\right.$

MittleTertiär-Yormation $\left\{\begin{array}{l}\text { Konchylien meist lebender } \\ \text { Genera, meist erlosehener } \\ \text { Arten. Viele Univalven. }\end{array}\left\{\begin{array}{r}\text { Fort Washington, Marylund; } \\ \text { Virginien?; Vunce's Ferry, S.・C.: } \\ \text { Claiborne, Alabama. }\end{array}\right.\right.$

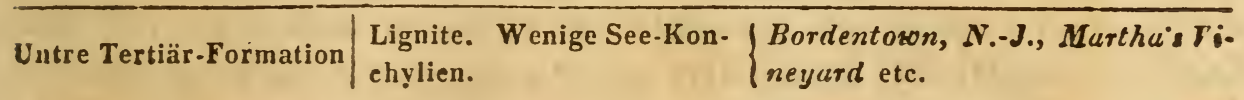

Die Tertiär-Bildungen im Ganzen genommen ziehen auf der Küsten - Gegend N. - Amerikas von New-Jersey an $\left(40^{\circ} \mathrm{Br}\right.$.) bis Florida herab $\left(30^{\circ} \mathrm{Br}\right.$.) und dann längs des Golfs von Mexico bis zur Mün. dung des Mississippi. Weiter westwärts ist wenig Geologisches bekannt geworden, doch hat Nutrax am Red River Konchylien der Eisensand-Formation entdeckt. Auch scheinen diese Bildungen an ihrem südlichen Ende einen breiteren Strich, als an ihrem nördlichen einzunehmen, wie sie weiter hinauf in den östlichen Staaten nur noch Insel-artig vorkommen: auf Mortha's Vineyard (Massach.), auf Elisabeth Island, Long Island (N.-York) u. s. w. Auf Macrure's geognostischer Karte ist dieser tertiäre Bezirk irrig als Alluvial-und Diluvial-Land, doch seinen Grenzen nach richtig, angegeben.

Die obere Meeres-Formation insbesondere (obre Tertiär - Formation, in welcher jedoch dort noch nie eingeschaltete Süsswasser-Schichten wahrgenommen worden) wurde zuerst durch vas Rensselaer nachgewiesen und nachher von Morton (Journ. Acad. Nat. scienc.) genauer untersucht. Ihre Schichten bestehen oft nur aus losem, gelbem, thonigem Sande mit Konchylien; zuweilen sind sie hart und kieselig, öfters nur aus gelbem und grauem Thone zusammengesetzt, oder aus Allem zugleich gemengt; aber die unterste Lage ist jederzeit ein bleigrauer Thon oder thoniger Mergel. Zuweilen sind verkleinerte Konchylien eingemengt; aber im Allgemeinen sind auch die zärtesten Bivalven noch ganz und wohl erhalten und das Gebirge mithin aus ruhigem Meere abgesetzt. - Was Conyreare und Phillips über diese Formation in Europa sagen, passt vollkommen auch auf viele der transatlantischen Ablagerungen: die Fossil-Reste sind meist wohl erhalten, zuweilen Arten- und Geschlechter-weise gesondert, wenige Arten sind ausgestorben, oder in entfernten Meeren heimisch; die meisten stimmen mit denen der benachbarten Küsten überein. In andern Gegenden N. - Amerikas aber sind in diesen Schichten ausgestorbeue und entfernt lebende Arten berrschend, 
obschon noch durchau verschieden von den Arten des London clay und Grobkalkes. Von alleu bis jetzı daraus erhaltenen Arten [deren Anzahl nach einer spätern Nittheilung der Verf. auf $300 \mathrm{zu}$ bringen hofft] sind etwa 40 mit den an den Nord-Amerikanischen und Westindischen Küste lebenden übereinstimmend; viele fossile Arten kommen in Amerika und Europa zugleich vor, wie noch einige davon an beiderlei Küsten leben, zum Beweise wie ausgedehnt die Verbreitung und wie gross die Dauer einer einzelnen Art seye. - Diese Formation erscheint zuerst in New-Jersey, S.W. von Salem, und setzt durch alle südlichere - Staaten fort, 100-150 Engl. Meil. weit westwärts ins Land reichend.

Die mittle Tertiär-Fornation (London Thon, Grobkalk) erscheint ebenfalls unter manchfaltigem Aussehen: oft bietet sie Schichten eines bräunlichen Kiesel-Sandes, worin die Testazeen an schönsten erhalten sind; - oder solche ron zerreiblichen körnigem Kalksteine mit verkleinerten 'Testazeen - Resten oder selbst ganz daraus zusammengesetzt, von heller Eisenocker - Farbe, gewissen Abänderungen des Pariser Grobkalkes sehr ähnlich; - endlich auch solche von festem hartem Kalkstcin mit körnigen Bruche und voll grüner Körner, reich an Thon und an Fossil-Resten, welche jedoch meist nur in Stein-Kernen bestehen. Wie diesseits des Ozeans, so sind auch dort zwar nur wenige ausgestorbene Genera bemerkbar, aber meistens ausgestorbene, obschon den lebenden zuwcilen äusserst ähuliche Arten, wovon manche mit jenen in Fronkreich und England übereinstimmen. Diese Formation findet sich im Norden zuerst beim Fort Washington an Potomac in Maryland; dann in Virginien, doch in nicht näher bekannten Orten; zu Vance's Ferry in S.-Carolina, zu Claiborne in Alabama, wo die Fossil-Reste an häufigsten und am besten erhalten sind und die Schichten auf weissem zerreiblichem Sekundär - Kalk voll Nummuliten ruhen, und dieser wieder auf Grünsand.

Die untere Tertiär-Formation (in Europa: Formation des plastischen Thones) besteht aus Wechsellagern von Sand und hies mit verschiedener Farbe, der Thon häufig mit Ligniten, mit vielem Eisenkies, auch mit Bernstein. Zu Gayliead, Murthu's Vineyard hat Нгтенсоск neulich eine Kieselbreccie darin entdeckt. Diese Gebilde entsprechen eigentlich nur den oberen Schichten dieser Formation in Europa. Sic enthalten Steinkerne von nur wenigen See-Konchylien: Tellina, Venus u. 8. w., die Quarz-Breccie insbesondere noch Knochen und Zähne von Squalus, Crocodilus u. 8. w. Jons Fren hat diese Formation in Amerika zuerst nachgewiesen, welche stellenweise vou den Inscln Neu-Englands bis zu den Staaten an Golfe von Mexiko vorzukommen scheint, insbesondere in Diartha's Vineyard, zu Sund's Point auf Long Island, zu Bordentuwn, Whitehill u. a. in New-Jersey, auf dem Telegraph Hill bei Bultimore, zu Cape suble in Maryland u. i. e. a. südlicheren Gegenden. All' diese Gebirge ruhen auf der Eisensand-Reihe. 


\section{$-115$}

Beschroibung der fossilen Konchylien (S. 18 ff.).

I. Arca.

1. A. Limula n. sp., Tf. I, Fig. 1, ähnlich $S_{\Delta x}$ 's A. ponderosa, zu Newbern in N.-Carol., am James River, in Virg.: obere Tert. - Form.

2. A. Iransversa SAX Journ. Acad. Nat. Hist. II, 269, Connad Tf. I, Fig. 2, zu Newbern, zu Suffolk in Viry.: obre T.-F. - , dann kleiner an der Potomac-Mündung in $\mathrm{Crag}$; und an der Küste lebend.

3. A. stillicidium n. sp., Tf. I, Fig. 3, ähnlich der A. incongrua $S_{A Y}$, A. nodosa Wood., an St. Mary's River in Maryland: obre T.-F.

4. A. idonea n. sp. Tf. I, Fig. 5, ebendaselbst.

5. A. ce ntenaria $S_{\Delta Y}$ l. c. IV, 138, tb. X, fig. 2, Conr. p. 16, Tf. I, Fig. 4, zu York-Town, in Virg.: obre T.-F.

6. A. incile $S_{A X}$ 1. c. IV, 138, tb. X, fig. 3, Conr. Tf. II, Fig. 1. Am James River bei Smithfield in Virg.: obre T.-F.

II. Pectunculus.

7. P. pulvinatus Lamk., Conr. S. 17, Tf. II, Fig. 2, zu York Tuwn: obre T.F. [ist keineswegs die Lamarck'sche Art].

8. P. subovatus SAY l. c., CoNr. Tf. II, Fig. 3 (? P. variabilis Sow.). Zu York Town häufig; zu Suffulk in Virg.: obre T.-F.

III. M u rex.

9. M. umbrifer n. sp. Tf. III, Fig. 1. Am James River und zI York Town: obre T.-F.

10. M. exilis n. sp. Tf. III, Fig. 2. Am James River: obre T.-F.

IV. Fusus.

11. F. sulcosus (Pyrula s. Conr. Journ. Accid. N. H. VI, tb. Ix, Fig. 8), S. 18, Tf. III, Fig. 3. Am James River: obre T..F. 12. F. strumosus n. sp., Tf. III, Fig. 4, ebendaselbst.

13. F. trossulus n. sp., Tf. IIl, Fig. 5. ebendas.

14. F. tetricus $n$. sp., Tî. III, Fig. 6, ebendas.

15. F. rusticus (Conr. I. c. VI, tb. IX, fig. 2) Tf. IV, Fig. 1. An St. Mary's River in Maryl.: obre T.-F.

16. F. parilis n. sp. Tf. IV, Fig. 2, ebendas.

17. F. cinereus SAY I. c. II, 236, und Amer. Conch. Nro. III, Tb. xxix) p. 19, Tf. IV, Fig. 3. Am James River: obre T.-F. An den meisten Küsten lebend, häufig, Austern - Bänke zer. störend.

V. Buccinum.

18. B. porcinum SAx 1. c. IV, 126, Conr. Tf. IV, Fig. 4. Zu York Town: obre T.F. 


\section{$-116$}

19. B. I aqueatum . sp., Tf. IV, Fig. 5. Am James River: obre T..F.

20. B. altile n. sp. Tf. IV, Fig. 6, ebendas.

VI. Cypricardia.

21. C. arata n. sp. Tf. V, Fig. 1. Zu Newbern, am James River; zu York Town, bei Easton, und in der Cumberland Co. in New-Jersey.

VII. Cardita.

22. C. planicosta Conr. Tf. V, Fig. 2 (Venericardia pl. Lumk, Sow.) zu Piscataway in Maryland, und zu Claiborne in Ala. bama in der mittlen T.-F., wie in gleicher Formation in Europa an vielen Orten.

VIII. Artemis.

23. A. a cetabulum Conr. S. 20, Tf. VI, Fig. 1 (二Artemis s. Cytherea concentrica auctt. [non Lank.], welche an dortigen Küsten lebt. Dieses Genus, von PoLI benannt, ist nicht mit dem gleichnamigen und verwandten OKen's zu verwechseln, aber identisch mit Orbiculus MegerLe, Identillaria Sскuн. und Exoleta Brown). Am St. Mary's River, zu Easton, am James River, zu Suffolk: obre T.-F.

IX. Lucina.

24. L. acclinis n. sp. S. 21, Tf. VI, Fig. 2. Zu York Town: obre T.-F.

(Heft II.)

X. Crass atella, (ein Geschlecht, dessen 11 lebenden Arten nur in Austral-Asien wohnen, ausser Pholadom y a das einzige, welches in $\mathbf{N}$.-Amerika in der obern Tertiär-Formation fossil und nicht auch an der Küste le. bend vorkommt).

25. C. alta n. sp. Tf. VII. Zu Claiborne, mittle T.-F., der Cr. tu. mida verwandt.

26. C. Marylandica n. sp. Tf. VIII, Fig. 1. Am Choptank River bei Easton in Maryland: obre T.-F.

27. C. protexta n. sp. Tf. VIII, Fig. 2. Zu Claiborne in Alabama: mittle T.-F.

28. C. undulata $S_{\Lambda Y}$ (1. c. IV, tb. xI, fig. 2) Conr. S. 23, Tf. IX, Fig. 1. An James River und zu York Town, und eine Varietät in St. Mary's Co. in Maryland: obre T.F.

29. C. melin a Tf. IX, Fig. 2. In Cumberland Cu. in New-Jersey: obre T.-F., mit Perna maxillata u. a.

XI. Turbinella.

30. T. pyruloides n. sp. S. 24, Tf. X, Fig. 1. Zu Claiborne: 


\section{$-117-$}

mittle T.F. Ganz das Anschen der Pyrula laevigata mit den Falten von Turbinella, eine der eigenthümlichsten Forwen jener Gegenden!

XII. A n cillaria (fehlt in der obern T.-F. gänzlich).

31. A. altile n. sp. Tf. X, Fig. 2. Zu Claiborne: mittle T.-F.

32. A. subglobosa n. sp. Tf. X, Fig. 3. Ebendaselbst.

33. A. scamba n. sp. Tf. X, Fig. 4. Ebendas.

34. A. staminea n. $s p$. Tf. X, Fig. 5 ; ebendas. Könnte mit Lamakck's nahe verwandter A. canalifera ein neues Genus Olivula zwischen Oliva und Ancillaria bilden Ldiese Art steht nicht so sehr der Anc. canalifera, als der A. plicaria nabe, und ist eine wirkliche Ancillaria].

XIII. M a c t ra.

35. M. delumbis n. sp. S. 26, Tf. XI. Von James River und Suffolk: obre T.-F.

XIV. Pholadom ya.

36. Ph. abrupta n. sp. S. 26, Tf. XII. Von York Town: obre T.-F.

XV. 0 strea.

37. O. radians n. sp. S. 27, Tf. XIII, Fig. 1. Zu Vance's Ferry in S.-Carolina und $\mathrm{zu}$ Claiborne: mittle T.F.

38. O. sella formis n. sp. Tf. XIII, Fig. 3. Zu Claiborne ebenso.

39. 0. Carolinensis n. sp. Tf. XIV, Fig. 1, der lebenden O. compressirostra Sax verwandt. Aus dem Santee-Kanal in S.Carolina sehr häufig ausgegraben : ? mittle T.-F.

40. O. Virginian a Gmen. Lank. var. Conr. S. 28, Tf. XIV, Fig. 2. Von Suffolk in Virginien: obre T.-F. Diese Varietät ist fossil im Crag unter den Strassen von Easton an der Ostküste Marylands u. a. a. O. eben so häufig, als in manchen Ge. genden Europa's, und als lebend an den Küsten von NowJersey. Eine sehr nahe verwandte, vielleicht identische Art bildet ein zusammenhängendes Lager durch S.-Carolina, Geurgien, Alabama und Mississippi, welches Fincr einer eigenthümlichen Formation "Calcaire os tree" zuschreibt.

Findet das Werk hinreichende Unterstützung, so gedenkt der Verf. bimnen 2 Jahren es mit der Abbildung von 300 Arten auf 100 Tafeln zn beendigen. Der Preiss jeder Licferung von gleicher Ausdehumb mit diesen beiden ist 1 Dollar.

[Dic Abbildungen sind sohr gut, die Beschreibungen genügend, nur ist zu bedauern, dass die verschiedensten Gencra ohne alle Orduung durcheinander auf je einer Tafel abgebildet und auf einer Seite beschrieben vorkommen. Es wïrde dem Absatze des Werkes, dessen Vollendung wir in Interesse der Wissenschaft mit grösster Ungeduld entgegen seben, gewiss förderlich seyn, wenn cutweder eiue systematische 


\section{$-118$}

Ordnung eingehalten, oder aber, wie bei dem verwandten Sowbrax'schen Unternehmen, jedesmal wenigstens nur Arten eines Geschlechtes auf demselben Blatte beschrieben und abgebildet würden, so dass man die einzelnen Blätter dann bcliebig ordnen und sich das Nachschlagen und Vergleichen somit wesentlich erleichtern könnte.]

P. PARTSCH: über die sogenannten versteinerten Ziegen. klauen aus dem Plattensee in Ungarn und ein neues urwelt. licbes Geschlecht $z$ weischaliger Konchylien: Congeria. (Annal. d. Wien. Mus. d. Naturgesch.1835, I, 93-101, Tf. XI, XII). Der Plattensee wirft die sg. versteinerten $\mathrm{Ziegenklaueu}$ fortwährend aus. Das Volk sagt, dass sie von den Ziegen eines reichen Hirten herrühren, welcher von König LadisLaus nach seiner Vertreibung um Geld angesprochen, solches zu besitzen läugnete, aber, nachdem er Gott zum Zeugen angerufen, sich wahnsinnig mit seiner Heerde in den See stürzte und ertrank. C. D. BARTsch (Ungar. Magaz. II, Presb. 1782) hielt sie für Austern.Reste, - Beudant (Voy. en Hongr. Paris 1822, II, 498) ebenfalls für die abgerollten Spitzen von Austern. Andre haben sie für Chamiten und selbst Fisch₹ähne angesehen. Vor einigen Jahren sandte Dr. Ris, Brunnenarzt zu Füred, in Folge einer Aufforderung v. Schrenere's den Ursprung dieser Körper auszuforschen, Muscheln vom Dorfe Tihany am Plattensee ein, für deren Steinkerne er die Ziegenklauen hielt; $P_{\text {ARtscr }}$ sprach diese Muscheln damals zwar irrthümlich für Miesmuscheln an, erkannte jedoch richtig, dass die Ziegenklauen die abgerollten Spitzen dieser Muscheln seyen. Seine deshalb niedergeschriebenen Bemerkungen begleitete Rrs mit einigen Zusätzen und liess sie drucken. (Vergl. das Ungarische Journal: Tudományos Gyüjtemény, 1820, Heft XI, S. 37 bis 47). Dieser Muscheln von Tihany waren zwei Arten; die Umge. gend von Wien lieferte eine dritte zum nämlichen Geschlecht gehörig. Bouв́ (im Jourı, de Géol. Paris 1830, II, 375) erwähnt dieser Muscheln unter dem Namen "grosser Bivalven von einem neuen Geschlechte mit der äussern Gestalt der Isocardien, aber einem abweichenden Schlosse." Desanyes sagt von der dritten der erwähnten Arten (Bullet. géol. Paris 1832-1833, III, in einem von Bouś gegebenen Verzeichniss tertiärer Fossilien von Matzleinsdorf, eincr Vorstadt Wiens), dass sie zu Mytilus oder einem neuen Geschlecht zwischen Mytilus und Isocardia gehöre; wobei bemerkt wird, dass Münster dieses Genus Enocephalus, und eine [dieselbe?] Art E.carditaeformis nenne. Partsch nennt seit längerer Zeit das Gesćblecht $C$ ongeria (von congeries, eine Zusammenhäufung von Ähnlichkeiten mit andern Geschlechtern) und definirt solches in folgender Weise: 


\section{$-119$ \\ C o ing e r i a}

testa fossilis aequivalvis, latere posteriore plus minusve hians. Vabvae inaequilaterae convexae obliquae, curinatue, - spathulatae triangularesve aut semiglobosae, - basi ut plurimum acutse et hine intrinsecus lamina nonnunguam septiformi instructue. Nates plus mimusve inflexae et suitortuosue. Cardo edentulus. Ligamentum internum, duplex: unum in rima lonyitudinali marginis anterioris valvarum, alterum in fovea triangulari sub apice. Impressiones musculares duae: una magna sublateralis in parte superiore et latiore valvarum, altera parva in prominentic subcochleariformi sub fovea ligamenti apicalis, linea elevata subflexuosa ad basin decurrente fulcrum quasi simulante instructa. Verwandt mit Mytilus, lsoeardia, Cardita, Hippopodium, Megalodon, Myoconcha. Arten 4, fossil.

1) C. subglobosa (Tf. xr, Fg. 1-10) testa subglobosa, apricibus incurvatis, appendice tumescente semilunari instructis. Lic von Bovb und Deshayes erwähnte Art (s. o:). Unterliegt sehr vielen Abänderun. gen ihrer Proportionen, ist im Allgemeinen kugelförmig, etwa wie Isocardien, doch viel unregelmässiger; voru unter den Buckeln, wo sonst der halbmondförmige Eindruck bei Venus u. s. w. bemerkbar, ist hier eine queer halbmondförmige Anschwellung; darunter ist eine klaffende Stelle für den Byssus. Hinten, wo bei lsocardia das Band liegt, klafft die hier in einen zusammengedrückten Flügel [fast wie Alasmodonta] verspringende Muschel nach dessen Zerstörung. Die einzelne Klappe von innen gesehen, ist durch jenen Flügel fast quadratisch, der grössere Muskeleindruck ist nächst der dem Buckel diagonal entgrgengesetzten Ecke; von ihı setzt der Mantel-Eindruck am untern und hintern Rande bis unter das Schloss fort. Der vordere Theil ist oft viel dicker von Masse, als der hintre, und bleibt beim Abrollen der Schaale durch das Wasser noch zuletzt allein übrig. In der Umgebung von Wien: so in der Lehmgrube der Ziegelöfen nächst Brum am Gebirge, 2 Meilen von Wien bei Mödling, wo lose Klappen, selten die ganzen Schaalen, In unzähliger Menge in gelbem feinem Quarzsand liegen, der einige Fusse mächtige Lager im Tegel oder blaulichen plastischen Mergel, der Basis der dortigen tertiären Formation, bildet; weit seltener, aber besser erhalten im Tegel selbst, stets mit Melanopsis Martiniana, wie sie dann in jedem tieferen Brunnen in und um Wien gefunden wird; zu Brunn aber mit derselben, mit Fischknochen, 2 neuen $C$ ardien, Congeria spathulata, Unio n. sp., Melanopsis Bouei, M.n.sp. Neritina, Planorbis und Helix. Daher wohl vordem Bewolner süssen od'er halbgesalzenen Wassers.

2) C. triangularis (Tf. xII, Fg. 5-8) testa triangulari alata, arguto carinata, apertura ninima lanceolatu. Von vorn oder hinten fast kreisrund, vom Rücken einer Klappe aus gesehen, gleichseitig dreieckig. Vorderseite ganz flach, mit sehr kleiner Öffnung für den Byssus, von zwei halbbogen-förmigen Kielen (um die grösste Peripherie der Schaale) eingefasst; Hinterseitc in der Art verlängert und verflächt, dass der 
Kiel, der untere und der obere Rand jenes dreiseitige Dreieck bilden; hinter dem Kiel noch ein abgerundeter, mit ilmm paralleler Wulst. Die Buckeln fast gar nicht eingerollt, sondern kurz und gerade. Die sg. Ziegenklauen sind nichts Anderes, als einzelne Klappen dieser Art, wovon der vom Schloss entfernteste viel dünnschaaligere Theil ganz zerstört, das Schloss selbst abgerollt, und die Oberfäche polirt ist (Fig. 1-4). Bruch schaalig, Schaalen faserig. Findet sich in der SandSchichte zwischen Tegel und jüngstem Grob- (Leitha-) Kalke äusserst selten vollständig zu Tihany, wogegen der nahe Plattensee die.Ziegenklauen häufig auswirft; - dann in stets zerbrochenen Exemplaren zwischen Gaya und Bisenz in Mähren, und auf der Hohenleithen zwischen Wolkersdorf und Gaunersdorf im Untermanhartsberger Kreise in Nieder. östreich. v. Férussac fübrt bei Melanopsis Martiniana diese Reste als solche eines unbekannter, Geschlechtes aus der Familie der Mytili an.

3) C. B alato nic a (Tf. xir, Fg. 9-12) testa elongata, subtriangulari, obsolete carinata, apertura ovata. Ist weniger aufgeblasen als vorige, von vorn gesehen nur unregelmässig oval, jedoch mit sehr weiter Byssus - Öffnung; der Kiel abgerundeter und länger, als die obre und untre Kante, so dass er ein ungleichseitiges Dreieck bilden hilft; auch liegt er nicht völlig auf dem vorderen Rande. In Innern fehlt die scharfe Rinne, welche dem Kiel der vorigen entspricht. Inwendig im Buckel entwickelt sich ein Scheidewand-artiges Blä:tchen mit dem Ligament.Grübchen weit mehr als bisher. Zu Tihany am Plattensee, Balaton, mit dem oben erwähnten neuen Cardium, Paludina? lenta und Planorbis, in Quarzand.

4) C. s pathulata (Tf. xir, Fg. 13-16) testa oblonga, oblique spa. thulata, incurva; laters anteriore rotundata, obsolete carinata: aper. tura minima lineari; apice et fovea ligamentî productis; apicibus sub. cucullatis. Viele Exemplare sind gebogen, $2^{\prime \prime \prime}-2^{\prime \prime}$ und darüber lang. Die Jungen scheinen der fossile Mytilus polymorphus Bové u. A. (Driessena polymorpha van Beneder) zu seyn. Mit der ersten Art zu Brunn, selten anderwärts in Quarzsand, wie am Rennwege in Wien, zu Oedenburg in Ungarn; junge sind allerwärts im Tegel ge. mein. [Die drei letztgenannten Arten, deren Schloss nicht überall genau beschrieben worden, jedoch je nach den Arten ziemlich abweichend zu seyn scheint, gehören mit genannter Driessena polymorpha und einer neuen lokalen Art vaN BenEDEN's (l'Instit. 1835, Nr. 97 und 102), so wie mit dem wohl eine eigene Art bildenden M y tilus Brardii, was Alles Salz - und Süss-Wasser-Bewohner sind, wohl offenbar in dasselbe Geschlecht; welchem - soferne Hr. Partrch seine Congeria früher nirgends publizirt hat, auch Enocephalus noch nirgends charakterisirt worden, von Driessena aber kürzlich das Thier anatomisch zerlegt, und mit den $\mathrm{Ch}$ a mace e $\mathrm{n}$ etwas näher verwandt befunden worden ist - der Namen Driessena bleiben muss; die Conge- 
ria subglobosa aber kann vielleicht, durch Schloss und SpiralBuckeln abweichend, diesen Geschlechts - Namen behalten müssen Br.]

[v. Münster:] Verzeichniss der Versteinerungen, welche in der Kreis - Naturalien - Sammlung zu Bayreuth vorhanden sind. Bayreuth 1833, $8^{\circ}$. Die vom Grafen Münster dahin abgetretene Sammlung enthält aus dem Bereiche des Oher-Maynkreises und etwa der Umgegend folgende Bestandtheile, nach den Formationen geordnet aus der

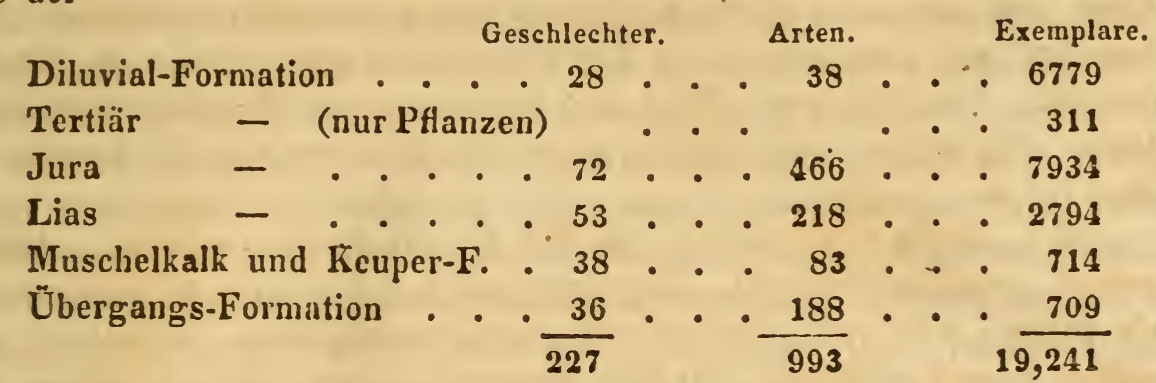

[Diese letztere Additions-Weise passt nun freilich nicht für die Genera, welche sich oft in verschiedenen Formationen wiederbolen. Dieses Verzeichniss kann übrigens in vielen Fällen zur Verständigung bequeme Dienste leisten, obschon man keine Beschreibungen oder Diagnosen, sondern nur Namen, Fundorte, Zustand und Anzahl der vorhande. nen Exemplare darin zu suchen hat.]

W. Nrcor: über die Struktur einiger fossilen Hölzer von Mull, Nord-Afrikn in dem Karoo-Grund in N.0. vom Cap der guten Hoffnung (JAMEs. Edinb. n. phil. Journ. 1835, XVIII, 335-338). Diese Hölzer hatte $J_{\text {Amsson }}$ dem Verf. zur Untersuchung übergeben.

I. Fossiles Dikotyledonen-Holz auf der Insel Mull von R. H. Cunningham gefunden. Nach Cunningr. liegt dieses Holz auf Mull, $2 E$. Meil. W. von Tabermory, unter Trapp in anselnnlicher Erstreckung längs der Küste. Einige der untersuchten Stücke waren bis 6" -8 " dick, graulich, auf frischem Bruche graulich schwarz; der Queerbruch uneben oder muschelig, der Längenbruch zuweilen undeutlich faserig. Alle Stücke waren mit Quarzadern durchzogen, welche drüsige Krystallisationen zeigten und gaben mit dem Stahle Funken. Die vegetabilische Struktur ist so undeutlich, dass es schwer fällt, die richtigen Durchschnittsflächen zu nehmen, die Markstrahlen in Zahl, Breite und Ausdehnnng denen einiger Ahorne ähnlich; Gefässe zahlreich, doch durch die Einwirkungen, denen das Holz vor der Versteinerung ausgesetzt gewesen, sehr zusammengedrïckt, nur stellenweise zylindrisch. Sic stehen so dicht, . dass man kein Zellgewebe dazwischen unterscheiden kann. Die Jahresringe haben " 
diesem Fundorte gehören der gleichen Art an, - es sind die einzigen Beispiele des Vorkommens von Dikotyledonen-Holz in Sekundär-Gesteinen [?], die der Verf. bis jetzt gesehen.

II. Fossiles Holz aus Ägypten und Nubien von Verb Monro nitgebracht. - Es waren 7 Exemplare, alle [?] verkieselt; 2 zeigten äusserlich einige vegetabilische Struktur und bestunden Innen ganz aus gelben Jaspis ohne organisches Gefüge; - cin drittes bestelıt nur aus fast ganz incohärenten Fasern, und taugte nicht zur weitern Untersuchung; - die vier andern sind unzweifelhafte Baumreste, eines von einer Konifere, die andern von Dik otyledonen. Die Masse, welche die Koniferen-Reste enthält, ist ein Aggregat aus nicht über Zoll-langen Holz - Stücken, Quarzkörnern und ein Zäment aus kohlensaurem Kalke mit etwas Eisen und Thon. Die Holzstücke, in allen Richtungen liegend, sind Aussen graulichschwarz; eines ist Innen haarbraun und zeigt scine vegetabilische Textur nicht bei auffallendem, sondern nur bei durıhfallendem Lichte: sie gieicht auf dem Queerschnitte der netzförmigen noch lebender Koniferen; zur Untersuchung des Längenschnittes ist das Exemplar nicht geeignet. - Die drei andern Exemplare sind offen. bar von Dikotyledonen-Stämmen: die ganze Textur gibt sich schon auf dem Queerbruche kund und an dünnen Queerschnitten sieht man auch schwach das zellige Gefüge. Die drei Exemplare gehören einer und derselben Art an: die Form und Anordnung der Gefässe, sowohl als die zellige Textur hat einige Ähnlichkeit mit der des Mahagonis. Nach Jameson Torrie's Angabe hat Moxro obige Holzbreccie bei Abvosambal oder Ipsambul in Nubien gefunden, wo braune, oft eisenreiche und harte Sandsteine, die durch Verwitterung der sie umgebenden weicheren Massen oft stalaktitische u. a. eigenthümliche Formen darbieten, mit Konglomeraten konische Hügel bilden, die ein neuerer Reisender für Vulkane angesehen; das obige Exemplar lag in eiver Schichte an Rande eines grossen Spaltes, welcher S.O. vom alten Schlosse Kalad Adde $1 \frac{1}{2}$ Stunden von Ipsambul die. Sandsteinschichten durchsetzt. Das andere Holz ist vom Gebel Ataka und Wadi el Tiheh, 3 Stunden S.0. von Cairo, woselbst nach ST. JoHv fossile Stämme von $3^{\prime}$ Dicke und $40^{\prime}-52^{\prime}$ Länge vorkommen, die auf der Spitze der Berge, in Höhlen, Schluchten, Flussbetten ordnungslos umherliegen.

III. Fossiles Koniferen-Holz vom Karav-Grund, 400 Meil. N.O. vom Kap, durch James Scotr 'mitgebracht. Verkieselt. Schon das äussere Ansehen verräth den vegetabilischen Urspruug und die angeschliffenen Endfächen zeigen die Koniferen-Textur. Diese wird in dünngeschliffenen Blättchen deutlicher. Die Jahresringe sind ausserordentlich ungleich. Die Zellen-Poren sind wie bei den lebenden A ra ucarien. Die Textur zeigt Spuren starker Zerdrückung und Quetschung. Dieses fossile Holz bedeckt a. a. O. den Boden zwanzig Engl. Meilen weit. 
R. Harean: über die fossilen Knochen von Megalonyx (Journ. Acad. Philad. 1831, April > Sinnm. Americ. Journ. of Scienc. 1831, July; $X X, 414-415)$. Das Museum der Akademie der Naturwissenschaften zu Philadelphia ist in Verhältnisse der Zeit seines Bestehens eines der ansehnlichsten in Amerika. Es enthält anch einige Knochen von Megalonyx aus der White Cave in der Grafschaft Edmondston, Kentucky, 120 Meil, S.W. von Lexington am Green River. $E_{6}$ ist eine Salpeter-Höhle, wie deren in den westlichen Kalkgegenden viele sind, und welche oft trackne, unzersetzliche Leichnahme der Aborigines enthalten.

Der Megalonyx verbindet in seinem Skelette mit den Zähnen des Faulthieres manche Charaktere des Ameisenfressers, des Armadills und Orycteropus. Es ist $\frac{1}{3}$ kleiner als das Megatherium, welchem CuVIER $7^{\prime} 4 \frac{1}{2}$ " Höhe gibt, da das Exemplar wenigstens, wovon jene Knochen abstammen, 5' Höhe, und die. Grösse des gemeinen Ochsens hatte, obschon es nur erst $\frac{3}{4}$ ausgewachsen zu seyn scheint. - Ochsen-, Hirsch-, Bären- und Menschen-Gebeine erhielt man zugleich mit den vorigen.

Roberton hat einen Ornitho-Koprolithen in Süsswasserkalk zu Meilleries-Saint-Sauveur, 3-4 Stunden von Valognes gefunden. Der Kalk ruht auf Geschieben, und es ist ein mehr Tuff-artiger Theil desselben, welcher den Koprolithen mit Saurier-Zähnen, vielen kleinen zerbrochenen Bu lime [Paludinen?] und Carpolithen geliefert hat. Unter letzterem befindet sich C. thalictroides var. Websteri, wie auf Wight (Bull. géol. 1835, IV, 415).

Zufolge einer Nachricht J. Prinsep's hat Dr. Spilsburx im Nerbudda-Thale in Ostindien das rechte und linke Schenkelbein eines Elephas primigenius von $15^{\prime}$ Höhe gefunden. Auch hat man am nämlichen Flusse zum Erstenmale Reste eines fossilen Büffels gefunden (Journ. of the Asiat. Soc. of Bengal, 1834. August $>J_{\text {AMEs. }} \mathbf{N}$. Edinb, philos. Journ. 1835, XVIII, 196).

\section{Verschiedenes.}

Bodssivgaut: Besteigung des Chimborazo am 16. Dezember 1831. (Aus dessen Voyage aux volcans de l'équateur $>$ Ann. chim. phys. 1835, LVIII, 150-180). Der Verfasser wollte von Rio Bamba aus eine Beobachtung mittler Temperatur in ansehnlicher Höhe reran. 
stalten und versuchte daher die Besteigung in Gesellschaft des nachher in Quitu ermordeten Majors Hall. Der Weg, welchen Humbordt genommen, war nicht mehr zu erfragen, indem von seinen Begleitern nic. mand mebr vorhanden war. Es musste daher ein solcher erst gesucht werden, und zwar von der Meyerei $(3800 \mathrm{~m})$ aus, wohin man sich am 11. Dezember begab. Die Seite des Berges gegen Arenal ist sehr steil: Piks von Trachyt treten überall unter dem Eise hervor, doch hatte Hunbordr diesen Weg befolgt; - die Seite gegen Chillapulla unfern Mocha ist wenig geneigt, aber dehnt sich sehr weit aus; gleichwohl glaubte man auf ihr am besten zum Ziele zn bommen. Man versuchte es am 15. Dezember, aber in $5115 \mathrm{~m}$ Seehöhe zeigte sich, dass man in den weichen Schnce so tief einsank, dass nicht mehr möglich war, weiter zu kommen. Die Temperatur war hier $2^{\circ} 9 \mathrm{C}$. um $1_{2}^{\frac{1}{2}}$ Uhr: eine Bouteille mit Schnee gefüllt ward zur Analyse der dazwischen befindlichen Luft mit zurüekgenommen. - Am folgenden Tage um 7 Uhr versuchte man die Besteigung von der andern Seite: nan gelangte um 2 Uhr nach unsäglichen Mühen und Gefahren in $6004 \mathrm{~m}$ Seehöhe, die grösste Höhe, welche ein Mensch wohl noch erstiegen hat, als die vorvorgerückte Tageszeit und von unten heraufziehende Wolken zur Rückkehr nöthigten, wornach man um $8 \mathrm{Uhr}$ wieder auf der Meyerei anlangte. Das schönste Wetter hatte die ganze Unternehmung begünstigt. Während des Gehens wurde möglichst wenig und nur leise gesprochen, weil solches in jenen Höhen die Lungen ganz ausserordentlich angreift und grosse Ermüdung herbeiführt. Die Gesichter waren verschleyert, was genügte, um einer furchtbaren Entzündung der Augen und des Gresichtes vorzubeugen, welche diejenigen Berg - Reisenden zu befallen pflegt, die ohne diese Maasregel in Sonnenscheine lange auf dem Schnee verweilen, so dass man dieser Erscheinung zu Folge solche Entzündungen nicht von der verdünnten oder äusserst trockenen Luft (welche letztre dort gar nicht besteht) ableiten kann. Ja Schwarz-Färbung des Gesichtes soll schon gegen die zweite Hälfte des Übels genügen, wie denn in der That nach der Besteigung des Antisana des Verfassers Neger von der Entzündung des Gesichtes verschont blieb, obschon seine Augen eben so scbrecklich litten, als B's. Von allen anderen schlimmen Zufällen, wie Übelkeit, Erbrechen, Blutung der Augenlieder und des Zahnfleisches, Blutstürzen u. dergl. litten die Reisenden gar nicht, weil sie seit langen Jahren schon an die verdünnte Luft gewöhnt waren. Diese Gewöhnung erklärt auch, wie die Leute jener Gegend noch in des $3000^{\mathrm{m}}-400 \mathrm{~m}^{\mathrm{m}}$ hoch gelegenen Städten sich bequem bewegen, ungemeine Behendigkeit und Leichtigkeit der Bewegungen hei Stiergefechten entwickeln und ganze Nächte hindurch tanzen können. Zwar stellte sich während des Gehens eine grosse Mattigkeit ein, von der man sich aber binnen einiger Augenblicke Ruhe immer wieder völlig erholen konnte. Man ging daher nicht $7-8$ Schritte ohne zu ruhen. Das Haar-Hygrometer zeigte nahe bei der höchsten Station $91^{\circ} 5$ Feuchtigkeit in einer Wolke, $84^{\circ}$ ausser derselben, wie denn überhaupt über den an der 
Oberfläche ganz aufgeweichten Gletschern der Anden die Feuchtigkeit inmer ganz ausserordentlich gross ist, wäbrend B. zu Santa Fé denselben Hygrometer auf $26^{\circ}$ herabsinken sah. Auf dem höchsten erreich. ten Punkte stand der Barometer auf 13" 8"1 5, der Thermometer auf 708; eine Höhle zu Beobachtung der Boden.Temperatur bot sich nicht dar. - B. und Andre haben in den Anden die Beobachtung gemacht, dass man bei gleicher Höhe durch das Steigen über steinigem Grunde weit weniger angegriffen werde als auf Schneeflächen, und dass durch eine eigene Beschaffenheit der Luft, Soroche (Schwefelkies) bei den Eingebornen genannt, die von Ausdünstungen des Bodens berrühren mag, das Athmen besonders erschwert werde. Nun hatte Saussure die Unreinheit der im Schnee eingeschlossenen Luft bereits dadurch darge. than, dass er solche mit salpetrigem Gase mengte, wo gleiche Volumina von beiden 1,85 bis 1,86 Gemenge gaben, während solche von salpetrigem Gase und atmosphärischer Luft nur 1,00 lieferten. Doch hat $\mathbf{S}$. diese Schneeluft qualitativ nicht weiter untersucht. B. unterwarf daher die Luft in der am ersten Tage mitgebrachten Flasche, nachden der Schnee geschmolzen war, einer Analyse, wo sich ein Gehalt in 82 Theilen von 68 Stickstoff auf nur $14(0,16)$ Sauerstoff zeigte, obschon bei Füllung der Flasche noch imner viel atmosphärische Luft mit zu. getreten war. Doch kann man andrerseits etwa einwenden, dass das aus dem geschmolzenen Schnee entstandene Wasser aus der mit ihm eingeschlossenen Luft vorzugsweise Sauerstoff absorbirt und so ein Stickstoff-reicheres Gremenge zurückgelassen habe. - Mehrere Physiker wollen in grossen Höhen den Himmel viel dunkler blau oder selbst schwarz gesehen haben. Dieses scheint dem Verfasser aber ebenfalls nur nach längerem Aufenthalte über Schneefeldern Statt zu finden und theils auf einer bloss optischen Täuschung durch den Gegensatz, theils auf krankhafter Affektion der Augen zu beruhen. - Sterne konnte er am hellen Himmel auch in der günstigsten Lage bei Tage nicht sehen.

Die geognostischen Ergebnisse haben wir S. 74 ff. aus einer andern Quelle bereits mitgetheilt.

\section{Erdbeben.}

Vom 28. Juni bis 19. Juli 1834 wüthete ein Erdbeben in dem Bezirke Tschang-té-Fou der Provinz Honan, und erstreckte sich in minderem Grade westlich bis zur Provinz Chan - si, nördlich bis zur Provinz Pé-tchi-li und östlich bis an die von Chan-tong. Im Hauptorte des Bezirks Woun-gan wurden viele Personen unter dem Schutte ihrer Häuser begraben, und 195 benachbarte Meiereien zerstört; und es sollen im Ganzen 100,000 Häuser zusammengestürzt, 4000 Personen umgekommen und 700 tüdtlich verwundet worden seyn. Im Bezirke TséTcheou hat sich die Erde während der Erschütterung an vielen Orten geöffnet und etwa 4000 Personen verschlungen. Der Bezirks - Gouver- 
neur ist mit Frau und Bedienten zerschmettert worden. - Wie viele Häuser in den Bezirken Thang-In, Lin-T'schang, Ngan-Yang, WouTchi zerstört worden, wie viele Personen umgekommen, lässt sich gar nicht angeben. - In Gebiete von Pong-Tchin ist ein grosser Strum schwarzen Wassers aus der Erde hervorgebrochen, welcher Güter, Häuser, Menschen und Thiere mit sich fortgeführt hat und noch zur Stundo nicht versiegt ist (Ann. d. voyag. 1835, VII, 258-25.9).

Im Jänner 1835 ward die Stadt San Vincente in Gratimala nebst 12 Dörfern durch einen Erdstoss fast gänzlich verschüttet. Dio Schiffbrücke zu Truxillo und Omoa and der Kai von Sastodilla wurden mit vulkanischer Asche bedeckt (Globe and Travell. $>$ Ann. voyag. l. c. p. 260).

Am 20. Februar 1835 hatte ein Erdbeben die Stadt Talca [huanha?] zwischen Santiago und $\boldsymbol{l a}$ Conception gänzlich zerstört : die Städte $\boldsymbol{C a}$ racio, Conquenes, Lanares und Chiliano sind [vom Meere?] verschlungen worden; zu la Conception und Talcahuanka steht nur ein Haus noch, und alle mit der Wiederherstellung des Kathedrale beschäftigt geweseuen Arbeiter sind umgekommien. $\mathrm{Zu}$ la Conception erfolgte die Erschütterung um $11 \frac{1}{2}$ Uhr Mittags. $\mathrm{Zu}$ Tulcahannha stieg das Meer $33^{\prime}$ über seine gewöhnliche Höhe und warf die Corvette 'Mapocho auf die Mitte des öffentlichen Platzes und die übrigen Schiffe kamen in grosse Gefahr (Globe and Traveller $>$ Ann. d. voyag. 1835, VII, 262-263).

Anı 15. März 1835 schreibt man aus Sunta Martha in Columbia, dass man 7 Stunden lang starke vulkanische Detonationen, man weiss nicht woher, vernommen, und dass solche zu Bogota, Popayan, St. Jean de Nicaragua, Venezuela und Curaçao, mithin in einem Unkreise von 250-350 Meilen nach N., S. und O. die Bevölkerung in Schreeken gesetzt; und am nämlichen Tage ward ein Theil der Insel Jamaica mit vulkanischem Staube bedeckt (Ann. d. voy. l. c. p. 261).

Am 16. Juni 1835, 29 Minuten nach Mitternacht, weckte eine furchtbare Detonation, ähnlich einer starken Artillerie-Salve, die Bevölkerung von Palma auf Majorca und trieb sie ins freie Feld; sie hatte sich jedoch auf den mittel-westlichen Theil der Insel beschräldkt und sich von S.W. nach N.O. fortgepflanzt. Zwei an der Dragonnera liegende Kriegsschiffe hatten nicht das Mindeste davon bemerkt. Zwei Nächte später um dieselbe Minute erfolgte eine ähnliclre, doch schwächere Detonation und die dritte an 20. Juni, 8 Uhr 16 Minuten Abends in Begleitung einer heftigen Erschütterung (ib. p. 252-253).

G. Brschopf: zur Kenntuis der Aachener Thermen (Kastx. Arcli. f. Chem. 1833, VII, 327-328). In dem Kaissrbade zu Aachen, im Schwerdtbade und im Bade zur Goldmühle in Burtscheid sind die schwarzen Marmor-Platten, womit die Leitungen gedeckt sind, und 
welche nur mit den Dämpfen des Wassers, nicht mit diesem sclbst in Berührung kommen, auf ihrer inneren Fläche so bedcutend angegriffen und erweicht, dass man mit den Händen viel schwarze Brei-artige Materie abnehmen kann, welche aus kohlensaurem Kalk, Eisenoxyd, Thon. erde und (färbender) Kohle besteht, wie der Marmor selbst. Auch etwas Gyps konnte daraus durch Wasser ausgezogen werden, und Kohlensäure mit etwas Schwefelwasserstoffgas entwickelte sich durch. Salzsäure, woraus mithin die Anwesenheit ron etwas Schwefelwasserstoff sogar in denjenigen Quellen erhellet, in welchen Monнerm selbst mit den empfindlichsten Reagentien keine Spur davon entdecken konnter Vou dem Kochsalze der Thermen fand sich keine Spur in jeuer aufgelösten Masse des Marnors, weil er mit dem Wasser nicht selbst in Berührung gekonmen war.

S. Batp: neue Analyse des Thermal. Wassers ron Iavey ") bei St. Maurice (Aun. chim. phys. 1835, LVIII, 109-111). Nach noch vollständigerer Fassung ergab sich in Oktober 1833 eine Temperatur des Wassers an der Quelle von $45^{\circ} \mathrm{C}$. (statt $43^{\circ}, 5$ ); nach dem Erkalten bis auf $15^{\circ}$ eine Eigenschwere von 1,00114 (statt 1,00102), und eine $\mathrm{Zu}$ sammensetzung in 1000 Theilen Wassers auf $0^{\circ}$ und $0^{\mathrm{m}}, 76$ Luftdruck von

Kubik-
Centimeter.

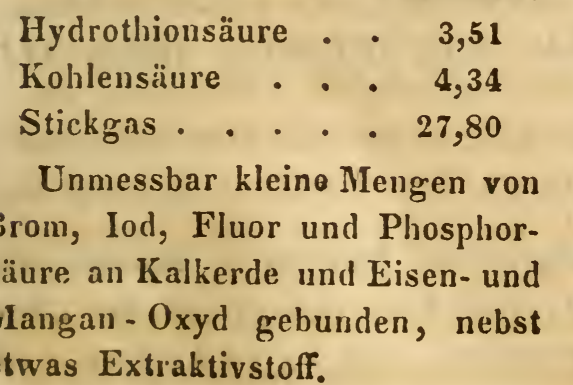
etwas Extraktivstoff.

Chlor-Kalium . . . 0,0034

- Sodium . . . . 0,3633

- Lithium . . . 0,0056

- Calcium . . . 0,0015

- Magnium . . . 0,0045

Wasserfreies schwefelsaures

Natron . . . . 0,7033

Wasserfreie schwefelsaure

Talkerde . . . . 0,0068

Wasserfreier schwefelsaurer

Kalk . . . . . 0,0907

Wasserfreier schwefelsaurer

Strontian . . . 0,0023

Kohlens. Kalkerde . . 0,0730

$\begin{array}{r}\text { Talkerde } \\ \text { Kieselerde . . . . } \\ \hline\end{array}$

*) C̈Ler diu frühere Analyoe vergl. Jahub. 1833, S. 62 und 254. 
Die königl. Sozietät in London setzt zum Preisse die königl. Medaille für ein Werk aus, das ihr vor dem 1 Juni 1837 überreicht wird, unter dem Titel "Contributions towards a System of Geological Chronology, founded on an Examination of fossil Remains and their attendant Phenomena".

Einführung von Fröschen und Schlangen in Irland. Nach Donat's, eines Irländers und Bischoffs von Fesulae Beschreiburg von Irland vom J. 820 gab es damals weder Schlangen noch Frösche in Irland. Letztere scheinen erst i. J. 1696 durch ein Mitglied des Trinity College in Dublin aus England nach den Universitäts - Park verpflanzt worden, von wo sie sich bald verbreiteten. Schlangen gibt es erst ganz seit Kurzem da. Sie sind ebenfalls dahin verpflanzt und vermehren sich reissend un St. Patrick (Dublin Med. a. Chem. Journ. $V, 481>J_{\triangle M B 8 .}$ Edinb. Journ. 1835, XVIII, 372-373).

Farines hat am 6. Mai 1835 der philomatischen Sozietät von-Perpignan eine "Statistik der Bohrarbeiten nach Artesischen Brunnen im Dept. der Ost-Pyrenäten" von $1829-1833$ mitgetheilt. Es werden 18 Fälle aufgezählt, wo man $33-180^{\mathrm{m}}$ tief gegangen und trinkbares Wasser von $14^{\circ}$ bis $17^{\circ}, 5 \mathrm{C}$. Temperatur erhalten hat, das jedoch in keinem Falle über Im,5 über die Erdoberfläche stieg ('Institut, 1835, III, 236 - 237).

Mantell hat 1834 von der geologischen Sozietäł in Lonilon die Wortaston'sche goldene Medaille für seine Entdeckungen in der "fossilen vergleichenden Anatomie" insbesondere über I g u a nodon und Hy la os a urus, und

Ch. Lxert von der philosophischen Societät in London die königl. Medaille für Geologie und Mineralogie für seine "Principles of Geology" erhalten (Jambs, Edinb. n. phil. Journ, XVIII, 364). 
Über

\section{die Rheinischen und Eifeler erlosche- nen Vulkane, vorziiglich in Bezie-. hung anf Dr. HibBer'y's Geschichte der ersteren,}

vol1

Herrn General van deR WYCK.

Herr Ам Boué sagt im Résumé des progrès de la Géologie pendant l'année 1832 (Bulletin de la Société géologique de France $1833, p . x x x$ ) iiber Dr. Hibbert's History of the extinct Volcanos of Nenwied, Edinburg a. London 1832: "Dieses interessante Werk vereinigt eine Menge bekannter Beobachtungen mit vielen anderen, welche bis jetzt noch nicht im Druck erschienen, und vor Allem neue Ansichten über die Ablagerungen und vulkanischen Zufälle, welche in diesen Gegenden Statt hatten." Ferner (p. xxxı) „man sieht, dass der Autor die neptunischen und vulkanischen Ablagerungen chronologisch hat ordnen und beschreiben wollen; es ist ein Versuch, der noch nicht so vollständig und unter Einfluss der neuesten Ideen, welche unter den Geologen im Schwunge sind, gemacht worden ist."

Die Neuheit vieler Ansichten und Ideen des Herrn Dr. Hibbert ist nicht in Abrede zu stellen. Ob sie alle richtig mit der Natur und mit dem jetzigen Stande der Wissen- 
schaft im Einklange sind, wollen wir sehen, und dabei die Bemerkungen machen, welche uns zur Beleuchtung oder zur Berichtigung des Gegenstandes dienlich vorkommen werden. Dieses erachten wir der Wissenschaft schuldig zu seyn.

Werfen wir zuvörder'st einen Blick auf die schöne Karte, welche dem Werke vorangeht. Der angenommene Maasstab ist für einen allgemeinen Überblick himreichend und diese Karte gibt einen viel bessern Begriff der Gegend, als die zu ihrer Zeit schön gestochene Nos'sche, auf welcher unter andern aus einem Berge zwei gemacht sind unter den Namen von Veitskopf und Kamperkopf, wodurch die Gegend von Glees, Wassenach und den Kunksköpfen auf eine unkenntliche Art dargestellt ist. Man kann von Geognosten, welche sich selten auf geometrische Vermessungen einlassen können, keine topographische Genauigkeit verlangen, wie erwünscht dieselbe auch seyn möchte; aber man sollte doch, selbst in ungefähren Darstellungen, vermeiden, irrige Begriffe zu veranlassen. Hievon ist die Hibbert'sehe Karte auch nicht frei.

Betrachtet man z. B. die Art, auf welche der Hochsimmer und der Nichenicher-Sattel angegeben sind, so gibt man beiden fast gleiche Girösse und Höhe, da doch letzterer als ein übernus kleiner Zwerg in Vergleich mit dem ersteren erscheint und nicht den achten Theil des Raums einnimmt, der ihm auf der Karte gegeben ist.

An der Stelle des Pleiter-Humrichs sind zwei Bergkuppen angegeben, wo nur ein alter Vulkan mit seinem Krater vorhanden ist, der eher genannt zu werden verdient, als iler kleine Nickenicher-Sattel, obschon die Bedeutung dieses letztern, wie klein auch, nicht zu verkemnen ist. Hier gewinnt die Nos'sche Karte an Richtigkeit.

Die Höhe der Kunkshöpfe ist der des Veitskopfs sehr nutergeordnet; auf der Karte ist es umgekehrt.

Petrachtet man die Art, wie die kleinen Ausbrüche bei Boos dargestellt sind, so möchte derjenige, der das Terrain kennt, seinen Augen fast nicht mehr trauen. 


\section{$-131$}

Das basaltische Lava-Riff zwischen Obermendig and Thïr ist mit der Lava der Niedermendiger Steinbrüche in Verbindung gebracht. Beide, verschiedener Natur, sind durch ein Thal, worin ein Bach fliesst, getrennt.

Die Lava bei Glees hat ihren unverliennbaren Ursprung im Veitshopf. Dieses ist auf der Karte nicht ersichtlich.

Die Überbleibsel des Lavastroms vom Bausenberg nach Gönnersdorf bestehen aus einer schmalen Verketiung von zertrümmertem Basalt, wovon hier und da einzelne, oder auch gehäufte Blöcke liegen, oder kleine Thurm-ähnliche Massen hervorragen, welche seine Richtung angeben. Auf der Karte kommt er ununterbrochen und zu breit vor.

Den Eltringer-Bellenberg und die Kottenheimer-Bïden, welche zusammengenommen einen Vulkan bildeten, sucht man vergebens; obschon sie als solche der Autor verkennt, möchte man doch gern die wahren Formen angegeben finden. Dem Lavastrom, der aus demselben hervorquoll, und in welchem sich die Meyener Mïhlensteinbrüche befinden, ist folglich auch nicht der wahre Ursprung angewiesen.

Die Schlacken - und Lapilli - Gebilde sind nicht Basalt, obschon sie aus demselben entstanden seyn künnen. Eine Unterscheidung dieser Gebilde vermisst man gänzlich; und doch bestehen die höchsten vulkanischen Kuppen, so weit sie sichtlich sind, nur allein aus Schlacken-Anhäufungen: so der Hochsimmer, der Hochstein oder Forst, der Bausenberg, der Veitskopf, die Kunlishöpfe, der Nastberg, der Rolheberg, der Pleiter-Humrich, die Wanerhüpfe, der Langenberg, der Carmelberg etc.

Nur von der topographischen Abtheilung des KöniglichPreussischen Generalstabes könnte man eine genaue geognostische Karte dieser interessanten Gegenden erwarten. Möchte einer der Offiziere dieses Generalstabes, zugleich Geognost, unter Bewilligung der hohen Regierung die Bearbeitung solch einer Karte zur Herausgabe übernehmen! Dieses wiirde viele schwankende Begriffe berichtigen und der Wissenschaft sehr beförderlich seyn. 
Wir sehen aus der Vorrede, dass Herr Dr. Hibbert mit seinem Werke sich zum Ziele setzte: einen regelmässigen geschichtlichen Überblick der vulkanischen Ausbrüche des Neuwieder Kessels in ihrer verwickelten Beziehung zu den tertiären oder späteren Ablagerungen zu geben, und alle verschiedenen vulkanischen Er'scheinungen, welche dieser Kessel, in Verbindung mit gleichzeitigen physischen Umwälzungen darbietet, in einer Art geschichtlicher Darstellung zu liefern.

Diese Aufgabe ist gross und viel umfassend. Wäre sie gelöst, so wäre vielleicht der Schleier gelüftet, und man würde auf dem Wege seyn, die Bildung unseres Planeten darzulegen. Aber so lange man sich noch streitet über chemische oder dynamische Ursachen der Vulkanität; über Seyn oder Nicht-Seyn der Erhebungs-Kratere; über ihre Allgemeinheit oder Lokalität; über ante-diluvianische und post-diluvianische Ergebnisse; über vorgeschichtliche und geschichtliche Ereignisse; über ur'weltliche und gegenwärtige Epochen; über die Zeiträume der verschiedenen Bildungen und Ablagerungen, ihre Natur, Anzahl und Ordnung, so wie über die Epochen ron gewaltigen Umwälzungen und von Ruhe; über die verschiedenen Wasserbedeckungen, ihren Ursprung, ihre relative Höhe; über die Richtung und Intensität ihrer Strömungen; über die Bildung und Verkettung der Gebirge überhaupt; selbst noch über die verschiedenen Thalbildungsarten; über die Ursache der Gebirgs-Erhebungen und die verschiedenen geologischen Zeiträume, welchen sie angehören; über die Entwicklung der Gasarten aus dem Innern der Erde und ihre Expansiv-Kraft, über die unterirdischen Oxydations - Prozesse; über das Verhalten der Atmosphäre zu den verschiedenen geologischen Perioden; so lange mangelt einem Ver'suche zu solch einer Lösung der' eigentliche Boden, worauf er zu grïnden wäre.

Unter diesen Bewandtnissen möchte man geneigt seyn, den Muth aufzugeben, und nicht mehr an geschichtliche geologische Darstellungen denken. Aber obschon die Zeit zu solchen Darstellungen noch nicht reif scheint, so sehen wir 
doch am Horizont eine Zukunft aufgehen, in welcher diess der Fall seyn könnte.

Über demselben sind drei Sterne empor gekommen, auf welehe sich so viele Hoffnung gründet.

Das Werk von Klöden über die Gestalt und Urgeschichte der Frde (Berlin 1529) ist in der geologischen Literatur eine Erscheinung, die vielleicht bis jetzt nicht genug gewürdigt ist. Die darin aufgestellte Idee hat nichts Widersprechendes in sich; die auf dieselbe sich gründende Theorie ist mit Scharfsinn durchgeführt und gewährt einen tiefen Blick in die Entwicklung der Welten-Systeme im Allgemeinen und unseres Planeten mit seinem Trabanten im Besondern. - Ist einmal die Möglichkeit der angenommenen Axen-Veränderung der Erde anerkannt, welches wohl nls der schwierigste Punkt in der Kuöden'schen Theorie vorkommen möchte, so finden hierin viele Erscheinungen, wie die fossilen Tropen-Pflanzen und Thiere und die Verbreitung der nördlichen Gesteinblö̈cke, eine mehr genügende Erklärung als in andern darüber aufgestellten Hypothesen. Das Verdienst dieses ausgezeichneten Werkes ist erkannt (siehe u. a. Zeitschrift für Mineralegie, Jahrg. 1S27, I, S. 226 und Jahrbuch für Mineralogie, Jahrg. 1830, S. 102). Indessen, die Früchte, welche es zu tragen vermag, sind noch zur Reife zu bringen. - Betrachtet KLödeN diese Wissenschaft aus einem kosmischen Gesichtspunkte, - so fassen Andre mehr bestimmt das Materielle, das unmittelbaren Beobachtungen und Untersuchungen unterworfen bleibt, ins Auge.

Éte de Beaumont hat die Grundlagen, auf welche die Theorie der Gebirgs-Erhebungen gebaut war, erweitert, wodurch die verschiedenen Erhebungs - Epochen mit denen der Bildung der älteren und jüngeren geschichteten Gebirgsarten in Verbindung gebracht werden. Die Beobachtungen hoch berühmter Vorgänger benutzend, hat er die Gebirgszüge, mit lnbegriff ihrer nahen oder entfernten Parallelen, 
nach ihren verschiedenen Richtungen klassifizirt, und sie dem geologischen Zeitraume, dem sie angehören, zugewiesen. Diese Darstellung der Gebirgszüge liönnte die Idee anregen, dass die Erdkugel in Zonen, welche unter gewissen Deklinations - und Inclinations. Winkeln von der Erdaxe abweichen, getheilt seyn müsste. Solch eine Erdstruktur ist nicht vorauszusetzen, und die beständige Gleichheit der Richtung von gleichartigen Erhehungen, wenn sie sich bestätigt, muss auf andern Ursachen beruhen. Diese Theorie, welche zur Aufklärung der Struktur der Erdrinde viel beizutragen vermag, gibt Anregung zu fernern Untersuchungen. Durch diese, wie sich denken lässt, wird sie modifizirt werden, aber nicht untergehen. Die Theorie wird bleiben mit dem Namen, der sie in das Leben rief.

Nach der Theorie von Lyell geht die Natur ununterbrochen in ihrem schaffenden Wirken fort, und alle Kräfte, welche den gegenwärtigen Zustand herbeiführten, bleiben nach ihm in geologischer Hinsicht in einer fortwährenden Thätigkeit. Dieses kündigt der Titel seiner lehrreichen Principles of Geology (drei Theile in $\mathrm{S}^{0}$, London 1832-1833) an, da er dieselben qualifizirt als einen Versuch, die` früheren Veränderungen der Erd-Oberfläche durch Ursachen, welche noch stets in Wirkung sind, zu erklären.

Sein Werk, reich an wichtigen und schätzbaren Beobachtungen, trägt das Gepräge nicht allein einer rastlosen Thätigkeit, sondern auch eines eleganten Vortrages, verbunden mit ungewöhnlichem Scharfsinn und viel umfassender Gelehrsamkeit. - Man kann es als Moderator der 2 vorerwähnten Theorie'n betrachten, welchen es wahrscheinlich einiges Feld wird einräumen müssen. - Solchergestalt können sich die Differenzen ausgleichen, wobei für die Wissenschaft grosser Gewinn zu hoffen ist; - desto mehr, weil diese drei Sterne zu einer Zeit aufkommen, wo so viele Sterne erster Grösse am geologischen Himmel ihren Glanz verbreiten, von denen Zurechtweisungen zu erwarten sind, welche zum Ziele führen müssen : zur höchsten Wahrscheinlichkeit in 
Riicksicht des Vergangenen und zur Wahrheit für die Gegenwart. Sonach können wir erwartungsvoll der Zukunft entgegen sehen.

Obschon wir das Geschichtliche in genlogischer Hinsicht vor der Hand als unreif ansehen, so hindert dieses nicht, dass ein Versuch auf dieser Bahn seine gute 'Seite haben kann, wäre es denn auch nur, um zu beweisen, dass jetzt noch nicht die Zeit dazu gekommen ist und man dieses erst von der Zukunft hoffen darf.

Im Anfange seines Werkes spricht Dr. Hibbert die Meinung aus, dass das Schiefer-Grauwacken - Gebirge nicht mit einem einzigen Male, nach der Theorie des Herrn ELIE de Beaumont, sich aus dem Schoose der Erde erhoben hat, sondern bei verschiedenen Convulsionen. Darüber bin ich mit ihm einverstanden; aber hinsichtlich der Anzahi von sechs Katastrophen, welche er S. 6-S angibt, möchte ich bemerken, dass wir die Anzahl der Statt gehabten ErhebungsConvulsionen keineswegs so genau bestimmen können.

Wenn man im Ahrthale wandert, sieht man manchmal in Brücken oder am Wege Grauwacke - Platten, welche die Merkmale von sehr kleinen Wellenschlägen tragen, ähnlich den wellenförmigen Sandstein - Platten, welche man bei G. MantelL, The Geology of the south-east of England, London 1S33, S, 213-214 sehr naturgetreu beschrieben findet. Wenn man erwägt, dass solche kleine Wellenformen nur in horizontaler Lage unter seichtem Wasser gebildet werden können, und wenn man hierbei die grotesken Formen betrachtet, in welchen das Grauwacken-Schiefer-Gebirge, vorzüglich in der Gegend von Altenaar, durcheinander geworfen und in verschiedenen Lagen gehoben ist, - so wird es klar, dass solche Umwälzungen nicht einer einzigen Bewegung zuzuschreiben sind. In diesen Gegenden findet man überall die Spuren, dass diese Schiefer-Formation vielen gewaltigen Zerrüttungen unterworfen war, daher ein konstantes Streichen und Fallen hier selten vorkommt. 


\section{$-136$}

Die Richtung der verschiedenen Thäler in dem Bezirke, welchen der Autor zu seiner Untersuchung erkoren hat, wird im 3ten Kapitel (S. 9) abgehandelt. - Für eine allgemeine Übersicht kann es hinreichen, aber ohne eine genaue topographische Karte sind solche Angaben wenig zuverlässig. Nach der Karte des Autor's und nach seiner eigenen Bemerkung weichen einige bedeutende Theile, sowohl des Netten- als des Brohl-Thales von der angegebenen Hauptrichtung ab. - Im Allgemeinen halten wir dafür, dass man es mit den Thal-Richtungen, vorziiglich bei Neben-Thälern, so sehr genau nicht nehmen kann, und dass viele $\mathbf{A b}$ wechslungen darin vorkommen, welche mit den angeblichen Richtungen nicht zusammentreffen, und also auch nicht dienen können, um die Folgerungen, welche man aus denselben ableiten will, zu unterstützen.

Der im 4ten Kapitel (S. 15) beschriebene Zustand im Anfange der tertiären Epoche des Rhcinlandes beruht auf Hypothesen, deren man eine Menge, alle von gleicher Wahrscheinlichkeit, machen kann. - Die Trennung des NordEuropüischen Basins vom Oceun (vermittelst einer Ketto von sekundären Gebirgen, welche verschwunden seyn muss), ist wahrscheinlich nur eine flüchtige Idee eines der ersten Geologen, so wie die Voraussetzung, dass die Gewässer voun Bassin zwischen Bingen und Basel zur Zeit, als das Taunus- und Hundsrïcken - Gebirge noch aneinander geschlossen waren, in umgekehrter Richtung, das heisst, vom Norden nach Süden strömten.

Das jetzige Gefälle des Rheins, von Basel bis Bingen, wird nicht Viel von 510 Pariser Fuss abweichen. Wenn nun das Wasser, um diese Höhe über dem jetzigen Rhein erhoben, gegen das vereinte Taunus- und Hundsrïcken-Gebirge anlehnte, so würde es mit dem jetzigen Wasserstande zu $\mathbf{B a}$ sel übereinkommen; - um wie viel höher mïsste das Wasser dann noch seyn, un seinen vorausgesetzten Abfluss in das schwarzc Mecr bewirken zu kïnnen! - Gewiss um 'mehr noch als der' Taunus über dieser Wasserhöhe hervor- 


\section{$-137$}

ragen würde, - demnach müssten viele der Gebirge im Schwarzwalde um ein Bedeutendes in den Schoos der Erde zurückgewiesen werden, um sie erst viel später, als ihre Erhebungs - Epoche nach der Theorie des Herrn ELIE DE Beaumont bedingt, erscheinen zu lassen.

Man wird doch wohl nicht im Ernste behaupten wollen (1S8), dass gleichzeitig mit der Erhebung der Alpen das Terrain bei Basel erst auf die jetzige Höhe gebracht ist, dass diese Erhöhung allmählich nach Bingen hin abgenommen hat, und dass solchergestalt dem Rhein ein umgekehrtes Flussbett vorbereitet wurde! Kann man solche plutonische Wirkungen voraussetzen, ohne dieselben nach Will. kür zu modeln ؟

Das Einzige, was wir rücksichtlich dieses Bassins als geologisch gewiss annehmen können, ist: dass, nachdem die tertiären Bildungen vorüber und die letzten Diluvialfluthen gewichen waren, der Bruch zwischen dem Taunus und dem Hundsrücken noch nicht völlig zu Stande gekommen, und das Rheinthal zwischen Basel und Bingen einen Binnenseo bildete; - dass unterhalb Bingen ein Wasserfall entstand, der stets an Höhe abnahn, je mehr die GrauwackenSchiefer-Felsen seiner Gewalt unterlagen, womit der Binnen-See allmählich niedriger wurde, endlich verschwand und seine Niederungen dem Rheinstrom Preiss gab. Im neunten Jahrhundert war der Rhein bei Bingen noch nicht schiffbar und die Güter wurden von Asmanshausen bis Rüdesheim über Land von Schiff zu Schiff befördert.

Auf gleiche Art war der Neuwieder Kessel ein BinnenSee, der sich endlich hei Andernach Luft machte. Dem Vorkommen nach ist die Öffnung zu Andernach einigermassen älter als das Binger Loch. Ein Basaltriff bei Unkel bildete oberhalb dieses Ortes vielleicht auch einen kleinen Binnensee.

\section{Laacher See.}

Der Lancher See wird durch Dr. Hibbert als ein Krater angesehen, und sein 5 tes Kapitel von S. 21 bis S. 27 
ist der Begründung dieser Ansicht gewidnet. Manches eingeflochtene Geschichtlich-Geologische wird durch nichts verbürgt; es berührt Dinge, worüber die Ansichten der geschätztesten Geologen noch sehr auseinanderlaufen. Wir kömnen nicht anders urtheilen, als nach Demjenigen, was wir zu sehen und zu beobachten vermögen.

Die Vulkanität hat über den ganzen Erdboden einen allgemeinen Charakter, wonach eine Gegend als vulkanisch erkannt wird; aber jede vulkanische Gegend hat einen besonderen Charakter, der sie von anderen unterscheidet: Dieses muss als Leitfaden bei anzustellenden Untersuchungen und Beobachtungen zu Grunde gelegt werden. - In meiner Übersicht der Rheinischen und Eifeler erloschenen Vulkane (Bonn 1826) habe ich solche unterscheidende Charakterzüge S. 3 und 4, nach meiner Ansicht, angegeben.

Diesem gemäss ist der Laacher See, im Verhältniss zu der Vulkanität der Gegend, als einfacher Krater betrachtet eine zu kolossale Erscheinung. Es kommt hier auf die Bedeutung des Worts an.

In allgemeinen Sinne sind die Vulkane erhobene Berge aus vulkanischen Produlktea zusanmengesetzt, wovon der obere Theil aus konglomerirten Schlacken besteht, worin sich eine trichterfürmige Vertiefung befindet, die den eigentlichen Feuerschlund oder Krater ausmacht. Dieser ist also von einem Schlacken-Kranz umgeben, der öfters durch einen ausgebrochenen Lavastrom zum Theil zerrissen oder zerstört vorkommt, und so den cratère égueulé der Franzosen bildet. Wenn man also von einem Krater spricht, so wird der hier aufgestellte Begriff, der mit dem Laacher See nichts gemein hat, in Anregung gebracht.

Findet man eine runde trichterförmige Vertiefung durch einen vulkanischen Ausbruch gebildet, die mit Wasser angefüllt ist, so nennt man diese ein Krater-Meer oder Maar (craterlac). Diese Benennung aber passt nicht auf den Laacher See. Es ist nicht allein die Grösse, die dagegen spricht, sondern auch die Form. Wo findet man die schroffen, 


\section{$-139$}

beinahe senkrechten Wände der Ulmer- und Weinfelder Maare? - Die umringenden Grauwacken-Schiefer-Gebirge sind nicht allein unter flachen Abdachungen abgerundet, sie entfernen sich auch an vielen Stellen bedeutend vom Wasserspiegel und zwischen beiden kommen Ackerland und ausgedehnte Wiesen vor, welche denn auch zum Krater mitgerechnet werden müssen, wodurch dieser ungeheuer gross wird und noch mehr die runde Form verliert. Bei den Thomashöhen allein muss ein Seitenausbruch des Kruster Ofens angenommen werden, der die Tiefen des See's erreiohte, aber nicht aus seiner Tiefe hervorkam.

Dr. HibBert vergleicht seinen Krater des Laacher See's mit der Monte Somma am Vesuv. - Diese ragt nm $\mathbf{3 5 0 0}$ Fuss über die Meeresfläche: der Laacher See kaum 500 Fuss; sie ist trocken und umfasst zum Theil ihren Stellvertreter, den Vesuv: der Laacher See ist mit Wasser angefüllt; die Somma ist gänzlich ans vulkanischen Produkten, welche an der innern Seite schroffe, aufrechtstehende Wände bilden, zusammengestellt: der Laacher See hat als Kranz grösstentheils Grauwacke - Schiefer-Gehirge mit flachen Böschungen, und an den Stellen, wo vulkanische Schlacken-Konglomerate oder Basalt hervortreten, zeigt es sich deutlich, dass sie ihrem Ursprung nach dem See nicht angehören. - Hibeers's Vergleichung hat also keine befriedigenden Gründe. Wenn der alte Krater der Somma grösser war als der, welchen der See bilden sollte, was zu bezweifeln ist, so kan man bei der erster'n eine Kraftäusserung voraussetzen, welche sich im Revier der Rheinischen und Eiféter Vulkane, nach dem dortigen Vorkommen, nicht vermuthen lässt. Die Natur bleibt sich überall gleich. - Wenn man von dieser Wahrheit durchdrungen ist, wird man einsehen, dass es nicht nöthig ist, nach ausserordentlichen Erklärungen zu greifen da, wo sie selbst die einfachen Ursachen ihres Wirkens für uns entfaltet.

Könnte der Laacher See auch ein Explosions-Krater seyn - Dr. Hibbert ist damit im Reinen und lässt S. 23, 
die Trümmer zum grössten Theile, wo nicht gänzlich in den grundlosen Schlund zurückfallen, und was nach Aussen geworfen wurde, durch die Fluthen wegspühlen. Bei solch einer gewaltigen Operation müssten doch wohl einige abgebrochene und zerrissene Schiefer-Wände zurückgeblieben seyn, und auch wohl hier oder da eine Spur von zerstreaten Schiefer-Blöcken; - beide sucht man vergebens. Von den "abrupt rocks of clay-slate", welche der Autor will bemerkt haben, ist hier nichts zu finden: die wenigen schroffen Abhänge neben den Thomashïhen sind nicht dafür anzunehmen.

Von $\mathbf{S} .23$ bis $\mathbf{S} .160$ spricht der Verf, sehr in Gegensatz mit dem früher Aufgestellten, von the declivity af the high slate rochs which form the bounding sides of the Crater. So ist es recht. Dasjenige, was declivity hat, kann nicht von derselben Seite abrupt seyn. Dem, was in den Krater zuriickfiel, kann man nicht nachtauchen. Eine Explosion von zwei und einer halhen Stunde Weges im Unfange, oder nahe genug von drei Viertel-Stunden im Durchmesser, findet ihren Widerspruch in der Natur der Vulkanität der Gegend. In besserer Übereinstimmung damit wïrde, das PulverMaar (immer submarinisch) stehen, wenn man dieses dafür wollte gelten lassen. In diesem Falle müsste man um dasselbe Grauwacken-Schiefer-Trümmer verbreitet finden, aber wenige oder gar keine vullianische Auswïrflinge, vorzüglich nicht an der O.-Seite. Hierbei ist indessen der Rümersberger Ausbruch zu beachten.

Ist der Laacher. See ein Erhebungs - Krater@ - Auch hiermit ist Dr. HıввERT, obschon er dagegen S. 21 protestirte, im Klaren. Um die Spalten ausfindig zu machen, welche nach der Theorie des Herrn von Buch (durch die Herrn Dufrénoy und Elie de Beaumont im zweiten Theile Ihrer Mémoires pour servir à une description gérlogique de la France, Paris 1834, S. 223 u. f. gründlich auseinandergesetzt) bei jeder Erhebung von Bedeutung vorkommen, greift er erstens nach dem Theile des Brohlthals, welchen er von Wassenach bis an den Rhein abmarkt, und ferner 
nach ander'n ersonnenen Spalten, woraus basaltische Lava und Säulen vulkanischer Stoffe hervorgesprudelt seyn sollen, die nachher by common disintegrating and levelling agents unkenntlich geworden sind. Als eine andere Spalte wird, freilich etwas zweideutig, das Gleeser Thal angeführt. Wenn dasselhe als in der Nachbarschaft des Kraters vom Veitskopf befindlich angegeben wäre, statt unfern des Krater's vom Laacher See, dann wäre die Angabe getreu; denn es liegt jenes Thal dem Veitskiopfe näher.

Alle diese sogenannten Spalten sind weit entfernt, denjenigen ähnlich zu seyn, welche durch Erhebungs - Kratere, nach der oben erwähnten Theorie, entstehen. Die ganze Neuwied-Rheinische- und Eifeler Vulkanität, so weit ich sie kenne, bietet kein Beispiel von einem Erhebungs - Krater, und ich glaube nicht, dass Herr v. Buch dort suchen wird, um Belege zur Unterstiitzung seiner Theorie zu finden. Erhebungen, die keine Erhebungs - Kratere sind, kommen hier in Menge vor, - aber auch Versenkungen.

Ist denn der Laacher See ein Versenkungs-Krater@ Dieses bringt uns der Sache näher. Wenn hier der Ausdruck Krater keine andere Bedeutung hat, als eine grosse trichterförmige Vertiefung, so kônnen wir uns dieser Ansicht anschliessen. In meiner Schrift über die erloschenen Vulkane sagte ich: Das Entstehen des Laacher Sce's ist gleichzeitig mit der Bildung des Thon- und GrauwackenSchiefer-Gebirges, welches ihn ungürtet. - Der Thon- und Grauwacken-Schiefer wurde in horizontaler Lage gebildet. Die in Rede stehende Gebirgs-Bildung geschah zu der Epoche, worin der Thon- und Grauwacken-Schiefer durch plutonische Einwirkung, sehr nahe mit vulkanischer verwandit, aus dieser Lage gehoben wurde. Hiedurch entstanden bedeutende Erhöhungen und damit auch Zerreissungsund Zerber'stungs - Thäler und andere Vertiefungen, wovon in diesen Gegenden der Laacher See die beträchtlichste ist. Dass hiebei an dieser Stelle vulkanische Gasarten sich Luft gemacht haben können, - wer wollte solches in Abrede 
stellen! - Aber diese künnen hier nie, nach meiner Ansicht, zu den bildenden Potenzen erhoben werden.

Der trachytische Feldspath, wovon der Autor S. 25 spricht, wird nur in Auswürflingen gefunden und nicht in solcher Menge, dass sich daraus für den Laacher See etwas folgern liesse. Der Ursprung desselben, und auch des vulkanischen Tuffs, findet sich zur Genüge in den vier Vulkanen, welche den Laacher See unfassen. Ausgeworfene Fragmente von Granit sind mir in diesem vulkanischen Reviere nicht vorgekommen; der ausgeworfene Glimmerschiefer wird in der Gegend von Wehr gefunden. Was den trachytischen Feldspath, der nach der Meinung des Autors unter Wasser blieb, anbelangt, - so können wir diesem nicht nachforschen, eben so wenig, als den vermutheten Gängen von trachytischem Feldspath (presumed dykes of trachytic feldspar), welche in einem idealen Durchschnitte zu sehen sịnd.

Hiermit schliesst das erste Kapitel über den Laacher See (Chapter V). Es liegen zwei Ansichten desselben bei, beide getreu. Die erste, mit Talent aufgenommen, gibt einen anschaulichen Begriff dieses See's und seiner Umgebungen. - Die ältere Geschichte wird nun durch die anderen Theile des vorgenommenen Bezirks durchgeführt und der Laacher See erst im XXII. Kapitel S. 145 wieder zur Sprache gebracht. Wir wollen letzteren jetzt vornehmen, um bei demselben Gegenstande zu bleiben.

Der Laacher See hat eine Periode von Inactivität gehabt. (Er ist wohl nie aus derselben herausgetreten.) - Während dieser vorgeblichen Periode, welche mit der tertiären Zeit zusammentraf, wurde der ungeheure Krater mit Trümmern, Trachyte-dykies und mit vulkanischem 'Tuff angefüllt, über welchen sich plastischer Thon und Sand ablagerten. Zur Zeit als die Tertiär-Periode ihrem Ende nahte, wurden die vullianischen Kräfte wieder rege. Sie äusserten sich, 1) rings um den Rand des See's, 2) in dem See seltist und 3) sie 
hielten an bis zum Schlusse des tertiären, oder bis zum Anfang des gegenwärtigen Zeitraumes.

Die Ausbrüche um den Rand des See's erklärt der Verfasser durch die Spalten, welche er angenommen, aber nicht gesehen hat.

Den ersten Ausbruch beschreibt er S. 148:

One slight eruption may be described as existing on the northerly margin of the lake, which is indicated by the many blocks of a dark-coloured basalt, unscorified, or very little so, containing crystals of augite, which we find halfconcealed by underwood or the deep volcanic sand of the lake. These blocks will be found to lie to the east of the very while and promine:zt remains of the plastic clay deposit, which appear in a sort of patch upon the north side of the lake.

Dieser plastische Thon kommt eigentlich auf der N.O.Seite des See's vor. Was östlich von demselben liegt, kann nicht auf der N. - Seite vorhanden seyn; darum ist es zweifelhaft, welche Basalt-Blöcke vom Autor gemeint werden. Im S.O., nicht weit von diesem Thone, liegen einige BasaltBlöcke, welche sich nicht allein durch ziemlich grosse Augit-Krystalle, sondern auch durch grosse Glimmerblätter auszeichnen. Dem Ursprung dieser wenigen Blöcke kann, wegen der Waldung, nur mit Mühe nachgesucht werden. Etwas mehr entfernt stösst man auf einige Trümmer der Thomashühen, wo dichter Basalt in grossen Felsmassen ansteht. Diese können nicht gemeint seyn. Auf der N.-Seite des See's, in einer ziemlichen Entfernung vom besagten Thone, findet man die Überbleibsel eines basaltischen Lava-Ausbruches vom Veitsliopf: Dieser Basalt ist porös und zum Theil zu Mühlenstein verwendbar.

Man sieht deutlich (S. 149); dass der Veitskopf dem Autor im Wege ist; - warum würde er sonst diesen so bedeutenden Vulkan verkleinern! Sein Krater (Vent) wird beinahe der Wirkung des ausspülenden Regens zugeschrieben; seine Lava-Ausströmungen heissen two slight flows, wovon doch der nach Glees zu sehr beträchtlich ist. Wie ist 
es möglich, dass der Veitskopf durch Tuff, aus dern Krater voin Laacher See ausgebrochen, erhöhet seyn sollte, da der Kraterkianz dieses Vulkans keinen Tuff, sondern nur allein vulkanische Schlacken aufweist @ Dieser Vulkan ist dem Bausenberge in Grösse oder Unfang nahe genug gleich und übertrifft ihn sehr an Höhe. - Man verlangt indessen alle vulkanische Produkte, welche den Laacher See unringen, demselben als Krater zuzuschreiben und schliesst die Augen für Alles, was diese Ansicht schwächen kann. Damit wird der aufgefasste Begriff der Natur, nicht die Natur selbst so wie sie ist, ins Ange gefasst.

Unter b sagt der Verfasser: On the southwesterly margin of the Laacher See ì little to the north of the $A b$ bey of Laach, is another eruption of basaltic lava, resembling in character that of the Veitskopf. Und dieses nennt er an inconsiderable Eruption. Wenn der Verfasser darunter den Beller Rothenberg N.W. vom Laacher See versteht, so muss er durch ein sehr verkleinerndes Auge gesehen haben. - Eben so wird der Tüllenberg übergangen und wahrscheinlich (S. 150) three or four minor eruptions of scoraceous basalt (am Fusse desselben werden einige Basalt-Trümmer gesehen) an seiner Stelle erwähnt.

Unter the Eruplion on the easterly margin of the Crater of Laach, so wie dieselbe beschrieben ist, versteht der Verfasser zweifelsohne die Thomashöhen. Der Basalt steht hier mit dem Crufter-Ofon in Verbindung. Nähere Untersuchungen, durch Inbefangene angestellt, werden vielleicht diese Ansicht bestätigen.

In einer zweiten Section (S. 150 bis 162) beschreibt der Verfasser die späteren Ausbrüche des Laacher-See-Kraters so ausführlich, als ob er denselben beigewohnt hätte. Unter den S. 151 wiederholten idealen Durchschnitte liest man, dass der frühere Zustand dieses Kraters ihm offenbart ist durch eine Art augenscheinlicher Gewissheit, welche ihn selbst seiner letzten geologischen Geschichte einverleibt (- this early slate of the crater of Laach, as it is revealed 
to us by a species of evidence, which incorporates itself with its latest geological history). Es lässt sich denken, dass derjenige, der solche Offenbarungen hat, damit viele Bogen anfüllen kann.

Einen gedrängten Auszug der Beschreibung dieser Ausbrüche findet man in diesem Jahrbuche, Jahrg. 1S34. S. 677.

Die dritte Sektion (S. 162) handelt von der verlängerten Dauer der letzten Ausbrüche des Laacher Kraters sammt den mehr allgemeinen Erscheinungen, welche er rings um sich darbietet.

Hier kommen wir näher zur Sache. Wir wollen zuförderst den Autor selbst sprechen lassen.

"Es ist jetzt nöthig, zu bemerken," sagt Hibbert "dass die erneuerten Zuckungen des Laacher Kraters eher durch eine Folgereihe kleiner Ausbrüche aus kleinen Öffnungen, welche sich in verschiedenen Theilen des Kraters entwickelten, charakterisirt waren, als durch einen grossen Ausbruch aus dem ganzen Unfange der ausgedehnten Öffnung dieses See's. Folglich würde das Phänomen einige Ähnlichkeit haben mit theilweisen Auswürfen von erdigen Stoffen, von Schlamm und Bruchstücken verschiedener Felsarten, welche einige wenige Vulkane der jetzigen Zeit charakterisiren."

"Zu gleicher Zeit scheint die Kraft, mit welcher der grüsste Theil des Krater-Inhaltes aufbrach, so gewaltig gewesen zu seyn, dass dieser hoch in die Atmosphäre geschleudert und den Luftströmungen, welche sie über einige Meilen der den See umringenden Oberfl̈̈che zerstreuten, preisgegeben wurde."

"Die verschiedenen Bruchstücke von Ur - oder ältern vulkanischen Felsen aus der Tiefe des Schlunds hervorgeschleudert, von Wolken des Süsswasser-Sandes und mit tuffartigen Theilen vermischtem Lehme begleitet, welche während dem Aufbruche des Inhalts vom Laacher-Becken ausgeworfen zu seyn scheinen, haben durch ihre Anhäufung rings um den Krater-See seinen ursprüunglichen Umfang an einigen Stellen bedeutend veréngert. 
Wenn ich recht verstehe, so sind nach einer sehr langen Pause erst einzelne kleine Ausbrüche entstanden, welche abwechselnd eine Zeitlang anhielten. Nachher ereignete sich der gewaltige Ausbruch, wodurch das See-Becken wiederum von Neuem ausgeleert wurde. Bei der Erneuerung der Thätigkeit des Vesurs im Jahre $\mathbf{7 9}$ ist es umgekehrt zugegangell. Der Anfang war der verheerende Ausbruch, wodurch Pompeji und Herculanum vergraben wurden. - Es ist übrigens ausser unserm Bereiche, so tief in die Vergangenheit zurück zu schauen.

Die Aufgabe ist hier, aus Dernjenigen, was sich unsern Beobachtungen darbietet, den Ursprung der vulkanischen Pro: dulste, womit das Neuwieder Thal überlagert ist, zu erklären.

Die Quantität vulkanischer Stoffe, welche der Verfasser aus dem Laacher See als einem Krater hervorkommen lässt, unterstützt mit einer Zugabe von Rieden her, ist dazu hinreichend.

Indessen sehen wir den Laacher See mit einer Menge Vulkane umgehen, zuun Theil in ihrem offenbar kenntlichen Wesen, wie mit dem Veitshopfe, den Kunkshöpfen, dem Hochsimmer, dem Forst oder Hochstein, dem Ettringer Bellenberg mit dem Kottenheimer Büden, dem Nichenicher-Sattel, dem Plciter Humrich, dem Carmelberg, - zum Theil durch Einstürzungen und Versenkungen zerrüttet, wiie der Cruf1er Ofen der Tüllenberg, der Beller Rothenberg, der Eicher Sattel, der Nastberg, der Kurretsberg, der Langenberg, dio Waner-Köpfe etc.

Haben diese ihre natürlichen Wirkungen geäussert ja oder nein

Als ein gewisses Zeichen ihrer Wirkung erkennen wir an vielen die deutlichsten Lavaausströmungen. Diese konnten nicht, so wie der Bimsstein, vullianische Asche etc., durch Wasser - oder Luft-Ströme von ihrem Ursprunge entfernt werden. Die Schlünde, welche einmal Lava ergossen, haben auch andere vulkanische Produkte ausgeworfen. Andere Vulkane zeigen keine Lava-Ausströmungen, sondern bloss ihre unverkennbaren Kratere; wieder andere sind durch nach- 
folgende vulkanische Umwäizungen und Einsenkungen aus ihrer vorherigen Form geworfen; - aber aus den Überbleibseln lassen sie sich restauriren, eben so gut, wie die altgriechischen Tempel aus ihren Ruinen.

Waren jene Vulkane mit dem Krater des Laacher See's, so wie Dr. Hıвbret denselben und seine Wirkungen beschreibt, zugleich thätig̣ und müssen die vulkanischen Produkte der Gegend beiden zugeschrieben werden Ursache, so verdoppelt, würde die Wirkung überbieten.

Der Geologe hat also Wahl zu bestimmen, zwischen Demjenigen, was anschaulich ist und sich klar und deutlich zeigt, und Demjenigen, was auf Vermuthungen beruhet und was er nur zur Begründung eines Haufwerkes von Hypothesen nöthig hat, welche man nach Belieben wechseln und auf diese oder jene Weise zusammenstellen kann.

Die erloschenen Vulkane stehen handgreiflich da. Der Laacher See verhält sich ganz friedlich. Die an denselben anstossenden Wiesen haben zum Theil eine Grundlage von angehäuftem Muschelsande und von SüsswasserMuscheln, und es verlohnte sich der Mühe zu untersuchen, wie weit diese sich erstrecken. Man findet keine Spur eines gewaltigen Ausbruchs. Nur allein am Fusse des Crufter-Ofens, an der Stelle, wo dieser sich in den See verliert, zeigt sich ein Ausbruch, der diesem Vulkan angehört. Sonst sind alle festen Ungebungen neptunischer Art.

Man schiesst nicht Schrot aus Vierundzwanzig - Pfünder'n und macht keinen Lütticher Mörser, um Handgranaten zu werfen. Sollte die Natur weniger konsequent als der Mensch seyn

Nein, - der Laacher See war nie ein feuerspeiender Krater. Versenkungen, durch plutonische oder vulkanische Potenzen verursacht, kömmen an seiner Bildung Antheil gehabt haben, und somit ist es zulässig, dass er bei den Versenkungs-Krateren in Erwähnung gebracht werde.

Da der Laacher See von drei Vulkanen (der vierte ist mehr entfernt) umgeben ist, welche sehr nahe seine Ufer 
berühren, so fragt sich: warun die Ausbrüiche derselben nicht der Linie des geringsten Widerstandes folgten und sich nicht in den See Luft machten $\$$ Der Crufter-Ofen hat es zum Theil gethan; übrigens ist diese Frage nicht bestimmt zu lösen, denn wir wissen nicht, wie es in der Tiefe beschaffen ist. Die Vulkane mit ihren Produkten sind einmal da, wir müssen uns in dieser Beziehung begnügen mit einer Hinweisung auf eine Thatsache, welche mit dieser unterirdischen Absonderung in Vergleich gebracht werden kann, und welche man S. 69 u. f. meiner Übersicht beschrieben findet. Die Vulkane dieser Gegend, in Vergleich mit andern, sind ausserordentlich niedrig. Die nächste Ursache davon muss in einer geringeren Kraftäusserung gelegen seyn, welche man einer höhern Lage des vulkanischen Heerdes zuschreiben könnte. Denn je tiefer der Heerd liegt, desto mekr Gewalt muss er ausüben, und desto mehr Material hat er vor sich empor zu heben und davon seinen Kegel zu bilden. Bei dem Laacher See, als vulkanischer Krater betrachtet, müsste der Heerd einen viel tiefern Sitz gehabt haben, als die Vulkanität der Gegend demnach in Anspruch nimmt. - Warum hat diese denn keinen Vesuv gebildet, statt eines See's, der in Nichts durch einen gewaltigen Ausbruch bezeichnet wird $s$ - Wenn man annimmt, dass die noch thätigen Vulkane mit dem Feuerkerne der Erde durch Spalten und Klüfte in Verbindung stehen, dann kann man auch dabei annehmen, dass die erhärtete Erdkruste nicht überall die nämliche Dicke habe, und dass sie da, wo sich Vulkane befinden, bedeutend dünner seyn könne. Während der Thätigkeit der Rheinischen und Eifeler Vulkane müsste demnach die erhärtete Erdkruste in der Gegend noch sehr dümne gewesen seyn, und nach dieser Theorie wäre es als möglich zu stellen, dass die fortgesetzte Erhärtung die Gemeinschaft mit dem Erdfeuerkern abgeschnitten hätte, woraus dann die Erlöschung dieser Vulkane zu erklären wäre.

Hätte nun der Laacher-See-Krater einen tiefern Heerd 


\section{$-149-$}

als die ihn umringenden Vulkane gehabt, so müsste demnach seine Thätigkeit von längerer Dauer gewesen seyn, und in diesem Falle würden wir, statt eines See's, einen völlig ausgebildeten Vulkan haben.

\section{Rieden.}

Dr. Hibzert scheint sich S. 27 u. f. auf seine Riedensche-Ausbeute viel zu Gute zu thun, und man muss gestehen: mit einigem Recht, vorzüglich wenn er diese Gegend noch in eben dem unwirthsamen Zustande fand, worin ich dieselbe verlassen habe. - Ich halte es indessen für hörhst zweifelhaft, ob seine Ansichteu über ihre geologischen Verhältnisse mit ihrer wahren Beschaffenheit im Einklange sind.

Sein geological Map of the Basin of Rieden, S. 28, ist weit entfernt von einer richtigen topographischen Aufnahme mit Nivellirungen verbunden, welches ich in der vom Autor angeführten Stelle meiner Schrift als nöthig angab, um von dieser Gegend eine deutliche Vorstellung zu geben, und Aufgaben der Art können auch nicht ohne Mitwirken der Landes-Regierung gelöst werden. - Auch will ich dem Verf. verzeihen, dass er in der erwähnten Stelle: Man betrachte nur etc. mit: We can observe only etc., übersetzte, und was den Ausdruck despairing Sentiments anbelangt, so möchte dieser schwerlich einer vernünftigen Auslegung fähig seyn.

Der Geologe in seinen Untersuchungen ist der freiesto Mann von der Welt. Was ihn im Augenblicke nicht anspricht, vorzüglich in reichhaltigen Gegenden, lässt er seinem Nachfolger, dem man doch auch einige Nachlese zumuthen kann.

Die Hibbert'sche Nachlese hat geliefer't:

1) Eine kleine Karte, welche das Terrain nicht gitt so, wie es ist.

2) S. 28, Sect. I. Einige Betrachtungen über die Spaltungs-Thäler der Gegend, worüber, ohne genaue Vermessungen, nicht zu urtheilen ist.

3) Die Angabe von Kraterformen, welche ich auch ge- 


\section{$-150$}

sehen habe. - Nur stellt der Autor darüber einige Нypothesen auf, welche denselben einen sehr grossen vulkanischen Wirkungskreis anweisen, viel grösser als die Überbleibsel andeuten.

4) Einiges über den Trachyt dieses Reviers. Wir erlassen unserem Verf. gerne seine Hypothesen dariber; hat man diese durchgemacht, so ist es eine wahre Erholung, wenn man S. 32-35 die Beschreibung von dreizehn Species von Trachyt liest und damit wieder in das Gebiet des Wirklichen versetzt wird.

5) Ebenso anziehend ist die Beschreibung der verschiedenen vom Verfasser im Riedener Becken vorgefundenen Tuff-Arten. Die Hypothesen über ihre Entstehungsweise, welche vorangehen, haben etwas mehr Wahrscheinlichkeit. Nur wollen wir bemerken, dass der vulkanische Schlamm (Moya), so wie er aus dem Vulkane hervorgestossen ist und an der Stelle bleibt, wo er sich niedergelegt hat, nicht so, wie der Autor die Tuff-Arten beschreibt, stratificirt segn kann. Stratification entsteht durch Niederschlag aus Wasser. Ist die ausgestossene Moya im Wasser entbunden, und hat sie sich nachher in Strata deponirt, so ist es keine Moya mehr. - Auch sind wir mit dem idealen Durchschnitte des Riedener Kraters nicht einverstanden; von so gewaltigen Ausbrüchen sind keine Spuren vorhanden.

6) Eine Beschreibung, S. 40, wie der Schlamm im Kessel (cauldron) gekocht, und wie er nachher über Berg und Thal sich ergossen hat, begleitet von einer Skizze, worüber die Topographie erröthet und wovon der Autor dennoch verlangt, dass sie möge betrachtet werden als the ultimate deductions of a very laborious and ledious investigation. Der Riedener Schlamm, nach seiner Angabe, hat das Becken von Laach und von Neuwied über'strönt, über Berge her, wovon der Verfasser sagt, dass sie damals niedriger waren und später erst durch basaltische Ausbrüche erhöhet worden. Dergestalt wird diese Hypothese über geologische Ereignisse, wovon keine Spur zu finden ist, bis S. 50 durch- 
geführt. Warum die Ursachen zu Rieden suchen, welche in der Nähe des überströmten Terrains, im Hochstein, im Hochsimmer, im Ettringer Bellenberg und Kottenheimer Büden, in den den Laacher See umringenden erloschenen Vulkanen zu finden sind $\$$ - Die Verschiedenheit der Tuff-Arten (in deren Beschreibung man dem Autor gerne folgt) deutet auch auf verschiedene Ursprünge, welche wirklich nachgewiesen werden können. - In meiner Schurift bemerkte ich, dass die Gegend von Rieden vorzugsweise den westlichen Wasserfluthen ausgesetzt war. Dieses wird auch durch die Karte, welche dem Werke vorangeht, bestätigt: denn westlich erblickt man keine tufaceous Deposits. - HibBERT nahm davon keine Notiz. Diese Fluthen passen nicht in seine Theorie. Auch hat er des jüngeren Sandsteins, der in sehr beträchtlichen Massen, von vulkanischen Gebilden umgeben, ansteht, nicht im geringsten erwähnt (ausgenommen in der aus meiner Schrift übersetzten Stelle, da doch dessen Bildung zu den Perioden gehört, welche er geschichtlich abhandelt, und die Sache geologisch bedeutungsvoll ist).

7) Einiges über die früheren basaltischen Ausbrüche, welche rings um das Riedener Becken statt hatten: - Wahres und Hypothetisches durcheinander. Ungeachtet einer eigenen Weitschweifigkeit hat der Verfasser doch seinen Nachfolgern auch über Rieden eine reichliche Nachlese und Vieles zu berichtigen überlassen.

Die pittoresken Ansichten: the Oen tone Quaries of the Gïnsehals, the valley of Rieden from the West, idem from the South East verrathen das nämliche leichte und schöne Talent, das wir bei der Ansicht vom Laacher See schon anerkannt haben.

In Kap. 7, S. 57 u. f. beschreibt der Verfasser zwei Kratere, wo ich gewöhnliche Gebirgsvertiefungen zu sehen glaubte, nämlich einen Krater von Fusel und einen von Wehr. Er begleitet die Beschreibungen mit seinen Нypothesen, wobei die kochenden Schlammkessel nicht fehlen. 


\section{$-152-$}

Ans der Beschreibung selbst erhellet, dass alle Merkmale dieser angenommenen Kratere, wenn sie je bestanden haben, verschwunden sind. Überhaupt hat der Verfasser die Kratere meist in den Niederungen gesucht, während ich sie da suchte, wo sie durch erhobene Kegel, verschlackte Kränze, oder andere positive Merkmale von Ausbrüchen bezeichnet werden. So habe ich in der Gegend von Fusel, den Engelskopf in Verbindung mit dem Schorkopf für den Vulkan gehalten, welchem hauptsächlich die vulkanischen Produkte derselben zuzuschreiben wären. Bei Wehr fand ich den merkwürdigen Mangeleibchenskopf, den ich als Beherrscher der dortigen Vulkanität angesehen habe. Untergeordnete Punkte trifft man vielleicht im Hüttenberg und Gillenberg, und eine Mitwirkung im Beller Rothenberg.

Im S Kapi., S. 68 werden einige basaltische und trachytische Erhebungen Volcanos genannt; auch kommen sie unter der Benennung Eruptions vor: eine wahre Sprachverwirrung.

Den Krater zu Boos hat der Verfasser S. 74 sehr vergrössert.

In so ferne die Ablagerungen des plastischen Thons aufgedeckt sind, hat man dieselben überhaupt sehr unregelmässig gefunden, und selbst bei sehr kleinen abgeschiedenen Anhäufungen oder Bänken. Dieses hält den Autor nicht ab ( $\mathbf{S}$. 80, 151), den hypothetisch mit Trümmern, Trahyt-Gängen, Tuff - und Sand angefüllten enormen Krater des Laacher See's, in letzter Instanz durch eine sehr regelmässige Ablagerung von plastischem Thon zu decken, welche er selbst über den ganzen Neuwieder Kessel ausdehnt.

Nachher zürnte der alte Krater über diese fremden Gäste, - warf sie heraus, weit und breit, so dass keine Spur von ihnen überblieb, - und gab sich, abgemattet, den Wasser-Fluthen preis.

Ist es zulässig, beim Vorfinden einiger isolirten Anhäufungen eines Gebildes, diese als die Überbleibsel von einem 


\section{$-153-$}

ehemaligen Ganzen anzunehmen, wenn keine Beweise einer Tremung von diesem Ganzen, noch die geringste Spur von dessen ehemaliger Existenz vorgefunden werden? - Verlangt man im Nenwieder Kessel einen Beweis einer kleinen abgesonderten Anhäufung von plastischem Thone, so betrachte man den, der in der Hohl bei Obermennich zu Tage kommt. Obschon nur wenig aufgedeckt, kann man aus den Ungebungen schliessen, dass hier keine beträchtliche Ablagerung zu vermuthen ist.

S. 96 wird das Roddermaar vulkanisirt und soll gasförmige Flüssigkeiten ausgestossen haben. Strininger sah hier gar nichts, was an Vulkanität erinnert; er sah die Sache so, wie sie sich wirklich verhält. Das Rodder Maar ist eine an sich geringe Vertiefung in einem Grauwacke-SchieferRücken. Merkwürdig genug ist es, dass dieselbe ein Wasserbecken bildet, da nicht weit davon ein Bach in einem bei 200 Fuss tiefen Thale strömt, welches diesen Gebirgsrücken vom Olbrücher Hügel trennt.

Der Kraterkranz des Bausenbergs ist oberhalb eines Lavastromes gebrochen (égueulé, échancré). Warum sucht man denn noch als Ursprung dieses Stromes nach einem ausserhalb des Kraters gelegenen Punlite: Man sehe meine Schrift S. 14. - Warum ist die Lava nicht in die SeitenThäler geströmt؟ Das eine oder andere wäre der natürliche Weg, nicht der Gebirgsrücken, worauf er sich befindet, wenn diese Thäler bei seiner Ausströmung schon gebildet waren. Sie sind also von einer spätern Entstehung als der Lava-Erguss, der durch spätere Ereignisse sehr zerstückelt ist.

Wer die Hibbert'sche Beschreibung des Herchenbergs S. 9S liest und diese mit derjenigen, welche S. 32 meiner Schrift vorkommt, vergleicht, muss über die Verschiedenheit der Auffassung des nämlichen Gegenstandes erstaunen. Am ganzen Herehenberg ist nichts von einem Krater zu sehen, es sey denn, dass man einen verlassenen Steinbruch dafür halten will. - Ich habe die stratificirten vulkanischen Pro- 
dukte, welche die obere abgerandete Kuppe dieses Berges bilden, als demselben fremd, und durch Wasserfluthen abgelagert, angesehen. Sollten sie aus dem Berge selbst hervorgequollen seyn, dann müssen sie in einem schon konglomerirten, halbverhärteten Zustande unter einem gewaltigen Wasserdrucke, emporgehoben seyn, wobei sie ihren eigenen Krater überdeckten und vergruben. Die abgerundete Form, welche sie über demselben annahmen, kann durch den Wasserdruck erklärt werden: aber woher die sehr deutliche Stratification!- -

Der Steinberg, S. 99 erwähnt, ist ein gehobener Basaltkegel, bei welchem keine Spur eines Lavastroms zu finden ist.

Der Autor sagt S. 105 : „Es ist kaum nöthig zu bemerken, dass überall, wo grosse Volumina elastischer Gasarten sich. durch Vulkane entluden, grössere oder kleinere regelmässige Kratere gefunden werden, deren Wände gänzlich oder zum Theil aus den lockern Stoffen zusammengesetzt sind, welche ich beschrieben habe."

"Aber bei anderen Ausbrüchen, welche öfters SchlackenHügel oder Schlacken-Kegel genannt werden, ist durchaus kein regelmässiger Krater zu bezeichnen. Es ist unterdessen gewiss, dass eben aus diesem Gebilde elastische Flüssigkeiten sich fiei gemacht haben etc."

Wenn man im Rheinischen vulkanisclien Gebiete und in der Eifel jeden Schlacken-Kegel untersuchen wollte, so würde dieses einen Zeitaufwand erfordern, wozu wenige Geologen sich hingeben möehten. Man begnügt sich gewöhnlich mit einigen. Die Schlacken-Kegel, welche ich während meiner Wanderungen besuchte, liessen sich zu vollkommen kleinen Vulkanen mit Kratern restauriren, da ich gewöhnlich an der Stelle der fehlenden Theile Spuren von Versenkungen fand. Indessen untersuchte ich nicht alle, und so bin ich nicht im Stande, in Abrede zu stellen, dass in der Reihe der erloschenen Vulkane, welche der Autor untersuchte, solche Schlacken-Kegel vorgefunden werden hönnen, welche zur Zeit der vulkanischen 
Aktivität nnch ihrer Erhebung bloss elastische Flüssigkeiten aushauchten; doch halte ich sie für höchst selten und bin fast der Meinung, dass diejenigen, welche man beim ersten Anblick als auf sich selbst stehend betrachtet, das ist in der Gestalt aus der Erde gehoben, in welcher sie gesehen werden, sich bei näherer Untersuchung zu einem Theile eines wesentlichen Kraters zurïckführen lassen. - Mir sind nur zwei Beispiele einer Schlacken-Erhebung ohne Merkmale einer Explosion vorgekommen, namentlich in Siegberg und im Wolsberg, nördlich vom Siebengebirge. Diese Berge bestehen aus trachytischen Schlacken und Tuffarten. Vermittelst der lockeren Anhäufungen und der Porosität dieser Gebilde sind, zugleich mit ihrem Emporkommen, wahrscheinlich elastische Flüssigkeiten ausgeströnt. Der Wolsberg wurde später von einem mächtigen Basaltpfeiler durchbohrt.

\section{Der Three-peaked Hill west of the Abbey of Laach,} dessen der Autor S. 108 erwähnt, kann nichts anders seyn, als der Beller Rothenberg, den ich (S. S meiner Schrift) für ein Überbleibsel halte von einem zum Theile versunkenen Vulkane.

Wer die Abschnitte the Eruption of Eitringen (S. 113) und the Lava Field of Kotlenheim and Mayen (S. 114) nit Aufnerksamkeit liest, dem wird die Bemerkung nicht entgehen, dass es den Schein hat, als ob es Dr. Hibiert mehr darum zu thun wäre, die Beobachtungen und Meinungen seiner Vorgänger zu schwächen, als der Wahrheit auf die Spur zu kommen, weil er nichts Geniigendes an die Stelle desjenigen liefert, was er verwirft, und über seine aufgestellten Vermuthungen selbst im Zweifel bleibt, also gar nichts aufklärt. Jeder, der Gelegenheit findet, seine Beschreibung mit dem Terrain zu vergleichen, wird nicht leicht seine isolirten Schlackenkegel, welche durch kleine unabhängige Öffunngen gasartige Flüssigkeiten, vulkanische Asche, Lapilli und Schlackenblöcke ausstiessen, in Schutz nehmen, sondern sich rom Zusammenhange der dortigen Schlacken- 
Wïnde und Kegel ubberzeugen. Die Formen fallen an Ort und Stelle zu deutlich ins Auge, und es ist unnöthig, dieses auf graphische Art zu versinnlichen. Das einzige, was ich bei näherer Ansicht meiner Beschreibung (S. 41) zu änderen habe, könnte seyn, dass ich die Himmelsstriche genauer hätte angeben können. Westlicher und östlicher Theil wird wohl nordwestlicher und südöstlicher Theil werden müssen, und so auch statt von N. nach S. von N.O. nach S.W. der wahren Erstreckung näher kommen.

Mit dem Mayener Lavastrom, wird es sich wohl so verhalten, als andere und ich angegegeben haben. - Alles deutet hier auf einen ursprünglichen Kraterkranz, der sich in N.O., aber hauptsächlich S.W.; geöffnet hat, um einem gewaltigen Lavastrom den Weg zu bahnen. Geübte Geognosten werden diese Ansicht nicht missbilligen.

Wenn einmal die Rheinische und Eifeler Vulkanität genauer untersucht wird seyn, als bisher geschehen ist, muss, meines Erachtens die Überzeugung, dass sie von einem sehr hohen geologischen Alter ist, mehr Feld gewinnen. - Man findet Lavaströme durch Thalbildung zerrissen, andere, welche die Thäler wïrden bedeckt haben, welche neben ihnen in gleicher Richtung fortlaufen, wenn diese bei ihrer Ausströmung schon vorhanden gewesen wären. Auch beurkunden viele Lavaströme bedeutende Bewegungen und Zuckungen, welche lange nach ihrer Erstarrung eingetreten seyn müssen. Hierdurch lässt es sich erklären, warum einige Lava-Ströme, nicht mehr in genauer Verbindung stehen mit den Krateren, welchen sie angehören. Alle Lava-Strörne sind bei ihrem Ursprunge weniger mächtig, weil dort nothwendig beim Ausströmen die meiste Geschwindigkeit Statt findet. Spätere Katastrophen, wenigstens so lässt es sich ansehen, sind eingetreten, vor welchen diese schwächeren Theile weichen mussten. Diese Hypothese wird bei vielen alten Vulkanen wohl den Vorzug haben vor derjenigen, durch welche man nach einem tiefer liegenden Schlunde unterhalb des Kraters sucht, weil ein Band gelöst ist, dessen vormaliges Bestehen 


\section{$-15 \%-$}

man nicht vorauszusetzen vermag. Indessen gibt es Beispiele genug von wirklich tieferliegenden Schlïnden, unter andern in den Eifeler erloschenen Vulkanen bei Gerolstein (man sehe meine Schrift S. 13). Bei jedem kommt es auf das lokale Verhalten an. Das Bestreben, dieses wohl aufzufassen, sollte billig immer voranstehen, nicht die auf blosse $\mathrm{H}_{\mathrm{y}}$ pothesen gegründeten Theorie'n, welche man erst dann wagen darf, wenn die anzustellenden Untersuchungen erschöpft sind.

Was den Ursprung der Niedermendiger Lava (116 u. f.) anbelangt, so wünschte ich überzeugende Gründe zu finden, um meine Ansicht (S. S. m. S.) aufzugeben. Ein SchieferHügel, von welchem dennoch der Strom nach dynamischen Gesetzen eine ganz andere Richtung hätte nehmen mïssen, ist dazu nicht geeignet; - auch nicht der Ursprung aus gemer water Spalte S. 119 zu finden, der ausserdem dieses Unnatürliche hat, dass zwei höchst verschiedene Lava-Arten vom nämlichen Ursprung hergeleitet werden. Da nun die Spalte gerade in der Mitte, oder zwischen beiden Lava-Arten angenommen wird, so müsste dieselbe zur Rechten die eine, und zur Linken die andere Art ausgestossen haben.

Die Beschreibung der Niedermendiger-Lava von S. 121 bis $\mathrm{S} .125$, in so fern ich sie zu beurtheilen vermag, ist einige Kleinigkeiten abgerechnet, naturgetreu. Diese aber' passt nur allein auf die Niedermendiger-Lava, und in keinem Theile auf das Basalt-Riff, welches in gebogener Form von Obermendig nach Thür sich ausdehnt, und das unser Verf. doch als zu dem nämlichen Strome gehörig betrachtete. Hätte Нıввеrт dieses Riff untersucht, so wäre er zweifelsohne von vielen I'rthürnern zurückgekommen. Wenn beide Theile identisch seyn sollen, wie muss man es dann erklären, dass es ihm nicht aufgegefallen ist, dass in diesem Riff keine Mühlensteine gebrochen werden. Diese wären da viel leichter zu gewinnen.

Weil die Ungehungen des Laacher See's der Hauptsitz der Haüyne zu seyn scheint, so bestärlkt das häufige 


\section{$-158$}

Vorkommen derselben in der Niedermendiger Lava die Vermuthung, dass der Ursprung dieser in der Nähe des See's zu suchen ist. Im Thür-Obermendiger Basalt-Riff wird man vergebens nach Haüyne suchen.

Da die gehörige Untersuchung des Crufter-Ofens, des Nickenicher Rothenbergs, des Eichersattels mit ihren Dependentien, wegen ihrer Verwickelung vielleicht mehr Zeit erfordern würde, als der Verfasser auf seine ganze Exkursion verwendet hat, so wird man mir wohl zu gut halten, dass ich die beiden (vermeinten) Zurechtweisungen meiner Schrift, welche S. 126 vorkommen, wobei er noch einen bedeutenden Lava-Strom übersah, nicht beantworte.

Alles muss unbedeutend werden, so auch (S. 12S) del Fornicher-Basalt (der Alkenhofer gehört wahrscheinlich zu dem nämlichen Strome); Alles, was einmal ausgebildeter Vulkan war, wird zu einem Schlacken-Hügel, der blos einige elastische Dünste ausstiess, reducirt, - um dem Laacher See in der Vulkanität eine Rolle aufzubürden, die er selbst von sich abweiset.

Das 20. Kap. von S. 129 bis S. 144 erscheint mir der interessanteste Theil des ganzen Werkes. Wenn man einige Hypothesen, welche durch nichts verbürgt werden und auch wenig zur. Sache thun, absondert, so findet man mehrere Beobachtungen und Ansichten, welche das Gepräge des Naturgetreuen tragen.

Untergeordnet bleibt die Frage, ob das Lummerfeld das Äussere eines zugeschlämmten Kraters trage, und ob davon sich Spuren zeigen. Diese, wenn sie gefunden würden, wïren eine schồne Bestätigung der HIBBERT'schen Ansicht über die Trass-Bildung im Brohlthal. - Auch scheint mir der Basaltstrom von den Kunhskïpfen nach Glees zweifelhaft. Wenn ich mich des Terrains genau erinnere, so müsste dieser Strom zun Theil bergangegangen seyn. Wahrscheinlich 
hat man dem Ausgehenden eines Lava-Stromes aus dem Veilskopfe diesen Ursprung gegeben.

Übrigens hat der Autor in diesem Kap. so viel Eigenes geliefert, dass er die Quellen von einigen aus fremden Werken entlehnten Stellen, welche beinahe wörtlich übersetzt sind, wohl hätte angeben können.

Es würde zu weit führen, wenn ich alle Punkte berühren wollte, wo Dr. Hibbert anders sah, als ich. Er versäumte beinahe keine Gelegenheit, um diese Meinungs-Verschiedenheit bemerkbar zu machen. Warum hat er es nicht auch da gethan, wo er vom Bimsstein handelt Hier hatte er wenigstens eine triftigere Veranlassung, meiner Ansicht zu begegnen, da sie von der seinigen zu sehr abweicht.

S. 172 Sekt. II handelt „über den Anfang der Bimsstein-Ausbrüche aus den Humrichen etc., der gleichzeitig ist mit dem Schluss der tertiären Epoche."

Die Ansicht, dass keine basaltischen Ausbrïche mehr Statt fanden, als die tertiäre Periode ihrem Ende nahete, und dass hiermit die Bimsstein-Ausbrüche einen Anfang nahmen, scheint dureh das Vorkommen des Bimssteins begründet; aber diese Ausbrüche überschritten nicht den Rückzug der Diluvial-Überschwemmung.

Warum dér Bimsstein aus Spalten in den HumrichsVulkanen, und nicht aus den Hauptkrateren derselben geworfen seyn muss, begreife ich nicht. Wäre nur eine einzige Spur solch einer Spalte nachzuweisen! - Aus diesen vermeinten Spalten haben nur dann und wann, aber während eines langen Zeitraumes, kleine Bimsstein-Ausbrïche Statt gehabt. Die Form der Bimssteine deutet nach Hiвbert auf solch einen Ursprung. - Sind denn auch die Geschiebe im Rhein durch abrundende Siebe gedrängt - Jede Steinart bricht nach ihrem Gefüge und nach ihrer Textur und verliert ihre scharfe Kanten durch Reibung. Hat der zarte Bimsstein seine Ecken und Kanten behalten, so ist er keinen Reibungen ausgesetzt gewesen.

Vox Bucr (Taschenbuch, Jahrg. 1S21, S. 436) sagt mit

Jahrgang 1836. 
wenigen Worten, aber bedeutungsvoll: - „zwischen Coblenz und Andernach, wo die Lavenströme durch angeschwemmte Bimsstein-Schichten vei-deckt sind ete." Dieses charakterisirt das Vorkommen des Bimssteins am Rhein. Kein Atom Bimsstein gibt es im ganzen Reviere, das nicht durch Wasser niedergeschlagen wäre. Die Ablagerung könnte nicht allgemeiner und auch nicht regelmässiger seyn. Woraus wird denn abgeleitct, dass der Bimsstein nur in kleinen Mengen ausgebrochen sey@ Viel eher lässt sich aus solchen Ablagerrungen auf etliche wenige aber kräftige Ausbrüche schliessen. Die Verbreitung der Bimsstein-Lager deutet auf den Hochsimmer, den Forst, den Ettringer Bellenberg mit den Kottenheimer Büden als ursprüinglichen Sitz der BimssteinEruptionen. Übrigens sehe man meine Schrift S. 45, verbessere aber zuvor die eingeschlichenen Druckfehler.

Die zwei Kapitel 24 und 25 von S. 174 bis S. 205 bewähren, meines Erachtens, meine in Anfang ausgesprochene Ansicht, dass die Zeit noch nicht reif ist, um Geschichten der geologischen Bildungen aufzustellen, sonder'n, dass es mehr Noth thut, dazu Materialien zu sammeln, welche auf richtige Beobachtungen gegrïndet seyn müssen. Die Natur ist regelmässig in ihren Erscheinungen: wer sie beschreiben will, sollte ihrem Beispiel folgen.

Nachdem der Verfasser das Vorkommen und die Ablagerung des Bimssteins vorgetragen hat, folgen: The vavious earlhy or mincral Deposits, which subsisted at the close of the tertiary epoch, worunter the deposit of Travertine, Gerölle or gravel elc., - Loam mixed wilh volcanic matter, the volcanic Sand deposile in the Lake of Neuwied. Nachher wird das Abschliessen der tertiären Epoche durch die Diluvial-Fluth (welcher ein untergeordneter fast lokaler Ursprung gegeben wird) verhandelt; später kommt erst (S. 1S5) der Löss zur Sprache. Will man Geschichte schreiben, so lässt man nicht die Französische Revolution vorangehen, um nachher auf die Reformation zurückzukommen. Der Autor beabsichtigte die Geschichte der geologischen Gebilde 
und Umgebungen yon Neuwied: er snusste sich folglich an die Ordunng des dortigen Vorkommens halten. - Nun sind die Bimsstein-Ablagerungen jünger, als diejenigen des Lösses, und beide jünger als der Travertin, während der vulkanische Sand, Asche, Lapilli in allen Perioden erzeugt seyn können. Dieses macht den Vortrag verworren; man hat Mühe, sich durchzuwinden. Obschon der Verfasser nacher mit Wiederholungen (welche er sehr liebt) $\mathbf{S}$. 207-212 etc. auf den Bimsstein zurïcklkommt, so wird hier die Ordnung nicht hergestellt, vielweniger der Ursprung und die Verbreitung des Bimssteins genïgend erklärt. Diø Winde und Iuftzüge lässt er hier eine Rolle spielen, wogegen ihre Natur am besten spricht; denn sie sind veränderlich und halten nicht den nämlichen Strich, wie die Bimsstein - Ablagerungen.

Dass alle vorweltlichen C'uvier'schen Thiere im Neuvieder Kessel leben mussten, lässt sich denken.

S. 175 finden wir: by this time, also, the greater part of the plastic clay and sand of the basin of Neuwied had been removed, and had undergone a distant transportation.

Wer die Wirkung des Wassers nur einigermaasen beobachtet hat, weiss, dass dieses Element, wenn dasselbe in Bewegung ist, in allen Thonarten den grössten Widerstand findet. Die letzten Rhein-Rectifikationen haben dazu noch neue Belege geliefert. Viel eher gleitet das Wasser über den Thon her, als dass es denselben angreift. Daher wird im Wasserbau häufig der Thon angewendet, um dem Durchdringen des Wassers Einhalt zu thun. Wenn plastischer Thon den Neuwieder Kessel einst bedeckte und derselbe wirklich weggeschwemmt wurde, so muss solches durch eine Stromkraft geschehen seyn, die sich unter keinen geologischen Umständen im Neuwieder Kessel denken lässt. Hier hat das Wasser' nur' deponirt, nicht weggenommen.

Demjenigen, der die Natur auf solch eine Weise auffasst, ist leicht zu verzeihen, dass er die ausgesprochenen 


\section{$-162$}

Meinungen Anderer in einer davon abweichenden Zusammenstellung und in einem verkehrten Lichte vorträgt. Von solch einer Kombination gibt S. 193 ein Beispiel, wo der Autor sagt:

M. De Wyck, in endeavouring to estimate the force of the diluvial current of the Lover Rheinland, has referred the rounding of some of the hills of the Basin of Neuwied to the last cxtraordinary flood, which he conceives to have surmounted the highest volcanic summits, and to have swept over the basin of Neuwied in a direction of west to east. Hence the westerly rounding of the Plaidter Humrichs, the Veitskopf, the Kottenheimer Büden and other hills. He adds that the Correlsberg (by wich, I suspect, he means the Krufter Humrich of other writers) is towards the northwest torn asunder and fallen in; floods of water having carried most of it away, so as even to render its volcanic form doubtful; - and that around the foot of this hill lava blocks lie wildly dispersed, none of them being in the place where their consolidation first took place.

$J$ am by no means convinced of the accuracy of these observations. Although many volcanic hills must have doubtless undergone some alteration in their form from diluvial currents, it is by no means to the extent ascribed; nor is it accurately stated that the direclion of the torrent was from west to east, or that all the volcanic hills shew that in this direction they had yielded to the force of the diluvium. If , for instance, the flood has produced any remarkable effect apon such an cxpcsed volcanic hill as the Hochsimmer, which is doubtful, it is not shewn on its westerly but on its southerly flank; and in the cuse of the Weinberg of Nickenich, the breach of the volcanic hill is not on the west, but un the north-east. Great, therefore, as must have been the force of the diluvial torrent, such slalements as these are evidently incorrect.

Wenn ich meine Übersicht von Anfange bis zum Ende durchgehe, finde ich nirdendswo, dass ich versucht habe, die Kraft der Diluvial - Strömung abzuschätzen. Man ver- 


\section{$-163$}

gleiche die Hibber sehe Anführung mit den Stellen meiner Schrift S. 1S-21, woraus sie genommen zu seyn scheint. Muss man nicht schliessen, dass, wenn er diese Anführung aus seinem Gedächtnisse gemacht hat, dieses ihm sehr untreu war, und dass sein Genius mir Dinge unterschiebt, welche mir nicht, vorzüglich nicht in dem gegebenen Gewande angehören - S. $18-21$ ist mehr die Rede von. den Merkmalen der vormaligen hohen Wasserstände als von der Stromkraft und Richtung. Die Richtung wird erst $\mathbf{S}$. 40 vorgenommen. Von dem Corretsberge wird S. 51 gesprochen, unter der Kategorie der Einstürzungen. Woher denn: He adds etc., als ob es in einem Zuge fortginge $؟$ - Undeutlich wird auch sehr willkürlich mit doubtful iibersetzt. Nach Hibbert war meine Darstellung einseitig, da ich die Sache, zwar gedrängt, aber doch von mehr als einer Seite betrachtete.

Der Autor widerlegt in seinem Eifer Sachen, die meinem Werke fremd sind. Dass Vertiefungen, welche durch Ausbrüche entstanden, wie am Hochsimmer und an Woinberg of Nickenich, nicht den Wasserströmen zuzuschreiben sind, ist einleuchtend.

Die Belege, welche ich für die Strönung der Wasserfluthen von Westen, S. 40-46 zusammengetragen habe, hat der Verfasser nicht gehörig untersucht, und die wichtigsten in der Eifel vorkommenden nicht untersuchen können, denn diese gehören nicht zu dem von ihm gew:ihlten Bezirke.

Es scheint, dass Dr. Hibbert die Ablagerungen des Lösses zu der nämlichen Periode rechnet, in welcher die Ablagerungen des Bimssteins vorgingen.

Dass beim Beschlusse der Löss-Ablagerungen die der Bimssteine ihren Anfang nahmen, wird bestätigt durch das Alterniren dünner Lagen von beiden, da wo die Haupt-Ablagerungen des Lösses aufhören. - Dennoch kann zwischen den ersten Ablagerungen des Lösses und der letzten des 
Bimssteins ein sehr grosser Zeitraum liegen, der noch viele andere Naturereignisse in sich verborgen hält.

Der Löss kann sehr wohl unter Wasserströmungen aus dem Süden gebildet seyin, während bei den Haupt-Bimsstein-Ausbrüchen andere Strömungen Statt fanden.

Wenn man erwägt, dass in der grossen tertiären Periode mehr als eine organische Welt untergegangen ist, so bleibt Raum übrig, einige in sich verschiedene BildungsZeit-Abschnitte zu ordnen. Dieses kïnnte vielleicht das Resultat werden einer zu wünschenden näheren Entwicklung der Klöden'schen Theorie. Die Wasser-Pedeckungen werden darin wahrscheinlich die meist befriedigenden Erklärungen und Erlăuterungen finden. Indessen ganz ins Reine kommt man schwerlich damit. Hier offenbart die Vergangenheit sich nur durch Zeugen, die nicht sprechen und zum rechten Verständnisse mehr als gewöhnlichen Scharfsinn erfordern.

Die Art, auf welche Dr. Hibbert S. 204 und 205 die Rheinenge bei Andernach durch Löss abdämmt, streitet gegen alle Erfahrungen, welche bis jetzt über den Lauf des Wassers genacht sind. Man kann sich das Wasser nicht anders als stark von Löss getrübt vorstellen, wobei die Fluissigkeit des Wassers jedoch in seiner Integrität bleibt. Ist solches Wasser in einer strömenden Bewegung, so deponirt es uberall, wo der Strom abnimmt, also in allen Erweiterungen der Strombahn. Überall, wo diese enger wird, da vermehrt sich die Schnelligkeit des Stromes, was allen Niederschlag hemmt. Wemn der Andrang gross wird, kanm diese Vermehrung eher zur Erweiterung des Engpasses mitwirken. Löss ist nicht das Material, welches im Stande wäre, eine Andernacher Enge zu verschliessen. - Das einzige Denkbare hier'zu würde seyn, dass der Neuwieder Kessel ${ }^{\ulcorner}$mit einer starken Eisdecke belegt, diese beim Aufbrechen so viele grosse Eisschollen vor und in dem Engpasse aniäufte, dass dadurch eine Eis-Abdammung zu Stande kam, welche mit dem Aufthauen des Eises ge- 


\section{-. 165}

löst werden musste, folglich von lieiner Daker seyn konnte. Auch kann man sich von Löss keinen haltbaren Damm im Rheine denken. Ist diese Abdammung nöthig, um die geologischen Ereignisse im. Neuwieder Kessel zu erklïren@ Keineswegs.

Wo ich einen Krater sah, machte Dr. Hibbert daneben eine Spalte und findet (S. 206) die Frklïrung meiner Ansicht exceedingly perplexed. Wenn ich nun seine geologischen Doctrinen eben so finden möchte, sind wir dann auf dem Wege zur Klarheit zu kommen@ Gar nicht. - Ich werde versuchen, melı. Deutlichkeit in den Vortrag meiner Ansicht zu bringen:

Von Obermendig nach Thür dehnt sich ein gebogenes Basalt-Riff aus. An der konkaven Seite ist es steil und abschüssig, an der konvexen Seite herrscht eine flachere $\mathbf{A b}$ dachung. Die konkave Seite trägt alle Spuren eines gewaltigen Abbruches. Will man das Abgebrochene ergänżen, so finde ich kein anderes Mittel als das, welches ich S. 51 meiner Schrift angedeutet habe. An gehobenen Basalt ist hier nicht zu denken; viel weniger daran, dass dieser Basalt mit der Niedermendiger Lava einen gleichen Ursprung haben sollte.

In 30. Kapitel S. 229 entwickelt der Verfasser zum vierten Male (m. s. S. 16, 75, 185) seine Theorie über den Strom der Gewässer von Bingen ab in suidlicher Richtung und wie dieser Strom sich gewendet hat. Die dazu gehörigen Skizzen, wobei die Pfeile die Sache recht evident machen (!), fehlen auch hier nicht. Er muss seinen Lesern wenig Gedächtniss zutrauen, dass er solche Wiederholungen für nöthig erachtet. - Willkommen ist mir hier seine Bemerkung (S. 231): But our history now draws near to a close. Hier breche ich ab; denn das Übrige, was sich noch hätte bemerken lassen, ehe man zum Schlusse S. 261 gelangt, ist von keinem erheblichen Interesse für die Geologie*).

") Man sche aucb Gütt. gel. Anz. 1835, S. 1795. 


\title{
Weitere Nachrichten
}

über

\section{die Hessberger Thierfärten, von}

\author{
Hrn. Prof. F. S. VoIG'T
}

zu Jena.

Eiu Schreiben au den Geheimen-Rath v. Leosirard.

(Hiezu Tf. III.)

Als ich Ihnen im Februar v. J. 'meine erste briefliche Notiz") zusandte, war mir noch kein Urtheil anderer Naturforscher über diesen Gegenstand zugekommen. Ich kannte nur das Sickler'sche Programm mit der lithographirten Abbildung, und besass die erwähnte Steinplatte von Hildburghausen.

Seitden habe ich Gelegenheit gehabt, die in verschiedenen Zeitblättern dariiber gemachten Anzeigen und Urtheile zu lesen, vorzüglich aber mich selbst an $0 \mathrm{rt}$ und Stelle zu begeben, die meisten dort befindlichen Exemplare zu betrachten, auch in den Steinbrüchen hintér.Weitersrode selbst dem Brechen beizuwohnen und der bewussten Spuren mel-

*) N. Jahrbuch 1835, III. Heft, S. 322. 


\section{$-167$}

rere aufdecken zu sehen; so dass ich, wenn es dessen noch bedürfte, die Wahrheit der Erscheinung nun auch noch als Augenzeuge zu bekräftigen im Stande seyn würde.

An erfreulichsten war es mir aber, theils dort im Bruch, theils durch die Güte des Herrn Bauinspektors Buck mehrere sehr schöne Exèmplare zum Geschenk zu erhalten, so dass ich jetzt zusammen gegen 8 Zentner Steinplatten, worunter sechs vorzügliche, sämmtlich verschiedener Art, in meiner Sammlung aufstellen kann.

Mit Herrn Consistorialrath SickLer befuhr ich die ganze Gegend. Er machte mich insbesondere darauf aufmerksam, dass der Höhenzug des bunten Sandsteins, in welchem die Steinbrïche liegen, sich in einer Länge von eilf Meilen bis über Schleisingen hinaus erstrecke. Man sieht diesen Zug ziemlich parallel dem höheren Hauptgebirge des Thïringer Waldes entlang, in einigen Meilen Entfernung von demselben. Dass es wirklicher bunter Sandstein sey, beweist sich schon durch den überlagernden Muschelkalk und durch unmittelbare Verfolgung vom Urgebirge her. Übrigens hat sich auch meines Wissens nie ein $\mathbf{Z}$ weifel dagegen erhoben.

Der herrliche Blick von den Höhen des der Stadt Hildburghausen gegenüberliegenden Stadtberges, theils südlich nach Coburg und weiterhin südwestlich bis in die Gegend des Mains, nebst den Basaltkegeln bei Meiningen, andererseits über die Werra nach Thüringen hinüber, lässt allerdings der Phantasie weiten Spielraum zur Bildung einer Hypothese über die Katastrophen, welche zur Zeit jener vorweltlichen Geschöpfe Statt gefunden haben können. Soviel scheint gewiss, dass die Fläche, auf welcher sich die eingedrückten Spuren der Tatzen finden, also die wahre Ebene, worauf sie gingen, ganz gelinde nach dem Waldgebirge zu ansteigt, und dass es immer ein und dicselbe ist, welche sie enthält*). Ob dieses Ansteigen, wahr-

*) Es hatte sich nämlich, weil man auch Abdrücke in einem cinc Stunde davon entfernten höheren Steimbruche gefunden, dic 
scheinlich vom Ufer aus bis zum Gebirge, eine Folge der Hebung des letzteren, - oder ob die Urgegend iiberhaupt geneigt gewesen - scheint sich für jetzt noch nicht ausmitteln zu lassen.

'Ich übergehe hier eine weitere Beschreibung des Steinbruchs eine Viertelstunde hinter dem Dorf Weitersrode, da sie im SickLer'schen Programme ausführlich gegeben ist. Seitdem habe ich erfahren, dass man, bei erweitertem Brechen, immerfort auf solche Fährten stösst.

Die Vorräthe, welche zur Zeit meiner Anwesenheit in Hildburghausen (Anfang Juni v. J.) gesammelt waren, bestanden vornämlich in :

1) der Originalplatte, nach welcher Hr. Kessler die Lithographie zu dem Sickler’schen Programm („Sendschreiben etc.“) gefertiget, in herzoglichen Schlossgebäude aufgestellt;

2) einem sehr grossen. Exemplar (die grössere Tatze soll 22" haben) im Besitz des Herrn O. L. R. Nonne, welches, soviel ich mich erinnere, dem hier Fg. 1 von mir abgebildeten gleicht;

3) dem grossen Vorrath bei Hrn. Maurermeister WivZER, in dessen Hause aufgestellt;

4) Den sehr grossen Blöcken und Platten im Bauhof, bei Hrn. B. I. Buck;

5) den Exemplaren im Steinbruch selbst; und

6) einzelnen bei verschiedenen Liebhabern in der Stalt, die ich jedoch nicht alle gesehen.

Ich gehe jetzt zur Betrachtung dessen über, was mir die Untersuchung einiger dieser Abdrücke geboten hat. Es ist dabei meine Absicht, nur meine Meinung auszusprechen. Nur durch gemeinschaftliche Thätigkeit lässt sich volle Aufklärung erwarten. Indem ich daher jede andere Vermuthung auf sich beruhen lasse, kamn ich nur nicht bergen, dass ich

Meinung verbreitet, als wiederholten sie sich in verschiedenen Höhen übereinander. In Hiidburghausen hat man dicss nic behauptet. 
die Annahme, als seyen es Fährten von Beutelthieren, immer noch nicht theile. Demn erstens ist hierfür noch nirgends ein Beweis vorgebracht worden, und zweitens haben wir ja offenbar Thiere mit vier Händen, also Guadrumanen, vor uns, und keine Pedimanen*). Ich habe auch schon in meiner früheren Mittheilung angeführt, dass weder die Abbildungen der letzteren in Cuvier's Mammifères, noch auch die Exemplare unseres hiesigen Museums - die einzigen, die mir bis jetzt zum Vergleich offen standen - damit Ähnlichkeit zeigen.

Von wirklichen Knochen hat sich bis jetzt, meines Wissens, auch noch keine Spur erhalten. Das Exemplar, dessen ich in meinem Schreiben an Sie erwähnte, und wovon mir Hr. Sickler eine Erinnerungs-Zeichnung gesandt, ist weg, und ein anderes, was ich betrachtet, zeigt zwar allerei Figuren, aber wahre Knochen auch nicht.

Nachdem ich nun im verwichenen Sommer auf alle Weise versucht, mir weitere Mittel zur Auflklärung zu verschaffen, erfuhr ich Anfangs September, dass sich bei $W e i$ mar eine Menagerie wilder Thiere befinde. Ich eilte daher am ersten mir freien Tage - leider wusste ich nicht, dass es gerade der letzte war, wo sie gezeigt wurden - hiniiber. Schon durch mehrere Erfahrungen belehrt, dass die Besitzer nie eigene Versuche mit ihren Thieren anzustellen erlauben, hätte ich doch hierzu die Anfrage gewagt, wenn nicht bei der damaligen ganz ausserordentlichen Dürre weit und breit un den Vogelschiessplatz, wo sie aufgestellt waren, der Boden dermassen hart und trocken gewesen wäre, dass es mir nicht einmal gelang, auch nur von meinem eigenen Fusse die Sohle einzudrücken. Ich begnügte mich daher, einen Wärter zu veranlassen, dass er den Thieren ihre Sohlen herzeigen liess, und konnte so, trotz der Störung durch die Schaulustigen, mehrere, wemn auch nur eilige, Zeichnungen, die wenigstens im Umris s genau waren, abnehmen. Ich 


\section{$-170$}

theile hier eine vom rechten Hinterfuss eines jungen Mandril (B), und den Umriss einer Bären-Sohle (A) mit. Letztere hätte ich gewünscht, noch mehr ausführen zu können: allein das Thier bielt nicht still, und ich hatte überhaupt meine Intention mehr auf Affen, als auf Bären gerichtet. Ich bedaure diess jetzt um so mehr, als ich jetzt glaube, hiezu ein Original gefunden zu haben.

Fig. 1 der III. Tafel stellt nämlich einen Block von 50 Rheinländische Zoll Länge, 11-12" Breite und 2" Dicke dar. Es ist ein dichter, fester, feinkörniger Sandstein von gelblicher Farbe, aus dem eine Stunde über dem Hessberger liegenden, von mir nicht besuchten, Steinbruche. Seine Oberfläche ist sehr uneben und enthält mehrere $\mathrm{Ab}$ drüicke. Zueist (a) einen schönen, über anderthalb Zoll hervorstehenden, grossen Tatzen-Abdruck eines offenbaren P I antigraden mit deutlich zugerundeter Ferse und Krallenspuren. Das Thier muss in weichen Boden getreten seyn, da die Ballen tiefe Löcher, wie durch emporgehobene Kothklumpen entstanden, zeigen, ähnliche Ausfressungen auch noch an anderen Stellen sichtbar sind. So zeigt die innre Zehe nur den Umriss; es fehlt ein Stück an der Seite, die grössere Hälfte ist aber deutlich konvex vorhanden. Der Rand der äusseren Zehe ist beim Brechen verloren gegangen, es ist daher auch nichts von einer fünften Zehe zu sehen, wemn anders eine dergleichen vorhanden war. Queer über die halbe Sohle läuft eine erhabene Leiste, wie deren mehrere anastomosirende zu sehen, und die ich noch immer, wie alle jene für Pflanzen ausgegebene Spuren, für Abdrücke von Rissen halte. Ich besitze solcher netzartiger Figuren auf mehreren meiner Steimplatten, und habe ihrer in Menge an Ort und Stelle verglichen. So lange ich aber mit Pflanzen umgegangen bin, ist mir noch nie ein Vegetabil vorgeliommen, welches, in so weiter Verbreitung wie diese, lediglich nur horizontale Äste, und nie mit einer Spur vertikaler Wurzeln oder Stengel gezeigt hätte. Ich habe zwar im vergangenen Sommer viele unterirdische Sprossen von 
Sparganium ramosum in Schlamm unserer Saale gefunden, die, dicken Spargeln gleich, wohl den Vertheidigern jener Hypothese willkommen seyn würden. Allein erstens lagen sie nicht oberflächlich, sondern mehrere Zoll tief, zweitens hatten sie stets an ihren Knotenstellen reichliche Wurzeln nach unten und Halmsprossen nach oben, und drittens anastomosirten sie nie! und ich möchte auch wissen, wie sich eine Anastomose queer von der Mitte eines Stabes zum andern (wie der Queerbalken im Buchstaben $\mathbf{H}$ ) bilden sollte $\$$ Auch dürfte ein Auftreten auf solche Netze die Führten mehr verändert haben, als der Fall ist*).

Ich glaube nun nicht zuviel zu wagen, wén ich jene grosse Tatzen-Spur $(\alpha)$ für die eines Bären, vielleicht gar des berühmten Ursus spelaeus selbst, anspreche. Die Ähnlichkeit mit dem Umriss einer Bärensohle Fg. A ist in der That auffallend genug, und die grössere Breite könnte sich aus dem tieferen Eintreten erklären.

Die Länge dieses Abdruckes ist genau 12", die grösste Breite S". Er steht über $1 \frac{1}{2} "$ vor.

Neben ihm ein anderer, gerade halb so grosser (b), von höchst sonderbarer Form, den ich mich nicht zu deuten getraue. Man möchte (im Scherz) versucht seyn, an einen kolossalen Laubfrosch zu denken; denn auch die schiefe Fingerstellung hat etwas Amphibisches. Drei kugelrunde Ballen (wovon der mittle etwas abgesplittert) verlaufen sich in eine Fläche, als wenn es Schwimmhaut wäre. In der Mitte bildet sich ein erhabener, aber flacher Ballen, und von da geht er in eine lange Sohle aus. Die Länge dieses.

*) Indess will ich nicht unterlassen, eine Stelle aus einem Schreiben des Herrn Bauinspektors Bucr an mich anzufüliren. „Ich fand gestern eine Ranke in der Thonschicht, die auf eine gewisse Länge mit dem Stein so verwachsen war, wie bekannt ist; dann aber wurde die Thonlage mürber, magerer, ich möchte sagen staubiger, und die Ranke lag darin, obne dass sic den Stein berührte, ringsum von Thon ungeben etc." Auch sey sie gewunden gewesen, aber nachmals zerbrückelt u. s. w. 


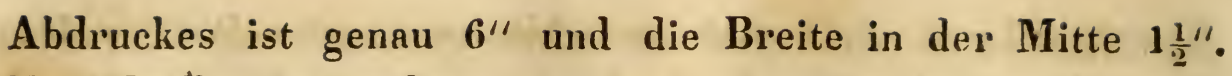
Von Krallen keine $\mathbf{S}_{\mathrm{i}}$ ur.

Über demselben, am oberen Rande, überhaupt aber am ganzen oberen Theil der Tafel, auch hie und da seitwärts, zeigen sich noch viele kleinere, meist sehr undeutliche, Fährten. Ich habe nur eine, die vollkommenste, oben rechts ausgeführt. Sie sieht, oberflächlich angeschaut, einem Tannenzapfen ähnlich, genauer betrachtet, möchte ich sie aber für den schuppigen Fuss einer Schildkröte halten.

Ich verdanke dieses und das folgende Exemplar dem Herrn Buck.

Fg. 2 ist eine $1 \mathrm{~S}^{\prime \prime}$ lange, $15^{\prime \prime}$ breite, $\mathbf{2}^{\prime \prime}$ dicke behauene Platte von ziemlich ebener Oberfläche, aus dem bekannten Bruch hinter Weitersroda. Es ist derselbe Sandstein, der auch die zuerst bekannt gemachten Abdrücke enthält. Er ist chloritisch grünlich, voll grüner Pünktchen, auch etwas Glimmer enthaltend, und von hartem, etwas grobem Korn. Er blättert sich hin und und wieder schieferig.

Das hier abgebildete Exemplar zeigt einen sehr grossen Abdruck von 10 $\frac{1}{2}$ "Länge und 6 " Breite einer Hinterhand mit einem über einen Zoll herausstehenden flachgewölbten Daumenballen. Er ist nicht scharf begrenzt, die Oberfläche ist, zumal an den Fingern, schiefrig abgesplittert, und die zwei äusseren sind sichelförmig gebogen. Nägelspuren bemerkt man nicht. Davor steht die kleinere $\mathrm{Pfote}$, gleichfalls mit nach derselben Seite gerichtetem Daumen, und ganz in derselben Stellung und Entfernung wie bei den von Sickler bekannt gemachten. Wenn man daher mit demselben Thiere zu thun hätte, mit etwa einem auf dem nassen Letten abgeglittenen Eindrucke, so dürfte diess sehr zur Vorsicht beim Deuten anrathen*).

*) Wie leicht man sich täuschen kann, habe ich vor wenigen Monaten zu bemerken Gelegenheit gehabt. Auf alle solche Eindrücke jetzt aufmerksam, beobachtete ich vorigen Herbst auf der staubigen Landstrasse zwischen viclen gut ausgedrückten nackten Menschenfüssen auch scharf ausgepresste solche, wie ich sie Fig. C mittheile, 
Mit Fg. 3 wollte ich nur eine vergleichende Abbildung von der im vorigen Frühjahr empfangenen grossen Platte geben; das Quadrat ist daher nur ein Ausschnitt derselben: Hier zeigt sich die Hohlung der Hand, welche auf ein greifendes, wahrscheinlich auf Bäumen kletterndes Thier deutet. Der eine Nagel liegt queerüber, eine sonderbare Anomalie, die ich bei keinem andern Exemplar bemerkt, welche daher ein Zufall seyn kann.

Ich habe hierzu, zum Vergleich, die Hinterhand eines jungen Mandril, Fg. B, gezeichnet, wie ich 'sie nach dem Leben aufgenommen. Allerdings sind die Stein-Figuren viel plumper: es kann ja aber eine andere Gattung gewesen seyn; iberhaupt ist wahrscheinlich, dass das vorweltiche Thie. nicht mehr lebend existirt.

Dass kein Affe in Lauf die Ferse aufsetzt, also dann stets digitigrad ist, wird noch von Desmarest im Art. Singe des Dictionnaire des Sciences naturelles p. $\mathbf{2 6 6}$ ausdrücklich bemerkt.

Betrachtet man die Abbildungen des hochbeinigen jeune Mandril, des Babouin, der Simia sinica und vieler anderen in Fr. Cuvier Mammifères, so wird die Ähnlichleit der Grösse der Tatzen und ihrer Stellung gewiss auffallen. Die Opossum desselben Werkes haben dagegen vorn stets fünf gleichstehende Finger, mit fünf krummen Krallen, wovon gewiss die des Daunenfinger's im Abdruck sichtbar seyn würde.

Übrigens wiederhole ich, dass ich keiner andern Erklärung entgegen bin, sobald sie mehr als blosse Meinung und auf irgend einen Beweis gestuitzt ist, von dem mil bis jetzt noch nichts bekannt geworden. Es gibt ja anderwärts so viele Gelegenheit, die Sohlen und Fährten fremder Thiere

die mich Anfangs stutzig machten. Bald aber fand ich, dass sie von, in blossen Füssen gelienden Weibern, zumal Bauernweibern, herrührten, deren Tritte icb nachher öfter verfolgt habe. 
zu untersuchen, dass wir gewiss bald einigen Zeichnungen und Beschreibungen derselben entgegensehen dürfen.

Schliesslich kann ich mich auch der Bemérkung nicht enthalten, dass es mir wahrscheinlicher ist, diese natürlichen Fährten seyen zuerst durch einen trocknen Flugsand überdeckt, und nicht durch sandhaltige Gewässer überschwemmt worden. Denn letztere hätten wohl schnell die Schärfe der Ränder verwaschen und die Abdrücke undeutlich gemacht. 


\section{Über \\ das Genus Delthyris, von}

Herrn L. v. Buch.

(Aus zwei Briefen an den Prof. Browr.)

Ich habe vor einem Monate eine Arbeit über Delthy$r$ is vorgetragen. Was den Namen anbelangt, so drückten zwar die Englischen Geognosten mir schon in Bonn ihr Bedauern aus, dass man sich in Deutschland eines andern Namens für Spirifer bediere, wodurch die Übereinstimmung mit einer Bezeichnungs-Weise wieder verloren gehe, die in England und Frankireich uun schon einmal eingeführt sey. Das sohien mir sehr begründet, um so mehr als Dalman's Verwerfung dieser Benennung nur auf seichten Gründen und auf dem Umstande beruht, dass Sowerby eine unïberlegte Zeichnung von dem an sich überaus zarten und dïnnen Spiral-Gerüste im Innern gegeben hat, wie es mit Kalkspath-Krystallen bis zur Berührung derselben unter sich iiberzogen, verdickt, und nur eben dadurch erhalten ist. Ich habe mir daher seitdem immer selbst wiederholt, wir müssen zu "Spirifer" zurückkehren; denn sich zu verständigen ist Hauptzweck. Ich habe indess einen Mittelweg eingeschlagen und "Del th y ris" dennoch anzuwenden gesucht. 
Delthyris untersclieidet sich von Terebratula*) dadurch, dass der Heftmuskel bei dieser durch das Deltidium immer mehr vom Schlossrande entfernt wird, bei Delthyris aber sich in Fasern am Schlossrande vertheilt, und häufig von oben herab gegen den Schlossrand zurückgehalten wird. Hieraus eitspringt eine Menge anderer wesentlicher Verschiedenheiten, die ich hier nicht alle aufzählen will. Die gegitterte Area (a, b, e) ist die nächste davon;

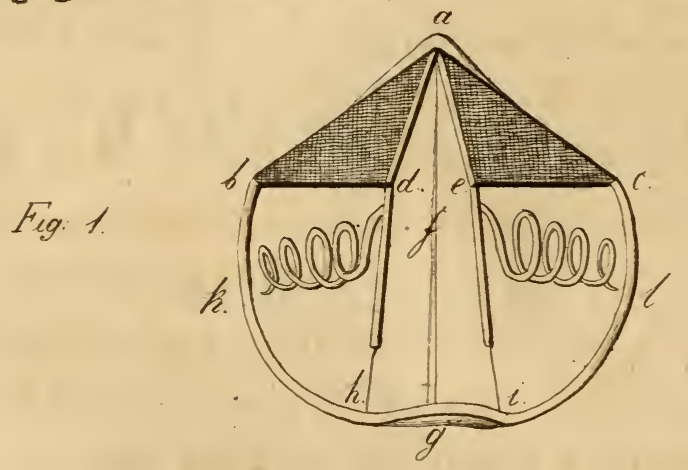

damn die folgenden, wẹlche weit um sich greifen. Die dreieckige ëffunng des Delthyris ist zu beiden Seiten von einer kleinen geraden Leiste (ad und ae) eingefasst: diess sind die beiden von der Area getrennten und mit ihr nur wenig verwachsenen Zähne der Dorsal-Schaale, welche die Hälfte der Ventral - Schaale umfassen und halten. Diese Zäline würden also ziemlich frei stehen und durch die Last der' daranhängenden untern Schaale zerbrechen, hätten sie

*) Herr von Buch bemerkt bei dieser Gelegenheit, dass er meine Vereinigung der T. subsimilis mit T. I a cun os a und der T. pr:mipilaris mit T. Wiisoni nicht billige, wie ich solche gelegentlich der Anzeige seines schönen Werkes über Te rebrateln in diesem Jahrbuche sowohl als in den Berliner Jahrbücher für wissenschaftliche Kritik, und theilweise in der Lethäa vorgenommen. Auch T. digon a und T. viciualis seyen konstant verschie. den. Da er sich auf die schon in seinem Werke angegebenen Grimie beruft, ich aber meine Ansicht rücksichtlich der 2 ersten Falle noch nicht aufgeben kann, so glaube ich ihm wenigstens schubiig zu seyu, seiner Verwahrung hier inzwischen eine Stelle auzuweiseu. Rücksichtlich $S \mathrm{t}$ y gocephalus, Uncites u. a. Arten, schıeibt er, würdeı wir uns verständigen können,

Bronv. 
nicht noch eine Unterstützung. Diese ist in der Terebiatel niemals (was ich $\mathrm{S}$. 69 meines Buches bei T. gr'yphus Gegentheiliges gesagt habe, ist übertrieben). Diese Unterstützung ist nach den ver'schiedenen Abtheilungen von Delthyris verschieden. Bei Spirifer aperturatus besteht sie in zwei senkrechten Lamellen, welche ron der. Spitze der Schaale an von den Leisten ad und a e nach dem Grund der Unterschaale hinab und bis gegen deren Mitte hinein gehen, deren Sinus von beiden Seiten einfassen, und auf dem Kerne, den IIysterolithen, zwei Spalten hinterlassen. Zwischen den Lamellen befinden sich die Ernah. rungs-Organe, durch diese Scheidewände von den Armen getrennt, deren Gerüste daher jene Organe nicht, wie bei der Terebratel, an die Dorsal-Schaale andrücken kamn. Dadurch entsteht es dann, dass bei $\mathfrak{S} p$ irifer der Mantel schou vom ersten Anfange des Schuabels, nicht erst von der Mitto wie bei den meisten Terebrateln an, einsinkt und eine Rinne bildet. Die Arme sind nun genöthigt, sich nach a us sen auszudehnen, mit auseinander gerichteten Ėuden (k, I). Dagegen sind sie in allen bis jetzt untersuchten Terebrateln gegen einander nach innen gekehrt, wie man auch in OwEx's schüner Zeichnung von Terebratula sehen kann.

Bei andern Abtheilungen des Geschlechtes verhält sich die Sache verschieden. Bei Sp. rostratus erreichen die dicken Lanellen fast den Stirnrand bei h und i, verbinden sich jedoch nicht mit dem mittlen Dissepimente fg. - Dagegen geschieht Letzteres allezeit bei $0 \mathrm{rthis}$ und auch bei Pentamerus, Gypidia und Verwandten. Nach allem Diesem theile ich Delthyris auf die Art ein, wie die beigefügte Tabelle ergibt. 
eine dreieckige Öffnung steht mit ihrer Basis auf dem Schlossrand, mit sühligen und mit senkrechten Streifen bedeckt, daher gitterartig gestreift. terstehende Lamellen unterstützt. Die Spiral-Leisten der Arme stehen in

\section{Spirifer.}

Die Dorsalschaale hat in der Mitte eine schon vom Schnabel ausgehende Rinne (dorso canaliculata), die Ventral-Schaale eine entsprechende Wuist, die beiden Unterstützungs - Lamellen der Zähne bleiben nuvereinigt und entfernt.

\section{A la ti.}

Schlossrand so breit oder breiter als die Muschel. Scharfe Ränder zwischen Area und Pücken - Flä he. Unterstuitzungs - Lamellen nicht bis in die Mitte der Dorsal-Schaale.

\section{Rostrati.}

Schlossrand schmäler als die Muschel. Aborerundete Kanten zwischen Area und Rücken - Fläche. Unterstützungs-Lamellen bis gegen den Rand der Dorsal-Schaale reichend.

\section{\begin{tabular}{l|l} 
Osteolati & A perturati
\end{tabular}} mit glattem Sinus. mit gefaltetem SiS. 1. ostiolatus
Schloth.
2. bijugatus
n. Hlississ.
3. pinguis So-
WERBY.

4. Tas mann Fan Diemen.

5. pelargonatu s Schr.

6. cuspidatus Mart.

7. speciosus Schl.

S. distans $\mathbf{S}$. 9. trapezoidaI is Dhum.

10. heterocly$t$ us.

11. cristatus.

12. crispus.

13. comprima$\mathrm{t}$ u s Schr.

14. a $I$ at u s.

15. f rag ilis.

10. trinngula$r$ is MART.
$S$ in u a $\mathrm{t}$. Sinus mit deutlicben Seiten.
I m press i. Seiten des Sinus verlaufen über die ganze Rückenfläche.
* glatte.

S. 1. rostratus. $t$ us.

2. trigonalis.

3. subconicus Mart.

4. a t t e u u a tus Sow.

5. bisulc atus. 6. choristites Fisch.

7. $s$ t riatus Sow.

8. striatiss im us Schr.
2. nucleifor$\mathrm{mis}$.

3. line atus.

4. curvatus.

5. obla tus. gefaltete.

6. Walc ot ti.

7. a c. ut us.

8. octoplicatus.

9. verruco$\mathrm{s}$ us.
Sp. 1. excis us. 2. resupinat us. 


\section{$-179$}

t h y $r$ is,

der Spitze im Schnabel der Dursal-Schaale. Die Area ist zugleich nit Die Zähne der Dorsal-Schaale sind in Innern durch 2 senkrécht darunentgegengesetzter Richtung auseinander.

\section{Orthis.}

Die Dorsal-Schaale ist in der Mitte erhaben, sogar gekielt (dorso curinata), die Ventralschaale ist flach oder konkav. Die UnterstützungsLamellen der Zähne vereinigen sich in der Mitte der Dorsalschaale.

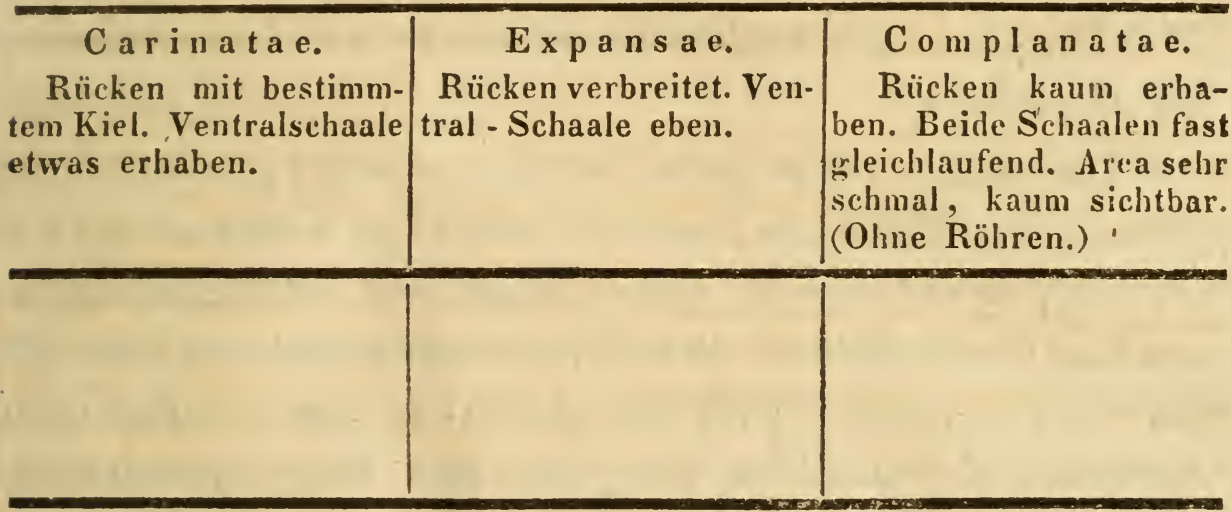

0. 1. c a llactis.

2. calligramma.

3. de mis s a.

4. testudinaria.

3. e l e g a $\mathrm{t} u \mathrm{I}$ a.

6. Lians, Eifel.
0. 1. m in uta.

2. e $u g l y p h a$.

3. zon a t a.

4. transversalis.
L e p t a e $n$ a.

1. rugos a.

2. Martini etc. 
Die Geschlechter Pentamerus, Gypidia u. a. mögen nun selbst zusehen, wie sie unterliommen, oder sich deutlicher entfalten. Was ferner Sie über Strygocephalus, Uncites u. s. w. sagen, ist sehr begründet; der erste hat durch die gegitterte Area offenbar weit mehr Ansprüiche auf Delthyris, als auf Terebratula, und meine neuere Untersuchung hat mir gezeigt, dass die Verwachsung ani Schnabel kein Deltidium ist. Die Gründe jedoch, alle diese Gestrlten zu eigenen Geschlechtern zu erheben, scheinen imir ungenügrend.

Das ganze oder theilweise Zuwachsen der dreieckigen Öfrinung von Delthyris, wie Sie es in der Lethäa bei $\mathbf{C}_{\mathrm{yr}}$ tia trajezoidalis darstellen, hängt von zufälligen Umständen ab, wie auffallend diese Erscheinung auch seyn mag*). lch besitze einen Spirifer aperturatus von Pokroi in Lilhauen, der in nichts von jenen vom Bensberge verschieden ist; dennoch sind diese stets offen, während der erste eine zugewachsene Öffnung hat. Orthis umbraculum in der Eifel ist allezeit zu, in Schweden offen. Dieses Verwachsen geschieht ron oben herab, daher wird der Heftmuskel von der Spitze gegen den Rand herabgedrückt, während bei der Terebratel das Deltidium denselben vom Schlossrande weg und aufwärts drückt. Daher ist die Streifung der verwachsenen Stelle auch von unten konkav; bei dem Deltidium ist sie es von oben. $\mathbf{P}_{\text {Ander }}$ hat die meisten $\mathbf{O}_{\mathbf{r}}$ this-Arten verwachsen gezeichnet; doch auch sehr viele offen. Man erkennt leicht, ob diese Verwachsung ursprünglich ist, und wo sie nie Statt gefunden hat; denn diese Erscheinung ist von den Zähnen der Dorsal-Schaale abhängig, welche sich gegen einander ausbreiten, bis sie zusammenstossen. Ist das Loch offen, so erscheinen, wie oben erwähnt,

-) Zu dieser Ausicht biu ich seither auch gekommen, hauptsächlich durch Untersuchung einer schönen Suite von $S$ pir if e re n aus den: Bergkalk von Turnuy, die ich Hrn. Puzos verdanke.

Brons. 


\section{$-181$}

die Zahnleisten ad und ae; ist es aber verwachsen, so sind diese Leisten zu konkaven Anwachs-Bögen fortgesetzt und

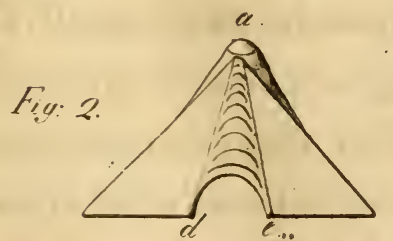

daher nicht mehr sichtbar. Übrigens ist aus Ihrer Darstellung klar, dass Sie selbst Cyrtia wie Atrypa nicht vertheidigen, und $\mathbf{O r}$ this von $S_{p}$ irifer nicht sehr verschieden glauben.

Wie Sie in der Lethäa keinen wesentlichen Unterschied zwischen Spirifer ostiolatus und Sp. speciosus erkennen, so ist es auch mir vorgekommen, dass Ühergänge vom quadratischen $\mathbf{S}$ p. ostiolatus vom Bensberg an bis zu dem $12 \mathrm{mal}$ breiteren als langen $S$ p. triangularis vom Schulenberge, von Clausthal u. s. w. so genau fortsetzen, dass keine Grenze anzugeben möglich ist. Daher halte ich wenig auf solche Dimensions-Verhältnisse, mehr auf die Gestalt und den Zustand des Sinus, welcher durch alle Formen beständig bleibt.

Ich habe meinen Aufsatz mit folgender Betrachtung iiber die geognostische Vertheilung von Delthyris gecndigt: Noch ist es nicht möglich, eine genane und bestimmte Altersfolge in den Arten dieses Geschlechtes nachzuweisen, zum wenigsten so weit es die Transitions-Formationen angeht; doch scheint der Zeitpunkt, in welchem dieses gelingen wird, gar nicht mehr ferne. Schon jetzt sicht es ans, als sey man wohl berechtigt zu glauben, dass in Nllgemeinen Orthis älter als Spirifer seye. Denn Hisinger, der. wie ich glaube, in seiner trefflichen geognostischen Beschreibung von Gothland der erste war, Transitions-Gehirgsarten durch Hülfe der darin enthaltenen organischen Reste in verschiedcne Formationen zu trennen, hat nachgewiesen, dass die ältere Abtheilung auf dem Festlande von Schweden und auf Öland vorzüglich durch eine grosse Manchfaltigkeit 
von Trilobiten und durch 0 rthoceratiten ausgezeichnet wird, die neuere dagegen auf Gotlland durch Enkriniten und Zoophyten. Nun finden sich nur zwei 0 r th is-Arten, welche beiden Abtheilungen gemein wären: O. transversalis und 0 . pecten; die übrigen gehören alle der Trilobiten-Sektion. Dagegen findet sich in dieser nur ein Spirifer; alle übrigen sind dem Enkriniten-Kalke eigen. Das bestätigen noch mehr PANDER's mühsame und nützliche Untersuchungen bei Petersburg (Beiträge zur Geognosie des Russischen Reichs, Petersburg 1S30). Die Hügel, welche diese Hauptstadt ungeben, werden durch Schichten der Trilobiten-Formation gebildet: sie gehören zum $\mathrm{k}$ a mb rischen System. Nun beschreibt Hr. Pander genau 38 Arten Terebrateln mit am Buckel gewaltig aufgebläheter Ventral-Schaale (Atrypa), wie sie den ältern Gebirgsschichten so eigen sind, und nicht weniger als 93 verschiedene Arten yon $0 \mathrm{rthis}$, und alle diese verschiedene Gestalten sind auf 19 Tafeln zum Theile vortrefflich abgebildet worden. Mögen auch sehr viele zu je einer Art zusammenfallen, so wird noch immer eine fast Erstaunen erregende Anzahl übrig bleiben. Unter diesen sind sehr viele von einer Abtheilung, die noch gegenwärtig, ausser durch PANDER's Werk, so gut wie unbekannt bleibt: nämlich die einfach gefalteten Arten; dagegen kennt $P_{\text {ANDER }}$ von den Spiriferen gar keine "geflügelte" in jenen Trilobiten-Schichten, und von andern nur zwei sehr kleine aus der Sektion der "Rostrati sinuati" und zwei aus der Abtheilung der "Rostrati impressi", welche letztere an sich Orthis schon so nahe steht. Damit stimmt nun ziemlich gut die tabellarische Übersicht, welche MURCHIsos über seine Entdeckungen in Wales bekannt gemacht hat. In den ältesten Schichten unmittelbar über den Trilobiten finden sich 14 neue Arten von $0 \mathrm{r}$ th is angegeben, und die geflügelten $\mathrm{S}_{\mathrm{p}} \mathrm{i}$ $r$ if eren sind weit davon nach oben im Alter entfernt. In Deutschland ist das kambrische System gar nicht ausgedehnt, 
und kaum zu finden. Vergebens sucht man es in dem weit verbreiteten Grauwacken- und Schiefer-Gebirge der Ardennen, der Eifel, des Westerwaldes und des Harzes. Von Trilobiten sieht man nur Calymene Blumenbachii, welche allen Formationen gemein ist, und Orthoceratiten fast gar nicht. Um so häufiger ist das Heer der geflügelten Spiriferen am Rheine vom ersten Auftreten des GrauwackenGebirges an der Ruhr bis zu den-Ufern der Nahe. So auch im Harze, zun wenigsten im Oberharze, der gewiss wie das Rheinische Gebirge dem Silurischen System angehört. Gehen wir zu neueren Haupt-Formationen über, so verschwindet Orthis ganz und erscheint auch nie wieder. Der Zechstein, welcher in seinen organischen Produkten so viele Übereinstimmung mit dem Kohlenkalkstein und so durchaus gar keine mit dem ihm viel näher liegenden Muschelkalke besitzt, enthält demgemäss auch wirklich einige $\mathbf{S}$ piriferen, welche völlig die des Kohlenkalks sind: Spirifer trig on a lis, und andere, in denen die Ähnlichkeit doch einmal sehr gross bleibt, wie $S$ pirifer pelargonatus, Sp. cristatus, Sp. heteroclytus u. s. w. - Der Muschelkalk behauptet auch hier seinen sonderbaren eigenthümlichen Charakter. Keines der in ihm vorkommenden Produkte hat Ähnlichkeit mit dem, was ihm vorangeht oder nachfolgt. Nur eine einzige Delth yris - Art ist in ihm aufgefunden worden, freilich auch sehr häufig da, wo sie vorkommt. Es ist $\mathbf{S}$ p. fragilis, der nur sehr entfernt an $S$ p. speciosus des Silurischen Systems erinnert. - Der viel entferntere Lias erscheint in seinen oberen Schichten wieder mit Formen, welche entweder denen in der Grauwacke gleich sind, oder doch mit ihnen in der nächsten Verwandtschaft stehen, als sey die Welt des Muschelkalks gar nicht dazwischen. Nur sind die geflügelten Spiriferen wirklich mit $S$ pirifer fragilis vom Schauplatz abgetreten, der Lias enthält nur Rostraten. Sprostratus ist von dem in der Grauwacke gar nicht verschieden; $S p$. Walcoti $i, S$. verrucosus, 


\section{$-184$}

Sp. octoplicatus haben wenigstens mit $S p$. acutus der Grauwacke sehr viel gemein. Mit ihnen verschwindet diese Form gänzlich von der lebenden Welt: nicht in der Jura-Formation, noch weniger in der Kreide oder in Tertiär-Schichten ist etwas gesehen worden, was an Spirifer erinnern könnte. 


\section{Betrachtungen}

über

\section{die Cephalopoden-Schaten, \\ v 01}

Herrn Voltz.

Blanville bringt in seiner neuen Klassifikation der Cephalopoden diese Thiere in drei Klassen, die Orthoceren, Decaceren und Myriaceren, welche letztere die Ammoniten, Nautilen und Belemniten enthalten. Inzwischen begreife ich nicht, wie man diese drei Genera zusammenstellen könne. Die Belemniten stehen so bestimmt den Decaceren nahe, dass man sie mit ihnen vereinigen muss. Es sind doch gewiss schwimmende, wie die Nautilen wohl Gasteropoden - ähnliche Cephalopoden gewesen sind. Von beiden waren die Ammoniten wieder weit entfernt, wie sich schon aus der Betrachtung des Siphons und der Concamerationen ergibt.

Im Nautilus ist kein eigentlicher Siphon *) vorhanden; die einfachen Scheidewände besitzerr nur Öffnungen in For'm trichterartiger Fortsätze, die mit ihren Spitzen unzusammenhängend ineinanderstecken. Doch geht eine häutige Röhre durch alle diese Trichter hindurch und hängt mit

*) Vgl. Buckuaxd im Jahrb. 1835, S. 631, dessen Aufsatz jedoch Herr VoLt\% wohl noch nicht kenuen konnte.

D. $\mathrm{R}$. 
dem Herzbeutel zusammen, aus welchem die PerdicardialFlüssigkeit eintreten kann. Die Schaale hat zwei MuskelEindrücke, wo das Thier angewachsen ist, und welche begreiflich mit der Verlängerung der Schaale selbst beständig gleichmässig voranrücken müssen. Diess geschieht, indem an ihrem vorderen Rande beständig neue Anwachsstreifen hinzukommen, während an dem hinteren andere durch neue Kalkmasse bedeckt werden. Die Bildung der Scheidewände dagegen erfolgt nur periodisch schnell und hört dann wieder auf längere Zeit auf. Daher muss das an den Muskel-Eindrücken festsitzende Thier sich bald näher, bald entfernter von der letztentstandenen Scheidewand befinden. Schwimmt das Thier aber im Meere, so ist sein Hintertheil in einer gewissen Entfernung von der letzten Scheidewand, und das Wasser"), welches sich mit kondensirter Luft in den Kammern befindet, wird durch diese luft in den Raum zwischen der letzten Scheidewand und dem Thiere getrieben. Die häutige Röhre ist dann in die Länge gezogen, leer, folglich dünne, und füllt lange den Raum der Trichter nicht aus, sonst könnte kein Wasser von der verdichteten Luft aus den Kammern durch die Trichter-Öffnungen in jenen Raum getrieben werden. Will sich das Thier schnell in die Tiefe des Meeres versenken, so drückt es sich durch Stützung auf die Muskel-Eindrücke wieder fest an die letzte Scheilewand an, treibt das Wasser in die Kammern zuriick und die Flüssigkeit des Perikardiums in die Röhre, welche dadurch anschwillt, die Trichter verstopft, und zugleich dem Thiere einen neuen, kräftigen *s) Anhaltspunkt gewährt, wodurch er sich noch fester in seine Schaale einzwängen kann. Diess thut das Thier, sobald es eine Gefahr bemerkt, um sich zu sichern; denn die gänzliche Zurückziehung tief in seine Schaale ist sein einziges Schutzmittel, da es weder

*) Nach Ower sagt Bennet ganz bestimmt, dass die Kammern Wasser enthalten; nothwendiger Weise ist aber auch Luft darin.

*) Die Haut dieser Röhre, an einem Exemplare unscres Museums erhalten, ist ziemlich dick. 


\section{$-157^{\circ}-$}

wie Loligo u. a. Acetabuliferen schnell schwimmen kann, noch den Dintenbeutel der Sepie, um das Wasser zu trüben, noch die Operkeln der Ammoniten besitzt, um die Schaale zu schliessen. Die Mittel dieses Thieres, seine spezifische Schwere schnell zu vermehren und sich in die Tiefe zu versenken, sind daher eben so stark, als nothwendig. Hätte daher Nautilus einen ununterbrochenen Siphon, wie Ammonites, Belemnites und Spirula, so würde ihm sein einziges Schutzmittel abgehen.

Die Ammoniten müssen eine sehr verschiedene $\mathbf{O r}_{\mathrm{r}}$ ganisation gehabt haben. Zwar ist ihr Sipho ununterbrochen, wie in Belemnites, Orthocera und Spirula; aber er ist randlich, ungegliedert, zusammenhängend und von den Scheidewänden unabhängig, - bei jenen vielgliederig und aus ineinandersteckenden Trichtern zusammengesetzt, deren jeder ein unmittelbarer Theil einer Scheidewand ist. Auch das Operkel der Ammoniter (Aptychus v. Meyer) und ihre viellappigen Scheidewände deuten auf eine Organisation, welche von der des Nautilus eben so verschieden, als von jener aller andern Cephalopoden gewesen ist. Das Thier hatte nämlich gewiss auch einen Fuss, wie die Gasteropoden, was der Deckel ganz dẹutlich zeigt, welcher mit dem der letzten die grösste Ähnlichkeit hat. Bald ist er ganz wie bei Fusus gebildet (Aptychus elasma), bald mit dem von Natica übereinstimmend (A. imbricatus), bald endlich jenem von 'Turbo entsprechend (A. laevis). 


\section{Das}

\section{B e c k n d e s D $\boldsymbol{D}$ e $\boldsymbol{r}$, von}

Hril. Prof. Ezquerra del $B_{A}$ yo in Madrid.

Hierzu Tf. IV.

Das tertiäre Becken des Duero - la Cuenca del Duero hat, manche hleine Windungen seiner Rande abgerechnet, eine ungefähr kreisrunde Gestalt. Der Durchmesser beträgt etwa dreissig deutsche Meilen. Genauer genommen könnte man die Form unseres Beckens als eine ovale bezeichnen; der grösste Durchmesser aus $\mathrm{N}$. nach $\mathrm{S}$. hat 30 Meilen, der kleine nur 22 Meilen. Nach Süden hin werden die Rande des Beckens durch granitische Ausbrüche der Sierra de Avila gebildet; gegen Westen durch eine primitive Rinde (verschiedener Glimmerschiefer), welche etwas aufgerichtet ist und das bergige Land von Salamanca und Zamora zusammensetzt; die Ursache dieser Aufrichtung war ebenfalis eine granitische Eruption. Im Norden wird unser Becken durch kürnige Kalke begrenzt, ähnlich jenem des Thales von Gastein im Salzburger A/penlande. Der ganze östliche Theil des Beckens besteht aus aufgerichteten Schichten sekundärev Gebilie: diese setzen zugleich den Raul zusammen. Im 
S. O., von Segovia bis jenseits Sepulveda, erstreclit sich eine grosse Hippuritenkalk-Formation. Die Felsschichten, auf welchen die letztere Stadt erbaut ist, zeigen die seltsamsten Störungen; wie solche bei manchen Steinkohlen-Lagern vorzukommen pflegen. Das Phänomen dürfte von eiuer theilweisen Senkung herrühren; denn die meist wagerechten Schichten nehmen plützlich eine vertikale Stellung an und bilden beinahe einen spitzigen $W$ inkel, ohne übrigens gebrochen zu seyn, obwoh! der Kalk jetzt sehr fest und dicht, ist, was nicht der Fall gewesen seyn kann zur Zeit der Senkung, sonst würden die Schichten gebrochen und zertrümmert erscheinen, während sie sich, weichem Wachs gleich, gebogen haben müssen. In dieser seltsamen wilden Gegend verliert der kleine Castilla-Fluss seinen Namen; er ergiesst sich in den Durator, welcher später in den Duero tritt. - Den nordöstlichen Theil des Becken-Randes habe ich nicht untersuchen können, obwohl es mein lebliafter Wunsch war, demn ich hätte alsdann mein Profil vom EbroBecken mit dem des Duero-Beckens in Zusammenhang zu bringen vermocht. Indessen lässt sich, meiner Überzeugung nach, mit ziemlicher Sicherheit annehmen, dass die Scheidung beider Becken in jener Richtung durch seliundäre Ablagerungen bewirkt wird, die nämlichen, welche die Serra de Monca:'o zusammensetzen (Wiener Sandstein-Formation).

Als die salzigen Wasser der sekundären Epoche unsere Halbinsel verliessen, musste das Becken, von dern ich rede, von Flüsses durchströmt werden, welche in verschiedenen Zeiten ihren Lauf änderten, bis sie endlich denjenigen annahmen, der ihnen heutigen Tages eigen ist; durch ihre Absätze, durch die Niederschlïge, welche sie lieferten, entstanden die tertiären Gebilde. Ich glaube letztere in drei HauptGruppen abtheilen zu können: eine untere, die ich Nagelflue nennen will, eine mittle, die gypsige, und eine obere, die kalkige. Diese drei Gruppen haben eine bekannte GesanmtMächtig!keit von (i00 Span. Fussen. Die Lagen derselben stellen sich alle als ziemlich wagerecht dar; beiden Nivellirungen, 
zu denen man sich veranlasst sah, als der Kanal von Kastilien gebaut wurde, erlangte man die Überzeugung, dass jene Lagen sich gegen eine rom Laufe des Duero bezeichnete Linie senken, wie solches aus der Richtung der Flüsse im voraus zu vermuthen war. Das erste der beigefügten Profile zeigt das kleine Dorf Puente Duero zur Seite des Flusses gelegen, welcher ihm den Namen verliehen hat.

Der Lauf des Duero und seine hauptsächlichsten $\mathbf{Z u -}$ . flüsse werden auf eine Strecke von 2 bis 3 Stunden durch Auswaschungen der beiden obern Gruppen an der rechten und linken Flussseite bezeichnet. Die Theile, welche sich qu erhalten wussten, erscheinen als Berge, die senkrecht aus den Thälern emporsteigen und deren ebene Oberfläche die unfruchtbaren Plateau's des alten Kastiliens zusammensetzt, in der Landes-Sprache Páramos genannt. In der Umgegend von Valladolid und von Valencia lässt sich am steilen Gehänge der Páramos die Aufeinander-Folge der Schichten bis zu Höhen von 500 Fuss beobachten; man sieht, wie die Lagen von einem Berge zum andern sich gegenseitig entsprechen, und wie diess selbst bei Hügeln auf Entfernungen von 4 bis 5 Stunden Statt hat. Ich sage Hügel, denn nicht immer waren es grosse Páramos, welche dem Einwirken der Wasser widerstanden; mitunter sieht man isolirte Hügel von Säulen-Gestalt. Es lässt sich nicht einsehen, wie diese Abspühlungen und Auswaschungen das ausschliessliche Werk atmosphärischen Einflusses seyn sollen, wenn man bedenkt, dass alte Festen am Rande von Berg-Gipfeln erbaut sich zu erhalten wissen. Ein unermesslicher Zeitverlauf würde nothwendig gewesen seyn, um diese grossen Thäler aufzuschliessen, und die Formation des Duero-Beckens ist, wio wir sogleich sehen werden, nicht sehr alt. - Betrachten wir jede der Gruppen nach ihren Einzelnheiten.

In der Höhe herrscht Kalk, der zuweilen mit kieseligen und mergeligen Schichten wechselt. Die oberste Lage, nnangebaute Ebenen bildend, besteht aus kieseligem Süsswasser-Kalk. Hin und wieder finden sich grössere und 
kleinere kieselige Nieren, die leicht der Zersetzung unterliegen, so dass das Gestein das Aussehen erlangt, als wäre es von Würmern zernagt; es ist diess ein Merkmal, wodurch die erwähnte Schicht von allen andern kalkigen der Formation sich auszeichnet. Lymneen und Planorben findet man häufig darin. Die Mächtigkeit der Gruppe beträgt $\mathbf{S 0}$ his 100 Fuss. Der kieselige Kalk in der Gegend von Almedo hat durchaus die nämlichen Charaktere wie jener im Cerro de Bullecas: er führt Feuersteine, Halbopal und Chalzedon.

Die zweite Gruppe, von mehr als 200 Fuss Mächtigkeit, besteht aus thonigen Schichten, die zu mehreren Malen mit Mergeln wechseln, sowie mit Lymneen-Kalk. Die Thon-Lager sind voll von sehr weissen Gypsspath-Zwillings-Krystallen, ähulich denen von Montmartre. Stellenweise erscheinen die Krystalle in dem Grade gehäuft, dass der Thon nur das Bindemittel derselben ausmacht. Es ist diess ein Unterscheidungs-Merkmal beider Becken. In jenem des Ebro zeigt sich der Gyps fast stets roth gefärbt und kommt in einfachen Krystallen vor. - In der Gegend von Olmedo und von Valladolid werden. jene schönen Zwillings-Krystalle von Gyps gewonnen; man benutzt dieselben bei der Wein-Bereitung, um sie unter die Trauben zu mengen.

Die Mächtigkeit der unteren Gruppe kennt man nicht; indessen hatte ich Gelegenheit, in Steinbrüchen, so wie an Stellen, welche des Kanals wegen aufgeschlossen worden, dieselbe einigermaasen kennen zu lernen. Auf eine Lage von Planorben führendem Kalk, die mir als die letzte der Gyps-Gruppe gilt, folgt ein Nagelflue - Band von 20 Fuss Stärke; sodann wechseln mergelige und thonige Lagen mit der Nagelflue und mit sehr losem Sande. Unmittelbar unter der ersten Nagelflue-Schichte erscheint eine Lage feinkörnigen kieseligen Sandes, in welcher man Überbleibsel grosser Sängethiere trifft; es sind jedoch nur isolirte Erscheinungen: die Thiere dürften bei einer örtlichen Katastrophe ungekommen seyn. In der Gegend von Becerril ist die Sand-Lage dicht genug, um als Baustein zu dienen, zumal da man kein anderes Material 
hat. Als ich am Orte war, fand man mehrere grosse Knochen; Zähne sind leider bis jetzt nicht vorgekommen. Bei Valladolid wurde im verflossenen Jahre ein vollständiges Gerippe ausgegraben, von den Arbeitern jedoch zu Stücken zerschlagen. Über dieses Gerippe waren dic seltșamsten Geriichte in Umlauf. In der Nähe der letzten Stelle traf man in der Kalklage unterhalb der Nagelflue Gebeine von Menschen. Wahrscheinlich hatten die Völker, von denen Spanien in ältester Zeit bewohnt wurde, hier eine Begräbniss - Stätte; alle Schïdel trugen unverkennbare Spuren, dass sie mit grossen Eisen-Nägeln durchbohrt worden. Das grosse Gerippe, von dem ich vorher geredet, galt als das eines ungeheuern Riesen: ich war so glücklich einen Mahlzahn zu sehen: er stammt von Mastadon, und in unserem Naturalien-Kabinet bewahrt man von dem nämlichen Orte Bruchstücke mehrerer grossen Mahl - und Stoss-Zähne von Elephanten. - Auf die Knochen führende Schicht folgt mitunter eine thonige Lage, die sehr reich ist an wohlerhaltenen Planorben und Lymneen. - Von fossilen Pflanzen-Resten ist mir im ganzen Duero-Becken nicht eine Spur vorgekommen; allein diess beweist keineswegs, dass nicht welche vorhanden seyn dürften, denn Nahrung müssen die grossen Grasfresser gefunden haben. An gewissen Stellen waren die Mollusken sehr hüufig, aber die Zahl der Gattungen nur gering. Während der ganzen Bildungs - Epoche dieser Formation - und die Dauer derselben muss ziemlich lang gewesen seyn, da Absätze von so weiter Erstreckung und von so beträchtlicher Mächtigkeit entstunden - lebten Planorbis marginatus Limnea palustris und Paludina impura. Alles dieses sind noch lebend vorhandene Gattungen, und daraus ergibt sich meiner Ansicht zu Folge die Neuheit des Gebildes; ich werde dasselbe als mit dem Süsswasser-Kalke des Wiener Beckens gleichzeitig betrachten.

Der Boden, auf welchem Madrid erbaut wurde, und der im zweiten Profil angegeben, ist auch tertiäres Gebilde und jenem rom Duero ganz analog, allein er gehört 


\section{$-193-$}

schon zum Becken des Tajo; beide Becken sind durch die grosse Cordilliera de Guadanama geschieden. Im TajoBecken zeigt sich der Gyps meist faserig, oder enthält wenigstens im Innern grosse, mit Krystallen ausgekleidete, Drusenräume; auch kommen beträchtliche Salz-Ablagerungen vor, wovon im Duero-Becken nur Spuren vorhanden sind. Fossile Überbleibsel findet man weniger häufig, aber es gibt mehr Gattungen. 


\section{Brief wechsel.}

\section{Mittheilungen, an den Geheimenrath v. LEONHARD gerichtet.}

Böckstein, 18. Okt. 1835.

Der Kontrolleur der hiesigen Werke, Herr Sigmund von HelmREICHEN, ein tüchtiger Bergmann, machte mich auf einige sehr interessante Fälle von Verschiebungen der Rauriser kontemporären Gänge aufmerksam, die ich an Ort und Stelle besichtigte und Ihnen hiemit mittheile.

Fg. 1 auf Tf. . . . . a) der Erz-führende Treberling-Gang. b) der schwarze Neuner (tauber Gang). Letzterer hat eine bedeutende Mächtigkeit und seine Ausfüllung theilt sich in mehrere parallele Blätter; 5 davon werden durch a durchsetzt, eines aber durchsetzt und verwirft den erzführenden Gang. Fig. 2. a ist das Hangendtrumm, c das Liegendtrumm des Erzganges Haberländer, letzteres durchsetzt den ganzen mächtigen Neuner b, während erstres durch den Neuner verdrückt und verworfen wird. Fig. 3. Der Haberländer Erzgang a wird von 4 Blättern des Mirchen Neuners b verdrückt, durchsetzt und verworfen, während er selbst die andern Neuner Blätter durchsetzt. Fig. 4. a die 3te Feldstrecke, b die 4te Feldstrecke, c der Hauptlauf auf Haberländer. Bei d ist eine bedeutende Gangverschicbung, von der man im höheren und tieferen Horizont bei f und e keine Spur bemerkt. Fig. 5. a der Herrustollen Erzgang. b der schwarze Neuner. a streicht aus N.O. in S.W., verflächt bis $d$, wie die meisten übrigen Erzgänge in S.O., wendet aber bei d das Verflächen un und fällt bis c in N.W., streicht aber dann mit seinem ihm eigenthümlichen südöstlichen Verflächen wieder fort ins Feld. Zwischen c und d setzt der Neuner b aus N.W. in S.O. durch den Gang a und verwirft ihn. Diese Verwerfung geschieht adäqnat dem Verflächen der Gänge an diesen Punkte; reduzirt jedoch auf das Haupt-Verfächen des Ganges a scheint hier eine Rutschung im 
Liege nden des b geschehen zu seyn, was aber als Täuschung erscheint, wenn man annimmt, dass die Rutschung wie gewöbnlich in Hangenden des Verwerfers b geschah, jedoch ihre Wirkung sich nicht über die Wendepunkte des Verflächens des Ganges a, nänlich über c und d hinaus erstreckte, daher die Verwerfung adäquat dem widersinnigen Verflächen der Gangstrecke $\mathrm{c} d$ geschehen musste. So dürften, wenn nicht alle, doch die meisten der Rutschungen im Liegenden der Yerwerfer nur scheinbar und Täuschung seyn, entweder bedingt durch andere benachbarte Gänge, oder ähnliche Erscheinungen, wie die so eben erwähnte.

RUSSEgGer.

Basel, 23. Okt. 1835.

Ich sende Ihnen anbei den Bericht über die Verhandlungen unserer naturforschenden Gesellschaft vom August 1834 bis Julius 1835. Sie finden darin unter Anderem S. 49 die zuverlässigsten Angaben über die Höhe des Nullpunktes des Rhein-Messers bei Basel über der See *), welche beträgt

$$
\begin{aligned}
& \text { nach meiner Berechnung von } 1831766 \text { P. F. } \\
& \text { - Buchwelder . . . . . } 777 \\
& \text { - Hauptm. Michaelis . . } 752 \\
& \text { - Hofr. Horver . . . . } 762
\end{aligned}
$$

Der mittle Rhein-Stand liegt $6^{\prime}$ höher. Diese Angaben, sämmtlich auf einer Reihe von Beobachtungen beruhend, weichen nicht sehr von einander ab, wohl aber von dem Resultat des Hrn. General van DER Wyck in dritten Heft Ibres Jahrbuches von 1835, und wozu er durch eine ungefähre Berechnung des Rhein-Gefälles gelangt. Angaben, wie die von MIÜlLer und EBeL, welche auf einzelnen ältern und dazu uicht einmal genau angegebenen Beobachtungen beruhen, können doch kaum mit Bestimmungen, die eine ganze Reihe von Beobachtungen unfassen, auf die gleiche Linie gestellt werden.

\section{P. Merian.}

Lym, 11. November 1835.

Im ersten Hefte des Jahrbuches für 1835, S. 126 ff. ist die Rede von neuen Beobachtungen über das Grundeis. Ich erlaube mir, Ihnen

*) Am a. 0. heisst es:

¿Die Beobachtungen am Rhein-Messer werden auf Anordnung der Kantonal - Bau-

Behörde seit dem Monate März 1808 regelmässig fortgefülurt.

Der Mittelstand der 26 Jahre 1809 bis 1835 beträgt . . . . . 6',56

Der höchste jährliche mittle Wasserstand fand i. J. 1832 Statt mit . 8, 11

Der niedrigste jährliche mittle Wasserstand fand i. J. 1832 Statt mit 4',53

Der höchste bezeichnete Khein. Stand trat ein den 31. Dex. 1801 mit $\overline{21^{\prime}, 8}$

Der niedrigste bezeichnete $R / h e i n$.Stand trat ein den 4. Febr. 1830 mit $0^{\prime}, 9$ 
eine Bemerkung mitzutheilen, welche einiges Licht wirft auf den Einfluss eckiger Körper beim Gefrieren. In meinem Garten ist ein WasserBehälter, zu dem man auf einer Treppe hinabsteigt. Im letzten Winter nahm ich zu zwei Malen, als der Frost bei Wolken-freiem Himmel und dem schönsten Mondlichte eintrat, Folgendes wahr: Die Eislage, welche sich gebildet, hatte in beiden Fällen eine Stärke von ungefähr 6 Linien. Auf dem Eise sah man die Kanten aller Treppen-Tritte auf das Genaueste durch weisse Linien verzeichnet. Beim Untersuchen und Zerbrechen des Eises war überall eine dichte und durchsichtige Masse zu bemerken; nur in der Nähe der weissen Linien zeigte sich das Eis schwammiger und dicker. Die grössere Dicke und das Schwammige rührte von zahllosen bleinen Luft - Blasen her, die im Eise enthalten waren. Nun fragt es sich: warum die Blasen nur über den Kanten der Steine, nicht über ihren Flächen gefunden werden? und wesshalb das Phänomen bloss in mondklaren Nächten und bei heiterem Himmel $\mathrm{zu}$ sehen gewesen?

Als ich im Herbste dieses Jahres durch St. Saphorin kam - der Ort liegt, wie Sie wissen, an Genfer See zwischen Vevay und Lausanne - sah ich ein schönes Nagelflue - Profil ; um die Strasse breiter machen zu können, war dasselbe entblösst worden. Ich nahm von der sehr dichten Nagelflue, mit durchaus späthigen Kalk - Zäment, einige Handstücke mit, welche ich erst hier genauer untersuchte; lassen Sie mich Ihnen berichten, was ich daran beobachtete. Mehrere Rollstücke tragen die auffallendsten Merkmale, dass andere Geschiebe in sie eingedrungen sind. Die Eindrücke bei d Fg. 6 auf Tf. II entstanden augenfällig auf solche Weise, bei a, b und $\mathrm{c}$ sieht man noch die kleinen Rollstücke, wie sie in das grössere Geschiebe eingedrungen sind. Ähn. liche Erscheinungen habe ich auch an Nagelfuen von Ruti wahrgenommen; bei jenen von Zürch und vom Rigi sah ich sie nicht. Man musste nun sich zu überzeugen suchen, ob nur die Nagelfluen mit kalkigem und nicht mit sandigem Bindemittel solche „Eindringungen" zeigen. Nach den Handstïcken zu urtheilen, welche ich beobachten konnte, bestehen die Rollstïcke, die Eindrücke erlitten, aus Kalk und zumal aus $\mathbf{s c h w a r z}$ gefürbtem Kalk, mehrere der eingedrungenen Geschiebe scheinen mir kieseliger Natur. Dass die Vertiefungen von Reibung herrühren, glaube ich niclıt; wäre diess der Fall, so würden dieselben sich fast immer kreisrund zeigen, die Form des eingedrungenen Rollstückes sey welche sie wolle. Im Gegentheile aber haben die Weitungen genau die Gestalt des eingedrungenen Geschiebes, wie diess der Fall seyn würde, hätte man letzteres in weichen Thon gedrückt. - Mir scheint es, dass alle diese Rollstücke lange Zeit hindurch gleichsam in einem "Bade von kohlensaurem Kalke" befindlich gewesen, der durch überschüssige Kohlensäure im aufgelösten Zustande erhalten wurde. Die Kohlensäure wirkte ohue Zweifel in irgend einer Weise auf die KalkRollstiicke, und vielleicht in besonderem Grade auf einige unter ihnen. Wurde ibre Oberfläche aufgelöst, oder fand bloss ein Erweichen bis 
auf gewisse Tiefe Statt? Sollte eine galvanische Aktion an den Kontakt. Punkten von Rollstücken verschiedener Natur die besondere Thätigkeit der Auflösung dieser oder jener Stelle zugefïhrt haben: sollten die Vertiefungen so entstanden seyn? - Herr Fournet, dem ich die Handstücke vorlegte, und der sich von der Thatsache überzeugte, ist der Mcinung, die Geschiebe könnten durch Wärme von Neuem erweicht worden seyn, manche Nagelfluen dürften durch Feuer Änderungen erlitten haben. - Sicher bietet sich uns hier ein schönes chemisch-geolo. gisches Problem zur Lösung dar, und es scheint mir nicht im geringsten an den nöthigsten Anhalts-Punkten zu fehlen. Man muss 1) wissen : ob nur die Nagelfluen mit kalkigem $Z$ äment solche Eindrücke zeigen? und 2) müssen durchdrungene und eingedrungene Geschiebe aller Art gesanmelt und analysirt werden. - Ich schreibe an unsere Freunde Studer und Escher in Zürch, um sie zur Untersu. chung der Nagelfluen ibrer Gegend in dieser Hinsicht aufzufordern, und mit dem Anfang des Fiühlings werde ich mich nach Genf begeben, un an den Ufern des See's zu beobachten und zu sammeln.

\section{P. Lortet.}

Warschaı, 24. Dez. 1835.

Von unserem Freund, dem Herrn Inspektor BloEde, der in vorigen Herbst nach Finnland reiste, um für einen gewissen Hrn. v. OMelianorF einen von ihm neu eröffneten Bergbau auf Kupfer und Zinnerze zu Pitkaranda im Kreise Serdopol am Üfer des Ladoga-Sec's, im Gouvernement Petersburg, zu besichtigen und ein geognostisch-bergmännisches Gutachten darüber abzugeben, erhielt ich unlängst einen Brief, welcher eine erste Notitz über die dortigen Gebirgs-Verhältnisse enthält. Scinem Wunsche gemäss theile ich Ihnen diese zur Bekanntmachung im neuen Jahrbuch der Mineralogie mit.

"Nicht weit hinter Petersburg auf der Strasse nach Wiburg beginnt der Finnländische Granit mit seinen manchfaltigen Begleiteru und bildet eben so die Ufer des Ladoga-See's. Die bisher ganz unbekannte Erzlagerstätte zu Pitkaranda wird, weil sie im Granit aufsetzt, dort allgemein für einen Gang, oder gar für mehrere gehalten; aber alle Verhältnisse weissen darauf hin, dass sie ein Lager oder wenigstens eine ähnliche gleichzeitige Bildung mit dem Granit ist, wie alle anomalen Einschichtungen von Gneiss, Glimmer und Thon-Schiefer, die man für Lager anspricht. Dass nun aber für diese Felsarten durchaus auch eine plutonische Entstehungsweise eingeräumt werden muss, weun diese für den Granit klar bewiesen werden soll, davon habe ich mich in Finnland bereits üterzeugt. Die Zusammensetzung der dortigen Lagerstätte bilden cine Menge einzelner Lagen, die mehr und weniger scharf contourirt, aber deutlich geschichtet sind und zun Theil unter sich abwechselu. Ihr Bestand ist Granat, Malakolith, Grünstein, Strahlstein, 
Hornblende, Quarz, Glimmer, Feldspath und niehrere andere aus diesen gemengte Gesteine; nur unmittclbar in Hangenden und Liegenden ist es fest mit Granit verwachsener Hornblendeschiefer. Die Mächtigkeit beträgt 6 bis 8 Lachter. Jede von diesen Schichten entspricht im Strejchen und Fallen gleichen Verhältnissen der ganzen Masse, und diese letzte steht wieder mit Schichtungen von schieferigen Felsarten, worunter auch Thonschiefer, in Parallelismus, die in der Umgegend vor. kommen. Gewiss ein beachtenswerther Umstand. Eine Veränderung des Gesteins in Kontakt mit Granit, mit Hornblende-Schiefer etc. habe ich ungeachtet der genauesten Durchforschung, noch nicht entdecken hönneu, eben so wenig, als mir diess bis jetzt auf Gesteins-Scheiden von anderweitigen Punkten gelungen ist. Ebenfalls wohl auch ein Beweiss, dass hier mehr gleichzeitige Bildung, als spätere Durchbrechung Statt gefunden habe, und dass plutonische Entstehungsweise nichts weniger als den Begriff von Lager aufhebt. Nächst Kupfer und Zinnstein brechen auf dem Lager von Pitkaranda Schwefelkies, Magnetkies, Magneteisenstein, Bleiglanz, Zinkblende und von erdigen Begleitern besonders Kalkspath. Zum Theil sind Kupferkies und Zinnstein vergesellschaftet, häufiger aber ist dieser mehr an die Grünstein - artigen, jener mehr an die Malakolith - und Granat-Lagen gebunden, und ausserdem scheint es auch noch, als wemn des Einen Vorkommen. auf Kosten des Andern hervorträte. Der Kupferkies hat bei Weitem das Übergewicht und geht selbst mit vortrefflichen Anbrüchen stellenweise zu Tage aus. Der Zinnstein kommt meist in büschelförmig zusammengehäuften, nadelförmigen Krystallen vor und hat desshalb Äınlichkeit mit Schörl: Überhaupt steht dessen hiesiges Vorkommen wohl einzig da, aber doch kann er nicht ganz seine Gemeinschaft mit anderweitigem Vorkommen abläugnen, denn, ausserdem dass er, obwohl höchst selten, Molybdän unter seine Begleiter aufnimmt, imprägnirt er auch wie anderwärts so fein das Gestein, dass ihn nur erst die Schlich-Ertragsprobe zum Vorschein bringt. Für seine Benutzung kann ich aber keine grossen Erwartungen hägen, obgleich hier sehr viel darauf gerechnet wird; in Gegentheil möchte es für die Zugutmachung der Kupfererze besser seyn; wenn er gar nicht vorhanden wäre. Übrigens lässt sich dieses Lager gegen eine Werst lang verfolgen und ist ganz unverritzt, denn von altem Bergbau ist hier keine Spur. Wahrscheinlich ist es ein Seitenstück zu der Kupfererz - Lagerstätte von Oryärfvi, wo seit langer Zeit der einzige metallische Bergbau von Fimnland umgeht: ein Punkt, der häufig in mineralogischen Handbüchern zitirt wird. Ein einziger fataler Umstand ist für die Bebauung des Lagers, dass es kaum 150 Lachter vom See abliegt und diesem unter $00-70^{\circ}$ zufällt.

In geognostischer Hinsicht eröffnet Finnland ein weites unangebautes Feld, wovon sich eine reiche Ausbeute machen liesse; aber ausser den Postwegen gibt es keine Zugänge und höclsstens nur Fusssteige zwischen den höchst vereinzelten Dörfchen. Alles, was ich bis jetzt gesehen, hat mich zum Theil höchst frappirt und überzeugt, dass 
Alles das, was bis jetzt von Finnland bekannt, ohne sonderlichen Werth ist. Fast kann man als ausgemacht annehmen, dass alle hiesigen Gebilde der plutonischen Erzeugung anheimfallen nüssen, wenn sie nicht sonst alle neptunisch seyn sollen. Ihre Übergänge, ihre Verwebungen und gegenseitige Wechsellagerung lässt sie kaum von einander trennen. Höchst frappant sind in dieser Hinsicht grosse Strecken in den Gebirgen, wo durch Waldbrand zugleich auch die Bedeckung so zerstört worden ist, dass grosse. Gesteinsflächen wie polirt vor den Augen liegen. Es ist ein schauderhafter Anblick, der bis in das Innerste der Seele eine Öde bringt, die mit Schrecken erfüllt. Dagegen erblickt man wieder Gesteins-Verhältnisse, die ich kaum geahnt habe, und die in demselben Maase anziehen, als die verkohlten Baumstumpfen auf dem gebleichten Gestein abschrecken. Bald glaubt man in deu neben- und durch-einander verschlungenen Granit-, Gneiss-, Glimmerschiefer- und HornblendeGesteinen Platten von Band, bald von Trümmerachat vor sich zu haben. Es gibt an solchen Stellen Punkte, wo man fast schwören möchte, dass der Granit die andern durchbrochen hätte und ganz vorzüglich häufig ist ein glimmerreicher Hornblende-Schiefer von ihm durchästelt, verrückt und abgeschnitten; doch sieht man wieder aufs Granze, so spielt der erste gegen den letzten wieder, nur eine sehr untergeordnete Rolle, und Alles erscheint aus einem Guss. So habe ich denn noch keine rechte Basis gewinnen können, und natürlich habe ich auch noch zu wenig gesehen. In der Untersuchung der Inseln des Ladoga-See's, die ich angefangen hatte, da sie sich als Theilganze leicht übersehen lassen, hat mir der schuelle Winter einen Strich durch die Rechnung gemacht."

Bloede schreibt mir ferner, dass er bei Zarsko: Selo unweit Petersburg im Allgemeinen die Pander'schen Beobachtungen (geognostische Beiträge zur Kenntniss Russlands) bestätigt gefunden habe. Wenn man an diese Punkte einen Neptunisten führt, so muss ihm wahrhaftig das Wasser aus den Augen springen, so evident ist hier die spätere Zerrüttung des Thonschiefers und des Übergang-Kalks ausgesprochen. Man fühlt den Granit und Porphyr etc. im Aufsteigen begriffen, der mit der Schwedischen Übergangs-Formation theilweise verbunden ist, und muss den Gründen von Pander Recht geben, womit er, unbewusst der Folgerungen, die sich aus dem Faktum ziehen lassen, die Identität der Petersburger Formation nit dem Schwedischen Übergangs-Gebirge vertheidigt. Es ist diese Gebirgs-Entblösung, so unbekannt und unbeachtet sie bis jetzt gebieben ist, ein gewichtiger und gewaltiger Stützpunkt für die plutonische Hypothese und nach so vielen anderen Beziehungen vorzüglich für das Schichtungs-Verhältniss sehr belchrend. 


\section{- 200}

Catania, 15. Januar 1836.

Seit meiner Zurückkunft aus Deutschland habe ich Mancherlei für unsere Akademie gearbeitet. Besonders beschäftigte mich eine Abhandlung über die Jura-Gebilde von Tauromina, und eine andere über Valle del Bove; von beiden schmeichle ich mir, dass sie vicht ohue allgemeines Interesse seyn werden. Es ist Ihnen nicht unbekannt, dass Bous:") meine Angaben über die Jura-Formation von Tatromina in Zweifel gestellt und gesagt hat, man müsse die Äusserungeu von Fr. Horpmany und Constant Prévost abwarten. Diess veranlasste mich un so mehr, eine ausführliche Schilderung des erwähnten Gebildes zu liefern und die Angaben aller charakteristischen Versteinerungen beizufügen, welche ich aufzufinden vermochte. Nachstehendes möge Ihnen einen vorläufigen Begriff von seiner Zusammensetzung geben:

1. Grauer Kalk; mit Adern von Kalkspath und mit Nieren von Rogenstein; voll Enkriniten; bildet mäch-/ tige Bänke, die mit braunlichem Sandstein wechseln; licgt unmittelbar über Kohlenschiefer und ist das tiefsto Glied der Gestein-Bildungen von Tauromina.

2. Röthlicher Kalk und blauer Mergel; mit Kalkspath-Adern; enthält Ammonites gigauteus, so wie andere Ammoniten und Belemniten. Der Mergel wechselt mit braunem, Muscheln-führendem Sandstein; unter Andern finden sich Plagiostoma 1 a evius cuInferior oolith. lum, Pecten inaequicostatus und Terebratula glo b at a darin.

3. Grauer Kalk; die obre Lage schieferig; mit ooli-j thischen Nieren; nach der Höhe zu Feuersteine ein-
schliessend, hin und wieder auch Muscheln.

Forest marble.

4. Weisser Meruel mit Resten von Pectines und) von Terebrateln; an manchen Stellen, wie u. A. bei $0 x$ fordclay. Moso, setzen Gänge von kohlensaurem Eisen darin auf.)

5. Kalk mit Enkriniten und Nummuliten, auch mit/ Überbleibseln von Korallen.

Coralrag.

6. Schiefriger Thon mit Streifen weissen, zuweilen/Kinmeridgeauch bituminösen Mergels.

clay.

7. Weisser Kalk von kleinkörnigem Oolith - Gefüge, P o r I a n ddas ins Dichte sich verlauft.

s t 0 il e.

\section{Gemmellaro.}

Burg Haardt in Rheiubaiern, 18. Januar 1836.

Ich lesc eben, dass nach Hicorexir im Ohio. Thale Salz u u ter Kohlen vorkonme, und die Kohle mit dem New-red-Sandstone verbunden,

-) Bullet. de la Soc. géol. de France. Vol. V, p. 191. 


\section{$-201$}

mithin lauter Steinkohle sey. Auch sollen die Salzquellen am Ohio reich an Kohlen-Wasserstoff und Steinöl seyn. Ich theile Ihnen diese Angabe, deren Richtigkeit ich zwar nicht verbürgen kann, die mir aber sehr glaubhaft scheint, nur mit, wegen Ihrer Auffindung des Salmiaks bei Duttweiler, als Produkt eines brennenden Kohlen-Flötzes. Sollte sich nänlich, wie HiLdretr nit Entschiedenheit behauptet, in Amerika Steinsalz unter Steinkohlen finden, so wäre nicht abzusehen, warum diess in Europa nirgends der Fall seyn könnte. Dann hätten wir sicher auch in unserem Duttweiler Steinsalz und das räthselhafte Phänomen des Salmiaks wäre erklärt - was um so weniger auffallen kann, als man ja das Steinsalz jetzt in den verschiedensten Formationen, selbst den jüngeren tertiären, wie EzQurRrs gezeigt, gefunden hat.

\section{Chr, Kapp.}

Lyon, 17. Febr. 1836.

In den Steinbrüchen des Gryphiten-Kalkes, 1 Stunde N.W. von Lyon, hat man kürzlich einen I chthyos a urus-Kiefer entdeckt, woran besonders die $4^{\prime}$ lange Unterkinnlade wohl erhalten ist. Sie lag mit cinem Schulterblatte und einem Oberarmbein in einer Schichte voll Gryphiten und Ammoniten, und ist mit erstren in städtischen Museum niedergelegt.

In den Jurakalk-Brüchen, welche die vielen $\mathrm{Z}$ a $\mathrm{m}$ ie $\mathrm{n}$ geliefert haben, entdeckte ich unlängst noch zwei andre Pflanzen-Reste, welche Brongnart für Sphaenopteris macrophylla und eine mit Thuytes verwaudte Konifere erkannt hat; die auch zu Stonesfield vorkom. men. Auch sollen sich jetzt Früchte da finden.

LORTET.

\section{Mittheilungen, an Professor Brons gerichtet.}

Moskwa, 17. Dez. 1835.

Mit dem neuen Jahre hoffe ich den Druck der "Oryktographie" anfangen lassen zu künnen; der der Topographie des Mosliowischen Gouvernements ist längst vollendet. Über unsern Kalk bleibt jetzt kein Zweifel mehr: er gehört zur Oolithen-Gruppe und ist an mehreren Stellen von Dolomit begleitet. Ein Erdfall hat uns die Überzeugung gegeben, dass dieser Oolithenkalk auf Lias mit Belemniten und mit Am. in ou ites elegans Rein. ruhe. 


\section{$-202$}

Auf der beiliegenden neuesten Tafel XLVII der "Orylitographie" finden Sie (Fig. 8, 9, 10) eine Schnecke, die mir neu zu seyn scheint: Paranoma testa univalvi brevispirali, valde compressa, apertura ovato-oblonga. Ich hatte zuerst ein kleines Exemplar (Fig. 8) an der Protva lose in Kalkstein.liegend gefunden, war jedoch zweifelhaft gebliebén, ob ich ihre Zusammendrückung für zufällig halten solle. Bei meiner letzten Exkursion in diesem Jahre aber entdeckte ich sie an einer ganz anderen Stelle, an der Moskwa in Miatschkova, und zwar grösser (Fig. 9, 10) und von erstrer vielleicht spezifisch verschieden. Die mit abgebildete ? Nassa findet sich in einer räthselhaften schwarzen, Eisenocker-reichen Erde voll Ammoniten und Belemniten an der Jausa aufgeschwemmt. Die Aneinanderreihung unserer Formationen wird dadurch schwierig, dass zu wenige Stellen entblösst sind; Kreide findet sich nicht; - bei Svenigorod kommt Kalktuf vor mit Helix, Plan orbis und Blätter-Abdrücken; alles Übrige fällt in Diluvium und Alluvium zusammen.

\section{G. Fischer von Waldheim.}

Hildesheim, 18. Dez. 1835.

Es würde mich sehr freuen, wenn Sie in meiner Arbeit über die Nord-Deutschen Versteinerungen *) wirklich hin und wieder etwas Brauchbares gefunden haben sollten. Mindestens ist mein Wille gut und durch viele Mühseeligkeiten erprobt gewesen. Vielleicht wird der Verleger auch die blassen Abdrücke der Abbildungen nochmals kopiren lassen, wodurch allerdings einem grossen Fehler abgeholfen würde, obschon deren Zeichnungen ziemlich korrekt sind und sie daher nit dem Texte zusammengenommen für ihren $Z$ weck wohl genügend seyn dürften $\left.{ }^{*}\right)$. Gegenwärtig lasse ich noch viele $\mathrm{Lima-}$ und PholadomyaArten nebst der Menke'schen Schildkröte und einigen anderen Dingen lithographiren. Leid ist mir aber, dass ich durch einen mir irrthümlich angegebenen Fundort verleitet worden bin, Sowerby's Eu omphalus rugosus auf Tf. XI, Fig. 1 (aus der Steinkohlen-Formation) mit aufzunchmen. Mit Nächstem erwarte ich viele Jura-Versteinerungen zur Vergleichung von Herrn Voxtz zu erhalten; wünsche aber auch die tertiären Gegenstände genauer kennen zu lernen, da ich die bei Sternberg vorkommenden Sachen nächstens zu beschreiben gedachte ${ }^{\text {\% }}$ ). Sechszig Arten von da besitze ich bereits, worunter Marginella auriculata (die kleine Sizilianische Form), Murex brandaris, M. craticulatus bis jetzt noch nicht angegeben waren.

*) V'gl. Jahrb. IS35, E. 730.

- Diese Verhesserung würde wesentlich scyn und denı Buche eine Brauchbarkeit gewähren, die ihm mit den ersten Rang unter den verwandten sichern wïrde.

Broxx.

*) Vgl. Jahrb. 1835, S. 431 und 447. 
Meine bisherige Ansicht von den hiesigen Formationen habe ich diesen Sonmer überall, wo ich gewesen, bestätigt gefunden. Die Walkerde bei Geerzen hält Yourz indessen für Bradfordclay, und ich stimme ihm darum jetzt gerne bei, da mich meine kleine Bibliothek über diese Bildung früher nicht genügend belehrt hatte. Unsere oberen Liasmergel mit Trigonia navis, Nucula Hausmanni, Ammonites costatus, A. Murchisonae werden sich von den Posidonien-Schiefern wahrscheinlich noch eben so scharf als vom Dogger trennen lassen, behalten aber mit letzterem Cerithium echinatum und Ammonites Parkinsoni gemein. - Im Portlandkalke habe ich neulich eine grosse, schöne Krebs-Scheere gefunden, die erste aus dieser Bildung. Eben so erhielt ich aus den oberen Sandmergel - Lagen des untern Liassandsteines hier in der Nähe eine Venus und eine Lima (? L. p u n c lat a), so dass deren Trennung vom Keuper immer richtiger erscheint.

RÖMER.

Mudrid, 21. Dez. 1835.

Sie werden die Versteinerungen erhalten haben, die ich auf meinen Sommer-Ausflügen gesammelt und an Sie abgesendet habe *). Nächsten Sommer denke ich die Gegend von Alcarah, Almaden und vielleicht auch von Teruel zu bereisen. Sie können sich keine Vorstellung von der Grösse unserer Mineral-Schätze, insbesondre dem Reichthum an Kupfer machen, das bloss wegen Mangels an bergmännischen Kenntnissen nicht ausgebeutet wird. Vor wenigen Tagen brachte mir Jemand ein grosses Handstück aus einem Quarzgange in den Gebirgen von $\mathbf{A l}$ barrain, welches auf einer Seite mit einem mehr als Linien-dicken Silber-Übergang versehen war; der Schlich gab 0,03 Silber. - Der Lehrkurs an unserer Bergschule wird am 7. Jänner eröffnet. - Mitten in der Mancha kommt eine grosse Basalt - Formation vor, welche Le Play, Hausmans u. s. w. nicht beachtet haben. Ihr Ausbruch mag es gewesen seyn, der die Aufrichtung der Schichten in der Formation von Almaden veranlasst hat. Dieser Basalt enthält deutlichen Olivin und einer unserer Ingenieure, Herr Prado, hat mir gesagt, dass er auf eine Erstreckung von mehr als 7 Stunden das herrschende Gestein seye. Sobald ich dahin komme, werde ich lhnen eine weitläufige Beschreibung davon schicken.

\section{Ezquerta del Bayo.}

*) Ein Thcil derselbeu ist zu Bestimmung der fossilen Arten S. 102 bereits benützt worden.

BR. 
Urach, 20. Jänner 1836.

In Folge Ihres Aufrufes im Jahrbuche übersende ich Ihnen von Terebrateln aus dem Württembergischen Alles, was ich habe. Ob Ihnen einige derselben hinsichtlich der Formation neu sind, muss ich dahin gestellt seyn lassen: die Terebratula inconstans Sow. ist wenigstens, so viel mir bekannt, durch mich zuerst bei uns und zwar im Coralrag aufgefunden worden; auch habe ich sie sonst noch bei Niemanden gesehen. Die Terebrateln aus dem Portlandstone wage ich nicht zu bestimmen. - Die Angabe in der Lethaea, dass derselbe bei uns nur auf Einsingen beschränkt seye, wird sowohl nach jetzigen, wie nach später fortzusetzenden Forschungen berichtigt werden müssen. Diese Formation ist bereits unferu Einsingen, in Denken-Thal bei Ulm, zu Ringingen, Gerhausen, am Jakobsberge bei Ehingen, zu Urach, Münsingen, bei Zwiefalten, Wechingen und Gachingen aufyefunden worden. Sie enthält äusserst wenige Petrefakten, wesshalb sie bisher übersehen worden ist, unterscheidet sich aber dem Kenner auf den ersten Blick. Hier und bei Münsingen lässt sich der Portlandstein sehr weit verfolgen: er nimmt die grössten Höhen ein und hat eine Mächtigkeit von wenigstens $100^{\prime}$. Bei der neuen, im vorigen Sommer hier angefangenen Strasse nach $U / m$ hat sich ein überhaupt höchst nerkwürdiges Profil ergeben; doch obschon hiebei viele Tausende von Zentuern Portlandstein zerschlagen worden, habe ich aller Bestellungen und aller eigenen Mühe ungeachtet (ausser den Münsinger Terebrateln *) auch nicht e in Petrefakt von dort erhalten. Ich hoffe, dass der nächste Sommer ausgiebiger seyn werde.

\section{F. von Mandelsloh.}

Strasburg, 8. Febr. 1836.

Iclı übersende Ihnen hiebei Gyps - Abgüsse eines Zahnes von ? P ala e otherium crassum und eines Fussknochens eines? Säugethieres, welche nit noch anderen Resten von solchen mitten in den SchildkrötenSchichiten des Portlandstones von Solothurn lagen. Herr Gresscy hat selbst welche dort im Jura - Gesteine innliegend gefunden, ohne an diesen Spuren von Verrückungen und andere Veränderungen zu bemerken. Es sind dieselben Schichten, welche auch Nerinea depressa und Zïhne von Pycnodus, Gyrodus u. s. w. einschliessen.

Voltz.

Fine der T. digon a sehr nale stehende, aber Aache Form. Br. 


\section{Neueste Literatur.}

\section{A. Bücher.}

1530.

Cur. Pander: Beiträge zur Geognosie des Russischen Reichs, Petersburg.

1533.

J. Mawe: New descriptive catalogue of Minerals etc. Fth edit. London $8^{\circ}$.

E. M. Patrin : listuire nuturelle des Minéraux; avec 40 planches.

C. SAUCERotTE: Élemens d'histoire naturelle, présentant dans une suite de tableaux synoptiques accompagnées de figures un précis complet de cette science. Minéralogie avec 3 pỉanch. $t^{0}$ Paris.

Conversations un Mineralogy, with plates, 2d edit. I, II, Lond. 12.

1534.

J. C. Freyesleben : Magazin für die Oryktomraphie von Sachsen, Heft VI.

ED. KAYSER: Beschreibung der Mineralien-Sammlung des Herrn Medizinalrath BergemanN in Berlin, mit 3 Kupfertafeln, Berlin $8^{0}$.

G. E. KAYSER: de cyclo quodam legum duodecim, secundum quas crystalli generum Feldspathi familiae singulariorum geminatim conjunctae inveniuntur. Dissert. inangur. Accedit tabula aenea. Berolini $5^{n}$.

KIRCHNER: de petrefuctis et fossilibus, quae Soraviae et in vicinis agris reperiuntur commentatio. Soralk, $15 \mathrm{pp} ., 2 \mathrm{tt}$., $4^{0}$.

F. v. Kodels: Tafeln zur Bestimmung der Mineralien mittelst einfacher chemischer Versuche auf trocknem und nassem Wege, München, II. Aufl., 68 SS. $8^{0}$ (Jahrb. 1833, S. 550).

Catalogue of the Museum of GIDEON MANTELL, as nevily arranged at Brighton. 
N. F. Moors: ancient Mineralogy, or an Inquiry respecting Mineral Substances mentioned by the ancients, with occasional Remarks on the uses, to wich they were applied. $192 \mathrm{pp}$., New York.

S. G. Morton: Synopsis of the Organic Remains of the Cretaceous Group of the United States, illustrated by nineteen plates, to wich is added an appendix, containing a tabular view of the Tertiary Fossils hitherto discovered in North-Amerika, $10 \pm \mathrm{pp} .8^{\circ}$. Philudelphia.

A. Petzond: Leitfaden für den Unterricht in der Mineralogie für Gymnasien, hohe Bürgerschulen, Pealschulen und Gewerbschulen, Neisse und Leipsig, 1834, $8^{0}$.

C. B. Prest : Anleitung zum Selbststudium der Oryktognosie in technischer Beziehung; II. Heft, praktische Oryktognosie, Pruy $8^{0}$ (vgl. Jahrb. 1833, S. 550).

F. Reıch: Beobachtungen über die Temperatur des Gesteins in verschiedenen Tiefen in den Gruben des Sächsischen Erzgebirges, in den Jahren 1830-1832, Freiberg, $8^{\circ}$.

P. SAv1: sulla scorza del globo terrestre e sul modo di studiarla, $108 \mathrm{pp} .8^{\circ}$.

H. WaCkENRoder: chemische Tabellen zur Analyse der unorganischen Verbindungen. 6 Tafeln in Fol., 3te Aufl., Jena.

Yourg and J. BrRD: a Geological Survey of the Yorkshire Coast, describing the Struta and Fossils occurring between the Humber and the Tee's, from the German Ocean to the plain of York; 2 d edit., $368 \mathrm{pp} ., 18 \mathrm{pll}$., $4^{\circ}$. Whitby.

\section{5.}

H. ENGLIsH: Mining Terms: the explanation of the Terms used in the Mining Districts of Cornwall and Derbyshire, with the Spanish Terms used in Mexico, Columbia, Peru etc., London [2 shill.].

H. Exgrish: Generad Guide to the Companies formed for Working foreign Mines, with their Prospectuses and much useful information, London [2 shill.].

H. Engusu: Compendium of useful Information, relating to the Companies formed for Working British mines, London [2 sh.].

H. Englisu: Complete View of the Joint Stock Companies formed during the Years 1824 and 1825, behing $62+$ in number, with Particular's of Companies formed antecedent to that Period and now in Existence [2 sh.].

[Diese drei zusammen 1 Band zu 5 shill.]

Le Buanc et Watter: Métallurgie pratique du fer, Livrais. II [vgl. S. 62]. 


\section{Zeitschriften.}

Bulletin de la Société géologique de France (Paris $\mathbf{8}^{\circ}$ ).

Vol. IV, $1535 *$ ).

Pouillon Boblaye: Bericht über die Arbeiten der geologischen Sozietã t in den Jahren 1832-1833, p. I-LX und 1-10.

$$
\text { Vol. VI, 1S35. 65-320 \%) und I-LXI. }
$$

Fapines: über die artesischen Brumnen im Depart. der Ost-Pyrenäen, S. $71-74$.

Boвraye : über hochgelegene jugendliche Muschel-, insbesondre Austern-

Bänke in Schottland (aus dem Scotsman, 1834, 1. Nov.) S. 74-78.

Boubée, Michelin, Boué, C. Prievost und Rozet darüber, S. 78-80.

C. Prévost, Pozet und Bozraye: über Erscheinungen im Pariser Becken, S. 81-82.

BoulLete : über einen Titaneisen-Krystall, S. 85.

Hiricart-Ferpand: über Süsswasser- und Seemuschel-Schichten im unregelmässigen Tertiär-Gebirge von Château-Landon, S. 90-93.

Verhandlungen darïber, S. 93-95, 114, 115.

C. Prévost darüber, S. 292-294.

BovirLet: über See-Konchylien im Süsswasserkalk der Limagne in Aurergne, S. 99-100.

Badvely: über Gold zu Quebec gefunden, S. 104-105.

Provana de Collegro: Bemerkungen über einige Punkte der Schweitzer Alpen, S. 106-114.

Donvando: Besteigung des Ätna, S. 124.

Cr.Ėient Muldet : Bericht über die Archive der Gesellschaft, S. 128-132. Putos: über die fossilen Reste im bunten Sandstein zu Ruaux in den Voyesen, S. 136-139.

RoBert: Chalzedon-Krystalle in Geoden der Manche, und Palaeotherium-Reste in Grobkalk, S. 139.

Devaux : über Naphthaline, eine neue brennliche Substanz, S. 139-140. Dusakdir: über das Wasser-Ergebniss der artesischen Brunnen, S. $144-148$.

Bows: Bericht über die mineralogischen Vorträge zu Stuttgart im Herbst 1834 , S. $150-154$.

VIRLET: Beobaclitungen in Franche Comté über die Höhlen und die

Theorie ihrer Bildung, S. 154-164.

Razovмowsky: über Moos-Achate, S. 165-168.

Steininger: über Halocrinites und $\mathrm{Helix}$ (Tf. x, Fg. 11 und 12). S. 169.

Scrmenuriva: über Kunst-Produkte in den Lütticher Höhlen, S. 170-173.

*) Fortsetz. v. Jahrb. 1835, S. 462-464.

**) Fortsetz. v. Jahrb. 1835, S. 464-465.

Jahrgang 1836. 
Bunst : ïber einen Karpolithen aus dem Sekundăr - Gebirge des Culvadus-Depts. (Tf. F, Fg. 15, ein Zapfen), S. 175-176.

MiLcet : geologische Notitz üher das Arrondissement von Belley (Ain) S. $176-181$.

Eudes Descongcharps: geologische und paläontologische Bemerkungen üher ein Kalkfölz, welehes in einigen Gegenden des Calvados den Polypenkalk der Normandie überlagert, S. 181-192.

Rozex: über dic Jura-Hebungen, S. 192-211.

Vinckt: neue Idee'n über dic Natur der Kometen, die Bildung ihres Schweifes, die Acrolithen, den Ursprung der Erde und der Planeten, die Entstehung der Berge, der Erhebungs - Kratere, die Emporhebung Schwedens u. s. w., S. 212-223.

Puviè: geologische Konstitution der Muschel-Gruben von st.-Michelen-l'Herm (Tendée); S. 224-230.

Roenzox: iber die Bohrbrumen zu Soisy-sous-Etiolles, S. 232.

Vorrz: Bericht ïber Graf Mandessun's We't ïher die Hürttemberyische $A l), S .234-235$.

A. Armand : Reste zahlreicher Insekten in den Mergeln der Gyps-Formation zu Puy, S. 235-236.

Laizer: Säugethier - und Reptilien-Reste im Süsswasserkalk von Puy de Dôme", S. 23i-238.

LEFEBrR: : über aufrechtstehende Baumstïmme zu Bourg, im DordugnęDept., S. 238.

Jufhéxox: legt seine geologische Karte über die Bretagne und Normundie vor, und theilt Bemerkungen mit über das Übergangs - Gebirge beider Provinzen, S. 288-289.

A. D'Arcusac: Ergebniss einer Abhandlung über die untern Tertiär-Gebirge des Aisne-Depts. (pi. I1), S. 240-247.

Pissis: Analyse eines hydraulischen Kalkes, S. 249-250.

DrfrésoY: über die Tertiär-Gebirge in süd-Frankreich, S. 250-251.

Diskussionen über die Schichten des Pariser Beckens, S. 252-253.

Pнкето: über die Tertiär-Gebilde in Bormida- und Scrivia-Thale,

S. 254 .

Boulctet : neue fossile Süsswasser-Konchylien in Auveryne, S. 255.

D'Onalus: über die geologischen Phänomene, welche das Relief des

Hundsrücks und von Estremadura hervorgebracht, S. 255-259.

Brefor: Marmor bei Gremoble, S. 260-263.

Galeotri: geologische Übersicht von Sü̈-Brabant, S. 264.

Colmeno: über Thonschiefer zu Hal und Ronquières Lin Belgien?], S. $272-275$.

Bentuand-Gesun: über die Bildung des Ligniten-Puddings zu Cadibonn bei Sasona in Ligurien; - und Diskussionen daruber, S. 28:-285.

Éme un Beaumort: über die unmittelbare Auflagerung des TöpferthonGebildes auf Kreide zu Bus-Meudon, S. 285-286.

G. Troost : über Übergangs-Versteinesungen in Tennessee. S. 289-290. 
Bouś: über die Route von Arezzo nach Terni und durch den Furlo nach Pesaro, S. 291-292.

Drovet: Notitz über die kieseligen Kalke und die weissen und grünen

Mergel des Bezirkes von Epernay (Marne), S. 294-296.

Beobachtungen über den plastischen Thon und den Übergang des Grob-

kalkes in Kreide (vgl. S. 285), S. 297-300.

VirLet : über Erdbeben in den Cordilleren, S. 303-305.

Arvé: Betrachtungen über natürliche Krystallisations - Erzeugnisse, S. $305-307$.

Pelckrier: über eiserne Nägel ? in fossilem Palmen-Holz, S. 309-310. YIRLET: Bemerkungen uber eine Schichte faserigen Brauneisensteins zu Sargans im Kanton St. Gallen, und über die Veräuderungen, welchen sie nach ihrem Niederschlage ausgesetzt gewesen, S. $313-320$.

Rozet : Übersicht der Arbeiten der geologischen Sozietät und der Furtschritte der Geologie in Frankreich vom 1. Nov. 1833 bis dahin 1834, S. 1-LxI.

The London and Edinburgh Philosophical Magazine and Journal of Science (vgl. Jahvb. 1835, S. 340).

1335, VI, nr. 2, 3, 4, 5, 6.

J. T. W. Johrston: über den Dimorphismus des Barytokalzits, S. 1-4.

Pircr. Phillips: über die Menge des Wassers im krystallisirten Baryt und Strontian, S. 52-53.

Proceedings of the geological Society of London, 1834, 19. Nor. bis

3. Dezember.

A. Cloyne Austen: Bericht über das gehobene Gestade und andre neus Stürungen bei Hope's Nose in Devonshire, S. 63-64.

H. D. Rogers : geologische Thatsachen über die Geologie des zentralen und westlichen Nordamerika, hauptsächlich gesammelt aus ungedruckten Mittheilungen neuerer Reisenden, S. 64--66.

DE LA Beche: über den Anthrazit bei Biddeford in North-Devon, S. $67-68$.

Trevelyan : über das Vorkommen von Granat-Bruchstücken im Millstone Grit, S. 76.

II. J. Вкооке: mineralugische Notitzen, S. 76-77.

W. H. Milcer : über die Form von Schwefel-Nickel u. a. Substanzen, S. $104-107$.

D. Bhrwater: Notitz über die optischen Eigenschaften eines neuen Minerals, welches für eine Varietät des Cymoplrans gegolten, $S$. $133-134$.

Proceedings of the Geological Society of London, 17. Dez. 1834.

Allan Cunninguam: über die physikalische und geologische Bildung, der Gegend westlich der Grenzkette zwischen dem Uunters river 


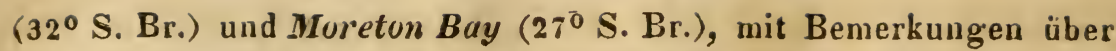
die Geologie von Moreton Bay und Brisbane River in New South Wales, S. 147-149.

H. E. Strichland: Bericht über die Land- und Süsswasser-Konchylien, welche mit Land-Vierfüsser-Knochen unter Diluvial-Geschieben zu Cropthorn in Worcestershire gefunden worden, S. 149.

D. Wrchams: über die Knochen gewisser Thiere, welche neuerlich im Magnesiankalk-Konglomerat von Durdham Down bei Bristul entdeckt worden, S. 149-150.

E. M. Crarke: über eine neue Erscheinung in der Magneto-Elektrizi. tät, S. 169.

Proeeedings of the Geological Society of London, 17. und 21. Januar 1835.

Вовтоск: Bericht über die Zerlegung des Mineralwassers von der $\mathbf{S t}$. Pauls-Insel in $38^{\circ} 45^{\prime} \mathrm{S}$. Br. und $77^{\circ} 53^{\prime}$ O. I., S. $312-313$.

J. Mrchés : über die Kreide und den Feuerstein von Yorkshire in Vergleich zu denen der südlichen Grafschaften Englands, S. 313.

Woodbixe Parish: Bemerkungen zu einer Suite von IIandstücken aus der Nähe von Bognor, S. 313.

Basil Halc: Notitz über den Mangel von Perpendikuiarität an deu steheuden Säulen des Tempels von Jupiter Serapis bei Neapel, S. $313-314$.

R. Isp. Murchison: über ein äusseres Lias-Becken an den Grenzen von Salop und Cheshire, mit kurzem Bericht über den untern Lias zwischen Gloucester und Worcester, S. 314-315.

R. J. Murchisox: allgemeine Übersicht der New-red-Sandstone-Reilue in den Grafschaften Salop, stafford, Worcester und Gloucester, S. $315-318$.

Сн, Daubeny : über Dr. Ure's Abhandlung in den Philosophical Transactions über die Moira-Salzquelle, und über das Verhältniss von Bromine in den Wassern verschiedener Meere, S. 321-324.

Proceedings of the geological Suciety of London, 4. Febr. 1835.

R. J. Muncurson: über gewisse Kohlen-Züge in Salop, Worcestershire und Nord-Gloncestershire, S. 376-379.

Си. T. BEкE: über den historischen Beweis vom Vorrücken des Landes gegen das Meer am Ende des Persischen Mcerbusens, nebst cini. gen kurzen Bemerkungen über das Gopher-Holz der Schrift, als Antwort an Carren, S. 401-408.

1835, VII, nr. 1, 2, 3.

TH. WeAVEr : über die alten Goldwerke in der Grafschaft Wicklow in Irland, S. 1-6.

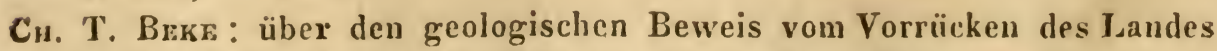
an Eude des Persischen Meerbusens, S. 40-46.

R. J. Murcuison: über das Silurische Felsarten-System, S. 46-52. 


\section{$-211$}

Proceedings of the geological Society of London, 1835, 20. Febr.

Greenougu's Schlussrede bei der Jahres-Versammlung; S. 52-63.

Eow. Chardesworti : über Kalkspath-Gänge in fossilem Holz, S. 76-77.

- - Beobachtungen über die Crag-Formation und ihro organischen Reste, mit einem Versuch die tertiären Schichten über dem London-Thon in Suffulk einzutheilen, S. 81-94.

Proceedings of the geological Society of Loniton, 1835, 20. Febr.

Greenougi's Schlussrede (Fortsetzung), S. 142-152.

C. B. Rose: Skizze der Geologie von West-Nurfolk, nebst Karte, S. $171-182$ (F. f.).

W. G. CARTER: über alte und neue Bildung von Delta's im Persischen Meerbusen durch den Euphrat und Tigris, als Antwort an Beкs, S. $192-202$ (F. f.).

Proceedings of the geological Suciety of London, 1835, 20. Febr.

Greenough's Schlussrede (Schluss).

H. English : the $(Q u a r t e r l y) M i n i n g R$ eview, or Journal of Geology, Mineralogy and Metallurgy, nr. 1-VII. 1834 bis zum 15. Juli 1835 [die Nummer zu 5 shill.].

E. Fr. Glocker: mineralogische Jahreshefte, - zugleich als fortlaufende Supplemente zu des Verfs. Handbuch der Mineralogie v. J. 1831; Nürnberg $8^{\circ}$ (Heft I und II, 1831-1832, S. 1-165; III, 1833, S. 166-296 und IV, 1834, S. $297-544$ bilden der I. Band, Nürnberg 1835, mit Pegister, S. $545-558$.

Die neuen Entdeckungen eines jeden Jahres sind nach folgendem Schematismus geordnet: I. Geschichte der Mineralogie; II. Neueste Literatur; III. Krystallographie und Gestalt - Lehre überhaupt; IV. Mineral-Physik; V. Mineral-Chemie; VI. Spezielle Oryktognosie; VII. Geognosie (Geologie ist ausgeschlossen). 


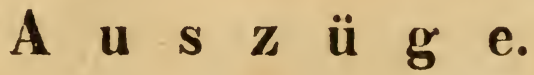

\section{Mineralogie, Krystallographie, Mineralehemie.}

Durrínoy: über den Dreelit (Aun.d. Chim. et de Phys. Septbr. 183.5, 102 etc.). Diese neue, dem Marquis De Drée zu Ehren benannte Substanz wurde vor Kurzem auf den Halden der verlussenen Bleigrube la Nuisiere unfern Beaujeu entdeckt. Kernform, wie es scheint, ein Rhomboeder mit Winkeln von ungefähr 93 bis $94^{\circ}$; Audeutungen von Durchgängen in der Richtung der Kernflächen. Weiss, in Bruche glänzend. Eigenschwere zwischen 3,2 und 3,4. Etwas härter, nls Kalkspath. Vor dem Löthrohr zu weissem blasigem Glase schmelzhar. In Salzsäure, unter Einwirken von Wärme, theilweise lösbar. Vorkommen in einem "Arkose"-ähnlichen Gestein, welches hãufige Einschlüsse einer, dem Haloysit zunächst stehenden, Substanz aufzuwcisen hat. Analyse :

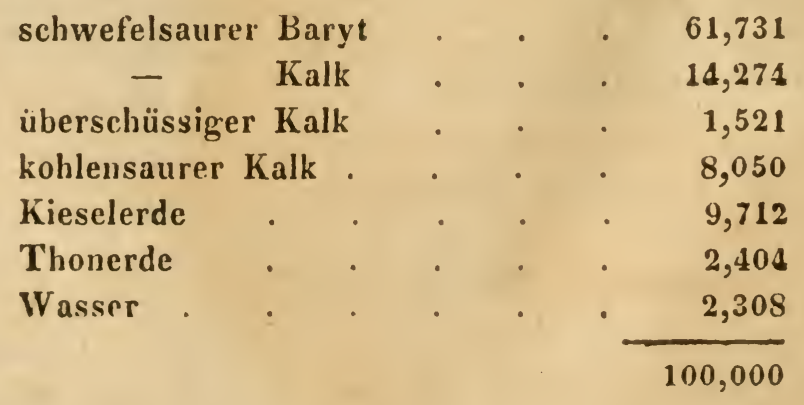

F. vov Kobelt: über deu Nickel-Wismutlgganz (Endmañ und Schweigger-Seider, Journ. f. Chem. VI, 332 ff.). Diese neuc Miuernl-Gatıung konmt in der Grünau in der Grafschaft Sayn-Altenkirchen mit Quarz und Kupferkies vor. Die sehr kleinen Krystalle sind Oktaeder; auch die Formen des Würfels scheinen vorzukommen. Spaltbarkeit naclı den Oktaeder-Flächen. Vollkommen metallischer Glanz, 
lichte stahlgrau; Pulver grau. Hänte zwischen Flussspath unı Apatit. Chemischer Bestand:

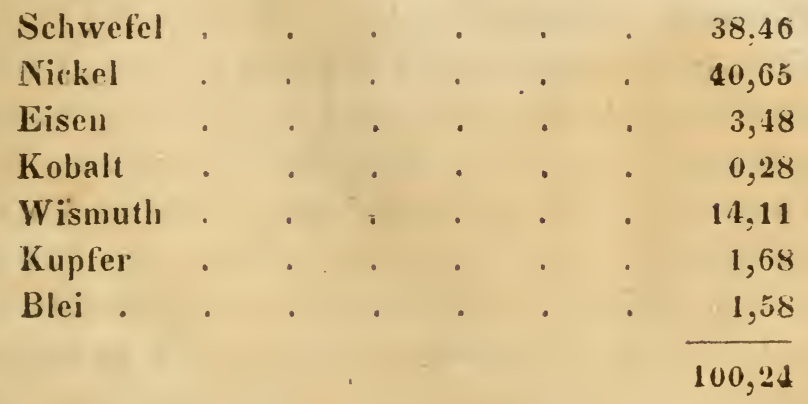

Glocker: Heues Vorkommen von Amiath, Bergkork und Papier-Asbest bei straschkau in Mähren (Erminas und Schweng. ger - Seider, Journ. f. Chen. VI, 328 und 329). Besonders das nörd. liche Mähren ist sehr reich an köruigem Kalk; das Gestein führt die verschiedenartigsten Mineralien, und bei Straschkau in der Herrschaft Noracetz, woselbst der Kalk zwischen Gneiss auftritt, U. A. Skapolith, Struhlstein, Serpentiu, Talk und vorzüglich schönen zart- und lang-faserigen, scidenglänzenden, schneeweissen Amianth. Der Amiauth und der ilı begleitende Bergkork sitzen im Kalkspath, welcher den körnigen Kalk in, bis $\frac{1}{2}$ Zoll starken Adern durchzieht. Der Bergkork zieht sich auch trummartig in den Kalk hinein und gestaltet sich mitunter zu einem wahren Papier-Asbest, dessen Blätchen so dïnne sind, wie bei dem aus Derbyshire. In einer der Amianth-Layen kommeu längliche Stücke von Schillerquarz vor, dessen Entstehung durch innige Verbindung des Amianths mit dem Quarz lies offen vor Augen liegt.

R. Hermañ: Audyse eines Dolomites aus der Gegend vun Véréï (G. Fischer de Wandeim, lêté séculaire de Linné. Moscou, 183.5, p. 29 etc.) :

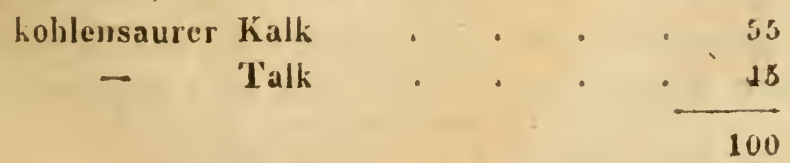

A. Quenstent: über die After-Krystalle des Serpentins (Poggend. Anu. d. Phys. 1825, Nr. 11, S. 370 ff.). Zu Snarum im Kirchspiel Modum (Normegen) kommen Serpentin-Krystalle vor, die ungeachtet ihrer häufig veidrückten und gerundeten Gestalten und ihres Flächen-Reichthuns : in der Form wie in den Winkeh genau mit jenen 
des Olivius übereinkommen. Sie sind auf die homogene SerpentinMasse aufgewachsen, so dass Krystallé und Muttergestein wie durch einen Guss geformt zu seyn scheinen. Auch finden sie sich in Zwillingen nach demselben Gesetz, welches beim Chysoberyll so oft beobachtet wird, bei Olivin jedoch noch nicht bekannt ist. Manche Krystalle sind von Bitterspath-Massen durchdrungen; sie lassen deutlich eine Schicht von unreinem Bitterspath erkennen, welche sich zwischen deu eingeschachtelten Kern und die äussere Schaale, parallel mit den Krystall-Flächen eingelagert hat, so dass nıan oft die Flächen des inneren Kernes und der äusseren Schaale zugleich beobachten kann. Es musste also der ursprüngliche Krystall später fortgewachsen seyn, eine Erscheinung, die bei Quarz, Idokras, Epidot, Barytspath und vielen andern Mineralien sich so oft wiederfindet, wo ebenfalls bcim spätern Fortwachsen Flächen entstanden, die der Krystall anfünglich gar nicht zeigte. Die erwähnten Serpentin-Krystalle von Snarum tragen das Gepräge der After-Bildung in manchen andern Merkmalen. Sie sind durchaus strukturlos, nicht selten zerfressen und vou gelblichbraunen Adern durchzogen. Ein Krystall von mehr als 4 Zoll Länge und 3 Zoll Breite zeigt sich im Innern noch mit völlig unzersetzter Olivin - Masse angefüllt. An ilım sieht man deutlich, wie die Umwandlung von Aussen nach Innen begann, wie Serpentinschnüre den Olivin durchziehen, die Masse entfärben, porös machen, und so allmählich die Verwandlung vollenden. Die braunen Schnüre, welche Gebirgsmasse und Krystalle gleichmässig durchziehen, scheinen nichts, als halbzersetzter Olivin. Was die Frage betrifft, wie der chemische Prozess gewesen sey, durch welchen die Massen verwandelt wurden, so bemerkt der Verfasser, dass beide Mineralien in Rücksicht auf ihre Zusammensetzung einander durchaus nicht fern stehen. Der Serpentin hat die Formel:

und der Serpentin

$$
3 \dot{M g} \underline{\mathrm{H}}^{2}+2\left\{\begin{array}{l}
\dot{\mathrm{M}}{ }^{3} \\
\dot{\mathrm{Fe}}^{3}
\end{array}\right\} \ddot{\mathrm{Si}}^{2}
$$

$$
\left.\dot{\mathrm{IV}}^{3}\right\} \ddot{\mathrm{Si}}
$$

Beide unterscheiden sich also, abgesehen von ihren Verhältnissen, nur durch ihren Wassergehalt. Lässt man zu 4 Atomen Olivin

$$
=\dot{M} g^{12} \ddot{S}^{4}=2 \dot{M} g^{3} \ddot{S}^{2}+\dot{M} g^{6}
$$

$$
\begin{aligned}
& 6 \text { Atomen Wasser } \\
& \text { so erhält man Olivin }
\end{aligned}
$$$$
=2 \dot{M} g^{3} \ddot{S}^{2}+\dot{M g} \dot{H}^{2}
$$

und $3 \dot{M}$ werden ausgeschieden. Fe tauscht sich mit $\dot{M} g$ aus. Wasserdämpfe reichen also einfach genug zur Unwandlung hin, und will maı nuch den Bitterspath erklären, so lässt mau noch Kohleusäure hinzutreten. 


\section{- 215}

Da der Bitterspath die ganze Masse durchzieht, überhaupt das MutterGestein sich von den Krystallen in nichts unterscheidet, sondern beide lomogen ineinander übergehen: so sicht man sich gezwungen, bèiden gleichen Ursprung zuzuschreiben. Von dieser Seite betrachtet, bekonmt die Frage auch noch ein grosses geologisches Interesse. Ansehn. liche Olivin-Massen mussten vorhanden seyn, lie wie ihre Krystalle zu Serpentin umgeändert wurdon. Die Art, wie diess geschah, muss vorläufig hypothetisch bleiben: aber auf jeden Fall sind heiss eindringende Laven, welche die vorhandene Masse sogleich umhüllten, dem Prozess weniger günstig. $\mathrm{Da}$ die heissen Dämpfe in unserer heutigen Geologie eine so beliebte Rolle spielen, so sollen sie auch hier als Erklärungsgrund angesehen werden. Wenn gleich nicht aller, so mag doch mancher Serpentin, so merkwürdig auch sein geognostisches Verhalten, auf diese Weise entstanden seyn. Sonit scheinen die AfterBildungen für den geologischen Unwaudelungs-Prozess auf heissem Wege eine ähnliche Wichtigkeit erlangt zu haben, wie die petrifizirten organischen Wesen für die Meeres-Bildungen.

F. Th. Merbach: chemisclue Zusammensetzung mehrerer Sächsischen Kalksteine (Jahrb. für den Berg - und Hütten-Mann aul d. J. $1836 \%$ ), S. 78 ff.).

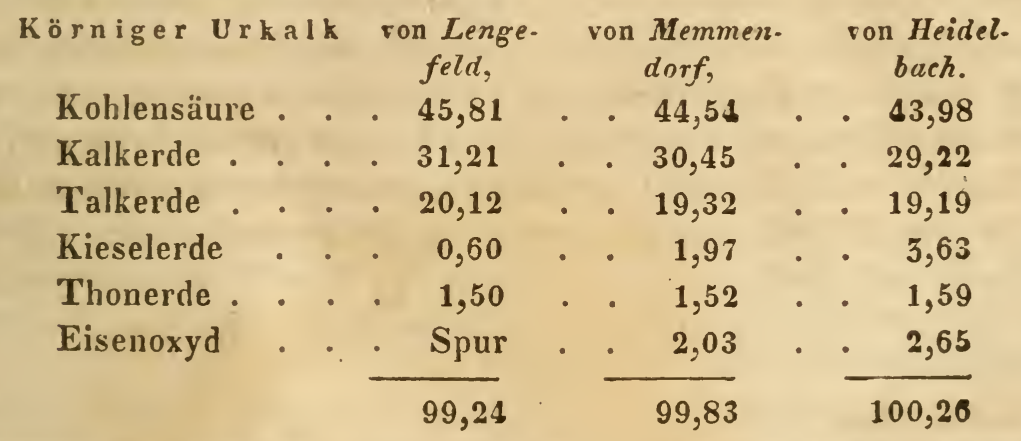

Ausserdem fand M. einen Talkerde-Gehalt im Mergelkalk von Helbigsdorf und Steinbach, im $\mathbf{K a l k s t e i n}$ von Helbigsdorf und Kaltofen, im Plänerkalk von Koschütz, und der Mergelkalk von Schueinsdorf ergab sich als 12,18 p.C. Talkerde haltig.

Kuternatzoch: Analyse des weissen Zinnsteine von Altenberg (A. a. O. S. 77). Das Mineral wurdo als inniges Gemenge von Zinnoxyd und Thon erkannt.

*) Freib. 1888. 


\section{$-216$}

Kersten: Analyse der grünen Kobaltbiuthe vou schneeberg (A. a. O.). Bei Gelegenheit der Zerlegung von hobaltblüthe aus schneeberg wurde beobachtet, dass die schönen pfirsichblüthrothen Kirystalle schon bei geringer Hitze mit ihrem chemisch gebundenen Wasser auch ihre Farbe verlieren und, mit Beibehaltung i!ser Durchscheinheit, spangrün werden. Diess veranlasste Versuche mit einem Strick Kobaltblüthe, deren Krystalle eize unrein grrüne Furbe hatten, wobei sich ergab, dass diese Krystalle wasserfreier arseniksaurer Kobalt, also sehr wahrscheinlich parasitischer Bildung sind.

IV. H. Miller: über die Gestalten des ges chwefelte n Nickels und anderer Substanzen (Lond. and Edinb. phil. Mag. 1835, Febr., pag. 10 t etc.). Eignet sich nicht zu einem Auszuge, auch würde dieser, ohne Beifügung der Figuren, unverständlich bleiben.

Dufrínoy: Analyse des Bleigummis (Ann. de Chim. et de Phys.; Août, 183.5, p. $\$+0$ etc.). Bis jetzt kannte man nur Iluelgoat in Bretagne als Fundort dieser Substanz; von Danhauser wurde sic neuerdings in der Bleigrube la Nuisiere bei Beaujeu entdeckt, woselbst das Mineral begleitet von phosphorsaurem, kohlensaurem, schwefelsaurem und molybdänsaurem Blei in quarzigem Ganggestein vorkommt, und zwar, wie zu Huelgoat, in kleisnierenförmigen und traubigen Massen, theils gelblichweiss, aussen sehr glänzend und splittrig im Bruche, theils grünlich und von strahliger Textur, wie der Wavellit. (Die Fasern scheinen nadelförmige Krystalle.) Härte zwischen Kalkspath uná Apatit. Eigenschwere $=4,88$. Vor dem Löthrolır dekrepitirend: auf kohle sich anfblähend und zu weissem schlarkigem Email Hiessend. In starken Säureu lösbar. Analyse:

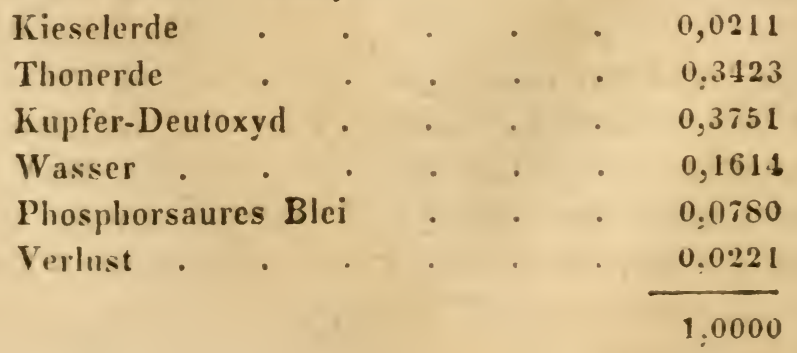

Glocker: Magueteisen mit Augit und Grallat bei Reschitz in Mälren (Ekmanx und Schweigger-Seidel, Journ. fïr Chem. VI, $322 \theta_{0}$ ). Mähren ist sehr reich an den manchfaltigsten Eisenerzen. Eisenglanz, Roth - und Braun - Eisenstein, Eisenkir's und Magneteisen sind an vielen Orten zu findeu. Unferi Reschitz bi!det Magneteisen 
mit Granat und Augit eine stockförmige Masse im Grueisse. Angit macht, wie es scheint, den vorherrschenden Theil, jener Masse aus. Theils stinmt derselbe vollkonmen mit dem körnigen Sablit und Kocko. litı überein, theils mit dem schwarzen körnigen Augit von Arendal. Mitten im Augit liegen hin und wieder grössere Hornblende-Pàrtieen. Auch Partieen und Trümmer von Quarz, Feldspath und Albit kommen vor, seltener von Skapolith, so wie Krystalle von Titanit. Mit dem Augit ist rother Granat in grösseren und kleineren Massen verwachsen. Das Magneteisen bricht derb und ist klein- und feinkörnig abgesondert. - Die Gesammt-Verhältnisse haben mit jenen von Arendal grosse Ähulichkeit.

Derselbe: über das Steinmark vou Lettowitz im Brünner Kreise (A. a. O. S. 329 ff.). Vorkommen in Trümmern in sehr verwittertem Serpentin. Das Steinmark hat beinahe Kalkspath-Härte, zeigt rundzellige und eckige Vertiefungen und Eindrücke von Krystallen, und hàt schwache Andéutungen einer faserigen Struktur. Möglich ist, dass dasselbe sein Entstehen einer Unwandelung des Pikrolithes verdankt.

Ar. Brongriart : über die Gegenwart einiger Metalle im oberen Sandsteine von Paris. Der Verf. benachrichtigte die Akademie (l'Institut. 1836, IV, 65-66), dass der Herzog von Luynes in diesen Sandsteine aus einem Bruche vor Orsuy an der Strasse nach Palaiseau, so wie zu Saint Clair und zu Sceaux-les-Chartreux, wo solclier in Verbindung mit eisenhaltigem Sandsteine vorkommt, Kobalt cntdeckt habe, und zwar im Betrage von 0,015, mit 0,040 Mangan, mit Eisen-Peroxyd, Kupfer u. s. w. Brongriart liess die Zerlegung in der Manufaktur zu Sévies durch Malagutri wiederholen, wo sich der Sandstein zusamengesetzt zeigte aus

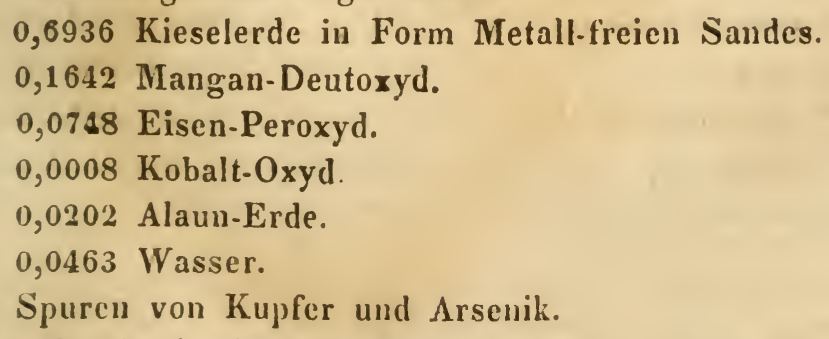

Dieser Sandstein ist schön schwarz mit ockergrelben Adern, nus glänzenden, scharfen, rein krystallinischen Körnern zusammengesetzt, daher vielmehr durch unvollkommene Krystallisation als durch mechanische Zusammenhäufung von Sand entstanden. Dasselbe Sandstein-Gebilde führt häufig auch Eisenoxyd-Hydrat, wclches zu Ferté-sous-Jouarre', wo es die Meulières begleitet, insbesondere im Bruche Tarteret, in 
Form kleiner Kügelchen vorkommt und Mangan enthält. Die Analyse derselben ergab

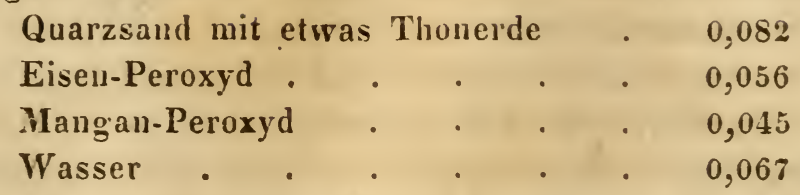

Etwas tiefer, in den ersten Miergel-Gyps-Lagen, kommt das Mangan in kleinen Blättchen und in Dendriten-Form häufig vor; und da wo das Gyps - Gebilde in den Grobkalk übergeht, sollen sich Spuren von Zink-Oxyd finden.

In den tertiären Gebirgen hatte man bis jetzt nur das Vorkoinmen von Eisen, Mangan und ? Zink-Spuren im erbsenförnigen Eisen gekannt; das Vorkommen von Kobalt darin ist neu; auch hatte man seine Verbindung mit Mangan nur zu Rengesdorf in der Lausitz beolsachtet, wo der Kobalt auf einem Quarzgange in Thonschiefer bricht. Weitere Forschungen werden zweifelsohne noch mehr Metalle in solchen jüngeren Bildungen nachweisen.

P. A. v. Bonsdorfa: Analyse des Figuren : Labradors von ojamo in Finnland (Verhandl. der k. Schwed. Akad. der Wissensch. 1833, hgg. 1834, S. 14-17).

Brooke: mineralogische Notitzen (Lond. a. Edinb. philos. Mag. 1835, VI, 76-77). Es war ein Irrthum, dass Br. früher den Zurlit für Wollastonit gehalten. Er hat erstren jetzt ächt von Monticelri, und findet ihn selbstständig. - Phur.ips hat in seinen Elements of Mineralogy einen Krystall angeblich von Bounnow's biegsamem Silber abgebildet. Der Krystall ist ein modifizirter verdrehter Kubus und das Mineral Schwefel-Silber. Ein BR'x. zugekommenes von Bournow selbst bestimmtes Exemplar des biegsamen Silbers ist identisch mit Haidinger's Sternbergit, - Auch hat Phichips einen Krystall vou weissem Tellur, den er von Вrоoкe erhalten, dargestellt. Es ist aber nicht gewiss, dass die Substanz wirklich weisses Tellur ist, obschon sie in kleinen silbeıweissen glänzenden Kryställchen nicht selten auf blättrigem Tellur zu finden ist.

\section{Geologie und Geognosie.}

KarL von RAumer: über Basalt-Bildung (Lehrb. d. allg. Geosraphie, 2. Ausgabe, Leipzig; 1835. S. 482 ff.). "Schon früber nannte 
ich den Basalt: ein in und mit den verschiedensten Gebirgs - Bildungeu, vom ältesten Granit bis zum jüngsten tertiären Kalkstein herab, auftretendes Schmarotzergestein. Er ist gleichzeitig mit allen jenen Formationen entstauden, aber als eine ihnen fremdartige, ja meist feind. seelige, eisensteinartige Bildung. Zuweilen schickte sich der Basalt in das Schichtungsgesetz der Haupt. Formation und bildete besiegt untergeordnete Lager in derselben: läufig aber konstituirte er ungestaltete oder gangförnige, die Schichten durchsetzende und durchtrünmernde Massen. Wegen seines einstigen Conflikts mit der sich gleichzeitig mit ihm bildenden Hauptformation unwickelt er oft Stücke derselben; so fundet man Granit-, Sandstein- und Kalkstein-Brocken in den Basalten der Granit - Sandstein - und Kalkstein - Fcrmationen ; oder ungekehrt, das Haupt-Gestein umwickelte Basaltstücke. Des Basalts Eisenuatur wirkte zugleich hin und wieder (ob elektrisch?) auf das umgebende Gestein : dasselbe anschmelzend, entfärbend. - Höchst merkwürdig bleibt die auffallende Ähniichkeit des Basaltes und Dolerits mit den Meteorsteinen, auf welche Ähnlichkeit Mous zuerst aufmerksam machte. Rose's genaue Untersuchung bestätigt diess, da er in den Meteorsteinen vou Iueenas: Magnetkies, Labrador und Augit fand; der Olivin der Pallas'schen und andern Eisenmassen war früher schon bekannt. Alle diese oryktognostischen Bestandtheile stimmen mit denen des Basaltes überein. - Wie sich nun die Meteorsteine seit vielen Jahrhunderten in der Atmosphäre bilden, so bildeten sich vielleicht die Basalte in den Gewässern der Vorzeit, alis welchen sich die ủbrigen Gebirgs-Formationen niederschlugen, als Vorfahren der Meteorsteine, und waren eben so absouderliche Frendlinge in den alten Neeren, wie diese in Luftbreise. - Man gönne meiner Hypothese neben so, vielen andern eine friedliche Ruhestätte * $) .6$

\#) Requiescut in mari! Amen! dmen! Von meiner Seite wenigstens hat die Verblichene keine Störung zu fürchten. - Aber Herr vor Raumer wird mir eine Bemerkung erlauben, die nicht seiner abgeschiedenen Hypothese, sondern ihm gilt. Herr vox RAumer nennt meine Schrift über die Basalt-Gebilde eine, nit grossem Fleisse gemachte, Compilution. Nun weiss ich nicht, was Herr von RavMER unter Compilıtion versteht; Sammelwerk würde das deutschthümliche Wort seyn. Allerdings habe ich auf meinen, der Basalte wegen unternommenen, Reisen Beobachtungen ges a m $\mathrm{m}$ elt, und dass mein Buch, neben einer getreuen Zusammenstellung des bekannt Gewesenen, Neues und Eigenthümliches enthält, darüber haben Geologen und Chemiker des In- und Auslandes, w o h l. vertraut mit der Literatur, längst öffentlich abgeurtheilt. Sollte Herr vor RAUMER zu wissen wïnschen: was ich in denı Werke über Basalte als mein Eigenthum vindizire? so dient zur Antwort: jene Beobachtungen, Thatsachen, Behauptungen und Hypothesen, wabei keine Auktoritiit, keine Quelle genannt ist. Und wäre man artig genug, diese meine Erklärung in Zweifel stellen zu wollen, so kann ich mit andern Beweisen aufwarten. I on meinen, in den Jahren 1826 bis 1830 nach basaltischen Gegenden - Wetterau, Ingels-Gelirge, Rhïn, Spessart, Wester-Wuld, Khein-Ufer, Sieben-Gebirge, Eifel, Hessen, Thüringen, Scliwïbische Alp, Sïd-Frustkreich - unternommenen Wanderungen zurückkehrend, versäumte ich nie. in den Sitzungen der hiesigen Gesellschaft für Natur. Wissen. 
Christax Kapp: Sterblichkeit der Erde (Iertha, Almanach für 1836, Kempten bei Dannheimer, S. 130). Die Erde habe, als e in. zelner Weltkörper, nothwendig Anfang und Ende. Letzteres sey, als Gegenbild des Aufaugs, nur mit diesem, aus dem Stande der Dinge, wie sie jetzt sind, zu erklären. Astronomische, plıysikalische, chemische und geologische Thatsachen leiten zusammen mit Sicherheit auf Eine Ansicht, welche frei in der Mitte aller sich halte. Schon die Gestalt der Erde, die Anordnung und las Wesen ihres Baues zeige, dass sie ursprünglich in einem flüssigen Zustande war. Da nun die Wäıme das Einzige ist, was Alles im Fluss zu halten in Stande sey, so sey dieser Zustand ohme Zweifel feuerflüssig zu denken. Diess werde aus geologischen Gründen noch kenntlicher. Im Wechselverhältniss mit dem umgebenden Weltraum habe die Erde sogleich einen Theil ihrer Hitze entbunden. Mit dieser ersten Abnahme der Temperatur a uf de $\mathrm{l}^{\circ}$ Oberfläche consolidirte sich aber die elastisch-flüssige Feuer-Gestalt der Erde, die nichts, kein Aton aus ihrem Gebiete, auch keiue Wärme völlig entfliehen lasse. Das erste Land, das erste Meer und der erste Dunstireis seyen Resultate eines Attes, und gleichzeitig habe sich das Innere der Erde, dadurch dass ilıre Oberfläche erstarrte, von dieser (von der anfïnglichen Rinde) geschieden. Die plutonischen Massen, die in verschiedenen Perioden -und Epochen der Erd-Ausbildung durch die erstarrte Rinde brachen, erschütterten Meer und Land, machten diese Kruste immer grösser, immer festęr und der Wäıme, die von Innen emporquillt, undurchdringlicher: die erschütterten Wasser gewannen die Gewalt, schon gesprengte Fels-Massen weiter und weiter fortzuwälen und jerie Gesteine niederzuschlagen, welche die min. der dichten und die sihlechtesten Leiter der Wärme sind. Aber seit der letzten umfassenden Katastrophe, die nach den Mythen den ältesten Nationen in dem Namen Sündfuth symbolisirt wurde, habe dic Oberfläche der Erde im Grossen weder an Wärme verloren, noch gewonnen. Auch seyen die Höhe des Meeres-Spiegels und die Reiche der lebenden Organismen seitden dieselben geblieben. Doch die Mächte des inuern wirken noch in der Tiefe fort. Gebannt durch die erstarrte Festigkeit der Erdrinde kündigen sie nur hie und da durch Erdbeben und vulkanische Ausbrüche die Gewalt an, mit der sie vormals schalteten und wirkten. Aber sie verloren nichts von ihrer intensiven Kraft. Fort und fort waltend, von unten aus die Erdrinde durch still anhaltende

schaft und Heilkunde, meinen Kollegen über neue Thatsachen, die ich "compilirt" halte, Bericht zu erstatten. Die Protokolle der Gesellschaft ergeben das Weitere. - - Fast möchte ich glauben: Herr von Raømer keune meine Schrift bloss rom Hörensagen; auf solehe Gedanken führen die abgeriss e nen StelIen. welche er hervorlıebt, um den rulkanischen Ursprung des von ihm sogenannten. Schmarotzer.Gesteins * zu verdächtigen. Alle Einreden, alle Zweifel, die er dadurelı stellen und anregen zu hönnen vermeint, findet der unbefangene Leser in meinem Euche bereits beseitigt, oder doch berïcksichtigt und gewürdigt.

LIONHARD. 
Tlı̈̈tigkeit vergrössernd, müssen sie nothwendig einstmals, neue Nĩassen gewaltsam aus: 'ussend, diesen Kerker, der sie seit einigen Tausend Jahren fesselt, sprengen. Nur so, nur aus sich selbst, könne in Lauf der Jabrtausende die Erde in einer Epoche, die unser Weltsystem erschüttern würde, cinstmals ihren Untergang sich bereiten. Unter der Ansicht, dass die Entstehung der Erde mit der Entstehung unseres Weltsystems im Ganzen einen Akt bilde, erinnert den Verfasser, gegen die Theorie'u moderner Naturphilosophen, an Ocaers, Lagrange und Audere, so wie an jene fernen Gestirne, deren wandelbares Licht, cin Zeichen eigner Welthildungs-Prozesse, mit lesbarer Hieroglyphen-Schrift in den Werken der Astronomen beschrieben steht. Ähuliche GrundAusichten enthält srine 1834 bei Schwerzerbart in stuttgart erschienene Schrift: Neptumismus und Vulkanismus.

P. Knigut: Geologic vou Erris in der Grafschaft Hayo (Journ. of the geol. Soc. of Dublin, I, f5etc.). Berg-Reihen und-Gruppen sind hoch, schön und von sehr manchfaltigen Formen. In der Maume-Thomaus-Peihe, welche aus N.O. nach S.W. zieht, steigt der höchste Punkt zu 2400 F, an. Sie besteht ganz aus Glimmerschiefer und Quarz; die Gestein - Lagen nähern sich in Allgemeinen dem Senkrechten. Ähnliche Felsarten setzen bis Bullycroy fort. Der Boden der Oberfiiche besteht meist aus feinkörnigem Quarzsand. Die Curslieweund Kinucklettur-cuss-Berge, im Allgemeinen zu $1500 \mathrm{~F}$. ansteigend, in den erhabensten Punkten aber 2370 F. erreichend, haben eine ähuliche greognostische Zusammensetzung, wie die Maume-Tlomaas-Berge. An Corlieve-Gipfel nimmt das Quarz-Gestein Glimmer-Blättchen und Feldspath-Theilchen auf, so dass es ein granitisches Aussehen erlangt. Nordwärts vou Owenmore, am Slieve-fyaugh in 960 F. Meereshöhe, schliessen sich die Sekundär-Gebilde an die primitiven an. Unmittelbap über den Glimmerschiefer liegt, am Fusse der Croghane-Berge, der alte rothe Sandstein. Darüber treten, mit einander wechselnd, schieferiger 'Thon und Sandstein auf, welche der Kohlen-Formation anzugehören scheinen. Eine der denkwürdigsten geologischen Thatsachen dieser Gegend ist das Vorhandenseyn von Porphyr-Gängen, dic sehr ungleiche Mïchtigkeit haben, aber alle parallel streichen. Wo sie auftreten, haben mehr und minder bedeutende Änderungen und Störungen im Glimmerschiefer Statt gefunden: der ausserdem gewöhnlich dunkel gefärbte Glimmerschiefer wird lichtegrau und zeigt sich sehr zrrsetz.t. - Der Tarmon-Berg, südwärts Mullet, besteht aus Granit. Quarz-Gängge setzen darin auf. Weiter nördlich, gegen die Küste hin, zeigt sich wieder Crlimmerschicfer, der hier sehr reich an HornblendeBeimengunge'n ist. Fleischrothe Feldspath-Adern durchiehen hin und wieder das Gestein. Der Granit seheint den Glimmerschiefer durchbrochen zu laben. - Im N. des Trurmon- Berges besteht dir Inalbinsel 
vorherrschend aus einer schieferigen Felsart, einem Gemenge aus Feldspath, Glimmer und Hornblende. Hin und wieder tritt auch Glimmerschiefer auf. - Der fruchttragende Boden zeigt sich, bei seinem bekannten Ursprung aus der Zersetzung von Felsmassen, in der geschilderten Gregeud sehr verschieden. Da, wo quarzige Gesteine vorherrschen, findet man, in geringer Tiefe unter der Oberfläche, weissen kieseligen Sand. Im Mullet-Bezirk zeigt er sich manchfaltiger durch verschiedenartige Beimengungen, und bildet, längs der Küste, ausgedehnte Hügelzüge, von denen bei Stürmen Staubwolken von 50 bis 60 Fuss Höhe weggetrieben worden. Dieser Sand führt viele zerkleinerte Muschel-Theilchen, so wie Partikeln von Glimmer und Hornblende. Eine nicht uninteressante Thatsache zeigt sich an der Westküste, Leam gegenüber. Hier wird, bedeckt von Sandlagen, die 30 bis $50 \mathrm{~F}$. Höhe haben, ein so dichter Moorboden gefunden, dass er wie Kohle brennt. Bei Cartron wurden, an der Meeresfäche und tief unter dem Niveau des Hochwassers, Baunstämme ausgegraben, die senkrecht standen, so wie dicselbeu einst gewachsen seyn müssen; man traf sie im Moorboden, der nur mit einer grringmächtigen Triebsandlage bedeckt war.

Chr. Kapp: ïber die Goodwin Sands (Hertha, Almanach für 1836, Kempten, S. 134), bezweifelt die Ansicht, dass diese räthselhaften Sandbänke durch die Überfluthungen unter Herneich I und II entstanden, und stellt die Frage 1) ob sie nicht so alt sind, als die Lostrennung Frankreichs von Englund, die er, falls sie je Statt gefunden, in der Diluvial-Katastrophe sucht, und 2) ob ihre Entstehung nicht mit den Wirkungen der Kräfte zusammenhänge, welche, seit jener Zeit, die nahen Länder.Strecken Skandinaviens fortan emporheben. Letztere Frage unterstützt er, in Zusammenhang mit der ersteren, durch Bemerkungen über die Nord- und Ost-See-Länder, S. 168-176, und empfiehlt genauere Nachforschung in alten Landes-Chroniken. Neuerdings hat sich crwiesen, dass Grönlands bekannte Küsten fortwährend sich senken. Sie bilden also eine Gegenseite zu jener Skandinavischen Hebung und zu derjenigen, die auf der andern Hemisphäre unter andern Verhältnissen an vielen Punkten im Norden des stillen Ozeans und in mehreren seiner süllicher gelegenen Inseln in best $\mathrm{im}$ te $\mathrm{n}$ Pichtungen Statt findet.

Peter Merran theilte, bei Gelegenheit eines Berichts, welchen er in der naturforschenden Gesellschaft zu Basel über Peicu's Beobachtungen der Gesteins - Temperatur in verschiedenen Tiefen der Gruben des Sächsischen Erzgebirges erstattete, eine Notitz mit iiber e in e 
natürliche Eishöhle, welche'im Kanton Busel existirt*). Dicselbe liegt beim Kalkofen, einem Hofe zwischen Oltingen und Zeylingen, am nördlichen Abhange der Spitzfluh. Die Fluh besteht ans Muschelkalk und bildet einen mächtigen Schuttabhang, der nur mit einem dünnen Walde überwachsen ist. In einigen Löchern zwischen den mit Moos und Bäumen bewachsenen Kalkstein - Blöcken findet sich Eis, welches sich nach Aussage der Anwohner gewöhnlich bis Ende Juli erhalten soll. Ein schwacher, kalter Luftzug strömt aus den Löchern hervor. Auch in diesem Luftstrom stand ein Thermometer (bei einem Besuche in Mai 1821) keinen vollen Grad über dem Eispunkt. Die Verbältnisse sind hier offenbar denen des Sauberges und mancher anderer genauer beschriebenen Eishöblen sehr ähnlich. Eine grosse Menge unter sich zusammenhängender, feuchter Höhlungen, in welche dis kalte Winteriuft wahrscheinlieh reichlicher hineinzieht, als die wärmere Luft in den milden Jahreszeiten, wodurch mit der Zeit eine Abkühlung der Räume entsteht, welclse durch die beim Hindurchströmen der Luft Statt findende Verdünnuug noch vermehrt wird, scheint das hauptsächlichste Element zur Entstehung des auffallenden Phänomens zu seyn. - In einiger Entfernung von diesen Eislöchern, in demselben Walde und an demselben Abhange, fliesst mit ziemlich spärlicher Wassermenge ein Brunnen hervor, der in der Umgegend durch sein sehr kaltes Wasser bekanı, ist. Den 7. Mai $1821 \mathrm{um} 2$ Uhr Nachmittags bei einer Luft-Temperatur von $16^{\circ}, 2 \mathrm{R}$. im Schatten auf freiem Felde, und bei $12^{0}, 5 \mathrm{R}$ : Temperatir im Walde, stand das Thermometer im Wasser des Brumnens auf $5^{0}, 0$ R. - Bei dieser Gelegenheit wird an die besonders niedrige Temperatur der sehr reichlich fliessenden Badequelle von Eptingen erinnert, welche Str̈̈нLin im Juni 1826 auf $5^{0}, 2$ R. bestimmt hat, eine Erscheinung, die wohl einer nähern Unter. suchung werth wäre.

Christan Kapp: über die Bildung der Erde und Meteolsteine (Deutscher Kalender für 1835 , Kempten bei Dannheimer, S. 72). Antediluvische Meteorsteine seyen so gut, als antediluvische Fulgurite, blosse Fiktionen. Auch die räthselhaften Nephrite lies. sen sich nicht wohl für alte Meteorsteine erklären. Vollends sey die

*) Diese Mittheilung wurde veranlasst durch die, im Reich'schen Werke enthaltenen: Beobachtungen über das perennirende Eis in den Gruben des Sıulerges bei Ehrenfriedersdorf. Durch den Statt gefundenen Abbau ist dieser Berg von nahe liegenden, parallelen, tief niedlergehenden, mit losen Gesteinstücken erfüllten Spalten durchfurcht, die sowohl unter sich, als mit einer mächtigen, vor dem Berge liegenden Gesteinhalde zusammenhängen. Feuchtigkeit durchdringt alle die, aứ solche Weise gebildeten, manchfaltigen Zwischenräume, und es findet sich dadurch die Lokalität künstlich zu einer Eishöhle unıgewandelt. Ein kalter Wiud entströmt den Höhlungen, und an einzelnen Stellen häufen sich in den Zwischenräumen des Gesteins bleibende Massen von Eis an.

Jahrgang 1836. 
Ansicht, welche die ganze Erde durch einen Zusammenfluss von Meteorsteinen entstehen lasse, gänzlich verfehlt. Auch sey das Innerste der Erde nicht als fester Kern, vielmehr als Heerd und Sitz der höchsten Expansion zu denken. Der Verfasser verweisst über das Nähere dieser letzteren Ansicht, der die spezifische Schwere der Erde keineswegs widerspreche, áuf seine Abhandlung über das erste Lebensalter der Erde, s. neues Jahrb. 1834, II, 151-204, III, 253-300.

J. Lavress: Analyse des Wassers aus dem Mittelländischen Meeve (Journ. d. Pharm. Février, 1835).

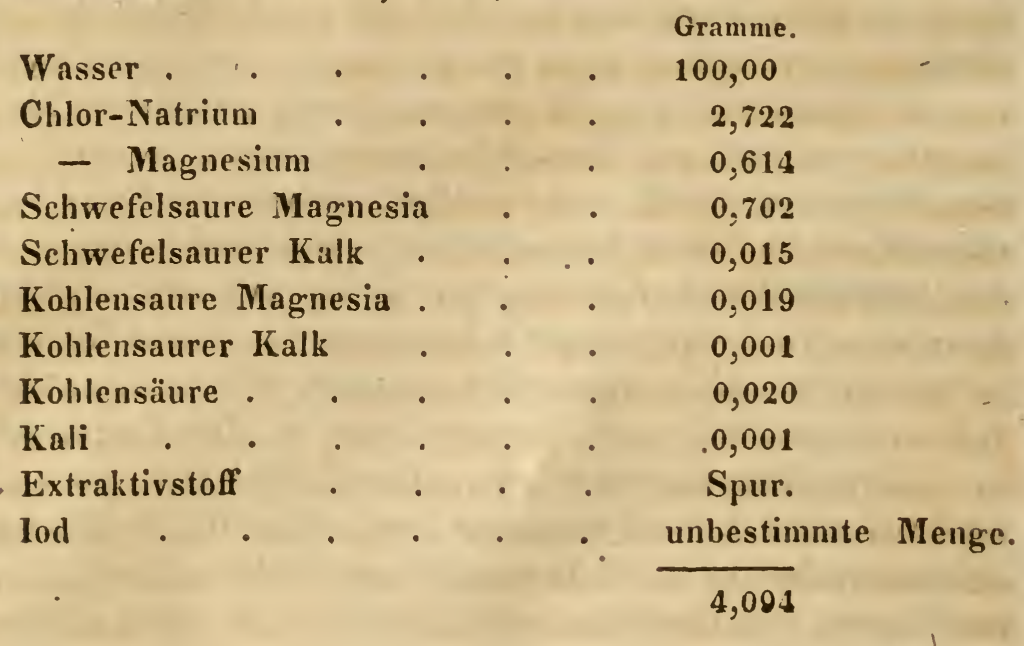

Beck: geognostische Bemerkungen über einige Theile des Münsterlandes, mit besonderer Rücksicht auf das Steinsalz-Lager, welches die Westphälischen Soolen erzeugt (Karsten, Archiv für Min. VIII, 275). Zu einem gedrängten Auszuge pignet sich diese sehr umfassende Abhandlung nicht; wir müssen desshalb, bei dem im Augenblick äusserst beschränkten. Raume, uns deren Anzeige vorbehalten.

Al. Burnes: ̈̈ber die Geologie der Ufer des Indus, des Indischen Kunkasus und der Tartarischen Ebenen bis zu den Kästen des Kaspischen Meeres; vorgeles. bei der Lond. geolog. Soz. 1833, 18. Deż. (Lond. a. Edinb. n. philos. Mag. 183t, I V, 225-228). Der Vf. bereiste die genannte Gegend in den Jahren 1831 und 1832. Die Provinz Cutch an der O. - Mündung des Indus ist gebirgig, der Boden felsig oder sandig, überstreut mit Lava-Massen; sie liefert Schwefel, Steinkohle, Eisen und Alaun. Das Delta des Indus besteht aus einer Reihe verschiedenfarbiger Schichten von Erde, Thon und Sand, 
welche bald parallel sind, bald Schwalbenschwanz-artig aneinanderstos. sen. Die Basis des Deltas hat 125 Engl. Meil. Breite; die See ist auf 3 Meil. Erstreckung vom Ufer aus getrïbt durch den Fluss-Schlamm. Von dem Meére an längs des W.-Ufers des Indus erstreckt sich die Kette der Hala-Gebirge nordwärts bis zum Indischen Kaukasus im N.W. von Cabuol und besteht grossentheils aus hartem NumınlitenKalkstein. Längs des Fluss - Ufers aufwärts erreicht man Hydrabad, auf feinkörnigem Muschel-führendem Kalke erbaut. Zu Schwan in $26^{\circ}$ 22' Br. und zu Curachée gibt es keine Quellen. Die Insel Bukhur in $27^{0} 42^{\prime} \mathrm{Br}$. besteht aus Kiesel-artigen Steinen (flints). Am östlichen Ufer, ihr gegenüber, bildet dieser Stein eine $40^{\prime}$ hohe Wand, worauf das Dorf Roree steht. In $28^{\prime} 55^{\prime} \mathrm{Br}$. fallen die Flüsse des Punjab in den Indus. Zu Kara Bagh in 330 . durchschneidet er einen Bergzug, welchen Elphinstóne als Salz-Gebirge bezeichnet. Das Salz kümmt darin in 1' dicken Lagern vor, welche durch dünue Thonschichten von einander getrennt sind. Mit Ausuahme dieses, von tiefen Schluchten durchschnittenen Gebirges von etwa $1800^{\prime}$ Seehöhe ist der Bezirk von Punjal ganz flach. Zwischen den Flüssen Sutlege und Lahore besteht die Gegend aus erhärtetem, zuweilen kiesigem Thone. - Aufwärts bei Attuch ist der Indus von dunklem Glimmerschiefer eingeschlossen, welcher sich südlich bis zun Salz-Gebirge erstrecken soll; sein Sand ist hier Gold-führend. - Zu Lahore fand im Februar 1832 ein so starker Erdstoss Statt, dass mehrere Thäler mit herabgestürzten Felsmassen ausgefüllt und die Bevölkerung von Badakhshan grösstentheils zerstört wurde. Einige Gebäude des Mogolischen Kaisers in dem Punjub sind durch Salpeter-Effloreszenzen übcrzogen und bis auf den Grund im Verfall. Weiter westlich vom Indus kommt bituminöse. Kohle zu Collat vor und dehnt sich noch das Salz-Gebirge aus. Der Fluss von Caboul fliesst in einer schmalen und $2000^{\circ}$ tiefen Schlucht, deren Wände aus Sandstein, Quarzfels und fast senkrecht aufgerichtetem Glimmerschiefer bestehen, und $C_{a b o o l}$ selbst liegt $6000^{\prime}$ über dem Meere. Fii, schöner weisser Marmor bricht in seiner Nähe, zuweilen mit Asbest überzogen, und Geschiebe von sehr ungleicher Grüsse, lose oder zı einem Konglomerate verbunden, bedecken die Gebirge. - - Von C11bool nach Balkh und den Tartarischen Ebenen überschritt der Vf. den Indischen Kaukasus, welcher die W.-Fortsetzung des Himalaya ist und dessen höchster Theil Hindoo Koosh genannt wird. Aber nur ein cinziger Gipfel desselben, der Koh-i-Baba $1^{0} \mathrm{~W}$. der Route von Cabuol nach Bumeean, von wo das Wasser schon nordwäıts in den Oxus fliesst, ist mit ewigem Schnee bedeckt. Einige Schluchten haben $2000^{\prime}-3000^{\prime}$ hohe Wände. Der höchste, zwischen Cabool und Hajeeguls beobachtete Pik besteht aus Gneiss oder Granit, der zuweilen von Eisen durchdrungen ist. Ihm folgen blaue Schicfer und Quarzfels, und Steil-Ahlıänge von Glimmerschiefer, über welche Massen von grünem Granit ı. a. Felsarten herabgestürzt sind. Tiefer hiuab kömmt ein Kalk-Konglomerat vor, dam Abhänge von röthlichem und purpurfarbenem, und Grahte 
vou erhărtetem Thone. Die Ungebung von Bameean soll Gold, Blei, Kupfer, Zinn, Antimon, Schwefel und Eisen liefern. - Die tieferen Pässe des Hindoo Koosh bestehen hauptsächlich aus sehr bartem hellbraunem Kalkstein, worauf Sandsteine folgen, in deren einen gerundete Kieselsteine in regelmässigen $Z$ wischenräumen eingebettet liegen. $\mathrm{Zu}$ Khouloom erreicht man die Ebenen von Turkistan, welche der Oxus bewässert, und welche sich bis zum Kuspischen Meere immer tiefer senken. Der Oxus, auf der Hochebene von Pameer entsprungen, ergiesst sich in den Aral, und es scheint dem Vf. keineswegs, dass er früher dem Kaspischen Neere zugeflossen sey; denu was man zwischen Astrubud und Khina trocknes Flussbette nennt, dürften Reste alter Kanäle seyo. Die Eingebornen behaupten jedoch, dass der Aral noch einen unterizdischen Abfluss in das $\mathbb{K}$ aspische Heer habe, und man zwischen beiden an einer Stelle, Fura-guombuzgenanut, das Wasser in der Tiefe rauschen höre. Jedenfalls ist merkwürdig, dass man in dem Sandrücken, nahe dabei, Wasser nahe an der Oberfläche findet, welches man weiter südlich in 100 Faden Tiefe vergeblich suchen würde. Badiklishan scheint der Mittelpunkt des obenerwähuten Erdbebens von 1832 gewesen zu seyn: die Zerstörungen waren noch grösser, als zu Luhore. Der Ort ist seiner sclionen Rubinen wegen beruhmt, welche in Kalkstein eingebettet vorkommen. - Die Gegend nördlich vom Oxus bis Bolihara besteht aus gelblichem, oft oolithischem Kalke, welcher oft vou losem Kies, in deu Ebenen vou hartem Thon bedeckt; oder unter Hügelu von Flugsand verborgen ist. Salz-haltige Quellen und SalzAblagerungen findet man hin und wieder in den Thälern.

Dotgras: über die Vulkane von Worthe in de sandwichs. Inseln (Journ. of the roy. Geogr. Soc. > Berghats Annul. 1835, XI, 404-405). Vyl. Jahrb. 1535, S. 486. Der Vf. hat drei Reisen nach den hrateren des Manna Roa, des Kirauea und des Mauna Kea gemacht. Der M. Kuah hat einen sanften Abhang, der bis 1500 ' Seehühe angebaut ist; die Wald-Region mit Akazien und manchfaltigen $4^{\prime}-40^{\prime}$ hohen Baum-Fahren dicht bewachsen, reicht danu bis zu $8700^{\prime}$ liuauf, wo die Gras-Region ganz plötzlich beginnt und sich bis gegen 11,700' Hühe erstreckt. Auf sie folgt, cben so scharf abgeschnitten, die [nackte?] vulkanische Region, in welcher noch ein Vaccinium, ein Syngenesist und ein Juncus in 12,000' Höhe die oberste Gienze aller Vegetation andeuten. Mit 12,700' gelangt man auf ein ausgedehntes, mehrere Fuss hoch mit Sand, Kies, Steinen, Schlacken und Asche bedecktes Plateau, aus welchem 11 Spitzen hervorragen, welche aber während des Besuches keincrlei Thätigkeit zeigten. Schnee war, obschon zur Winterzeit, wenig vorhanden; in Sommer fehlt er in dieser Hühle gänzlich. - Der Krater des Kirauea liegt nur 3973’über dem Bleere, ist aber nicht auf der Spitze eines Kegels, sondern stellt eine 
blosse Vertiefung an der Ostseite des M. Roa dar, weleher selbst auf seiner Spitze in 14,000' Seehöhe eine Feuer-speiende Spitze besitzi. Der Kirauea - Krater (Byros nennt ihn Vulkan Peli) hat 5 Engl. Qua. drat-Meilen Ausdehnung, etwa $1000^{\prime}$ Tiefe und fast senkreclite innere Wände, an denen man jedoch bis zu $50^{\prime}$ über der thätigen vulkanischen Mündung hinunter klimmien kann. Hier bietet sich eines der grossartigsten Natur-Schauspiele: 2 Lava-See'n, einer in S.W. von $3600^{\prime}$ Länge und eyrunder Gestalt, und einer in N. von $1200^{\prime}$ Durchmesser und Kreisform, beide in fast ununterbrochenem Zustande des Siedens, beide fortwährend von N. nach S. (5 Engl. Meil. in 1 Stunde) strömend. Der [endliche] Abfluss derselben scheint an der Ostküste der Insel bei dem Orte Punabalu Statt zu haben, wo die Lava oft übergeströmt ist. Der am S.-Ende des kleinern Soe's befindliche Abfluss bildet in elliptischem Bogen einen Fall von 456' Spannung und 43' [?] grösster Höhe. Das wälırend des Falles nach oben entweichende Gas bricht dessen Kraft und reisst Lava-Theile mit sich fort und zieht sie zur Form von Haaren und Flachs - Fäden aus, welche der Wind danu umlertreibt, und deren eine grosse Menge um den Vulkan zerstreut licgen. „Das Geräusch aller Dampf-Maschinen in der Welt würde gegen das dieses Lava-Falles nur cin GeR̈üster seyn".

Founet : über die verschiedenen Ereignisse und a ufein. auderfolgenden Formationen, welche den jetzigen $Z_{u-}$ stand der Gänge in der Umgegend von pont Giband veranlasst haben, nach Becquerez's Berichte (Acal. d. sc. de Puris, 1833, t. Nov. > l'Institut, 1833, 16. Nov.; I, 228-22.9). Die Urgebirge um Pont Gibuud enthalten eine Menge von Spalten, welche theils mit Trünmern benachbarter Gesteine, mit erdigen und metallischen Stoffen die von Aussen oder von Innen gekommen, angefüllt sind, theils vulka. nischen Materien oder Wasserströmen zun Austritte dienen. Die Erzgänge enthalten alle ungefähr dieselben Substanzen: Bleiglanz, Schwefelkupfer, Schwefel-Antimon u. s. w. Das sie umschliessende Gebirge besteht auf den Plateau's zumal aus Glimmer - Schiefer, in den Thaltiefen mehr aus talkigen Gesteinen, und der ganze Gebirgsstock ist von Granit-Massen durchsetzt. Die Gänge der andern Gebirgsart wechseln auch, wie in Cornwall, ihre Erzführung. Im Glimmer- und Talk-Schiefer sind sie vorzugsweise erzreich. Die Protogyne tritt in den Thälern durch Zersetzung der sie umschliessenden Talk-Gesteine hervor, zerfällt aber sclbst durch den Übergang von Feldspath in Kaolin. - Die Gänge sind von zweierlei Art: es sind entweder auf feurigem Wege ausgefüllte Spalten, voll Porphyr, Trachyt u. s. w., worin die Kieselerde sich mit andern Stoffen verbunden liat, - oder sie sind auf nassem Wege ausgefüllt worden durch Einwaschung von oben, oder durch Quellen von unten in allen andern Fällen, wo die Kieselerde für sich, 
abgesondert, neben den stärksten Basen vorkonmt (die häufig mit Kohlensäure vereinigt sind), ohne Silikate zu bildeu, wie doch der Fall seyn müsste, weun die Ausfüllung nach der Meinung anderer Geologen durch Sublimation erfolgt wäre. Eine Temperatur, hinreichend um die Kieselerde in Dampfform aufzutreiben, häite selbst wenigstens die Oberflïche der übrigen Ausfüllungsstoffe und der Kluftwände schmelzen, verglasen müssen. - Ist die Ausfüllung von oben erfolgt, so zeigt sich glcichwobl einige Veränderung der in den Klüften miteinander in Kontakt gekommenen Mineralien: Talk und Glimmer der Schiefer sind in eine graue schmutzende Materie verwandelt; in Talkschiefer hat sich der Speckstein in sehr fettigen Trümmerchen und Nierchen ausgeschieden; im Granit der Feldspath sich in Kaolin verwandelt, was im massigen Gebirgs - Granit nie geschieht. - Die Ausfüllung von Iunen durch Quellen 'setzte zuerst Kieselerde, Schwefeleisen und Arsenikkiese auf Trümmer von Urgesteinen ab, und zwar wahrsciejnlich so rasch, dass keinerlei Krystallisation Statt fand. Andre Niederschläge legten sich dann un dieselben. Der Verf. unterscheidet noch vier andre Perioden, in welchen die letzteren entstanden sind. Bei der zweiten wurden die schon vorhandenen Gangspalten erweitert und kleinere Trümmer setzen von ihnen in die Wand - in Dach und Sohle - fort. Auch diese neu entstandenen Räume wurden nun theils durch Einfüllung ältrer Gestein-Trümmer und abgelöster Gangquarzstücte von oben, theils durch Quarz und Schwefel aus Quellen von unten ausgefüllt: aber durch einen splittrigen, zur Krystallisation geneigten, zuletzt mit krystallikchen Zuspitzungen versebenen Quarz, und der Schwefel bildete mit Kiesen, Bleiglanz und Quarz in kleiuen Krystallen abwechselnd Schichten um die älteren Nieren. In der dritten Periode erweiterten sich die Gänge abermals und mit demselben Erfolge; jedoch scheinen die Blendeund Bleiglanz-absetzenden Quellen dadurch aus den Gängen abgewendet und Auflösungen von schwefelsaurem Baryt oder mindestens von solchen Salzen hiueingeleitet worden zu seyn, die durch ihre Reaktion dergleichen hervorbringen konnten. So findet man im Gange von Barbéco auch Stücke, deren Kern ein Urgebirgs-Trünmer und umgeben ist von splittrigem Quarz, von Schwefel-Blei und -Ziuk, und der Baryt nimmt an seiner Berührungs. Fläche nit der Gebirgsart eine violette Färbung an, dic sich von derselben weg mehr und mehr verliert: die Wasser scheinen also auf die älteren Gebirgs-Arten eine auflösende Wirkung gehabt zu haben. In der vierten Epoche hat die inkrustirende Thätignkeit der Quellen nachgelassen, die Saalbänder bildeten sich, die Ausfüllungen dauerten fort, von Aussen kamen zälse fettige Thene, oft mit abgeriebenen Theilen aus den Gängen selbst, von Inuen wirkteu die Quellen. Oft scheinen die Saalbänder nur durch eine tiefe Umänderung der Gebirgsart entstanden zu seyn, was durch die Annahme eives verlängurten Aufenthaltes des Wassers in den Gangspalten erklärlich wäre, während zugleich Pyrite und die ersten kohlensauren Salze entstunden. Die fünfte Periode scheint der 
der grossen Alluvionen und Basalt - Ausbrüche zu entsprechen; dic Kiesel-Absetzungen dauern fort, Eisen und Mangan bilden sich im Hydrat-Zustand, nur die Kalkerde eignet sich die Kohlensäure an, welche in dieser Periode in Menge sich aus Wassern und vulkanischen Spalten entwickelt. - Würde man das Grubenwerk geschlossen verlassen, so würden sich mit der Zeit zweifelsohne wieder andere bauwürdige Kiesel- und -Kalk-haltige Eisenhydrat-Erze darin erzeugen. Freies Mangan ist nicht häufig: Kiesel kommt an mauchen Stellen vor; der Kalk ist dem der Stalaktiten ähnlich, zuweilen krystallisirt. Die Zersetzungen durch die atmosphärischen Agentien finden in der Weise Statt, dass beide Elemente der Schwefelmetalle sich oxydiren, freic Basen und Säuren bilden, die sich dann andrer Bestandtheile bemïhtigen um ganz neue Verbindungen einzugehen. Das erdige und derbe Eisen-Hydrat entsteht offenbar durch Zersetzung von Pyriten, die oft noch seinen Kern ausmachen; - das pulverige Eisenhydrat aus der Zersetzung des kohlensauren Eisens, das blassgrüne Arsenik-Eisen aus Arsenik-Kiesen; - auch das haarförmige phosphorsaure Eisen ist ein neueres E:zeugniss. Auch der Bleiglanz zersetzt sich, wie das Schwefeleisen, und verwandelt sich zuweilen in ein schwarzes schmutzendes Pulver, zuweilen in schwarzes und weisses, glasiges oder erdiges kohlensaures Blei, das mit Bleiglanz gemengt bleibt; zuweilen endlich in kleine Oktaeder von Scliwefelblei. Die Blende verwandelt sich in schwefelsaures und saures schwefelsaures Zink. Das Schwefelkupfer in Kupfer-Sul. phat und - Karbonat und in Kupfer-Protoxyd.

Dic Beobachtung der Erscheinungen der Mincral-Quellen dürfte unsere Theorie der Gänge sehr zu erhellen dienen, u. u.

R. J. Murchison: über das Silurische Felsarteu-System (Lond. u. Edinb. philos. Magaz. 1835, rII, 46-52). Mit Beziehung auf seine frühere Arbeiten über einen Theil der sg. Übergangs-Formation (vergl. Juhrb. 1836, S. 70) $\frac{464}{\text { schlägt } M . ~ n u n n e h r ~ f o l g e n d e ~ T e r-~}$ minologic vor:

$$
\text { Früher. Jetzt. }
$$

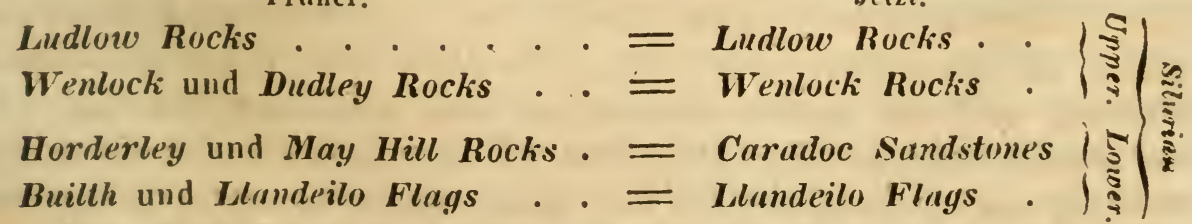

Das Wort Silurian bezieht sich auf den Wohnsitz der alten Silurier in der Gegend, worin M. diese Felsarten in ihrer vollen Eintwickelung beobachtet hat. Der Ausdruck Caradoc ist von dem wohlbekannten Bergrücken Caer Caradoc daselbst abgeleitet.

Das grosse Werk des Verfs. über diese Gebilde mit einer detaillirten Karte und vielen Tafeln mit Abbildungen fossiler Körper ist fortwälırend in Arbeit. 
Rich. Phillips: Versuch über die physischen und astronomischen Ursachen der geologischen Veränderungen auf der Erd-Oberfläche und der Erd-Temperatur (Monthly Magazine, 1813, und dessen Twelve Essays, etc. 1820; dann dessen Es. say on the physico-astronomical cause etc., London, 1832, $800 \mathrm{pp}$. $3^{0}$. $>$ Loudon's Magaz. of. natural history, 1832, Jan. p. 102. $>$ Bull. géol. de France, 1833, III, pg. cxxIII-CxXIT). Phillips ist seit 1813 der Meinung, die geologischen Veränderurgen hönnten von der Bewegung der Apsiden-Linie um die Elliptik während des Zeitraums von 20,930 Jahren abgeleitet werden, weil die Extremitäten dieser Linie die Yunkte des Apheliums und Periheliums bilden. Die Differenz des Abstandes der Erde in diesen zwei Fällen beträgt 3 Millionen Meilen, woraus wieder eine Differenz von Aktion und Reaktion hervorgeht, genügend um die Gewässer zu zwingen, sich nach der Abueigung des Peribeliums im Punkte der grössten Thätigkeit zu fügen. Das Fortschreiten der Apsiden-Linie ändert die Neigung der Punkte tes Aphelium und Perihelium um $47^{\circ}$ und folglich auch die Richtung der grössten und geringsten Wirkung und Gegenwirkung. So, sclieint es, sey diese Kraft genügend um eine Vermisderung der schiefen Neigung von einer Minute in 120 Jahren, oder von $1^{0}$ in 7200 Jahren zu begreifen. So würden nach einem zehnmaligen Umlauf der Apsiden-Linie, oder nach einem zehnmaligen Übergange des Ozeans von einer. Halblugel in die andre der Wendekreis endlich nach Liverpool gelangen.

Dassen: A bhandlung über das Entstehen der losen Steine, die aufder Drente'schen Heide und anderwärts vorkom m e n (vas der Hoever en de Vriese Tijdschrift voor natuurlijke Geschiedenis en Plyysiologie, 1835, II, 255-295). Das Skandinavische Urgebirge stieg weich unter dem Meere empor und hob das bereits erhärtete Übergangs-Gestein mit sich. Wo solches mächtig lagerte, drückte es ersteres zusammen, so dass grosse, weiche Massen desselben aus den entstehenden Rissen emporsprützten, auf ihrem Wege durch die Luft rundliche Formen annahmen und nach dem Niederfallen durch Fortrollen sich noch mehr abrundeten. Wo aber das Übergangs - Gestein nicht mächtig war, wurde es ebenfalls zu Blöcken und Trümmern zerrissen, die sich bei der Fortbewegung abrundeten, was ihre geringere Härte begünstigte. Von der gehobenen Strecke floss das Meer strömend $a b$, riss tiefe und lange Thäler in den weichen Grund, erhitzte sich, löste im heissen Zustande viele Stoffe chenisch auf, erlangte eine grössere Eigenschwere und ward so fähig, auch jene Felsblöcke mit sich zu tragen, bis sich seine Ströme in Nord-Deutschland und Holland allmählich abkühlten, seine chemisch gelösten Bestandtheile sich niederschlugen, seine Tragkraft schwand, und somit auch Sand, Thon und Blücke sich schichtenweise a'setzten. Diese Theorie scheint 
dem Verf. einfach, da sie aus der ausgemachten Thatsache der Gebirgs-Hebung nothwendig folge.

Eudìs DesLongchamps: geologische und paläontologische Bemerkungen über ein Kalkflötz, welches in einigen Gegenden des Calvados-Depts. den Polypiten-Kalk überlagert (Bullet. géol. 1835, VI, 181-192). Über dem Polypiten-Kalke der Normandie ruht ein Flötz, welches die Geologen von vorigem bis jetzt nicht gesondert hatten, das aber rücksichtlich seiner geognostischen Kennzeichen und seiner fossilen Konchylien, deren nur wenige in jenen hinabgehen, sehr davon verschieden ist, obschon beide einerlei Polypiten-Peste einschliessen. G. B. Sowerby hat es 1832 nach Ansicht des Gesteins und seiner organischen Einschliusse für den Pisolith der Engländer erklärt, welche Benınnung nun der Verf, obschon sich gegen diese Vergleichung vielleicht Einiges einwenden liesse, hier beibehalten will.

Der Englische Pisolith ist ein Glied des Coralrags, welcher zwar in Nornzandie überhaupt wohl, aber nirgend mit diesem Pisolith zusammen, vorkommt. Man sieht den Coralrag von Benerville bis Villerville, unweit Trouville und anderwärts zwischen dem Kinmeridge- oder Honfleur-Thone und dem Oxford- oder Dives-Thone liegen, wo er aber auch nicht eine fossile Art des Pisolithes darbietet. Lezterer ruhet unmittelbar auf dem Polypiten-Kalke, der dem Englischen Forest marble zu entsprechen scheint, so dass, wäre Sowerby's Ansicht richtig, da, wo der Pisolith auf dem Polypiten - Kalke ruhet, die mächtige Formation des Oxfordthones und Kelloway rocks gänzlich mangeln müsste. Gehört also der Pisolith dem Coralrag an, so muss man anvehmen, dass 1) das Mecr auf dem Polypiten - Kalk in einigen Gegenden nichts, in andern das mächtige Gebilde des Dives - Thones abgesetzt habe; 2) daher sich der Coralrag bald auf den Dives - Thon, hald auf den Polypiten-Kalk uumittelbar ablagerte und im ersten Falle als Pisolith ein ganz eigenthümliches Ansehen gewann und grösstentheils abweichende Konchylien-Arter in sich aufnahm.

Der Normänn'sche Pisolith ist mässig fest, zuweilen zerreiblich, zuweilen sind seine Korallen-Reste durch Kalkspath-Massen voll weisser Oolithe verkittet; manchmal wird er durch Einseibung von Schwefeleisen sehr hart. Seine Farbe ist gewöhnlich matt weiss, sein Bruch frisch und oft körnig; er ist an den meisten Orten voll kleiner Korallen-Trümmer, Echiniden - Reste und wohlerhaltener meist kleiner NIuscheln. Liegt darin eine einzelne Muschelschaale horizontal, mit der vertieften Seite nach unten, so hat sie unter sich eine von der GebirgsArt leer-gebliebene, und nur mit Kalkspath-Krystallisationen ausgefüllte Höhle gebildet, woraus man schliessen muss, ihre Unterlage sey bereits erhärtet gewesen und habe daher nicht mehr von unten in jene Höhle 
eindringen können: diess ist dort eine schr gewöhnliche Erscheinung. Merkwürdig ist, dass in diesem an Konchylien so reichen Kalke alle Polythalamien, wie Belemniten, Nautilen und Ammoniten, gänzlich fehlen. - An der Küste kann man den Pisolith von Lion bis Lauyrune verfolgen, wo er sich westwärts auszukeulen scheint; - südlich geht er bis Ranville, 2 Stunden von Caen, wo er auf Polypiten-Kalk liegt, und längs der Orne weiter bis sallenelles, um dort einen isolirten Pels zu bilden; - seine Verbreitung nach Osten ist nicht genau bekannt; - westlich von der Orne findet man ihn zu Blıinville, Bínouville, Saint-Aubin-d'Arquenay, Ouistreham, Colleville, H'rmanville, Lion, Luc und Laugrune wieder. Seine Mächtigkeit beträgt $8^{\prime}-30^{\prime}$. Bald ist der Pisolith unmittelbar von Dammerde bedeckt und dann besteht sein obrer Theil aus zerspaltenen und zerreiblichen Täfelchen; bald folgen auf ihn (zu Hermanville, Colleville und Sullenelles) einige grau-gelbliche 'Thonschichten, im Ganzen $3^{\prime}-6^{\prime}$ mächtig, nit hartem Mergel-Kalk wechsellagernd, welche beide Gesteine Pholadomya plicata n. sp., grosse Terebrateln, Austern, insbesondre 0. minima Defr., Gervillia aviculoides Sow., Avicula pectinata Sow., Pectines, Ammoniten u. s. w. mit oder ohne Schaale enthalten, und von DE CAUnoNT als dem Dives-Thone und Kelloway rock entsprechend angegeben worden, nach der Sowerby'schen Ansicht aber vielmehr dem Kimmeridge - Thon verglichen werden müssen. Überall, wo dieser Thon den Pisolith bedeckt, löst er sich nicht in die oben erwähnten TäfeJchen auf, sondern ist hart, hauptsächlich durch eingeseihetes Schwefeleisen, mit ebener Oberfläche, von einer Menge senkrechter, zylindrischer, $2^{\prime \prime \prime}-4^{\prime \prime \prime}$ weiter, unten abgerundeter und $6^{\prime \prime \prime}-12^{\prime \prime}$ tiefer Lücher durchbuhrt, in welchen sich ausser dem von oben hereingesunkenen Thone noch Reste ausgestorbener Arten von Bohrmuscheln finden, wie auf der Oberfläche selbst nicht selten sekundäre Austern-Schaalen anhängen (Lion, Hermanville, Colleville, Sullenelles).

Aber ganz dieselben Bohrlücher findet man auch unter dem Pisolith auf der Oberfläche des Polypiten-Kalkes wieder (zu Ranville, Ebisey, Bénouville; zu Luc und Saint-Aubin de Lauyrune an Stellen, die von der Fluth bedeckt werden), der jedoch vom Pisolith durch einige zwischen gelagerte Flötze getrennt ist (von Laugrune bis Lion etc.). Ein Theil derselben ist mergeliger Kalk voll Terebrateln von 2-3 Arten und voll Korallen, worunter Spiropora caespitosa vorwaltet. Ein andrer ist mehr kalkiger Art, hart wie Marmor oder fast zerreiblich, mit sehr schönen Konchylien, Polyparien, Krustazeen und wohl erhaltenem Apiocrinites rotundus. An der Oberfäche finden sich mit ockriger Erde erfüllte Stellen, aus welchen der Regen die Erde bimen 1-2 Jahren auswäscht und die Versteinerungen dazwischen in so vollkommenem Zustande hinterlässt, dass man Terebrateln mit aneinander beweglichen Klappen und wohlerhaltenem iunerem Gerüste u. dgl. erhält. Diese-Kalk - Schichten sind es hauptsächlich, von welchen die 
darüber und darunter folgenden den Namen Polypiteu-Kalk im weiteren Sinne des Wortes erhalten haben.

Die Versteinerungen des Pisoliths sind von Psammobia 3 Arten, von Donax 3, Trigonia 4, wobei T. costata, von einem ueuen verwandten Geschlechte 1 Art, Saxicava phaseolus n. sp., Fistulana subtrigona; Cardium 2-3 Arten; Schlotheimia antiquata Desc. ; von einem mit Lucina verwandten Geschlechte 7 Arten, wovon eine auch im Polypiten-Kalke; von ? Is ocardia 2 Arteu; von Astarte und Verwandten 10-12, von Pectunculus 3-4, CuculI a ca 12-15, Nucula 2, Modiola 6, Lithodomus 3 Arten, wovon eine auch im Polypiten-Kalke; von Myoconcha 1, Perna 1, Avicula 5-6 Arten, worunter A. costata nit dem Polypiten-Kalk gemeinschaftlich; von Lima 7-8 Arten, deren einige, und von Pecten und Ostrea je $3-4$ Arten, welche alle sich im Polypiten-Kalk wiederfinden; von Orbicula 1 Art; 10-12 Terebrateln, wobei T. digona, T. te traëdra, T. rigida, T. hemisphaerica, T. truncata, T. reticulata und T. coarctata, welcbe beide zu Lamarck's T. decussata zusammengehören; $2-3$ kleine Nerineen; 1 mit Neritina verwandte Art; $5-6$ Turbo- und Trochus-Arten; 1-2 Pleurotomarien; 2 verwandte Arten; 1 Melania?; 4 Patellen, wobei P. rugosa Sow.; 1 kleine Emarginula: 1 kleine Fissurella; 2 kleine Arten eines mit Delphinula oder Solarium verwandten Geschlechtes, dessen Nabel so weit als bei Planorbis ist, und 2 kleine Pter n c e re n.

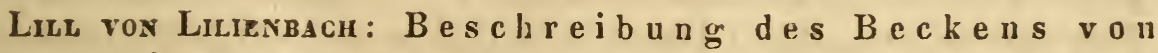
Gallizien und Podolien (Mém. d. l. Soc.géol. de Fr., 1833, I, 45-105). Dieses Becken liegt zwischen dem $37^{\circ}$ und $44^{\circ}$ W.L. und zwischen dem $47^{\circ} 25^{\prime}$ und $50^{\circ} 25^{\prime}$ N.B., und bildet nit der Bukowina eine Fläche von 900 Deutschen Quadratmeilen. Es ist nur der S.W.- Theil des ungeheuren Beckens, das fast ganz Polen und einen grossen Theil von Russland in sich fasst. Es hat Alluvial-Land, tertiäres, sekundäres und Übergangs-Gebirge, welche wieder aus tertiärem Kalk, Sand, Sandstein und Molasse, aus Kreide, Grüusand und Jurakalk, aus rothem Sandstein und Orthozeratiten-Kalk bestehen. Die Schichten liegen im Allgemeinen horizontal und gestatten daher bei ihrer auf grosse Erstreckuugr andaueruden Einförmigkeit leicht, sie zu verfolgen. Wirft man einen Blick auf die geognostische Karte, so erscheint das grane Becken so von Alluvionen bedeckt, dass nur von Krackau und Wieliczka an längs des ganzen nord-nordöstlichen Abhangs der Karpathen ein schmaler Streifen Karpathen-Sandstein von gleichbleibender Breite zum Vorschein komnt, die übrigen Formationen aber, mit Ausnahme einzelner kleiner von einander gesonderten Flecken tertiären oder in der That nur selten sekundären Gebirges, nur an den Wänden der cugen Thäler des Iniester und seiner Zuflüsse, weniger des in gleicher Richtung fliessenden 
Sereth, erscheinen: und zwar das Übergangs-Gebirge nur im östlichsten Theile derselben, wo das Wasser bereits am tiefsten eingeschnitten hat.

I. Alluvionen. Die neueren sind theils mechanische, wie Sand, Thon, Lehm, und Geschiebe, welche tiefer als erstere liegen und unter welchen man nächst dem Fusse der Karpathen auch solche von den granitischen Felsarten in der Mitte dieser Kette bemerkt, - theils chemische, wie Kalktuff, Torf, Sumpferz und Scliwefel, erstrer von mehreren Quellen abgesetzt. Im Lehme von Lemberg kommen Landund Süsswasser-Konchylien vor. Jene mechanischen Niederschläge finden sich hauptsächlich läugs der Flüsse und in deren Überschwemmungs-Gebiete. - Die älteren mechanischen Alluvionen aber nehmen Stellen hoch über diesem letzteren ein und werden wie die neueren eingetheilt; sie enthalten Knochen von Elephanten und Mastodont e n und haben oft bis $30^{\prime}$ Mächtigkeit. Grosse Granit-Blöcke aber, oft in ansehnlichen Höhen abgelagert, verdanken ihre Entstehung vielmehr der Hebung von Gebirgen.

II. Tertiär-Formatiou. A. O b c rer Kalk. Er begreift theils den gewöhnlichen Grobkalk, theils eine kompakte Varietät mit See- und Süsswasser-Konchylien in sich. 1) Zu oberst liegt ein braunlicher oder öfters weisslicher kompakter Kalk, welcher erste in dümen Schichten nur auf dem Sandsteine vorkommt, während der letzte of mit dem eigentlichen Grobkalk wechsellagert. 2) Dieser liegt tiefer und besteht aus Kugelkalk, weissem zerreiblichem Kaik und mergeligsandigem Kalk. 3) Eine dritte Gruppe besteht aus kalkigem und quarzigem Sandstein, Agglomeraten, Muschel-Sand und -Thon; wovon der. Sand und Sandstein am verbreitetsten sind. Gyps bedeckt die Kalksehichten in grosser Ausdebnung. - - 1) Die erste Gruppe enthält Venericardien, Mytilites (Modiola) acuminatus Scнцотн., Limneen, Serpeln, Cerithium scaber, Paludina pygmaea und P. in fl a t a und findet sich zu Lemberg, Tarnopol, Hluboczek, Zborou, Horostiow, Postolumka, am Podhorze, zu Hatni u. s. w. - ? Der Grobkalk unschliesst Ostrea, Pecten, Eschara, Venericardia imbricata Lamk., V. (Chama) rhomboidea Brocci., Pectunculus, Cidaris, Cerithium scaber, Tellina pellucida Broccir, Lucina albella Lamk., Cardium obliquum Lмк. Serpula, Trochus sulcatus, und ist selten von vorigem bedeckt; liegt auf Übergangs-Kalk Podulien in zu Trembowla, Czortkow, Zaleszczyky, Bilczaauf Kreide zu Brzezany, Nisniow, Monasterzyska - auf Kreide-Gyps zu Rohatyn, - auf Molasse zu Mokrotyn, - auf tertiärem Sand zu Mikolaiaw, Polana, Rawa, Slowila, Tluste, Tirleiow etc. - 3) Der Sandstein ist arm, der Muschelsand und Thon reich an fossilen Arten: doch sind deren Trümmer öfters zu einem harten Sandstei. zusammengekittet. Jene Arten sind: Serpula, Cerithium mutabile Lıмк., C. scaber Brug., C. margaritaceum, C. tricinctum, Patella, Trochus turgidulus, Turritella, Conus striatulus, Lenticulites discorbinus Schoth., Dentalium eburncum, Delphinula, 
Venericardia imbricata, V. rhomboidea, Modiola, Ostrea, Pecten pleuronectes, P. orbicularis, P. Polonicus, Pectunculus pulvinatus, Tellina pellucida, Lucina albella, Cardium obliquum, Mya gigantea, Nucula, Isocardia, Astarte senilis, Saxicava, Teredo, Fischknochen, Rhinoceros tichorhinus, Pflanzentheile. - B. Lignit-Sandstein. Thonige Sandsteine mit quarzigen Massen verbunden, wechsellagern mit schieferigem Sandstein, enthalten ansehnliche Braunkohlen-Lager und eingestreute Bernsteine. Sie enthalten zu Lemberg, Podhorze und Myssin bei Kolomea zugleich viele fossile Arten, zumal auf den Schichtflächen: Patellen, Pecten orbicularis, P. cornea Sow., P. rigida, Is ocardium, Pectunculus pulvinatus, P. Insubricus, Venericardia, Cardi u m, M y a.

III. Sekundäre Formationen sisd in der Mitte des Beckens am meisten entwickelt. 1) Die Kreide ist einförmig, geschichtet und enthält Gyps und Schwefel. Zu oberst ist sie reii, zart, in Wechsellagerung mit einigen härteren Schichten und Feuerstein-Lagen, fast ohne Versteinerungen. Zu unterst ist sie mergelig und enthält untergeordnete Thoimergel-Schichten, die etwas sandig, graulich oder blaulich sind und Baumblätter enthalten. Ilıre Schaalthier-Reste stammen hier bei Lumbery von $S$ ole $n \mathrm{rag} i n a, A m m o n i t e s$ inflatus, A. planulatus und A. comprimat us Schlotr., Madrepora, Nucula pectinata, N. striata; bei Makrotyn von Lima, Avicula, Inoceramus; bei Mlagyerow von Pecten pleuronecte s und grossen Ammoniten, bei Szczerzic von Pecte n as per Lank., P. a r a chnoides DeFr. und Pectunculus; im Königreich Polen hat Puscri gefunden: Belemnites mucronatus, Gryphaea dilatata, Millepora, Ananchites ovata, Spatangus cor anguinum, Galerites albogalerus, Cidarites, Pecten arachnoides, Mytiloides labiatus, Gryphaca a uricularis, G. columba, Ammonites constrictus, A. Selliguinus, Terebratula carnea, Rostellaria, Fissurella, Trochus. Den Schwefel-führenden Gyps, welchen L. zu dieser Formation bringt, rechnet Bouś noch zu den tertiären Bildungen. - - 2) Der Gr ü n s a nd ist grob oder fein, mit Quarz und Chalzedon - Trümmern: er besteht aus Wechsellagerungen von Kalksand und sandigem Kalk. In den von einigen Konchylien hinterlassenen Räumen hat sich Kalkspath angesetzt. Von MI a repora, Os trea, Pecten pleuronectes sind einige Reste, oft zerbrochene hinterblieben.

3) J u rakalk. Er ist in Bestand und Lagerung sehr einförmig. Die Formation bestelit aus einem an Versteinerungen nicht armen, kompakten, auch oolithischen oder dolomitischen Kalke mit einigen KieselKonkrezionen, und hat eine wagerechte, oft blättrige Schichtung. Die Oolithe mit den lithographischen Schichten kommen im Norden, im Königreich Polen vor, die Dolomite im Süden, der kompacte Kalk am Rande des Gallizischen Beckens an der Weichsel bei Tiniec und 
Krackat. Bei Podyorsze fand man einen A m moniten, anderwärts E chiniten und Frchtel's Holnth u ria tremula darin; im Künigreich Polen zitirt Puscu Madrepora (Astrea) cavernosa, Fungites, Ammonites planulatus, A. depressus, A. macrophthalmus, Nautilus, Lenticulites, Belemnites m uc ronat us, B. a cuarius, Trigonia cost ata, Bucardites hemicardius, Is ocardia, Tellivites donacinus, He. licites ampullaceus, H. globositicus, Strombus, Terebratulites obliquus; T. Helveticus, T. varians, Echinites.

IV. Übergangs-Formation: erscheint nur im östlichsten Theile des Beckens in den tieferen Thälern, wo bei der völligen Horizontalität der Schichtung dieselbe Schichte an vielen Orten beobachtet werden kaun. 1) Der rothe $S$ a ndstein, zweifelsolne der Reprïsentant des old red, ist quarzig, etwas thonig, feinkörnig, mit Säuren brausend. $\mathrm{Zu}$ oberst enthält or G or go n e n und bis $2^{\prime \prime}$ breite und 4" lange Sol e n a e e n [C n u l a ri a? fragt Boví] zu Zalesacayky. 2) Der Orthoceratiten-Kalk ist etwas krystallinisch, euthält Schieferthon-Schichten, ist zuweilen ohne Versteinerungen und dann sehr bituminös, oder enthält 5 " lange und $2^{\prime \prime}$ dicke 0 rthoceren, 0 . vaginatus, O. undulatus, O. nodulosus, Terebratulites vestitus, T. striatulus Schl., Eschara, Trilobites, Productus intermedius, P. comprimatus s. artifex Schl., Spirifer (Terebratulites) speciosus, Hysterolithes hystericus, Tentaculites annulatus, Retepora etc. Dieser Kalk ist in bezeichnetem Becken die unterste der bekannten Felsarten.

Edw. Charlesworth: B e ob a chtungen über die CragFormation und ihreorganische Übérbleibsel, mit e inem Versuch, die Tertiär-Schichten über Londonthon in Suffulk unterabzutheilen. Vorgeles. b. d. geolog. Soz. am 27. Mai. 1835 (Lond. a. Edinh. Philos. Magaz. 183.5, VII, $81-94$ ). Vom Crag handeln 1-2 Notitzen in den geologischen Transaktionen, inshesondere TAYLor in B. $\mathbf{I}, 371-373$; - von dem in Norfulk R. C. TaYLor in Geology of Norfolk 182\%, und S. Woopwand Outlines of the Geolugy of Norfolk; über ihn und den viel entwickelteren in Suffulk hat LxeLL in Sommer 1831 einige Beobachtungen gesammelt und in seine Principles aufgenomnien; endlich charakterisirt Phillips den bekanntesten Theil dieses Gebildes gut in seinem Guide to Geology, während ein viel beträchtlicherer und in seinen Charakteren abweichender Theil bis jetzt wenig beobachtet worden ist.

Den gewöhnlichen neunt Cr. "rothe n C rag," den letzteren "Coralline Crag." Ersterer lässt sich in Norfolk, Suffolk und lıauptsächlich längs der S.O.-Küste von Suffulk und Essex am besten 
beobachten, wo auf der Spitze der vorstehenden Klifis der eisenschüssige Sand voll gerollter Muschel-Trümmer in $5^{\prime}-20^{\prime}$ mächtigen Schichten ungleichförmig, und ohne eine Änderung bei der Annäherung zu erfahren, gewöhnlich den Londonthon überlagert, an dem allmählich verflächten Rande der landeinwärts, ziehenden Buchten aber scine Lagerung nur undeutlich erkennen lässt. Der heller gefärbte Coralline crag aber, reich an eigenthünlichen, eine frühere Bildungszeit andeutenden Fossil-Resten und zwischen vorigem und dem Londonthon liegend, lässt sich ain schönsten beobachten in Bruche zu Tattingstone an der West-Grenze des Crags zwischen den Flüssen Orwell und Stour, dann in Sudbourue Park 20 Meil. östlich von vorigem, und vorzüglich zu Ramsholt *) am östlichen Ufer des Deben. Er ist vou vorigem scharf gesclieden, ohne Übergang. Die Lagerung ist

1) Alluvionen und Geschiebe 2u I. Tatting- II. Sudbmurne III. Ramsholt.
stone,
Park,

2) Rother Cray . . . . Sandlager mit einigen Konchylien, 15', Sandlager mit vielen Konchylien unter $45^{\circ}$ cinschiessend, aber in falscher Schichtung, 4'.

$4^{\prime}$

3) Coralline Crag (bei I $=70$ Yards weit geöffnet)

$$
6^{\prime}+\cdot 12+\cdot \tau^{\prime}
$$

Der Coralline Crag besteht aus kieseligem Sand mit viel kalkiger Materie, durch welche er jedoch nur wenig Zusammenhang erhält; seine Schichten zeigen in Farbe und Erstreckung keinerlei Abwechslung und Unregelmässigkeit: sie sind ruhig niedergeschlagen, voll KonchylienResten, welche nicht abgerolit, nicht ocherig gefärbt, oft fast so gut als im Pariser Grobkalk erhalten sind und vorherrscherid den Geschlechtern Pectunculus, Cyprina, Cytherea, Astarte, Venericardia, $\mathrm{O}$ strea und $\mathrm{Pecten}$ angehören. In grossen Gruppen von Balanus-Schaalen liegen die Deckel noch innwendig: ein weiteres Zeichen, dass sie nicht von der Stelle geführt seyn können. Nicht nur entluält dieses Gebilde viel mehr Arten, als der rothe Crag, sondern es sind ihm auch ungekehrt einige Genera, wis M u rex und B u c c :num (auch Cypraea, Tellina etc.) ganz fremd, welche in diesem durchaus verbreitet sind. Die zahlreichste Sammlung fossiler Reste aus den Crag besitzt Searees Wood Esq. zu Hasketon bei Woolbridye; sie enthält dreimal so viel Arten, als man bis jetzt überluaupt aus dem

₹) Einer späteren Eemerkung gemäss ist diese Fundstelle jetzt so untergraben, dass man, un zu samucln, nicht mehr gut zukommen kann. Günstiger ist zu diesem Behufe der Bruch im Pfarrorte Sutınn, welcher einem sehr gefalligen Besitzer, Hr. Colcuester von Ipsuvich gehört. 
Crag gekannt hat. Ausser vielen Polyparien, R a diarien und Krustazeen-Resten besitzt er noch an

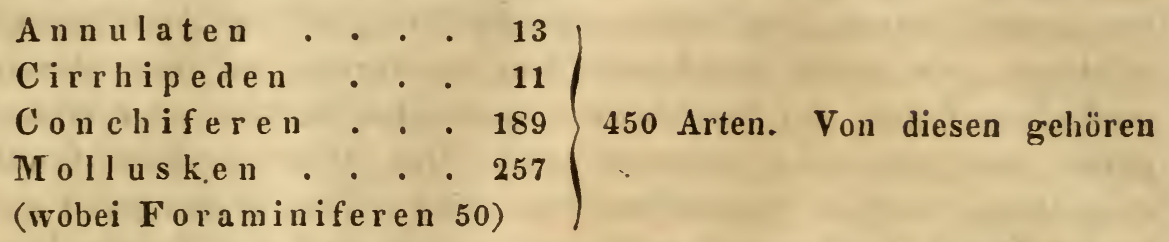

80 allein dem rothen, 200 dem Coralline Crag und 150 sind beiden gemein; sämmtliche Foraminiferen gehören dem letztern ausschliesslich an; alle Arten des letztern stammen gleichwohl nur von 2 Lokalitäten. Woop ist der Meinung, jener seye durch Zerstörung dieses letzteren entstanden.

TAYLOR hat hereits bemerkt, dass zu Aldborough an der Ostgrenze der Crag einen eigenthümlicien Charakter annehme und sich in ein weiches poröses Gestein voll Korallen und Spongien verwandle. Derselbe Fall findet aber auch zu Sudbourne und dem nahen Orford Statt (beide Orte dem Marquis von Hertrond gehörig), wo zwar der Versteinerungen (ausser an dem schon erwähnten Punkte zu Sudbourne) weniger sind, aber der Boden an vielen Stellen zur Beobachtung aufgeschlossen ist. Die Korallen sind hier in den manchfaltigsten Arten und Geschlechtern so häuig und dicht über und in einander gewachsen, dass sie oft das Gestein fast gänzlich zusammensetzen und nur die Zwischenräume mit Sand, Muschel- und Korallen - Trümmern ausgefüllt sind, welche zugleich das Ganze verkitten, wie das Alles eben noch heutzutage in Korallen-Riffen Statt zu finden pflegt. Bleiben diese Gesteins-Schichten eine zeitlang dem Regen ausgesetzt, so wäscht dieser den Sand zuweilen rein zwischen den Korallen heraus. Diese KorallenSchichten sind aber ein Äquivalent der vorhin erwälnten untern Muschel-reichen Schichten des Crag: sie sind wie jene in ruhigem, tieferem Wasser gebildet; sie enthalten viele Korallen, welche auch in den Schichten von Rams.sholt eingestreut vorkommen; sie haben manche Konchylien mit ihnen gemein, enthalten aber nirgend den Fusus contrarius, noch Murex- und Buccinum-Arten. - $\mathrm{Zu}$ diesen Korallen gesellen sich dann melor Echiniden, als soust irgend in tertiären Bildungen vorkommen, aus den Geschlechtern Cidaris, Echinus, Scutella und Fibularia. Dagegen hat der untere Theil des Crag nur sehr wenige - Сн. sah selbst nur $2-$ Zähne von Squalus-artigen Fischen, und diese wohlerhalten, entdecken lassen, während solche im oberen Crag, den Arten des Londonthones auf Sheppey ähnlich, sehr gewöhnlich, selbst an den Wurzeln abgeschliffen, hart und dunkel von Farbe sind. Sie finden sich in Gesellschaft abgerundeter KnochenTrümmer, welche, dicht und dunkel wie jene, nicht näher bestimmt werden können, nit Ausnahme der Elephanten-Knochen, welche in Norfolk nicht selten, jedoch unter Verhältnissen vorkommen, dass es schwer ist zu sagen, ob sic dem Crag oder dem Diluviale beizurechnen 
seyen, das zuweilen $80^{\prime}-200^{\prime}$ Mächtigkeit hat. Dagegen ist noch keine Spur von Säugethier-Resten im Coralline Crag vorgekommen.

Die Verschiedenheiten zwischen dem obern und untern Crag können herrühren entweder von der, während des Absetzens verminderten Tiefe des Meeres, und beide dürften dann als fast gleichzeitig betrach. tet werden, -- oder von einem Absatze derselben in selsr ungleichen Zeit-Perioden, wofür mehr Gründe zu sprechen scheinen. Die wenigen Fundorte der tieferen Ablagerung sind in der Mitte, an der östlichen und an der westlichen Grenze der Formation vertheilt, und dass man sie bis jetzt nicht an mehr Stellen entdeckt hat, mag nur im Mangel an hiureichend tiefen Nachgrabungen seinen Grund haben. Die obere Abtheilung hat 150 Konchylien. Arten aus der untern, aber auch die Terebratula plicatilis mit der Kreide gemein, aber erstre mögen durch Zerstörung der unteren Abtheilung, wie letztre durch Zerstörung von Kreide-Schichten, in die obre gelangt seyn, nach welcher Aunahne dem rothen Crag in Suffolk nur 80 eigene Arten verblieben, so viel nämlich, als deren WOodward für ihn in Norfulk aufzählt. Die M u rexund $\mathrm{B} \mathrm{u}$ c cin um-Arten sind zweifelsohne erst später entstanden, und daher dem rothen $\mathrm{Crag}$ allein verblieben. Frach Deshayes gehören 68 von 110 Arten des Crag ausgestorbenen, und $44(0,40)$ noch lebenden Arten an; die des Coralline Crag dürften nehr ausgestorbene Arteu liefern, sind jedoch mit den lebenden noch nicht verglichen. Ëbrigens hat man vielleicht auch die Arten aus der jugendlichen Ziegelerde vom Nar in Suffolk u. a. O., welche mit den noch lebenden des Allantischen Ozeans übereinstimmen, nicht sorgfältig von denen des Crag geschieden.

[Rücksichtlich der nähern Bestimmung der fossilen Reste in beiden Abtheilungen dieser Formation érfahren wir durch diesen Aufsatz leider nichts. Vielleicht würde sie zur Parallelisirung nit den blauen Mergeln und dem rothgelben Sande der Sisbapenninen und Süd-Frankreichs führen.]

\section{Petrefaktenkunde.}

Qunsstedr: über die Identität der Petrifikate des Thürin. gischen und Englischen $\mathrm{Z}$ echsteines (WIEgr. Arch. F. Naturgesch. 183.5, I, 75-95, Tf. I). Über die Versteincrungen des Thüringischen Zechsteines hat v. Schlotneim (Denkschr. ה. Münchn. Acad, 1816). über die der Englischen SEDGwick (Geol. Transact. Old series, IV) geschrieben, ohne auf jene Arbeit Rücksicht zu nehmen, obschon ihr kennbare Abbildungen beigegeben waren. Der Verf. war in der Lage, nach diesen Vorgüngren, die nun in Berlin aufgestellte Scurorurm'sche 
Sammiung mit den durch Hru. v. Deches aus England dahin mitgebrachten Zechstein-Versteinerungen für gegeuwärtige Arbeit vergleichen zu können.

1. Producta aculeata (Gryphites aculeatus Schrotr.) Fg. a a, b. Die stark gewölbte, durch eine tiefe Furche getheilte Obeıslappe, die konkave durch eine Erhöhung ebenfalls zweitheilige Unterblappe hat die Art mit mehreren andern gemein. Ihre Oberfläche ist neiten, und danu nur unbestinmt gestrahlt. Was sie aber stets auszeichnet, sind die walzenfürmigen, bis $2^{\prime \prime}-3^{\prime \prime}$ langen, wahrscheinlich beim Athmen dienenden Röhren, wclche längs des Schlossrandes der gewölbten Klappe jederseits eine bogenförnige, längs des der vertieften eine geracle, dicht an den Rand gerückte Reihe von jedesmai etwa 6 dieser Röhren bilden, und zuweilen auch noch auf der sonstigen Oberfläche der Schaale zerstreut vorkommen, und welchen Rühren, einzeln genommen, aif der ihnen entgegengesetzten Klappe jedestinal cine kleine Vertiefung entspricht, die bisher noch nicht beobachtet worden waren *). Zu dieser Art gehörte P. c a lva Sow. von Sunterland, $1{ }_{2}^{1} \mathrm{mal}$ so breit als lang, mit deutlichen Röhren und Verriefungen, eine in ganz Thüringen vorkommende Form; - P. horrida Sow, um die Hälfte grüsser, fast so lang als breit gestreift (daun P. antiquata auctt.; nicht Sow.), ebenfalls in 'Thüringen; - P. humerosa Sow. der Steinkeru der letztern, welchem auch die Kerne andrer Arten ähnlich, und damn mit ihm verwechselt worden sind, vorzüglich in Dolomiten beider Länder; endlich eine Menge kleiner ludviduen, welche Sowerby's Pr. aculeatus, Pr. spinulosus und Pr. Flemingii aus Schottischem Kohlenkalke ganz entsprechen, sey es, dass diese Arten wirklich beiderlei Gebirgs-Schichten gemein, oder dass der Schottische Fundort unrichtig angegeben worden, oder endlich das verschiedene Aıten in der Jugend ähnliche Formen besitzen.

2. Delthyris undulata (Spirifer undulatus Sow. $=$ Ano. mites a latus v. Schlotr.). Der Mittellappen in beiden Klappen glatt, nur der Sinus der Rüchenklappe mit einer kleinen charakteristischen Rippe jeder Flügel mit 12-16 dergleichen; die Wellen - förmigen Anwachsstreifen sehr zierlich, in den Steinkernen von Humbleton aber begreiflich nicht deutlich. Scheint von P. specios a nur wenig abzuweichen.

3. Terebratulites cristatus r. Sснготн. zu Glücksbrün und In misleton. Rückenschaale mit glattem Sinus, der von den 2 stärksten Rippen ciingefasst ist und noch 3-4 schwächre, doch scharfe jederseits neben sich hat; Zuwachsstreifung zierlich; Schnabel stark übergebogen.

* Der ly. irrt aber, wenn er meint, dass sie in der Lethäa anzugeben verges se n worlen, indem ich selbst jetzt bei den fleissigsten Nachsuchungen nur an einigen meiner Exemplare undeutliche, zu keiner allgemeinen Angabe berechtigende Spuren davnz zu entdecken vernag.

-j Nuch sowerby ist P. calva fast quadratisch, P. hor $\mathrm{r}$ ida vierseitig und noch מ.owist.

HR. 
Wird bis $2_{2}^{\prime \prime}$ breit. Ist mit D. octoplicata Sow., aus Derbyshire, wahrscheinlich identisch, auch der D. crispa Dalm. mindestens sehr nahe; eine vorkommende Varietät mit mehr Falten scheint multiplicat us benaunt worden zu seyn.

4. Terebratula Schlotheimii v. Buch Tereúr. 39 , gerade wie zu Humbleton, wird mit zunehmendem Alter aus einer $\mathbf{P} \mathbf{u} \mathbf{n}$ a ce eine $\mathrm{Couc}$ innee und dann von Hrn. v. Buch unter T. I a c u n s a p. 50 nithegriffen, obschon die Übergänge vorliegen; der starken Dichotomie der Falten wegen ninmt ibre Anzahl im Sinus von 2 auf 8-10 zu. Dazu gehört, als Mittelform zwischen den andern Deutschen und den Englischen, die T. I a cun os a v. Schlotr. vou Schmerbach.

5. Terebratulites sufflat us v. Schloth., v. Buch p. 102, nebst 6. T. elong a t a kommen beide auch $\mathrm{zu} H$ umbleton vor. 1:I ihrer Gesellschaft an beiden Orten noch viele junge undeutliche Brut: Terebr. Iatus, T. complanatus, T. intermedius u. s. w.; so wie auch

7. der T. pelargonatus v. Schrotr. mit sehr hohem Sclinabel, feiner dichotomirender Streifung und einer anscheinend verwachsenen Delta - förmigen Öfrung, die sie zur Cyrıia machen würde, nur undeutlich sich an beiden Orten findet.

8. Pleuronectes dis c if o r m is pusillus v. Schlotr. zu Glïcksbrunn und zu Humbléton, $\frac{1}{2}^{\prime \prime}$ lang, aus den aneinanderstehenden Buckeln und dem äusserlichen [?] Ligamente als eine L i m a zu erken. nen. Sie ist gleichklappig, vorn nur wenig abgeschnitten, nach hinten unmerklich ausgebreitet; das vordere Ohr der rechten Klappe für den Byssus wenig ausgeschweift; - nicht gestreift. Der Vf. behauptet, duss die $\mathrm{Plag}$ iostom e $\mathrm{n}$ ältrer Formationen sich $\mathrm{im}$ m e durch Zähne au Schlossrande ( $\mathrm{Limea,} \mathrm{Lim}$ a r c a) von den eigentlichen Lin e n unterscheiden, und bildet als Beleg P lagiostoma mi n u t u m v. Schцоті. (Fg. 5 a, b, c) ab.

9. Aviculaspeluncaria Q. (Gryphites speluncarius v. Schorr., Avicula gryphaeoides Sow., O r bi c u l a v. Bucr) Fg. 1 a, b, c. Zu Glüclisbrumn und zu Humbleton häufig. Frei, un gleichklappig, ziemlich rund. Rückenklappe stark gewölbt mit eiıer mittlen Depression von dem Schnabel bis zum entgegenstehenden Rande, mit feinen dichotomirenden, bis auf $60-80$ zunchmenden, abwechselnd kleineren, gekörnelten Strahlen, fast wie bei Mo not is sali. naria. Die rechte Klappe nur $\frac{3}{4}$ so gross, flach, fast kreisrund, nit un. deutlichen Strailen, aber merklicheren Zuwachsstreifen; vorn und oben mit einem schmalen tiefen, fast bis zum Buckel reichenden Ausschuitt für den Byssus.

Schlossrand fast gerade, wie bei Avicula; auch befindet sich, wie bei dieser, die stärker ausgebreitete Seite der Klappen auf der dir Einkrümmung des Burkels entgegengesetzten Seite, im Gegensatze mit Exogyra und Gryphae a. Höhe zu Länge zu Dicke $=8: 9: 3$; Breite des Ohres $=2 ;$ Länge des geraden Schlossrandes $=4 \vdots$ hinten 
ist derselbe gebogen und hat gegenüber auf der gewölhte Klappe einen Lappen, welchen Herr vor Buch als Analogon des hintercn Ohres Letrachtet. Dieselbe Ungleichheit der Klappen (2:1)-und derselbe Ausschnitt für den Byssus findet sich auch bei der flacheren Monotis de c u s s a t a v. Müsst. (Tf. I, Fg. 3 a, b bei Quenst., obgleich solches von Mürster nicht angegeben, oder selbst geläugnet wird), mit welcher jene Art auch im Übrigen grosse Ähnlichkeit hat. Auch die Avicula inaequivalis ist sehr ähnlich, so wie eine noch unbenannte Aluschel in weissen Sandsteine über dem Schieferthon der Brora (Tf. I, Fg. 4 a, b) mit 20-30 schärféren Pippen, in welcher die kleine Klappe mit dem Byssus - Ausschnitte nicht einmal bis in die Hälfte der andern reicht. Alle strahlig-gestreifte $\mathrm{A}$ vic u l a e älterer Formationeu haben diese auffallende Ungleichtieit der Klappen und ermangeln der äussern faserigen Harnsubstanz, womit die stets ungestrahlten Schaalen der lebenden Arten überzogen sind. Auch Monotis substriata v. Mürst. ist eine solche Avicula, wo jene Ungleichbeit nur minder gross ist, und M. salinaria scheint ebenfalls dazu zu gehören.

10. Mytulites kerato $\mathrm{phagus} \mathrm{v.} \mathrm{SchLotr.} \mathrm{repräsentirt} \mathrm{un-}$ sere glatten Aviculae in Zechsteine und ist Avicula keratophaga Q. Sie ist sehr klein, ohne besondere Zeichnung der Oberfläche und ihr Schloss ist unbekannt. Sie ist von einer in den obern JuraSchichten der Mark vorkommenden Form, von Avicula alata Kü̈D. Tf. III, Fg. 3, nicht zu unterscheideu, die sich wieder an Sowerby's Avicuia ovata enge anschliesst und völlig das Schloss von Gervillia besitzt: dieses ist nämlich gerade, gekerbt, vorn auf einer breitern Fläche mit 2 gerundeten Faltenzähnen, wovon sich der vordere wieder spaltet. So mögen auch die ąndern glatten Avicula e der Jura-Formation zu Gervillia gehören. Mytilus socialis aber ist weder Avicula noch Gervillia, denn er besitzt auf der vorderen Seite der linken Klappe 2 zahnartige Erhöhungen, zwischen die der Zahn der rechten Klappe einpasst, und auf der Hinterseite des Schlosses lange Faltenzähne, dergleichen auch in A. I a e vig a t a Kцӥр. (Tf. III, Fg: 2), welche im Rüdersdorfer Muschel - Kalke noch häufiger ist, sich ebenfalls schön beobachten lassen. Eine weitere Gruppe des A vicu I a-Geschlechtes bildet dann Pterine a Gor.dF. des Ïbergangs - Gebirges.

11. M y tulites striatus $r$. Schготн. ist nach dem geraden Srhlosse und den auseinanderstehenden Buckeln eine $\mathrm{Cu}$ cull a e a, deren Buckeln nach vorn gehen und deren Schaale nach hinten stark ausgebreitet ist. Ihren dichten Strahlen nach stimmt sie ganz mit A rca tumida Sow. (Tf. $47 \mathbf{7}, \mathrm{Fg} .2$ ) übercin. Sie kommt in Thüringen, wie in England vor. Cucullae a sulcata scheint der Beschreibung zufolge nicht sehr verschieden davon zu seyn.

12. Tellinites dubius v. Schцоти. begreift sowohl cine glatte Area, welcho entschieden auch zu rumbleton vorkommt, als eine 
? Modiola in sich, dergleichen auf dem Englischen Zechsteine nicht fremd sind.

13. Trochilites helicinus v. Schlotr. kaum über 't" gross, mit 4 gerundeten Ungängen, worauf oben 2 deutliche Streifen forthufen, einige andere aber nur undeutlich zu erscheinen pflegen. Von Humbleton finden sich ganz ähnliche Exemplare in der Sammlung. PHILLIPs hat diese Art unter Turbo angeführt.

14. Encrinites ramosus v. Schцoth., Trochiten rund, mit ziemlich grossem Nahrungskanal, auf den Gelenkflächen mit dichten, dichotomischen Strahlen; die der Hülfsarme in kleinerem Maasstabe diesen ganz gleich. Ist als Cyathocrinites planus MiLs. pg. 86 im Engl. Zechstein bekannt.

15. Escharites retiformis v. Schrotr. Meist nur abgediricht. Von Goldruss als Gorgonia infundibuliformis gut abgebildet; von Eirrenberg mit Eunice a Lamouroux's verbunden, doch von beiden Geschlechtern verschieden. Der Verf. nennt sie daher Gorgonites retiformis. Bei Phiblips erscheint sie als Retepora flustracea. Sie ist im Englischen Zechstein so häufig, als im Thüringischen. Die Längen-Äste sind unter sich ganz gleich und tragen auf jeder Seite drei regelmässige Zellenreihen; die Queeräste keine. Ist aber die Kruste abgelöst, so sieht man die gestreifte Achse ohne Zellen an den Hauptästen, und die Queeräste verschwinden oft ganz. Die Gesammtform scheint becherförmig gewesen zu seyn.

16. Gorgonia dubia (Krone yon Encrinites ramosus v. Schotr. collect. $=\mathrm{Retepora} \mathrm{virgulacea} \mathrm{PhiL.)} \mathrm{ist} \mathrm{eben}$ so häufig im Zechstein beider Länder; scheint ebenfalls becherförmig zu seyn, und von der Wurzel an gleichmässig dichotome und abneh. mende $\mathrm{Zweige} \mathrm{zu}$ haben, welche auf ihrer Kruste 8-10 Längenreihen von Zellen haben mögen; fehlt die Kruste aber, so sicht man nur die gestreiften Äste. Gehörte nach Ehrenberg zu Prymnoa Lamix., wahrscheinlich wei! Ehrenberg in dem schuppigen Ansehen eines zersetzten Stammes schuppige Polypenzellen zu erkennen glaubte. Die Verzweigung ist vielmehr die von Gorgonia, die Zellenstellung aber ver. schieden.

17. Gorgonia a n ceps ist nicht becherförmig, sondern bildet einzelne dickere dichotome Äste, von welchen feine fiederständige $Z_{w e i g e}$ wegtreten. In Thüringen, mit vorigen und noch einer vierten Art, nebst einer $R$ e t e pora.

18. Cala m o pora spongites Goldr. im Zechstein, scheint dem Verf. von andern Formen abzuweichen durch Dünne der Zweige, büschelförmige Stellung und dichotome Theilung derselben, mit dem Habitus eines Gorgonien-Zweiges, so dass der Verf. auf eine andere Art schliesst.

19. Der Fis ch von Sclimerbach, dessen Schoorn. S. 29 rühulichst erwälnt, hat viele Ähnlichkeit mit Acrolepis Sedgwickii Agıss., von dem er inzwischen durch cinige auffallende Merkmale abweicht. - 
Der Pygopterus Scoticus Ag. wird in Thuringen durch P. Hum. bold tii ersetzt. - Dessgleichen Platysomus striatus und Pl. macrurus durch Platysomus gibbosus und Pl. rhombus: nam Palaeoniscus elegans durch P. Freieslebeui.

Einst muss daher ein grosses Seebecken, 60 geogr. Neilen lang von Nord-England bis zum Thüringer Walde grereicht haben, an dessen nördlichens und südlichem Ufer einerlei Geschöpfe lebten, welche, nach dem Klaffen obiger Avicula e u. a. Merkmaien zu urtheilen, ruhig im Schlamme begraben wurden.

E. Löw : über das Zusammenvorkommen fossiler Thierknochen mit Kunstprodukten in den Saudgruben des Kreutzberges bei Berlin (KARst. Arch. 1835, VIII, 479-487, Tf. IX, Fg. 7-9). Nach den früheren Entdeckungen (Jahrb. 1832, S. 360) hat man in den beiden letzten Jahren in den Sandgruben an nördlichen Abbange des Kreutaberges noch gefunden von

1) Elephauten: 5 Backenzähne, 2 Stosszähue, 1 Calcaneum, 1 Astragalus;

2) R h i n o c ros: \& Backenzähne;

3) fos silen P ferde n: 4 Backenzähne, 1 Nittelfuss und 1 Mittelhand-Knochen;

4) fossile n $0 \mathrm{chsen:} 1$ Mittelfuss-Knochen;

5) Hirs che n: 1 Stück Geweilue;

6) Wiederkäuern von der Grösse eines Schafes: I Backenzahn;

7) viele unbestimmbare Knochen-Trümmer ;

alle etwas abweichend von den analogen in den Skeletten noch lebender Thier-Arten, und alle in Zusammenhalt, Farbe und Ankleben au die Zunge sich gleich verhaltend. Auf derselben, anscheinend noch unverritzten Lagerstätte wurden aber auch zwei kleine, mit grosser Mühe zu Keil-förmigen Schneide-Instrumenten zugerichtete Steine, ein sauber polirter Feuer-(Fg. 7) und ein Saud-Stein (Fg. 8) gefunden, welche mithin aus der Zeit stammen, wo der Mensch nit dem Gebraurh der Metalle noch nicht vertraut gewesen. Die Schichtenfolge an Kreutzherge ist von oben nach unten (ausser einem Lehme oder vielmehr Mergel, welcher das Plateau, jedoch nicht bis zu seinem höchsteu Punkte. bedeckt und daher von etwas unsicherer Altersfolge ist):

1) Dam me rde und Flugsand, mit einzelnen, bis $8^{\prime}$ grossen Übergangsgebirgs-Trürnmern . $\cdot{ }^{\circ} \cdot \dot{*}$

2) Grobkörniger Diluvial-Sand, ohne alle Geschiebe und Versteinerungen; nur in seinem untern Theile mit Mam mont - Resten

3) Grober Grus, mit Urgebirgs - Jura - und Feuerstein-Trümmern und vielen, ihrer Abstaınung entsprechenden Versteinerungen, durch weisse Kalkmasse (Kreide-Theile) 
gebunden. Die meisten Kuochen und obige bciden Kunst-Produlite stammen daraus; gleichwohl ist diese Schichte völing unveritzt gewesen.

4) S and, mit mehreren, wenig anhaltenden Thounergel. Schichten, scharfkürnig, doch mit grüssern abgerundeten Geschieben von Granit, Gneiss, Übergangskalk und Feuerstein; der Thonmergel mit ähnlichen Trümmern, in rothes Eisenoxyd verwandelten Schwefelkies-Knollen und Braunkohlen-Theilchen, ebenfalls Knochentheile der uben genannten Thiere enthaltend; der Nergel nie; diese Schichte ist bekannt bis zu .

A. Catucho: memoria geognostico-zoologica sopra alcune conchiglis fossili del Calcare jurese, che si eleva presso il lago di sunta Croce del territorio di Belluno (Hadova 183t, $20 \mathrm{pp}$. 40. 2.2 tav. lith.'. Wir haben in geognostischer Beziehung von diesem Euche schon gesprochen* ) und theilen nun, nach eigener Ansicht desselben einen Auszug über die darin abgehandelten Versteinerungen nit.

Der Vf. beginnt mit einer Nachweisung der Struktur der LaMarch'schen $R$ udis te $n$, hauptsächlich nach Des Mousins, - mit der Uniterscheidung eines vierfachen Vorkommens derselben in der erwähnien Lokalität: als Unterklappe [!], als Kern oder Birostrit mit einer dünnen innercn Schaale bedeckt, und ohne solche. Jene immere Scharle ist flatt und der Länge nach faserig, während die äussere gerippt und queer blätrig, in jenen Gegenden auch nie porüs ist. Allein bekannflich zeigen die Radioliten - Schaalen sich aus Blättern in melireren sich.kreutzenden Richtungen zusamnengesetzt, wie wir es auch an unseru Exemplaren aus dieser Gegend fiuden, zwischen welchen sechsseiting prismatische Zellen übrig bicihen, die an mehreren dieser Exemplare auch deutlich, obschon ausgefüllt sind; diese Schaale kann sich der Länge nach in kọzentrischen Lagen abblättern, und je dünner dia übrig bleibende Lage eben noch ist, desto ebener legt sie sich über den Kern: je dicker, desto mehr nimmt sie dif gerippte, gefaltete u. . w. Form der Oberfläche der Schaale an.

Die im Kalke des Piné vorkommenden Versteinerungen sind:

1. Sphaerulites duplovalvata $\mathrm{C}_{\text {AT. }}$ 13, tb. I, fig. 1 .

Länge bis $3^{\prime \prime}$, inmen ein Kiel. [Wegen dieser angeblich doppeiten Schaale vergl. oben.]

2. Sphaerulites unbellat a CAT., 14, tb. I, fig. 2.

Über $3^{\prime \prime}$ breit; mit 2 inneren Kielen [ist wohl nur ein Derkel].

3. Sphacrulites Da Rio Cax. 14, tb. I, fig. 3, 4.

* Hippuriten mit gefurchtem Kern und glatser Schaalo.

4. Hippurites Fortisii Cat. Zool. fos.s. 171, tr. VI.

*) Jahrb. 1935, S. 89. 
5. Hippurites fitoloides Cat. ib. 173, tv. VII.

6. Hippurites nanus CAtr. 15, Tf. II, Fg. 2.

7. Hippurites turriculatus' Cat. Zool. foss. 172 (Forris viagy. in Dalmat. I, Tf. VII, Fg. 14).

Hippuriten mit glattem Kern und gefurchter Schaale.

8. Hippurites turricula CAт. 16, Tf. 1, Fg. 5.

9. Hippurites contortus CAT. 16, Tf. II, Fg. 3.

10. Hippurites dilatatus Cat. 17, Tf. II, Fg. J.

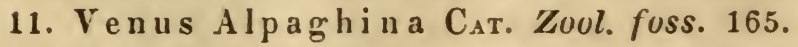

12. Venericardia ?crenata Cat. ib. (Gualt. Tf. 52, Fg. E).

13. Plagiostoma gigantea Sow. Cat. 10.

14. Podopsis truncata? Lamk. Cat. 10.

15. Podopsis arcuata CAT. 11, 17, Tf. II, Fg. 6.

16. Gryphaea dilatata Sow., Cat. 11.

17. Turitella Borsonii C.st. 1S, Tf. II, Fg. 5 ; Zool. foss. 170, Tf. III, Fg. E.

18. Natic a Cat. 11.

19. Cas $\mathrm{s}$ is Cat. 11.

20. Ovula Cat. 11 .

21. Amplexus flexuosus Cat. 11, 19, Tf. II, Fg. 4 [ist Batolites Mr.].

Es ist auffallend, den Vf. so sehr bei einer vorgefassten Meinung rücksichtlich seines Jurakalkes beharren zu sehen, obgleich alle Versteinerungen, die er selbst richtiger bestimmt hat, offenbar der Kreide angehören. Selbst sein Plagiostoma giganteum und Gryphaea dilatata sind zweifelsohne nur mit ähnlichen Arten aus der Kreide verwechselt. Seine beiden $\mathrm{R}$ a diolit e $\mathrm{n}$ fallen indess wahrscheinlich in eine, seine $7 \mathrm{Hipp}$ urite $\mathrm{n}$ jedenfalls in eine geringe Anzahl zü sammen, welche nur durch Dimensions-Verhältnisse und Form von einander abweichen, die ja bei allen festgewachsenen Konchylien und bci den $R$ udiste $n$ insbesondere so veränderlich bei jeder einzelnen Art sind. Die Turritella Borsonii ist, wie twir nach Ansicht des früher abgebildeten Original-Exemplares schon gelegentlich bemerkt, eine ausgezeichnete $\mathrm{Ne}$ r in e a-Art, die er jetzt mit der Schaale abbildet. Aber auch hier ist der Verf. so beharrlich bei seiner früheren Ansicht, dass er (S. 12) also argumentirt: weil die Turritellen des Pine die Charaktere der Nerineen an sich tragen, so gebört das Genus Nerinea zu Turrite 11 a.

H. NYat: Recherches sur les Coquilles fossiles de la Province d'Alvers (Bruxelles, $36 \mathrm{pp}$. et 5 pll. lithh. $8^{\circ}$, 1835). Allein durch die Arbeit DB ra Jonkatre's über die As tarten und durch jene über das Becken von Antwerpen geleitet begann der Verf. seine verdienstlicheu Nachsuchungen nach den tertiären Resten dieser Provioz und 
entdeckte daselbst allmâhlich 136 Arten, 18 aus dem kleinen Becken von Buom, welches dem London clay entspricht und 12 Arten $(0,66)$ mit der Englischen Formation dieses Namens gemein hat, - und 118 in dem bei Antwerpen selbst, welche Lokalität so sehr mit dem Englischen Crag übereinkommt, dass über 65 Arten (an 0,60) beiderlei Lagerstätten gemein sind; weit geringer ist dic Übereinstimmung mit den Subapenninen, dem Moellon und dem Tegel. Etwa 30 Arten im Ganzen sind als neu angegeben und gut abgebildet; einige andere von da hatte LA JoNKAIRE schon früher beschrieben.

\section{II. $\mathrm{Zu}$ Antwerpen.}

\section{Zu Boom.}

A $x$ in us angulatus Sow.

A s t a $r$ t e Kickxii N. I, 31.

Ve ne ri c ardia deltoidea Sow.

A r c a duplicata Sow.

N u c u l a pectinata Sow.

- Deshayesiana Duchaвт., III, 63.

- Duchastelii N. III, 64.

Natica-?

Ple u r ot o m a colon Sow.

- exorta Sow.

Fus u s (M u r. Sow.) trilineatus N.

- ( - - ) rugosus Lamk.?

Triton( - - ) argutus N.

Rostellaria Parkinsoni Mant.

(Kreide).

Cassidaria Nystii Krckx., V, 39.

Nautilus Deshayesii Dexr.

N. Aturi Bast.

A minonites Wapperi de Koninck.

De n t a lium acuticosta Desh.

\&A vicula paradoxa N. V, 55.
B a I a n u s crassủs Sow.

Fis tul a n a contorta Desh.

Solen ensis Lamk.

My a intermedia Sow.

M a c t r a arcuata Sow.

cuneata Sow.

C o r b u l a rotundata Sow.

- elegans Sow.

- pisum Sow.

- bicostata Ny8т. pl. I, fig. 10.

- planulata Nrst. I, 11.

Ps a m mobi a solida Sow.

Tellin a obliqua Sow.

- ovata Sow.

- zonaria BAsT.

- muricata Rev.

- donaciformis N. I, 17.

- astartea N. I, 18.

$\mathbf{L}$ u c in a radula Lamk.

- curviradiata N. I, 20.

Axinus unicarinatus N. I, 22.

Ast a r te planata Sow.

- Omalii Lajonk.

- rugata Sow.

- Basterotii Lıjonk.

- corbuloides Lajonk.

- Burtini Lasonk.

- obliquata Sow.

- Galeotti N. I, 30.

- Nystiana Kickx, II, 32.

Cyprina islandicoides Lamr.

- angulata N.

(? Venus angulata Sow.)

- tumida N. II, 35.

Cy the re a cxoleta Lauk. 


\section{$-248$}

II. Zu Antwerpen.

Cytherea transwersa Sow.

- $\quad$ cycladiformis N. II, 38.

- trigona N. II, 39.

Ve nu s turgida Sow.

- lupinoides N. III, 41.

- radiata Brocchi III, 42.

Ve nericardia semilis Sow. chamaeformis Sow.

Venericardia orbicularis Sow. - scalaris Sow.

Cardiu m Parkinsoni Sow.

- angustanum Sow.

- edulinum Sow.-

- ?

Is ocardia cor Sow.

- Junulata N. III, 53.

Cucullaea elongata Sow. pusilla N. III, 55.

Pectunculus variabilis Sow.

$\begin{array}{ll}- & \text { scalaris Sow. } \\ \text { kalk). } & \text { nanus Desh. (Grob. }\end{array}$

Nucula margaritacea Desh.

- nitida N. III, 62. (später N. laevigata N.)

Mytilus antiquorum Sow.

Pinna? margaritacea Desh.

Lim a nivea ReN.

Pecten grandis Sow.

- complanatus Sow.

- Jacobaeus LaMK.

- striatus Sow.

- sulcatus Sow.

- reconditus Sow.

- obsoletus Sow.

- Gerardii N. III, 75.

Ostrea undulata Sow.

- cucullaris Lamk.

- ungulata N. Iv, 78.

A no nia ? tenuistriata Desh.

Lingula mytiloides Suw. IV, 80.

F issurella Graeca Link.

Pileopsis Ungarica Lamk.

Calyptraea trochiformis Lamk.

\section{Zu Antwerpen.}

B ull a lignaria Lis.

- constricta Sow.

- elliptica Sow.

A u ricul a buccinea Sow., Broccry.

- pyramidalis Sow.

Melania terebellata N. Iv, 9.

Natica glaucinoides Sow.

- hemiclausa Suw.

- patula Sow.

Sc al a ri a lamellosa Brocchr.

- frondosa Sow.

Trochus laevigatus Sow.

- senilis Sow.

- octosulcatus N. IV , 18.

- Kickxii N. IV, 19.

- Robynsii N. V, 20.

- Solarium N. V, 21.

T'urbo moniliferus S. (Greensan!).

Turritella triplicata Brocchr.

Cerithium tricinctun -

- sinistratum N. V, 25.

Cancellari a Jonkairiana $N$ : $\mathbf{v}, 28$.

C a u ce ll a ria costulata Lamk.

(Grobkalk).

F us u s contrarius Lamk.

- corneus $\mathrm{N}$.

(Murex corneus Sow.)

Murex alveolatus Sow.

Rostellaria pes pelecani Pank.

$$
\text { - macroptera Sow. }
$$

Cassis bicatenatus Sow.

- striata Sow.

Buccinum elongatum Sow.

- reticosum Sow.

- rugosum Sow.

- granulatum Suw.

- elegans Sow.

- labiosum Sow.

- lamellilabrum N. v. 48.

Terebra inversa N. $\mathbf{v}, 49$.

Voluta Lamberti Sow.

Cypraca coccinelloides Sow.

De ntalium hemiclausun N. v, 53 :

?Cyclas depressa N. v, 56 . 
Nicon: über die Struktur der horizuntalen Äste der Co. nifere n, ein Vortiag bei der Britischen Versammlung in Dublin, 11. August 1835 (James, Édinb. n. phil. Journ. 183.5, XIX, $101-403$ ). Wie gewagt es sey, auf die blosse Ansicht eines Schnittchens Koniferen-Holzes neue Genera zu gründen, geht aus der Betrachtung der Holz-Struktur an der obern und der untern Seite der horizontalen Äste der Koniferen hervor. Die Markröhre liegt der obern Fläche näher als der untern; das Holz der obern Seite ist blasser, und wie das des Stammes beschaffen, während an der untern Seite das Holz dunkler, dichter, auf den Queerschnitte die Zellen enger, die Zellenwände dicker, auf dem radialen Längenschnitte die Zellen mit kleineren, wenigeren und undeutlicheren (? obscure) Scheibchen oder Poren, und auf diesem wie auf dem konzentrischen Längenschnitte die Zelien mit zahlreichen Fasern durchkreuzt sind, die an der Oberseite ganz fehlen. Die Äste von zehn verschicdenen $\mathrm{P}$ i u us-Arten haben alle, mehr oder weniger dasselbe Resultat geliefert.

Inzwischen kann die genaue anatomische Untersuchung der Pflanze in solchen Fällen zu -ihrer richtigen Klassifikation führen, wo die äusseren Charaktere Zweift übrig lassen. So hat der Miro von Neuseeland, woraus man einen Podocarpus gemacht hat, gänzlich die Struh. tur der wahren Dikotyledonen, und umgekchrt stimmen Tasmannia dipetala (T. insipida Brown), die man zu den II agnolien gestellt, und T. a romatica rücksichtlich der Struktur ihres Holzes gänzlich mit den Koniferen, insbesondere den Araucarien übcrein, nur dass ihre Struktur feiner und unbestimmter, und dass bei der zweiten dieser Arten die Spiegelfasern krummlinig sind; sie zeigen auf dem Queerschnitte 1-2 Reihen viereckiger Öffnungen, welche $3-4 \mathrm{mal}$ so gross als jene in den $\mathrm{Z}$ wischensteilen sind.

J. T. Mackay und Whitsa: Eericlit über fossile Equiseten bei Carrickfergus (Journ. of tice geol. Soc. of Dublin, I, I, 79-81). Zwischen Carrickfergus und Kilrootpoint in Irland, etwas über gewöhnlichem Hochwasserstand hat die Küste auf eine Strecke hin das Ansehen, als ob sie dicht mit aufrechten eiscrnen Spitzen bedeckt wäre, welche $2^{\prime \prime}-6^{\prime \prime}$ lang und $2^{\prime \prime \prime}-4^{\prime \prime \prime}$ dick sind, und noch $1^{\prime}-1 \frac{1}{2}^{\prime}$ senkrecht in den Boden hinabzureichen scheinen. Nirgends sieht man sie eine horizontale Richtung annehmen, auch unter der Oberfäche nicht. Sie sind ganz hohl und brechen leicht am Boden ab. Es sind Überrindungen von Pflanzen mit eisenschüssigem Sand, in welchen jedoch die Substanz der Pflanzen gäuzlich verschwunden ist. Equiseten, Triticum junceum und Polygonum amphibium wachsen umher. Mackar hält nach genauerer Prüfung dic überrindet gewesenen Gewächse für Equisetum fluviatile und E. limosum. 


\section{$-250$}

Eudes Deszorgchamps: Abhandlung über die Teudopsiden, den K a mars verwandt (Mém. Soc. Linn. de Normandie $V, 1835$ $>$ l'Instit. 1835, IV , 134). Der Name Teudopsis rührt von zəv Sis, der Griechischen Benennung der Kalmars. Der Charakter des Geschlechtes ist folgender:

Thier unbekannt; - Schaale fossil, hornartig, dünne, verlängert, flach oder hinten und unten etwas vertieft, längs ihrer Mitte mit einer Längenfalte, welche an ihren beiden Enden manchmal gespalten ist, gewöhnlich begleitet von einem Sack voll schwarzer fast pulverartiger Materie.

Die drei ihm bekannten Arten nennt der Verf. T. Agassizi, T. B unellii und T. Caumontii. $Z$ u diesem Geschlechte scheinen die Reste zu gehören, welche in DE LA Beche's Manual unter dem Namen Onychote uthis angusta Mürst., Loligo pris c a Rürp., Loligo antiqua Müssr. und $S$ e pia hast a e formis Rüpr. aufgeführt werden.

Eudès Deslongchamps: A b handlung über die fos silen Arten des Muschel-Genus Münsteria (Mém. Soc. Linn. de Normandie, $\boldsymbol{V}, 1835>$ l'Instit. $1836, I V, 134$ ). Schaale 2klappig, gleichklappig, sehr ungleichseitig, voru und hinten klaffend; Klappen dreieckig; Buckeln klein, randlich, ganz vorn; Schlossrand gerade mit einem elastischen Ligament in seiner ganzen Länge; Schloss linienförmig, olne Zähne. - Familie der S ol e no ide n Lamarck's. Arten 6, nämlich M. a n a tif ormis [!], M. prael onga, MI. c une at a, M. c analifera, M. sulcata, M. l a mellosa. Zwei dieser Arten stammen aus dem lithographischen Kalk Pappenheims, vier aus der Gegend von Caen.

Seit Verlesung dieser Abhandlung scheint DE LA BECHE (S. 424 seines Manuals) diese Muscheln als Aptychus la evis latus, A. la evis longus, A. imbricatus depressus, A. imbricatus profundus, A. bullatus und A. elasma aufgeführt zu haben. [Da der Vf. die Original - Abhandlung von MExeR's nicht kannte, so ist nicht zu wundern, wenn er demungeachtet seinen Vortrag abdrucken liess.]

L. v. Bucr: Note über die Austern, Gryphäen und Exogyren (Ann. scienc. nat.; Zool., 183.5; III, 296-2.99). Man ist darüber einverstanden, dass die wesentlichen Charaktere im Schlosse der Austern, Gryphäen und Exogyren dieselben sind, und zwischen diesen drei Formen, welche im Übrigen als Gruppen desselben Geschlechts willkommen sind, sic'^ Übergänge gestalten. Die Austern entwickeln sich in einer Fläche ohne verhältnissmässige Dicke; - die Gryphäen nehmen an Tiefe zu, nnd sind oft viel länger als breit; - 
die Exogyren endlich haben Neigung aussen eine Kante zu bilden, welche zwei sehr ungleiche Seiten trennt. Diese Verschiedenheitèn scheinen doch inmer auf Abweichungen in der Organisation zu beruhen.

Die Gryphäen haben auf ihrer rechten Seite, gegen welche hin der Buckel gerichtet ist, immer noch einen schmäleren Lappen: eine äus. serliche Rinne trennt ihn der Länge nach von der übrigen Schaale; bei Gr. a r c u a t a geht diese Rinne bis in die Spitze des Buckels fort, bei den übrigen Arten hört sie an dessen Basis auf; bei erstrer wird sie durch den Muskel-Eindruck hervorgebracht, welcher innwendig auf derselben (oder etwas ousserhalb) steht; bei den andern liegt dieser mehr nach innen gegen die Mitte hin. Bei diesen ist dieser Lappen ein Äquivalent des rechten Ohres der Pectines, das sich gleich dem linken in minder schiefer Form bei einigen $\mathrm{A}$ ustern, wie 0 . carinata, noch erkennen lässt. Ostrea vesicularis hat noch einen Überrest des linken horizontalen Ohres neben dem Muskel-Eindruck; die ihr zum Verwechseln ähnliche Gr. dilat a t a hat davon keine Spur meir. Beide unterscheiden sich übrigens von andern durch das vertikale Schloss und die rudiale Streifung der Oberklappe. Wie am Rand der Pectines, so setzen die Anwachsstreifen der Gryphäe n an der Rinne ab; die des Lappens, gleich denen des Ohres der Pectines, liegen wie auf einem blossen Anhange darneben, nur die Gryphaca arcuata ausgegenommen. Die Austern haben daher noch horizontale oder gar keine Ohren; die Gryphäen nur ein sehr schief längs der ganzen Schaale hinziehendes; ihr andres ist gänzlich verschwunden. Die Exog y re n lassen nicht selten einen Lappen, wie Gryphae a a r u a ta wahrnehmen, und eine Rinne, auf oder ausser welchem innwendig der Muskeleindruck sitzt; wozu die Kante, die scitliche Krümmung des Buckels und die Einschliessung des oberen Theiles des Ligamentes in demselben noch als weiter unterscheidende Merkmale des Geschlechtes Exogyra kominen.

W. Gregory und P. Walker: Kop rolith-A n aly s e n, vorgetragen bei der Wern. Soz. in Edinb. am 29. Nov. und 13. Dez. 1834 (JAMEs. Edinh. n. phil. Journ. 152t, XVIII, 16t-165). Ein Koprolith von Burdiehouse war in einer abgerollten Masse von Thoneisenstein eingeschlossen und schien auf dem Bruche aus derselben Masse, wie die einschliessende Materie, zu bestehen. Das Mineral enthielt viel Schwefeleisen eingesprengt, und die Analyse wurde durch die Ungleichförnigkeit des Gemenges schwierig und unsicher. Einer hohen Tenıperatur ausgeseizt, entwickelte sich Wasserdampf mit viel bituminöser Materie und etwas Ammoniak, woraus, wie aus dem Vorkommen von Phosphorsäure, sich mit grösster Bestimmtheit auf den organischen Ursprung schliessen lässt. - II. Ein anderer Koprolith von Fifeshire zeichnete sich durch noch stärkeren Gehalt an Phosphorsäure aus, und wenn er in einer 
Glasrühre der Hitze ausgesetzt wurde, so entwickelte sich Wasser mit viel Anmoniak und ein Geruch nach in hoher Temperatur sich zersetzender Thier-Materie

I. II.

Organische Materie
(1. mit Schwefeleisen und Kieselerde)

Kohlensaure Kalkerde

Talkerde

Eisenoxyd mit etwas Alaunerde

Phosphorsaure Kalkerde . .

Fluorkalzium (bei II. Fluss-Säure)

Mauganoxyd

Phosphors. Talkerde

Wasser (und bei I. Verlust)
4,134 - 3,380

61,000 . 24,255

13,568 . 2,888

6,400 - Spur.

9,576 . 63,596

Spur . Spur.

$5,332 \quad$ - 3,328

Arth. Connelu: Nachträgliche Notiz zur chemischen Analyse der Thierreste von Burdiehouse *) (Janes. Edinb. n. phil. Journ. 1834, XVIII, 387-388). Der Verf. hatte bei seiner früinern Zerlegung von Koprolithen Flusssäure nicht auffinden können, was ihm jedoch später gelang. - I. ist ein Flossenstachel von G y a c a nt h u s formosus AG.; II. bietet zur Vergleichung die Ergebnisse der DuMExil'schen Zerlegung frischer $\mathrm{He}$ eht-Stacheln. III. sind in Kalkstein eingebettete, bis $\frac{3}{4} "$ lange Schuppen von Megalichthys, welches Geschlecht dem Lepidostcus nahe steht. IV. gibt das Resultat der Cherreul'schen Ánalyse der Schuppen der noch lebenden L e p idosteus-Art. Setzt man voraus, dass, in Verhältniss als die organische Materie zerstört wordęn, bei III Kieselerde-Hydrat, bei I Kieselerde und kohlensaurer Kalk eingedrungen seyen, so stimmen die fossilen Reste mit den analogen frischen in auffallender Weise rücksichtlich ihrer Zusammensetzung überein; das umschliessende Kalkgestein selbst enthält einen ansehnlichen Antheil organischer Materie.

I. II. III. IV.

Phosphors. Kalkerde * . $\quad$ ( $\quad 53,87 \quad 55,26 \quad 50,94 \quad 46,20$

(bei I. u. III. mit etwas Fluorkalzium!

Kohlens. Kalkerde

$33,86 \quad 6,16 \quad 11,91 \quad 10,00$

Kieselerde (bei III als Hydrat)

Kali, Natron, theils als Chloride

10,22

36,58

, $\left.71^{\circ}\right) \quad 1,32^{\circ}, 47$

Bitumen oder (bei II. und IV.)

thierische Materie.

,54 37,36

, 12

41,20

Phosphors. Talkerde

Spur

Spur

2,20

*) Vgl. Jahrb. 1835, S. 503.

*) Natron und Verlust. 
Wraster: über den Pech-See auf Trinidad (dessen Voyage mude in the years 1829-31, by order of the Lords Commissioners of the Admiralty, vol. II. $>$ James. Erlinb. n. philos. Journal, 183.5, XVIII, 331-334). Dieser Bericht weicht in einigen wesentlichen Stücken von dem frühern Alexander's ") ab, und endiget mit einer Auwendung auf die Tlseorie der Steinkohlen-Bildung. Die "Pechgründe" finden sich etwa 24 Engl. Meilen vom Spanischen Haven zu Point Breea und sollen 1500 Acres Ausdehnung besitzen. Landet man an dieser Spitze, so wird man sogleich durch grosse auf Sand umberlie. gende Pech - Blöcke und von den Wellen bewegte Pech-Geschicbe überrascht. Man geht und fährt auf Pech, das jedoch im Allgemeinen nur eimen dünnen, doch oft unterbrochenen Überzug über den Boden bildet. Felder und Gärten sind darauf angelegt und zeigen eine üppige Vegetation; 'doch könmt auch der andere Boden darunter an vielen Stel. len zum Vorschein. Den etwas höher liegenden Pechsee erreicht man $1 \frac{1}{4}$ Mei!. vom Meere , wo er ganz von Wald eingeschlossen ist; er ist $\frac{1}{2}$ E. Meil. lang und $\frac{1}{16}$ M. breit. Er hat in der That das Ansehen eines See's, ist jedoch vou vielen tiefen Spalten durchzogen, worin frisches, gutes Wasser steht und sich auch stellenweise über die Oterfläche ausbreitet, darin Fische und Frösche leben. Das Pech ist hart genug, um eine Person zn tragen; ist es aber von der Sonne erwärmt, so kann jene mit der Oberfäclse so tief einsinken, dass sie ibr Nachbar aus dem Gesichte verliert. Manche Pflanzen wachsen auf dem Peche da, wo sich keine Spur von Erde findet, und ihre Menge ist im Zunehmen. Etwas nordwärts sieht man eine Quelle von flüssigem Theer. Zwischen Point Breea und Point Niparina ist eine Pech-Bank, woraut $10^{\prime}-12^{\prime}$ Wasser steht, worauf Schiffe zuweilen ihre Anker werfen und Fische sehr häufig sind. Am Serpent's Mouth sind einige Pech-Riffe, welche bald wachsen, bald verschwinden und mit dem Schlamm-Vulkan in Verbindung stehen sollen. Das Pech ist eine matt schwarze, feste Substanz mit ebenem Bruche, lässt sich leicht mit dem Federnesser schaben, riecht widerlich wie Kohlen-Theer, sinkt in Salzwasser schuell unter und fäıbt Papier matt braun. Bei etwa $155^{\circ} \mathrm{C}$. schmilzt es unvollkommen zu einer weichen Masse, ohne auseinanderzulaufen. Weingeist, Salpetersäure, kaustisches Alkali wirken nicht darauf. Es ist daher vom eigentlichen Peche selir verschieden und kann nicht zu denselbeu Zwecken gebraucht werden. Auf Trinidad dient es zu Verbesserung der Wege und zum Verkitten von Steinen unter. Wasser; auch zur GasGewiunung. Ls steht der Steinkohle näher, als dem wirklichen Peche. Der Verf. glaubt nicht an den vegetabilischen Crsprung der Steinkohle, sondern nimmt an, dass dicse nichts als eine noch mehr erhärtete Substauz gegenwiitiger Art seye. Die Koblenlager pflegen Reste von Pflanzen aus einem heissen und feuchten Klina einzuschliessen. Fahren, Schilfe und Palmen, worunter cine eigene „Pechsce-Palme", siud

4) Jahrb. 1933, S. 629. 
aber auch die hăufigsten Gewächse an dieser Stelle: ja sie wachsen auf dem Pechsee. Würde der Pechgrund jetzt von neuen GebirgsSchichten bedeckt, so würde man bei späteren Wiederauffinden desselben das Pech in Steinkoble verwandelt, und charakteristische Steinkoblen-Pflauzenreste in den sie begleitenden Felsschichten antreffen. Die Pechlagen im Meere, welche weich genug sind, um den Anker eindringen zu lassen, müssen auch vermögend seyn, Seekonchylien in sich aufzunehmen. See- und Fluss-Fische, wie sie $\mathrm{im}$ Wasser über und zwischen dem Peche leben, würden mit in diese Erdschichten eingeschlossen werden.

Unterme e ris cher W a $1 \mathrm{~d}$ z u Dieppe, Seine inférieure (Ann. d. Voyag. 183t, Avril, II, 11t-115). Am. Fusse der steilen Ufer, westlich von Cay d'Ailly, hat man seit einigen Jabren fossile Baumstänme in den Alluvionen bemerkt. Durch den-letzten Sturm in Februar 1834 wurde eine grosse Anzahl von solchen unterhalb des Dorfes Saint Aubin vor Dun, 4 Stunden von Dieppe, so ausgewaschen, dass sie bei niederem Wasserstande entblösst liegen. Sie deuten einen ganzen verschütteteu Wald an, sind in Torfmasse verwandelt, jedoch enthalten viele von ihnen noch ein ganz gesundes Herz von schön rothgelber Farbe. Es sind Eichen- oder Kastanien-Bäume, auch wohl Tannen u. a. Arten, welche alle gegen N.W. zu gefallen sind. Zum Brennen taugen sie wenig.

Ch. Morren: über die Gleichzeitigkeit des Bibers der Torfmoore in Flandern mit dem Menschen (vorgel. b. d. Akad. zu Brïssel ain 4. Apr. 1835, > l'Instit. 1835, III, 180-181). Neue Beobachtungen haben die schon früher aufgestellte Ansicht des Verf's. bestätigt. Er hat kürzlich aus den Torfmooren der Gemeinde Destelberghe-lez-Gand $\mathrm{Ocl}$ s en-Schädel, Hirsch-Reste, vier Schweinsund zwei Hunds-Schädel mit zwei Schädeln jenes Bibers und dem Unterkiefer eines Menschen zusammenliegend gefunden, und zwar $40^{\prime}$ tief in einen Süsswasser - Torfe, welcher $3^{\prime}$ hoch mit Sand und dann mit Humus bedeckt war, auf welchem nach unten zunächst ein durch Eisén - Pliosphat grün gefärbter Sand mit Tausenden von $\mathbf{P}$ a I u din e n und Planorben u. s. w. folgte. Dasselbe Torfmoor hat eine kupferne Lanze geliefert, ähnlich jener, welche DE Bast und Montfaucon als zu Téralphène bei Alost und zu Paris gefunden, beschrieben haben; - ferner ein kupfernes mit einem Öhre versehenes Instrument, welches dem bei DE BAst pl. xII, fig. 11 ganz gleich ist, und dergleichen sich die Gallier viel bedient haben. 


\section{V e r s u c h}

einer geographisch-geognostischen Eintheilung des westlichen Deutschlandes nebst generellen Andeutungen zur geognostischen Konstitution der verschiedenen GebirgsAbtheilungen desselben,

Bruchstück eines zum Behufe geognostischer Detail-Untersuchung der Gebirge West-Deutschlands entworfenen Planes, vou

Herrn Dr. von Kuipstein.

Ohne Rücksicht auf geognostische Konstitution würde sich schon für die Gebirge West-Deutschlands nach der geographischen Beschaffenheit desselben eine mit jener ganz in Allgemeinen beinahe korrespondirende generelle Eintheilung ergeben. Das grosse Längentha! des Rheins, so wie das Queerthal des Mains bieten zwei natürliche Haupt-Abschnitte, nach welchen drei grosse Abtheilungen erhalten würden, nämlich :

1) die südlichen Länder auf der rechten Rhein-Seite bis zum linken Main-Ufer (Württembery, Baden und ein Theil von Hessen-Darmstudt;

2) die grosse Gebirgsfläche zwischen dem Rhein, Main, der Fränkischen Saale, der Werra und Weser; 
3) das ganze Deutsche Gebiet des linken Rhein-Ufers.

Doch ist diese geographische Eintheilung nicht ganz dazu geeignet, mehrere grosse geognostische Gebiete passend zu sondern. Wir nehmen, dieses zu bezwecken, noch folgende geognostische Begrenzungen zu Hiilfe:

1) die östliche Demarkations-Linie des transitiven Schiefer-Gebirges auf der rechten Rhein-Seite von Stadlberge über Sachsenberg, Frankenberg, Marburg, Giesen, Butzbach, Homburg bis ungefähr zum Ausfluss der Nidda in den Main.

2) Eine Linie durch den nördlichen Spessart, die das Primitiv-Gebirge des Spessarts suidwärts lässt und so die nordwärts bleibenden Kupferschiefer-Bildungen von demselben trennt.

Nach dieser geographisch-geognostischen Abmarkung würden 4 grosse Gebiete oder 4 Haupt-Gebirgsgruppen für WestDeutschland erhalten, eine südliche, eine östliche, eine nördliche und eine westliche. Wir unterlassen es, auf eine Darlegung von Gründen, auf welchen hauptsächlich die versuchte Eintheilung beruht, weiter einzugehen. Zum Theil ergeben sie sich aus der nachfolgenden weiteren Ausführung selbst, theils gehen sie auch aus Grundsätzen hervor, welche wir an einem anderen Orte zu entwickeln Gelegenheit finden werden.

\section{Südliche Hauptgruppe.}

Die Primitiv-Grebirge des westlichen Deutschlands sollen einen vor\%ngsweisen Bestandtheil dieser Hauptgebirgsgruppe bilden. Ihre Massen grösstentheils unmittelbar vom bunten Sandsteine umlagert, erscheinen in 3 vereirzelten Partieen, getrennt dureh grosse Vertiefungen, in welchen sich das jüngere Sekundär-Gebirge absetzte. Die obersten Formationen desselben, oner die Oolith-Bildungen, sind in Folge des Einflusses später umgestaltender Kräfte ihrer eigenthümlichen äusseren Gestaltung nach grösstentheils scharf getrennt von den untern Bildungen, wesshalb sich ihren Hauptverbreitungs- 
Gebieten nach recht passend aus diesen beiden FormationsGruppen auch zwei besondere Gebirgs - Abtheilungen bilden lassen. Zwei andere werden ferner durch die weit getrennten Primitiv-Gebiete des Schwarzwaldes und Odenwaldes bezeichnet und einer fünften dürften vielleicht noch die flachen Gegenden zwischen der Iller, dem Bodensee, dem Schwarzwald und der Donau angehören. Es werden demnach für die südliche Hauptgruppe folgende 5 Abtheilungen crhalten :

1) Odenwald, Spessart und Bauland.

2) Nechar-Gegenden.

3) Schwarzwald.

4) Rauhe Alp.

5) Gegenden zwischen der Donau, dem Bodensee und der Iller.

\section{Begrenzung der südlichen Hauptgruppe.}

Der Rhein von seinem Ausflusse aus dem Bodensee bis zur Müudung des Mains, der Main bis zur Mündung der Kahlbach; Grenze der östlichen Hauptgruppe bis zur Mündung der Lohr; der Main abwärts bis zum Einfluss der Tauber, diese bis zu ihrem Ursprung; Linie zum Ursprunge der Würnitz, die Wörnilz bis zu ihrer Mündung bei Donauwörth; die Donau bis zur Iller, diese herauf bis zur Vereinigung mit dem Koslanzer Thal bei Inmensladt, das Kostanzer Thal bis Raufen, Linie zur Weissach; das Thal der Weissach und der Bregenzer Bach bis zum Bodensee; die nördlichen Ufer desselben bis zum Rhein-Ausfluss.

\section{Abtheilung. Odenwaldu. s.w.}

Die plutonischen Primitiv - Bildungen zwischen Neckar und Main, so wie noch eine kleinere Partie derselben auf der rechten Main-Seite den suidlichen Theil des Spessarls bildend, sollen ihr angehören. Obwohl die hierher gehörigen Formationen an Verbreitung von dem innerhalb der Abtheilungs-Grenze sio umgebenden bunten Sandstein übertroffen 
werden, so stehen sie gleichsam als die Kern- oder ZentralMassen unter den weiterhin noch dieser Abtheilung anheimfallenden oben an. Sie sind ferner durch eigenthünliche höchst manchfaltige Zusammensetzung. im höchsten Grade ausgezeichnet. Granit, Gneiss und Syenit, reich an untergeordneten Einlagerungen, erscheinen zumal in den vielartigsten Wechsel. Doch scheinen diese zum Theil an anderen Orten mit reichen Erz-Lagerstätten gesegneten Bildungen in diesem Gebirge, so weit man es bis jetzt kennen lernte, nur zu geringer Hoffnung für die Auffindung bauwürdiger Massen berechtigen zu wollen. Ost- und südwärts sind die primitiven Formationen des Odenwaldes überlagert durch bunten Sandstein, welcher nach jener Richtung in beträchtlicher Verbreitung bis in das Bauland sich erstreckt, alsdann nordwärts über den Main hinübersetzt und die kleinere Partie primitiven Gebirges des Spessarts umgibt.' Unter den Gebirgs-Bildungen dieser Abtheilung gewinnt er bei Weitem die beträchtlichste Verbreitung. In ihrem östlichen Theile, im Bauland, erscheint alsdann noch der auf dem bunten Sandstein ruhende Muschelkalk in nicht unbedeutender Ausdelnnung, indem er bei Weitem den grössten Theil dieser Gegend einnimmt, oder vielmehr den beträchtlichsten Antheil an der Konstituirung des östlichen Theils der Abtheilung nimmt. In einigen kleineren isolirten Partieen kommt er auch noch weiter westlich im bunten Sandstein, so wie auf der Grenze zwischen diesem und Gneiss vor. Hiernächst die grösste Ausdehnung gewinnend, lehnt sich dem nördlichen Saume des Odenwälder Primitiv-Gebirges eine halbinselförrmig in das Alluvial-Land des Rheins und Mains sich erstreckende Partie von Todtliegendem an. Auf seiner Sïd-Grenze tritt zwischen ihm und syenitischem Granit der sehwarze Porphyr von Darmstadt hervor. Noch andere vulkanische Bildungen, vorzugsweise aber Basalte, kommen in einer nicht unbeträchtlichen Anzahl kleiner isolirter Massen innerhalb der verschiedenen Gebiete der plutouischen Primitiv-Bildungen, des bunten Sandsteins und 


\section{$-259$}

des Todliegenden zum Vorschein. Hierher gehören auch einige kleine Trachit-Kuppen.

In die Grenzen dieser Abtheilung fällt ferner der zwischen Main und Neckar befindliche Theil der grossen Alluvial-Ebenen der rechten Rhcin-Seite, aus welcher am Bergstrïsser Gebirge, so wie an den Gehängen des nördlichen Odenwaldes Diluvial-Anschwemmungen heraufsteigen und mitunter weit in die grösseren Gebirgs - Thäler aufwärts reichen.

Eine weitere Eintheilung der Gebirgs-Oberfläche dieser Abtheilung ergab folgende 6 kleinere Gruppen:

1) Gruppe des Oden:waldes.

Hauptgruppen-Grenze von der Mündung der Modaubach in den Rhein bis zur Mündung der Gersprenz in den MIain; die Gersprenz aufwärts bis Grossbieberau, das kleine Thälchen über Rodau nach Assbach; Linie nach Ernsthafen; die Modau bis zu ihrer Mündung.

2) Westliche Gruppe des Odenwaldes.

Der Rhein vom Einfluss der Weschnitz bis zur Modau; die Modau bis Ernsthafen; Linie nach Assbach; das Thälchen über Rodau nach Grossbieberau; die Gersprenz bis zu ihrem Ursprunge, Linie bis zum Ursprunge der Weschnitz, diese bis zu ihrer Mündung.

3) Gruppe des südlichen Odénwaldes.

Linie von der Quelle der Gersprenz zu der der M̈̈̈mmling, das Mümmling - Thal über Hüttersklingen und HüttenThal bis Eberksberg, Linie zum Ursprung des Zell-Thales am Erbucher Jagdhaus; dieses über Breitenbach und Kirchzell herab bis zum Zusammenfluss mit der Mudau bei Buch; die Mudan bis zu ihrer Entstehung bei Obermudau; Linie zum Ursprung der Elzbach, diese bis zum Neckar; der Neckar bis zum Rhein.

4) Östliche Gruppe des Odenwaldes.

Nordost-Grenze der südlichen Odenwald-Gruppo rom Urspirung der Gersprenz bis zum Zusammenfluss des Zellbach 
mit der Mudau, diese bis zu ihrer Mündung; der Main bis zur Gersprenz; diese bis zu ihrer Quelle.

5) Spessart-Gruppe.

Grenze der Hauptgruppe von der Mündung der Tauber bis zur Mündung der Kahlbach; der Main bis zur Mündung der Kahlbach.

6) Gruppe des Baulandes.

Gegen Westen begrenzt durch die südliche und östliche Odenwald-Gruppe. Der Main von der Münòung der Mudau bis zur Tauber, die Tauber bis Mergentheim; Linie nach Krautheim; die Jaxt bis zum Neckar.

\section{Abtheilung. Neckar-Gegenden.}

Das weit ausgedehnte Selkundär - Gebirge, die Einsenkung zwischen dem Schwarzwalde und Odenwalde erfüllend, südwärts bis zur Schwäbischen Alp sich erstreckend und gegen Osten sich zum Theil in die Baier'schen Niederungen sich verlierend, soll diese Abtheilung umfassen. Muschelkalk und Keuper, beide durch einen so hohen Grad von Ausbildung in diesen Gegenden bekannt, konstituiren bei Weitem den grössten Theil ihres ganzen Oberflächen - Gebietes. Während jener jedoch, von diesem bedeckt, durch Erosion der Wasserströmungen nach und nach mehr entblösst wurde, bildete er weniger ausgedehnte Gebirgs - Gebiete, als der Keuper, sondern ist gar häufig nur auf die Nähe der Thal-Einschnitte beschränkt. Die Schichten beider Bildungen, wie es scheint, grösstentheils in ungestörter Entwickelung abgesetzt, auch befreit geblieben von ihre räumliche Verhältnisse störenden; späteren Veränderungen, behalten mit der Ausnahme, dass sie sich allmählich gegen das nördliche Ausgehende etwas heben, allerwärts ein ziemlich gleiches Niveau bei. Aus diesem Grunde sieht man selten den Keuper in Vertiefungen des Musohelkalkes 
abgelagert *), sondern stets über demselben in ungleich höherem Niveau, entweder. in zusammenhängenden, weit verbreiteten Gebieten, oder auch in zerrissenen Massen. Der bunte Sandstein setzt auch in einigen nicht sehr ausgedehnten Partieen aus dem südlichen Theile des Odenwaldes, so wie aus dem nördlichen des Schwarzwaldes in die Abtheilung der Neckiar-Gegenden herüber, ohne jedoch an irgend einem Punkte im Innern derselben zu Tage aufgefundèn $z u$ seyn. Ganz isolirt kommt der Lias vor und zwar auf den Fildern bei Stuttgart und Tübingen, in abgerissenen Partieen über dem obersten Keuper die höheren Stellen des Gebirges einnehmend, und nordöstlich Bruchsal bei Langenbrücken und Uppstadt, wie es scheint in Vertiefungen des Keupers - vielleicht auch des Muschelkalkes.

Tertiäre Bildungen dürften, ausser dem sehr beschränlkten Braunkohlen-Gebiete in Neckar - Thale bei Dietesheim, wohl in dieser Abtheilung bis jetzt keine andern bekannt geworden seyn. Die verschiedenen kleinen Süsswasserkalk - Bildungen des Neckar-Thales fallen der Epoche des Diluviums anheim, das nicht allein an manchen Stellen des Nechar-Thales, sondern auch in verschiedenen kleinen Thälern, zumal in dem der Elsenz in nicht geringer Mächtigkeit und Verbreitung auftritt.

Ausser der Basalt-ähnlichen Masse des Weilerberges bei Sinsheim wurden nirgends plutonische Bildungen bekannt.

Die Abtheilung zerfältt in die folgenden 5 kleineren Gebirgs - Gruppen.

1) Gruppe des Kraichganes.

Der Rhein vom Einfluss der Kraichbach bis zur NeckarMündung, der Neckar aufwärts bis zur Lainbach, diese bis zu ihrem Ursprunge; Linie nach Goxheim, die Kraichbach bis zu ihrer Mündung.

-) Diese Ausnahme findet nur da Statt, wo der Keuper nuf der unteren Muschelkalk - Abtheilung rubt. 
2) Gruppe des Zabergaues.

Die Pfinz von ihrem Ausflusse bis zu ihrer Quelle, Linie nach Neuenbürg; die Ens bis zu ihrer Vereinigung mit dem Neckar, der Neckar bis zur Lainbach; Grenze der Kraichgau-Gruppe bis zur Mündung der Kraichbach.

3) Gruppe der Filder.

Nördlich umgeben von der Zabergıu-Gruppe; der Neckar vom Vereinigungspunkte mit der Ens aufwärts bis Horb, Linie nach Thalheim, das Thälchen herab bis zur Waldbach, diese bis zur Nagold; die Nagold bis zur Ens.

4) Gruppe des Löwensteiner Gebirges.

Das Neckar-Thal vom Rems-Thal bis zur Mündung des Kochers; dieser bis zur Lain, die Lain bis Lainzell, Linie nach Gmünd, das Rems-Thal bis zum Neckar.

5) Gruppe der Kocher- und Jaxt-Gegenden.

Die Jaxt von ihrer Muindung bis Krautheim, Linie nach Mergentheim; Grenze der Hauptgruppe bis Dinkelsbühl; Linie über Ellwangen bis zum Zusammenfluss der Lainbach mit dem Kocher; der letztere bis zum Neckar.

\section{Abtheilung. Schwarzwald.}

Wie schon angedeutet, sind im westlichen Deutschland 3 isolirte Gebiete primitiv-plutonischer Bildungen vorhanden, die in gerader Richtung von Süden nach Norden sich erstreckend an Höhe und Umfang. gegen Norden allmählich abnehmen. Den Grundsätzen unserer Eintheilung gemäss konnten dieselben' nicht ein und derselben Abtheilung eingereiht werden. Ihre Lage ist so beschaffen, dass die zwei nördlichen kleineren am füglichsten zu einer sich vereinigen und die südliche grössere Partie die Zentral-Masse einer anderen, der des Schwarzwaldes abgibt. In ihrer geognostischen Haupt-Konstituirung kommen beide Abtheilungen ziemlich überein. Wie im Odenwald ist auch der primitive Kern von buntem Sandstein, zumal auch hier auf der Ostseite uugeben. Beide gehören Elis dB Beaunosit's Erhebungs- 
System des Rheins an, dessen Massen-Aufrichtung kurz nach der Ausbildung des bunten Sandsteins Statt hatte und nicht in eine Periode nach dem Absatze der Oolith-Bildungen, wie es Herr Schwarz in einem Sendschreiben an Herrn E. DE BEAUmont darzuthun versucht*), gesetzt werden kani. Zu den verbreitetsten Bildungen innerhalb dieser Abtheilung gehört noch der Muschelkalk, welcher ostwärts her ihre Grenzen überschreitet und in den oberen Neckar. und Danau-, so wie in den Nagold-Gegenden sich ausbreitend am bunten Sandsteine gegen Westen sein Ausgehendes erreicht. So weit uns die Primitiv - Bildungen des Schwarzwaldes bekannt sind, erscheinen sie einfacher zusammengesetzt, als . die des Odenwaldes. Dagegen wird diese geringere Manchfaltigkeit der Hauptmassen durch frequentere besondere Lagerstätten ersetzt, auf welchen man an verschiedenen Stellen nicht unergiebigen Bergbau treibt.

Die übrigen, an der Konstitution dieser Abtheilung Theil nehmenden Bildungen sind, rücksichtlich ihrer Verbreitung, von geringer Bedeutung. Die beachtungswertheste Stelle in jeder Beziehung nimmt unter ihnen, noch die im Breisgau mitten aus dem Rhein-Thal isolirt aufsteigende vulkanische (zum grösseren Theil doleritische) Masse des Kaiserstuhls ein. Im Westen und Süiden erscheinen. noch verschiedene partiell verbreitete Massen der Jura-Formation. Auch lehnen sich dem westlichen Rande des primären Gebirges verschiedene isolirte Partieen von Todtliegendem und der Steinkohlen-Bildung, so wie des transitiven Schiefergebirges an. Von besondrem Interesse sind, in Bezug auf diese früher am Schwarzwald ganz unbekannt gewesene Formationen,

*) Siehe Jahrbuch 1833, I, S. 36. Hiernach müssten Musche!kalk und Keuper, so wie die Oolithenreihe (deren Massen an $\operatorname{der} A l p$ ciner viel später wirkenden Kraft ihre Niveau-Veränderung verdanken) durch die Erhebung des Rhein-Systems mit aufgerichtet seyn. Wie wenig diese Hypothese Haltbares besityt, werde ich vielleicht an eineın anderen Orte näher zu erläutern Gclegenheit finden. 
die neucren Entdeckungen des Herrn Walchner, so wie des Herin v. Kettner, dessen zuvorkommender Gefälligkeit wir eine schöne Reihe von Hand-Exemplaren des nördlichen Schwarzwaldes verdanken.

In dem der Abtheilung zufallenden Theile des RheinThales lehnen sich Diluvial-Anschwemmungen häufig dem Gehänge des älter'n Gebirges an, so wie auch an ver'schiedenen Stellen vereinzelte Tertiär-Ablagerungen bekannt wurden.

Kleinere Gebirgs-Gruppen und ihre Begrenzung.

1) Gruppe der Enz.

Die Murg von ihrer Mündung bis Freudenstadt, Linie zur Quelle des Glatt, das Thal desselben bis zum Neckar, dieser bis Horb; westliche Grenzen der Filder- und Zabergau-Gruppe bis zum Rhein.

2) Murg-Gruppe.

Die Kinzig von ihrem Ursprunge bis zu ihrer Mündung, der Rhein bis zum Austluss der Murg, diese bis zu ihrer Quelle; Linie bis zum Ursprunge der Kinzig.

3) Gruppe der Kinzig.

Vom Ursprunge des Hölle - Thales bis zur Vereinigung mit der Treisam, diese bis zum Zusammenfluss mit der Elzach; die Elzach bis zu ihrer Mündung; der Rhein bis zum Einfluss der Kinzig, diese bis zur Vereinigung mit der Gutach; die Gutach bis zu ihrem Ursprunge bei Tryberg; Linie über Föhrenbach nach Neustadt, das Thal herauf bis zum Tilisen; Linie bis zur Entstehung des Hülle-Thals.

4) Donau-Gruppe.

Die Wutach von Neustadt bis Blomberg; Linie nach Doneschingen; die Brichach bis Villingen; Linie zum Ursprung des Neckars, der Neckar bis zum Glatt; das GlattThal bis zu seinem Ursprunge; Linie nach Freudenstadt; Linie zum Ursprunge der Kinzig, diese bis zur Vereinigung mit der Gutach, die Gutach bis zu ihrer Quelle; Linien über Vührenbach nach Neustadt. 


\section{$-265$}

5) Gruppe der Wutach.

Vom Feldsee oder dem Ursprunge der Wutach bis zu ihrem Einfluss in den Rhein, dieser bis zur Winsbach; das Winsbach-Thal bis zu seinem Ursprung; Linie bis zum Feldsee.

6) Gruppe des Feldberges und Kaiserstulles.

Der Rhein vom Einfluss des Winsbach bis zur Mündung der Elzach; das Elzach-, Treisam- und Hölle - Thal herauf bis zur Entstehung der letzteren; Linien über den Feldsee bis zum Ursprung der Winsbach.

\section{Abtheilung. Raue Alp.}

Diese Abtheilung umschliesst hauptsächlich die OolithBildungen von Oberschwaben; bei Weitem der grösste Theil ihrer Fläche wird von der Jura-Formation, welche neuerdings durch die scharfsimigen Beobachtungen des Herm Grafen vos Maxdelscohe in verschiedene, der Englischen Folge äquivalente Glieder getrennt wurde, eingenommen. An steilen nordwestlichen Abfalle tritt in der ganzen Längen-Erstreckung des Alp-Gebirges in einem schmalen wenig unterbrochenen Streifen der Lias unter dem Jura hervor und unter jenem der Keuper. Nur die niedersten Gebirgstheile dieser Abtheilung gegen N.W. einnehmend, hängt es unit dem auf der linken und weiter nordwärts auch auf der rechten Neckar-Seite in ungleich grösserer Ausdehnung und in mächtiger Entwickelung sich ausbreitendem Keuper-Gebiete der Abtheilung der Neckar-Gegenden zusammen. Im Westen tritt noch ein kleiner. Theil des den bunten Sandstein des Schwarzwaldes nach dieser Seite ungebenden Maschelkalkes innerhalb die Grenzen dieser Abtheilung heriiber. Auch nimmt sie auf der Süd- und der Suidost-Seite verschiedene auf die linke Donau-Seite hinübersetzende Partieen des grossen Molasse-Gebietes von Oberschwaben auf. Ihnen reihen sich noch einige andere Tertiär-Bildungen an, wie zumal verschiedene Süsswasser-Kalke in ter Gegend 


\section{$-266$}

von $U l m$ in kleinen Vertiefungen oder Thälern des Jurakalkes abgesetzt. Kalktuffe, wohl noch neuer als diese, treten nicht selten in den $A l p$-Thälern auf.

Besondere Aufmerksamkeit verdienen die in dieser Abtheilung isolirt hervortretenden Basalte, so wie die sie einhüllenden Trümmergesteine. Sie dürften als unbedeutende, aus der Tiefe höher heraufgetriebene Verzweigungen eines mächtigen vulkanischen Rückens gelten, welcher in der HauptLängenrichtung des Alp-Gebirges aufgestiegen und die OolithMassen aus ihrem ursprünglichen Niveau zu ihrer jetzigen Höhe gleichförmig, ohne beträchtliche Schichten - Störungen zu veranlassen, emporschob.

Kleinere Gruppen und ihre Begrenzung.

1) Gruppe des Hohenzollern.

Der Neckar von der Vereinigung mit dem Echaz-Thale bis zu seinem Ursprunge; Linie nach Villingen; die Donau bis zum Lauchart-Thale; dieses bis zu seiner Quelle; Linie zuin Ursprung der Echaz; die Echaz bis zum Neckar.

2) Gruppe der Teck.

Gegen S.O. an die Gruppe des Hochzollern sich lehnend. Die Vils von ihrem Ausfluss aufwärts bis Geisslingen; Linien über Urspring, Luitzhausen nach Ulm.

3) Gruppe des Aalbuches oder des Hohenrechberges.

Gegen S.0. die Grenze der Teck-Gruppe. Der Neckar vom Einfluss der Vils bis zur Mündung der Rems, die Rems bis Gmünd; Linie nach Lainsell, die Lain bis zum Kocher; dieser bis zu seiner Quelle; Linie zum Ursprung der Brenz, das Brenz-Thal bis zur Donau, diese bis $\mathrm{Ulm}$.

4) Gruppe des Brauneberges.

Der Kocher von Aalen bis zum Einfluss der Lain; Linien über Ellwangen nach Dinkelsbïhl; Hauptgruppe-Grenze bis Donauwörth; die Donau bis zur Brenz; das Brenz-Thal bis zu seinem Ursprunge; Linie zur Kocher-Quelle. - 
V. Abtheilung. Gegenden zwischen der Donau, dem Bodensee und der Iller.

Dieser Abtheilung dürfte das weit verbreitete Oberschwäbische Tertiär-Gebict, so wie die isolirten vulkanischen Berge des Heggaues anheim fallen. Da mir die Bekanntschaft mit ihnen gänzlich abgeht, so darf ich es nicht wagen, eine Eintheilung in kleinere Gebirgs - Gruppen hier zu versuchen. Es dürfte seine grosse Einförmigkeit auch wohl nur eine Abtheilung in zwei bis drei solcher Gruppen gestatten.

\section{Östliche Hauptgruppe.}

Die östliche Hauptgruppe dürfte vorzugsweise das von der rechten Main-Seite nordwärts zwischen der Ostgrenze des transitiven Gebirges und der Fränkischen Saale, so wie der Werra bis zur Diemel hin sich ausbreitende ältere Sekundär - Gebiet mit den verschiedenen darin verbreiteten Tertiär - Bildungen etc. in ihre Grenzen aufnehmen. Mächtige vulkanische Massen treten aus demselben hervor und gruppiren sich in 4 besonderen Partieen, wonach das Ganze am füglichsten in 4 Abtheilungen zerfällt. Diese sind:

1) Abtheilung des Habichtswaldes und der Eder-Gegenden.

2) Abtheilung des Vogelsgebirges und der Wellerau.

3) - der hohen Rhön.

4) - des Meissners und Knölls.

\section{Begrenzung.}

Gegen Westen von dem Ausflusse des Nilda in den Main bis nach Warburg an der Diemel an die nördliche Hauptgruppe sich lehnend *). Die Diemel bis zu ihrer

*) Diese Grenze fällt ungefähr mit der östlichen Demarkations-Linie des Rheinischen Schiefer-Gebirges (wie sie sich aus ihrer näheren Beziehung weiter unten ergeben wird) zusammen. 
Mündung in die Weser, diese aufwärts bis zum Zusammenflusse der Fulda und Werra. Die letztere aufwärts bis Meiningen; Linie nach Melrichstadt. Die Fränkische Saale bis zu ihrer Mündung, der Main bis Lohr; der Lohrerbach aufwärts bis zu ihrer Quelle; Linie zum Ursprung der Kuhlbach; diese bis zu ihrem Ausflusse in den Main; der Main bis zur Mündung der Nidda.

I. Abtheilung des Habichtswaldes und der EderGegenden.

Im westlichen Theile das ältere Sekundär - Gebirge mit der Kupferschiefer-Formation vorwaltend verbreitet; eine abgerissene Partie der ältern neptunischen Formationsreihe noch aus demselben hervortretend. Grünsand, vielleicht auch Keuper im Süden übèr dem weit ausgebreiteten bunten Sandstein in partiellen oder zerrissenen Ablagerungen. Der letztere den grössten Theil der Oberfläche einnehmend. Häufige Muschelkalk-Partieen sind darüber, zumal im nordöstlichen Theile der Abtheilung. Mehrere Tertiär-Gebiete, von nicht beträchtlicher Ausdehnung. Die sekundären und tertiären Bildungen der nordöstlichen Partie durchbrochen von der vulkanischen Masse des Habichtswaldes und einer Menge sie umgebender isolirter Basalte von geringerem Umfange. Die Abtheilung erhielt folgende Eintheilung in kleinere Gruppen:

1) Westliche Gruppe der Eder.

Gegen W. und N. an die 1. Abtheilung der nördlichen Hauptgruppe grenzend; gegen $\mathbf{S}$. die $\boldsymbol{E} d e r$ bis Frilzlar. Alsdann das Thal der Elbebach über Neuenburg nach Ippinghausen; Linie nach Freienhagen; das Thal über Volkardinghausen und Landau herunter bis zum Zusammentritt mit der Tuife; diese bis zu ihrem Ausflusse in die Eder bei Warburg.

2) Östliche Eder-Gruppe oder Gruppe des Habichtswaldes.

Eingeschlossen von der Ost-Grenze der vorhergehenden Gruppe, von der Diemel bis zu ihrer Mündung; von da bis 
zum Zusaumenfluss der Fulda und Werra; die Fulda bis zurn Einfluss der Eder; die Eder bis Fritzlar.

3) Südliche Gruppe der Eder.

Gegen W. begrenzt von der 2. Abtheilung der nördlichen Hauptgruppe; die Ohm von ihrem Ausflusse in die Lahn bis Kirchhain; Linien über Erksdorf nach Neustadt; das Thälchen über Mamberg und Wiera herunter bis zu seiner Mündung in das Schwalmthal; die Schwalm bis zu ihrem Zusammenflusse mit der Eder.

\section{A btheilung der Wetterau und des Vogels- gebirges.}

Im östlichen, wohl auch noch im nördlichen und südlichen Theile vorzugsweise das ältere Sekundär-Gebirge verbreitet. Wärend südwärts gegen den Main besonders in den Kinzig-Gegenden die ä!testen Selundär - Formationen unter dem bunten Sandsteine hervortretend dort mit diesem die ganze Folge des Kupferschiefer-Gebirges entwickeln, erscheinen im nördlicheren Theile einige der jüngeren SekundärBildungen über dem bunten Sandsteine ruhend. Gegen das Schiefergebirge des Taunus und des Westerwaldes hin sich tief herabsenkend bildet das Sekundär-Gebirge westwärts ein Becken von nicht unbeträchtlicher Ausdehnung, welches die tertiären Massen der Wetterau, unter denen besonder's das Braunkohlen - Gebirge eine so wichtige Rolle spielt, aufnimmt.

Aus der Mitte dieses ausgedehnten Sekundär- und Tertiär-Gebietes erheben sich die weit verbreiteten vulkanischen Reihen des Vogelsgebirges, nach allen Richtungen hin von ihrer hohen Zentral-Masse herab radienförmig sich verzweigend, umgeben von häufigen isolirten Partieen geringe-. ren Umfangs und kleinen basaltischen Kuppen und Kegel - Bergen.

Obgleich die geognostische Beschaffenheit der GebirgsPartie, welche im engern Sinne für das Vogelsgebirge gilt, 


\section{- $280-$}

wohl eine Absonderang von den dasselbe west - und siddwärts umgebenden Gegenden der Wetlerau gestattet hätte, so würde andrerseits die Sonderung dieses Gehietes in zwei Abtheilungen kein passendes geographisches Arondissement zur Folge gehabt haben. Wir zogen es desshalb vor, die Gegenden der Wetterau mit dem Vogelsgebirge zu einer Abtheilung zu vereinigen, und theilten dieselben in 8 kleinere Gebirgsgruppen, von welchen die 4 unter A aufgeführten grösstentheils der Wetterau (in weiterem topographischem Simne), die unter B dem eigentlichen Vagelsgebirge angehören.

\section{A. Welterau.}

1) $0 \% m-G r u p p e$.

Die Ohm von ihrer Mündung in die Lahn bis zum Einfluss der Flensunger Bach, diese bis zu ihrem Ursprunge bei Frcienseen; Linie nach Laubach; die Wetter bis zuın Einfluss der Münsterbach; die Münsterbach bis Ettingshausen; Linie nach Hattenrod; das Thal herunter bis Grossenbusech; die Wieseck bis zur Lahn; Grenze der Hauptgruppe.

2) Gruppe der. Wetter.

Gegen W. die Hauptgruppen-Grenze von der Mündung der Nidda his zuın Ausfluss der Wieseck in die Lahn. Von da bis Laubach gegen N. der Ohm-Gruppe sich anlehnend; Linie von Laubach nach der Friedrichshïtte; die Herloff bis zur Nidda, diese bis zum Main.

3) Gruppe zwischen der Nidda und Iinzig, oder IMain-Gruppe.

Umyeben von der Nidda von ihrer Mündung bis zur Laisbach, diese aufwärts bis Rannsladt; Linien über Ortenberg, Wippenbach, Büdingen, Gettenbach, Breitenborn bis zur Kinzig bei Wächtersbach; die Kinsig bis zu ihrer Mündung.

4) Kinzig-Gruppe.

Grenze der Hauptgruppe von der Kinzig-Mündung bis zur Vereinigung der Sirnbach mit der Fränkischen Saale; die Sinn his zur Mündung der Josbach: der Josgrund aufwärts bis Marpass; Linie nach Reinau, die Kinzig bis zum Main. 


\section{B. Vogelsgebirge.}

5) Südwestliche Gruppe des Vogelsgebirges.

Gegen W. an die Wetler-Gruppe, gegen S. an die NiddaGruppe sich lehnend; gegen $\mathbf{0}$. die Semenbach von Büdingen bis zu ihrem Ursprunge am Oberwald; Linien über den Taufstein nach dem Nidda-Teich; das Nidda-Thal herunter bis zur Laishach.

6) Südöstliche Gruppe des Vogelsgebirges.

Gegen W. die vorhergehende begrenzend; Linie vom Taufstein bis zur Quelle der Lüderbach; die Lüder von ihrer Quelle bis zum Einfluss in die Fulda; diese aufwärts bis zur Vereinigung mit der Flinder; die Flinder hinauf bis Flinden; Linien über Elm nach Schlüchlern; die Kinzig bis Wächtersbach; Grenze der Nidda-Gruppe zwischen Wächtersbach und Büdingen.

7) Nordöstliche Gruppe des Vogelsgebirges.

Die Schwalm bis zum Einflnss der Grausbach, diese bis zu ihrer Quelle bei Schorbach; Linie zum Ursprunge des Kemeroder Thales; dasselbe herunter bis zur Aula, diese bis zu ihrem Ausfluss; die Fulda bis zur Vereinigung mit der Lüderbach, das Thal derselben herauf bis zu seinem Ursprunge; Linie nach dem Taufstein.

8) Nordwestliche Gruppe des V'ogelsgebirges.

Gegen 0. von der Nordostgruppe begrenzt vom Taufstein his zum Einfluss der Grausbach in die Schwalm, die letztere bis Treysa; Linien über Wiera, Momberg, Neustadt, Erlisdorf, Allendorf nach Kirchhain; Grenze der Ohm-Gruppe bis nach Laubach, Linie nach der Friedrichsliüte; die Horloff bis zu ihrer Quelle; Linie nach der. Spitze des Taufsteins.

\section{Abtheilung der hohen $R h \ddot{n} n$.}

Die alten Feuerberge der Rhön von Vorgt zuerst beschrieben und von ihm wohl auch zuerst in ihrer wahren Natur erkannt, unter allen vulkanischen Gebirgen in WestDeutschland zur beträchtlichsten Höhe sich erhebend und 
unter ihnen wenigstens in den grossartigsten Formen erscheinend, bilden die Zentral-Kette dieser Abtheilung; doch gestalten sie sich nicht gleich dem nachbarlichen grossen Erhebungs - Krater des Vogelsgebirges *) mit seinen vielen Verzweigungen zu einer weit verbreiteten zusammenhängenden Masse. Basalte und Phonolite, die herrschenden Bildungen, steigen in isolirten Bergreihen und vielen kleineren vereinzelten Kuppen und Kegelbergen zum Theil über buntem Sandstein, theils über Muschelkalk empor. In der Richtung von N.N.W. nach S.S.O. von der Milseburg bis über den hohen Kreuzberg hin reihen sich die beträchtlichsten Massen aneinander und verzweigen sich in eine Menge vereinzelter Kuppen und niedrigere Partieen nord- und südwärts. So manchfaltig das vulkanische Gebirge in seinen geognostischen Erscheinungen sich darstellt, so monoton die Sekundär-Formationen, welche ausserdem an der Oberflächen-Konstitution der Abtheilung Theil nehmen. Hieher gehört zumal der bunte Sandstein, welcher vorzugsweise in den tieferen Gegenden zwischen dem Rhön- und VogelsGebirge fast allerwärts mit seinem rothen Mergelthone sich ausbreitet. In den nördlichen Gegenden beider Abtheilungen der Rhön und des Vogelsgebirges nur noch von vereinzelten kleineren vulkanischen Massen und partiellen

*) Die Hauptmasse dieses Gebirges dürfte wohl als ein ErhebungsKrater von ungeheurem Umfange gelten, wenn man nach den Eigenthümlichkeiten, welche ein solcher Krater nach Hrn. v. Bucr besitzen soll, davou abstrahirt, dass seine bis zur beträchtlichsten Höhe emporgestiegene Zentral-Masse nicht, eine Caldera hinterlassend, nach dem Innern zurücksauk. Statt blasenförmig erhobener Lava, die in ihrer Mitte oder da, wo sie an höchsten emporgedrängt, auch den schwächsten Stïtzpunkt hatte und in sich zurücksinken musste, stieg hier eine dichte Masse hervor. Nach dem Innern in Zusammenhange fortsetzend, behielt sie ohne nach der Emporhebung ihr Raumverhältniss zu ändern, das Niveau der ursprünglichen Erhebung bei. Aber die.Aufspaltungen (Barancos), welche in Radien un die Caldera der Insel Palma herum Statt hatten, sind am Vogelsgebirge nicht zu verkennen. Fast alle Thäler beginnen zunächst der höchsten Masse und ungeben dieselbe auffallend Radien - förmign. 
Muschelkalk-Ablagerangen unterbrochen, erscheint er allenthalben herrschend und setzt in grossem Zusammenhange nach Niederhessen, oder in die 4. Abtheilung der östlichen Hauptgruppe fort.

Neben dem bunten Sandstein scheint überhaupt von neptunischen Bildungen nur noch Muschelkalk in der RhönAbtheilung vorhanden zu seyn, wenn man noch einige bekannt gewordene kleine Gebiete der Braunkohlen-Formation davon ausnimmt. Wie im nördlichen Theile kommt der Muschelkalk auch südwärts in kleineren unzusammenhängenden Partieen vor, gewöhnlich tiefere Stellen in dem ungleich beträchtlicher ausgedehnten bunten Sandsteine einnehmend, aber auch in der Nähe vulkanischer Berge zu ungewöhnlicher Höhe ansteigend. Ausser den erwähnten BraunkohlenBildungen dürften nicht leicht noch andere Tertiär-Formationen in dieser Abtheilung aufgefunden werden.

\section{Kleinere Gebirgsgruppen.}

\section{1) Gruppe der Milsebsirg.}

Linie vom Einfluss der Haun in die Fulda über Friedewald zur Vereinigung der Ulster mit der Werra; die Ulster bis zu ihrer Quelle; Linie zum Ursprunge der Fulda, diese bis zur Mündung der Haun.

2) Gruppe des hohen Kreutzberges.

Grenze der Hauptgruppe von Neustadt an der Fränkischen Saale bis zu ihrem Zusammenfluss mit der Sinn, diese bis zur Josbach; das Josthal bis Marpass, Linie nach Reinau; die Kinzig bis zu ihrer Quelle, Linie zum Ursprung des Neuhofer Thales, dieses bis zu seiner Vereinigung mit dem der Fulda, die letztere bis zu ihrem Ursprunge; Linien über die Quelle der Ulster bis zum Ursprung der Sonderbach, diese bis zur Frönkischen Saale.

3) Gruppe zwischen der Werra und Ulster.

Von der Mündung der Ulsler bis zu ihrer Quelle begrenzt von der Milzeburg-Gruppe; von da bis zum Ausfluss der Sonderbach von der Gruppe des Kreutzberges; weiterhin 
umschlossen von der Hauptgruppen-Grenze bis zur Mïnlung der Ulster.

IV. Abtheilung des Meisners und Knölls.

Zwei mächtige vulkanische Massen, die des Meisners und Knölls, bezeichnen als die höchsten Gebirgspunkte diese Abtheilung, jener im Norden derselben über BraunkohlenGebirge, dieser im Süden über buntem Sandstein aufsteigend. Eine Partie vereinzelter kleinerer basaltischer Berge gruppirt sich in der Nähe dieser Hauptmassen um sie herum. Die darin verbreiteten neptunischen Bildungen entwickeln weit mehr Manchfaltigkeit, als die des Rhön-Gebirges. Verschiedene Muschelkalk-Partieen, zum Theil hier von grösserer Verbreitung als in den beiden vorhergehenden Abtheilungen, sind über dem weit ausgebreiteten, wohl auch hier den grössten Theil des ganzen Abtheilungs-Gebietes einnehmenden, bunten Sandstein vorhanden. Unter ihm tritt im südöstlichen Theile das Kupfer'schiefer-Gebirge, jedoch auch in nicht sehr beträchtlicher Ausdehnung, hervor. Im südwestlichen und nördlichen Theile erscheinen verschiedene Ablagerungen der Braunkohlen-Formation, unter welchen die von dem Basalte des Meisners bedeckte seit Volgt's Mittheilungen über dieses Gebirge, wegen ihren interessanten, durch den Kontakt mit dem Basalte sich ergebenden Verhältnisse rühmlichst bekannt ist.

Kleinere Gebirgsgruppen.

1) Gruppe des Meisners.

Die Fulda von ihrer Vereinigung mit der Werra bis zum Thale von Spangenberg oberhalb Melzungen, dieses bis zu seinem'Ursprunge, Linie nach Eschwege, das Thal von Eschwege herab bis zur Sontra, diese bis zur Werra; Hauptgruppen-Grenze bis zur Vereinigung der letztern mit der Fulda.

2) Gruppe des Knölls.

Die Fulda vom Einfluss der Eder bis zur Aula; diese herauf bis zum Kameroder Thale; das letztero bis zu seinem 


\section{$-235$}

Ursprunge; Linie zur Quelle der Grunsbach; diese bis zur Schwalm, die Schwalm bis zur Eder, die Eder bis zur Fulda.

3) Gruppe zwischen der Fulda und Werra.

Gegén N. begrenzt von der Meisner-Gruppe, gegen W. von der Gruppe des Knölls, gegen S. von der MilseburgGruppe; gegen 0. Grenze der Hauptgruppe vom Einfluss der Ulster bis zu dem der Sontra in die Werra.

\section{Nördliche Hauptgebirgisgruppe.}

Das beträchtliche Gebiet des Schiefergebirges, auf der rechten Rhein-Seite vom Taunus nordwärs bis zu den RuhrGegenden in zusammenhängender Verbreitung sich fort erstreckend, wird sehr passend ein für sich bestehendes grosses Gebirgsganzes, oder eine nördliche Hauptgruppe in der generellen Gebirgs-Abtheilung von West-Deutschland abgeben. Die älteren neptunischen Bildungen, bald weithin höchst monoton zusammengesetzt, bald durch manchfacheren Wechsel ihrer Bestandsmassen sich auszeichnend, sind in Verhältniss der ganzen Fläche durch nur sehr geringen Antheil an ihrer Konstituirung nehmende, plutonische Bildungen unterbrochen. Diese gehören, abgerechnet die vulkanischen Partieen des Siebengebirges und des Westervalde8, zuin grösseren Theile der mittleren Gruppe, oder dem sogenannten WERnER'schen Übergangstrapp an.

Es würde sich wohl der äusserste nördliche Theil von West-Deutschland, die Gegenden jenseits der Lippe oder die niedrigen Gebirgszüge jüngerer Selundär-Bildungen auf der linken Seite der Weser bis über Osnabrück hinaus fortziehend, füglich dieser IIauptgruppe noch einreihen lassen, indem sie sich zu einer besonderen Gebirgs - Abtheilung vereinigen. Da mir jedoch alle jenseits der Lippe liegenden Länder zu wenig bekannt sind, schliesse ich, den Versuch einer geognostischen Eintheilung derselben nicht wagend, sie vorlïufig noch von derselben aus. Vielleiclit 
dass sie weit mehr zufolge ihrer geographischen Lage, weniger aher mit Rücksicht anf geognostischè Konstitution geeignet sind, als eine 4. Abtheilung der nördlichen Hauptgruppe sich zuzugesellen. Vorerst mag dieselbe in folgende drei Abtheilungen zerfallen:

1) Westphalen.

2) Westerwald.

3) Taunus.

Die nördliche Hauptgruppe dürfte folgende Begrenzung erhalten :

Der Rhein von Mainz bis Wesel; die Lippe von ihrem Ausfluss bis Paderborn; Linie über Driburg nach Warburg; die Diemel bis Stadlberg; Linie bis zur Mündung des von Adorf herunterkommenden Thales; dieses hinauf über Adorf nach Beckhausen; Linie nach Rhena, alsdann das Thal über Atteringhausen, Ebbe, Hillershausen bis zur Eder unterlialb Orke, die Eder herauf bis Allendorf; Linie nach Ernsthausen; die Wetter herunter bis zur Lahn, die Lahn bis Giesen.' Linien über Butzbach, Ostheim, Obermörle, den Johannisberg, Ockstatt, Oberrossbach, Homberg, Bonamös; die Nidda bis zu ihrem Ausfluss, der Main bis zun Rhein.

\section{Abtheilung: Westphalen.}

Der nördliche Theil des transitiven Schiefer-Gebirges auf der rechten Rhein-Seite, oder die von ihm beherrscliten Gegenden zwischen der Lippe, dem Rhein und der Sieg, hier in etwas ausgedehnterem Sinne unter Westphalen bezeichnet, dürften sehr passend zu dieser grossen Abtheilung sich vereinigen. Das ältere neptunische Gebirge tritt zunächst seinem Nordrande am deutlichsten und schönsten in seiner Lagerungsfolge' entwickelt auf, wie wir es durch die verdienstvolle Arbeit des Hrn. v. Dechen*) kennen lernten.

-) Rheinland.Westphalen B. II, S. 1. - Herr v. Dechev hat später über die Folge dieser Bildungen ganz andere Ansichten entwickelt. Er scheint einen grossen Theil, weun nicht allen Grauwackenkalk 
Dem unter die Kreide-Bildungen der Ruhr-Gegenden einschiessenden Steinkohlen-Gebirge folgen im Liegenden, höchst gleichförmig und unter sehr dentlicher Entwicklung ibrer Typen, der Old red Sandstone, der jüngere Thonschiefer und das ältere Grauwackenschiefer-Gebirge mit seinen Kalksteinzügen im Hangenden. Diese nördliche Partie des Schiefergebirges von Westphalen dürfte jedem, welcher die Verhältnisse des Rheinisehen Schiefergebirges überhaupt zu studiren die Absicht hat, als die erste Schule zu empfehlen seyn. Süđwärts werden die Verhältnisse einförmiger. Das Grauwackenschiefer-Gebirge, aus welchem hin und wieder nur, seinen einfachen Charalster unterbrechende. Kalkstein-Einlagerungen hervortreten, setzt bei Weitem den grössten Theil der Gebirge dieser Abtheilung zusammen und es dürfte das gangreiche Thonschiefer-Gebirge des Siegner Landes mit ihm auch zusammenzustellen seyn*).

In tiefen Mulden des Grauwackenschiefer - Gebirges werden übrigens weiter südlich, zumal in der Gegend von Bildstein, Attendorn, Förde etc. auch Bildungen über den Massen jenes getroffen, welche entschieden dem jüngeren Thonschiefer angehören. Plutonische Bildungen treten in

dem Kohlenkalkstein zurechnen zu wollen und betrachtet die so klar entwickelte Bildung des zwischen dicsem und dem Old red Sandstone liegenden jüngeren Thonschiefers mit seinen plattenförmigen schwarzen Kalksteinen und Kieselschiefern als die unterste Schichtenfolge des Old reds (S. DE LA BEche geological mamual, deutsch durch v. Dechen p. 483). Gewiss haben ihm seine Beohachtungen in England sehr wichtige Anhaltspunkte zu Vergleichungen mit Deutschen Äquivalenten geboten und ilu wohl auch zu dieser Zusammenstellung veranlasst. Doch dürften einer festen Begründung derselben weitere sorgfältige Prüfungen noch vorangehen.

*) Ob der Siegen'sche so wie noch mehrere andere rücksichtlich ihrer Alters-Beziehungen noch eine problematische Stelle einnehmende Thonschiefer-Bildungen der älteren Grauwacke, oder einer jüngeren Bildung angehören, darüber dürfen wir mit Recht durch die interessante Arbeit des Hrn. Bergmeisters Schmidr zu Siegen, welche derselbe hoffentlich nicht lange mehr dem mineralogischen Publikum vorenthalten wird, gründliche Belehrung erwarten. 
höchst sparsamer Verbreitung auf. Ausser den isolirten kleinen Gebirgs-Partieen der Bruchhäuser Steine und bei Bildstein, so wie mehrerer unbedeutender diopitischer Massen im nördlichen Theile, dürften bis jetzt wenige andere dahin gehörige Bildungen aufgefunden seyn.

Eintheilung in kleinere Gebirgsgruppen.

1) Untere Gruppe der Ruhr.

Die Partie anf der rechten Seite der Ruhr von ihrer Mündung bis nach Waldringhausen; Linie bis zu: Saline bei Werl; das Thal über Schnidingen bis zur Alise, diese bis zu ihrem Ausfluss in die Lippe.

2) Obere Ruhr-Gruppe.

Westwärts der untern Ruhr-Gruppe sich anschliessend; die Ruhr von Waldringhausen bis zu ihrer Quelle; Linie nach Eckeringhausen; die Orke herunter bis zu ihrer Vereinigung mit dem die Hauptgruppen - Grenze bildenden Hillershäuser Thale; Hauptgruppen-Grenze über Stadlberg, Warburg, Paderborn bis zum Einfluss der Ahse in die Lippe.

3) Gruppe der rechten Lenne.Seite.

Nordwärts von der Lenne bis nach Waldringhausen die untere, und von hier bis zur Hauptgruppen-Grenze die obere Ruhr-Gruppe begrenzend. Die Lenne von ihrer Mündung bis zum Einfluss der Hundenbach; diese aufwärts über Oberalbaum bis Heimsberg; Linie nach Schwärre; von da das Thälchen herunter bis zur Vereinigung mit der $E d e r$ unterhalb Rüspe; die Eder bis zur Hauptgruppen-Grenze.

4) Gruppe zwischen der Wupper und Ruhr.

Begrenzt von der Gruppe der linken Lenne-Seite, von der Mündung der Wupper bis zum. Einfluss der Empe in die Ruhr; die letztere bis zum Rhein; dieser bis zur Wupper-Mündung.

5) Gruppe der linken Lenne-Seite.

Eingeschlossen von der Lenne von ihrer Mündung bis zum Einfluss der Bigge; diese bis zu 'ihrem Ursprunge; 
Linie bis zur Quelle der Agger; diese bis zu ilirer Mündung; die Sing bis zu ihrer Mündung; der Rhein bis zum Einfluss der Wupper; die Wupper his Gemark; Linie über Schwalm nach Övelsberg; die Empe bis zur Ruhr; die Ruhr bis zur Lenne-Mündung.

6) Sieg-Gruppe.

Vorn Zusammenfluss der Bigge mil der Lenne bis Rüspe an der Eder der rechten Lenne-Gruppe angrenzend; die Eder bis zu ihrer Quelle; Linie zum Ursprung der Sieg; die Sieg bis zum Einfluss der Agger, diese bis zu ihrer Quelle; Linie zur Quelle der Bigge, die Bigge bis zu ihrel Mündung.

\section{Abtheilung: Westerwald.}

Es umschliesst diese Abtheilung den mittlen Theil des Schiefergebirges auf der rechten Rhein-Seite, nämlich die Gegenden zwischen der Lahn und der Sieg. Sie haben die grösste Manchfaltigkeit in ihrer geognostischen Zusammensetzung aufzuweisen. Aus den Schiefer-Bildungen treten allenthalben entweder: Diorite, und Aphanite oder jüigere plutonische Bildungen hervor und verursachen an verschiedenen Stellen bedeutende Unterbrechungen, wie das Siebengebirge, der Westerwald, das Dillenburgische und ein Theil des Hessischen Hinterlandes. Die beiden ersten Gegenden sind bekannt durch vulkanische Bildungen, Trachyte, Basalte ete., die in denselben beträchtliche Verbreitungs-Gebiete zusammensetzen, und von welchen aus nach verschiedenen Richtungen in grösserer oder geringerer Entfernung sich noch Spuren vulkanischer Thätigkeit verfolgen lassen. Hierher gehören zumal die durch denkwürdige Erscheinungen so bekannt gewordene, nordwärts des zusaunsammenhärigenden Westerwülder Basalt-Gebietes hin sich vereinzelnden kleinen Basalt-Massen, die, bald kaum die Oberfläche erreichend gangförmig das Schiefer-Gebirge durchsetzen, bald in isolirten Kuppen über dasselbe hervortreten. 
Am Westerwald sind die bekannten Braunkohlen - Bildungen von nicht unansehnlicher Verbreitung. Der grösste Theil derselben bildet ein nicht unbedentendes zusammenhängendes Gebiet, aus welchem viele einzelne Basalte und trachytische Berge hervortreten. Durch die basaltische Hauptmasse wird dasselbe fast kranzförmig umschlossen.

Die älteren plutonischen Formationen nehmen südwärts in den Lahn-Gegenden bei Limüurg ihren Anfang, ziehen, nachdem sie in der Gegend von Weilburg mächtiger herrorgetreten, aber am $\mathbf{O}$ strande des Westerwaldes wieder sparsamer erscheinen, nordwärts ins Dillenburgische fort. Hier, so wie im Hessischen Hinterland treten sie am mäehtigsten entwickelt auf und sind durch die denkwürdigen Verhältnisse ihrer treuen Begleiter, der Schaalsteine, so ungemein ausgezeichnet. Ausser den Dioriten und Aphaniten sind auch noch einige unbedeuter:de Porphyr-Bildungen, zumal bei Dietz und Limburg, innerha!b der Grenzen dieser Ahtheilung bekannt geworden.

In derselben eine klare Folge der älteren neptunischen Bildungen speziell zu entwickeln, wie sie die Verhältnisse des Schiefer-Gebirges zunächst an seinem Nordrande ergeben, dürfte grösstentheils vielen Schwierigkeiten unterliegen, indem sie durch das so häufige Vorhandenseyn abnoriner Massen, zumal der Diorite, zu sehr unterbrochen sind und eine Menge Störungen und Veränderungen ihrer ursprüunglichen räumlichen Verhältnisse erlitten haben. Die Gegenden zwischen dem eigentlichen Westerwald und dem Siebengebirge, so wie der Theil des Siegner Landes, welcher dieser Abtheilung noch zufällt, alsdann einige Partieen der oberen Lahn-Gebirge, machen hiervon eine Ausnahme. Nicht allein im ganzen Westen ist allerwärts das ältere GrauwackenGebirge verbreitet, sondern es scheint auch noch den grössten Theil des Schiefer-Gebirges im östlichen Theile zu konstituiren. Doch ist es hier eine nicht leichte Aufgabe, die Demarkations-Linie des jüngeren Thonschiefers und des Old red Sandstone zu testimmen. Jener erscheint in den Lahn- 
Gegenden bei Weilburg und Wetzlar, im Dillthal, so wie im Hessischen Hinterlande grösstentheils unterbrochen durch Diorite und Schaalstein. Der Old red Sandstone scheint im Innern des Schiefer-Gebirges nicht aufzutreten, sondern nur auf den Ostrand, zumal auf die Lahn-Gegenden zwischen Wetzlar und Marburg beschränkt zu seyn. Er ist als die äusserste hangende Bildung desselben nach dieser Richtung hin zu betrachten.

Kleinere Gebirgsgruppen.

1) Obere Laln-Gruppe.

Die Dill von ihrem Ausflusse bis zu ihrer Quelle. Linien zur Sieg- und Eder-Quelle. Die Eder herab bis zur Grenzlinie der Hauptgruppe.

2) Wittle Lahn Gruppe.

Westliche Grenze der Nister und die Elz. Gegen $\mathbf{N}$. von der Sieg-Gruppe, gegen O. von der obern Lahn-Gruppe und südwärts von der Lahn umgeben.

3) Untere Lahn-Gruppe.

Die Wied von ihrem Ausflusse- in den Rhein bis zu ihrem Ursprunge; Linie bis zum Nister bei Hagenburg.

4) Gruppe des Siebengebirges.

Umgeben von der Sieg, dem Nister und der Wied.

\section{A btheilung: Taunus.}

Die ältesten Schichten (älteste Thonschiefer-Formation) des Schiefer-Gebirges, auf der rechten Rhein-Seite das Gebirge des Taunus im engeren Sinne konstituirend, sollen als Zentral-Masse dieser Abtheilung gelten. Mit dem Hundsrïck und Hochwald eine in ein und demselben Streichen fortlaufende mächtige Kette bildend, gibt sie, den iiltesten Erhebungs-System Elie de Beaumont's angehörend, den Südrand des grossen Rheinischen Schiefergebirges ib. Nordwärts lehnt sich ihm das ïltere Grauwackenschiefer-Gebirge an und nimmt Theil an der Zusammensetzung der Abtheilung 
bis zur Lahn. Von den ältern Massen des Taunus an bis dorthin umfasst es den grösseren Theil der ganzen Abtheilung. Fast bis zur Lahn hin zeichnet sicli diese Bildung durch einen höchst monotonen Charakter ihrer Massen aus. In den Lahn-Gegenden aber nimmt sie nicht allein Kalkmassen auf, welche sich auch längs dem östlichen Rand des Schiefer-Gebirges südwärts fast bis zu dem ältcren Gebirge des Taunus verfolgen lassen, sondern wird auch durch Diorite und Aphanite häufig unterbrochen. Die letzteren beginnen hier hervorzutreten als die äussersten Ausläufer gegen Süden der weiter nordwärts so mächtig auftretenden gleichnamigen Bildungen. Es finden sich demzufolge schon ansehnliche Schaalstein - Bildungen auf der linken LahnSeite ein *).

In den Lahn-Gegenden sind ausserdem auch noch in dieser Abtheilung der jüngere Thonschiefer, so wie der Old red - jedoch in nicht sehr beträchtlicher Ausdehnung vorhanden. Ferner finden sich im Süden in der Gegend von Wiesbaden und in Norden bei Limburg einige isolirte Basalt-Kuppen. Eben so fällt noch das am Suidrande des Taunus sich hinziehende kleine Grobkalk- (Süisswasserlkalk ) Gebiet dieser Abtheilung anheim. Sie wird demnach westlich vom Rhein, nördlich von der Lahn, östlich von eimer mit der Ausdehnungs - Grenze des Schiefer-Gebirges nach dieser Seite hin ungefähr zusammenfallenden Linien und südlich vom Main umschlossen.

\section{Kleinere Gruppen der Taunus-Abtheilung.}

1) Östliche Gruppe des Taunus.

Umgeben von der Lahn bis zum Einfluss der Embs, von dieser bis Camberg, alsdann von Linien über Neuweilnau nach Usingen; die Us bis Obermörle.

*) Sie scheincn jedoch hier nicht in der Ausdehnung verbreitet zu seyn, welche ihnen STift auf seiner Karte gibt: zumal dürften sie in der Gegend von Weilburg auf eine ungleich kleiuere Fläche beschränkt werdeu. 


\section{$-283$}

2) Südliche oder eigentliche Gruppe des Taunus.

Die Wisperbach von ihrem Einfluss in den $R h \in$ in bei Lorch bis zu ihrer Quelle; Linie über Langenschwalbach, Watzenborn, Haimbach, Idstein nach Camberg.

3) Westliche Taunus-Gruppe.

Umschlossen von der Hauptgruppen-Grenze und der östlichen und südlichen Gruppe dieser Abtheilung.

\section{Westliche Haupt-Gebirgsgruppe.}

Der nördliche Theil der Gebirgs-Gebiete der westlichen Hauptgruppe, welche ungefähr die Länder der Deutschen Staaten auf der linken Rhein-Seite einehmen soll, kommt mit der geognostischen Konstitution der nördlichen Hauptgruppe im Generellen so ziemlich iiberein. Dem älteren Thonschiefer des $\boldsymbol{H}$ undsrücks etc. folgt nordwärts der weit ausgebreitete Grauwacken - Schiefer der Eifel; ihm schliessen sich die Steinliohlen-Bildungen von Aachen, welche auch auf dieser Seite wieder von Kreide bedeckt werden, an. Dagegen wiederholt sich in den dieser Hauptgruppe zugetheilten Gegenden an Sïdrande des Hundsrïckens und Hochwaldes das Steinkohlen-Gebilde mit Old red Sandstone, welchen sich zunächst der bunte Sandstein der Haardt und die mittelrheinischen Tertiär-Bildungen anschliessen. Folgende 3 Unter-Abtheilungen umfasst das Ganze:

1) Eifel und hohes Vehn;

2) Hundsrïck und Hochwald;

3) Doinersberg und Haardt.

Grenze der westlichen Hauptgruppe:

Gegen O. der Rhein; gegen W. ungefähr die Grenze zwischen den Deutschen Staaten und den Niederlanden; gegen S. die Grenze zwischen den ersteren und Frankeich. Die politische Grenze gegen das Ausland kann hier mit der geognostischen nicht scharf zusammenfallen. Die $\Lambda$ bweichungen von der ersteren werden sich durch die Begrenzung der kleinern Gebirgsgruppen näher ergeben. 


\section{$-284$}

I. Abtheilung der Eifel und des hohen Vehns.

Die Abtheilung der Eifel und des hohen Vehns nimmt das grosse einförmige Grauwacken-Schiefer-Gebirge ein, welches sich von der linken Mosel-Seite an, zwischen dem Rheine, der Maas und der Our his nach Aachen hin erstreckt, so wie das hier dem Hangenden des Grauwacken-Schiefers sich anlegende Steinkohlen-Gebirge, - alsdann die das letztere bedeckenden Grünsand - und Kreide-Gebilde. Im östlichen Theile treten aus dem ausserdem durch einen - wie in den meisten übrigen Abtheilungen des Schiefer-Gebirges höchst monotonen Charakter ausgezeichneten GrauwackenSchiefer häufig wohl grösstentheils ihm angehörende Kalkstein-Einlagerungen auf, welche sich aus der Gegend:von Gerolstein in vereinzelten Zügen üher Blankenheim, am hohen Vehn hin bis nach Aachen verfolgen lassen. Es scheint fast nicht, als wenn in dieser Abtheilung die zwischen der älteren Grauwacke und den Steinkohlen liegenden Bildungen des Schiefer-Gebirges aufträten. Wenigstens dürften sie nur auf kleinere Verbreitungs-Gebiete beschränkt seyn *). Der in den westlichen Eifel-Gegenden sich über den Grauwacken-Schiefer ausbreitende bunte Sandstein scheint auch weiter östlich noch vereinzelt vorzukommen. Wenigstens wird ihm die Sandstein-Bildung der Bleierz-Lagerstätten von Commern beigezählt.

Eine besondere Auszeichnung verleihen den südlichen Gegenden dieser Abtheilung die bekannten so denkwürdigen vulkanischen Erscheinungen, welche sie für das Studium der neueren Vulkane zu einem der klassischsten Böden erheben. Es sind diess die neuerdings ron Herrn Professor Mitscherlich

-) Das Auffinden derselben, so wie ihre nähere Kenntniss inuss ge. naueren Untersuchungen vorbehalten bleiben. Diesen soll Herr vox Örnhausen in Schiefer-Gebirge der linken Rhein-Seite bereits ausser seinen früheren Arbeiten neuerdings wieder sich gewidmet haben, so dlass man berechtigt ist, höchst werthvollen Mittheilungen dieses verdienten Geognosten entgegen zu sehen. 
grösstentheils als Gasvullsane erkannten Krater und Feuerberge der eigentlichen Eifel und des Laacher See's, welchen weiter nördlich auch noch der Vulkan des Roderbergs bei Bonn angehört. Sie bezeichnen sämmtlich die neueste Epoche vulkanischer Thätigkeit und scheinen im westlichen Deutschland nur auf diese Gegenden der linken Rhein-Seite beschränkt zu seyn. Nirgends sind wohl diesseits des Rheins vulkanische Bildungen bekannt geworden, welche diesen an die Seite gestellt werden kömmen. Überhaupt dürften sie ausserdem in Deutschlánd - den Cammerberg bei Eger und einige andere Orte Böhmens ausgenommen - nicht weiter vorkommen. Was in Bezug auf solche Erseheinungen in Frankreich die Auvergne bietet, besitzen wir in einem noch ausgezeichneteren Grade durch die Eifel.

Kleinere Gebirgs-Gruppen und ihre Begrenzung.

1) Gruppe des Laacher See's.

Gebiet zwischen der Nordostgrenze der Eifel-Gruppe, der Ahr, dem Rheine und der Mosel.

2) Eifel-Gruppe.

Die Mosel vom Einfluss der Elz bis zur Luxenburger Grenze bei Wesserbillig; die Our bis zu ihrem Ursprunge; Linien über Kronenberg bis zur Quelle der Ahr; diese herab bis in die Gegend vom Aremberg; Linien über den Kellberg nach dem Ursprung der Elz; die $E l z$ bis zu ihrer Mündung.

3) Gruppe des hohen Vehns.

Südwärts an die Eifel-Gruppe, westwärts an die ErftGruppe sich anlehnend. Dürfte westlich bis zur Maas und Ambleve hin sich uusdehnen.

4) Erft-Gruppe.

Die Ahr; Linie vom Ursprung der Ahr bis zu dem der Urft, diese bis zum Einfluss in die Röhr, die Röhr bis Niedeggen; Linie zum Ursprung der Nafel, diese bis zu ihrem Ausfluss; die Erft bis zu ihrer Mündung.

Jahrgang 1836. 


\section{$-286$}

II. Abtheilung des Hundsrücks und Hochwaldes.

Die hohe Kette des Hundsrïcks, des Idarwaldes und des Huchwaldes zum Theil aus den ältesten Schichten des Schiefer-Gebirges (Thonschiefer mit Quarz und Talk des Taunus) bestehend, wird als Hauptmasse an der Zusammensetzung dieser Abtheilung Antheil nehmen. Dem hohen Rücken dieses Gebirges lehnt sich N.W. die ältere Grauwacke an und bildet zum grösseren Theile das bis zum linken Mosel-Ufer herab sich verflächende Gebirge. Am Südrande des Hundsrïchs und Hochwaldes, scheinen jedoch die zwischen dem ältesten Thonschiefer und dem Old red Sandstone ruhenden Bildungen gänzlich zu fehlen, indem der letztere grösstentheils abweichend auf jenem beobachtet wird. In ansehnlicher Verbreitung erscheint jüngere Grauwacke bis zum Glan und der Blins, der S.O.-Grenze dieser Abtheilung hin, ist aber hänfig durch abnorme Massen, vorzugsweise durch schwarze Porphyre unterbrochen, welche zunal in den Gegenden von Kirn und Oberstein in so beträchtlichem Umfange hervortreten. Im S.W.-Theile das Steinkohlen-Gebirge mächtig entwickelt. Über dem Old red Sandstone seine Stelle einnehmend, scheint es sich von seinem grösseren Verbreitungs - Gebiete (Suar-Gegenden) aus noch in verschiedenen partiellen Absätzen N.W. bis gegen Meissenheim hin verfolgen zu lassen. Bei Kreutznach tritt ferner nech über dem Old red Sandstone in nicht hedeutender Verbreitung bunter Sandstein auf. Eben so fallen einige in derselben Gegend vereinzelte kleine Ablagerungen von tertiärem Sande imerhalb die Grenzen dieser Abtheilung.

\section{Kleinere Gebirgsgruppen.}

1) Gruppe des Hundsrïcks.

Der: Rhein vom Einfluss der Nahe bis zur Mosel-Mündung; die Musel aufwärts bis Trarbuch; die Annes und Nenerbach herauf his zu ihrer Quelle; Linie zur Quelle der Hannebach; das Thal derselben herab bis Kirn. Die Nuhe bis zu ihrer Mündung. 
2) Gruppe des Hochwaldes.

Die. Mosel von Trarbach bis zum Einfluss der Saar, diese bis zum Neukybach, der Neukybach bis Metlnich; Linio xum Ursprung der Nahe bei Sellbach; die Nahe bis Kirn; Grenze der Hundsrück-Gruppe bis Trarbach.

3) Gruppe der Saar-Gegenden.

Grenze der Hochwald-Gruppe von Kirn bis zum Einfluss der Neukybach in die Saar; diese abwärts bis zur Nied; diese bis zum Ursprung der Nied Allemande; Linie zum Ursprung der Albe, die Albe bis zur Vereinigung mit der Saar; die Saar bis zu ihrem Zusammenfluss mit der Blins, diese bis zu ihrer Quelle oberhalb Blinsen; Linie zum Ursprung der Nahe.

4) Gruppe zwischen der Nahe und dem Glan.

Die Nahe vom Einfluss des Glan bis zu ihrem Ursprunge; Linie zur Quelle der Blins, diese abwärts bis zum Thale von Homburg; dasselbe herauf bis zu seinem Ursprunge; Linie zum Ursprunge des Thales von Waldmohr; dieses herab bis zum Glanthal; der Glan bis zu seiner Mündung.

III. Abtheilung des Donnersberges und dor. Ha ardt.

Diese-Abtheilung wird sich ungefähr auf die Baierischen und Hessisclien Lande der linken Rhein-Seite erstrecken. Die verbreitetsten und fast ihren ganzen Süden einnehmende Formation ist der bunte Sandstein des Hardt-Gebirges. Er setzt dieses Gebirge - einige kleine Basalte, die bei $\mathrm{Neu}$ stadt aus ihm hervorbrechen, abgerechnet - in ununterbrochener Einförmigkeit zusammen. Längs seiner Nord-und Nordwest-Grenze tritt der Old red Sandstone unter ihm hervor und breitet sich nordwärts nach dem Donnersberge hin aus. Das ganze auf der rechten Seite des Glans durch diese Formation zusammengesetzte Gebiet - bekannt durch die früher so ergiebigen Quecksilbererz - Lagerstätten fäll dieser Abtheilung zu. Die mächtige Masse augitischen 


\section{- $288-$}

und rothen Porphyrs des Donnersberges tritt aus ihr hervor. Es findet sich ausserdem diese Felsart noch an verschiedenen andern Punkten, zumal weiter nordwärts in Tertiär-Gebirge in vereinzelten kleineren Partieen. Den plutonischen Bildungen dieser Abtheilung gehört auch das auf der rechten Nahe-Seite oberhalb Kreutznach in mehrere kleine Gebiete sich trennende Porphyr-Gebirge. Ausserdem unschliesst sie sämmtliche Tertiär-Bildungen des linken Mittel-Rheins. Das flache niedrige Gebirge zwischen der Apellbach, der Eisbach von Grïnstadt bis Worms, und dem Rhein von Worms bis beinahe nach Bingen wird fast ganz durch dasselbe eingenommen. Bei Weitem der grösste Theil ist Grobkalk *). Jüngere tertiäre Sand-Bildungen, nur auf unbe: deutende Flächen beschränkt, bedecken ihn an verschiedenen Stellen. Am Fusse des Haardt-Gebirges ziehen sich ausser diesem grösseren zusammenhängenden Tertiär-Gebiete noch einige unzusammenlä̈ngende Grobkalk-Absätze hin. Südwärts von Neustadt aber scheint kein tertiärer Kalk mehr vorzukommen. Auch auf der linken Rhein-Seite haben mächtige Absätze von Diluvial-Bildungen Statt gehabt, die, wie am Rergsträsser Gebirge längs dem Fusse. des Haardt-Gebirges fortziehen und dem Gehänge des Grobkalkes gegen das Rhein-Thal sich anlehnen. Sie ziehen sich nicht allein weit in die Thäler des letzteren aufwärts, sondern überdecken, an manchen Stellen das Niveau desselben überschreitend, auch noch einen Theil seines niedrigen Plateaus.

\section{Kleinere Gruppen:}

1) Rhein-Gruppe.

Ungeben vom Rhein vom Einfluss des Eisbach bis zur Nahe-Mündung; die Nahe aufwärts bis zur Wiesbach, diese bis Rodenkirchen; Linien über Kirchheim Boland, Marnheim, Güllheim bis nach Grünstadt, die Eisbach bis zum Rhein.

*) Jüngerer Krobkalk nänlich oder Tegel-Formation.

D. $R$. 


\section{$-289$}

2) Gruppe des Donnersberges.

Der Glan von seiner Mündung aufwärts bis in die Gegend von Bruchmühlberg; Linien (die Kaiserstrasse) über Landstuhl nach Kaiserslautern, ferner Linien von da ïber Enkenberg, Alsenborn zum Ursprung der Eisbach, diese bis Grünstadt; Linien über Göllheim, Kirchheim Boland nach Rodenkirchen; die Wiesbach bis zur Nahe; die Nahe bis zur Glan-Mündung.

3) Haardt-Gruppe.

Der Rhein vom Einfluss der Eisbach bis zur Mündung der Lauter, diese bis Bobenthal; Linie nach Schönau; die Sauer bis zu ihrer Quelle; Linis nach Trutbert; das Thal herab bis zur Vereinigung mit dem Schweigenthal bei Neu. hornberg; das Schweigenthal bis zur Blins; das Blinsthal bis zum Homburger Thälehen; Linien von Homburg über Von gelberg nach Bruchmühlberg; die Südgrenze der Donnersberg-Gruppe. 


\section{B e ob a c h t ungen}

über Kiesel-Gebilde im Allgemeinen und Silizifikation der organischen Reste insbesondre, gésammelt in den sekundären Gebirgs-Formationen des Regen-Kreises im Königreich Bayern,

von

Herrn Ober-Bergrath voN VolTh.

Herr v. Buch hat in 2 Abhandlungen (Recueil de pétrifications remarquables, Ites Cahier, u. über die Silizifikation organischer Körper) schon in den Jahren 1828 und 1831 eine Hypothese über einen Gegenstand aus der Petrefaktenkunde aufgestellt, welcher gewiss die Aufmerksamkeit sowohl der Mineralogen als der. Chemiker verdient, und auch mich während eines zweimaligen langjährigen Aufenthaltes in Amberg (von 1504-1805 und von 1S20-1S29), in dessen Uingegend verkieselte Thier-Reste verschiedener Art theils eingewachsen oder gewöhnlicher ausgewittert, so häufig vorkommen, ungelegen beschiftigte, aber mir ungeachtet der vielseitigen Beobachtungen und Zusammenstellungen nie vollkommen deutlich wurde. Überhaupt in den literärischen Hülfsmitteln dieses. Theiles der Naturgeschichte auf mich selbst beschränkt, habe ich zwar jene Abhandlungen nur aus den in dieser Zeitschrift (Jahrbuch 1S31, p. 465 und 1832, 
p. 249) gegebenen Auszügen, und darum vielleicht nicht genug kennen gelernt, um mich über mein Bedenken mit Zuversicht bescheiden zu können; dennoch waren mir auch diese zu wichtig, um nicht vorläufig, bis mir etwa ein $\mathrm{Zu}$. fall die Einsicht der Abhandlungen selbst bescheren, oder ander's woher weitere Aufklärung verschaffen wird, eine Ausgleichung zu versuchen. Leider ist mir bis jetzt.weder die eine noch die andere geworden; da die Er'scheinung äber gewiss eine strengere Nachforschung verdient, so erlaube ich snir, dieselbe durch Aufzählung meiner Beobachtungen ïber die silizifizirten organischen Reste und die Kiesel-Konkretionen in den sekundären Formationen überhaupt neverdings in Anregung zu bringen. Die Einschaltung meiner Ansichten soll keineswegs bezwecken, den um die Geognosie und Petrefalitenkunde so hoch verdienten $\mathrm{H}_{\mathrm{r} n}$. v. Buch, wie mir schon früher (durch meine Abhandlung über den Jura-Dolomit in der v. Molc'schen Zeitschrift) das Unglück widerfahren ist, abermal entgegen zu treten; sondern einzig und allein, ihn zur freundschaftlichen Belehrung und weitern Verfolgung zu bewegen.

Im Auszuge (Jahrb. 1S31, p. 465) heisst es: „die Verkieselung findet nie auf der Schaale selbst Statt, sondern setzt stets eine vorexistirende organische Materie voraus" - und (Jahrb. 1832, p. 249) : „die verkieselnde Flüssigkeit ist von Innen herausgedrungen, nicht von Aussen abgesetzt. Die Muschel-Schaalen bestehen, parallel mit ihrer innern Oberfläche, aus wechselnden Schichten oder Blättern kohlensauren Kalkes und thierischen Schleimes, von der Obertlïche des Mantels ausgesondert. Jener hat eine unorganische Textur; er erscheint faserig...". Wenn man aus dickschaaligen Muscheln noch lebender Thiere queer über die Dicke der Sehaale geschnittene Streifen bis zur Durchscheinenheit dünne sohleift und unter das Vergrösserungsglas bringt, so zeigt sich jede Sehicht des kohlensauren Kalkes zwisehen 2 Membranen (Schleimliäuten@) aus melireren, von vertikal auf diesen stehenden und an beiden Enden zugespitzten $C_{y}$ linder. 
oder wahrscheinlicher vierseitigen Prismen zusammengesetzten Lagen dergestalt hestehend, dass die Endspitzen der Prismen (Fasern) der einen Lage immer in die Zwischenräume der Prismen der anliegenden eingefügt sind, - der Kern der Fasern oder Prismen nach ihrer ganzen Länge mit einer braunen Flüssigkeit ausgefüllt, die in den innersten Schichten wohl $\frac{2}{3}$ bis $\frac{3}{4}$ des Queerdurchmessers einnimmt, nach Aussen hin aber sich nach der Länge und Dicke der Fasern vermindert, und in den äussersten Lagen beinahe verschwindet. Wie der Körper des 'Thiers durch das Band und die Schliess-. muskeln, so ist der Mantel durch den Kreismuskel und zwischen diesen und dem Band noch an mehreren Stellen mit der Schaale verbunden. Von allen genannten AnheftungsPunkten dringen Muskelfasern tief in das Innere der Schaglen. Wenn man ferner erwägt, dass jener thierischer Schleim allenthalben zwischen die Berührungsflächen der Prismen eingedrungen ist, und selbst die Masse des kohlensauren Kalkes innig durchdringt (was durch das Lockerwerden und endliche Zerfallen der Schaalthier-Gehäuse während der Verwitterung in freier Luft zur Genüge dargethan wird) dass vom Bande aus längs seiner Erstreckung eine beträchtliche Anzahl der Muskelfasern in die Schaale fortsetzt dass ein manchfaltig sich verästelndes Gefäss sich durch den ganzen Mantel verbreitet und $Z$ weige an den Anheftungsstellen in die Masse der Schaale einsenkt; so dürfte

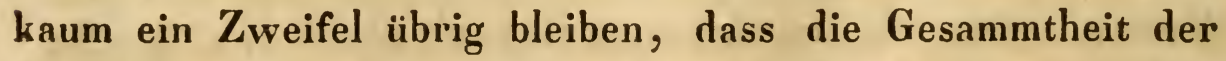
Schaalenmasse eben so organisch als die der Knochen der Wirbelthiere (und in ihrer Art die Holzfasern) sey. Es wäre sonach, wenn die organische Materie das Grundbedingniss der Silizifikation ist, dieses nicht bloss nach v. Bucr's Vermuthung auf die Membranen zu beschränken, sondern auch, wenn man übereinstimmend mit den heutigen Erscheinungen bei ähnlichen Ereignissen eine theilweise Zersetzung und Ausscheidung ihrer Materie durch Verwitterung in einzelnen Schaalen annimmt, die theilweise Silizifikation derselben leichter und naturgemässer zu erklären. 
Über die Textur 'der festen Theile im natürlichen $\mathrm{Zu}$ stande aus den übrigen Abtheilungen der wirbellosen Thiere, welche nicht weniger häufig in manchen Gegenden (und auch bei $A m b e r g$ ) verkieselt vorkommen, gibt keiner der Auszüge, und wahrscheinlich auch keine der Abhandlungen Aufschluss. Dass sie nicht durch die ganze Kette hin einerlei und gleichförmig sey, im Gegentheil bei jedem Gliede unter sich mehr oder weniger, sogar bedeutend abweiche, beweisst nach meinem Dafürhalten zu Genügen ihre auffallende Verschiedenheit in den kalzifirten *) Überbleibseln aller Echinodermen Cuvier's - und lässt mit grosser Wahrschejonlichkeit selbst bei den eben nicht so weit von einander abstehenden Familien der Muscheln und Schnecken die Erscheinung vermuthen, dass bei den ersten auch die umsichtigste Behandlung im Trockenen das Bersten der Ränder nur selten zu verhüten vermag, während man bei den zweiten, sie mögen im Wasser oder auf dem Lande leben, dasselbe nie gewahrt. Für die vollständige Begründung und systematische Durchführung der Hypothese scheint mir aber diese Kenntniss nicht gleichgültig zu seyn. Meine isolirte Lage machte mir es unmöglich, meine Untersuchung derselben unter dem Mikroskope über die Anodonten und Unionen hin. aus zu erstrecken und die Lücke auszufüllen.

„In jener vorexistirenden organischen Materie (so fährt der Ausżug, Jahrb. 1831, p. 465 fort, die Entstehung und endliche Ausbildung der Silizifikation zu erklären) bildet sich ein kleines Kügelchen von Kieselhydrat (Silex BrongN.), welches sich erhebt, ausdehnt, etwas starrer wird, doch ohne ganz zu erhärten. Ein neues Kügelchen dringt in dessen Mitte ein, und treibt es weiter auseinander, ein drittes folgt, und so entstehen konzentrische Kreise von Kieselsubstanz. . . ". Im Jahre 1804 wurde mir die Oberaufsicht über die k. Perlen-Fischereien in der Oberpfals

*) Im Gegensatze von silizifizirt, da kalzinirt gegenwärtig eine ganz andere Bedeutung erhalten hat. 
übertragen. Diess bewog mich, ausser dem administrativen und technischen Theile meines Amtes auch den naturhistorischen mit Eifer zu studiren und bei damals noch sehr mangelhaftem Unterricht in Schriften durch Beobachtungen in der Natur zu vervollständigen. Bei dieser Gelegenheit bemerlite ich vielfältig auf den inneren Flächen der ausgebreitet an den Ufern der Bäche liegenden Schaalen abgestorbener Unionen und Anodonten bald einzeln bald in grösseren oder kleineren Partieen genau lionzentrische Ringe. lhre Anzahl wechselte von 1 bis 5, selten 6, und nahm von Innep, nach Aussen zu. Hin und wieder waren die äusseren stellenweise unterbrochen. Ihr korrespondirender Durchmesser und ihr Abstand gegeneinander von ungefähr $\frac{1}{4}{ }^{\prime \prime \prime}$ bis $\frac{1}{3}$ '" blieb sich scheinbar ziemlich gleich. Die nicht ganz standhafte Dicke betrug beilïufig zwischen $\frac{1}{12}{ }^{\prime \prime \prime}$ bis ${ }_{10}^{1}$ "'. Die Farbe war graulich weiss, das Ansehen erdig, die Härte vom beinahe Zerreiblichen bis zu jener des Kalkspathes. Eben so ändert die Höhe von $\frac{1}{12}{ }^{\prime \prime \prime}$ bis $\frac{1}{10}{ }^{\prime \prime}$. Ihre chemische Beschaffenheit wenigstens qualitativ auszumitteln, könnte man ohne Mühe die erforderliche Masse sammeln. Einige Auflklärung dïrfte der Umstand geben, dass ich solche Ringchen nur in Gegenden fand, wo das Wasser ïber kieseligen Grund hinfloss. Die schillernde Perlmutterfarbe der Schaale hatte sich sogar zwischen den Ringchen unversehrt und lebhaft erhalten. Als Gehäuse parasitischer Thierehen kann man also auch diese Ringehen nicht und um so weniger betrachten, da sie viel zu gleichförrmig sind, um eine Hemmming der angefangenen oder eine Zerstörung der mehr oder weniger vorgerückten Ausbildung annehmen zu dürfen, und da sie nach meiner Beobachtung nur unter gewissen Verhältnissen und zu selten vorkommen. Übrigens gehören ähnliche Bildungen kieseliger konzentrischer Ringchen (und manchfaltiger ande:er (iestalten) an silizifizirten Thier-Resten in der Ungegend Ambergs nicht zu den ausserordentlichen Seltenheiten. Die Annahme einer natïrlichen Anlage, wemm nicht aller, doch vielleicht der meisten organischen Körper hiezu 


\section{$-295$}

gewinnt also durch diese Beobachtung einen sehr hohen Grad von Wahrscheinlichkeit; nur der Prozess des Fortschreitens, vielmehr des Überganges aus dem organischen Zustande in den verkieselten, wird dadurch einigermassen auf andere Art bezeichnet, als er in jenen Abhandlungen beschrieben ist.

Un aber mit möglichster Wahrscheinlichkeit den Gang des dabei Statt habenden Prozesses überhaupt, und die bei den allem Anscheine nach abwechselnd wiederholten Auflösungen, Fällungen und Verbindungen thätigen A'gentien und Reagentien insbesondere, und etwa auch, was zur Erklärung des Phänonens allerdings nothwendig seyn dürfte, ihre Zeit, Weise und Folge des Wirkens auszumitteln, dünkt mir eine vielseitige Zusammenstellung über diese Erscheinung in verschiedenen Gebirgsarten und verschiedenen Gegenden umsichtig gemachter Beobachtungen, so weit aussehend er ist, dennoch der kürzeste, immer der sicherste Weg. Diese Ansicht als richtig voransgesetzt lege ich die, während meines einstigen vieljährigen Aufenthaltes in $\mathrm{Am}$ berg und nun in Regensburg und auf den von da weg vorgenommenen vielfältigen $W$ anderungen, in jener Beziehung gesammelten Bemerkungen als einen vorläufigen Beitrag hier nieder.

Amberg ist, jene nach N., - und Regensburg, jene nach 0. ${ }^{*}$ ) ausgenommen, in allen Richtungen nahe und ferne von den meisten, verkieselte organische Reste (nitunter vielleicht auch blosse kieselige Konkrezionen) enthaltenden GebirysFormationen umgeben. Sie sind 1) dichter Jurakalk, 2) JuraDolomit, 3) lithographischer Schiefer', 4) grüner Sandstein, 5) Tripel. In allen diesen er'scheint zwar der verkieselnde Stoff lediglich und ausschliesslich als Hornstein, aber sowohl überhaupt in jeder derselben, als zum grössten Theile sogar in deren verschiedenen Lagen nicht nur der äussern Gestalt,

*) Granitgebirge gränzen nach diesen beiden Welt - Gegenden die sekundäre Formation schneidend ab. 
sonder'n auch der Textur und besonders seinen Übergängen nach standhaft verschieden. Ob jedoch, wo und wie er auch auftritt, sein Daseyn allemal und üherall durch Verkieselung organischer Körper bedungen werde, wird sich, wie ich glaube, aus den folgenden Thatsachen unschwer entwickeln lassen.

1) Bei Lengfeld, etwa $1 \frac{1}{2}$ Stunden unterhalb Amberg, sind in einem graulich-gelblichen dichten Jurakalke mehrere Steinbriiche von ungleicher, aber zum Theil bedeutender Tiefe und Erstreckung angelegt. Das Gestein ist von oben bis unten geschichtet; die Schichten wechseln unregelmässig mit einer Mächtigkeit von $3^{\prime \prime}$ bis über $2^{\prime}$, sind auf den Flächen sehr uneben und knotig, und liegen beinahe wagerecht mit einer äusserst geringen Neigung einerseits nach S.O. und andrerseits nach S.W. Alle Schichten enthalten in mehr oder weniger grosser Menge Hornstein - Gebilde von eyförmiger oder elliptischer Gestalt und 1 bis $4^{\prime \prime}$ Länge, wenn sie einfach, - von sehr manchfacher Form und Grösse, wenn derselbe mehrere vereiniget, gleichsam zusammengeflossen sind. Vorzüglich angehäuft finden sie sich gewöhnlich an den Absonderungs - Flächen der Schichten, welche daher fast immer auffallend klaffen. Die Hauptmasse des Hornsteins ist durchgehends lichte gelblichweiss von Farbe, und, mit Ausnahme einer sehr dïnnen etwas härtern Kruste, locker bis zum Zerreiblichen, manchmal bis zum Erdigen im Gefiuge, auch desswegen erdig im Bruche und undurchscheinend; sie gibt angehaucht einen schwachen Thon-Geruch und klebt ungemein stark an der Zunge. Säuren wirken nicht darauf. Im Innern derselben zeigen sich, in den höheren Schichten zusehends häufiger werdende Stellen, welche sich von Aussen nach Innen allmählig zu grauem, bald splittrigem, bald muscheligem, nicht selten aus konzentrischen Lagen bestehendem, durchscheinendem bis fast durchsichtigem Hormsteine, öfter mit einem quarzigen Kerne, verdichten, von kaum $\frac{1}{4} " \prime$ bis höchstens 4"' Dur'chmesser. An der Luft zerfallen diese Hornstein-Gebilde zuerst in nach der längern 
Achse sehr spitzwinkelig pyramidale oder prismatische, dann unregelmässige scharfkantige Bruchstïcke und endlich zu Erde *). Verkieselte Muscheln von 2 bis $3^{\prime \prime \prime}$, und zuweilen auch [Alveoliten von] Belemniten von 4-6"' Länge sind so vielfältig nicht nur auf ihrer Oberfläche sichtbar, sondern auch im Innern eingeschlossen, dass man auch da, wo man sie zufällig nicht zu bemerken vermag, allerdings ihre Gegenwart voraussetzen darf. - Dieses Vorkommen wiederholt sich, nụ weniger aufgeschlossen, im Steinbruche bei der Ziegelhütte am Haidweihen und auf noch einigen ander'n Punkten der Ungebung Ambergs unter fast ganz gleichen Umständen, und bezeichnet dadurch einen standhaften Charaǩterzug der Felsart. - Allein diese selbst enthält nicht nur die nümlichen organischen Reste, sowohl von demselben als von vielfach vergrö̈ssertem Maasstabe, sondern auch andere, z. B. Ammoniten, in Menge: aber alle im kalzifizirten $\mathbf{Z u}$ stande und mit grösstentheils unversehrter Schaale.

Auf mehreren ziemlich weit von einander entfernten Punkten sind verschieden gestaltete kieselige Konkrezionen, deren dicht kavernöse Oberfläche und verhältnissmässig geringes Gewicht jedem Beobachter auffällt, als Geschiebe einzeln zerstreut. Nach der Beschaffenheit der Fundorte gehören sie dem Jurakalk an. Die Farbe der Oberfläche ist bald graulich-ockergelb, bald eisenschwarz, und scheint von äusseren Uınständen abzuhängen. Wie die Oberfläche, so ist auch das Innere unregelmässig, doch bald weniger, hald mehr kavernös. Auf den Bruchflächen zeigt der Teig schwärzlichgraue, im Striche lichte gelbliche, auf den Wandungen der Höhlungen meistens viel dunkler schmutziggelbe Farbe. Neben und in die Höhlungen der immer bedeutend härtern Oberfläche sowohl als des Innern sind häufig, in

*) Die Eigenschaft, auf diese Art zu verwittern, findet sich auch bei den dichten, vollkommen ausgebildeten, gelben und schwärzlichgrauen Hornstein-Konkrezionen unter gewissen Umständen bestätigt. Mehr davon bei einer passenderen Gelegenheit. 
den dichten, mit der Feder ritzbaren Teig selten verkieselto Reste von $1 \frac{1}{2}$ bis 2"“ grossen Muscheln und anderen Weichthieren, wohl auch von Stylastriten eingesenkt, oft aber auch in den einen wie im andern nur üusserst sparsame Spuren derselben, hin und wieder auch diese nicht zu finden. Nach deni Anhauchen entwickelt sich starker Thongeruch; die Säuren werden schnell verschluckt; dennoch bemerkt man kaum ein schwaches Kleben an den Lippen.

Unter diesen Geschieben kommen ungleich mehrere vor, deren Textur stufenweise dichter und härter, überhaupt gleichförmiger wird, und endlich in den gewöhnlichen splitterigen oder muscheligen Hornstein übergeht. Die Grösse derselben wechselt zwischen einer kleinen Wallnuss und einer grossen Mannsfaust. Ihre Gestalt nähert sich bald der kugeligen, bald der elliptischen in manchfaltigen Abänderungen. Eben so manchfaltig sind von Aussen und Innen die Grundfarben und ihre Schattirungen. Am häufigsten erscheinen die Geschiebe im Innern vollkommen gleichförnig; und diese enthalten ausschliesslich die grossen, und nicht selten so grosse silizifizirte organische Reste (Muscheln, Ammoniten, Echiniten und ihre Theile, Fungiten, Serpulen u. s. w.), dass sie -je nach ihrer Gestalt bis an die Oberfläche derselben und darüber hinaus sich erstrecken - oder hängen öfters von der Grösse einer Haselnuss bis zu der eines Gans-Eyes und darüber meistens an unbestimmten Stellen jenen verkieselten Resten, zum Theil sie umhällend, an. Nur bei den Belemniten (fast immer Bel. unicanaliculatus

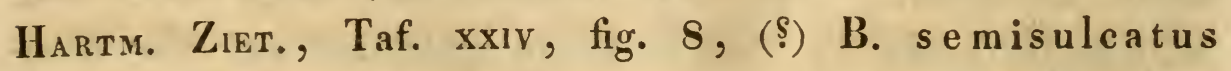
Münster) sitzen sie regelmässig am Grunde der Alveolenhöhle und bei einigen Arten der Fanilie der Echiniten an der Mundöffnung fest. - Bei Weitem seltener geht von der Oberfläche aus der splitterige oder muschelige Hornstein gegen den Mittelpunkt hin entweder ununterbrochen durch Analoge von Kachoiong, Feuerstein und Chalzedon fortschreitend, oder aus diesen innig verwachsene konzentrische Lagen bildend, zuletzt in graulichweissen, durchsichtigen, 
ungemein harten, wenn das Mittelfeld dicht ist, derben, wemn es eine Höhlung bildet, mit 6 gleichen Flächen niedrig zugespitzt krystallisirten gemeinen Quarz über. Soweit der Hornstein reicht, findet man in diesen Geschieben nur verkieselte organische Reste, doch öfter auch gar keine, immer nur kleine.

Besonders merkwürdig 'scheinen mir zwei Vorkommen des sphäroidischen Hornsteines, deren eines ich bei Germersdorf (auf der Strasse von Amberg nach Schwandorf), das andere bei Krummbuch beohachtet. An beiden Orten verliert sich die Ausscheidungs - Linie desselben unmerklich in dem ihn. umgebenden und damit innig verwachsenen Kalksteine. Zu Germersdorf ist selten ein sehr fester doch leicht verwitterbarer, zunächst unter Jura-Dolomit liegender Kalkmergel init vielen Kalkspathadern. Eine derselben durchsetzte eine etwa 3" im Durchnesser grosse Hornstein-Kugel mit hohleni von Quarzkrystallen ausgekleideten Mittelfelde beinahe durch deren Mittelpunkt, und verschob die beiden Hälften um 3 bis 4 "', ohne dass man die geringste Zersplitterung gewahren katn. - Bei Krummbach liegt er in einer jener Lagen dichten Jurakalkes, welche zum Kalkbrennen taugen, hat grauliche Farbe und ist durchgehends gleiclförmig und dicht. Durch Brennen wird er schwärzlichgran und erhält die Eigenschaft, der Luft ausgesetzt und in der hohlen Hand erwärmt nach und nach in konzentrische scharfliantige Stücke unter leisem Knistern zu zerfallen.

Am südöstlichen Fusse des Eisberges, dem Ersberge bei Amberg südwestlich gegenüber, wurde einst durch Steinbrechen ein unförmlich -schieferiges Kalkmergel - Lager entblösst, welches ehen so unförmliche Kiesel-Konkrezionen in grosser Menge nach verschiedenen Richtungen durchschwärmen. Beide Gesteinsarten verfliessen an ihren Gränzen unmerklich ineinander, und werden von den Schieferklüften, olne die mindeste Störung, in ununterbrochenen Flächen gespalten. Die Masse der Konkrezionen zeigt höehst selten einige Annäherung zu Hornstein, ist hie und da schwach -. 


\section{$-300$}

meistens stark - durchscheinend und stellenweise mehr als halbdurchsichtig, wechselt Fleck- und Streifen-weise mit blaulichgraner und graulichweisser Farbe, und zeigt einzelne ausgeschiedene dichte Quarzpunkte, seltener derlei Krystalle. Der Bruch ist flachmuschelig, mitunter kleinsplitterig. - Obwohl der Mergel kalzifizirte und häufiger silizifizirte Versteinerungen aus.mehreren Klassen des Thierreichs nicht allzusparsam enthält; so konnte ich in den kieseligen Konkrezionen doch nur jene, den Retikuliten so ziemlich ähnliche beobachten, welche zuweilen in den Geschieben mit der, mit diesen Konkrezionen übereirstimmenden inneren Masse gefunden werden.

Endlich dürfte noch angeführt zu werden verdienen, dass der Mittelraum der hohlen Kiesel-Konkrezionen, wiewohl selten und nur in Mergelschichten, Kalkspath-Krystalle, über dem derben oder lirystallisirten Quarz aufgesetzt, enthält. Ich bemerkte darin nie einen organisehen Rest.

So gross auch im Jurakalk der Umgebung Ambergs die Zahl der in Kiesel-Konkrezionen eingeschlossenen oder doch von denselben begleiteten verlieselten organischen Reste ist, so ist doch die von jedem Anhängsel freeie, sowoh! der Summe als den Arten nach, ungleich grösser. Aber auch diese findet man in der Regel nur ausgewittert und lose umherliegend. Dagegen bieten einige der letzteren, in Vergleichung mit den erstern, hinsichtlich des Prozesses ihrer Verkieselung äusserst interessante, bisher vielleicht umbekannte Erscheinungen dar. Ich will nur einige derselben hier aufführen.

In verschiedenen Graden uivollkommen, oder nur an einzelnen Stellen rein silizifizirte organische Reste, besonders Muscheln, Belemniten und sogenannte Fungiten (Karyophyllarien Lamx.) gehören nicht zu den Seltenheiten ersten Ranges. Seltener sind Klappen der Muscheln, deren äussere und innere Fläche vollständig silizifizirt, der dazwischen befindliche Raum aber nach seiner ganzen Ausdehnung leer, oder nur mit einzelnen kieselig-stalaktitischen 
Gebilden, zum Theil von einer Fläche bis zur andern reichend, zum Theile nur mehr oder weniger aus einer oder der andern hervorragend, besetzt - noch seltener ähnlich gestaltete silizifizirte Bruchstücke von Belemniten. Hohle Karyophyllarien und Polyparien dagegen mit knotighöckriger innerer Fläche, vorzüglich die kleinern Arten derselben, werden an manchen Plätzen desto zahlreicher getroffen.

Die Belemniten, vielmehr ihre Scheiden, kommen in Hinsicht der Silizifikation unter viererlei Formen vor: 1) Das konzentrisch-strahlige kalkige Gefüge ist vollkommen erhalten und mit einer mehr oder weniger, immer sehr dünnen Kieselrinde (von kaum $\frac{1}{20}{ }^{\prime \prime \prime}$ ) eingehüllt. So finden sie sich (Ineistens in Kalkmergellagen) zu Garmersdorf bei Amberg, am Eisberge u. a. e. a. O. 2) Unter der etwas dickeren Kieselrinde ist das konzentrisch-strahlige Gefüge verschwunden, und durch unregelmässig angehäuften rhombischen Kalkspath ersetzt. Aus einer mächtigen, im Korne dem Dolomite sich nähernden, Schicht zwischen zwei KalkmergelLagern und zunächst unter vollkommen ausgebildetem JuraDolonite gelagert, am Eisberge ragen dergleichen Belemniten auf den vertikalen Klüften einzeln hervor. 3) Äusserst selten findet man auch verkieselte Bruchstücke von Belemniten, welche aller Ausfüllung entleert und daher hohl sind. Diese Hülsen sind an den rechtwinkelig abgebrochenen Enden dessenungeachtet gewöhnlich mit lieseligen, meistens in der Mitte durchbohrten Platten verschlossen und immer ziemlich $\left(\frac{1}{4}-\frac{1}{3}{ }^{\prime \prime \prime}\right)$ dick. Gewöhnlicher, vielmehr standhaft findet sich diese Erscheinung an den Resten jener Belemniten wiederholt, welche mit dem Ende an der Alveolenhöhle in kieseliger Konkrezion festsitzen, so oft von der Aussenwand der Schaale noch Überbleibsel sich zu erhalten das Glück hatten. - Bei allen drei Vorkommen bemerkte ich ausschliesslich nur Belemn, unicanaliculatus Harrm. (Zieten @), B. semisulcatus v. Münst. als Grundlage. Die Oberfläche ist gemeinhin glatt oder nur wenig rauh, 
doch zeigen sich am dritten schon, obwohl etwas undeutliche, verschieden gewundene Zeichnungen. 4) Auf einigen verkieselten hohlen Bruchstücken, allem Anscheine nach der nämlichen Art, treten dieselben dicht gedrängt und wohl $\frac{1}{3} " \prime$ erhaben über die ganze Oberflïche rerbreitet, hervor, und bedecken sogar, wo sie sich aus der zerstörenden Wirkung des Rollens gerettet haben, die Schliessplatte der Bruchflächen. Ihre Ziige sind im Allgemeinen allerdings geeignet, die von Hrı. v. Buch aufgestelle Ansicht über die Grenze der Silizifikation zu bestätigen, weichen aber nicht nur nnter sich, sondern auch von jener Ansicht, besonders nuf den Schlicsplatten so bedeutend ab, dass man ihr unbedingt beizustimmen noch Anstand nehmen dürfte, wenn

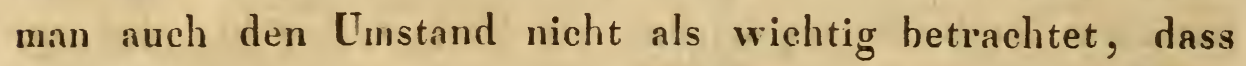
diese Zeichnungen öfter's ganz fehlen und, wo sie vorhanden sind, nur auf der Oberfäche erscheinen. Der Annahme, dass eine orler auch mehrere ursprünglich daruber gelegene Lagen der Scheide später zerstört wurden, wiederspricht die übrige Beschaffenheit aller Stiicke anf das Entschiedenste. - Die Verkieselung dringt überdiess zu beiden Seiten der Rinne längs ihrer Erstreckung bis gegen die Mittelachse der Scheide und bildet dort eine offene Röhre. Zwischen dieser und der äusseren Wand der übrigens leeren Scheide hat sich in inrer ganzen Linge hin, meistens beide beriihı'ud, ein kleintraubiges Kiesel-Konglomerat angehäuft. Aber auch die, gegen das Imnere der Scheide gekehrte Fiäche der Bekleidung des Alveoles wird, weun auch nur in hëchst seltenen Fällen, dicht von den erwähnten Zeichnungen ïberzogen. Auffallend ist dabei an den vorgefundenen Exemplar, dass den nach oben aus dem Bruchstücke vorragente Theil des Sipho und die von jener Bekleidung entblïssten Stellen der Konkameration äusserst kleine QuarzKrystalle dicht überdecken, während die eigentliche Silizifikations-Masse aus splittrigem Hornstein besteht.

Verkieselte Echiniden aus mehreren Gattungen und in mehreren Arten gehören mitunter zu den zahlreichsten 
Petrefakten der Umgegend Aimbergs, und sind bei Weitem häufiger als die lialzifizirten. Dass ihre Schaalen zuweilen und wenigstens stellenweise hohl sejen, kann ich nur aus der Beschaffenheit einiger Bruchstücke muthmaasen; dagegen findet man entschieden die Zähne und alle jene, Theile, welche $W_{A L C H}$ als ihre Knochen angibt, fast ausschliesslich hohl, wenn sie, was meistens der Fall ist, silizifizirt sind.

Auch von den Stylastriten Martin (Crinoideen MiLx.) ") kommen daselbst beinahe aus jeder Gattung einzelne Theile, vorzüglich Glieder der Säulen einer oder der anderu Art in grosser Menge und fast durehgehends in verhieseltem Zustande vor. Gewöhnlich sind auch die silifizirten Stylastritẹn gleich den Echiniden hohl, und beide von der Natur auf bestimmte Plätze angewiesen.

Ich glaube, dass es, um dieses Phänomen nach seiner ganzen Wichtigkeit zu würdigen, nicht überflüssig seyn dürfte, auf den wesentlichen Unterschied der Textur, welche den Schaalen der Muscheln und den Scheiden dér Belemniten einer-, und sämmtlichen Theilen der Echiniden und Stylastriten andrer-seits sowohl im natürlichen als kalzifizirten Zustande eigenthümlich ist, die Aufinerksamkeit der Naturforscher zu lenken. $O b$ diese auch die Erscheinung verdiene, dass zum Theile oder ganz verkieselte Petrefakten, besonders Ammoniten und Beleminiten, ein oder auch mehrmal gerade, selten wellenförmig durchbrochen, und die Bruchstücke mehr oder weniger verschoben oder von einander gerückt und wierler mit derselben Verkieselungs. Masse, hier immer Hornstein von gleicher Farbe und Beschafferbeit, zusammengekittet gefunden werden, überlasse ich ihrem Urtheile.

Wenn man die petrifizirten thierischen Reste an dem Jurakalk der Gegend Ambergs in Bezug auf Silizifikation

*) Ich folgte in der Benennung der Familien oder Abtheilungen Bross's System der urweltichen Pflanzenthiere, Heidelb. 1825. 


\section{$-\quad 304$}

und Kalzifikation unter einander vergleicht; so ergeben sich, nach den bisher gemachten Beobachtungen folgende Resultate: Einige Arten kommen aussehliesslich silizifizirt, andere ausschliesslich kalzifizirt, und noch andere in beiderlei $\mathrm{Zu}$ stande vor. Es wäre allerdings sehr belehrend und daher von hohem Interesse, die Versteinerungen der drei Kategorieen, wenigstens zum grössten Theile, jiamentlich zu kennen; allein die eingewachsenen kalzifizirten Petrefakten kö̈nnen nur selten und mit grosser Kunst und Mühe so gut erhalten ausgeschlagen werden, dass sie aufbewahrt zu werden verdienen, - und die losen sind durch Rollen meistens so abgenutzt und dadurch so unkemntlich, dass sie zu bestimmen alle Arbeit verloren ist; - manche endlich bleiben standhaft, in der Kalzifikation und Silizifikation, so undentlich, dass man ihre thierische Abstammung kaum mit Gewissheit zu unterscheiden vermag. Das Verzeichniss würde also sehr mangelhaft ausfallen, und selbst dazu erkenine ich meine Kenntnisse in der Petrefaktenkunde nicht genügend *). - Petrifizirte Reste aus dem Pflanzenreiche fand ich nur kalzifizirt und auf einer einzigen, überdiess sehr bedenklichen Stelle. Es waren in der Lagerstätte Stückchen Holz von $1 \frac{1}{2}$ bis 2 Zoll Länge und $1 \frac{1}{4}-1 \frac{1}{2} "$ Breite und Dicke mit wie abgesägt ebenen Bruchflächen, dichtem Gewebe, geraden ziemlich gedrängten Fasern und, fast wie bei Buchenhol\%, breiten Spiegeln. Ausgelöst und zum Theil schon in der Lagerstätte zerfielen sie in unregelmässige Splitter. Die Lagerstätte ist am südwestlichen Abhange des Galgenberges und scheint nach der gewaltsamen Biegung der Schichten, obwohl nur auf einer sehr beschränkten Strecke, eine grosse Störung erlitten zu haben. Gerade auf dieser Stre:ke befinden sich jene Holzstücke, liegt aber auch der Jurakalk unmittelbar auf dem Liasschiefer, der verkohlte

*) v. Schцотивп zälilt der einen wie der andern eine grosse Anzahl auf. 
und kalzifizirte und mit Eisenozyd innig durchdrungene Holzstücke in nicht unbedeutender Menge einschliesst.

Aus dem oben Gesagten dringt sich von selbst die Frage auf: besitzen alle Schichten des Jurakalkes die Eigenschaft oder Fähigkeit, die organischen Reste zu silizifiziren@ Und im Verneinungsfalle: welche, und welche nicht ș - Wenn die Rede davon ist, jeder derselben in der vielgliederigen Reihe des dichten Jurakalkes den gehörigen Platz anzuweisen, so dürfte ein geübter Geogn.ost darüber in Verlegenheit kommen. Denn die Formation endet nordwärts nach allen Richtungen in geringer Entfernung von Amberg, ist daher nicht oder doch sehr wenig entwickelt, und sogar stéllenweise sehr verworren. Bezieht sich aber die Frage nur auf die besondere (oryktognostische) Beschaffenheit der Lagen, so ist schon aus dem Umstande, dass man die verkieselten Reste beinahe nur ausgewittert findet, noch mehr aber aus den Fundorten und den hin und wieder denselben anklebenden Gesteins-Stückchen dargethan, dass, zwar nicht ausschliesslich doch bei Weitem vorzugsweise; die dem dichten Jurakalk hier häufig untergeordneten KalkmergelLager die Lagerstätten der verkieselten organischen Reste seyen. Eben so gewiss erhellt aber auch aus den Fundorten, dass nicht alle, oder diese nicht überall und nicht alle $\mathbf{A r}$ ten thieriseher Körper zu silizifiziren gleiche Fähigkeit besitzen, mögen ihnen Körner von grünem Eisenoxyd - Hydrat eingemengt seyn oder nicht; und dass mehrere, jene Reste silizifizirende Lager, besonders die mehr thonigen, ausserdem auch keine Kiesel-Konkrezionen enthalten. Diese Eigenschaft theilen auch, in höherem oder geringerem Grade, die Lager und Bänke des dichten Jurakalkes; denn sehr viele Arten der organischen Reste aus verschiedenen Klassen kommen in denselben nahe um Amberg sowohl silizifizirt als kalzifizirt, dagegen anderwärts nur in letzten Zustande vor. Einen schlagenden Beweiss von der Nothwendigkeit der Prä- und Ko-Existenz gewisser Wechsel-Beziehungen zwischen dem organischen Reste und dem ihn umhüllenden 
Gesteine bei dem chemischen Prozesse der Silizifizirung oder Kalzifizirung liefert nach meines' Ansicht eine, obwohl jetzt noch einzeln stehende Thatsache. Die oberste weisse Schicht des dichten Jurakalkes, welche in der Ungebung Ambergs gänzlich margelt, erstreckt sich von Tegrenheim bei Rcgensburg gegen W. mit einer heträchtlichen Aushreitung. in $\mathrm{N}$. und S. Allenthalben führt sie eine grosse Menge der manchfaltigsten thierischen, Versteinerungen, und nicht selten hesteht sie partieenweise lediglich aus denselben. Allein nirgend und nie hat man auch nur eine, den Schmelz der hie und da erscheinenden Z:̈hne (von Sauriern@) ausgenommen, anders als im kalzifizirten $Z$ ustand gefunden, obwohl er viel Kieselerde enthält, - sehr stark und fast diamantglänzende, nit 6 Endflächen niedrig zugespitzte \&uarzlirystalle, öfter die innere, seltener (zugleich oder allein) die äussere Wandung der Schaalthiere bekleiden, - derber lichtgrauer Quarz den Raum zwischen beiden Wandungen bald zum Theile, bald ganz erfüllt, - und derber und krystallisirter Quarz zuweilen die eine oder auch alle Seiten der anstossenden Höhlungen überzieht; - bis man ror wenigen Jahren am Fusse des Kapfelberges bei Abach in jener, hier von Grünsand unmittelbar überlagerten, Schicht einen Steinbruch eröffnete, und eine, wegen des innigen Verwachsenseyns mit dem Gesteine unbestimmbare Art von Echiniten entdeckte, welche nur dadurch auffiel, dass sie silizifizirt ist. - Mir scheint daher, dass man in dem Zusammentreffen manchfacher solcher Wechselbeziehungen zwischen den organischen Resten und dem Gesteine in der Uingegend Ambergs, and von diesem in der nahen Grenze und den Lagerungs-Zerrüttungen des dortigen dichten Jurakalkes den vorzüglichen Grund von der Entstehung der in der That beispiellos vielen silizifizirten organischen Resten suchen müsse. Worin das Wesen jener Beziehungen bestehe, ob der Silizifikations-Prozess bei allen, wenn schon sämmtlich in Hornstein verwandelten, Arten der orgnnischen Reste der nämliche, und namentlich der von der Silizifikation der Muscheln angegebene sey, dürften nur 
umfassende Beobachtungen entscheiden. Bei der endlichen Zusammenstellung derselben möchte es vielleicht nicht überflüssig seyn, auch die Glattheit sowohl der äussern als innern Oberflächen und selbst jener der Schaalen-Lagen an den meisten verkieselten Arten, die innige Kontiguität und Kontinuität der Verkkieselungsmasse bei denselben, und das öfter höchst betrïchtliche Missverhältniss dieser Masse zu dem anhängenden oder eingeschlossenen organischen Reste in die Rechnung aufzunehmen. Befremden muss den Naturforscher, dass einschaalige Schaalthiere, wemn man Ammuniten und Belemniten nicht dazu rechnet, bei Amberg eben so selten, als zahlreich die zweischaaligen sind.

2) lch habe früher in einer ander'n Zeitschrift ausgeführt, dass im Jura-Dolomit viele und mancherlei organische Reste vorkommen. Seitdem wurden in den Steinbrïchen, welche in dieser Gebirgsart für den Festungsbau von Ingolsladt angelegt sind, deren noch ungleich mehrere entdeckt. So rein er an manchen Stellen von Kicselkonkrezionen ist, so dicht erfüllt ist er damit an andern. Diu Hauptmasse derselben besteht aus graulichweissem bis dunkelgrauem Hornsteine mit splitterigem und muscheligem Bruche. Die Farben wechseln meistens lagenweise bald scharf abgeschnitten, bald ineinander übergehend, bald parallel laufend, bald wegen der stellenweise ungleichen Dicke der Lagen ver'schieden abweichend. Der graulichweisse ist schwach durchscheinend, der graue endlich halb durchsichtig. Quarz erscheint darin Lagen- und Nester-weise, derb und krystallisirt. Die gewöhnliche Gestalt ist einfach oder iistig zackig; doch geht sie auch in unebene Nieren und Kugeln über. Man findet deren nicht selten von 30 Pf, und darüber. - - $Z_{\text {wei }}$ Vorkommen scheinen ganz isolirte Ausnahmen zu machen. Bei Neuburg an der Donau senkt sich der Quarz als ein untergeordnetes, an beiden Saalbändern innig mit dem Dolomite verwachsenes Lager in den Strom*); bei

*) Der Arragonit von Wolstein bei Feumarit bricht suf cinem ähulichen Lager, innig verwachsen wit Kalkspath, in dem Jura. 


\section{$-308$}

Oberhaunstatt bildet er fast vollkommene Kugeln mit abwechselnd verschieden farbigen, nach Innen allmählich durchscheinenden Lagen und meistens quarzigem derbem und krystallisirtem Kern. Nicht selten schweben die Lagen, nur an einzelnen Punkten durch Stütš̀en verbunden, sind dann stellenweise unvollendet und mit Quarz-Krystallen bekleidet. Einzelne, verschieden gestaltete Knollen zeichnen sich durch schairf abgeschnitten farbige, dünne, mit allen Biegungen der Oberfläche bis ins Innerste parallele Lagen aus, und zeigen hin und wieder dadurch unverkembar, dass diese Knollen aus mehreren zusammengewachsen sind.

Von den organischen Resten des dichten Jurakalkes sind mehrere Arten auch in den Jura-Dolomit übergetreten; einige derselben scheinen, nach den bisherigen Beobachtungen zu fehlen, dagegen manche neue hinzugekommen zu seyn. Allein nicht eine, weder der ersteren noch der letzteren, wurde im Dolomite oder auch in den eingeschlossenen Kiesel-Konkrezionen bis jetzt irgendwo verkieselt gefunden. Äusserst selten ist sogar die Schaale kalzifizirt erhalten, sondern meistens bloss der Abdruck derselben oder der Steinkern zurückgeblieben, welchen gewöhnlich rhombische Krystalle des Dolomites noch undeutlicher machen. NurPolyparien, vorzüglich aus der Sippe derStern-, seltener derPoren-Polyparien, kommen hin und wieder in vollkommen reinen, manchmal ausgezeichnet deutlichen und schönen kalzifizirten Exemplaren vor. - Wenn man den ungleich grösseren Gehalt des Dolomites an Kieselerde mit dem viel geringeren des dichten Jurakalkes vergleicht, so muss ihre so genau übereinstimmende Eigenschaft Kiesel-Konkrezionen zu bilden, und ihre dennoch so höchst verschiedene Fähigkeit organische Reste zu silizifiziren, jedem denkenden Geologen auffallen, er mag dem Dolomite als solchem einen neptunischen Ursprung geben, oder eine spätere

Dolomite; Kiesel-Konkrezionen habe ich hier weit umher vergebens gesucht. 
vulkanische Umwandlung unterlegen, - die Kiesel-Konkrezionen als ursprünglich ausgeschieden oder erst nachher entstanden annehmen.

3) In den lithographischen Schiefer ist, obwohl er bei Pappenheim oder Solenhofen und bei Hemau auf dem Jura-Dolomite nach mehrern Wechsel-Lagerungen unmittelbar aufsitzt, aus diesem und dem dichten Jurakalk nur eine kleine Anzalil ihrer eigenthümlichen organischen Réste aufgestiegen, dagegen eine grosse Menge fremder eingewandert. Er hesteht auf weit ausgedehnte Strecken hin einzig aus dem ihn konstituirenden Kalkmergel, wechsellagert aber auch auf andern Stellen verschiedene Male mit dünnern und dickeren Streifen von grauem oder gelblichgrauem, mehr oder weniger reinem und durchscheinendem Hornsteine von sehr manchfacher Erstreckung. Wahre Konkrezionen scheinen ganz -zu fehlen. - Seine erhaltende Kraft ist, im Widerspruche mit jener des Jura-Dolomits, bekanntlich zum Erstaunen gross; weichflügelige Insekten, Stelleriden, sogar fleischige Theile (Eingeweide der Fische, Vermikuliten *) u. m. a.) hat sie der Zerstörung entrissen. Aber eben so gross und vielleicht noch grösser ist seine silizifizirende Eigenschaft. Es lohnte-der Mühe zu untersuchen, ob nicht eben diese der Grund von jenier sey *\%). Gewiss ist, dass wenn nicht alle, doch die meisten harten Theile der Thiere aus allen Klassen mit einer Kieselrinde überzogen, viele aber

*) Dafür muss ich mit Gr. v. Miüsster die räthselhaften Gebilde ge. radezu erklären.

**) Gr. v. Mǚster sagt in seinen (nicht in den Buchbandel gekomnenen) „Bemerkungen zur nähcrn Kenntniss der Belemuiten“ S.7: In den (über den lithographischen Schiefern befindlichen) Hornstein-Lagen ist die Schaale sehr oft ganz oder doch theilweise verschwunden, daher dort sehr viele einzelne Alveolein-Kegeln mit wenigen Überresten der Schaale gefunden werden. Diese zeigt sich dort grösstentheils ganz hornsteinartig, und die obere Spitze des Alveolen-Kegels in Chalcedon verwandelt. Auch kommen daselbst zureilen Exemplare vor, die im Innern der dichten Schaale noch ihre strahlige und blättrige Textur haben, wäbrend die äussere Schaale in Horustein verwandelt ist. 
von Kicselerde ganz durchdrungen sind *). Dessen ungeachtet erscheinen in diesen Gesteinen die Reste einiger Thiere, besonder's der Schaalthiere, und darunter sogar solcher, welche im Jurakalke der Ungebung ron Amberg keineswegs selten silizifizirt vorkommen, nur oder doch bei Weitem häufiger im kalzifizirten Zustande. - Am meisten überraschte mich, dass in denselben so wenig als in jeder ander'n der angeführten Gebirgsarten das - mit so manchen der dar'in silizifizirten organischen Reste höchst ver'wandte Band (Ligament) der Muscheln verkieselt oder auch nur erhalten bisher beobachtet wurde.

4) Zwischen den Jura-Dolomiten und dem Grünsandstein ist um Amberg und in dem ganzen östlichen Theile des Flötzgebietes eine meistens sehr nächtige Formation von durch Thon zum Theile fester', zum Theil lockerer gebundenem $S$ andsteine eingeschaltet. Obgleich der lithographische Schiefer hier allentlialben mangelt, so kann dieser Sandstein doch als sogenamntes Äquivalent desselben nicht angesehen werden; die hin und wieder darin zerstreuten Versteinerungen bezeichnen ihn vielmehr als eines der untersten Glieder der $\mathrm{K}_{\mathrm{r}}$ eide-, oder bestimmter zu sprechen, der Grünsandstein-Formation. Er enthält unzusammmenhängende, ver'schieden ausgedehnte und gebildete Niederlagen vorn sandigem, Lagen- und Nester-weise grünliehgrauem und graulichschwarzem, ziemlich festem Thone, welchen dio Töpfer der Gegend benützen. In der östlicheren von zweien solcher, nur durch einen Rücken des Jura-Dolomits getrennten Thongruben sind ihm manchfach doch meistens dendritisch gestaltete Kalkmergel-Konkrezionen eingemengt; die westliche, von diesen völlig frei, führt dagegen eben so

*) Der unermüdete und sinnreiche Physiker und Naturforseher, Geistl. Rath und Prof. Prcker. in Eiclestätt hat, mit Hülfe verdünter Salpetersäure, melirere undeutliche Petrefakten dieses Gesteines, namentlich Vermikuliten, von der verdunkinden kalkigen Einhiillung mit dem glücklichsten Erfolge befreit, und höchst deutlich dargestellt. 
manchfach gestaltete, von Faust- bis iber Mannskopf-grosse, lsnoilige Kiesel-Konlirerionen. Sie sind stumblhaft nach einer Seite hin unvollendet und hohl, erscheinen daher immer als unförmliche Schaalen. Die his in die tiefsten Buchten stätig fortlaufenden alggerundeten Ränder bewähren, dass die Gestalt ưrsprïnglich ist. Durchgehends, nur mehr oder weniger ausgeschieden und daher in die Angen springend, sind sie parallel mit den Unebenheiten der Oberfläche durch $\frac{1}{2}$ bis 2"“ dicke graulichgelblichweisse im Bruche erdige, und $\frac{1}{2}$ bis 1'“ dicke, gelblichgraue, dichte Lagen oder Bänder gestreift. Damit stimmt auch die innere Fläche der Schaale bis auf unbedeutende Abweichungen überein. Alle meine Nachforschungen nach Versteinerungen in denselben waren fruchtlos.

Der unterlagernde Jura-Dolomit schliesst zwar an beiden Stellen ziemlich viele Kiesel-Konkrezionen ein; allein sie weichen von deu eben beschriebenen in der Gestalt, dem Gefüge, kurz in allen Eigenschaften zu weit ab, um diese ihrem Ursprunge nach als identisch mit jenen, und folglich nur als eingewandert in ihre dermalige jüngere Lagerstätte betrachten zu können. Zwischen diesein Sandstein und dem nach aufwärts folgenden Grünsandsteine liegt ferner, nebst einigen andern, ein bald mehr bald weniger mächtiges Lager von Bohnerz in rothem Lehm. Die Bohnem haben die Grösse eines Hirsenkorus bis zu der eines Mannskopfes und darüber, sind öfter schon bei der der Wallnuss, immer aber bei der weiter zunehmenden hohl, und dam mit einer dicken oder dünnen Lage faserigen Brauneisensteins von Innen bekleidet. An beiden Enden mit 6 gleichen Flächen niedrig zugespitzte sehr stark glänzende Quarz - Krystalle *) sitzen nicht selten entweder mit einer der Endspitzen oder einer der Seiten-

*) Ich beschreibe absichtlich die Krystallform so genau, da mich Erfahrungen, besonders auf Glashütten, belehrten, dass nicht aller Quarz in den chemischen Eigenschaften sich gleich ist, und mir die Krystallform hiernach, besonders in der Zuspitzung, abzuändern scheint. 
Flächen ganz oberflächlich auf jenem faserigen Brauneisenstcin. Organisehe Reste wurden noch nicht gefunden.

5) Der Tripel ist durch den westlichen Theil des nördlichen Bayerns und der südlichen Oberpfalz ziemlich allgemein verbreitet. $\mathbf{E r}$ vertritt hier in der Reihenfolge der Gebirgsarten nach den gegenwärtigen geognostischen Ansichten die Stelle der mittlen und ober'n Glieder der Kreide-Formation - freilich in Vergleichung mit diesen sowohl hinsichtlich der chemischen Beschaffenheit, als der eingeschlossenen Versteinerungen ein sehr heterogener Stellvertreter. Er wird wie der Grünsandstein und gewöhnlich mit ihm mehrmal und oft auf ansehnliche Strecken hin unterbrochen, und erreicht nur läings seiner nördlichen Gränze und hier nur auf wenigen Stellen eine bedeutende, melirere Lachter betragende Mặchtigkeit. Diese entlang haben sich auch die übrigens sehr seltenen Kiesel-Konkrezionen und Versteinerungen auffallend angehäuft.

Gewöhnlich hängen die Kiesel-Konkrezionen, in Folge ihrer Entstehungs-Art (einer allmählich fortschreitenden inneren Aussinterung) mit dem Tripel innig zusammen, erscheinen daher ausgewittert als verschieden gestaltige, meistens längliche Knollen, bilden aber in der Lager'stätte manchfach gewundene und sich zertrümmernde kleine Gänge, - deren Ausfüllung gegen die Saalbänder hin aus einem innigen Gemenge von Tripel und Hornstein, dann aus reinem Hornsteine und endlich, besonders an der nörởlichsten Grenze hin, aus meistens in einander verfliessenden breiteren und schmäleren Lagen von Feuerstein-, Chalzedon- und Quarzähnlicher Beschaffenheit besteht, welche, wemn sie hohl sind, mit einer Kacholong- oder $\mathbf{O}$ pal-artigen, im Wasser durchscheinend bis durchsichtig werdenden, dickeren oder diinneren Rinde, bekleidet sind. Auf den innern Flächen der hohlen Konkrezionen zeigt sich nicht selten die nämliche Textur in vielartig getropften Gestalten und mit der Oberfläche parallelen Lagen. Die vorherrschende Farbe ist roth in mancherlei Schattirungen; alle andern spielen melır oder weniger in dieselbe. 


\section{$-313$}

Ein Anstrich von Fettglanz spricht sich fast durchgehends, nur mehr oder weniger deutlich, auf dem frischen theils muscheligen theils splittrigen Bruche aus. - Hierin stimmen, die von der Holzfaser bedungene Textur abgerechnet, auch die im Tripel nicht selten vorkommenden Holzsteine grösstentheils überein. - Verkieselte thierische Reste scheinen denselben nur, an der östlichen Grenze innezuwohnen. Sie bestehen meistens aus $\frac{1}{2}$ bis $\frac{3}{4} "$ langen, dicht zusanmengedrängten Exogyren, welche kaum 500 Schritte davon, in der obersten Lage des Grünsandsteines, eben so zusammengehäuft, doch unverkennbar kalzifizirt sind. Der Teig der Kiesel-Konglomerate besteht aus einfachem milchweissem, flach- und klein-muscheligem, wenig splittrigem, oft kavernösem Hornsteine, welcher viel Quarzsand, wie ihn der Grünsandstein enthält, aufgenommen hat. Ich fand sie nur ausgewittert. Bei Wackersdorf, wo diese Konkrezionen ungemein käufig und bis an 3 Zentner schwer umherliegen, verschwinden die Exogyren, und tretèn ganz andere und dar'unter viele einschnalige Seethiere an ihre Stelle.

Der Silizifikations - Stoff der im Tripel selbst liegenden thierischen Reste (ausschliesslich marinische Schaalthiere und Echiroderınen) nähert sich im äussern Ansehen dem gemeinen undurchscheinenden Quarze, durchdringt aber nicht die ganze Masse derselben, denn der Raum zwischen der äusseren und inneren Fläche ist standhaft entweder ganz oder zum grössten Theile hohl. Auf den Schaalen der erstern finden sich zuweilen leichte Andeutungen von Zeichnungen, die an jene der Versteinerungen im dichten Jurakalke erinnern. - In und um Wackersdorf wird die Braunkohle von einem 3-4' mächtigen Lager sehr feinkörnigen verhärteten Tripels bedeckt, welcher hier mit Resten (Wurzeln, Stängeln, Blättern und Früchten) noch unbestimmter (Schilf:̈hnlicher؟) Pflanzen erfüllt ist - weiter gegen N.W. hin aber, bei Penkhof unweit Amberg, wo bisher noch keine Braunkohlen gefunden wurden, nur von den ersteren und 
letzteren einzelne Überbleibsel zeigt *). Von den, mit jenen der Braunkohle identischen, Früchten **) ist nur die Schaale, von den Blättern der Abdruck, von den Wurzeln und Stengeln hingegen nebst der Rinde auch die Ausfüllungsmasse, doch diese fast inmer lose und beweglich in jener liegend, erhalten. Der Verkieselungs-Stoff derselben nähert sich einigermassen dem Holzopal ohne Holzfasern, entwickelt aber angebaucht starken Thon-Geruch.

Za den beachtenswürdigeren Kiesel-Gebilden der Oberpfalz rechne ich endich in Beziehung auf meinen Gegenstand ein ungemein zartes, schwammig-poröses, sehr leichtes und zerreibliches Hineral, welches man auf mehreren Stellen in verschiedener Tiefe als ein dem Tripel untergeordnetes, nur wenige Zoll mächtiges Lager bei Amberg getroffen hat. Es saugt unter Verbreitung eines merklichen Geruches begierig und in grosser Menge Wasser ein, ohne zu zerfallen oder lockerer zu werden, und beherbergt seh. wohl erhaltene Reste aus dem Thier- und Phanzen-Reiche - letztere ganz ïbereinstimmend mit denen bei Wackiersdorf.

Nicht als wollte ich dadurch irgend einer der, durch den Regenkreis aus S.O. in N.W. auf mehreren Punkten bereits aufgeschlossenen, Braunkohlen-Niederlagen im geognostischen Systeme irgend einen Platz anweisen, sondern lediglich um die interessante Erscheinung für die Zukunft in Gedächtnisse zu erhalten, erwähne ich in Vorbeigehen auch noch, dass aus der Braunkohlen-Grube zu Kneiling bei Regensburg*a:), wo silizifizirte organische Reste und selbst Kielel-

$\Rightarrow$ Sciцотн. Nachtr., I. Abth., S. 68 und 69 , Tâb. XXI, fig. 8, 9 und 10 .

*) Darunter auch Folliculites Kaltennordhemiensis, - Leoshard's u. Buoxy's neues Jahrb. für Mineralogie etc. 1833, lfeft II, S. 177, 'Tab. IV, Fig. A, - überhaupt in den Oberpfälz'schen BraunkohlenAblagerungen fist allgemein verbreitet.

ow*) Die der Versammlung der Naturforscher zu Stuttgart von Herrn Prof. Kurr vorgezeigten thierischen Reste (11. Jahrb. für 1835, Heft I, S. 55) sind vicht aus der Braunkohlen-Niederlage zu Wuckersilurf (nicht Wackiendurf), wo bisher noch keine dergleichen 
Konkrezionen so äusserst sparsam einheimisch sihd, sehr viele silizifizirte Holzstücke von verschiedener Grösse, sogar Stücke und Stammtrümmer von 2 bis 3 Zentner ausgefördert worden.

In dem erwïhnten Jahrbuche von $1 \mathrm{S32}$ schliesst der Auszug (Heft II, S. 250) nit der Bemerkung: "Polythalamien (mit Ausnalıne der Scheide der Belemniten) verkieseln selten!“. Dieser Ausspruch gilt nicht, oder nur mit grosser Beschränkung von der Ungegend Ambergs. Zwar findet man verkieselte Polythalamien dort nicht so häufig, als manche andere thierische Reste; doch sind verkieselte A mmoniten verschiedener Arten mit vollkommen erhaltener Konkameration eben nicht so gar selten, und verkieselte Alveolen von stets einer und derselben Art B elemniten in vollständiger Bildung ungleich mehr als silizifizirte Scheiden. Inmer habe ich von den letztern nur kieselige hohle Rinden oder Überziige, doch diese wie jene in nicht unbedeutender Menge gefunden. Kräftiger kann somit meines Erachtens diese Gegend ihre ausserordentliche Silizifikations-Fähigkeit nicht beurkunden und die Erscheinung selbst die Abhängigkeit ihrer Entstehung von dem Daseyn gewisser Verhältnisse beweisen.

Wenn man die angefiihrten Thatsachen nach ihren verschiedenen Eigenthümlichkeiten zusammenstellt, die anscheinend sich wechselseitig unterstützenden mit den ihnen mehr oder weniger widersprechenden abgleicht, und durch $\mathrm{Zu}_{\mathrm{u}}$ that ähnlicher Beobachtungen und Er'scheinnngen aus, im Regenkreise nicht einheimischen, Gebirgs - Formationen ei: Ganzes rundet; so dürfte es nicht schwer fallen, nach und

gefunden wurden, noch zu Thalheim, sondern aus jener bei Kneiting gekonmen. Eben hier wurden auch Abdrüche von Planorben-älulichen Schnecken in der Braunkohle entdeckt. Man vergleiche äbrigens Kufersterv's Äusserung in Heft II, S. $181 \mathrm{~d}$. Jahrbuches. - In einer Thonschicht zwischen Braunkohlen traf mau bei Thulheim zerdrückte kalzinirte Schnecken, denen unserer Zeit sehr ähulich, wo nicht mit ihnen identisch. 


\section{$-316-$}

nach zu einem ziemlich wahrscheinlichen Schlusse zu gelangen, ob überhaupt, oder doch in wie fern die organische Materie als natürlich chemisches Agens die Ausscheidung der Kieselerde oder ihre Bildung in so manchfaltigen chemisch abweichenden Formen veranlasse, und die Silizifikation der organischen Reste als Haupt- oder Neben-Sache hewirke - ob dabei der angegebene Prozess, oder ein anderer, und welcher, Statt habe. Noch ist, nach meinen Ansichten, der Gegenstand zum Spruche nicht reif, aber seiner Wichtigkeit wegen der weitern Prüfung durch Naturforscher aus allen Gegenden desto dringender zu empfehlen. 


\title{
B e m e r k u n g e n
}

über einige Abweichungen der Krystall-Formen durch Vergrösserung einzelner Flächen, und Hindeutung auf ein Flächen-Krystall-

$$
\text { System, }
$$

\author{
von
}

Herrn Professor Ancker

in Grälz.

Über den Werth der Krystallisations-Gestalten zur vollständigen Bestimmung der Mineral-Spezies und das grosse Interesse, welches dieser Theil des Wissens in der Mineralogie gewährt, dürfte es bei der allgemeinen Anerkennung es überflüssig seyn, etwas erörtern zu wollen, so wie die übrigen Kennzeichen, als: Härte, Gewicht u. a. m. als unbezweifelt für sehr werthvoll zur Bestimmung der naturhistorischen Spezies anerkannt sind. Letztere dürften besonders für den Techniker noch mehr Werth erhalten; indem derselbe seine zu benützenden Mineralien, als z. B. Brauneisenstein, Eisen- und Kupfer-Kies u. s. w. grösstentheils nur in derben und feinkörnigen Massen in der Natur antrifft; dann einige zu benützende Mineralien, als z. B. der Opal, Uranerz, Steinkohle u. a. m. noch bisher gar nicht krystallisirt angetroffen worden sind. 
Ferner begründet der Techniker die Benützung der Mineralien grösstentheils auf diese Eigenschaften, als: auf Glanz, Farbe, Härte u. dgl.

Die Veranlassung zu den nachfolgenden Bemerkungen über die Abweichungen einiger Krystall-Formen nach den jetzt bestehenden Krystall-\$ystemen war: dass ich mehrere dergleichen Krystall - Gestalten zu beobachten Gelegenheit hatte; wozu noch besonders die Abhandlung von MitscherLıcн übẹr die Veränderung der Krystall - Formen und ihrer Winkel-Verhältnisse bei verschiedener Temperatur (in PoGgexdorff's Annalen der Physik in Jahrg. 1827, 11. Heft) meine Aufmerksamkeit über diesen Gegenstand auf sich zog und die Idee in mir erregte, dass die Bildung der KrystallGestalten in der Natur sowohl an der Oberfläche, als im Innern der Erde ebenfalls bei verschiedenen TemperaturVerhältnissen erfolgt seyn dürfte $§$ daher die Winkel-Abweichungen bei gleichen Krystall-Formen nicht selten erscheinen könnten!

$\mathrm{Zu}$ diesen Abweichungen und Veränderungen der Krystall-Gestalten folgen hier einige Belege:

Ich erhielt für unsere Mineralien-Sammlung an Joanneo durch die Gnade Sr. kais. Hoheit des Erzherzogs Јонамn mehrere Smaragd-Kystalle vom Heubachlhal in Salsburg, worunter sehr viele Krystalle sich befanden, welche bei einem von Krystall-Systemen unbefangenen Mineralogen offenbar für ein vierseitiges ungleichwinkliges Prisina gehalten worden wärren, wo an den schärferen Seitenkanten 2 kleine, kaum noćh bemerlsbare Kombinations - Flächen sich zeigten, und nach Werner's Erklärungs - Art als gerade Abstumpfung der schärfern Seitenkanten anzusehen gewesen wạ̈ren. Bei einigen dieser Krystalle verschwanden diese 2 kleinen Flächen fast gänzlich, und das orthatype vier'seitige ungleichwinkelige Prisma erschien in seiner Vollkoumenheit.

Gewöhnlich, wie bekannt, kömmt der Snıaragd in 6seitigen regelmässigen Prismen krystallisirt vor, folglich nach 


\section{$-319-$}

Mонь' Krystall - System er in das rhomboedrische System gezählt wird.

Diese Abweichung von der gewöhnlichen Form erklärt man sich zwar auf folgende Art: dass 4 der gegenüberstehenden Flächen vom 6seitig regelmässigen Prisma sich so vergrössern, dass die 2 andern gegenüberstehenden entweder ganz oder fast verschwinden; in einem solchen Falle, sagt man, geben damn die Winkel-Verhältnisse oder die Theilbarkeit den gehörigen Aufschlúss.

Die Winkel der Krystall-Gestalt geben in den Fällen, als sich einzelne Flächen dergestalt vergrössern, dass einige dabei ganz verschwinden, keinen $\Lambda$ ufschluss, indem sich die Winkel-Verhältnisse in diesem Falle wirklich verändern. Die Theilbarkeit gibt zwar in solchen Fällen oft die wesentlichsten Aufschlüsse; allein nicht selten sind bei KrystallGestalten keine Theilungs - Flächen zu ersehen oder zu erhalten.

Endlich sagt man, dass bei ähnlich abweichenden zweifelhaften Fällen ohnehin die übrigen Kennzeichen, als z. B. Härte, Gewicht u. dgl. m. die naturhistorische Bestimmung der Spezies begründen würden; dadurch erschiene aber die Krystall-Gestalt als untergeordnetes Kennzeichen, und würde von dem al!gemein angenommenen hohen Werthe zur Bestimmung der Mineral-Spezies etwas verlieren.

So erhielt ich auch aus Brasilien mehrere lose in $\mathrm{Ok}$ taedern krystallisirte Krystalle von oktaedrischem KupferEr'z (Roth-Kupfererz), wobei einige sich befanden, welche offenbar zum pyramidalen Krystall-Systeme (zwei- und einaxigen Systeme) gehörten; indem zwei Axen von der dritten verschieden und nur in einer Stellung auf der Axe die Basis quadratisch und in den übrigen zwei Stellungen verschoben erschien.

Von Schwarzenbach in Kärnthen erhielt ich aus dem dortigen Bleibergwerke krystallisirte gelbe Bleispäthe (pyranidalen Blei-Baryt), wobei melırere vierseitige tafelartige 


\section{$-320$}

Krystalle verschoben ungleichwinklig vorkamen, welche man allerdings in das orthotype Krystall-System zählen würde.

Dergleichen Abweichungen dürften, in Bezug auf die dermalen bestehenden Krystall - Systeme, vielleicht noch viele nachzuweisen seyn@ worüber ich meine Beobachtungen noch fortsetzen werde. Eben so erscheint durch Vergrösserung einzelner Flächen der Würfel der Mineralogen sehr oft nach den geometrischen Begriffen als rechtwinkelig vierseitiges Prisma, als z. B. bein hexaedrischen Eisenkies, oktaedrischen Fluss - Haloid und noch vielen andern Mineralien, und dennoch zählt man dergleichen vorkommende vier'seitig rechtwinklige Prismen von diesen Mineralien in das Tessular-Systern.

Ferner zeigen sish im Augit-Geschlechte nicht selten, an den schiefwinklig vierseitigen orthotypen Prismen, Kombinations-Flächen an allen vier. Seitenkanten (gerade Abstumpfung der Seitenkanten). Würden sich diese letztern so veryrössern, dass erstere verschwänden, so erschiene ebenfalls ein vierseitig rechtwinkliges Prisma. Nach diesen Ansichten können also die rechtwinlilig vierseitigen Prismen in drei von einander verschiedenen Krystallsystemen, näinlich : im orthotypen, tessularischen und pyramidalen Krystall-Sy'steme vorkommen, wodurch die bestehenden Krystall-Systeme nicht sehr scharf begränzt von einander geschieden sich zeigen, und in dergleichen vorkommenden Fällen muss die Krystall-Gestalt gleichsam zwangartig in dieses oder jenes Krystall-System passen.

Diese angeführten Zweideutigkeiten könnten vielleicht nur durch die Einführung eines sogenannten Flächen-Krystall-Systemes einstens beseitigt werden, welches auf ähnliche Ar't verfasst werden und auf denselben Grundsätzen beruhen möchte, wie in Leonhard's Jahrbuch für Mineralogie etc. 3. Heft 1530 in dem Aufsatz unter dem Titel: Versuch eines Formen-Systems, zu ersehen ist.

Bei einem auf derlei Grundsätze gestützten KrystallSystem dürfte Folgendes erzweclit werden: 
1) Unsere mineralogisch-krystallographischen Bemerkungen und Ansichten würden alsdann mit den altherkömmlichen und allgemein angenommenen geometrischen Begriffen und Bemerkungen in grössern Einklang kommen. So würde der mineralngisch angenommene verlängerte $W$ ürfel stets nur als ein rechtwinkliges vierseitiges Prisma angesehen werden.

So die Hälften- und Viertel-Krystall-Gestalten immer als ganze Gestalten betrachtet und nach Beschaffenheit ihrer Flächen benannt werden.

2) Jede Krystall-Gestalt würde der sinnlichen Wahrnehmung nach den naturhistorischen Forderungen jederzeit genau entsprechen, und alle Vorstellungen von Ergänzungen der mangelnden Flächen, so wie die Erklärungen durch Schnitte dadurch beseitigt oder wenigstens entbehrlich werden.

3) Die Beschreibung einer Krystall-Gestalt würde jederzeit genau der Gestalt entsprechend erscheinen, wenn selbe nach der wirklichen Beschaffenheit der Flächen, ihrer Winkel, Kanten und ihrem Beisammenseyn entworfen wird.

Würde man nach den jetzigen krysta!lographischen Ansichten eine Kombinations-Krystall-Gestalt, z. B. wenn sich das Hexaeder mit dem zweikantigen Tetragonal-Icositetraeder kombinirt"), schon für erklärt halten, oder vielmehr der Beschafferheit dieser Gestalt als genau entsprechend annehmen wollen, so dürfte nur dagegen zu erwähnen seyn, dass. diese Kombinations-Flächen verschiedene For'm annehmen; je nachdem selbe grösser oder kleiner sind, so werden bei dieser obenbenannten Kombinations-Krystall-Gestalt anfangs die Tetragonal-Icositetraeder-Flächen, wo sie noch klein sind, als dreiseitige, und bei Vergrösserung derselben als fünfseitige Flächen erscheinen; daher durch den alleinigen Ausdruck der Kombinations-Gestalt noch nicht die genaue Form, welche derselben entsprechen soll, angegeben ist.

*) Nach Werner: der Wïrfel mit dreiflächiger Zuspitzung an allen Ecken, die Zuspitzungs-Flächen gerade auf den Flächen dus Würfels aufgesetzt. 
Würrden aber bei einem erwünschten sogenannten Flächen-Krystall-System die Flächen, Kanten und ihre WinkelVerhältnisse gerade so, wie sie an was immer für einer Kombinations-Krystall-Gestalt vorkommen, beschrieben werden, so dürfte eine derlei Beschreibung jederzeit entsprechend seyn, und eine getreue Verzeichnung darnach entworfen werden können. Den naturhistorischen Forderungen in der Naturgeschichte, dass Alles der sinnlichen Wahrnehmung und Anschauung entsprechen sollte, würde auf diese Art Genüge geleistet werden. Die mathematische Betrachtung würde ihre Aufmerksamkeit bei einem derlei Krystall-Systeme vorzüglich auf die Beschaffenheit der Kanten, Flächen, ihrer Winkel-Verhältnisse und Verbindungen derselben mit einander richten, und dadurch die Wissenschaft an Interesse keinen Verlust erleiden, und die Verbreitung derselben durch die Annäherung an ein mehr natürliches Krystall-System befördert werden. 


\section{Über \\ Onychoteuthis prisca v. Mönst. *), \\ eine Vorlesung,}

bei der Strasburger naturhistorischen Gesellschnft

am 17. November 1835 gehalten

von

Hrn. Voltz $\left.{ }^{*}\right)$.

Vor etwa einem Jahre hat Agassiz 製) in der Sammlung der Miss Phipot in England eine merkwïrdige Versteinerung aus dem oberen Lias von Lyme Regis gefunden. Es ist die Onychoteuthis prisca des Grafen Münster, wovon Zieten auf Taf. XXV seines Werkes mehrere Exem. plare unter dem Namen Loligo Bollensis und L. Aalensis abgebildet hat. Aber das Exemplar von Lyme Regis endiget hinten in den Belemnites ovalis,

Herr von $\mathrm{Z}_{\text {IETen }}$ hat wohl Recht gehabt, diese Art von Versteinerung nicht mit den Sepiostarien zu verwechseln, weil die Scheidewände, welche das umpassend soge-

") In Keferstein's Deutschland, 1828, V , 581, und im Jahrhuch $1830,443$.

**) Vgl. Buckland über Belemnoapia S. 36, und v. Merek über Onychoteuthis prisca S. 55.

Sahrb. 1835, S. 168. 
nannte Schwammgewebe der Sepien-Knochen bilden, hier fehlen: Diese Scheidewände sind hornartige Blätter mit Kalkmasse durchdrungen, welche mithin, wenn sie in jenem ersten Falle existirt hätten, eben so wohl hätten versteinern und sich erhalten müssen als die Schaale, und noch leichteı. als der Dintensack, den man in diesen Onychoteuthen noch sieht. Ausserdem zeigt die Rückenfläche dieser letzten, statt der körnigen Beschaffenheit der Sepien - Knochen und selbst der Sepia hastaeformis Rüppelu's von Solenhofen, nur Zuwachsstreifen, welche die Enden einer Reihe von übereinanderliegenden Blättern sind. Was aber die $\mathbf{O}$ nych oteuthis prisca hauptsächlich von den Sepiostarien unterscheidet, das ist die deutliche Anwesenheit der Zuwachsstreifen an den Seiten- oder Hyperbolar-Gegenden, wie bei den Belemniten, welche dagegen den Sepien-Knochen ganz abgehen.

Jene Fossil-Reste sind aber auch keine Loligo-Leisten, weil das Anwachsen dieser hornartigen Theile, wie v. ZIETEN auf Tf. XXV, Fg. S von einem lebenden Loligo so gut dargestellt hat, gänzlich auf dem spitzen, bei erstren aber, nach Fg. 5, 6 und 7 von Z ZiETEN, an dem entgegengesetzten Ende Statt findet.

Die Wachsthums - Weise ist genau, wie ich sie an der Rücken-Gegend des Alveolen-Kegels der Belemniten auf meinen Tafeln *) unter Fg. I und $\mathrm{K}$ dargestellt habe; Tf. XXV, Fy. 5 bei $Z_{\text {IETEN }}$ gibt dieselbe Wachsthums-Art an dem hinteren oder Spitzen-Theile an, wo man die oberen Blätter der Schaale unbeschädigt ${ }_{\downarrow}$ sieht. Andere Systeme von Zuwachsstreifung nimmt man auf dem vorderen Theile der Schaale wahr, welche aber tiefer liegenden Blättern angehören; - und eben so bemerkt man auch in den Alveolen der Belemniten Anzeigen verschiedener Streifen, welche

-) Vgl. Observations sur les Bélemnites in der ersten Lieferung der Mémoires de la Société Shistvire naturelle de Strasbuurg > Juhrb. 1830, 407 ff. 
einen andern Verlauf haben, als die Zuwachsstreifen der Rücken - und der Seiten-Gegenden.

Auch ist noch zu bemerken, dass bei den Belemniten das Wachsthum der Scheide auf ganz andre Weise voranschreitet, als das des Alveoliten. Bei diesem bemerkt man Zuwachsstreifen auf der äusseren Oberfläche, und sie ist nothwendig durch zwei verschiedene Membranen gebildet worden, wovon eine die Rücken-Region erzeugte, die immer weit über die-Bauch-Region vorspringt und einen sehr verlängerten Lappen bildet, dessen Zuwachsstreifen schwibbogenfürmig sind, mit nach vorn gekehrten,' in der RückenLinie liegenden Spitzen. Diese Rücken-Gegend ist von, den Seiten-Gegenden der Schaale durch zwei gerade Linien, die sich gegen die Spitze zusammenneigen und von mir den Namen der.Asymtoten erhalten haben, getrennt, während die durch die andere Membran gebildeten Zuwachsstreifen $\mathbf{H y -}$ perbeln gleichen, welche auf den Bauch- und Seiten-Gegenden beschrieben worden und deren beiden Schenkel sich den zwei Asymtoten bei ihrem raschen Verlaufe nach vorn immer mehr aufwärts annähern.

Die Zuwachsstreifen der Scheide dagegen gewahrt man nur im Innern der konischen Höhle, und nicht auf der äussern Oberfläche (Fg. D und $H$ meiner Tafeln): sie sind auf ganz andere Weise geordnet. Auf dem Rücken bilden sie eine tiefe Einbucht statt des langen Lappens am Alveoliten; auf dem Bauche bieten sie eine viel breitere, aber seichtere Einbiegung dar, und so entsteht an den Seiten, den Hyperbolar-Gegenden des Alveoliten entsprechend, jederseits ein vorwärts gehender Lappen. Man begreift demnach, Qass der Rücken-Lappen des Alveoliten weit aus der Scheide hervorstehen könne; und dass solches wirklich der Fall seyn müsse, ist klar, indem sonst der Rücken-Lappen an dem Fossile von Lyme Regis und den Figuren von $Z_{\text {IETEN }}$ keine Zuwachsstreifen zeigen könnte, in sofern die Scheide selbst dergleichen auf ihrer äusseren Oberfläche nie besitzt. 
Wenn ferner diese Zuwachsstreifen der Scheide angehörten, so müssten sie auf der Rücken - Linie rückwärrts gegen die Spitze der Belemniten gekehrte Buchten, und nicht vorwärts stehende Lappen bilden.

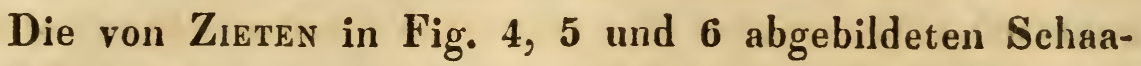
len, die wohl drei verschiedenen Arten angehören könnten, bieten auf ihren beiden Seiten zwei Systeme schiefer Streifen dar, welche von den Zuwachsstreifen des Räcken-Lappens sehr verschieden von ihnen durch zwei gerade Linien getrennt sind, welche den Asymtoten der Alveoliten entsprechen, und diese zwei Systeme von Streifen auf den Seiten des Onychoteuthis sind die Hyperbolar-Streifen dieses Alveoliten. Das wird man insbesondere leicht einsehen, wenn man die Struktur der hornartigen Leiste von Loligo sagitta") und ihre Beziehungen mit den Belemniten und Sepiostarien betrachtet. Sie hat keine Hyperbolar-Gegenden. Ich werde in einer der nächsten Sitzungen, wo ich alle Cephalopoden-Schaalen mit einander zu vergleichen denke, darauf zurückliommen.

ZiETen's Fig. 7, welche wohl einer vierten Art angehören könnte, zeigt Längen - Streifen und selbst - Rippen ; aber die Rücken - Gegend der Belemniten zeigt ebenfalls Längen-Streifen und selbst eine mittle Rippe; in derselben Figur sieht man auch die Hyperbolar-Streifen, welehe aber nicht ganz sind; die Bauchstreifen fehlen. Es scheint, dass sich die Streifen auf dieser Dorsal-Ausbreitung nur noch theilweise, wie in den Loligo-Schaalen gebildet haben, welche oft keine Bauch-Streifen (L. vulgaris) haben, oder zuweilen dergleichen auf dem vertieften Theile der Spitze, einer rudimentären Alveole, zeigen (L. sagit ta).

Nach dieser Erklärung sieht man, dass die Fossil-Reste von Lyme Regis und von Zieten's Loligo Bollensis und

*) Wahrscheinlich in FÉrussac's Werk über die Ce ph al opoden?

Broxr. 


\section{$-327-$}

L. Aalensis sehr gut Demjenigen entsprechen, was wir bereits über die Struktur der Belemniten kennen. Es wäre sehr zu wünschen, dass man ähnliche instruktive Exemplare auch von jenen grossen Arten entdeckte, die im Unteroolith vorkommen. Unglücklicher Weise aber brechen darin keine Mergelschiefer, wie im Lias, worauf sich diese Theile so schön erhalten, so dass wenig Aussicht auf einen solchen Fund bleibt. 
Über

das geologische Alter

der

\section{Ka lka l pen von Uri, von}

Hrn. Prof. B. Studer.

Mit Profil auf Tf. V, Fg. 1.

So wie in einer frühern Epoche der Geologie die Briefe von Escher über den Gotthardl als die Grundlage aller damaligen Arbeiten über die Schweitzeralpen betrachtet werden konnten, so wird auch die neuere Durchschnitts-Zeichnung, die H. Dr. Lusser i.J. 1 S29 in den Schweitzerischen Denkschriften bekannt gemacht hat, gewiss noch lange eine ehrenvolle Stelle unter den Monographie'n der. Schweitzerischen Geologie behaupten. Nicht nur die Genauigkeit der darin aufgezeichneten Beobachtungen sichert ihr diesen Rang, sondern die Natur selbst hat das Reuss - Thal und die Gotthardts - Strasse ausgezeichnet als die Grenzmarke zwischen der östlichen und westlichen Schweitz, und alle speziellen Untersuchungen in der vom Rhein, oder in der von der Rhone umflossenen Hälfte der Schweitzeralpen werden durch Beziehung ihrer Resultatè auf jene gemeinschaftliche Mitte an Interesse und allgemeiner Bedeutung Vieles gewinnen.

Der Mangel an literarischen Hülfsmitteln und die Entfernung von grösseren geologischen Sammlungen haben $H_{r}$. 
Lusser verhindert, die von ihm anfgefundenen Petrefakten näher zu bestimmen, und auf diesem Wege die in seinem Profil bezeichneten Sedinent - Formationen mit denjenigen des geologischen Systems zu parallelisiren; er hat daher allgemein die vier Bildungen zwischen den Feldspath-Gebirgen und der Molasse nur als Niederschläge 1ter, 2ter, 3ter und 4 ter Art unterschieden, und unter diesen Benennungen in sein Profil eingetragen. Durch Vermittlung von Hrn. ARnold Escher hat sich Hr. Lusser bereit finden lassen, die ganze Sammlung von organischen Überresten, die er auf seinen vieljährigen Reisen in den Gebirgen der Urkantone zusammengebracht hat, uns zur Einsicht nach Bern zu übersenden; wir haten dieselben sorgfältig untersucht und verglichen, und obgleich, wie man es von alpinischen Petrefakten gewohnt ist, nur wenige eine genauere Bestimmung erlaubten, so glaube ich doch, dass das Ergebniss dieser Untersuchung über da's Alter der verschiedenen Niederschläge

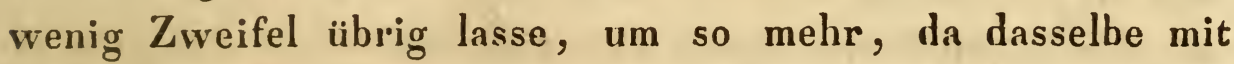
den Alters-Bestimmungen der Formationen in der westlichen und östlichen Schweitz aufs Befriedigendste übereinstimmt.

Wenn wir nämlich in der westlichen Schweitz die Lagerfolge in der Hauptkette betrachten, welche das Wallis von den Kantonen Bern und Waadt trennt, so zeigt sich über dem Gneiss-Granit mit nördlicher Einsenkung:

1) eine aus verschiedenartigen Gesteinen zusammengesetzte Formation, in weleher besonders dolomitische Kalksteine, Quarzfels, bunte Schiefer und oolithische Eisensteine sich auszeichnen, in der Höhe sich verbindend mit schwarzem, oder grauem Kalk und Schiefer (Bex, Lauterbrunnen, Haslithal). Die Petrefakten charakterisiren diese Bildung, die im Mittel kaum Tausend Fuss mächtig ist, als Lias oder unteren Oolith. Über ihr folgt:

2) eine mehrere Tausend Fuss mächtige Folge von dunklem Kalk und Schiefer, worin man bis jetzt, und zwar als grosse Seltenheiten, nur vereinzelte B el e mnit en aufgefunden 
hat. Diese und ein grosser Ammonit (A. gigas Z. §), der in die Familie der Planulati zu gehören scheint, vorziiglich aber der paläontologische Charakter der Unterlage und der Decke, lassen in dieser Mittelstufe Glieder der jurassischen Epoche vermuthen. An ihrer obern Grenze verbindet sie sich

3) mit einer ebenfalls sehr mächtigen Folge von Kalk-, Schiefer und Quarzsandstein-Lagern, worin läufig grüne (Eisensikkat-)' Körner eingesprengt sind, zuweilen so dicht gedrängt, dass der Stein zu einer schwärzlich grünen Masse verschmilzt. - Nummuliten, die ganze Bänke fast ausschliesslich erfüllen, Exogyren, Diceras, Hippuriten, Spatangen u. s. w. bezeichnen diese Bilàng als Kreide.

Zwischen dem Genfer- und Thuner-See finden wir diese Formations-Folge auf die Hauptkette beschränkt, über welche die Pässe des Sanetsch und der Gemmi führen. Eine mächtige Gyps-Bildung und das Längenthal von Frutigen scheiden sie von nördlicheren alpinischen Sediment-Systemen, die einen andern Charakter tragen, obgleich sie zum Theil derselben Alters-Epoche angehören. Östlich vom Thunersee n'eer breitet sich das System jener Hauptkette, oder de: Wildhorn-Masse, über den ganzen Raum aus, der von den Feldspath-Gebirgen und der Miolasse eingeschlossen wird, und besonders die Kreide-Gruppe gewinnt eine immer grössere Mächtigkeit und bildet eigene Ketten und ausgedehnte Gebirgs-Massen, die sich von der nördlichen Grenze bis in die Nähe der Hochgebirge erstrecken.

In der östlichen Schweitz liat man bis jetzt nur Kreide-Petrefakten anfgefunden. Die Nummuliten, Turriliten, Ostraceen u. s. w. der Säntis-Gruppe, die Exogyren, Clypeaster und Kamm-Austern von Einsiedlen und Glarus, die Fische vom Blattenberg, die Nummuliten der Pantenbrïcke zeugen für die grosse Ausdehnung, welche diese einzige Formation in jenem Theile der Alpen erreicht, und die Übergänge der Nummuliten-Gesteine in glänzende Thon-, Talk- und Glimmer-Schiefer, der Sandsteine in Quarzite, 
und der dichten in krystallinische Kalkarten oder in Dolomit bringen diese Kreidemassen den Feldspath-Gebirgen so nahe, dass man in Verlegenheit ist, wo man noch zwischen beiden nach älteren Sediment-Formationen suchen solle. Ja nach neueren Beobachtungen möchte man sogar geneigt seyn anzunehmen, dass diese Kreide-Bildungen sich südlich vom Vorderrhein tief nach Graubündten hinein ausbreiten.

Die Verhältnisse in Reussthal und an den Ufern des Urnersee's, die wir nun nach den Angaben und Sammlungen von Hrn. LuSSER näher untersuchen wollen, zeigen uns, wie die alpinische Kreide, die von Unterwalden her durchstreicht, bereits an Mächtigkeit alle älteren Sediment-Formationen weit übertrifft, während doch diese noch nicht, wie weiter östlich, ganz verdrängt erscheinen.

\section{Niederschläge erster Art.}

Unmittelbar über dem Granit liegt, nach Hrn. LusSER, mit nördlicher Einsenkung, ein dichter hellgrauer Kalk mit strohgelber, staubartiger Aussenfläche, wahrscheinlich also dolomitisch, in der Tiefe auch mit starkem Kieselerde-Gehalt; auf diesen Kalk folgt schwarzer, glimmeriger ThonSchiefer mit Nieren von Rotheisenstein; hierauf bunter Schiefer, zum Theil dem Wetzschiefer genähert, und endlich harter, sehr feinkörniger graulichschwarzer Kalk. Stellenweise werden die Schichten sehr eisenschüssig durch Einmengungen von Eisen-Silikat-Körnchen (Chnmosit), so dass ein oolithischer Eisenstein entsteht; oder sie enthalten sehr viele eirgesprengte Körnchen von Magneteise॥, odev es drängen sich Nester von Eisen-Glimmerschiefer ein. Die Mächtigkeit der ganzen Formation betrïgt 300 bis $400 \mathrm{~F}$. Es sind dieselben Steinarten, die auf Stufistein an der Jungfran in gleicher Lagerung vorkommen; Hr. A. Escher hat sie auf der Sandalp am Tödi in Glarus wiedergefunden; sie scheinen daher, mit geringer Unterbrechung, lïngs der ganzen nördlichen Grenze der mächtigen, aus Gneiss, Glimmerschiefer und Granit bestehenden Gebirgsmasse des 
Finsteraarhorns, als die tiefsten Glieder des Kalk-Gebirges vorzukommen, denn die Jungfrau steht mehr am westlichen, der Tödi am östlichen Ende dieser Gebirgsmasse.

Die Petrefalsten in der LuSSER'schen Sammlung, die dieser Bildung angehören, stammen mit wenigen Ausnahmen vom Ribiboden an der Windgälle, oberhalb Amsläg, her. Es sind folgende :

1) Ammonites, beschädigter Abdruck von 6 Zoll Durchmesser auf schwärzlichgrauen, feinsplittrigem Kalk, worin auch Belemniten-Stiicke $e^{\text {vorkommen. Wahrschein- }}$ lich aus der Familie der Ariătes, ähnlich A. Bucklandi Sow.

2) Ammonites, Bruchstïck einer einzigen Windung im vorigen Kalk. Starke Rippen, die sich in einen Knoten geendigt $\mathrm{zu}$ haben scheinen und dreifach getheilt über den breiten Rücken laufen. Der Durchmesser: der Windung muss wohl 6 bis $S$ Zoll betragen haben. Ähnlich A. Humphresianus Sow. oder A. Bollensis Ziet.

3) Ammonites, mehrere Bruchstücke in dem oolithischen, eisenschüssigen Kalke. Vollkommen übereinstinmend mit Ammoniten von Stufistein und wahrscheinlich A. annularis ZiET.

4) Ammonites, zerquetschte Windung in derselben Steinart. Runder Rücken mit dicht gedrängten Rippen, dio von weniger zahlreichen starken Seiten-Rippen auslaufen. Scheint derselbe A., den ich von Stufistein besitze und mit einer Spezies aus dem untern Oolithe von Lac Bourget verglichen habe; vielleicht auch zu Nr. 2 gehörend.

5) Ammonites, in schwärzlichgrauem Kalk. Stark gerundeter Rücken mit kreisförmigem Durchschnitt, die Seitenrippen scheinen nach oben Knoten gebildet zu haben und zertheilen sich von da aus in zwei Rippen, die auf der Mitte des Rückens durch eine Hoblkehle unterbrochen werden. Gut übereinstimmend mit A. bifureatus ZiET.

6) Ammonites, im gleichen, mit schwarzem glimmerigem Thonschiefer verwachsenen Kalk. Der Rücken einer 
Windung. Zu den Coronarii s gehörend und $\operatorname{dem} A$. coronatus selbst sehr nahe stehend.

J) Belemnites, in dem Kalk Nr. 3. Bruchstücke von $1 \frac{1}{2}$ Zoll Länge, die Seitenfurche so lang als das Stück. Ähnlich B. subhastatus. Andere ziemlich häufige Belemniten lassen keine nähere Bestimmung zu.

S) $Z_{w}$ eischaalige Muscheln, im Kalk Nr. 3. Vielleicht Amphidesma recurvum ZiEt. Deutliche, konzentrische Wachsthumsringe.

9) Grosse Bivalve. Hintertheil einer Schaale, mit unregelın̈ssigen Wachsthums - Ringen, ohne Spur von Längen-Rippen; in oolithischem mit Thonsubstanz durchwachsenem schwarzem Kalk. Ähnlich Römer viI, 2 oder 11.

10) Pecten, die Ohren nicht erhalten, 20 Rippen. In der vorigen Steinart, zugleich mit Nr. S. Vielleicht P. vimine us GoldF.

11) Pecten, die Ohren nicht erhalten, glatt, flach. Vielleicht P. obscurus GoldF. Im Kalk von Nr. 9, von Lauweli an der Windgülle.

12) Posidonia, mehrere vertiefte Abdrücke in einem eisenschüssigen verworren schiefrigen schwarzen Thonschiefer, von Bietschen. Scheint unzweifelhaft P. Bronnii Z., oder die Art in der Lethäa xvill, 23.

13) Terebratula, in graulichschwarzem, zum Theile eisenschüssigem Kalk, vom Scheidnüsli (Windgälle?). Scheint T. ornithocephala.

14) Terebratula, die Schlossränder unter sehr sumpfem Winkel zusammenstossend. Von eben daher. Vielleicht zu T. biplicata Var. lata v. B. gehörend.

Aus diesen Béstimmungen ergibt sich mit ziemlich starker Wahrscheinlichkeit, dass Lusser's Niederschläge 1 ter Art dem Lias oder den tiefsten Gliedern der Oolithreihe eingeordnet werden müssen.

Jahrgang 1836. 
Niederschläge zweiter Art.

In dieser zweiten Formation begreift $\mathrm{H}_{\mathbf{r}}$. Lusser einen in Phomboedrische Stücke spaltenden, in Anschlagen klingenden Kalkschiefer, im Inner'n dunkel, an der Aussenfläche hell blaulichgrau. Die Mächtigkeit desselben steigt wohl bis auf 2000 Fuss. Von organischen Überresten ist noch nieınals eine Spur darin gefunden worden.

Es ist diess der nämliche Kalk, Jer an den höhern Felsen der Jungfrau, der Blïmelisalp und überhaupt in diesem Theile der Berner Hochalpen in grosser Mächtigkeit auftritt. Auch ieh habe bis jetzt keine Petrefaliten darin entdecken können.

Niederschläge dritter Art.

Auch diese, an Mächtigkeit der vorigen nicht nachstehende Bildung ist von allen organischen Überresten entblöst, und ihr geologisches Alter lässt sich daher nicht direlst ausmitteln. In de: Tiefe erscheint in grosser Ausdehnung Taviglianaz-Sandstein, von demjenigen der westlichen Schweitz nicht verschielen; anf ihn sehr fester Sundstein-Schiefer und Thonschiefer; dann gröherer Sandstein und Konglomerate mit kalkigem Zäment; zuletzt wieder Sandstein-Schiefer.

In der westichen Schweitz scheinen diese Sandsteine durch die obere Kalk- und Schiefer-Masse vertreten zu werden. Sie stieichen über das Surenen- und Schächtrithal nach dem Linthal und erhalten in den hinteren Gebirgen von Glarus eine grosse Mächtigkeit. Vermuthlich bildet diese Formation in der mittlen und östlichen Schweitz eine den Flysch-Linsen der westlichen Alpen analoge Einlagerung in die regelmässige Sediment-Folge.

\section{Niederschläge vierter Art.}

Die verschiedenen, von Hrn. Lusser sorgfältig beschriebenen Gebirgsarten dieser weit verbreiteten Formation stimmen unverkennbar überein mit denjenigen, die wir in den 
Luzerner A!pen ( $J . d . M .1834)$ und in den Gebirgen der westlichen Schweitz (Geol. der westl. Alpen) beobachtet haben. Sie enthalten auch die nämlichen Petrefakten, und diesen zu Folge muss die ganze Bildung als Kreide und Grünsand betrachtet werden. - Hr. Lusser unterscheidet von Unten nach Oben (von Brunnen bis Schwytz scheint sein Profil eine Umstïrzung anzudeuten) folgende Abtheilungen: a, b, c. Grauer, in der 'Tiefe Breccien-artiger, zum Theil eisenschüssiger Kalkstein und Kalkschiefer, mit wohl erhaltenen $\mathbf{N u m m u l i t e n}$.

1) Nummulites laevigatus, wie es scheint, nicht verschieden von den Nummuliten, die in so grosser Menge in den jüngeren (iliedern dieser Formation vorkommen.

2) Belemnites: unbestimmbare Arten, theils von den Surenen in schwarzem Kalk, theils aus dem Schächenthal in kieseligem granem Kalk. Obgleich Hr. L. diese Stücke hieher zählt, scheinen sie doch seinem Profil zu Folge eher in die vorige Formation zu gehören.

3) Sandsteinschiefer mit Trümmern eines kleinen A mmonite $n$ und mit Pentacriniten-Gliedern. Ähnlich den Stücken aus der Gamchilucke (G. d. w. A. p. 69). Möchte auch der vorigen Formation angehören. Eben so das folgende Stück.

4) Dichter schwärzlich rauchgraner Kalk mit kleinmuschligem Bruch, identisch mit dem Kalk der obern Kalkund Schiefer-Grujpe der westlichen Alpen. Auf der einen Seite ein Abdruck von Aptychus imbricatus M., nur 3 Linien lang; auf der andern der eines Ammoniten, wahrscheinlich aus der Familie der Planulati. Aus einer der ersten Schichten am Achsenberg.

d. Schuppig - körniger Kalk, zuweilen mit eingesprengten grünen Körnern. Die Aussenfläche rauh, bräunlich, mit hervorstehenden faustdicken Warzen, die aus fest mit dem Kalk verwachsenen Quarze bestehen. Als Petrefakten enthült derselbe : 


\section{6}

1) Ostrea carinata Goldf. Die Höhe, wohl das Dreifache der Dicke, ist gleich 2 Zoll, die Länge mag wohl 6 Zoll betragen haben. Breite des Rückens 2-3 Linien. Von der Rüki am Rophaien (Gipfel des Achsenberges).

2) Exogyra aquila GoLdF. Sehr gut erhalten, bei 3 Zoll lang, mit scharfem, erhöhtem Kiel. Von ebendaher.

3) Terebratula plicatilis v. B. Im aufgebogenen Mittelstïck 12, in den Seiten \& Rippen. Mit Exemplaren aus der weissen Kreide und aus dem Saroyischen Grünsand vollkommen übereinstimmend. Vom Rophaien.

4) Terebratula, übereinstimmende Art mit einer häufig im Savoyischen Grünsand vorkommenden Spezies, die v. Bucr wahrscheinlich der T. biplicata beizählt: länger als breit, beträchtlich dick, mit fast unmerklichen Falten.

5) Terebratula, vielleicht nur ein jüngeres Exemplar, der vorigen, aber auch ganz übereinstimmend mit T. s emiglobosa aus dem Plänerkalke.

6) Spatangus retusus GoLdF. Übereinstimmend mit den Spatangen der westlichen Schweilzeralpen (G. d. w. A. p. 102) und des gelben Kalks von Neuchätel. In schwarzem, feinsplittrigem Kalk von der Gosalp im Isithal.

e. Sehr feinkörniger lichtgrauer Kalk, nur selten mit Muschel-Abdrücken (es befinden sich keine in der Samılung).

f. Ratuher, thoniger Kalkschiefer, öfter's mit Kieselerde gemengt; mit untergeordneten Lagern, die Petrefakten und grüne Körner einschliessen.

1) Nummulites laevigatus. In dunkelm, oolithischem Grüukalk. Von Sissigen, ferner oberhalb Bauen, am Rütlli u. s. w.

2) B elemuites. Unbestimmbar. Im nämlichen Gestein. Vom Rüttli.

3) Pecten. Ein gestreifter, im Grünsand der mittlen Schweilz sehr häufiger Pectinit, mit 30 Rippen. Ähnlich P. i mbric at us Desh. oder P. subimbricatus Goldr. 
g. Dichter grauer Kalk, dickgeschichtet, mit sehr vielen halbmondförmigen braunen, stinkspathartigen Fragmenten von organischen Überresten. Es ist der Schratte $\mathrm{n}$ kalk der Luzerneralpen (J. d. M. 1834), der Kalk der Schweiffen oberhalb Habkeren (G. d. w. A. p. 106). Er enthält :

1) Grosse Univalve mit breiten Windungen, die einander überdeckt zu haben scheinen; vielleicht Tornatella gi$\mathrm{g}$ a $\mathrm{n}$ te a, aber zu fest mit dem Stein verwachsen, als dass ganze Individuen losgeschlagen werden könnten. Dasselbe Petrefalit ist in den Schweiffen sehr häufig. Die Etiquette lautet: "vom Seelisberg, woselbst auch flach abgerundete Gryphiten vorkommen." In bräunlich grauem Kalk, schuppig ins Dichte, mit vielen Nestern und Adern von Kalkspath.

2) Die halbmondförmigen Fragmente gehören, nach Analogie anderer Fundorte, Hippuriten und Diceras an.

h, i, k. Kalksteine, die meist durch Thon, Kieselerde oder grüne Körner verunreinigt sind. Nummuliten einschliessend.

I. Lichtgrauer schuppiger Kalk, häufig von Spathadern durchzogen. Abwechselnd mit thonigem Kalkschiefer und Schichten oder Nestern, die nur aus grünen Eisensilikat-Körnern bestehen (Chamosit). Sehr reich an Petrefaliten.

1) Nummulites laevigatus, in ungeheurer Menge, so dass öfters die Steiumasse ganz verdrängt wird.

2) Pectunculus (§). Vollständiger Abdruck einer Schaale, der vollkommen mit Venus $\mathbf{C y p r i a ~ B r o c c h i ~ u ̈ b e r - ~}$ einstimmt. Von Seewen.

3) Pecten. Kreisrund, glatt, mit feinen Queerringen, flach. Vielleicht P. orbicularis Sow. - Ebendaher.

4) Inoceramus concentricus Sow. Sehr gut erhaltene Exemplare sind von H'n. A. Escher z.n Seewen aufgefunden worden. 


\section{$-338$}

5) Turbo rotundatus Sow. Von der Abbildung und von Exemplaren aus dem Savoyischen Grünsand nicht zu unterscheiden. Vom Schwytzer-Hacken.

Noch andere ausgezeichnete Grünsand-Petrefakten, theils von den zuletzt angeführten Fundorten, theils von Einsiedeln, sind in der Geol. der westl. Alpen p. 112 aufgezählt; andere dagegen, die sich im Berner Museum befinden, aus dem Grunde nicht berïcksichtigt worden, weil sie mit keinen Abbildungen Übereinstimmung zeigen. 


\title{
Briefwechsel.
}

\section{Mittheilungen, an den Geheimenrath v. LEONHARD gerichtet.}

\author{
Lyon, 3. Dez. 1835.
}

Nichtlange nachdem ich an den Nagelfluen von St. Saphorin die Beweise von einem Statt gefundenen Wicder-Erweichen gewisser Geschiebe wahrgenommen, sah Herr Rozer ähnliche Thatsachen an den Nagelfuen von Spyssel, mit denen die Bitumen-Quel!en vorkommen. Allen Nagelfluen stelst demnach sicher kein rein neptunischer Ursprung $\mathrm{zu}^{*}$ ). In uosern Konglomeraten suchte ich bis jetzt vergebens nach ähnlichen Phänomenen, wohl aber sah ich Rollstïcke, die in Folge erlittenen Druckes zerbrochen und durch kalkigen Kitt von Neuem gebunden worden waren. - Sie erinnern sich, dass ich lhnen über die Verhält. nisse der Erzgänge von riemne Einiges mündlich mittheilte. Neulich war ich an Ort und Stelle und sah einen mächtigen Barytspath-Gang aufgeschlussen, welcher Bleierze führt. Die grösste Masse dieses Ganges bestand aus einer Barytspath-Breccie; die Barythspath-Trümmer waren gebunden durch Blende. Bleiglanz kam an dieser Stelle besonders häufig vor vud schien ehenfalls Zertrümmerungen erlitten zu ha. ben. Der Barytspath, wie derselbe im Hangenden und Liegenden des Ganges vorlanden ist, zoigt sich ziemlich frisch; aber alle in der Mitte befindlichen Fragmente sind mehr oder weniger zersetzt, theils staubartig, theils erscheint er wie durch Feuer geröthet.

\section{LORTET.}

Holzappel, 13. Dez. 1835.

Dịe sekundären Bildungen auf unserem Gange, das Weissbleierz etc., erreichen selten melir als eine gegen 10 Lachter betragende

*) Man vergleiche die Ansichten Sruden's in der. für die zweite Ausgabe meiner Grundziige der Geologie (S. 183 und/184) wir mitgetheilten Note.

LхомнАвп. 
Seigerteufe unter Tage. Bis zu disser Teufe sind aber auch alle primitive Ausfiillungsmassen, den Quarz ausgenommen, durchaus zcrstört, und nur höchst selten findet sich stelleuweise noch etwas Bleiglanz, nie aber Blende noch Spatheisenstein, welchem etliche Lachter tiefer, die Spuren der Verwitterung aufgedrückt sind.

Un desto überraschender war die Erscheinung, Weissbleierz in einer gegen $30 \mathrm{~L}$. betragenden Seigerteufe anzutreffen, ohne wie bei $\mathrm{Nr} .1^{*}$ ) die geringste Auflösung in dem primitiven Bleiglanz wahrzuuehmen, oder ohne dass der leichter auflösliche Spatheisenstein im Mindeśten durch die Verwitterung gelitten, wozu alle Bedingungen auf der Fundstätte vorhanden sind. Übrigens unterscheidet sich, wie ich schon bemerkte, das Weissbleierz in der'Teufe von demjenigen, welches uäher an Ausgehenden vorkommt, durch Farbe etc., und ich habe, im Falle Sie Versuche damit anstellen wollten, zu diesem Zwecke noch ein kleines Stückchen beigelegt ${ }^{* * a *}$ ) und bin bereit, wenn Sie es wünschen, über das Vorkomanen näher zu berichten ${ }^{m}$ mats).

\section{Schneider.}

Krakou, 27. Dez. 1835.

Im verflossenen Sommer hatte ich Gelegenheit, die Gegenden der Steinkohlen-Formation und des darüber liegenden Muschelkalkes, der Galmei, Bleiglanz und Brauneisenstein fährt, im Freistaate Krakaı näher zu untersuchen. Die zu unterst liegenden Steinkohlenflötze werden noch grösstentheils durch Aufdeck-Arbeit gewonnen, da die darüber liegende Erde höchstens 6 Lachter beträgt. Die Flötze sind bis jetzt wenig bekannt; aber diess weiss man, dass mehrere übereinander liegen, von einander durch Sandstein getrennt, dessen Korn sehr verschieden ist, und vom sehr feinen wächst bis zur Haseluuss-Grösse; nur selten konmen Faust-grosse Stïcke vor, die aus gemeinem Quarz bestehen. Die Kohle wird unmittelbar durch blaugrauen Schieferthon bedeckt, der eine Menge von Blätter - Abdrücken enthält, die zu den Fahren gehören, und von Puscr aufgezählt sind. Unmittelbar auf die Kohlen-Formation folgt Muschelkalk, der nachstehende Glieder zeigt:

a) Mergelthon von blutrother und grünlicher Farbe wechsellagert miteinander. An sehr vielen Punkten kommt diese Schichte zum Vorschein, obne dass man sie im Zusammenhange auffásseu könnte. Auf dem Kohlenflötze Hruzik in Jaworzno sind durch Aufdecke-Arbeit diese Mergel-Schichten

-) Die Nummer bezieht sich auf ein Prachtstück dieses Weiss - Bleierzes, welches ich der Güte meines verehrten Freundes verdanke. Das Aussehen des Erzes ist durchaus eigenthümlich.

**) Befindet sich in den Händen meines Kollegen GmeLrs, von dem wir weitere Aufschlüsse zu erwarten haben.

-*) Weitere Mittheilungen werden vom mineralogischen Publikum nit grösstem Danke aufgenommen werden. 
über dem Kohlen-Sandstein deutlich zu sehen. Versteinerungen sínd bis jetzt hierin nicht gefunden. Diese Schichten korrespondiren mit den Deutschen, und besonders mit denen aus dem Flussgebiet der Weser. Darauf ruht eine mächtige Ablagerung

b) Gresehichteten derben Kalksteins in Wechsellagerung mit mergeligem Kalkstein. Der Kalkstein ist grau und blaulichgrau, und wird durch Schnüre von Kalkspath durchzogen. Die mergeligen Schichten sind schiefrig und blaulichgrau, durch Verwitterung werden sie gelblich, oder schmutzig braun. Manche Schichten des Kalksteines sind sehr reich an Versteinerungen; nur die mergeligen enthalten selten etwas von organischen Wesen. Auf grauem, derbem, vollkommen reinem Kalkstein liegt

c) die metallische Ablagerung, aus Galmei und Bleiglanz bestehend. In den Galmei - Gruben von Dlugosryn und Luszowice beobachtete ich drei Schichten von kohlensaurem Zinkoxyd aufeinander gelagert, mit demselben Streichen und Fallen des zu unterst liegenden Kalksteins. Ihre Mächtigkeit schwankt zwischen 2 bis 12 Zoll, öfters keilen sie sich aus, und dann verflèchten sich dieselben, als dünne Adern in den trennenden verhärteten Mergel. Die Abänderungen des Galmei sind sehr verschieden. Nur selten findet sich reines kohlensaures Zinkoxyd; und dann ist diess Mineral deutlich körnig, dunkel perlgrau, auch von schönem Diamantglanz. Die Färbung scheint von fein eingemengter Zinkblende herzurühren, dena in Salpetersäure aufgelöst wird deutlich Schwefelwasserstoff entwickelt. Gewöhnlich ist das kohlensaure Zinkoxyd mit Thon und Kalkstein innig gemengt, und nur durch das spezifische Gewicht erkennbar. Kieselzinkspath findet sich seltener und zwar nur in Luszowice.

Bleiglanz kommt vergesellschaftet mit den Zink - Fossilien vor und ist in ihnen eingesprengt, oder bildet dünne Schichten, die sich gewöhnlich auskeilen, ohne auf längere Strecken auszuhalten. Krystallisirt habe ich den Bleiglanz nicht gesehen, sondern nur in einem deutlichen körnigen Zustande. Äusserst selten findet sich Vitriolbleierz in wasserhellen Krystallen (Cune if orme, Haur). In dem söhligen Kalkstein ist zuweilen Bleiglanz in kleinen Kugeln zerstreut, welche in ihrem Innern konzentrisches Gefüge wahrnehmen lassen.

d) Auf dem metallführenden Flötze liegt unmittelbar ein grauer feinkörniger Dolomit, deutlich geschichtet, und darauf folgt ein mächtiges Lager von mergeligem Kalksit. von braunlicher Farbe, aus dem sich blättrige Theile von Kalkspath ausscheiden; wodurch die ganze Masse in scharfkantige Stücke zertheilt wird. Durch Aufnahme von mehr Thontheilen wird das Gestein derb und durch die ganze Masse sind kleine Dendriten zerstreut. Die Mächtigkeit dieses obersten Lagers beträgt 20-30 Lachter, und an manchen Orten ist es durch viele Petrefakte charakterisirt. Vor Kurzem erhielt ich durch die Güte des Hrn. ЈАковошsкI aus Krzeszowice mehrere Knochen im Gestein eingewachsen, und Hr. Prof. Kozurowski hatte die Güte solche zu bestimmell. 
Nachfolgend die Bemerkungen meines gelehrten Freundes. „Es ist einigem $Z_{\text {weifel }}$ unterworfen, ob die mir zur Untersuchung zugeschickten versteinerten Kunchen dem Plesiosaurus angehören. Die drei ersten Knochenstücke stellen deutlich die Wirbelbeine dar. Ihre Grösse ist zwar gering, denn kaum gleichen sie einer Erbse, doch lassen sie' deutlich erkennen die Dornenfortsätze und ein jeder zwei Queerfortsätze. Zwei andere Knochenstücke sind etwas gebogen, den Rippeu am älılichsten, wie es scheint, in der Richtung der Länge des Thiers abgeflacht. Aus ihrer Grösse kann man urtheilen, dass sie demselben Geschöpfe angehörten, von dem die Wirbelbeine herkonmen. - Die andern zwei Knochenstücke scheinen längliche Knochen, vielleicht Finger- o!ler Zelien-Knochen zu seyn.

Einige andere, ancierswo gefundene, gehören zu den breiten und flachen Kuochen, und dem Verhältnisse ihrer Grösse nach scheinen sie nicht der nämlichen Thier-Gattung anzugehören, Die grösste Ähnlichkeit haben sie mit den Knochen eines Beckens.

Nach der Grösse der oben bemerkten Knochen urtheilend, kann man mit der grössten Wahrscheinlichkeit annehmeu, dass das Gerippe des ganzen Thiers niçht mehr als einen Fuss Länge hatte. - Die Bildung dieser Knochen scheint mir ganz anders zu seyn als die, welche wir bei Plesiosauren antreffen. Der Bau der Wirbelbeine stimmt nicht mit denen beim Plesiosaurus überein. Der Körper nämlich eines jeden Wirbelbeines ist rund, beinahe zylinderförmig; die Länge gleicht der Breite, Sein Bogen nimmt die ganze Länge des Wịrbels ein. Die Ränder des Körpers gehen allmählich in die Gelenkflächen über, die von einer Seite konvex, von der andern konkav erscheinen. - An den Körper der Wirbelbeine sieht nan von den Seiten keine ovale Gelenk-Flächen zum Ansatz der Rippen. Die Queerfortsätze erheben sich nicht sehräg in die Höhe, sondern sie erstrecken sich mehr horizontal seitwärts, und sie machen die grösste Breite der Wirbclbeine aus. Der Dornenfortsatz ist so klein, dass er nur wie eine crista erscheint. Indem man diesen Bau genau berücksichtigt, seheint es, dass die Krochen durchaus nicht dem Plesiosaurus angeliören können. Andrerseits aber geräth man wieder in einen Zweifel, demn die zwei oben erwähuten Rippen sind unten etwas stumpf, und es scheint, als wenn sie mit BauchRippen viclleicht artikulirten, wie das bei den Plesiosauren seyn sollte. Abec wiederum ein Widerspruch: denn das andere Ende der Rippe ist stumpf abgeschnitten, nicht gespalten. - Die Zehenglieder bei Plesiosaurus sind kurz: die aber, welche ich vor mir habe, sind bedeutend länger und scheinen von gut ausgebildeten Zehen herzukommen. Wegen Mangrels der. Schädelknochen und anderer von demselben Thier ist es äusserst schwer die Gattung zu bestinmen, zu welchem die Knochen gehören. Spätere Forschungen werden das vielleicht ermitteln lassen."

Zeuschner. 
An Bord der Gölette Enrichetta, 17. Jănner 1836.

Nuw habe ich zwar noch nicht von Europa überhaupt, da ich nach Athen reise, bevor ich nach Alexandria schiffe, aber doch in jeden Sinne von meinem Vaterlande Abschied genonmen. Ich schreibe Ihnen gegenwärtig am Bord der Östreichischen Gülette Enrichetta auf der Höhe vou Polu, der Spitze Istriens. Meine Reise vou Wien nach Triest musste schnell geschehen, daher ich auch in naturwissenschafticher Beziehung wenig unternehmen konnte. Ich habe mich in Wien mit herrlichen Instrumenten ausgerüstet, worunter einige ganz neue befindlich sind, z. B. eine Art des elektrischen Multiplikators, um Temperaturen in Vertiefungen der Erde zu messen, ohne hinabzusteigen. Alle diese Instrumente werden mir, da ich, wie gesagt, den Umweg über Griechenland mache, von meinem hochgeehrten Freunde, dem H'n. Direktor Baumgarterer nachgesendet. In Adelsberg besuchte ich die berühmte Grotte. Sie ist in Betreff des Umfanges und der StalaktitenBildung mit Recht berühmt; sehr ekclte mich jedoch bei ihrem Besuche an, als ich bemerken musste, welche Mühe man sich gibt, allen interessanten Particen die gezwungensten Ähnlichkeiten unterzuschieben, um so das mit Gewalt auszuzeichnen, was schon an und für sich die Natur so gross, so wunderherrlich, so unübertrefflich gestaltet hat. Der Grottenführer zeigte mir'ein Exemplar des Prote us anguinus: es war lebend, $10 \mathrm{Zoll}$ lang und sehr gesund. Er bot es mir für 1 Gulden an. In der Höhle hatte man auch Knochen eines grossen Landthieres gefunden, die ich für Bärenknochen halte. Sehr interessant wäre eine genaue Untersuchung des ganzen Karstgebirges mit seinen Höhlen, warmen Quellen, periodischen See'n und Krater-ähnlichen Vertiefungen. Man sicht nur dichten Kalk, der, in welcher Schichtenfolge weiss ich nicht, Terebrateln, Hippuriten und $\mathrm{Nummuliten}$ führt. Von Triest aus, wo ich mich 15 Tage aufhielt, besuchte ich das wunderherrliche Venedig und ging über Treriso, Udine und Monfalcone wieder nach Triest zurück. Als ich von Optschina, auf der Höhe des Karstes, nach Triest herabsticg, beobachtete ich höchst interessante Schichtungen der Gebilde des Meeressandsteius und Meereskalks. Dieselłen bedecken hier den Fuss des Karstes: Kalkstein mit Terebrateln, Hippuriten und Nummuliten. Zuerst beobaclutete man den Meeressandstein gleich unterhalb Optschina in einer Meereshöhe von 1100 Wiener Fussen: er ist deutlich. und dünn geschichtet, zeigt in der Anordnung seiner Gesteinslagen grosse Regelmässigkeit und wechselt in dünnen Lagen nit Meereskalk. Weiter unterhalb wird die Schichtung sehr ungeregelt, die Gesteinslagen richten sich auf, stellen sich auf den Kopf, machen die manchfaltigsten wellenförmigen Biegungen, fallen gegen ihre früher beobachtete Stellung widersinnisch, bilden durch zunehmende Biegung förmliche Nester und wechseln nun, ausser mit Kalk, auch mit sehr düı. nen Thon- und Sand-Schichten. Von Versteinerungen sal, ich in diesen Gebilden nichts als die Reste heutiger See-Algen. Da die SchichtungsVerhältnisse dieses jungen Gebildes aus Mecres.Sandstein, Mecreskalk 
und Thon wirklich sehr interessant sind, so lege ich Ilınen einen Durchschnitt dieser Felsbildung ( $\mathbb{T f}, \mathbf{V}, \mathbf{F}_{\mathbf{g}}-\mathbf{b}$ ) aus zwei Standpunkten aufgenommen, bei. Diese Bildung gibt übrigens zu erkennen, dass das Adriatische Meer einst viel höher stand und sein Spiegel wenigstens bis Optschina, wenn nicht weiter hinauf reichte. Am 15. Nachts schiffte ich mich in Triest nach Patras in Griechenland ein, von wo ich nach Athen und von da nach Alexandria reise, wo ich bis Anfang März einzutreffen gedenke. Bei meiner Einschiffung in Hafen von Triest beobachtete ich höchst ausgezeichnet das Leuchten des Meeres. Die Nacht war sehr finster und warm. Das Boot, welches mich zur Gölette brachte, liess bei -jedem Ruderschlag einen langen feurigen Streifen hinter sich, und eine ähnliche, noch schönere Erscheinung brachte jeder Ruderschlag selbst hervor, indem sowohl beim Ein-als Auftauchen des Ruders das Meer förmlich Funken sprühte, was, so viel ich bemerken konnte, vorzüglich von den Luftblasen herrübrte, die sich dabei im Meere bildeten, und von denen sich jede als ein leuchtendes Kügelchen darstellte. Das Ganze war eine wirklich schöne, herrliche Naturerscheinung, und ich bedauerte nur, kein Thermometer bei der Hand gehabt zu haben, um Luft- und Meeres-Temperatur zu untersuchen. Am Tage darauf war grosse Windstille. Die See, ruhig und glatt wie ein Spiegel, prangte im herrlichsten, ihr eigenthümlichen, grünlichen Blaue. In der Ferne sahen wir die Julischen Alpen mit ihrem schneebedeckten Terglou; ein Anblick, der gewissermassen eine Sehnsucht nach der Heimath in mir erregte, die ich nicht unterdrücken konnte, und die besonders Hochländer in jenen Jahren um so leichter befällt, in denen das Herz noch ganz seine Rechte ausübt. - Nachträglich zu meinen Durchschnitten über die Ablagerung des Meeres-Kalkes und Meeres-Sandsteins bei Optschina kann ich nicht umhin, die Ansicht zu äussern, dass mir bei dem Ánblicke der Biegungen und Krümmungen der Schichten dieser Felsgebilde scheint, dass weder Emporhebung noch eine andere Ursache von unten auf wirkend daran Antheil hatte, sondern diess rein nur Folge des Wellenschlags und Wogenspiegels des Meeres war. Ich kann vor der Hand die Richtigkeit dieser Behauptung noch nicht nachweisen, werde mich aber bemühen diess zu thun, und mache vor der Hand nur darauf aufmerksam, indem vielleicht wichtige Folgen sich daraus ergeben können. In der Nacht vom 19. auf den 20. d. M. (heute am 21. auf der Höhe von Durazzo im Türkischen Albanien) hatte ich Gelegenheit, das Leuchten des Meeres während eines heftigen Sturmes wiederholt zu beobach. ten. Es fing um 9 Uhr eine halbe Stunde vor Ausbruch des Sturmes an, indem sich einzelne Funken an Vorder- und Hinter-Theilc des Schiffes zeigten, wo die Reibung zwischen Schiff und Meer am stärksten ist. Dieser Funken wurden nach und nach mehr, endlich zeigten sie sich auch im Momente der Schaumbildung entfernterer Wellen, schwammen sichtbar eine Strecke in und auf dem Meere fort und verschwanden dann. Als der Wogen-Andrang und der Wellenschlag während des Sturmes so heftig wurden, dass das ganze Mcer un das Schiff mit Schaum 
bedeckt war, leuchtete auch dieser, nur nicht so anhaltend, als die grössern, deutlich mitten in ihm sichtbaren, leuclitenden Punkte, die ihr gelblichweisses Licht noch weit ausser dem Bereiche des Wogenschaums beibehielten. In Momente des grössten Sturms war das Schiff wie von einem Feuermeer umgeben, jede Woge war die Quelle eines funkelnden Lichtstroms. Der Sturm kam aus Nordost und die Nacht war warm. Ich konute von keinem Thermometer Gebrauch machen, denn der Sturm war so heftig, dass man keinen Augenblick aufrecht stehen kounte, und dass in Verlaufe der Nacht beinahe die ganze Scliffs-Equipage, Passagiere wie Matrosen, selbst solche, die schon sehr viel zur See waren, seekrank wurden. Ich kann, das Detail des Geseheneu berücksichtigend, unmöglich jenen beipflichten, die die Ursache dieser Erscheinung in leuchtenden Thierchen, in der Phosphoreszenz von See-Algen etc. suchen, sondern bin vielmehr nachstehender Ansicht. Die Erscheinung ist eine rein elektrische. Gewisse Verhältnisse, Statt findend zwischen Luft und Wasser (der Erfahrung zur Folge besonders bei oder vor Sturm und während südlichen Winden) bedingen einen elektrischen Zustand des letztern, der, befördert durch die Reibung des Schiffes mit dem Wasser und des letztcrn unter sich, eine Lichtentwicklung hervorbringt, die mit Entstehung der Luftblasen durch die Reibung enge verknuipft ist und selbe während der Dauer ihrer Existenz begleitet. Ich halte daher alle jene leuchtenden Punkte, so wie den leuchtenden Srhaum selbst für nichts anders, als Luftblasen, leuchtend geworden durch die aus dem Wasser sich mittelst der Reibung entwickelt habenden Elektrizität. Dass auch das aufgefangene Wasser leuchtet, wenn man es wieder umrührt, ist Folge derselben Ursache; denn es findet nur Statt, wenn das Experiment sogleich geschieht; lässt inan hingegen das aufgefangene Wasser eine Weile stehen und so sich wieder in einen andern elektrischen Zustand versetzen, so hört auch die Leuchtungs-Fäligkeit auf. Dieses leuchtende Fluidum, oder wie ich es neunen soll, hängt auch Körpern an, die im Meere sich befinden, wäh. rend es in diesem Zustande ist, z. B. Pudern, Jnfusorien u. s. w. lch freue mich, darüber mehr zu beobachten. Sehr interessant wäre es zu wissen, ob und welchen Einfluss Schiffsbeschläge aut diese Erscheinung haben.

An 26. Januar.

In Corfu, den Regierungssitz der Jonischen Inseln, wo die Hauptstadt mit ihrer Umgebung am Fusse der Englischen Festungen, die ganz den Stempel des üppigen, vollen Südens an sich trägt, einen so herrlichen Anblick gewährt, konnte ich leider gar nichts unternehmen, weil ich, als von Triest kommend, wo die Cholera seyn sollte, wovon aber Niemand daselbst etwas weiss, nicht aus der Kontumaz durfte.

Patras am 2. Februar.

Endlich bin ich in Patras angelangt, nachdem wir von Corfu aus widriger Winde wegen, statt 2 Tage, in denen man gewöhnlich die 
Reise zurücklegt, 8 Tage gebraucht haben. Wir segelten am Sta. Maura (wo am Kap Dukato der Leukadische Felsen sich befindet), an Theaki (Ithaka) und Cephalonia vorüber, sahen die Insel Zante mit dem schönen Monte Scopo, bielten uns heftigen Sturms halber 3 Tage im Hafen der Insel Petala auf und betrachteten lange das im Griechischen Freiheitskampfe so berühmt gewordene, unglückliche Messolonghi. Auf der Insel Petala ging ich zweimal ans Land. Sie, so wie die unliegenden kleineren Inseln bestehen aus einem weissen, dichten Kalkstein, der stellenweise Neigung zur krystallinischen Struktur zeigt. Über seine Stellung kann ich gegenwärtig gar nichts sagen; denn ich fand in der Nähe kein anderes Gestein, was einen Fingerzeig geben könnte, auch fand ich im Kalksteine keine Versteinerungen; jedoch scheint er mir ein jugendliches Gebilde zu seyn.

Am 30. Jänner fand ich auf Petala blühend: Arum dracunculus, 4 Arten Aspidium aus dem südlichen Europa, Am ygdalus persica, Hyacinthus, Ornithogalum, Cheiranthus Cheiri, Ranunculus calthaefolius, Citisus u. s. w. Vorherrschend sind Genista corsica, Olea europea, Phlomis fruticosa, Scilla maritima und eine prächtige baumartige Euphorbia. Mich begleitet als Botaniker von Seite des Wiener Naturalien. Kabinets, Theodor Keтschi, ein kenntnissvoller junger Mann, der voll Eifer für die Wissenschaft sich entschloss, als Mineur der Expedition zugetheilt zu werden. So viel mir die stürmische See erlaubte, machte ich Beobachtungen über die Temperatur des Meeres und fand: Luft-Temperatur $=\mathrm{T}$, und MeerTemperatur $=\mathrm{t}$ gesetzt, am :

22. Jänner. Höhe von Albanien 11 Uhr V. $\mathrm{T}=+9,3 ; \mathrm{t}=+10$

$\begin{array}{rrr}3 & \text { "N. } \mathbf{T}=+9,8 ; \mathrm{t}=+10,3 \\ \text { 23. Jänner. Höhe von Corfu } 11, \mathrm{~V} \cdot \mathrm{T}=+8,2 ; \mathrm{t}=+10,3\end{array}$

3 "N. $\mathrm{T}=+9,3 ; \mathrm{t}=+10,7$

24. Jänner. Hafen von Corfu 1 , $\mathrm{N}$. $\mathrm{T}=+10,0 ; \mathrm{t}=+7,7$

5 " $\mathrm{N}$. $\mathrm{T}=+9,0 ; \mathrm{t}=+8,0$

25. " " " $\quad 11$ " V. $\mathrm{T}=+8,3 ; \mathrm{t}=+\mathrm{7,2}$

3 "N. $\mathbf{T}=+9,6 ; \mathrm{t}=+7,6$

26. "Höhe von St. Manura 11 ," V. $\mathbf{T}=+8,8 ; \mathrm{t}=+\mathbf{7 . 2}$

3. "N. $\mathrm{T}=+9,6 ; \mathrm{t}=+7,8$

27. " " " " 11 " V. $\mathbf{T}=+12,0 ; \mathrm{t}=+11,1$

3 "N. $\mathrm{T}=+12,8 ; \mathrm{t}=+11,0$

28. "Zwischen Maura u.

Cephalonic . 11 " V. $\mathbf{T}=+8,9 ; \mathrm{t}=+10,0$

3 "N. $\mathrm{T}=+9,3: \mathrm{t}=+11,1$

29. Jïnn. Höhe des Kap Scrophes 11 "V. $T=+\varepsilon, 6 ; t=+10,3$

3 "N. $\mathrm{T}=+10,0 ; \mathrm{t}=+11,2$

2. Febr. Höhe von Messulonghi 11 "V. $\mathbf{T}=+7.4:+=+10,2$

3 "N. $\mathbf{T}=+9, j ; 1=+11,8$ 
Durchgehends zeigte sich das Meer beträchilich wärmer, ausgenomhuen im Hafen von Corfu und bei Sta. Mauru, wo vielleicht Strömungen, die daselbst Statt finden, die Abweichung bedingen.

Auf Petala, wo die dortigen Schafhirten ihr Feuer mit Lorbeerzweigen unterhielten, was sehr idillisch gelassen hätte, wäre das Ausschen der Hirten nicht so lumpig, und gäben ihre langen Messer und Pistolen nicht. ein mehr räuberisches als hirtenmässiges Ansehen, sahen wir Pelikane, weisse Störche und Lämmergeyer und ausser diesen eine Menge verschiedener Enten, wareu aber nur so glücklich, einen Storch und einige Enten zu erlegen.

Auf den Bergen um Messolonghi und Patrass, die, wie ich sie schätze, theilweise $6000^{\prime} \boldsymbol{P}$. Höhe vom Meere aus erreichen, liegt tiefer Schnee, währrnd auf den Ebenen und Inseln Alles grünt und die Früblings - Pflanzen schon ihre Prachtkleider anziehen. Dieser Kontrast ist wirklich bezaubernd schön und macht besonders auf uns Nordländer einen tiefen Eindruck; denn es ist eine uns überraschende Verbindung der südlichen Pracht mit dem Holien, Ernsten, wahrhaft Grossen unserer heimathlichen Gebirge. Beiliegend meine Adresse. In einigen Tagen reise ich von hier zur See, da der Landreise wichtige Hindernisse entgegenstehen, nach dem Isthmus von Korynth und von da nach Athen. Anfaugs März hoffe ich in Ägypten einzutreffen.

Russegger.

\section{Neapel, 31. Januar 1836.}

Seit läıger als einem Monate bin ich zurück von meiner Reise nach Sizilien und Kalabrien. Wäre ich nicht seitdem bedeutend un. wohl gewesen, Sie würden keineswegs bis jetzt auf Briefe von mir gewartet haben.

Auf Sizilien beschäftigte mich fast ausschliesslich die Untersuchung des Ätna. Die Thatsachen, welche ich zu beobachten Gelegenheit fand, stellte ich in einer Ablıandlurg zusammen, die von mir in einer Sitzung der Accadenia Givenice zu Catunia vorgetragen wurde. In nächsten Bande der Schriften dieser Gesellschaft wird mein Aufsatz gedruckt erscheinen; er führt den Titel: Parallelo tra $i$ tre Volcani ardenti delle sicilié.

Kulabrien untersuchte ich mit besonderer Sorgfalt. Es bot sich nir zu nicht wenigen interessanten Beobachtungen Stoff, namentlich zu solchen, welche vielleicht gewisse noch zweifelhafte geologische Fragen werden aufklären helfen. So glaube ichu. a., die e $n$ ts $c$ heidendsten Beweise gefunden zu haben, dass der Granit ein Erzeugniss des Feuers, "nd dass diescs Gestein nur durch Emportreibungen aus der Tiefe an der Erdoberfläche erschienen 


\section{8}

ist. Über beide Punkte war ich, ich gestehe es Ihnen offen, früher noch immer zweifelhaft. Ich schreibe Ihnen nächstens ausführlicher über diese Materie.

L. Pilla.

\section{Clermont-Ferrand, 17. Februar 1836.}

Ihre Ansichten über den plutonischen Ursprung des körnigen Kalkes, welche Sie mir vor einiger Zeit mittheilten, riefen mir Erscheinuıgen ins Gedächtniss, welche ich vor längerer Zeit zu Chalvignac unfern Mauriac (Cantal) gesehen. Es ist diess die Lagerstätte von körnigem Kalke, deren DuFrÉxoy in den Mlémoires pour servir à une description géol. de la Fr., T. I, $p$. 271 gedenkt. Mein Tagebuch enthält Folgendes: der Gang von körnigem Kalk, durch Steinbruchbau aufgeschlossen, scheint anzudeuten, dass jenes Grestein im feurig-flüssigen Zustande durch Glimmerschiefer und Gneisse hindurch emporgedrungen ist. Eine Speckstein-ähnliche Lage trennt den Kalk vom Gneiss; die Beschaffenheit der letztern Gebirgsart deutet auf erlittene Änderungen hin u. s. w.

\section{Peghoux.}

Athen, 23. Febr. 1836.

Sie erhielten mit meinem letzten Brief einen Durchschnitt der Sandstein-Auflagerungen, wechseInd mit dichtem Kalkstein und Thon, zwischeu Optschina und Triest. Ich benannte diese Auflagerungen MeeresSandstein und Meereskalk, da sie nicht nur den Stempel junger FelsGebilde im Betreff ihrer Struktur im Kleinen an sich tragen, sondern auch ihr Habitus im Grossen auf ihren Ursprung aus Meeresfluthen hindeutet. Da ich jedoch auf der Reise hieher hinlänglich Gelegenheit hatte, an den Küsten von Griechenland jene Gebilde kennen zu lernen, welche der Greognost eigentlich unter dem Namen junger Meeressandstein und Meereskalk begreift, so kann ich nicht umhin zu bemerken, dass jene Felsgebilde mit diesen in keine Kategorie zu setzen sind. Nicht der Umstand, dass man ausser See-Algen in dem Triestiner Sandstein keine Versteinerungen trifft, wenigstens mir sind keine bekannt, ist das Kriterium dieses Unterschieds; denn mir sind auch Ablagerungen der jüngsten Meeres-Gebilde bekannt, die ganz und gar Versteinerungslos sind: sondern besonders sind es die feinkörnige Struktur, das innige Gemenge der Theile, und vorzüglich die Höhe, zu welcher die Triestiner Fels-Gebilde emporsteigen, die sie als interessante Bildungen der Meeresfiuthen auszeichnen. Auf meiner Reise hieher hatte ich oft Grelegenheit, die Küsten des Meerbusens von Lepanto, zwischen Morea 
und Rumili, näher zu betrachten und fand: beinahe überall, besonders aber in der Nähe des Isthmus von Korinth, bilden junger Mecressandstein, junger Meereskalk und Meeressand das Küstengestein und steigen bis zu-Höhen von $300^{\prime}$ empor. Häufig führen diese Felsgebilde Versteinerungen und zwar die in den anliegenden Meeren noch lebenden Konchylien-Arten. Sehr oft wechselt der Meeressandstein mit Muschelbänken, Ablagerungen von grösstentheils sehr gut erhaltenen Meeres-Konchylien, verbunden durch ein kalkig sandiges Zäment. Merkwürdig ist es, dass, z. B. zwischen Lutrachi und Kalimathi auf dem Isthnus, der eigentliche Meeressandstein, dort wo er mit Muschelbänken wechselt, nur sehr wenige oder gar keine Versteinerungen enthält. Solche versteinerungslose Bänke sicht man oft von der Müchtigkeit mehrerer Klafter. In dem auf Meeressandstein liegenden Konchylienführenden Meeressand fand ich bei Korinth auch eine alte Lampe von Thon, dem Ansehen nach aus der Zeit des Aufenthaltes der Römer in Griechenland. Der Sandstein besteht aus Kalkstein., Hornstein-, Jaspisund Grünsandsicin-Geschieben von verschiedener Grösse, durch ein kalkiges Züment zu einer festen Masse verbunden. Die Versteinerungen sind, wie gesagt, meistens schr gut erhalten. Der Meeressandstein umschliesst viele kleine Höhlen, die jedoch durch ihre Form und durch den Umstand, dass sie einen gewissen Horizont nicht übersteigen, offenbar ihren Ursprung durch die Einwirkung der Meeresbrandung zu erkennen geben. Man bemerkt diese Höhlen bis zu einer Höhe von $200^{\prime}$ über dem gegenwärtigen Seespiegel. Was das ältere Gebirge der Küste Griechenlands im erwähnten Terrain betrifft, so glaube ich, von Patras bis zum Isthmus, sowohl auf Morea als in Rumili nachstehende Folge nachwei-

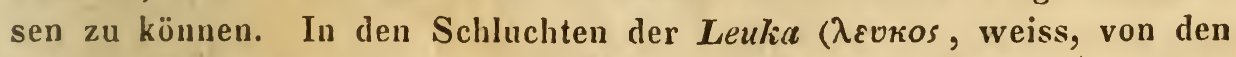
weissen Kalk - Geschieben) bei Patras, fand ich als Grundlage rothen Sandstein mit Einlagerungen von rothem, grünem, blauem und weissem Hornstein und Jaspis, welche hie und da so häufig werden, dass sie den Sandstein ganz verdrängen und ihn zu vertreten scheinen. Diesen rothen Sandstein fand ich wieder in den Bergen am Schlosse Rumili, in Lepanto und in Trisonic in Rumelien. Auf diesem Sandstein, oder dem ihn vertretenden Hornstein, wie bei Akrokorinth, liegt dichter Kalkstein, meistens weiss, doch auch bunt gefärbt, häufige, nierenförmige Einlagerungen von Jaspis und mitunter auch Feuerstein enthaltend, die sich oft mit scheinbar gangartigem Verhalten durch bedeutende Strecken fortzichen und in diesem Falle aus sich aneinander reihenden Linsen bestehen. Versteinerungen sah ich in diesem Kalksteine keine. Er bildet die nächsten Berge an der Nord- und Süd-Küste des Meerbusens von Lepanto, und ich möchte ihn dem Erwähnten und dem Folgenden gemäss der untern oder alten Kreide zurechnen.

Auf diesem Kalkstein fand ich, namentlich bei Lepanto, grünen versteinerungslosen Sandstein liegen, dessen Verhältnisse ich jedoch nicht näher untersuchen konnte. In dem darunter liegenden dichten Kalkstein entspringen bei Lukrati warme Quellen, deren Temperatur 
$+26^{\circ} \mathrm{R}$. bei einer Luft-Temperatnr von $+11,4^{\circ} \mathrm{R}$. betrug. Das Wasser der Quellen hat einen salzigen Geschmack und entwickelt ctwas hydrothionsauren Geruch. Geschmack und niedere Temperatur dürften wohl vom beigemengten Meereswasser herrühren. Im Bezug auf das Leuchten des Meeres hatte ich Gelegenheit Beobachtungen zu machen, die mir darthun, dass meine früher geäusserte Ansicht bei Weitem nicht auf alle Fälle anwendbar ist, denu in einigen Häfen, wamentlich Lepranto und Trisona, fand ich ganz bestimmt, dass das Leuchter des Meeres die Folge der Phosphoreszenz verschiedener Schleimthiere, be- sonders Medusen, war, welche Thiere wir auch fiengen und die erwähnte Eigenschaft an innen mit Musse beobachteten. Eine zweite interessante Phosphoreszenz bemerkte ich einmal des Nachts am Ankertau unserer Gölette. Dasselbe war vom Seewasser nass, und so oft man es mit dem Finger strich, entwickelte sich intensiver Glanz eines weisslich gelben Lichtes. Geschah das Streichen hingegen mit einem Metall, so erfolgte nichts. Sehr leid war mir, dass ich dic schünen Porphyre und Trachyte der Insel Egina nicht näher untersuchen konnte. In 8 Tagen beiläufig reise ich auf der Üstreichischen Kriegs-Korvette Veloce nach Ägypten.

\section{Russegger.}

\section{Aarau, 8. März 1836.}

In Luzern habe ich in der Nager'schen Sammlung ein Fossil gefunden, das, wie ich glaube, noch nicht bekannt geworden. Es kommt in selir kleinen auf Adular aufgewachsenen, beinahe schneeweissen, Krystallen von starkem Glasglanze vor. Ich kounte denselben auch mit dem Vergrösserungsglase nicht so viele Flächen abgewinnen, dass ich daraus die Krystallisation hätte konstruiren können. Es ritzt den Kalkspath. Eine vollständigere Charakteristik hoffe ich Ihnen später mittheilen zu können, in so fern ich dieses Jahr meine Reise realisiren kann.

\section{WANGER。}

\section{Giesen, 9. März 1836.}

Da Sie das Münzenberger Molasse-Gebiet in der Wetteran kennen, so interessirt es Sie wohl zu, erfahren, dass ich darin jüngsthin verschiedene Süsswasser - Konchylien auffand, welche der Gattung U n i o angehören. In der äitern Grauwacke des Schneeberges bei Gladenbach finden sich einige an Versteinerungen sehr reiche Schichten. Am frequentesten erscheinen verschiedene Arten von $D$ e I th y $\mathrm{r}$ is, besonders macroptera, so wie von Terebratula und Orthocera etc. Auch fand sicli dort das noch nicht gar lange durch Graf MüNster bestimınte Plenrodictium problematicum nicht selten. 
Die Lagerstätte der Zinnobererze bei Gladenbach ist mir jetzt auch etwas näher bekannt geworden. Sie finden sich in dem häufig in eine hornsteinartige Masse übergehenden Kieselschiefer des jüngern Thonschiefers, welcher hier eine mäclitige Mulde im älteren GrauwackenGebirge auszufüllen scheint. Kieselschiefer, schwarze plattenförmige Kulksteine und Thonschiefer setzen in starkem Wechsel die Formation zusammen. Über einige in Gebiet des Schiefer-Gebirges dieser Gegenden zum Vorschein kommende, ausgezeichnete Syenite werde ich Ihnen demuächst etwas Näheres mittheilen.

\section{A. v. Klipstein.}

\section{Stuttgav't, 17. März 1836.}

Das Bohrloch, welches Graf v. MandeusLohé bei Neufen auf Liaskohle niederschlagen liess, ist, wie er mir erzählte, jetzt $980^{\prime}$ tief, immer in Liasschiefer, das letzte Bohrmehl hatte grauen Schiefer mit Belemniten-Resten, stets ohne Wasser: ein Beweiss, dass sich die Filder von Degerloch bis an die Alp bedeutend gehoben haben.

Der Mytilus amplus, Repräsentant des Portlandstone, wurde nun auch bei Wasseralfingen gefunden, v. Mandecscoup fand den Portlandstone schon an zehn Orten auf der $\boldsymbol{A l p}$.

HEHL.

\section{Tharandt, 17. März 1836.}

Ich sende Ihnen hier das Verzeichniss derjenigen Subscribenten, welche sich ferner zur Unterstützung der Untersuchungen über die Alters-Verhältnisse zwischen Granit und Kreide in Sachsen gefunden haben *):

Zahl der

Aktien.

Sr. Königl. Hoheit Prinz-Mitregent Friedrich August, Herzog zu Sachsen . . • . • . • . • . 15

Sr. Königl. Hoheit Prinz Johans, Herzog zu Sachsen . $\quad 15$

Herr Geheimerrath und Oberhofmeister v. MiLtitz in Dresden 5

" Prof. Carl Naumani in Freiberg . . . . . 2

"Prof. Breithaupt in Freiberg .. . . . . . . . 1

" Bergmeister v. Weissfenвach in Freiberg. . . . 2

"Bergamts-Assessor v. Beust in Freiberg. . . . 1

"Oberstollen-Faktor v. WArssdonfF in Freiberg . . 1

"Friedricr Peri aus Glaubitz . . . . . . 1

"Oberberghauptmann v. VeLthem in Berlin . . . 5

*) S. oben S. 14 ff. 
Herr Gel. Oberbergrath KaRsten in Berlin

"Geh. Bergrath v. Dechen in Berlin.

In Dresden zirkulirt die Aufforderung noch, desshalb konnten hier noch nicht alle Unterschriften von da nachgetragen werden. Die Untersuchungs - Arbeitcn begiune ich nun mit dem nächsten günstigen Frülsjahrs - Wetter.

\section{Bernhard Cotta.}

\section{Bern, 3. Mai 1836.}

Escrier und ich entwarfen gemeinschaftlich eine geologische Karte und melirere Profile über einen Theil von Bündten. Der Text beschäftigt mich gegenwärtig. Escher wird dieser Arbeit die ihm eigenthümliche Untersuchung über Glarus anschliessen. Später wollen wir sodanı den, schon so oft von mir durchreisten, und dieses Jahr wieder zu besuchenden südlichen Theil von Bündten folgen lassen. Auf solche Weise wird es uns müglich werden, nach und nach ein breites Profil durch die ganze Kette vom Bodensee bis.Mailand zu führen. Die Neuchateler lassen nächstens den I. Band ihrer Memoiren erscheinen. Sie finden darin die Abhandlung von Montmontiv über die Kreide und mehrere Aufsütze von Agassiz. - Wanger's unglückliches Ende kàn Ihnen kaum bekannt geworden seyn. Von einer Reise heimkehrend fuhr er mit dem Eilwagen Nachts in einer Fähre über die Aar. Durch das Scheuwerden der Pferde wurde die Führe auf einer Seite hinuntergedrückt; der Eilwagen und ein grosser Güterwagen stürzten ins Wasser, 
das Schiff über șic, und ungeachtet schneller Hülfe verloren dennoch vier Personen das Leben, unter ihnen der arme WaNger.

\section{B. Studer.}

\section{Irakau, 31. Mai 1336.}

Sie erhalten hier meinen Bericht über die im verflossenen Sommer ausgeführte Kurpathen - Reise. Meine Reise ging über Saçz (Sontsch), Gorlice, Jasto, Dynow nach Jurowce; von da wandte ich mich in das San-Thal und durchschnitt das Stonne-Gebirge von Mrzyglód über Leszczawka nach Dobromil (welches sich am Flusse San von Süden nach Norden zieht, und bei der Stadt Sanok anfängt, bei Dubiczlio aber endigt). Aus Dobromil wandte ich mich nach Sambor und Drohobycz und bestieg von da die hohen Karpathen gegen Kropiwnik, untersuchte entlang dem Flusse Stryi das Gebirge bis Synowuzlio: von da machte ich einen Abstecher zu den Eisenbergwerken von Skole, besuchte ferner Bolechów und Dolina, und ging über Zurawno nach Lenberg. - Dieser bereiste Theil der Kcrpathen ist ein undaukbares Gebirge für den Geognosten: man indet nur den ewigen KarpathenSandstein, an Modifikationen und Eigenthümlichkeiten arm: graue Sandsteine von feinerem und gröberem Korne mit untergeordneten Lagern von Suhieferthon, der öfters in Thonschiefer überzugehen scheint, ist sein steter, an allen Punkten gleicher Charakter. - Auf der ganzen Reise fand ich keine Petrefakten in diesem Sandsteine, ausgenommen Fucoides Targionii, der an vielen Punkten sich zeigt und darum die charakteristische Versteinerung des Karpathen - Sandsteins bildet. - Seine Schichten sind in der Regel S.W. geneigt, unter einem verschiedenen Winkel; ausuahmsweise nimmt er eine gerade entgegengesetzte Richtung, dic vom Lmkippen herrührt, welches bei der allgemeinen Hebung, die von Norden wirkte, Statt fand. Aber sie finden sich auch gebogen und gewunden auf manchfaltige Art, und ein recht merkwürdiger Punkt findet sich in Berge Trepczanska-Gora am San-Flusse, dem Dorfe Micdzybrody gegenüher, das eise Meile von Sanok entfernt liegt. Die Schichten sind gebogen in ganz entgegengesetzten Richtungen, auf den Kopf gestellt und gebrochen. Die beigefügte Zeichnung gibt Ihnen ein Bild davon ('Tf. V, Fg. $2 *$ ).

Als untergeordnete, den Karpathen-Sandstein eigenthümliche, Felsart, betrachte ich die lichtgrauen schiefrigen Kalkmergel nit vielen Fucoiden-Abdrücken, die als mächtige Lager hervortreten. - Ich will sie aufzählen, in dem ich mit den westlichen anfange.

1) In Dorfe Rybie, das mitten in den Bieskirlen liegt, etwa 5 Meilen von Wieliczka entfernt, tritt dieser Kalkmergel in zwei parallelen

") Durch ein Verselien ist diese Zeichnung oben zn Hrn. Kessegaen's vorletztem Bricf zitirt wordeu.

D. $\mathrm{R}$. 
Lagern, von denen das nähere bei Wieliczka etwa $100 \mathrm{~F}$., das zweite entferntere mehr als 1000 F. mächtig ist. - Sie haben S.W. 11- 10 Einfallen unter $15^{\circ}$. Das erste besteht aus schieferigem Kalkmergel; das andere zeigt mehrere Verschiedenheiten, als Sohle hat es blutrothen Mergel, der sich in Kalkmergel unbildet: seine Farbe verliert an Röthe und wird grünlichgrau. Stellenweise sondern sich Schichten von reinem Kalkstein, seitener Kieselschiefer aus. - Fucoides Targionii findet sich auf den Absonderungen in grosser Menge. - Diess Gestein verwittert leicht an der Luft und zerfälit in eine unendliche Menge kleiner scharfkantiger Stücke, und man erkennt aus der Ferne, dass hier kein Sandstein sich befindet. - Im Dorfe Kamionna, nürdlich von Rybie, zielıt sich derselbe Kalkmergelzug ins Gebirge hinein. - Ich muss noch eines merkwürdigen untergeordneten Lagers in Karpathen-Sandstein in demselben Dorfe erwähnen; es sind nämlich in den thonigen Schichten dem Sandsteine untergeordnete Blöcke von ziemlicher Grösse, 5-8 Fuss im Durchmesser, ganz zugerundet, aus dichtem, grauem Kalkstein, ziemlich reich an Petrefakten, hesonders an Terebrateln: er hat grosse Ähnlichkeit mit dem grauen Kalkstein des Tatra.

2) Bei Labowa, im Thale der Kamienica, zwei Meilen von Saçz ist ein kleines 100 Fuss mächtiges Lager von Kalkmergel in Karpathen-Sandsteine. - Die Schichten sind ziemlich dick und mit vielen Kalkspath-Adern durchzogen, und fallen S.W. 9 unter $20^{\circ}$, also entsprechend dem allgemeinen Fallen des Karpathen-Sandsteins.

3) Auf der Chaussée zwischen $\boldsymbol{S a c ̧ z ~ u n d ~ G o r l i c e , ~ z w i s c h e n ~ d e n ~}$ Dörfern Paszyn und Strzylawka deckt der untenfliessende Gebirgsbach ein Lager von rothem Mergel auf, der etwas weiter mit grüngefärbten abwechselnde Schichten bildet.

4) Bei dem Dorfe Wapowce, eine Meile von Przemysl entfernt, ragen am San sehr mächtige Felsen empor von lichtgrauem schieferigen Kalkmergel, ungefähr $6000^{\prime}$ stark, der deutlich zwischen Karpathen-Sandstein eingelagert erscheint. Wo sich die Schieferung verliert, da werden die Schichten dicker, -und sind gewöbnlich dichter Kalkstein. - Auf den Schieferungs - Flächen ist eine unendliche Menge von Fucoides Targionii. Die Schichten sind westlich, unter einen Winkel von $60^{\circ}$ grneigt. Mit den Mergeln von Wapowce stehen ähnliche Gesteine in Verbindung, sic können als Verlängerung angesehen werden, nämlich in den Waldungen von Kniazyce; die ein ähnliches Einfallen unter $75^{\circ}$ zeigen.

5) Der hohe über den Stryi-Fluss hervorragende Felsen von Kropiwnik, einem Dorfe in Samborer Kreise, worauf ein schönes Wohnhaus erbaut ist, besteht aus einem Lager dieses lichtgrauen MergelSchiefers, der mitten im Karpathen-Sandstcin eingelagert ist; seine Schichten fallen ebenfalls S.W. 8 unter $65^{\circ}$ und haben in der Sohle braunen Schieferthon, darauf folgt weisser feinkörniger Sandstein, den brauner, fast schwarzer Hornstein bedeckt: dann folgen die lichtgrauen, öfters auch grünlichen Schiefermergel mit Fucoiden. Wenn die Schichten dieses 
Gesteins dicker sind, so ist gewühnlich in der Mitte Hornstein ausgesondert. - Die Mächtigkeit dieses Lagers beträgt efwa 200 Fuss.

6) Bei Jurowce, einem nahe bei Sanok gelegenen Dorfe, kommt Mergelschiefer mit einer anderen Farbe und verschiedenen Versteinerungen vor: er ist lichtbraun und gewöhnlich dickschiefrig: einige Schichten haben von 4-8 Fuss Mächtigkeit: stellenweise finden sich dunkelbraune Hornstein-Schichten ausgesondert, die mit Thon verbundene jaspisartige Gesteine hervorbringen; statt Fucoiden findet sich eine unendiche Menge Fisch-Schuppen, die aber zicmlich undeutlich sind: andere Ëberrestc sind mir nicht vorgekommen. - Gerieben riecht das Gestein bituminös. Die Jurowcoer Mergelschiefer sind ziemlich mächtig, beiläufig $2000 \mathrm{~F}$ : ihr Neigungswinkel ist dem allgemeinen des Karpathen-Sandsteins entgegengesetzt, nämlich N.O. 9-10 unter $65^{\circ}$. In den nördlich und südlich angränzenden Dörfern aber, bei Falijüuka und Pubiedna, sind die Karpathen-Sandstein-Schichten S.W. geneigt: es ist diess also ein partieller Bruch.

7) Ganz ähnliche lichtbraune Mergelschiefer mit Fisch-Schuppen sind nördlich von Jurouce im Dorfe Lubna bei Dynow. - Uber ihre Lagerung kann ich wenig sagen, inden sie stark mit Erde bedeckt sind, und nur hie und da zeigt sich etwas vom anstehenden Gesteine.

8) In derselben Gegend bei dem Dorfe Ulanice kommt ein Lager von kieseligen Gesteinen in Sandstein vor, welche als ein vortreffliches Material zum Strassenbau benutzt werden, und durch eiuen grossen Steinbruch aufgedeckt sind. Unter lichtbraunem Mergelschiefer kommen kirselige Gesteine vor, und zwar zuerst eine weisse auf den ersten Anblick Kreide-artige Felsart, die aber keine Kalktheile hat, denn sie besteht aus feinen, nicht zusammenhängenden Körnern von-weisscm Quarz; darunter folgt weisser feinkörniger Sandstein, der in den untern Schichten grau wird; dann wiederholt sich der weisse lose Quarz, mit strichweise ausgesondertem Kieselschiefer in den untern Abtheilungen; danu hommen dicke Schichten von brannem Sandstein, der schieferartig wird, und zuletzt in schwarzen Schieferthon übergeht; zu unterst folgen mächtige Schichten von Kieselschiefer mit schwarzen und braunen Farben in vielen Schattirungen, die öfters sehr gefällig aussehen. An einem etwas entfernteren Punte in derselben Schlucht ragen an Bache Felsen von dunkelbraunem Mergelschiefer, der in Schieferthon übergeht und durch Fisch-Schuppen charakterisirt ist. - Diese Mergelschiefer sind wahrscheinlich die Unterlage der hieseligen Gesteine. Diese verschiedenen Schichten siud ungeführ 200 Fuss mächtig, und neigen sich südlich unter $35^{\circ}$. Wenig mächtige Schichtrn von dunkeiund hell-braumen Itorustein, stets begleitet von weissem feinkürnigem Sandstein, finden sich an vielen Punkten in den östlichen Frarpathen mitten in Karpathen-Sandstein: und diess kann zum Theil als charakteristisches Kennzeichen der Formation angeselien werden. Ich hege keine Zweifel, dass die Eisensteine, die im gewöhnlichen FarpathenSandstein dïnne Schichten bilden, oder von braunen und graucu 
Hornsteinen begleitet werden, keine besondere Formation ausmachen, denn ihr Streichen und Fallen ist das des Sandsteines. Der Eistnstein ist ein derbes Fossil mit ebenem Bruche von blaulich grauer Farbe, zuwcilen auch gelblich. Durch Verwitterung wird er ganz schwarz, besonders auf Absonderungs - Flächen, was von Mangan herrührt; zugleich verliert er seine Festigkeit und ist leicht zerbrechlich; - seine Bestandtheile sind: kohlensaures Eisenoxydul und kohlensaure Kalkerde mit Thonerde gemengt, er ist also cine Art von thonigem Spliärosiderit. In einigen Abänderungen überwiegen die kalkigen Theile, in anderen dic thonigen, und somit entstehen zwei Arten. - In technischer Hinsicht sind diese Unterschiede wichtig, denn die kalkigen Abänderungen sind ergiebiger an Eisen, als die thonigen, die für gewöhnlich etwas mächtigere Schichten bilden. - Mit fremden Gemengtheilen ist der Eisenstein nicht verbunden, ausgenommen mit Schwefelkies, der in grösserer Mcuge angehäuft in manchen Lagern das Erz untauglich macht, wie z. B. das Eisensteinlager im Dorfe Imielnica. In den thonigen Eisensteinen finden sich angehäuft Abdrücke von Fucoides Targionii und cin anderer Fucoid, der wegen Unvollständigkeit nicht zu bestimmen war. - Sie liegen gewölnlich auf den Flächen der Schichtung. - Die Mächtigkeit der Eisensteinflötze ist gering, sie schwankt von 2-7 Zoll: diess habe ich beobachtet bei Kropiwnik, Sopotria, Skole, Korostiw. Gewöhnlich sind 2-3 parallele Eisensteinlager durch ein thoniges Mittel von 3-9 Fuss geschieden. Man hat sie wegen ihrer gêringen Mächtigkeit und steilen Einfallens als Gänge betrachtet; aber das ist ein Irrthum, denn alle Sandstein-Schichten fallen, wie die des Eisens, steil cin. Der Bergbau wird hier ohne System betrieben, man geht mit der Arbeit verschwenderisch um: nur ihre unglaubliche Wohlfeilheit erlaubt hier Eisen bei solcher Unwirthschaft zu produziren. - Herr ScHNEIDER $*$ trennt die kalkigen und thonigen Eisensteine und betrachtet sie als zwri Glieder: die ersten, gewöhnlich von Hornstein begleitet, haben eine etwas verschiedene Physiognomie von den thonigen; sowohl die ersten als die andern sind in Karpathen-Sandstein eingelagert un'd darum können keine Alters-Unterschiede festgesetzt werden. Bei Dobromil, am Fusse der Karpathen, tritt eine eigenthümliche Formation auf, durch unzählige Salzquellen charakterisirt, die vom Karpathen-Sandstein wohl getrennt $z u$ werden verdient, und darin stimme ich vollkommen mit Hrn. Schneider überein: - Ich will sie die Salz-Formation nennen. - Sie besteht aus abwechselnden Schichten von Kalkstein, Mergel, Hornstein, weissem und blaulichgrauem Sandstein: Gyps findet sich in der letzten Gebirgsart eingelagert und mit $\mathrm{ihm}$ die Kochsalzflötze. Ob deren mehrere vorhanden sind, lässt sich hier jetzt nicht entscheiden. Diese verschiedenen Schichten der Salzformation haben dasselbe Streichen und Einfallen wie der Karpathen-Sandstein, und da sie am Fusse des Gebirges erscheinen, sind sie bedeckt durch den südlich gelegenen,

*) Kanstex: Archiv für Mineralogíe, Geoguosie, Bergbau, VII. Band. 
das Gebirge bildenden Karpathen-Sandstein. - Unmittelbare Bedeckungen habe ich nicht wahrgenommen. Im vorjährigen Berichte schilderte ich dic verschiedenen Hornstein - artigen, kalkigen und mergeligen Gesteine der Salz-Formation von Szumina und starosol; vollkommen ähnliche Schichten fand ich jetzt bei der Salz-Coctur von Lacko, in der Nähe des anmuthigen Städtchens Dobromil, und hier sind auch dieselben verschiedenartigen Schichten S.W: geneigt. - Unter den Gesteinen von Szumina kommen weisse Sandsteine v̈or mit abwechselnden Lagern von braunem Schieferthon, der öfters für Thonschiefer könnte genommen werden. - Weiter gegen Osten von Dobromil nehmen die weissen Sandsteine an Bedeutung zu, bilden grössere Berge, und werden durch Lager (einige Lachter mächtig) von braunem Schieferthon begleitet. Bei Hoszów an der Chaussée zeigen sich ungeheure Wände dieses Sandsteins. - Eine eben so bedeutende Felsart der Salz-Formation macht der blaulichgraue Sandstein: in dem die deutlich unterscheidbaren Körner von Quarz durch blaulichen Thon zusammengekittet werden, der der Gebirgsart die Farbe gibt. Die dicken Schichten dieses Sandsteins werden undeutlich durch gewöhnliche Verwitterung. Öfters wechsellagert er mit blauem un! grauem Schiefertion, der meistens die Oberhand gewinnt; Fraueneis von wasserbellen und rothen Farben kommt eingesprengt im Sandstein vor, viel grössere Massen finden sich aber im Thone, wie u. a. bei Truskowiec. - An manchen Punkten bildet faseriger Gyps Schnüre, die diese Gesteine durchziehen. - Alle Salzthone, wozu diese gehören, haben nach der Beobachtung des Herrn BergKommissär RudorfF eingesprengte mikroskopische Schwefelkies - Krystalle, von welchen der Eisengehalt der Salzsohlen herrührt. Die Mächtigkeit der Salz-Formation ist schwer zu bestimmen: denn erstens wird diese Formation von aufgeschwemmtem Gebirge bedeckt, und zweitens sind die Gesteine sehr geneigt, sich zu zersetzen. Es gelang mir auf einem Durchschnitt, den ich aus Dolina nach Zurawno machte, das Salzgebirge in einer Strecke von vier Meilen zu beobachten und somit ungefähr seine Mächtigkeit zu ermitteln. Die Tour ging über folgende Dörfer: Stoboda, Troscianiec, Belejów, Turza wielka, Borynicz. Ich fand als seine Glieder: blauliche Sandsteine oder Schieferthon mit eingesprengtem Gyps. Welches Alter der Karpathischen Salz-Formation zugeschrieben werden darf, kann man jetzt, wie ich glaube, nicht mit Bestimmtheit angeben; die Petrefakten, die sich ziemlich häufig bei Niebylow, Kniazdwor und Perehinsk nach dem Zeugnisse des Hrn. RuDoLFF finden, sind kaum untersucht; nur das ist eine ausgemachte Sache, dass dic Salz-Formation durch Karpathen-Sandstein bedeckt wird; ob sie aber ein Gliẹd desselben ist, oder eine selbstständige Formation, muss noch unentschieden bleiben. - Dass die Salz-Formation, die sich am Fusse der Karpathen von Dobromil bis gegen Bukowina hinzielıt, nicht tertiär ist, wie es Hr. BouÉ in Journal de Géologie: sur le sul terticire de la Gallicie behauptet, daran zweife ich gar nicht. - Ein wenig beachteter Gegenstand sind die Bergöl-Quellen der Karpathen: 
sie sind bcsouders in dem östlichen Theile angehäuft, alle treten aus geschichteten Felsarten, nämlich aus Karpathen-Sandstein oder aus Gesteinen des Salzgebirges hervor, die auf der Grenze mit dem erwälın: ten Sandstein liegen. - In der Nähe dieser Quellen sind nicht die mindesten Andeutungen von plutonischen Felsarten. Bei der kleinen Stadt Górlice im Jasloer Kreise zeigen sich die ersten Bergöl-Quellen, die gegen Osten bedeutend sich auhäufen. - Auf einem Hügel in der Nähe vou Górlice ist ein kleines Wasserbecken, aus dessen Wasser voin Zeit zu Zeit, fas! periodisch, einige Tropfen von dunkelbraunem Bergül aufsteigen, und wïhrend 24 Stunden sammelt sich $\frac{1}{8}$ Quart. - Weit bedeutender sind die Quellen von Siary, einem 2 Stunden von Gorlice entfernten Dorfe, wo das Sammeln des Bergöls einen Erwerbzeig der Einwohner ausmaclit; sie nennen es Ropa. Es werden 3-4 Lachter tiefe Brumen in einen quarzigen Karpathen-Sandstein gehauen, der durch grünen erdigen Chlorit lauchgrün gefürbt ist, aus welchen dann täglich 3-4 Quart dieser dunkelbraunen Substanz geschöpft werden: in verscliedenen Brunnen ist sie melır oder weniger flüssig. Wo nur Bergöl vorkommt, da schwimmt es über Wasser, und wird auf eine recht praktische Art gewonnen. Auf langen Stangen wird am Ende einc Art Besen, die - aus einer eigenthümlichen Juncus-Art gemacht ist, befestigt und in den Brunnen eingetaucht; - so, dass sich das über Wasser schwimmende Bergöl darauf ansammelt, herausgehoben und sodann mit der Hand in ein Geschirr ausgepresst wird. Diese einfache Gewinnung ist vorziiglich zweckmässig. Auf dem uördlichen Abhange des Thales, etwa 300 Schritt von den Brunnen, breitet sich eine Fläche von etwa 100 QúadratLachter Raum mit thonigem Bergtheer bedeckt aus, dessen Kruste 1-2 Fuss dick ist. - Es war grade ein warmer Sommertag, als icb, auf den Bergen herumsteigend, zufällig auf diese Fläche gerieth; ich blieb förnlich stecken und konute nur mit Mühe wegkommen. - Die "Ropa" ist kohlschwarz, brennt mit starker dunkelrother Flamme, und hinterlässt eine thonige Schlacke; crwärmt wird sie halbflüssig. - Eine schwache Bergöl-Quelle befindet sich im Dorfe Kroscienko, welches nicht zu verwechseln ist mit dem gleichnamigen bei saczawnica gelegenen Dorfe : dieses liegt bei dem altertbümlichen Städtchen Krosno. Bedeutender sind die Quellen von Golcowa, einem nahe bei Jasiennica gelegeuen Dorfe. In Tyrawa Solna am San sind die Wasser, wo Bergöl sich zeigt, durch diese schwarze Substanz ganz bedeckt. Die ergiebigsten Quellen, die ich besuchte, sind die von Boryslau, eincm bei Drohobycz geiegenen Dorfe, am Fusse der Kurpathen. Mehr als 30 Brunnen in einem kleinen Hïgel, der aus Schuttland besteht, geben brannlichgrünes Öl, und zwar täglich über 4 Quart. - Im Allgemeinen hisben mir die Bewohner erzählt, dass in warmen Tagen das Bergöl ergiebiger fliesst als in kaiten. Auch am Fusse der Krarpathen in Truskowiec bei Drohubycz liegen melirere zicmlich ergiebige Quellen übereinander. - Aus was für cinem Gesteine sie zum Vorschein kommen, lässt sich nicht entscheiden, deun bei Truskourec fïngt das Salzgebirge 
an. Ausser diesen Bergöl-Quellen finden sich noch sehr viele; aber mit einem leereu Namen-Verzeichnisse will ich sie nicht belästigen: wenn ich sie künftig besucht habe, will ich weiteren Bericht geben. - $\mathrm{Zu}$ dieser Art von Quellen dürfte auch wohl die von Turasowka (einem nahe bei der Stadt Fr rosno liegenden Dorfe, im Jastoer Kreise) gerechnet werden; Bergöl wird aus ihrem Wasser nicht ausgeschieden, allein der daraus entwirkelte Geruch zeigt deutlich an, dass sich hier gasförmige Naphtha befindet. - Die Quelle ist im Viereck eingefasst, und es scheint, als wäre sie im vollen Sieden: so stark quillt das Wasser auf. Blasen bilden sich in Menge und sammeln sich in Ecken an, wo das Wasser nicht durch das neu heraufsteigende Gas beunruhigt wird. - Ein brenuender Span in die Nähe der Blasen gebracht, entzündet das eingeschlossene Gas und eine dunkelrothe $2-5$ Fuss hohe Flanme steigt empor, bedeckt die ganze Oberfläche des Wassers, dann beschränkt sie sich auf eine Ecke, geht in der Runde herum und wird niedriger; sobald aber neues Gas mit Wasser aus dem Innern der Kanäle zufliesst, steigt plötzlich die Flamme wieder auf, und nach 1 bis 3 Minuten verlischt sie. - Die Zusammensetzung dieses brennbaren Gases ist bis jetzt nicht analysirt worden; sein Geruch deutet eine Art flüchtiger Naphtha an. Die Quelle von Turasowka ist schon seit 200 Jahren bekannt; die Beschreibung von Rzaçczysskr stimmt vollkommen mit den flüchtigen Beobachtungen überein, die ich angestellt habe.

\section{ZEUSChNer.}

\section{Mittheilungen, an Professor Bronn gerichtet.}

Hildesheim, 8. F.ebr. 1836.

Ich lasse jetzt vier weitere Tafeln, Abbildungen zu meinem Werke, fertigen, und, da ich mit den vorliegenden Proben von meinem neuen Lithographen zufrieden bin, so sollen auch die 12 alten umgezeichnet werden, wobei ich noch zahlreiche Verbesserungen, von unendlicher Verschönerung abgesehen, anbringen kann. Ich habe auch wieder viel Schönes und Neues bekommen. Die bisher unter Placuina aufgeführten Schaalen (Tf. IV, Fg. 2, 3) habe ich gestern zu meiner grossen Freude als Pollicipes (P. jurensis mihi) erkannt und auch die dritte grössere Schaale dazu gefunden.

RöMER.

Berlin, 26. Febr. 1836.

Friedricu Dubors hat seine schönen Sammlungen hier mit Pariser Versteinerungen verglichen, und gefunden, dass dic Tertiär-Formation 
im Osten des Granit-Zuges der Ukraine, am Dniepr, ganz verschieden von der Subapenninen-Formation von Volhynien und Podolien ist. Es finden sich zu Boutschack am Driepr: Terebellum fus iforme, Cassidaria carinata, Buccinum reticulatum, B. stromboides, Rostellaria fisurella, Tritonium pyraster, Fusus funiculoides, F. clavellatus, Cerithium lima, Turritella imbricataria, Trochus agglutinans, Tr. monilifer, Solarium plicatum, Voluta costaria, Natica epiglottiua, Fisisurella neglecta, Calyptraea trochiformis, Bulla cylindrica, welche alle auch zu Grignon vorkommen. Die Formation des Calcaire grossier stand so isolirt, dass diese Entdeckung sehr wichtig zu seyn scheint, um seine grössere Verbreitung glaublich zu machen. Ja, noch mehr! Selbst zu Achalziké in Armenien hat Hr. Dubors Petrefakte gesammelt, welche auf Pariser Formation hindeuten: Turritella imbricataria, Rostellaria fissurella, Voluta harpula, Melania cancellata und Cancellaria evulsa.

\section{L. voN Buch.}

Bayreuth, 1. März 1836.

Von vielen Seiten aufgefordert, habe ich mich mit Hrn. Schneider von Hof zur Herausgabe einer Gaea Baruthiensis, nämlich der Gebirgsarten des Obermain-Kreises mit ihren Versteinerungen verbunden. Die erste Lieferung, das Oolith - Gebirge in sich begreifend, liegt zur Versendung fertig (23 Exemplare von Gebirgsarten mit 77 Arten Versteinerungen). Die zweite soll die Granite, Syenite, Gneisse, Glimmerschiefer, Eklogite und Gabbro's, welche alle das Fichtelyebirge in den manchfaltigsten Abänderungen darbietet; - die dritte die Trias mit ihren Gruppen und mit den Ober-Fränkischen Seltenheiten aus den organischen Reichen, - die vierte endlich die noch übrigen Massen - Gesteine, das ältere Schicht - Gebirge vom Zechsteine an, so wie die jüngern und jüngsten Erzeugnisse darlegen ").

Der Gaea Baruthiensis reihen sich unmittelbar meine Centurien seltener Petrefakten aus dem Obermain-Kreise an: Die erste erscheint im Herbste dieses Jahres: ich hoffe in derselben wirkliche Seltenheiten liefern zu können, wie z. B. aus dem Lias: Zähne und Wirbel von Ichthyosaurus und Mystriosaurus; vielleicht sogar Knochen und Zähne von Pterodactylus macronyx.

Nach demjenigen, was ich diesen Sommer bei dem Losarbeiten eines Placodus - Unterkiefers aus dem Gesteine für die hiesige Kreis-Sammlung beobachtet habe, besitzt dieser Fisch Vorder- und EckZühne, wie die angefügte Skizze zeigt; aller Wahrscheinlichkeit nach

*) Das Format der Gebirgs.Arten ist 120 “; der Preis jeder Lieferung 25 Gulden 


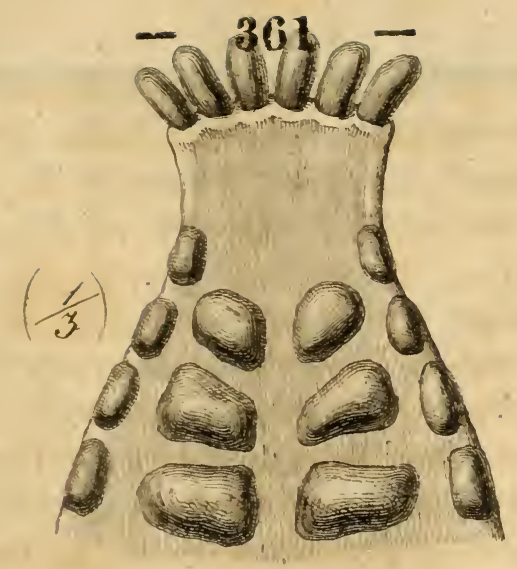

sind es diese Zähne, welche uns AGASsiz für Schlundzähne angab, was ich aber nie zugeben konnte: denn diese fehlen bestimmt den Placoiden [?]; zu der beigefügten Zeichnung muss ich jedoch bemerken, dass an dem dargestellten Exemplare die Vorderzähne nur durch die vorhandeneu Alveolen angedeutet werden.

Braun, Prof.

\section{Breslau, 18. März 1836.}

Mir ist es endlich geglückt, Blüthen aus der Braunkolle der Wetterail zu erhalten, in denen ich noch Antheren mit wohlerhaltenen Pollenkörperchen entdeckte. Die nähere Beschreibung und Abbildung dieser merkwürdigen Pflanze der Vorwelt, die ich der Mittheilung des Hrn. Hofrath Keferstein verdanke, werden die nächsten Verhandlungen der K. K. Leopold. Karolin. Akademie enthalten.

\section{F. R. Goepert.}

Stockhorm, 10. Mai 1836.

Ich habe den Winter über an einer Lethaea Suecica, fast nach Jem Plane einer Fauna oder Flora, gearbeitet, und bereits 28 Quart - Tafeln mit Versteinerungen durch unsern geschicktesten Lithographen in naturhistorischen Fache, Herrn Whight, lithogrophiren lassen. - Nrusson hat sein Werk über Kreide-Versteinerungen noch nicht fortgesetzt, und ich zweifle, dass er es thun wird. In Augenblicke will or eine Reise nach Englınd machen. Ausserdem nimmt ihn sein Werk mit Abbildungen über die Schwedischen Wirbelthiere sehr in Anspruch; Fries und Wrigrr beschreiben und zeichnen eben unsere Fische, worüber ein Heft schon erschienen ist. 


\section{Neueste Literatur.}

\section{A. Büch er.}

\section{4.}

ק. Hisinger: Upplysningar rörande geognostika Kartan öfver medlersta och södra delarne of Sverige. Stockholm, $56 \mathrm{pp} .8^{\circ}$. (Eine Erklärung zu der schon in vorigen Jahre erschienenen geognostischen Karte von Schweden.)

1835.

Cep. Bo1D : a description of the Azores or Western Islands from personal observation, comprising remarks on their peculiarities, topographical, geological, statistical etc. London $373 \mathrm{pp}$., with 4 lithoyr. plates and 1 map.

Dufrénoy: Mémoive sur les terruins tertiaires du bassin du midi de la France, Paris $8^{\circ}$.

Gus. Givli: Progetio d'una carta geognostica ed orittognostica della T'uscana per servive alla tecnologin o al modo di rendere utili i minerali del gran ducato alle arti ed alle manufacture. Siena in. $4^{0}, 2 t p p$. ed i carta.

Hogard : tablean minéralogique des roches des Vosges, $80 \mathrm{pp} .8^{\circ}$. El)inal (Extrait des Annales de la Société d'émulation des Vosges).

Huoc: Coup d'oeil sur les mantagnes de la Sibérie et sur l'origine et ies progrès de la richesse minérale dans l'empire Russe, $60 \mathrm{pp}$. $8^{\circ}$. Paris.

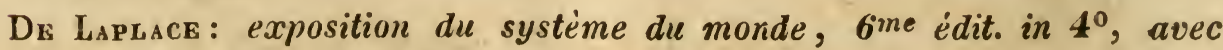
rortrait, Paris [ $\left[\begin{array}{ll}15 & F r\end{array}\right]$.

Lindesy and Hutton : the fossil Flora of Great Britain, 18.35, Or itober: Thuites expansus, Sphaenopteris arguta; Pecopteris dentata; Tympanophora simplex; Lonchopteris. Mantelli; Zamia pectinata; Bechera grandis; Zamin taxina; Sphaenopteris cysteoides; Taeniopteris vittata (v.S. 63). 
Carmelo jaravigna: Materiali per la compilazione della orittognosini Etner. $66^{\circ} \mathrm{pp} . \mathbf{t}^{\circ}$. Catanea [? aus den Akten der Soc. Givenia].

Morin: Mémoires sur les encombremens des ports de mer. $40 \mathrm{pp} .8^{\circ}$. a st. Brienx.

Mullinger Higgins: the Earth, its physical Condition and most remarquables Phenomena. London $8^{0}\left[\begin{array}{llll}9 & s h . & 6 & d .\end{array}\right]$.

R. I. Murchison: Geulogy of the Counties of Salop, Hereford, Radnor, Montyomery, Brecknock, Caermarthen, Monmouth, Worcester and Gloucester, with large geological maps, numerous coioured sections, and many Plates of urmmblished Organic Remains. London.

v'Omalius D'Halcoy: élémens de géologie, ou seconde partie des Elémens d'histoire náturelle inorganique, $2^{\text {me }}$ édit., $7 \pm 2 \mathrm{pp} .8^{0}$, arec 1 pl. et 1 carte.

J. Phichips: a guide to Geology, the $2^{d}$ edition, Lonilon 120, with plates [.5 shil.].

Reboul: Essui de géologie descripative et historique - Prolégomènes et periode primaire, $276 \mathrm{pp}$. in $8^{\circ}$. Paris.

Riviére: Curte géognostique du département de la Vendée; trois fiuil. . les: les sables, Saint-Michel, Maillesais.

A. Salacroux: nouveaux élemens a'histvire naturelle, continant la z00logie, la butınique, la minérulogie et la géologie, avec $32 \mathrm{pll.g}$

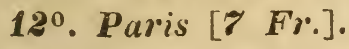

P. Savx: studii grologici sulla Toscana e alterazioni Plutoniane sofferte dalla calce carbonata compatta cioè alberese, sua conversione in calcare salino ed in dolomite, con 2 carte cul. $8^{0}$ Pisa ( $2 \frac{1}{4}$ lire).

C. U. Shepard: 'Treatise on mineralugy, consisting of descriptions of the species, with five hundred woodcuts. II. voll. $675 \mathrm{~m} .12^{\circ}$. New Haven (hiemit vollendet).

T. Thomson: Outlines of Mineralogy, Geology and Mineral Analysis. Londun, II, $8^{\circ}$ [I Pf: 12 sh. - als dritter Theil von dessen General System of Chemistry].

1536.

H. T. DE LA BEcuE: Anleitung zum naturwissenschaftlichen Beobachten. I. Geologie, mit 138 Holzschnitten, aus dem Englischen von REHвоск, mit einer Vorrede von H. v. Deches. Berlin $\mathcal{8}^{\circ}$. erscheint heftweise.

H. T. DE LA BECHE: Untersuchungen über theoretische Geologie, a. d. Englischen von C. Harthane, wit 8 lithogr. Tafeln (VII u. 252 S.) gr. 8n. Quedlinburg.

A. Boù: Guide du géologue volageur, sur le modéle de l'Agenda geognostica de Mr. Lkonhard, Paris, II, 5.93 et $594 \mu . \pm^{\circ}$, avec 1 tabl. in fol. et \pm jll.

Geognostisches Bild des Irarzes, nach Fr. Hoffmans's Beobachtungen, pine Karte von Jubius und Bergeaus, herausgegeben von Brose. Braunschweig in Fol. ( 1 fl. $30 \mathrm{kr}$.) 
J. Burkart: Aufenthalt und Reisen in Mexilio in den Jahren 1825 bis 1834, Bemerkungen über Land, Produkte, Leben und Sitten der Einwohner und Beobachtungen aus dem Gebiete der Mineralogie, Geognosie, Bergbaukunde, Meteorologie, Geographie etc. II. Bände, 286 und 392 SS. mit XI Kupfertafeln, Stuttgart, $8^{\circ}$.

de Bylandt-Palstercanp: théorie des Volcans, $\boldsymbol{I I I}, \mathcal{8}^{\circ}$ (89 Bogen und 1 Tabelle), mit Atlas in fol. mit 17 Kupf., Paris.

B. Cotra: geognostische Wanderungen. - I. Geognostische Beschreibung der Gegend von Tharand, mit 1 geogu. Karte in Fol., und 3 lithogr. Tafeln in $4^{\circ}$; - VIII und 176 SS. $8^{\circ}$. Dresd. u. Leipz. [2 Rthlr.].

C. Hartuan: Lehrbuch der Mineralogie und Geologie zum Gebrauche für höhere Lehranstalten und zum Selbstunterricht für jeden Gebildeten, mit 2 Kupfern. Fol. Nürmbery, VI und 268 SS. $8_{\text {‘d }}^{\circ}$ [4 Thlr, 16 Gr.].

A. v. Humboldt, G. Ehrenberg und G. Rose: Reise nach dem Ural, dem Kolywanischen Gebirge, zur Grenze der Chinesischen Songarei und zum Kaspischen Heere im Jahre 1829. - Mineralogischer und geognostischer Theil nebst Reisebericht, mit Karten, Kupfern und Holzschnitten. II Bände, Berlin $8^{\circ}$.

J. Fr. KRÜGER : Handbuch der Naturgeschichte. Dritter und letzter Band: Naturgeschichte des Erd-Körpers (Mineralogie). Quedlinburg und Leipaig, 301 SS. $8^{\circ}$.

Cr. Lyesx: Elements of Geology, intended for the use of students and young Persons; with mumerous illustrations of fossil remains, London $12^{\circ}$.

Fr. Mors: leichtfassliche Anfangsgründe der Naturgeschichte des Mineralreichs; zum Gebrauch bei seinen Vorlesungen, I. Theil, Terminologie, Systematik, Nomenklatur, Charakteristik. 2te Aufl. XXX und 524 SS. mit 31 Kupfertafeln, Wien [6 fl.].

C. F. Nauranx: Erläuterungen zur geognostischen Karte des Königreichs Sachsen und der angrenzenden Länder-Abtheilungen. 1. Heft, zur Sektion XIV der Charte: geognostische Skizze der Gegend zwischen Taucha, Strehla, Bräınsdorf und Altenburg, XXVI und 16S SS. Dresd. und Leipz. [1 Rthlr.]

Nrussor: Icones petrifuctorum Sueciae, Fasc. I, Tab. I-x: Animalia articulata et Mollusca Cephalopoda, Holm. (4 Rdr., 16 sk.).

G. G. Pusch : geognostische Beschreibung von Polen, so wie der übrigen Nord-Karpathen-Länder. Stuttgart $8^{\circ}$, I, 1833, II mit Karte (vgl. Jahrb. 183t, 644).

Saunt (W. D.): an Essay on the Coincidence of Astronomical and Geological Phenomena, addressed to the Geological Socicty of France, $30 \mathrm{pm} .8^{\mathrm{c}}$. London.

(Nimmt R. Phille's Ansicht auf, dass mit dem Vorrücken der Äquinoktien die Wasser-Masse auf beiden Hemisphären alle 25,800 Jahre einmal zu- und ab-nehme und sieht die Korallen- 
reichen nordischen Erdschichten als Erzeugnisse wiederkehrender wärmerer Meere an).

C. G. A. r. Werssenbacin: Abbildungev merkwürdiger Gang-Verhältnisse aus dem Sächsischen Erzgebirge, XIII und 63 SS. und XIX lith. Taf. in gr. $8^{\circ}$. Leipzig [4 fl. $48 \mathrm{kr}$.].

H. J. VAN DER WYCK: Übersicht der Rheinischen und Eifeler erloschenen Vulkane und der Erhebungsgebilde, welche damit in geognostischer Verbindung stehen, nebst Bemerkungen über den technischen Gebrauch ihrer Produkte, Il. Auszg. Manuheim, 174 SS. $8^{0}$.

The History and Description of fossil Fuel, the Callieries and Coal Trade of Great Britain, London, $\mathcal{S}^{n}$, with numerous wood engravings [12 sh.].

H. G. Brovx: Lethae a geognostic a oder Abbildung und Beschreibung der für die Gebirgs-Formationen bezeichnendsten Versteinerungen, III $-v$. Lief., mit xvir lithogr. Tafeln $4^{0}$ und 18 Bogen Text, 8 ${ }^{n}$. Stuttgart (vgl. Jahrb., 1835, S. 238 und 459).

F. A. Rö̈rer: die Versteinerungen des Norddeutschen Oolithen-Gebirges, II. Lieferung, Tafeln xirl - xIV und Text pg. 75-134. Hannover, gr. $4^{0}$ (vgl. Jäırb. 1835, S. 730, und 1836, S. 63).

\section{B. Zeitschriften.}

1. Bulletin de la société géologique de France (Paris $\left.\mathbf{3}^{\circ}\right)$.

$$
\text { Vol. VII, 1-112 (vgl. S. 207). }
$$

E. Roвert : Notiz über seine Reise in Island, S. 5-12.

Riepr: Notiz über die geognostischen Beziehungen und die Gruben des Rathhausberges zu Gastein in Salzbury, Tf. I, S. 13-18.

Keichau: Notiz über die Erdbeben in Norwegen, S. 18-21.

- Einige Thatsachen über die neuere Emporhebung Skandinaviens, S. 21-25.

GLocken: geognostische Bemerkungen in Oberschlesien, insbesondre über Diorit und Amphibolith, S. 26-27.

JACKson: über Trapp-Dykes in Konglomeraten bei Boston, S. 27.

LardY: Note über den Einsturz eines Theiles des Dent du midi, S. $27-30$.

D'Archiac: über die Lagerung des Kalkes von Châtau-Landan (vgl. VI, $92)$, S. $30-35$.

Rivrène: Grundzüge der Geologie der Vendée, S. 35-38 (l'Instit. 1836, IV, 209-210).

Buckland: über die Auftreibung der Porphyre von Gembloux und $\boldsymbol{C a}$ radoc, S. 39-40.

Aricr: Beobachtungen über den Vesuv und den Ätna, S. 40-48.

Nopor: über die Lagerung des Bleiglanzes von Courcelles-Frémoy, S. $49-50$.

Jahrgang 1836. 
Scrmsurixa: Beschreibung fossiler Knochen in pathologischem Zustande aus den Lütticher Höhlen, S. 51-61.

Deshayes: Beobachtungen über Bele mn it en, S. 61-62.

Provana de Collegio: über Oysans, S. 63-01.

Corder und Riviére darüber, S. 64-67.

C'oquaxd: über die Gebirgs-Bildungen zwischen les Sables - d'Olonnes und la Gachère, insbesondere der Amphibclit von la Bauduère und den Meeres-Torf der Côte-dıs-Granges im Vendiè, S. 74-83 (l'Instit. 1836, IV, 210-211).

Michelix: über das Diluvial-Gebilde auf den Höhen um Sainte- Irenehould im Murne-Dept., S. 83.

LErMERIE : über die geclogische Lage Lyons, die Haupt - Kalkformation des Rhone-Depts., ïber ihre Emporhebung und die des Ur-Gebirges zwischen Lyon und Mâcon, Zusätze von Pozet, S. 84-90.

Elie d: Beaunont: Murchison's und Sedgwick's Eintheilting des ITales schen Übergangs-Gebirges, S. 90-91.

Pixgec: über die allmäbliche Senkung der Westküste Grönlands, S. $96-97$.

Rivisns: über Hebungen an der West-und Nord-Küste Franlireichs, S. $97-98$.

Aвıсн : ̈̈ber Hydrochlor-Ammoniak-Bildung nach vulkanischer Eruptionen, insbesondere an Vesuv den 26. August 1834, S. 98-102.

Cromzer: über die fossilen Reste am Gergovia-Berge, S. 104-106.

Coquaxd: mineralogische Notiz über l'Esterel und im Allgemeinen über das Var-Dept., S. 107-112.

2. Transactions of the geological Society of Loudon, London, $4^{\circ}, I V, I, 1835$, with 14 colour. maps and sections.

Buckend and DE LA Beche: über die Umgegend von W'eymonth.

SEDGwrK: über die Cumbrian Numtains.

- über die Kohlen-führende Kette ron Penigent bis Kirliby Strphen.

3. J. C. Freiesteben: Magazin für die Oryctographie von Sachsen, VII. Heft, Freiberg, 313 SS. $8^{\circ}$ [3 fl. 18 kr.] - rgl. S. 205.

4. Jahrbuch für den Berg- und Hütten-Mann auf das Jahr 1836, hgg. von der künigl. Berg-Akademie in Freiberg, 176 SS. $8^{\circ}$. Freiberg. 


\section{A $\mathbf{u}$ s $z$ ï, g e.}

\section{Mineralogie, Krystallographie, Mineralchemie.}

v. Kobels: über Epidot-Gabbro (Erdanan und SchweiggerSeidec Journ. f. Chem. V, 212). In der Nähe von Grossurl in Sulzburgischen findet sich ein Gabbro-artiges Gestcin, bestehend aus grauem Diallagon und einem dichten Mineral, welches weder Labrador noch Allit ist, sondern mit Epidot übereinkommt. Es zeigt keine Spur von Spaltbarkeit; ist im Bruche splittrig und uneben; von Farbe graulichgrün; an den Kanten schwach durchscheinend; matt oder wenig fettartig schimmernd. Härte zwischen Orthoklas und Quarz. Spezifisches Gewicht $=3,2$. Vor dem Löthrohre anschwellend und mit geringem Schïumen zu einem weisslichen Glase schmelzend. Durch Salzsäure nur unvollkommen zersetzbar; nach dem Schmelzen vollkommene Gallerte bildend. Chemischer Gehalt nach Bessard :

\begin{tabular}{|c|c|c|c|c|c|c|}
\hline Kieselerde & & & & & & . 40,00 \\
\hline Thonerde & & & & 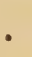 & & . 26,46 \\
\hline Eisenoxyd & • & & & & & . $\quad 6,33$ \\
\hline Kalkerde & & & & . & & 20,66 \\
\hline Talkerde & • & & & ${ }^{\circ}$ & & 3,60 \\
\hline Kali . & & & & & & 1,50 \\
\hline
\end{tabular}

Diese Mischung stimnt mit der Formel überein :

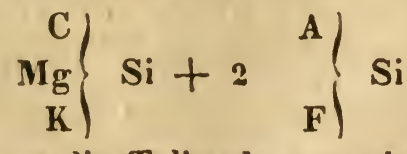

Es ist möglich, dass die Talkerde von eingemengtem Diallagon lierrührt; jedoch wurden zur Analyse nur solche Stücke ausgewählt, welche keinen Diallagon zu enthalten schienen. Das Mineral ist also dichter Kalk. Epidot, und man könnte den Gabbro, welchen es mit Diallagon zusammen. setzt, zum Unterschied von Labrador-Gabbro, Epidot-Gabbro nemnen. 
A. Lavrest: Analyse des Spodumens aus dem Flussbette der Arriege (Ann. de Chim. 1835, LIX, 107 etc.). Vorkommen in Schrift-Granit. Eigenschwere $=2,638$. Gehalt :

$$
\begin{aligned}
& \text { Kieselerde . . . . . 62,6 } \\
& \text { Thonerde . . . . } 24,6 \\
& \text { Eisenoxyd . . . . } 0,1 \\
& \text { Natron . . . . . } 8,9 \\
& \text { Kalkerde . . . . } 3,0 \\
& \text { Talkerde . . . . . } 0,2 \\
& \text { Verlust . . . . . } 0,6 \\
& \overline{100,0}
\end{aligned}
$$

Derselbe: Zerlegung eines neuen Minerals, Wichtyn genannt (Ibid.p. 109). Fundort Wichty in Finland. Schwarz. Bruch nuschelig. Zwei deutliche, aber schwierig zu entblössende Durchgänge, die auf ein rhombisches Prisma hinweisen. 'Ritzt Glas. Vor dem Löthrohre schmelzbar zu schwarzem Email; mit Borax zur grünen Perle. Folgt dem Magnet. Eigenschwere $=3,03$. Gibt bei der Kalzination kein Wasser; Säuren wirken nicht darauf. Die Analyse ergab:

$$
\begin{aligned}
& \text { Kiesclerde . . . . } 56,3 \\
& \text { Thonerde . . . . 13,3 } \\
& \text { Eisen-Peroxyd . . . . 4,0 } \\
& \text { Eisen - Protoxyd . . 1 13,0 } \\
& \text { Kalkerde . . . . . } 6,0 \\
& \text { Talkerde . . . . } 3,0 \\
& \text { Natron . . . . 3,5 } \\
& \text { Verlust . . . . } 0,9 \\
& 100,0
\end{aligned}
$$

Die Formel wäre:

$$
\mathrm{Si}^{+} \mathrm{Rr} \text { oder } \mathrm{Si}^{2}(\mathrm{Al}, \mathrm{Fe})+\mathrm{Si}^{2}(\mathrm{Na}, \mathrm{Ca}, \mathrm{Mg}, \mathrm{fe} \mathrm{F}) \text {. }
$$

Graf Trolle Wachtmeister: blaues arseniksaures Kupferoxyd a us Cormwall (Berzelius, Jahresber. 1834, S. 177). Gehalt :

Arseniksäure

Phosphorsäure 20,79

Kupferoxyd . 3,61

.

Thonerde . . . . . . . . . . 8,03

Eisenoxyd . . . . . . . . • 3,41

Kieselerde (wahrscheinlich von der Gangart) . . 4,04

Gaingart (von der Analyse nicht abscheidbar) . $\quad 2,95$ 
MitschbrLich untersuchte die verschiedensten Tbouarten, von Porzellanthon bis zu dem in jüngeren Formationen vorkommenden Thon, und fand in allen gegen 4 Procent Kali, nebst etwas Natron (A. a. 0., S. 166).

Graf Trollb- Wachtmeister: Analyse eines weissen Granats (A. a. Ó., S. 171). Vorkommen zu Tellemarken in Norwegen, begleitet von Thulit und blauen Idokras. Gehalt:

\begin{tabular}{|c|c|c|}
\hline Kieselerde . & • · · & 39,60 \\
\hline Thonerde . & . & 21,20 \\
\hline Kalkerde . & . & 32,30 \\
\hline Mangan-Oxydul & & 3,15 \\
\hline Eisen-0xydul . & . & 2,00 \\
\hline Verlust . . & & 1,75 \\
\hline
\end{tabular}

Formel :

$$
\left.{ }_{m n}^{C}\right\} S+A S \text {. }
$$

H. Frick: über die chemische Zusammensetzung des Thonschiefers (Poggend. Ann. d. Ph. 1835, B. XXXV, S. 188 ff.). Die bis jetzt bekannt gewordenen Analysen haben sebr verschiedene Resultate gegeben und sind, wie es scheint, mit solchen Abänderungen des Gesteins angestellt worden, welche im Übergangs-Gebirge vorkommen; aber die geringe Übereinstimnung, die sie dessen ungeachtet zeigen, macht es wahrscheinlich, dass der Thonschiefer kein einfaclses Mineral, wie Glimmer, sey, sondern eine sehr fein gemengte, nur scheinbar gieichartige Gebirgsart. Der Verf. versuchte, ob sich der Thonschiefer, wie C. Gmenis vom Phonolith und Basalt, und Berzelius von den Meteorsteinen gezeigt, durch Behandlung mit Säuren in einen darin zerlegbaren und in einen unzerlegbaren Bestandtheil trennen lasse. Zur Analyse des Thonschiefers durch Trennung in seine Gemengtheile dienten verschiedene Abänderungen von Gosiar an Harze, von Bendorf bei Koblenz und von Lehsten in Thüringen. Berechnet man nach den Resultaten der Analysen der Gemengtheile die Zusammensetzung des Ganzen, so stellt sich das Verhältniss der Bestaudtheile folgendermaàsen : 


\section{$-370$}

\begin{tabular}{|c|c|c|c|c|c|c|c|c|c|c|c|}
\hline & & & & & Von Goslar & & & von Bendor & & & von Lehister \\
\hline Kieselsäuro & - & & - & • & - $\quad 59,92$ & • & & - $\quad 62,59$ & - & & - 64,58 \\
\hline Thonerde . & - & - & - & • & 14,89 & & - & 16,88 & - & & 17,10 \\
\hline Eisenoxyd . & . & - & - & • & 9,03 & 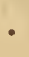 & & 8,42 & - & & $\pi, \downarrow 3$ \\
\hline Magnesia . & - & - & - & - & 4,42 & - & & 2,26 & - & & 2,29 \\
\hline Kalkerde . & - & - & . & - & 0,51 & - & 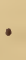 & 0,24 & - & & 0,16 \\
\hline Kali : . & - & - & - & - & 2,75 & - & • & 3,31 & - & & 2,93 \\
\hline Wasser & - & - & . & . & 4,45 & - & & 4,03 & - & & 4,08 \\
\hline Kupferoxyd & $\cdot \cdot$ & & - & $\bullet$ & 0,25 & - & & 0,13 & - & & 0,30 \\
\hline Kohlensaurer & Kalk & & - & & 2,43 & . & & 1,22 & & & 0,53 \\
\hline Kohle und $\mathrm{V}$ & & & & & - 1,35 & & & 0,92 & & & - $\quad 0,00$ \\
\hline & & & & & 100,00 & & & 100,00 & & & 100,00 \\
\hline
\end{tabular}

Aus dieser Analyse ergibt sich, dass der Übergangs - Thonschiefer von der grossen Gebirgs-Formation, welche das Rheinische SchieferGebirge und das Übergangs-Gebirge in Harz und im Thüringer. Walde ausmacht, so wie wahrscheinlich sämmtlicher Übergangs - Thonschiefer sich durch Behandlung mit Säuren in zwei, und, wenn man die kleine Menge des eingemengten kohlensauren Kalkes dazu rechnet, in drei Gemengtheile zerlegen 'lässt. Die Zusammensetzung der ersten zwei Gemengtheile ist sich nicht gleich, aber die Bestandtheile sind dieselben, und die relative Menge derselben nicht bedeutend verschieden. Eben so ist das Verhältniss des in Säuren auflöslichen Geniengtheils zu dem in Säuren unauflöslichen bei den drei untersuchten ThonschieferAbänderungen nicht gleich, selbst nicht einmal bei verschiedenen Stïcken eines und desselben Thonschiefers; aber auch hier sind die Verschiedenheiten nicht sehr bedeutend. Dennoch sind diese Unterschiede zu gross, als dass man es wahrscheinlich finden könnte, dass die Sauerstoffwengen der einzelnen Bestandtheile des Thonschiefers in einem einfachen Verhältnisse ständen. In der That findet man diess auch nicht, wenn man die Zahlen, die den Resultaten der Analysen beigesetzt sind und den Sauerstoffgehalt der gefundenen Bestandtheile angeben, vergleicht. Am meisten scheint noch ein solches einfaches Verhältniss Statt zu finden, wenn man die Zusammensetzung des ganzen Thonschiefers betrachtet; hier hat es fast den Anschein, als wäre der Sauerstoff der Kieselsäure dreimal so gross als der der Basen, und als enthielte der Thonschiefer neutrale kieselsaure Verbindungen; indessen ist das Verhältuiss der Kieselsäure durchgelıends zu gross, und die Abweichungen sind zu bedeutend, um sie nur Fehlern der Analyse zuzuschreiben. Aus diesem Umstande würde sich allein schon ergeben, dass der Thonschiefer der Übergangs-Formation kein einfaches Mineral sey, was noch unzweideutiger aus seinem Verhalten gegren Säuren hervorgeht; dass aber die Zusammensetzung der Gemengtheile, in welche man den Thonschiefer durclı Säuren zerlegen kann, nicist mit der Lehre der bestimmten Proportionen übereinstimnt, zeigt, dass.der Thonschiefer auch nicht als ein Gemenge von zwei einfachen Mineralien, sondern als ein Produkt der Zersetrung von andern Gebirgsarten zu betrachten sey; aber die 
nahe L̈bereinstimmung in der Zusammensetzung der Thonschiefer-Abänderungen, die wie die analysirten zu einer und derselben Formation gehören, zeigt auch, dass bei der Bildung dieser Thonschiefer-Abänderungen sehr nahe stehende Umstände Statt, gefunden haben. Hieraus fulgt indessen nicht, dass man dieselben Schlïsse auch auf den sogenannten Urthonsciiefer auszudehnen habe. Derselbe schliesst sich zu nale an den Glimmerschiefer an, um nicht anzunehmen, dass er, wie dieser, reine Glimmermasse, oder ein Gemenge von Glimmer und Quarz sey. Dieses auszumachen, erforderte aber eine besondere Untersuchung, die wiederum ohne eine voliständige Analyse des Glimmerschiefers selbst nicht $\mathrm{zu}$ bewerkstelligen ist.

A. Laurent und Ch. Holms: Labrador - Feldspath in Laven des Vesuv (Ann. de Chim. et de Phys. Novbr. 1835, p 332). Gewisse vesuvische Laven enthalten sehr gewöhulich weisse, glasige Krystalle, die bis jetzt für gewöhnlichen Feldspath angesehen wurden. Eur DE Beaunont vernuthete, dass solche dem Labrador angehören dürften, und die approximative Analyse bestätigte diese Ansicht vollkommen.

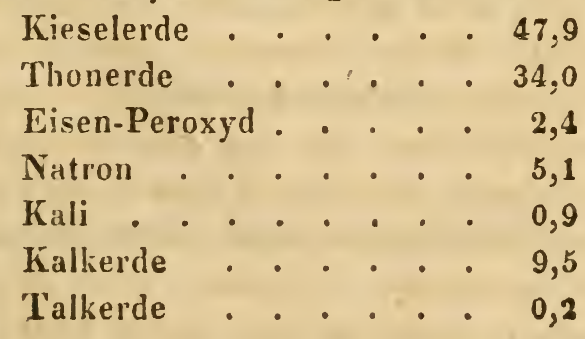

J. GввнакD: mineralogische und geologische Bemerkun. gen über Schoharie (Silmman Americ, Journ.; XXVIII, 172 etc.). Scliwefelsaurer Strontian, von Barytspath und Kalkspath begleitet, kommt in einem, auf Grauwacke gelagerten Kalk vor; Kalk, welcher unter der Grauwarke erscheint, enthält Favositen. In losen Blöcken von Granit, Gneiss und Hornblende-Gestein finden sich Granat, Augit, Skapolith und Epidot. Sunpferz ist sehr häufig, dessgleichen Kalktuff. Verkieste Enkriniten und Orthoceratiten trifft man im Schiefer-Gestein. Uufern der Stadt Sharon, nahe bei Schwefel-Quellen, koumt Anhydrit vor.

D. Dara: neues System krystallographischer Zeiclüu (Ibid. 250 etc.). Zu einem Auszuge nicht geeignet. 
Sinsard: Uranglimmer in Chesterfield (Ibid. 383). Wurde neuerdings mit Turmalin verwachsen entdeckt, welcher von Albit begleitet wird.

A. Laurent und Ch. Holms: künst liches Magne te isen (Ann. de Chim. et de Phys. Novbr. 1835, p. 330). Die Beschickung in dem Schmelzofen zu Châtillon. sur Seine ist ein Gemenge aus Eiser.Silikat, aus Eisen-Protoxyd und Eisen-Peroxyd. In den Drusenräumen der geschmolzenen Masse findet man sehr vollendete Krystalle, Formen, wie solche beim natürlichen Magneteisen gefunden werden: regelmässiges Oktaeder, entkantetes Oktaeder, Rauten-Dodekaeder u. s. w. Auch Glanz, Härte und andere Merkmale stimınen genau mit deuen jenes Minerals überein. Resultat der Analyse:

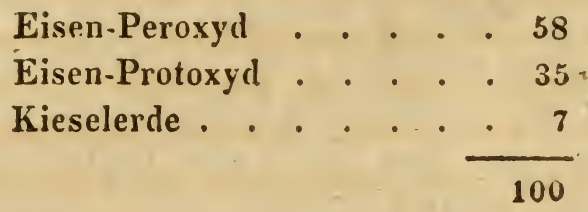

\section{Geologie und Geognosie.}

Ére de Beaumont: Thatsachen, die Geschichte der Berge in Oisans erläuternd (Ann. des Min. 3me série. T. V, ر. 3 etc.). Der Name Oisans dient im Besondern, zur Bezeichnung sämmtlicher Berg-Gehänge, deren Wasser oberhalb Vizille der Romanche zufliessen; eine geologische Arbeit muss sich indessen nothwendig'auch auf die entgegenliegende Abhängen ausdehnen, und in solcher Hinsicht gebraucht man den eriähnten Namen für mehrere durch Lage und mineralischen Bestand ziemlich ausgezeichnete Gebirgs - Ganze. Das erste derselben ist das südwestliche Ende der Reihe prinitiver Gipfel, welcher von der Ornex-Spitze und von Mont-Blanc bis zum TailleferBerge im W. des Fleckens Oisans und selbst bis zu den mehr niederen Gipfeln sich ausdehnt, die Vallonnais und Entraigues beherrschen. Eine zweite Masse, der ensten, wie es das Ansehen hat, unterirdisch verbunden, zieht vom Col de Glandon nach den hohen Gipfeln der Montagnes des Grandes Rousses, ostwärts von den Flecken Oisans und Huez und endigt, steil abfallend, an den Romanche - Ufern unterhalb Mont-de-Lans. Die dritte Gruppe, Gegenstand dieser Abhandlung, liegt vereinzelt vor beiden und scheidet das Becken der Romanche von dem der Durance und von den Quellen des Drac. Der erhabenste Gipfel, la pointe des Arfines oder des Ecrins, den Kulninations-Punkt des 
Pelvoux - Berges bildend, zwischen Val-Louise und Saint-Christophe, hat nach Duraxd und Lecherc eine Meereshöhe von $4105^{\mathrm{m}}$. Es ist diess. der erhabenste Punkt in'Frankreich. -- B es clíreibung der Felsarten. Der Granit, die Central-Masse der Berge ausmachend, von denen E. DE B. zunächst redet, führt Talk, es ist sogenannter Protogyn. Stets nimmit man darin zwei Feldspathe wahr: einen grünlichweissen, zum Grünen sich neigenden, fast dichten, und einen weiss, roth oder röthlichblau gefärbten; der letztere zeigt sich immer ziemlich regelrecht ausgebildet, und seine mehr und minder grossen, häufig isolirten Krystalle verleihen der Gestein - Masse ein Porphyr - artiges Aussehęn. Kleinkörnige Granite, auch Eisenkies - haltiger Feldstein setzen als Gänge in Granite auf. Der Granit zeigt keine Schichtung, wohl aber Abtheilungen in Lagen, welche der gebogenen äussern Oberflüche der Massen parallel laufen; ausserdem finden sich prismatische Absonderungen durch fast senkrechte Spalten hervorgerufen. - Im Vergleich zum Granit ist der Gneiss weit minder häufig im Innern der GebirgsGruppe. Hin und wieder (Dorf St. Christophe) geht der Granit in Gneiss über, der oft Talk enthält. Bei den genannten Dorfe weichen die Gneiss - Lagen wenig vom Senkrechten ab und streichen gegen N. Im untern Theil des Mouvane-Thales herrscht Gneiss, dessen L:gen überall an granitische Massen gelehnt scheinen. Bei Chaufrant geht der Gneiss in eine Art griinen Thonschiefers über. Am garizen üusserên Umfange der Berg - Gruppe herrscht der Gneiss. Mitunter eignet sich derselbe ein granitisches Gefüge an. Nicht selten durchsetzen ilın kleine, scharf begrenzte Protogyn-Gänge, welche eckige Gneiss - Bruchstücke umbüllen. Dieșe kleinen Gänge verfliessen nitunter in einander, und verwerfen sich. Der Gneiss enthält oft Lagen von HornblendeSchiefer, welche von zahllosen kleinen Feldspath-Gängen durchzogen werden. - Die Gneiss-Berge von Oisans, fast immer kahl und von schwärzlicher Farbe, sind auf eigenthümliche Weise zerschnitten und ausgezackt; sie stellen sich oft als Pyramiden dar, welche nur mit ihren Füssen verbunden sind, und solche Gruppen erheben sich auf den Seiten einer Haupt-Pyramide. - - Eigentlicher Talkschiefer scheint in der Gebirgs-Gruppe selbst nicht vorzukommen; allein es tritt derselbe auf, so wie man sich davon eutfernt, beim Absteigen ins Joufrey-Thal, dessen beiden Gehänge fast ganz aus jenem Gesteine bestehen. - - In den manchfaltigen Arten von Protogyn und von Greiss kommen ungemein häufig kleine Epidot-Gäinge vor, welche zugleich sehr häufig Quarz, Albit und Chlorit führen. - Oberhalb la Grave, am Eingange der Combe de Malval wird ein Bleiglanz - haltiger Quarzgang am rechten Ufer der Romanclue abgebaut; er streicht aus N. 40 W. und neigt sich etwas nach S.W., und schneidet die Blätter-Lagen des Gneisses sehr bestimmt; indessen nehmen diese in der Nähe des Ganges ein geringeres Fallen an. - Allgemeine Struktur der Berg-Gruppe, von welcher der Weiler la Berarde kreisförmig umgeben ist. Mit Ausnahme der Öffuung, durch welche der Vénéon abfliesst, lässt 
jener Circus nur ätisserst wenige und méist sehr hohe Ausschnitte wahrnehmen (Culs de la Pisse, de la IInamle, de Sais u. e. a.). Gelit man vom äusseren Fusse der kreisförmigen Primitiv - Masse alis durc! das Rumanche - oder Guisune-Thal und steigt an Gehänge liman und bis zu den Gipfeln, ia wclchem dasseibe endigt, so sieht man, dass, wäl:rend nach Aussen eine melir oder weniger regelmässige Neigung Statt hat, der Abfall gegen das Innere schr steil ist. Vom Col des Berches aus lassen sich die gewaltigen Schnicefelder überselien, welche das Nord-Gehänge des Circus bedecten, von der hohen Spitze des grossen Gletschers an bis zur Aignille dil midi de la Grure, deren Enden als Gletscher in die Combe de Maluval hinabreichen. Wenige fast schwarze Feisen-Spitzen unterbrechen das Einförmige der ziemlich gheichförmig gegen $N$. geneigten Oberfläche. Noch besser lässt sich das Verhalten des Süd-Gehänges der Berge genannt l's grandes Rousses, im W. des Col des Berches, zwischen lu Maurienue und dem Dauphiné auffassen. - Lagerungs. Beziehungeuder sogenannten Urgesteine und der Flötz-Gebirgsarten. Das 'Thal von Beauroisin zieht auf dem grössten Theil seiner Längen.Erstrectiung au der Grenze beider Felsmassen hin. Die Tiefe des Thales besteht atis Gueiss, der sich an der N.W. - Seite bis zu grosser Höhe erhebt und, ohne von andern Gebilden überdeckt zu werden, zerrissene Gipfel zusammensetzt; nach S.O. aber steigt der Gneiss nur pinige hundert Meter tiber das Niveau des Giesbaches und wird sodann durch ein sehr mächtiges System von Flützgosteinen überlagest, welctie durch die geringe Stärke ihrer Schichten, durch ihr Regrelvolles und durch die gleichmässige Art, wie sie an Abhängen sich darstellen, denjenigen durchaus ähniich getroflen werden, welche Barcelonette und Embrun beherrschen, die man auf den Diablerets und am Pilatus findet. Jenes mächtige Schichten-System bildet hier die Spitzen der Aigliere und des Clonzis, welche auf ihrem nordwestlichen Gehänge Gletscher tragen, die sich ins Beantoisin-Thal hinunterziehen. Gletscher, Lavinen und Giessbäche führen Bruchstücke der erwähnten Flötz-Gebirgsarten in Henge in die Thaltiefe. Man bemerkt darunter zumal einen grünlichen quarzigen Sandstein, der selır viele weisse Feldspath - Theilchen enthält; ferner Fragmente voa schwarzem thonig-kalkigem Schiefer und von dichtein schwärzlichem Kalkstein, der bin und wieder späthige Punkte zeigt, auc:ı von kleinen KalkspatisSchnüren durchzogen ist. Die Sandstein-Trümmer herrschen vor, sowohl was ihre Zahl, als was die Grösse betrifft; letzteres ist eine Folge der Festigkeit des Gesteins. Augenfä!lig nimmt unter den erwähnten Schichten der Kalk den geringsten Raun ein, Sandstein und schieferiger Thon. herrschen vor. In den Schichten der unmitielbaren Umgebung von ValLouise kommen Nummuliten in grösster Menge vor, und so lassen sich diese Lagen als identisch mit denen des Dept. der Basses-Alpes betrachten, welche von den nämlichen fossilen Körpern ganz erfüllt sind und den Kreide-Bäsken am Munche-Ufer gleichzeitig erscheinen. Unzweifelhaft ist, dass dic Braunbohlen von Ruquevaire und von Garbanne 
larüber ihre Stelle einnehmen. Die Schichten dieses Nutnnuliten-fül,rendeu Gebildes, welche das S.O -Gehänge der Beaurvisin-Schlucht zusammensetzen, obwohl im Ganzen sehr regelrecht, zeigen dennoch stellenweise Biegungen und Störungen, welche durch die ihnen zur Unterlage dienenden Prinitiv.Gesteine erklairbar werden. In der befragten Schlucht, unterhalb der Spitze des Clouzis sieht mau an einer Stelle, wie sogenannte Primitiv-Gesteine zwischen den, der Kreide gleichzeitigen Schichten eingedrungen sind, so dass diese theils über, theils unter jenen ihre Stelle einehmen. Beim Hinabsteigen von Entraigues nach dem Dorfe Ville-de-Val-Louise, ehe Villard erreicht wird, sieht man das System von Sandstein, von schwarzem schiefrigem Thon und von dichtem schwärzlichgrauem Nummuliten - fülırenden Kalk sich gegen den Gneiss lehuen. Die Lagen der letzteren Felsart fallen unter 45 bis $50^{\circ}$ gegen S.O.; wie es scheint, schneidet der Gneiss die Fortsetzung der Sandund Kalk-Grebilde ab. In der Nähe von la Grace, so wie bei Champoléon, an zwei sieben Stunden von pinander entfernten Stellen, treffen die Primitiv - und Jurakalk.Gebilde unter sehr denkwürdigen Umständen zusammen. Etwas nordwärts vom Weiler Frécux, eine halbe Stunde. gegen W. von Grave, auf einer das Rómunche-Thal begrenzenden angebauten Höhe crheben sich steile Gehänge, deren untere Theile aus Gneiss, aus feinkörnigem Granit und ans einem grünlichen, etwas Hornblende-fülurenden Gestein bestehen; die Lagen dieser Felsarten streichen N. 200 O. und senken sich unter 700 gegen W.N.W. Auf ihrer Oberfläche ruht unnittelbar ein sehr fester, weisslicher, kaum Spuren von Schichtung zeigender Sandstein, der aus Quarz-Körnern und einzelnen Barytspath-Krystallen besteht, welche ein lebliaft aufbrausendes Bindenittel, zum Theil Kalkspath, verkittet. Unmittelbar darüber liegt cin grauer, fein und sehr geschlossen körniger Kalk, der mit dem Sandstein da, wo beide Felsarten einander begreuzen, zusammenfliesst. Der Kalk ist nicht selır mäclitig, und auf ihn folgt zuerst ein durch seine schwarze. Farbe ausgezeichneter körniger und sedann ein minder dunkel gefürbter Kalk. Darauf kommen, in aufsteigender Ordnung: dichter Kalk mit verschiedenen organischen Uberresten; 'schwarzer Schiefer; dichter Kalk, grau, etwas schieferig, Belemniten und Enkriniten in grosser Menge enthaltend (es sind die nämlichen, welche am S.W. - Fusse der Mont-Blunc-Gruppe, zu Petit-Coeur in Tarentaise, und in der Frey im Isère-Departement gefunden werden), auch nicht näher bestimmbare Bivalven siud darin vorhanden. Diesen Kalk rechnet der Verf. zum Li a s. Über dem Kalke erscheint eine ziemlich mächtige Bank eiues sehr schieferirgen Kalkes, den ein schwarzer Schiefer bedeckt, welcher frei von fossilen Resten und durchaus den Gesteinen ähulich ist, vou denen in dieser Gregend dic Anthrazit-Lagerstätten gewühulich begleitet werden. Die !etzteren Lagen bilden den Anfang ausserordentlich mächtiger Folgen von schwarzem thonig-kalkigem Schiefer, von Kalk und von Sandstein, welche alle Berge im N. von la Grave, von Villard-d'Areine und von Col de Lautaret zusammensetzt und durchaus der Jura-Formation 
anzugehören scheint. Der untere Theil der Gehänge, welche das $\boldsymbol{R} 0$. manche-Thal begrenzen, im S. von lı Graze und von Villard-d'Areine, bestelit aus Lagen des nämlichen Systems, die sich bis zum Fusse der steilen primitiven Berge erstrecken, weiche in die Region evigen Schnees emporsteigend und mit Gletschern überdeckt die Vossprünge der Masse der Aiguille die nidi de la Grave bilden, deren Höhe $3,986 \mathrm{~m}$ beträgt. Diese Masse besteht zumal aus Gneiss, der stellenweise in Granit übergeht. Der untere Theil der primitiven Gesteine, welche mit der Masse der Aiguille du midi de la Grave zusammenhängt, besteht aus Protogyn. Und diese Theile werden von den selundiaren Lagen unterteuft; man kann die Berührung mit dem Granit oder Protogyn in der Nähe betracliten und auf weite Strecken verfolgen. Die Kontakt-Ebene, un. gefähr der Schichtung der sehundären Lagen parallel, senkt sich unter 60 bis $70^{0}$ in 0.S.O. Die an den Gianit unmittelbar anstosscude Lage ist ein grauer köruiger Kalk mit kleinen Spath-Güngen; je mehr man sich von der Grenze entfernt, um desto feiner wird das Korn des Kalkes, und in einer Weite von ungefähr 2 Metern erscheint schon dichter schwarzer Kalk nit Belemniten. - - Diese Beobachtungen hatte ÉLib DE Beaumont bercits in Jahre 1827 gemeinschaftlich mit Fínéor gemacht. In Jahre 1830 besuchte er, begleitet von Brocharis dE Villiers, Dufrénoy und Ch. D'OrbigNi, abermals das Romanche-Thal. Bei Untersuchung des granitischen Gehänges dem Villard-d'Areine gegenüber fand man in der Nähe der Grenzlinie zwischen dem Granite und dem Kalk, auf welchem derselbe ruht, jenes Gistein verändert, das Korn mehr geschlossen, die einzclnen Gemengtheile nicht so deutlich unterscheidbar, wic höher aufwänts. Stellenweise zeigt sich eine Breccic, aus eckigen oder wenigg abgerundetẹ Granit-Bruchstücken bestehend, deren sandartig erscheinendes Bindemittel nichts anderes seyn dürfte, als fein zeriebener Granit. Wo das Trümmer-Gebilde den Kalk berïhrt, ist dasselbe zum Theil zersetzt. Die Auflagerungr-Flächo des Granits auf den Kulk ist sehr geneigt, nach dem Berg-Innern zu sich senkend. Beide Felsarten greifen manchfach ineinander ein; man kann sich Handstücke verschaifen, welche zur Hälfte aus Kalk, zur Hälfte aus Granit bestehen. An den Kontakt-Stellen wird der Kalk im Allgemeinen blaulichgrau, etwas durchscheinend, wenig krystallinisch, hart und zerklïftet gefunden; er zeigt in Allgemeinen, dass er ähnliche Änderungen erlitten, wie andere Kalksteine dieser Gegenden, welche von sogenannten Primitiv-Gesteinen durchbrochen oder in ihren Lagerungs - Verhältnissen gestört worden. Erst 1 his 2 Meter abwärts vom Granit erlangt der Kalk das ihm gewöhnliche Aussehen wieder; er erscheint sodann braunlichgrau, dicht, etwas mergelig, in Lagen von ungeführ 8 Zoll Mächtigkeit. Steigt man vom Granite an über den Kalk hinunter, so lïsst sich die Folge der Lagen desselben beobachten. Nach einigen Metern.wird der Kalk mergelig und geht selbst in schwarzen, wenig festen, schieferigen Mergel über; noch weiter abwïrts erlangt der Kalk seine frühere Beschaffenbeit wieder: er ist weniger mergelig 
and fester. In verschiedenen Höhen und bis auf einge Meter vom Granit findet man ziemlich viele Belemniten und Anmoniten, die un. zweifelhaft zu jenen gehören, welcbe die Jura-Formation charakterisiren. Es ergibt sich sonach, dass der erwähnte Kalk deuselben Gebilden angehört, welche die nacıbarlichen Berge zum 'Tlseil zusammensetzen, und die oberhalb Heaux über den prinitiven Gesteinen gelagert sind. Auch bei Champoléon, einem Dorfe in Departement der hohen Alpen, sieht man den Granit an einigen Stellen unter, an andern über den Systemen der Jura-Schichten. - Am Fusse des Berges, genannt le Puy. de-Peorois, zeigt sich ein Streifen schwarzen thonigen Kalkes, der einige Lagen von Sandstein und vou dichtem grauem Kalk enthält und ganz durchdrungen ist von regellosen Massen von Hornblende - oder Augit-Gesteinen, belannt unter dem Namen Variolite du Drac, welche jedoch hier nicht wie gewöhnlich von Gyps begleitet werden. Gewisse Kalkschichten enthalten Belemniten und Enkriniten in Menge, ferner Polypiten, Bruchstücke von grossen Bivalven, von Ammoniten- und Echiniten-Stacheln, so dass jene Schichten angenfälig gleichfu!ls als zum Jura - System gehörend betrachtet werden müssen. Die Vario. lite führen mehrere Kupfererze. In einem Kalkblock sah Beauront cinen kleinen Gang von Barytspath mit Bleiglanz und Blende. - Der ganze Strich sekundärer Formationen, auf welchen die Weiler von Chatelar, Gondoins, Fermonis und Peorois erbaut sind, hat grosse Störungen erfahren. - Am steilen Süd-Gehünge des Puy-de-Peorois, längs der Schlucht, welche sich vom Tourou-Berge herabzieht, ist die Lagerung des Granits auf den sekundären Schichten ebenfalls deutlich walızunehmen. Er bedecht hier einen schwarzen, zerreiblichen thonigkalkigen Schiefer. Je weiter vom Schiefer ab, um desto mehr zeigt sich der Granit krystallinisch. Der Schiefer lässt keine Spur erlittener Änderungen wahrmehmen. Seine Schichten neigen-sich gegen das BergInnere. Nach einer Seite zieht sich dér Schiefer bis zum Weiler des Gondvins, wo derselbe auf dem an Fossilien reichen Kalkstein zu ruhen scheint, von welchem die Rede war; nach der anderu Seite erstrects er sich ziemlich weit aufwärts in die Schlucht. - Oberhalb des Weilers des Fermonts in einer sehr steilen Schlucht, die in Granit des Puyde.Peorvis anfüngt, und deren unterer Theil in dem Schicfer ausgehöhlt ist, sah der Verf. folgenden Durchschnitt aus der Tiefe nach oben:

1) thonig-kalkiger Schicfer.

2) Grauer dichter Kalk; eine Lage von einigen Dezimetern Mächtigkeit.

3) Thonig-kalkiger Schiefer, sehr zerreiblich: Stärke $=1$ Meter.

4) Grauer dichter Kalk mit vielen späthigen Punkten und kleinen Kalkspath-Gängen; 1 bis 2 Meter mächtig.

5) Ein Granit-artiges, wenig ausgezeichnetes Gestein, von nur 1 bis 2 Dezimeter Stärke.

6) Grauer körniger Kalk, vicle Braunspath-Krystalle enthaltend; Miichtigkeit $=2$ bis 3 Dezimeter. 
7) Thonig-kalkiges Gestein, ganz durchdrungen von Braunspath. Krystallen; 2 bis 3 Dezimeter stark.

8) Grauer kleinkörwiger Kalk mit Kalkspath- und Barytspath-Schnüren : einige Dezimeter mächtig.

9) Schieferiger Sandstcin mit kohligen Adern (vinules charbonnenses), von dem in dem Jura-System dieser Gegenden vorkommenden Sandstein nur dadurch verschieden, dass er etwas liärter und mehr eisenschüssig ist: enthäl kleine Gänge von Barytspath und von Bleiglanz; 2 bis 3 M.

10) Dichter quarziger Sandstein mit Feldspath-Krystallen, fust ohne Schichtung; fülıt kleine Gänge und Nester von Barytspath und von Quarz; 2 M.

11) Grobkörniger quarziger Sandstein, vielé Feldspath-Krystalle enthaltend, zumal in der Nähe des darüber gelagerten Granites. Hin und wieder umschliesst die Felsart kleine Bleiglanz-Nester.

12) Granit, der bis auf 1 oder 2 Dezimeter Entfernung vom Sandsteine sich minder krystallinisch zeigt und häufige kleine Gänge und Nester von Barytspath und Bleiglanz aufzuweisen hat. Höher aufwärts wird das Gestein mehr und mehr krystallinisch. Aus Granit besteht die ganze obere Masse des Berges.

Was besondere Beachtung verdient, ist der Umstand, dass da, wo Granit mit schwarzem Glimmer und rothem Feldspath, welcher die er. habensten Berge der Gegend um Champoléon zusammensetzt, mit sekundärem Gestein, Kalk, Sandstein oder Variolit zusammentrifft, an der Grenze diese Felsarten sowohl als der Granit erzführend geworden sind, und Nester so wie kleine Gänge von Bleiglanz, Blende, Eisenund Kupferkies, Barytspath und Braunspath umschliessen. Die sekundären Gesteine sind krysta!linischer und fester in der Nähe der Kontakt-Oberfläche ais ausserdem, während das Gegentheil hinsichtlich des Granites Statt hat. Und alle diese Erscheinungen lassen sich an melreren Orten und unter denselben Umständen beobachten, so dass die Gegenwart der metallisclon Substanzen und des Barytspathes nicht als zufälig anzusehen, sondern für eine Folge des Beisanmenseyns der beiden Gesteine gelten dürften. Die Überlagerung des Granites rülırt keineswegs von äussern und bloss mechanischen Ursachen her, es ist nicht von einem Bergsturze oder von ähnlichen Ereignissen die Rede, sondern vom Wirken der Gewalten in den untern Tiefen, von Phänomenen analog der ersten Ausfüllung metallischer Gänge. Die Art, wie der Barytspath und die metallischen Substanzen auftreten, machen es glaubhaft, dass dieselben zwischen dem Granit und den geschichteten Felsmassen eingedrungen sind und die Ablosungen beider gleichsam haben verkitten helfen. Die Auflagerungs - Weise der Primitiv - Gesteine auf dem Jurakalk - Gebilde an den verschiedenen beobachteten Stellen und sänmtliche bei solchem Verhältniss wahrgenommene Erscheinungen, wie sie im Vorhergehenden geschildert worden, thun deu Weichheits. 
Zustand, oder den Zustand unvollkommener Erkaltung dar : in welchem sich die ersteren befanden, als sie ihre Stellen einnahmen.

J. Nöggentu: über das Vorkommen des Goldes in der Eder und in ihrer Umgegend (Kapstexs Archiv für Min., VII. B., S. 149 ff.). Die Nachrichten über das Vorkommen des Goldes in lem erwähaten Flusse und in dem Gobirgs-Gebiete, welches denselben seine Wasser zusendet, sind sehr alt. Der Vf. fügt der von W. L. V. EschWeGE ${ }^{\circ}$ ) gregebenen Mitheilang folgende Notitzen bei. Die ältesten gedruckten Nachrichten über las Gold-Vorkommen an Eisenberge bei Corbach ist bei Acricola zu finden. Er spricht von Gold-Gängen. Auch Brëcknax erwähnt derselben, und nach ihm sollen 1560 noch 27 Mark Gold gewonnen worden seyn. Wie Carcurs erzählt, so wurde noch gegen die Mitt: des vorigen Jahrhunderts bei Goldiausen am Eisenberge "aus einem Trümmchen und aus den Halden" Gold gewaschen. Nach Kupsteis sah, man die in die Éder fallenden Gold-führenden Bäche Himne (Wmine) und Irombecke für dic einzigen Goldhringer jenes Flusses an. (Allein wie Escrwegr behauptet, so ist noch in vielen andern Bäclen dortiger Gegend Gold gefunden worden.) Bei Ulumasx lesen wir, dass Kar der Grosse das erste Goldbergwerk in Aner Walde bei Frankenberg éröfnet habe u. s. w. Dic Kompagnie, deren Stiftung rox Eschwege's Werk ist, begaum ihre Arbeiten zu Berghein an der Eder. Das Gold kommt in dünnen Blättchen von kaum crliennbares Grösse bis $\frac{1}{4}$ Linie Breite und Länge vor. Mit ansitzendem Gestein will man es nie getroffen haben. Magneteisen, Roth- und BraunEisenstein sind die schweren, beim Waschen übrig bleibenden, metallischen Theile. - Der oben erwähnte Eisenbery, eine Fortsetzung des liohen Süderländischen Übcrgangs-Grobirges im Herzogthum I'estphalen, besteht aus Thonschiefer-artiger feiukörniger Grauwacke, welche Ahdrücke von Posidonia Becheri und von Ellipsolilithes compress us füht. Auch Kieselschiefer nimmt an der Zusammensetzung des Berges wesentlichen Antheil und bildet zumal das Hangende, obwohl auch beide Gesteine mehrmals zu wechsein scheinen. Die Schichten streichen zwischen St. 6-4, und fallen gegen S.O. Der einst so bedeutende Gold-Bergbau hat vielleicht ausschliesslich anf der Scheide beider Gebirgsarten Statt gefunden; denn auf dem Streichen derselben liegt ein Pingenzugr vón ungelälır $\frac{1}{2}$ Stuude Erstreckung. Auf den Halden findet man vorwaltend die erwähute Thonschicfer-artige Grauwacke; von Gang-Massen lieine Spur. Dass die Produkte des Eisenberger Gold-Berghaues an den tiefern wasserreichen Punkten verwaschen worden sind, ist wahrscheinlicher, als dass man sich früher bloss

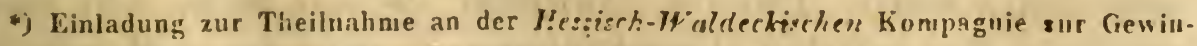
wung des Goldes aus dem Eder-F7usse (1532). 
auf das Verwaschen von Geröllen and Dammerde beschränkt haben sollte. - Das Frebirgs. Verhalten bei Beringhausen an der Hopke, wo früher Gold-Gruben gewesen seyn sollen, stimmt durchaus mit denen vom Eisenberge überein. Frankenberg, der cberste Punkt an der Eder, hat seinen Sitz in Übergangs-Gebirge. - Die Bäche bei Hertahausen, welche. man chemals für die einzigen Goldbringer der Edder zu halten geneigt war, kommen alle aus der Gegend vom Eisenberge herab. Alte Alluvionen kömen das Gold dieses Berges oder der Fortsetzung seiner oder verwandter Lagerstätten sehr verbieitet haben, und daher kann die Uz'sprungs-Quelle des Goldes anderer Bäche die nämliche gewesen seyn mit denen von Hertahausen. - Die in cie Eder mündende Orke führt kein Gold, aber die aus den Waldeckiscken kommende $A h r$ ist Gold-fuhrend, und nach Vereinigung derselben mit der Orles wird letztere es auch. Die Ahr aber empfängt ihr Gold von mehreren Nebenwassern und Schlachten, welche ihr aus der Gegend des Sisenberges zugehen. Alle Gold-führenden, der Eder zufliessenden Bäche liegen auf der nördlichen Seite dieses Flusses. Nach v. EschwEGE sollen auch andere, auf der entgegerogestzten Fluss-Seite laufenden Bäche, welche natürlich ihren Erzgehalt nicht vom Eisenberge erhalten können, Gold-führend seyn. Und was nicht unwichtig, ist, dass im Bereiche dieser Bäche wieder Kieselschiefer-Lager in der Grauwacke vorkommen. Der Verf, ist weit entfernt anzunehnen, dass bei jedem Kieselschiefer der Gegend Gold vorkommen müsse, denn der Umstand, dass in allen Bächen, welche westlich von der Orke auf dem Süd-Abhange des Sïlerländischen Gebirges bis nach Berlenburg herab. fliessen, selbst in mehreren dieser Bäche, welche ihr Bett zum Theil im Kieselschiefer haben, kein Gold gefunden wurde, spricht gegen eine solche Hypothese. Aber dass bei gewissen Kieselschiefer-Bildungen, oder ganz in ihrer Nähe in der Grauwacke das Gold vorhauden ist, dürfte kaum in Zweifel zu stellen seyu. Es fehlt nur noch das eingesprengte Gold in der Felsart selbst zu finden. Die dünnschieferigen Grauwacken mit Posidonia und Ellipsolithes, welche den Kieselschiefer begleiten, ist $\mathbb{N}$. besonders geneigt für die Gold-fübrenden Gesteine zu halten.

F. Dreves: ïber den frühern Gold-Bergbau im Waldeckischen. (A. a. O. S. 167 ff.). In der nordwestlichen Fortsetzung des bei Wildungea sich entwickelnden Grauwacken und Thonschiefer-Gebirges erhebt sich der Eisenbery, 1 Stunde westl. von Corbach zu einem der höchsten Punkte dieser Gegend. Nach N.'und S. zichen sich vom Eisenberge aus, in niedrigerem Niveau, Berg-, oder richtiger Hügel-Rücken, welche ebenfalls dem 'Thonschiefer-Gebirge angehören und die vor ihnen ausgebreitete Kupfer-Formation gleichsam als eine Mauer oder Wand umgebeu. Der Kalkstein dieser Formation, - denu das Kupferschiefer- 
Flötz zeigt sich nur selten, - ist ein konstanter Begleiter des Thonschiefers und bildet auf dessen ganzem Zuge von Wildungen aus über Waldeck u. s. w. bis zum Stadtberge die Scheide zwischen Thonschiefer und buntem Sandstein, der die östliche Hälfte des Waldeck'schen konstituirt. In dieser ganzen Ausdehnung zeigt das Kupferschiefer-Gebirge vielfache Anomalie'n. Abgesehen davon, dass die manchfaltigen Kalksteinarten, welche den Kupferschiefer des Thüringerwald-Randes bedecken, sich hier abwechselnd bloss auf Rauchkalk - hin und wieder mit Nestern von Kalkmergel, - Stinkstein und Zechstein beschränken, sowie abgesehen davon, dass der hiesige Kupferschiefer selbst sich wesentlich von dem obigen unterscheidet, indem bei geringem $\mathrm{Bi}$ tumen - und Kohlen-Gehalt die Schwefel-Verbindungen des Kupfers fast ganz darin fehlen und sich fast keine Spur eines Silber-Gehaltes darin zeigt, - ist der Kupfer-Schiefer hier von weit geringerer Ergiebigkeit an Kupfer, dessen er höchstens 3 bis 4 , gewöhnlich aber nur $1 \frac{1}{2}$ Prozent enthält, und lagert sich unnittelbar auf Thonschiefer oder Grauwacke, da hier das Todtliegende gänzlich fehlt. Was dem Kupferschiefer entzogen worden ist, das scheint dem Zechstein des Hangenden zugesetzt worden zu' seyn; denn dieser ist reich an eingesprengten Partikelchen Kupferglanz. Der Eisenberg selbst besteht aus einer, an der O.- und S.O. - Seite steil abfallenden, nach den übrigen Richtungen hin mehr Terrassen-förmig abgestuften Thonschiefer-Masse mit sanft gerundetem Gipfel. Im Ganzen genommen nähert sich der Thonschiefer des Eisenberges bald mehr dem Kiesel-, bald dem Grauwacken-Schiefer, die tieferen Schichten an der nordöstlichen und an der nordwestlichen Seite scheinen, dem Ausgehenden nach, aus reinerem Kieselschiefer zu bestehen. Der Thonschiefer des Eisenberges streicht zwischen St. 4 und 5, im Durchschnitt St. 4,4, und fällt gegen Südost unter abwechselndem Winkel. Dic Petrefakten beschränken sich auf Posidonia Becheri, die an westlichen Abhange des Gipfels in grosser Menge vorkommt. Hier beurkundet ein mehrere Hundert Sehritt fortsetzender Pingenzug den frühern Berybau der auf zwei güldischen KupfererzGängen geführt wurde. Die Erze dürften einen nicht unbedcutenden Gold-Gehalt besessen haben.

Boblaye und Virlet: über die Emporhebungen der Bergketten in Griechenland (Bullet. de la Soc. géol., T. V, p. 207 etc.). Im Allgemeinen haben die Ketten eine geradlinige Richtung; das bohe Arkadien erscheint nur in Folge der minder häufigen Biegungen mchrerer verschiedenartigér Ketten als Gebirgs-Masse; die Berge von Voidia, Ziria, die trachytischen Höhen von Methana, Aegina und einige Eilande des Archipels sind isolirte Gruppen. - Gleich den Küsten von Norwegen und Schottland erscheint Griechenland zerrissen und zerstückt in grössere und kleinere Inseln und Felsmassen. Eine Erhebung

Jahrgang 1836. 
in Massen hat das tertiäre Gebilde von Morea zu einer mittlen Höhe von 2-300 Metern emporgetrieben: in den Eilanden des Archipels fand ein solcles Ereigniss nicht Statt, diess beweisst das Niedere des absoluten Niveau's ihrer Gipfel. - Die Verf. unterscheiden in Griechenland neue Erhebungs-Systeme, deren ältestes sie als das olympische bezeichnen. Sein Streichen ist ungefähr N. $42^{\circ}$ in $45^{\circ} \mathrm{W}$, und es lässt sich dasselbe durch Macedonien und Thessalien hindurch nach Dalmatien und Illyrien und bis Kärntien verfolgen, wo es durch das Pyrenäische System Beaviont's modifizirt worden. Das Pindische Sys te $m$ streicht aus N. $24^{\circ}$ in $25^{\circ}$ W., vom äussersten nördlichen Ende Albaniens bis Lepanto u. s. w. 'Im N. von Morea sind Störungen eingetreten zwischen der Periode der Kreide-Bildung und jener der tertiären Ablagerungen; dadurch entstand das Achuische System, aus N. 590 in $60^{\circ} \mathrm{W}$. streichend. Die Katastrophe ging der Bildung der tertiären Trümmer-Gesteine von Nord-Morea voran. Das Erymanthische System, aus $\mathrm{N} .65^{\circ}$ nach $70^{\circ} \mathrm{O}$. ziehend, hat noch minder bedeutende Spuren hiuterlassen, als das vorhergehende; es fällt zwischen die Entstehung der tertiären Konglomerate und jene der Subapenninen-Gebilde. Auf Skyros haben Trachyte, welche die Schiefer durchbrachen, die Insel in zwei Hälften geschieden und die sekundären Formationen emporgehoben. Das Argolische System besteht aus kleinen Ketten und erhabenen Kämmen; seine Richtung ist ungefähr aus 0 . in W. In Thessalien haben mehrere Kalke das nämliche Streichen. Das System des Tenare zieht aus N. $4^{\circ}$ in $5^{\circ} \mathrm{W}$. Wie in Ungarn, Siebenbürgen und am Eude der üstlichen Alpen hat dieses System wenige Schichten-

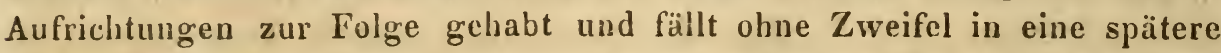
Zeit, als die neuesten Theile des Subatluntischen Gebietes. Das Dardanische System ist im nördlichen Griechenland vorhanden. Sein Streichen N. $40^{\circ}$ O. Es hat die Dardanellen erzeugt, den Süsswasserkalk von ililiodromia emporgehoben u. s. w. Das Subatlantische Gebiet und die alten Alluvionen wurden, in der ganzen Runde um den Peloproines, in Masse emporgehoben, jedoch nur allmählich, wie solches die wagerechten Terrassen am Ufer darthun und die aufeinander folgenden Pholaden-Linien. - Auch kreisförmige Erhebungen hatten in Morea und im Archipelayıs Statt. Der Berg Ziria ist cines der ausgezeichnetsten Beispiele; ferner gehören dahiu : 'der Voidia-Berg, der SantaMeri, die grossen Trachyt-hassen von Aegina, Kaimeni, Milo u. s. w.

A. D'Orbignx: geologisehe Notizen über Patagonien, BuenosAyres, Chili und des hohen Peru (Bullet. géol. V, 420 und 421). In einem Theile von Brasilien, so wie in den östlichen Distrikten von la luta fand der Verf. meist schicferige Urgebilde und das unermessliche tertiäre und Alluvial-Becken der Pampas von Buenos-Ayres : alten Meeresboden, welcher sich über, 200 Stunden weit in der Richtung aus 
O. nach W. erstreckt. Das tertiäre Gebirge erscheint wenig manchfultig; Thone, Sand und Molasse, in den untern Lagen hin und wieder Versteinerungen, Gebeine von Säugethieren in den obern, auch Fluss - Konchylien kommen vor. Die Andes - Kette ist mit plutonischen und vulkanischen Felsarten bedeckt, über welche Bimsstein-Konglomerate und Asche verbreitet sind. Das Plateau zwischen der grossen Andes-Kette und den östlichen Kurdilleren bestebt aus altem Sandstein, über welchem hin und wieder ein Kalk mit Productus, Spirifer und Terebratula auftritt, so unter anderen am Titicaca-See. Meerische Petrefakten kommen hier in einer absoluten Höhe von 12,000 F. und darüber vor. Die östliche Kette hat einige granitische Gipfel; aber in den Theilen gegen 0. steigen Schiefer und andere Felsarten mit Trilobiten zu den erhabensten Stellen empor und verdrängen dic primitiven Gebilde. Auf dem östlichen Gehäuge sind alte Sandsteine, zuweilen Petrefakten enthaltend, schr mächtig entwickelt; sie ruhen auf Chiastolith-führendem Schiefer, und zeigen Spuren erlittener Störungen, denn ihre Sclichten neigen sich nach allen Seiten, obwohl das gemeinste Fallen gegen O.N.O. ist. Diese Formationen setzen den Rand des grossen Beckens von Majos zusammen, dessen Grund mit neuen Alluvionen bedeckt ist. In der Provinz Chiquitos herrscht Glimmerschiefer, der gegen S.O. an den Ufern des Paraguay von altem Sandstein bedeckt wird. Eine primitive Kette, welche so gut als unbekannt ist und auf den Karten fehlt, schneidet das Becken der Pampas von jenem von Patagonien, das aus tertiären Ablagerungen besteht, die in ihrer Folge viel Ähnliches zeigen mit den Formationen der Gegend um Paris. So findet man u. a. Austern-Bänke über Knochen-führenden Lagen abgesetzt, welche auf Gyps ruhen; auch sind Wechsel-Lagerungen von Süsswasser - und von marinischen Erzeugnissen Wahrnehmbar. Die steilen Ufer von $100-200$ Meter Höhe gewähren schöne Durchschnitte, wie u. a. längs des RioNegro. In den Ebenen von Patagonien sind zahlreicle Salzsee'n vorhanden, und selbst in weiter Entfernung vom Meere; süsses Wasser ist hier sehr selten.

Fabian: über das Verhalten der Soolquellen bei Salze, nebst einer Darstellung von den neuerlich darauf vorgenommenen Schacht - Arbeiten, durch welche es gelungen ist eine in ihrem Salz-Gehaltgesunkene Quellewieder zu heben (Karsten, Archiv f. Min., VIII. B., S. 52 ff.). Im Ganzen mehr halurgischen Inhaltes und zu cinem Auszuge nicht geeignet.

W. Gregory: über das Petrol vou Rangoon (Erpmann und Schweigger - Semel, Journal für praktische Chemie B. I, S. $1 \mathrm{ff} .>$ JaMes. Edinb. Journ. 1835, XVIII, 38t-385). Aus den Versuchen 


\section{$-384$}

von Christrson, so wie aus denen des Verfassers geht hervor, lass die Meinung, welche Reichenвach über die Bildung des Stein. öls äusserte, wichtige Modifikationen erleiden müsse, indem das Steinöl nicht überhaupt das Terpentinöl der Pinien der Vorwelt ist; und man darf nunmehr dem Schlusse-nicht entsagen, dass es zweierlei Arten von Steinöl gebe, wovon die eine Terpentinöl, die andere dagegen ein Erzeugniss der trockenen Destillation ist. Von den Bergwerken, aus welchen das Paraffin-haltige Petrol herkommt, weiss man mit Sicherheit nichts. Wenn es Stciukohlenlagen sind, so müssen diese Steinkohlen offenbar eine ganz verschiedene Beschaffenheit haben von der unserer gewölnnlichen Steinkuhle, welche, wie Reichesbacil sehr richtig bemerkt, nie in einer hohen Temperatur sich befunden haben können.

Ausbruch des Vesuv. Am 13. März 1835 Abends kündete eine heftige Erschütterung des Vesurs wieder vulkanische Phänomene an. Eine Mündung öffnete sich und warf Rauch und Asche aus. Am 14. war der Bodeu des neugebildeten Kraters von vielfarbigen Flammen beleuchtet. Diese Explosion war mit einem dumpfen Donner, gleich dem Brausen des stürmischen Meeres, und von wiederholten Erschütterungen des Berges begleitet. Im Innern des alten Kraters entstanden zwei Spalten, aus welchen vielfarbige Rauchwolken emporwirbelten. Am folgenden Tage wurden aus mehreren kleinen Kratern, die in den im letztverflossenen August Statt gehabten Eruptionen entstanden waren, vulkanische Materien ausgeworfen, und aus dem grossen Krater fiel ein Aschenregen, welcher ebenfalls in mehreren Farben spielte.

(Zeitungs - Nachricht.)

Prinsep: Vorkommen des Platins in Ava (Asiatic researches, V. XVIII, P. II, p. 279). Den von Lave erhaltenen Mittheilungen zu Folge kommen gemengt mit dem Goldstaube, welcher nördlich von Ava gefunden wird, Metallkörner vor, ganz wie Eisen aussehend, die vom Magnete angezogen werden. Viel Erz findet sich auch unter dem Goldstaube aus den kleinen Flüssen, die in der Richtung von Banman kommen und in den Irawadi fallen. Dass das Erz Platin ist, hat Prinsep's Analyse dargethan. Die begleitenden Substanzen sind: Spinell, Augit, Quarz, Smaragd, Goldkörner und Magneteisen.

Pleischl hat Kali und Iod im Karlsbader Wasser nachgewiesen (Erdm. u. Schweig. - Seid. Journ. V, 39 ff.). 
G. Rose: über die Gebirgsarten, welche mit dem Namen Grünstein und Grünstein-Porphyr bezeichnet werden (Pog. GEND. Ann. d. Phys. XXXIV, 1 ff.). Die als Grünstein oder Grünstein-Porphyr bezeichneien Gebirgsarten sind untereininder von sehr verschiedener mineralogischer Beschaffenheit. Sie scheinen dem Verf. fünf verschiedenen Gebirgsarten anzugehören, welshe er vorläufig nit dem Namen Diorit, Diorit-Porphyr, Hypersthenfels, Gabbro und Augit-Porphyr bezeichnen will. Sie tragen folgende Charaktere:

1) Di orit, körniges Gemenge aus Albit und Hornblende. Der Albit - weiss, meist nur durchscheinend, nicht selten grünlich. weiss gefärbt, wahrscheinlich durch beigemengte Hornblende - ist in der Regel deutlich spaltbar nach zwei Richtungen, die sich unter einem Winkel von ungefähr $93^{\circ}$ schneiden. Im Ganzen sind die Spaltungs-Flächen nie so vollkommen, wie die des Feldspaths. Die Hornbleude - grünlichschwarz bis schwärzlichgrau, und undurchsichtig ist spaltbar nach den zwei Richtungen, die sich unter dem Winkel von $124^{\circ}$ schneiden. Vor dem Löthrohr schmilzt sie auf Koble zu schwarzem Glase, das schwach magnetisch ist. - Als zufällige Gemengtheile finden sich: Quarz, Glimmer, Eisenkies und Magneteisen. - Quantitatives Verhältniss der Gemengtheile, so wie Grösse des Kornes derselben sind sehr verschieden. Zuweilen ist das Gemenge so grobkörnig, dass die vorwaltende Hornblende über einen Zoll gross ist (Bogoslonesk im Ural). Ähnliche grobkörnige Gemenge finden sich auch unter den von den Alten verarbeiteten Dioriten. Häufiger sind Diorite von mittlerem Korne. Bei Dioriten mit vorwaltenden Albit liegt zuweilen die Hornblende in einzelnen Krystallen und Körnern im körnigen Albit; und eben so liegt bei Dioriten mit vorwaltender Hornblende der Albit in einzelnen Krystallen in der körnigen Hornblende. Ein Stïck Diorit von Alapajewsk in Ural hatte ein spezifisches Gewicht von 2,792. Diorit kommt unter dem Grünsteine des Urals ziemlich häufig vor, und setzt in nördlichen Ural den grössten Theil des Hauptrückens zusammen. Deutliche Gemenge bilden in andern Ländern u. a. die Diorite von der Rothenbury am Kiffhäuser in Thüringen, von Eberbuch und von der Riesensüule im Odenwalde, vom Ehrenberge bei Ilmenau, von Hodritsch bei schemnitz u. s. w. Diorite mit schr vorwaltender Hornblende kommen am Ural ebenfalls häufig vor; sie finden sich am Harz an der Russtrappe und am Mahnberg an der Ocker, zu Mitweida im Erzgebirge u. a. s. v. a. 0.

2) Diorit-Porphyr besteht aus einer Hauptmasse mit inliegenden Albit- und Hormblende - Krystallen. Die Hauptmasse - wie bei allen Porphyren, wahrscheinlich ein feinkörniges Gemenge vorzüglich von den Substanzen, die darin krystallisirt vorkommen - ist theils grünlich- oder schwärzlich-grau, theils grünlich-oder graulich-weiss, aber stets trüb; ihr Bruch ist uneben, feinsplittrig, matt. Vor dem Löthrohr schmilzt sie zu schwärzlichgrünem Glase. Der Albit findet sich bald in weissen, glänzenden, deutlich spaltbaren, scharf begrenzten Zwillings- 
Krystallen, bald sind seine Krystalle weniger scharf begrenzt, etwas grünlich oder graulich gefärbt und von splittrigem Bruche. Die Hornblende ist graulichschwarz und hat sehr vollkommene und glänzende Spaltungs - Flächen. Die Krystalle sind lang, Säulen - förmig, oft von bedeutender Dicke, und mehr oder weniger fest mit der umgebenden Grundmasse verwachsen. $\mathrm{Zu}$ den zufälligen Gemengtheilen gehören die nämlichen, die sich auch in den Dioriten finden; der Quarz, meist in an den Kanten abgerundeten Hexagon - Dodekaedern, kommt am häufigsten vor. - Albit und Hornblende erscheinen oft in fast gleicher Menge in der Grundmasse inliegend, und nehmen nicht selten so viel Raum cin, wie die Grundmasse. Spezifisches Gewicht eines Diorit-Stïcks aus der Goldwäsche Pitalewsky bei Bogoslowsk = 2,584. - Am Ural wird der Diorit-Porphyr häufig und ausgezeichnet getroffen; ferner erscheint derselbe in Mexico und Chili, zu Veröspatak in Siebenbürgen, zu Schemniz (hier wird der Silber-Bergbau darin getrieben); die Siebenbürgischen und Ungarischen Porphyre sind meist zersetzt, und letzteren ist Talk zufällig beigemengt.

3) Hypersthenfels, ein körniges Gemenge aus Labrador und Hypersthen. Die körnigen Zusammensetzungs-Stücke des Labradors siad vorzüglich in zwei Richtungen spaltbar; der Winkel ist fast derselbe, wie beim Aibit; auch kommen sie unter den nämlichen Verwachsungen vor, die besonders in grobkörnigen Abänderungen, wie in jenen von der $\boldsymbol{P}$ auls-Insel bei Labrador, deutlich sind. In grobkörnigen Abänderungen ist der Labrador graulich-, in weniger grobkörnigen Schnee-weiss, und im letztern Falle, da auch die chemisch-physikalischen Merkmale zu ejner scharfen Bestimmung nicht zureichen, vom Albit schwer zu unterscheiden. Am leichtesten dürfte Labrador daran zu erkennen seyn, dass er nur mit Augit (Hypersthen und Dialag mit eingeschlosseu), nie mit Hornblende gemengt vorkommt. Von den Spaltungs - Flächen des Hypersthens ist jene meist am vollkommensten, welche mit den andern Winkel von $134^{\circ}$ macht. Zuweilen haben die vollkommensten Spaltungs - Flächen geradlinige Umrisse (Hypersthenfels von Monzon in Tyrol), und bilden alsdann symmetrische Sechsecke mit zwei Winkeln von $118^{\circ}$ und vier Winkeln von $121^{\circ}$. Der Hyperstheu ist schwärzlichbraun, schwärzlichgrün bis grünlichschwarz; einige braune Abänderungen (Panls - Insel und Penig in Sachen) erscheinen auf der vollkommensten Spaltungs - Fläche fast kupferroth, und von metallischem Perlmutterglanz. Die körnigen Zusammensetzungs-Stücke des Hypersthens sind zuweilen an den Grenzen gegen den Labrador mit grünlichschwarzer Hornblende verwachsen. Ohne Verwachsung mit Hypersthen, in deutlichen Krystallen und in Körnern, kommt die Hornblende in Hypersthenfels nie vor. Zu den uuwesentlichen Gemengtheilen gehören Olivin, Glimmer, Apatit, Titaneisen und Eisenkies: - Im Allgemeinen ist in Hypersthenfels die Masse des Labradors vor der des Hypersthens vorherrschend. - $\mathrm{Zu}$ den Fundorten des Gesteines gehören ausser den erwähnten noch: 
Buchan bei Neurode in Schlesien, Elfalen in Schweden, Cornisge auf der Insel Skye. Am Harze ist der Hypersthenfels schr häufig und macht den grössten Theil ler dort vorkommenden Grünsteine àus; aber er erscheint hier meist wenig ausgezeichnet. Am ausgezeichnetsten ist er an der Peters-Klippe unfern des Büchenberges bei Wernigerode, an der Heinrichs - Klippe beim Mägdesprung, in Hütlethal bei Klausthal u. s. w.

4) G a b b r o, körniges Gemenge aus Labrador und Diallag, dem vorigen sehr verwandt; nur ist der Labiador nicht immer so deutlich spaltbar. $\mathrm{Zu}$ den unwesentlichen Gemengtheilen gehören Glimmer, Eisenkies und Titaneisen; häufiger findet sich in einigen Abänderungen des Gabbros Serpentin, doch nur dann, wenn dieser selbst in grüsserer Menge mit jenem Gestein vorkommt, wie u. a. bei Flurenz und Brianfoul. Nicht selten ist das Gabbro-Gemenge selur grobkörnig und gewòhnlich herrscht der Labrador vor. Am Ural findet sich eigentlicher Gabbro eben so wenig, wie ausgezeichneter Hypersthenfels. Bei Neu. rode in Schlesien trifft man dagegen sehr grobkörnige und deutliche Gemenge, ferner an der Baste am Harze, bei La Prese in Veltlin und unfern Ayaraca in Peru.

5) A u g i t - Pórphy r besteht aus einer Grundmasse mit inliegenden Hornblende- [Labrador-?] urd Augit-Krystallen. Die Grundmasse hat gewölinlich eine grüne oder graue Farbe, wie jene des Dio. rit - Porplıyrs; zuweilen ist sie dunkel und alsdann selır Basalt-ähnlich. Schmilzt in der Platin-Zange gewöhnlich nur an den Kanten zu schwärzlichgrünem Glase. Yon Chlor-Wasserstoff-Säure wird ihr feines Pulver unter Abscheidung der Kieselsäure aufgelöst; die Auflösung enthält 'Thonerde, etwas Eisenoxyd und viel Kalk. Ob auch Talkerde und ein Alkali darin vorhanden, ist wahrscheinlich, doch nicht untersucht. Die Labrador-Krystalle sind die Feldspath-ähnlichen, und, wie die eingewachsenen Stücke, immer Zwillinge. Ihre Farbe ist schneeweiss, oder durch Einmengung der Grundmasse grünlich und graulichweiss. Nicht selten sind sie sehr klcin und undeutlich; bei Ajatskaja in Ural werden dieselben von mehr als einem Zoll Länge getroffen. Die Augit-Krystalle haben die Form, welche ihnen gewöhnlich zusteht, wenn sie eingewach. sen vorkommen. In vielen Fällen zeigen solche Krystalle nur zwei Spaltungs-Flächen, die sich unter Winkeln von $124^{\circ}$ schneiden, wic bei der Hornblende. Diess sind die Krystalle, welche der Verf, nach ihrem häufigen und ausgezcichneten Vorkommen im Ural, Ur alit genannt hat. Er hält sie für Augit-Krystalle, die mit Beibehaltung ihrer äussern Formen sich in Hornblende. Masse umgeändert haben. Zuweilen haben die Uralit-Krystalle noch einen Kern von Augit, der lichter und gras. grüı ist, und dessen Spaltungs - Flächen den äussern Frystall - Flächen des Uralits vollkommen parallel sind. $\mathrm{Zu}$ den unwesentlichen Einmengungen gehört nur fein eingesprengter Eisenkies. In manchen AugitPorphyren sind Labrador und Augit in ziemlich gleicher Menge vorhanden; häufiger finden sich jedoch solche Gesteine, die entweder Labrador 


\section{$-388$}

oder Augit allein, oder statt des letztern Uralit enthalten, oder es erscheint einer jener Gemengtheile sehr vorherrschend. Zuweilen wird die Hauptmasse Mandelstein - artig, und in den Blasenräumen werden Quarz, Zeolithe und Kalkspath, auch Epidot getroffen. Unter allen, mit dem Namen Grünstein bezeichneten, Gebirgsarten findet sich der AugitPorphyr am häufigsten. Er fehlt in wenigen Gebirgen, wo Grünsteine vorkommen; im Ural erscheint derselbe in bedeutender Menge und Manchfaltigkeit. In Deutschland hat der Harz das Gestein in den schönsten Abänderungen aufzuweisen (Gegend zwischen Elbingerode und Rübeland, zwischen Blankenberg und Hüttenrode u. s. w.).

P. Merian: über die in Basel wahrgenommenen Erdbeben (Basel; 1834). Als Resultat ergibt sich folgende Zahl der Tage, an welchen zu Basel Erderschütterungen wahrgenommen und aufgezeichnet worden :

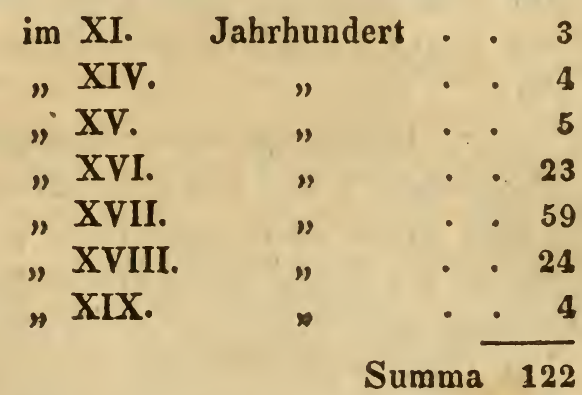

Nach den Monaten geordnet, stellen sich 118 dieser Tage so:

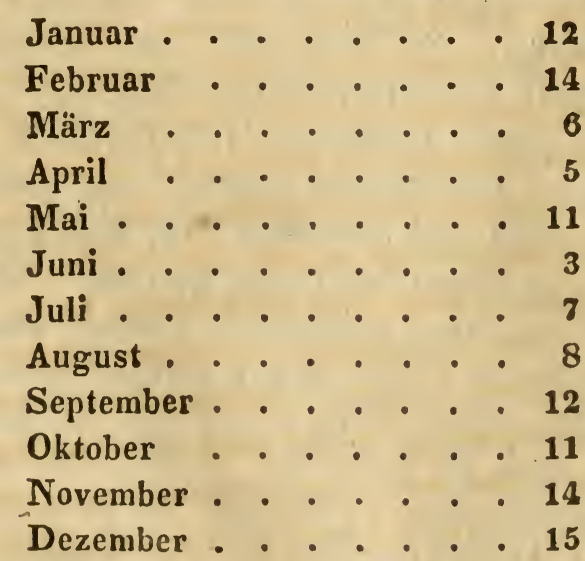

Das heftigste Erdbeben war jenes am 18. Okt. 1356 beginnend. Es kam eine Feuersbrunst hinzu, und durch diese, wie durch die ErdErschütterung verloren 300 Menschen das Leben. Auch die Erdbeben vom 21. Juli 1416, 7. September 1601 und 17. November 1650 verdienen besonderer Erwähnung. 


\section{$-389$}

KeILHAv: geognostische Karte von Jemtland und dem nördlichen Amt von Trondhjem (Berzelius, Jahresber.; 1834, S. 398). Auf einer Reise in Jemtland und in nördlichen Ante Trondhjem hat der Verf. Beiträge zu einer geognostischen Karte von diesen Landschaften, und besonders von dem Theil gesammelt, welchen die ÜbergangsFormation einnimmt. Er hat daraus einen Entwurf zu einer geognostischen Karte, besonders von Jemtland, ausgeführt. Dabei schilderte er die geognostischen Verhältnisse der von ihm besuchten Stellen und wendet besondere Aufmerksamkeit auf die Überlagerung der ÜbergangsGebirge über den Urgebirgen. In Übcreinstimmung mit seinen frühern Ansichten fand er nirgends eine scharfe Grenze zwischen beiden, sondern beide stets in Übergang auf eine Weise mit einander gemengt, die mit der Vorstellung von dem plutonischen Ursprung der einen, und dem neptunischen der andern unvereinbar ist.

Sinken des Meeres. Zu Montevideo beobachtete man am 15. und 16. Sèptember 1835 eine ausserordentliche Natur-Erscheinung. Die See sank plötzlich, so dass der Hafendamm trocken gelegt und die Anker an den Schiffen sichtbar wurden. Das Wasser stand $20^{\prime}$ tiefer als gewöhnlich, und blieb so 30 Stunden lang, worauf das Meer seine gewöhnliche Höhe wieder erreichte.

(Zeitungs - Nachricht.)

J. Houman: Notitz über Isle de France und Bourbon (Voyage round the world, III, p. 183 etc., London, 1835). Isle de France und die benachbarten kleinen Inseln sind durch submarine Ausbrüche entstanden; liesse sich zwischen jenem Eilande und Bourbon, wo noch ein Vulkan brennt, eine Verbindung finden, so würde hinreichende Aufslärung zu erhalten seyn. Nach Brunels, eines glaubwürdigen Berichterstatters, Erzählung, soll am 4. Aug. 1786, Morgens 35 M. nach 6 Uhr auf Isle de France ein Erdbeben eingetreten seyn. Auf heftige 0.und O.S.O.-Winde, die vier Tage lang anbielten, folgte eine Stille; da hörte man ein unterirdisches Getöse; welches mit einer plötzlichen Explosion endigte und gleichzeitig liessen sich zwei heftige Bebungen des Bodens verspüren, von denen eine eine horizontale, die andere eine vertikale Richtung nahm. Das Barometer blieb unverändert. Wie es scheint, so entströmten dem Vulkan auf Bourbon während jener Erd-Erschütterung sehr grosse Laven-Mengen. - Die basaltischen Säulen mit ihren verschiedenen Neigungen, die eigenthümliche Bildung von Isle de France - welches Eiland in drei Berg-Gruppen geschieden erscheint, Port Louis, Savannal und Grand Port, zwischen welchen Haufwerke poröser und blasiger Felsmassen gefunden werden - reden der oben aufgestellten Ansicht das Wort. In der Mitte dieser Gruppe steigt der Piton de Milieu ungeführ $1000 \mathrm{~F}$. über die Fächen empor; er besteht 
aus ähnlichen Gebirgsarten. In den Höhlungen der Insei finden sich Schlacken. - Von sogenannten Primitiv-Gesteinen, von fossilen Überbleibseln meerischer Thiere nicht eine Spur.

St u rmfluth. Zu Kiel trat, in der Nacht vom 18. auf den 19. Dezember 1835 gegen 3 Uhr Morgens, unter Donner und Blitz, eine Sturmfluth ein, wie man seit Menschengedenken sie nicht erlebt hatte. Sie richtete bedeutende Verwüstungen in allen viedrig gelegenen Gegenden der Stadt und deren Umgebung an. Am 19. Dezember fiel das Wasser un 2 Fuss, war indessen immer noch sehr hoh.

(Zeitungs - Nachricht.)

Bergsturz in Graubündten z u besorgen. Bei Felsbery droht ein Bergsturz. Hinter dem Rande einer senkrechten Felswand ziehen sich dic Spalten netzartig und in wirrem Laufe in śblosungs-Breiten von 2 bis 6 F. durch den Waldboden hin; ihre Tiefe übersteigt hin und wieder $600 \mathrm{~F}$. senkrecht ins Berg-Innere hinab; andere eben so mächtige Klüfte sind zum Theil mit einem bewachsenen Boden bedeckt, so dass man sorglos auf verborgenen Tiefen umberwandelt. Hat man den Muth, auf einer Brücke von Baumstämmen eine grössere Kluft zu überschreiten, so steht man gleichsam auf einer Insel-Gruppe von gelösten Felsküpfen, und wird leicht von der Besorgniss eines Losbruches unter seinen Füssen jeden Augenblick bedroht. Die grösseren Sprünge und Klüften mögen schon seit vielen Jahrhunderten da gewesen scyn, aber neben diesen älter'n Ablosungen zeigen sich auch neue Erüche und Senkungen in Menge, in welchen hin und wieder grosse Steinblöcke und grünende Bäume eingesunken sind. Schauerlich ist der Blick in die Tiefe der Spalten, wo das Auge keinen Grund erreichen kann; und wer die innern Zerklüftungen der grössern Einzelmassen betrachtet, kamn sich des Gedankens nicht erwehren, dass sie bei irgend einer kräftigen Einwirkung der Kälte, des Regens und des Frühlings - Thautretters zu einem theilweisen Ruin der anliegenden Thalfläche hinabstürzen werden. Kommt es bloss zum Überstürzen der oberen Felshänge, so dürften sie sich vielleicht als ein schützender Steindamm vor dem Dorfe aufschichten. Erfolgt aber durch den Druck der iinen eigenen Schwere eine allgemeine Ablösung von der Unterlage, so ist mit grosser Bestimintheit vorauszusagen, dass der ganze lossgetrennte und bereits hängende Hintergrund nit einem Massen-Gehalte nachstürzen wird, der keine Abschätzung zulïst, so dass das Dorf, ja der ganze Thalgrund und das Flussbett des Rheins nit cincr furchtbaren Ïberschwemmung bedroht wird.

(Zeitungs - Nadehricht.) 


\section{1}

C. KRug von Nidda: geognostische Darstellung der Insel Island (KaRsten's Archiv für Min. VII. B., S. 421 ff.). Der ganze Fläcbenraum des Eilandes, gegen 1800 Q.-M., enthält nur zwei Formationen; die eine, welche den Grund dieses nordischen Ozeans zu bilden scheint; woraus Island und die F'aröer hervortauchen (denn beide Inseln bestehen aus derselben), ist die Trapp-Formation; die andere, welche den Kern von Island ausmacht und als Ursache des Vorhanden. seyns dieser grossen Insel betrachtet werden muss, ist der $\mathrm{Tr}$ a c h y t mit seinen mächtigen Anhäufungen von vulkanischen Tuffen und Konglomeraten, und mit seinen Laven-Strömen. Wo das Trapp-Gebirge tief genug entblösst ist, findet man un ter ihm ein durch vulkanische Einwirkung stark umgeändertes Gebirge. Schichtung und andere Merkmale lassen dasselbe als neptunische Ablagerung erkennen. Es ähnelt den Thon-Schichten des bunten Sandsteins, oder der Keuper - und LiasFormation; die Thone sind aber in hartgebrannte klingende Massen umgewandelt. Ausserdem findet sich keine Spur, auch nicht ein Geschiebe eines andern Gesteins, oder eines Aufwürflings, der auf eine andere Felsart als Trachyt hinweist. - Das Einfache des geognostischen Baues der Insel liegt in dem Gesetze, welches das Aufbrechen des Trachyts befolgt hat, d. h. in seinēr geraden ununterbrochenen Längen-Erstreckung, die genau mit seinem Emporsteigen aus der Tiefe zusammenhängt. Der Trachyt ist die Ursache, dass die ganze Insel über die Meeresfläche erhoben wurde; der Trapp würde den Seegrund, wo er gebildet ist, nicht verlassen haben, hätte er nicht dem aufsteigenden Trachyte folgen müssen. Die Trapp - Masse bildete in der Meerestiefe eine mächtige Decke über den empordrängenden Trachyt. Bei ihrer Sprödigkeit konnte'sie der Kraft von unten nicht nachgeben, ohne in eine furchtbare Spalte zu zerspringen, deren Grösse mit der Mächtigkeit des Widerstandes, folglich mit der Kraft des empordrängenden Trachyts im Verhältniss steht. In der Spalte fand der Trachyt seinen Ausweg nach oben; aber auch jetzt war der Widerstand nicht völlig beseitigt, den selbst die zersprengte Trapp-Decke noch leistete; die Spalte war zu eng für die Trachyt-Masse, die sich nur dadurch Platz machen konnte, dass sie an beiden Rändern der Spalte die Trapp - Masse ergriff und theilweise mit in die Höhe riss. Was früher Spalte war, bezeichnet ein breiter TrachytStreifen, der sich aus S.W. nach N.O. mitten durch die Insel erstreckt. Auf seinen beiden Rändern findet man das 'Trapp - Gebirge, zerrissen, zerborsten, wic es bei den erlittenen Einwirkungen nicht anders der Fall seyn kann.' In Trachyt ist der Sitz der vielen Vulkane. An der Westküste von Island findet sich die lange, weit ins Meer erstreckte Landzunge, die sich in ihrer äussersten Spitze in Sneefield-Jökul endigt, dem höchsten Berge dieser Zunge, welche von ihm den Nanıen Sneefield-Syssel erhalten hat. Diese Landzunge ist von ihrer Wurzel bis zu Sneefield-Jökul nur trachytisch, und bildet cine Rcihe von EruptionsKegeln, die meist ansehnliche Lavaströme ergossen haben. Selbst in ihrer Verlängerung rückwärts bach dem Lande zu finden sich cinzelne: 
Eruptions-Kegel und Trachyt-Berge mitten in Trapp. Die Landzunge ist nichts, als ein Nebenarn der grossen Trachytmasse. - Die orographische Beschaffenheit des Landes hängt nur von beiden GebirgsFormationen und ihrer gegenseitigen geognostischen Beschaffenheit ab; die zur Trapp-Formation gehörendeu Gebirge zeigen sich auffallend verschieden in ihren Formen von den trachytischen. - Die engeren Fiorde (Meerbusen) an der Ostküste sind Spalten in Trapp-Gebirge das sehr mächtig und hoch erhaben ist; an mehreren Stellen erreicht es Seehöhen, die $4000 \mathrm{~F}$. übersteigen. Die Fiorde, oft kaum eine halbe Meile breit, greifen $5-7$ Meilen in das Gebirge hinein. Auf beiden Seiten sind sie von schroffen, senkrechten Felsenmauern eingeschlossen. - Das ganze Trapp-Gebirge auf Island ist Bruchstück der grossen Trapp-Masse, die in der Meerestiefe ausgebreitet liegen mag; der aufsteigende Trachyt riss nur Theile vom Ganzen loss. Die Veränderung im Niveau, welche die Trapp-Masse erlitt, ist ungemein beträchtlich. An der Ostküste steigen die steilen Felsenmauern oft zu einer Meereshöhe von $4000 \mathrm{~F}$. an, und die der Nord- und West-Küste zu 2500 bis 3000 F. - - Die Schichtung des Trapp-Gebirges ist horizontal, oder nur wenig von der wagerechten Lage abweichend. Die Neigung der Schichten ist dieselbe geblieben, welche sie bei ihrem Entstehen auf dem Meeresgrunde erhielten. Wo ein Fallen wahrzunehmen, beträgt dasselbe selten mehr als $5^{\circ}$, und ist stets nach dem Innern der Insel zugekehrt. Die Streichungs-Linie dieser Schichten ist mit dem äussern Pande der Küste parallel, die Richtung des Fallens mit den Fiorden und Spaltenthälern. - Ausser den vielen erwähnten Queerthälern findet sich im Trapp-Gebirge des Ostlandes ein ausgezeichnetes Läugenthal, das Langar-Fliot-Thal, welches mit der Grenze des Trachyts parallel läuft. Es trägt nicht den Charakter einer engen Gcbirgs-Spalte, ist im Verhältniss der Breite gegen die Höhe seiner Seitenwände einer flachen Furche zu vergleichen, und hat ganz das Ansehen, als wenn es die Scheide-Linie hätte werden sollen, über der sich der Trachyt erbeben wollen. Jenseit der Jökulsaae stellt sich der Übergang aus Trapp in Trachyt ein, jedoch ohne bestimmte Grenze; beide Formationen sind bei ihrer Berührung gleichsam in einander verschmolzen, erst auf den Höhen findet man deutlichen Trachyt. Die Trapp-Felsen auf der OstSeite des Thales erheben sich zu steilen Mauern. lhre regelmässige Schichtung ist durch die ganze Masse zu verfolgen und schon in Entfernungen von 3-4 Meil. erkennbar durch den Schnee, der auf den wagerechten Schichtungs - Flächen einen Ruhepunkt findet. - In den TrappTheile, welcher auf der Westseite des Trachyt - Streifens liegt, wiederholen sich die Erscheinungen, wie solche die Ostküste aufzuweisen hat. - Die nordwestliche Halbinsel, die West-Fiorde genannt, ist mit dem Haupttieile Islands nur durch eine schmale Landzunge verbunden. Sie verdankt ihre Erhebung cinem eigenen trachytischen Kerne, der sich wahrscheinlich in ihrer Mitte befindet. Ihre steilen Küsten - Gebirge bestehen aus Trapp, der in zahllose Fiorde zerrissen ist. Die Hölıe der 
Vorgebirge dieser Halbinsel schwankt zwischen 2000 und $2500 \mathrm{~F}$, die beiden Eisberge aber, der Dranga - und Glaama - Jökul überschreiten jene Höhe bei Weitem. - Das Thal der Nordur-Aae, nordwärts von der Hvit-Aae, ist auf beiden Seiten von geschichteten Trapp - Wänden umgeben. Am nördlichen Rande findet man einen kleinen EruptionsKegel von kaum $300 \mathrm{~F}$. Höhe, der einen gewaltigen Lavastrom ergossen hat, welcher sich, wie diess am Heckla und an vielen anderen Eruptions-Kegeln der Fall, unter einer Decke rother Schlacken verliert. Am Ende des Ausbruches wurden' losgerissene Lava-Stücke und rothe Schlacke ausgesshleudert, die sich in und um den Krater ablagerten. Die Lava ist trachytischer Natur, wie alle übrigen auf Island, die aus Trachyt hervorgebrochen sind: Feldspath-Lava mit Krystallen glasigen Feldspaths und Olivin-Eiuschlüssen, aber ohne Spur von Augit. Der Trachyt dürfte nicht tief unter dor Trapp-Decke vorhanden seyn. Der Bäula, ein ausgezeichnet schöner Kegelberg, dessen Abhänge unter einem Winkel von ungefähr $40^{\circ}$ ansteigen, erhebt sich in seiner. blendendweissen Farbe über die dunkeln Trapp-Höhen auf der Nord-Seite der Nordur-Aae. Er besteht aus säulenförmig abgesondertem Trachyt und erscheint auf den Trapp aufgesetzt. Die Spitze des Bäula mag eine Höhe von 300 Q.F. haben, deren Hälfte der Trapp-Berg-Rücken einaimmt. - Südwärts von der Nordur-Aae folgen, durch Bergrücken von 500-600 F. Höhe geschieden, melırere parallele Thäler, in deren Tiefe viele heisse Quellen hervorsprudeln. Auch sie scheinen die valkanische Thätigkeit in geringer Tiefe unter dem Trapp zu beweissen. Heisse Quellen sind zwar dem Gebiete des Trapps nicht fremd, aber im Allgemeinen nicht so stark und keineswegs mit jenen mächtigen WasserEruptionen zu vergleichen, die man im vulkanischen trachytischen Gebiete trifft. Jene Trapp-Thäler machen die einzige Ausnahme: in ihnen finden sich Thermen von ansehnlicher Grösse. - Im S. der Hrit-Aae erhebt sich das steile Gebirge der östlichen skurdsheide, aus W. nach 0. erstreckt. Es besteht aus Trapp; die horizontale Schichtung macht die senkrechten Wände künstiichen Mauern ähnlich, die Skardsheide erhebt sich zu einer Höhe von wenigstens $3000 \mathrm{~F}$. und schliesst sich dem Gebirgs-Plateau an, welches vom Vulkan Skialdbreid nach dem Baldjökul erstreckt ist. Der Trapp geht dabei unmerkbar in Trachyt über. Im S. der Skurdsheide breitet sich zu ihrem Fusse eine weite meist sumpfige Ebene aus, aus der am Eingange der Hvalliord der ebenfalls aus Trapp bestehende isolirte Alkre-Field zu $2000 \mathrm{~F}$. emporsteig t. - Überall, wo die Küsten Islands aus Trapp bestehen, zeigen sich tiefe spaltenförmige Fiorde; die Erscheinungen wiederholen sich und beweisen dadurch eine grosse Gesetzmässigkeit. Die Richtung der Fiorde auf der Trachyt-Grenze ist stets rechtwinkelig. Das Streichen der Trapp-Schichten ist längs des äussern Küsten-Randes; von aussen zeigen sie sich völlig horizontal, die Fall-Linie ist nach dem Innern des Landes gerichtet. - - Der trachytische Theil, von Island war bis jetzt sehr wenig bekannt; die Natur setzt durch die ausgebreiteten 
Eisberge sehr grosse Hindernisse entgegen, welche ein Vordringen ins Innere der Insel höchst schwierig, wo nicht unmöglich machen. - - Zwei Jökul-Züge erstrecken sich minder parallel durch das Innere des Landes; sie sind nichts anders, als die Eisdecken zweier entsprechenden Höhenzüge, welche dieselbe Richtung von S.W. inach N.O. verfolgen. Zwischen beiden Höhenzügen liegt eine muldenförmige Niederung, deren Richtung, wie jene der Höhenzüge, die uordöstliche ist: dieselbe, welche die Grenzlinie des Trapps befolgt, die bezeichneude für den trachytischen Theil Isands; alle reihenförmigen Erstreckungen vulkanischer Essen sind ihr unterworfen. Der Trachyt ist aus der weiten Spalte, die er sich im Trapp geöffnet hat, hervorgestiegen. Es scheint, als wenn er sich zu einem einzigen Gewölbe von einem Rande des Trapps zum andern hätte aufblähen wollen; die Weitung oder Spannung aber war zu gross, un dem Gewölbe in der Mitte Haltung zu geben; es senkte sich hier wieder ein, und bildet nun die langen Mulden, vọn denen die Rede war. Die Form beider trachytischen Gebirgszüge ist die von langgezogenen Plateaus und glockenförmigen Kuppeln mit sanftem SeitenGehänge. Der untere Theil der Trachyt-Gebirge ist meist von mächtigen Tuff - oder vulkanischen Konglomerat - Bildungen umlagert. - Auf dem östlichen Gebirgszuge sind uur drei Punkte ihrer Meereshöhe nach gemessen worden:

Der Oester oder Eyafiäl-Jökul, wach Ohlsen, Vetlesen und Frisack, 5334 Par. Fuss;

der Orä̈a-Jökul, nach Paulsex, $=5561$ P.F.;

der Smör-Field, nach OHLsex und Vetresex, $=5400$ P. F.

Die mittle Höhe des ganzen Gebirgszuges kann zu 5000 F. angenommen werden. Über die Mecres - Erhebung des zweiten Gebirgszuges lässt sich noch viel weniger sagen, bis jetzt ist nicht eine einzige Höhe bestimmt worden; es scheint, dass dieser $\mathrm{Zug}$ dem ersten nicht nachstehe. Ist das mittle Meeres-Niveau des Trapps auf 3000 Fuss festzusetzen, so übertreffen demnach beide trachytische Gebirgszüge jeve Höhen um $2000 \mathrm{~F}$., und mit derselben fällt die reihenartige Erstreckung der ansehnlichsten vulkanischen Essen, welche in Island aufgebrochen sind, zusammen. Der Oester-oder Eyafiäl-Jökul, der Katlegiaa, der Sida-Jökul und der Orä́fa-Jökul liegen in gerader. Linie reihenförmig nach N.O., und, verlängert man die Linie dieser vulkanischen Essen jenseit des Oester-Jökuls nach S.-W., so trifft sie die Reiłe der kleinen Westmann-Inscln, deren grösste einen Eruptions - Kegel hat, welcher viel Lava ergossen hat. - Als Deweis der reihenartigen Erstreckung vulkanischer Ausbruchs-Öfnungen auch jenseits des Landes in das Meer hinein gelten die vulkanischen Inseln, welche in der Verlängerung jener Reihen aus, dem Meere hervorgehoben sind. Das Verhältniss der Westnann-Inseln zum ersten trachytischen Gebirgszuge wiederholt sich jenseits des Kaps Reikianaes. Dic Vogelscheeren sind eine Reihe vulkanischer Inselu und Klippen, welche mehrere Meilen weit ins Meer gegen S.W. sich erstrecken. In XIII., XV., XVI. und 
XVIII. Jahrhundert haben sie Ausbrüche gehabt. - Die nuldenförnige Niederung, welche, von beiden trachytischen Gebirgszügen eingeschlossen, die Mitte von Island in nordwestlicher Richtung durchzieht, ist wegen der Manchfaltigkeit vulkanischer Erscheinuugen von hohem Interesse. Die weite Ebene zwischen dem Tingvalla-See und dem Markarfliot, nur wenig über dem Meere erhaben, durch viele breite und gefahrvolle Flüsse nach allen Richtungen durchschnitten, ist ausgezeichnet durch zahlreiche frühere Eruptionen, die an weit erstreckten Lavenfeldern zu erkennen sind, ferner durch viele fortdauernd thätige Thermen, unter denen der berühnte Geiser. Aus der Ebene erhebt sich einer der HauptVulkane Islands, der Heckla, als isolirter Kegelberg von Materien gebildet, welche durch wiederholte Ausbrüche aufgehäuft worden. Die meiste Lava ist aus Öffnungen am Fusse geflossen. Im S. des Heckla breitet sich bis zum Tindfield ein weites Lavenfeld aus. Eine überaus grosse Zahl einzelner kleiner Eruptions-Kegel, welche sich kaum einige hundert Fuss über ihre Grundfläche erheben, ist über das schwarze Feld wie gesäet: man erkennt sie an der hochrothen Farbe ihrer Kratere und Spitzen. - Die Höhe des Heckla beträgt nach Ohlsen, VetLEsen und Frisack, 4795 Par. F. - Deu Hauptvulkan der SneefieldSyssel ist der Sneefiled-oder Wester-Jökul am äussersten Ende der Landzunge. Seine Forın verräth den alten Vulkan in Trachyt; seit der geschichtlichen Zeit hat derselbe keine Thätigkeit gezeigt, aber der Fuss ist nit zahlreichen Lavenströrien unlagert. Die Höhe des Berges kann ohne grossen Fehler zu 5000 F. angenommen werden. - Nach O. vom Sneefield erstreckt sich der vulkanische Gebirgsrücken, welcher den mittleren Theil der Landzunge einnimmt, und der fast ganz aus vulkanischen Tuffen und Konglomeraten besteht. Längs dieses Gebirgsrückens haben sich zahlreiche Eruptions-Kratere geöffnet, aus denen Lava-Ströne theils nach $N_{\text {. }}$, theils nach $S$. ergossen worden. - - Der Verf. nimmt von gewissen Gebirgen an, dass die beiden grossen Agentien, Wasser und Feuer, auf sie ihren Einfluss geübt, so dass Bildungen hervorgebracht worden, welche die Eigenschaft beider Entstehungsweisen in sich vereinigen und das Verschiedenste verbunden zeigen. Das Trapp-Gebirge, die Hälfte von Islands Flächenraum einnelımend, zeigt die gleichförmigsten und regelmässigsten Schichten - Abtheilungen. Das Trapp-Gebirge homnte durch die regellose Gewalt vulkanischer Ursachen nicht das werden, was dasselbe hier ist. Der Ozean, unter dessen Bedeckung scine Bildung vor sich ging, hat einen mächtigen Einfluss ausgeübt. Der Isländische Trapp hat nach dem Vert. darin Ähnlichkeit mit dem Gneisse, dass sie bereits in Betreff der Schichtung mit neptunischen Gebirgen iibereiustimmen, während die Beschaffenheit des Gesteins auf vulkanischen Ursprung hinführt; beide sind jedoch darin verschieden, dass das Aufsteigen des feurig - flïssigen Trapps aus den untern Räumen gleichzeitig mit seiner Ausbreitung in Schichten geschah, während der Gneiss, wie der Verf. anniinmt, ein Niederschlag der Gewässer ist, der später, viell eicht lange Zeit nach seiner Ablagerung der 
vulkanischen Umänderung beim Durchbrechen des Granits ausgesetzt wurde. Der Gneiss wäre folglich ein geschichtetes Gebirge, später vulkanisch umgeändert; der Trapp dagegen ein vulkanisches Gebirge, das geschichtet ist. - Wenn der Verf. von Schichtung des Trapp-Gebirges redet, so will er darunter nur das Raum - Verhältniss verstanten wissén, nicht aber die Entstehungsweise, die von der neptunischen gänzlich abweicht. Er versteht in dem erwähnten Sinne unter Schichtung die Aufeinanderfolge verschiedener, nach Länge und Breite ausgedehnter Lagen von verhältnissmässig geringer Dicke, nicht aber die Entstehung durch Absatz aus bedeckendeu Gewässern; denn eine solche Bildung ist mit dem Trapp, der als vulkanisches Erzeugniss aus der Tiefe kommt, nicht zu vereinigen. - Das Trapp-Gebirge Islands ist auf das Regelmässigste durch das Ganze seiner Masse geschichtet. Steile Felsmauern, mitunter $4000 \mathrm{~F}$. hoch, sind in horizontale, vollkommen parallele Schichten oder Lagen abgetheilt, die man über grosse Längen-Erstreckungen verfolgen kann, und jede Schicht hat ihre besondere Auszeichnung, weiche sie von den über- und unterliegenden scharf unterscheidbar macht; die eine ist säulenförmig abgesondert, die andere durch ihre bedeutende Mächtigkeit, eine dritte durch ihre verschiedene Farbe u. s. w. bezeichnet. Bei näherer Untersuchung ergibt sich eine Schicht als ein feinkörniges doleritisches Gemenge, die andere als ein porphyrartiges; in der einen herrscht dieser, in der andern jener Gemengtheil vor; die eine enthält in ihren Blasenräumen diese, die andere jene Mincralien u. s. w. - Die Schichtung des Trapps mag in einer mechanischen Einwirkung des bedeckenden Wassers seinen Grund haben. - Die Ka. näle, durch welche eine feurig-flüssige Trapp-Masse aus dem Erd-Innern zur Oberfläche stieg, sind die zahlreichen Spalten, welche das GrundGebirge des Trapps und theilweise auch die Massen des letztern durchschnitten haben. Diese Räume findet man mit den manchfaltigsten Trapp-Abänderungen angefüllt: so vielerlei, wie die, in Schichten ágelagerten, Gesteine; jeder Gang scheint verschieden von dem andern. Mitunter endigen sich Gänge auch in einer der Schichten, oder man sieht, wie die flüssigen, in den Spalten aufgestiegenen Massen sich seitlich bewegten, um eine Schicht zu bilden. - Die Trapp-Schichten sind nichts anders, als die feurig-flüssigen Massen, welche den Erd-Innern durch die ,Spalten entstiegen und an der Oberfläche in horizontaler Verbreitung sich ergossen. Sie sind meist mächtig, oft 50 bis 60 F., und über Flächenräume von vielen Quadrat-Meilen ausgebreitet. - Ohne die Trennung der Isländischen Trapp-Gesteine in fein- oder grob-körnigen Dolerite, in Wacke-artige Gebilde u. s. w. zu berücksichtigen, lässt sich die Gesammt. Masse derselben in eine obere und untere Abtheilung tremnen. Das charakterisirende herrschende Gestein der letzteren ist ein krystallinischer sehr feinkörniger Dolerit. Dichte Basalte finden sich auf Island nirgends. Mit den Doleriten wechseln die verschiedenartigsten Abänderungen von Wacke-artigen Gesteinen, bald braun, bald grün gefärbt, und in ihren Blasenräumen und Klüften die bekannten 
zeolithischen und quarzigen Einschlüsse enthaltend. In dieser untern Abtheilung des Trapps, bezeichnet durch schwarze Dolerite mit vorwaltendem Augit, findet man neptunische $Z$ wischenlager von Thonen und thonreichen Sandsteinen. Einzelne derselben haben 20-30 F. Mächtigtigkeit, aber sie sind in ihrer Erstreckung nicht ausdauernd; stellenweise verschwinden dieselben gänzlich, oder sie verdrücken sich zu schwachen Bestegen. Die Thone sind gehärtet, getrocknet, aber ohne Spur von Sinterung. Diese Thon-Schichten bilden die Lagerstätten des Surturbrandes, des Isländischen bituminösen Holzes. Häufig beträgt die ganze Mächtigkeit des Thonlagers nicht mehr als 6 Zoll, darin ist ein schmaler Streifen bituminösen Holzes von 1 bis $1 \frac{1}{2}$ Zoll Stärke eingeschlossen, und demnach ist die schmale Thonhülle von 3 bis 4 Zoll Stärke hinreichend, das Holz gegen Verkohlung zu schützen. In den Trapp-Gebirgen, welche auf der nordwestlichen Seite des grossen 'Trachyt-Streifens liegen und die N. und W.-Küste Islands bilden, ist das Vorkommen des Surturbrandes eine sehr gewöhnliche Erscheinung. Ziemlich regelmässig zeigen sich drei getrennte SurturbrandLagen über einander; die oberste ist meist gegen $600 \mathrm{~F}$., die mittle die beste und gewöhnlich $3-4 \mathrm{~F}$. starke - ungefähr $150 \mathrm{~F}$, und die unterste nur wenige Fuss über dem Meeresspiegel erhaben. Auch an der N. - Küste trifft man den Surturbrand, aber stets nur in der geschichteten Trapp - Formation, $\mathbf{n i c h t}$ in den Trachyten, in den Tuffen und Konglomeraten. Die Kohle ist stets fest und dicht, sie zeigt die vollkommenste Holz-Struktur; viele Stücke sind frischem unverändertem Holze auf das täuschendste ähnlich. Alle Holzstücke, welche man aus dem Thone herausbrechen kann, deuten auf grosse, starke Stämme hin, welche zuweilen mit Ast-Ringeu von 5-6 Zoll Durchmesser versehen sind; die fussstarken Stämme sind durch die Last der darüber ruhenden Felsen-Massen breit zusammengedrückt und in sehr schmale Streifen eingezwängt. Von Blättern und Früchten trifft man die Spuren. Das bituminöse $\mathrm{Holz}$ ist theils braun, theils pechschwarz und glänzend und sieht in letzterem Falle wie Pechkohle aus. Auf der nordwestlichen Halbinsel soll mit den Surturbrand-Lagen ein schwarzer SchieferThon vorkommen, in dem man zahlreiche und wohlerhaltene Abdrücke von Blättern wabrnimmt, denen der Pappeln, Weiden, Birken und Eichen sehr ähnlich. Die Holzstämme, welche das Material zum Surturbrande nüssen geliefert haben, sind, wie noch jetzt das Treibholz, welches häufig an den Küsten vou Island strandet, durch herrschende Winde und Meeres-Strömungen aus weiter Entfernung von Kontinenten herbeigeführt worden. Eisenkiese fehlen in den bituminösen Hölzern Islands gäuzlich. - Die obere Abtheilung der Trapp-Formation zeichnet sich durch das Vorwalten des Feldspaths und das Zurücktreten des Augits aus. Der Magneteisen. Gehalt ist so beträchtlich, wie in der unte. ren Abtheilung. Durch grösscre Krystalle eines rissigen glasigen Feldspaths wird porphyrartiges Gefüge hervorgerufen. Mandelstein-Struktur ist bei Weitem weniger häufig; als Ausfüllung der Blasenräume, häufiger 
in Klüften und Rissen, kommt Chabasie vor. Die porphyrartigen Gesteine werden oft den Trachyten sehr ähnlich; aber sie zeigen dieselbe horizontale Schichtung, wie die untere Abtheilung, und sind auf dieselbe Weise durch stromartigen Erguss aus den Gang - und Spalten - Räumen entstanden. - So reich Islands Trapp - Formation an Mandelstein - Einschlüssen, so arm ist dieselbe an dem Teige der Felsarten selbst verbundenen Mineralien. In der untern Abtheilung der Trapp-Formation kommen augitreiche Dolerite ziemlich oft vor. Olivin fehlt; von Hornblende und Glimmer trifft man keine Spur. Eisenkies erscheint hin und wieder in eingesprengten Körnern. Die Feldspath-reichen Gesteine der obern Abtheilung enthalten stellenweise kleine Opal - Nieren. - Die Ausfüllungen der blasigen Räune mit manchfaltigen schönen Mineralien der Quarz - und Zeolith - Gattungen gehören zu den besondern Auszeichnungen der augitischen Trapp-Formation; beide sind in der Regel streng von einander geschieden. Die Chalzedone, Quarze und Achate kommen meist auf sehr regellosen Höhlen und Klufträumen vor, die theilweise zusammengebrochen, und durch solche Ausfüllungen wieder zusammengekittet sind; als die umschliessenden Felsarten findet man in der Regel braune Wacken. In den kleinen Blasenräumen der Dolerite erscheinen nur Zeolithe und hauptsächlich Chabasie-Rhomboeder, so wie Strahl-Mesotyp. Analzim stellt sich sehr selten ein und nur in den Blasenräumen der schwarzen Dolerite. Noch seltner ist Apophyllit. Eine sehr grosse Seltenheit in den blasigen Weitungen des Isländischen Trapps ist der Kalkspath. Der berühmte Doppelspath kommt in einer Spalte am nördlichen Ufer des Rôdefiordes auf der Ostküste in ungefähr $1000 \mathrm{~F}$. Höhe über dem Meere vor. Eine Spalte von $2 \frac{1}{2}$ bis $3 \mathrm{~F}$. Breite und 20 bis $25 \mathrm{~F}$. Länge ist ganz mit dem reinen Kalkspath erfüllt; sie keilt sich nach beiden Seiten aus. Die Fortsetzung in die Tiefe kennt man nicht. An der Oberfläche ist der Kalkspath sehr zerstört durch einen Gebirgsbach. Der Kalkspath der Spalte zeigt sich durchaus nicht krystallisirt; es ist nie Raum für eine Druse zur Ausbildung von Krystallen vorhanden gewesen; die ganze Masse besteht aus unzählig verschiedenen Individuen, die sich gegenseitig in der Ausbildung ihrer Formen gehindert haben; sie sind in ganz unbestimmten Flächen, unter denen sie sich gerade berührten, verwachsen, ganz auf dieselbe Weise, nur in weit grösseren Maasstabe, wie die einzelnen krystallinischen Theile eines grobkörnigen Kalksteins "). Die Räume, in denen sich Stilbite finden, dürften sich erst durch spätere Zerspaltungen des Kalkspaths geöffuet haben; auf den Kalkspath-Flächen kommen die zierlichsten Stilbit-Krystalle vor ${ }^{* *}$ ). Was die Bildungsweise

*) Von der Oberflächen - Beschaffenheit zweier seltenen Prachtstücke Isländischen Kalkspaths, welehe ich besitze, habe ich in meinem Buche über die Basalte, I. Ab. theilung, S. 240 und 241 geredet.

LEOXHARD.

*) Auch mitten im klarsten durchaus spaltenfreien Kalkspath finden sich Stilbit-kinschlüsse; ich kann solche Stücke aufweisen.

L. 
der Kalkspath-Massen betrifft, so bleibt es am wahrscheinlichsten, dass die feurigen Dolerit-Ströme, als sie durch zahlreiche Spalten aus der Tiefe aufstiegen, Kalkschichten durchbrachen, ein einzelnes Bruchstück in ihrem Teige eingehüllt mit in die Höhe führten und zu klarem Kalkspathe umwandelten *). - - Von den Gängen des Trapp-Grebirges bemerkt der Verf., dass sie, abweichend von den Erzgängen, durchaus keine Verwerfung und Störung der durchschnittenen Schichten wahrnehmen lassen. Die Räume, welche man jetzt mit Trapp erfüllt sieht, dürften einst_leere Spalten gewesen seyn, durch mechanische Kräfte aufgerissen. Die Trappmasse fand die Spalten schon, mögen sie auch, wie solches wahrscheinlich, durch dieselben Kräfte aufgerissen worden seyn, welche die Bestandtheile des Trapps im Erdinnern im feurigen Flusse vereinigten. Es ist nicht gut einzusehen, wie die Trennung des Gebirges durch eine Gangspalte von verhältnissmässig geringer Mächtigkeit gegen ihre Ausdehnung im Streichen und Fallen anders entstanden seyn könne, als durch gewaltsame Verschiebung des einen oder des andern getrennten Gebirgstheils. Eine solche Verschichung hat bei erzführenden Gangspalten nach der Richtung der Schwere Statt gefunden; mag nun der Gebirgstheil im Hangenden des Ganges gesunken, oder der andere Gebirgstheil im Liegenden von unten nach oben gehoben worden seyn. Vertikale Verschiebungen sind bei den Trapp-Gängen Islands nicht zu beobachten; dagegen findet man Erscheinungen, welche eine Verschiebung nach horizontaler Richtung in hohem Grade wahrscheinlich machen. Auf ähnliche Weise nämlich, wie man an ErzGängen Friktions- oder Spiegelfächen findet, sind sie auch da, wo breite getrennte Gebirgstheile bei ihrer vertikalen Verschiebung sich beruihrt haben, und fast an allẹ Trapp-Gängen auf Island; die Friktions-Fliichen sind noch weit deutlicher, die eingezackten Furchen tiefer und weiter. Die Streifung der Friktions-Flächen lauft stets horizontal, mit der Streichungs-Linie parallel. - Sehr häufig sind die Ausfüllungs-Massen der Gänge in Säulen abgesondert; die Säulen stehen senkrecht auf den Saalbändern. - An der nördlichen Seite des Rôdefiordes sieht man zu beiden Seiten eines Ganges, der aus einem augitreichen Dolerit besteht, Saalbänder eines rothbraunen, jaspisartigen Eisenkiesels liegen, die 9-12 Zoll Mächtigkeit haben. Das Neben-Gestein besteht aus gewöhnlichen durchbrochnen Dolerit-Schichten. - An der untern - nie an der obern - Fläche vieler Dolerit-Schichten nimmt man Schlacken-Krusten wahr. - An mehreren Stellen der Ostküste, wo das Trapp-Gebirge hoch über dem Meeres - Spiegel erhoben, und durch Fiorde und

*) Es kann mir nur sehr erfreulich seyn, dass ein so glücklicher Beobachter, wie der Verf., an Ort und Stelle, was die Bildung des berühten Islïndischen Doppelspaths betrifft, zu derselben Meinung gelangte, welche ich bereits vor vier Jalıren aussprach und drucken liess. Wahrscheinlich ist Herrn Krug vov Nidda die Stelle über den Kalkspath in meinen "Basalt.Gebilden" Il. Abth., S. 242 ff. entgangen.

LEONHARD. 
Spalten-Thäler tief genug eingeschnitten ist, sieht man das Grund-Gebirge darunter zum Vorschein kommen, welches alle Merkmale einer normalen neptunischen Ablagerung trägt. Es war dasselbe früher ein geschichteter Thon oder Letten, der starke vulkanische Einwirkungen erlitten hat. An der Ostküste fand der Verf. mehrmals Bruchstücke eines dunkelblauen Obsidians von grobschieferiger Textur. Diese Obsidian-ähnlichen Massen stammen aus der Nähe der Handelsstadt Diupa$v 0 g$ am Berufiord. Hier schliessen zwei parallele Dolerit-Gänge einen 10 F. starken, gebrannten Thonstein - Keil ein, von dem untenliegenden Thon-Gebirge abstammend. In unmittelbarer Berührung mit den Gängen ist der Thon, etwa 9-12 Zoll stark, in den erwähnten Obsidian umgewandelt. - Einzelne Thonstein - Stücke erlangen durch deutliche Ausscheidungen von Quarz und Feldspath einige Ähnlichkeit nit rothem Porphyr.

HrLlhouse: Erscheinungen beim Bohren eines artesischen Brunnens zu st. George bei Demerara (Athenaeum, Nr. 325, p. 57). In $120 \mathrm{~F}$. Tiefe, in unmittelbarer Nähe von thonigen Alluvionen und von Glimmerschiefern fand man eine gesäuerte Quelle. In 10-12 F. unter der Oberfläche des Bodens durchbrach man ein regelloses Haufwerk liegender Baumstämme, ähnlich denen, welche im Lande unter dem $\mathrm{Na}$. men Courida bekannt sind. In $50 \mathrm{~F}$. Tiefe wiederholte sich die Erscheinung, und das Haufwerk lag zwischen blauem und röthlichem Thone von $12 \mathrm{~F}$. Mächtigkeit; die ïbrigen durchbrochenen Schichten bestanden aus Thon von grosser Reinheit. Hrlenouse schliesst aus jener Thatsache, dass zur Zeit, als jene Pflanzen-Reste abgelagert wurden, dieser Theil der Amerikanischen Küste in einem 50 F. tieferen Niveau als gegenwärtig bewohnbar gewesen seyn müsse.

J. Bryce: ïber Diluvial. Wirkungen in nördlichen Ireland (Journ. of the geol. Soc. of Dublin. Vol. I, P. 1, p. 34 etc.). Der Verf. untersuchte die Grafschaften Down, Antrim, Derry, Donegal, Tyrone und Armagh. Der südliche Theil der Grafschaft Down wird von einer Granit-Kette durclizogen, welche von New-Castle bis Louth und Armagh sich ausdehnt. Über den Granit treten gegen S. quarzige Schiefer auf, die in Chlorit-Schiefer und in Grauwacke übergehen; nach N. folgt auf den Granit Grauwacke, auch zeigen sich Hornblende-Gesteine und Porphyre. Die Grauwacke ist sehr verbreitet; nur im Becken zwischen Comber und Newtownards wird sie durch Bergkalk überlagert und durch rothen Sandstein; Trapp-Gebilde bedecken den übrigen Theil im N.O. des untersuchten Landstrichs, und erstrecken sich über ganz Antrim und uher einen grossen Theil von Derry. Unter der weit ausgedehnten Trapp-Ablagerung findet man Kreide, Greensand und Lias, 
welche auf rothem Sandstein ruhen. Von der basaltischen Area ziehen sich zwei Rücken, einer längs des westlichen Ufers von Lough Neagh, der andere bis zum Sleivegallion-Gebirge. Zwischen beiden Rücken nélhmen Ablagerungen von Steinkohlen, von rothem Sandstein und von Bergkalk ihre Stelle ein. Im übrigen Theil vou Derry herrscht Glimmerschiefer; darüber treten Bergkalk, alter und neuer rother Sandstein auf. Der Glimmerschiefer setzt bis Tyrone fort, so dass er den nördlichen Theil der Grafschaft einnimnt, während in der Mitte derselben Thonschiefer und alter rother Sandstein vorhanden sind, die sich gegen 0. und W. erstrecken und auf welche im S. Bergkalk folgt. Um Donegal erscheint Granit; er durchschneidet die Grafschaft von 0 . nach W. und wird von Gneiss begleitet, dem manchfaltige Gesteine untergeordnet sind. Von Übergangs.Gestein kommen Thonschiefer und Grauwacke vor, und im südöstlichen Theil der Grafschaft herrscht Bergkalk. Der Verf. bringt die Diluvial - Wirkungen in drei Klassen: in solche, welche die Basalt-Area betreffen, in andere, die sich auf die primitiven GebirgsMassen beziehen, und in jene, die den Grauwacke-Distrikt betreffen. Die Oberfläche des Basalt - Gebietes hat lose Blöcke und Rollstücke in Menge at:fzuweisen; in Thälern und anderen Vertiefungen des Bodens liegen ganze Haufwerke, welche durch ihre langgezogenen Gestalten sich von den bekannten Kegel - Formen basaltischer Berge sehr unterscheiden. Das Streichen der aus solchem losen Material bestehenden Hügel ist aus N.W. in S.O. Auch an den entlegensten Stellen ist im Allgemeinen ein gewisser Parallelismus wahrzunehmen. Die beiden HauptLängenthäler folgen der nämlichen Richtung. Alle diese Thatsachen sprechen dafür, dass die Diluvial-Strömung ibren Lauf aus N.W. nach S.O. genommen. Die Lagen, welche jene Hügel zusammensetzen, bestehen aus Thon, Sand und aus Gestein-Bruchstücken verschiedenster Grösse. Zuweilen zeigen sich regelrechte Schichten, deren Längen-Erstreckung der Richtung des Streichens entspricht. - GlimmerschieferRollstücke, in allen Abänderungen, wie solche im westlichen Derry-anstehend vorkommen, sind am häufigsten; nach diesen folgen, was die Menge betrifft, Granite, Gneisse und Syenite, in ihren Varietäten den gleichnamigen Gesteinen vou Donegal entsprechend. Mit diesen findeu sich Trümmer von Konglomeraten und Sandsteinen, von Petrefakten-fülırendem Kalk, von Kreide und von Feuersteinen. Weun man bedenkt, dass diess sämmtliche Material über Höhen von 300 bis 1500 Fuss verführt worden, so ergibt sich ein ungefährer Maasstab für die Grösse der Kraft, welche dabei thätig gewesen. - Über der Oberflüche des Grauwacke-Gebietes in Down besteht der Detritus hauptsächlich aus Grauwacke; ferner kommen Trapp-Rollstücke in Menge vor, und ausserdem Geschicbe von Kreide und von Feuersteinen, jedoch minder häufig. Zwischen Hollywood und Dunaghadee zeigen die Kreide-Massen bedeutende Grösse und sind ganz erfüllt mit den charakteristischen Versteinerungen. - Im Lagan-Thale unfern Lisburn widerholen sich Erscheinungen, wie die beschriebenen. Das allgemeine Streichen der 
Diluvial-Hügel bleibt das nämliche. Der Detritus besteht zumal aus Sekundär - und Trapp-Felsen von Antrim und Derry, und aus sehr manchfaltigen Trümmern primitiver Gesteine. Von Grauwacke ist nichts vorhanden̆. Das lose Material dürfte meist aus nordwestlichen Gegenden stammen. - $\mathrm{Da}$, wo die Mourne-Berge gegen 0 . endigen, liegen zahllose Granit-Blöcke auf der Oberfläche des Bodens, die von einem aus W. kommenden Strome herbeigeführt scheinen. Auch längs den Süd-Gehängen jener Berge findet man Haufwerke solcher Rollstücke. An der Westseite von Cloughmore liegt auf einem Schiefer-Berge, in 960 Fuss Meereshöhe, ein grosser Granit-Block. Cloughmore findet man von allen nahen Berge durch tiefe Thäler geschieden, und die Stelle wo das Gestein, von dem jener Block entnommen worden, ansteht, ist einige Meilen entfernt. Wir haben es also hier mit ähnlichen Ereignissen zu thun, wie im Jura-Gebirge. - - Die erwähnten Thatsachen und andere, welche der Verf. anführt, ohne dass solche hier eine umständliche Erwähnung verdienten, beweisen die grosse Gewalt der aus N.W. kommenden Diluvial-Ströme, welche über die ganze Oberfläche vom nördlichen Irland sich ausbreiteten in einer Zeit, wo die BelfastBucht noch nicht bestand, aber nach Erhebung der basaltischen Berge. Die Diluvial-Ablagerungen dürften, nach dein Verf., ziemlich gleichzeitig erfolgt seyn.

Boussingaute: Nachtrag zu der Notiz über seine Ersteigung des Chimborazo (Poggend. Ann. d. Phys. 1835, B. XXXV, S. 167 ff.). "Ich glaube", sagt der Verf. in einem an A. von Humbordt gerichteten Schreiben, „dass meine Beobachtungen über die Vulkane der Andes - Kette auf das Einfachste und Bestimmteste die, gegen L. von Bucr's Theorie der Erhebungs-Kratere gerichteten Einwürfe lösen können. In der That ist auch unter allen Vulkanen der Äquinoktial-Region in Amerika nicht ein einziger Kegel, der durch den Ausfluss einer flüssigen Lava gebildet wäre. Alle Kegel, welche den hohen Rücken der Kordilleren krönen, sind aus fragmentarischen Massen verschiedener Grösse zusammengesetzt, und diese Massen sind das Resultat der Zerstücklung und der Zerspaltungen, welche die unterirdischen und elastischen Dünste, bei Erhebung eines Theils der Trachyte als Kegel, bewirkt haben. Ich glaube nämlich, dass man sorgfältig zwei Erhebungs - Epochen unterscheiden muss, die der ganzen trachytischen Mauer, welche die Kordilleren bildet, und die der Kegel selbst, welche, jenseits der Grenze des ewigen Schnee's, die offenen Feuerschlünde enthalten. Bei der ersten Erhebung war die Trachyt-Masse noch in einem erweichten Zustande, bei der zweiten bloss theilweisen Erhebung, die da Statt fand, wo der geringste Widerstand war, muss die Trachyt-Masse schon erhärtet gewesen seyn, wie es die immer scharfkantigen, nie abgerundeten Fragmente zeigen, aus deuen die vulkanischen Kegel der Andes. 
Thette von Quito zusammengesetzt sind. Diese Idee'n über die Erhebungen der Kordilleren sind in mir nicht seit meiner Rückkunft nach Paris entstanden; sie haben sich mir gleichsam selbst aufgedrungen, als ich an den Krateren jener Vulkane meine chemischen Versuche über die Natur ausgestossener Dämpfe anstellte. Betrachtet man die geographische Karte des Nevado de Antisana, so kann man sich vorstelleu, dass in Nordost der Hütten (Hacienda de Antisana) die grosse wassergleiche Hochebene einst den Horizont begrenzte. Sie lief ununterbrochen, über zwanzigtausend Meter weit, gegen den Abfall der Kordilleren (nach Papallacta) hin. Heerden von Lama's weideten schon damals in der unermesslichen Ebene, Menschen besuchten dieselbe. Ausser den Pferden uud Rindern war alles, wie jetzt. Da entstanden nach einem heftigen Erdbeben grosse Spaltungen im Trachyt der Hochebene, und unter furchtbaren Detonationen stieg der nun mit Schnee bedeckte Berg aus Fragmenten schwarzer trachytischer Felstrümmer zusammengesetzt, hervor. Ausströmungen von Wasserdampf, kohleusaurem Gas, geschwefeltem Wasserstoff und Schwefeldampf begleiteten das Phänomen, und dauerten Jahrhunderte fort, indem sie immer an Intensität abnahmen. Am Antisuna haben die Ausströmungen schon ganz aufgehört: man erkennt nur noch die Öffnungen, aus denen die Dämpfe und Gasarten hervortraten. Unter den alten Bewohnern der Gegend aber ist noch mancher, der in seiner Kindheit jene dampfartigen Emanationen, wo sie wie kleine Rauchsäulen in der kalten Luft aufstiegen, bemerkte; der Nevado von Antisana, das heisst der ewig beschneite Theil (ein sich inselförmig erhebender Berg) ist also anderen späteren Ursprungs, als die Hochebene und die Masse der Kordilleren. Vulkanische Kegel sind nicht durch überfliessende Laven gebildet, sie sind erhoben als scharfkantige, erhärtete, fragmentarische Massen."

Featherstonehaugh: Gegend zwis chen dem Missouri und Red River (Srlman, Americ. Journ.; XXVIII, 379). Dem Berichte liegen kolorirte Durchschnitte bei von der Küste von Neu, Jersey und vom Red River bis zur Mexikanischen Grenze.

Leopond von Bucr hielt in der K. Akademie zu Berlin am 26. März 1835 eine Vorlesung über Erbebungs - Kratere und Vulkane. Zweck des Vortrags war, auf's Neue zu zeigen: dass Erbebungs. Kratere keineVulkane sind, dass der Unterschied zwiscben beiden wohl begründet und wichtig ist, und dass a ucls selbst die Kegelder Vulkane nur durch plötzliches Emporheben, niemals aber durehein Aufbanen von Lavenströmen gebildet seyu köunen (Poggend. Aun. d. Phys. XXXVil, 169 ff.). 
J. C. Escher von der Listh: Beiträge zur Gebirgskunde der Schweitz. Aus hinterlassenen Manuscripten mitgetheilt von A. Escher (Fröber und Hesr Mittheilungen aus dem Gebiet d. theoret. Erdkunde, I, 171 ff. u. 537 ff.). Es enthält disser, zu einen Auszuge nicht wohl geeignete, an interessanten Beobachtungen übrigens reiche Aufsatz die Reise des so höchst achtbaren Schweitzer Geologen von Zürich über die Allmannskette an die Linth, ins Sernfthal; über Martinsloch ins Flimser-und Vorder-Rheinthal bis Illanz; durchs Lugnezthal über la Greina ins Livinerthal; ins Verzaskerthal, durch dieses hinaus nach Locarno; durchs Val Maggia über den Fusio-Pass nach Airolo; über den Gotthard nach Zïrich. Sodann Wanderungen aus dem Linththal über den Kisten-Pass ins vordere Rheinthal; durch's Sunwixerthal,über la Greina und durch's Munteraskathal ins Blegnothal; durch Val Canaria, Val Terma und Val Priora nach Airol im Livinerthal. Den Beobachtungen J. C. Escher's hat A. Escher, der Sohn, Bemerkungen beigefügt.

H. J. Freiherr van der Wyck: Übersicht der Rheinischen und Eifeler erloschenen Vulkane und der Erbebungs-Gebilde, welche damit in geognostischer Verbindung stehen (Mannheim; 1836, 2te Ausgabe). Wir müssen uns darauf beschränken, eine Andeutung vom Wesentlichen des Inhalts dieser interessanten und belehrenden Schrift zu geben. Sie zerfällt, die Einleitung und Entwicklung allgemeiner Ansichten abgerechnet, in folgende Abschnitte: Laacher See; Verkettung der vulkanischen Ausbrüche; Lava-Ströme; Hauptzüge, welche den gegenwärtigen Zustand dieser erloschenen Vulkane erklären; Wasser-Bedeckungen; Ablagerungen vulkanischer Produkte durch Wasser; Lagen von gelber Mergelerde; mehr als eine Wasser-Bedeckung; Alter der Vulkanität am Rhein und in der Eifel, Perioden ihrer Thätigkeit in Verbindung mit den Wasser - Bedeckungen; Strömung der Wasserfluthen von Westen; Einstürzungen; Kessel-Thäler; submarinische Ausbrüche; vulkanische, trachytische und basaltische Reviere; Verschiedenheit jedes einzelnen Gebildes in sich selbst; Natur-Erscheinungen und Merkwürdigkeiten; Sauerquellen; Mofeten; physische Eigenschaften der basaltischen Gebilde; besondere Merkwürdigkeiten; Produkte für Mineralien-Kabinette; Produkte zum technischen Gebrauch u. s. w. - Zur zweiten Ausgabe dieser Sehrift sah sich der Verf. dadurch bestimmt, dass seine Ansichten von Hibbert (History of the exlinct volcunos of the basin of Neuwied etc. London; 1832) angegriffen wurden. Die Gegenreden vaN DER Wycks kennen unsere Leser be-. reits aus diesem Jahrgange des Jahrbuches S. $129 \mathrm{ff}$.

R. J. Murchison: über den Old red Sandstone in den Graf$\mathrm{s} \mathrm{c}$ b a f te $\mathrm{n}$ Hereford, Brecknock und Caermarthen, mit ve rgle i c b e n d e $n$ 
Beobachtungen über die im N.W.-Rande des South-WelshKohlenbeckens eingetretenen Störungen. Vorgel. b. d. Lond. geolog. Soz., 1834, 8. Febr. (Lond. a Edinb. phil. mag. 1834; IV, 228-230). Kohlen-führender Kalkstein des Kohlen-Beckens von SüdWales steht in Brecknockshire und Caermarthenshire in Verbindung mit dem Old-red-Sandstone; er besitzt eine oolithische Struktur, enthält viele Höhlen, und bietet in mehreren Schichten an einer an Torfmoore ansteigenden Felswand bei Gwinfe in Caermarthenshire eine sehr stark polirte Oberfläche dar, deren Bildung irgend einer schwachen Säure des Moores zugeschrieben wird *). Ausserdem stellen sich folgende Übergangs-Gesteine dar:

r. der Old red Sandstone stellt 3 Gruppen dar. a. Konglomerat und Sandstein. Die höchsten Bergspitzen, wie der Brecon- und der Caermurthen - Fan bestehen jederzeit oben aus einem Konglomerat - Lager, darunter aus mächtigem Sandstein - Gebilde, ohne Kalk - Lager und ohne alle organische Reste. - b. Cornstone und Mergel bilden die mittle Gruppe, und sind als wellenförmige Massen über den grössten Theil von Herefordshire verbreitet. Rothe Thonmergel bilden die Hauptmasse, welche einige Schichten von konkrezionärem Kalksteine (Cornstones) und von Sandstein enthält. Krustazeen und Fische haben Reste darin hinterlassen. - Der Dachstein (Tilstone) gehört der dritten Gruppe an und stellt den Übergang zum Ludlow-Stein oder höchsten Gliede der Grauwacken-Reihe dar. Man kann einen, aus ihm bestehenden, geradlinigen Steil-Abfall vom N.W.-Ende des Mynidd-Eppint an bis fast zur Mündung des Towey, 35 Meilen weit verfolgen. Dieses Gebilde enthält in Cuermarthenshire, wie in seiner N.0.-Verlängerung in Shropshire Versteinerungen, als: Lingula, Avicula, 3-4 Arten Univalven, eine kleine Orthoceratiten-Art u. s. w. - - Der Verf. bat die Grenzen einiger (in der vorhergehenden Sitzung beschriebenen) abgesonderten Becken des Old red Sandstone, welche über die BinnenFläche der unteren Grauwacke-Gesteine zerstreut sind, dieses Jahr westlich bis zur Teme-Quelle, und 25 M. weit N.W. über die früher angegebene Grenze hinaus verfolgt. Der völlige Mangel aller vegetabilischen Reste selbst in mehreren tief aufgeschlossenen Durchschnitten lässt keine Hoffnung in dieser Gegend noch Kohle darin zu finden. Die grösste Mächtigkeit der ganzen Formation mag 10-12,000' betragen.

2. Aussenlagerungen von kohlen führendem Kalksteine; Stö. rungen des Old red Sánòstone. Eine merkwürdige Aussenlagerung von kohlenführendem Kalksteine und Milstone grit nimmt die Spitze eines Old-red-Sandstone-Berges im S. von Crickhowell ein, und heisst der Pen Cerriy Calch. Sie ist von der Hauptlagerung desselben Gesteins 4-5 M. entfernt, und durch das tiefe Uske-Thal davon getrennt,

*) Säuren machen also das Rauhe glatt und das Glatte rauh, wie der Hauch das Warme kalt und das Kalte warm !

D. $\mathbf{R}$. 
vor dessen Aushöhlung sie nach der geringen Neigung ihrer Schichten zu urtheilen, mit ihr im Zusammenhang gestanden haben muss.

Im Rande des Kohlenbeckens von S.-Wales von Caermarthen-Fan an bis zur Breite von Llandello beobachtet man eine grosse Menge mächtiger und zusammengesetzter Störungen. Das grösste Phänomen der Art bietet die Auftreibung des Fan Sirgaer, wodurch der Old red Sandstone $700^{\prime}$ hoch über seinen regelmässigen Horizont bei Cerrig Ogof gehoben worden ist. Die grösste Einsenkung dagegen ist an der Stelle, wo der geglättete Kalkstein vorkommt. Die ausserordentlichste Erscheinung von allen aber ist jene, wodurch die Aussenlagerung von Kollen-führendem Kalkstein, die den Namen Castel.Cerrig-Cennen erhalten, gebildet worden. Sie erhebt sich Insel-förmig misten aus einem Thale von Old red Sandstone, weit entfernt von der Stanm * Masse mit entgegengesetztem Einfallen ihrer Sclichten. - Durch diese Hebungen und Senkungen sind überall grosse Massen Kohlen-führenden Kalkes, vom Umfang des Kohlenfeldes an bis zur Fläche des Old red Sandstone treppenförmig übereinander geschoben worden.

R. J. Murchrson: allgemeiner Überblick über die New-redSandstone-Reihe in den Grafschaften salop, Stafford, Worcester und Gloucester (Lond. geol. Soc. 1835, \%. Jänn. $>$ Lond. a Edinb. philos. Mag. 1835, VI, 315-318). Conybeape hat mit dem Ausdruck $\mathrm{New}$ red $\mathrm{Sandstone}$ alle Gebilde zwischen der Steinkohlen-Formation und dem Lias bezeichnet. In den eben genannten Gegenden zeigen sich aber wesentliche Unterabtheilungen, genau entsprechend denen, welche SEDGwick in einem ausgedehnteren Masstabe in N.O.-England beobachtet hat; nämlich von oben nach unten:

1. Red and green Marls: unser Keuper. Diese "rothen und grünen Mergel" sind am meisten in Gloucestershire und Worcestershire entwickelt, wo sie einen weissen Sandstein untergeordnet enthalten, der von manchen Deutschen Keuper-Sandsteinen nicht zu unterscheiden ist. In diesen Mergeln liegen die meisten Salzquellen, hier wie in Salup und Cheshire; wenige kommen aus dem unteren Sandsteine. Gyps ist darin weniger entwickelt, als in den S.W.-Bezirken Enylands; der Muschelkalk fehlt ganz; die Auflagerung ist gleichlörmig, der Übergang allmählich in

2. Red Sandstone and Conglomerates: oder bunter Sandstein, Grés bigarré. Im N. von Shrewsbury findet die stärkste Entwicklung dickschichtiger Sandsteine von grauer und röthlicher Farbe in den Bergen von Hawkstone, Wern, Grinshill, Nesscliff u. s. w. Statt. Hin und wieder enthalten sie Kupfer und Mangan - Erze mit schwefelsaurem Strontian und Chalcedon. Sie erstrecken sich bis in Staffordshire und das östliche Shropshire, wo sie viele Lagen quarzigen Konglomerats aufnehmen, deren Zerfallen einige Landstriche wild uad 
unfruchtbar macht, während aus den rein sandigen Schichten um Kidderminster das fruchtbarste Getreideland hervorgeht. Die Hauptmerk. male dieser Formation sind; dicke Schichtung, falsche Schieferung und Mangel an Zusammenhalt.

3. Calcareous Conglomerates: unser Zechstein u. s. w. In nördlichen Worcester und in Salop erheben sich Kalk-Konglomerate steil unter jenen Sandsteinen hervor, welche man als Äquivalente der Dolonit-Konglomerate in S.W. und der Magnesian - Kalksteine im N.O. von England betrachten muss. Man brennt Kalk daraus, und sieht sie um Lickey, in den Clent Hills, zu Enville, in den Bowells, zu Coton etc. zwischen Kidderminster und Bridgnorth. Die hauptsächlich eingelagerten Kalktrümmer, die zuweilen oolithisch sind, scheinen von Orelton und den Clee Hills zu stammen. Die unreineren Schicliten, welche in Calcareous Grit übergehen, enthalten Bruchstücke von Old red Sandstone, Quarz und Kohlen-Grit mit Pflanzen-Abdrücken. Dieses Konglomerat kömmt aber nur im rothen Sandstein von Apley, Nedge Hill, Lilleshall u. so w. an der östlichen Grenze des Coalbrook-daler Kohlen-Feldes vor.

4. Lower New Red Sandstone: das Rothe Todliegende. In Worcester und Salop liegen diese Sandsteine und thonige Mergel (zuweilen mit Grits) oft von sehr ansehnlicher Mächtigkeit unter jenen Konglomeraten und gehen nach unten mit gleichförmiger Lagerung in das Steinkohlen-Gebilde über. Dás sieht man zumal im östlichen Theile der Lickey-Berge an der S. - und O.-Scite des Coalbrook-daler und einiger Theile des Shrewsbury'er Kohlenfeldes. An dem Cantern-Ufer bei Bridgnorth und längs einem Theile des Severn-Bettes fallen diese Schichten gleichförmig von dem sie unterlagernden Kohlengebirge weg. Ähnliche Beziehungen sieht man zu Wellbatch bei Shrewsbury und noch besser zu Coedway bei Alberbury. Zuweilen hat dieses Gebilde eine grosse äussere Ähnlichkeit mit dem Old red Sandstone, in anderen Gegenden mit dem Steinkohlen-Grebilde; zu Lilleshall und Wellbatch hat man Pflanzen-Eindrücke darin gefunden.

Der Verf. verfolgt die Grund - oder Auflagerungs-Linic? (buse-line) des New red Saudstone vom May Hill in Gloucestershire bis zum Oswestry Kohlenfeld, und bemerkt einige Änderungen in ihrer Richtung, zumal in der Gegend zwischen Nevent und den Malvern Hills, wie zwischen Kidderminster und Bridgnurth. Längs dieser Linie kommen einige bemerkenswerthe Konglomerate vor, wie zu baffield Camp bei Ledbury, am Rosemary Rock bei der Rrücke von Knightwick an der Ostseite der Abberley Hills und an den Seiten der Stagbury und Warshill Hills bei Bewdley. Sie sind dem rothen Sandstein untergeordnet, und enthalten Trapp-Trümmer, die sich von Bergen in ihrer unmittelbaren Nähe ableiten lassen. Feldspathige Trapp-Gesteine sind in den Malvern- und Abberley-Hills schon scit längerer Zeit bekannt, und kürzlich vom Verf. auch in den Stagbury und Warshill Hills entdeckt worden. Dic auf den Seiten dieser Berge lagernden Konglomerate 
enthalten Bruchstücke von Quarz, Glimmer, Grauwacken und Oldred Sandstone etc.; obschon sie aber die Basis des New-red-Sandstone-Gebildes ausmachen, möchte der Verf. doch diese Konglomerate nicht als Äquivalente des Lower red Sandstone, der in das Kohlen-Gebilde von Shropshire unmittelbar übergeht, ansehen, weil eben inr südlichen Worcestershire und in Gloucestershire die Formation nur sehr wenig Entwicklung zeigt. An 2-3 Stellen der östlichen Abfälle der Malvern Hills haben diese Konglomerate eine geneigte Schichtung und erheben sich über die ihnen zustehende Fläche, und zu Great Malvern hängen sie in gestörter Lagerung mit einem Fallen von $30^{\circ}-35^{\circ}$ an der steilen Seite des Syenites, eine Aufrichtung der Schichten dieser trappischen Berge nach der Absetzung der Konglomerate andeutend.

A. Postels: Bemerkungen über die Vulkane der Halbinsel Kamtschatka, gesammelt auf einer Reise um die Welt in den Jahren 1826-1829 unter v. LütKe's Leitung (Mém. de l'Acad. d. St. Petersbourg 1833, II, 11-28, Tf. I-VII). Der Verf. verweilte in jenen Gegenden im Herbste 1827 und im Sommer 1828. Nähert man sich der Halbinsel von S. her, so gewahrt man ihre vulkanisclsen Piks schon aus 100 Ital. Meil. Entfernung. Vom Lopatka-Vorgebirge $\left(51^{0} 3^{\prime} \mathrm{N}\right.$. Br. $)$ bis zur Avatscha-Bai $\left(53^{\circ} \mathrm{N}\right.$.) erstreckt sich eine mächtig hohe Gebirgs - Kette mit kammförmigem Gipfel und steil ins Meer fallenden Felswänden. Von ihr gehen in N.W. - Richtung höhere Gebirgsreihen zur Hauptkette, welche die Halbinsel von S.W. nach N.O. durchschneidet. Fünf vulkanische Kegel erheben sich hoch aus dieser Masse. N.O, von Avatscha-Bai der Küste entlang reihen sich acht höhere daran. Die Benennungen dieser Vulkane sind, vom südlichsten an, folgende:

1) Die erste Sopka

2) Die zweite Sopka

3) Die dritte Sopka oder Hodutka Ausbrüche.

4) Die Assatschinskaja-Sopka in $52^{\circ} 2^{\prime}$ N. , warf im Juni 1828 Asche aus, welche N.0. bis zum Peter-Pauls-Hafen, 120 Werst weit, getrieben wurde.

5) Die Wiljutschinskaja-Sopka (Tf. I), in $52^{\circ} 43^{\prime} 30^{\prime \prime} \mathrm{N} ., 7$ Ital.

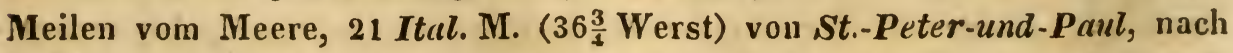
2 Messungen 1044 oder 1057 Toisen hoch; der Gipfel oft von Rauch umgeben; 20 Werst südlich von den $33^{\circ}-34^{\circ} R$. heissen Quellen von Porotunka.

6) Die Avatschinskaja- oder Gorälaja-Sopka (Taf. II, III, V B), in $53^{\circ} 17^{\prime} \mathrm{N}$., 15 Werst vom Mecre, 28 Werst von St.-Peter-und-Paul, nach 2 Messungen 1430 (LüTKE) oder 1250 (LENZ) Toisen hoch, rauclit seit undenklichen Zeiten und hatte heftige Eruptionen in Sommer 1737, 24 Stunden lang während, und mit Aschenregen und Erdbeben bei $L 0$ patka endigend; - im Jahre 1773 (oder 1772) und in Jahr 1827, 6 


\section{$-409$}

Wochen vor Ankunft der Reisenden, wo man am 27. Juli bei bewölktem Himmel zuerst eine Flamme auf dem Gipfel des Berges bemerkte. Vom 28. Morgens $10 \mathrm{Uhr}$ an fiel 3 Tage lang Regen und Asche unter starkem unterirdischem Getöse und einigen heftigen Stössen. An 29. Morgens fand eine starke Erderschütterung Statt, so dass sich zu Avatscha das Zimmerwerk einiger Hütten trennte. Mit einer sogleich nachfolgenden Explosion nahmen Regen und Asche zu. Über Nacht verzog sich das Gewölke, der Berg erschien deutlich beleuchtet von vielfarbigen Feuern, die sich vom Krater zum Fusse herabzogen und von glühenden Feuerkugeln, welche der erstre aussprühete. Von nun an während zwei Tagen verschwanden alle Erscheinungen allmählich bis auf den gewöhnlichen Rauch des Kraters und einen feurigen Streifen, welcher 8 Tage lang aın südwestlichen Abhange sichtbar blieb. Am 25. Sept. 1827 versuchten die Fremden eine Reise nach dem Berge, konuten jedoch nach 2 mühevollen Tagen nur die Hälfte seiner Höhe erreichen. Sie kamen zuerst durch das Gebirge, welches aus rothem Thonschiefer, aus schieferigem Grünstein, mit eingesprengtem Eisenkies, und aus Jaspis und Horustein mit $45^{n}-60^{\circ}$ S.W. Schichtenfalles bestund und mit grossen Geröllen von dichtem Grünstein und Dolerit besäet und von Sümpfen und dichten Wäldern aus Birken, Zwergkiefern und Erlen bedeckt war. Weiterhin lichteten sich die Waldungen, das Gras des Bodens verdorte allmählich, mächtige Massen von Trachyt-Porphyr bis $20^{\prime}$ dick und mit Schwefel angeflogen lagen am Boden zerstreut. Man erreichte den sog. Verbrannten Strom, einen unübersehbaren Sehauplatz vulkanischer Verwüstung, gebildet aus zerstreuten und aufgethürmten Trümmern von Dolerit, Trachyt, Tuff, Bimsstein und Schlacken, und zerrissen von tiefen durch Wasserfluthen gebildeten Schluchten und Gräben, in welchen entwurzelte und wieder begrabene Bäume hervorragten. Am Fusse des Berges selbst wälzt sich in oft 10 Fuden tiefen Gräben ein zäher AschenKoth herab, Steine stürzen periodisch von den Höhen nieder, unterirdisches Gerassel nimmt zu und ab, alles organische Leben ist erstorben. Aus S.S.O. zwischen zwei Arme des Berges gelangt ersteigt man seine Seiten, bis zu den Knieen in Asche watend. Kleinere Kegel bis von 12' Höhe und $30^{\prime}$ Umfang stossen hier und dort Rauchsäulen aus, welche nach Schwefelleber riechen, und die Ränder der Öffnungen, welche über $70^{\circ} \mathrm{R}$. zeigen, sind mit Salmiak und Alaun beschlagen. Trichterförnige Vertiefungen bis von $10^{\prime}-15^{\prime}$ Durchmesser, in der Mitte mit kleinen Lüchern versehen, und Längenrisse, aus welchen dichter Rauch quoll, erschienen auf dem Wege, der Boden dröhnte hohl, das unterirdische Krachen nahm zu, bis zum Ende des Streifens, der eine Woche nach der letzten Eruption von den Einwohnern von Avatscha noch glühend geselien worden und den Reisenden von Ferne ein vom Krater herabziehender Lavastrom geschienen hatte. Aber es war ein über $\mathbf{1}_{2}^{1}$ Werst breites Riff aus Trachyt-Masse mit Krystallen glasigen Feldspathes, das sich $15^{\prime}-20^{\prime}$ hoch mit steilen Wänden und scharfkantigen Zacken erhob und in der Mitte und an den Seiten von tiefen Abgründen durchzogen 
war, woraus dicke Rauchsäulen aufstiegen und Schwefel und Salze absetzten. Der Wind riss viele minder feste Theile los und stürzte sie mit Geräusch in die Tiefe. „Diese Trachyt-Masse ist ohne Zweifel eine im Heerd des Vulkans verbrannte Gebirgsart, welche, nachdem dieser einstnals einen Riss erhalten, durch die Kraft der innern elastischen Flüssigkeiten über die Oberfläche des Berges gehoben wurde"; . . ... "nicht bei der letzten Katastrophe gebildet, sondern schon früher, denn die Einwohner kennen sie seit Menschengedenken;... und da sie vielleicht schon seit Jahren dem anhaltenden unterirdischen Feuer ausgesetzt war, so ist's nicht unnatürlich, wenn sie den Eiawohnern des Avatscha - Dorfes glühend erschienen.“... „Bei der Annäherung an dieselbe empfand man noch eine Wärme, wie von einem geheitzten Ofen". - Nirgends war eigentliche Lava zu sehen. - Hier mussten die Reisenden umkebren; aber des Nachts gewahrten sie mehrere kleine Feuer über jenen Dampf ausstossenden Spalten. Die Wärme des Bodens hatte überall den Schnee weggeschmolzen. Die erwähnten kleinen Kegel waren vor dem letzten Ausbruch von den Führern nie bemerkt worden. Auch war der S.W.-Rand des Kraters dabei theils eingestürzt, theils geborsten. Die Steinmassen, welche die Reisenden schon in 6 Werst Entfernung vom Fusse des Berges gesehen, müssen Auswürflinge desselben seyn, da sie, nicht durch die Asche theilweise vergraben, oberflächlich liegen, mit Schwefel beschlagen und scharfkantig sind.

In Sommer 1828 wurde eine zweite Reise, und zwar über das Dorf Avatscha bis auf die Höhe des Berges unternommen. An der Küste stehen Jaspis, Thonschiefer und Grünstein an, deren Geschiebe auch mit solchen von grauem Trachyt voll Augit - Krystallen, von Dolerit und rother Augit - Lava unherliegen. An einer ganz isolirten, losen, scharfkantigen Trachyt-Porphyr-Masse vorbei, wurde von S.W. her abermals der "verbrannte Strom" erreicht, und von hier auf einem an der S.O. Seite hinziehenden Kanme die Höhe bestiegen, welche in $7000^{\prime}$ noch durch eine sattelförmige Vertiefung von der Spitze getrennt ist. Aber der durch eine Drehung des Windes auf die Reisenden herausgetriebene Rauch nöthigte sie bald zum Rückzuge, nachdem sie mit einem Blicke die ganze anfänglich erwähnte Vulkanen-Reihe verfolgt hatten. - Die ungeheuren Wassermassen, welche überall die tiefen Schluchten ausgehöhlt, scheinen nicht genügend von blossem Regen und Schnee-Schnelzen abgeleitet werden zu können; sie müssen sich aus dem Krater selbst ergossen haben, da ihre Tiefe bis 12 Faden, ihre Länge bis 6 Werst und ihre Breite in der Niederung bis 2 Werst beträgt (E. HopMANi hatte den Krater erreicht und einige hundert Schritt im Umfang und $30^{\prime}$ tief, den Boden geschlossen gefunden). Östlich von dem Vulkan zicht nach W. fort ein $5000^{\prime}$ hoher Bergrücken, die Koselskaja-Sopka (Tf. VC), welcher der Rest eines alten grösseren Kraters zu seyn scheint.

7) Die Korätskija- oder Strülotschnaja-Sopka (Tf. IV, und V A) in $53^{0} 19^{\prime}$ N. , $24 \frac{1}{2}$ Werst vom Meere, 31 W. von St. - P'te'v-und-Pauls- 
Haven, 1896 Toisen hoch, mit kammförmig durchgerissenem Gipfel, aus dessen Nordseite man hin und wieder Rauch aufsteigen sieht, doch ohne bekannten Ausbruch. Trachyt, Tuff und vulkanisches Glas liegen um ihn her, und heisse Quellen kommen nördlich von ihm hervor.

8) Die Schupanovskaja - Sopka (Tf. V D), in $53^{\circ} 35^{\prime} 30^{\prime \prime} \mathrm{N},, 38$ Werst vom Merre, 63 W. vom St-Peter-und-Pauls-Haven, mit platterem Gipfel als die übrigen, ohne Rauch, hat keinen bekannten Ausbruch gehabt.

9) Die Kronotskaja-Sopka (Tf. VI A), in $54^{\circ} 8^{\prime} \mathrm{N}$., westlich vom Vorgebirge Kronoki, 30 Werst vom Meere, $220 \mathrm{~W}$. vom St.-Peter-undPauls - Haven, nach zwei Messungen 1694 and 1764 Toisen hoch, mit spitzem Gipfel, welcher beständig dampft.'

10) Die Klutschefskaja - oder Kamtschatskaja-Sopka (Tf. VII), in $56^{\circ} 8^{\prime}$ N., 70 Werst vom Meere, 350 W. vor st. - Peter-und-PaulsHaven, 1585 Toisen hoch!, entwickelt fortdauernd Rauch, hat aber neuerlich keinen Ausbruch gehabt. Trachyt, Lava, Obsidian und heisse Quellen umgeben sie.

Nach Krascheninikofr hätte er jährlich $2-3 \mathrm{mal}$ Asche ausgeworfen und alle 8-10 Jahre eine Eruption gehabt. Von 1727 bis 1731 brannte er, während heftiger Erdbeben, ohne Aufhör. Vom 25 Sept. 1737 an hatte er 8 Tage lang einen der grössten Ausbrüche, wobei der ganze Berg zu glühen schien, und zuletzt Asche, poröse und verglaste Felsmassen auswarf. Vom Oktober bis nächsten Frühling währten Erdbeben in Nishnekumtschatatsk. Nach Steller erfolgte ein anderer Ausbruch i. J. 1740 ; nach Took zwei andere 1762 und 1767, wo bei dem ersten geschmolzener Schnee und Asche die Umgegend überschwemmten.

11) Die Tolbatschinskaja-Sopka (Tf. VI, B) liegt in S.O. von voriger, entwickelte Rauch seit langer Zeit, ward zu Anfang des 18ten Jahrhunderts mit einem benachbarten Berge durch einen neugebildeten Krater vereinigt, der bei einer Eruption i. J. 1739 durch Feuerkugeln die benachbarten Wälder schrecklich verheerte, nachdem im Dezember 1738 ein furchtbares Erdbeben Statt gefunden (KrascheniniкоғY).

12) Die Schtschapina-Sopka, südwestlich von voriger, scheint erloschen.

13) Die Schewelitsch - Sopka, westlich von 10, wirft noch Rauch aus. In ihrer Nähe sollen noch die Uschakoffskaja - und die Krestoffskaja-Sopka liegen.

14) Die Apalskuja-Sopka liegt auf der Westseite der Halbinsel, 100 Werst vom Dorfe Bulscheretsky und soll noch periodisch rauchen.

Die Kamtschatskaja-Sopka scheint, allen Nachrichten zufolge, die nördlichste in der ganzen Reihe zu seyn, welche $5^{\circ} \mathrm{Br}$. weit S.W. bis zu der ersten Sopka längs der Ostküste in gerader Linie fortsetzt, von welcher nur die Kamtschatskaja-Sopka westlich weit abliegt. Noch südlicher geht die Reihe der Sopki in gerader Richtung noch $5^{\circ}$ weit in die Kurilische Insel-Kette über, worin die Insel Alaid ein noch 


\section{$-412$}

rauchender Vulkan ist und die Sopka auf Paramuschir, 30 Werst von Lopatka, i. J. 1793 einen Ausbruch hatte. Nach Took kommen noch Vulkane vor auf Ikarma, Tschirikutan, Racak, Aetopow, Montowa und Tschiripowaja; heisse Quellen aber noch auf vielen andern. Vielleicht stehen selbst die Vulkaue der Japanischen Inseln mit dieser Peihe in Verbindung.

Bouś theilt einen Bericht über die Geognosie Indostans (aus den Gleanings in sc.) mit, welchen wir hier, da wir jenes Journal nicht besitzen, entlehnen (Bull. géol. de France, 1833, III, pg. $L X-L X I)$.

Nr. 1 enthält: Über die Alluvionen von Benares; - FravkLIN über den bunten Sandstein und Trapp von Bundulkund zwischen Rewah, Jubulpoor und Sagor (p. 13); - und Calmigrr: geognostische Skizze des Landes zwischen Saugor und Mirzabor. Bei Gangor kommen Trapp-Gebirge, bei Huttah Lias und bunter Sandstein, bei Beharma Sandstein, zwischen Mohowah und Johargong Lias, endlich bei Punnah Sandstein vor. In der Nähe des letztern Ortes hat der Verf. vier Diamant-Lagerstätten besucht, nämlich zu Singpoor Shaid, Tehran, Dehlan, Chooponah. Die einen sind in einem harten, von ChloritSchiefer bedeckten Sandsteine, die andern in einem eisenschüssigen Kiesel-Agglomerat, mithin wie in Brasilien. Bei ähnlichen Gruben zu Dukhan herrscht Sandstein. - Zwischen Punnah und Ehatterkote gibt es Granit, Syenit und Porphyr. - Auch findet man in diesem Hefte Analysen von Kalk, Dolomit und Kunkur.

Nr. 7: Macpherson: geognostische Skizze der Gegend zwischen Hydrabad und Masulipatam.

Nr. 8, S. 246. Scotrs geognostischer Umriss des Gebietes von Assum und Sylhet.

Nach Nr. 9 bestehen die Gebirge von Casiah aus Sandstein und sekundärem Kalk. Nach Jones, über den N.W.-Steinkohlen - Distrikt längs des Damoda, zu Jeria oder Jeriagerth und zu Sanampar in Perganna of Shergerh, uinmt das erwähnte Gebirge eine Fläche von 56 Meilen Erstreckung ein. Derselbe theilt auch (S. 265) die Analyse einiger Dolomite und (S. 205) des Eisens von Burdwan mit.

In Nr. 25 und 26 hat Dr. Buchanan die Mineralien der Gebirge von Rajmahal-Cluster verzeichnet;

In Ni. 29 Everest geognostische Bemerkungen über die Gebirgsarten zwischen Calcutta und Ghazipour mitgetheilt.

In Nr. 30, S. 191 hat sich R. Luovd mit dem Archipel von Tennasserim beschäftigt.

Nr. 31 enthält eine Untersuchung Evenest's über das Alter des rothen Mergel. Sandsteins und der sekundären Kalk-Absetzung des 
Distrikts Bharpour, Torapass und Kutsapass; er glaubt jenen zum bun. ten Sandstein, diesen zum Lias bringen zu müssen.

In Nr. 32 liefert derselbe eine Untersuchung über die Felsarten des Bezirkes Ramgerh, und

in Nr. 33 Prinsep die Analyse der Steinkohle, des Eisen.führenden Sandes von Ranigony und des Graphites von Ceylan [vgl. Jahrb. 1833, S. 552]. Zu Hosungabad an den Ufern des Bhoora-Nuddea kommt Steinkohle vor.

In Nr. 35, S. 371 spricht ein Ungenannter von den Felsarten des Gebirges von Chera-Punji, und in

Nr. 36, S. 422 : Everst von den granitischen Felsarten, der Grau. wacke und dem Kalke von Pinang. - Zu Singhara bei Khetri im Gebiete von Shekawati gibt es Kupfergruben (S. 380).

Von den Nachrichten Herbert's und Gerhard's über den Himalayn (in Heft 33) ist anderwärts Ausführlicheres mitgetheilt.

W. C. Trevelyan hat im Milstonegrit-Fels von Shastoe bei Newcastle am Tyne seit 1826 kleine eckige, durchscheinende Gran atStücke in grosser Menge gefunden; später auch in einer ähnlichen Felsart bei Kirkstull in Yorkshire und zu Stirling in Schottland. Auch kleine abgerollte Hornblende-Stückchen kamen zuweilen damit vor. Sie mögen von den Felsarten herrühren, aus deren Trümmern sich das Gestein gebildet hat (Lond. a Edinb. Philos. Mag. 1834, VI, 26).

R. J. Murchison: Tabelle über die Folge der oberien Grauwacken-Reihe in England und Wales, zumal in Salop, Herefori, Montyomery, Radnor, Brecknock, Chermarthen, Monmouth, Worcester, Stafford und Gloucester (James. Ediub. n. phil. Journ. 183t, XVII, 635-368). Das Folgende ist bloss ein Auszug aus einem Werke des Vfs., worin er nicht nur die älteren Gebilde dieser Gegenden bis zur Steinkohlen-Formation herauf, sondern gelegentlich auch die jüngern Formationen, die Syenit - und Trapp - Gesteine zu beschreiben gedenkt, und dessen hauptsächlichster Zweck ist, die Reihenfolge der einzelnen Glieder jener älteren Formation genauer und mit Berücksichtigung ihrer organischen Einschlïsse darzustellen, die abgebildet werden sollen. 


\section{$-414$}

Obere Grauwacken-Reihe (III.

\begin{tabular}{|c|c|c|c|}
\hline Formationen. & $\mid$\begin{tabular}{c|} 
Grösste \\
Mäclitigkeit.
\end{tabular} & Glieder. & Lithologische Charaktere. \\
\hline $\begin{array}{l}\text { I. Kohlcu-füh- } \\
\text { render Kalk. }\end{array}$ & - $500^{\prime}$ & $\left.\begin{array}{l}\text { Kalkstein } \\
\text { Schiefer }\end{array}\right\}$ & \\
\hline $\begin{array}{l}\text { II. Old - red- } \\
\text { Sandstone. }\end{array}$ & 10,000 & $\begin{array}{l}\text { a. Rothes Konglo- } \\
\text { merat und Sandstein. } \\
\text { b. Cornstone und } \\
\text { thonige Mergel. } \\
\text { c. Tile stones etc. }\end{array}$ & $\begin{array}{l}\text { a. quarziges Konglome- } \\
\text { rat über dick geschichteten } \\
\text { Sandsteinen. } \\
\text { b. rothe und grüne, kon- } \\
\text { krezionäre Kalke mit flecki- } \\
\text { gen Thonmergeln u. Sand- } \\
\text { stein-Schichten. } \\
\text { c. Biegsane, sehr glim- } \\
\text { merige, harte, rothe u. grüne } \\
\text { Sandsteine. }\end{array}$ \\
\hline $\begin{array}{l}\text { III. Ludlow- } \\
\text { Rocks. }\end{array}$ & 2,000 & $\begin{array}{l}\text { d. Obrer Ludlow- } \\
\text { Fels. } \\
\text { e. Aymestry und } \\
\text { Sedgeley Kalkstein. } \\
\text { f. Untrer Ludlow- } \\
\text { Fels. }\end{array}$ & $\begin{array}{l}\text { d. Etwas glimneriger, } \\
\text { grauer, dünnschichtiger } \\
\text { Sandstein. } \\
\text { e. Etwas krystallinischer, } \\
\text { oder grauer u. blauer tho- } \\
\text { niger Kalkstein. } \\
\text { f. Sundiger dunkler Schie- } \\
\text { fer mit Konkrezionen erdi- } \\
\text { gen Kalkes. }\end{array}$ \\
\hline $\begin{array}{l}\text { IV. Wenlock } \\
\text { and Dudley } \\
\text { Rocks. }\end{array}$ & 1,800 & $\begin{array}{l}\text { g. Wenlock - und } \\
\text { Dudley-Kalk. } \\
\text { h. Wenlock - und } \\
\text { Dudley-Schiefer. }\end{array}$ & $\begin{array}{l}\text { g. Konkrezionäre, graue } \\
\text { und blaue, etwas krystalli- } \\
\text { nische Kalke. } \\
\text { h. Dunkle Thonschiefer, } \\
\text { selten glimmerig, mit Nie- } \\
\text { ren erdigen Kalkes. }\end{array}$ \\
\hline $\begin{array}{l}\text { V. Horderley } \\
\text { and May Hill } \\
\text { Rocks. }\end{array}$ & 2,500 & $\begin{array}{l}\text { i. Flags. } \\
\text { k. Sandsteine, Grits } \\
\text { und Kalke. }\end{array}$ & $\begin{array}{l}\text { i. Dünnschichtiger, unrei- } \\
\text { ner, muschelführender Kalk } \\
\text { u. dünnblättriger, glimmeri- } \\
\text { ger, grüner Sandstein. } \\
\text { k. Dünnschicht. rothe, } \\
\text { grüne, weisse Frecstones, } \\
\text { Kongl., sandige Kalke etc. }\end{array}$ \\
\hline $\begin{array}{l}\text { VI. Builth and } \\
\text { Llandeilo } \\
\text { Flags. } \\
\end{array}$ & 1,200 & 1. & $\begin{array}{l}\text { I. Dunkle Flags, meist kal- } \\
\text { kig, mit etwas Sandstein u. } \\
\text { Schiefer. }\end{array}$ \\
\hline $\begin{array}{l}\text { VII. Long- } \\
\text { mynd and } \\
\text { Gwastaden } \\
\text { Rocks. }\end{array}$ & $\begin{array}{l}2,000 \text { bis } \\
3,000\end{array}$ & \begin{tabular}{|l|} 
m. Das ganzo Süd- \\
Wales'sche \\
fer-System.
\end{tabular} & $\begin{array}{l}\text { m. Harte dichtlörnige, } \\
\text { graue, grïne, purpurne } \\
\text { Sdst. Rothe u. graue Quarz- } \\
\text { Konglomerate; Schicfer. }\end{array}$ \\
\hline
\end{tabular}


bis VII.) von oben nach unten.

Bezeichmende organische Reste.

Lokalitäten.

Korallen, verschieden von den tieferen.

Producta hemisphaerica;. P. Martini; Spirifer triangularis; Fisch-Zähne ;

Lilleshall, steeraways,

S.-Ende der Clee, Hills, Llanymynech, Shropshire. Rand d. S'Walesschen Kohlenbeckens.

a. Ohne organische Reste.

a. Caermarthen etc.

b. Fische neuer Genera.

b. Mittel- und NordHerefordshire etc.

c. Caermarthenshire

c. Avicula n. sp.; Pileopsis n. sp.; kleine Orthoceren; kleiue Fischstachelu. etc.

d. Avicula n. s., A. retroflexa, A trypa n. sp., Cypricardia n. sp., Homalonotus Knightii, Leptaena lata, Orthis nn. spp., Orbicula m. spp. 2 ; Orthocera it.; PIcurotomaria it., Turbo, Serpula?

e. Pentamerus Kuightii, Pileopsis vetusta, Belle rophon n. sp., Lingula et Astarte it., Terebratula Wilsoni, Calamopora fibrosa.

f. Phragmoceras n. g. 3 spp.; Asaphus caudatus, Cardiola n.g., Pentamerus, Atrypa galeata, Pleurotomâria, Orthocera pyriformis.

g. Korallen und Krinoideen in grösster Menge; Bellerephon tenuifascia, Euomphalus rugosus, E. discors, Conularia4sulcata; Pentamerus, Naticas pirata, Leptaena euglypha, Spirifer lineatus, Terebratula cuneata, Producta depressa, Orthocera, As a phus caudatus, Calymene Blumenbachii.

h. As a phus caudatus, Cal. BIumenbachii, Lingula, Orthis, Cyrtia trapezoidalis, Delthyris, Orthocera annulata, Crinoideen.

i. Pentamerus laevis, P. oblongatus, Leptaena, Pileopsis, Orthis callactis, Terebratula, Crinoideen, Tentaculiten.

k. Nucula, Pentamerus, Trilobites (Cryptolithus), Orthis 14 spp.

1. Asaphus Buchii, Agnostus u. a. Trilobiten, von den obigen verschieden.

d. Ludlow Castle etc.

e. Aymestry etc.

f. Herefordshire etc.

g. Shropshire etc.

h. Salop etc.

i. Salop etc.

k. Shropshire etc.

Wenige organische Reste, dergleichen jedoch m. Salop etc.

tiefer noch folgen.

1. Shropshire etc. 
Huar: vulkanische Umbildungen in Calabrien (Isis 1833, S. 593). Der Vulkan der gänzlich unbebauten Serra di Buda in Innern Calabriens hat die Form eines abgestutzten Kegels, oben mit einer Ebene von etwa 50' Durchmesser. Er brannte, vor 300-400 Jahren, erlosch nach einigen Tagen gänzlich; doch mangeln die genauern Berichte darüber. „Er besteht aus Granit, Gneiss und Glimmer [-Schiefer?], die als gewaltiges Haufwerk durcheinander aufgethürmt sind. Oben, im gan. zen Umkreise der Ebene ist der Granit nach innen in eine vollständige Lava umgewandelt, durchaus wie sie der Vesuv und Ätna auswerfen. An einigeu Stellen ist das Gestein tiefer von der Umwandlung ergriffen. An den meisten Orten des Randes kann man $2^{\prime}-4^{\prime}$ grosse Stücke loshreclien, die aussen vollstäudiger Granit, innen vollendete Lava sind; die Mitte ist Ühergang. Zuerst verliert das Granitkorn allen Glanz und wird matt und weiss; dann wird das Korn des Gesteins unbestimmt; darauf werfen sich Blasenräume, unbestimmt in die Länge gezogen; dann wird Alles blasig; die Blasenräume werden schwarz, innen mit irisirendem Schmelz überzogen, und nun erst schwärzt sich Alles und geht in Lava über. - In der Mitte der Ebene ist fine abgerundete grauitgneissige Masse, durchaus ohne Spur von Veränderung: rings um dieselbe Alles Schutt und Getrünmer. - Dic mitgenommene Sammlung wird gewiss Interesse gewähren. Als Resultat meiner Beobachtungen ergab sich, dass der Berg nicht an der Spitze, sondern ringsum an den Seiten ausgebrocisen; dass es zu keinem Lavastrom gekommen; dass schon nach einigen Tagen der Gipfel in den Krater sank und dadurch den Ausbruch löschte: dass mithin das Gestein, das jetzt in der Mitte der Kegelebene liegt, ehemals in der Spitze des verlängerten Kegels gewesen. - Ähuliche Gebilde sind in Calabrien nicht selten. In Sizilien sind jene merkwürdig, die zwischen Lava und Basalt schwanken aber zu keinem von beiden gehöreu."

Tounnat: Beobachtungen über die vulkanischen Felsarten der Corbières (Mém. Soc. géol. d. Fr., 1833, I, 3.9- 1 t, Pl. V, und l'Instit. 1833, I, 10). Lie Corbières bilden eine kleine Berg-Gruppe an der Nordseite der Pyrenäen im Aude-Departement. Die zu beschreibenden Felsarten habeu vicle Analogie mit den von Panassou, CharpenTIER und Boué beschriebenen Ophiten der Pyrenäen. Sie bilden fast stets kleine Kegel oder Höcker, die, unter dem sekundären Kalke hervorkommend, sich an ihn aufzulagern scheinen. Unterirdische Kräfte haben sie an den Stellen des schwächsten Widerstandes, im Mittclpunkte von Erhebungs-Kratereu, am Fusse steiler Gebirnswände und in tiefen Kalkschluchten hervorgetrieben, und dabei wahrscheinlich viele Zerreissungen des sekundären Gebirges verursacht. Sie sind fast stets von einem sekundäreu Ḱalke, dem Jurakalke ähulich, umgeben und bedeckt, der, wo er sich ilınen annähert, eigenthümliche Charaktere annimnt und in Rauchwacke übergeht. Sie sind ohne Schichtung, ohne. Versteinerungen, 
aber begleitet von röthlichen Mergeln und faserigem Gypse, der Quarz. Prismen einschliesst. Diese zwei letztern Felsarten zeigen daun meist aufgerichtete, oder gewaltsam gewundene Schichtung. Das Hervorbrechen dieser Felsarten scheint zu Anfang der tertiären Periode und unmittelbar nach den Zerrüttungeu des sekundären Bodens Statt gefunden zu haben, jedoch zu wiederholten Malen während eines längeren Zeitraumes, und ohne parallele Richtung der hebenden Kräfte. Wurde mit den vulkanischen Felsarten Schwefelsäure - haltendes Wasser ausgeworfen, so erklärt sich aus der lange fortdauernden Einwirkung auf den Kalk die Bildung des Gypses, der in seiner Mitte oft grosse Blöcke jener Felsarten enthält. Eine Reihe von Beobachtungen nöthigt den Vf., diese Ansicht auf alle sekundären Gypse auszudehnen, selbst wenn sie mit vulkanischen Felsarten nicht in Berührung stehen.

Die feurigen Gebilde der Corbières ähneln der Wacke der Deutschen oder dem Grob - Ophyt PaLassov's, sind matt, theilen sich leicht in vieleckige Stücke, enthalten Kügelchen verschiedener Materien, und scheinen im Allgemeinen aus Augit, veründertem Feldspath, Thon und Eisenoxyd zu bestehen; die Blasenräume enthalten öfters krystallisirten Rosenquarz und Kalkspath-Drusen. Alle Varietäten, in welchen diese Gesteine erscheinen, gehen in einander über. Auch Eisenglanz, Glimmer-Schüppchen und grüne Körner, wohl vom Chromoxyd, kommen vor.

Günstige Lokalitäten zur Beobachtung der angredeuteten "`erhältnisse sind:

1) Lambert, südlich von Narb́onne, an der Höhe von Prat de Cest neben der Strasse nach Perpignan.

2) Sainte Eugenie, Frayssinelle und la Quille in N.W. von Narbonne. An erstrem Orte sieht man Olivin-haltige Kugel-Basalte in konzentrische Absonderungen zerfallen, in deren Nähe, wie Pareto zuerst beobachtet hat, die Sekundär-Felsarten, welche an den Gyps und die Wacke sich annähern, wie mit einem grünen glänzenden Firniss feurigen Ursprungs überzogen sind. Der den Gyps umgebende und beherrschende Kalk ist mergelig, mit kleinen Spathadern durchzogen, zerfällt in röthliche Mergel, und enthält Madreporen, Orbitolithes concava und Podopsis. Bei la Quille werden die Quarz-Krystalle im Gyps so häufig, dass dieser einer Breceie gleicht. Die nüchst den heraufgetriebenen Felsarten befindlichen, durch sie umgeänderten und zerrütteten Kalkschichten sind sehr oft, statt in einer der herauftreibenden Kraft entgegengesetzten Richtung gerade in einer gegentheiligen geneigt [dunkele Ausdrucksweise!], woraus deutlich erhellt, dass vor dem Erscheinen der Feuer-Gesteine die Lagerung des sekundären Ki:Ikes schoon gestört war, und dass diese die Unorduung nur noch vermehrt haben.

3) Gléon und Villesèque scheinen der Heerd der vorzüglichsten Thätigkeit gewesen zu seyn. Man sieht an einigen Stellen dic FeucrGesteine deutlich unter dem Kalk hervorkommen. Sie haben eine sehr grosse Mächtigkeit und Ausdehnung, bilden kleine vulkanische Kegel 
ohue Kratere, und sind - gleich dem mit ihnen gleichzeitigen, meist seitlich angelagerten Gypse - bedeckt von einem ungearbeiteten Gypse, der Gesteins-Trümmer ganz anderer Art einschliesst.

4) Roquefort.

5) Fitou (cfr. Bové Journ. géol.). Diorit trägt einen Kalk vom Ansehen des Jurakalkes, welcher unten, wo er auf erstrem aufliegt, schwarz, bituminös, an einigen Stellen aber roth und zellig ist. Jener ist grau, krystallinisch, reich an Feldspatl, manchen Graniten ähnlich, geht in weisse Feldspath-Gesteine über, zersetzt sich leicht zu einem FeldspathSchutt, oft von Kaolin-ähnlichem Ansehen, doch durch Hornblende verunreinigt. Rauchwacke und Kalk umgeben diese Diorite von allen Seiten und trennen sie vom Gypse. Zu dem Gypse gelangt man über ein Plateau, das aus ihnen besteht; und der Gyps selbst, durch Brüche aufgeschlossen, zeigt sich allerwärts von den oben erwähnten Feuer-Gesteinen umgeben. Er ist körnig, faserig oder späthig, und enthâlt Krystalle von bipyramidalem Quarz und Schwefeleisen.

$\mathrm{Da}$ in den Corbieres Dolonite überall in der Nähe der Feuer-Gesteine auftreten, so schreibt derVf. dem Ausbruch der letztern und der damit verbundenen Talk-Entwicklung die Umwandlung von Kalk in Dolomit zụ.

A. Descenevez: Beobachtungen über den Cantal, die Monts Dore und über die Zusammensetzung vulkanischer Felsarten (Mém. soc. géol. de France, 1834, I, Ir, 175-195, pl. xiv). Der Verf. hält die Theorie der Erhebungs - Kratere für unerschütterlich fest begründet, aber nicht für anwendbar auf

I. die geologischen Erscheinungen im Cantal.

Form und Lagerungs -Verhäl tnisse. Ein Bergkamm umgibt ringförmig die Zentral-Niederung des Cantal, aus deren Mitte sich der zierliche Kegel Puy-Griou erhebt und einen Überblick über den grossen Krater um ihn her gewährt. Einzelne Spitzen erbeben sich nicht beträchtlich über jenen Kamm und selbst der Plumb du Cantal steht nur $200^{\mathrm{m}}$ über dessen östlichen Theil empor: er steigt, gleich einigen anderen Punkten, allmählich von aussen, sehr steil von innen an; im Allgemeinen aber sind beide Abhänge der Kraterwand gleich steil, oft fast senkrecht. Im N. derselben stellt der Bataillouse-Berg einen Knoten dar, von welchem mehrere Höhenzüge strahlenförmig auslaufen, und zwischển deren einigeı und den Gebirgen des Lioran noch ein Circus liegt, den man als kleineren Krater angedrückt an den grössern betrachten könnte. Beobachtet man den grossen Krater von Inneu, so gewahrt mau an vielen Stellen das Ausgehende ungleicher, wellenförmiger, unterbrochner Trachyt-Lagen, welches Queerschnitte radialer, mit Konglomeraten wechsellagernder Trachyt - Ströme sind (Eruptions - Kratere), die aber keineswegs als Ring - oder Bogen - förmige Ausgehende durchgebrochener Schichten (Erhebungs - Kratere) angesehen werden 
können. Auch fehlen die radialen Zerreissungs-Thäler der ErhebungsKratere, welche indessen Durrénor und ÉLie de Beauront naclizuweisen gesucht haben. Denn die Thäler der Cère und der Jordanne, die des Cul de Cabre und des Font de Cére an beiden Enden der von der Bataillouse ausgehenden Vic - und Mandailles - Thäler sind zu hoch und zu oberffächlich, als dass sie dieses Ursprungs seyn könnten. Zwar scheineu eine Menge Thäler strablenförmig gegen den Krater zusammenzulaufen; untersucht man es aber genauer, so kommen sie von einer gemeinsamen Gebirgs.Axe herab, die vom Plomb ausgeht, die Berge des Lioran, Bataillouse, Peyrearse trägt, und worauf die Jordunne, die Cére, der Alagnon, die Rue, der Mars, die Marone, der Brezons, der Prés entspringen: es ist eine Anordnung der Thäler, welche allen GebirgsAxen eigen ist. Zwar sind einige unter ihnen auffallend tief, wie die Thäler des Mars, der Rue u. s. w., bleiben jedoch durch ungcheuer hohe und so dünne Steinwände vom Krater getrennt, dass oben aut dem Graht der letztern kaum Raum für einen Fusssteig übrig ist, was bei Aufreissungs - Thälern, eines Erhebungs - Kraters wenigstens, unerklärlich seyn würde, wenn auch nicht behauptet werden soll, dass diese Thäler nicht durch Aufreissen entstauden,seyen. Wohl aber vertragen sich alle diese Erscheinungen mit der Theorie der EruptionsKratere, wornach diese Thäler entstanden wären durch spätere Auswaschung. Es ist zwar richtig, dass sich die Trachyte nicht sehr weit von dem Krater hinweg erstrecken; aber deren Ströme, die gleichwohl 4-5000 Länge haben, müssen früher zur Ruhe gekommen seyn, da sie nicht sehr mäclitig sind und einen weniger homogenen und verglasten, mithin einst weniger vollständig flüssigen Trachyt enthalten, als jene ain Hunt Dure. Inzwischen sind alle Schichten von der Krater-Wand aus nach aussen geneigt, und zwar unter Winkeln vou $100-120$, stärker als die Obe:fläche des Ring - Gebirges selbst, so dass sie, bis zum Mittelpunkte ergänzt, einen spitzeren Kegel als diese Oberfläche in demselben Falle geben würden. Man hat die Ursache dieser Aufrichtung gegen den Mittelpunkt hin geglaubt in den Phonolithen zu finden, welche mitten im Krater einige Kegel und namentlich den Puy Griou zusammensetzen, die selbst wieder in Kreise um eine zentrale Vertiefung stehen, welche jedoch dem Verf. eine blosse Aushöhlung im Trachyt-Tuff zu seyu scheint, und an deren Pande man in der That auch den Phonolith auf diesem Tuffe liegen sieht, während alle Anzeigen gewaltsamer Hebungen, welche doch gerade hier am stärksten seyn müsste, fehlen; denu die Trachyte schiessen unter den Phonolith des Grivu ein, statt sich mit jhm zu heben, die Trachyt-Tuffe und - Konglomerate, worauf die Phonolith-Kegel ruhen, sind nicht durcheinandergestïrt, sondern zieheu sich in regelmässigen fast horizontalen Schichten fort. Hätte ein tiefer verborgenes Gestein die Gebirgsmasse gehoben, so müssten diese Schichten sich nach der Mitte hin wölben; hätte es ein Gus-Ausbruch gethan, so würden nach dessen Vollendung die Schichten durch ihr eigenes Gewicht gegen die Mitte eingesunken, und in beiden Fällen 
müssten diese sehr zertrümmert worden seyn. Die Beobachtungen in der Mitte des Kraters entsprechen mithin so mächtigen Erschütterungen nicht, als mit der Hebung des äussern Gebirges verbunden gewesen seyn mussten.

G e birgs - Arten-Verhält nisse. Der Verf. wendet sich nun zur Untersuchung der Natur und des Alters der verschiedenen Gesteine selbst. 1) Zuerst brachen die Trachyt e durch Granite und Tertiär-Gesteine vielleicht aus manchen Spalten hervor, die sich aber jedenfalls in einem gemeinsamen Mittelpunkte vereinigten, und nun den Krater bildeten. Ihre rauhe und wenig krystallinische Beschaffenheit zeigt, dass sie dickflüssig gewesen seyn müssen, woraus sich "auch die geringe Erstreckung ihrer Ströme erklärt. Nachfolgende Ergüsse vereinigten sich mit Kies und mit Trümmern schon erkalteter Trachyte zu Trachyt-Konglomeraten, welche die höchsten Stellen, zumal nächst den Grahten der Gebirge einnehmen, während die Tuffe mehr am Fusse abgelagert sind. Einige isolirte und ringsum steil abgeschnittene Trachyt-Massen muss man um so mehr als Dykes betrachten, da sie, gleich den Wänden des Plomb du Cantal und des Puy de Grion, wel. ches offenbar Camine des unterirdischen Feuerheerdes gewesen, in allen Richtungen von Plonolith - und Basalt - Gängen (von unten ausgefüllten Spalten) durchsetzt sind, wodurch sich auch das Vorkommen der rothen und grauen Trachyte in diesen beträchtlichen, doch ungleichen Höhen erklärte, die den unteren Gegenden gänzlicì fehlen. Auch haben einige dieser hohen Trachyt - Streifen völlig das Ansehen von Strömen. Dass sich jedoch die Mündungen jener Kamine gerade auf den höchsten Stellen befinden, erscheint nicht mehr überraschend, sobald man den Krater als einen Eruptions - Krater betrachtet, der zur Zeit ihres Ausbruches vielleicht noch nicht ausgetieft war, sondern noch erfüllt seyn konnte mit vulkanischen Aușwurfs-Stoffen. Spuren exzentrischer Ausbrüche sieht man auch nicht selten in der Nähe. Die Obsidian-Gänge (an 2-3 Orten des Cantal vorkommend) scheinen an das Ende der Trachyt-Periode etwa in die Zeit der Dykes zu gehören. Mehrere Dykes werden von Gängen eines schwarzen Gesteins durchsetzt, welches tafelförmig, kompakt, homogen, mit Feldspath-Nadeln versehen, doch ohne Hornblende ist, auch einige flache Becken auf dem Plateau. im Osten von Dienne ausfüllt, von Btrat als "trachyte homogène compacte", von Bovillex als Phonolith betrachtet worden ist, und später als der Trachyt entstanden ist. Es ist das Äquivalent von Beudast's halbverglas. ten Trachyten Ungarns und von HuмвоцDT's schwarzen Trachyten der Kordilleren. Zu wenig beträchtlich, un den Widerstand der schon auf ihnen ruhenden Massen zu überwinden, mussten sie sich an allen diesen Orten einen seitlichen Ausweg suchen. So kann man, olne scharfe Grenzen dazwischen annehmen zu wollen, in der Geschichte der Trachyte drei Perioden annehmen: a. die der Ströme mit erdigen und domitischen Trachyten, b. die der Dykes mit rothen Horublende - reichen und mit grauen und violetten porphyrischen Trachyten, und c. die der Gänge 
nit grauschwarzen Trachyten voll kleiner blättriger Feldspath-Krystalle. - 2) Auf diese folgen die Phonolithe, welche sich in weichem 'Teig-artigem Zustande um ihre Ausfluss - Stellen anhäuften und sich darüber zu Kegeln erhoben, wie sie bereits im Innern des grossen Kraters von Cantal nachgewiesen worden. Sie sind älter als die Basalte sowohl in Cantal, als nach Burat im Velay; denn nicht nur steht dieser Annahme keine wesentliche Erscheinung entgegen, sondern auch die grosse Säulen - förmige Phonolith-Masse, Roche Blanche oder Roc Douzieres genannt, in Falgoux-Thale wird durch einen eingedrungenen grosseu Basalt - Gang völlig zerfetzt, dessen Verzweigungen auch in die ihn umgebenden Trachyte und Konglomerate gedrungen sind. Auch enthalten die Basalte von Puy-le-Froid in Velay PhonolithEinschlüsse. Daher haben die Phonolithe nicht das entsprechende Alter, welche die Hebung des Kraters von Cantal erforderte. Die Phonolithe bilden einen mineralogischen Übergang von den Trachyten zu den Basalten: sie haben mit ersteren die blättrigen Feldspath-Krystalle, die (selten nur fehlende) Hornblende, den Mangel des Augits und die helle Färbung gemein, sind jedoch mehr zeolithisch, reicher an Alkali, von Tafel-Form, und sind anders zu Tage gehoben worden; den Basalten nähern sie sich durch ihr dichtes krystallinisches Ansehen, ihre prismatische Struktur und ihren reichen Zeolith - Gehalt, und D. glaubt Zirkon und Olivin darin erkannt zu haben; aber sie entfernen sich wieder durch den Mangel des Augits, durch einen geringeren Gehalt an Eisen - und Mangan - Protoxyd, und durch ihre Erhebung in Kegeln, während die Basalt-Dykes jederzeit nur wenig aus den Spalt - Mündungen hervorstehen; inzwischen ist obiger phonolithische Roc Douzières ein wahrer Dyke. - Nach dem Ausbruche der grossen Masse der Phonolithe wurden an mehreren Stellen noch einige Spalten erfüllt mit einem kompakten oder schiefrigen, erdigen oder perlmutterartigen, grünen bis gelblichen Gesteine, wovon die schieferige Varietät von Burat als besondere Gruppe "Trachyte schistoide" aufgeführt wird, welche sich aber weit mehr dem Phonolith anschliesst, der auch am Dyke der Roche Blanche so allmählich in dieselbe übergeht, dass letztere den ganzen westlichen Theil des Dyke's zusammensetzt. Dieses Gestein wird weniger von Säuren angegriffen, ist weniger hart als es zu scyn scheint, voll matter Flecken und kleiner Höhlen, und scheint bloss ein durch saure Dämpfe umgewandelter Phonolith zu seyn, welche Dämpfe sich mit einem Theile der Basen vereinigt haben zu Salzen, die nachher von Wasser ausgewaschen wurden. Diese Dämpfe mögen Schwefelsäure gewesen seyn, da deren Vorhandengewesenseyn aus den Alaun-Breccien des MandailleThales erhellet. Diese Phonolith-Gänge sind jedoch nicht beträchtlich und stark genug, um einer eignen Ausbruch-Periode zu entsprechen. 3) Das Emporquellen der $\mathrm{B}$ a s a Ite in einem sehr flüssigen Zustande seheint erfolgt zu seyn, als das Innere des Kraters noch ganz und unversehrt war; sic vermochten nicht die Decke zu durchbrechen, über welcher die Plionolithe erstarrt waren; sie erscheinen daselbst nur in 
Form von Gängen und zwar in geringer Anzahl; eben so, jedoch weit häufiger auf dem Graht des Kraters; 2000m von dessen Rande entfernt breiten sie sich seitlich über dem Ausgehenden der Gangspalten aus und bilden Ströme, welche im Verhältnisse, als der Abhang geringer $\left(4^{\circ}-5^{\circ}\right)$ wird, auch langsamer flossen, seitlich zusammentraten und nun eine ununterbrochne Hülle über die Oberfläche des Fusses des Kegels bilden. Die entferntesten, durch den Lauf am meisten abgekühlten Basalt - Massen an Fusse erstarrten und theilten sich zuerst in Prismen, wodurch nun auch der noch hölser befindliche Theil ebenfalls zurïckgehalten an der Oberfläche zuerst erstarrte und dann sich im Innern in geneigte Prismen sonderte im Verhältniss, als die Erstarrung voranschritt. Im Allgemeinen ist die Neigung der Prismen jedoch ohne Beziehung zur Lage, worin die Lava erstarrte. In den Trachyt - und PhonolithGängen, in den Basalt-Gängen und Strömen sind die Zusammenziehungsoder Krystallisations - Oberflächen immer parallel oder senkrecht auf die Saalbänder, welches in Übrigen die Neigung der Gänge seye. - Die Basalt - Ausbrüche gehören wenigstens zwei verschiedenen Perioden an. Die älteren Basalte sind nach Burat, da sie den Trachyten und Phonolithen noch näher stehen, auch Feldspath-reicher; aber der Verf. ist ungewiss, ob er mit ihm die neueren Ströme von Graveneire u. a. zur zweiten Periode rechnen solle, und vielleicht gehören die Wacken, obschon sie einen eigenthümlichen Gang verfolgen, einer mittlen Periode an; denn nicht selten sind sie ganz unabhängig von den neueren Augit-Laven abgesetzt. In der That nehmen auch mehrere Auvergner Geologen 3 Basalt-Epochen an. - Die Basalte haben sich theils in Strömen ausgebreitet, theils sich in Dykes erhoben (Plomb, Puy Gros, Bonnevie), theils haben sie Gänge ausgefüllt. Die Dykes gehören den alten Basalten an, die Gänge scheinen aus verschiedener Zeit zu stammen. Ihr Basalt ist zuweilen hellgrau, etwas körnig, obue allen Peridot, wahrscheinlich weil er sehr heiss in Trachyt-Spalten emporsteigend die Saalbänder schmolz und durch Assimilirung des Feldspathes den PeridotGehalt verlor, wie das an vielen Orten geschehen, wo Trachyt und Basalt miteinander in Berührung sind. Am Fusse des phonolithischen Puy d'Usclade ist ein Gang sehr Augit-reichen Basaltes, wie er anderwärts weder in Dykes noch in Strömen, sondern nur in Konglomeraten des Cantal vorkonmt, dergleichen einer über dem Weiler Benex von einem Phonolith-Gang durchsetzt seyn soll, was auf ein höheres Alter hinweisen würde. Wie bei den Trachyten und Phonolithen, so darf man auch bei den Basalten annehmen, dass die Gänge jünger, als die Ströme seyen, welche durch ihren Ausbruch erst die Spalten für die Gänge öffnen mussten. In der That sind anderwärts auch eben die Augit-reichsten Basalte die jüngsten, im Gegensatze mit der Erscheinung von Usclade; sie scheinen jedoch im Cantal nur höchst selten bis zu Tage gelangt zu seyn. - Emporhebungen haben an diesen Vulkane also nur lokal durch die Dykes und durch die Gäuge Statt gefunden : die Basis der steilen Kraterwände ist horizontal geschichtet; anscheinende Störungen 
zeigen sich nur auf den Kämmen, wo eben die zahlreichen phonolithischen und basaltischen Dykes und Gänge nothwendig eine grosse Menge lokaler Hebungen bewirken mussien. So sind an der Roche blancle namentlich Trachyt-Massen von den ansteigenden Phonolithen mit emporgehoben worden; Basalt hat später die hiebei gebildeten Spalten ausgefüllt, Tagewasser haben die Konglomerate zerrissen und vielleicht die neueren, jedoch unter der Oberfläche zurückgehaltenen Basalte in ihrem Aufwalleu noch manche Störung bewirkt. Aber die durchbrochenen Granit- und Kalkstein - Massen finden sich von den plutonischen Gesteinen nirgend in einer Weise mit in die Höhe getragen, welche auf eine allgemeine Hebung hindeutete. Nur zu la Vayssiere zwischen Murat und Chazes sind die Kalkschichten unter $>24^{\circ}$ geneigt, in einer der Annahme einer allgemeinen Hebung entgegengesetzten Richtung: ein lokaler Wacke-Ausbruch, mit dem zentralen walırscheinlich in Verbiudung, ist die Ursache davon. Man sagt zwar, der tertiäre Boden sey allgemein gewölbt. nach jenem zentralen Vulkane hin, aber die Frage ist, ob diese Wölbung eine Folge oder nicht vielleicht eine bedingende Ursache der Hebung gewesen? - Nach Lecoe wären es die neueren Vulkane hauptsächlich gewesen, welche die Monts Dore gehoben, was aber nicht wahrscheinlich, weil deren Ausbrüche weit entfernt von den gehobenen Mittelpunkten erfolgt sind; aber die hiemit verbundeneu Erschütterungen mögen viele Spaltungen bewirkt haben, welche später durch Tagewasser zu Thälern ausgeweitet worden. Und wirklich deuten die mächtigen Konglomerat-Massen auf gewaltige Wasserfluthen hin. Aber die Ausbrüche sind keineswegs unter Wasser erfolgt : es sind vielmehr Wälder an jenen Stellen gewachsen, deren Dikotyledonen-Stämme man verkohlt noch einzeln oder Lager - weise unter den Konglomeraten verschüttet findet. Jene Wasser haben dann Vieles im Ansehen der Gegend geändert.

Allgemeine Folgerungen aus den auseinandergesetzten Thatsachen: 1) der Krater von Cantal ist kein Erhebungs., sondern ein Eruptions-Krater ; 2) 6 verschiedene Eruptions-Perioden haben die alten Trachyte, die Trachyte der Dykes, die grauschwarzen Trachyte der Gänge, die Phonolithe, die alten und die neuen Basalte, welche alle auch in der genannten Ordnung in einander übergehen, geliefert. Diese Perioden waren so weit von einander getrennt, dass zwischen $z$ weien derselben eine üppige Wald-Vegetation sich zu entwickeln Zeit gefunden. 3) Auch nach der Bildung des Eruptions - Kegels hat keine allgemeine Hebung des Landes mehr Statt gefunden; wohl aber sind in jeder Periode lokale und oft von einander unabhängige Hebungen und Verrückungen erfolgt, - kurz: der Cantal ist ein grosser, jetzt erloschener Vulkan.

II. Es war dem Verf. nicht gestattet, eben so gründliche Untersuchuniren in den Monts Dore zu veranstalten, gleicliwohl haben sie ihn von einem analogen Verhalten derselben überzeugt. In der Kreisförmigen Vertiefung zwischen dem Roc de Cuzeau und dem Puy de 
Sancy erkennt er ebenfalls einen Krater, von welchem strahlenförnig mächtige Ströme ausgegangen sind, und durch die der Krater-Rand selbst verändert worden. Er unterscheidet ein dreifaches Alter der Trachyte in Strömen, Dykes und Gängen; aber die Periode der GangTrachyte und die lokalen Störungen haben eine viel beträchtlichere Entwickelung erlangt. Auch hier stehen die äusseren radialen angeblichen Zerreissungs - Thäler nicht im Zusammenhang mit dem Innern des Kraters, fehlt die sichtliche Ursache der Emporhebung, und sind die Basalte in ähnlicher Weise aussen abgesetzt. Man hat sie hier zwar ebenfalls in den mitten in einer parabolischen Vertiefung gelegenen Phonolith - Kegeln, nämlich den Felsen von Sanadvire, Tuillière und Malviale erkennen wollen; aber die Phonolithe zeigen sich nach neueren Untersuchungen auch an mehreren Stellen um den Lac de Guery und bilden die Puys de Triouleroux und de la Clé du Lac in dessen Osten, von welchen Gesteineu einige aus der Zeit der Trachyt - Gänge zu seyn scheinen. Auch hier, an der Strasse von Mhirat le Queyre sieht man den Phonolith in zwei grossen Gängen gegen das eine ihrer Saalbänder in Büat's "trachyte schistoide" übergehen. Die Ansicht scheint sich in der That zu bestätigen, dass die Ausbrüche der Monts Dore viel rascher als im Cantal aufeinander gefolgt und im Velay fast ineinander verflossen seyen; denn in jenen sind die unteren Trachyte grau, basaltisch, Hornblende-reich, fast wie zur Zeit der Trachyt-Gänge; während die grauschwarzen Trachyte und die Phonolithe am See von Guery fast in einander verschmelzen. Die Konglomerate der Monts Dore enthalten abgerundete und scharfkantige Stücke von Granit, Protogyne und Euryt: solche von Kalkstein sind nicht bekannt; sie mögen daher auf Urgebirgen ruhen. Auch die Monts Dore sind daher ein erloschener Krater, dessen Wandungen durch exzentrische und ungleichzeitige Ausbrüche entstellt worden sind.

III. Über die Zusammensetzung der plutonischen Giesteine. Trachyte, Phonolithe und Basalte, in derselben Esse gesclmolzen, durch dieselben Öffnungen ausgegossen, enthalten dieselben Bestandtheile, jedoch in ungleichen Menge-Verhältnissen, nämlich: Kieselerde, Alaunerde, Eisen-Oxyd, Kali, Natron, zuweilen auch Kalkerde, Talkerde und Mangan - Oxyd. Die Kieselerde verhält sich hiebei immer als Säure, und alle Verschiedenheit der Gesteine beruht daher in den Basen. Unter diesen können sich Alaunerde und Eisen-Peroxyd, dann Eisen- und Mangan-Protoxyd, Kalk und Magnesia als isomorphe Stoffe leicht gegenseitio vertreten. Alaun- und Talk - Erde machten diese Gesteine jedoch strengflüssiger, beide Protoxyde leichtflïssiger, die Alkalien g!asiger. Aber die für sich unschmelzbaren Silikate werden schmel\%. bar, wenn je 2-3 miteinander verbunden'sind, und auch von der Sättigung der Säure häıgt die Schmelzbarkeit wesentlich ab, indem die Silikate und Bisilikate viel schmelzbarer sind als die Verbindungen, welche melır, oder welche weniger Kieselerde enthalten. Hiedurch blieben die Phonolithe melir teigig und konnten sich die grauschwarzen Trachyte 
in dünnen Tafeln über die Gebirgs-Oberfläche verbreiten: obschon beide ungefälı gleichviel Alkali enthalten. Aber jene Phonolithe sind durch einen mittelmässigen Gehalt an Eisen-Sesquisilikat grünlichgrau, diese Trachyte durch einen stärkeren Antheil von Eisen - Silikat grauschwarz gefärbt und diese zugleich leichtflüssiger geworden. Die Färbung der Gesteine hängt daher nịcht allein von dem Vorhandenseyn gewisser Metalle, sondern auch vor ihrer Verbindungs. Weise ab und bedingt hiedurch mehr noch, als der Alkali-Gehalt, ihren Flüssigkeits-Grad, wovon wieder andere Erscheinungen abhängen. Wirklich enthalten die alten Trachyte und die Phonolithe 0,14-0,15 alkalische Basen, ohne eben so flüssig gewesen zu seyn, als die Basalte, welche nur 0,07-0,08 dieser Basen besitzen; während der grauschwarze Trachyt und die Basalte ihre Leichtflüssigkeit ihrem Gehalt an Eisen-Protoxyd verdanken. Roth, Schwarz, Blau und Dunkelgrün zeigen Eisen-Protoxyd, - Weiss, Zeisiggelb und Gelb Peroxyd an, wie es die Domite und manche Trachyte färbt. Da nun in hoher Temperatur das kieselsaure Eisen durch Verlust von Sauerstoff in Eisen - Protoxyd übergeht, so müssen diese Domite und Trachyte nur einer mässigen Hitze ausgesetzt, nur in teigigem Zustand gewesen seyn; eine Temperatur-Zunahme hat das Eisen in den Oxydul-Zustand zurückgeführt, eine neue Menge hinzugefügt und die schwarzen flüssigen Basalt-Laven gebildet. Wenn nun gleich nach Obigem der häufige Farbenwechsel eines Gesteines die Erforschung der Farben-Beziehungen zu erschweren scheint, so muss man berücksichtigen, dass derselbe in jedem Gestein doch nur innerbalb gewisser Nüanzen Statt findet und nicht in die einer andern Klasse übergeht.

Grelis hat gezeigt, dass die Phonolithe aus einem Gemenge von Feldspath und in Säuren löslichem Zeolith bestehen. Aber diese theilweise Löslichkeit kommt nach des Verfs. Versuchen allen vulkanischen Gesteinen zu, und das Yerhältuiss der löslichen zu den unlöslichen Theilen ist in einer und dersclben Felsart sehr veränderlich. Die verschiedenen Gesteine geben, zu unsichtbarem Pulver verkleinert, an kalte mit gleichviel Wasser verdünnte Hydrochlorsüure ab:

1) Rother Trachyt von Bataillouse . . . . 9,25

2) Grauschwarzer Gang-Trachyt von Griou . . 14,50

3) Dunkelgrauer Trachyt von der Queuille (Dienne) . 13,50

4) Phonolith von Griou . . . . . . 14.

5) " " Roche blanche . . . . . 7,33

6) Schieferiger Gang-Phonolith von Peyrearse . . $\quad 5,33$

7) Gang-Eurit von der Conelle, homogen, gelblich . 3.

8) Basalt von Plomb du Cantal . . . . . 25.

Die entstandene Auflösung enthält fast nur Alaunerde, Eisen - Protoxyd und Alkalien, und fast keinen Kalk, ausgenommen Nr. 4, das seinen Kalk-Gehalt vielleicht während des Durchbruches durch tertiäre Kalk - Schichten aufgenommen hat. Auch erhellt aus obigen Versuchen, dass die Trachyte keineswegs, wie die meisten Lehrbücher angeben, bloss aus derbem und glasigem Feldspath zusammengesetzt sind, da sie 
sich theilweise in Säuren lösen, was kein Feldspath thut. - Die Ergebnisse dieser letzten Untersuchungen lassen sich daher so zusammenfassen: die Trachyte enthalten gewöhnlich bis $\frac{1}{7}$ ihres Gewichtes Alkali, neben Peroxyd oder Protoxyd von Eisen; das Menge-Verhältniss des letzteren scheint ihren Flüssigkeits-Grad zu bedingen. Die Phonolithe enthalten ungefähr eben so viel Alkali und d:s Eisen-Protoxyd wird ein wesentlicher Gemengtheil, obschon in geringerem Verhältniss. Die Basalte enthalten um die Ḧ̈lfte weniger Alkali, aber viel mehr Protoxyd, und die Talkerde kommt durch den Augit in grosser Menge hinzu. Hornblende ist oft häufig in den Trachyten, zuweilen in den Phonolithen, selten in den Basulten; Augit ist zuweilen in den Traclyyten, nie in den Phonolithen, häufig in den Basalten. Peridot ist in den Trachyten zufällig, zuweilen auch in den Phonolitheu vorhanden, häufig und wesentlich aber nur in den Basalten, zumal den neuesten. Die Trachyte enthalten auch Zeolithe, Stilbit, Chabasie, Mesotyp; die Phonolithe mehr; die Basalte am meisten. So nehmen die Alkalien von einer Seite $a b$, das Eisen-Protoxyd und die Talkerde zu, indem Hornblende und Feldspath sich vermindern, Augit, Peridot und Mesotyp sich vermehren: und zwar beides in derselben Folgenreilhe, in welcher die verschiedenen vulkanischen Gesteine aus dem Schoose der Erde hervorgebrochen, und während der ganzen Zeitdauer dieser Ausbrüche haben in der mineralisch-chemischen Zusammensetzung der Gesteine nur allmählich und gleichmässig fortschreitende Änderungen Statt gefunden, was auf ein ähnliches Verhalten der wirkenden Kräfte in dieser Zeit hindeutet. Es bleibt daher übrig, auch die Erscheinung der Trapp- und Grün-Steine, so wie endlich der sg. Urgebirgs-Arten in rückwärts gehender Stufenfolge zu vergleichen, in wie fern sie denselben oder ähnlichen Gesetzen unterworfen seyn mügen.

A. Bové über Élie de Beaumont's Theorie der Emporhebung der Gebirgs - Ket te n (Janes. Edinb. n. philos. Journ. 183t, July; XVIII, 123-14.9). De Beaumont hat in Brochant's Übersetzung von Dќ ца Beсне's Handbuche eine neue und verbesserte Auseinandersetzung über seine 13-14 Epochen der Gebirgs. Hebungen gegeben. In dereu prster Abtheilung gibt er die Theorie selbst, in der zweiten deren Anwendung auf sein System. In erstrer Beziehung scheint er nur Lyelz'N zum Gegner zu haben, dessen Ansicht von der Emporhebung der Gebirgs - Ketten durch, sich ins Unendliche wiederholende kleine örtliche Bewegungen ihm mit Recht missfullen dürfte, obschon man darum nicht eben genöthigt - seyn würde, jede Gebirgs - Hebung als in einem Augenblick vollendet anzusehen. Man kann sich nicht gut denken, dass ein Gebirge in seiner ganzen Ausdehnung und mit allen seinen Schichten durch zahllose kleine Bewegungen immer in derselben Richtung gehoben wordén sey (Sausstre, Вrochant). - BouÉ ist kein unbedingter Anhänger vou E. v. B's. Theorie; noch immer ist die genaue Riclitung der 
meisten Bergketten, das Ende und die des Streichens ihrer Schichten unbekannt, und auf den geographischen Karten sind die dessfalsigen Angaben meistentheils fehlerhaft, kurz die Unsicherheit ist in dieser Beziehung so gross, dass er lieber gar keiner vorgefassten Theorie folgen will; und E. DE B. hat noch nicht einmal versucht, auch nur für Eurupa die Grenzen eines jeden seiner Hebungs-Systeme auf einer Karte aufzutragen, so dass BouÉ dessen System lediglich für allgemeine und vage Wahrnehmungen erklärt; jedoch könne es immerhin als ein Anhalt dienen, um darnach, von Gebirge zu Gebirge reisend, deren für die Theorie wichtigsten Verhältnisse genau zu prüfen. - E. D. B. setzt die Zahl der in jeder Gegend Statt gefundenen Hebungen gleich der Anzahl von in derselben Gegend bemerkbaren verschiedenen Richtungen von Gebirgeu; allein jede Hebung dürfte mit einer anderweitigen Senkung verbunden gewesen, und beide durch verschiedene Zufälle angedeutet geblieben seyn. Es ist daher nöthig 1) die Form und Richtung des Gebirges selbst, 2) die Aufrichtung der Schichten gegen einander und gegen den Meeres-Spiegel, 3) die Einsenkungen des Bodens, Thäler, Klüfte, Spalten, Rücken, Gänge, Dykes u. s. w. gemeinsam im Auge zu behalten, wenn man die Zahl in einer Gegend Statt gefundener Dislokationen bestimmen will. - Die Zahl der Dislokationen soll nach E. D. B. nirgend sehr gross seyn: sie haben schon seit Fuchsex und WERNER zur Unterscheidung der Formationen geführt, und er denkt, dass sich endlich eine gewisse Übereinstimmung in der Bedeutung der Worte Dislokation und Formation ergeben werde; - daun aber dürfte nach BovÉ der letztere Ausdruck nie in der Ausdehnung genommen werden, dass der Gyps von Montmartre, der Grobkalk von Paris etc. als Formationen gelten. Auf der andern Seite scheinen ihm die Statt gefundenen (12) Dislokationen (nach E. D. B. selbst genomınen : in der Stärke, dass sie ganze Gebirge emporheben kounten) nicht zahlreich genug, um den verschiedenen Richtungen der Gebirgsketten zu entsprechen, die in Europa allein schon so manchfaltig sind, und deren Zahl auf der ganzen Erd-Oberfläche 2-3mal so gross seyn mag. Versuchte man erst nur jene auf eine Karte aufzutragen, ihre Richtung scharf zu bezeichnen und sie zu begrenzen, so würde jeder leicht sehen, was an Elie de Beaumont's Theorie seye, Er würde sehen, dass z. B. wohl die Richtung der Inseln Corsika und Sardinien und die ihrer hauptsächlichsten Vorgebirge, aber keineswegs die des Streichens ilırer Schichten der durch sie gezogenen Linie entsprechen. Wie aber will man überhaupt den von E. D. B. überall wiederholten Satz beweisen, dass alle gleichzeitig gehobenen Gebirgsketten und Gesteins - Schichten parallel streichen müssen, und dass nicht gleichzeitig gehobene auch beständig nicht parallel seyn dürfen? Diese Frage hat BovÉ schon früher aufgestellt, aber ohne sie bis jetzt beantwortet, oder in E. D. B's. neuer Auseinandersetzung auch nur berücksichtigt zu finden. Ferner macht derselbe selbst die Br'merkung, dass wegen der sphärischen Gestalt der Erde die Erhebungs-Lịien Zirkel-Abschnitte beschreiben müssen, und 
dass sie sich auf den Tangenten von diesen befinden. Er macht. selbst auf die Erscheinungen aufmerksam, dass Erhebungs - Linien (wie die des Mont Pilas aus N.O. nach S.W.) manchmal in der Richtung älterer Brüche ausbiegen (im S. von Côte d'Or und in Saone-etLoire-Dept. in der Richtung des älteren Rheinischen Systemes - so auch an a. 0.), und dass ganz, oder bis auf einige Grade, parallele Erhebungs-Linien sich periodisch zu wiederholen scheinen (Mont Pilas und Côte d'Or, Pyrenäen, Corsika und Sardinien parallel zum System. von Westmoreland und Hundsrück, Bocage, Nord-England; - das System von Wight parallel zu dem der Niederlande und Galles; das der West-Alpen parallel zum Rheinischen). Rücksichtlich der Erscheinungen aber, wie gekrümmter Gebirgszüge (der Deutsche Jura von schaffhausen über Regensburg nach Coburg), der Gebirgszüge mit horizontal gehobenen oder gar mit in anderer Richtung als sie selbst streichenden Schichten (Thüringer Wald, nach HeIM geol. Beschr. II , 18), endlich rücksichtlich der von Thurmane (Méme. d. Strasb. II), Schwarz (Jahrb. 1833, I), Pasini (Annal. Lomb. Venet. I, I) und Hibiert (Extinct. Volc. of New-Wied) gemachten Einwendungen gibt E. D. B. gar keine Antwort. Auch gesteht E. D. B. selbst zu, dass öfters verschiedene Formationen mit gleichförmiger Lagerung in einander übergehen; dass aber in diesen Falle wenigstens die bis dahin lebenden organischen Wesen dislocirt worden seyen, und daher den Grenzschichten beider Formationen nur wenige Arten gemeinsam sind.

Folgendes sind die 12 Systeme Elie de Beavmont's:

1) Das von Westmoreland und dem Hundsrück, welche beide (nach Bové) vor der Entstehung der Dudley - Formation als Inseln aus dem Ozean heraufgeragt haben mögen, und wozu noch die alten Ketten der Britischen Inseln, die des N.W. - Deutschlands, des Erzgebirges, der Sudeten, ein Theil des Schucurwaldes, der Fogesen, des Mont Pilas, Britanniens, die Montagne Noire in S.-Frankreich, der Bigarre- und der Canigou-Berg in den Pyrenäen, ein Theil in der Mitte von Frankreich, einer von Corsika, Skandinavien (Westmannland, Jemtland, Lappmarken) und von Finnland gehört. Die Gebirge bestehen aus Gneiss, Glimmerschiefer, Thonschiefer, Quarzfels, Grauwacke, und die Hebungs.Linie streicht nach N.O. etwas 0 , oder nach S.W. etwas W. (hora 3 -4). Die Hebung dieser Gebirge muss vor Bildung des Old red Sandstone und der neueren Sekundär-Formationen Statt gefunden haben, eine Ansicht, welche durch die völlige oder fast völlige Horizontalität der Orthoceratiten- und Trilobiten-Kalke in Schweden, im Baltischen Russland, in Podolien, zu Dudley und Tortworth (welche jedoch später noch verrückt worden), der Anthrazit-führenden Sand- und KalkSchiefer Süd-Islands, der Konchylien-reichen Kalke Canadas noch unterstützt wird. Jedoch gibt es in Europa Hebungen parallel zu vorigen, aber neuer in Alter, und andere von abweichender Richtung aber gleichem Alter, in welcher Beziehung die Ur-Schiefer des Riesen- und Eulen-Gebirges mit einem Streichen von N.N.O. nach S.S.W., oder von 
N.N.W. nach S.S.O, und zuweilen von W.N.W. nach O.S.O., und der Primär-Theil des Böhmerwald-Gebirges mit einem Streichen nach W.S.W. anzuführen sind; - damals bildete sich hier der Kontinent, worauf späterhin die Insel-Vegetation entstand, welche in den Schlesischen und Bölımischen Koblen-Schichten begraben liegt: eine Folgerung, zu der man nur mit Zuhülfenahme noch anderer Merkmale gelangt, als E. D. B. gebraucht. Sollte dieser aber alle diese Hebungen in verschiedene Systeme zerlegen wollen, so müsste er beweisen können, dass sie zu anderen Zeiten entstanden sind, während Bové die Ansicht zulässt, dass in jeder Epoche mehrere Bewegungen in gleicher oder ungleicher Richtungr Statt gefunden haben.

2) $\mathrm{Zu}$ gleicher $\mathrm{Zeit}$ mit vorigen bestund schon eine Reihe untermeerischer Gebirge aus neueren Übergangs-Gesteinen (Bové mém. géol. I, 19): aus cinem Theile von ihnen hat E. D. B. sein zweites Erhebungs - System, das des Ballon's (Vogesen) und der Bocage-Gebirge (Calvados) gebildet, zu welchem auch ein Theil des Innern von Britannien, des S.O.-Endes der Vogesen und der Lozère, die AnthrazitGebirge S.-Irlands, einige Grauwacke- und Schiefer-Gebirge in Devonshire und Somersetshire, nach Bovś auch noch die Grauwacken-Berge N.W. von Hagdebury, die Berge von Sandomirz in S.W.-Polen und die Gebilde des N.N.O. - Abfalles des Harzes gehören. Dieses System, ebeufalls älter als der Old red Sandstone, bietet Abweichungen in der Richtung der Dislokationen dar, indem die herrschende Richtung der Hebungs-Linien mit den Lokal-Meridianen-Winkel von $74^{\circ}$ (nach W.) bildet, jedoch Variationen von $90^{\circ}$ bis $67^{\circ} 30$ zulässt. Nach Weaver aber haben die Anthrazit-Gebirge S.- Irlunds ein allgemeines Streichen von W. nach O. mit einem Fallen nach S. und N. In Devonshire und Somersetshire ist das Streichen aus W. $10^{\circ} \mathrm{N}$. nach $0.10^{\circ} \mathrm{S}$. - Auf der andern Seite glaubten Sedgwick, te La Beche und Conybeare in W. - England und S. - Irland gleichzeitige Hebungen theils aus O.N.O. gegen W.S.W., theils aus 0 . nach W. wahrgenommen zu haben, und Bové selbst hat in Ungarn Störungen aus 0 . nach W., neuer als die vorigen, bemerkt (Bullet. géol. IV, 75).

3) Das dritte Erhebungs - System, das von Nord - England, ist auf SEDGwick's Beobachtungen über eine Axe Kohlen - führender Berge gegründet, welche England von S. nach N. (genauer von S. $5^{\circ}$ O. nach N. $5^{0}$ W.) durchzichet und ebenfalls noch vor der Bildung des Old red Sandstone die grossen Faults von Derbyshire, am Fuss des Crossfeld und des Craven Hills etc. veranlasst hat, wahrscheinlich in Verbindung mit dem Ausbruche der Trapp- und Toad-Gesteine. E. D. B. glaubt, dass zu diesem Systeme auch die Verrückungen in den Malvern Hills bei Bristol, an der W.-Küste des Manche-Depts., vielleicht in den Bergen von Tarere, der Maures - Kette und der Urgebirge auf Corsika gehören. Bovḱ hatte bereits schon vordem Brüche in gleicher Richtung in Ungarn, Steyermark und Kärnthen, jedoch aus viel neuerer Zeit, 
wahrscheinlich erst nach Entstehung des Grünsandes, nachgewiesen (Resume 1832, p. 121 und Bull. géol. IV, 75).

4) Das vierte Erhebungs-System ist das von den Niederlanden und S.-Wales. Freiesceben u. A. haben in rothen Sekundär-Sandsteine und Zechsteine von Mansfeld Faults und Einbiegungen in der Richtung fast aus 0 . nach W. nachgewiesen, welche E. D. B. lediglich ein besondrer Fall von jenen Unregelmässigkeiten in der Schichtung zu seyn scheinen, die allen Sedimentär-Ablagerungen bis zum Zechstein aufwärts von der Elbe an bis Wales gemein seyen, und $\mathrm{zu}$ welchen er demnach alle Biegungen der Koilenschichten der Niederlande und am Kanale von Bristol rechnet. Diese Bewegungen fallen vor die Bildung des Sekundär-Konglomerats von Malmedy und des Magnesian - Konglomerats von England, welches SEDGwrck für jünger als den Magnesian-Kalk NordEnglands hält. Auch die von den Horizontal-Schichten des VogesenSandsteins bedeckten Kohlen-Gebilde von Saarbrücken müssen von denselben Störungen betroffen worden seyn. - BouÉ hatte zwar schon frülıer (Bull. géul. IV, $\boldsymbol{F} 6$ ) noch nevere Fälle von Aufrichtungen aus O. nach W. angeführt, welche aber für E. D. B. keine Schwierigkeiten mehr darbieten, seitdem er in seiner neven Entwicklung die periodische Wiederkehr von Aufrichtungs - Linien in paralleler Richtung gestattet. Inzwischen ist Bovi neulich zur Überzeugung gelangt, dass in den Kohlen-Gebilden Unregelmässigkeit der Schichtung durch die Art des Niederschiags bewirkt worden, welche mit den spätern Schichten-Stö-

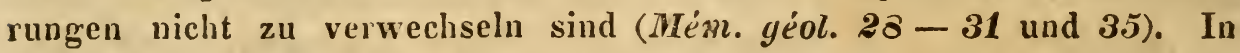
den ältern Formationen des Schwarzwaldes findet nach Meniav ein [ursprüngliches] Streichen der Schichtung von O. nach W. Statt, und ähnliche Fälle wiederholen sich in sü̈-Schlesien, Südermanland und Smalana, die zu den Erhebungs-Epochen keine Beziehung haben.

5) Das Rheinische Erhebungs-System. Die Vogesen und die Haard, der Schwarz- und Oden-Wald bilden 2 Gruppen, welche mit zwei langen, bognigen, doch unter sich und zum Rheine parallelen Steil-Abhängen aus $\mathrm{N}: 21^{\circ} \mathrm{O}$. nach $\mathrm{S} .21^{\circ} \mathrm{W}$. streichen. Die Abhänge der Vogesen bestehen lediglich aus Vogesen- und buntem Sandstein, welche von Muschelkalk und Keuper ungleichförmig überlagert werden. Allein E. DE B's. Beobachtungen reichen nicht bis zum Schwarzwalde hinüber, wo der bunte Sandstein auf dem geneigten Tafellande sowohl als am Fusse der Abhänge vorkommt, und welchen Pozet gleich den Iogesen als eine Zentral-Masse nit divergirenden Zweigen betrachtet. - E. D. B. glaubt noch Spuren derselben Störung in der Richtung einiger Ketten zwischen der Loire und saone, in den Bergen von Zentral- und s.Frankrвich und im Mittelländischen Theile des Var-Depts. zu entdecken, obschon die Gebilde zwischen der Kohleu - Formation und dem bunten Sandstein dort nicht vorhanden sind.

6) Das System des Thüringer Waldes, des Böhmerwald-Gebirges und von Morvan. Nach Bouś (Mém. géol. VI, 48) haben sich die Jura-Gebilde in See'n und grossen Goition theils horizontal, theils mit 
schwacher Neigung der Schichten abgesetzt und ein Theil derselben ist später aufgerichtet worden, so dass mitunter schwer ist zu sagen, wo die Neigung der Schichten eine ursprüngliche oder eine später erfolgte seye. Inzwischen gibt E. D. B. dem Systeme jener Hebungen, welche den bunten Sandstein, Muschelkalk und Keuper sowohl als ältere Gesteine betroffen, eine Richtung von W. $40^{\circ}$ N. nach $0.40^{n} \mathrm{~S}$, und schreibt ihnen die Entstehung der steilen Wände zu, an deren Fusse die Jura-Schichten horizorital abgelagert worden sind. Die Bewegung traf in die Zeit zwischen Keuper und untern Lias-Sandstein. Das N.O.Dentschlund, der Thüringer Wald, der W.-Böhmerwald, die Gegend von Autun und Avallon und in Griechenland das Olympische System lieferten Beispiele für E. D. B. - Im N.O.-Deutschland sind die Schichten der Gebilde von bunten Sandstein bis zum Jurakalke gebogen und greneigt, so dass es schwer zu sagen ist, ob diese Schichten je horizontal gewesen: nach E. D. B's. Ansicht würde ihre Störung mitten in die Zeit der Jura-Bildung fallen. - Bei Ilmenaı wie anderwärts sieht man Fauits sich von den ältern Kohlen-Gebirge an bis zum bunten Sandstein erstrecken (Vorgr, voN Hoff), obschon bei Eisenach der Zechstein den Sekundär-Sandstein in horizontaler Schichtung überlagert. - Um Coburg liegen Lias und der untere Jurakalk in horizontalen Schichten über dem Keuper, welcher Vertiefungen im Muschelkalk ausfüllt und ihn selbst stellenweise bedeckt. Bei Blumenroth aber ist der obere Theil des Keupers mit einem untergeordneten Lager von MagnesianKalk aufgerichtet. - Fichtelgebirge und Böhmerwald stehen mit dem Thüringerwald durch den Frankenwald in Verbindung, dessen Schichten nach vos Hofw aus N.O. nach S.W. streichen, während in beiden ersten (wenigstens im westlichen Böhmerwalde) ihre Richtung aus O.N.O. nach W.S.W. geht und ihre Aufrichtung vor der älteren Kohlen-Bildung in Böhmen und Bayern erfolgt zu seyn scheint. - Andrerseits ist das Olympische System das älteste in Griechenland, und die Störung hat dort nur Urgebirge betroffen. - Aus N.W. nach S.O. nahezu streichen auch der Bleking in Skandinavien, ein Theil des Harzes, die Berge von Alvensleben und in der Lausitz, die Flötz-Kette in Westphalen, die Berge in Süd-Schlesien, die Kette in Süd-Polen und der ältere Theil von Sizilien, obschon ihre Aufrichtung in eine andere Zeit als die obige fällt.

7) Die Erhebungs-Linie des Systems des Mont Pilas im Forez, der Cóte d'Or, der Tafelländer von Larzac, der Cevennen und des Erzyebirges streicht, fast wie die des ersten Systemes, von N.O. nach S.W. oder von $0.40^{\prime \prime}$ N. nach W. $40^{\circ}$ S. und hat sich zwischen den Perioden der Jura- und Kreide - Formation gebildet, auf deren letztren Vertheilung diese Hebung dann von Einfluss gewesen. Einzelne Spuren von ihr bemerkt man noch von der Elbe bis zur Dordogne. Im Erzgebirge deutet das Vorkommen der Kohlen-Lager auf eine schon frühere Hebung in der ersten Periode, und da auch die Hebungs-Linie aus N.O. nach S.W. streicht, so ist nicht abzusehen, warum dieses Gebirge nicht 
überhaupt der ersten Periode zugetheilt worden ist. Nach Navmans in. zwischen streichen die Schichten der schieferigen Gesteine in hora 7,4, oder aus W.N.W. nach O.S.O. Narh den mehrfachen, schon crwähnten Hebungen des Er:- und Riesen-Gebirges in fast allen Richtungen muss Süd-Bölmen schon frühzeitig cin Kaspisches Meer gebildet haben, in dem sich der Reihe nach die Steinkohlen - Formation, der rothe Sekundär-Sandstein, die Kreide und einige Tertiär-Schichten mit Ligniten ablagerten, von denen nur der Grünsand mit der unteren Kreide sich über die kreisförmige Gebirgs - Einfassung des Beckens in die flache Umge gend hinaus erstreckte, was eben auf das Alter dieser Hebung hinweiset, welche vom Sekundär-Sandstein an bis zu dieser Zeit keinem Mcere von aussen einzudingen gestattete; - oder es müsste dieses Becken erst vor der Kreide-Bildung durch Einsinken eines bis dahin vorhande. nen Tafellandes entstanden seyn, was aber, da schon ein Trilobitenkalk darin vorkommt, zur Annahme führen würde, dass sich erst nach dessen Absetzung der Gebirge in Ganzen gehoben, und dass sich dann der Sekundïr-Kalkstein und die Steinkohlen als Land- und Fluss-Erzeugnisse auf diesen Tafelland abgesetzt häten, ehe das Einsinken erfolgte. Zur Zeit der Kreide-Bildung trennte ein grosser Spalt aus N. nach $\mathbf{S}$. das Er: vom Riesen-Gebirge, und eine unermessliche Menge von Quarz-Geschieben bedeckte dessen horizontalen oder wenig geneigten Boden. Damals sollen die Sycnite heraufgestiegen seyn und die Kreide überdeckt haben, welchen Ereignisse man zweifelsohne die Aufrichtung einiger unteren Schichten der Jura-Formation (Müsster bei Keferst. VII, p. 1) zuschreiben darf, wie Naumarv davon das örtliche Einfallen des Grünsandes mit $45^{\circ}-70^{\circ}$ bei Mariaschein, Liesdorf und Weilaen bei Aussig ableitet, obschon dessen Schichten ausserdem beharrlich die älteren Bildungen söhlig überlagern. - Die westlichen Karpathen streicheu ebenfalls von N.O. nach S.W., bestehen jedoch fast gänzlich aus Grünsand-Schichten, aus deren Aufrichtung sich ergibt, dass jene dem achten Systeme angehören müssen.

8) Das System des Mont Viso. Nach E. D. B. sowohl als nach Boú verdanken die meisten Höhen der Alpen ihre Bildung einer Reihe aufeinanderfolgender Formationen; das Streichen ist N.N.W. nach S.S.O. und dic Französischen Alpen, das S.W. - Ende des Jura von Nizะa bis Lons le Saulnier, von Noirs Hontiers bis zun S.-Theile von Valencia, endlich das Pindische System in Griechenland liefern auffallende Beispicle der Emporhebung parallel zu Mont Viso, welche in die Zcit zwischen der Bildung von Grünsand und chloritischer Kreide und der der weissen und mergeligen Kreide fallen soll, was aber für manche dieser Fälle zweifelhaft, da schon beim Riesen-Gebirge Beobachtungen eines hiemit parallelen Streichens aus anderer Zeit beigebracht worden.

9) Die Pyrenüen, in welchen alle cinzelne Bergzüge vom Cap Ortegal in Gallizien bis Cap Creuss in Catalonien cinen auffallenden $\mathrm{Pa}$ rallelisıus des Streichens aus W. $18^{\circ}$ N. nach $0.18^{\circ} \mathrm{S}$. wahrnehmen lassen, so dass der Verlauf etwas schief auf die Linie geht, welche 
beide Endpunkte mit einander verbindet, ist zwischen den Kreide - und frühesten Tertiür-Bildung gehoben worden. Pareto rechnet mit E. D. B. die Apenninen zum nämlichen Systeme ('Transact. géol. III, 353), aber die Hebungs-Linie wie die mit Fener-Gesteinen erfüllten Dykes und Gäuge streichen in Italien aus S.W. nach N.O. Inzwischen scheint die Richtung des Systemes nicht überall dieselbe, und Fener-Erzeugnisse dieser Periode haben nicht selten ältere Spalten erfüllt, welches auch deren Richtung seyn mochte, wie das E. D. B. selbst für die Ophite anerkennt. - E. D. B. rechnet diesem Systeme ferner bei : das steile Gehänge der S.-Alpen, die Julischen Alpen, einen Theil von Kroatien, Dalmatien und Busnien, das Achaische System in Griechenland, die Ust-Karpathen, einige Theile des Harzes, die Entblössungen in der Gegend von Bray und der Wealds von Surrey, Sussex und Kent. Vor allen Dingen jedoch dürften hier die Fülle auszuscheiden seyn, wo Entblössungen nicht durch Hebung, sondern durch blosses Verschwinden von auf ursprünglich konvexen Flächen aufgelagerten Schichten entstehen, wie denn die Entblössungen, Hebungen und Hebungs - Kratere in der Kreide zu Beine bei Grignon und Meudon nie hieher bezogen worden sind. Ferner ist es zwar gewiss, das der Grcensand zu beträchtlichen Höhen emporgehoben und aufgericltet worden, aber, wic es scheint, in sehr verschiedenen Richtungen. So ist das Strcichen der Ost-Karpathen und ihrer Längenthäler aus N.W. nach S.O., in den West-Karpathen aus N.O. nach S.W.; da aber E. D. B. nach Ansicht der Karten die Richtung der letztern für parallel zu der der West-Alpen hält, so folgert er, dass beide zum nämlichen Systeme gehören. An Ort und Stelle aber würde er bemerkt haben, dass das Streichen der Schichten diagonal zu dem des Gebirgs-Kammes, mithin auch abweichend von dem der West-Alpen seye, so dass entweder deren gleichartige Schichten wegen ihres verschiedenen Streichens zur verschiedenen Periode gehören, oder dass Schichten in gleicher Periode gehoben verschiedenen Richtungen folgen, was wahrscheinlicher ist. Am Fusse der Karyathen fehlen die alpinen Felsblöcke, und das alte Alluvium und die neuesten Tertiär-Schichten sind horizontal; aber die Molasse lüngs der WestAlpen ist enporgehoben.

10) Das Streichen der Gebirge und Gebirgs-Schichten auf Korsika und Sardinien, welche beide zwischen die Zeit des Entstehens der zweiten Pariser Tertiär-Formation und des Sandsteins von Fontainebleau gehoben worden seyn sollen, ist zu wenig beobachtet, um sie zum Typus eines eigenen Systems zu machen, mit welchem nach E. D. B. auch die Entstehung der Thäler der Loire, des Allier und der Rhone, so wie der Ausbruch einiger Basalt-Kegel in Nord-Deutschland zusammenfallen soll, welche letetere Krferstein in parellete Zonen aus $\mathbf{O}$. nach W. ordnet. - Mit jener Richtung aus N. nach S. fillt auch das Streichen der Schichten in Wermeland und Dalacarlien, im Ural, in den Aldan. Bergen Sibiriens, in S.W.-Harz, im oberen Leine-Thale in Hannover, an den Ufern der Weser und Fulda und in einigen Bergen um Paiderburn 
zusammen, welcho alle in vou dem obigen verschiedenen Zeitpuubten aufgerichtet worden.

11) Die West-Alpen sind der Typus des eilften Systems, und sollen durch eine Reihe von Hebungen mit langen Zwischenräumen und in verschiedenen Richtungen, worunter die aus N. $26^{\circ}$ O. nach S. $26^{\circ} \mathrm{W}$. vorherrscht, entstanden seyn. Die Montblanc-Kette muss die neuesten derselben erfahren haben, da daselbst die Felsblöcke auf der obersten Molasse zerstreut liegen, was (nach v. Buch und r. Ravmer) der Benensung "Protogyne", welche Junive der Gebirgsart des Montblanc gegeben, günstig ist. - STUDER hat es nicht so leicht gefunden, als E.D.B. es glaubt, in den Alpen die Grenzen der in einander eingreifenden Hebungs-Systeme zu verfolgen, wie denn an einigen Stellen im Kanton Bern die aufgerichteten Schichten ihre Richtungुen ändern ohne allen Bruch und ohne merkbares Eingreifen anderer Systeme. - Da im Innern der Alpen der bergige Boden schon früher aus dem Wasser emporgestiegen, so konnten die Störungen nur noch die Kreide-Formation treffen; an ihrem Rande aber (Superga bei Turin, Grosse Karthause in Provence, Entlibuch) sind die mittlen Tertiär-Schichten mit aufgerichtet worden, und die Entstehung des Phonoliths von Hohentwy scheint damit in Verbindung zu stehen; - nach E. D. B's. Ansicht auch die Richtung der Ostküste Spaniens, eine Bergkette in Morocco u. s. w. Die Hyäne, der Höhlenbär, der Sibirische Elephant, das Mastodon, das Nashorn und Flusspferd scheinen ihm in dieser Katastrophe untergegangen zu seyn, was aber nach Boú̇ noch der Bestätigung bedarf. Die Molassen vom Entlibuch sind zwar gehoben und aufgerichtet, aber wie es scheint, ohne jene obere Abtheilung, welche, so reich an Konchylien, bei Zürich, zwischen Thun und Bern, im Aargau u. s. w., ihre söhlige Lagerung behalten hat. - E. D. B. sieht die Nagelfluhe des Rigi als einen Theil der Molasse an, der sie aber wegen ihrer Höhe $\left(1875^{\mathrm{m}}\right)$, ihrer Einschlüsse von $\mathrm{Fucus}$ intricatus nicht alıgehören kann, sondern zur Kreide gerechnet werden muss (vgl. Studer im Jahrb. 1834, 704), was auch rücksichtlich der von Murchison, SEDGwick und Beaumont für tertiär erachteten Gesteine in den Thälern am nördlichen Fusse der Ost-Alpen (ausser den fluviatilen Ligniten von Hering) zu Gosau u. s. w. gilt. - Auch in Upland, Smaland (wo jedoch alle Gesteine, jünger als die ältern Übergangs-Formationen, fehlen), in Nord-Russland (dessen Hebung ErmaN in die Zeit nach den ersten Flötz-Ablagerungen setzt) und einem Theile des Riesengebirges berrscht obiges Streichen.

12) Die grosse Alpen-Kette von Wallis bis Nieder-Östreich streicht aus $0 . \frac{1}{3}$ N.O. nach W. $\frac{1}{2}$ S.W.: ihre Hebung fällt in die Zeit zwischen die tertiären Anschüttungen und die älteren Alluvial-Gebilde; sie war mit einem plötzlichen Schmelzen ungeheurer Schnee-Massen verbunden, durch deren Wásser die Alpen-Blöcke umbergeführt worden, deren Grösse nach $\mathbb{N}$. Rhein-abwärts rasch abnimmt, und welche nocb gegen O. vicht weiter als bis zum Ausgange des Inn-Thales reichen, so dass 


\section{$-435$}

man in Östreich nur kleine Geschiebe findet. Die Rollsteine N.-Europas leitet E. D. B. ans einer andern Periode ab. - Auch die Berge sainte Beaume, Sainte Victuire; Leberon, der Ventoux, der Pilatus, die zwei Mythens bei schuytz, die höheren Gebirgs-Züge in spanien und die nördliche Kette in Sizilien stimmen in jenes Streichen ein. - Endlich setzt E. D. B. mit dieser Periode die Bildung einiger grossen Thäler in Cantal und Nont Dore in Verbindung, welche ihm Erhebungs - Kratere zu seyn scheinen. - Auch die Fogares-Kette in Transylvanien und der Balkan zeigen ein paralleles Streichen; aber in crsterer ist nur der Greensand, in letzterem allein der alpine Jurakalkstein gehoben.

Es bleibt noch übrig, die Erscheinungen einiger bis jetzt nicht erwähnten Gebirgs-Züge zu betrachten. Die Alleglany's und die Guults von Malabar haben keine Beziehung zur Hebungs - Periode der Pyrenïen. Erstre bestehen bloss aus krystallinischen, sandigen und älteren Schiefern, ohue Kreide-Ablagerungen auf ihren Höhen; an ihrem Fusse liegt jedoch das Kohlen-Gebilde und in einiger Entfernung der rothe Salz-führende Sandstein, und die von Amerikanischen Gebirgsforschern gelieferten Durchschnitte zeigen, dass ihre Hebung vor der Kohlen-Bil. dung erfolgt ist, wenn sie gleich später noch Störungen erlitten haben. Die Gaults aber streichen nach HArDie u. A. aus N. nuch S., oder aus N. etwas W. nach S. etwas 0 ., und sind aus Granit, krystallinischen Schiefern und Trapp-Gesteinen zusamnengesetzt, was jede Ideen-Beziehung mit den Pyrenäen ausschliesst; sie scheinen ebeufalls vor der Bildung der Steinkohlen und des rothen Salz-führenden Sandsteins in Indien gehoben zu seyu. Eher mag die Hebung der Gebirge der Krim und des Kaukasus mit der der Pyrenäen zusammenfallen. - E. D. B. setzt die Gebirge Norwegens, die Küsten vom Nord-Cap in Europa bis zum Weissen Vorgebirge in Afrika, den Atlas und die ZentralKetten des Kaukasus und des Himalayn den-West-Alpen oder einer Linie parallel, die man auf einem Globus von der Mitte Maroccos an bis in den Norden des Birmanen-Reiches ziehen köunte. - Aber auf diesen Parallelismus die Annahme einer gleichzeitigen Hebung der Nor. wegischen Gebirge zu gründen, ist ganz hypothetisch, da daselbst alle Flötz- und Tertiär-Gesteine fehlen. Was die Himalaya-Kette betrifft, so hat sie nach Rrtek's trefflicher Karte (Berlin 1832) nicht die angegebene, sondern cine Richtung aus N.W. nach S.O., nach HARDIE genauer aus N. $25^{\circ}$ W. nach S. $25^{\circ}$ O.; Konchylien-führende Kreide-Lager bedecken ihre Höhen und schwach geneigte Molasse-Schichten ihre südliche Basis, so dass ihre letzte Hebung nach der Molasse-Bildung erfolgt zu seyn scheint. Ausser in den Thälern sind Ur-Gesteine nur an den Seiten des Indau-Kooh bemerkt worden. - Auf die parallele Richtung der Thäler des Ganges und der Lombardey (Po) etc. lässt sich keine Folgerung gründen. - E. D. B. sieht die historische Erdfluth, jetzt nur noch als ein örtliches Ereigniss an, und, obgleich er die gcologischen Unwälzungen 'von noch wirkenden Kräften ableitet, so gesteht er doch neuerlich $z u$, dass diese jetzt minder gewaltig, als vordem, 
und mit Perioden der Ruhe wirken. Die Gebirgs - Hebungen sind ihm die Folge der allmählichen Abkühlung der Erde, der immer weitern Zusammenziehung ihres flüssigen Kernes und der danit fortdauernd abnehmend :n Wärme-Kapazität der bereits erstarrten Kruste.

A. Eaton: über geologische Äquivalente (Sillm. Amer. Journ. of Scienc., 1832, Oktob.; XXI, 132-138). In vielen Fällen sind die Lagerungs-Verhältnisse zur Bestimmung einer Gebirgs - Formation nicht klar genug. Man bedarf selbstständiger Merkmale. Die Ver̀steinerungen liefern die brauchbarsten: Viele sind bereits bekannt, welche in derselben Formation in Europa und in Amerika wieder vòrkommen. Nur die Kreide - Formation in Europa zeigt grosse Verschiedenheiten ") und die "Ferriferous Rocks", welche in Amerika in mehr ais 200 Meilen Läugen-Erstreckung das Thoneisenerz-Lager führen, scheinen in Europa fast ganz zu fehlen. Die Felsarten und (80) Versteinerungen Nord-Amerikas sind nach des Verfs. eigenen Bestimmungen *), wobei er die Mollusken hauptsächlich nach Sowerey, die Krustazeen nach Brongriart, die Radiaten nach Goldfuss benaunt hat:

\section{Urgesteine.}

\section{Gneiss, schieferiger Granit \\ Körniger Quarz \\ Kürniger Kalkstein \\ olme alle Versteinerungen.}

\section{II. Üb ergangs. Gebirge.}

Argillit.

Thonschiefer: Orthocera, Filices.

Wackenschiefer: Terebratula (Art unbestimmt).

Erste Grauwacke.

$\left.\begin{array}{l}\text { Milstonegrit } \\ \text { Old red Sandstone }\end{array}\right\}$ ohne Versteinerungen.

Metall-führender Kalkstein.

Berg- oder Enkriniten-Kalk: Encrinus transversus E. worst).

Konchylien-Kalk (Shelly): Fungites polymorpha; - Calyme. na Blumenbachii; - Orthocera anuulata, O. striata, 0. undulata; - Spirifer ambiguus; - Ostrea (9"lang, $3^{\prime \prime}$ breit); Asaphus, Ogygies latissimus E. $†$ ); - Fungites discoidea;

*) S. Mortos Jahrb. 1837, S. 246-250. - Eıtox hält die Amerikanische Kreide für tertiär.

$\mathrm{BR}^{*}$

*) Wir hoffen nur, dass er Schilfe, Lycopodien und Schlangen nicht mehr miteinander verwechsele! Wenigistens müssen wir bedauern, die Autoren obiger Benennungen nicht genaue: angegeben $z \mu$ finden.

$\mathrm{BR}$.

***) Setzt queer durch die Steinschichten: Glieder niederig.

E.

t) In der Lias-artigen Schichte zwischen dem Konchỵlien - und Kiesel-fülırenden Kalkstein. Es hat 25 Glieder, die Seitentheile $1 \int_{2}$ so breit, als das Ditteltheil, 
Columnaria sulcata; - Productus hemisphaericus; - Scalaria semicostata; - Encrinus curvatus E. ${ }^{*}$ ): - Lithodendron dichotomum.

Kieseliger Kalk (Cherty, cornitiferous Limerock, wegen der C eratiten, Hornsteine): Cyathophyllum ceratites, C. vermiculosum, C. flexuosum, C. vesiculosum, C. helianthoides, C. quadrigeminum; - Orthocera paradoxica; - Conularia quadrisulcata: - Productus depressus; - Gorgonia ripesteria; - Gryphaea Maccullocha; - Terebratula dimidiata, T. octoplicata, T. pectita?, T. affinis?; eine Menge von CidaritesStacheln [!?], wovon einige $14-15$ vorstehende Ringe und $\frac{1}{2}$ "Länge haben [sind Tentaculiten]; - Syringopora ramulosa.

\section{Untres Sekundär. Gebirge.}

\section{Zweite Grauwacke.}

Kohlenschiefer und Grit: Filices, Equisetace ae, Binsen-artige [?]; Lycopodiaceae; Cycadae ${ }^{* *}$ ); Palmae; Cannae; Cacti.

Geschieb-und Schiefer-Wacke: Encrinus dicyclus ${ }^{*}$ ); - Pentacrinites tuberculatus; - Orthocera conica; - Cancer triloboides; - Asaphus caudatus; - Spirifer Walcottii, S p. nov. spec.; - Bellerophon tenuifascia?; - Coscinopora macropora; - Gorgonia bacillaris.

Milstone Grit: ohne Versteinerungen.

Neuer rother und grauer, Salz-führender Sandstein : Lingula mytiloides; - Encrinus giganteus E. †).

\section{Obere Sekundär-Gebirge.}

Oolithische Felsreihe.

Shellgrit, Kalk Grit: Bellerophon (2 Arten); - Terebratula perovalis, T. ovoides; - Spirifer at tenuatus?, Sp. trigon a lis?

Coralrag: Encrinus interruptus E. $t+$ ), E. teretiformis E. $t+f)$; - Orthocera circularis; - Madrepora limbata; Astrea stylophora, A. porosa; - Sarcinula auleticon, S. microphthalma; - Diploctenium pluma; - Lithodendron caespitosum; - Columnaria alveolata (sehr häufig über der

dieses ist $51 / \mathrm{J}^{\prime \prime}$ lang und halb so breit als lang; Mittelglieder oben weit und schicf mach hinten gekrümmt und gegen die Seiten tief cingesenkt.

5) Stielglieder von einander unterschieden mit doppelten Rändern, immer gekrüumt.

Bei Glenns Fulls.

E.

**) Singen aber nicht! Sic werden doch wohl besser den Namen Cycadeae behalten!

***a) Paare vou niedrigen Stielgliedern wechseln mit je eínem höheren.

Brows.

†) Säule ästig, selır lang.

E.

t+) Hohe Stielglieder, zwischen denen je 1-2 niedre erscheinen.

E.

tt†) Säule schnell an Dicke abuehmend, Gliedcr eben, meist blass und weiss. $\boldsymbol{E}$. 
Pucker Street Cavernam Helderberg); - Catenipora a uletic on; Cyathophyllum hypocrateriformis; - Gorgonia infundibuliformis; - Asaphus Hausmannii; - Terebratula spiriferoides E. (beide letztere sehr schön längs der Südküste des Erie-See's, zumal bei Eighteen-mile creek).

\section{Tertiär-Gebirge.}

Plastischer und mergeliger Thon: verkohltes Holz oder Lignit, mit kleinen B e rnstein-Stücken und grossen Massen vou SchwefeEisen, Eisenstein und Sumpferz. Plicat ula pecti noides im Py. rit. - In einer Art grünen Kalksandes in Neu Jersey die vielen vou Morton beschriebenen Versteinerungen; wozu noch $\mathrm{Nantilus}$ imperialis kommt, den E. mit SAY's Exogyra costat a im grünen Sande gefunden.

Seesand (Bagshot Sand) und Crag: sind ohne Versteinerungen, ausser jenen, die in den grünen sandigen Mergel-Schichten enthalten sind.

Schnecken-Mergel, meist in Vertiefungen niedergeschlagen oder eingewaschen, mit Planorbis obtusa, P. alba, P. paludosa, P. annulata; - Bulla rivalis; - Limnea longiscata, L. minima (Varietät der vorigen?); - Coenomyce muscioides (in dem Tuffe, der eine besondere Schichte des Schnecken-Mergels ausmacht, längs des Erie - Kanals, zumal von 1 Meile westlich von Ninemile creek an).

Nach des Verfs. Meinung fehlt die Kreide in Nord-Amerika ganz; der Grünsand ist neueren Bildungen eingemengt worden, wie denn ältere Ablagerungen sich öfters in die neueren hinein erstrecken; und so sind auch fossile Reste, welche in Europa für die Kreide bezeichnend sind, mit den tertiären durcheinander gekommen; umgekehrt aber können in ein Steingebilde keine Theile von Organismen gelangen, welche crst nach dessen Niederschlag geschaffen worden sind. Die Lignite, der Bernstein, das Eisen scheinen ihm chtsclieden für eine tertiäre Formation zu sprechen. - Eine feblerfreiere Liste mit genauerer Angabe der Fundorte soll später folgen.

-Rebour: Abhandlung über die tertiären Ausfüllungs-Gebirge (Mém. de la Suc. géol. de France, 1834, I, Ir, 197-213).

1) Eintheilung dieser Gebirge. Die von einer früheren z.u einer sekundären Lagerstätte fortgeführten Gebirgs-Arten (terrmins de transport), umgeschüttete oder Schutt-Gebirgsarten, bestehen aus Sand, Lehm, Kies, grösseren Geschieben und Felsblöcken, haben theils Vertiefungen ausgefüllt (T. de comblement, Ausfüllungs-Gebirge), theils sind sie über tiefer gelegene Ebenén ausgebreitet worden(T. d'atterrissement, Auscluwenaungs-Gebirge). Dic ersten hat man Diluvial-Gebilde genannt: 
eine fehlerhafte Benennung, weil sie weder alle von einer einzigen Fluth herrühren, noch überhaupt alle durch Überschwemmungen entstanden sind. Regen - und Fluss - Wasser haben sie von den Bergen herabgeführt. In der Oberfläche der letztern befinden sich zweierlei Vertiefungen, nämlich theils schmale und lange, von den Bergkämmen zu den Ebenen herabgehende (Thäler, Schluchten u. s. w.), welche gewöhnlich noch von den Gewässern durchströmt werden, durch deren auswaschende Thätigkeit sie entstanden und immer weiter ausgebildet worden sind, - und rundliche oder ellipsoidische von ganz verschiedener Entstehung, auf deren Grunde stehende Gewässer, See'n vorhanden sind oder gewesen sind, ehe sie durch Ausfüllung verdrängt worden, welche Vertiefungen aber ebenfalls durch solche der ersten Art unter sich und nit diesen in Verbindung gesetzt zu, werden pflegen. Die ubersten dieser Gebirgsbecken enthalten daher im Allgemeinen das älteste Ausfüllungs-Gebirge.

2) Die Ausfüllung der obersten Gebirgs-Becken, besonders jener in granitischem Gebirge ist noch am unvollkommensten erfolgt, weil sie den Quellen der Ströme zu nahe liegen, wo die fortführende sowohl als die einschneidende Gewalt der letztern noch schwach ist, daher sind sie gewöhnlich noch mit See'n erfüllt, und in der ganzen Pyrenäen - Kette sind die See'n des Mont Perdu vielleicht die einzigen, welche noch in deren Kalk-Region bestehen, und zwar in $2600^{\mathrm{m}}$ Seehöhe, wo sie nur noch von 2-3 Spitzen überragt werden. In der Primär-Region dagegen sind noch mehrere, in $1400^{\mathrm{m}}-1500^{\mathrm{m}}$ Hölie vorhanden, wie der von Secoulége im Oo-Thale, aus dessen Nähe die Quellen der Sègre, der Ariège und der Essern herabkommen. Auch die Granit-Gruppen von Neige vieille bei Barège und in der Gegend von Cauterêts sind noch mit See'n gekrönt. Andere Becken aber in den obersten Regionen der Pyrenäen sind bereits ausgefüllt worden, wie das von Castillon unterhalb Barrat im Lys-Thale in $2200^{\mathrm{m}}$ Höhe gelegene, in dessen Schuttboden sich der Bach des benachbarten Gletschers eingewühlt hat, - und das im Thale Breas, dessen in $1500 \mathrm{~m}$ Höhe befindlicher See i. J. 1788 durch einen ungeheuern Erdfall ausgefüllt worden. Auch sind es überhaupt nur Felsstürze, durch welche dicse Ausfüllungen bewirkt werden können, da die Bäche in ihrem kurzen Laufe bis dahin weder Stärke genug erlangen, grössere Steine fortzuschaffen, noch Zeit genug gewinnen, diese Steine zu Sand zu verkleinern.

3) Die Ausfüllung der mittlern und untern Becken konnte in einfach gestalteten Ketten, wie die Pyrenäen sind, bald bis zum Verschwinden der anfänglichen See'n vor sich gehen und der frübere Durchbruch der Abfluss-Schwéllen noch hiebei behülflich seyn. In den zusammengesetzteren Alpen aber, deren Systeme sich so manchfaltig kreutzen, sind noch viele dieser [auch später entstandener] Becken mit stehenden Gewässern erfüllt geblieben.

4) Die Ausfüllungs - Gebirge derselbèn werden unter den folgenden Nummern unter $A$ bis $D$ bescbrieben. 
5) (A) Die Nage Iflu e ist das erste dieser Gesteine. Nach StuDER liegt sie zum Theil auf alten Gebirgs - Arten aus der Zeit vor den rothen Molassen und Thonen, theils wechsellagert sie mit den mittlen Tertiär-Molassen, theils endlich liegt sie zwischen den oberen MuschelMolassen und Muscheln selbst. Dass sie in See'n entstanden, deren Wasser ihre zusammengeflössten Geschiebe mit einander verkittet, erhellt im Allgemeinen aus der beschränkten Erstreckung ihrer einzelnen, obschon oft sehr mächtigen Ablagerungen und aus der oftmaligen Bedeckung tertiärer Schichten mit Süsswasser-Psephiten, in Besondern aber aus dem von ÉLIE DE BEAUMONT oberhalb la Vurreppe in RoiseThal (Isère) beobachteten Eingeschlossenseyn dreier Wechsellagerungen von Ligniten mit Süsswasserkalk in einem $500^{\prime}$ mächtigen Geröll-Konglomerate, zu dessen Bildung, aus der vollendeten Unwandlung der vegetabilischen Materie in Braunkohle zu schliessen, Jahrhunderte fortgewirkt haben müssen. Da die Anhäufung der Geschiebe in den GebirgsSee'n begreiflich von dem ersten Hervortauchen der Gebirgs - See'n an bis zur gänzlichen Ausfüllung der Becken fortgewährt haben muss, so kann man die unteren, mittlen und oberen Lager derselben nicht aus einem gleichen Zeitalter herschreiben.

6) (B) Leh m, Sand und Quarz-Geschiebe. Liegen in cinem Thale mehrere Becken untereinander, so blieben im ersten die Geschiebe in Gemenge mit Sand und Lehm zurück, und die folgenden erhiclten nur den feineren Sand und den Lehm, welche das Wasser über die Abfluss - Schwelle des ersten mit hinweg nehmen konnte, bis dasselbe ausgefüllt war. Daher in den tieferen Becken so oft nur die oberen Schichten aus gröberen Geschieben bestehen, wie man insbesondere im Tet-Thale am Fusse des Canigou in den Pyrenäen bemerkt. Der Bergstrom hat vom Canigou herab das, durch einen Kalkstein-Damm vom Tet-Thale gesonderte, kleine Becken von Vernet nit Granit-Trümmern erfüllt, nach dem eine Stunde tiefer liegenden Becken von Prades aber eine $30^{\prime}-40^{\prime}$ mächtige Lage nur von Lehm, Sand und Kies gebracht, worauf dann erst ungleich geschichtete grössere Geschiebe und Blöcke ruhen. - Auch die Becken am Fusse der Alpen lassen ähnliche Erscheinungen wahrnehmen. Im Lyoner Becken reichen die Geschiebe vor den granitischen Dämmen, welche die Wasser der Rhone und Saone aufgehalten, bis zur Höhe der Hügel an deren Seiten hinan. Die nachfolgenden Becken in der Kalk - Gegend, welche die Rhone durchfiiesst, waren seichter, breiter und mit weiteren Abfluss - Öffnungen versehen: daher die Lehmschichte in ihnen minder dick ist, und die GeschiebIage darüber oft nur wenige Fuss über dem Flussspiegel reicht. Bei der nachherigen Vertiefung der Abfluss-Schwellen durch den Strom ward ein Theil dieser Materialien immer wieder weiter mit fortgeführt, bis er das Meer erreichte, in dessen Golfen daher die untersten dieser Schichten aus den frühesten Zeiten rühren können. Im Garonne-Becken sind bei der Einmündung des Lot die obersten Tertiär - Schichten durch mü̈chtigen Süsswasserkalk vou dem Ausfüllungs-Gebirge getrennt. Sehr 
selten trifft man grössere Blöcke in diesen oft geschichteten Gemengen aus zerriebenem Gestein (Kies, Sand oder Lehm), worin jedoch mithin nichts auf eine grosse Überschwemmung, nichts auf ein Diluvium hindeutet. - Die tertiären Säugethier-Knochen sind darin in verschiedenen Höhen zerstreut, und oft eingehüllt in den diese Ausfüllungen unterteufenden Niederschlägen. So liegen die Hirsch-, Rhinozeros-, Hippopotamus - und Elephanten-Reste des kleinen Beckens von Riège bei Pézenas zusammengebacken mit Kies und Sand in dem Süsswasserkalk über Meereskalk und unter dèm Ausfüllungs-Gebirge, während anderc, doch in nur geringer Anzahl, in den mittlen und obern Schichten dieses $40 \mathrm{~m}-50 \mathrm{~m}$ mächtigen Lehm - Lagers zerstreut sind; und so finden sich im Lyoner Becken die Elephanten-Knochen in um $70^{\mathrm{m}}$ von einander verschiedenen Teufen des Sand- und Lehm-Niederschlags begraben, auf welchem die Geschiebe ruhen. - Die vergleichende Betrachtung einzelner Becken wird dazu dienen, die Lokal - Verhältnisse zur unterscheiden, welche die sonstigen Verschiedenheiten in diesen Absätzen bedingt haben.

7) (B. a) Ausfüllungs-Gebilde des Ost-Pyrenäischen Meerb us ens. Drei Bergströme, der Tech, die Tet und der Agly, haben von den Pyrenäen herab gegen $O$. fliessend den alten Meerbusen ausgefiillt, welcher im S. von den Alberes, im $\mathrm{N}$. von den Corbieres begrenzt wird, indem sie gegenwärtig ein grosses Delta aus Sand, Lehm- und QuarzKies, welche unter einem einst 200m höher reichenden Meere zu dieser Form zertheilt worden, zu durchlaufen haben. Seit dem Zurücksinken des Seespiegels scheinen diese Materialien zwischen dem Agly und der Tet noch von Strömen hin und her geworfen, zwischen der Tet und dem Tech aber unberührt geblieben zu seyn. Die höchste der von ih. nen gebildeten Terrassen, auf deren einer Banyuls-les-Aspres liegt, übersteigen die höchsten Tertiär-Gegenden, welche keine Hebungen erfahren haben, nicht. Die erwähnten Bergströme haben abwärts bis zum Seespiegel Durchschnitte dieser Schichten geliefert, und Bohrversuche haben gezeigt, dass dicselben noch vicl weiter bis zu unbekaninten Tiefen nicdergehen. Grauer und gelblicher Sand und Lehm mit röthlichen Adern bilden darin bald regelmässige Schichten von geringer Erstreckung, bald ungleiche Anhäufungen, in welchen beiden Kies - und Quarz-Geschiebe mehr eingestreut, als eingeschichtet erscheinen: Granit ist selten darunter. Die kalkigen Niederschläge aber bilden kaum 0,01 der ganzen Masse. Über ihr, selbst nach dem obersten Kieslager abgesetzt, welches die Flüsse vor ihrem Einschneiden in dieselbe noch ausgestreut, findet man tertiüre See-Konchylien, welche Desnayes ihren Arten nach in die neueste Tertiär-Periode verweiset; sie finden sich nur am Rande der Ausweitungen, welche die Flüsse in ältern Ausfüllungs - Gebirge gebildet, nur ihn geringer Entfernung von diesen und nicht ausserhalh der Grenzen jener Ausweitungen, eingeschlossen in einem Lager von Sand, wie ihn diese Flüsse noch gegenwärtig absetzen. Die verschiedenen Niveau's dieser Muschelsand-Bänke gestatten uns, das allmähliche 
Finsinken des Meeresspiegels zu verfolgen; doch ist nicht genau gemessen, wie weit sie hinaufreichen. Die der Tet bei Nafiach haben wenigstens $120^{\mathrm{m}}$ Seehöhe; die von Banyuls ist nicht über 70 . Obschon aber demnach beide aus einer verschiedenen Zeit herstammen müssen, so sind ihre Konchyl-Arten inzwischen doch die nämlichen geblieben. In dem Sande zunächst dem Tet-Bette, am Meere, findet man alte Pachydermen-Knochen nach $60^{\mathrm{m}}$ unter der Fläche des Muschelsándes von Nafiach.

8) (B. b) Das Ausfüllungs-Gebirge des nördlichen Pyrenäen-Beckeus von dem Anhange der Corbières an bis zum Ozean ist von Daubuisson und neuerlich von Borbée (Bull. géol. $T, 146$ ) beschrieben worden. Dieses Lehm - und Sand-Gebilde erhebt sich wie das von Roussillon bis über das Niveau des tertiären Meeres. Seine Mächtigkeit bei Toulouse beträgt wenigstens $800^{\prime}$, da es $200^{\prime}$ über die Ebene ansteigt, in welcher ein $600^{\prime}$ tiefer Bohrversuch es nicht durchteufen konnte, - wie es auf demselben Wege erwiesen ist, dass es 50 Stunden vom Meere entfernt noch über $150^{\prime}$ tief unter dessen Spiegel reicht. Das Gebirge besteht aus thonigen und sandigen Lehmen, aus Kies und aus Quarz-Geschieben. Dieser Lehm wird stellenweise zu Thon und Mergel in mächtigen und regelnässigen Schichten; und der Sand bindet sich zu Molasse. Aber See-Konchylien kommen nicht darin vor, sondern nur einzeln eingestreute Land-Konchylien. Dieses von der Garonne durchströmte Gebirge hat eine Einfassung von tertiärem Meereskalk, welcher im W. zwischen La Réole und Langon beginnt, und auf den sich ebendaselbst ein tertiärer Süsswasserkalk stützt, der die nördliche Einfassung auf dem rechten Ufer der Garonne bis oberhalb Toulouse bildet hier vom Lot und Tarn durchschnitten wird, zwischen deren Einnündungen in die Garonne dieser Kalk aber unmittelbar auf dem Ausfüllungs - Gebirge ruhet, welches ein Parallel - Erzeugniss des tertiären Meereskalkes seyn dürfte, da es sich mit ihm auf seiner westlichen Erstreckung bis zum Meere zu verbinden scheint. Es ist gewiss, dass auch der Süsswasserkalk von Aiguillon und Agen auf diesem Gebirge ruhet, denn nicht nur beobachtet man dessen Ansteigen über dem letzten bei Agen deutlich, sondern ein $400^{\prime}$ tiefer Bobrversuch ist auch in der Tiefe nirgendwo mehr auf diesen Kalk gestossen. Es wird demnach klar, dass alsbald nach der Emporhebung der Pyrenäen die Ausfüllung des Meerbusens an deren nördlichem Fusse durch die Zuführungen der Flüsse begonnen habe; gleichzeitig gebildete meerische Kalkbänke schlossen den Golf von W. her ein und gestalteten ihn zum geschlossenen Becken, als das Mecr unter deren Niveau hinabsank, und so einen Theil des Ausfüllungs - Gebirges trocken legte. Landgewässer breiteten nun den Süsswasser - Kalk an der Nordgrenze über dasselbe aus, auf welchen sich endlich noch ein anderes neueres (doch noch tertiäres) Ausfulllungs-Gebirge aus Lehm, Sand und Kies vom linken Ufer des Tarn an bis zum Plateau von Naurvuse herlagerte, welchem allein alle fossile Knochen der Gregend anzugehören scheinen. 
9) (B. c) Das A u s füll ung s-Ge bil de des Cevennen-PyrenäenBeckens ist von den es rund umgebenden Gebirgen vom Vorgebirge la Nourelle bis zu dem von Cette herabgekommen. Die Geschiebe sind fast alle quarzig, mit wenigen von näheren Anhöhen herrührenden, kalkigen und basaltischen untermengt. Der Lehm ist roth oder blassgelb, durch Zertrümmerung umschliessender Kalkberge entstanden. Alle KalkGebirgsarten der Gegend, die Glauconie, der Oolith des Lias haben die Eigenheit sich zu zersplittern, und sich an der Oberfläche mit einem rothen oder gelblichen Staub z.u bedecken, welcher von den Regenwasseru leicht wieder weggenommen wird, und so zur Bildung der LehmAblagerungen beiträgt, zu denen sich aber noch die Puzzolane erloschener Vulkane in der Nähe gesellen, welche als Zuthat zu hydraulischen Mörteln und feuerfester Töpferwaare brauchbar sind. Auch der Stauh der Süsswasserkalke wird röthlich, aber der der tertiären Meereskalke bleibt grau. Der rothe Lehı der Knochenhöhlen ist des oben erwähn. ten Ursprungs, nimmt aber durch Zersetzung thierischer Theile in fortdauernder Feuchtigkeit eine schwarze Farbe an, die er durch Austrocknung wieder gegen rothe untauscht. Diese meistens Kies enthaltende Lchme sind in unregelmässigen Bänken von geringer Erstreckung abgelagert, über denen sich nie Vertiefungen in Folge späterer Überschwemmungen, noch unregelmässige Anbäufungén von ähnlichen Materien gebildet haben. - Dieses Becken begreift die drei kleineren der Aude, des Or.b und des Hérault in sich. Das Ode-Becken hat noch eine besondere Unfassung von Kalkbergen und enthält regelmässiger geschichtete Lehm - Niederschläge, welche zu Ziegeln brauchbar sind, ohne alle Quarz-Geschiebe, da dicjenigen, welche die Aude mit von den Pyrenäen bringt, bisher in einem höheren Becken zurückgehalten worden sind, dessen letzten Niederungen man kürzlich trocken gelegt hat. Das Plateau des Libron zwischen dem Orb und dem Hérault enthält, so tief auch die Tagewasser eingeschnitten, nur rothen Lehm mit QuarzGeschieben überladen, in einer Längen-Erstreckung von fast 3 Stunden gegen die Gebirge und in einer Breite von einer Stunde am Mecre. In den Becken von Béviers und Pézenas bildet er eine Ebene in $130^{\mathrm{m}}$ Höhe; zwischen der Pégue und der Tougue setzt er einige kleine Plateau's zusammen: zu Bunrgade bei Clairac reicht er, einem Bohrversuche von 100' Tiefe zufolge, bis unter den Meeresspiegel. - Die thonig-quarzigen Schicfer an den Quellen des Libron, der Peyne und der Tougue miissen die Quarz-Geschiebe geliefert haben.

10) (B) Die Quarz-Trümmer des Ausfüllungs-Gebirges insbesondere, oft in ausserordentlicher Menge umhergestreut, cha. rakterisiren vorzüglich dessen ältesten tertiüren Schichten, jedoch nur der nittlen und unteru Regioneu, während die Gewässer dersclben Gegenden heutzutage nur Granit-, Gueiss-, Porplyr - und Diorit - Trümıner mit sich führen, was sich nur durch die Annahme erklären lässt, dass vorliegende Thonschiefer- u. a. - Gebirge, welche jene ungeheure Masse von Quarz - Trümmern geliefert, schon lange gänzlich zerstört worden 


\section{$-444$}

seyn; denn die zentralen Granit-u. a. pyrogene Massen selbst kömnen nicht erst neuerlich entstanden, jünger als die von ihnen emporgehobenen Gebirge seyn. So ist das obere Sekundürkalk-Plateau, welches sich zwischen Lot und Dordogne 10 Stunden weit von Soullac bis Cahor's in $700 \mathrm{~m}-S 00^{\mathrm{m}}$ Seehöhe erstreckt, grüsstentheils rou einer nicht mächtigen, ganz mit Quarz - Trümmisn durchsäeten Lehmbank bedeckt, die sich nur von einer sehr frühzeitigen Zerstörung alter Gebirge an den Quellen jener Flüsse herleiten lässt und eber unter dem Meere, als in einem See (wo sie wahrscheinlich gebunden worden seyn würde) vor dem Ende der Sekundär - Periode abgesetzt zu seyn scheint. So bestehen $\frac{\tau}{s}$ der Geschiebe in der berühmten Crau - Ebene aus 'Quarz und sind geröhnlich grüsser, als die der Durance und der Rhone. Sie ruhen auf einer Nagelflue, welche nach ihrer Zusammensetzung und Lagerung jener zwischen den letzten Sekundär-Schichteu entspricht, und sind nach Debors-Añ́ (Ann. chim. XVII, 223) von einem meerischen Tertiär - Kalke bedeckt, welcher auch ilıre obersten Flötze durchdrungen und verkittet hat. Auch hier kann nur das Alter ihrer Entstehung ihre Verschiedenheit -von den Geschieben jener beiden Flüsse erklären: v̀or dem Niederschlage des meerischen Tertiär - Kalkes und bevor die Alpen-Geschiebe herabzurollen begannen, müssen hier ansehnliche Quarz-führende Gebirge in Trümmer gegangen seyn.

11) (C) Loses tertiäres Gerölle, geschichtet oder nicht, überdeckt die vorigen Sand- und Lehm-Bänke in ungleicher Mächtigkeit, welche im kleinen Becken der Roise im Isére-Thale, und in Thale der Dopa Baltea, welche wie die Isère vom Montblanc herabkommt, $500 \mathrm{~m}$ beträgt. Es ist zum Theile geschichtet, und diese Schichten sind das Erzcugniss wiederholter Überschwemmung, nicht durch Ströme, sondern unter Meer- oder See-Gewässern eutstanden. Denn Strüme müssen das Material wohl herbeigeführt, aber nur die. Wellenbewegung eines horizontalen grüsseren Gewässers kamn dasselbe später über die Unterlage von Lehm und Sand zu Schichten abgeebnet haben. In den-innern Gebirgs - Becken bildet das Gerölle gewöhnlich nur eine, oberflächliche, Schichte; in den äussern und amMeeres-Gestade ist es horizontal in verschiedenen Höhen untereinander abgesetzt während des allmählichen Sinkens des Seespiegels. Denn die Geschiebe der Flüsse werden vor deren Mündungen von dem bewegten Meere zertrümmert und noch mehr abgerundet und $\mathrm{zu}$ horizontalen oft stundenlangen Lagen ausgebreitet, wovon die äusseren Thäler der Garonne und des Adour Beispiele liefern. Sinkt dann das Meer einige Meter tiefer, so schueiden die Flüsse in die nun trocken gelegten Geröll-, und selbst darunter in die Sandund Lehm - Bänke ein, über die sie bisher weggegangen; der Wellenschlag erweitert die neuen Mündungen und eine neue Geröll-Schichte entsteht bald auf gleiche Weise darin. Die Tet bietet in ihrem Thale zwei, die Arriege und die Garome bis vier solcher alten Gestade stufenartig übereinander. 
12) (D) Granitische und porphyrische Felsblöcke von 30-40 Kubikmeter finden sich zwischen dem Gerölle, welche die Loire in den Vertiefungen ihres Thales zurückgelassen hat. Die neuliche Verschüttung des Thales von Bagnes in Wallis durch eine mächtige Lavine gibt uns ein genügendes Beispiel von furchtbaren Wirkungen, welche der Durchbruch der See'n, deren geöffnete Becken wir in den Hochgebirgen noch wahrnehmen, hervorgebracht haben müsse. Schon aubaltende Regen können zuweilen fast eben so beträchtliche Folgen veranlassen. Aber die merkwürdigsten der vorhandenen Block - Ablagerungen gestatten nach der Beschaffenheit des Bodens keine von beiden Erklärungsweisen, indem tiefe Thäler, grosse See'n oder selbst Meeresarme sich zwischen ihnen und den Gegenden ihrer Ahstammung befinden. So trennen die Rhone und die Aar jetzt die alpinen Granit-Blöcke des Jura von den Alpen. So trennt das Baltische Meer die Skandinavischen Granit - und Übergangs - Blöcke jetzt von den Skandinavischen Berghöhen. Nach Doconiev wären die Alpen-Blöcke vor der Aushöhlung des tiefen Thales nach dem Jura herüber gelangt. Nach L. von Buch (Bullet. d. scienc. nat. 1828, Mai, p. 5) hätten Strömungen, bewirkt durch die Hebung der Alpen, sie auf dem unebensten Boden mit einer Kraft, entsprechend einer Geschwindigkeit von $357^{\prime}$ in einer Minute, Mcilen weit nach dem Jura fortgeschleudert, während der Durchbruch bei Bagnes ihnen nur eine Schnelligkeit von $30^{\prime}$ zu geben vermochte. Es bleibt daher wohl die Annahme allein wahrscheinlich, dass die Kraft, welche diese Berge zu $10-12,000^{\prime}$ enaporgehoben, auch zur Fortführung der Blöcke hinreichend gewesen zu einer Zeit, in welcher vielleicht das 800'-900' tiefe Becken des Genfer See's noch nicht eingesunken, selbst der Durchbruch der Rhone noch nicht erfolgt war. Lässt man daher jener Zentral-Gebirgsmasse das Alter, wovon sic die Anzeigen trägt, so könnte das Einsinken jener Stellen mit der Emporhebung der Glauconie-artigen oder fast tertiüren Gesteine des Wallis, des Arve. Thales, zu Fiz und an den Diablerets zusammenfallen. Auch in den Pyrenïen finden sich; der gewöhulichen Annahme entgegen, solche Felsblücke: aus porphyrischen Granit bestehen sic häufig im AusfïllungsGebilde des Oueil-Thales bei Bagnères-de-Luchon. Dieses Gebilde liegrt von zwei Schiefergebirgs-Rïndern cingeschlossen, ist durch das ím uäıItchen Schiefer ausgehöhlte Becken von Arboust getrennt von dem Zentral-Kamme der Station von Oo, von welchem sie herabgekommen sind. Dieses Becken hätte also zuerst bis zum Pande von ähnlichen Trümmern angefüllt werden müssen, oder es ist erst nach der Ablagerung jener Blöcke entstanden. Derselbe Fall zeigt sich in dem, ebenfalls in Schiefer ausgehöhlten Gouroum - Thale auf dem andern Ufer des Bergstromes wieder, der von der Station von $\mathrm{Oo}_{0}$ [wohl nur ein Schutz. Gebäude?] nach Bagneres-de-Luchon herabkommt. Ferner in dem weiten Becken des Barousse, dessen Boden dicht erfült ist mit granitischen Geröllen und Blöcken, welche nicht rückwärts durch die [einzige] Öffnung, sondern nur über die jetzt hohen Kalk- und Schicfer-IVände dieses 


\section{- 446}

Beckens hinweg in dasselbe gelangt seyn künnen. Derselbe Fall zeigt sich endlich in den letzten Abstufungen der Kette, wo der ganze Lauf des Mas Dazil und des Mirepoix von der untern Kalk.Zone umfangen ist, aber gleichwohl Beckeu voll grober Granit-Geschiebe durchschneidet, deren heutzutage auch nicht eins von dem Orte ihrer Abstammung aus in dieselben gelangen könnte. So müssen lange und wiederholte Änderungen der Oberfäche von Innen heraus in diesen Gegenden erfolgt scyn, bis dieselben ihre gegenwärtige Gestalt und Zusammensetzungen erlangten. Die Felsblöcke der Alpen ruhen auf Molasse, und die Aushöhlung des Genfersee's kaun daher erst nach der Zeit ihrer Bildung erfolgt seyn. Die Aushöhlung der Manche dagegen hat früher Statt gefunden, denn zur Zeit der Kreide-Bildung hing England noch mit dem Kontinente zusammen, während zur Zeit der Entstehung der tertiären Becken von Paris und London es schon getrennt war. Aber von Skandinavien herüber muss Fortführung von Felsblöcken zu verschiedenen Zeiten Statt gefunden haben, weil nach Brongniart nicht allein die älteren, sondern auch die Basalt Blöcke des Plateau's von Uddewalla, an der Oberfläche der Gebirgs - Abfälle die Spuren ihres Fortgleitens hinterlassend, sich im Allgemeinen von N.N.O. nach S.S.W. fortbewegt haben, während Pazoumowski andere Ströme in der Richtung von N.W. nach S.O. verfolgt hat. Nach Élie de Beaumont finden sich die Fels. blöcke in den meisten Alpen-Thälern der letzten der Stufen angehörend, welche sich über die grosse Geröll-Ablagerung erheben, und diese selbst erscheint hin und wieder nur noch stufenartig an den Seiten der Thäler, die einst von ihr erfüllt waren, und zwar mit scharfeckigen SteinTrümmern durchmengt, in Folge des periodischen Einsinkens der Wasscrfläche, unter der sie sich zuerst abgesetzt hatten, wie das oben erklärt worden. Wo aber die Geschiebe ohne Unterbrechung von den Flüssen längs ihres Laufes abgesetzt worden, da bemerkt man jene Abstufungen der Schichtung nicht.

Die sogenannten "diluvialen"Tertiür-Gebirge sind daher durch Flüsse von den Gebirgen herabgefübrt und zu Ausfüllung tieferer Einsenkungen der Oberfläche der Erde verwendet worden. So findet man in denen des Innern der Gebirge grosse Geschieb-Anhäufungen, welche unter stehenden Süsswassern oft zu Psephiten verkittet worden. An den Fuss derselben aber konnten die grösseren Stein-Trümmer erst gelangen, nachdem die höheren Becken bereits damit ausgefüllt waren, wesswegen diese Trümmer hier über den Sand- und Thon-Bänken liegen. Die neuesten Thäler sind in dem Ausfüllungs-Gebirge ausgehöhlt worden, welches auf das letzte [?] Süsswasser-Gebilde gefolgt und, wic dieses, nit Pachydermen - und Ruminanten - Knochen durchsäet ist. In Folge dieser neueren und durch das periodische Einsinken des Wasserspicgels öfters wiederholten, jedesmal tiefern Aushöhlung der Thäler sind die stufenförmigen Ablagerungen entstanden, von welchen jede tiefere, weiter vorspringende Stufe auch einem späteren zeitweiligen Gestade zu entsprechen pflegt. 
J. Hardie: Geologie des Oodipoor - Thales (Fortsetzung, JAMES. Edinb. n. phil. Journ., 1833-3t, XVI, 59-6\%, - vergl. Jahrb. 1833 , S. 566). Die Gebirgs - Arten dieses Thales gehören zur Thonschiefer-Reihe; es sind: thonige und kalkig-thonige Schiefer, Grünsteine, Grünsteinschiefer, Quarzfels, Kalkstein, auch Kalkschiefer, alle meist deutlich geschichtet, die Schichten steil aufgerichtet, vertikal, sehr verdreht und stellenweise wenig parallel zu einander; docb ist das herrschende Streichen aus N.N.W. nach S.S.O.; das Fallen nach O.N.O. Diese Gebirgsarten erstrecken sich über einen grossen Theil von Indien und bilden namentlich den wilden und unwirthlichen Gebirgszug im $\mathbf{S}$. von Newar, der sich an die zentrale Granit. Achse der Aravulli-Bergkefte anschliesst, welche, obschon oft unterbrochen, doch eine grosse Erstreckung besitzt, und deren höchste Spitze der Aboo-Berg von 5000' Seehöhe zu seyn scheint. Jene Kette hat eine etwas bogenförmige Richtung aus N.N O. nach S.S.W., und reicht von der Grenze von Guzerut bis zu jener von Dehlie. Am östlichen Abhange derselben haben die Schichten im Süden ein S.O., in der Mitte ein S. und in Norden ein N.O. Streichen; an der Westseite aber folgt es wieder andern Richtungen. Auf beiden Seiten der Kette senkt sich die angrenzende Gegend schr allmählich zu Niederungen, Ebenen und Sandsteppen herab; im Süden von Mewar ist das Tafel-Land von Malwa aus ungeheuren Massen aufgelagerten Trappes zusammengesetzt, deren östliche Grenzen noch gar nicht genau bekannt sind.

Unmittelbar östlich vom Oudipoor - Thal tritt eine Reihe von Urgebirgs-Arten auf, worunter Gneiss mit Hornblende-Gesteinen und Granitähnliche Gebirgsarten vorwalten; sie erstreckt sich längs obengenannter thoniger Bildủngen südwärts bis zu den Bergreihen nächst dem Dhabour - See, dringt nordwärts in die Urgebirge im N. des MewarDistriktes ein, und wird östlich von Thonschiefer und Quarzfels begrenzt, welche sich unter den Sandstein von Malwa einsenken. Obschon aber die Gebilde des Oodipoor - Thales gegen die dieser anderu, primären Reihe fallen, welche wieder gleichförmige Lagerung mit den zuletzt erwähnten haben, so dass die hebende Kraft von W. her, und zwar am stärksten in der Gegend des Aboo gewirkt zu haben. scheint, so folgt daraus doch nicht, dass jene ersteren die nachfolgenden Gebirgsschichten ursprünglich unterteufen.

Die Gruppen felsiger Berge im 0. der Aravulli-Kette zu untersuchen, beginnt der Verf. zu Meirta in den Ebenen von Mewar am Rande des Oodipoor - Thales. Bei Meirta (dem frühern Wohnorte des Britischen Agenten am Hofe von Oudipurr) hat die Ebene 2000' Seehöhe und ist von Dammerde bedeckt, aus welcher jedoch Felsmassen häufig hervorbrechen. Am häufigsten darunter ist ein Gestein mit dem mineralogischen Charakter des Granites, welches aber bald in mächtigen Schichten, bald in regelmässig prismatischen Massen mit ersteren wechsellagernd auftritt - grob - oder fein - körnig ist - und ïlucrgelıt in Pegmatit aus eckigen Konkrezionen von rothem Feldspath und 
durchscheinendem Quarz mit oder ohne Glimmer, oder in syenitischen Granit und in manchmal Grünstein - artiges Hornblende-Gestein, worin die Hornblende zuweilen von Chlorit und Steatit begleitet, oder davon ersetzt wird, und der Feldspath graulich zu seyn pflegt. Ein Epidotartiges Mineral und Schillerspath finden sich in allen Abänderungen dieser granitischen Gebirgsart ein (Marmor, zu Bauwerken brauchbar, findet sich an vielen Orten Zentral - Indiens). - Fünf Meilen W. von Meirta liegt ein Bett von grobkörnig krystallinischem Kalkstein oder Dolomit von unrein weisser Farbe mit eingestreuten kleinen Eisenkies. Körnern, - welchem ein undeutlich geschichteter Syenit-Gneiss nit Quarz und graulichem Feldspathe, dann ein Granit-Gestein oben bezeichneter Art folgt, das bis $40 \mathrm{M}$. östlich von Meirta anhält und dann in Gesteine der Glimmerschiefer-Reihe : als Hornblende - Schiefer, ChloritSchiefer, Quarz-Schiefer mit körnigem Kalkstein u. s. w. übergeht; nach welchen endlich Thonschiefer und Quarzfels folgen, die unter die jungen Sandsteine im N. von Mewar einschiessen.

Unmittelbar in W. von Meirta erscheint in Wechsellagerung mit Gneiss und Hornblende-Gesteinen ein Zug von röthlichem und weissem körnigem Feldspathe mit Schiefergefüge und kleinen Chlorit- oder Glinmer-Schüppchen, Werner's Weissstein entsprechend. In Gebirgszuge, der das Oodipoor-Thal begrenzt, nimmt er noch mehr überhand, wechsellagert mit durchscheinendem Quarzfels, dessen parallele äusserst dünne Platten durch kleine Glimmerschüppchen von einander getrennt werden. Zuweilen wird dieses Gestein schwerer als gewöhnlich, hell gelblichgrün, schmilzt vor dem Löthrohr zur dunkelbraunen Schlacke und scheint sich wie Epidot zu verhalten, der allmählich in Quarz übergeht. Weiter westlich wird der Quarzfels immer mehr durch Wechsellagerungen von Glimmer - und Hornblende - Schiefer verdrängt, wovon der letztere zuweilen sehr glimmerreich ist. So gelangt man allmählich zu den östlicheren der Grenzgebirge, bestehend aus Quarzfels, welcher nach W. hin mit Thonschiefer in Wechsellagerung tritt. Dieser Quarzfels fühlt sich seifenartig an, wegen seines Gehaltes an Talk, der die vollkommene Krystallisirung gehindert zu haben scheint. - Der Damm des Oodissayor-See's gibt gute Gelegenheit die östlicheren Grenz-Gebirge zu studiren. Aus den Gebirgen mündet uämlich eine enge und tiefe Schlucht aus, durch welche früher der Bedus floss, der aber nun hinter einem hohen, starken und wohlgebauten Damme („Bund") zu einem See von ansehnlicher Tiefe und Erstreckung angeschwellt und theilweise durch eine (künstliche) enge Spalte nächst dem südlichen Ende des Burds abgeleitet ist. Diese Spalte ist senkrecht über $50^{\prime}$ breit, fast 200 Yards lang, und durchschneidet das Gebirge rechtwinkelig auf das Streichen der Schichten, welche wie jenes aus N.N.W. nach S.S.O. gehen, aber fast vertikal aufgerichtet sind oder steil gegen O.N.O. einfallen. In der Mitte erheben sich die Wände des Spaltes $160^{\prime}$ hoch. Schieferiger, fast stets durch Eisen gefärbter (rother, blauer etc.), Quarz oft mit Glimmerschuppen, ist das hauptsächliche Gestein darin; scine Schichten 


\section{9}

haben $2^{\prime \prime}-2$ 'Mächtigkeit, und die Furm gerader und sehr weit fortgehender Tafeln. Oft nimmt dieser Quarz viel Feldspath auf, wird körnig, Gra. nit-artig. Gegen das östliche Ende des Spaltes erscheint eine $80^{\prime}$ mächtige Schichtenfolge zerreiblichen, seifenartig anzufühlenden Talkschiefers, welcher der Länge nach von vielen, oft nicht zolldicken, geraden, der Schichtung parallelen, gleichdick bleibenden Quarz-Laven durchzogen ist, deren Masse ganz mit der der vorerwähnten Gebirgs - Art übereinstimmt. Der allmähliche Übergang dieser Gesteine in einander erhellt jedoch noch deutlicher, indem schon frïher eine Talkschiefer-Lage in das Quarzgestein eindrang, und indem der Talkschiefer-Fels selbst, je näher er dem Quarzfels ist, ein desto mehr Granit - artiges Ansehen besitzt, Quarz-Krystalle, Feldspath, Glimmer u. s. w. aufnimmt.

Endlich noch weiter nach W. geht der Talkschiefer eben so allmählich in Thonschiefer über.

Schluss des vorigen (l. c. 1834, April, XVI, xxxII, 278-285). Zwei Meil. N. vom Bund setzt ein andres Queerthal durch die Grenzkette, dessen Eingang durch den Dubaree - Thorweg geschützt ist. Neun Meilen weiter W. gegen Oodipoor erscheint zuerst eine Fortsetzung der Quarzfelsen des Oodisayor bund, mit fast vertikaler Schichtung; sie werden selbst mehr und mehr Thonschiefer-artig, und endlich wechsellagern Thon- und körniger Kalk-Schiefer voll Glimmer-Blättchen mit einander, welche durch Aufnahme von Kalkspath-Blättern zu "Calschistes" der Franzosen werden. Endlich folgen Wechsellager von Thon-, kalkigem Thon-, kieseligem Thon-Schiefer und Quarzfels, wornach der Weg durch die hügelige Ebene des Oodipuor-Thales hinzieht (Handstücke all der manchfaltigsten Abänderungen des Thonschiefer-Gebildes hat der Verf. im Museum der Asiatischen Sozietät zu Calcutta niedergelegt). - In der Ebene ist der Boden von Kunkur und Ackerland bedeckt, so dass man nur an den Ufer-Wänden des Bedıs die tieferen Gesteins - Lagen beobachten kann. Grünsteine und Grünstein-Schiefer wechsellagern dort mit Thonschiefern. Erstere sind denen der Trapp-Formation älınlich, schwärzlich, mit feiner Porphyr-Textur und zuweilen eingeschlossenen Kalkspath - Krystallen, manchmal auch mit prismatischen Abänderungen zwischen Schiefer-Schichten eingelagert. - Damit innig verbunden findet sich eine Reihe von Gesteinen aus Grünstein. Grundmasse ohne Hornblende (ein dichter Feldspath mit feinen Quarz-Körnern, grau und etwas Porphyr-artig) welche wie die obigen nit Thonschiefern wechsellagern, die, denen des Grenz-Gebirges ähnlich, oft durch Kupfer blaulich gefärbt, feinschieferig, Grauwacke-artig mit häufigem Glinmer, eine Granit-Textur annehmend, die Schichten bäufig stark verdrelıt, gehoben, zerrissen sind, so dass sie lokal nach allen Richtungen einfallen, jedoch meistens der Vertikai-Stellung sich nälern, und ein von N.N.W. nach S.S.O. streichendes Band bilden, gleich den Grenz-Gebirgen.

Zwei Meilen N. von Oodipoor jedoch bemerkt man im. Bedus-Bette 
eine merkwürdige Ausweichung der obenerwähnten Gesteine von jener Richtung: die Stellung der Schichten ist fast vertikal, ihr Streichen aus O.N.O. nach W.S.W., der Thonschiefer ist deutlich geschiefert, die übrigen Felsarten aber zeigen nach, regelmässigen $Z$ wischenräumen wiederkehrende Absonderungs-Linien, die ihnen eine in verschiedenen Schichten gröbere und feinere Schiefer-Textur verleihen. Diese AbsonderungsLinien stehen senkrecht auf den Horizont und ziehen rechtwinkelig zum Streichen der Schichten, nämlich von N.N.W. nach S.S.O., was für alle Gesteine dieser Reihe gilt. - Einige Grünsteine zeigen dreifache Absonderungen : die Schichtungs-Flächen, die zu ihnen rechtwinkeligen $\mathrm{Ab}$ sonderungs-Flächen, und endlich einen Anschein von horizontaler Schichtung, der von der Neigung dieser Felsart an der Atmosphäre zu zerfallen herrührt. (Einen verwandten Fall bemerkt man in Rajpootana zu Deosa, 40 Meilen O. von Jeepoor. An einem isolirten Berge, aus Wechsellagerungen durchscheinenden Quarzes, dünnschieferigen Gneisses und eines besonderen wellenartigen Gueisses gebildet, bemerkt mau Absonderungs-Flächen rechtwinkelig auf die Schichten. Einige Gneisse haben eine Neigung zur konzentrisch-blättrigen Struktur, und ihre Schichten eine Zeit lang an der Oberfläche befindlich erscheinen durch sie wie aus $\mathrm{Zylindern}$ zusammengesetzt).

Die Bergkette, welche die westliche Grenze des Oodipoor-Thales ausmacht, hat eine ähnliche Form und Zusammensetzung, wie die in Osten. Unmittelbar im S. der Stadt senkt sich ein Berg seiner Länge nach von $S$. nach $N$. herab, indem er allmählich in die obige Richtung umbiegt, bleibt jedoch von demjenigen, worauf die Stadt liegt, durch die tiefe Schlucht getrennt, dnrch welche der Haupt-Damm des PucholaSeè's aufgeführt ist, welch' letzterer selbst in einem schmalen LängenThale zwischen jenem und einem anderen westlichern Bergzuge sich befindet. Der Stadt-Berg besteht aus Quarzfels, jenem am OodisagorDamme ähnlich; er wechsellagert an desseh Fusse zu beiden Seiten mit Thonschiefer und geht in solchen über. Die Berghöhe westlich vom Puchola ist aus Thonschiefer zusammengesetzt, der in Grünstein-Schiefer übergeht, aus welchem sich grosse Platten brechen lassen. Der östliche Berg mit seinen Schichten streicht $\mathrm{N}$. nach 0 . und $\mathrm{S}$. nach W., der westliche aber in N.N.W., so dass, wenn der erstre nicht im Süden steil abgeschuitten wäre, beide in ihrer Verlängerung zusammentreffen würden, und das Puchola-Becken hat demnach eine etwas dreieckige Form. Der Berg, worauf die Stadt steht, erhebt sich am N.-Ende des Puchola, zu einem der Achse des Thales entsprechenden breiten Tafelberg, dessen Schichten vom Wasserspiegel auf von $S$, nach $N$. streichen. Eine Meile N. von der Stadt fällt auch diéser Berg steil in die Niederung ab. Seine Schichten sind Quarzfels, beiderseits von Thonschiefer begrenzt, mit Spuren von Schichten-Störung. Weniges nördlicher ist ein anderer isolirter Berg, westlich von oben erwähnter, in ihrem Streichen abweicheuder Schichtenreihe, der aus Wechsellagern von hartem, kieselhaltigem, körnigem Magnesian-Kalk und körnigem Quarze besteht, 
die aus $S$. nach $N$. mit geringer Abweichung nach N.W. streichen. Viele dünne Quarz-Lagen durchsetzen den grauen Kalk, welcher an der Luft verwitternd schwärzlich wird, während die weissen Quarzblätter fast in Form von Bienen-Zellen über der Oberfläche hervortreten. Bittcrerde macht einen beträchtlichen Bestandtheil dieses Kalkes aus, welcher zu Mörtel nicht brauchbar ist; auch enthält er Eisen und Mangan. - Damit kömmt, in ihn übergehend, ein grauliches eckig-körniges Gestein aus Quarz und gemeinem wie glasigem Feldspathe vor. Glimmerschïppchen und rhomboidale Kalk-Krystalle sind selten darin. Es gelıt in Quarzfels über, der sich mit dem südlicher beschriebenen zu verbinden scheint.

\section{Petrefaktenkunde.}

Jac. Green, M. D.: A Munoyruph of the Trilubites of North America; with [35] coloured models of the species. (Philadelphia, 93 p). I $p l ., 8^{\circ}, 1833$.)

In der Einleitung (S. 5-24) gibt der Verf. die Meinung zu erkennen, dass fossile Reste eben keine so zuverlässige Merkmale zur Unterscheidung der Formationen seyen. Identität der Arten möge jedoch eher Identität der Formationen andenten, als Verschiedenheit der Arten Verschiedenheit der Formationen, Zu Unterstützung jener Anșicht beruft er sich auf eine Stelle in Eclectic Review, 1832, Juli, wornach "Encriniten, Entrochiten [!] und Pentacriniten in Schieferthou, Grauwacke, Übergangs-Kalk, Alpen-Kalk, Lias, Muschel-Kàlk und Kreide gefunden worden seyen und mithin diese drei Spezies [!!] unmöglich irgend eine besondere Gesteins-Formation andeuten künnen." [Wenı Gewährsmann und Nachbeter noch zur Stunile solche Oberflächlichkeit und Uukenntniss dér Gegenstände verrathen, welches Vertrauen darf man dann in ihre Äusserungen setzen? Und doch wird eine grosse Anzahl von Personen nun nicht ermangeln, den Monographen der Amerikanischen Trilobiten selbst als cine bequeme Autorität für jene Meinung anzuführen! Ref. will beilïufig noch benerken, dass alle Crinoideen-Säulen, die er bisher unter dem Namen von Pentacriniten aus N.-Amerikanischen Übergangs - Gebilgen erhalten hat, wohl eine fünfblättrıge Zeichnung der Geleuk - Flächen besitzen, aber keine Pentacriniten sind, - wenn gleich dieses Genus in Deutschland selbst dem Übergangs.Grbirge nicht ganz freind ist. - An einer indern Stelle gedenkt der Verf. der in Westindien lebenden Pentacriniten zum Beweise, dass dieses Geschlecht auch keineswegs ausgestorben seye; das ist aber seit lange bekannt, und daher auch seit lange nicht mehr behauptet worden! Endlich ersicht Ref. aus 2 erhaltenen Sendungen, dass die N.-Amerikanischen Geologen unter dem Namen Encriniten alle 
Crinoideen mit einfachem Nahrungs - Kanal des Stieles und selbst Pentatrematiten zusammenbegreifen.] - Hauptsächlich aber ist die Einleitung der allgemeinen Beschreibung der Trilobiten, der Darlegung des Ungeeigneten dieser Benennung, den literar-historischen Nachweisungen (Brongniart, Dalman, Wahlenberg, Dekay, Rasoumowsky) und der Aufzäblung und Diagnostik der durch die bisherigen Bearbeiter aufgestellten Trilobiten-Geschlechter (Calymene, As aphus, 0 gy gia, $\mathrm{Pa}$ radoxides, Agnostus, Isotelus Dekay, Nileus, Illaenus, Ampyx - wovon einige Arten zu Is ot elus -) gewidmet. Daran schliesst sich die Erwähnung einer von Rasounowsky in den Annales des sciences naturelles, vol. VIII, als Calymene beschriebenen, von Brongniart ebendaselbst als Asaphus bezeirhneten Art von TzurskoSelo, welche ein eigenes Genus bei Is otelus bilden müsse. Da diese Art Nord-Amerika fremd, so charakterisirt der Verf. dieses Geschlecht unter dem Namen Hemicrypturus, nur in der Einleitung (S. 20) auf folgende Art: Körper sich kugelnd; Kopfschild mit Augen, ungelappt; Abdomen dreilappig, 8gliederig; Schwanz mit bedeckten [ungegliederten] Rippenbogen und nacktem [gegliederten] Mittellappen. Der Verf. hat die obige Art im Baltimore College zu untersuchen Gelegenheit gehabt, und nennt sie, in Ermanglung eines ältern Art-Namens H. R a s o umowskii; rechnet jedoch noch As a phus expansus Danman's u. e. a. A. zum nämlichen Geschlechte. Darnach folgt die Aufzählung der bis jetzt bekannten Trilobiten-Arten, woran sich fünf von RapivesQUE nur unvollständig bezeichnete Trilobiten und Bilobiten aus den Vereinten Staaten anschliessen, welche dem Verf. zu Caly me e zu gehören scheinen. Schliesslich, gelegentlich der Bemerkung dass man die Trilobiten als Beweis gebrauchen wolle, dass manche Thiere viel früher als der Mensch erschaffen gewesen, freut sich der Verf., jeden bisherigen Versuch skeptischer Naturforscher gegen die Mosaische Weltgeschichte mit Triumph in die Flucht geschlagen zu sehen, obschon dieselben inmer wieder aufs Neue verdrehte Thatsachen als Waffen hervorsuchten. Einige scheinbare Abweichungen vom Wortlaute der Mosaischen Lehre jedoch za erklären gebe es drei Methoden: entweder anzunehmen, der anfängliche Schöpfungsakt habe sich nur auf einen kleinen Theil der Erd-Oberfläche und ihrer höheren Bẹwohner, so weit solche den wenigen ersten Menschen von nöthen gewesen, bezogen, während der Rest noch unter Wasser geblieben sey, und dann noch mancherlei geologische Veränderungen überstanden haben köune; oder Moses hat sich nur an die Erzählung des Hauptsächlichśten, der auf die Geschichte einfliessenden Schöpfungs-Stadien bezogen, ohne einiger dazwischenfallender von niederem Belange zu gedenken, welchen die fossilen Reste und manche Eigenhciten der Erd-Struktur angehören mögen; oder endlich, am besten dürfte seyn anzunehmen, dass unter den sechs Tagen eben so viele grössere Perioden verstanden seyen, wie denn die Hebräer den Ausdruck Tage und Wochen oft in solchem Sinne genommen. In keinem Falle aber können die Sekundär.Schichten und Diluvial- 
Ablagerungen von Lokal-Ursachen herrühren. Statt daher zu annähernden Kometen, zur Änderungen der Erdachse oder zu „solchen wilden phantastischen und gottlosen Theorieen" seine Zuflucht zu nehmen, solle man lieber mit H. DAvY "träumen, dass alle Sekundär-Schichten e $r$ schaffen worden seyen, schon mit den Resten erfüllt, als ob sie von lebenden Thieren seyen, damit durch sie die Spekulationen unserer geologischen Raisoneurs in Verwirung gerathen."

B. Ein besondere Anerkennung (S. 25-26) rühınt die Gefälligkeit der Privatpersonen und Vorsteher öffentlicher Institute, welche ihm ihre Trilobiten-Exemplare zur Fertigung von Gyps-Abgüssen überlassen haben. Es sind in Philadelphia: J. P. Wetherill, die Akademie der Natur-Wissenschaften, Pesle's Philadelphia Museum, P. A. Browne, Dr. R. Harlan, W. Hyde, J. Pierce, die geologische Sozietät, - Lambdin in Pittsburgh, D. Kerm in Reading; - in New-York: das Lyceum der Naturgeschichte, Dr. J. E. DekaY, PEALE's New-York-Museum; in Albany: das Albany-Museum, das Albany-Institut, Prof. T. R. Веск, Dr. J. Eights, - die Renssellaer-Schule; - in Baltimore: Dr. Joshus J. Сohen, das Baltimore College, das Athenäum, das Baltimore Museum, - endlich Prof. Hall zu Mount Hope.

C. Der beschreibende Theil des Werkes geht bis S. 93, worauf noch ein Arten-Register folgt.

I. C a l y mene.

1) C. B I umenbachii Brgn., S. 28: Kopfschild gerundet, mit 6 getrennten Hückern auf der Stirne, sehr vorstehenden Augen auf den Wangen; Körper höckerig. Glieder 14, Schwanz schmal. - Mehrere Arten sind unter diesem Namen verwechselt worden. Sehr häufig, wie zu Dudley, so in N.-Amerika: zu Lebanon, Ohio; an den Trenton Falls, N.-Y. (wo die Trilobiten zu Millionen vorkommen); ? zu Quebeck.

2) C. callicephala Grees, S. 30: Kopfschild vorn verschmälert (fast dreieckig), auf der Stirne nit einem Lilien-förmigen Eindrucke und mit sehr kleinen (tiefer unten stehenden) Augen; Abdomen im Ganzen 14 gliedrig; Körper flach. - Mittellappen durchaus fast gleichbreit; Rip. pen am Ende nicht gabelförmig getheilt; Länge fast $2 \frac{1}{2}$ Zoll. - In dunklem gelblichem Kalkstein von Hampshire, Virginien; vom Miami river bei Cincinnati, Ohio; in dunklem Kalke von Indiana; nie mit voriger Art.

3) C. selen ecephal a GreEN, S. 31: Kopfschild vorn gerundet (halbmondförnig), mit sehr verdicktem Rande ringsum und beiderseits dreihöckerigem Stirn-Vorsprung; Körper warzig. - Die drei Stirnhöcker jederseits sind ungleich, einer gross, zwei klein, weit nach oben, und die beiden Augen liegen in einer Linie mit dem untersten von ihnen. Glieder 14, doch ist der Schwanz nicht ganz vollständig. Rippen einfach. Ganze Länge $1 \frac{8}{4} "$, Breite des Kopfschildes $1 \frac{1}{4}{ }^{\prime \prime}$. Etwas ähnlich Dalman's C. pulchella. In aschgrauem Kalkstein New-Yorks, selten. 
4) C. platy s Grees, S. 32 : Kopfschild vorn gerundet, ? halbmondförmig [sehr warzig], Stirn-Vorragung jederseits mit 4 Höckern; der aufgeworfene Hinterrand des Schildes durch die zwei Längen-Furchen unterbrochen; nach aussen hin viel dicker. Drei der Stirnhöcker liegen in einer Linie neben dem Seitenrande der Wangen, und nehmen nach vorn an Grösse ab; der vierte liegt einwärts zwischen den 2 hinteren, und ist kleiner. Die Wangen sind kugelig-dreieckig. Die Augen liegen dem 2ten grossen Stirnhöcker aussen zur Seite. Rücken und Schwanz nicht unterscheidbar, im Ganzen 22gliederig [13 +9$]$. Ganze Länge $3^{\prime \prime}$; Breite des Kopfschildes fast $2^{\prime \prime}$. In Sandstein, am Helderberge.

5) C. microps Green, S. 34: Kopfschild vorn etwas verschmälert, halb elliptisch, mit sehr kleinen Augen, weit nach aussen und binten; Abdomen mit 14-18 Gliedern; Körper flachgedrückt. - Die Stirne fast in die Wangen verfliessend. Vor jedem Ange ist ein schwacher QueerEindruck; Abdominal-Glieder schwer zu zählen, mit Spuren von Spaltung. Mittellappen hoch. Länge $1 \frac{1}{4}{ }^{\prime \prime}$. In schwarzem Kalk, von Ripley, Ohio; selten.

6) C. anchiops GREeN, S. 35 : halbkugeliger Kopfschild vorn, Schwanz hinten rund; Augen genähert, gross, vorstehend; Glieder im Ganzen 20; Körper flach. - Stirue ohue Warzen. Augen fast ganz die Wangen bedeckend und mit einem inneren Anhang weit in die Stirne hineinragend. Zwischen den Rippen je 1-2 undeutliche Streifen. Länge fast $4^{\prime \prime}$, Breite über $2^{\prime \prime}$. Brongriart hatte einen von Hosack besorgten Abguss des vor dem Verf. liegenden Exemplares in seinem Werke zweifelsohne zu C. macrophthalma gerechnet. In Schieferthon von Ulster Co., New-York (nicht Albany).

7) C. diop s Green, S. 37, Fg. 2 : Kopfschild flach, gelappt, mit drei Queer-Runzeln an den Seiten der Stirne und sehrvorstehenden augenförmigen Zwillinghöckern; Glieder 18; Schwanz gerundet. - Stirne über den Wangen sehr erhaben, und von ihnen tief abgesondert; hinten jederseits mit einem runden Höcker neben dem Auge und von diesem durch die verlängerte Rückenfurche getrennt (doppeläugig); vor diesem Höcker mit drei Queer - Furchen. Unter dem Auge jederseits 2 BogenLinien die sich vorn mit einer tiefen kurzen Rinne kreutzen. Mittellappen sehr flach vorstehend, nicht bis zu Ende reichend, mit 18 Gliedern, von welchen 7 zum Schwanz zu gelıören scheinen. Rippen nach aussen gabelig. Länge $3^{\prime \prime}$. In grauem Kalkstein, Ohio.

8) C. macrophthal ma Bregn., S. 39: Koptschild vorn und Schwanz hinten verschmälert; Augen gross und vorstehend. Abdomen mit 12-13 Gliedern, welche stärker als am Schwanze sind (die von Brongnart angegebene Schnautzen-förmige Verlängerung des Kopfschildes und drei Queerfalten der Stirne hat der Verf. nicht entdecken können, doch hat Brongniart bekanntlich auch Amerikanische Exemplare gehabt; G. vermuthet, dass Brongrart dicse Art mit der folgenden verwechselt). Im Helderberg bei Albany; zu Coshuny creec unfern dem Seneca. See 
in New-York; zu Leheighton in Pennsylvanien; an den Ohiv-Fällen u. s. w.

9) C. b u fo Green, S. 41: Kopfschild gerundet, konvex, punktirt; Abdominal - Glieder 12, Schwanz verschmälert; Körper flach. Wangen ticf von der Stirne geschieden; am oberen Rande die (beschädigten) Augen. Glieder des Mittellappens alle doppelt. Seitenlappen breiter als dieser; ihre Rippen an deren Basis durch sehr tiefe Eindrücke getrennt, und mit tiefen Furchen durchzogen; Glieder des Abdomen 12, des Schwanzes 10. Länge $4 \frac{1}{2} "$, Breite des Schildes fast $2^{\prime \prime}$. In dunklem graulichem Kalkstein, aus New-Jersey, von?Patterson; selten.

C. bu fo, var. ra n a Green, S. 42: Stirne schmäler mit etwas verschiedenen Unrisse, der ganze, Körper gekörnelt, was bei voriger nur der Kopf ist. In dunklem, schieferigem Kalkstein von Seneca, Ontario Co., N.-Y.

\section{A s a phus Brongn., S. 43.}

1) A. laticostatus Green, S. 45 : Schwanz sehr lang, der Theil am Rande kaum häutig; Leder-Haut mit sehr kleinen Höckerchen; Rippen breit, konvex und wohl getrennt. - Nur ein Schwanz: ringsum beschädigt, logliederig, noch $2^{\prime \prime}$ lang, $3 \frac{1}{4} "$ breit; hinten endigt derselbe in einen häutigen Fortsatz. In hellem eisenschüssigem Sandstein, mit Produktus u. s. w., in Ulster Co., N.-Y., im Helderberg etc.

2) A. selenurus EAton, S. 46: Schwanz halbmondförmig ausgeschnitten, Rippen schmal, sehr deutlich, Abdominal - Glieder 12; Körper konvex. - Der halbmondförmige Ausschnitt des Schwanzes ist $\frac{1}{3}$ so breit, als dieser lang. In Bergkalk von Glenn's Falls und vom Becroft. Berg bei Hudson.

3) A. limulurus Green, S. 48: Schwanz lang mit einem Stachel, wie Limulus bewehrt; Abdominal-Rippen endigend in rückwärts gerichtete Stacheln. - An dem $1 \frac{1}{2}^{\prime \prime}$ langen, $\mathbf{1}^{\prime \prime}$ "breiten Stück ist das Abdomen mit $8 \ldots \ldots$, der Schwanz mit 10 Gliedern, und diese sind der Länge nach mit tiefer Furche versehen. Seitenränder des Abdomen sägeartig gezähnt, die des Schwanzes ganz. Kleine Körner scheinen die ganze Oberfäche bedeckt zu haben; eine Reihe grösserer ist auf jeder Seite des Mittellappens. In dunkelbraunem Kalkschiefer zu Luckport, N.-Y.

4) A. c a u d a t u s Brünnich, Brongn., S. '50: in aschgrauem Kalkstein von Ripley, Ohio; und nach Brgsss in Merige in Canada: an der Nordküste des Lake superior, am Ufer des Rainy River, am Lake of the Woods u. a. a. 0. Stets ohne Kopfschild.

?5) A. H a u 8 m a n n i Brongs., S. 52: wird nur aulf die Zitate in De lA Beche's Manual und in EAton's Text Book p. 31 hin angeführt. Ist dem A. I a ti c os t a t u s selir ähnlich, doch durch die Verlängerung des Schwanzes etc. verschieden. Was Eaton in seiner Sammlung und in der des Albany Institutes so etiquettirt und als aus den Coral rag 
am Erie - See und dem darunter liegenden Schiefer von Helderberg stammend bezeichnet hat, ist sicher von der Brongriartschen Art verschieden.

6) A. p l e uroptyx Grees, S. 55: Körper flachgedrückt, LederHaut mit sehr kleinen Höckerchen; Rippen gestreift, Schwanz kurz, spitz. - Kopf fehlt stets. Abdomen und Scluwanz sind nicht von einander zu unterscheiden und zählen im Ganzen 17 Glieder. Mittellappen flach. Steht dem A. c a ud a $\mathbf{s}$ nahe, unterscheidet sich aber durch kleine Längen-Vertiefungen auf jeder Seite des Mittellappeus, durch schmälere Rippen, und durch den Mangel häutiger Ausbreitungen an deren Ende. In grauem Kalkschiefer des Helderberg-Gebirges und des Genessee-Flusses, $\boldsymbol{N}_{\text {. }} \boldsymbol{Y}$., mit andern Trilobiten.

7) A. m i c ru r u S Green, S. 56: Schwanz verschmälert, spitz, Körper sehr kouvex, Rippen gestreift, am Rand (schmal) kuum häutig. Abdomen und Schwanz sind nicht zu unterscheiden, zusammen 18gliederig, $2 \frac{1}{2} "$ lang. In schwarzem Stinkkalk der Trenton Falls.

8) A. We therilli Green, S. 57: Kopfschild hinten bogenförmig, gefurcht, Abdomen 12gliederig; Schwanz kaum häutig; die Leder-Haut kaum punktirt. - Unriss regelmässig oval. Wangen sphärisch-dreieckig; die Augenhöcker scheinen rund, nicht halbmondförmig gewesen zu seyn. Mittellappen am Abdomen mit 12 doppelten, Schwanz mit 6 einfachen Gliedern; wo die Epidernis wohl erhalten, erscheinen alle Glieder einfach. Das letzte Schwanzglied ist länger, als an irgend einer andern Art. Abdominal-Rippe mit tiefer Längenfurche, und endigend in zurückgekehrte Spitzen: Schwanz-Rippen ausgehöhlt, in die schmale Umfangshaut endigend. Länge $1 \frac{3}{\frac{1}{4}}{ }^{\prime \prime}$, Breite $1 \frac{1}{4}^{\prime \prime}$. In Kalkschiefer bei Rochester, Munroe Co., N.-Y.

\section{Paradoxides Brongr., S. 59 .}

1) P. B ol t o n i Bigsby Jour'n. Acad. nat. sc. Philad. IV, $>$ Greex S. 60, Fg. 5: Ey-förmig, blind, Oberfläche mit kleinen Höckerchèn und Streifen; Kopfschild vorn gerundet, dessen beide Ecken in einen breiten Dorn ausgehend; Abdomen 14gliederig, Glieder Sichel-förmig zurückgekrümnt, Schwanz häutig, sägerandig. - Ganze Länge $5 \frac{t}{5}{ }^{\prime \prime}$, Breite des Kopfschildes $4 \frac{3}{5}{ }^{\prime \prime}$, dessen Länge in der Mitte $1_{9}^{1}{ }^{\prime \prime}$. Stirne und Wangen gleich breit, diese dreieckig, flach, erheben sich jedoch gegen die Stirne zu einer scharfen Kante; Stirne vorn gerundet, vorn jederseits mit einer schiefen, nach innen gabelfürmigen Kante. Abdomen und Schwanz nicht unterschieden, ersteres $3 \frac{1}{2} "$ lang, mit 14 $\frac{1}{5}^{\prime \prime}-\frac{1}{3}{ }^{\prime \prime}$ breiten gefurchten Rippen; nur die drei hintersten sind breiter; Mittellappen 'vorn $1 \frac{1}{2}$ '. breit, von der 6 Rippe an schmäler werdend, am Ende noch $\frac{1}{5} "$ breit. Seitenlappen fiach, vorn $1 \frac{1}{2} "$ breit, mit sichelförmigen Rippes. In schwarzem Schieferkalk, welcher über dem Salz-führenden Sandsteine liegt und mithin jünger als andere Trilobiten-führende Gebirgs-Arten ist, zu Lockport, N.-Y.

[P. Harla n i ist viel lüuger und crst später cntdeckt.]. 


\section{0 gyg i a Brongn., S. 63 .}

1) O. Sillimani wird von Brongntart in DE ha Beche's Manual aufgeführt, als an Mohawk river bei Schenektady vorkommend. Der Verf. kennt sie nicht, vermuthet aber, da I s o t e le $\mathbf{n}$ in dieser Gegend häufig und die Verwechslung leicht, dass irgend ein Kopf - oder Schwanz-Stück aus diesem Geschlechte von Brongniart als $\mathbf{O}$ g y g i a angesehen worden ist.

V. I s otelus De Kay Ann. Lyc. N.-Y. I, 17t-I75, Green, S. 64 ("̈бos, gleich, und $\tau \varepsilon \lambda o s$, Ende). Körper oval, oft zusammenge: zogen, nicht selten ausgebreitet; Kopfschild breit, vorn rund, an Form und Grösse dem Schwauz - Stücke gleich, aber mit 2 Augen - förmigen Höckern. Stirnfortsätze hinten mit 2 halbmondförmigen Endigungen [?]. Abdowen 8gliederig. Schwanz ohne Gliederung, so breit als der Kopfschild. Längenlappen sehr deutlich getrennt. Dieses Genus unterscheidet sich von Calymene durch 8 Rumpfylieder und nicht netzförmige Augen; von Asaphus ebenso durch die Augen, durch den Mittellappen doppelt so breit als die Seitenlappen, durch den nicht häutigen Rand längs der Seiten; von $\mathrm{Og}$ ygia durch die eingerollte Form, die Abrundung der hinteren Ecken des Kopfschildes und die deutliche Gliederung der Längenlappen etc. [Uns scheint ausser etwa dem zweiten dieser Unterschiede von Ogygia keiner nur irgend wesentlich, und selbst dieser nur etwa zur Bildung eines Subgenus geeignet.] Sehr reich an Trümmern dieses Geschlechts ist zumal das Gebirge am. West Canada Creek bei den Trentun Falls, 13 Meilen nördlich von Utica, N. - Y., wo Reste 15" langer Exemplare vorkommen, mit Enkrinen, Fungiten, Nautilen, Produktenu. s. w.

1) I. gigas Dekay, Green S. 57 (Asaphus platycephalus STоскеs, Lond. geol. Transact. N. S. I): Kopf sphärisch dreieckig, mit, punktirter Oberfläche; zwischen den Augen gegen den Vorderrand abfallend, sein Hinterrand konkav. Augen hoch, fast gestielt, die Cornea halbınondförmig, selır glänzend. Scitenrippen mit tiefer Längen-Furche, dic sich gegen die schmalern Enden hin verliert. Auf dem Schwanze sieht man den Mittellappen und einen Saum längs des Randes kaum an. gedeutet. Ganze Länge $6^{\prime \prime}-11^{\prime \prime}-17^{\prime \prime}$. In Thonschiefer von Cincinnati, Ohio; im Kalk von St. Joseph, Canada.

2) I. p I a n u s DeKay, Green S. 68: Kopf und Schwanz runder und flacher, als bei vorigem. Ganze Länge $2^{\prime \prime}, 1$, Breite $1^{\prime \gamma}, 1$; Länge des Kopfes $0^{\prime}, 6$, des Abdomen $0^{17}, 8$, des Schwanzes $0^{\prime \prime}, 7$. Wohl nicht das Junge von voriger Art, wie Dekay vermuthete. In Thonschiefer von Newport, Kentucliy.

3) P. c y clops Green, S. $69^{\circ}$, Fg. 7: Kopfschild vorn gerundet, Hach; Augen rund, sehr nahe; Schwanz eyförnig, lang zugespitzt. Vordertheil des Kopfes, länger, als bei beiden vorigen; Augen an dessen hinterem Rande. Abdomen 8gliederig; dessen Mittellappen kạum breiter, 
als beide Seitenlappen. Hinterrand des Schwanzes runder, als der Kopfschild. Länge fast $3^{\prime \prime}$. Im westlichen Theile des Staates von NewYork, in aschgrauem Kalkstein.

4) I. $\mathrm{meg}$ a lops GREBN, S. 70: Kopfschild vorn fast gerundet, hinten bogenförmig; Augen gross, rund, sehr vorstehend. Schwanz fast kreisrund, mit breiter Einfassung; Abdomen 8gliederig. - Kopfschild dem von 1 ähnlich, doch vorn runder, binten bogenförmig. Augenhöcker halbkugelförmig, nahe am Hinterrande des Kopfes in der Verlängerung der 2 Furchen desAbdomen stehend, dessen Mittellappen viel breiter, als die Seitenlappen, ist. Schwanz fast kreisrund, konvex, Länge fast 5", Breite 3". Im schwarzen Übergangskalk der Trenton Falls, New-York.

5) I. s t e go p s Green, S. 71: Kopfschild vorn und Schwanz hinten verschnälert; Lederhaut mit sehr kleinen Punkten. - Kopf fast sphärisch dreieckig, Augenhöcker vorstehend, näher an Seiten - als HinterRande, und überragt von einem Augenlied-förmigen Vorsprung, welcher in eine gebogene Linie (Naht) hiuten bis zum Hinterrande, vorn zum Seitenrande fortsetzt, welche bei andern Is ot el us-Arten weniger deutlich zu erscheinen pflegt. Abdomen ? Sgliederig; Schwanz kleiner als der Kopfschild. In Thonschiefer zu Newport, Kentucky.

VI. Cryptolithus Green, S. 72. Körper einrollbar; Kopfschild halbmondförmig, konvex, eingefasst mit einem halbzirkelförmigen, Netz-artigen Rande, und versehen mit einer sehr vorstehenden Stirue; doch ohne Augenhöcker. Abdomen sehr zusammengedrückt dreilappig. Reste davon sind häufig in schwarzem Kalke bei den Trentons- und Glems-Fällen, nach Bissby auch im Kalk über Sandstein auf der Insel Montreal, und Brongniart's Abbildungen zufolge (Tb. IV, Fg. 5, 7 A B C) in Russland und Llandillo in Wales, - an den meisten Orten mit Augen-tragenden Trilobiten (also gegen Brongniart's und WahLeNBERG's Meinung).

1) Cr. tesselatus Green, S. 73, Fg. 4: Kopfschild halbkugelfürnig, längs dem Rande vorn mit drei, an den Seiten mit mehr Reihen Punkten geziert. Abdomen und Schwanz sehr zusammen [flach ?]gedrückt, 10 gliederig, Seitentheile der Rippen gefurcht, Schwanz verschmälert. Ganze Länge $\frac{1}{2} "$. Ähnlich As aphus granulatus. Datm. (tb. II, fig. 6, - BrongN. tb. III, fig. 7), an dessen Kopfschild aber dic hinteren Winkel viel mehr verlängert sind, so dass dieser wenigstens eine andere Art desselben Geschlechtes auszumachen scheint.

Ob die von J. BigsBy beschriebene und abgebildete Art von Montmorency bei Quebec, Canada (Lyc. of nat. hist. N. - Y. p. 21t) eine eigene Art ausnache, in welchem Falle G. den Namen Cr. Big s bii dafür vorschlagen würde, ist zweitelhaft. Der Kopfschild hat nächst der Basis beiderseits drei sehr schwache Queerlinien, welche bei mehreren Calymenen als Furchen erscheinen. Mitten auf der Stirne ist oft cin Erbsen - förniger Vorsprung. Der ganze Rand ist punktirt 
mit dichtstehenden Punkten, die eingedrückt zwischen die erhabenen Maschen eines Netzwerkes stehen, dessen Linien sich in zwei Richtungen kreutzen. Parallel den Seitenrande ziehen der Linien vier hin.

Endlich gehört zu diesem Geschlechte EAtos's Nuttainia conce utrica [als eigene Art?] in Wacke-artigem Argillit am ChamplainKanal, zwischen der Stadt Waterford und dem Mohawk.

VII. Diple u r a Green, S. 78: Körper zusammenziehbar, nicht sebr flach gedrückt, allmählich abnehmend. Kopfschild beulig, dreilappig, mit vorstehenden Wangen und schiefen ringförmigen Augenhöckern. Abdomen 14 gliederig, ungelappt, mit Doppelrippen (daher der Name). Schwanz fast kreisrund, schmäler als der Kopfschild, mit einer Epidermis bedeckt [d. h. ungegliedert].

1) D. D e k a y i Green, S. 79, Fg. 8, 9: Kopfschild halbmondförmig, etwas dreieckig, punktirt; Abdomen fast ungelappt mit 14 gedoppelten Gliedern, Augen schief abwärts gebogen; Wangen erheben sich kegelförmig bis in die, auf ihrer Mitte vertieften Augenhöcker [der nur sehr schwach angedeutete Mittellappen ist fast doppelt so breit als jeder Seitenlappen, und auf letzteren finden sich noch Spuren einer abermaligen Theilung]. Länge bis 5". Zu Lockport, N.-Y., in grauem Kalkstein von Northumherland, und zu Lehighton in Pennsylvanien, in der Ulster Co., N.-Y.; in braunem und grauem Kalkstein der Munroe, de Steuben und der Madison Co. (Cazenvia), N.-Y.

VIII. Trimerus Green, S. 81: Körper sich kugelnd, nach hinten abnehmend, zusammengedrückt. Kopfschild beulig, undeutlich gelappt, mit 2 nur wenig erhabenen Augenhöckern. Abdomen durch zwei schwache Längenfurchen dreilappig und mit 13 Doppelgliedern; Seitenlappen schmäler als der mittle; Schwanz stumpf zulaufend, beulig, 10 gliederig. - Unterscheidet sich von $\mathrm{C}$ a I y me $\mathrm{ne}$, den er älnnlich, durch Form des Kopfschildes, Stellung und Struktur der Augenhöcker und die undeutlichen Lappen; von Dipleura durch den gelappten Schwanz, aber undeutlichere Lappen des Abdomen.

1) T. delphinoeephalus Green, S. 82, Fg. 1: Kopfschild halbmondförmig, nach seinem Vorderrande halb-elliptisch, vorn zusammengedrückt; Augenhöcker sehr klein aber sehr vorragend, die Doppelgliederungen fast nicht in Lappen unterschieden; Schwanz verschmälert; Körper etwas höckerig. - Stirne zwischen den Augen konvex, über dem Vorderrand von einer starken Kante eingefasst, längs des Hinterrandes mit einer Queer-Furche. Wangen klein, dreieckig, in ihrer Mitte die Augenhöcker tragend, welche nicht netzförmig, doch oben mit einer ovalen Öffuung versehen sind. Mittellappen des Abdomen breiter als jeder der kouvexen Seitenlappen, und jedes seiner Glieder ist voru verflächt, das Einkugeln zu begünstigen. Die Krusteu-artige Bedeckung des Schwanzes dicker, als anderwärts, daher seine Gliederung unvollkommen. Die ganze Oberfläche fein erhaben gedüpfeit. Lünge 2"-10". 
In Versteinerungs - reichem Kalkstein von Williamsville, Niagara Co., New - York.

IX. Ceraurus GreEN, S. 83: Körper sehr flach gedrückt, nach hinten wenig abnehmend. Kopfschild wenig dreilappig; Wangen gross, flach, mit kleinen entferntstehenden Augenhöckeru; die 2 hintern Ecken in je einen langen [auswärts stehenden] Dorn fortsetzend. Abdomen 12gliederig, Schwanz am Ende abgerundet, aber jederseits mit einem etwas bogenförmigen Anhange (daher der Name), wie bei Paradoxides, wo aber alle Rippen in etwas kürzere Anhänge ebenfalls verlängert sind, und die Augen fehlen. Eine von Razoumowsry (Amn. sc. nat. VIII) abgebildete Art, von den Yaousa-Ufern bei Moskau?, scheint das Mittel zwischen beideu Geschlechtern zu halten. - Sehr selten.

1) C. pleurexanthemus Green, S. 84, Fg. 10: Kopfschild hinten bogenförmig abgeschnitten, daher im Ganzen halbmondförmig, die Hörner des Halbmondes sehr verlängert, schlank, erst nach aussen, dann wach hinten gehend. Augen etwas gegen den vordern Rand gerückt. Jede Rippe mitten auf dem Seitenlappen mit einem zierlichen Wärzchen besetzt, welche zusammen eine Linie von jedem der Augen an bis zu

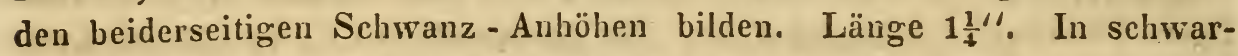
zem Kalkschiefer von Newport, N.-Y.; nur einmal.

X. Triarthrus Green, S. 86: Körper wenig konvex, ?sich kugelnd; Kopfschild ..... Abdomen nur dreigliederig, mit länglichen schmalen keilförmigen Seitenlappen; Schwanz breit, gerundet, ohne häutige Ausbreitung. Bildet ein Mittelglied zwischen Agnostus und den andern Trilobite n. [Ist ähnlich dem Stirntheile mancher Paradoxiden?]. Viele kommen mit einander vor.

1) T. Beckii Gneen, S. 87, Fg. $6:$ (Brongniartia carcinodea Eat. geol. Text Book) Schwanz fast rund, mit 2 Punkten. Das vordere Abdominal-Glied geht ungelappt queer über die ganze Breite des Rumpfes; in der Mitte setzt es ununterbrochen in die zwei folgenden Glieder und den Schwanz fort (Mittellappen), welche Fortsetzung beiderseits ebenfalls ununterbrochen in zwei schiefe Seitehlappen übergeht, die den Raum zwischen dem ersten Glied und dem Schwanze einnehmen. Die zwei vertieften Punkte des Schwanzes liegen in der Hälfte seiner Länge, gleichsam als Andeutungen weitrer Theilung desselben in 2 Glieder. Selten erkennt man eine Queervertiefung, welche die Trenuung des Schwanzes vom Abdomen auch auf dem Mittellappen andeutet. Länge bis $\frac{1}{2} "$. In schwarzen schieferigem Kalkstein am Kamal bei Cahooes Falls u. a. v. a.' O. in New-York.

- XI. Nuttain ia Eaton, geol. Text Book et (exclus. N. c o n c e n t rica) GreEN S. 88: Kopfschild dreilappig, wovon der mittle Lappen sehr vorstehend, die 2 seitlichen fast halb- oder viertel-kugelfürmig sind; der. ganze Vorderrand ist mit einem punktirten Stirubande 
eingefasst. Rumpf deutlich dreilappig, der Mittellappen fast halbzylin. drisch und schmäler als jeder seitliche!

1) N: sparsa Eat., Green, S. 89: Stirnband vorn schmal, Punkte darauf unregelmässig zerstreut, ohne mit Maschen-Fäden abzuwechseln; Kopf zusammengedrückt mit zerstreuten Punkt-Stichen; sein mittler Lappen breiter als die seitlichen, längs rektangulär. Kopf $1 \frac{1}{2}$ " lang und $22^{1}$ " breit, das ganze Thier daher wohl bis 7 " lang. - Green findet jedoch diese ganze von $\mathbf{E}_{\Delta T 0 N}$ entlehnte Beschreibung sehr unpassend, und hält das ganze Fossil, wovon man nur 1 Exemplar kemnt, welches EAton besitzt, für ein Asaphus-Kopfstück. - In der dritten Grauwacke Eatox's in Coeymans, 16 Meil. S.W. von Albany.

N. concentrica Eat. (siehe Cryptolithus).

XI. Brongniartia E. (Brongniartia Eaton, Text Bools) Green, S. 90: Abdomen stets, Schwanz öfters dreilappig (Eaton).

1) B. platicephala Eat. Text Book, Tf. II, Fg. 20 (nicht As aphus platycephalús Stockes, wie Eaton anninmt, da dieser zu Isotelus gigas gehört; - aber Ogygies latissimus Ear. in SiLun's. Journ. XXI, 136) > Green, S. 91: Kopf und Vorder-Abdomen breit und flach, Abdomen mit 10 an den Einsenkungen zum Mittellappen vorwärts gekrümmten Gliedern; Postabdomen und Schwanz mit 15 an der Einlenkung zurückgebogenen Gliedern, deutlicher dreilappig, seine Glieder doppelt (EaTov). Kopfschild ohne Augen, aber mit einer Maulbeerblatt - ähnlichen Zeichnung. Ganze Länge 6", Breite 3". In 'der obern, weichen und schiefrigen Varietät des zu Fertigung des Lias-Z̈̈ments zu Chitfeningo gebrauchten Gesteius, und unmittelbar unter dem Geoden-führenden Kalkfelse, worauf der Corniten-führende ruht.

Dr. JAM. EIghts wird nächstens unter andern einen lebenden Trilobiten beschreiben, den er von den Falkland-Inseln mitgebracht und im Albany-Institut niedergelegt hat. Er ist dem Paradoxides Boltoni ähnlich, aber nicht ąus demselben Geschlechte, indem er mit Augen, wie Calymene bufo, und mit vielen kurzen, unter dem Körper verborgenen Bewegungs-Organen versehen ist (S. 92-93).

Auf der lithographirten Tafel ist, wie sich aus obigen Zitaten schon ergibt, von (fast) jedem dieser Genera eine Spezies abgebildet.

Mit dem Werke wird eine Sammlung von 35 schönen Gyps-Abırïssen ausgegeben, welche sämmtliche hier beschriebene Arten nach den besten bisher bekannt geworlenen Exemplaren darstellen. Beide sind nebst andern Abgüssen interessanter Versteinerungen zu haben bei Jo. sepr Brano, Lehrer der Kunst Vögel, Säugethiere und Reptilien zuzubereiten (Nr. 12, Castle street, Philadelphia).

J. Green: Beschreibung einiger neuen Nord-Amerikanischen Trilobiteu (Silum. Jutrn. 1834, Jan.; XXV, 334-337). 
1) Calymene ?odontocephala Green, Schild fast dreieckig, Stirne jederseits durch eine tiefe Rinne von den Wangen getrennt und ihr Vorderrand wie ein etruskischer Kapitälchen-Rand gekerbt, indem wechselsweise viereckige Theile des äussern Randes cin-, und solche des inuern ausspringen. Auf der Stirne bei den Augenhöckern jederseits zwei vertiefte faltige Stellen. Wangen 3eckig. Augenböcker in einer Vertiefung stehend. Rumpf und Schwanz unbekannt. In weichem grauem Sandstein in New-York (? Utster Co.) durch Dekay gefunden.

2) Asaphus astragalotes Green, Schild...; - Abdomen und Schwanz mit 4 Gliedern an ihren äusseren Rande von einer Haut ein. gefasst; deren Seitentheile breit und mit einer Längenrinne. Spindel sehr konvex, fast bis zu jener Einfassung am Ende reichend, welche auch noch durch einen dünnen Fortsatz der Spindel gestützt zu werden scheint. - Oberfläche gekörnelt. Mehrere Exemplare, alle von gleicher Beschaffenheit, in weichem, dunklem Thonschiefer vom GreenvilleCanal in Ober Canada, im New-Yorker Lyzeum.

3) A. tetragonocephalus Greser. Schild lang halbmondförmig, sein Vorderrand fast gerade, Hörner etwas über das Abdomen hinaus verlängert. Stirne vorn schmal, jederseits mit 2 schiefen kurzen Gruben, vor deren vordercr noch eine kleine Vertiefung liegl. Wangen sehr gross, gegen die Stirne genommén; Augenhöcker wenig, zuweilen fast nicht kenntlich. Abdomen aus 12 . Gliedern, deren Rippen mit einer Längenrinne versehen sind und frei endigen, einen zackigen Rand bildend. Spindel sich, um einige Glieder vor dem Ende des Schwanzes, allmählich verlicrend. Schwanz kurz, rund und ohne die sonst gewöhnliche häutige Ausbreitung. In bituminösem Kalkschiefer, zu ? Newport, in New-York.

4) Paradoxides Harlaui Green. Schild - Form nicht deutlich, doch die Stirne hoch fortziehend. Die Stirne hat hinten 3 QueerRinnen, die vordere schief; davor ein starker Höcker. Wangen in Form sphärischer Triangel. Augen scheinen zu fehlen. Abdomen und Schwanz zusanmen 17 gliederig, ilıre Trennung nicht zu erkennen. Mittellappen durch einen tiefen Seitenlappen jederseits eingefasst, stumpf endead. Seiten flach. Sie scheinen eine häutige Einfassung gehabt zu haben. Jede Rippe mit einer Längenfurche. Ganze Länge und Breite 9" $4^{\prime \prime \prime}$. - Angeblich von? Trenton Falls in New-York; - aber das Gestein ist Kieselschiefer! Ähnlich P. Tessini.

J. Grens: Beschreibung einer neuen Trilobiten-Art von Noma scotia (Transact. geol. Soc. Pennsylv. 1834, I, 37-39). As aphus crypturus Grens, cauda acuta, articulis terminalibus obscuris, parte marginali vix membranacea, corpore convexo. Kopfschild.... Vom Rumpf sind noch 11 Spindel- und 10 Seiten-Glieder vollständig erhalten. Rippen gerundet, olne Rinnen und Wärzchen. Die Art ist an der 
Eigenlıeit kenntlich, dass die vier vordersten Spindelglieder lăuger [breiter ?], als die dazu gehörigen Seitenglieder [Rippen] sind, da nach Brongniart die Spindel selten $\frac{1}{5}$ von der ganzen Breite des Körpers einnimmt. Eine Epidermal-Hülle bedecht die Endglieder des Schwanzes, und was man sonst "Hautrand um die Loben" genannt, fehlt hicr gänzlich. Körper konvex. Länge und Breite fast $3^{\prime \prime}$. Hüchst bemerkenswerth ist, dass dieser Trilobit in Magneteisen abgedrückt ist, während andere Exemplare in Übergangs - Schiefer, noch andere aber theilweise auf diesem und auf jenem zugleich 'abgedrückt vorkommen. Sie stammen nebst einer T'erebratel aus einem Übergangs - Schiefergebirge über Granit, welches Kalk und Magneteisen untergeordnet enthält, in Nuva Scotia, und zwar bei Clements, am Moise-Fluss beim Anapolis - Becken.

Sars (Pfarrer zu Kiud bei Bergen in Norwegen): über einigo ne ue oder unvollständig bekannte Trilobiten (Is:s 1835, S. $333-343$, Tf. viII, Ix).

1) Olenus forficula n. sp. (S. 333, Tf. VIII, Fg. 1, a-f). Findet sich nur in Kopf - und Schwanz - Stücken in Kalk - haltigem Alaunschiefer von Ruselökbucken bei Christiania, bloss in Gesellschaft einer kleinen Battus-Art, des Anomites lenticularis Wahlens., einer gestreiften Terebratula und einiger Fucoiden. Der Kopfschild fin. det sich nur in seine, durch die Gesichtsnaht angedeuteten, drei Theile zerfallen; der Stirntheil ist konvex, länglich, vorn breiter als hinten, hat 2 undeutliche Queerfurchen, vorn eine kurze Längsfurche, hinten eine Spitze in der Mitte. Gesichtsnoht etwa wie bei Trilobites min or Вовск (Magaz. for N'aturvidensk. Christ. 1827, Heft I, Fg. 12). Seitentheile mit konvexen Backen, und hinten ausserhalb in ein zugespitz. tes, gekrümntes Horn auslaufend. Der halbkreisförmige Kopfschild rings mit einer Kante eingefasst. - Rumpf unbekanut. - Schwanzschild luäufig, halbkreisförmig, hinten mit einer Kante; Spindel stark erhöht, mit 5-6 ziemlich deutlichen Riugeln; Seitenlappen ziemlich flach mit 2 starken Queerfurchen, die vordere mit Wülsten, die andere mit Stachelu. Der Schwanzschild hat nämlich auf jeder Seite einen zugespitzten, hinten gerade ausgestreckten und etwas einwärts gekrümmten Stachel, der 1-21 $\frac{1}{2}$ al so lang ist, als der Schwanzschild selbst (bei dersclben Art?).

2) Battus pusillus n. sp. (S. 334, Tf. VIII, Fg. 2 a, b) begleitet den vorigen, ist von $B$. pisiformis sehr verschieden, halbkreisformig, der Mittellappen vorn jederseits mit einem kleinen halbmondförmigen Fortsatz und bis gegen das vordere Ende durch tiefe. Furchen von den Seitenlappen geschieden, hinten gerändet.

3) Ampyx rostratus n. sp. (S. 334, Tf. VIII, Fg.3) klcin, ziemich breit, rundlich und durch sein Horn ausgezeichnet. Der Kopfschild 
ist rundumgerändet, und geht hinten jederseits in ein (abgebrochenes) Horn aus; der Stirntheil kegelförmig verlängert, der Länge nach mit einer erhöheten Kante versehen, und in eine lange dünne pfriemenförmige Spitze auslaufend, welche über einmal länger ist, als der Kopfschild. A. nas ut us vollständig erhalten würde vielleicht eine eben solche Spitze darbieten, aber seine Stirne ist anders geformt und an der Basis mit Seiten - Eindrücken versehen. - Rumpf 5- (vielleicht 6-) glicderig; Spindel zienlich breit und nicht sonderlich erhaben; Glieder mit tiefer Queerfurche. - Schwanzschild halbmondförmig, an Hinterrande mit einer niedergehenden, dicken, längs gestreiften Kante; Mittellappen ziemlich breit, nicht sonderlich erhaben, glatt, ohne Spur von Queerfurchen, jedoch mit 6 Queerreihen von je 4 runden, ziemlich flachen, sehr kleinen Knoten. - A. nasutus, diese und die folgende Art unterscheiden sich daher als besonderes, wohl begründetes Genus von den übrigen durch die Spitze des Kopfes, durch den völligen Mangel der Augen und die geringe Gliederzahl. Vielleicht kommt dazu noch As. granulatus, dessen Rumpf ebenfalls wirklich nur 6gliederig, und mitten auf dessen Stirne S. öfters cine kleine kreisrunde Warze gesehen, die in einen dünnen, doch abgebrochenen Stachel fortgesetzt hatte. - A. rostratus findet sich in schwarzen Übergangs-Kalkstein bei Ladegaarts Oen und Hjortnaestangen bei Christiania, seltener als folgender, mit As a p us, Calymene, Orthoceratiten, Lituiten u. s. w.

4) Ampyx mammillatus r. sp. ? (S. 335, Tf. VIII, Fg. 4 a-d) steht dem Amp. nasutus noch näher als voriger, seine Stime hat aber an der Basis jederseits eine ziemlich grosse, flach ovale Erhöhung, welche rings nit Furchen begrenzt und mitten mit einer kleinern Furche versehen ist. Vielleicht ist diese Art mit A. nasutus sogar identisch, so dass diese Merkmale bei Dacmax's Exemplaren nicht deutlich gewesen wären. Die Stirn ist wie bei diesem mehr oder weniger stark erhöhet und den vorderen Rand überragend, nach vorn in eine konisch zugespitzte Warze ausgehend, welche gewöhnlich abgebrochen, an einem Exemplare aber wie bei Amp. rostratus dïnne und lang erscheint. Vorderrand des Kopfschildes deutlich gerändet, ein wenig vertieft. - Kopfschilder von ${ }_{2}^{\prime \prime}$ bis $1 \frac{1}{2}$ " Breite finden sich mit voriger Art, zuweilen in Menge. Oft kommt damit auch ein Schwanzschild vor, dreieckig, hinten etwas zugespitzt, an den Seiten mit einer dicken längsgestreiften Kante, an der Spindel konvex mit vielen Queer-Ringen, auf den Seitenlappen schwach queergestreift, am Vorderrande mit stark vertiefter Queerfurche : er marg derselben Art angehören.

5) A saphus dilatatus Dalm. (S. 336, Tf. VIII, Fg. 5 a-b) war nach einem stumpfen Gyps-Abgusse beschrieben und abgebildet worden. Die Stirn ist viel schmäler, als sie bei Damman (Tf. III, Fg. 1) erscheint, vorn oval und erhaben, hinten flach und eingekniffen, an jeder Seite mit 5 vertieften Eindrücken, wovon der vordere undeutlich, der hinterste am deutlichsten ist. Die Gesichtsnaht ist charakteristisch: sie bildet vorn am Kopfschild einen breiten Bogen, geht nach hinten und 
innen zum Auge, darauf gerade gegen den Seitenrand und macht wieder eine kleine Biegung nach hinten. Augen stark vorragend, mit vielen ausserordentlich kleinen runden Knoten besetzt. - Schwanzschild hat mehr Rippen (10), als D. angibt, welche queergestreift und durch breite Furchen geschieden sind; auch der Mittellappen ist vorn schmäler und geht weiter nach hinten. Endlich zieht sich daran zwischen den Seiten-Lappen und dem fein wellenförmig gestreiften Rande eine charakteristische Grenzlinie wellenförmig hin, mit einspringender Bucht vor jeder Rippe und mit ausspringender vor jeder Zwischen-Furche. Diese Schwanzschilde haben 1-1 $\frac{1}{2}$ Daumen Breite und finden sich häufiger, als die Kopfschilde, die oft auch in ihre drei Theile zerfallen sind. Gemein bei Christianiu, auch bei Eger, Morlum: überall in schwarzen Übergangskalkstein; in Schweden fehlend.

6) A s aphus grandis n. sp. (S. 337 , Tf. Ix, Fg. 6 a , b). Ein Exeinplar von Aggersbakken bei Christiania; dem A. e x te n u a u s DAxM. am nächsten stehend, aber sehr abweichend durch seine stark konvexe längliche, vorn zugerundete, mitten etwas eingekniffene und jederseits mit einigen undeutlichen Eindrücken versehene Stirn. Gesichtsnaht wie bei voriger Art, jedoch vorn unvollständig erhalten, und die zwei von ihr beschriebenen Bögen vor und hinter dem Auge grösser; das Auge viel kleiner, auf dem konvexesten Sritentheile sitzend; hintere Ecke des Kopfschildes . . . nicht erhalten. - Rumpf 8gliederig, die Spindel schmäler als bei A. extenuatus. - Schwanzschild zwar sehr beschädigt, doch sehr verschieden von dem des letzten, ziemlich glatt, mit vielen an der Spindel (12 sind noch erhalten) sehr deutlichen, an den Seiten sehr schwachen und schmalen Rippen; Spindel viel länger und schmäler als bei A. extenuatus, duch nach hinten breiter als in der Mitte. Ein, wahrscheinlich zur nämlichen Art gehöriger, riesenhafter Schwanzschild von gleicher Fundstätte hat an der Spindel gegen 20 auf die Seitentheile fortsetzende Ringe; diese endet hinten in einen abgerundeten flachen, breiten Knoten; der breite Pand ist ganz glatt. Hinterrand des sich allmählich verschmälernden Schildes etwas abgerundet. Dieser Schild lässt anf ein Fuss-langes Exemplar schliessen.

7) Calymene speciosa DaLm. (S. 339 , Tf. IX, Fg. 7). Einige an den vorhin genannten Orten gefundene Bruchstücke sind besscr erhalten, als das Datman'sche. Die allgemeine Form des Kopfschildes gleicht v. Sternberg's 'If. I, Fg. 5, der diese Art auch ganz nahe steht, aber der stark konvexe, ganz glatte Stirntheil ist verhältnissmässig viel kleiner; seine 4 Einschnitte beschränken sich auf die Seiten, und die 2 hintersten haben zwischen sich einen, jederseits an der hinteren Ecke der Stirne stehenden erhabenen Knoten. Scitentheile tief geschieden, wenig konvex, wie mit Nadelstichen zierlich punktirt. Gesichtsnaht stark und von ungewöhnlichem Verlaufe: sie geht von einer geraden Queerkante dicht vor der Stirne [hinter dem Vorderrande gelegen] aus, krümmt sich im Bogen nach hinten, und dann S-förmig vach innen, hinten (Ausschnitt für die Augen?), aussen, hinten und innen, um 


\section{$-466=$}

sich in die starke Qucerfurche am Hinterrande des Schildes zu begeben. Die Hinterecke des Kopfschildes jederseits in ein (abgrebrochenes) Bogenhorn verlängert.

8) Calymene clavifrons DaLr. (S. 339, Tf. IX, Fg. 8 a, b). Bruchstück eines Kopfschildes von Ladegarts Oen, etwas vollstäudiger las bei Dalman. Stirne fast kugelförmig vorstehend, mit Einschnitten wie bei voriger Art, doch die zwei vordersten jederseits sind schwächer und die 2 Knoten hinten kleiner; Oberfäche durch zablreiche kleine Knoten rauh; Seitentheile verhältnissmässig klein; Gesichtsnaht ungefihr wie bei voriger Art, doch noch, weiter nach hinten gehend, und dort kleinere Bicgungen zeigend. Ränder . . ; Horn . . . .

9) Bemerkungen über die Unterseite des Kopfes bei einigen Trilobiten (S. 340). Beobachtungen darüber haben Dekax, Stokes und Markein (Dalman Pal. p. 35) geliefert. Der Verf. hat sich instruktive Exemplare von Asaphus expausus durch vorsichtiges Sprengen aus dem Gesteine verschafft und theilt hier mehrere Abbıldungen mit. Unten entspringt nämlich von dem mittlen Theile des halbmondförmigen Vorderrandes des Kopfschildes, mittelst einer Naht daran befestigt, ein horizontal nach hinten gehender, flacher, spitz zweilappiger, etwas gebogener Fortsatz, dergleichen von genannten Naturforschern bereits bemerkt worden ist. Von unten geseleen ist dessen Hauptkörper rundlich viereckig, gewölbt, die zwei hinteren Ecken in Form je eines kleinen Knotens. Vom Hintertheil seiner zwei Seitenränder und von seinem Hinterrande aus verlängert er sich in einen Anhang, welcher hinten durch einen fast halbkreisförmigen und nach vorn nicht ganz bis zum Körper reichendeu Ausschnitt in zwei hinten zugespitzte, aussen bogenförmig konvexe und nach oben umgekrümmte Lappen, etwa von gleicher Erstreckung mit dem Kopfschilde, geschieden, und wịe diese längsgestreift ist. Von dem vordern Theile der zwei Seiteurânder des Körpers entspringen zwei queergestreifte fast eyförmige Flügel, welche nach aussen und bis zu $\frac{3}{4}$ der Länge des Körpers nach hinten gehen, sich dabei mit ihrer Fläche in eine senkrechte Lage nach oben umbiegen und sich nit ihren äusseren Enden auf eine merkwürdige Weise in die Gesichtsnalıt verlieren. Da alle diese Theile nur dünue sind, so bieten sie von oben gesehen die nämlichen Formen nur mit entgegengesetztem Relief dar, so dass hier vertieft, was dort erlö̈het ist, u. s. w.

Bei Illaenus crassicauda (S. 341, Tf. IX, Fr. 10) sind diese Theile ähnlich, doch dünner und gebrechlicher, in Verhältriiss zum Kopfschilde kleiner, ihr Körper konvexer, schmäler, oval, von Rande des Kopfschildes etwas entfernt stehend, und von jenem Anhange daher rings umgeben, welcher schmal, hinten zugerundet (nicht 2lappig), an den Seiten gerade ist, und sich vorn bis zum Rande und seitwärts in die Flügel verlängert, dic aber $S$. nicht weiter verfolgen konnte.

Von As aphus dilatatus (S. 342, Tf. IX, Fg. 11) hat der Verf. diese Theile häufig in Gesellschaft der Trilobiten selbst, jedoch abgerissen 


\section{$-467$}

davon gefunden. Der Körper ist stark konvex, oval, vorn zugerundet, hinten schmäler, mit einer starken Vertiefung an jeder Seite des Endes, veben und hinten ungeben von einem dünnen und schmalen Anhange, der hinten queer abgeschniten, und dessen hiedurch entstehenden zwei Ecken wieder abgestutzt sind. Beide Theile sind fein wellenförmig in die Länge gestreift. Von den aufsteigenden Flügeln war nur der unterste Theil sichtbar.

Wahlenberg's Eutomostracites Bucephalus (N. Act. Upsal. VIII, 37, tb. I, fig. 6) ist nichts anders, als ein solcher Theil, vielleicht von Olenus Tessini herrührend; - dessgleichen die Abbildung von Воеск (Magaz. for Naturvidensk 1827, Heft I, Fg. 16), von einer andern Art.

Diese Theile können keine Kinnladen seyn, da sie nur ein Stück ausmachen. DaLman vergleicht sie dem Vorsprunge unten an Kopf [?] des Limulus; aber sie sind nun nach S's. Beobachtung hiezu viel zu zusammengesetzt, und durch eine Naht mit dem Kopfschilde verbunden. Auch findet sich in der Mitte des Randes desselben bei Illaenus crassicauda und Asaphus palpebrosus hinten eine stumpfe Ausbiegung, welche richtiger mit jenem Vorsprung vergliclsen werden kann. Jedenfalls aber mögen diese Theile mit dem Munde in Verbindung gestanden und zu dessen Schutz, zur Befestigung der Kiefer etc. gedient haben.

Edw. Hitchсоск: Beschreibung der Fuss-Spuren von Vögeln (Ornithichnites) im New red Sandstone von Massaclusetts (Sildim. Amer. Journ. 1836; XXIX, 307-340, mit 3 lithogr. Tafeln). Der Verf. hat in genanntem Gesteine auf meh!eren Punkten Eindrücke von Vogel-Füssen gefunden, denen er den Namen $0 \mathrm{rnithichnites}$ (von opvis und fixvos: Vogel Führte) beilegt. Sie bilden, abwechselnd vom rechten und vom linken Fusse hinterlassen, ganze Peihen. Ihre Form und der Mangel aller Eindrücke eines dritten und vierten Fusses lassen keinen Zweifel uiber ihren Ursprung von Vögeln übrig.

Die Fundorte sind 1) ein Bruch im S.W.-Theile von Montagne, keine halbe Engl. Meile vom Connecticut-Flusse, nicht $100^{\prime}$ über dessen Spiegel, wo die Schichten $5^{0} 0$. fallen; - 2) ein Bruch bei Horse Race unfern der Stadt Gill unmittelbar am N. - Ufer desselbin Flusses, 3 Meilen über Turners - Fällen und 8-9 M. nördlich von vorigem; die Schichten fallen $300 \mathrm{~S}$. unter das Flussbette ein : - 3) ein Bruch im S.O. - Theile der Stadt Northampton an der O. - Seite des Mount Tum, über 30 Meilen S. vom zweiten; der Schichten-Fall ist $10^{\circ} \mathrm{O}$.; die Eindrücke finden sich hier in drei mit cinander unregelmässig wechsel. lagernden Varietäten des Gesteines : in einem röthlichen glimmerreichen Sandstein-Schiefer (dem red marl der Geologen?), einem grauen glimnerigen Sandstein, und einem sehr harten Sandstein aus Thon und Sand; - 


\section{8
$-\quad 4$}

4) in cinem hurten grauen Schiefer aus dem Kanale in Süd-Hadley, uahe bei dem daran liegenden Dorfe; diese genaunte Grafschaft liegt aut der 0.Seite des Connecticut, dem Mount 'Tom gegenüber; - 5) und in cinem groben Gritsteine am Mount Holycke im nördlichen Theil von Süd-Hadley. Vermuthlich kommen aber diese Fussspuren unbeachtet noch an vielen andern Punkten im Sandsteine des Connecticut-Thales vor, der sich noch 60-70 Meil. S. vom Tom-Berge erstreckt. Sie werden nur auf frisch aufgedeckten, nicht auf dem Wetter schon lange ausgesetzt gewesenen Schichtflächen gefunden.

Die Eindrücke sind theils drei-, theils vier-zehig, und in letzterem Falle mit vier nach vorn gerichteten Zehen oder mit einer Hinterzehe. Die Mittelzehe ist die längste. Das Ende der Zehen ist zugespitzt, oder stumpf und die Zehen breit; im ersten Falle bemerkt man selten, im letzten gewöhnlich noch abgesonderte Klauen. Die Gesteins-Blätter bis zu $2^{\prime \prime}-4^{\prime \prime}$ über und unter der Fläche, worauf der Eindruck ursprünglich gemacht worden, biegen sich diesem Eindruck genäss ebenfalls abwärts, und stellen ihn daher von unten gesehen wie Horh-Relief dar, jedoch deutlicher darïber, als darunter, und un so undentlicher, je mehr sie sich von jener Fläche entfernen. Jenes Hoch-Relief gibt zuweilen das deutlichste Bild des Abdruckes, da nämlich in gewissen Fällen der Sand und Schlamm, welche sich zuerst in die entstandene Vertiefung der ursprünglichen Oberfläche hineingesetzt haben, eine härtere und nicht schieferige Konkrezion bilden, während der Eindruck selbst wegen der schieferigen Beschaffenheit des Gesteines sich selten in der richtigen Fläche und deutlich umgrenzt erhalten lässt. Die Einbiegungen der Schiefer-Blätter über dem Eindrucke fehlen zuweilen auch, wo die Unterlage aus feinerem Materiale gebildet, eine Einfüllung aus demselben Stoffe nachgefolgt und grüberer Sand darüber hergeflöst worden ist. Die Eindrücke des rechten und linken Fusses lassen sich von einander erkennen, wo sie in grösserer Anzahl regelnässig aufeinanderfolgen, obsclion sie dann meistens in fast ganz gerader Livie [schnürend] liegen, da nänlich die Vorderzehen-Spitzen von dieser Linie an auswärts, die Hinterzehe aber, wo sie vorhanden, einwärts stehen, da an den längeren und dann gewöhnlich etwas bogenförmigen Zehen die konkave Seite des Bogens ebenfalls einwärts liegt, und da die Ferse immer auf der äusseren Seite mehr vorstehet. Die Abstände der in Einer Reihe liegenden, zumal kleineren Fährten sind oft ungleich, als ob sich der Vogel bald langsam, bald schnell bewegt hätte. Ein Gleiten der Füsse auf den SchieferFlïchen scheint nirgends Statt gefunden zu haben, obschon deren Neigung bis zu $30^{\circ}$ steigt und die Reihen der Fussspuren in verschiedener Richtung darüber hinguhen; die Gesteinschichten scheinen demnach érst später aufgerichtet worden zu seyn. - Manche Reihen von Eindrücken sieht man sich durchkrcutzen; manche von gleicher Vogel-Art herrührend ziehen, einige Fuss auseinander, parallel nebeneinander fort.

Der Verf. hat theils in Schlamme längs der Flüsse, theils im Schnee die Fussspuren noch lebender Vogel-Arten beobachtet, die ihm mit einigeu 
der oben erwähnten grosse Ähnlichkeit zu haben scheinen: es sind vorzüglich Hühner-artige und Sumpf-Vögel. In Fg. 13, 14, 18, 19, 20 gibt er ebenfalls Abbildungen davon. Die der Wasservögel, insbesondere Enten Fg. 12, stehen rechts und links mehr von der Mittellinie al, und lassen die Schwimmhaut zwischen den Zehen deutlich erkennen. [Die in gerader Linie folgenden - schnürenden - Fussspuren deuten daher auch hier auf hochbeinige Thiere]. Diese lebenden Vögcl-Arten geben aber bei Weitem kleinere Spuren, als mehrere der fossilen.

Diese Fussspuren unterscheidet der Verf. nun in folgende Geschlechter und Arten, deren aber jede Art wohl die mehrerer Vögel-Arten in sich begreifen kann, und wovon wir auf Tf. $V$ die Umrisse mittheilen:

A. Pa chydactyli mit kurzen, dicken, gleichbreit bleibenden Zehen.

1) Orn. giganteus (Tf. I und Tf. II, Fg. 21) Tf. v, Fg. 1: nur mit drei Vorderzehen, ohne die Klauen 15" Engl., mit diesen 16"-17" lang; Entfernung der aufeinander folgenden Spuren $4^{\prime}$, zuweilen auch (im Laufe ?) $6^{\prime *}$ ); Dicke eines Zehens $1_{\frac{1}{4}}^{\prime \prime}$, Breite $2^{\prime \prime}$. Innere Zehe mit 2, Mittelzehe mit 3 Verdickungen oder Gliederungen. Am Mount Tom häufig. Zuweilen mehrere Reihen miteinander.

2) 0. tuberosus (Fg. 2 u. 5) Fg. 2, mit 3 Vorderzehen, $7 "-8$ " lang, auf der Unterseite mit mehreren Ballen versehen, Klauen zuweilen deutlich $1 "-1 \frac{1}{2} "$ lang. Gliederungen wie bei vorigem. Entfernung der Füsse 24"-33". Mit vorigen und zu Horse Race drei Mal. Kleiner als die vorige Art, die Zehen etwas mehr auseinander stehend, der mittle verhältnissmässig kürzer; ohne Zwischenformen.

2) a. O. tuberosus dubius ist voriger ähnlich, Fährten noch kleiner, 4" lang, 12 " entfernt.

B. Le ptodact y li.

3) 0. ingens, Fg. 3, mit drei schmalen, lang zugespitzten Vorderzehen, die von der Ferse an 15" - 16" Länge haben, ohne kenntliche Klauen; hinter der Ferse ist ein Anhang $8^{\prime \prime}-9^{\prime \prime}$ lang und einige Zoll breit, welcher das Ansehen darbietet, als hätten sich über der Ferse stehende Federn mit dem Fusse in Schlamme abgedrückt. Die ganze Spur besitzt daher $2^{\prime}$ Länge und die Entfernung zweier Spuren muss gegen 6 ' betragen. Der blaue Schlamm, woraus die Felsart gebildet ist, war im weichen Zustande durch den tiefen Eindruck des Fusses eines schweren Vogels rings um den Vordertheil des Eindrucks einige Zoll in die Höhe getrieben worden. Von Horse Race.

3) $\alpha$. O. ingens minor (Fg. 3) ist dem vorigen ähnlich, doch nur $12^{\prime \prime}$ lang, die Entfernung ist $42^{\prime \prime}-45^{\prime \prime}$. Der Feder-Anhang ist nur

*) Es ist niclit angegeben, ob diese Fntfernung nur zwischen zwei Spuren, oder mit Inbegriff von einer derselben (wie es sollte und wohl auch geschehen zu sèyn scheint) gemessen seye; es lässt sich mithin auch die eigentliche S $\mathrm{ch}$ it $\mathbf{t}$ weite e ines und desselben Fusses nicht augeben (sie ist, wenn vorige Annahue richtig, doppelt so gross, als jene Entfernung). 
schwach eingedrückt. Man würde denken können, die Platte mit diesem Eindrucke seye über oder unter derjenigen gelegen gewesen, in welcher der Fuss ursprünglich abgedruckt worden, und desswegen kleiner und undeutlicher, wenn nicht zugleich der Schritt viel geringer wäre. Von Horse Race.

4) 0. diversus mit drei Vorderzehen, die von der Ferse an $2^{\prime \prime}-6^{\prime \prime}$ Längen haben; dahinter ein Federbüschel, wie bei vorigem; Schritt $8^{\prime \prime}-21^{\prime \prime}$ lang. Diese ungleichen Grössen-Verhältnisse scheinen auf viele Arten hinzudeuten; doch lassen sich keine Grenzen für sie ziehen; der Verf. beschränkt sich dalier nur folgende 2 Varietäten noch herauszuleben; doch man wird diese Art vielleicht nur für Junge der vorigen halten: sie ist 50 mal so häufig.

4) a. 0. diversus clarus (Fg. 10, 16, 17, 23, 24) Fg. 4a; Fuss ohne den Federbüschel 4 " -6 "lang; die Zehen etwas genähert und zugespitzt, die innere kürzer als die äussere; Federbüsclsel deutlich, 2 "-3"lang; Ferse knotig, Schritt 18"-25"lang. An den 2, und wahrscheinlich den 4 erstgenannten Fundstätten.

4) $\beta$. O. diversus platydactylus (Fg. 4, 6?, 7, 8) Fg. $4 \beta$. Kleiner, Mittelzehe nur $2^{\prime \prime}-3^{\prime \prime}$ lang, gegen das Ende hin sich sehr verdickend; Federbüschel deutlich und gross, doch zuweilen, wo der Fuss nicht tief eingesunken, mangelnd; Schritt $6^{\prime \prime}-8^{\prime \prime}$ lang. Von Horse Race, auch von IIcunt Tom und von Süd-Hadley. Mit dem Federbüschel wird der Fuss bis zu 6" lang. Doch zeigen sich in den Ausmessungen noch mancherlei Verschiedenheiten: die Schrittweite nimmt bis $\mathrm{zu} 10^{\prime \prime} \mathrm{zu}$.

5) 0. tetradactylus Fg. 5 , mit 3 Zehen nach vorn, $2 \frac{1}{2} "-3 \frac{1}{2} "$ lang; Zehen schlanker, als bei vorigem; Hinterzehe fast unter rechtem Winkel nach innen stehend, nicht mit der Ferse zusammenhängend, sondern im Abdrucke erst in einer kleinen Entfernung von ihr beginnend, als seye sie am Thiere selbst höher angefügt und schief nach unten gerichtet gewesen. Schritt ? 10" $-12^{\prime \prime}$ lang. Kein Federbüschel. Zu Horse Race. Kleine Abänderungen in der Länge der Zehen, der Höhe der Anheftung der Hinterzehe, des Abstands - Winkels derselben deuten auf Vögel verschiedener Arten und vielleicht versehiedener Geschlechter hin; auf sehr hartem Boden, wo der Fuss weniger einsinkt, bleibt die hochgestellte Hinterzehe ganz unabgedrückt.

6) 0. palmatus (Fg. 15) Fg. 6. Nit allen 4 Zehen nach vorn gekehrt, doch ohne Schwimmhaut dazwischen, wie man nach dem Namen vermuthen möchte. Ferse breit, dic 2 äussern und 2 innern Zehen näher beisammen und auf eine läugre Strecke, wie es scheint, nit einander verwachsen als die 2 mitteln, längsten; die innern Zehen an kürzesten. Fuss $22_{2}^{1 \prime \prime}-3^{\prime \prime}$, Schritt 8 " lang., Die Stellung der Zehen kommt bei keinem lebenden Vogel vor.

7) 0. minimus (Fg. 9) Fg. 7. Drei Zehen in Ganzen, olue Hinterzehe und Federbüschel, $\frac{1}{2} "-1 \frac{1}{2}$ "lang; Schrittweite $3^{\prime \prime}-5^{\prime \prime}$; Zehen fast gleich lang, sehr breit. Zu Horse Race. 
Vergleicht man die Abdrücke dieser Füsse mit denen noch !eben. der Vögel, so dürfte sich ergeben, dass wenigstens mehrere derselben $z u$ den Grallae gehören, nit denen sie die dreiZehen und den weiten Schritt (im Verhältniss zur Grösse des Fusses) genein haben. 0. dive rs us und das Haushuhn haben einen gleich grossen Fuss, 3" lang, jener aber einen Schritt von $10^{\prime \prime}-i 2^{\prime \prime}$, dieses nur von $6 "-7^{\prime \prime}$ u. s. w. O. platydactylus und Arde Canadensis haben auch einen gleich langen Fuss von 3", jener aber einen Schritt von 8", diese von 6", so dass auch diéser Sumpfvogel, gleich der kleinen Amerikanischen Schuepfe, noch immer einen kürzeren Schritt hat, als der fossile. 0 . giganteus und 0 . ingens sind aber so gross, dass sie sich mit keiner lebenden Art passend vergleichen lassen. Struthio Camelus, die grösste lebende Vogel-Art, tritt bei einem fast $8^{\prime}$ hohen Individuum nit einem nur $10^{\prime \prime}$ laingen Fusse atif, und wird bis $9^{\prime}$ boch und 100 Pfund schwer. O. gigan te us mit $17^{\prime \prime}$ langem Fusse muss daher wenigstens doppelt so schwer gewesen seyn $\left.{ }^{*}\right)$. Doch zeigt $R$ he a an der Stelle der Hinterzehe einen Knoten, der auch bei 0 . ingen s angedelltet zu seyn scheint. Dagegen finden wir weder unter allen Wad-und Lauf-Vögeln eine Art mit einem Federbüschel an der Ferse, noch lässt sich denken, dass er dem Vogel labe nützlich seyn können, wenn er ihm nicht sogar hinderlich war. Fast nur bei den Raub- und Hühnerartigen Vögeln [bei einigen Schwalben etc.] gibt es bis auf die Zehen befiederte Füsse, zu denen man aber jene Fussspuren kaum dürfte zäh. len können, da sie nothwendig von Vögeln herrühreu, die solche wo nicht unter Wasser, doch an dessen Rande, auf oft überschwemmtem Grunde in Schlamm zurückgelassen haben müssen.

Wir müssen diese Spuren daher einem vorweltlichen Typus der Grallatoren zurechnen. Dasselbe gilt von 0 . palmatus, obschon wir dafür gar kein lebendes Analogon mehr kennen.

Dass das Gebirge, welches jene Abdrücke enthält, wirklicher New-red-Sandstone seye, ist kaum einem $Z_{\text {weifel }}$ unterworfen. Er reicht über 100 Englische Meilen weit von New Haven in Connecticut bis zur Nord-Grenze von Massachusetts mit einer Breite von 8-24 Meilen und mit einem östlichen Einfallen von $5^{n}-30^{0}$; so dass seine ältesten Schichten nur längs der Westseite des Thales zu Tag kommen; die jüngeren, von Grünsand überlagert, bestehen aus manchfaltigen Wechsellagerungen von schiefrigen Sandsteinen, rothem und grauem Konglomerat - Sandsteine, sehr groben Konglomeraten, Schiefern, rothen Mergeln und Stinkkalk. Mögen einige Geolgen nun

*) Es ist bei diesen Untersuchungen überall nicht auf die relative Länge der Zchen im Verhältniss zu ihrer Dicke Rücksicht genommen. Zu welch' unrichtigen Resultaten würde man aber gelangen, wollte man, die Länge der Zehen beim Strausse zum Maasstabe genommen, aus der Länge der Zehen des Reihers auf die Grösse des ganzen Thiers schliessen, oder durch Vergleichung der Grösse der Sehwimm. füsse der Gans mit denen des Flan,ingo die Höhe des letzteren berechnen! 
auch die tieferen Abtheilungen dem $01 d$ red Sandstone zuschreiben: die Fussspuren kommen nur in den jüngeren, einige Hundert $(600-700)$ Fuss unter ihrer obersten Grenze vor, deren lithologischen Charaktere, deren Mineralgehalt an Gyps, Kupfer (mit schwefelsaurem Baryt und Strontian und magnetischen Eisensand) mit Ausnahme des Steinsalzes, und deren Versteinerungen sich wie auderwärts in dieser Formation verhalten. Die organischen Reste bestehen in Knochen eines Wirbelthieres (kein Fisch), dergleichen noch nie unter dem New red Sandstone vorgekommen, welche Bemerkung sich denn auch, auf die Urheber dieser Fussspuren selbst beziehet, und in Fischresten aus dem Geschlechte Palaeothrissum, wie in Deutschland, Frankreich und England. Ja, einer dieser Fundorte der letztern in Sunderland liegt nur 1 Meile von einer der reichsten Fundstellen der Vogel-Spuren und in der Fortsetzung zum Theile der nämlichen Gestcinsschichten. Nur schwache junge tertiöre oder selbst quartäre Ablagerungen bedecken in nämlichen Thale diese Formationen noch. Endlich kam in diesem Sandsteine zu West-Springfield noch ein Koralloid, Gorgonia Jacksoni vor, das, obschon es nicht vollständig war, doch $18^{\prime}$ Länge und $4^{\prime}$ Breite besessen, woraus so wie aus der Grösse jener Vögel man auf ein ehemals wärmeres Klima schliessen darf.

Je mehr Schịeferlagen des Gesteins über dem Eindrucke dessen Vertiefung nachahmen, desto ruhiger muss der Niederschlag cines feinern Materials auf der festen Unterlage später erfolgt seyn. Nun aber liegen die Vertiefungen der obern Lagen oft nicht senkrecht, sondern bis $1^{\prime \prime}-2^{\prime \prime}$ vor-, rück- oder seit-wärts von dem Eindrucke, was wohl ebenfalls auf ein ruhiges Zusammensinken eines locker schlammigen Niederschlages hindeutet, während sich neue Schichten drückend auf ihn legten, und dabei die Bewegung des Wassers die darin noch halb suspendirten Theile etwas verschob. Auf trocknem Lande, wenn auch am Rande des Wassers, sind diese Eindrücke schwerlich entstanden: Wind, Regen u. s. w., oder zuletzt die Kraft, welche ihre Überdeckung mit andern Schichten bewirkte, würde sie in wenig Tagen oder Wochen zerstört haben.

Gegenwärtig leben in Massachusetts kaum 50 Arten Grallae aus 20 Geschlechtern; und doch würde man nach allem Nachforschen viclleicht kaum von dreien derselben Fussspuren auffinden können. Wären die Arten daher einst noch zahlreicher gewesen, als jetzt?

Hausmans über R. Bunsers in den Kalktuff-Ablagerungen der Gegend von Göttingen entdeckte Kunst. Produkte und Thier-Fährten (Gött. gel. Anz. 1835, S. 1089 ff.). Durch den, während der letzten Jahre bedeutend vermehrten Steinbruchs.Betrieb in dem Kalktuff der Ungegend von Göttingen sind einige nicht uninteressante Verhältnisse dieses Gesteins zu Tage gelegt, welche theils über das relative 
Alter desselben ein helleres Licht verbreiten, theils aber einen unzweideutigen Beweis des Vorkommens von Kunst-Produkten in einem Gebilde darlegen, welches ausser einer grossen Menge von Resten noch lebender Geschöpfe auch Überbleibsel von Thieren enthält, die aus der Reihe der lebenden Wesen verschwunden sind. Eine solche Erscheinung in den Kalktuff - Ablagerungen unserer Gegend dürfte vielleicht aus dem Grunde einer genauern Beachtung nicht unwerth seyn, als wir durch fortgesetzte Beobachtungen auf den Felde an ersten Aufschluss über jene merkwïrdige Periode erwarten dürfen, die uns unvermerkt aus der Zeit der geologischen Mythe in die Gegenwart herüberführt, und alle die interessanten Betrachtungen gestattet, die sich an eine solche Übergangs.Periode knüpfen lasseu. Schon v. Schцотнeim erwähnt, in seiner Abhandlung über den Kalktuff, der Entdeckung von Menschenschädeln in den Tufflagern der Umgegend von Meissen und Bilsingsleben. Leider aber sind die Verhältnisse, unter denen diese menschlichen Überreste aufgefunden worden sind, nicht näher untersucht, und jener berühmte Geognost bemerkt selbst, dass es voreilig seyn würde, sich schon mit fruchtlosen Erklärungen dieses Umstandes zu beschäftigen, da es überhaupt noch mehrerer genauen Untersuchungen über das Vorkommen dieser Knochen bedürfe, ehe man diese wichtige Erscheinung als eine entschicdene Thatsache annehmen könne. Bei der Abteufung einer Steingrube unnittelbar oberhalb der kleinen Ortschaft Lengler $n$ *), links vom Wege nach Enmenhausen, sind in Laufe dieses Sommers von den Arbeitern Bruchstücke Altdentscher Aschenkrüge in ciner Kalksandschicht des Travertius unter Verhältnissen aufgefunden worden, welche beweisen, dass diese Gregenstände noch während der Bildung dieser Ablagerung an ihre Stelle gekommen seyn müssen. Die Ablagerung ist an diesem Punkte mit einer $2^{\text {mi }}$ mächtigen Schicht homogener Dammerde bedeckt, welche weder Kunst-Produkte noch Schuttmassen von Kalktuff entluält. Dieser Umstaud verdient besonders hervorgehoben zu werden, weil daraus hervorgeht, dass die unterliegende Tuffmasse nicht etwa schon früher cinmal von Menschenhänden berührt worden ist. Unter der Dammerde befindet sich eine feste $1^{\mathrm{m}} .3$ mächtige Lage von hartem und theilweise porösem Tuff, an dem sich ebenfalls keine durch Menschenhand bewirkte Veränderung erkennen lässt. Diese Lage zeigt ein deutliches, wie wohl geringes Einfallen nach Norden und ist mit mehreren engen Klüften durchsetzt, in welche sich, wie es bei diesem Gestein häufig der Fall ist, die Dammerde verflösst. Unter diesen festen Lagern, also in einer Tiefe von $3 \mathrm{~m} .3$ unter der Oberflüche, trifft man endlich auf die Lagerstätte jener Kunst-Produkte. Sie liegen auf einer Fläche von 1 qu in einer lockern Tuffschicht, die durch keinen Ablösungs-

*) Dem dasigen Prediger, Herr Kravold, der zuerst das Vorkommen von Kunst-Produkten im Tufflager, wovon die Rede, beobaehtete, gebührte das Verdienst, dass er die Unterbrechung der weitern Ausgrabungen bis zu einer geuaueren Untersuchung veranlasste. 
Raum von den darüber liegenden festen Gestein gesondert ist, bald sandige, bald grandige Beschaffenheit zeigt, und mit einzelnen grösseren Massen von Kalktuff untermischt ist. Die Überbleibsel der Aschénkrüge, welche sich hier gefunden haben, gehören offenbar mehreren Exemplaren an. Sie bilden ebren so wie die in der Höhle von Bize von Marcel DE Serres aufgefundenen Töpferwaaren, eckige, nicht abgerundete Bruchstücke, die theils lose ohne Ordnung umberliegen, theils aber auch von festem Gestein völlig umschlossen sind *). Sehr merkwürdig ist das gemeinschaftliche Vorkommen dieser Kunst-Erzeugnisse mit einer grossen Menge Thierknochen, welche schichtweise dic lockere Tuffmasse durchsetzen. Diese Knochen gehören Hirschen und kleineren Nagethieren au. Es haben sich indessen auch Backenzähne von Fleichfressern darin gefunden - ein Umstand, der um so auffallender erscheint, als man bisher nur Überreste von Pflanzenfiessern in den Travertin-Ablagerungen beobachtet hat. Eben so bemerkenswerth ist das Vorkommen von Flussmuscheln, welche man nicht an anderen Punkten der Ablagerung, aber sehr häufig in dem Flusssande antrifft, von den sie gewöhnlich unterteuft werden ${ }^{*}$ ). Es steht zu hoffen, dass die nicht unbedeutende Zahl der an dieser, Stelle gesanımelten Knochen hinlängliche Mittel zur Entscheidung der Frage geben wird, ob dieselben noch lebenden oder bereits ausgestorbenen Thierarten angehören. So viel lässt sich indessen schon jetzt mit Gewissheit angeben, dass die erwähnten Tuffmassen in gleicher Tiefe mit den aufgefundenen KunstProdukten Überreste ausgestorbener Thierarten enthalten. Eine andere Erscheinung, welche über dis: Entstehungsart dieser Tuff-Ablagerung näheren Aufschluss verspricht, und wie so viele andere Thatsachen ebenfalls darauf hinweisst, dass diese Gebilde nicht einer grösseren in Strömung begriffenen, oder stagnirenden Wassermasse ihre Entstehung verdanken, sondern sich auf ähnliche Weise, wie der Torf auf einem sumpfartigen Boden erlioben, der den kalkhaltigen Gewässern hinreichende Oberflache zur langsamen Verdunstung darbot, ist nicht weniger interessant. Es haben sich nämlich, fast im Mittelpunkte der Rossdorfer Ablagerung, Führtrn von Thieren in einer Tiefe von mehreren Fussen unter der Oberfläche auf den Absonderungs - Flächen des Gesteins

*) Dass diese Bruchstücke altdeutsehelı Aschenkrügen angehören, beweisst sowohl ihre Gestalt, als auch die Beschałfenheit ihrer Masse. Sie bestehen wie gewōhn. lich aus einer roh verarbeiteten ungebrannten Thonmasse, die nur an der Aussenseite durch schwache Feuter-Einwirkung erhärtet ist. Bei der weiteren Ausgrabung wurden ausserdenı noch zwei kleine Feuersteine hervorgearbeitet, welche offenbar durch Kunst ihre Gestalt erhalten haben. Sie sind nämlich zu ziemllch reg̣elnässigen, äusserst scharfkautigen Bruchstücken geschlagen, und haben vielleicht als Werhzenge zum Zerschneiden gedient.

*) In Übereinstimnung nit den Beobachtungen ron Marcen DE SERres über die Knochen der Hölle von Bise, zeigt sich auch hier, dass die aufgefundrien Knochen ihre animalische Substanz noch nicht völlig verloren haven. Sie schwïrzen sich, in eincr Glasrölıre erhiızt, bedentend, und geben dabei brenzliche ammoniakalisch reagirende Dämpfe aus. 
gezeigt, die mit Ausnalıme weniger von Hirsch-artigen Thieren herrüh. ren. Das Gestein, auf dem diese Abdrücke sichtbar sind, bildet horizontal gelagerte oft $1 \mathrm{qm}$ grosse Platten, welche selten die Dicke von $\frac{1}{2}$ Fuss erreichen, und aus einem festen, dabei aber porösen Tuff bestehen. Bei genauerer Betrachtung der Gestalt und Lage dieser Spuren lassen sich mehrere der verschiedenen Arten von Fährten erkennen, die in der Jägersprache mit den Worten: Beitritt, Burgstall, Kreuztritt etc. bezeich. net werden. Unter diesen Abänderungen bemerkt man den Beitritt am häufigsten - eine Fährte, welche dem Rothwilde eigenthümlich ist, wenn es in vertraulichen Beisammenseyn einherschreitet. Nicht nur dieser Umstand, sondern auch die ausserordentliche Menge der Spuren, welche man auf den einzelnen Platten beisanmen erblickt, beweisst, dass die Thiere, die sie zurückgelassen haben, in grosser Anzahl und ungestört an diesem Orte beisammen gelebt haben müssen. Die meisten dieser Fährten stimmen an Gestalt und Grösse vollkommen mit denen noch jetzt in diesen Gegenden lebender Hirscharten überein. Andere indessen übertreffen die Fährte eines Sechzehnenders an Breite um mehr als 3 Linien. Diese Dimension scheint mit der Grösse der Hirschkno. chen im Verhältniss zu stehen, an deuen diese Ablagerungen sehr reich sind, und die offenbar erloschenen Thierarten angehören. Aber auch Fährten von andern zweilufigen Thieren haben sich gefunden, von denen besouders einige eine genauere Untersuchung verdienen *).

Die Auffindung von Bruchstücken altdeutscher Thongefässe in Kalktuff bei Lenglern ist die erste sichere Erfahrung über das Vorkommen von Kunst. Produkten in den Tuff-Ablagerungen der Göttinger Gegend, und um so beaclutungswerther, weil einerseits über die Periode der Entstehung jenes, in Leinethal weit verbreiteten Gebildes ein neurr Aufschluss, und andererseits die erste Kunde darüber erlangt wird, dass diese Gegenden bereits von Menschen bewohnt waren, als hinsichtlich des Bodens und der belebten Geschöpfe noch ein von dem gegenwärtigen abweichender Zustand herrschte: Bei Weende am Fusse des Hainberges u. a. e. a. O. sind zuweilen Aschenkrüge in der Nähe des Kalktuffs, aber stets üb er deniselben gefunden. Die bei Lengler'n im Innern des Kalktuff - Lagers entdeckten Überreste stamnen claher aus einer sehr viel früheren Zeit als jene Gefässe; denn Jahrhunderte müssen über die Bildung der bedeckenden Tuffmasse und über die Aufschwemmung der mächtigen Dammerdeschicht verstricheu seyn. Indessen

*) Bei einem dieser Abdrücke beträgt die grōsste Breite der einzelnen Schalen ur ${ }^{11} \int_{2}$ Pur. Zoll, die Länge aber nicht weniger als 6 Zoll. Diese einzelnen Scha. len laufen nach vorn hin sehr spitz zu, stehen zwei Zoll vom hinteren mehr ab. gerundeten Ende am niichsten zusammen, entfernen sich aber wieder an den Spitzen um $21 / 2$ Zoll von einander. Diese grosse Fährte muss noch dazu einem jüngeren Thicre angelıört lıaben, da die Spitzen der Schaleu durchaus nicht abge. rundet, sondern sehr scharf zulaufend sich darstellen. Ganz neuerdings sind auch Föhrten von einhufigen Thieren gefuuden, die indessen nicht scharf genug ausge. drückt sind, um eine genauere Bestimaung zu gestatten. 
unterscheiden sich die älteren Gefässe durch ihre Masse und Bildung nicht wesentrich von den neneren, wie auch in vorstehender Notitz bemerkt worden. Die grobe und unvollkommen verarbeitete Thonmasse enthält kleine Brocken von den Kalkstein- und Mergelarten, welche in der Gegend von Lenglern sich finden, und durch die ungleiche, im Ganzen aber schwache Einwirkung des Feuers erscheint die weiche, leicht zerbrechliche Hauptnasse in Innern bräunlich, röthlich, oder noch in der ursprünglichen Schwärze. Die Scherben sind von verschiedener Stärke; die meisten rühren von grossen Aschenkrügen ber; ein Bruch. stück hat einen enghalsigen Gefässe angehört. An mehreren Stücken hat die Aussenfläche verschiedenartige, eingeschnittene und eingestochene Verzierungen. - Die Auffindung von Thierfährten im Rossdorfer Kalktuff vermehrt die wenigen, mit Sicherheit bekannten, Erfahrungen von Spuren dieser Art, durch eine neue, völlig unzweideutige. Hinsichtlich derselben verdient besonders hervorgehoben $\mathrm{zu}$ werden, was sich übrigens auch schon aus obiger Mittheilung ergibt, dass sie die Fährten selbst und nicht, wie bei den im bunten Sandstein der Gegend von Hildburghausen gefundenen, die Ausfüllungen der Eindrücke darstellen *).

Eudès Deslongchamps: Abhandlung zur $\mathrm{N}$ a t u r ge s chich te der fossilen Krustazeen (Mém. de la Soc. Linn. de Normandie, $V, 1835>l^{\prime}$ Instit. 1836, I $\left.V^{\prime}, 133-134\right)$. Der-Verf. hat um Caen gefunden :

1) von Homolus: einen fast vollständigen, und am ehesten mit diesem Genus übereinstimmenden Cephalothorax zu Langrune in der über dem Polypenkalk liegenden, dem Pisolith der Engländer vergleichbaren Schichte; ein ähnliches, aber $1 \frac{1}{2}$ mal so grosses Stück in den Brüchen von Ranville, welche ebenfalls im Polypenkalk und Forestmarble stehen. Der Verf. nennt die Art H. A uduini.

2) Von Orithya: ein Exemplar, welches durch seine Schale und die Stellurfg der Warzen darauf zunächst mit 0 . ma xillaris Desr. übereinstimmt, aus der chloritischen Kreide der Vaches noires. $\mathrm{Zu}$ dieser Art gehört auch der Brustschild aus dem Grünsande von Lyme, welchen DE LA BECHE (in den Geulog. Transact. B, I, I) abgebildet, wesshalb die Art den Namen O. Labechii erhält.

3) Von ? Crangon: zwei Exemplare einer neuen Art, ?C. Magnevillii D., aus einem weichen, porösen, etwas grobkörnigen Gesteine

*) Indem nun die ausgemachten Erfahrungen von dem Vorkommen von Thierfährten in Gesteinmassen sich vermehren, verdienen auch einige frühere-, unbeachtet gebliebene Angaben darüber geprüft zu werden; und besonders dürfte das von Dr. PLAGge im Himnöverschen Magazin v. J. 1827 S. 476 beschriebene Vorkommen von Eindrücken der Füsse von versehiedenen Thiergattungen, und angeblich auch von Menschen, auf der Oberfäche des Flötzsandsteins am Istberge bei Bentheim eine gründliche Untersuchung verdienen [vgl. auch Jahrb. 183ذ, S. 628. D. R.]. 
bei Vaucelles und bei Venoix; und mehrere Bruchstücke derselben Art im Polypiten-Kalk bei Ranville. Das Verhältniss zwischen der Länge der Füsse ist nicht, wie bei den lebenden Arten des genannten Geschlechtes, wesshalb solche vielleicht ein neues Genus andeuten, dem der Verf. aber noch keinen Namen geben will, weil er über zu viele andere Charaktere nicht im Klaren ist.

4) Von Palinurus Regleyanus Desmar. Drei in Rollsteinen eingeschlossene Exemplare mit Brustschildern und Theilen von Füssen und Fülılern, welche nicht mehr zu zweifeln gestatten, dass jene Art wirklich zu Palinurus gehöre.

5) Von Pagurus: üfters das fünfte Glied der vorderen Beine (mit dem unbeweglichen Schenkel der Scheere), wonach der Verf. 3 Arten unterscheidet.

H. R. Göppert : Dank und Bitte an die Schlesier (Verhandl. d. Schles. Gesellschaft, 1835). Des Verfs. Arbeit ïber die Schlesischen fussilen Fahren ist zu einer allgemeinen Monographie sämmtlicher untergegangenen Arten geworden, deren 268 sind, wovon 96 in Schlesien vorkommen und 56 neu und Schlesien eigenthümlich sind. Diese Monographie umfasst 60 Bogen Text und 44 Tafeln mit 250 Figuren, wovon bereits 36 vollendet sind. Der Preiss wird so niedrig gestellt werden, da die Leopoldinische Akademie die Herausgabe übernommen und nur deren Kosten zu decken beabsichtigt, dass die Aaschaffung des Werkes leicht seyn wird. Eine ähnliche Ausdehnung dürften die übrigen Familien der vielen fossilen PHanzen Schlesiens erfahren. Gleichwohl sind noch grosse Striche dieses Landes, wo mehrere Formationen: das Übergangs - Gebirge, die Steinkohlen - Formation, die Kreide und die Braunkohlen Pflanzen-führend sind, noch fast ununtersucht, wie reichliche Unterstützung der Verf, auch seit einem Jahre von so vielen vaterländischen Naturforschern erfahren hat. Diese bittet er daher, ihr Augenmerk auch auf die übrigen Gegenden zu richten und geht sie mit allen übrigen an, seinem Werke vor dessen Herausgabe den möglichen Grad von Vollständigkeit zu geben, da ihm jeder auch der geringfügigste Beitrag bei der nunmehrigen allgemeinen Tendenz seines Werkes willkom. men seyn würde.

CoRtesi sulla scoperta del scheletro di un quadrupede colossale fra strati marini fatta in un colle del Piacentino (Piacenza). Es ist nach einem Berichte des Dr. Malacarne in der Biblioteca Italiana (1834, LXXV, 107 - 109), dass wir von dem Inhalte genannter Schrift Nachricht ertheilen. .Cortesi hat nämlich im Herbste 1831 abermals fossile Reste eines riesenmässigen Thieres entdeckt und zwar in einem röthlichen Sandboden über $1000^{\prime}$ hoch über dem Meeresspiegel auf dem 
Gipfel des Montegioco unmittelbar bei Castell' arquato unfern Velleji. Es sind einige Zähne, ein Halswirbel (?Atlas), der ganze Unterkiefer, ein Astragalus, ein ?'echter Femur, welche auf einem Raum von 18 nach allen Richtungen beisammen lagen, einem Thiere, wie die gröss. ten unserer Nashorne, angehört haben mussten und dem Verfo von Rhinoceros leptorhinus Cuv. herzustammen scheinen.

v. Sternerg: über verschiedene Fucoiden (Vortrag am 20. Sept. 1833 bei der Versamml. in Breslau; Isis 1834, S. 648-649). Zur Versammlung in Wien war vom Grafen Müsstek ein Fossil-Rest, bei Grabung eines Brunnens im Liasschiefer zu Banz gefunden, eingesendet worden unter dem Namen Algacites crispiformis v. Schцoтн., welcher inzwischen einer genauern Untersuchung unterworfen worden. Es zeigte sich denn bei der von Sternerg unternommenen Prüung sowohl, als bei der anatomischen Zerlegung durch Corda in Prag, dass diese Pflanze zwar durch ihre Ablosbarkeit vom Gestein und durch eine Art von Längenstreifung mit der Schlotheim'schen, Sphaerococcos crispiformis v. Sterno. (welche Brongniart nicht als Fucoide an. erkenmen will) übereiustimme, jedoch von ihr verschieden sey: im Baue sowohl als in Vorkommen, da diese andere früher in einem Braunkohleu-Schiefer am linken Ufer der Eger in Böhmen gefuuden worden, nun aber sammt der Berglehne in den Fluss hinabgerutscht ist. Die Abbildung soll in VII. Heft der Flora der Vorwelt nebst dem Ergebnisse der Cords'schen anatomischen Untersuchung über sie und eine ebenfalls ablösliche Fukoide von Monduinu bei Rimini mitgetheilt werden.

Sterninger theilte der geologischen Sozietät in Paris Zeichnungen seines neuen Halocrinites elongatus aus der Eifel und semer Helix Mattiaca aus dem tertiären Kalke von Wiesbaden mit (Bullet. géol. 1835, VI, 169-170, Tf. I, Fg. 11 und 12), die sich von H. verin iculata Drap. durch die Form des Peristoms und eine ziemlich grosse Nabelspalte unterscheidet, und mit den gewöhnlich ebendaselbst vorkommenden, zuweilen noch farbig gebänderten $H$. hortensis und H. nemoralis nicht zu verwechseln ist.

Marcer de Sernes: über die Unterscheidungs-Merkmale im Skelett [vielmehr im Schädel] des Hunds, des Wolfes' und des Fuchses (Biblioth. univers. 1835, LVIII, 230-245). 
H. Rathke: über fossile Knochen aus den Felsenhöhlen bei Schlangenbery - Smë̈nogorsk (N. Mém. de l'Acad. nat. Mosc. 1S3t, III, 265-280). Bei Smeänogorsk am Altri-Gebirge sind sehr geräumige Höhlen, welche Dr. GEBLER zu Barnaul bereits (im Bullet. de l'Acud. Musc. III, 232-2+0) beschrieben hat. In ihnen kommen viele Knochen vor. Einige von Bos und Equus stammend, aus der Tscharysch-Höhle hat FischER untersucht (Bull. III, 382-384). Reicher ist die Chanchura-Höhle, deren Knochen nun theils RatuкE hier, theils Fischer in einer nachfolgeuden Abhandlung beschrieben.

Die von Rathke untersuchten Knochen hatte Geblek theils schon 2 Jahre früher an Escнsсногтz, theils kürzlich an den Verf. eingesendet. Sic stammen von Hy ena, Ursus, Phinoceros, Bos und Equus. Sie waren nicht gerollt, aber, ausser jenen der Fusswurzeln und Zehen, alle zerbrochen, zum Theile schon ehe sie in der Höhle begraben wurden, ob aber durch das Gebiss von Raubthicren, konnte nicht deutlich ermittelt werden. Sie waren etwas kalzinirt, gelblich oder bräunlich, nicht nit Kalksinter überzogen, sondern bedeckt oder erfullt mit gelblicher Erde, und ihres thierisches Leimes nicht völlig ledig.

I. Hyaena spelaea. Eine rechte Unterkiefer-Hälfte, vorn und hinten abgebrochen, jedoch mit des 3 hinteren Backenzälnen, alles Erhaltene sehr ähnlich dem Fragmente von Gailenreuth (Cuv. oss. $\boldsymbol{\mu l}$. xxxir, fig. 1).

Länge vom Hinterrande der Eckzahn-Alveole bis zum Hinter.

Rande der 4ten Backenzahn-Alveole in Pariser Maas . $3^{\prime \prime} 5 \frac{1}{2}^{\prime \prime \prime}$

Breite des Astes am 2ten Backenzahn . . . . . . 1 $1^{\prime \prime} 6^{\prime \prime \prime}$

1 - - - - . . . . . . . $1^{\prime \prime} 10_{2}^{111}$

Zweiter Backenzahn lang . . . . . . . . . $11 \frac{1}{2}{ }^{\prime \prime \prime}$

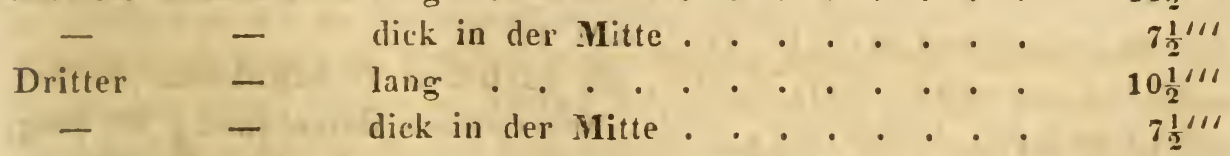

2) Ein Eckzahı der linken Seite: ganze Länge . . . . 2 " $4^{\prime \prime \prime}$

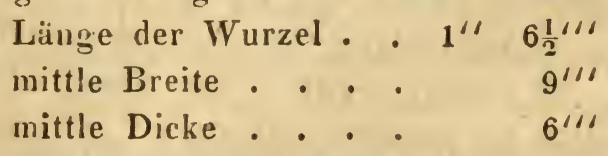

3) Ein Oberkiefer-Stück mit dem dritten Backenzahne

Zahn: Höhe der Krone . . . . . . . . $8 \frac{1}{2}{ }^{\prime \prime \prime}$

Läıge derselben . . . . . . . . . 1" $1^{\prime \prime \prime}$

Länge der grössten seiner 4 Wurzeln . . . 9 9 9

4) Ein erster obrer Backenzahn: Höhe der Krone 9"', Dicke 6"'.

5) Eine Tibia, deren obres Gelenkstück abgebrochen ist.

Alle Zähne sind sehr abgenutzt, mithin von einem alten Thiere, an Form und Grösse verschieden von denen der 3 lebenden Arten, übercinstimmend mit H. spelaea.

II. Ursus: Ein sehr grosser Eckzahn, dessen Krone, obschon 
an der Spitze etwas abgenutzt, im Verhältnisse zu ihrer ganzen Länge weit dicker ist, als bei U. arctos und U. maritimus.

Ganze Länge . . . . . . . 3". $7^{\prime \prime \prime}$

Länge der Wurzel allein . . . . . 2". $4^{\prime \prime \prime}$

Grösste Breite derselben (obschon beschädigt) 1". $1^{\prime \prime \prime}$

Grösste Dicke derselben . . . . . $9 \frac{1}{2}{ }^{\prime \prime \prime}$

III. Rhinoceros tichorhinus Cuv.

1) Zwei abgenutzte (wahrscheiulich Milch-) Backenzähne, ähnlich denen bei Cuvikr (II, pl. II, fig. 1, 2, 5).

2) Ein rechter und ein linker sehr wohl erhaltener Talus, jeder $3^{\prime \prime}$ breit und hoch.

3) Ein äusserer linker Metacarpus, lang . . . . . . 5 $5^{\prime \prime} 6^{\prime \prime \prime}$ breit in der Mitte. . $1^{\prime \prime} 8^{\prime \prime \prime}$ dick daselbst . . . 1"

Die drei letzten Stücke sind ganz ähnlich den entsprechenden bei dem in Sibirischem Eise gefundenen Nashorne, und Abbildungen żufolge sehr verschieden von denen der Flusspferde, Tapire, Anoplotherien und Paläotherien.

IV. Equ u s.

1) Siebzehn verschiedene Backenzähne, von der Grö́sse wie bei einer unserer mässig grossen Rassen, auch ihnen ähnlich, aber schärfer ausgeprägt und insbesondere die Leisten auf der äusseren Fläche sehr viel stärker hervorragend.

2) Linker Talus : breit an der untern Gelenkfläche $2^{\prime \prime}, 1 \frac{1}{2}^{\prime \prime \prime}$, in der Nitte $2^{\prime \prime}$, hoch bis $2^{\prime \prime} 4^{\prime \prime \prime}$.

3) Ein etwas kleinerer.

4) Ein rechter Metacarpus: lang $8^{\prime \prime} 6^{\prime \prime \prime}$, am oberen Gelenkrand breit 1" $4^{\prime \prime \prime}$, dick $1^{\prime \prime} 3 \frac{1}{2} " \prime$; - in der Mitte breit $1^{\prime \prime} 6^{\prime \prime \prime}$, dick $1^{\prime \prime} ;$ - am untern Gelenkrand breit 1" $11^{\prime \prime \prime}$, dick 1" 6"

5) Ein etwas kleinerer, rechter, mit ähnlichen Verhältnissen.

6) Ein linker Metatarsus, doch ohne unteren Gelenkrand, 8" lang, oben $2^{\prime \prime}$ breit und $1^{\prime \prime} 7_{2}^{1 / \prime \prime}$ dick.

7) Untre Gelenkstücke von einem Metatarsus und einem Metacarpus.

8) Untere Hälfte einer linken Tibia, am Gelenkende breit $2^{\prime \prime} 10^{\prime \prime \prime}$, dick am äusseren Rande $2 " 2^{\prime \prime \prime}$, am innern $2^{\prime \prime} 9 \frac{1}{2} "$.

9) Obrer Phalanx des Hinterfusses $2 " 11^{\prime \prime \prime}$.

Alle diese Theile $(2-9)$ ganz übereinstimmend in Form und Grösse mit den gleichnamigen bei unsern Pferden mittlen Schlages.

V. B o s.

1) Ein letzter und ein vorletzter Backenzahn aus einem linken Unterkiefer; der letzte hoch $2^{\prime \prime} 6^{\prime \prime \prime}$, lang $1^{\prime \prime} 6 \frac{1}{2} " \prime$, breit an der Basis 9 ", vorn $6 \frac{1}{11 \prime \prime}$; - der vorletzte hoch $2^{\prime \prime} 6^{\prime \prime \prime}$, lang $1^{\prime \prime} 2 \frac{1}{2} " \prime$, breit an der Basis [?] 1" 11"', vorn 7". Ziemlich übereinstimmend mit den ihnen entsprechenden Zähnen bei Bos Urus, aber an der Basis dicker und an der Krone viel schmäler. Von den Zähnen der Hirsche weit mehr verschieden. 
2) Zweiter Backenzahn des rechten Unterkiefers, etwas beschädigt, hoch ...., lang $1^{\prime \prime}$, breit $7 \frac{1}{2}{ }^{\prime \prime \prime}$. Kaufläche sehr abgerieben und verhältnissmässig viel breiter, als beim Auer- und beim. Haus-Ochsen.

3). Zwei Metatarsi ausgewachsener Individuen, doch das obere Gelenkstück abgebrochen.

A. B.

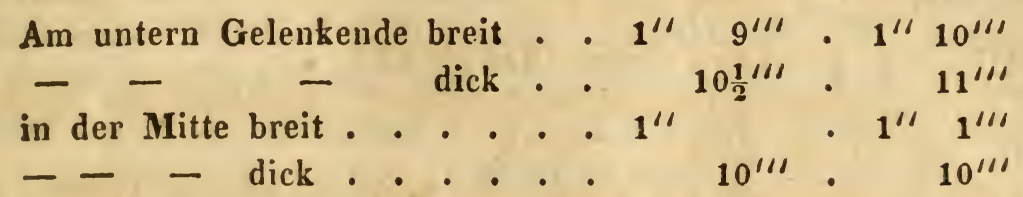

Beide schlanker, als bei einer Holländischen Kuh, ihre Hinterseite nicht tief gefurcht, wie bei Hirschen, sonderis platt, und die Grube der rechten und linken Seite des unteren Gelenkstückes weniger tief.

4) Zwei untre Hälften von Metacarpus, der eine a) am Gelenkende 2", der andere b) $=3$ " $10^{\prime \prime \prime}$ breit und dieser $1^{\prime \prime} 9^{\prime \prime \prime}$ in der Mitte dick.

5) Unterhälfte eines Metatarsus, am Gelenkende $3^{\prime \prime}$ breit, in der Mitte $1^{\prime \prime} 6^{\prime \prime \prime}$ dick.

6) Untre Hälften von 4 Tibien

A. u. B.

C.

D.

Gelenkende breit . . . . $3^{\prime \prime} \quad$. $2^{\prime \prime} 9^{\prime \prime \prime}$. $2^{\prime \prime} 5^{\prime \prime \prime}$

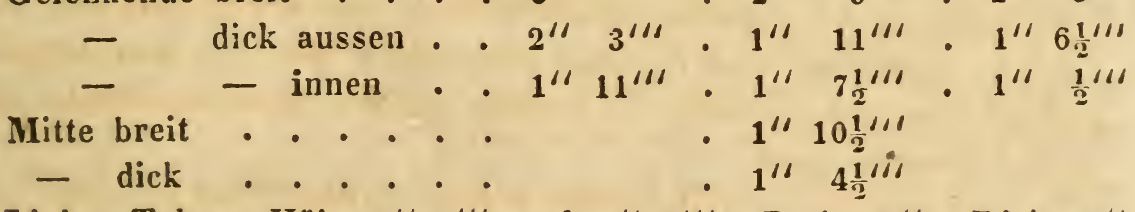

7) Linker Talus: Höhe $3^{\prime \prime} 4^{\prime \prime \prime}$ und $3^{\prime \prime} 3^{\prime \prime \prime}$, Breite $2^{\prime \prime}$, Dicke 1" $6 \frac{1}{2}{ }^{\prime \prime \prime}$. Ein anderer ist etwas kleiner.

8) Zweiter Phalanx des Vorderfusses 1" 11" lang, an beiden Enden $1^{\prime \prime} 6 \frac{1}{2} "$ " breit.

Die von $4 \mathrm{~b}$ an bis 8 aufgezählten Reste stammen von einer $0 \mathrm{ch}$ sen-Art, welche dem Auer-wie dem Haus-Orhsen an Grösse überlegen gewesen, und rühren viclleicht von Bos prinigenius her, wovon Schädel kürzlich in Sibirien gefunden worden seyn sollen. Der Phalanx ist auch jenem von Jena (Bojax. in Act. Leopold. XIII, II) sehr ähnlich. Dagegen müssen die Theile 3 und 4 a einer weit kleiner Art eigen gewesen seyn.

Ausserdem lagen noch cinige andere für die nähere Bestimmung allzusehr beschädigte Knochen, wahrscheiulich von Ochs und Pferd, in der Sammlung.

G. Fischer von Waldhem: Untersuchungen über die fossilen Knochen in Russland, Nr. II (Nouv. mém. acad. nat. Mosc. 1834; III, 281-298). [Vgl. Jahrb. 1835, S. 616.] Paleas hatte in Sibirien bereits mehrere Knochen-Höhlen beobachtet. Die Höhle JamaséTasch („Felsmauer") zwischeu Orlofka und Schaitan-Aul, welche sehr 
geräunig ist und bei [in ?] welcher der Sym-Fluss über eine Werst weit durch Kalk-Gebirge unterirdisch fortfliesst, ist sehr feucht: Wasser tropft überall von ihrer Decke lind bildet an der sudlichen Seite kleine Stalaktiten. In ihrem N.W.-Theile kommen viele Gebeine von Menscher, Pferden, Rehen u. a. Thieren vor; aber diese Höhle ist von Baschkiren früher bewohnt gewesen (PaLLAs II, 455). - Die Höhle von Kisrietasch am linken Ufer des Juriusen enthält viele Knochen, aber auch Russ, Schafdung und andere Anzeigen, dass sie bewohnt gewesen. - Die Höhlen von Läkle, von der Inia u. a. haben Paldas nichts Merkwürdiges dargeboten. - - Andere Hühlen, deren fossile Kuochen auf ein höheres Alter schliessen lassen, hat nun vor einigen Jahren Gebler besucht und die einen an 'Tschurych (in Bulletin der Akademie, III, 232) beschrieben. Sie liegen auf dem rechten Ufer des Tscharych bei dem Dorfe Tschagyrskaia, 90 Werst S O. von Sméinugorsk in einem aus N.O. nach S.W. ziehenden Kalkberge, welcher blaues und grünes Kupfer-Karbonat, Schwefelblei, weissen Bleispath, Silber u. s. w., aber keine Versteinerungen enthält. In einer derselben kommen fossile Knochen vor. - Die andern dieser Höhlen liegen am kleinen Flusse Khanhihra, welcher in die Iria niiesst, die sich selbst in den Tscharych ergiesst, und etwa 27 Werst von Tschaguirskail entfernt; die eine ist $12 \mathrm{~W}$. von der Mündung des Baches in einen steilen Kalkberge; ihr Eingang befindet sich an der Nordwest - Seite desselben, 20 Toisen über dem Bache, ihr Boden ist fast horizontal; sie geht 7 Toisen weit gerade aus, dann nach N.O., nach 0 , nach N., nach $O$. und wieder nach N.N.O. Ihre ganze Länge ist $37 \mathrm{~T}$., ihre Breite $1 \frac{1}{2}-3 \mathrm{~T}$., ihre Höhe $1-1 \frac{1}{2} \mathrm{~T}$. Links steht sie mit einer andern, eben so grossen Höhle in Verbindung. Alle Vertiefungen ihres Bodens sind erfüllt mit Thon, welcher bis $1 \mathrm{~T}$. nächtig und besonders in seinen obern Schichten voll fossiler Kuochen ist. Sie liegen in der ganzen Ausdehnumg der Höhle ohne alle Ordnung durcheinander. Wo die Thonschicht dünne wird, erscheinen sie zuweilen an der Oberfäche. Die Knochen sind besser erhalten, als in obiger Höhle: es sind vorzugsweise Zähne, Kinnladen - selbst ganze Sclıädel - und Fusswurzel- und Zehen-Glieder, von Herbivoren sowohi, als von Raubthieren, einige von sehr kleinen Arten. Von dieser Höhle aus kann man eine andere sehen, welche sich gleich am Eingange $4 \mathrm{~T}$. tief steil hinabsenkt und ganz mit Thon, der nur wenige Knochen enthält, angefüllt ist. - Endlich finden sich in dieser Gegend noch 2 audere, aber nur kleine Höhlen.

Unter den aus dieser Höhle stammenden Knochen hat der Verf. folgende Reste erkannt:

I. Arctomys, Murmelt hier.

1) Ein fast vollständiger Schädel (Tf. XXI, Fg. 1, 2), woran nur die Schneidezähne, die Nasen- und Intermaxillar-Beine fehlen. Er hat je 5 Backenzähne mit 3höckerigen Kronen. Der Schädel gleicht dem des A. B o b a c, ist aber mehr verlängert, das Hinterhaupt breiter, die 
Parietal- und Occipital - Leisten sind höher, der Jochbogen stärker. Er hat folgende Dimensionen :

Von der Hinterhaupt-Leiste bis zur Nasenbein-Naht o . $2^{\prime \prime} 6^{\prime \prime \prime}$

Unten, vom Rand des Ausschnittes des Hinterhaupt.Lochs

bis zur Incisiv-Naht . . . . . . . . . . $2^{\prime \prime} 9^{\prime \prime \prime}$

Länge der Parietal-Leiste . . . . . . . . . $1^{\prime \prime} 3^{\prime \prime \prime}$

Breite des Hinterhaupt-Beines . . . . . . . . . $1^{\prime \prime} 7^{\prime \prime \prime}$

Höhe desselben mit dem Hinterhaupt-Loche . . . . $1^{\prime \prime} 8^{\prime \prime \prime}$

Länge des Basal-Beines . . . . . . . . . . . 7 g

- - Gaumens . . . . . . . . . . . . . $1^{\prime \prime} 4 \frac{1}{2}{ }^{\prime \prime \prime}$

- - Alveolar-Raumes . . . . . . . . . $11^{\prime \prime \prime}$

Abstand des Jochbogens vom Schädel . . . . . 9 9 9

2) Rechter Unterkiefer-Ast, ohne Gelenkkopf (XX, 5) mit einigen hinteren Mahlzähnen:

Länge des Bruchstücks . . . . . . . . . . $2^{\prime \prime} 3^{\prime \prime \prime}$

Höhe hinten . . . . . . . . . . . . . $99_{2}^{1}{ }^{\prime \prime \prime}$

- beim zweiten Mahlzahn . . . . . . . $7^{\prime \prime \prime}$

II. Myoxus, Siebenschläf er (XX, 1,2,3).

1) Ein Schädel, grösser als bei M. Glis. Die Schneidezähne haben vorn der Länge nach eine eingedrückte Linie; Backenzähne sind 3, von vorn na:h hinten an Grösse abnehmend. Seine Länge ist

von den Hinterhaupt-Gelenkköpfen bis zur SchncidezahnSpitze . . . . . . . . . . . . . $1^{\prime \prime} 9^{\prime \prime \prime}$

von der Hinterhaupt-Leiste bis zum Nasenbéin-Ende . . $1^{\prime \prime} 4_{\frac{1}{2}}^{\prime \prime \prime}$

Länge der Interparietal-Beine . . . . . . . . $4^{\prime \prime \prime}$

- - Parietal-Beine. . . . . . . . : . $\mathbb{4}_{3}^{11 \prime \prime}$

- des Stirnbeines . . . . . . . . . . . $3^{\prime \prime \prime}$

- der Nasenbeine . . . . . . . . . $5^{\prime \prime \prime}$

Höhe des Occipital-Beins . . . . . . . . . $11^{\prime \prime \prime}$

Breite - - . . . . . . . . . . $1^{\prime \prime} 1^{\prime \prime \prime}$

Länge des Alveolar-Raudes . . . . . . . . . 4 $4^{\prime \prime \prime}$

Sänge der Pauke . . . . . . . . . . . $4_{4}^{3}$. .

Zwischenraum zwischen deren beiden innern Enden . . $2^{\prime \prime \prime}$

Länge des $Z_{\text {wischenkieferbeins unten }}$. . . . . . $\quad 4^{\prime \prime \prime}$

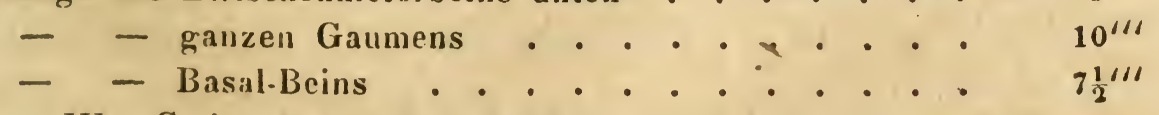

III. Cricetus, Hamster.

1) Ein linker Unterkiefer-Ast (XX, 8). Die hinteren Anbänge sind weniger lang und gekrümmt, als an der lebenden Art.

Seine Länge ist . . . . . . . . . . . 1" $1^{\prime \prime \prime \prime}$

Höhe bei den hintern Ästen . . . . . . 6 6 6"

- - dem 1ten Mahlzahn ... . . . . $\mathbf{4}^{\prime \prime \prime}$

- bis zur Spitze des Schneidezahns . . . . 6 $6^{\prime \prime \prime}$

2) Ein anderer Ast ohıe Backen-Zähne $(\mathrm{XX}, 6)$ vom uämlichen Thiere? 


\section{$-484$}

IV. Mus, Ma us.

1) Ein Unterkiefer-Ast ohne Backenzähne, wie es schcint, vom Subgenus Hypudaeus.

V. Putorius, Iltis.

1) Ein Schädel, dessen Theile mehr, als beim gemeinen lltis, ausgeprägt sind (XXI , 3,4). Die Parietal-Leiste beginnt vom Stirnbeine an, verlängert sich über das Parietal-Bein und geht in eine kurze aber hohe Leiste des Hinterhaupt - Beines über. Die Glenoid-Höhle ist, Alles gegen den gemeinen Iltis verglichen, länger und breiter und der Schläfenfortsatz, welcher sie aufninmt, viel grösser, die Pauke schmäler, in Form einer mehr verlängerten Röhre, der äussere Gehöhrgang gerundet mit dünnen Wänden. Alle Nähte sind bereits verschwunden. Die Ausmessungen ergeben:

vom Hinterhaupt-Kondylus bis zum Schneidezalın-Rand . $3^{\prime \prime} 6^{\prime \prime \prime}$ von der Hinterhaupt-Leiste bis zum Nasenbein-Rand . . $3^{\prime \prime} 4^{\prime \prime \prime}$

Länge der Hinterhaupt-Leiste . . . . . . . . $5 \frac{1}{2}{ }^{\prime \prime \prime}$

Höhe derselben . . . . . . . . . . . . $22_{2}^{1111}$

Länge des Gaumens . . . . . . . . . . . . $1^{\prime \prime} 9^{\prime \prime \prime}$

vom Ausschnitt des Hinterhaupt-Loches bis zum Hinter-

Rand des Gaumens" . . . . . . . . $1^{\prime \prime} 5^{\prime \prime \prime}$

Länge der Glenoid-Höhle . . . . . . . . $7^{\prime \prime \prime}$

Breite derselben . . . . . . . . . . . . $2^{111}$

Alveolar-Rand vom Höckerzahn bis zum Eckzahn . . . $1^{\prime \prime} 1^{\prime \prime \prime}$

Länge der Eckzahn-Alveole . . . . . . . . $3^{111}$

Breite des Höckerzahns . . . . . . . . . $4 \frac{1}{2}^{\prime \prime \prime}$

dessen grösste Länge . . . . . . . . . . • $3^{\prime \prime \prime}$

2) Ein Unterkiefer ( $\mathrm{XX}, 4)$ eines andern Individuums, dessen Gelenkkopf und aufrechter Ast stärker, als beim gemeinen Iltisse sind.

VI. Ursus, B är. Ein untrer Eckzahn (XXII, 5), unter den von RathKe untersuchten Resten etc.

VIf. H y a e $\mathrm{n}$ a.

1) Rechte Unterkiefer - Hälfte (XX, 1) völlig wie jene bei Cuvier (oss. III, pl. xxix, Fg. 14).

2) Ein obrer Eckzahn (XX, 3) 2" 6"l lang, und bei der Basis der Wurzel $9^{\prime \prime \prime}$ breit. Denn ein kleinerer (Fg. 4) von einem jüngern Thiere ciner andern Art.

3) Ein hinterer Backenzahn $(\mathrm{XX}, 2)$ ist mit der stärksten Wurzel $1^{\prime \prime} 10^{\prime \prime \prime}$ hoch, die Krone 1" $2 \frac{1}{2} "$.

VIII. Rhinoeros.

1) Viele Backenzähne, wovon aus dem Oberkiefer der zweite, ein Milchzahn von $1^{\prime \prime}$ Breite aussen, $1^{\prime \prime} 3^{\prime \prime}$ Breite innen, $1^{\prime \prime} 1^{\prime \prime \prime}$ Länge von vorn nach hinten und $1^{\prime \prime} 10^{\prime \prime \prime}$ Höhe mit der stärksten Wurzel (XXIII, 3, 4), - der dritte linke von $1^{\prime \prime} 5^{\prime \prime \prime}$ äusserer Breite, $1^{\prime \prime} 4^{\prime \prime \prime}$ innerer Breite, $1^{\prime \prime} 5^{\prime \prime \prime}$ mittlerer Länge und $1^{\prime \prime} 9 \frac{1}{2} " \prime$ Höhe mit der Wurzel (XXIII, 5, 6), - und der fünfte oder letzte linke (XXIII, 1, 2) 
von 1" $11^{\prime \prime \prime}$ äusșere Breite, $1^{\prime \prime} 7^{\prime \prime \prime}$ innerer Breite und $2^{\prime \prime} 3^{\prime \prime \prime}$ Höhe nit der Wurzel abgebildet sind.

1X. Bos, $\mathrm{O} \mathrm{chs}$.

1) Ein linkes Oberkiefer-Stück mit dem 3.-5. Backenzahne (XXIV, 7), welche viel grösser als beim gemeinen Ochsen sind. Die Krone des linken Backenzahns ist $11^{\prime \prime \prime}$ hoch, $9 \frac{1}{2}^{\prime \prime \prime}$ breit, und von vorn nach hinten $1^{\prime \prime} 1 \frac{1}{2}$ "' lang.

2) Trümmer eines linken Unterkiefer-Astes mit dem 4.-6. Backenzahn (XXIV, 2). Die Krone des vierten ist $10^{\prime \prime \prime}$, die des fünften $1^{\prime \prime}$ $1^{\prime \prime \prime}$ lang, und bei beiden $6^{\prime \prime \prime}$ breit.

3) Der letzte untre Backenzahn (XXIV, 3) ist nicht breiter als die untere Backenzähne überhaupt, $9^{\prime \prime \prime}$ lang und mit der kleinern Wurzel $2^{\prime \prime} 7^{\prime \prime \prime}$ hoch.

4) Ein Astragalus so gross, als der von RAtнкE unter Nr. 7 beschriebene.

Ausserdem sind die Knochen des Bos latifrons Frscir. (Bull. I, 81 , pl. II) in Sibirien ziemlich häufig; seltener aber werden an den Küsten solche des B os canaliculatus Fiscr. (ib. 85, pl. III) gefunden; neuerlich hat der Verf. jedoch auch den Stirn - und HinterhauptTheil eines Schädels dieser Art aus der grossen Schlucht von Chablowa, 5 Werst von Moscau erhalten, der etwas kleiner als die Sibirischen und noch mit viel engerem $Z$ wischenraume zwischen den Hörnern versehen ist; eine Abbildung desselben befindet sich in der „Oryctographie de Moscou" (pl. III, b). Die Ausmessungen der Schädel dieser Art sind :

aus
Sibiriea, Mon

von der Hinterhaupt-Leiste bis in die Mitte des

Stirnbeines ..... . . . . . $\mathbf{1 1}^{\prime \prime} 2^{\prime \prime \prime} 8^{\prime \prime} 7^{\prime \prime \prime}$

Länge der Basis der Hörner .. . . . . $8^{\prime \prime} 8^{\prime \prime \prime} 5^{\prime \prime}, 8^{\prime \prime \prime}$ - des Kanals zwischen ihnen .. . . . $7^{\prime \prime} \quad 6^{\prime \prime}$

Breite desselben in der Mitte . . . . . $5 \frac{1}{2}^{\prime \prime \prime} 4^{\prime \prime \prime}$ - vorn und hinten ... . . $1^{\prime \prime} 1^{\prime \prime \prime} \quad 11^{\prime \prime \prime}$

Höhe des Kanals bis zur Basis der Hörner . . 11"' $\mathbf{7}^{\prime \prime \prime}$

- Hinterhaupts vom obern Rande des Occipital-Lochs bis zu Leiste . . . . . $4^{\prime \prime} 5^{\prime \prime \prime} 3^{\prime \prime} 5^{\prime \prime \prime}$

Grösste Breite des Hinterhaupts . . . . . $8^{\prime \prime} 2^{\prime \prime \prime} 7^{\prime \prime} 6^{\prime \prime \prime}$

- Entfernung zwischen den Hörnern unten $13^{\prime \prime} 4^{\prime \prime \prime} 8^{\prime \prime} 6^{\prime \prime \prime}$ X. Cervus, Hirsch.

1) Ein Mahlzahn (XXIV, 4), wie es scheint, von C. megaloceros [? C. megaceros Hart.], ähnlich dem bei Buckind (Tf. IX, Fg. 1, 2). Ohne die Warzel ist er hoch $2^{\prime \prime} 8^{\prime \prime}$, breit $7 \frac{1}{8} "$ " und lang $1^{\prime \prime} 4^{\prime \prime}$. Ausserdem finden sich in Russland noch anderwärts fossile HirschReste. Im Gouvt. Casan sind in einer Mergelschichte Geweih - Stücke mit 2" 2" Durchmesser gefunden worden. - Im Gouvt. Tula auf den Güteru des Grafen Bobrinsur sind Hirsch- und Rennthier-Knochen 
im Torfe vorgekommen. - In Liefland beim Flusse Felline hat man eine schaufelförmige Geweihstange gefunden, welche zu einer eignen Art gehürt, welche Fischer Cervus Fellinus genannt hat (Bullet. 1831, III, pl. II). - Bei Wereia, Gouvts. Moskwa, ist ein ElennSchädel vorgekommen, welcher nach der eingeschickten Handzeichnung davon zu C. megaloceros gehört. Er wiegt 1 Pud, 10 Pfund, ist $15 \frac{1}{4}$ Werschok laug und $5 \frac{1}{2} \mathrm{~W}$. breit. Die rechte Schaufel ist 1 Arschin $6 \mathrm{~W}$. lang, $9 \frac{1}{2} \mathrm{~W}$. breit, die Weite von einer Schaufel zur andern ist $1 \mathrm{~A} .11 \mathrm{~W}$.

XI. Equus, Pferd.

1) Mehrere Backenzähne, welche sich durch ihre Höhe und ihre starke Pippen auszeichnen (vgl. RathкE, S. 480). Einer der stärksten hat, obschon die Wurzel etwas abgebrochen, ist, 3 " 4 "“".

2) Ein sehr abgenutzter Eckzahn (XXII,6) hat noch 1"6" Höhe, die Krone 6" Breite; er ist sehr gekrümmt und das Loch in seiner Mitte sichtbar.

3) Ein noch problematischer Zahn (XXII, 7-9), ähnlich dem Schneidezahn eiues Pferdes, hat $1^{\text {" }} 9$ "' Länge, an der Krone 6" Breite, scharfe Ränder, aber nicht das gewöhuliche Loch in der Mitte.

Farines: Notiz über das neulich entdeckte Vorkommen von Lignit zu Puziols (Aulle) (l'Instit. 1834, II, 127-128). Diese Notiz ward bei der philomatischen Gesellschaft zu Perprignan vorgelesen. Das Braunkohlen-Gebirge wurde erst kürzlich zu Paziols bei Entstehung eines Wasserrisses, und in ansehnlicher Entfernung davon bei Anlegung eines Wässerungs-Grabens, an beiden Ufern der Vèrdouble entdeckt. Es besteht aus buntfarbigen Mergeln, Lehm und Sand, welche in 2 Meter dickep Lagen mit bräunlichgrauem Sandstein wechsellagern; - der Mergel ist reich an effloreszirendem Eisenkies; noch reicher der Saudstein. Das Dach bilden Alluvial-Geschiebe und darüber Süsswasserkalk. Die Sohle gekört zur Kreide-Formation. Die Lignite sind darin nicht Lager-, sondern Block-weise in allen Richtungen vertheilt, faserig, holzartig, von Stänmen, Ästen, Zweigen, Früchten, welche alle von Koniferen herzukommen scheinen. Man kamn unterscheiden:

1. F a scr-Lignit, Varietät $A$; schwarz, hart, Politur-fähig, sich dem Gagate nähernd, von Eigenschwere $=2$; in der Hitze Dampf und bituminösen sauer-stechenden Geruch verbreitend, mit Flamme verbrenuend bis auf 0,15 gelblicher eisenselsüssiger Asche. In Kontakt mit dem Sandsteine ist dieser Lignit oft von Eiseukies durchzogen, der die Rinde stelienweise zu ersetzen scheint, und sieh innerlich zu schünen Krystallen ausgebildet hat. Hin und wieder ist jedoch die ursprüngliche Rinde des Holzes erhalten, und die Epidermis löst sich leicht in Form bituminöser Kürnchen ab, welche den Bernsteine ana$\log$ sind. 
2. Faser-Lignit, Varietät B ; braun, zerreiblich, leicht zerreissend, viel minder hart, unter dem Messer zerbrechend; wird durch Schaben etwas glänzend, ohne Politur-fäbig zu seyn, hat 1,5 Eigenschwere; gibt in der Hitze wenig Danpf, brennt mit mehr Flamme und viel stärkerer Wärme-Entwicklung. Ausgetrocknet verliert er $\frac{2}{3}$ seines Gewichtes, und wenn man ihn nachher verbrennt, gibt er noch 0,12 gelbe ockrige Asche. Uberhaupt ist er reicher an Eisenkies, als der vorige.

Beiderlei Lignit-Arten kommen ohne Unterschied im Sandstein wic in den Thouschichten darüber und darunter vor, sind mithin gleiclizeitiger Bildung, beide von Stämmen wie von Zweigen entstanden. Konchylien kommen nicht damit vor. Sie liegen im Becken von Tuchan, das nur eine Abfluss-Rinue, das Bett des Verdouble, besitzt, vor dessen Bildung hier Süsswasser stagniren mussten.

J. Harr: Betrachtungen über den fossilen Hirsch von Irland: Cervus megaceros (Joun. of the Dublin geol. Soc. 1:33, I, 20-23). Dr. Mocrewux scheint der erste zu seyn, welcher (Plilosuph. Transuct. XLIX, 16:97) diese Art beschrieben, sie aber ihrer Geweihe wegen mit dem Nord-Amerikanischen Elen u oder Mo os e verwechselt hat. Das einzige ganz vollständige Skelett der fossilen Art ist vom Erz-Diakonus Mavrsell in Schnecken-Mergel unter Torf zu Rathcunnon bei Bruff in Limerick 1824 gefunden, der Dubliner königl. Gesellschaft geschenkt, vom Vf. aufgestellt und beschrieben worden. Das fossile Thier unterschejdet sich von der Amerikanischen Art auf folgeride Weise. 1) Seine Schaufeln werden nach aussen hin breiter, bei dieser sind sie innen am breitesten, Cuv.; 2) die Enden, welche aus den Schaufeln hervortreten, sind länger und schlanker; 3) die Schaufeln sind nach aussen, dort nach hinten gerichtet; die Geweihe sind viel grösser und dennoch der Schädel absolut kleiner: nur $1^{\prime} 10^{\prime \prime}$ statt $2^{\prime \prime}$ lang und zwischen den Geweilsen 4 " statt $6 \frac{1}{3}$ " breit, obschon diese mit ihren Spitzen $9^{\prime} 2^{\prime \prime}$ statt $3^{\prime} 7^{\prime \prime}$ weit auseinander stehen; 4) auch das Weibchen scheint, was Cuvien schon vermuthet, mit einem Geweihe versehen, welches dem der lebenden Art fehlt: jedoch ist dieses Gehörne kleiner, schlanker und gerader. Die Art wirft ihr Geweihe jährlich ab. 5) Die Knochen der Gliedmaasen sind stärker und dichter, als an der lebenden Art, um des schweren Geweihes ungeachtet, welches an dem Dubliner Exemplare 80 Pf. avoirdup. wiegt, kräftige Bewegungen vollbringen zu kömnen.

Der Fundort der fossilen Art ist a) Mergel, oft unter Torf, in Thälern abgesetzt, worin die Knochen am besten erhalten und nach ApJoHs's Untersuchung nur ihrer thierischen Materie beraubt sind; b) Torf selbst, worin dic Kuochen, welche durch freje Säure eineu 
grossen Theil ihrer unorganischen Bestandtheile verloren, eine Weichheit zu besitzen pflegen, welche der des frischen Torfes gleich ist, so dass man sie nicht aus demselben herausnehmen kann. c) In einem Falle war es lehmiger Sand eines Berges bei Enniskerry, $40^{\prime}$ hoch über dem Bache, woselbst die Knochen ebenfalls viel von ibrer thierischen Materie verloren $\mathrm{zu}$ haben scheinen.

R. E. Grant: über einen fossilen $Z$ ahn, der im rothen Sandstein über der Steinkohlen-Formation in Berwickshire gef unden worden (L'dinb. n. phil. Journ. 1833-1831, Nr. 31, S. 38-43). Dieser Zahn ist vom Lord GreEvor gefunden und für einen Fischzahn gehalten worden (I. c. Nr. 30). Cuxfre dagegen hatte ihn für den Eckzahn eines Wolfes erklärt, jedoch ohne ilnn geniggend aus dem Gesteine herausgearbeitet zu haben. Aber der Zahn ist schlanker, gerader, mehr zusammengedrückt, oben mit einer nur so dünnen und weichen Schmelzlage, dass das schlechteste Messer wie in Gyps einschneidet ${ }^{*}$ ); an âussern Rande der Basis seiner Krone ist er breit ausgefurcht; an der Basis der konkaven Seite breitet er sich plötzlicher aus. Die Eckzähne der Säugethiere liefern überhaupt die schlechtesten und trüglichsten Merkmale: sie sind am veränderlichsten bei einer und derselben Art, und wieder am ähnlichsten. bei Arten verschiedener Geschlechter und selbst Ordnungen. Nach ihnen folgen die Lückenzähne, daun die Schneidezähne, die Reisszähne; am besten sind die Höckerzähne. Der gegenwärtige Zahn besteht aus weicher KnochenMasse ohne Schmelz - Überzug, wic bei niedrigeren Wirbelthieren, ist inwendig an der Basis hohl, und zeigt auf dem Queerschnitte konzentrische Ringe um diese Basis, wie es bei keinem Säugethier, wohl aber bei Reptilien und Fischen gefunden wird; er ist ohne Wurzel, welche bei keinem Säugehtier-Zahne von dieser Form fehlen würde, um ihn in der Alvenle zu befestigen. Alle wesentlicheren Charaktere stimmen daher mit denen der Zähne von wohl tausenderlei $\mathrm{F}$ isch-Arten überein, so dass der Verf. nicht zweifelt, dass der fossile Zahn dieser Abstammung seye. So ist er namentlich den Zähnen von Lophius und von Lepisosteus sehr ähnlich; aber der Verf. hatte nicht Zeit genug, die Verwandtschaft der Fischart näher zu bestimmen, welcher dieser Zahn angehört haben mag.

Eichwald: kurze Notizen über einige vorweltliche Thiere der Polnisch-Russischen Provinzen (an die zoologische Sektion der Breslauer Versammlung 1833 eingesendet; > Isis 1834, S. ôs1-686).

*) Der Knochenkern der Zähne der Wirbelthiere mit warmem Blut ist hïrter, als der Schmelz bei den kaltblütigen, der bei den Fischen sogar oft gauz fehlt. 
1) Elephas (mamonteus Fiscri.) hat viele Reste geliefert, mit welchen insbesondere das Museum der medizinisch - chirurgischen Akademie in Wilna reichlich ausgestattet worden. Man fand a) StosszahnFragmente, Backenzähne u. a. Knochen an beiden Ufern der Wilna zu verschiedenen Zeiten; - b) einen über $3^{\prime}$ langen Stosszahn in der Swenta beim Dorfe Uschpole im Wilkomir'schen Kreise; - c) den Un. tertheil eines rechten Oberarms im Muchawetz im Kobryn'schen Kreise; - d) einen Unterkiefer aus dem Bug in der Byalistocker Provinz; e) einen Oberschenkel zu Hrynischki unfern Rossiene; - f) andere Knochen im Mosyr'schen Kreise des Rinske'schen Gouvts.; - g) einen schön erbaltenen Unterkiefer im Pinske'schen Kreise, u. A.

2) Elephas pygmaeus Fiscr. lieferte a) einen schönen obern vordern Backenzahn aus der Uscha beim Dorfe Obrynka in Lithauen; b) einen andern von Jatra im Grodno'schen Gouvt.

3) Elephas campylotes, Fiscr. ist noch seltener: nur Backenzahn-Fragmente sind von ihm vorgekommen; häufiger ist

4) Elephas proboletes Fiscr. gewesen. Einzelne Backenzähne aus Lithauen, insbesondere aus der Wilna. Ein schöner Unterkiefer mit den hinteren Backenzähnen ist mit einem Oberkiefer - Fragment mit 2 Backenzähnen, welche durch die schräge Stellung der auf der Kaufläche vorstehenden Schmelzfalten sehr bezeichnet sind, nebst einem Stosszahn-Stücke, mehreren Wirbeln, einer Rippe, einem Oberarm- und drei Fuss-Knochen im Lehme bei Sawadowze in Haysin'schen Kreise Podoliens gefunden worden.

5) Mastodon bietet Reste in Volhynien und Podolien, insbesondere eine halbe Unterkinnlade von M. medius E. aus Volhynien, im Volhynischen Lyceum aufgestellt, und durch ihre Zähne von Mi. giganteus Cuv. verschieden; - einen ungeheuren $Z$ wischenkiefer - Knochen $65 \frac{1}{2}$ Pf. schwer, mit beiden Stosszahn-Alveolen ohne Zähne, bei Rachnow Cassowy in Podolien nebst einem Schulterblatt-Stücke, Vorderarmbein-Presten u. s. w. gegraben, alle stark von Eisen durchdrungen und ersterer noch von einer Hornstein.Masse durchsetzt; - einen dreihügeligen Backenzahn, dem des M. giganteus am nächsten stehend, von Tultschin in Podolien, meist in Bojanus Sammlung. Getreue Abbildungen der interessantesten aller dieser Reste sollen in den Akten der Leopoldiner Akademie gelicfert werden.

6) Rhinoceros ist durch vollständige Schädel aus Volhynien (Lyzeum von Kremenez) und den linken vorletzten Oberkiefer-Zahn aus dem Minskischen Gouvt. angedeutet.

7) Equus. Zähne in grosser Mengè überall in Lithauen, von denen des lebenden Pferdes kaum zu unterscheiden. Ein HinterschädelTheil, von dem des letztern verschieden, ist bereits in des Verfs. „Zoologie" (III, 352) charakterisirt worden. Im südlichen Pudolien und Volhynien lebten zu Hemodot's Zeiten viele (weisse) wilde Pferde, die auch von dessen "Kallhippiden" viel gezogen wurden (Histor. lib. IV, 
cap. 32), wie nach Straeo der wilde Esel, Onager, welche beide Arten jetzt in den Osten des $K$ aspischen Meeres zurückgedrängt sind.

8) Dinotherium proavium E., grösser und sonst abweichend gegen die Deutschen u. a. Arten, hat ebenfalls zu Rachnow Cussuwy zwei untre Backenzähne, schwarz und schwer durch Eisen, hinterlassen. Der vordere ist dreihügelig und bis auf den Grund der Hügel abgenutzt, und dem Ural'schen Zahne bei Pallas (Act. Petrop. 1777, II, tb. rx, fig. 4) auffallend ähnlich; der hintre ist 2hügelig und wohl erhalten.

9) Bos primigenius Frscr. Reste in Lithauen bäufig, zumal beim Dorfe Hodycischki unfern Swienciany, und rücksichtlich seiner Hörner mit dem schönen Hasscebev'schen Shelette ganz übcreinstimmend. Dagegen sind fossile Auer-Knochen noch nirgend ausgegraben worden; aber es ist bemerkenswerth, dass nach Nicetas Choniates, aus dem Anfange des XII. Jahrbunderts, der Kaiser Androvikus Kominents sich i. J. 1312 viel mit Jagen und Durchstechen der "Z u m pre n" (jetzt in Polen Zubr, spr. Subr) in Tauroscythien oder der Krimm beschäftigte, von wo der Auer nun völlig zurückgedrängt ist bis zum nördlichen Abhang des Elbruz, jenseit des Kuban, woselbst er sich durch das ganze Land der Abchasen findet, die mit den Mingreliern sich, gleich den Germanen, seiner in Silber gefassten Hörner bei ihren Trinkgelagen bedienen.

10) Cervus Alces hat ein fossiles Geweibe in Gesellschaft von Elephanten Knochen am $\boldsymbol{B} u g$ in der Bialistocker Provinz, einer Gegend hinterlassen, wo jetzt diese Thiere nirgend mehr leben, obschon sie nach Jurrs CaEsar mit dem A uer zugleich den Herzynischen Forst bewohnten.

11) Von Cervus elaphus findet man viele noch sehr frische Geweihe in Lithunen, Vulhynien, im Biclowitzker Walde und in Porlo!ien, au Russischen Buy, obschon auch er jetzt ausgestorben. SrRabo (geogr. Bücher, edit Siebenkees p. 407) gedenkt ihrer noch mit wilden Schweinen, Eseln, Dorkadeu (Reh oder Antilope subgutturosa GüsD.) und dem Kolos (Antilope Saiga oder Scythica Palc.), von welchen heutzutage auch die Esel bis jenseits der Emba im N.O. des Kaspischen Meeres und in die Kirgisensteppe, jene erste Antilope bis in die Steppen westiich vom dem Kaspischen Meere und gegen Persien verdrängt ist, die letzte aber nur vom Dniepr theilweise gegen Süd-Podolien und die Ukraine zurückgewichen ist. Ost-Europor ist reicher an Elephanten Pesten und denen einiger anderen Pachydermen; der Westen hatte mehr Raubthiere, Palae otherien, Anoplotherien u. s. w.

Marcer, de SERHes: Benerkungen über die grossen Höhlenbär-Arten (Biblioth. univers. 183.5, LVIII, Scienc. et Arts, 
171-191). Schon i. J. 1826 hatte der Verf. eine dritte grosse Höhlen bär-Art, den Ursus Pittorii zu den zwei bereits bekannten, dem U. spelaeus und dem U. arctoideus hinzugefügt, aber ihm bypothetisch eine gewölbte Stirne zugeschriebẹn, in welchem Irrthum ihm auch Junes Prctet gefolgt ist, als er die Reste des U. s pela a u s von Mialet ${ }^{*}$ ) zu U. Pittorii rechnete. Da der Verf. seitdem in den Besitz von 12 Schädeln dieser 3 Arten aus der Höhle von Fausan oder der Minerva (Hérault), aus denen von Mialet, Jobertus (Gard) und von Nabrigas (Lozère) gelangt ist, so ist er nun im Stande, den Irrthum aufzuklären.

1). U. spelae us unterscheidet sich von allen bekannten Arten vermittelst seiner durch zwei nebeneinanderliegende Höcker stark aufgetriebenen und daher vorn steil absetzenden Stirne, zwischen welchen Höckern eine Vertiefung von der Verbindung des Stirnbeines mit den Wandbeinen hinten bis zu den Nasenbeinen vorn herabzieht. Jene Wölbung fiudet nur bei unserem lebenden U. arctos, aber in viel geringerem Grade noch Statt, bei U. aretoideus ist sie schwach, bei U. Pittorii gar nicht vorhanden. - 2) Der Postorbital-Fortsatz des Stirnbeines ist bei $U$. spelaeus äusserst stumpf, und nur in seiner Fortsetzung, kurz ehe er sich mit dem der entgegengesetzten Seite zur Sagittal-Leiste vereinigt, nänlich erst über dem äussern Gebörgange, mehr bemerkbar. Er ist bei U. arctoideus etwas, bei U. Pittorii viel stärker. - 3) Der zwischen beiden Seiten - Leisten liegende Winkel ist beim erstren spitzer und reicht weiter nach hinteu, als an irgend einer andern Art, und der wirkliche Aufang der Sagittal - Leiste kommt esst über deu Kronen-Furtsatz des Unterkiefers zu liegen. Beim U. a r cto ide us licgt jener Winkel weiter vorn, und die Stirne bildet ein gleichschenkeliges Dreieck; bei U. Pittorii liegt er am weitesten vor, so dass die Stirne ein gleichseitiges Dreieck darstellt und die SagittalLeiste an längsten erschcint. - 4) Die Verläugerung der ungeheuren Sinus frontales bis zum Hinterhaupt-Beiue veryrössern die Ausdchnung des Antlitzes bei U. spelaeus eben so sehr, als sie die Gehirnhöhle verengeru und zurückdrängen. - 5) Die Occipito-Parietal-Leisten sind stark, doch nicht in dem Grade wie bei U. Pittorii entwickelt; dagegen ragen die Wandbeine vorn, nächst ihrer Verbindung mit dem Stirnbeine und etwas über dem schuppigen Theil des Stirnbeine's und der Keulbein-Fliigel an U. spelaeus "unendlich “ viel weiter auseinander, als bei $\mathrm{C}$. Pittorii, verhältnissmässig etwa so weit, als bei U. a r ctoideus. Die Augenhühlen sind bei U. spelaeus heiter, bei U. Pittorii länger. - 6) Legt man den Oberschädel des U. spelacus ganz horizontal, so trift eine Linie von der Occipito-Parietal-Vorragung aus senkrecht auf die Hinterhaupt-Gelenkköpfe. Bei U. Pittorii stehen diese weiter nach hinten, als bei den andern. - 7) Zwischen die. sen Köpfen and jener Vorragung befindet sich am Hinterhaupte des

*) Siehe Jahrb. 1837, S. 245 if. 
U. spelaeus jederseits, an der obern oder hinteren Fläche des Occipitalbeines, eine sehr deutliche Grube, und die Muskel-Eindrücke am Rande der 2 Seiten - Leisten des Hinterhauptes sind weniger stark und zahlreich, und jene auf der Hinterhaupt - Fläche selbst viel minder deutlich, als bei U. Pittorii, dessen Kopf- und Hals -Muskeln stärker waren; diese Vertiefungen alle sind bei U. Pittorii viel geringer und bei U. arctoideus ist das Hinterhaupt ganz flach. - 8) Die Gegend an der Wurzel der Nasenbeine ist bei U. spelaeus eingedrückt, so dass sich diese nach vorn zu erheben scheinen, während sie bei U. a rctoideus fast horizontal sind, bei U. Pittorii aber sich nach vorn senken, und daher der Schnautze ein schlankes und spitzes Ansehen geben; und die vorderen Nasenöffnungen sind von vorn nach hinten mehr verlängert, als bei U. Pittorii, zwischen welchem und jenem andern in dieser, Beziehung der U. arctoideus gewisser Maasen das Mittel zu halten scheint. Die Schnautze hat bei jenen beiden Arten gleichen Unfang, ist aber bei U. Pittorii länger, mithin schlanker; der Abstand vom Suborbital-Loch und dem Vorderrande des Eckzahn-Alveole ist bei beiden gleich gross. - 9) Die Unterseite bietet keine erhebliche Verschiedenheiten und der Abstand der beiden Jochbogen ist verhältnissmässig gieich; aber die Breite des Schädels zwischen diesen Jochbogen ist an geringsten bei U. Pittorii, wesshalb diese abstehender und entwickelter scheinen. - 10) Der Abstand der innern Seiten der zwei Backenzahn-Reihen ist beim U. Pittorii an kleinsten, und beim U. a r ctoideus, obgleich sein Schädel kleiner als bei beiden andern ist, um 5 Millin. grösser, als bei beiden andern. - 11) Die ganze Länge der Backenzahn-Reihe ist bei dieser Art - auch verhältnissmässig genommen - viel kleiner, bei U. spelaeus kaum merklich grösser, als bei U.Pittorii und U. a r ctoideus. - 12) Der vorderste Backenzahn ist bei jenem fast so breit als lang, bei U. Pittorii viel schmäler als lang, wodurch er sich dem bei U. arctoide us viel mehr nähert. Auch der hinterste Backenzahn ist sich in beiden letztern Arten zienulich ähnlich, und zwar am hinteren Rande nit zahlreicheren runden Höckerchen gekrònt und auf der Kaufläche mit mehrfältigen erhabenen Ringchen versehen, als bei U. spelaeus. - 13) Der Abstand des Eckzahns vom vorderen Mahlzahn ist bei den zwei grösseren Arten fast gleich; beim U. a r cto ide us ist er viel kleiner, auch stehen sich bei ihm die zwei Eckzähne viel näher und sind selbst dünner als bei den andern; - die Schncidezähne bilden eine kürzcre Reihe. - 14) Bei U. Pittorii hatte der Verf. auch die Alveole des Lückenzahnes gefunden, welcher dem $U$. spelaeus immer, dem U. arctoideus wohl nur, wenn er nicht mehr ganz jung ist (wo er deren unten sugar 2 besitzt), zu fehlen pflegen; diese Alveole war $0 \mathrm{~m}, 008 \mathrm{lang}, 0^{\mathrm{m}}, 005$ breit und $0 \mathrm{~m}, 015$ tief, mithin keineswegs in Begriffe sich zu obliteriren, sordern einem bleibenden Zahne angehörig. - Auch der Unterkieter bictet mehrere Verschiedenheiten dar. 15) Beim U. spelacus ist er viel stärker, längs der Backenzähne böher und unten der Länge nach gewölbter; die Grube zur 
Befestigung des Masseter scheint viel stärker entwickelt. Die Symphyse ist viel länger, als beí $\mathrm{U}$.Pittorii, auch dicker; - der Kronenfortsatz ist gerader und breiter, vom Gelenkkopfe entfernter, und der Abstand der beiden Kinnladen in der Zahnlücke hinter dem Eckzahne viel be. trächtlicher, als bei U. Pittorii. - 16) Das hinterste der drei KinnLücher steht unter dem vordersten Mahlzahne, bei U. Pit torii und U. arctoideus vor ihm. - Bei U. arctoide us ist der Unterrand der Kinnlade ganz gerade und der Gelenkkopf kaum über der Kaufläche der Zähne. Der vorderste der falschen Mahlzälne unten, der Eckzahn und der hinterste Backenzahn sind grösser und stärker, als bei U. Pittorii, während der vorletzte Backenzahn bei beiden fast gleiche Dimensionen besitzt. Jener vorderste Backenzahn insbesondere ist bei $U$. spelaeus länger von vorn nach hinten, und stets mit 2 deutlichen Wurzeln versehen, welche bei U. Pittorii zusammenschmelzen. Die untern Schneidezähne sind bei U. spelaeus nicht allein merklich breiter, als die obern, sondern auch als jene des U. Pittorii, wo sie in einem vicl dünneren Kinne sitzen. Die Zahulücke hinter dem Eckzahn ist viel kürzer, als bei diesem letzten. - Bei U. arctoideus aber, wo alle Dimensionen um etwa $\frac{1}{5}$ kleiner, als an den zwei vorigen sind, ist die ganze Zahnreihe des Unterkiefers um den vordersten Backenzahn kürzer und alle Backenzähne sind schmäler; der Eckzahn immer viel schwächer; der erste Backenzahn hat gewöhnlich auch zwei getrennte Wurzeln, die indessen manclrmal zusammenschmelzen. - 17) Die Schädel im Ganzen betrachtet haben vom Schneidezahn-Rande bis zum Hinterhaupt-Höcker bei

$$
\begin{aligned}
& \text { U. Pittorii }=0^{\mathrm{m}, 509} \text { bis } 0 \mathrm{~m}, 549 \text { Länge und darüber, } \\
& \text { U. spelaeus }=0^{\mathrm{m}}, 475, " 0^{\mathrm{m}, 527}- \\
& \text { U. arctoideus }=0^{\mathrm{m}, 400 "} 0^{\mathrm{m}, 420}-
\end{aligned}
$$

18) Am bequemsten lassen sich mithin diese Höhlenbär - Arten so charakterisiren :

U. spe la e u mit gewölbter Stirne und dicker Schnautze,

U. P it torii mit flacher Stirne und schlanker Schnautze,

U. arctoideus, kleiner, mit wenig gewölbter Stirne und kurzer aber breiter Schnautze.

Was die übrigen Knochen des Skelettes anbetrifft, so behält sich der Verf. vor, später darauf zurückzukommen, und bemerkt für jetzt bloss [was auch andere Beobachter schon gethan], dass Cuvier mit Unrecht das bei einem einzigen Exemplare des Oberarmbeins von U. spelaeus vorgekommene Loch für den Durchgang der Arm-Arterie über dem inuern Gelenkkopfe, als spezifisches Merkmal für den U. arctoideus angesehen habe. Dieses Merkmal seye ein bloss individuelles gewesen, und die Uuterscheidung nach der Grösse dieser Knochen wichtiger. 
W. A. Thompon: Lebensdauer der Kröten u. s. w. von festem Material eingeschlossen (Silmman, Americ. Journal $\boldsymbol{X X V}, 41$ etc.). Buckuand's Versuche veranlassten den Verf. zu ähnlichen Experimenten. Reptilien wurden eingeschlossen in 2 verschiedene Gestein-Stücke; einmal in Räume von 12" Tiefe und 5" Durchmesser, und sodann dieselbe Anzahl Kröten in Räumen von kleincn Dimensionen. Nach Jahresfrist fand man die in den kleinen Weitungeu enthaltenen Thiere sämmtlich todt, während die meisten von den im Sandstein befindlichen noch Jebten, sie hatten nur sehr an Gewicht abgenommen. Man schloss die Kröten von Neuem auf ein Jahr ein, und nach Ablauf dieser Frist waren alle abgestorben. Kröten, die in eine wohlverwahrte Öffnung von $5^{\prime \prime}$ Tiefe und $3^{\prime \prime}$ Durchmesser in einen Apfelbaun eingeschlossen worden, waren nach Jahresfrist alle todt. In Staate von New-York hat man Kröten und Fische unter folgenden Lagen getroffen :

1) Kröten in sekundärem Saud- und Kalk-Stein;

2) in Thon-Schichten, etwa 12-15 F. tief, die bein BrunnenGraben aufgeschlossen worden;

3) in Baumstämmen an, dem Luftzutritt durchaus unzugänglichen Stellen.

In Kalk. und Sand-Stein waren die Weitungen nicht grösser, als der Körper dieser Thiere, und, wie es scheint, hatten letztere diese Stelle seit der Bildung der Felsarten nicht verlassen. Das Material musste bei seinem Absatze so weich gewesen seyn, dass es sich nach der Gestalt des cinzuschliessenden Körpers modeln konnte. Augenfällig ist, dass wenn ein lebendes gesundes Reptil in einem Raume von der Grösse eingeschlossen würde, in welchem man solche Geschöpfe gewöhnlich findet, es nicht die Hälfte der Zeit leben könnte, als diess bei BuckLarids Versuchen der Fall war; denn Nahrung und Luft kann kein Thier entbehren, das den Gebrauch seiner Organe hat. Allein man weiss, dass Kröteu u. s. w. im Erstarrungs.Zustande melırere Jahre verblieben sind, ohne dass sie Lebenszeichen gaben, und dass sie auflebten, so wie man dieselben der Lutt und zugleich einer höheren Temperatur aussetzte. Daraus ergibt sich, dass Athem und Kreislauf des Bluts bei kaltblütigen Thieren für die Lebensdauer während der Winterzeit nicht unumgänglich nothwendig sind; ferner scheint es, dass die, in den Magen aufgenommene, Nahrung nach dblauf von 3 bis 4 Jahren noch eben so unverändert und unverdaut bleibt, als wäre dieselbe erst vor wenigen Augenblicken aufgenommen worden, vorausgesetzt, dass die Erstarung uberwinternder Thiere keine Stürung erleide, selbst was den niedern Temperatur. Grad betriff. Mit gutem Grunde kann man annehmen, dass seit der frühesten Bildung unserer Erde, Wärme und Kälte stets abgewrchselt haben, wie solches noch gegenwärtig der Fall ist, und dass die thierische Konstitution unverändert nach den nämlichen Prinzipien geregelt worden; wäre demmach ein Reptil während seiner Erstarrung in Sand oder Kalk eingelagert worden, so ist kein Grund vorhanden, 
wesshalb seine Vitalität nicht durch Jahrtausende hindurch fortdauero küınte. Wenn Nahrung, Athem und Kreislauf des Blutes nicht uner lässliche Bedingungen sind für die Lebensdauer solcher Geschöpfe, so ändert die Zeitdauer nichts, tausend Jahre oder ein Tag zeigen sich für sie nicht verschieden. Zutritt vou Luft und höliere Temperatur sind erforderlich für das Wiederauflebcu solcher erstarten Thiere. Es fehlt uns an Nachrichten über Kröten oder andere Reptilien, die im Sandstein oder in Kalkstein eingeschlossen gefunden worden in Europa oder Amerika, ausgenommen in solcher Breite, wo die Kälte jene Geschöpfe torpid macht; möglich ist es darum, dass die Thiere in ErstarrungsZustande sich befanden, als sie in noch weichen Gestein - Massen eingeschlossen wurden. Die Einrede, dass die Thiere bei der jährlichen Wiederkehr höherer Temperatur hätten belebt werden müssen, lässt sich dadurch bescitigen, dass ein Gestein in einer Tiefe von 15-20 F. eine weit niederigere Temperatur hat, als die Atmosphäre; übrigens bleibt es zweifolhaft, ob ein in $15-20 \mathrm{~F}$. Tiefe in Gestein eingeschlossenes Reptil, ohne dass freie Luft-Circulation Statt hat, wieder sollte belebt werden können. Frösche und Kröten bliełgen, im südlichen Theil der Hudsons-Bucht und in Canada, Jahre lang in ErstarrungsZustande und belebten sich sodann wieder. In dieser Breite bleiben Kröten vom 1. November bis zum 1. Mai torpid'; im Sommer zeigen dieselben gewölnlich in 8-10" Tiefe unter den Boden, oder in noch geringerer Tiefe unter einem Stein, Merkmale des Lebens; in Winter beharren sie unter solchen Verhältnissen bis zum Mai in torpiden Zustande, zu welcher Zèit die kleinen Insekten ihren Winter-Aufenthalt verlassen und sie mit Nalırung verselien. In diesen Klimaten ist die Erde zur Winterzeit bis auf $15-18^{\prime \prime}$ Tiefe in der Regel gefroren, und alle darin eingeschlossene Wesen erscheinen erstart und lebenslis. Auf warmblitige 'Thiere, wie z. B. Murmelthier, Igel u. s. w., obwohl sie wälrend der kulten Jahreszeit im Erstarrungs-Zustande verbleiben, wirkt die Kälte ganz auders, als auf kaltblütige Geschöpíe, bei denen der Kreislauf des Blutes vor sich gehen kann unabhängig von der Thïtigkeit der Lunge. Wenn die Luft-Temperatur unter $50^{\circ}$ F. sinkt, so fangen kaltblütige Thiere an, ihre Sensibilität zu verlieren: kommt dieselbe auf $40^{\circ}$ zurück, so werden dieselben torpid, und wenn eine solche Temperatur unverändert bleibt, so beharren sie in jenem Zustande, wie diess wiederholte Erfahrungen und Versuche dargethan. Was Kröten und Frösche betrifft, die man beim Brunnen-Graben in 12-15 F. Tiefe gefunden hat, so ist kein Grund vorhaiden, wesshalb man nicht annehnen küunte, dass sie in Erstarrungs - Zustande seit dem Diluvinm verblieben wäre, da das meiste Material, welches über den festen GesteinSchichten sich befand, in jenem Zeitraume durch gewalthätige Wirkungen des Wassers entfernt worden, und jene Geschöpfe zu derselbru Zeit eingeschlossen worden seyu dürten, als das Material bewegt wurde. - Bri der Voraussetzung, dass die innern Theile von GesteinSchichten, aus welchen kalte Quellen hervortreten, nit dem Wasser 
ungefähr gleiche Temperatur haben, lässt sich annehmen, dass Kröten, wenn sie in einem solchen Gestein eingeschlossen waren, nicht wieder belebt werden könneu, bis die Felsmassen wärmer geworden sind, als das in Sommer aus denselben hervorbrechende Wasser, und dass unter gewöhnlichen Umständen jene Geschöpfe im Frühlinge nicht eher den torpiden Zustande verlassen, bis die Luft wärmer wird, als das zur Sommerzeit herausquellende Wasser. - Dass in allen Fällen, wo Kröten von Gesteinen umschlossen gefunden worden, Spalten oder Risse vorhanden seyn mussten, um Luft und Insekten zur Nahrung jener Geschüpfe zuzulassen, und dass diess den Forschungen genauer Beobachter entgangen seyn sollte, ist gegen alle Wahrscheinlicbkeit, zumal da solche Erscheinungen besondere Theilnahme und Neugierde erwecken, und da die Öffnungen ursprünglich gross genug gewesen seyn müssten, um den Körper des Reptils aufzunehmen. - - Der Verf. wurde zu diesen Betrachtungen veranlasst, theils durch grosse Hechte, welche er, aus gefrorenen Teichen und See'n in gefrorenen Zustande in andere Wasserbehälter brachte, wo sie wieder auflebten, theils durch Schlangen, die augenfällig steif gefroren waren und wieder zum Leben kamen, als man sie der wärmern Luft aussetzte. Kröten kommen beim Pflügen häufig ohne Lebenszeichen zum Vorschein und fangen erst bei läugerer Einwirkung warmer Luft an, sich zu regen. - - Die Versuche BuckLasd's dïrften demnach nicht zureichen, um die Frage zu entsclieiden über die lange dauernde Vitalität in Gestein-Schichten gefundener Reptilien. - Zum Schlusse gedenkt der. Verf. einer Kröte, welche in der Stadt Tomipson beim Brunnen-Graben in $10 \mathrm{~F}$. Tiefe, in einer aus Thon und Gruss bestehenden sehr festen Gestein.Lage getroffen worden; der wärmeren Luft ausgesetzt, belebte sich das Thier, starb aber nach kurzer Zeit. Die erwähnte Gestein - Lage ist frei von Rissen und Spalten und kein Eindringen von Luft oder Wasser in dieselbe denkbar. Das eingeschlossene Reptil entbehrte folglich jede Einwirkung von Wärme, vor Wasser und blieb ohne Nahrung. Dieser Fall scheint mit BuckLaxd's Schlusse in geradem Widerspruch.

Sturge von Birmingham las bei der Britischen Versammlung in Dublin eine Nachricht über eine lebend in einer kleinen Höhle einer festen Masse von New red Sandstone $10 \frac{1}{2}$ ' tief gefundene Kröte, welche noch 4 Tage fortlebte (Janes. Edinb. n. phil. Journ. 1836, XIX, 405).

\section{Verschiedenes.}

Reichenbacu: über den Meteorstein-Fall z u Stannern bei Blansko in Müliren, am 25. Nov. 1833 (BaUmgarts. Zeitschrift für 
Phys. 1834, III, 73 - 77). Reichenbacr liess durch ausgesandte Boten sich zuerst von allen Seiten Kunde verschaffen über die Winkel, unter welchen an jenem Abende das blendend helle Meteor erblickt worden, und über die Gegend, wo man die einem starken Kanonenschusse mit nachfolgendem Kleingewehrfeuer ühnliche Detonation am stärksten vernommen hatte; dann durchstreifte er täglich mit $60-70$ Mann die so bezeichnete Gegend, un die an der Stelle der Detonation muthmasslich gefallenen Meteoriten aufzusuchen, und entdeckte am 11ten Tage einen, an den folgenden Tagen noch zwei kleinere Meteorsteine, welche áussen schwarz, innen körnig, grau, mit metallischen Punkten versehen sind, die Hagnetnadel ablenken und nach vorläufigem Versuche Eisen, Schwefel, Thonerde u. s. w. enthalten. Er beschäftigt sich mit einer genauen quantitativen Analyse. [Vgl. Jahrb. 1833, S. 125.]

v. Holger: Analyse des Meteorsteins von Stannern im Mai 1808 gefallen (a. a. O. 1833, II, 293-307, nach dem, bei der Versammlung d. Naturf. in Wien ans 26. Sept. 1832 gehaltenen Vortrag). Cerer und $\mathrm{Zinn}$ ergeben sich zum ersteu Male als (freilich ganz schwache) Bestandtheile der Meteoritel. Nach 5 Analysen ist Folgendes die Zusammensetzung des Steines: der Körper bestund deutlich aus zwei Gemengtheilen, einem Thonsilikate und einem Manganeisenoxydul-Silikate (abgesehen von einem schwachen Gehalt an Schwefel, Kobalt, Cerer und Zimn).

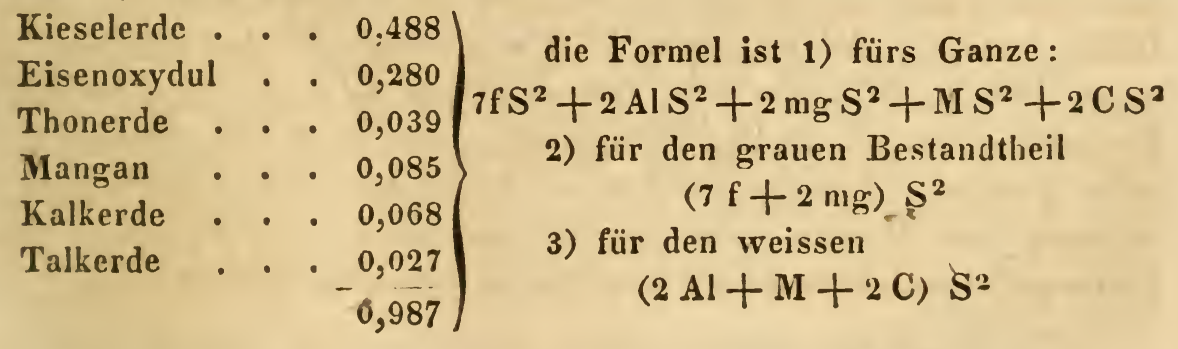

v. Hoiger: Bemerkungen zur Berzelius'schen Analyse des Mete ore is ens von Bohumiliz (Baumgartr. Zeitschi'. 1833, II, 35-37). Jene Analyse war früher (in derselben Zeitschrift 1, 290 und Jahrb. 1833, S. 335) mitgetheilt worden. v. Holger sucht aus der Verschiedenheit des von Berzerrus und von ihm selbst eingehaltenen anatytischen Verfahrens den Grund nachzuweisen, warum in beiden Fällen so ungleiche Resultate erzielt worden.

v. Schreıbra: über die neulichst bei Magdeburg zufälig aufgefundeno problematische Metall - Masse (ebendaselbst 1833, II, 1-11). 
Das von ApEL in Göttingen unter dem Namen "Magdeburger Molybiän. haltiges Meteor-Eisen" in den Handel gebrachte und von STronerer in einen Berichte an die K. Akademie der Wissenschaften als solches bestätigte (vgl. Stroneyer, Jahrb. 1833, S. 74, 555 und 682) Erz weicht so schr vou anderm Meteoreisen $a b$, dass man an seiner Ächtheit $z u$ zweifeln berechtigt ist. Ausser Nickel, Kobalt und Kupfer enthält es nämlich nach Stroneyer noch Molybdän, welches bis jetzt in keinem Meteoriten entdeckt worden; dann nach APEL's brieflicher Nachricht GediegenKupfer und Buntkupfererz; seine Oberfläche ist umeben und zerklüftet, ohne jene bei Meteoriten gëwöhnlichen Finger-artigen Eindrücke, stark und bis zu ungleicher Tiefe verockert, obne die eigentiümliche Rinde der Luftsteine. Die Farbe im Innern ist nicht, charakteristisch weissglänzend, sondern dunkeleisengrau, und das Gefüge nicht so dicht und derb. Das Erz wird von der Feile fast gar nicht und nur schwierig von Scheibe und Schmirgel angegriffen, und ist vollkommen ungeschmeidig, während hohe Geschmeidigkeit eine auszeichnende Eigenschaft des Meteoreisens ist. Die krystallinischen Figuren desselben kamen weder durch Ätzen der Flächen mit Scheidewasser, noch durch Erhitzung zum Vorschein, sondern auf dem erstren Wege überzogen sie sich mit kupferrothem Schimmer, auf dem zweiten wurden sie mit kleinen unregelmässigen blauen Flecken bedeckt. Daher scheint diese anfänglich $100 \mathrm{Pf}$. schwere (wahrscheinlich aber auch da schon aus mehreren Stïcken bestandene) Eisenmasse nur das Produkt eines grösseren Schmied -heerdes, nicht aus Erzen, sondern aus allerlei gemengten alten Guss - u. a. Eisenstücken zusammengeschmolzen; zumal da hiemit auch noch andere kleine vollkommen rohe Schlacken zusammengefunden worden.

Bergrath WEHRLE hält diese Masse für ein etwas silberhaltiges Hüttenprodukt, wie es in Ungarn unter der Benennung "Eisenkloss" [anderwärts unter dem Namen "S a u", daher "die Magdeburger S a u"] beim Kupferschmelz-Prozesse häufig vorkommt, und erwiess auch sogleich dessen Silber-Gehalt im Betrage von ungefähr 6 Prozent durch einen Versuch.

Strongurr- (vgl. Jahrb. 1833 , S. 682) und v. Holger sind mit einer quantitativen Analyse dieses Körpers beschäftigt.

P. Mreran: über die Gestalt der Hagel-Körner (Bericht über die Verhandl. der naturh. Gesellschaft in Basel, 1835, S. 57 ff.). Die Graupel-oder Riesel-Körner besitzen inmer die Gestalt eines oben abgestumpten Kegels nit kugelförmig zugerundeter Basis. Sie bestehen aus einzelnen Schneenadeln, welche strahlenförmig von der Spitze gegen die Basis auslaufen. Diese Thatsache scheint von den Meteorologen bis jetzt übersehen worden zu seyn, ungeachtet sie bei näherer Untersuchung bei jedem Graupelschauer sich leicht bestätigen lässt. Das Graupelkorn wird zun Hagelkorn: indem an die spärliche Basis des 
Kegels eine Schicht von klarem dichten Eis sich anlegt; auch bei fernerem Zuwachse findet dasselbe inmer vorzugsweise an der Basis Statt, so dass die gewöhuliche Gestalt der Hagelkörner eine birnförmige ist, derjenigen des Graupelkorns ähnlich, woraus sie entstanden sind. Die Spitze des Kegels ist durch das strahlig abgesonderte, aus undurchsichtiger Schneesubstanz bestehende Graupelkorn gebildet, der untere rundliche Theil ist festes klares Eis. Diese Gestalt der Hagelkörner ist längst beschrieben worden, unter andern schon von Descartes; sie scheint aber melır als etwas Eigenthümliches besonderer Hagelfälle betrachtet worden zu seyn, bis LEOpoLd von Buch (Berliner Abhandlungen voll 1814) auf ihre Beständigkeit aufnerksam machte. Dir Grund zur Entstehung ist offenbar abzuleiten von der Beständigkeit der Lage, welche Graupelkörner und Hagelkörner beim Falle belialten. Der Zuwachs fiudet inmer nur, oder doch vorzugsweise an der untern Seite Statt, wo neue wässerige Theile getroffen und mit dem Korn vereinigt werden. Der Unterschied zwischen Graupel-Dildung und Hagel-Bildung scheint darin zu liegen, dass bei ersterer die wässerigen Theile unnitte:bar von der Dunstform in den festen Zustand übergehen, bei letzterer aber vorher noch der tropfbar flüssige Zustand eintritt. - Der regelmässige 'Typus verschwindet, wenn unregelmässige Winde die konstante Fallrichtung stören, oder unregelmässige Schmelzung herbeifül. ren, oder auch wenn einzelne Körner zusanmensiatern; denn die Birnförmige Gestalt ist allerdings die gewöhnliche, aber nicht die ausschliesslich Statt findende. Die Bildungsweise der Hagelkörner aus Graupelkörnern beweisst zur Genüge, dass nicht ein Zerspringen rundlicher Eiskugeln die Ursache der birnförnigen Gestalt seyn kann, wie ältere Naturforscher muthmaasten: sie beweisst aber auch die Unzulässigkeit der bekannten VoltA'schen Theorie über Hagel-Bildung, welche ein unregelmässiges Hin- und Herwerfen der anwachsenden Hagelkörner nothwendig voraussetzt. Schliesslich wird noch des aus klaren Eiskügelchen bestehenden gefrorenen Regens gedacht, als einer von der GraupelBildung gänzlich verschiedenen Erscheinung, welche namentlich, wenu sogenanntes Glatteis sich bildet, gar nicht so selten ist, als manche Physiler behaupten. Die wasserhellen Kugeln, zu welchen unter solchen Uniständen das Wasser erstarrt, beweissen die Unstatthaftigkeit derjenigen Theorie'n, welche die in ihrem Bau viel komplizirteren Hagelkörner aus gefrierenden Regentropfen entstehen lassen wollen.

Grosse Kälte z u Roeruas in Norwegen. Zwischen Weihnachten und Neujalı, im Winter $183 \frac{5}{6}$, fiel eine ansserordentliche Mienge Schuce. Am 31. Dez. Abends war es so kalt, dass Quecksilber, welches un 7 Uhr in einer Thretasse in die Luft gesetzt worden, vor 9 Uhr gefroren war. Am Neujahrstage fror das Quecksilber, wenn die Masse nicht zu gross war, fast augenblicklich. Den ganzen Tag liess 
es sich hämmern und unter dem Hammer formen, wie ein Stück weissglühenden Eisens; man konnte dasselbe zwischen den Fingern zerbrechen, und in der hohlen Hand schmolz es erst nach Verlauf einiger Minuten. Ein Spiritus - Thermometer (von dem jedoch die Zuverlässigkeit zweifelhaft ist) zeigte am Abend des Neujahrtags, da die Kälte am stärksten war, $34 \frac{10}{2}$ R. Am 21. Januar war die Luft ganz gelinde. Auch in Moskau soll, den Aussagen glaubwürdiger Reisenden zufolge, im Februar d. J. die Kälte $34^{\circ}$ erreicht haben, so dass das Quecksilber fror.

(Zeit.-Nachr.)

S. Berthelot: Notizen über das Ungewitter, welches die Insel Teneriffa im Nov. 1826 verheerte (Ann. chim. phys. 1835, LVIII, 204-218). Die furchtbaren Verheerungen jenes Gewitters (das sich übrigens über den ganzen Archipel der Kanarischen Inseln verbreitete) sind nur begreiflich, wenn man das Terrain der Insel berücksichtigt, welche in minder heftigem Grade auch schon in Jahr 1706 und 1722 furchtbar heimgesucht worden war. Ein über 1900 Toisen hoher Berg, welcher die Wolken auf sich heranzieht, - eine seinen Fuss rings umgebende Kraterwand von 1250 bis 1555 Toisen Höhe, die nur an wenigen Stellen dnrchbrochen ist, um den von erstrem herabkommenden Wasserfluthen einen Durchgang zu gestatten - die hohe Lage des Kraterbodens zwischen beiden (die Canadas, $1200-1400$ Toisen hoch), von dem das Wasser auf seinem ganzen Wege bis zum Meere ein sehr starkes Gefälle erhält, hier enge und tiefe Wasserrisse, welche die Fluthen nicht alle in sich aufnehmen können, und durch rasche Einstürze erweitert werden, dort flache Flussbetten, welche von denselben alsbald überströmt die angrenzenden Ebenen nicht gegen Überschwemmung zu schützen vermögen, - da Vertiefungen, wo das hoch anstehende Wasser keinen Abfluss findet (in der Laguna), - ein vulkanischer Boden, der bald so fest ist, dass alles auf ihn fallende Wasser tieferen Stellen zugeführt wird, bald so locker, dass er dasselbe grösstentheils einsaugt und durch dasselbe beschwert in Masse nach der Tiefe gleitet: - dieses sind die wichtigsten Momente, welcho die Folgen jenes Naturereignisses bis $\mathrm{zu}$ einem so furchtbaren Grade $\mathrm{zu}$ steigern vermochten. - Am 6. Nov. Morgens war der Barometer in grosser Bewegung, die Luft ausserordentlich durchsichtig und Schallleitend mit starker Refraktion, im lnnern der Insel schwül und drückend, das Meer unruhig, der Wind drehte sich in allen Richtungen; um Mittag zeigten sich dicke Wolken und Sturm, das Meer ging höher, um 3 Uhr wurden 3 im Haven losgerissene grosse Schiffe ans Ufer geworfen, der Sturm stieg fortwährend, um 9 Uhr scheiterte ein Dreimaster, der Regen goss sich dabei in Strömen herab, im Gebirge war Wolkenbruch überall, helles Licht strahlte heller als Nordlicht, und leuchtende Kugeln bewegten sich nach Mitternacht im Horizont; erstres schien aus der Oberfäche der Wasserfluthen selbst hervorzugehen; erst um 8 Uhr des 
Morgens am 7. November begannen diese Erscheinungen sich zu mildern. - Ganze Weinberge und Wälder waren in dieser Zeit theils von den Fluthen fortgerissen, theils vom Sturme zusammengebrochen; tiefe Thalschluchten waren hier entstandeu, dort hatten sich solche mit Schutt ganz ausgefüllt; in den Canadas waren Vertiefungen bis von 600 Schritten im Umkreise und $20^{\prime}-30^{\prime}$ Tiefe, theils durch Wolkenbrüche, theils durch die Wirkung von Wasserhosen gebildet, der ganze Weiler Quiquixa war mit dem Boden, worauf er stund, in eine Schlucht hinab. geglitten, eine ganze Vorstadt des Havens Orotava und das Dorf la Quancha mit 52 Einwohnern und über 300 Thieren waren fortgerissen, und mehrere Befestigungen, eine grosse Bastion in der Bai Sainte Croix mit ihrer Artillerie und das feste Schloss Candelaria am Haven von Orotava bis auf die Spur verschwunden.

So waren binnen nicht 20 Stunden 232 Personen und 936 Stück Vieh ums Leben gekommen, 307 Gebäude fortgerissen, und noch 114 beschädigt worden, 5 grosse Schiffe mit Maun und Maus untergegangen und eine ungeheure Fläche kulturfähigen Landes theils weggeschwemmt, theils verschüttet worden.

Heber : über klimatische Veränderungen (Life of Bishop HEBer I, SO u. $532-535>$ Sillim. Amer. Journ. of Scienc.; 1831, April; XX, 130-133). Die Norweger fürchten sich sehr, ihre Wälder auszurotten, deren Existenz sie die verhältnissmässige Milde ihres Klimas zuschreiben. Eben so führt man mit Rücksicht auf die Schilderungen der Alten Scythien als ein Beispiel an, wie durch fortschreitende Kultur, Ausrottung der Wälder und Abtrocknung der Sümpfe das Klima verbessert worden sey. Aber das Klima Scythiens und überhaupt der Küstenländer nördlich vom Schwarzen Meere ist heutzutage keineswegs milder, als zu jener Zeit, und auf der andern Seite ist das Land auch noch eben so wild, so öde, wie dort. Wälder haben da nie existirt. Das Klima ist dort strenger, als in Frankreich und Deutschland unter gleichen Breiten, wie dessen Strenge überhaupt in beiden Hemisphären von Westeu nach Osten zunimmt.

Ac. J. Adre: über die Dehnbarkeit verschiedener Stein. arten in der Wärme (JAMEs. Edinb. n. philos. Journ. 1835, XIX, 207). A. hielt einen Vortrag über diesen Gegenstand in der königl. Soziełăt von Edinburg am 20. April 1835. Er bediente sich bei seinen zahlreichen Versuchen eines Pyrometers, womit er im Stande war, Längen von зоюоб Zoll zu messen. Die erhitzten Exemplare selbst hatten in der Regel 23". Der angewendete Wärmegrad beschränkte sich jedoch, da diese Versuche keinen geologischen, sondern einen technischen 
Zweck hatten, auf den Siedepunkt des Wasser bei $212^{\circ}$ F., oder bei $180^{\circ}$ über der herrschenden Luft-Temperatur [?].

Längen-Ausdehnung bei Erhitzung auf $1000 \mathrm{C}$.

Römischer Mörtel . • . . . . . . . . . . .

Sizilianischer weisser Marmor . . . $\quad .0011041$

Marmor von Carrara . . . . . $\quad .0006539$

Sandstein vom Liver Rock im Bruche von Craigleith .0011743

Gusseisen, 2" im Quadrat . . . • .0011468

" $\quad \frac{1}{2} "$ im Quadrat . . . . 0011022

Schiefer aus dem Penrhyn-Bruche in Wales .0010376

Ruther Granit von Peterhead . . . . .0008968

Arbroath Pavement . . . . . .0008985

Caithness Pavement . . . . . .0008947

Grünstein von Ratho . . . . ' . . . . . . 0008089

Grauer Granit von Aberdeen . . . . .0007894

Schwarzer Marmor von Galuay in Irland . 0004452

Ziegelstein . . . . . . . $\quad .0004928$

Verbandlungen aus dem Gebiete der Mineralogie, Geo10 gie und Petrefakten-Kunde bei der BritischenVersammlung in Dublin im August 1835 (Jayes. Edinb. n. philos. Journ. 1835, $X I X, 372-400)$.

A. Geologie und Geognosie.

Griffiт legte seine seit Jahren bearbeitete geologische Karte von Irland mit Erläuterungen vor, welcher J. Brxce, Sedcwxck, Murchison, Portrock und Grenough Bemerkungen beifügten (S. $372-379$ und $382-384$ ). Wir werden auf diese Aḅhandlung ausführlicher zurückkommen.

Verschoyle sprach von einem Systeme von Trapp-Dykes, welche durch die Grafschaften Mayo und Sligo ziehen. Sie sind sehr häufig, lang und gerade in diesen Gegenden, unter sich vollkommen parallel und zeigen auffallende Einwirkungen auf die Nachbargesteine. $\mathrm{Er}$ hat in einem Landstriche von 13 Engl. Meilen Breite, aus O. nach W. streichend und nur etwa $4^{n}-5^{0}$ nach $N$. abweichend, 11 dieser Dykes untersucht. Derjenige, welcher von Rinvoe Point nach dem Bette des Bonnet bei Dromahair, Grafschaft Leitrim zieht, ist 63 Meil. lang und $40^{\prime}$ breit; ein andrer von Broad Haven nach Agrishead hat 45, und andere haben 30 M. Länge. - Griffitr bemerkte, dass eine Abhandlung von Lieutn. James über einen ähnlichen Gegenstand in den Verhandlungen der geologischen Gesellschaft von Dublin erscheinen werde, und Capt. Portгоcк fügte bei, dass die Dykes in Tyrone genau von $\mathrm{N}$. nach $\mathrm{S}$. gchen.

Professor Phucips theilte das Ergebniss seiner Forschungen über fossile Astaciden mit, welche ihm bei einer früheren Versammlung 
anempfohlen worden waren. Die im Meere lebenden Arten dieses Geschlechts unterscheiden sich von denen des Süsswassers durch die Queer-Theilung der Schwanzflosse and [?] durch grosse zweifingerige Klauen am vorderen Fuss-Paare, welche Charaktere auch alle vom Verf. untersuchten fossilen Arten zeigen. Um mittelst dieser Arten einzelne Gebirgs. Schichten mit einander zu parallelisiren, scheinen sie sich nicht eben sehr zu eignen. Eine Art findet sich durch alle Schichten des Lias und der Oolithe wieder, vom alleruntersten bis zu dem allerobersten; eine zweite ist auf den Coralrag beschränkt; vier gehören dem Grüusande an. Einige von diesen Arten sind mehr lokal, audere scheinen eine grössere geographische Verbreitung, als irgend eine Art unserer Tage besessen zu haben. [Jene zwei ersten Astaciden sind wabrscheinlich der A. rostratus und A. ornatus Phill. Yorksh. welche mir, der erste fast ohne $Z_{w}$ eifel, mit $P$ alinurus Regleyanus Desm. zu Glyphea v. Mex. gehörig scheinen. Br.]

Sidnex Surtr zeigte ein, Fox angehöriges, Exemplar eines Echinus aus dem Bergkalke der Grafschaft Kildare vor.

Lieutn. Stothed beschrieb das Vorkommen einer kleinen isolirten Granit-Masse in der Grafschaft Cavan, mitten zwischen Übergangsund Sekundär-Gebirgen. Der Granit zeigt seine gewöhnliche Einwirkung auf die ihn umgebende Grauwacke, welche durch verschiedene Härte-Grade übergehend sich allmählich in Quarzfels umwandelt. Dieses Vorkommen, entfernt von den grossen Granit - Gebilden von Down, Galway und allen andern in Irland, erläutert manche Erscheinungen im. Schiefer - Gebirge, dessen zerbrochenen und unzusammenhängenden Zustand und sein wellenförmiges Ansehen.

Professor Phillips theilt seine Erfahrungen über die geologische Verbreitung der Belemniten mit. Von 100 jetzt bekannten Arten finden sich 34 in England. Alle sind auf Lias, Oolith und Kreide beschränkt. Eine Abtheilung, durch eine schwache Anschwellung der Spitze und eine seitliche Spalte ausgezeichnet, ist auf Kreide beschränkt; die mit stumpf dolchförmiger Spitze gehören dem Grünsande an; die mit einer Rinne am Hintertheile finden sich im Mittel-Oolith; die mit einer scitlichen Rinne im Unteroolith und Lias, und die olne alle Rinne sind auf den Lias heschränkt [diess mag für England streng gültig seyn, erleidet aber auf dem Kontinente manche Ausnahmen, Br.]. - Agsssiz theilt seine Beobachtungen in der Sammlung der Miss Pнinpor mit, wornach die Belemnite $n$ und sg. fossilen Loligo-Arten zusammengehören : die Belemniten-Scheide ist analog der Spitze am einen Ende des Sepien-Knochens, der fossile Loligo dem äusseren Theile des Be1 e m n it e n-Knochens, der Alveolit der Belemniten dem innern Theile des letztern, so dass Sepien und Belemniten (ganz genommen) nur durch die relativ ungleiche Entwicklung einzelner Gegenden ibrer Knochen von einander abweichen.

Lieutn. Denhan legte eine Karte vor zur Erläuterung des Verhaltens von Ebbe und Fluth im Dee und Mersey. 
Grifritr theilte Nachricht mit über ein ausgedehntes Muschelkieslager in der Grafschaft Wexford. Es zieht 70 Meil. weit und 18 Meil. breit längs der Küste. Die Lagerung gibt $5^{\prime}$ Thon, $7^{\prime}$ Mergelthon, $7^{\prime}$ Mergel, $\boldsymbol{7}^{\prime}$ Sand, $1^{\prime}$ Kies nit einer grossen Menge von Seekonchylien [uoch lebender Arten?].

Williams berichtete über die fossilen Pflanzen in den KohlenDistrikten zu beiden Seiten des Bristol-Kanales, nämlich in Devonshire und in Pembrokeshive. An beiden Orten sind sie am häufigsten in den Schiefern, welche die Anthrazit-Lagen von einander trennen. Demungeachtet scheinem ihm beide Ablagerungen von ungleichem Alter: in Devon eine wahre Übergangskohle in Schiefer eingeschlossen, in Pembroke und Caermarthen dem Bergkalk untergeordnet. Er legte Musterstücke dieser Pflanzen vor. Auch Liasfische.

Agassiz legte der Versammlung die 5 bis jetzt erschienenen Lieferungen seines Werkes über fossile Fische und 112 gezeichnete Tafeln mit Englischen Fischen vor, und bemerkte, dass die Gesetze stratographischer Verbreitung, welche er zur Zeit, wo ihm nur 500 Arten bekannt gewesen, aufgestellt hatte, durch die Kenntniss von weiteren 400 Spezies nur bestätigt worden seyen. Alle Arten organischer Körper, deren Reste in einer Formation enthalten sind, gleichviel ob in deren oberen oder unteren Schichten, scheinen ihm in der Regel gleichzeitig mit einander gelebt zu haben und in einem kurzen Zeitraume durch irgend eine innere, von kosmischen Ursachen unabhängige Erd-Revolution begraben worden zu seyn. Die Koprolithen, welche in manchen Schichten allein vorkommen ohne unmittelbare Reste der Thiere, von welchen sie stammen, und welche man gewöhnlich erst in den darauf folgenden Schichten findet, scheinen A. während der schon begonnenen Agonie dieser Thiere abgesetzt, und da jene Exkremente nicht lange im Wasser liegen können, ohne gänzlich aufzuweichen, augenblicklich von der sich niederschlagenden Schichte umschlossen worden zu seyn; diese Thiere selbst sind ihnen dann in der sogleich darauf folgenden Schichte gefolgt. - Einen Fisch aus New red Sandstone von Roan Hill, Dungorman, Kirchspiel Killyman, Grafschaft Tyrone, wovon Ровтьоск einige -Exémplare vorlegte, erkannte A. für eine neue Palaeoniscus-Art, welche sich durch ihre gestreckte Form und die weit nach hinten stehenden und einander selbst näher gerückten Rücken - und After - Flosse auszeichnet, und welcher er den Namen P. catopterus beilegte. Es ist die erste, welche in einer Formation über Magnesian - Kalk gefunden wird.

Dr. Traibu legte die Skizze einer physikalischen Geographie und Geologie von Spanien vor, beschränkte seine Bemerkungen jedoch hauptsächlich auf die Provinz Andalusia, worin die manchfaltigsten Formationen von dem ältesten Urgebirge an bis zum tertiären vorkommen. Der Glimmerschiefer daselbst enthält Eisen-Glanz, Blei - Erz u. s. w., und zwar letzres in solcher Menge, dass man jährlich 35,600 Tonnen 
davon gewinnt. Die Spalten des sekundären Kalkes enthalten interes. sante Knochen-Reste: er setzt nach Afrika über. Itn folgen New red Sandstone, Gyps und Mergel voll Steinsalz und Salz-Quellen. Oolithe kommen bei Cartua, Kreide mit Feuersteinen zu Labriga vor.

Sитти von Jordunhill berichtete über einige, in einem SandsteinBruche bei Glusgow, nächst der Wasserleitung des Forth - und ClydeKanals über dem Kelwine-Fluss, gefundene Baumstämme, aus deren aufrechter Stellung hauptsächlich er folgert, dass sie an Ort und Stelle gewachsen seyen.

Whewell sprach über einige mit der Geologie verwandte Gegenstände, über mittlen Fluth-Stand, Erd-Magnetismus und Zentral-Wärme.

HARTop beschrieb einige merkwürdige Faults in der südlichen Abtheilung des West-Bezirkes von Yorkshire und versprach seine Beobachtungen fortzusetzen.

Murchison und Sedgwick setzten ihre Ansichten über die Gliederung der ältern Formationen bis zum Old red Sandstone aufwärts, wie sie in England und Wales vorkommen, auseinander. SEDGwick theilte die alte Übergangs - Reihe in $\boldsymbol{N}$.-England und Wales in drei Gruppen : die untere Cunbrian-Gruppe aus Schiefer bestehen, ohne organische Reste, die mittle aus Schiefer, Konglomerat und Porphyr mit FossilResten, und die obere Cumbrian-Gruppe, reich an Kalkstein, voll Versteinerungen, und sich an Murchisons Silurisches-System anschliessend, welches bis zun Old red Sandstone hinaufreicht, und worüber sich derselbe in seinem eben erscheinenden Werk verbreitet. Er hält dieses System in Norwegen für sehr ausgebreitet, und berichtet fossile Fische in Old red Sandstone gefunden zu haben, welche Agassiz für identisch nit den Fischen von Caithness erkläre.

DaUBENy verlangte Unterstützung in seinen Untersuchungen über Natur und Erscheinungen der Mineral-Wasser.

Dr. JАсов thcilte eine Notiz über fossile Madreporen in Queens County mit.

Prof. Phiclips redete vom Vorkommen einer tertiären Ablagerung an der Nordküste Englands bei Burlington.

Sedgwick las einen Brief Lyer.L's über die Fossile des Crag.

B. Oryktognosie und Mineralchemie.

Eтtrick schlug verschiedene Verbesserungen an den Davy'schén Sicherheitslampe vor, welche im Prinzip richtig, bei der Anwendung aber oft dadurch gefährlich werde, weil die Arbeiter die Maschen des Draht-Netzes, um ihre Pfeifen unzuzünden u. so w., erweiterten.

Fox berichtete von einem Versuche, wornach geschmolzenes Eisen nicht auf den Magnet wirkt, was gegen die Ausicht vom Zentral-Feuer spricht.

Jounston sprach vou den optischen Eigenschaften der $\mathrm{Chab}$ asie mit Beziehung auf Brewsten's Versuche, bei welchen nicht genau berücksicbtigt worden war, dass es verschiedene Arten jenes Ninerals gebe. 
Daubexy erwähnte, wie L. v. Buch's Meinung, dass kohlensaure Talkerde in gewissen Fällen durch vulkanische Thätigkeit sublimirt worden seye, zwar mit den Erfahrungen der Chemiker seines Wissens sich nicht vertrage, aber gleichwohl während seines Aufenthaltes in Italien Colonel Robinson eine grosse Menge von Magnesia-Karbonat in einer der verschiedenen Höhlungen einer oberen Lava-Schichte entdeckt, und er selbst eine Menge derselben als Überzug von Lava gefunden habe. Dr. Dalton bemerkt hiebei, Dr. Henrey habe ihn benachrichtigt, dass, wenn die angewendete Hitze einen gewissen Grad erreiche, sie allerdings eine Menge dieses Salzes emportreibe.

Convell erläuterte die Möglichkeit, auf chemischem Wege Schuppen von Fischen und Anphibien, von einander zu unterscheiden (wovon ausführlicher in einem besondern Auszuge).

Moor legte eine Destillir-Röhre vor, welche zur Bereitung arzneylicher Flüssigkeiten gedient hatte und an beiden Enden, nämlich da wo sie mit $\mathrm{Holz}$ in Berührung und mit Bindfaden umwickelt gewesen, ganz zerfressen war. Eine schwarze Materie aus Blei-Oxyd und -Chlorid hatte sich gebildet, zweifelsohne durch galvanische Thätigkeit.

Auch wurde eine Substanz, Sumpf-Talg genannt, vorgelfgt, welche in Kugelform von 6-7 Pfund Schwere vorkommt, zuweilen aussieht, als scy sie in eine Tonne eingepresst gewesen und in einigen Gegenden zur Fertigung von Lichtkerzen verwendet wird. Geschmolzen und in Wasser tropfend, nimmt sie das Ansehen von Talg an. Dr. Nerce ist der Meinung, dass diese Substanz Fettwachs von Elenn u. a. in jenen [?] Gegenden gestorbenen Thieren seyen (ib. S. 404).

Vorträge, welche in den Versammlungen der geologigischen Sozietät von Cornwalt in dem Jahre bis zum io. Oktober 1834 gehalten worden.

H. S. BoAsE: über ein seltenes granitisches Gestein, gefunden in den Mauern der alten Narine-Kapelle zu Penzance.

W. J. Henwood: 'über einige eigenthümliche Gang - Erscheinungen neuerlich beobachtet in dem Cormuall'schen Bergwerks-Bezirk.

J. Carie: Notitz über einen eigenthümlichen Gang in Huel Bosaeern zu st. Just.

W. J. Hexwood: nachträgliche Bemerkungen über die Erz-führenden Gänge in Cornwall.

H. S. Bosse: über Zusammensetzung und Struktur der Granit- und Schiefer-Gesteine an ihren Verbindungs-Stellen.

W. J. HENwood: ausfühlichere Nachrichten von einigen Versuchen über die stündlichen Änderungen der Magnet-Nadel im leeren Raume, mit einem Versuche, die täglichen Änderungen des Erd-Magnetismus z.u erklären.

W. J. Heswood: Untersuchung der Cornwall'schen Spiegclfächen क 
(Slickensides) und Nachweisung, dass sie nicht mechanischen Ursprungs seyn können.

H. S. Bosse : Versuch über die Natur der Schichtung.

W. J. Henwood: Untersuchung, in wiefern die Gänge in Cormwall Andeutungen von Emporhebung oder Einsinken der Schichten darbieten.

R. Носкіng: über die fossilen Knochen, welche vom Pentuaner Wasch. werk ins Museum gebracht worden sind.

R. Fox: Notiz über einige elektro-magnetische Beobachtungen in der Huel-Jewel-Kupfergrube.

H. S. Bosse: Skizze der Geologie von Forfarshire.

R. TREgsskis : Bemerkungèn über die Theorie'n der Mineralgänge.

J. Armstrong: Bericht über die Salz-Quellen und die Steinsalz-Formation von Hallein in Ober-östreich.

W. J. HeNwood: Notitz über die Wirkung eines Blitzes zu East Huel Crofty Mine.

J. RuLE: Notiz über die Natur der Gesteine in der Nähe von Real del Monte.

J. Hancock: Notiz über Sprengen der Felsen und Beschreibung einer neuen Vorrichtung zum Entzünden des Schusses unter Wasser.

J. CARne: Bericht über die Zinn-Ausbeute, welche Cornwall und Devon in Jahre bis Ende des Johannis-Quartals 1834 gegeben haben.

A. Jenkin: Bericht über die Kupfer-Ausbeute, wolche Cormwall, und welche Grossbritannien und Irland in Jahre bis zum 30. Juni 1834 gegeben.

Mineralogis che Verhandlungen bei der 29. Versamml ung der Helvetischen Sozietä $\mathbf{t} d$ er Naturwissenschaften, zu Luzern an 28. - 31. Juli 1834 (Bibl. univers. 1835, LVIII, Sc. et Arts, 42t-43t).

v. Charpentier las e ine Nachricht über eines der wichtigsten. Ergebnisse der Untersuchungen von Venetz iiber denfrüheren und jetzigen Zustand der Gletscher. Die Felshlücke in den Thälern der schweitz sind nicht durch Wasser, sondern durch die Gletscher von den Höhen herabgeführt, wie sich aus ihrer Form, verglichen mit der in den Morainen, und aus einigen andern Umständen ergibt. Сн. selbst fügt hinzu: die erstere Ansicht würde nicht ausreichen, alle Erscheinungen zu erklären; die See'n namentlich müssten schon ganz mit Blöcken erfüllt scyn. Fossile Palmstämme deuten zwar an, dass die Schweitz einst eine höhere Temperatur besessen: das war aber vor der Erhebung der Alpen; nach der Erhebung waren aber die Alpen höher, die Temperatur kälter und die Gletscher ausgedehnter, als sie es jetzt noch sind.

Hrrzel-Escher hielt einen Vortrag über die E införmigkeit in der Gestaltung der Abhänge der Hochalpen, mit einem 


\section{$-\mathbf{5 0 8}$}

Versuche, solche zu erklären und einige Folgerungen d a ra u f u g r ü nden. In 5000'Seehöhe, an der obern WaldregionGrenze, wo die Weideregion anfängt, sieht man lachende Ebenen $\frac{1}{3}$ Stunde breit und oft mehrere Stunden lang sich längs der Berge erstrecken, welche nach oben durch senkrechte Felswände, durch Felder ewigen Schnee's oder durch Gehänge voll Felstrümmer und Geschieben begrenzt sind. In der Wald - Region selbst aber sind die Abhänge steil und laufen in Schluchten und Trichter zusammen, weil hier die Bäume das Gestein gegen den Einfluss der Atmosphärilien schützen, es mit ihren Wurzeln festhalten, und die von der Höhe kommenden Felstrümmer anhäufen, bis sie sich allmählich in fruchtbare Pflanzen. Erde verwandeln. Wo aber in dieser Gegend die Wälder fehlen, da zerfällt das Gestein rasch, der Thalboden bedeckt sich mit Trümmern und die Thalwände rücken schnell aus einander, so dass man schon aus der Erfahrung mehrerer Jahre auf die ganze Zeitdauer schliessen kann, welche das ganze Thal zu seiner Bildung bedurfte, und die Nothwendigkeit einleuchtet, die Wälder allerwärts sorgfältiger zu erhalten.

Lardy theilt eine Notiz über die Gebirge, welche die Bäder von Lavey i m Waadlande u $\mathrm{m}$ ge be $\mathrm{n}$, mit. Es sind theils Feldspath - und Glimmer - Gesteine, wie Gneiss und Glimmerschiefer, worin der Quarz durch körnigen Fe!dspath ersetzt ist, theils Kalksteine mit Kalkschiefer in Wechsellagerung: jene nach $\mathbf{S}$., diese nach $\mathrm{N}$. einfallend. Die Quelle entspringt im Thale, an einer Stelle nahe an der Grenze bei beiderlei Gesteins-Gruppen.

\section{M i ne r a li e n- H a n d e l.}

Herr NAGER Sohn in Luzern wünscht seine ganze Mineralien-Sammlung zu verkaufen. Sie zählt über 4000 Stücke, darunter kommt vor eine Menge Sphen, Eisenglanz, Rutil, rother Flussspath in Oktaedern, Axinit, Korund u. s. w. Vieles in ausgezeichneter Schönheit. 


\section{Über \\ einige neue Pflanzen \\ in der \\ Keuper - Formation bei Bayreuth, \\ von}

Herrn Grafen G. zU MÜnster.

Aus der Keuper-Formation des Obermain-Kreises in Baiern - vorzüglich aus der Gegend von Bayreuth - habe ich seit einiger Zeit viele seltene und zum Theil ganz nene vorweltliche Pflanzen erhalten. Ein grosser Theil derselben wird im nächsten Hefte der Flora der Vorwelt vom Grafen Sternberg bekannt gemacht werden; namentlich einige neue Arten Aethophyllum, versehiedene noch unbekannte Arten $\mathrm{C}_{\mathrm{J}} \mathbf{c}$ aditen, von welchen eine Art an der Wurzel einen rasenförmigen Polster von feinen kurzen Blättchen liat, aus welchem hohe Stengel mit langen schinalen Blättern aufsteigen, dann eine zierliche neue Voltzia, der geschuppte Stamm einer kleinen Pecopteris, aus welchem kleine zierliche Fiederblättern nach beiden Seiten gewachsen sind u. s. w.

Neuerdings ist bei den Bohr- und Schürf - Versuchen auf Steinkohlen ein neues Lager vorweltlicher Pflanzen in einer Lettenkohle der liesigen Keuper - Formation entdeckt worden, aus welchem ich ver'schiedene neue und bemerkenswerthe Pflanzen erhalten habe, von denen sich auch schöne 
Exemplare in der hiesigen Kreis-Sammlung befinden. Bei vielen derselben zeigt sich eine grosse Übereinstimmung mit den Pflanzen aus den Oolith - Formationen von England. Nachstehende Arten, welche nicht mehr im nächsten Heft der Flora der Vorwelt aufgenommen werden konnten, scheinen mir eine vorläufige Erwähnung zu verdienen.

1) Eine neue Art Glossopteris, von welcher einzelne Blätter die Gestalt der Gl. Nilssoniana AD. BR. haben; allein die bei dieser $A_{r}$ t stark hervortretende MittelRippe ist bei der neúen Art so schwach, dass sie auf der obern Seite selten zu erkennen ist, und nur auf der untern Seite zeigt sich die Mittelrippe von der Basis bis kaum zur Hälfte des Blattes; noch auffallender ist der Unterschied bei den Seiten-Nerven, welche bei der neuen Artt vielfach getheilt und sehr anastomosirend sind, während GI. Nilssoniana wenig getheilte und nio anastomosirende Seiten-Nerven hat. Auch bei dieser Art sitzen die Blätter, wie bei der weit grössern Gl. Latifolia im Keuper von Bamberg, zu vieren quirlförmig mit der stiellosen Basis um den Stengel. Die Blätter, welche von $\frac{1}{4}$ " bis zu $3^{\prime \prime}$ Länge vorkommen, sind nicht breit, aber sehr in die Länge gedehnt, die kleinsten etwas mehr eyförmig; zuweilen finden sie sich haufenweise in solcher Menge eng zusammengebacken, dass die ganze Masse nur aus Blittern zu bestehen scheint, von welchen in der Regel die vegetabilische Blatt-Substanz noch ganz als Kohle erlialten ist, aber sehr leicht abspringt. Selten sind aber ganz vollständige Blätter zu bekommen. Bei einigen zeigen sich auf der untern Seite zwischen den SeitenNerven sehr feine erhabene Pünktchen, welche - mit der Lupe betrachtet - Fruktifikationen zu seyn scheinen.

leh nenne diese Art wegen der lang gedehnten Gestalt der Blitter Gl. elongata.

2) Nicht selten kommt eine mir neu scheinende Art Taeniopteris mit der eben beschriebenen Glossopteris vor, welche grosse Ähnlichkeit mit Pecopteris macrophylla Ad. Brongin, Marantoidea arenacea Jäger, 


\section{$-511$}

hat, und gewissermassen den Übergang zwischen T a e ni o pteris und Pecopteris bildet, daher ich diese Art einstweilen Taeniopteris in termedia genannt habe. Sie zeigt sich in kleinen und grossen, schmalen und breiten, sehr kurz ge stielten Blättern, von welchen die längsten Bruchstücke, welche ich gefunden, 10" bis 12" lang sind. Bei vielen Bruchstücken ausgewachsener Blätter zeigen sich dentliche Fruktifikationen; sie kommen wie feine längliche Punkte an der untern Blattseite zwischen den SeitenNerven reihenweise aneinandersitzend vor, jedoch stets mehr gegen den Rand des Blattes, als in der Nähe der Mittelrippe.

Da bei einigen Blättern die Seiten-Nerven gerade und selten getheilt oder gegabelt sind, während bei andern Blättern diese Nerven gebogen und stets getheilt sind, so ist es möglich, dass die vielen Blätter, welche nie unverletzt vor'kommen, verschiedenen Arten angehören.

3) Vorzüglich merkwürdig sind die häufig vorkommenden, theils weniger vollständigen Bruchstücke von Blättern und Stengeln verschiedener Arten Phleb op te ris, von welchen sich eine Spezies durch ihre besondere Grösse auszeichnet. Die einzelnen Theile der durcheinander liegenden Blätter sind so verschieden, dass man versucht wird, viele besondere Spezies daraus zu bilden. Bei genauer Prüfung und beim Auffinden vollständiger Pflanzentheile ïberzeugt man sich aber, dass man nur wenige Arten vor sich hat, deren Verschiedenheit eben so sehr in der wechselnden Form der Blatt-Nerven als in der Gestalt der einfachen Blatt-Fiedern gesucht werden muso.

Die grösste Art, welche ich Phlebopteris speciosa genannt habe, hat Blätter, welche, nach den Fuss langen Bruchstücken zu schliessen, einige Fuss lang gewesen seyn müssen : sie sind einfach gefiedert; die an der Basis breiten, nach oben zugespitzten $2^{\prime \prime}$ bis 4 " langen Fiederchen 
haben zwischen den in 5 und 6 Ecken *) bestehenden HauptNerven noch ähnlich vertheilte, sehr schwache und oft kaum bemerkbare Neben - Nerven. Die bald mehr bald weniger gestielten Blätter sitzen fächerförmig oder bũschelweise zu je 7 bis $1 \mathrm{~S}$ an der Spitze schmaler langer Stengel beisammen, und diese letzteren scheinen astweise an starken Stämmen gesessen zu haben, da einige dergleichen Stämme mit ansitzenden Stengeln, jedoch ohne Blätter vorkommen, dagegen wohl die einzelnen Stengel mit noch an der Spitze ausgebreiteten Blättern. Diese Art muss vollständig einen sehr bedeutenden Uinfang gehabt haben, und kommt in einigen Spielarten vor, welche sich wieder den folgenden Arten so nähern, dass es oft schwer wird, eine richtige Grenze zu ziehen.

4) Eine 3te andere Art, die viel kleiner bleibt und in alten wie in jungen Exemplaren sehr kurze abgerundete Fiederchen mit etwas veränderter Nerven-Bildung hat, nenne ich Phl. brevipinnata.

5) Eine Spezies mit sehr schmalen und bis zu $6^{\prime \prime}$ langen Fiederblättchen hat eine ähnliche Nerven-Bildung, wie Phl. polypodioides Ad. BrongN., und einen glatten, nicht wellenförmigen Rand: Phl. longipinnata.

6) Eine 4te Art, welche eben so schmale und lange Blattfiedern hat, ist am Rande der Fiedern sägeartig gezähnt und hat eine komplizirte Nerven-Bildung: Phl. serrata.

7) Die 5te Art hat sehr breite Fieder-Blättchen und so vielfach verzweigte und anastomosirende Nerven, dass sie bisher in einigen Sammlungen für Dikotyledonen-Blätter gehalten wurden; sie kommt auch im Keuper von Bamberg und Coburg vor (vid. Berger Versteinerungen der Coburger Gegend, Tab. IV, fig. 1, 3, 4, 5 und 7 ) und scheinen zur Phl. Nilsonii Ad. BR. zu gehören; andere Blätter haben grosse Ähnlichkeit mit Phl. Phillipsii. 
Bei allen diesen Arten von $\mathrm{Ph}$ le b opter is sitzen die Blätter büschelweise oder fächerförmig an langen Stengeln; ganz junge Blätter sind zusammengerollt. Dieses nämliche Vorkommen findet sich auch bei einer eigenen Abtheilung von Pecopteris in der hiesigen Keuper-Formation, welche hinsichtlich ihrer Blattnerven zu Ad. Brongniart's Abtheilung der Pteroiden gehören würde. Die Blätter sind bei den mir bekannten Arten an der Spitze langer Stämme Fächerförmig zu 5 bis 9 und mehr Stück ausgebreitet, sowohl bei den alten, als den ganz jungen kleinen Exemplaren, obgleich bei den letzten stets nur 5 Blätter gefunden werden. Von 3 Arten haben sich Exemplare init den an der Spitze der Stengel sitzenden Blättern gefunden.

8) Am vollständigsten sind einige Exemplare von der Pecopteris longicaulis. Das eine davon hat einen über 6" langen Stengel, welcher oben $2^{\prime \prime \prime}$, unten nur $1 \frac{1}{2}{ }^{\prime \prime}$ dick ist; oben an der Spitze erkennt man deutlich' wenigstens 9 Blätter, welche sehr fächerförmig ausgebreitet sind, so dass die äussern Seitenblätter etwas herabhängen. Man glaubt ein haumartiges Fahrenkraut im Kleinen zu sehen. Die Blätter gleichen etwas denen von Pecopteris lonchitica Ad. Bronan. pl. 84 , fig. 4 u. 6 ; die Fiederblättchen sitzen jedoch noch näher zusammen. Die unten nah an der Basis des Stengels sitzenden Blattfiedern sind sehr kur'z und werden gegen die Mitte des bis zu " "langen Blattes am längsten, nehmen aber gegen die Spitze zu wieder ab. Die Blattnerven sind theils einfach, theils doppelt gegabelt. Die Fruktifikationen sind wie bei Pecopteris crenifolia Phillips, pl. VIII, fig. 11 und 12, welche von Ad. BrongNiart ohne Nerven abgebildet (l. e. pl. 132, fig. 1, und pl. 133, fig. 2) und Phlebopteris propinqua benannt worden ist. Diese Art kommt in Keuper-Mergel von Phantaisie vor.

9) Pecopteris polypodioides. Vom Stamm ist nur ein Bruchstück von $1 \frac{1}{2}$ " Länge vorhanden, welches etwas über eine Linie breit ist; aus diesem breiten sich 7 bis $\mathrm{S}$ 


\section{$-514$}

grosse Blätter fächerförmig aus. Schon an der Basis des Stengels fangen die Fiederblättchen an, erst nur 3 bis 4 Linien lang, dann länger bis zu $1 \frac{1}{2} "$. Die Gestalt der Blätter ist gerade so, wie bei Phlebopteris polypodioides Ad. Brongr. pl. 83, fig. 1; die Blattnerven aber sind gegabelt, wie bei Pecopteris longifolia Phill. pl. VIII, fig. S. Die Fruktifikationen erscheinen unter den Blättern wie kleine sternförmige Punkte in 2 Reihen neben der Mittel-Rippe, fast wie bei Phlebopteris §propinqua Ad. BRonGN., jedoch nach Verhältniss nur halb so gross.

10) Pecopteris angustifolia. Aus einem gemeinschaftlichen Stamm breiten sich 5 bis 6 Blätter fingerförmig aus, an welchen die Blattfiedern, wie bei den vorigen Arten, schon an der Basis anfangen; die ersten 7 bis $S$ Fiederchen sind sehr kurz, fast halbzirkelfürmig wie bei P. Desnoyersii, Ad. Br. pl. 129, fig. 1; dann folgen unmittelbar lange schmale glattrandige Fiederchen von $\frac{1}{2}$ "Länge, welche in der Mitte des langen Blattes 2" Länge erreichen, aber nur etwas über eine Linie Breite haben. Das Blatt gleicht sehr der Phlebopteris propinqua Ad. Br., pl. 132, fig. 1 und pl. 133, fig. 2, und hat die nämlichen grossen Stern-förmigen Fruktifikationen, so dass es nur durch den wellenförmigen Rand der Fiedern unterschieden ist. An einigen Blättern sitzen auch die Fruktifikationen so nahe beisammen, dass sie fast die untere Blattseite bedecken und die einfach gegabelten Nerven nicht zu erkennen sind. Letzteres scheint auch der Fall bei den von Brongiart abgebildeten Blättern gewesen zu seyn, da die Nerven weggelassen sind; auch Puiluips hat pl. S, fig. 11, hei der sehr ähnlichen P. crenifolia keine Nerven abgebildet.

11) Ausser diesen 3 langstieligen Arten von Pecopteris kommen noch Bruchstïcke von verschiedenen Arten vor, welche ebenfalls in diese $\mathrm{Abtheilung} z u$ gehören scheinen. Eine Art mit kleinen schmalén Blättern hat Fruktifikationen, 
genau wie bei Phlebopteris Schouwii Ad. Brosar. pl. 132 , fig. 5.

12) Bei einer andern Art sind die Blattfiedern, welche so eng am Blattstiel zusammensitzen, dass sie sich berühren, durch die Fruktifikationen in 2 Reihen Quadrate getheilt, welche dem ganzen Blatte ein gegittertes Ansehen geben. Auf jedes Quadrat kommt ein 2- bis 3mal gegabelter Seiten-Nerv: Pecopteris clathrata.

13) Aus Brongmiart's Abtheilung Neuropteroides kommen verschiedene Arten $\mathrm{Pecopteris} \mathrm{im} \mathrm{hiesigen} \mathrm{Keu-}$ per vor; einzelne Bruchstücke davon gleichen der P ec. Whitbiensis Ad. BR. pl. 109, fig. 2-4, der Pec. tenuis Ad. Br. pl. 110, fig. 3, 4, der Pec. Beaumontii Ad. Br. pl. 112, fig. 3, der Pec. Williamsonis Ad. Brongn. pl. 110, fig. 1, 2, und der Pecopteris Meriani Ad. Brongn. pl. 91, fig. 5 und gehören wohl zu diesen Arten.

14) Eine andere grössere Art hat ganz das äussere Ansehen und die Nerven-Vertheilung des Genus Neuropteris, allein die Fiederchen sind mit. ihrer Basis an die Spindel angewachsen: sie scheint mir neu zu seyn; ich habe sie Pecopteris Braunii genannt.

15) Eine doppelt gefiederte Art, von welcher ich ein grosses Blatt gefunden habe, hat Blattfiedern, welche in der Nähe des Hauptstiels der Pecopteris recentior Phill. pl. 8, fig. 15 an den Spitzen der obern Seitenfiedern aber der P. hastata Phill. pl. S, fig. 15, gleich kommen.

16) Auch aus der Abtheilung der Sphaenopteroides Bromgniart's kommen einige Arten Pe copteris im Bayreuther Keuper in ziemlich vollständigen Exemplaren vor, deren doppelt und dreifach gefiederte Blätter rasenförmig beisammensitzen; die einzelnen Blattfiedern, von welchen einige im nächsten Hefte von Sternberg's Flora der Vorwelt werden beschrieben werden, sind aber so verschieden, dass man beim Mangel vollständiger Pflanzen 4 bis 5 Arten vor sich zu haben glaubt; einige gleichen denen von Pec. cristat a $\mathrm{A}_{\text {D. Br., }}$ pl. 125, fig. 4, 5; andere der P e c. 
Schönleiniana AD. BR., pl. 126, fig. 6; einige der Pec. Sulziana Ad. Brongr., pl. 105, fig. 4, und andere Bruchstücke scheinen neuen Arten anzugehören. Einzelne Blätter zeigen Fruktifikationen, ähnlich denen von Pecopt. curtat a Phill., pl. S1, fig. 12.

17) An Cycaditen finden sich in der oben bemerkten Lettenkohle ebenfalls einige neue Arten, unter andern $\mathbf{P}$ terophyllum angustissimum, eine sehr zierliche Pflanze mit langen sehr schmalen Fiederblättchen. Im Allgemeinen sind die Blätter zwar denen von Pterophyllum Jaegeri Ad. Br. ähnlich, allein die Fiederchen sind nicht halb so breit und kürzer, so dass sie dem Cycadites pecti-

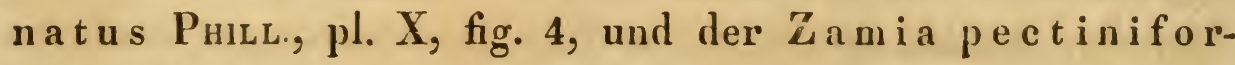
$m$ is näher kommen. Das grösste vollständige Blatt meiner Sammlung ist 9" lang, die einzelnen Fiedern $\frac{1}{2}$ " bis $\frac{3}{4}$ " lang und $\frac{3}{4}$ "' breit.

18) Pterophyllum variabile. Bei den Blättern dieser Art ist die Breite der einzelnen Fiederchen sehr veränderlich, da sie bald die einfache Breite von $\frac{5}{4}$ "', bald die doppelte von $1_{2} \frac{1}{2}$ ' bis $3^{\prime \prime \prime}$ haben. Die Länge derselben ist Ewischen 6" bis S" $^{\prime \prime}$. Die Mittelrippe des Blattes hat, wie bei der vorigen Art, eine Reihe erhabener Punkte in der Mitte.

19) Pterophyllum latifolium hat kurze Blattfiedern, welche gegen $3^{\prime \prime \prime}$ breit und nur $6^{\prime \prime \prime}$ lang sind. Die feinen Nerven sind wie bei $\mathbf{P}$ t. Jaegeri Ad. BR.

20) Vom Genus Nilssonia Ad. Br. kommen 5 Arten vor, die mir neu scheinen. Die grösste Art hat $\frac{3}{4} "$ breite und 2 bis $2 \frac{1}{2} "$ lange sehr zugespitzte Blattfiederu; es sind jedoch nur Bruchstiicke des Blattes gefunden worden.

21) Die kleinste sehr zierliche Art hat so kleine Fiederblätchen an dem langen Blattstiel, dass die Nerven nicht deutlich zu erkennen sind; parallel mit dem Rande lauft ein vertiefter Eindruck um die Blattfiederchen: ich nenne diese Art Nils. elegantissima.

22) Nicht viel grösser ist eine andere Art, an welcher 
die breiten Fiederchen fast immer zusammengewachsen sind; das ganze Blatt ist kaum $2^{\prime \prime \prime}$ breit, wie ein Fiederblättchen von Pecopteris angustissima; ich nenne sie Nils. contigua.

23) Sehr gross mit stumpfen, zum Theil zusammengewachsenen Fiederblättchen ist $\mathrm{Nils}$ s peciosa.

24) Den Übergang zwischen den beiden letztern Arten bildet Nils. intermedia.

25) Ausser den bemerkten Pflanzen kommen noch Bruchstücke anderer Arten; Samenkörner, viele Stengel und Stämme etc. vor, welche ich noch nicht Zeit hatte zu untersuchen. Von den neuen Arten lasse ich gute Abbildungen der schönsten Exemplare für Graf Sternberg zeichnen. 


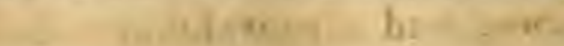

Die

\section{Phosphate des Eraberges}

bei Amberg,

von

Herrn Ober-Bergrath von Vorтн.

Seit mehr als 5 Jahrhunderten *) wird das Innere der Umgegend von Amberg nach ihrer ganzen Erstreckung und bis auf die Teufe des Wasserspiegels durch Bergbau abwechselnd aufgeschlossen; seit $1764 \%$ ) besitzen wir durch voN LORIS unermüdete Forschungen eine bergrechtliche Ge-é

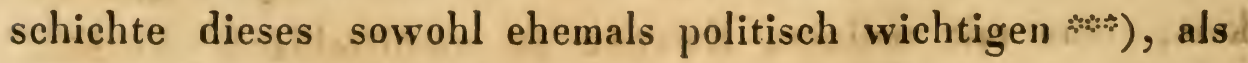
jetzt noch mineralogisch merkwürdigen $\dagger$ ) Bergreviers, wie sich deren kaum ein anderes rühnen kann; seit 1792 liegt die bergmännisch-technische Darstellung des Bergbaues in

*) Die älteste Urkunde ist von 1326 , setzt aber ein viel hüheres Alter des dortigen Bergbaues voraus.

*) Sammlung des Baierischen Bergrechts.

*) Ambergs Handel mit seinem Produkte (Eisen) ging einerseits bis Kionstantinopel, andrerseits bis Stucliholm.

†) Das Eiscustein-Lager erstreckt sich nordwärts von Schuabelweiss und kî́berg bei Regensburg über Kinlmind Leonberg, Bodenwöhr, Ensdurf, Altenricht, Engelsilorf, Krimbach, Amberg, Siebeneichen, Sulzbach, Miles, Langenbruck, Küniystein, Krotongen und Nasliz; westwärts über Kelheim, Weltenburg und Hirnheim, jedoch immer in abgerissenen, oft sehr weit entfernten Mittelu. 
selbem und die oryktognostische Beschreibung der Erze und einiger ihrer zufälligen Begleiter von FLURL *) vor den Augen des gelehrten Publikums; seit Jahrzehenden hat kaum e in reisender Mineralog die Oberpfulz besucht, ohne dem Erzberge einige Augenblicke seine Aufnerksamkeit zu schenken; dennoch sind heute noch seine geognostischen Verhältnisse und sogar seine oryktognostischen Fossilien (die Petrefakten ausgenonmen) w), wenn ich den geognostischen Systemen und oryktognostischen Lehrbüchern trauen darf, noch so unbelsannt, als wäre erst vor wenigen Jahren daselbst ein unbedeutender Bergbau unternommen worden.

Zwar ist auch die Absicht der gegenwärtigen Abhandlung nicht, in eine umständliche Zergliederung der geognostischen Verhältnisse desselben einzugehen; da aber selbst die schulgerechteste oryktognostische Beschreibung eines Minerals nach äussern Kennzeichen, physischen Eigenschaften und chemischen Bestandtheilen ohne eine, sey es auch nur allgemeine, Andeutung des geognostischen Vorkommens den dermaligen Forderungen der Wissenschaft nicht mehr entspricht; so bin ich wohl genöthigt, eine liurze geognostische Beschreibung des Erzberges und seiner Umgebung vorauszuschicken, werde mich jedoch nur auf Dasjenige beschränken, was mit meinem $Z_{w e c k e}$ in unmittelbarer Verbindung steht.

Der Erzberg bei Amberg ***) ist ein Glied jener Hügelkette, welche von ihm nach S.O. über den Galgen - und Mariahilfs-Berg nach Krumbach, Engelsdorf, Paulsdorf und Altenricht, nach N.W. über Karmensülden, Rosenberg und

*) Beschreibung der Baierischen und Oberpfälzischen Gebirge.

*) Noch in Hefte III, S. 300 dieses Jahrbuches von 1831 heisst es bloss, dass Kakoxen später auch in Baiern benerkt wurde. Auch in Burs's Lelirbuch der Oryktognosie von 1832 ist der Fundort Ambery nicht aufgeführt.

*) In der Oberpfalz gibt es melirere Gebirge, welche Erzberg ge: nannt werden. 
Sulzbach sich verlängert, mehrmalen von Schluchten durchschnitten wird, und die äusserste Grenze der Jura - und der sie fast allenthalben begleitenden Grünsand-Formation bildet. Ke uper-Sandstein (?) von graulich oder gelblichweisser Farbe und manchfaltigem Korn, meistens ohne sichtbares Bindemittel, von verschiedener Festigkeit, mit bald häufigen bald sparsamern röthlichen Feldspath-Körnern und mit Lagen und Nestern graulichblaulichen oder schwärzlichgrauen plastischen Thones unmittelbar auf Granit ruhend erscheint längs der ganzen Erstreckung der Hügelkette als die tiefste Unterlage. Wenige Fusse unter seiner Oberfläche tritt ein, meistens kaum $6^{\prime \prime}$, zuweilen aber auch bis $4^{\prime}$ mächtiges, Lager unten röthlichbraunen und gewöhnlich sehr sandigen, oben dunkelzinnoberrothen reinen $T$ hon-E is ensteins auf. Bald erhebt er sich, aus S.O. sänftig ansteigend, in Gestalt von Hochebenen, Rücken und Kuppen zu einer beträchtlichen Höhe, bald senkt er sich gegen N.W. mehr oder weniger steil abstürzend bis unter den Grund des Hauptthales. Er ist in Bänke von verschiedener Dicke getheilt, welche gegen S.W. sich neigen. Nach dem Streichen folgen sowohl die Ablosungs-Flächen der Bänke als das Eisenstein-Lager genau den Biegungen der Oberfläche. Vertikale Klüfte durchsetzen ihn unter stumpfen Winkeln, und sondern ihn dadurch in parallelepipedische Blöcke, haben aber nur selten eine merkliche Störung in der ursprünglichen Lagerungs-Richtung hervorgebracht.

Ein rauchgrauer, kalkiger, ziemlich grobkörniger $S$ andstein, der nach den eingeschlossenen Petrefakten zur Lias-Formation gehört, überlagert scharf abgeschnitten den Keuper-Sandstein. In den Senkungen des letztern erreicht er meistens eine ansehnliche Mächtigkeit, auf dessen höhern Punkten lingegen verliert er sich verhältnissmässig immer mehr und hin und wieder ganz, und bedeckt dann nur dessen südöstliches und südliches, seltner auch dessen südwestliches Gehänge. $\mathrm{Er}$ besteht aus Bänken von verschiedener Dicke, welche nur eine sehr geringe Neigung 


\section{- $521-$}

aus N.W. in S.O. und aus N.O. in S.W. haben, und ebenfalls, aber unregelmässiger von vertikalen Klüften durchsetzt werden, ohne die Lagerung merklich zu verrücken.

Bald unmittelbar auf diesem Sandstein liegend, bald mit dieser obern, nun schieferigen Lage wechsellagernd, bald von einer dünnern Schicht des Lias - Schiefers unterlagert, steht ein zweites unten gelblichbraunes, oben kirschrothes, stellenweise von etwa $2^{\prime \prime}$ bis über $2^{\prime}$ mächtiges Thoneisenstein-Flötz an, welches in den ersten beiden Fällen vielen Sand aufgenommen hat, und im letzten, verbunden mit einiger Mächtigkeit, in die Eisenniere übergeht. Es enthält gewöhnlich einige der der Lias-Formation eigenthümlichen Petrefakten, zuweilen aber auch nur deren Abdrücke.

Von Paulsdorf aus sich allmählich erhebend zieht der Lias-Schiefer über den Galgenberg und Neuricht und endlich über die nicht unbeträchtlichen Anhöhen bei Immenstälten und Ḧ̈hengau hin. Weder dieses Ansteigen, noch die gross wellenförmige $O$ berfläche, noch die manchmal über 6" klaffenden vertikalen Klüfte äussern einen merklich störenden Einfluss auf die nur wenig aus N.W. in S.O. und aus N.O. in S.W. geneigten Blätter und Bänke. Eine der Bänke führt, dem Erzberge nach S.O. gegenüber, den $\boldsymbol{B} \Omega$ logneser Spath in Gesellschaft mit krystallinischen GypsNieren, und einen etwas tiefer liegenden 6seitig-prismatischen Selenit *).

Auf dem Lias-Schiefer ruht, an dessen südwestliches Gehänge angelehnt und bald stumpf abgeschnitten, bald übergehend, der nach unten groblë̈rnige und ziemlich feste, nach oben allmählich kleinkörnige und lockere jüngere Lias-Sandstein in mehreren an Mächtigkeit, Kor'n und Farbe sehr abwechselnden Bänken. Auch diese zeigen nur eine äusserst geringe Neigung aus N.W. in S.O. und aus N.O. in S.W.,

*) Dic übrigen nicht hieher bezüglichen Vorkommen glaube ich unerwähnt lassen zu dürfen. 
und setzen jenseits der zuweilen einige Fuss weiten Klüfte darin unverrückt fort. In dem kleinkürnigen Sandsteine findet man fast allenthalben 2 Thoneisenstein-Flötze. Das untere, körniger. Thoneisenstein, weiter gegen W. meistens sehr feinkörnig und 2 bis $4^{\prime}$ mächtig, besteht hier aus Linsen - bis fast Bohnen - grossen Körnern und misst 2 bis $4^{\prime \prime}$ in seiner Mächtiglkeit. Das zweite, nur wenige Fuss darüber entfernte, ist feinkörniger Thon-Eisensandstein und hier 3 bis $6 "$ mächtig. Nur an wenigen Stellen (auf dem Mariahilfs-, dem Galgen- und dem Erz-Berge) ist auch das Daseyn des, diesem Sandstein ebenfalls angehörigen oolithischen Eisensteines zu erkennen. Überall liegt der letztere hier dem darüber gelagerten Jurakalke so nahe, dass er mehrere Zoll tief von unten in denselben eingedrungen ist. - Wie der Keuper-Sandstein bildet dieser Lias-Sandstein, wo er mächtiger und, so zu sagen, selbständig auftritt, ziemlich hohe verschieden gestaltete Rücken und Kuppen, deren Oberfliiche jedoch beinahe in eine und dieselbe HorizontalEbene zu fallen scheint. Nirgend erstreckt er sich gegen N.O. weit jenseits des Jura-Kalkes; dagegen ist er hin und wieder auf dem Liasschiefer übergreifend gelagert.

Sowohl der dichte als der dolomitische $\mathbf{J}$ ura-Kalk erscheint, gleich den vorhergehenden Gebirgs-Arten, durchgehends nur auf dem südwestlichen Gehänge der Hügelkette, und, obschon selten in einiger Mächtigkeit, doch gewöhnlich wie jene verhältnissmässig am mächtigsten gegen das südöstliche Ende jedes Kettengliedes. Eben so neigen sich die $\frac{1}{2}$ bis 12' dieken Bänke mit einem Fallwinkel von wenigen Graden aus N.O. in S.W. und aus N.W. in S.O. Die vertikalen Klüfte, welche ihn in verschiedenen Richtungen durchsetzen, wechseln in ihrer Breite von kaum $1^{\prime \prime \prime}$ bis zu $3^{\prime}$ und darüber, und werden von den Ablosungsfli:chen der Bänke, vorzüglich aber bei ihrem Übertritte aus dem dolomitischen in den dichten Jurakalk, manchfaltig aus der geraden Linie verrückt. - Nach der Erstreckung aus S.O. in N.W. begleitet er die Hügelkette ohne Unterbrechung; 
nach der Erhebung des Gehänges aus S.W. in N.O. hingegen findet er sich zum grössten Theile nur stellenweise, doch im Allgemeinen eine gewisse Regelmässigkeit beobachtend. In S.O. jedes Kettenglieds bedeckt er nämlich das Gehänge von dessen Fusse bis zum Rücken und meistens sogar in übergreifender Lagerung. Je weiter man gegen N.W. vorschreitet, desto mehr entfernt er sich vom Fusse, so dass er zuletzt den Kuppen und Rücken nur schildförmig aufliegt. Hie und da fehlt in diesem Falle auf solchen Punkten auch bald der jüngere Lias-Sandstein, bald mit ihm der Lias-Schiefer, bald die gesammte Lias-Formation, so dass der Keuper-Sandstein zu Tag ansteht.

Die jüngste Gebirgs-Art, auf welcher sich das erwähnte, über einen Flächenraum von mehreren Quadrat-Meilen ausgebreitete Eisensteinflötz gelagert hat, ist der Jurakalk "). Allein selten liegt es unmittelbar auf diesem als ganzem Gestein; gewöhnlich hat sich ein Kalk - und Hornsteiı-Gerölle desselben zwischengelagert. Häufiger sind die Stellen, wo es von einer der, die Grünsand-Formation konstituirenden Sand- oder Thon-Schichte unterlagert wird, und sogar bald mit der einen bald mit der andern wechsellagert *). Ja! die einen oder die andern und selbst alle diese Erscheinungen vereinigen sich hin und wieder innerhalb eines Fliichenraums von wenigen $\mathbf{1 0 0}$ Quadrat-Lachtern. - Das Flötz ist vielfältig unterbrochen; die Erzmittel liegen bald weit voneinander entfernt, bald nahe nebeneinander - bald am Fusse, bald verschieden hoch auf den Abhängen der Hügel, aber stets auf den nach S.W. gekehrten

*) So bei Schu'abelweiss, Kalmúng, Leonberg, Muhlós, Kelheim, Weltenburg u. s. w.

$\Rightarrow$ A Ausserdem sind seine Unterlagen: 1) von einem innigen Gemenge aufgelösten Jurakalkes und Liasschiefers gehundener oolithischer und körniger Thoneisenstein auf der Bucher - und EgelsriederZeche bei Bodenwöhr; 2) körniger Thoneisenstein mit Liasschiefer auf dem Galgen- und zum Theil auch auf dem Erz-Berge bei Ambery und zu Langenbruck; 3) Keuper-Sandstein zu Engelsdorf u. s. w.

Jahrgang 1836. 
und, wenn sie sich genähert sind, aus S.O. nach N.W. aufsteigenden, - meistens in Mulden, Kesseln und ähnlichen Vertiefungen eingeengt: nur ausnahmsweise in Ebenen ausgebreitet. - Seine bei Weitem vorherrschende Errführung besteht aus dichtem Brauneisensteine *), dessen Klüfte und Höhlungen meistens mit verschieden gestaltetem, bald bunt angelaufenem, bald von Brauneisenrahn überzogenem faserigem Brauneisensteine bekleidet 'und nicht selten, von Krummbach anfangend, auf,allen nordwestlichen Erzmitteln im obern Theile des Flötzes mit grössern oder kleinern Massen krystallisirten grauen Braunsteines mehr oder weniger ausgefüllt sind. Er enthält zuweilen Partieen eisenschüssigen kohlensauren Zinkoxydes und geht stellenweise in schaaligen und stängeligen Thoneisenstein, und unter noch nicht hinlärglich ausgemittelten Lagerungs-Verhältnissen in Gelberde über **). Auf 'Thon gelagert ist er von fremden Einschlüssen frei; wemn er hingegen auf jenem Kalk- und IIornsteinGerölle oder einem der Sandsteine ruht, so hat er stets mehr oder weniger und zuweilen so viel davon aufgenommen, dass er nur als Bindemittel erscheint. Versteinerungen enthält er ursprünglich nicht; die hin und wieder gefundenen stammen, je nach ihrer Lagerung in demselben, entweder aus der Jurakalk-, oder der Lias-, oder der GrünsandFormation ab.

Von der um Amberg überhaupt nur wenig entwickelten Grünsand-Formation erreicht den bezeichneten Iliigelzug fast ausschliesslich nur die untere Gruppe - Thon, loser Quarzsand und Sandstein von verschiedener Farbe und Beschaffenheit, mehrmalen wechsellagernd und verschieden mächtig $\%$; doch scheint, nach den bisherigen

*) Ich glaubte, der Deutlichkeit wegen, der Wernen'schen Schule folgen zu müssen.

"*) Auch ein brennend-kochenillrother Ocker kam ehedew häufig vor, und wurde von den Malern sehr gesucht.

wa) Der Tripel, hier das oberste Glied der Formation, tritt beinahe allenthalben unmittelbar darüber auf. 
Beobachtungen, auch nur längs denselben jene Schicht teigartig - weichen, an der Luft schnell erhärtenden Fluss - und Phosphor-sauren Kalkes, welche allem Anscheine nach in Beziehung auf die Phosphate eine wichtige Rolle spielt, als untergeordnetes Glied der Formation vorzukommen *). Ihre Lagerungs-Stelle in der Reihenfolge zu erforschen, habe ich mich vergebens bemüht; kleine Schurf-Versuche auf dem Ausgehenden der Formation, den Rücken des Erzberges entlang haben bloss gelehrt, dass sie von einer nach unten ziemlich grob-, nach oben sehr fein-körnigen thonigen Quarzsand-Schicht und dann von Tripel bedeckt wird, und bald auf einer ähnlichen Sandsteinschicht, bald unnittelbar auf dem Eisenstein-Flötze liegt. - Die untern Thonlagen der Formation führen, besonders in der Nachbarschaft des Eisensteinflötzes, vielfältig Nieren konzentrisch-stängelig abgesonderten Brauneisensteins (verwitterte Eisenkies - Nieren), theils mit krystallisirter, theils mit gameiner Oberfläche, so wie derben und krystallinischen retraktorischen Magneteisensteins und Nester grauen Braunsteins.

Durchgehends ist das nordöstliche Gehänge des gesammten Hïgelzuges und die nordwestliche Abdachung jedes einzelnen Hügels beträchtlich steiler geneigt, als das südwestliche Gehänge und die südöstliche Abdachung.

Nur in geringfügigen Nebendingeu, was in Gebirgen dieser Art auf einzelnen Stellen überall gefunden wird, weicht der Erzberg bei Amberg von dem geschilderten allgemeinen Formations-Charakter ab. Seiner südöstlichen Abdachung hat der Durchbruch der Vils, der ihn jetzt von dem in dieser Richtung einst anstossenden Galgenberge trennt, ein fremdartiges schroffes Ansehen gegeben. Hier liegt am Fusse des südwestlichen Gehänges in einer (gemeinschaftlich mit dem in S.W. gegenüberstehenden, gegen N.O. steil

*) Gegen S.O. zcigen sich Andeutungen ihres Daseyns auch noch auf der Pingarten-Zeche bei Bodemö̈hr. Von andern Punkten fehlen die Beobachtungen. 
abfallenden Eisberge gebildeten) ungefähr bis zu dessen halber Höhe allmählich nach N.W. ansteigenden Mulde der erste ergiebige Erzpunkt (der vordere Erzberg). Er erhebt sich aus der Tiefe derselben nach ihrer ganzen Erstreckung hin, mit allen ihn konstituirenden Schichten auf jenem Gehänge über den Jura-Kalk sich verbreitend und mit regelmässig fortschreitender Abnahme seiner Mächtigkeit, aus S.O. gegen N.W. allmählich bis an und endlich übergreifend bis auf den Kamm des Hügels. Auf dieser Stelle hat zwar die oben angefühte Fluss - und Phosphorsaure Kalkschicht unfern vom Kamme hin und wieder eine Mächtigkeit von 2-3 Fussen; allein sie liegt meistens nur wenige Zoll unter der Ackerkrume, und ist durch den Ackerbau und durch das, von den wiederholten BergbauUnternehmungen veranlasste Abrutschen des ganzen Gehänges in ihren Lagerung,-Verhältnissen so zerrüttet, dass man sie nimmer zu erkennen rermag *). Im Dache dieses Erzmittels wurde zuerst der anfünglich für $\mathrm{Z}$ e olith $*$ angesprochene, dann als Lasionit bekannt gemachte $\mathrm{W}$ avellit beobachtet. Ausserdem wurde aber auf demselben bei Eröffnung eines alten Stollens in kröupeligem Eisensteine zwischen 1805 und 1807, an einem ziemlich nahe zu Tage liegenden Punkte kirystallisirtes Eisenblau entdeckt.

Beiläufig in der Mitte des Erzberges befindet sich der zweite mächtige Erzpunlit (der mittle Erzberg), in eine kesselförmige Verticfung des Jura-Kalkes eingeschlossen, ursprünglich sehr nahe gegen den Rücken des Hügels hinaufgerüclit, nun aber durch mehrmaligen Abbau in einen mehrere Lachter tiefen Sumpf (Huhle genannt) verwandelt. Die Lagerung ist daher gänzlich zerrüttet. Überdiess sind die Ründer des Kessels von alten und neuen Halden

") Mehrere 100 Fuhren des erhärteten Phosphorites sollen nach der Aussage alter Berglcute ehedem als Scliutt auf dic Strasse gefahren worden seyn.

**) FuUri's Bescbreibung der Baierischen und Oberpfälzischen, Gebirge', S. 550 . 
und Pingen allenthalben so bedeckt, dass man kaum hoffen darf, irgendwo die unverwundete Oberfläche zu treffen. Einzelne verlorene Stücke des Eisensteines zeigten jedoch vor wenigen Jahren noch unverkennbare Überbleibsel von Erdeund Metall-Phosphaten *).

Am zussersten nordwestlichen Ende des Erzberges ist auf einer kleinen Ebene des südwestlichen Gehänges, beträchtlich höher als das vorhergehende gelegen, das dritte letzte mächtige Erzmittel (der hintere Erzberg) ebenfalls in eine kesselförmige Vertiefung des Jura-Kalkes eingelagert. Auch dieses wurde ehemals nach seinem ganzen Umfange bebaut, aber, wie man aus der geringen Senkung der Oberfläche schliessen muss, auch bald wieder verlassen. In der jüngsten Zeit belegte man dasselbe abermals, und ersank mit einem nicht ferne vom nordwestlichen Rande des Kessels abgeteuften Schachte im Dache des Eisenstein-Flötzes eine reiche Niederlage von $\mathrm{W}$ avellit und $\mathrm{K}$ akoxen. $\mathrm{Ob}$ auch die teigartig-weiche Fluss- und Phosphor-saure Schicht getroffen wurde, konnte mir kein Bergmann sagen, und ich aus der Halde nicht mehr ermitteln. - Das Vorkommen jener beiden Phosphate bietet eine merkwürdige Erscheinung für den Geognosten dar. Von einer strenge eingehaltenen Scheidelinie aus wurde nämlich mit den Strecken in nördlichen Richtungen ausschliesslich $W$ avellit, in südlichen ausschliesslich Kakoxen erbrochen. Den Wavellit begleitete eine nicht bedeutende mächtige Lage sehr Braunstein-haltigen Eisensteins (Schwarz-Eisenstein?), und vorzüglich häufig und weiss erschien er auf dieser.

*) Das dem feinkörnigen Lias-Sandstein untergeordnete Sandeisenstein-Lager, welches längs dem Erzberge eine Mächtigkeit von mehreren Lachtern hat, ist hier auf den Klüften vielfältig nit einem Steinmark-ähnlichen Mineral in konzentrisch-schaliger halbkugelförmiger Gestalt begleitet. Der frische Bruch scheint ein verstrickt-faseriges Gefüge zu verrathen. 


\section{$-528-$}

Die Ausbreitung des einen wie des andern gegen S.O. betrug nur etliche Lachter*).

Da sämmtliche Erzpunkte schon öfter bebaut wurden, so kann man allerdings die Frage aufwerfen, ob das krystallisirte Eisenblau, der Wavellit und der Kakoxen wenigstens in gewisser Art ursprünglich oder, veranlasst durch den Bergbau, später (sekundär) entstanden sind. Vieles spricht für das Frrste, aber auch Vieles für das Zweite. Durch die Abrutschungen und Niederkesselungen wurde den Tagewässern der Zutritt in das Innere der Schichten geöffnet, damit jener theilweisen Auflüsung der Fluss- und Phosphor-sauren Kalkschicht der Weg gebahnt, und damit die Möglichkeit, ja hohe Wahrscheinlichkeit der spätern Entstehung gegeben. Diese wird anscheinend bis zur Gewissheit gesteiger't, wenn man erwägt, dass im Kessel des hintern Erzberges die Schnee - und Regen-Wässer, mochte er auch danit bis zum Überfliessen gefüllt seyn, in wenigen Tagen versiegten, dass der Wavellit und Kakoxen dort in der Nähe einer Abrutschung ausschliesslich sich angesiedelt hatten und dass sogar während des letzten Abbaues sich weisse Guhren und stalaktitische Gebilde ${ }^{*}$ ) an dem Grubengezimmer ansetzten; dass endlich die Stelle, anf welcher das krystallisirte Eisenblau vorkam, bis in den Jura-Kalk auffallend zerrüttet war. Allein ebendaselbst wurden auch schon in den alten Halden und lose über Tag liegend kugelige Massen des Wavellits bis zur Grösse einer starken Mannsfaust,

*) (Aus später eingelaufenen brieflichen Nachrichten des Hrn. Verfs.) Der Wavellit hat sich auf dem hintern Eraberge auch in die Kluft des hie und da über dem Eisensteine ausgebreiteten Hornsteines hineingezogen. Er ist dann konzentrisch oder sternförmig angehåuft, faserig bis schmal strahlig und besonders von starkem Seidenglanze. Mit ihm zugleich ist auch der Scluwarzeisenstein eingedrungen, ohne jedoch die sehr weisse Farbe des Wavellits zu verdunkeln. Den Kern des Wavellits (Mittelpunkt) bildet hier eiu opakes bräunliches halbkugelförmiges Körnchen.

**) Wegen Mangels einer chemischen Untersuchung kann ich sie nicht nüher bestimmen. Säuren bewirkten kein Aufbraussen. 
und bei Krummbach im zuverlässig unverritzten Gebirge (es wäre dem, dass man einen anstossenden tiefen Hohlweg als Leitungs-Kanal annehmen wollte) und eben so bei Pingarlen (jedoch hier stets von ockergelber Farbe) hin und wieder Partieen desselben gefunden. Die gewichtigste Bedenklichkeit gegen die Hypothese späterer Einsinterung dünkt mir, besonders unter den e inf achen Verhältnissen, wie sie hier gegeben sind, die Thatsache, dass die dadurch erzeugten Mineralien, laut der bekannt gemachten Analysen, nicht nur von der Fluss- und Phosphor-sauren Urlage, sondern auch unter sich in ihrer chemischen Beschaffenheit und zwar nicht etwa bloss in quantitativer (worauf nach meiner Ansicht, wie schon aus den folgenden Beschreibungen der äussern Merkmale jener Mineralien erhellen dürfte, überhaupt kein zu grosser W erth zu legen ist), sondern und vorzüglich auch in qualitativer Hinsicht so wesentlich abweichen.

Dass ich mich mit den folgenden Beschreibungen jener Phosphate nicht strenge an die gewöhnliche Form und innerhalb der vorgezeichneten Grenzen gehalten habe, sollen mir, wie ich hoffe, nicht nur die Orylktognosten, sonder'n auch die Gengnosten gerne vergeben.

Der Phosphorit (Apatit), aus welchem das vorhin erwähnte Fluss - und Phosphor-saure Kalklager ohne alle fremde Beimischung and Beimengung besteht, erscheint unter viererlei äussern (iestalten. 1) Den bei Weitem vorherrschenden Theil bildet die in der Lagerstätte teigartigweiche Masse. In diesem Zustande ist sie gelblichweiss, mit einzelnen stärker gefärbten Partieen, - fast mager anzufühlen und im Anhauen und Kneten ziemlich kurz. Nach dem Trocknen klebt sie nur wenig zusammen, doch ziemlich stark an der feuchten Lippe, schmutzt äusserst leicht ab, und bekommt eine mehr oder weniger fette ockergelhe Farbe mit eingesprengten gelblich-weissen Punkten und Flecken. Im Wasser zerfällt sie schnell unter Entwicklung von häufigen Luftbläschen. Sio verschluckt die aufgetropfte Salpeter-Säure begierig, und wird davon ohne Anwendung 


\section{$-530$}

der Wärme kaum oder nur wenig und sehr langsam angegriffen. Trocken und nass knirscht sie milde unter den Zähnen, und hat einen eignen etwas bitterlichen Geruch. 2) Eine unzählige Menge verschieden grosser und gestalteter Konkrezionen (dichter Phosphorit oder Apatit) erfüllen den Teig. Die Grösse wechselt zwischen der eines Hirsekorns und eines Kindskopfes; die Gestalt ist ursprünglich manchfaltig sphäroidisch, meistens mit mehr oder weniger knolliger Oberfläche. Sehr häufig findet man aber auch ganz unversehrte Bruchstücke jeder Grösse mit vollkommen scharfen Kanten. Gewöhulich bersten nämlich die grössern Konkrezionen schon in der Lagerstätte nach allen Richtungen gleich den Mergel-Nieren, und nicht selten schliessen die manchmal weit klaffenden Spaltrisse selbst dergleichen Bruchstücke ein. Im Innern ist ihre Farbe Fleckund, mit der stellenweisen Oberfläche parallel, Streifen-weise gelblichweiss, verschieden satt ockergelb und hie und da lichter oder dunkler roth. Ihre Masse ist gleichartig erdigdicht und derbe, leicht mit dem Messer zu schaben und spröde. Das Verhalten' gegen die Säuren stimmt mit jenem des Teiges überein. 3) Bisher sammelten die Mineralogen diese Konkrezionen auf den Feldern, über welche sie auf eine nicht unbedeutende Erstreckung in grosser Anzahl zerstreut umher liegen. 4) Auch diese nur*) enthalten den faserigen Phosphorit oder Apatit, dessen allein in den oryktognostischen Werken erwähnt wird. Er bekleidet die Wände der Risse und theilweise auch die Oberfläche, und umhüllt die zwischen jenen eingeschlossenen und auf diese von ihm aufgekitteten Bruchstücke ${ }^{* *}$ ) in ein- bis fünf-facher

*) Weder im Innern noch auf der Oberfläche der aus der Lagerstätte gegrabenen Stücke war eine der zwei folgenden äussern Gestalten wahrzunehmen, obwohl alle Vorbedingungen dazu in gleichem Grade vorhanden waren.

*) Die letztern scheinen mir in Folge vorausgegangener Zerstörungen der primären auf die gegenwärtige sekundäre Oberfläche gelangt zu seyn. 
Überlagerung und meistens in kleintraubiger Gestalt. Obwohl die Lagen immer sehr dünne sind, so kann man sie doch mit Hülfe der dazwischenliegenden halbdurchsichtigen Streifen und des Suchglases deutlich unterscheiden. Er sitzt stets scharf abgeschnitten auf dem dichten auf; doch wird der letztere unverkennbar, bald in kleinerer bald in grösserer Errtfernung von der Berührungsfläche beginnend, allmählich dichter, fettlicher und durchscheinender im Bruche. Die übrigen Eigenschaften theilt er mit den bereits bekannten Phosphoriten. 5) Bis jetzt scheint den Oryktognosten ganz entgangen zu seyn, dass der Phosphorit auf dem Erzberge bei Amberg, auch krystallisirt erscheint. Wo er als solcher vorkommt, liegt er standhaft unmittelbar über dem faserigen *). Die Krystalle sind zwar durchgehends mikroskopisch-klein, gewöhnlich dicht zusammen- oder auch übereinander-gehäuft, oft innig verflossen und meistens stark Glas-glänzend, dennoch hin und wieder schon unter einem guten Suchglase deutlich als wenig verschobene Rhomben mit etwas konvex-gebogenen Flächen zu erkennen **). Von oben besehen haben sie, wenn ihre Oberfläche rein ist, wegen ihrer Durchsichtigkeit die Farbe der Unterlage; von der Seite (im Querbruche) zeigt sich die derbe Masse derselben lichtegrau. Eingedrungene Eisenoxyd-Auflösungen (denn auch der krystallisirte Phosphorit saugt noch mit verhältnissmässiger Hast reines und tingirtes Wasser ein) ändern die Urfarbe verschieden ab. Graubraunes (§̣isen-, $\$$ Mangan -) Oxyd ${ }^{* * *}$ ) erfüllt die Haarrisse, überzieht die

*) Mehr als wahrscheinlich sind die durchscheinenden dichten lichtgrauen $Z$ wischenlager des faserigen Phosphorites, wenigstens auf der Oberfläche, krystallisirt.

$*$ Freilich stinmt diese Krystall-Form mit den bisher angegebenen nicht, dürfte aber doch in dás Krystallisations - System einzureihen seyn, wenn fernere chemische Analysen nicht etwa ein anderes Verhältniss seiner Bestandtheile nachweisen.

*\#z) Nicht selten überzieht auch ein Anflug von röthlichgelbem, gelblich-oder röthlich-braunem Eisen-Oxyde die Wändê der Risse und Spalten. Das graubraune bildet öfter Moos-ähnliche Dendriten. 
Oberfläche stellenweise, durchdringt selbst den 'Teig jener Stücke, vorzüglich deren, welche reichlich faserigen und krystallisirten Phosphorit führen*). - Von versteinerten organischen Resten sind mir ungeachtet aller Aufmerksamkeit nur ein paarmal im dichten Phosphorite Bruchstücke solcher Terebrateln zu Gesicht gekommen, wie sie der Grünsand enthält **).

Alle Oryktognosie'n geben den Wavellit nur als krystallisirt vorkommend an. Auch auf dem Erzberge bei Ainberg findet man ihn bei Weitem am häufigsten in dieser äussern Gestalt und in allen aufgezählten Gruppirungen, am seltensten jedoch in halbkugeliger Anhäufung. Ausserdem erscheint oder vielmehr (denn beide Fundörter sind nun abgebaut und verlassen) erschien er aber hie und da, abgesehen von dem vorhin erwähnten noch ungewissen Guhrund Stalaktit-Gebilde, auch verhärtet-erdig und dicht, und zwar nicht nur auf dem hintern Erzberge, sondern auch schon (weiter gegen S.O.) bei Krummbach. Auf der letztgenannten Grube war der dichte, frisch gebrochene glasigdurchsichtig, etwas ins Milch-Blaue spielend, erfüllte die Räume oder bekleidete als mehr oder weniger dicker Überzug mit kleintraubiger Oberfläche die Wände der Höhlungen und Klüftchen des Brauneisensteins, und hatte die Härte beinahe des Flussspaths. In kurzer Zeit wurde er allmählich trüber und endlich schwach-durchscheinend, bekam eine

*) Auch auf der Suttlerin bei Mitterteich und Fuchsmühl begleitet verhärtet erdiger Phosphorit (jedoch durch mehrere abweichende Merkmale ausgezeichnet) das in einen Basalt-Krater abgelagerte Eisenstein-Flötz.

*) Man wird mir zutrauen, dass nur erhebliche Bewegrgründe mich vernochten, nir so spät noch die Ehre zu vindiziren: dass ich zuerst auf das Daseyn des Phosphorites, des Kakoxens, des JuraDolomites und so manch audern Minerals (man sehe hieriber MocL's angreführte Zeitschrift) in meinem Vaterlande aufmerksam gemacht, dadurch Fure's Beschreibung der Baicrischen und Oberpfälzischen Gebirge bereichert und eine vollstïndigere Geognosie Baierns vorbereitet habc. 
schmutzig weisse Farbe, und verlor immer mehr den $\mathrm{Zu}$ sammenhang; gegenwärtig (freilich nach einem Verlaufe von 9 bis 10 Jahren) ist er, aller Vorsicht zum Trotz, fast ganz in einen nur schwach zusammenklebenden, je nach der Farbe des untenliegenden Brauneisensteins heller oder dunkler gelben, gelbrothen oder bräunlichen Mulm iibergegangen. - In den auf dem hintern Ersberge zu Tage liegenden Wave!lit - Kugeln zwischenlagert und umschliesst der dichte Wavellit den faserigen und strahligen, oder bekleidet die Wände der Höhlungen, stellenweise in diesen übergehend und auch scharf abgeschnitten. Er ist an der Oberfläche hin und wieder von eingedrungenem Eisenoxyde verschieden gelblich oder röthlich gefärbt, im Innesen aber standhaft schneeweiss, wenn auch der angrenzende faserige stark ins Graue zieht. So lange er auch den Einiwirkungen der Atmosphärilien ausgesetzt war, hat er doch so wenig als der faserige an Härte verloren. - Der aus der dortigen Grube frisch geförderte dichte Wavellit kommt; zum Theile als 1 bis $2^{\prime \prime \prime}$ dicker Über'zug mit kleintraubiger Oberfläche, schneeweisser Farbe und versteckt - faseriger 'Textur, zum Theile in unförmlichen, $\frac{1}{2}$ bis $\frac{3}{4}$ " dicken Platten vor, hat dann eine stalaktitische 0 berfläche, ist meistens von einer dünnen oder dicken Rinde faserigen Wavellits überzogen, mehr oder weniger mit verschieden farbigem Brauneisenstein mechanisch gemengt, daher lichter oder satter gelblichbraun gefärbt und merklich härter und bedeutend schwe:rer als der weisse. Er scheint den Übergang in $\mathrm{K}$ a k oxen (vielleicht auch ein zwischen beiden stehendes Mineral) zu bilden *).

Dieses wird mir noch um so wahrscheinlicher durch den Umstand, dass der reine Wavellit im Allgemeinen eben so häufig in dünnen Lagen, als der Kakoxen in dicker

*) Weisser, (von Eisen- und Kupfer-Oxyd) gelber, gelbbrauner, blauer und grüner Wavellit kommt auf einem. in, Spatheisenstein und Kupferkies - führendem, Thonschiefer aufsetzendem Quarzgange am Schwarzenberg bei Kemnath in der Obierpfulz vor. 
Anhäufung dem Brauneisenstein aufsitzt, dass die Oberfläche dieser Anhäufungen sich öfter der stalaktitischen Bildung deutlich nähert, und der Kakoxen sowohl chemisch als mechanisch Eisen-Oxyd in sehr manchfaltigen Verhältnissen aufnimmt, sogar dessen zuweilen so viel enthält, dass er einerseits gewissen lichte - gefärbten Abänderungen des zartfaserigen Brauneisensteins ähnelt, andererseits in dichten Kakoxen, höchstens mit versteckt-strahligem Bruche, übergeht. - An Manchfaltigkeit der äussern Gestalten steht er dem in der Grube Hrbek (dem ersten und bis jetzt einzig bekannten Fundorte) vorkommenden nicht nach, wenn er, kleine Nüanzen mit eingerechnet, ihn darin nicht übertrifft. So z. B. zeigt er, besonders als dünner Anflug, taubenhälsiges Farbenspiel, in Kugel-Abschnitten mikroskopisch kleinnierige Oberfläche u. dgl. Die merkwürdigsten und seltensten derselben sind, dass sowohl der halbkugelige als der flach ausgebreitete, wenn er eine etwas beträchtlichere $\mathrm{Di}$ mension erreicht, in Lagen von verschieden ockergelben Schattirungen wechselt, von einem dichten braunschwarzen pechgliinzenden Eisen-Oxyd (Stilpnosiderit @) ein-bis zweimal zwischen - oder über-lagert wird, kleine Partieen verwitterten Hornsteines einschliesst, oder Warellit überzieht, oder Moos-ähnlich oder dendritisch angehäuft erscheint, und dass er dreierlei Krystall-Formen nachbildet. - Alle AfterKrystalle haben vollkommen glatte Flächen und scharfe Kanten; alle sind zusammen-, doch die einen nur nebeneinander-, die andern zwei auch übereinander-gehäuft. Die einen der letztern stellen vollkommen rechtwinkelige oder, wenn je, nur höchst wenig verschobene, mit dichter Kakoxen-Masse erfüllte Würfel, - die andern sehr kleine rechtwinkelige niedrige dünne (tafelähnliche) 4 seitige Prismen mit 2 bedeutend breitern und 2 schmälern Seitenflïchen und meistens mehr oder weniger abgestumpften Seitenkanten bis zugeschärften Seitenflächen dar, sind unregelmässig hoh! und scheinen auf den Innenwänden mit Krystallen bekleidet zu seyn. - Die erste Gestalt ist bei flüchtigem Anblicke 
keilförmig, entwickelt sich aber bei strengerer Untersuchung als 4seitige dünne Prismen mit langyezogen - zugeschärften Seitenflächen. Sie sitzen auf dichtem Kakoxen und umschliessen, wie dieser, rechtwinkelig - 4seitige, sehr dünne, glısglänzende, der Schärfe der Stahlnadel widerstehende, in der Mitte durch neue Aufsätze verdickte Prismen (Tafeln)*). Diese sowohl als die würfeligen After-Krystalle üherzieht gelblich- bis schwarzbraunes Eisenoxyd (§) als mehr oder weniger dicker Anflug, - Alle Gestalten des Kakoxens erscheinen eben so oft auf gemeinem als faserigem Brauneisensteine **).

Den Fundort des krystallisirten $\mathbf{E}$ is en bla ues auf dem Erzberge bei Amberg habe ich bereits angegeben. Seine Farben gingen in etwas beträchtlicheren Stücken vom Wasserhellen durch das Lichte-Milchblaue einer-, und durch das LichteOckergelbe bis in das Satt-Grüne und das Dunkel-Indigblaue andererseits üher. Die Krystalle waren stets klein und sehr klein, jedoch beinahe durchsichtig. Sie sassen meistens so lose auf, dass es ungemein schwer war, sie zu erhalten; - aber auch der Eisenstein war so locker, dass er unter der Hand und von selbst zerfiel.

Ein nach Breithaupt's Charakteristik ***) in den äussern Kennzeichen mit dem Stilpnosiderite Ulumans's genau übereinstimmendes Mineral ist der gewöhnliche Gefïhrte des Kakoxens; es über-, zwischen- und unter-lagert ihn manchfaltig, kommt aber auch weit entfernt von der Lagerung des Kakoxens und auf vielen andern Eisenstein-Gruben (zu Buch bei Bodenwöhr, zu Hartenstein unweit Sulzbach u. a. m. O.) vor, und liegt sogar zuweilen zwischen dem fasrigen

*) Ähnliche Krystalle, ganz in Stilpuosiderit eingehïllt, habe ich auf der Bucher-Zeche hin und wieder beolsachtet.

**) Die chemische Analyse wird uns belehren, in wie fern dieser Kakoxen mit dem Böltmischen identisch sey. Ich vermuthe nicht unwichtige Abweichung.

* Handb. d. Mineral. v. Hopfmann, fortges. v. BreithaUpt, Bd. IV, Abth. 2, S. 188-191. 
Eisensteine. Meistens findet es sich derb mit gross - und klein-nieriger Oberfläche, aber auch nicht gar selten in bis Papier-dünnen krummschaaligen abgesonderten Stücken. In der letzten Gestalt ist es öfter Tombak - braun, selten (zu Hartenstein) sowohl auf der äussern als innern Fläche vorzüglich schön Gold-farbig angelaufen. Das Moos- und Baumartige umschliesst häufig einen verhärtet erdigen, mit der Oberfläche parallel konzentrisch - schaaligen Zitronen-gelben Ocker*). Auch hier stehen die Gruben, welche dieses Mineral in grosser Menge führen, in dem bösen Rufe, dass sie Kaltbruch des Eisens veranlassen. - $\mathbf{O b}$ es dessenungeachtet als phosphorhaltig erlilärt oder geradezu dem Brauneisenstein untergeordnet werden kann, muss die chemische Analyse entscheiden; ich glaubte, es hier als zu wenig bekannt erwïhnen zu müssen. Eben so problematisch ist ein Nineral des Eræberges bei Amberg $\%$, welches als Eisenpecherz angesprochen wird und nicht minder als Kaltbruch verursachend im Verdacht steht. Mit, dem EisenpechErz Werner's ${ }^{*}$ ) oder dem Triplit Hausmann's und der neuen Oryktognosten $\dagger$ ) hat es allerdings Farbe, Glanz, Bruch, Gestalt der Bruchstücle, Strich, Härte und spezifisches Gewicht in hohem Grade gemein; allein ein BlätterDurchgang ist nicht zu bemerken, und die Durchscheinenheit

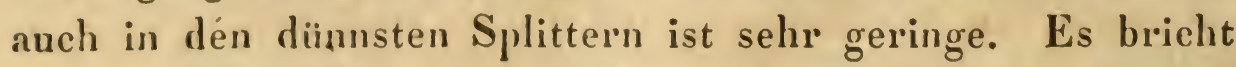
nur in derben Massen, und lisst sich aus dem umgebenden Brauneisenstein meistens leicht absondern. Von dem gleichfalls Eisenpecherz genannten Eisensinter tt) ist es also

") Wenn dieser Ocker Kakoxen ist, so kommt derselbe auch auf der Bucher-Zeche vor. Unerwartet wáre mir diess aus mehreren Grïnden nicht.

क) Auch auf den Gruben bei Buch, Pingurten, Sulzbach u. s. w. findet sich dasselbe in verschiedner Menge und von mancherlei Farbe.

*a) Handbuch der Mineralogie von Hofpmass, Bd. Ill, Abtheilung 2, S. $300-302$.

t) Lehrb. d. Oryktognosie von Buum, S. 367.

t†) Zu Paulsdorf bei Amberg kommt Eisensinter auch im Liasschiefer vor. 
nicht minder verschieden. Finige, obschon zięmlich weitschichtige, Analogieen waren mir Grund genug, meine längs dem ganzen Zuge der Eisenstein-Formation wiederholten Besuche der Erzhalden auch dazu zu verwenden, ob ich nicht Übergänge dieses Minerales in jenes, dem Stilpnosiderit ähnliche, wenigstens nach den äussern Merkmalen, zu ermitteln vermöchte; allein es war verlorene Mühe. Vielleicht gewährt uns ein Chemiker doch die Erfüllung meines Wunsches.

Boussingault zähit unter den über die Natur der Phosphorsäure in den natürlichen Phosphorsalzen untersuchten Mineralien auch das phosphorsaure Ble i von Amberg auf "). Offenbar ist hier ein Irrthum in der Bezeichnung des Fundortes eingeschlichen, der um so mehr Berichtigung fordert, da er folgerecht auch zu irriger Ansieht über die geognostische Beschaffenheit der Umgegend Ambergs verleitet. Die Angabe, dass dieses Bleierz aus den Niederschlags-Gebirgen stamme, setzt es ausser allen Zweifel, dass dasselbe von Bleiseysach oder Freyung (5 bis 6 geometr. Stunden nördlich von Amberg) aus jener weit ausgebreiteten, allem Ansehen nach sehr jungen Formation **) gekommen ist, welche einst so reichliche Ausheute lieferte, und noch jetzt wegen der manchfaltigen chemischen und mechanischen Verbindungen des Bleies merkwürdig ist.

*) N. Jalırb. für Mineralogie, Jahrg. 1834, Heft V, S. 563 und 564 .

**) Gänzlicher Nangel an Versteinerungen, die meistens unnittelbare Auflagerung auf Granit und sein Gerölle ohne alle Begleitung fremdartiger Schichten, der allgemeine Verfall des alten Bergbaues und die Unzulänglichkeit der Aufschlüsse durch die neuen Versuche setzen mich ausser Stand, ihre Lagerungs-Verlıälnisse bestimnter anzugebeu. 


\title{
Über
}

\section{das fossile Genus Nerinea, von}

\author{
Herrn Prof. Voltz *).
}

Eine Vorlesung bei der Strasburger Akademio.

Geschlechts-Charakter: Schaale dick, gegen den Mundrand hin dünne, thurmförmig oder fast zylindrisch. Mundöffnung scharfrandig, mehr oder weniger rhomboidal, mit wenigstens einer 'Falte; ihre untere Seite ist mit der obern parallel, die äussere mehr oder weniger mit der Spindel. Der untere Rand verlängert sich schief gegen die Spindel in einem Kanal, und ist nur selten, in der Nïhe des äusseren Randes, mit einer leichten Falte versehen. Letzterer eŕhebt sich fast senkrecht gegen den vorletzten Umgang, und tritt in dessen Nähe zurück; innerlich zeigt er meistens vorstehende Falten, deren Anzahl his zu dreien steigt. Der obere Rand ist durch eine Schwiele gebildet, welehe sehr schief gegen die Spindel gerichtet ist und über den untern Rand überragt; fast immer zeigt sie eine Falte. Auch die Spindel hat unten eine mehr oder minder deutliche Falte, welche sie vom Basal-Rande trennt, und über

") Ist auch im Institut, 1835, III, 425-426 im Auszug erschienen.

BronN. 
welcher zuweilen noch eine zweite ist. Im Innern sind alle Falten stärker, als in der Nähe der Mundöffnung.

B e m e rk ungen. Die Nerineen unterscheiden sich von den meisten übrigen Kanchylien durch die Art von Bucht, womit der äussere Rand sich in der Nähe des vorletzten Unganges endiget. Ist auch der sehr dünne und daher leicht vergängliche Mundrand fast nie erhalten, so erkennt man jene Bucht doch aus der nächst der oberen Naht der Umgänge stark nach hinten zurückgebogęnen Zuwachsstreifung, während solche bei den Cerithien, Melanien, Pleurotomen u. s. w. an dieser Stelle nach vorn tritt, so dass bei letzteren insbesondere die tiefer stehende Bucht die Naht gar nicht mehr beriihrt.

Ein anderer merkwürdiger Charakter der Nerineen beruhet noch in der Art des Zuwachses der Falten, welche gegen die Öffnung hin schwach sind, im Innern der Schaale aber so stark werden, dass sie deren Höhlung fast ganz ausfüllen: das Thier sonderte kalkige Materie nicht allein in der Nähe der Öffnung, sondern fortdauernd auch auf der ganzen Oberfläche seines im Innern eingeschlossenen Körpers ab, so dass sich die innere Höhlung allmählich in einem Grade verengt, dass man nicht begreiferr würde, wo das Thier selbst bleiben könne, wenn man sich nicht erinnerte, dass nächst der Mundöffnung die Schaale dünne und die Falten klein sind.

Die Spindel ist nur bei einigen kegelförmigen Arten genabelt, bei den zylindrischen sielit man sie nie durchbohrt. Der Kanal, womit sie endigt, ist bei Nerinea depressa nur unvollkommen, wie bei der Abtheilung Potaunides in Geschlechte Cerithium.

Um die $\mathrm{Nerineen}$ wohl zu studiren, muss man stets einige Exemplare zersägen, damit die Stellung der Falten im Inneren der Umgänge sichtbar werde; nur auf diese Weise ver'nag man die Kerne, welehe man so oft allein findet, richtig auf ihre Arten zurückzuführen; und so ist es auch bei Beschreibung der Arten selbst wesentlicher, die 
Beschaffenheit der Falten in ihrem vollständigen Zustande im Imner'n der Schaale, als die in der Nähe der Öffnung anzugeben.

Selten sieht man die Naht der Umgänge in einer Rinne verlaufen; vielmehr sind diese fast stets aussen konkav, und die Naht befindet sich daher auf der Erhöhung, welche sich auf diese Art zwischen zwei konkaven Ungängen bilden muss, Zuweilen aber sind die Umgänge auch flach und die N erin e en gleichen ihrem äussern Ansehen nach den Proto-, Terebra-, Turritella- oder Cerithium-Arten, unterscheiden sich aber immer durch die Zuwachsstreifen.

\begin{tabular}{|c|c|c|c|c|c|}
\hline Arten. & Nabel. & Form. & U nı gä n g e. & \multicolumn{2}{|c|}{ O berflächc. } \\
\hline Nerinea. & $\begin{array}{l}\text { Weite (in } \\
\text { Millime- } \\
\text { tern). }\end{array}$ & $\begin{array}{l}\text { D. Dicke un- } \\
\text { ten (in Millime- } \\
\text { tern). } \\
\text { Hölie. Dicke } 2 u\end{array}$ & $\begin{array}{l}\text { A. = Anzahl. } \\
\text { F.= Formaus. } \\
\text { sen. Höhe zur } \\
\text { Breite. }\end{array}$ & $\begin{array}{l}\text { Vertikale } \\
\text { Z. }=\text { Zu- } \\
\text { wachs-Strei- } \\
\text { fung. } \\
\text { B. Bucht } \\
\text { derselben. }\end{array}$ & $\begin{array}{l}\text { Spirale } \\
\text { St. = Strei- } \\
\text { fen. } \\
\text { R.=Rippen. } \\
\text { K. = Kno- } \\
\text { ten auf je I } \\
\text { Umgang. }\end{array}$ \\
\hline
\end{tabular}

s uprajuren. sis (Jolrz).

o. $\left\{\begin{array}{l}\text { F. lang kegelf. A. }=12+ \\ \text { D. }=40 . \\ \text { V. F. }=1: 4,5 \text { V. konkav. }\end{array}\right.$

Z. sehr fein. R. 6-7 fein.
Gos a

(Row.) Kern Tf.

$\mathrm{XI}, \mathrm{rg} .20$. f. lang kegelf.

1). $=50$

v. $=1: 0$
A. $=12+$

F.

V. $=3: 2$

\begin{tabular}{|c|c|c|c|c|c|}
\hline $\begin{array}{l}\text { rinod os a } \\
\text { (Vor.zz). }\end{array}$ & U. & $\begin{array}{l}\text { r. sehr lang ke. } \\
\text { gelf. } \\
\text { D. }=25 . \\
\text { V. }=1: 8\end{array}$ & $\begin{array}{l}\text { A. viele. } \\
\text { F. flach, knotig. } \\
\text { V. }=3: a\end{array}$ & Z. schief. & $\begin{array}{l}\text { St. 1, obet } \\
\text { K. } 3 \text { Reihe } \\
\text { zu } 16 \text { Kino } \\
\text { gleich gros }\end{array}$ \\
\hline $\begin{array}{l}\text { e longat a } \\
\text { ( loter.). }\end{array}$ & 0. & $\begin{array}{l}\text { f. fart walzenf. } \\
\text { D. = } 25 \text {. }\end{array}$ & $\begin{array}{l}\text { A. selir vicle. } \\
\text { F. flach, dochid. } \\
\text { Nälite erliöhet. }\end{array}$ & $\begin{array}{l}\text { Z. senkrecht } \\
\text { sehr deutl. } \\
\text { B. tief. }\end{array}$ & $\begin{array}{l}\text { St. etwa } \\
\text { undentl. } \\
\text { deu flach } \\
\text { Theile. } \\
\text { R. und } K \\
\text { keine. }\end{array}$ \\
\hline $\begin{array}{l}\text { depresesa } \\
\text { (lotede. }\end{array}$ & 3. & $\begin{array}{l}\text { r. Ianz kegelf. } \\
\text { D. } 35 . \\
\text { 1. }=1: 2 \text { [?] }\end{array}$ & $\begin{array}{l}\text { A. 11-12? } \\
\text { F. flach, ohne } \\
\text { Vordick. } \\
\text { V. } 5: 3 \\
\text { Kerue mit selir } \\
\text { wölblgenUmgan. } \\
\text { gen, wie Cy clo- } \\
\text { stom a. }\end{array}$ & $\begin{array}{l}\text { Z. fast o. } \\
\text { Nähte fast } \\
\text { unnerkbar. }\end{array}$ & $\begin{array}{l}\text { St. keine. } \\
\text { R. keine. } \\
\text { K. keine. }\end{array}$ \\
\hline
\end{tabular}


Dieses Geschlecht ist ghnzlich fossil, beginnt im untern Oolithe und erlischt im unteren Theile der Kreide-Gebilde. Zwar haben die Herren Sedgwick und Murchison dergleichen noch in einem viel höheren geologischen Niveau, nämlich in dem berühmten Gosau-Thale gefunden; - aber die alpinischen Gebirge in der Nähe granitischer Hebungen, welche vor ihrer Bildung Statt gefunden, scheinen oft fossile Arten einzuschliessen, die man nur in ältern Formationen zu finden gewohnt ist.

Hier folgt eine Übersicht der Charaktere derjenigen Arten, welche das Museum zu Strasburg besitzt.

\begin{tabular}{|c|c|c|c|}
\hline Innere Falten. & L a gerung. & Fundort. & B en erk ungen. \\
\hline $\begin{array}{l}\text { o. = oben. } \\
\text { 1. = links (Spind.). } \\
\text { r. = rechts. } \\
\text { u. }_{\text {Ort, Zahl, Richtung. }}\end{array}$ & si & 7 & $\int_{12}^{2}$ \\
\hline
\end{tabular}

Falten 3.

fo. 1, scharf, nach aus -

$\left\{\begin{array}{l}\text { 1. 1, unten, ringförm. } \\ \text { r. 1, unten, nach oben. }\end{array}\right.$

F. 2 .

o. keine.

1. I Einbiegung oben lüngs des Kanals. Kimmeridge-K.

r. I mitten, unvollstän. dig in der Jugend, mehr unten im Alter.

Obrer Coralrag.

F. 4.

o. 1.

I. I, unten.

r. 1, stark, unten.

u. 1, klein am Kiele.

F. \%。

o. I sehr scliwach, innen. Nerineeu-K.

I. I schwach, untell.

\section{Portland-Kalk. Besanģon.}

Hrute Shoule; Bruckner, pl. I, fig. I Trécnurt. [schon oben citirt] konumt hiemit selir gut überein.
F. 1.
Nerinea-K.
Hesute Sunne;
o. I mit breitem Grunde, ? liumeridge-K. spitter nach allssen.
BruckNer, pl. I, fig. I u. (Kern) u. Wenn min. der abgeriebene Exemplare Knötelıen? über der Naht hätten, könnte es $\mathbf{N}$. B e a mont i seyu (Fg. 7).

IPorrentruy: le

Saone: Ray.

Douls : Montbéliurd.

Solnthurn; Montbéliverd, le

Röner's Abbildungen u. das Strusburger Museum haben nur Kerme; eine Beschreibung lat erstrer noch nicht gegeben. Bunné; Besurn- 


\begin{tabular}{|c|c|c|c|c|c|}
\hline Arten.' & Nabe 1. & For m. & U m g än ge. & 0 be $\mathrm{fl}$ & c li e. \\
\hline Nerinea. & $\begin{array}{l}\text { Weite (in } \\
\text { Millime- } \\
\text { tern). }\end{array}$ & $\begin{array}{l}\text { D. }=\text { Dicke un- } \\
\text { ten (in Milline- } \\
\text { tern). } \\
\text { H. Dicke \&u } \\
\text { Hölie. }\end{array}$ & $\begin{array}{l}\text { A. E Anzahl. } \\
\text { F. Form aus- } \\
\text { sen. } \\
\text { V. Höhe zur } \\
\text { Breite. }\end{array}$ & $\begin{array}{l}\text { Vertikale } \\
\text { Z. Z Zu- } \\
\text { wachs-Strei- } \\
\text { fung. } \\
\text { B. }=\text { Bucht } \\
\text { derselbeu. }\end{array}$ & $\begin{array}{l}\text { Spirale } \\
\text { St. = Strei- } \\
\text { fen. } \\
\text { R. = Rippen. } \\
\text { K. = Knnten } \\
\text { auf je 1 } \\
\text { Umgang. }\end{array}$ \\
\hline
\end{tabular}

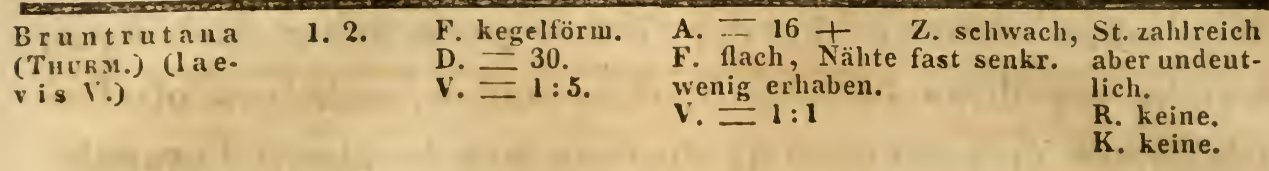

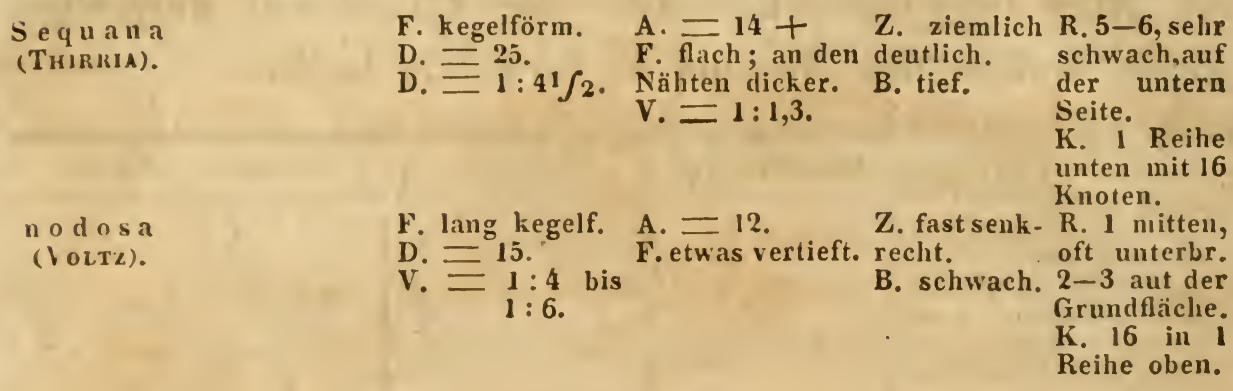

e I e g a us ( Тับหน.).

o. F. lang kegelf.
v. $=7$.
v. $=1: 7$.
V. $=1: 1,2$.

F. $\overline{\text { flach. }}$.

$20-25$

Z. gebogén. 1 fache Rin. ne unten. K. 2 Reihen darüber, mit je $16-20 \mathrm{~K}$., die öfter in körnige Rei. fen zusam. mentliessen ; d. obre Reilie fehlt denobe. ren Umgän. gen.

f as cinta (VGLTZ).

0. $\begin{array}{ll}\text { F. fast zylin- A. sehr viele. } \\ \text { driscl. } & \text { F. tlach. } \\ \text { D. }=5 . & \text { V. }=1: 2 .\end{array}$

Z. keine.

R. aussen 6 b. 7, abwech. selnd stär. ker, d. untre an der Naht an stärksten ; - un. ten $5-6$.

c y lindric a (VOITZ).

triplicata (VoLTL).
0. F. fast walzenf. A. sehr viele. Z. senkr. D. = 10. F. flach, d. letz. B. seicht. ten etwas koll.

F. walzig. A. selır viele. Man kennt nurden Kern. vex. V. $\mathrm{i}: 2$.

R. 5-6 un. deutlich. K. keine. V. $1: 2,5$. 


\begin{tabular}{|c|c|c|c|}
\hline Innere Falten. & L a g e r u n g. & Fundort., & Bemerkungen. \\
\hline $\begin{array}{l}\text { o. 三 oben. } \\
\text { 1. } \equiv \text { links (Spind.). } \\
\text { r. E rechts. } \\
\text { ur. unten. } \\
\text { Ort, Zahl, Richtung. }\end{array}$ & & I. & 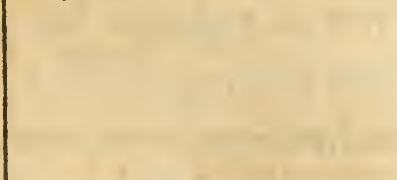 \\
\hline $\begin{array}{l}\text { F. } 5 . \\
\text { o. 1, gross, nach aussen, } \\
\text { mit } 3 \text { Rinnen. } \\
\text { 2, nach oben, ihr } \\
\text { Rücken verdickt. } \\
\text { r. } 2 \text {, unverdickt, die } \\
\text { obere klein, über o.; } \\
\text { die untere sehr gross, }\end{array}$ & Nerineen-K. & $\begin{array}{l}\text { Haute Saone: } \\
\text { Etruviux. } \\
\text { Hasute Sunne: } \\
\text { Trécourt. Por- } \\
\text { rentruy: Mont } \\
\text { terrible. Meuse: } \\
\text { Ferdun. }\end{array}$ & $\begin{array}{l}\text { In ilteren Umgängen nel. } \\
\text { men die Falten fast die } \\
\text { ganze imnere Oberflache ein. } \\
\end{array}$ \\
\hline
\end{tabular}
gegen 1. 2.

F. 3 .

Nerineen-K.

Trécourt.

o. 1 scharf, n. aussen.

1. I stärker, unteI.

r. I dick, unten, zwischen beiden.

F. 6.

o. I stark, scharf, nach aussen; 1 schwach, vorn 0 .

1. 2 scharf, die obere schwich, d.untre stark.

r. 1 dick, unten, gegen die dritte.

1 schwach, oben vorn 0 .

F. 3 .

o. 1, innen.

1. 1, unten.

r. I, unten, stark.

Coralrag.

Polypen-K.

Coralrag ;

Nerineen-K.

Coralrag :

Calvidos: Crnupville u. St. Murtin La Lieue. Meuse: Dun.

Calvudos Lisieux.

Meuse: Dun, Fer- Dem Kerndieser Artgleicht dun. der von N. t u bercula ta DEPr. in DE Blaiv ville M/Llacol. pl. XXI, bis fig. 3 ; und lict.d. sc. nat; Coquill., p. 34, fig. 3 .

Wird am zweiten Urte viel grösser, als am ersten.

terrible.

St. Martin la Lieue bei Lisieux.

F. 2 .

r. I mitten stark.

r. I unt. sehr schwach.

\section{Coralrag ;}

-

Culvados: Trou- In Trigonienkalke dieses ville.

Culvados: Be. nerville.
F. 3 .

o. 1, innen, schwach.

1. 1, scliwach.

r. 1, mitten, scliwach, wagerecht.

F. 7 .

o. 1 .

1. 2.

r. 4; die unterste zweitheilig.
Kinmeridge-K. Hante Saone: Iyle-ferroux.

Inferior Oolit.

Mosel: Corny. Das Muscum besitzt uur cinen Kern voll Hrn. SImon in Mets. 


\section{Übersicht und Abbildungen}

der

\section{bis jetzt bekannten Nerinea-Arten,}

von

H. G. Bronn.

(Hiezu Tf. VI.)

Die voranstehende Ablandlang des Hrn. Voutz, welcher mir auf die zuvorkommendste Weise auch die ganze von ihm gebildete und benützte Sammlung von N e ri n e e n im Strasburger Museum zur weitern Benützung zugestellt hat, ist die Veranlassung zur gegenwärtigen Zusammenstellung geworden.

Defrance hatte 1825*) dieses Geschlecht unter dem Namen Neriné (Holl schreibt Nerina, Deshayes Nerinaea, die meisten übrigen Autoren $\mathrm{Nerinea)} \mathrm{zuerst}$ aufgestellt, war jedoch zweifelhaft geblieben, ob er es wegen der ihm nicht ganz deutlich erschienenen Form der Muridöffnung neben Cerithium, oder wegen der SpindelFalten, deren Anzahl er auf zwei mit einer ausseren entgegenstehenden setzte, neben Pyramidella zu stellen habe. Gegenwärtig neigen sich die meisten Naturforscher zor ersten Ansicht, oder ordnen mit Rang ${ }^{*}$ ) das Geschlecht bei

*) Im Dictionnaire des sciences dhistoire naturelle, vol. XXXIV, 462, Art. Neríné.

*) Manuel de l'histoire naturelle des Mollusyues et de leur conquilles, Paris 1829. 
Cerithium nur als Unterabtheilung ein, während Puscu es als die ursprüngliche Form von $\mathbf{P}_{\text {yramidella betrach- }}$ tet *), wie dena dieses Geschlecht bis auf wenige Arten zu einer Zeit vorkommt, nach welcher erst Cerithium sowohl als Pyramidella auftreten. Deshayes betrachtet das Genus nach genauerer Beobachtung seiner Mundöffnung als ein Bindeglied zwischen Pyramidella und Lamarck's Canaliferen.

Obschon Knorr und Bruckner bereits Kernstüclie von diesem Geschlechte abgebildet hatten, so unterschied $\mathrm{D}_{\mathrm{k}-}$ FRANCE doch nur drei Arten, wovon er nur einer auf der ihre Abbildung enthaltenden Tafel einen Namen - N. $t$ uberculeuse - beilegte, worin Blainville ihm folgte. Aber eben diese Art ist eine künstliche Komposition aus den Resten mehrerer Species, wie ich unten zeigen werde, so dass man diesen Namen keiner Form zu erhalten im Stande ist. - Jetzt, nach kaum einem Decennium kennt man del Arten schon über dreissig, um deren Untersuchung und Bekanntwerdung sich Phillips, Schübler, Thurmann, Römer, Pusch, Catullo und zumal Voltz und Deshayes verdient genacht haben. Indem wir die zerstreuten Bekanntmachungen derselben sammeln und ordnen, glauben wir zu weitern Untersuchungen über dieses merkwiirdige Geschlecht anzuregen. - Man kann seine geographische Verbreitung bereits durch ganz Europa nachweisen, von Klein-Asien an bis nach West-Frankreich, von den Inseln des Mittelmecres bis nach England hinauf. - Wie bezeichnend das Geuus, im Ganzen genommen, auch für die Oolithe und hauptsächlich für den Coralrag seyn mag, so ist es doch keineswegs auf diese Formation beschränkt, sonder'n geht mitunter in jüngere Bildungen über $*$. Einige Arten kommen in zweifelhaften Gesteinen mit D i c e r a s vor, die man bald - und wohl

*) Polens Paläontologic.

* Die Angabe HoLL's ('Petrefl. 287) u. A. vom Vorkommen im Gryphiten- Kalk beruht auf früherer unrichtiger Bestimmung der Formation. 
mit mehr Recht - zu den Oolithen, bald zu der Kreide rechnet (N.imbricata, N.nodulosa, N. simplex); andre mit Ichthosarcolithen (und Trigonien) im Charente-Dept.*); eine findet sich in unzweifelhafter Kreide (N. B orsonii); noch andere in den sonderbaren Schichten der Süd-Deutschen Alpen und bei Neuchätel, welche Sekundär- und Tertiär-Versteinerungen im Gemenge miteinander darbieten (N. involuta, N. bicincta, N. flexuosa, $\mathrm{N}$. incavata, N. suprajurensis); eine endlich soll aus tertiären Bildungen herstammen.

Die Untersuchung der Nerinea-Arten bietet viele Schwierigkeiten dar, mehr als bei den meisten andern KonchylienGeschlechtern, da die Kenntniss von Zahl und Stellung der Falten im Innern hiezu eben so unerlässlich als die Vergleichung der äussern Oberfläche ist, und da die Bildung der erstern mit der der letztern in keinerlei Beziehung zu stehen scheint, so dass sich von einem auf das andere schliessen liesse. Auch die Art des Fossil-Zustandes ist manchfaltiger, als sie bei andern Konchylien zu seyn pflegt. Selten kommt die Schaale frei, in eisenschüssige Kieselmasse umgewandelt etc. vor, so dass man äussere und innere Beschaffenheit gleich gut und sclinell daran untersuchen kann; gewölınlicher ist sie mit der Gebirgsmasse erfüllt und umschlossen, bald so, dass sie sich auslösen lässt, bald ganz fest eingewachsen, wo dann im ersten Falle sich nur die äussere Oberfläche unmittelbar, im andern auch diese nicht einmal beobachten lässt; oder die in der Gebirgsmasse eingeschlossen gewesene Schaale ist wieder daraus versch wunden, wo man bei Untersuchungen an Ort und Stelle äussere und innere Beschaffenheit derselben im Abdruck erhalten findet; wenn aber in diesem Falle nur die losen Kerne eingesammelt worden, bleibt der äussere Zustand problematisch. Ist das Innere der Schaale mit Gebirgsmasse erfïllt, so findet man deren Beschaffenheit gewöhnlich deutlich, wenn man

") Jahrb. 1832, S. 364. 
in einer Höhe von 2-3 Umgängen die eine Hälfte senkrecht wegfeilt und polirt, so dass man dann einen senkrechten Queerdurchschnitt erhält, in welchem die Falten sehr deutlich vorzuspringen pflegen. Ähnlich muss man oft auch mit Kernen vèrfahren.

Ich habe versucht, die Arten nach der Summe ihrer natïrlichen Beziehungen an einander zu reihen; aber jedes Merkmal gab eine von den andern so abweichende ReihenOrdnung, dass ich auf allen Erfolg zu verzichten und eine ganz künstliche Anordnung derselben zu geben genöthigt bin, die jedoch in folgender Tabelle deutlicher hervortreten wird, wo bei den mit Fragzeichen angeführten Arten die Zahl der Falten nicht genau bekannt ist. 


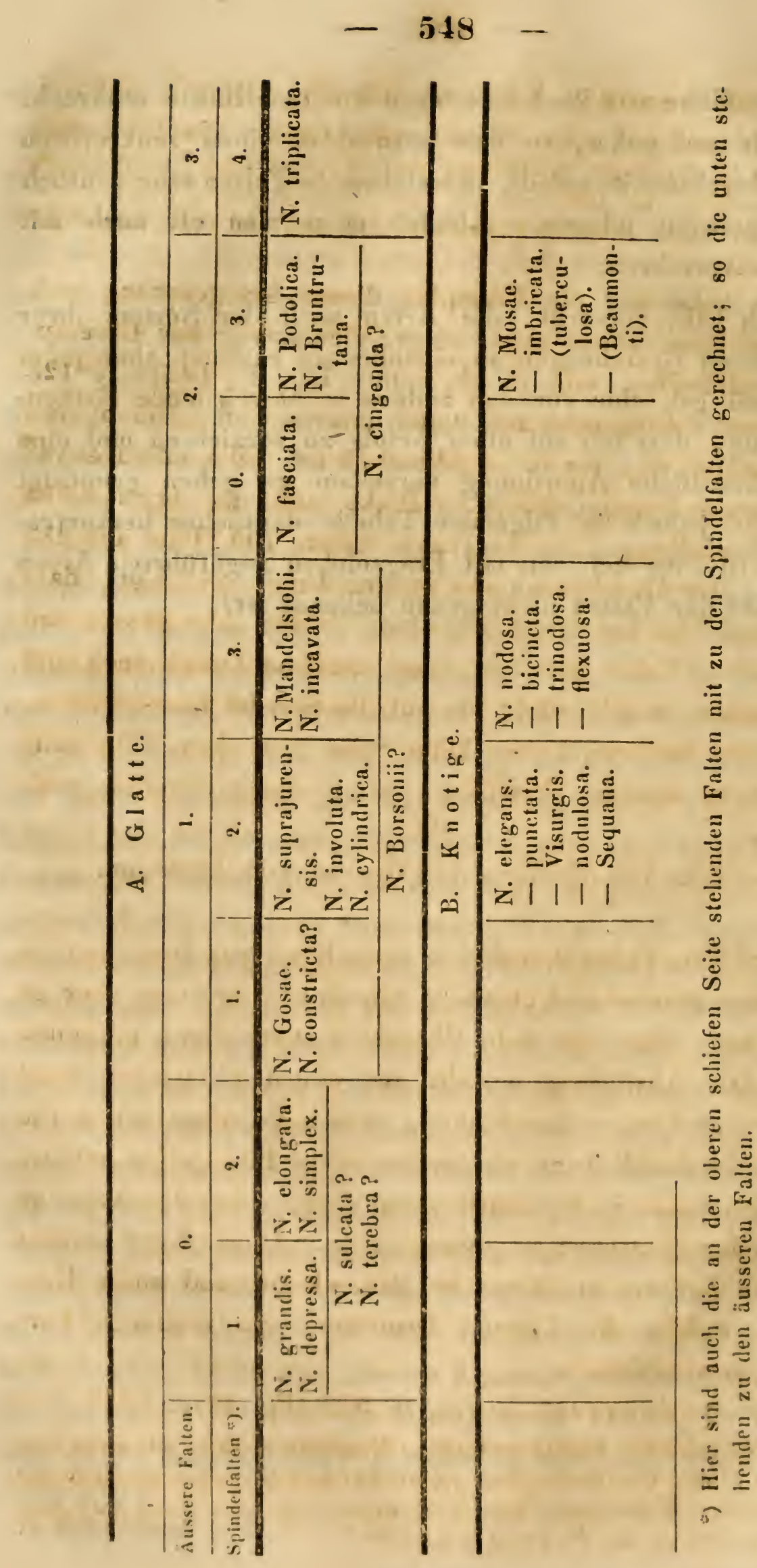




\section{N. grandis Voltz in. litt. (Fg. 1).}

Schaale dick und gross, Wendeltreppen - förmig; Oberfläche glatt; Ungänge in der Mitte sattelförmig vertieft, an beiden Nähten gleichın̈ssig verdickt, so dass hier ein jenem einspringenden gleicher ausspriugender Bogen entsteht; Falten nur eine, dick und rund, mitten auf der Spindel.

Ich habe nur ein Exemplar-dieser Art gesehen, welches mir Herr Voltz unter obiger Benennung zur Untersuchung mittheilte, wie es abgebildet ist. Es besitzt $0^{\mathrm{m}} 125$ Länge mit 6 Umgängen auf 0,060 unteren und 0,035 oberen Durchmesser da, wo es abgebrochen ist. Die unten etwas vorstehende Spindel hat 0,02 Dicke und eine etwa 0,012 dicke Ausfüllung. Die Umgänge haben 100 Höhe auf 232 Breite. Der Durchbruch des letzten Umganges zeigt, dass die. Spindel in der Mitte nur eine, jedoch sehr grosse und abgerundete Falte besessen; der nämliche Durchbruch und drei andere, welche nicht bis auf die Spindel hineinreichen, lassen von äusseren Falten keine Spur entdecken. Die sehr verwitterte äussere Oberfläche zeigt weder Streifen noch Knoten.

Aus dem §̣ortlandien der Gegend von Besançon.

Von Hrn. Puzos erhielt ich einen Kern mit ähulichen Dimensionen anscheinend ebenfalls von einer $\mathrm{N}$ erinea, aber so verwittert, dass sich kein Charakter mehr daran erkennen lässt. Die Ausfüllung besteht aus einem erhärteten Sand mit grossen Quarz-Geschieben, wesshalb schon allein die Oberfläche des Kernes ein undeutliches Bild geben müsste. Ich kann daher nicht einmal versichern, dass die Art eine glatte oder eine knotige gewesen seye. Dieser Kern stammt von den Bädern zu Reines im Aude-Dept. und sollte Geologen, welche die Gegend besuchen, zu weiteren (Forschungen veranlassen.

\section{N. depressa Voutz, S. 540 (Fg. 17 a, b).}

Gross, ziemlich kurz kegelförmig ; Ungänge niedrig, mit ganz cbener und glatter Oberfläche, doch spiralgefurehter Grundfliche; Nalt fust unbenerkbar; Falten nur eine, dick, welche von oben schief nach aussen in die Höhle der Umgänge hineintritt. 
Die Zeichnung nach einem angeschliffenen Exemplare der Strasburger Sammlung. Ein neuer Fundort ist nach GRESSLY der Schildkröten-Kalk - der Portland - Bildung untergeordnet - bei Solothurn.

3. N. elongata Voltz, S. 540 (Fg. 15 a, b).

? Bruckn. Merkwïrd. d. Landsch. Basel, p. 6, Tf. 1, Fg. I.

Fast walzenförmig; Ungänge sehr hoch, zylindrisch, nur an den Nähten etwas verdickt, nit sehr deutlicher Zuwachs - Streifung und mit etwa 12 erbabenen Spiral-Linien; Falten zwei, dick und niedrig, eine oben nächst der Spindel, die andere unten auf derselben.

Die Zeichnung gibt die Spiral-Linien etwas zu unbestimmt und zu zahlreich an. Sie ist nach einem GypsAbgusse und nach einem angeschliffenen Exemplare gefertigt, beides aus der Strasburger Sammlung.

4. N. s implex DESI. (in Exped. scientif. d. Morée, 1836, III, 185, Tf. xxvi, Fg. 4, 5).

Schaale sehr lang thurnförmig , glatt; Umgänge kaun sattelförmig vertieft, niedrig, zalıreich; Naht vertieft; Mündung schief quadratisch; Falten zwei auf der Spindel, aussen keine.

Die Oberfläche ist glatt; die eigentliche oder untere Spindelfalte ist sehr klein und stumpf; die andere, von oben tief in die Windung hineinragend, ist gross und stumpf. Eines der Exemplare hatte 0,215 Länge; das abgebildete Bruchstück mit 10 Umgängen besitzt 0,126 Länge auf 0,031 untren und 0,010 obren Durchmesser.

Vorkommen auf Morea in einem Gesteine mit Diceras, wie es zu St. Mihiel in Frankreich und am Mont Salève bei Genf vorkommt, folglich in den oberen Oolithen oder in den untern Kreide-Schichten.

5. N. constricta Röm. (Fg. 4, nach Röm.).

Nerine a constricta Rö̈r. Weser-Verstein. 143, Tf. xI, Fg. 30 (früher Fg. 24).

Diese Art weicht äusserlich von der folgenden nur dadurch ab, dass an Kern die Ungänge etwas höher sind, dass ihre grösste Vertiefung sich unter der Mitte befindet und dort weiter eine schmale Ririne bildet. Die Falten zu beobachten hatte ich nicht Gelegenheit: die eben erwähnte Rinne scheint jedoch als Abdruck einer äusseren Falte gelten 
zu müssen, und nach RöMEr kämen auf der Spindel keine Falten vor, was bei der grossen Ähnlichkeit dieser Art mit der folgenden noch weiterer Bestätigung zu bedürfen scheint.

In den Oolithen der Weser-Gegend.

6. N. Gros a e Rörr. (Fg. 5).

KNorr, Verstein. II, I, Tf. Cviri, Fg. 5.

Nerine a Gosae Röm. Weser-Verstein. 143, Tf. xi, Fg. 27

(früher Fg. 20); - Вrone b. Schust. im Jahrb. 1835, S. 146 (mit Ausschluss anderer angeführten Lokalitäten) und Lethäa, S. 398, Tf. XXI, Fg. 11 ; - Vourz S. 540.

Schaale lang kegelförmig, schraubenartig mit glatter Oberfläche; Umgänge in ihrer Mitte kantig und nur der untere rundlich vertieft, und sich nach beiden Seiten dachartig zur Naht erhehend; Falten zwei, wovon eine auf der Spindel, eine aussen in der Mitte.

Bei Bearbeitung des Artikels Nerinea in der Lethäa hatte ich die Beschaffenheit der Falten noch nicht beobachten kömnen, sie aber seitdem so gefunden, wie auch Voutz sie angibt. Römer sigt nichts darüber. Zu den bei Voltz angegebenen Fundorten gehört nun noch der Portlandkalk vom Langenberg bei Ocker unfern Goslar und auf dem Lindener Berg bei Hannover (Röm. in. litt.). Abbildung nach einem Exemplare von Ocker.

7. N. suprajurensis Voltz (Fg. 2 und 3 a, b).

KNorr Verstein. II, I, Tf. Cvir, Fg. 3, ? 6, 7.

Bruckner Merliwürd. d. Landsch. Basel, Tf. I, Fg. h, ?I und (Kern) $\mathbf{n}$.

Defrance im Dict. scienc. nat. XXXIV, 463.

Proto suprajurensis Voltz, Thurm. Porrentr. 12, 15.

Nerinea Bruckneri Thunm. Porrentr. 12 (Bruckn., fig. h). Nerinea suprajurensis Voltz in litt. u. Thirr. géogn. $d$. $l$.

Haute Saone 5, 6, 7 ; - Vortz in Jahrb. 1835, S. 62, und 1836, S. 540 ; - Brons Lethäa 397, Tf. XXI, Fg. 12 a, b. Nerinea Defrancii Deshax. Exped. d. Morée III, 186, pl. xxvi, fig. $1,2$.

Äussere Form, wie bei N. Gos ae: nur sind die Umgänge in ihrer Mitte (nicht dachförmig, sondern) sattelförmig mehr oder weniger ver. tieft, und diese Vertiefung hat eine grössere Ausbreitung als die Verdickung der Nähte; Oberfläche mit etwa 14, abwechselnd etwas stïrkern crhabenen Spiral-Linien versehen; Falten drei; eine oben, eine auf der Spindel unten, eine aussen über dieser. 
Den Durchschnitt der Umgänge sieht man bei Fg. 2; der Kern ist ganz wie bei $\mathrm{Fg} .8$ b. - Man kann übrigens zwei Varietäten unterscheiden: eine mit sattelförmig vertieften (Fg. 3), und eine lïnglichere mit ebenen, nur an der Naht verdickten Umgängen (Fg. 2). Die erste $\mathbf{F g}$. 3 a ist nach dem Gyps - Abgusse von einem schönen Exemplare von le Banné; die Oberflächen - Zeichnung Fg. 3 b nach einem Abdruck im Gestein von Busel gezeichnet. Ähnlich kommt diese For'm nach Deshayes mit Diceras zu St. Mihiel und, etwas kürzer und dünner, auf Morea vor. Die flache Varietät findet sich zu Montbéliard, zu Solothurn und in einem Pisolith zu Bailly bei Auxerre, wo Defrance der Nerineen zuer'st gedenkt, und wornach unsere Fg. 2 gezeichnet ist. Gehört hiezu auch die Art, deren er zu Nevers erwähnt Endlich findet sich diese Art in dem jetzt Neocomien genannten Gestein bei Neuchâtel, welches Oolith- und KreidePetrefakten durcheinander enthält.

8. N. eylindrica Voltz (Fg. 16 a, b).

Nerinea cylindrica Voltz in litt.; - Thirr. géogn. de la IIaite Suone 6: - Voutz im Jahrb. S. 542.

Schaale zylindrisch-kegelförmig; Umgänge sehr hoch, in der Mitte meist etwas gewölbt, mit $5-6$ spiralen Streifen und vielen feinen $\mathrm{Zu}$ wachs-Streifen; die Naht etwas gerandet; Falten 3 , wovon eine oben nächst der Spindel, eine aut derselben unten, und eine aussen in der Mitte des Unganges.

Zeichnungen nach einem Gypgs-Abgusse und nach einem angeschliffenen Exemplare.

9. N. involuta $n . s p$. (Fg. 25, verkleinert).

Gross, lang kegelförmig, Umgänge eben, sehr zahlreich, sich mit ilırem oberen Rande einander weit überdeckend; Falten drei; eine oben, eine auf der Spindel unten, und die grösste aussen nächst dem obern Rande, parallel der schicfen und schmalen Mundöffuung.

Ein Bruchstuick, $0^{\mathrm{m}}, 100$ lang, unten 0,050 , oben 0,040 dick, der vorletzte Ungang mit Hinzurechnung seines Schnabels etwa 0,045 hoch, aber durch den letzten bis auf 0,010 seiner Höhe umschlossen; dahrr die freie Höhe zur Breite des Unganges $=0,010: 0,050 ;$ der senkrechte Theil desselben 
ist 0,019 , so dass die 2 letzten Umgänge mit $0^{\mathrm{m}}, 015$ ihrer Höhe sehr dicht auf einander liegen.

In der merkwürdigen Formation des Gosau-Thales, welche tertiäre und sekundäre, insbesondere Kreide - Reste durch einander enthäit.

10. N. incavata $n$. sp. (Fg. 22).

Schaale lang kegelförmig; Umgänge in der Mitte sattelförmig vertieft, mit schief rückwärts ansteigenden Zuwachsstreifen ohne SpiralStreifung; Falten vier, wovon eine starke oben, eine schwache und eine starke auf der Spindel mitten und unten, eine aussen knapp über der letzten steht.

Die Umgänge haben 100 Höhe gegen 275 Breite der Schaale. Das dargestellte, oben angeschliffene Exemplar besitzt unten 0,015 , oben 0,007 Dicke bei 0,040 Höhe und S Umgängen; die Spindel ist unten 0,005 dick. Die äussre Form von N. Bruntrutana, aber aussen eine Falte weniger.

Ich habe zwei Exemplare von Wien erhalten, ohne Angabe des Fundortes. Entweder rühren sie mit N. bicincta von der Wand her, oder nach Hrn. Boué's Ansicht aus der obern Molasse von Olapian bei Mühlenbach in Siebenbürgen. Die Schaale ist in Kalkspath verwandelt, auch zum Theile daınit ausgefüllt.

11. N. Mandelslohi n. sp. (Fg. 26, verkleinert).

Schaale lang kegelförmig, Umgänge eben, glatt (ohne deutliche Streifung); Falten vier, wovon eine sehr hohe und schiefe oben, zwei scharfe mitten auf der Spindel, und eine dicke stumpfe aussen zwischen beiden stehen.

Das in der Zeichnung in halber Grösse dargestellte, mir erst kürzlich vom Hrn. Grafen von Mandelslohe zur Benïtzung mitgetheilte Exemplar stammt aus dem Coralrag von Sirchingen in der Wïrtlembergischen Alp, wo es mit andern Arten, wie es scheint, auch noch mit N. Bruntrutana, sich vorfand. Die Schaale ist verkieselt. (Später fanden sich mehr.)

12. N. Borsonii nol. (Fg. 12 nach Catullo).

Caturto in Giornale di Fifica, di Pavia, 1826, vol. IX, 291, fg...

'Turritella Borsonii Catule Zool. fossil. (Padova 1827) 170, 


\section{$-\mathbf{5 5 4}$}

239, Tf. III, Fg. E ; - in Annali di storia naturale di Bologna 1828, und in Memoria sopra alcune Conchiglie fossili $\left(\boldsymbol{P}_{a d} 1834,4^{\circ}\right)$ 18, Tf. II, Fg. 5.

Nerin e Férus. in Bullet. 1s2s, Févr.

Schaale sehr lang kegelförmig, fast zylindrisch, mit ebenen Um. gängen ohne Streifung; Falten .... : eine sehr hohe aussen, in der Mitte der Ungänge, wodurch die Umgänge des Kernes genau in zwei gleiche Hälften getrennt werden .....

Länge bis über 1'. Von den Spindelfalten ist uns nichts bekannt. Die von Catulco entlehnte Abbildung stellt den Kern dar, stellenweise mit der Schaale bedeckt. Schon im Jahr 1527 habe ich den von Catulco in der Zoologia fossile als Turritella abgebildeten Kern, dem er durch das Ansehen getäuscht doppelt so viele Umgänge zuschrieb als er wirklich besitzt, bei ihm selbst gesehen und für eine Nerinea erklärt, was etwas später F'Érussac nach der Zeichnung bestätigte, wodurch sich aber $\mathrm{C}_{\text {atullo nicht }}$ abhalten liess, uns mit folgendem Argument zu bekämpfen: "Diess Fossil aus der Jura-Formation ist eine Turritella, es hat die Falten von Nerinea: folglich haben die Turritellen der Jura-Formation Falten."

Vorkommen am Piné-Berge im Bellunesischen in einem Kalke, welchen Catullo der Jura-Formation zuschreibt, welcher aber durch viele Hippuriten, Sphäruliten, Batolithen (in Gesellschaft von $\stackrel{P}{P}$ odopsis und Plagiostoma) als Kreide charakterisirt wird.

13. N. fasciata Voltz oben S. 542 (Fg. 21).

Schaale Kegel-, fast Walzen-förmig; Ümgänge zahılreich, flach konvex, nit 4 erhabenen Spiralstreifen, wovon ein mittelmässiger am untern Rande, ein stärkrer in der Mitte und je ein schwacher über den vorigen verlaufen; Falten $1-2$, aussen, uämlich eine starke in der Mitte und eine nur schwache unten.

Bei etwas grösseren Exemplaren schalten sich zwischen die 4 erwähnten Spiral-Streifen noch 2-3 feine einzeln ein: Ich habe zwei äussere Abdrïcke und einen Gyps-Abguss der Schaale von Hru. Voctz gesehen; aber so scharf auch die ersten sind, so vermochte ich doch nichts von den feinen Kuötchen zu erkennen, welche Römer (Tf. XI, Fg. 13 a, b, c) auf den alternirenden Spiralstreifen angibt; wie er 
denn auch nur eine Falte, unten auf der Spindel, bemerkt, so dass man die Identität der Voltz'schen und der Römerschen Art bezweifeln muss.

Ich habe während des Abdruckes mehrere Exemplare von Hrn. Römer selbst erhalten, welche zwar zwei Arten anzugehören scheinen, jedoch nicht vollständig genug waren, um auch nur eine davon genügend zu bestimmen. - Beide hatten allerdings knotige Queerlinien, beide aber auch 2 Falten auf der Spindel und eime aussen, so dass sie sich der $N$. elegans und $N$. punctata verbinden. Die eine Form ist mehr kegelartig und hat mit N. elegans Ähnlichkeit. Mitten auf ihren Umgängen ist eine dickere Spirallinie mit etwa 20 Knötchen, darüber eine feinere, und dann ist die Naht selbst verdickt und knotig; alles weitre Detail der Oberflächen-Zeichnung ist undeutlich. Falten 3, eine oben in der Mitte, wie es scheint weiter nach aussen, als bei $\mathbf{N}$. elegans, eine auf der Spindel unten, und eine aussen zwischen beiden. - Die zweite Form ist zylindrisch; Umgänge mit $\boldsymbol{\gamma}$ gekörnelten Spiralstreifen, wovon oben zwei kleine, darunter 4 grosse und dann noch 1 kleiner stehen und die zwei mitteln der grossen sich etwas mehr genähert sind; Falten wie bei voriger, doch die obre mehr nach innen; vielleicht auch noch 1-2 kleine mitten auf der Spindel s Hier sind also die Falten, wie dort die Oberfläche undeutlich; beide Formen sind von N. fasciata gewiss verschie-

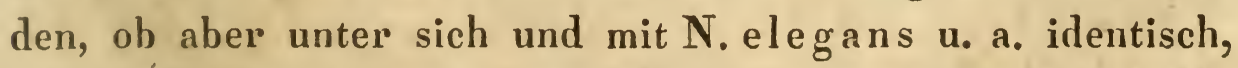
oder selbstständig, muss die Folgezeit noch lehren. Im oberen Coralrag am Lindener Berg bei Hannover und bei $\boldsymbol{H u}^{-}$ heneggelsen; an letzterem Orte in Gesellschaft einer noch kleineren ähnlichen Form.

14. N. Podolica Pusch (Fg. 11, nach Pusch).

Tierinea Podolica Puscir Poln. Paläontolog. . . . Tf. X, $\mathrm{Fg} \cdot 17$.

Schaale langr kegelfürmig; Ungänge eben, ungestreift, mit kaum verdickter Naht; Mundöffnung schief; drei fast gleich grosse scharfe Falten auf der Spindel, zwei aussen zwischen und unter den 2 untersten derselben. 
Diese Art, mir nur aus Puscr's Werke bekannt, ist äusserlich der N. Mandelslohi ähnlich, besityt aber eine äussere Falte mehr als diese. Der Abbildung zufolge hat die bis zur Spitze vollständig erhaltene Schaale bei $0^{\mathrm{m}}, \mathbf{1 6 0}$ Höhe und 0,040 untrer Dicke 24 Ungänge, deren Höhe und Dicke $=100: 233$ ist.

Vorkommen in Podolien.

15. N. Bruntrutana Thurm. (Fg. 13 a, b, 18 $a, b)$.

Bourget Pétrif. fig. 243.

Neriné Defrance im Dict. d. scienc. nat., Atlas pl. xxxiv, fig. $3 \mathrm{~b}$ (?), und $3 \mathrm{~b}$.

Nerinea Bruntrutana Thurm. $17 ;-$ Brovn Lethäa 399, Tf. xxi, Fg. 13; - Voutz Jahrb. 1836, S. 542.

Nerinea la evis Voutz früher, Thrra géogn. de la Haute

Saone 7.

Nerinea triplicata Pusch Poln. Palciontol., Tf. IX, Fig. $16 \mathrm{a}, \mathrm{b})$.

Schaale lang kegelfürmig; Ungänge sattelförnig schwach vertieft oder eben, glatt; Zuwachsstreifen fast seukrecht, fein; Nalıt in Form ciner erhabenen Linie; Falten 5, bis auf eine zusammengesetzt, nämlich: eine oben, nächst der Spindel, zwei auf der Spindel tiefer unten, zwei aussen, wovon die obre einfach ist.

Ein sehr schönes, von Hın. Voutz mitgetheiltes, in der Zeichnung (Fg. 13) dargestelltes Exemplar zeigt keine Spur von Knötchen an der Oberfliiche; den Vertikal-Durchschnitt eines andern habe ich in der Lethäa mitgetheilt. - Die zitirte Figur von Defrance scheint mir zu dieser Art zu gehüren, wie ich solche. denn auch, wenigstens den Falten nach ganz übereinstimmend, vom nämlichen Fundort Auxerre erhalten habe. Eine andere Fundstelle, welche den von Voutz angegebenen noch beigefügt werden muss, ist Chaumont über Neuchalel. Auch weicht die Polnische Form N. triplicata Puscri (Fg. 18) nicht weiter, als durch leichte Differenzen in den Proportionen ab. An der Maas soll diese Art ebenfalls vorkommen.

16. N. triplicata Votrz S. 542 (Fg. 24).

Schaale selir lang kegrelfürmig; Ungänge hoch, ..... . ; Falten 6, nåulich drei aussen, wovon die mittle nur schr schwach, dic untere 
aber stark und zweitheilig ist; drei innen, wovon jedoch die mittle eben. falls sehr schwach ist und manchmal doppelt zu seyn scheint.

Ich hatte zwei Kerne von Hrn. Voltz zur Ansicht und Zeichnung erhalten; die mittle der äusseren Falten ist ihrer Schwäche wegen in dieser nicht angegeben: es ist nämlich nur eine schwach vertiefte Linie.

\section{N. terebra Schübl.}

Nerinea terebra Schüвr., v. Ziet. Württemb. Verstein. 48, Tf. xxxvi, Fg. 3 ; - v. Mandelst. Alp 15; - ThirRia p. 5.

Ungänge sáttelfōrmig vertieft; Nähte scharf erhaben; Falten ... eine sehr grosse mitten auf der Spindel.

v. Zieten hatte die Zahl der Falten weder in der Beschreibung noch in der Zeichnung genauer angegeben, und da sich die Original-Exemplare nicht in der Stutlgarler Sammlung finden, so vermochte er auch nicht meiner spätern Bitte um genaue Untersuchung zu entsprechen.

Die Abbildung zeigt bei $0^{\mathrm{m}}, 030$ untrer und 0,007 obrer Dicke des unvollständigen, doch noch $0^{\mathrm{m}}, 1$ hohen Exemplares 10 Umgänge.

Im Coralrag zu Nattheim, und frageweise im Portlandkalk zu Fresne, St. Mamès an der obern Saone.

1S. N. sulc a t a Schübl.

Nerinea sulcata v. Ziet. ib. 43, Tf. xxxri, Fg. 4 ; - v. Maxdelsl. Alp, 15.

Umgänge in der Mitte flach sattelartig vertieft, oben und unten mit einer Kante längs der Naht versehen, wodurch diese scharf rinnenförmig wird. Zuwachs- und Spiral - Streifung gibt die Zeichnung nicht an. Falten ....

Das noch mit einer Spitze versehene $0^{\mathrm{m}}, 0 \mathrm{~S} 2$ hohe und unten 0,025 dicke Exemplar zeigt 10 Umgänge. Da keine Falten davon bekannt sind, so könnte in $\mathrm{Z}$ weifel gezogen werden, ob es wirklich zu diesem Geschlechte gehöre. Fand sich mit voriger Art.

19. $\leqq$ N. ..... (v. Ziet. ib. 4S, Tf. $x \times x v 1$, Fy. 5).

Ungänge hoch, sattelfürmig vertieft, sich zu scharfen Nähten erhebend, und in der Mitte mit drei gleichweit auseinander stehenden, auf der sehr schiefen und hohen Grundfläche aber noch mit mehreren andern, erhabenen 


\section{$-558$}

Spiral-Linien versehen. Falten unbekannt. Das Genus noch zweifelhafter, als bei voriger Art, mit der das bei ZiETEN abgebilde te Exemplar vorgekommen. Seine Spitze ist abgebrochen, die Länge beträgt jedoch bei $3 \frac{1}{2}$ Umgängen noch $\mathbf{0 , 0 4 5}$, die Dicke oben 0,006, unten 0,015.

20. N. cing enda Phill.

Unter diesem Namen bildet Phildips (Geology of Yorkshive, 1829, I, 157, 191, Tf. xı, Fg. 2S, 29) eine ausgezeichnete Art ab, deren Falten aber nicht genau genug angegeben sind. Auf der Spindel scheinen der Abbildung zufolge zwei Falten unten vorzukommen, zwischen welchen aussen eine sehr grosse steht; ausserdem könnten aber noch einige kleinere vorhanden seyn, und Phillips sagt von der äusseren Lippe, sie sey innen spiral wellenförmig [§]. Die Form nach der Zeichnung ist lang kegelförmig; die Oberfläche glatt; die Umgänge in der Mitte scharf oder dachartig vertieft, wie bei N. Gosae, und, wie es scheint, über der Basis mit 1-2 erhabenen Spiral-Linien versehen. Im übrigen ist diese Art nach Prillips sehr veränderlich.

Vorkommen im Unter-Oolith von Blue wick in Yorkshire.

Gehört vielleicht auch Melania vittata Philt. pl. vil, fig. 15 zu diesen Geschlecht $\$$

21. N. e legans Thurm. (Fg. 20 a, b, c).

Nerinea elegans Thurar. Porrentr. 17, Voutz im Jalirbuch 1836, S. 542 .

Schaale lang kegelförmig; Umgänge eben, nur dic Naht mit einer rundlich flachen Vertiefung; Oberfläche längs des obern und des untern Randes dieser Vertiefunr mit je einer Reihe von 16-20 aneinandergefügten Knötchen; dazwischen noch eine dritte viel feinere Reihe, welche Hr. Vout\% uicht bemerkt hatte; Falten zwei, eine oben, eine nach der Spindel unten.

Die untre Reihe von Knötchen fehlt ebenfalls an den ober'n Umgängen.

Ich hatte zwei Exemplare vom Mont terrible und den Cyps-Abguss eines Kernes von St. Martin in Calvados durch Hיn. VoLtz erhalten. Nach erstren ist die Zeichnung entworfen.

Hr. Voutz schrieb mir später, dass er die Formen von 
diesen beiden Orten für verschiedene Spielarten oder selbst Arten ansehe. Bei jenen vom Mont terrible sollen sich die Knötchen mehr zu Längenrippen aneinanderreihen, bei den grösseren von Calvados solche aber Queerrippen bilden. Doch hatte Voltz hievon auch nur ein Exemplar. Bei beiden wären die Falten ganz gleich. Vgl. N. f a s c i a t a Röм.S.555.

22. N. punctata Voltz in litt. (Fg. 23).

Schaale lang kegelförmig; Umgänge eben, etwas treppenartig ancinander gesetzt, mit drei gleichen Spiralreihen feiner spitzer Knötchen, wovon die mittle oft etwas stärker scheint. Falten 3, die kleinste oben, eine auf der Spindel unten und die grösste aussen unter der Mitte.

Auch die Kante, welche die Umgänge oben begrenzt, scheint etwas knotig zu seyn. Ein $0^{\mathrm{m}}, 020$ langes Exemplar, von Hrn. Voutz zur Ansicht erhalten, zählt 9 Umgänge und ist unten 0,005 dick; dieser unterste Umgang hat 0,004 Höhe.

Aus dem Portlandstone zu Vy-le-fcrroux an der oberen Saone.

23. N. Visurgis Röm. (Fg. 8 a, b).

N e rin e a v. Stronisecr in Karst. Arch. IV, 395 ff. $>$ Jalurb. 1833, S. 81.

Nerinea Visurgis Rör. Weser-Verstein. p. 10, 143, Tf. XI, Fg. 26, 28 (früher Fg. 8).

Schaale lang kegelförmig; Umgänge in der Mitte etwas verticft und daselbst mit zwei erhabenen gegliederten Spirallinien versehen; Naht erhöhet, knotig, mit etwa 24 Knoten auf einem Umgang: Falten stark, drei, wovon eise oben, eine auf der Spindel unten und eine aus. sen unter der Mitte.

Diese Art ist nach Rōmer's Abbildung nur dureh ihre Oberflächen-Zeichnung von N. suprajurensis verschieden; ich besitze einen Kern, den ich in der Lethäa zu dieser letztern bezogen, der aber dieser Übereinstimmung ungeachtet, wie Römer aus dessen Fundort folgert, wo er erst neulich auch die Schaale gefunden, zu N. Visurg is gehört.

Im obern Coralring am Spitzhut bei Hildesheim, zu Goslar, zu Hannover am Lindener Berg; am Osterwalde bei Hoheneggelsen und an der. Haferkost; - in Dolomit des Coralrags am Kahleberg bei Echte zwischen Göttingen und Braunschweig. 
24. N. nodulos a DESH. in Exped. d.Morée, III, 155, Tf. xxvi, Fg. 6, $\%$.

Schaale lang thurmförmig mit vielen uiedrigen Umgängen, welche in der Mitte sattelförmig vertieft, an ihren beiden Rändern verdickt und knotig sind; Falten drei, eine oben, eine auf der Spindel mitten, eine aussen dieser entgegenstehend.

Da Deshayes ausdrücklich sagt, dass die Ungänge längs einer jeden ihrer beiden Ränder konvex, dick aufgeworfen, and in regelmässige starke Knötchen getheilt seyen, so ist hiedurch diese Art von N. Sequana, wo die Knötchen über, und von $\mathbf{N}$. Visurgis, wo sie unter der Naht stehen, verschieden, der Zeichnung nach könnte man jedoch glauben, die Knötchen, deren $\mathbf{1 5}$ auf einen Umgang kommen, stünden auch hier unter der Naht; übrigens besitzen beide, bei gleicher Beschaffenheit der Falten, noch verschiedene Spirallinien auf der Oberfläche. Die etwas wellenförmige Naht befindet sich etwas unter der Mittellinie jenes SpiralRandes; die Basis des letzten Umganges zeigt noch einige spirale Linien. Die Spindel ist dünne; die innern Falten sind flach. Das abgebildete Bruchstiick hat 7 Umgänge auf 0,040 Länge, wobei sein obrer Durchmesser 0,010, der untre 0,017 beträgt.

Mit N. simplex.

25. N. speciosa Voltz in litt.

Schaale lang kegelförmig; Naht tief; Ungänge in der Mitte fast flach, längs beider Nähte gerändet, der untere Rand dicker und knotig mit je 20-22 Knoten; Oberfläche gegen die Spize undeutlich gegittert; Falten drei, eine oben, eine auf der Spiudel untenlängs des Kanales, eine aussen tief und dieser gegenüberstehend.

Erst während des Abdruckes dieses Aufsatzes erhielt ich einen Gyps-Abguss dieser Art nebst einer brieflichen Nachricht darüber von Hrn. Voltz. Die Zuwachsstreifung ist deutlich, senkrecht, und nur oben stark zurückgebogen. Auf allen, insbesondere den untern Umgängen sieht man längs der Mitte eine erhabene, etwas gekörnelte Linie, wie bei N. Se qu a n a herabziehen, yon der sich diese Art wenig za unterscheiden scheint: nämlich hauptsächlich nur durch die (wie bei N. Visurgis) zahlreicheren und kleineren 
Knoten des Unterrandes der Umgänge, und durch eine etwas gegitterte Beschaffenheit der Oberfläche der obersten, indem man dort über und unter der gekörnelten Mittellinie noch je eine feinere ehenfalls gekörnelte wahrnimint, welche von den mit den Zuwachsstreifen parallel von den Knoten ausgehenden Wülstchen durchkreutzt werden. Jedoch würde zu untersuchen seyn, ob wohlerhaltene Exemplare von $\mathbf{N}$. Sequana an der Spitze nicht eben diese Beschaffenheit erkennen lassen. Grundfläche der Umgänge mit etwa $\boldsymbol{Z}$ spiralen Streifen. Falten im Wesentlichen wie bei $\mathbf{N}$. S e qu a n a.

Das Exemplar, welchem ein kurzes Stück der Spitzo fehlt, hat auf 0,050 Länge 7 Umgänge, ist unten 0,020, oben 0,006 breit; der unterste Ungang hat ohne seine Grundfläche 0,010 , und mit dieser 0,015 Höhe.

Vorkornmen im Berner Jura in Coralrag.

26. N. Sequana Thirr. (Fg. 6 a, b).

Nerine a Sequana THrre. p. 7 ; - Röm. Weser - Verstein. 144; - Voctz in Jahrb. 1836, S. 542.

Sclıale lang kegelförnig; Umgänge sattelartig vertieft, mit schicfer Zuwachsstreifung; unten mit einer Reihe grösserer Knoten (12-16 auf einem Ungang) unmittelbar über der erhabenen Naht, und mit einer (oft undeutlichen) gegliederten Linie in der Mitte; Falten drei, eine obeu, eine auf der Spindel unten, eine aussen unten.

Kern ganz gleich dem der N. Visurgis u. a. glatten Arten. Herı Voutz erwähnt der geglicderten Mittellinie nicht, die ich auf einem von ihm erhaltenen Gyps - Abguss eines Exemplares von Lisieux finde. Auf einem natürlichen äussern Abdruck von da sehe ich sie ebenfalls nicht. Römar entdeckte diese Art auch im obern Coralrag zwischen Seesen und Dannhausen.

2\%. N. nodosa Voltz Jahrb. S. 542 (Fg. 9 a, b).

Neriné tuberculeus e Defr. im Dict. sc. nat. pl. xxxir, fig. 3 a, und ? $3 \mathrm{~b}$.

Schaale lang kegelförmig; Umgänge sattelartig vertieft, oben mit einer Reihe von je $12-16$ Knoten an der verdickten Naht eines jeden Unganges, mitten mit einer gegliederten Linie, und auf der Grundfäche noch mit einigen andern; Falten vier, näınlich drei oben und auf der Spindel, eiue aussen der mittlen entgegenstehend. 
Hr. Voltz führt zwar noch 2 schwache Falten weiter an, eine innen über der obersten und eine über der äusseren. Es sind aber blosse Linien, dergleichen auch 2-3 auf der Grundfläche des Kernes vorkommen, und selbst sie finde ich nicht bei allen Exemplaren.

Die Abbildungen sind nach Gyps-Abgüssen und nach natürlichen Exemplaren und Kegrnen von Verdun und von Dun von der Maas. Diese Art glaube ich insbesondere noch aus dem SCoralrag von Neuvisy in den Ardennen zu besitzen, wo sie mit A piocrinites mespeliformis vorkommt. Meine Exemplare stimmen rücksichtlich der grösseren Falten völlig überein, die 2 kleinen fehlen oder sind kaum angedeutet; aber ihre Oberfläche ist nicht vollständig erhalten.

N. nod os a Röm. 144, Tf. XI, Fg. 18 ist nach erhaltenen Original - Exemplaren weder die Voutz'sche Art, noch überhaupt eine $\mathrm{Nerinea,} \mathrm{da} \mathrm{sie} \mathrm{gar} \mathrm{keine}$ Falten besitzt.

2S. N. bicincta n. sp. (Fg. 14 a, b).

Schaale dick, lang kegelförmig; Umgänge káum vertieft, mit zwei Reihen von je 14 dicken, in der obern Reihe mehr in einander verfliessenden Knoten, welche fast die ganze Oberfläche einnelsmen, ünd nur in der Mitte eine vertiefte Furche übrig lassen; Falten vier; eine oben, zwei auf der Spindel und eine aussen bis unter die obere hineingreifend.

Ich besitze zwei Bruchstücke; das besser erhaltene und abgebildete hat auf 0,072 Länge $4 \frac{1}{2}$ Umgänge; der untere ist 0,031 , der obere 0,027 breit; ersterer hat ohne die schiefe Grundfläche 0,013 Höhe.

Aus dem Sandsteine der Gosau im Salzburgischen mit N. involuta, welchen LiLL im Jahrbuch mit Nr. 14 bezeichnet hat, und dessen Versteinerungen von mir ebendaselbst 1832, S. 177-179 aufgeführt werden. Dann an der Wand bei Wien.

29. N. trinodosa Voltz S. 540 (Fg. 10).

Schaale dick, lang kegelformig; Ungänge flach, mit drei gleichen Reihen von je $10-14$ dicken, runden Knoten, deren obere und untere 
längs der Naht verlaufen. Falten 4, eine oben, eine grössere und eine kleinere auf der Spindel unten, eine aussen unten.

Zeichnung nach einem von Hrn. Vourz erhaltenen GypsAbgusse. Die äussere Falte verläuft zwischen den 2 untern Knoten-Reihen.

30. N. flexuosa Sow. (Fg. 19 a, b).

Nerinea flexu os a Sow. bei Murchison in Geol. Transact. $\mathbf{N}$. S. IIl, 418, pl. xxxvin, fig. 16 .

Schaale nadelförnig, fast zylindrisch; Umgäng hoch, wenig sattelartig verticft, in der Mitte mit zwei erhabenen, etwas gekörnelten Linien mit 20-25 Körnchen auf einem Umgang versehen, oben und unten zur Naht verdickt, und unter dieser auf der Verdickung ebenfalls mit Spuren von Körnchen. Falten vier: cirei fast gleiche auf der Spindel und eine äussere, wodurch die Umgänge des Kernes wie bei N. B o rsonii in zwei gleiche runde Hälften getrennt werden.

Die Schaale scheint bei noch nicht $0^{\mathrm{m}}, 005$ untrer Dicke schon eine Länge 'von 0,050 zu besitzen. Der Name $\mathbf{N}$. flexuosa ist ungeeignet, da die an der Schaale oft bemerklichen Biegungen nur durch mechanische Verschiebungen im Gestein entstanden sind.

In der Gosau mit N. bicincta.

31. N. imbricata Deshay $1 S 36$ in Exped. d. Morée, III, 185, Tf. xxvi, Fg. 4, 5.

Schaale kegelförmig; Umgänge sich übereinanderschiebend, nit mehreren senkrechten regelmässigen Rippen; Spindel an der Basis durchbohrt; Falten drei innen, zwei schwache aussen.

Die Umgänge sind etwas aneinander abgesetzt; die Naht liegt daher in einer engen Rinne; die untre Spindelfalte ist am grössten, an ihrer Basis schmal, auf ihrem Rücken sehr breit, mithin von keulenförmigem Durchschnitte; die mittle ist hoch und dünne, die obre dick, niedrig, doch scharf; die Zwischenräume tief und schmal. Die äusseren Falten sind viel kleiner, dünner, scharf: eine steht der zweiten Spindelfalte entgegen, die andere unter der dritten: das Ganze fast wie bei N. Mos a e. Ein Bruchstiuck mit etwa 6 Umgängen hat 0,045 Länge auf 0,020 untre und 0,010 obre Dicke.

Auf Morea mit N. simplex. 


\section{N. Mos a e Deshay.}

Nerine a Mos a DEsir. im Dict. classiq. d'hist. nat. q:ol. XI, Art.

Nerinée, und in Coquill. caracter. 1831, S. 405, pl. Iv, fig. 1, 2.

Schaale kegelförmig; Umgänge in der Mitte etwas vertieft, längs der tiefen Naht oben und unten eine dicke Einfassung bildend, von welchen, insbesondere dem unteren. aus unregelnässige Wulst-artige Kínoten (18-20) über die Oberfläche herabzieien; Falten fünf : eine oben, zwei auf der Spiudel, wovon die untere am höchsten, und zwei aussen, wovon die untre klein ist.

Das von Deshayes abgebildete Exemplar hat von der Spitze an 0,160 Länge auf 0,070 Dicke. Höhe und Breite (im Ganzen) der 12 Ungänge verhält sich $=100: 325$. Von den äusseren Falten steht die obre sehr grosse in der halben Höhe der Umgänge, die untre ist klein und steht im äusseren unteren Winkel, gegenüber der untersten, grössten Spindel - Falté.

In einem weissen Oolith mit Diceras zu St. Mihiel im Meuse-Dept., und nach Michelin zu Pouilly.

N. tu b erculos a Derr.

in Dict. d. scienc. ditist. nat., 1825, XXXIV, S.462-464; Atlas des Coquill. pl. xxxiv, fig. 3 a-c.

N. tuberculata De Blainville, Malacologie (die gleiche Tafel).

Diese Art ist, wie schon mehrfältig angedeutet worden, und worin auch $\mathrm{H}_{\mathrm{r}}$. Voltz mit mir übereinstimnt, eine ganz künstliche, aus verschiedenen Elementen zusammengesetzte, wie demn Defrance selbst den angeführten Namen auch nicht einmal im Texte aufgenommen, sondern nur unter die Tafel mit den abgebildeten Elementen gesetzt hat.

Defrance nämlich unterscheidet im Text zwei Arten: eine mit Kuoten von Lizicux im Calvados, und eine ohne Knoten von Bailly bei Auxerre und Nevers. Obgleich nun auf der Tafel alle Figuren zu N. tuberculosa bezogen worden, so gehören sie doch wenigstens zwei verschiedenen Arten an. Ich selbst besitze von Auxerre die schlanke Form der N. suprajurensis (Fg. 2) und die N. Bruntrutana, 
welche beide keine Knoten lsaben, zu deren letzter aber gleichwohl der Durchschnitt Fg. (\$: b) 3 c bezogen werden muss. Voltz zitirt zu Lisieux die N. Sequana und. N. el egans mit Knoten; zu erstrer würde die äussre Ansicht Fg. 3 bezogen werden könuen, wenn Defrance nicht im Texte bemerkte, dass bei N. tuberculosa die Knoten-Reihe unter der Naht läge, welche in der Zeichnung darüber angegeben ist. Entweder scheint also der Zeichner den Gegenstand unrichtig dargestellt - jedenfalls hat er ihn verschönert, - oder Defrance sich die Schaale auf der Spitze stehend gedacht zu haben, wie das auch Deshayss bei Beschreibung der Griechischen Arten thut. Der Kern Fg. 3 a (@ und $\mathbf{3}$ b) aber stimmt mit N. nodosa Voutz recht gut überein, wie auch Voutz anführ't: dieser Art würde auch die von Defrance im Texte bezeichnete Stellung der Knos ten entsprechen. So gehören mithin allem Anscheine nach die zu N. tuberculosa tezogenen Abbildungen zu zwei, wenn nicht zu drei verschiedenen und bereits beschriebenen Arten. Es fragt sich nun, wie es sich mit

\section{N. tuberculos a Rōm. (Fg. 7)}

Rör. Weser-Verstein. 144, Tf. XI, Fg. 29

verhalte; wovon Römer zwar im Texte anführt, dass die Spindel faltenlos sey, dass er auch am rechten Mundsaume Falten vergeblich gesucht habe, was abe: beides wohl nur auf die Beschaffenheit in der Nähe der Mündung eines wohl erhaltenen Exemplares Bezug hat. Da er nieht selbst Eigenthümer desselben ist, so ist er nicht in der Lage, die Beschaffenheit der Falten durch Anfeilen desselben zu erforschen. Im Übrigen hat dasselbe Ähnlichkeit mit N. Sequana, deren Knoten aber grösser und weniger zahlreich sind, - und mit N. Visurgis, wovon es sich aber durch sichelförmige Zuwachsstreifen, dickere Knoten und den Mangel der zwei Linien auf der Mitte der Umgänge unterscheidet. Der Kanal ist kurz und ganz gerade.

In oberen Coralrag der Lindener Borges bei Hannover. 
N. pulchella Thurm. Porrentr. 17.

aus dem Nerineen-Kalke des Mont terrible, ist nach Voctz ein Cerithium.

Die Nerinea-Art, welche nach Deshayes mit Diceras am Mont Salève bei Genf vorkommt, ist nicht näher bekannt.

N e rine e n haben auch Dubors in Klein-Asien und Strickland in der Türkei beobachtet, wie sie mir mündlich mittheilten, aber deren Beschreibung noch nicht bekannt gemacht. 


\title{
Briefwechsel.
}

\section{Mittheilungen, an den Geheimenrath v. LEONHARD gerichtet.}

\author{
Nashville (Tennessee), 1. Februar 1836.
}

Seit meinem letzten Briefe habe ich meinen Wohnort geändert und lebe nun in einem Lande, wo nichts als Sand- und Kalk-Stein zu sehen sind; aber an petrefaktologischen Gegenständen ist viel Interessantes und Wichtiges vorhanden. Sie werden manche meiner Mittheilungen in den Verhandlungen der Französischen und der Pernsylvanischen geologischen Sozictät nicht übersehen haben. Eine Beschreibung des Tennessee-Staates liegt zum Drucke bereit; auch bin ich mit Übersetzung des GoLDyuss'schen Werkes beschäftigt. - Vor Kurzen fand ich einen Theil vom Vorderkopfe eines ungeheuren Thieres; wahrscheinlich gehört derselben zum Mastodon. Auch nicht wenige noch unbeschriebene Mineralien habe ich in unserem Staate gesammelt.

Troost.

Regensburg im März 1835.

Durch mancherlei Ereignisse verhindert bin ich erst dieser Tage dazu gekommen, die schon längst erhaltenen Hefte des N. Jahrbuchs für Mineralogie etc. (von 1835) allmählich nachzulesen. Im 3ten Heft fand ich zwei kurze Aufsätze, deren jedem ich einen vielleicht nicht ganz uninteressanten Zusatz beifügen kann. Der erste betrifft die

Geognostische Notiz über die Gegend von Carlsbad (S. 253). Im Jahr 1826 musste ich meiner sehr leidenden Gesundheit wegen den Franzenslrunnen gebrauchen. Diess gab mir Gelegenheit in Eger einen sehr fleissigen Mineralogen, den Magistratsrath GrüNER kennen zu lernen, welcher mir unter andern merkwürdigen Mineralien auch ein Stück Granit mit einer eingeschlossenen Horusteinniere von 
Carlsbad zeigte. Die Erscheinung war mir zu wichtig, um selbe nicht auf das Genaueste zu betrachten. Hr. Grüser bezeichnete mir zwar die Stelle, wo nach seiner Angabe dieses Vorkommen keineswegs sselten ist; allein ich vergass sie in mein Gedenkbuch einzutragen, und kann mich nur noch erimnern, dass sie eine aufstehende Wand bilde.

Die Hornsteinniere glich in ihre äussern Kennzeichen vollkommen jener, welche im Jura-Kalksteine um Amberg so häufig, und desswegen mir aus vielfältiger Autopsie nur zu wohl bekannt sind. - Der Granit war beinahe kleinkörnig und bestand aus den drei Gemengtheilen ungefähr in gewöhnlichen Verhältnisse. Allein seine Struktur schien mir, ohue mir es ganz deutlich machen zu können, etwas sonderbar. Endlich glaubte ich, mit Beihülfe eines guten Suchglases, auf einem Punkte etwas zu bemerken, das mir ein Bindemittel, und zwar von kalkartiger Beschaffenheit zu seyn dünkte. Ein Tropfen Salpetersäure bestätigte mir meine Vermuthung nicht nur auf dieser Stelle, sondern auch auf andern, wo man ein Bindemittel zu erkennen nicht vermochte.

Da ich den Fundort seitdem nicht mehr besichtigen konnte, so wäre es etwas mehr als vermessen, wenn ich (wollte ich es auch nur zu meiner eigenen Beruhigung versuchen) über die Entstehungsweise dieses Aftergranites eine Hypothese aufstellen würde; aber erlauben darf jch nir doch aufmerksam zu machen, dass beinahe in jedem Korne des als Erbsenstein bekannten Sprudelsteines irgend ein Gemengtheil des Granites als veranlassender Kern erscheint, - und zu fragen, wohè der nierenförnige Hornstein und der viele Kalk kommen mag, welchen cinige Quellen des Curlsbades abgesetzt haben und noch absetzen? Die, übrigens höchst lehrreiche, Beobachtung des Freiherrn vos HarDEls's dünkt nir geeigneter die Beantwortung dieser Frage zu erschweren, als zu erleichtern. Vielleicht gewïhrt ihre fortgesetzte Verfolgung auch hierüber noch genügende Aufschlüsse.

Der zweite Zusatz bezieht sich auf die Notiz:

Über Arragonit-Tropfsteine von Antiparus (S. 256). Das Merkwürdige des verhandelten Gegenstandes beruht darin, dass A r ragonit als Tropfstein erscheint. Wenn man nur jene kuhlensaure KalkArten als Arragonit erkennt, welchen was immer für ein Autheil von kohlensaurem Strontian beigemischt ist, so möchte das Vorkommen desselben in jener äussern Gestalt allerdings selten seyn; dennoch kamn ich ein Seitenstïck und zwar nicht aus der Ferne, sondern aus Deutschland, aus Baiern, neben das Griechische stellen. Es ist dieses der schon scit mehr als 40 Jahren von Oberverweser Brunskr entdeckte, aber in keinem oryktognostischen oder, wohin er sich seines Vorkommens wegens ganz und gar eignet, geognostischen Werke bisher angeführte Arragonit von Wolstein bei Neumarlt in der Oberpfalz *).

e) In der Note zu den Beobachtungen überkieselgebilde im Allgemei. $n$ e n etc. ist desscu iu Vorbeigetien begreits erwähnt (Jahrb. S. 307). 
Dieser Arragonit kommt in dem Jura-Dolomitc, welcher als isolirte, gegen $0 ., N$. und W. steil abfallende, vertikal zerklüftete Kuppe den Rücken des aus S.O. in N.W. ziehenden Hügels am äussersten nördlichen Ende bedeckt, auf einem schwebenden, durch die ganze Erstreckung des Dolomites sich verbreitenden untergeordneten Lager von $1 \frac{1}{2}$ bis $2^{\prime}$ Mächtigkeit vor, und hat sich allen Anzeichen nach aus dessen Hangendem ausgeschieden. Seine äussere Gestalt ist längs desselben traubig und Büschel-, eiufach und ästig Zapfen- und Kolben-förnig, auf dem Liegenden aber wellenförmig geschichtet mit vielen und manchfaltigen Erhabenheiten, die Oberfäche des letzten meistens glatt, die des ersten öfter mit spiessigen Krystallen bekleidet, die Dicke und Länge der Zapfen und Kolben, so wie Dicke der einzelnen Lagen und überhaupt die Gestalt äusserst verschieden. Gewöhnlich hat er eine faserige 'Textur: im Ganzen geht sie jedoch aus der dünnfaserigen durch alle Abstufungen bis in die (wiewohl selten nahe an $3^{\prime \prime \prime}$ ) dickstengelige über. Fasern und Stengel setzen nicht selten ununterbrochen durch die Lagen (über 6 " Länge) fort, und enden in eine mehr oder weniger langgezogrene 3 seitige Zuspitzung. Immer spielt auch die weisseste Farbe in Gelb mit Schattirungen bald in Braun, bald in Grau, bald in Roth. Am Seitensten erscheinen diese in der Nähe des Hangenden und Liegenden, wo zuweilen auch, besonders zwischen den Stengeln und Lagen, rothgelbes Eisenoxyd ausgeschieden liegt. Er ist im hohen Grade durchscheinend, oft, besonders der dickfaserige und stengelige, vollkommen durchsichtig.

Der Arragonit-Tropfstein von Wolfstein stimmt also in der Entstehungs - Art der äusseren Gestalt und dern Gefüge mit jenenı von Antiparos, unbedeutende Abweichungen abgerechnet, bisher ziemlich genau überein. Er unterscheidet sich aber wesentlich von demselben dadurch, dass or auf einem regelmässig streichenden Lager, vielleicht auch (die Gebirgsart von Antiparos ist nicht angegeben) dass er im Jurx-Dolonit, welchem zwar überhaupt kohlensaurer Strontian innewohnen soll, und endlich allem Anscheine nach dass er in Gemeinschaft mit kohlensaurem reinem Kalk-Tropfstein vorkommt. Nicht nur bedeckt dieser nümlich ciurchgehends den Arragonit-Tropfstein allenthalben, sondern wechsellagert auch mit dem geschichteten vielfältig, sitzt hie und da unmittelbar auf den Saalbändern, besonders häufig auf denen des Liegenden' auf, und erfüllt sogar den ganzen übrigen Raum des Lagers dergestalt, dass es als ein dichtes Ganzes sich darstellt.

Dieser Kalk-Tropfstein besteht aus blättrigem, konzentrisch-krummschaaligem, daher auf den parallelen Bruchflächen flachnierigen, weissem ins Rothe ziehendem, starkglänzenden, durchscheinendem Kalkspath, der in kleine 6 seitige mit 3 Endflächen zugespitzte Prismen krystallisirt; sehr selten bildet er Rhomben. - Jedoch theilt der auf den Saalbändern aufsitzende die satteren versehiedenen Fürbungen mit dem ArragonitTropfsteine, wird dann beinahe durchsichtig und zeigt eine starke Anneigung zur geradblättrigen rhombischen Textur. 
Das relative Alter der beiden Tropfsteine wird durch die angegebenen gegenseitigen Lagerungs-Verhältnisse deutlich genug bezeichnet. Der Dolomit ist in Hangenden des Lagers ein wenig mürber und bröckelig, dagegen im Liegenden einige Zoll tief sehr locker und wie aufgeweicht. Ein feiner, theilweise verbärteter, theilweise noch sehr weicher Schlamm, unten von grauer, nach oben von gelblichrother Farbe bedeckt, etwa 2 bis $3^{\prime \prime \prime}$ dick, dessen Saalband an den meisten Stellen, wo er nur vom Arragonit-Tropfstein hin und wieder verdrängt wird.

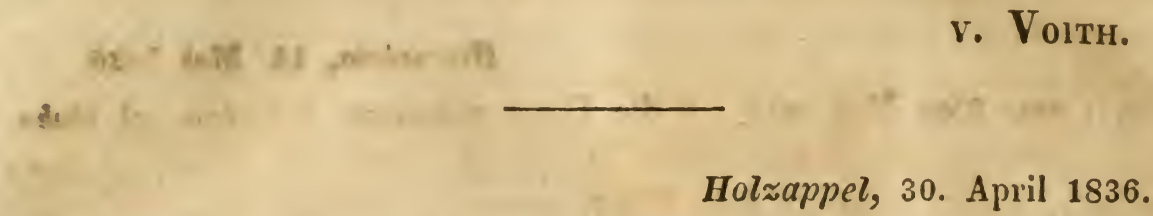

Suchen Sie es möglich zu machen, im Laufe dieses Jahres noch hieherzukommen: ich muss Ihnen einige äusserst interessante Erz-Lagerstätten zeigen. In unseren Gruben werden sie gewiss die Überzeugung erlangen $\left.{ }^{*}\right)$, dass die Rotheisenstein-Lagerstätten in unserem SchalsteinGebirge, worin dieselben in der hiesigen Gegend ausschliesslich vorkommen, nothwendig unter die gangartigen Vorkommnisse aufgenommen werden müssen, wenn Sie Sich davon nicht schon im Dillenburgischen überzeugt haben, wo sich dieselben von den hiesigen darin unterscheiden sollen, dass sie mit den dioritischen Gesteinen in unmittelbarer Beziehung stehen.

In einer andern Grube, die kaum eine Stunde von Holzappel entfernt ist, wird auf Bleierzgängen gebaut, die mit unserem Gang in die nämliche Bildung'szeit fallen, unter deren Ausfüllungsmassen Bleiglanz und Blende gegen die übrigen, Quarz und Spatheisenstein, prädominiren. In jener Grube wird von zwei Gängen aus dieser Formation ein dritter eingeschlossen, welcher niemals Quarz, äusserst selten Blende, dagegen derben Bleiglanz an beiden Saalbändern, und zwischen diesen Spatheisenstein führt. Das Gestein, worin derselbe aufsetzt, ist ein grünlichweisser talkartiger Schief:r, welcher in dem Grauwackenschiefer eingeschlossen und so wie dieser geschichtet ist, der häufig in seiner Mächtigkeit dergestalt wechselt, dass man die wichtigsten Stellen für aus dem Grauwackengebirge hervorgestossene Kuppen zu halten geneigt ist. Auf solchen Stellen kommen alsdann mehrere Erztrümmer neben einander vor, wovon die minder mächtigen durchaus Bleiglanz, die mächtigen hingegen zugleich Spatheisenstein schütten, und die Erztrümmer kommen und verschwinden mit jenem Gesteine. So wenigstens habe ich vor mehreren Jahren dieses Verhalten beobachtet.

Den IIolzappler Gang begleitet in jenem analogen Gestein, das in unserm Feld wohl Bestere führt, die sich aber erst ausserhalb demselben - auf der westlichen Fortsetzung - zu bauwürdigen Trümmern

*) Seit mehreren Jalıren schon zweife ich nicht mehr, dass die Verhältnisse sn $n$. geschen werden müssen, wie mein gelelirter Freund dieselben betrachtet. 
entwickeln, unter wirklich interessanten Erscheinungen. Der Begleiter unseres Ganges fehlt demselben auch auf der entfernten Fortsetzung in dem Werlauer Grubengebäude jenseits des Rheines nicht. Aber auch dort kommen, so viel mir darüber bekannt ist, keine bauwürdigen Trümmer darin vor.

\section{SchNEIDER.}

\section{Hohnstein, 14. Mai 1836.}

Seit dem 2ten Mai habe ich die Untersuchungs - Arbeiten bei Hohnstein begonnen. Die erste Arbeit besteht in zwei Steinbruch-artigen Entblösungen am Abhange des Wartenberges, welcher das linke Ge. hänge des Polenz - Thales bildet, da wo die Granit - Sandstein - Grenze von der Strasse durchschnitten wird. Án der unteren Stelle, etwa 80 Fuss über der Thalsohle, findet leider so starke Geröllbedeckung Statt, dass wir bei 10 Fuss Tiefe noch lauter Schutt vor uns sahen. Mit dem oberen Schurf erreichten wir dagegen sehr bald die deutliche Grenze der anstehenden Gesteine. Der Granit liegt sehr regelmässig auf dem Sandstein. Die Grenzscheide fällt kaum $30^{\circ}$ gegen N.O. und ist durch eine 2 bis $12 \mathrm{Z}$ oll dicke Thonlage von rother und grünlichgrauer Farbe bezeichnet. Zunächst unter dem Thon folgt gewöhnlich ein Konglomeratartiger Sandstein mit kalkigem Bindemittel und Geschieben von Kalkstein und Thoneisenstein. Er enthält Jura-Versteinerungen, obwohl nur selten. Während der Schurf-Arbeiten fand sich ein Bruchstück von Ammonites polygyratus Reis. und ein zweites recht deutliches von Am. Gowerianus Sow. Diess ist vielleicht derselbe Ammonit, welchen Graf Münster als A. coronatus von Hohnstein zitirt, denn wiewohl beide Arten sich sehr ähnlich sind, so scheint doch der gewölbtere Rücken und die sehr regelmässige Zerspaltung der Falten in drei bei dem Hohnsteiner Exemplar mehr für Gow erianus zu sprechen.

Dieser Konglonerat-artige Sandstein bildet kein Continuum, zuweilen folgt vielmehr unter dem Thon sogleich ein ungewöhnlich fester, fcinkörniger, eisenschüssiger und vielfach zerklüfteter Sandstein, der sehr häufig von glatten Reibungs-Flächen durchschnitten ist: vielleicht schon Quadersandstein. - Ich lasse nun zunächst besonders dicsen oberen Schurf nach allen Seiten erweitern, um wo möglich die Grenzen auf grosse Ausdehnung und an recht frischen Gesteinen zu evtblössen, denn bisher ist alles noch sehr zerklüftet und zum Theil auch verwittert.

Unverkennbar ist die Analogie der Gesteine dieses Schurfes mit den Lagen in Hohnsteiner Kalkbruche. Ler rothe und grüne Thon entspricht genau der sogenanuten rothen Lage, welche in der Kalkgrube 20 Ellen Mächtigkeit erreicht. Der Konglomerat-artige Sandstcin stinumt in aller Hinsicht mit dem der sogenannten "Sandwand" übercin, welcher auch dort überall mit Säuren brausst und sogar als Kalkstein gebrannt werden kann. Der Kalkstein und die "schwarze Lage" fehlen 
am Wartenberge, wie sie denn auch in Kalkbruche gegen S.O. und N.W. sich bald auskeilen sollen.

Auch hier also liegen die Schichten mit Jura-Versteinerungen über dem $Q$ uader-Sandstein, und über beiden liegt Granit.

Andere Geschäfte halten mich jetzt für eiuige Wochen von der Fortsetzung dieser Arbeite": ab; so bald sie wieder begonnen, melde ich Ilınen die ferneren Resultate.

Unterzeichnet haben neuerlich für das Unternehmen:

Herr Geheimerfiuanzrath Freiherr v. BerLePsch in Dresden

Aktien.

n Geheimerfiuanzrath HeYer in Dresden . . . . . . . 5

- Forstmeister vor $\mathrm{H}_{\triangle \mathrm{CK}}$ in Schundau . . . . . . . 1

" Staatsrath von Struve in Hamburg . . . . . . . 3

" Godeffrox in Hamburg . . . . . . . . . . 25

" Bergrath Реsch in Warschaue . . . . . . . . . . . 3

"Professor Carl Naumanin in Freiburg von neuem . . . . 3

" Bergmeister Hering in Johamn-Georgenstadt . . . . . . 1

" Emic Haspre in Schwarzenberg . . . . . . . . . . 1

$\begin{array}{rr}\text { Hiezu } & \frac{272}{272} \\ \text { Gibt } & \frac{1}{316} \\ \text { Bernhard Cotta. }\end{array}$

Darmstadt, 22. Mai 1836.

Es war meine Absicht, dieser Tage narh Heilelbery zu kommen; doch hält mich nun ein nicht unwichtiger Fund, welcher dieser Tage bei Eppe'sheim gemacht wurde und die ganz kurze freie Zeit, über welche ich disponiren kamn, in Anspruch nimmt, davon ab.

Mehrere, mit vielem Aufwand verbundene Versuche, welche ich auf die urweltlichen Seltenheiten in jener Gegend seither einleitete, fieleu grösstentheils erfolglos aus, bis endlich, als man im Begriff stand, dieselben abzubrechen, sich noch eine der grössten Seltenheiten fand der grösstentheils sehr schün erhaltene Oberkopf von Kavp's Dinotherium giganteum ungefähr $5^{\prime}$ lang und $3 \frac{1}{2}{ }^{\prime}$ breit, 4 bis 5 Zentuer schwer. Da dieses Stiick die sorgfailtigste Behandlung beim Heraufbringen aus der Tiefe und für die Vorbereitung zum Transport erfordert, muss ich nun die meinen anderen Ausflügen bestimmte kurze Zeit demselben widmen.

Ich boffe den Kopf bald abbilden lassen zu künnen und werde alsdann Honen norh Mehreres dariber mittheilen.

Bei Alzei fanden sich in dern hlauen Mergelthon des Grobkalkes unlängst hei Abscnkung eines Brunnenschachtes einige nur wenige Zoll mächtige Brrunkohlenlagen. 
In Offerbach bohrte man, bei einem vorigen Winter vorgenommenen Versuch auf Springquellen, den plastischen Thon an und durchsank ihn auf $200^{\prime}$ Tiefe. Nach einer Mittheilung des Herrn Doktor Gergens' zu Mlainz soll diese Bildung in Folge ähnlicher Versuche dort eben so wohl eine beträchtliche Mächtigkeit ergeben haben. Es dürfte hiernach zunal für die Inain-Gegenden um Offenbach, Frankfurt und Hanau anzunehmen seyn, dass der Grobkalk zum Theii nur in geringer Mächtigkeit über dem Braunkohlengebirge ruht, wie sich diess auch theilweise schon aus früheren Bohrversuchen ergab.

In der Nähe von Giesen wurden neulich von Landleuten Versuche uuf Braunkohlen angestellt und zwei Lager, das eine $7^{\prime}$ das andere $1^{\prime}$ mächtig, in einer Tiefe von $30^{\prime}$ unter der Thalsohle erbohrt. Man beabsichtigt nun diese Versuche auch noch in anderen Gemarkungen fortzusetzen.

\section{A. Kuipstein.}

\section{Burg Haardt in Rheinbaiern, 3. Juni 1836.}

Die Emporhebungen in Skandinavien, Spitzbergen und im stillen Ozean, die Senkung Grönlands und anderer Länder - Strecken erklären sicb nach meiner Überzeugung nur miteinander. Sie sind Symptome Einer umfassenden, vielgestaltigen Wirkung. Ihre Entdeckung gehört daher zu den wichtigsten Resultaten der neueren Naturforschung.

Im Magazin for Naturvidenskaberne wurde kürzlich die Ansicht aufgestellt, dass der Boden von Skandinavien, der sich allnählich fortdauernd hebt, in einer mehr oder minder fernen Epoche durch einzelue Stösse (nach Art des Erdbebens von Ghili 1822) plötzlich gehoben worden sey, an verschiedenen Stellen zu ungleich bedeutender Höhe. In der Hertha, Almanach für 1836, S. 173 habe ich eine ähnliche Ansicht mit der Bestimmung aufgestellt:

1) dass der Beginn dieser Hebung, wie sie heute fortwährt, auf die diluvische Periode zurückdeutet und

2) dass ihre Ausdehnung im wesentlichen Verbältnisse mit den so-

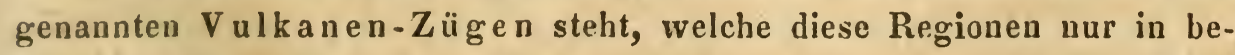
stimmten Entfernungen berühren, deren Natur und Richtung ich daselbst geschildert habe.

Auf die erste Annahme führte mich eine $\mathrm{Z}$ us ammenstellung der bisherigen Höhen - Berechnungen der Skandinavischen Hebungen in verschiedenen Gegenden. Denn aus diesen Berechnungen geht ziemlich allgemein hervor, dass manche dieser Strecken über die heutige MeeresHöhe ungefähr in derselben Zeit zu steigen begonnen haben, in welcher nach anderen Berechnungen die diluvische Katastrophe eintrat. Gleich in Nöggenatr's Üiersetzung von Cuvier's Umwälzungen der Erd-Oberfläche liegen Angaben, die mir, vor Jahren diese Ansicht erweckten. In Verbiudung mit ihr dürfte sich auch die Fortschaffung der 
grossen Skandinavischen Fels - Trümmer nach den diessseitigen Nordländern auf die einfachste Art erklären.

Wasser-Gewalt allein konnte diese Trünmer nicht lösen. Ihre Fortschaffung scheint mir bei den meisten eine mehr oder weniger unmittelbare Folge ihrer Lostrennung von anstehenden Massen oder eine Folge derselben Ursache gewesen zu seyn, der sie ihre Lostrennung verdanken. Dieser Trennung musste eine gewaltsame, wahrscheinlich dieselbe Erschütterung vorhergegangen seyn, welche durch das letzte kolossale Aufsteigen plutonischer (namentlich der jüngsten basaltischen) Massen die Ursache jener Fluth wurde. Die nähere Entwickelung dieser Ansicht gab ich gleichfalls in der Hertha (S. 169 ff. und vorher): ich nahm darauf Rücksicht, dass in Skandinavien die Basalt - Bildung nur zu geringem Durchbruch kam, und eile zum zweiten Punkte, zur A usdehnung, zu den Grenzen der skandinavischen Hebung. In der Hertha und früher in meinen Vermischten, bei Dannheimer 1833 erschicnenen, A ufsätzen, habe ich gezeigt, dass diese Hebuug in wesentlichem Verbande mit bestimmten Vulkanen-Zügen stehe und, sich weit erstreckend, erst in der Region des Schwarzen Meeres und schon desshalb da sich ende, weil hier die hebende Gewalt durch vulkanische Mändungen freien Ausgang hat, während sie in Skandinavien durch überlastende Massen ganz in der Richtung des in der Hertha dargelegten Vulkanen-Zuges gehemmt, mithin durch Widerstand zur Hebung gedrungen wird. Diese Hebungs-Linie ist bis zu ihren südöstliehen Grenzen frei von Vulkanen. Im Nordwesten hat die vulkauische Werkstätte der Tiefe auf Island einen ofenen Heerd sich gesehaffen, mithin das ganze Verhältniss, das hoch im Norden, in Spitzbergen noch Statt haben soll, um Island herum geändert. Die Verfolgung dieser Linie führte mich bis auf Grönland. Dass dieses sich senkt, ist in neuer Zeit als Thatsache erkannt worden. Man streitet einzig über den Grund der Scnkung, findet ihu unerklärbar, oder sucht ihn in einer Zusamnenzichung der Erde, irrig nur, wenn man dieses Wort im Simme der Münchner Naturphilosophie verstehen will. Nach der bisherigen Darstellung ist ganz einfach: die Senkung Grönlands eine ergänzende Seite der Hebung Skandinaviens und einer entgegengesetzten Hebung, deren Linie ich, geeigneten Ortes, im stillen Ozean nachweisen werde. Letztere Hebungs-Linie nenue ich cine entgegengesetzte, nicht nur aus geographischen Gründen man betrachte die Erde als Fläche, oder antipodisch, oder, wie sic ist, gleichzeitig in doppeltem Bezuge - sondern zugleich aus geologischen Verhältnissen. Sie ist Vulkanen-reich, darum auffallend unterbrochen, nach verschiedenen Richtungen stark divergirend und dem Anscheine nach nur in vercinzelten Punkten sichtbar. Aber diese Punkte lassen sich von Kamtschatka an bis tief nach Süden ganz so verfolgen, wie die Züge der unterneerischen Gebirge, wovon in der Hertha. Dadurch bekommen wir ein anschauliches Bild dieses grossen Erdprozesses im Ganzen und können sichere Blicke in die Gründe dieser Erscheinungen 
wagen. Dazu kommt die eigenthümliche Natur der Grönländischen krystallinischen (mit neptunischen Kalken überlagerten) Gebirgs - Arten. Diese plutonischen Massen scheinen durch ihren Reichthum an Labrador auf jüngeren Ursprung zu deuten und der Frage Raum zu geben, ob ihre Abküblung in der Tiefe noch anhalte, mithin zur allmählichen Senkung, wenn auch wenig, doch das Ihrige beitrage. Erscheinungen ähnlicher Art dürften dann unter ähnlichen Verhältnissen, zumal wo junge plutonische Felsarten, Protogyne und dergleichen auftreten, bald vielleicht allgemeiner beobachtet, und von wechselnden Sevkungen und Hebungen Eines und desselben Gebietes unterschieden werden. Letztere zeigen sich, scheint mir, als untergeordnete örtliche Phänomene meist vulkanischer Gegenden, wie um den Serapis-Tenpel bei Pozzuoli, welches in einem Vulkanen-Zuge liegt, dessen Beziehung auf den IsZündischen in der Hertha entwickelt ist.

Der Verfasser des Aufsatzes in Magazin for Naturvidenskaberne beschräıkt sich geistreich auf das Emporsteigen Skandinaviens und Spitzbergens und schliesst aus der verschiedenen Höhe der einzelnen Massen von Lehm, Muschel-führendem Sand und Torf in Skandinavien auf mehrere Hebungeu nach einander. Im Ganzen scheinen mir die Anfänge der hauptsächlichsten dieser Hebungen verschiedenen Epochen Einer Katastrophe anzugehören. Eine der letzten dieser alten, sicher noch diluvischen Epochen scheint mir durch plutonische Erschütterung die Länder-Strecken gesprengt zu haben, welche die Ostsee zu einem Binnen-Meere machten*). Die Gleichförmigkeit in Vertheilung der Massen und der bedeutende Umfang derselben fülnt auch den Verfasser jener Abhandlung auf die Vermuthung, dass wenigstens einige der verschiedenen Hebungen Skandinaviens fast allgemein waren. Von besonderem Gewicht bleibt seine Bemerkung, dass selbst in Spitzbergen ähnliche Lehmlager, wie in Skandinavien, etwa 20 Fuss über dem Ufer liegen, dass auch diese Insel an der allgemeinen Skandinavischen Hebung Theil genommen.

Zwar ist noch nicht entschieden, ob Spitzbergen fortdauernd emporsteigt, demnach bleibt diese Insel der extreme nördliche Punkt, von welchem aus jene Hebung nach verschiedenen Richiungen weiter

-) Jene Felsblöcke, deren ich oben gedachte, mögen grossentheils auf Eisschollen, ein kleiner Theil vielleicht noch über diese alten, in einer wenig spätern Epoche derselben Katastrophe gesprengten Landstrecken herübergekommen seyn, Herlhu S. 169. Eine andere oder gleichzeitige Epoche eben dieser Katastrophe lässt mir auf älnliche Art die bekannten Fels-Trümmer im Jura-Gebiete erklären. Die bisherigen Hypothesen über diese. scheinen mir theils nach vulkanisclsen, theils nach neptunischen Ansichten einseitig gerichtet. Ich nehme die Sachen na. türlich : eine Gebirgs - Erhebung (nachweisbar in jenen Regionen) riss die Mussen los, empörte die Gewässer umliegender alter See'n und schob gleichzeitig den Rücken, der jetzt diese Trümmer trägt, in Mitten der rings bewegten Region zu seiner he utigen Höhe empor. Auf diesem Weğe fält jede kiinstliche Erhlärmng, jede Beleidigung der Gesetze der Mechanih hinweg. Die ganze Erscheinung wird ein kleines natürliches Synptom der grossen Umwalzung jener Zeit. 


\section{$-586$}

verfolgt werden kann, ganz den Ansichten entsprechend, die ich in der Hertha über die Richtung der Skandinavischen Hebungs - Linie nach Südost über ihre Vertheilung im Norden oder Nordwest und über die Züge der untermeerischen Gebirge aufgestellt habe. Die Richtung der Linien dieser fortdauernden Hebung nach Süden scheint mir zugleich 'nit der Entleerung des alten Seebeckens dieser Region in Verbindung $z u, s t e h e n$. Diese. Entleerung habe ich in meiner Schrift über "den Ursprung der Menschen und Völker" und der "Athene" und "Hertha" efür die Folge einer post-diuvischen Katastrophe erklärt und mit der ramothrakischen Fluth aus Gründen zusammengestellt, die ich zu wiederholen unterlasse. Hier kam ich diese Regionen nur in Bezug auf die ältere diluvische Katastrophe berühren, weil diese nit der erst angeregten Frage nach meiner Ansicht in unmittelbarem Verhältnisse steht. Aus der geognostischen Beschreibung Polens von G. G. Puscr erhellt nämlich, dass die Haupt-Richtung des Polnischen Mittel-Gebirges der der Karpathen entspricht, eigentlich der der Tatra, denn diese Richtung geht von Westnordwest nach Ostsüdost, und eben sie bezeichnet die vulkanischen Zentral-Punkte in Klein-Asien und Island. Die Haupt.Erhebung jener Polnischen Gebirge aber ist nach Puscr (jünger zwar, als die Jurakalk-Ablagerung, doch) älter als das Diluvium. Mögen nun auch in der diluvischen Katastrophe in diesem Gebirgszuge bedeutende Erschütterungen Statt gefunden haben, - wenn Puscr sagt, dass die Frage, welche Umstände die alte tropische Pflanzenwelt dieser Regionen veranlasst und zerstört haben, wohl ungelöst bleiben werde, scheint er mir zu weit zu gehen. Vielmehr erklärt sich die Sache einfach : ich fasse sie hier nur in Bezug

a) auf den Ursprung der oben erwähnten Hebung und

b) auf die Länder, welche die letzten bedeutenden klimatischen Veränderungen damals schon erfahren haben.

$(\mathrm{Zu}$ a.) Welche Veränderungen die Ursache jener Hebungen in der Temperatur Anfangs, da sie plötzlich begonnen, plötzlich, - jetzt, wo sie allmählich fortwährt, allmählich verursachen musste, bedarf keiner weitern Bemerkung.

( $\mathrm{Zu}$ b.) Eben so klar ist auch der zweite Punkt. In Ihrem Jahrbuche habe ich 1834 (S. 299 und vorher) darauf hingewiesen, dass in allen Zeiten umfassender Katastrophen durch plutonische Gälırungen 'rschüttert die Wasser eine Gewalt, deren sie sonst entbehrten, gewonnen, gleichzeitig, zun Theil auch früher gesprengte Massen weiter und weiter zu wälzen und jene Gesteine niederzuschlagen, welche die minder dichten und schlechtesten Leiter der Wärme sind; dass dieses wie in früheren Katastrophen, so auch in der diluvischen der Fall war, ohne dass die Erde im Ganzen an Wärme verloren hätte. In die Tiefe durch die stärkere Erdkruste gebannt, waltet und wirkt die alte Erdwärne unablässig. In der diluvischen Katastrophe fand gegen die früheren nur der Haupt. Unterschied Statt, dass jene zwar noch 
massige, namentlich b a s a $\mathrm{t}$ is ch e Gebilde hervortrieb, aber, einzelne wenige Breccien eigner Art *) abgerechnet, nach begreiflichen Gründen ausser. Stand war, irgend eine gediegene, geschichtete neptunische Felsart zu erzeugen. Der Riesen-Schutt, den das Diluvium gerade da, wo das Klima am empfindlichsten sich änderte, zurückgelassen, musste nicht bloss die alten Risse und Spalten der Tiefe füllen, sondern.als der schlechteste Leiter der Wärne den belebenden Einfluss der aus dem Imnern heraufwirkenden Temperatur zurückdrängen. Und hiemit wäre, auf dem Fuss bestimmter Thatsachen, die Frage erklärt, für die allgemeine Bedeutung der letzten grossen Katastrophe ein neuer Beweiss in der allgeneinen Veränderung der Temperatur, und die Ursache dieser Veränderung keineswegs in einer blossen Fluth, vielmehr der Grund dieser Fluth gefunden, und die Streitfrage, ob die Erde im Ganzen erkalte, verneinend entschieden. Denn dass das Diluvium sei. nen Ursprung einer Schmelzung des Gletscher-Eises danke, wie BratMoxr geistreich vermuthete, ist schon darum unglaublich, weil das Daseyn solcher Gletscher vor dieser Zeit, wie ich in lirem Jahrbuche 1834, in Heft II und III gezeigt habe, höchst unwalıscheinlich ist.

C'Hr. Kapp.

Hohnstein, 8. Juli 1836.

Seit dem 4ten bin ich wieder hier und lasse weiter arbeiten, die deutlichsten Resultate verspricht offenbar die Steinbruch-artige Entblösung am Abhange des Wartenberges, von der ich schon in vorigen Briefe sprach. Ich kann da hoffen, die Grenze zwischen dem QuaderSandstein und den Jura-Schichten aufzuschliessen, was beim Hohnsteiner Kalkkruche vom Eigenthümer, Herrn Gutsbesitzer Hedenus nicht erlaubt wurde. In der Tiefe des Polenz-Thales, wa die Strasse vom rechten Gehänge herabkommt, lasse ich bohren, bei etwa 30 Schritt Abstand von der Grenze. Das Loch ist heute erst 6 Fuss tief und steht daher natürlich noch im Granit.

\section{Bernhard Cotta.}

*) Über diese spreche ich in meinem "Deutschen Kalender für das Jahr 1835“, Kemp. ten bei Danuheimer, S. 69 und füge hier zu den dort aufgeführten und erklärten Fällen noch folgenden: nach deu Berichte des Major MiтchecL über den Fluss Durling hinter Neu-Siid-Wrules in der New South Wules Gouvernment Guzette 1835 findet sich am Fuss alter Sandberge auch dort ein wellenförmiger DiluvialBoden aus einer harten kieselhaltigen Brecie. In meinem Kalender habe ich auch auf die Heidelberger sogenannte Kieskruste und auf ähnliche Frscheinungeu Rückslcht genommen. 
Lyon, im Julius 1836.

Ich bin zurück von mejnem Ausfluge nach St. Etienne. Manche interessante Erscheinungen sind mir vorgekommen; ich erzähle Ihnen solche auf die Gefahr hin, dass sie nicht alle neu für sie seyn sollten. - Am 11. Mai verliess ich die Rhone-Ufer, woselbst der Granit ziemlich häufig, durch Diluvial - Ablagerungen hindurch, zu Tage tritt. In ungefähr 1 bis 2 Stunden Entfernung vom Strome bören diese Phänomene auf. Nun führt der Weg über Granit und Gneiss bis in die Nähe von Rives-de-Giers, wo man den Glimmerschiefer erreicht und bald darauf den Sandstein des reichen Steinkohlen-Beckens. Es ist von jenem vou St. Etienne nur durch einen schmalen Bergzug geschieden, auf dem St. Chamoud liegt, und wo sich von Neuem Glimmerschiefer und Granite zeigen. Von hier machte ich einen Abstecher nach la Terrasse, einem Dorfe in anderthalbstündiger Entfernung an Fusse des Mont Pilat (660 Toisen) gelegen. Hier wollte ich den angeblichen Serpentin und seine Gewinnung sehen; es ist nichts, als Dol e rit. Man hat versucht, Bouteillen daraus zu bereiten; das Gestein ist leicht schmelzbar, aber die Flaschen zerspringen oft plötzlich. Ganz in der Nähe wird ein, zuweilen $30 \mathrm{~F}$. uud darüber mächtiger Quarzgang unter freiem Himmel abgebaut. Der Quarz ist fast überall sehr dicht und enthält einige Bleiglanz - Nieren. Der Gang setzt im Glimmerschiefer auf und streicht aus 0 . nach $W$. Maa bereitet Mühlsteine, nicht selten von 15 F. im Durchmesser, aus dem Quarz, und diese dienen, um das Mineral zu zerkleinern, welches in den Glashütten benutzt wird. Auf dem Rückwege nach St. Chamoud, in halbstündiger Entfernung von der Stadt, durchsetzt ein Grang aus schönem grobkörnigem Granit, der aus O. nach W. streicht, den Glimmerschiefer. Zwei Berge von denkwürdiger Form findet man hier und Spuren eines sogenannten Erhebungs - Kraters. In St. Etienne hatte ich mich der freundlichsten Aufuahme des Herrn Gruner aus Bern, Professors an der Bergwerkschule, und des Direktors dieser Anstalt, Herrn Fenéon, zu rühmen. Beiden verdanke ich vicle lehrreiche Aufschlüsse und mit letzterem besuchte ich St. Priest, eine Örtlichkeit von grösstem Interesse, nur $\frac{1}{2}$ Stunde nordwärts von St. Etienne, an der Grenze des Steinkohlen-Gebietes. Ehe der kleinc Hügel von St. Priest erstiegen ist, wird jeder Gebirgsforscher glauben, er habe es mit einem Basalt-Kegel zu thun, ähnlich jenem bei Homberg an der Ohm oder bei Amöneburg. Unser Hügel besteht indessen nur aus reinem Quarz, der, "als ungeheure Felsmasse inmitten einer Emporinebung des Kohlen-Sandsteins aufsteigt. Man sieht Sandstein-Stücke vom Quarz umschlossen und Quarz-Fragmente im Sandstein eingebacken; andere Parthieen sind Mittel-Gesteine: weder Quarz, noch Sandstein, sondern wahrer Arkose, wie bei Chessy. Ich fand in einen Quarzblock veränderten Schiefer eingebacken und Holz, ähnlich dem Holzopal. Auch schöne Breccien kommen vor, roth, schwarz und weiss gefïrbte QuarzTrümmer, durch ein quarziges Bindemittel verkittet. An obern Theile zeigen sich sehr Chalzedon-ähnliche Quarz-Massen. Gegen N., wo der 
Hügel senkrecht abfällt, nimmt man eine kleine Grotte von 12 bis $15 \mathrm{~F}$. wahr, und hier erscheint der Quarz in dünne, gegen S.O. sich senkende, Lagen getheilt; er hat ganz das Aussehen des Schiefers, so dass man glaubt eine, in Quarz ungewandelte, Schiefer-Masse zu sehen. Ich besitze ein Handstück von durch den Kohlenbrand vèrquarz. tem Schiefer; man sollte glauben, er sey bei der Butte de St. Priest aufgenommen worden. - Nordwärts und nach der S ite, wo der Lurau über Glimmerschiefer fliesst und den Fuss des Hügels von St. Priest bespühlt, hat eine Eisen-Gewinnung Statt. Man baut eine beträchtliche, von Erz - Theilen durchdrungene Glimmerschiefer - Masse ab. - Der Gipfel unseres Hügels ist ein vortrefflicher Standpunkt, um das KohlenBecken zu übersehen; deutlich sind an ihren Gestalten die SandsteinErhöhungen zu unterscheiden und die Schiefer- und Granit-Berge, welche dieselben einschliessen. Leider wurde ich durch ungünstige Witterung an Vollendung einẹs Panorama's gehindert, dessen Zeichnung ich begonnen hatte.

Ich habe mehrere brenneude Steinkohlen-Ablagerungen besucht. Bei Chateau-Gaillard dauert der Brand seit dreissig Jahren, zeigt aber gegenwärtig wenig Intensität. Man/sieht nur Fumarolen, denen wässerige und schwefelige Dämpfe entströmen. Aus der Ferne sind dieselben am trischen Grün des sie umgebenden Rasens zu erkennen. Bei Ricamarie kann man umgewandelte Sandsteine und Kohlenschiefer in Menge sammeln; von fortdauerndem Brande keine Spur. Dagegen brennen die Kohlen an Nerons-Teiche lebhaft. Hier erzeugen sich zierliche Krystalle von Salmiak. Ich habe jedoch nicht ausmitteln können, ob deren Bildung fortdauernd ist, oder, wie es scheint, vom Thätigkeits-Grade des Feuers und von einzelnen im Brand befindlichen Lagren abhängt.

Die Strasse von St. Etienne nach Annouay ist am Gehänge des Pilat ins Gestein eingeschnitten, zuerst in Glimmerschiefer, weiterhin in Granit. Vom erhabensten Punkte nach Bourg - l'argental hinabsteigend trifft man grossè Glimmerschiefer-Massen, in Granit eingeschlossen, zu Hundẹten an. Von Bourg-l'argental bis St. Julien-mollinmolette bleibt man stets auf Granit. Hier wurden vormals mehrere Bleiglanz-Gänge abgebaut. Das Verhältniss ist das nämliche, wie das Ihnen bekannte von Vienne. Ganz in der Nähe der erwähnten Gänge erhebt sich ein Serpentin-Hügel, denkwürdig wegen seiner Gestalt und um seiner gänzlichen Unfruchtbarkeit willen. Auf deren nachbarlichen Gehängen bemerkt man, mitten im Granit, einen Serpentin - Gang, weleher dasselbe Streichen hat, wie die erwähnten Bleiglanz-Gänge, ungefähr aus 0 . nach W. Der Scrpentin ist sehr dicht und von viclen Asbest-Schnüren durchzogen. - Von St. Julien bis zur Rhone schreitet man stets über Granit hinab, der hin und wieder von Quarz-G̈̈̈ngen durchsetzt wird. Unmittelbar oberhalb Boeuf betritt man das Diluvium, welches hier vorzïglich durch nächtige Lehm-Ablagerungen charakterisirt wird. 
Bonn, 30. Juli 1836.

Die anliegenden ganz oder theilweise durch einen sehr dünnen Überzug von Schwcfelkies schön bronzirten Geschiebe von Quarz und Grauwacke geben den auffallendsten Beweiss von der, unter günstigen Umständen, noch fortdauernden Bildung des Schwefeleisens in der gewöhnlichen natürlichen Verbindung mit metallischem Glanze. Sie haben sich in sehr bedeutender Anzahl in einer moorigẻn Erde, welche viele vegetabilische Reste enthält, nur sieben Fuss unter der Obcrfäche, im Alluvium bei Roisdorf ( $\frac{3}{4}$ Meilen von Bunn) an einer Stelle gefuuden, wo eine Sauerquelle, welche ausser Kiochsalz mehrere kohlensaure Salze, darunter auch kohlensaures Eisenoxydul, und sehwefelsaures Natron enthält, sich zu Tage drängt. Der Schwefelkies, welcher hier in der Moorerde wohl noch täglich sich fortbildet und die Geschiebe überrindet, ist das Produkt der Zersctzung des schwefelsauren Natrons, veranlasst durch die Gegenwart der organischen Substanzen, und der Verbindung des sich dabei darstellenden Schwefels mit den Eiscnoxydul im Mineralwasser. Mein College Brscuof hat den Prozess in seiner frühern Abhandlung über diesen Gegenstand genügend erläutert: aber ein so schlagender Beweis für die Richtigkeit seiner Ansichten, wie der vorliegende, war wohl kaum vorhanden. Über das Roisdorfer Vorkommen habe ich mit Brschоғ einen ausführlichen Aufsatz bearbeitet, der an PoggendonfF nach Berlin abgegangen ist, um seinen Annalen einverleibt zu werden. Diese vorläufige Notitz mochte ich Ihnen nicht vorenthalten: es ist gar zu erfreulich, wenn man so die Natur in ihren Operationen überraschen kann.

NögGERATH.

\section{Mittheilungen, an Professor BroN gerichtet.}

Bayreuth, 12. Juli 1836.

1. Unter den neuen Versteinerungen der hiesigen Kreis-NaturalienSammlung zeichnet sich der grosse sehr breite Kopf eines neuen $\mathbf{S}$ a u ri ers im Keuper-Sandstein aus, der eine grosse Menge nahe zusammensitzender Zähne verschiedener Grösse hat. Auffallend sind auf der Stirne 2 runde Löcher in der Hirnschaale, welche wie Augenhöllen aussehen, obgleich diese an den Seiten deutlich zu erkennen und grösser sind. Es scheinen dort Erhöhungen gewesen und abgebruchen zu seyn. Unter den mir bekannten Geschlechtern von Sauricrn der Vorwelt kann er nicht aufgenommen werden. Wegen seines dicken kurzen Kopfes scblage ich den Namen Capitosaurus arenaceus vor.

2. Bei Solentufen sind wieder Knochen cines $P$ te r o d a c t y l u s gefunden 
worden, welche von denen bisher beschiebener Arten wesentlich verschieden sind. Sie bestehen aus dem Oberschenkel-Knochen und dem Schiembein der linken Seite. Sie sind nicht dicker als die nämlichen Knochen vom Pterodactylus crassirostris und medius, jedoch fast doppelt so lang; auch ist der Oberschenkel-Knochen mehr gebogen, als bej den übrigen Arten. Ich habe einstweilen die Spezies, zu welcher diese Knochen gehört haben, Pterodactylus longipes genanut.

3. Unter den vielen weu(n Arten fossiler Fische, welche ich seit einem Jahre erbalten, zeichnet sich ein sehr grosser Fischkopf aus dem Jura-Kalk von Pointen unfern Kelheine aus, an welchem jedoch der vordere Theil fehlt: dennoch sind 77 Zähne im hintern Theile des Kopfes sichtbar, welche oben in 4, unten in 5 bis 6 Reilen eng nebeneinander sitzen und rund wie Sphaerodus - und Gyrodus - Zähne sind, von 2 bis 4 Linien Durchmesser. Dieser Kopf scheint einem sebr gros. sen Gyrodus gehört zu haben, den icil G. multidens nenne.

4. Nicht minder eine neue Art Hayfisch von Kelheim, die sehr schmal und lang ist und einem neuen Genus angehört zu haben scheint; es ist nur der hintere Theil des Fisches, bestehend aus einer langen Schwanzklappe, einer grossen breiten Rückenklappe und den 10 Zoli langen Körper bis zur Rückenflosse. Die ganze Haut, Klappen, Flossen etc. sind sehr ungleich chagrinartig gekörnt. Ich habe diesen neuen Fiayfisch nach einer der Harpyen A ellopos elongata genannt.

5. $\mathrm{Zu}$ den 7 Arten Belonostomus meiner Sammlung habe ich noch eine sehr ausgezeichnete Art aus Kelhein von dem als Naturforscher bekannten Forstrath Kocn in Regenshurg erhalten, bei welcheni die eigenthümliche Schuppen-Bildung dieser Fischgattung, die sie mit dem Aspidorhynchus gemein hat, sehr deutlich ist. Die grossen langen Schuppen in der Mitte der beiden Seiten, die enge zusammensitzenden, sehr schmalen und breiten Schuppen des Baucies, die spitzen Schuppen des Rückens und die kleinen Schuppen yon der After-bis zur SchwanzFlosse geben diesem Fisch ein eigenes Ausehen, 'da der Rücken wie gesägt, der Bauch wellenförmig, die Seiten getäfelt und der Schwanz fast gekörnt erscheint. Ich schlage den Nanen Belonostomus Kochii für diesen schönen Fisch vor. In den Belone-artigen langen Ober- und Unter-Kiefern sind die feinen spitzigen Zähne verschiedener Grösse schr deutlich zu erkennen.

6. In einer alten Sammlung fossiler Fische von Seefeld, welche ich in Insbruck kaufte, fand ich 11 verschiedene Arten, von welchen 5-6 neu und von Agassiz noch nicht beschrieben sind. Sie bestätigen die Ansicht dieses Naturforschers, dass die Formation der bituminösen Schiefer von Seefeld zun Lias gehört. Mit den Fischen kommt ein schöner Caulerpites vor, der mit den Eichstïdter Caulerpiten nahe verwandt ist; ich habe den Namen Caulerpites alpinus vorgeschlagen. Die Seefelder Fische gehören zu den Geschlechtern Tetragonolepis, Semionotus, Lepidotus, Pholidophorus und Microps. Ausser den mir bekannten 13 Spezies fand ich noch eincu schönen Seefelder Fiscb in 
Ferdinandeum zu Insbruck, welcher zu einem neuen Genus zu gehören scheint, dessen nähere Bestimmung ich dem Prof. Agassiz überlassen habe.

7. Aus der Braunkohle bei Seussen in unserem Fichtelgebirge, wo bisher an Fischen nur der Leuciscus papyraceus in einigen bedeutenden Spiel-Arten vorgekommen ist, erhielt die hiesige Kreis - Sammlung einen kleinen Lebias mit vielen vollständigen Blättern und Früchten.

Egs 8. Vom Placodus gigas im hiesigen Muschelkalk sind nu: auch vollständige Kopftheile gefunden worden, welche beweisen, dass die langen schwarzen Zähne, welche mit den Schlundzähnen der Cyprinoiden etc. einige Ähnlichkeit haben und in meiner Bekanntmachung dieser Zähne unter No. III abgebildet sind, Vorderzähne des Placodus sind, welche sowohl im Ober-als Unter-Kiefer sitzen und zwar in letzterem viel tiefer, als die Seiten-Zähne [vgl. S. 361].

9. Vor Kurzem habe ich die Kalkschiefer - Brüche von Regensburg bis Donanwörth besucht und meine früheren Bemerkungen über die Lumbricarien bestätigt gefunden. In $12 \mathrm{Schiefer-Brüchen} \mathrm{bei} \mathrm{Kel-}$ heim, in welchen Fische vorkommen, konnte ich keine einzige eigentliche Lumbricaria, sondern nur Koprolithen und Fisch-Eingeweide finden, während einige Stunden davon, bei Pointen, wo selten Fische gefunden werden, viele Lumbricarien, wie bei Solenhofen und E'ichstädt vorhanden sind. Auch in den Privat-Sammiungen von Fegensburg und Kelheim fand ich keine Lumbricarien von Kelheim, dagegen in einem Caturus von da den sehr deutlich abgedrückten Darm-Kanal mit seiner zickzackförmigen Streifung.

10. Bei genauer Untersuchung und Vergleichung der Versteinerungen, welche im feinkörnigen Eisen-Sandstein vom Kressenberge, und derjenigen, welche in der gleichen Schichte bei Solenhofen vorkommen, fand ich die grösste Ũbereinstimmung und überzeugte mich, dass die Überreste von Belemniten und Ammoniten, welche bei Solenhofen gefunden werden, keineswegs zu jenen obern feinkörnigen und hellen Schichten gehören, in welchen die vielen Versteinerungen der tertiären Formationen vorkommen, sondern einẹ tiefer liegenden Lage dunklen eisenschüssigen Sandstein, die entschieden noch Kreide - Formation ist, während die andere die unterste tertiäre Lage bildet.

Die Verwechselung des Gesteins ist hier eben so leicht müglich und fast so oft erfolgt, wie bei der untersten Lage des noch zur OolithFormation gehörenden Sandsteins und dem beinahe damit zusammenhängenden obern Sandstein der Lias-Formation oder auch zwischen dem obern Keuper-Sandstein und dèm untersten Lias-Sandstein.

11. Vor einiger Zeit habe ich in der Naturalien-Sammlung des Herzogs von Leuchtenberg zu Eichstädt die federförmigen hornartigen Leistchen eines vorweltlichen Loligo gefunden, welche denen des noch lebenden Loligo sagittata so ähulich sehen, dass ich sic Loligo subsagrittata genannt habe. Es ist das einzige Excmplar aus Solenhofer Schiefern, welches ich kenne, das unbestritten zum Genus Loligo gehört. Die übrigen hornartigen Leistchen in der Form cines dreischucidigen 


\section{$-583$}

Degens, welcher bisher gewõhnlich für die innern Leistchen von Loligo gehalten wurde, gehören nach meinen bestätigten Beobachtungen entweder zum Genus Onychoteuthis, oder einem neuen Geschlechte, sie an ihren Armen statt runden Saugnäpfchen Häkchęn (griffes ou cochets) haben. Von den 20 Spezies Sepien-artiger Cepbalopoden meiner Sammlung lasse ich die nerkwürdigsten abbilden, um. sie cähè bekannt zu machen.

12. Von Sulenhofen besitze ich den grossen Alveol-Kegel eines Belemniten mit der ungekammerten hohlen Fortsetzung der Schajale, neben welcher der beschädigte Sack einer sehr grossen 0 nychoteut h is liegt, umher zeigen sich einige kleine Häkchen (Crochets) aus den Armen dieses Cephalopoden. Beide Körper liegen so nahe zusammen, zum Theil übereinander, dass man anfänglich zu dem Glauben verleitet wird, sie gehörten zu einem und dem nämlichen Thiere, aber bei genauer Untersuchung zeigt sich, dass sie von 2 verschiedenen Thieren abstammen, dem Belemnites semisulcatus und der Onychoteuthis speciosa (der grössten mir bekannten fossilen Art). So viel Mübe ich uir auch gegeben habe, in den Schiefern des Lias und in den lithographischen Schiefern eine Belemnosepia BuckLand's zu finden, so ist es mir doch bisher nicht gelungen, in keiner mir bekannten Sammlung Deutschlands kommt eine wirkliche Belemuosepia vor, für welche ich die eben beschriebenen Körper anfänglich hielt.

13. In den lithographischen Schiefern von Solenhofen fand ich eine kleine sonderbare Art von freien Seesternen, welche ein neues der Comatula nahe verwandtes Geschlecht zu bilden scheint. Der runde Körper hat 10 feine fadenförmige ganz ungetheilte Arme, welche aus langen Gliedern bestehen, die aber so zart und dünne sind, dass man die Zahl der Glieder nicht erkennen kann. Ich glaubte anfänglich eine langbeinige After-Spinne - Phalangium - zu sehen, von welchen ich 3 fossile Expemplare aus dem Solenhofer Schiefer besitze, welche zwar 8 gegliederte Beine, aber überdem noch 2 fünfgliederige Taster haben. In meinem Katalog ist diese Spezies noch als Comatula paradoxa aufgeführt, die Afterspinne als Phalangites priscus.

14. Mit einigen seltenen Pflanzen vom Monte Bolca kaufte ich in Verona auch eine deutliche Squilla, welche mit der Squilla mantis (FABr.) und der Squilla scabricauda (LAMK.) grosse Ähnlichkeit hat. Mir ist unbewusst, ob sie schon irgendwo abgebildet und beschrieben ist; in meiner Sammlung hat sie den Namen Squilla antiqua.

15. Meine Sammlung vou Insekten aus Solenhofer und Eichstïdter Schiefer hat vor Kurzem wieder einen Zuwachs von 3 neuen Geschlechtern erhalten, und zwar einen grossen Scarabaeus, der über 2 Zoll lang ist, eine kleine Musca und eine Bicania (GERMAR).

Von meinen deutlichen und bestimmbaren Solenhofer Insekten hat der Professor German in Halle 19 verschiedene Arten abgebildet und beschrieben.

G. von Münster. 
Siegen, 12. Juli 1836.

Versteinerungen iu Kieselschiefer sind in den Lehrbüchern der Geognosie bisher noch nicht angezeigt worden*). Es möchte Ihnen also nicht uninteressant seyn, hiedurch zu erfahren, dass ich voriges Jahr bëi Förde in Kreise Olpe, Regierungs-Bezirks Arensbery in einem Kieselschiefer-Bruche einen Schraubenstein von Cyathocrinites pin. natus Goldf. (Tf. LVIII, Fg. 7 n, o) gefunden habe, welcher in hiesiger bergantlicher Mineralien-Sammlung aufbewahrt wird. - In Laufe dieses Jaḅres hat man auch in der Gegend von Brilon im Alaunschiefer, welcher in Westphalen stets deu Kieselschiefer begleitet, Posidonia Becheri entdeckt.

\section{Schmidt.}

Tharand, 30. Juli 1836.

\section{Über die Niederschöna-Schichten.}

Sie werden in meinen "geognostischen Wanderungen" gefunden haben, dass ich die Niederchönuer Schieferthon-Schichten mit PflanzenAbdrücken der Englischen Wealden-Formation vergleiche. Das ist Einigen auffallend gewesen, und ich sehe mich desshalb veranlasst, meine Gründe dazu weiter zu entwickeln.

Die Schieferthone mit Pflanzen-Abdrücken kenne ich in Sachsen nur zwischen den relativ untersten Schichten des Quader-Sandsteins, d. h. zunächst der Auflagerungsfläche (bei Niederschöna auf Gneiss, bei Weissig auf Granit). Der mächtige Schichten-Komplex des Sandsteins der sächsischen Schweitz enthält in der zugänglichen Region nirgends solche Schieferthone, und doch ist er an unzähligen Punkten von oben herein aufgeschlossen bis zu einer Tiefe von 6 bis 8 hundert Fuss; sind also hier - wie doch anzunehmen - jene Pflanzenschiefer vorhanden, so müssen sie der Sohle liegen, dic der Beobachtung unzugänglich ist. Die mittle und obere Region des Quadersandsteins enthält nichts, was auf Unterbrechung der Meeres-Bedeckung schliessen liesse; die fossilen Pflanzen von Niederschöna aber setzen durchaus eine fruchtbare Landfläche voraus.

Nach diesen Verhältnissen zu urtheilen, liegen die pflanzenhaltigen Schicferthoue durchaus nur zwischen den untersten QuadersandsteinSchichten; wäre man also berechtigt, sie als Formation zu trennen, so würde diese Schieferthon- und Sandstein-Formation zwischen den oberen Jura und den Quadersandstein einzureihen seyn. Das ist die Region der Wealden-Formation, und es kommt nun nur noch darauf $a n$, ob auch die organischen Reste zu einer solchen Trennung und Parallelisirung berechtigen, denn Mächtigkeit und Gesteins-Beschaffenheit kömmen bei so entfernten Lokalitäten nur wenig in Rücksicht kommen,

*) Vgl. Paradoxides H arlani, oben S. 462.

D. $\mathbf{R}$. 
da diese - besonders bei einer Nicht - Meeresformation - offenbar von zufälligen Lokal-Verhältnissen abhängig seyn mussten.

Wir fiuden bei Niederschöna Reste von Dikotyledonen-Bäumen, $\mathrm{Co}_{\text {. }}$ niferen, Cycadeen, Fahren und Lycopodien, also die sichern Zeugen der eigentlichen Waldvegetation, keine Wasserpflanzen, keine Andeutung vou der Nähe des Meeres, denn auch die zwischenliegendeu Sandstein-Schichten enthalten keine Seethiere, sondern, obwohl viel seltener, Ahdrücke von Landpflanzen (Pterophyllum cretosum Rerch.). Die Mee. resmuscheln beginnen erst in den darüber liegenden Schichten. Ge wisse neuerlich im Schiefer gefundene Abdrücke einer Anodonta àhnlichen Bivalve sind noch nicht sicher bestimmt, gehören aber jedenfalis eiver Süsswassermuschel an.

Die oft zahlreichen und sehr manchfaltigen Dikotyledonen - Blätter sind meist schmal und lang, den Blättern aus dem Geschlechte Salix am älulichsten, zum Theil aber auch breit, denen von Populus, Tilea und Acer vergleichbar. Besonders auffallend und von allen lebenden abweichend sind zwei zu ZENKER's Crednerien gehörige Arten mit sehr markirten, fast gleich dick bleibenden Rippen, deren eine (Rippe) am ganzen ausgezackten Rande hin verläuft, an jeder Auszackung eine verdickte Spitze bildend (Lethäa Tf. XXVII, 11). Beide Crednerien-Arten, welche bei Niederschönø gefunden worden, unterscheiden sich von denen ZENKER's noch besonders durch den Mangel der horizontalen BasilarNerven.

Von Koniferen werden mit breiten Nadeln besetzte Zweige und sehr deutliche Zapfen verschiedener Form gefunden (Lethäa XXVIII, 13).

Zweicrlei Wedel aus der Familie der Cycadeen (Pterophyllum) hat man bis jetzt bei Niederschöna entdeckt. Die eine Art ist ziemlich ähnlich dem Cycadites Brongniarti aus den Tilgate - Schichten, welches ManteLL abbildet (Lethäa XXVIII, 14), nur ist der Wedelstiel breiter (vielleicht gedrückt) und die Fiederchen sind länger.

Aus der Familie der Fahren finden sich in den NiederschönaSchichteu wenigstens 8 Arten, vou denen die fingerförmigen, Fucusähnlichen: Chiropteris obtusa und $\mathrm{Ch}$. elongata Rossu., mit ihten bei jeder Gabelnng zum inneren Rande laufenden Hauptrippen die merkwürdigsten sind. Sie wurden bisher und werden von vielen noch, für Fucus gehalten; Graf Sterneerg nannte sie Haliserites, Sie selbst haben sie in der Lethäa unter den Fucoiden abgebildet (XXVIII, 1) und auch Herr Prof. Göppert hält sie dafür. Daran ist die sonderbare Gestalt und die Undentlichkeit der meisten Exemplare Schuld, denn Niemanden kann es verdacht werden, wenn er ein solches einförmiges, dichotomes, gewöhnlich neben der stengelartigen Hauptrippe nervenlos erscheinendes Blatt für einen Fucus hält. Wer jedoch die Exemplare in Tharand sieht, deren schönste Herr Professor Rossmässcer schon auf Stein gezcichnet hat, der wird ihm gern beistimmen: ein Blatt mit feinen durch die Fläche verzweigten Nerven kann kein Fucus seyu. Wic käme auch eine so vereinzelte Wasserpflanze mitten 
unter die Festland-Vegetation? Es sind Fahrenwedel so gut wie Scolopendrium officinarum D. var. daedaleum, Sk. T. 38, b. - Pecopteris lienearis von Niederschöna ist schon dreimal abgebildet - von STERrberg, Brongmiart und Ihnen - leider aber auch schon doppelt benannt (Reichiana Brongr.). Fast eben so häufig ist Pecopteris Schönae REIcr.; seltener sind die übrigen zum Theil sehr zierlichen Fahren.

Fast vorwaltend ist unter den Niederschönaer Pflanzen ein Lyco-

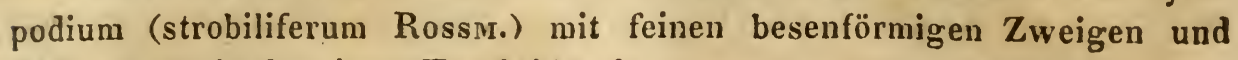
grossen zapfenförmigen Fruchtkätzchen.

Alle diese Pflanzen und Pflanzentheile gehören zu-den härteren, und man hat desshalb um die fossile Flora von Niederschöna zu ergänzen noch einige zartere, bis zur Unkenntlichkeit zerstörte Gewächse zu suppliren, um dann sich eine Idee von diesen Wäldern zu machen, deren Reste man in drei durch Sandsteinbänke getrennten Schichten über einander findet.

Vergleichen wir nun diese organischen Reste mit denen des Quadersandsteins und mit denen der Enylischen Wealden-Formation, so finden wir zunächst, dass sie mit den ersten durchaus $n i c h t$ übereinstimmen. Der Sächsische Quadersandstein enthält nur Seethiere, meist zweischaalige Muscheln. Der Zustand der Erdoberfläche, in welchem die Niederschöna-Schichten gebildet worden sind, muss daher ein ganz anderer gewesen seyn, als der, in welchem der eigentliche Quadersandstein sich ablagerte; denn die Pflanzen von Niederschöna sind nicht auf dem Boden des Meeres gewachsen, und auch nicht aus der Ferne herbei geschwemmt, das lehrt ihr allgemeiner Charakter und ihr wohlerhaltener Zustand: die Blätter sind nicht mazerirt, die Fahrenwedel zum Theil noch befruchtet, die abgefallenen Dikotyledonen-Blätter liegen dicht beisammen mit Koniferen-Zweigen, Fahren und Lykopodien, welche so leicht nicht abfallen und zum Theil sogar am Boden fest sitzen. Auch Stammtheile findet man dabei, nur undeutlicher als die Blätter und ganz breit gedrückt.

Die verschiedenen Zustände - die Festland-Vegetation und die Meeres-Bedeckung - haben demnach auf demselben Flächenraum hinter einander Statt gefunden; unrecht scheint es mir, die Produkte so verschiedenartiger Zustände genau in eine Formation verschmelzen zu wollen, weun auch durch die Gesteine ein Übergang bedingt und dadurch eine scharfe Trennung unmöglich wird.

Durch die organischen Reste also wird eine Sonderung der Niederschöna-Schichten vom Quadersandstein nöthig gemacht, obwohl die Gesteine eine solche Trennung sehrerschweren.

Die Wealden-Gruppe enthält nach Mantell's trefflichen Arbeiten Reste von Cycadecn, Fahren, Lycopodien, Palmen- und Schilf-ähnlichen Pflanzen. Ausserdem aber viele Süsswasser-Mollusken. Dykotyledonen und Coniferen werden von jenem gründlichen Forscher nicht erwähnt. Es ist also die fossile Flora von Sussex der Sächsischen allerdings nur 
ähnlich, keineswegs identisch, und jene vielen Süsswasser - Mollusken fehlen uns hier fast ganz, denn die Abdrücke von einer Anodontaähnlichen Muschel sind die einzigen Reste der Art, die bis jetzt bei Niederschöna gefunden worden sind. - Wer aber wird erwarten, dass die Flora und die Fauna des Festlandes an zwei so entfernten Punkten zu irgend einer Zeit gen a mit einander übereingestimmt habe? Nicht nur die Entfernung selbst, sondern auch die zufällige Beschaffenheit der Lokalität haben gewiss vor der Kreideperiode einen ähnlichen Einfluşs auf Thiere und Pflanzen geübt, als gegenwärtig. Nun scheint es aber offenbar, dass in der Wealden-Periode zu Sussex das Festland sumpfig und mit Süsswasser-See'n bedeckt war, während in Sachsen dichte Wälder vegetirten. Daher dort die grössere Mächtigkeit, die SüsswasserKonchylien, die vielen Arundinaceen und der Mangel an grösseren Dikotyledonen und Coniferen; daher hier der Mangel an Mollusken und Sumpfpflanzen und dagegen die Menge und Manchfaltigkeit der Dikotyledonen.

Der gleiche Hauptzustand der Erdoberfläche an beiden Orten - das gleichzeitige Hervorragen über den damaligen Ozean - ist doch unverkennbar. Der Charakter der Lebenwelt ist derselbe. Da nun auch die Lagerung übereinstimmt, so sehe ich nicht ein, warum man die Formation nicht parallelisiren sollte.

Die Spuren einer weit verbreiteten Festland-Vegetation zwischen den Meeres-Ablagerungen der Flötzzeit dürften immer ein wichtiger und willkommener Abschnitt seyn; sie bezeichnen das Erheben des Landes oder das Zurückweichen des Meeres auf eine so entschiedene Weise, dass sie zur Feststellung einer Formations - Grenze ausserordentlich geeignet sind. Immer aber wird sich eine solche Schichtengruppe mehr der darauf folgenden, als der vorhergehenden Meeresbildung anschliessen, denn die Zeit, welche erforderlich war, den trocken gelegten Meeresboden mit Vegetation zu überziehen, ist gewiss eine längere, als die der Zerstörung und Bedeckung durch neue überströmende Fluthen, und das Material der Bedeckung kann leicht dasselbe seyn, welches? die ganze folgende Meeres - Formation charakterisirt. So bei Niederschöna der Sandstein.

Eine Festland-Epoche erscheint zwischen den mächtigen MeeresAblagerungen nur wie eine einzelne aber bedeutungsvolle Fläche, wie ein neues Titelblatt im Innern eines Buchs, eine neue Schöpfungs - Periode bezeichnend. Nur wo Sümpfe und Landsee'n eigentliche SüsswasserAblagerungen begünstigten, wie in den Kohlen-Bassins, da erreichen diese einige Mächtigkeit und werden zu körperlichen Gliedern der geschichteten Erdrinde. Dennoch aber wird es gut seyn, auch die Flächenartigen Spuren als sichere Abschnitte zu benutzen, um die gleichzeitigen körperlichen Glieder zu parallelisiren. 
Sollten die Kohlen und die Pflanzen-Abdrücke von Wenig-Rackwitz bei Ottendorf in Schlesien eine andere Region im Quadersandstein einnehmen? sollten sie ausser den den Pappein, Ahornen und Weiden ähnlichen Blättern, wie $\mathrm{Hr}$. Prof. Göppent berichtet, wirklich auch Tange enthalten? das sind Fragen, deren Beantwortung wir hoffentlich von dem genamuten eifrigen Forscher zu erwarten haben.

\section{Bernhard Cotta.}

Brooklyn, 5. August 1836.

Später, als es meine Absicht anfänglich gewesen, komme ich jetzt von einer geologischen Reise in den Westeu vom Mississippi zurück. Von der Stadt Washington ging ich durch den Ohio- und -ChesapeakeKanal, die Kohlen-Region von Niaryland und Pennsylvanien nach Cleavelund am Erie-See, über Detroit und Michillimacinac zur Green-Bay, fuhr in einem Birkenrinde-Kanot auf dem Fux-river, dem Wisconsin und Mississippi bis zu den St. Anthony-Fällen, dann auf dem st. Peters bis zu seiner Quelle in Coteau des Prairies, ging nach dem BleiDistrikt in Michigan und Illinöis, nach den Kohlen- und Blei-Distrikten in Missouri, dann durch Missouri, einen Theil von Arliansan, dio Cherokee - Nation nach Fort Gibson, wo ich überwinterte; - wendete mich dann südwärts zum Red River und Fort Towson, östlich und nordöstlich durch die Cholitaw-Nation und Arkansas nach Memphis am Mississippi und kehrte auf dem Mississippi, dann durch Kentucky, Ohio, Pennsylvarien, New-Yurk, New-Jersey, Delaware und Maryland nach Wrashington zurück. So hatte ich Gelegenheit, die geologischen Umrisse einer sehr ausgedebnten Gegend kenuen zu lernen. Ich habe dabei die Pentremiten von $S_{A Y}$ in grosser Verbreitung gefunden in einem Enkriniten - Kalke über der Kohlen-Formation in Missouri, Arkansas und der Indianer-Gegend westlich von diesen Staaten. Melırere andere Arten dieses Geschlechts kommen in einem Kalksteine in Ohio vor, dessen Alter ich nicht genau kenne.

Die geologische Übersicht des States von New York schreitet nun voran. Man hat ihn in vier Bezirke getheilt, deren Untersuchung eben so vielen Geognosten übertragen ist. Ich bin als Haupt-Geologe für den ersten Bezirk angestellt, welcher 21 Grafschaften enthält und über 12,000 Quadrat - Meilen Ausdehnung hat. Herm Conkan ist ein andrer Bezirk übertragen. - Ich habe zu Erledigung meines Auftrages 4 Jahre Zeit, wo ich hoffe, damit fertig zu werden. - Ich werde Ihnen die geologischen Berichte über einige Staaten zusenden. Über den Staat von $\boldsymbol{N}^{\prime}$ 'W York soll jährlich ein populärer Bericht erstattet, die wissenschaftlichen Resultate aber dürften schwerlich vor Beendigung der ganzen Untersuchung bekannt gemacht werden.

W. W. Mather. 


\title{
Neneste Literatur.
}

\author{
A. Bücher.
}

\section{5.}

John Laubance: Geology in 183.5, a popular sketch of the progress, leading features and latest discoveries of this rising science, illustrated with diagrams and engravings, London $12^{\circ}$.

Rose's Mameal of analyticul Chemistry, new edition by GrIFFIN, Londun [16 shill. $]$.

URE's Dictionary of Chemistry and Mineralogy, with their applications. The fourth edition with numerous improvements and 9 engravings London $8^{0}$ [l guinee].

1536.

A. Bretrhaupt : vollständiges Handbuch der Mineralogie. Erster Band, allyemeiner Theil, mit 6 Tafein Zeichnungen. Dresden und Leipzig, 429 SS. [4 fl. $54 \mathrm{kr}$.]

Dufrénoy et Elie de Beaumont: Mémoires pour servir à une description géologique de la France, redigés par ordre du directeur de l'Administration générale des ponts et chaussées et des mines, suus le direction de M. Brochant de VILLIERs. T. III e $\boldsymbol{8}^{0}$. Paris.

Си. F. Hochstetrer : populäre Mineralogie, oder die Fossilien- und Gebirgs-Kunde für alle Stände, $282 \mathrm{~S}$. und 12 Steindruck-Tafeln. Reutlingen 1836, $8^{\circ}$ [3 fl. $24 \mathrm{kr}$.].

C. Kessuer: die Plastik der Urwelt im Werra-Thal bei Hildhurghausen, - oder die vorzüglichsten Fährten-Abdrücke urweltlicher Thiere aus den Sandsteinbrüchen bei Hildburghausen, nach der Natur lithugraphirt, mit einem Vorwort von Sickler, I. Heft, p. 1-8, mit VII Tafeln und I Karte. Hildburghausen [1 fl. $21 \mathrm{kr}$.].

Küнn: Handbuch der Geognosie ete. II. Band, $8^{\circ}$, mit 4 lithogr. Zeichn. in fol.; XVIII und 830 SS. [4 Rthlr.].

J. Laurance: Geologie im Jahr 1835, eine leicht fassliche Skizze der 


\section{$-590$}

Fortschritte, Hauptzüge und neuesten Entdeckungen in derselben. Aus den Englischen. Mit 19 Holzschnitten. Weimar, $8^{\circ}$.

LEBLanc et WaLter: Métallurgie pratique du fer etc. (vgl. S. 62 und 206) livr. III, IV et $\boldsymbol{V}$ [6- B. Text und $10 \mathrm{Kupf.Tafeln,} \mathrm{Paris}$ [12 franes jede Lief.].

K. C. v. Leonhand: Geologie, oder Naturgeschichte der Erde in allgemein fasslicher Weise abgehandelt, Stutty. in $8^{\circ}$, Ir Band, 3 Lieff. mit 7 Stahlstichen nnd 1 Lithographie [24 Gr.].

Phildips: Geology of Yorlishire, IId. vol. evith maps, sections, diagrams and very numerous plates of the organic remains of the monntain limestone. London $4^{0}$ [Subscriptiouspr. 2 Guineen].

N.B. die neue Auflage des 1. Bandes ist unverändert geblieben, nur sind die Lithographie'n norh weniger geglückt.

Rozet: traité élémentaire de géologie, Ière partie, Géognosie, 538 pp. $8^{\circ}$, avec un atlas de 13 planches in $4^{\circ}$. Paris.

Scminerling Recherches sur les ossemens fossiles découverts dans les cavernes de la jrovince de Liège. Vol. II, ame (et dernière) partie, gr. in $4^{0} ; 13 \frac{3}{4} f$. et $p l$. $x \mathrm{x}-\mathrm{xL}$. Liege [13 Thlr.]. (Das ganze Werk kostet $31 \frac{1}{2}$ Thlr.).

C. Silvertop: Geolugical Sketch of the Tertiary Formations in the Provinces of Granada and Murcia, Spain. London $8^{\circ}[16$ sh. 6 d.]. F. Urgen: ïber den Einfluss des Bodens auf die Vertheilung der Gewächse, nachgewiesen in der Vegetation des nordöstlichen Tyrols. Eine zu Regensburg gekrönte Preisschrift mit 2 Karten und 6 Tabellen. Wien 1836. $8^{\circ}$ [6 A. $18 \mathrm{kr}$.].

\section{IB. Zeitschriften.}

The London and Edinburgh Philosophical Magazine and Journal of Science.

1ミ35, VII, Nro. 4, 5, 6 u. 7 (Suppl.), S. 241-548 und (General-Index) S. 1-50*).

D. Brewster: Bcobachtungen in Beziehung auf Struktur und Entstehung des Diamants S. 245-250 [Jahrb. 1834, S. 225].

W. G. Canter: über alte und neue Delta-Bildung im Persischen Meerbusen durch den Euphrat und Tigris. Schluss. S. 250-256.

C. B. Rose : Skizze der Geologie von West-Norfolk, Fortsetzung, S. $274-279,370-376$ (F. f.).

Procedings of the Geological Society of London, 25. Febr. bis 2.9. April.

Davbexy: über die vulkanischen Schichten, welche bei einem Durchschnitt an der neuen Thermalquelle zu Torre delb' Anmuniata

*) Fortsetzung v. Jahrbuch 1836, S. 211. 
im Meerbusen von Neapel zu Tage gekommen; nebst einigen Betrachtungen über die von dieser u. a. Quellen, die mit den Vulkanen Campaniens in Verbindung stehen, entwickelten GasArten, S. $316-318$.

Freyer : über die Emporhebung des Landes an der West-Küste Sïd-Anerikas, S. 318.

W. J. Haniltox: Beschreibung eines Lagers von Seckonchylien lebender Arten zu Elie, an der S.-Küste von Fifeshire, S. 318-319.

Edw. Spencre: Beobachtungen über das Diluvial in der Nähe von Finchley, Middlessex, S. 319-320.

Ad. Sedgwick: Bemerkungen über die Struktur grosser MineralMassen und insberondere über die ehemischen Veränderungुen im Aggregat-Zustand geschichteter Felsarten in verschiedenen Perioden nach ihrer Ablagerung, S. 320-323.

W. H. Frtron: Notiz über die Verbindung der Portiand-mit den Purbeck-Schichten an der Küste von Dursetshire. S. 323-325.

J. Prestwich jun.: Beobachtungen über die Ichthyolithen von Gamrie in Banffshire und über die sie begleitenden rothen Konglomerate und Sandsteine, S. 325-326.

C. Belcher: Beschreibung geologischer Handstücke von der Westküste Africas und Beschreibung von Handstïcken auf der Insel Ascension gesammelt durch W. P. Henvan und mitgetheilt von R. HeNNah.

Pr. Grex Egerton: über ein Kiesbette, welches Seekonchylien lebender Arten enthält, bei The Willington in Cheshire, S. 326-327.

W. Buckraxd: Notiz über ein neulich entclecktes Riesen-Reptil, S. $327-328$.

Tн. Richardson: Analyse des Wolframs (Thomson's Records in Science, I, 452), S. 335.

S. Woodward: einige Bemerkungen über die Crag-Formation in Nurfolk und Suffolk, S. 353-355.

H. S. Bosse: Untersuchung über die Natur des Fels-Gefüges, S. 376-383 und $445-454$.

Proceedings of the Geological Society of London, 13.-17. Mai.

Сн. Lyeur. : über die Kreide- und Tertiär-Schichten der Dänischen Inseln Seeland und Möen, S. 412-414.

Pir. Grey Egerton: eine Eigenthümlichkeit in der Struktur des Halses der Ichthyosauren, S. 414-415.

R. I. Murchi;on: über gewisse Erhebungs- und Verschiebungs-Linien im New-Red-Sandstone von North Salop und Staffordshire und über die Trapp-Dykes darin zu Acton Reynolds bei Shrewsbury, S. $415-417$.

Edw. Charteswortr : über den Crag in einem Theil von Essex und Suffolk [Juhrb. 1836, S. $236 \mathrm{ff}$ ]].

Thouson und Stegr: Zusammensetzung des Gadolinits, S. 430-431. 
R. FiтcH: über den Korallinen-Crag von Ramsholt und Orford, S. 463-464.

Edw. Chareesworth: Antwort auf Woodward's Bemerkungen über den Coralline - Crag, nebst Beobachtungen über gewisse Missgriffe, welche bei Bestimmung des Alters der Tertiär-Schichten mit unterlaufen mögen, S. 464-470.

Proceedings of the Geological Society of London, 10. Juni.

H. T. De la Beche: Note über die mit dem New red Sandstone verbundenen Trapp-Gebirge in Devonshive, S. 513-515.

A. Sedgwick und Wraliamson Peile: über den Kohlen-Kalkstein-Zug längs der primitiven Cumbrian - Berge und über die Kohlenfelder auf der N.W.-Küste von Cumberland.

J. Trummer: Vorkommen von Seekonchylien noch lebender Arten in Geschiebe und Sand über einem Torflager mit eingeschlossenen Baumstämmen bei Shrewsbury, S. 516-517.

W. J. Broderip: Beschreibung einiger fossilen Krustazeen und Radiaten, S. 517 .

Pr. Grey Egerton: über die Entdeckung von Ichthyolithen im S.W.Theil des Nord-Staffordshirer Kohlenfeldes, S. 517-518.

G. Mantel. : über Vogelknochen in den Schichten von Tilgate Forest in Sussex, S. 518.

G. MıntelL: Bemerkungen über das Hufbein eines Pferdes aus dem „Shingle Bed" in den neuen pliocenen Schichten der Kliffe bei Brighton.

Daubeny: Analyse der neuen Mineralquelle bei Oxford, S. 518.

(Eine Pinte Wasser gibt 132,87 Gran fester Theile, lauter Salze, wovon $52,40 !$ phosphors. Natron.)

\section{S36, VIII, Nr. 1, 2, 3, 4, S. 1-352.}

W. Buckland: Notiz über die fossilen Schnautzen - Theile von 4 ausgestorbenen Fisch-Arten, welche zu Chimaera gebracht werden dürften, aus der Oolith- und Kreide-Formation Englands, S. 4-7.

C. B. Rose : Skizze der Grologie von West-Norfolk, Fortsetzung, S. $28-42$.

Proceedings of the Geological Society of London, 1835, 7. Nov. bis 18. Nov.

W. Buckrand : über fossile Chimaeren (s. o.), S. 71.

R. I. Murcurson: über die neuliche Entleckung von Palaeoniscus c atopterus Ag. im New red Sandstone zu Tyrone in Irland, S. 72-73.

Pingel: Notiz über einige Thatsachen, welche die allmähliche Senkung eines Theiles der Westküste von Grönland beweisen, S. $73-74$.

Frtzroy : über das Erdbeben an der Küste von Chili im Februar 1835, S. 74 .

R. E. Alrison desgl., S. 74-75. 
Н. Ј. Ввоокв : ӥber symiolische Bezeichunung, angewendet auf Mineralogie, S. 101-103.

S. Woodward: über die Crag-Formation, als Erwiderung auf Charbesworth's Antwort, S. 138-139.

Proceedings of the Geological Suciety of London, 1835, 18. Nuv. bis 2. Dez.

F. DARwis: geologische Bemerkungen auf einer Reise an der Ostund West-Küste Süd-Ameriku's in de: Jahren 1832-1835 mit einem Queer - Durchschnitt der Kordilleren zwischen Valparaiso und Mendoza, S. 156-159.

Belcher's, Bower's und Cuming's Briefe über die Wirkungen des Erdbebens zu Valparaiso im November 1832, S. 159-160.

Brooke: Thulit und Strömit, S. 169.

Woodeine Parisir: über die Wirkungen der Wogen bei den Erdbeben an den Küsten des stillen Ozeans, S. 181-186.

DeL Rro: über Riolith, Herrerit und Culebrit, S. 261-263.

W. Hoopkrs: Auszug aus einer Abhandlung über physikalische Geologie, mit einer weitläufigeren Auseinandersetzung über gewisse damit verbundene Gregenstände, F. f., S. 272-281.

Proceedings of the Geological Society of London, 1835, 19. Febr.

Сн. Lykru's Pede am Jahrestag der Gesellschaft, S. 313-345.

(? J de Carte Sowrpis) The London Geological Journal, London 1836, April ff. $8^{\circ}$ (in Quartal-Heften).

Nr. I et II sollen enthalten:

Tн. Belt: über die fossilen Schildkröten im Londonthon zu Harwich.

E. W. BrateEx jun.: Untersuchungen über den Ursprung der zusammengesetzten Struktur der Feuergesteine, insbesondere des Basalts und Granites.

Ebw. Cirarleswopth: über die Bestimmung des relativen Alters tertiärer Schichten.

J. E. Gray : ûber neue Arten fossiler Echiniden.

Chaning Peahce: über den Apiocrinites von Bradfurd.

Übersicht neuer geologischer Werke.

Notizen über neue Entdeckungen und Untersuchungen in der Geologie.

Transactions of the Geological Society of Pennsylvania, I, II, Philadelphia 1835, $8^{\circ}$ (S. 4 und 177-247). 


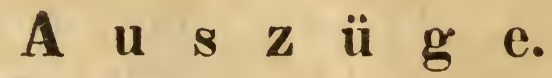

\section{Mineralogie, Krystallographie, Mineralchemie.}

Berzelius: Oure poudre (faules Gold) aus Porpez in SüdAmerika (XV. Jahres-Bericht, S. 205). Eine Art von Gediegen-Gold, das in vieleckigen Körnern vorkommt, die vorm Löthrohr schmelzen, wobei kleine Quarzkörner auf der Oberfläche hervortreten. Ein 0,623 Grm. schweres Korn wurde zusammengesetzt gefunden aus :

$$
\begin{aligned}
& \text { Gold . . . . . . 85,98 } \\
& \text { Palladium . . . . . } 9,85 \\
& \text { Silber . . . . . 4, } 4,17 \\
& 100,00
\end{aligned}
$$

Sranberg (a. a. 0. ) zerlegte ein für 0 smium-Iridium ausgegebenes Mineral aus Amerika, welches in kleinen weissen, runden Körnern vorkommt, von denen einige, die ausgezogen wurden, dem Magnete folgten; die übrigen hatten 16,94 Eigenschwere und bestanden aus:

$$
\begin{aligned}
& \text { Platin : . . . . } 55,44 \\
& \text { Iridium . . . . . 27,79 } \\
& \text { Rhodium . . . . } 6,86 \\
& \text { Palladium . . . . } 0,49 \\
& \text { Eisen . . . . . } \mathbf{4 , 1 4} \\
& \text { Kupfer . . . . . } 3,30 \\
& \text { Verlust, eine Spur von Os. } \\
& \text { mium mit einbegriffen } 1,98
\end{aligned}
$$

Glocker: über Graphit und Allophan von Petrow in Mähren (Erbmann und Schweigger-Seider, Journ. f. Chem., VI, $330 \mathrm{ff}$.). Unfern des genannten Dorfes findet sich ein 3 bis 5 Fuss mächtiges Braun- 
Eisenstein - Lager, welches zum Hangenden feinkörnigen Kalk hat, zum Liegenden aber den in der Gegend herrschenden Glimmerschiefer; es fällt unter $35-45^{\circ}$ nach $N$. Der Braun-Eisenstein verlässt aber seine normale Stellung, zieht sich mitten in den Kalkstein hinein, verliert darin allmählich an Mächtigkeit und keilt sich zuletzt ganz aus. In solchem Falle konmt der Kalk unmittelbar auf Glimmerschiefer zu liegen, und an dieser Grenze, wie zwischen Kalk und Brauneisenstein, tritt eine 4 bis 6" starke Graphit - Lage auf. Im Brauneisenstein sieht man eine ziemlich sveit fortsetzende, einige Linien bis $\frac{1}{2}^{\prime \prime}$ starke Lage Allophans. - Bis jetzt wurde der Allophan überall in Verbindung mit Eisenoxyd-Hydrat gefunden und dürfte sehr wabrscheinlich als Kieselbaltiges Thon-Hydrat in bestimmter genetischer Beziehung zu dem erwähnten Eisenerze stehen.

A. Lavrent u. Ch. Holms: Albit von Chesterfield (Ann. de Chim. et de Phys. Nov. 1835, p. 331). Vorkommen mit rothem und grünem Turmalin. Resultat der Analyse :

\begin{tabular}{|c|c|c|c|}
\hline Kieselerde & . . . & . $\cdot$ & 68,4 \\
\hline Thonerde & & & 20,8 \\
\hline Eisen und & Mangan & & 0,1 \\
\hline Kalkerde &.$\quad$ & & 0,2 \\
\hline Natron & • & & 10,5 \\
\hline
\end{tabular}

A. Connell: Zerlegung des Gadolinits (Jambson. Edinb. new phil. Journ., Jun, 1836):

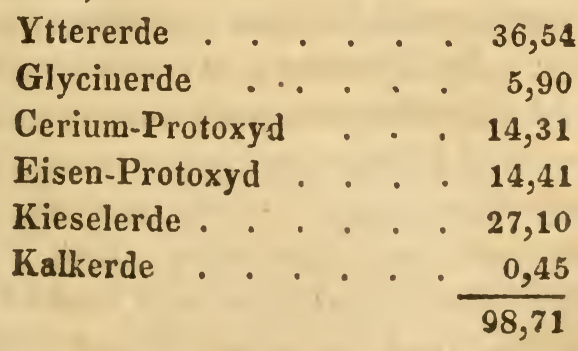

Forсmimmer: Oerstedin (Berzenus, XV. Jahresbericht, S. 207). Das neue Mineral findet sich bei Arendal, meist in Augit-Krystallen eingewachsen. Es ist braun, glänzend, krystallisirt in einer, zum pyramidalen Systeme gehörenden, sehr zusammengesetzten Form. Die PolWinkel der ersten Pyramide $=123^{\circ} 16^{\prime} 30^{\prime \prime}$. Ausserdem kommen zwei spitzigere Quadrat-Oktacder in derselben Stellung vor, beide quadratische Prismen, so wie auch eine achtseitige Pyramide wit ungleichen Winkelı. 
Das Mineral ist also in der Gestalt dem Zirkon ähnlich (dessen Winkel $123^{\circ} 19^{\prime}$ beträgt). Spez. Gewicht $=3,629$ Härte zwischen Apatit und Feldspath. Ergebriss der Zerlegung:

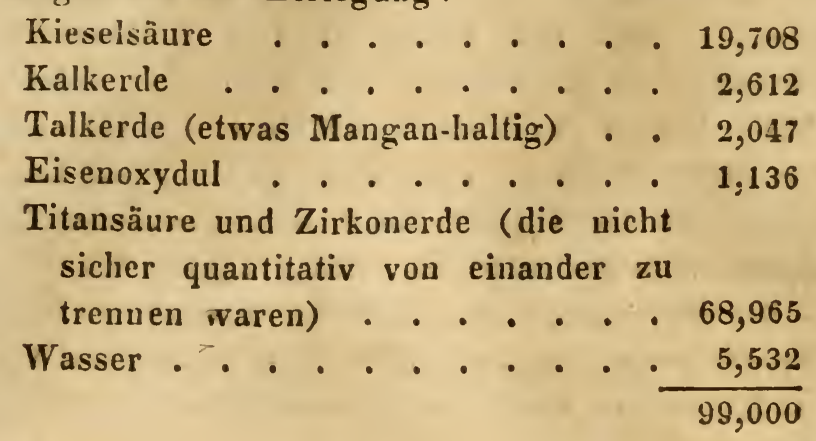

Shepard : über den Mikrolith, ein neues, in dem Tantalit-führenden Albit-Granit von Chesterfield (Massachusetts) vorkommendes Mineral. Fast mikroskopische Krystalle, reguläre Oktaeder und einige sekundäre Formen; unvollkommene Durchgänge; strohgelb, auch braun; durchsichtig; Bruch muschelig und harzglänzend. Vor dem Löthrohr nicht schneizbar; in Borax zum gelben, klaren Glase auflösbar. Als wesentlicher Bestandtheil nimmt S. Ceroxyd an (Sinuman, Amer. Journ. of Sc. XXVII , 361). Brrzelits (XV. Jahresher. S. 207) ist der Meinung, es könne die Substanz wohl Ceriumfluorid seyn.

J. Kuderasatsch: chemische Untersuchung einiger Abänderungen des Augits und der Hornblende (Poggend. Ann. d. Phys. XXXVII, 577 ff.). Aus H. Ross's analytischen Arbeiten ging im Allgenieinen das Resultat hervor: dass die Mineralien, welche Gestalt und Theilbarkeit des Augits haben, Zweidrittelsilikate von Kalkerde, Talkerde, Eisenoxydul und Manganoxydul sind. Ккарвотн fand im muscheligen Augit aus dem Rhöngebirge und im schwarzen krystallisirten von Frascati, ebenso Vauquelin in dem vom Ätna ein etwas abweichendes Mischungs-Verhältniss, namentlich einen Thonerde-Gehalt von 5 und mehr Prozent. Rose bestätigte den Gehalt von Thonerde im Augit von Frascati; er fand in verschicdeneu Analysen 5 bis 7 Proz. Der Augit, welcher diese Abnormität in der Zusammensetzung zeigt, findet sich in einze'ren Krystallen und Körnern eingewachsen in vulkanischem Gesteine, wälrend die von H. Rose analysirten Abänderungen meist grŏssere krystallinischn Massen in den Magneteisen - Lagerstätten Schwedens bilden. Es war darum auch von Interesse, durch erneute Untersuchangen die Mischung jener Varictät auszumittelı, um so melır, da man hoffen durfte, falls sich der Thonerde-Gehalt in melireren Augiten bestätigen würde, bestimmen zu können, welche Rolle dieser Bestandtheil - dessen Gegcuwart in der Horublende und im Diallag noch nicht 
enträthselt ist - unter den Mischungs - Theilen des Augits spiclen. Diess war die Veranlassung zu folgenden interessanten Aualysen:

I. A ugit vom Zigolon - Berge im Fassa-Thale. Krystalle in der bekannten Form, eingewachsen in Augit-Porphyr, in welchem ausserdem zahlreiche weisse Krystalle sich finden, die wahrscheinlich Labrador seyn dürften. Spez. Gew. des Augits $=3,358$. Resultate zweier Zerlegungen :

$$
\begin{aligned}
& \text { Kieselerde . . . } 50,09 \text {. . } 50,15 \\
& \text { Thonerde . . . . 4,39 . . 4, 4,02 } \\
& \text { Kalkerde . . . . 20,53 . . 19,57 } \\
& \text { Talkerde . . . . 13,93 . . : 13,48 } \\
& \text { Eisenoxydul . . . 11,16 . . 12,04 } \\
& \overline{100,10} \quad \frac{12,01}{99,26}
\end{aligned}
$$

II. Lose Augit-Krystalle von derselben Form, am Gillenfelder Maar in der Eifel vorkommend. Spez. Gewicht $=3,356$. Vier Zerlegungen gaben :

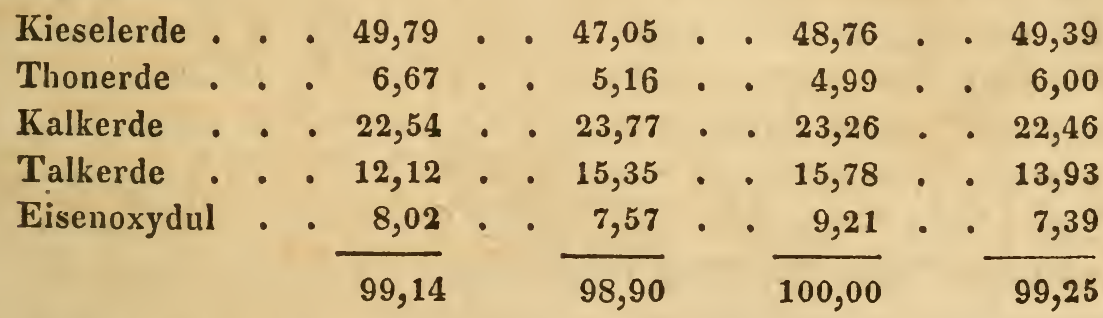

III. Augit aus dem Rhön-Gebirge. Grosse unregelmässig begrenzte Individuen. Spezifische Schwere $=3,347$. In zwci Analysen wurde erhalten:

$$
\begin{aligned}
& \text { Kieselerde . . . } 50,11 \text {. . } 50,73 \\
& \text { Thonerde . . . . 6,68 . . 6 6,47 } \\
& \text { Kalkerde . . . . 18,66 . . 18,90 } \\
& \text { Talkerde . . . 15,72 . . 16,91 } \\
& \text { Eisenoxydul . . } \frac{7,55}{98,72} \cdot \frac{7,26}{100,27} .
\end{aligned}
$$

Gehalt :

IV. Lose A u git-Krystalle von Ätna. Spez. Schwere $=3,359$.

$$
\begin{aligned}
& \text { Kieselerde . . . . 50,55 } \\
& \text { Thonerde . . . . } 4,85 \\
& \text { Kalkerde . . . . 22,29 } \\
& \text { Talkerde . . . . 13,01 } \\
& \text { Eisenoxydul . . . } 7,96 \\
& 98,66
\end{aligned}
$$

V. A ugit. Krystalle aus Laven vom I'esue. Die Analyse gab: 


\begin{tabular}{|c|c|c|c|}
\hline - & 598 & & \\
\hline Kieselerde & & & 30,90 \\
\hline Thonerde & . & $\theta^{\circ}$ & 5,37 \\
\hline Kalkerde & . & & - 22,96 \\
\hline Talkerde . & & • & . 14,43 \\
\hline Eisenoxydul & & & . 6,25 \\
\hline
\end{tabular}

Der Thonerde-Gehalt wäre sonach in den untersuchten Augiten zienslich konstant nachgewiesen, dagegen findet unter der SauerstoffMenge der Bestandtheile ein Verhältniss Statt, welches es eben so unbegründet als willkürlich erscheinen lässt, wenn man die. Thonerde zu den elektronegativen, als wenn man sie zu den elektropositiven Gemengtheiler: rechnet. Am meisten nähert man sich dem gefundenen Resultate, wenn man die Kieselerde ein Bisilikat und die Thonerde mit dem geringen Überschuss an Basen ein Trialuminat bilden lässt. Es scheint übrigens, dass Verunreinigung der Krystalle mit einer fremdartigen Masse die Ursache sey, wesshalb die Analysen kein entscheiden. des Resultat gaben. Höchst selten sieht man Krystalle, die in ihrem Innern durchgängig eine frische, homogene Beschaffenheit zeigen; sie sind vielnehr sehr häufig von kleinen Klüften und verwitterten Stellen unterbrochen. Hatte vielleicht der, aus einer zähen, geschmolzen-gestaltlosen Masse krystallisirende Augit nicht die Kraft, im Momente seiner Bildung erstere vollständig aus seinem Raume zu verdrängen; blieb er von einem Theile derselben durchdrungen, und war dieser Theil der glasigen Massen desshalb reich an Thonerde, weil letztere in die Bil. dung des Augits uicht mit einging? $\mathrm{Da}$ indessen Thonerde einen wesentlichen Bestandtheil in gewissen Hornblenden ausmacht, so könnte sie wohl auch wesentlich zur Zusammensetzung einiger Augite gehören.

Der Verf. fügt dieser Mittheilung das Resultat der Zerlegung dreier Mineral-Substanzen bei, welche zwar dem Wesen nach zur Hornblende gehören, weil sie mit derselben die unter einem Winkel von $124,5^{\circ}$ sich schneidenden Theilungs-Flächen gemein haben; von denen eine aber die Krystallform des Augits hat (Rose's Uralit), während die andern beiden ausser der erwähnten noch eine dritte gleich ausgezeichnete TheilungsRichtung haben, wohl die stumpfe Kante des Prismas von $124,5^{\circ}$ abstumpft.

Der Uralit aus der Nähe des Baltym-Sees im Ural enthält nach Kudernatscu :

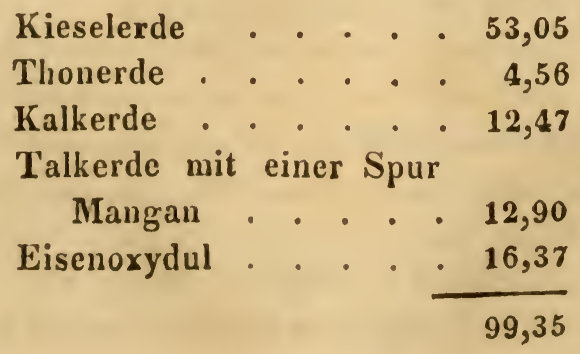




\section{$-599$}

Jenes zweite der erwähnten Mineralien, eine Hornblende von Kongsberg besteht aus :

$$
\begin{aligned}
& \text { Kieselerde . . . . 49,07 } \\
& \text { Thonerde . . . . 9 } 9,24 \\
& \text { Kalkerde . . . • 10,33 } \\
& \text { Talkerde, Mangan-haltig 20,29 } \\
& \text { Eisenoxydul . . . . } 9,77 \\
& 98,70
\end{aligned}
$$

Das dritte Fossil endlich, von welchem die Rede, eine Hornblende vom Dorfe La Prese zwischen Bormio und Tirano in Veltlin enthält :

$$
\begin{aligned}
& \text { Kieselerde . . . . . . . 45,31 } \\
& \text { Thonerde . . . . . . . . . 11,88 } \\
& \text { Kalkerde . . . . . . . . . . 10,49 } \\
& \text { Talkerde, Mangan-haltig . • . . 14,28 } \\
& \text { Eisenoxydul . . . . . . . . 15,93 } \\
& \text { Kieselerde - haltige Titansäure (wahr- } \\
& \text { scheinlich von eingesprengtem Titan. } \\
& \text { eisen herrübrend) . . . . . } 0,66 \\
& 98,55
\end{aligned}
$$

Berzelius: Untersuchung der Meteorsteine (K. Vetensi. Acad. Handl. 1834, p. 115 und XV. Jahresber., S. 227 ff.). Die Absicht der Analyse war: die Meteorsteine als Gebirgs-Arten zu studiren, und bestimmen zu können: aus welchen einzelnen Mineralien sie gemengt sind. Die erste Veranlassung war die Aufforderung, einen Meteorstein zu untersuchen, der am 25. November 1833 um 6 Uhr Abends unfern Blansko in Mähren gefallen war. Ausserdem analysirte B. noch bei Chrntonnay in Frankreich, bei Lautolax in Finland, bei Alais in Frankreich und bei Elnbogen in Bölınen (der verwünschte Burggraf) gefallenes, endlich auch das durch PaLLas bekannt gewordene Meteoreisen aus Sibirien. Das Resultat dieser Untersuchungen ist, dass die Meteorsteine Mineralien sind; - da es eine Ungereimtheit wäre anzunehmen, dass sich Mineralien in der Luft aus deren Bestandtheilen bilden sollten, so können sie nicht atmosphärische Produkte seyn, um so weniger, da viele von ihnen Gangtrümmer zeigen, d. h. Sprünge, die mit einem Mineral von anderer Farbe und wahrscheinlich anderer Zusammensetzung angefüllt sind; und noch weniger lässt sich denken, dass die Meteorsteine in den wenigen Augenblicken gebildet worden, welche die Anzichungskraft der Erde einem so schweren Körper in der Atmosphäre zu bleiben gestattet. - Sie kommen also wo anders, her. Auswürflinge von Vulkanen der Erde sind sie nicht, denn sie fallen überall, nicht bloss, oder nicht meistens in grösserer oder geringerer Nähe bei den Vulkanen; ihr Aussehen ist verschieden von dem tellurischer Mineralien, verschiedeu 
von Allem, was Vulkane der Erde aufwerfen. Das nicht oxydirte geschmeidige Eisen, welches sie enthalten, zeigt, dass nicht Wasser, selbst vielleicht nicht einmal Luft in ihrer ursprünglichen Heimath vorkomme. Sie müssen von einem andern Weltkörper abstammen, der Vulkane hat. Der uns nächste ist der Mond, und der Mond hat im Vergleich zur Erde Riesen-Vulkane. Er hat keine Atmospbäre, welche die Auswürflinge der Vulkane retardirt. Eben so wenig scheint es Wasser-Ansamnilungen auf demselben zu geben; - kurz, unter den wahrscheinlichen Arten der Abstammung, ist die Abstammung vom Moude die wahrscheinlichste. Aber einen Begriff von den wägbaren Elemen. ten zu bekommen, woraus ein fremder Weltkörper besteht, wäre es auch nur der uns so nahe befindliche Mond, verleiht einer solchen Untersuchung ein Interesse, das sie für sich selbst nicht haben würde. - Die allgemeinen Resultate dieser Untersuchungen waren folgende: es sind 2 Arten von Meteorsteinen auf die Erde berabgefallen. Die zu derselben Art gehörenden sind untereinander gleich zusammengesetzt und scheinen vou einem und demseiben Berge herzurühren. Die eine Art ist selten. Bis jetzt sind nur drei dahin gehörende Meteorsteine bemerkt worden, nämlich die bei Stannern in Mähren, die bei Jonzac und bei Juvenas in Frankreich gefallenen. Sie sind dadurch ausgezeichnet, dass sie kein metallisches Eisen enthalten, dass die Mineralien, woraus sie bestehen, mehr krystallinisch geschieden sind, und dass die Talkerde keinen vorherrschenden Bestandtheil darin ausmacht. Von diesen besass B. keine Probe zur Untersuchung. Die zweite Art wird von der grossen Anzahl der anderen, bis jetzt untersuchten Meteorsteine gebildet. Häufig sind sie in Farbe und Ansehen einander so ähnlich, dass man sie für aus einem Stück geschlagen halten sollte. Sie enthalten geschmeidiges, metallisches Eisen in veränderlicher Nenge. Wir haben Beispiele von ungeheueren Blöcken, die aus einem einzigen, zusammenhängenden Eisengewebe bestanden, dessen Höhlungen von der Bergart ausgefüllt waren und die gerade aus dem Grunde, weil sie durch das Eisengewebe zusammengehalten wurden, im Fallen ganz geblieben sind. Andere bestehen mehr aus Bergart mit weniger Eisen, welches dann nicht zusabzmenhängend ist; diese springen von der Hitze, welche durch die, von der ungehinderten und nach der Erde zunehmenden BewegungsGeschwindigkeit der Himmélskörper bewirkte, unermessliche Zusammendrückung der Atmosphäre während der wenigen Misuten, die sie zur Durchlaufung der Erdatmosphäre brauchen, hervorgebracht wird, und in Folge deren ihre äusserste Oberfäche stets zu einer schwarzen Schlacke schmilzt, die feiner als das dünnste Post-Papier ist. Man kanı daher sagen, dass die Meteorsteine, angenommen, dass sie voun Monde herstammen, nur aus zwei verschiedenen Vulkanen kommen, von denen der eine entweder häufigere Aufwürfe hat, oder dessen Auswürfe in einer solchen Richtung gehen, dass sie öfter zu uns gelangen. Ein solcher Umstand stimmt vollkommen mit dem überein, dass eine gewisse Gegend des Mondes die Erde beständig im Zenith hat, uad alle seine 
gerade herausgeschleuderten Auswürflinge gegen die Erde richtet, wohin sie gleichwohl nicht in gerader Richtung gehen, weil sie auch der Bewegung unterworfen sind, welche sie zuvor als Theile des Mondes hatten. Wenn es dicser Theil des Mondes ist, der uns die meteorischen Eisenblöcke zusendet, und wenn die übrigen Theile des Mondes nicht so mit Eisen überfüllt sind, so sehen wir einen Grund ein, warum dieser Punkt beständig nach dem magnetischen Erdball gewendet bleibt. - - Die Bergart der Meteorsteine bestelst aus verschiedenen Mineralien. Diese sind:

I. O livin. Er enthält Talkerde und Eisenoxydul, ist farblos oder graulich; selten gelb oder grün, wie es aller terrestrische ist. Dieses zeigt, dass kein Sauerstoff vorhanden war, um das Eisen zu oxydiren. Er ist, gleich dem terrestrischen, in Säuren löslich und lässt die Kieselerde gelatinirt zurück. Gleich dem ersteren enthält er Spuren von Zinnoxyd und Nickeloxyd. Hiervon macht jedoch der Olivin in dem von PaLias entdeckten Meteoreisen eine Ausnahme, denn er enthält kein Nickel, und seine Farbe ist grüulichgelb; aber er eńtbält Zinn. Der Olivin macht ungefähr die halbe Menge von der unmagnetischen Bergart aus. Den Olivin trennt man durch Behandlung derselben mit Säuren, indem man nachher die Kieselerde in kochendem kohlensáuren Natron auflöst.

Es bleiben danu zurück:

II. Silikate von Talkerde, Kalkerde, Eisenoxydul, Manganoxydul, Thonerde, Kali und Natron, die von Säuren nicht zersetzt werden, und in denen die Kieselerde 2 mal den Sauerstoff der Basen enthält. Wahrscheinlich sind sie Gemenge von mehreren, die nicht getrennt werden konnten. Man könnte auf cin Augit-artiges $\begin{array}{r}\mathrm{F} \\ \mathrm{C}\end{array} \mathbf{S}^{2}$ und auf ein Leucit-artiges Mineral schliessen, in welchem Kalkerde und Talkerde im ersten Glied einen Theil Kaii und Natron ersetzen $\left.\begin{array}{l}\text { Mg } \\ \text { N } \\ \text { K }\end{array}\right\} S^{2}+A S^{2}$. Dass hier der Augit nicht so gefärbt ist, wie der terrestrische, hat denselben Grund, wie die Farblosigkeit des Meteor-Olivins.

III. Chromeisen. Es ist in beiden Arten der Meteorsteine enthalten, in beiden in gleicher Menge; es hat noch nie darin gefehlt und ist die Ursache des Chromgehalts der Meteorsteine.

IV. Zinnoxyd, mit dem Chromeisen gemengt.

V. Magneteisen kommt vielleicht nicht in allen vor.

VI. Schwefeleisen ist in allen thalten. Alle Umstände scheinen darauf hinzudeuten, dass es von jedem Bestandtheil ein Aton enthält. Ein Ëberschuss von Schwefel in einer Masse, worin überall ein Uberschuss von Eisen vorwaltet, ist nicht denkbar. Ein Theil des Schwefeleisens folgt zugleich mit dem Eisen dem Maguet, ein anderer Theil bleibt in dem Steinpulver, welches an den Magnet nichts mehr 


\section{$-602$}

abgibt. Diess macht zuweilen mehrere Prozente aus. Ob es vermöge einer chemischen Verbindung etwa ähnlich der des Schwefelmangans in Helvin, oder nur vermöge der Adhäsion zum Steinpulver sich so verhält, liess sich nicht entscheiden; das letztere ist wahrscheinlicher, da $\mathrm{Fe} \mathrm{S}$ nur schwach magnetisch ist; indessen ist ersteres nicht unmöglich. Das Schwefeleisen ist die Ursache, dass das Meteorstein-Pulver bein Vermischen mit Salzsäure Schwefelwasserstoffgas entwickelt.

VII. Gediegen-Eisen. Dieses Eisen ist nicht rein, obgleich es sehr geschmeidig ist. Es enthält Kohlenstoff, Schwefel, Phosphor, Magnesium, Mangan, Nickel, Kobalt, Zinn und Kupfer. Es ist aber ausserdem noch gemengt mit, in seiner Masse einsitzenden, kleinen Krystallen einer Verbindung von Phosphoreisen, Phosphornickel und Phosphormagnesium. Diese sind in Satzsäure unlöslich und sondern sich bei der Auflösung ab. Ihre Menge ist ungleich. Das Elnboger

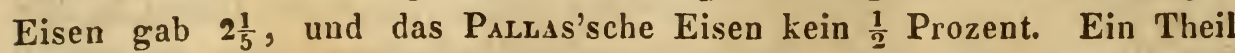
davon ist so fein in der Masse des Eisens zerstreut, dass sie bei der Auflösung des Eisens als schwarzes Pulver abfällt. Die Ursache derWIDMaNsstäDT'schen Figuren ist, dass die fremden Metalle nicht gleichförmig eingemischt, sondern in unvollkommen ausgebildeten, krystallinischen Anordnungen ausgeschieden sind.

Wird das Eisen in einer mit Säure vermischten Eisenvitriol-Solution aufgelöst, so löst sich das reine Eisen fast allein auf, und diese Legirungen fallen in Flocken ab.

Die bis jetzt in den Meteorsteinen gefundenen einfachen Körper machen gerade $\frac{1}{3}$ von denen aus, die wir kennen, nämlich Sauerstoff, Wasserstoff, Schwefel, Phosphor, Kohlenstoff, Kiesel, Chrom, Kalium, Natrium, Calcium, Magnesium, Alumium, Eisen, Mangan, Nickel, Kobalt, Zinu und Kupfer.

Folgende Analysen des Meteoreisens mögen hier angeführt und eine zu derselben Zeit von WeHrLe angestellte hinzugefügt werden:

PaLLAS'sches Eisen.

\begin{tabular}{|c|c|c|c|c|c|c|c|}
\hline & $P_{A L L A}$ & is'sches & Eisen. & $\begin{array}{c}E l n \\
\text { BerzeLros'sch } \\
\text { Analyse. }\end{array}$ & boger & $\begin{array}{c}\text { Eisen } \\
\text { Nach }\end{array}$ & n. \\
\hline Eisen & . . & 88,042 & . & •. . 88,231 & . $\cdot$ & . . & 89,90 \\
\hline Nickel & . & 10,732 & - & 8,517 & . . & & 8,44 \\
\hline Kobalt . & . & 0,455 & - & 0,762 & . . & . . & 0,61 \\
\hline Magnesium & . & 0,050 & . & 0,279 & & . . & $\overline{98,95}$ \\
\hline Mangan . & & 0,132 & & & & 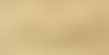 & \\
\hline Zinn u. Kupf & fer. & 0,066 & & & & & \\
\hline Kohle • & . . . & 0,043 & & spur. & & & \\
\hline Scliwefel . & . . & Spur & & & & & \\
\hline Phosphor-Met & talle & 0,480 & - & 0,211 & & & \\
\hline
\end{tabular}

Die Phosphor-Metalle enthielten: 
Pallas'sches Eisen. Elnboger Eisen.

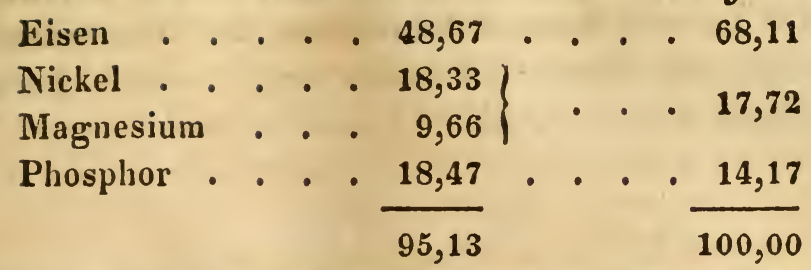

Auf grosse Genauigkeit können diese letzteren Resultate keinen Anspruch machen, da das ganze Quantum von Phosphormetall, welches zur Analyse angewendet werden konnte, bei der ersten 3 und bei der andern 2,8 Centigramme betrug. WEHRLE's Analyse stimmt noch näher mit der Berzelius'schen überein, wenn man nicht unbeachtet lässt, dass er in dem Eisen den Phosphor- und Mangan-Gehalt eingemengt hat, so wie auch die Talkerde, die mit dem Eisenoxyd als phosphorsaure Ammoniak-Talkerde niederfiel.

WenrLe gibt noch folgende Analysen von Meteoreisen an:

$$
\text { Agram. Cap. Lenarto. }
$$

\begin{tabular}{|c|c|c|c|c|c|c|c|c|}
\hline Eisen & & - & 89,784 & & 85,608 & & - 90,883 & \\
\hline Nickel & - & - & 8,886 & . & 12,275 & . & 8,450 & \\
\hline \multirow[t]{2}{*}{ Kobalt } & - . & . & 0,667 & - & 0,887 & . & 0,665 & Spur $\nabla$. Kupfer. \\
\hline & & & & & 98,770 & & 99,992 & \\
\hline
\end{tabular}

WenrLe hat bestimmte Verhältuisse zwischen den Metallen gesucht, was fruchtlos scheint. - Nach den Versuchen von Berzelius zerfällt der Meteorstein von Alais in Wasser zu einer Erde, die nach Thon und Heu riecht und Kohle in einer unbekannten Verbindung enthält. Diess zeigt, dass in der Heimath der Meteorsteine die Gebirgsarten, wie auf der Erde, zu thonähnlichen Gemengen zerfallen könnten. Es entstand nun die Frage: enthält diese kohlenhaltige Erde von der Oberfläche eines andern Weltkörpers organische Überreste, befinden sich also auf demselben organische Körper, mehr oder weniger analog den tellurischen? Die Beantwortung dieser Fragen fiel nicht bejahend aus; sie aber verneinen, hiesse mehr daraus schliessen, als man zu schliessen berechtigt wäre. Es ergab sich, dass die Erde verwitterter Nickelund Zinn - haltiger Olivin war. Der Magnet zog Eisenoxyd - Oxydul in schwarzen Körnern aus, unter denen vermittelst des Mikroskops Flittern von metallischem Eisen zu entdecken waren. Das Wasser zog schwefelsaure Talkerde mit kleinen Mengen von schwefelsaurem Nickel aus, aber nichts Organisches, wovon sich auch nichts mit Alkalien ausziehen liess. Bei der trocknen Destillation wurde Kohlensäuregas, Wasser und ein schwarzgraues Sublimat erhalten, aber kein brenzliches Öl, kein Kohlenwasserstoffgas, mit einem Wort: die kohlenhaltige Substanz war nicht von derselben Natur, wie der Humus in der tellurischen Erde. Der Rückstand war verkohlt und schwarz. Beim Erhitzen in Sauerstoffgas gab das Sublimat keine Spur von Kohlensäure oder Wasser, und verwandelte sich in cinen weissen, nicht krystallisirten flüchtigen Körper, der in Wasser löslich war, welches dadurch nicht sauer wurde, und 


\section{$-604$}

salpetersaures Silber nicht fällte. Was dieser Körper ist, weiss B. nicht; er ist ihm gänzlich unbekannt. Könnte er wohl ein unserer Erde ursprünglich nicht angehöriger Elementarkörper seyn? Diese Frage be. jahend zu beantworten, wäre eine Übereilung.

Fr. Kobhler: zur Naturgeschich te des Harmotoms (Poggerd. Ann. d. Phys. XXXVII, 561 ff.). Als Resultat dieser Untersuchungen betrachtet der Verfasser den Kalk- und Baryt-Harmoto in vorläufig in Form-und Mischungs - Beziehungen als auf gleicher Stufe stehend mit Pyrop und Granat, Achmit und Augit; die angestellte Vergleichung zwischen beiden gilt ihm jedoch nur als ein, vielleicht von der Wahrheit noch weit entfernter Versuch, die Mischungs-Verhältnisse beider Mineralien zu erklären. Der Baryt-Harmotom findet sich zuKongsberg und Strontiun auf Güngen in Gneiss, zu Andreasberg auf Gängen in Thonschiefer, und sehr wahrscheinlich zu Rudelstadt bei Kupferberg in Schlesien auf Gängen in Hornblende-Schiefer, von Baryt- und KalkSpath, Kupferkies und Silberglanz begleitet. Ferner erscheint jewer Harmoton im Porphyr-Mandelstein zu Oberstein, bei Dumbarton und Campsic unfern Glasgow in Schottland, und am Schifferberge bei Gie. sen im Basalt. Mit Barytspath zusammen und auf Erzgängen hat man bis jetzt nie Kalk-Harmotom gefunden. Er kommt in Basalt, Wacke und Lava vor und ist bei Weitem häufiger verbreitet.

F. X. M. ZIPpe: Analyse des Comptonits vom Seeberge bei Kaaden (Verhandl. d. Gesellsch. des vaterländischen Museums in Böhmeri, 1836, S. $39 \mathrm{ff})$ :

\begin{tabular}{|c|c|c|c|c|c|}
\hline Kieselerde & . & - & . & & 38,25 \\
\hline Thonerde & . . & - & . & 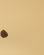 & 32,00 \\
\hline Kalk . & . . & - & . & • & 11,96 \\
\hline Natron . & - . & - & • & • & 6,53 \\
\hline Wasser & . . & . & . & & 11,50 \\
\hline
\end{tabular}

J. N. Fucus: ïber Isomerismus und Amorphismus (Erpmans und Scirweigger-Serdel, Journal für praktische Clsemie; VII, 345 ff.).

Derselbe: über den Graphit und verwaudte Gegenstände (A. a. $0.353 \mathrm{ff}$.).

Beide Aufsätze gestatten keine Auszüge. 


\section{$-605$}

Kuderkatsch: über den Plagionit (Poggend. Ann. d. Phys. XXXVII, 588 ff.). Das Ergebniss der Analyse war:

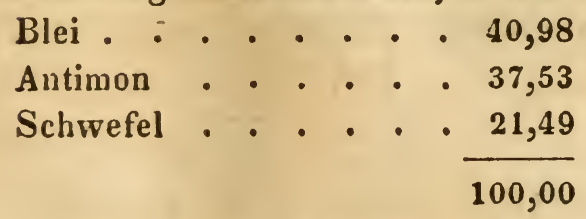

Aus dieser Zerlegung sowohl als aus einer frühern von H. Ross scheint hervorzugehen, dass der Plagionit eine eigenthümliche chemische Verbindung sey.

C. S. WeIss: über eine eigene Art von Krümmung an Bergkrystallen (Karsten, Arch. für Min. IX, 549 ff.). Am Gotthard und an der Grimsel finden sich Bergkrystalle von einer regelmässigen Art Krümmung. Sie sind frei gebildet, frei und ohne mechanischen Druck von aussen in einer Krystall - Höhle entstanden. Der Verf., dem wir in seiner ausführlichen Entwickelung hier nicht folgen können, thut dar, dass die Axen der verschiedenen Ansätze oder Fortsetzungen des fortwachsenden Individuums oder, wenn man lieber will, der fortwachsenden Gruppe, einer continuirlichen Veränderung ihrer Richtung unterworfen gewesen sind. Vor einer Reihe von Jahren schon wurde W. durch das Studium der innern Struktur-Beschaffenheit der hemiëdrischen Krystall-Systeme auf die Úberzeugung hingeleitet: dass es drebende Kräfte in der krystallinischen Struktur geben müsse. „Es bildet sich", sagt er, „ein in sich zurückkehrender Kreis, und eine Differenz der Richtung in demselben, d. $i$. der Drehungs $-R i c h t u n g$, wie denn überhaupt Drehung in der Natur, also Axendrehung u. s. f. physikalisch begreiflich wird, oder einen innern physikalisch nachweisbaren Grund erhält, durch Differenz in den Seiten zweier, in Bezug auf einander polarisirten, unter sich rechtwinkligen Dinensionen. Beim Quarz ergibt sich das Phänomen von Drehung und ungekehrter Drehung aus dem polarisirten Zustande seiner innern Struktur - Linien." „Was wir jetzt", so schliesst der Vf. den erwähnten Aufsatz, „als mechanische Drehung der gauzen Masse durch krystallinische Kräfte beim Fortwachsen hervorgebracht, an den rechts und links gewundenen Krystallen vom Gotthard und von der Grimsel vor uns sehen, ist eine in der That unerwartete, gewiss aber nicht geringe Bestätigung der Naturgemässheit der frühern Reflektionen über den innern physikalischen Zustand der krystallinischen Struktur geworden". 


\section{$-606$}

Fr. v. Kobell : über Krystall-System und Krystallreihe (Erdmane und Schweigger-Seidel Journal für Chemie VII, $153 \mathrm{ff}$.). Eignet sich nicht im Auszuge mitgetheilt zu werden.

Kleine mineralogische Notizen (aus Sibrim. Amer. Journ. of Sc. XVIII - XXIV). In Florida kommen die Gold-A de $\mathrm{rn}$ nicht in Glimmerschiefer, sondern in Talkschiefer vor (HAYDEN, KeATING). Auch in ganz Mexiko, wenigstens in einem über 1000 Meilen weit nach Süden ziehenden Distrikt davon, ist nach $\mathrm{E}_{\mathrm{AtoN}}$ alles Gold mit den begleitenden Metallen, als Silber, Quecksilber, Kupfer und Zink im Talkschiefer-Gebirge allein - nicht in den es begleitenden Gebirgsarten enthalten. Die Gangart ist ein Quarz, zwischen milchweiss und durchsichtig (ib. XX, 124).

Wenn man Alkohol - Dämpfe durch glühende Eisenröhren streichen lässt, so setzt sich darin viel $\mathrm{Koh}$ l.e, zum Theil in schönen KrystallNadeln ab. Conen in New York. -

Grosse Spodumen-Krystalle mit Beryllen in Granit kommen zu Chesterfield (in Massach.) vor, an dem berühmten Fundort der Turmaline.

Rothes Titanoxyd in schönen Krystallen findet sich bei dem Scifeustein-Bruch von Cummingham (in Massach.). J. Porter.

Schöne T op a s - Krystalle in einem Stück Granit mit fleischrothem Feldspath und krystallisirtem Quarze sind gefunden worden am Wege bei den White Mountains, $1 \frac{1}{2}$ Meil. abwärts von den Fällen des Amonoosuck, New Hampshive. Нгтснсосн (1. с. XX, 410).

Nach Corioli's Untersuchungeu ist die Härte des geschmolzenen und in der Luft erkalteten Bleis sehr veränderlich; beständig nur, wenn es bei abgehaltenem Luftzutritt ausgegossen, und dann der untere Theil der Masse geprüft wird (ib. XXI, 167).

Нrтснсоск hat kürzlich $\mathrm{ch} \mathrm{rom} \mathrm{s}$ a u res $\mathbf{E}$ ise $\mathrm{n}$ in beträchtlicher Menge in Serpentin in Blanforl, schön krystallisirten $\mathbf{S} p$ he $\mathrm{n}$ in augitischem Gneisse in Lee, natürlichen Alaun im Gneisse von Barre und Leominster gefunden (1. c. XXIV, 397).

A. Clapp von New Albany, Indiana, entdeckte auf einer Reise im J. 1831 an den Wasserfällen des South Brook zu Montgomery, Vermont, einen durch talkigen Schicfer heraufdringenden GrünsteintrappDyke von $3^{\prime}$ Mächtigkeit (ib. XXII, 189).

Nach Eatos ziehen die Urgebirge vom Lake George über den st. Lawrence zu Ogdensburg längs der N.O.-Seite der See'n Huron, Superior u. s. w. in einer Erstreckung von mindestens 1000 Englischen Meilen. Sie sind dann in $2-3$ kleinere Ketten getrennt. Von Little Falls am Erie-Kanal geht ein Gneiss - Zug ununterbrochen N.W.wärts bis zum äussersten Ende der grossen Kette der See'n (ib. XVIII, 376). 
Th. Richardson hat kürzlich den Wolfram zerlegt, aber ein Resultat erhalten, das von den frühern bei Vavquelis von 1796 und Berzelius von 1815 sehr abweicht, und auf verschiedene Arten zu deuten scheint:

\begin{tabular}{|c|c|c|c|c|c|}
\hline Scheelsäure • & . & $\begin{array}{l}\text {-Vauquelix. } \\
\text {. } .6700\end{array}$ & & $\begin{array}{l}\text { Berzelius. } \\
\text { • .7467 }\end{array}$ & $\begin{array}{l}\text { Richards. } \\
\text {. } \quad .7360\end{array}$ \\
\hline Mangan-Protoxyd & - &.$\quad .0625$ & . . & . .0564. & . . .1575 \\
\hline Eisen-Protoxyd . & - & . .1800 & - & . .1795 . & .1120 \\
\hline Kieselerde . . & . & . .0150 & & & \\
\hline
\end{tabular}

Thomson u. Steel haben folgende Zusammensetzung des Gadolinits gefunden:

Kieselerde • . .2433 oder 12.16 Atom oder 2. At. Ytter- oder 8 A. Yttererde • • . $.4533 \# 8.06$ - $\quad$ erde-Silikat. Ytt.-Sil. 4

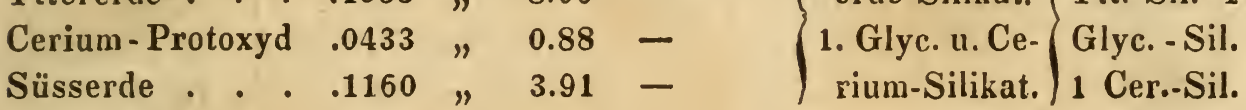
Eisen-Protoxyd . $1359 " 3$.

Platin . . . Spur

Mangan . . Spur

Wasser . . .0098

$$
1.0016
$$

(Tномs. Records of Science I, $408>$ Lond. a. Edinb. phil. May. 1835, VII, 430).

Steverson: Note über ein natürliches schwefelsaures Eis e n von Behar bei Patna (? Asiat. Joun. $>N$. Biblioth. univers. 1836, II, 185-186). Dieses Mineral wird von den Hindu'schen Fürbern zu Patna beim Färben gebraucht. Es findet sich in Stücken, aussen gelhlich, innen hellgrau, hat einen erdigen und körnigen Bruch, ist porös, opak, zerreiblich, leicht, hängt an die Zunge, schmeckt etwas sauer, lässt aber einen Zucker - artigen Nachgeschmack. Seine Bestandtheile sind:

$$
\begin{aligned}
& \text { Schwefelsaures Eisen • 0,39) } \\
& \text { Eisen-Peroxyd . . } 0,36 \text { bei } 0,02 \text { Verlust. } \\
& \text { Talkerde . . . . } 0,23 \\
& 0,98
\end{aligned}
$$

J. Stevenson: über eine natürliche schwefelsaure Alaunerde in den Alaunschiefern von Nepaul (? Asiatic Journ. $>N$. 


\section{$-608$}

Bibl. urivers. 1836, II, 185). Diese Substanz wird von den Ärzten zur Heilung von Wunden und Kontusionen gebraucht und von den Einwolnern von Tirshoot Sulajit (Weichstein) genannt. Sie ist sehr häufig, bräunlich, aussen opak und wasserfrei, innen von halbkrystallinischem Ansehen, von faserigem Bruch, Asbest-Glanz, porösem Gefüge, die Poren mit kleinen nadelförnigen Krystallen erfüllt; sie hängt etwas an die Zunge, ist zerreiblich und löst sich im Doppelten ihres Gewichtes destillirten Wasser. Sie besteht aus

schwefels. Alaunerde . . 0,95; bei unreinen Exemplaren nur 0,66. Eisen-Peroxyd . . . 0,03

Kieselerde . . . . . 0,01

bei 0,01 Verlust . . $\overline{0,99}$

Alcuaud d. $\ddot{A}$ : über Gediegen-Quecksilber im Granit zu Peyrat-le-Château, Haute Vienne (l'Institut 1836, IV, 172). Beim Graben in einem feinkörnigen, sehr quarzreichen Granite mit zersetz.tem Feldspathe, welches Gestein aber manchfaltig in Pegmatit, Gneiss, Kaolin etc. übergeht, hat man auf der Esplanade des Schlosses Peyrat, an der Strasse von Figeac nach Montargis bereits über $12 \mathrm{Pf}$. flüssiges Quecksilber gesammelt. Es findet sich an verschiedenen Punkten eines nur kleinen Bezirkes, welche aber in einer gemeinschaftlichen Fläche zu liegen scheinen, keine Spalten zeigen und auf eine Entstchung dieser Ablagerung entweder gleichzeitig mit der Bildung des Granites oder durch eine Sublimation von unten hinweisen.

Das Schwedische Mineral, dessen Winkel H. J. Вrооке in seiner Krystallographie zu $92^{\circ} 30$ und $87^{\circ} 30^{\prime}$ angegeben, und das er für Thulit gehalten, ist nicht solcher, sondern Mangan-Bisilikat oder Strömit (Lond. a. Edinb. philos. Journ. 1836, VII, 169).

\section{Geologie und Geognosie.}

J. Friven: mineralogische und geognostische Nachrichten über dic Grafschaft St. Laurence in New York (Silliman, Americ. Journ. XIX, p. 220 etc.). Bis jetzt waren die nördlichen Theile des Staates von New York wenig untersucht, die neueste Zeit fübrte zur Kenntniss der Fundorte mancher interessanten Mineralien. Die auf der Oberfläche vorhandenen Felsblöcke, mehr oder weniger abgeruudet, aber nicht von ausgezeichneter Grösse, bestehen zumal aus 
Granit, Gneiss und Porphyr; die meisten scheinen aus Caradı abzustammen. Bei Laurentia trifft men zahlreiche Blöcke zusammengesetzt aus Labrador, Hornblende und glasigem Feldspath: ein Gestein von solcher Natur wurde bis dahin in den vereinigten Staaten nicht nachgewiesen. Massen von Saidstein und von Übergangs - Quarz [?] kommen ebenfalls auf der Oberfläche vor, ihre Kauten zeigen sich scharf und sprechen dafür, dass dieselben aus der unnittelbaren Nachbarschaft. abstammen. In der Gegend von Heuvel herrscht ein, angeblich in Schichten von wenige Zolle bis zu 2 Fuss mächtig abgetheiltes, Gestein aus Quarz-Körneru und zersetztem Feldspath bestehend. Der Verf. betrachtet diese Felsart als zur sogenannten Übergangs-Zeit gehörend, denn sie soll hin und wieder mit Transitions-Kalk wechseln; auch will er in den "Üluergangs-Sandstein" hin und wieder Madreporen und Tubiporen bemerkt haben. Die Stadt Oydesburg liegt auf Diluvial-Boden, unter dem kieseliger Kalkstein [?] ansteht, der überaus unrein ist. Am nördlichen Ufer des Black Lake (schwarzen Sec's) wechseln. Lagen von Quarzfels und Kalkstein. Die ersten Primitiv-Gesteine treten um Hammond auf. Sie bestehen vorzugsweise aus Quarz, Feldspath und Hornblende. Geringmächtige Granit - Gänge durchsetzten einen Hornblende-Schiefer. Auch Dolomit kommt unfern Hammond vor. Er soll kleine gelbe Glimmerblättchen und Graphit-Partikeln, auch Krystalle von weissem Augit enthalten. Im Russie.Thale ein Lager von weissem [körnigem ?] Kalkstein, in welchem Chondrodit durch das Ganze der Masse verbreitet gefunden wird, ferner Apatit, Glimmer, Flussspath und Automolith in kleinen oktaedrischen Krystallen. Turmalin-Adern durchziehen den Granit bri Rossie. In der Gegend trifft man ausserdem in weissen Kalkstein: Grammatit, Graphit, Kokkolith, weissen Augit und Zoisit. In den Rossie-Bergwerken wurden früher gewonnen: Eisenglanz und Roth-Eisenstein, Eisenspath, Eisenkiesel, Eisenkies u. s. w. In dem aus Feldspath und Quarz gemengten Gestein unfern des Dorfes Gonverneur: Apatit-Krystalle von 3" Länge und 1" Durchmesser. Am Ufer des Osweyatchie Kalk mit Serpentin, Asbest, Magnesit und Kokkolith. Bein Dorfe Potsdam Granit und HomblendeSchiefer und in diesen Gesteinen grosse Hornblende-Krystalle, Talk, Sahlit, Skapolith, Eisenglanz, Kupferkies u. s. w.

J. Burkart: geognostische Verhältnisse der Silber-Bergwerke von Veta grande in der Provinz Zacatecas in Mexilio (Karsten, Archiv für Mineral., VI, 319 ff.). Der Gang Vetu grande (grosser Gang), am nördlichen Gehänge des Gebirges von Zacatecas, setzt im Übergangs-Gebiet: Grünstein, Thon- und Kicsel-Schicfer auf. Er steigt fast aus der Ebene empor, welche das Grebirge in W. begrenzt, streicht - St. 7 bis $7 \frac{4}{\alpha}$ und mit südlichem Fallen von 60 bis 630 - auf der N.-W.-Scite, wahe unter dem Gipfel des Cerro del Angel, 
8800 Rheinl. F. über dem Meere, vorbei, und lässt sich, 3200 bis 4000 Lachter weit, bis an den östlichen Gebirgsfuss verfolgen, wo er sich in der Ebene verliert. Er keilt sich bisweilen nach dem Tage hin so aus, dass er nur mit vieler Mühe durch Schürfen aufzufinden ist; im Allgemeinen wird derselbe jedoch in höheren Gebirgstheilen mächtiger getroffen, als gegen den Fuss. Die Mächtigkeit wechselt zwischen 1 und 11 Varas (4 $\frac{2}{5}$ Lachter). Auf der Grube Urista (es bauen über 20 Gruben auf dem Gange) erscheint der Gang in drei Trümmer getheilt. Oft liegen diese Trümmer, nur durch schmale Klüfte getrennt, nahe bei einander, an anderen Stellen beträgt die gegenseitige Entfernung 20 bis 25 Varas, und die Trümmer werden durch Grünstein-, Grauwackeund Thonschiefer-Mittel von einander abgesondert. Hangendes, und Liegéndes dieser Trümmer sind von mehr und minder mächtigen. Bestegen begleitet. Einfach gestreifte Spiegelflächen, auf der Gangmasse wie an den Sahlbändern, kommen vor und am häufigsten am Hangenden. Die Gang-Ausfüllung besteht aus Quarz, Hornsteiu, Braunspath, Stücken des Neben-Gesteins, selten Kalkspath, noch seltener Barytspath. Von metallischen Substanzen werden getroffen: Gediegen Silber, Hornsilber, Rothgültigerz, Glanzerz, Schwarzgültigerz, Silberschwärze, Bleiglanz, Blende, Antimonglanz und Eisenkies. Auch Gypsspath-Krystalle, ganz neue Bildungen, stellen sich in Drusen des Ganges und in den Rissen versetzter Wände ein.

do Villeninue: Durchschnitt, beim Ausgraben des Marseiller Schiffs.Werftes a ufgeschlossen (Ann. du Midi de la France. Bullet. de la Societ. géol. de Fr., III, p. XXIV). Den dichten Kreide-Kalk bedeckt in ungleichförmiger Lagerung ein Mergel und ein bituminüser Kalk mit Abdrücken von Palmen, Weiden, Schilfen und Moosen, so wie mit Paludinen und Limneen. Ein Sand, welcher Abzeichen der Bearbeitung durch Menschenhände trägt, und Römische Ziegel zugleich mit Muscheln aus dem Mittelländischen Meere enthält, ruht auf jener Ablagerung.

Héricart de Thery: über einige Phänomene beim Bohren artesischer Brunnen im Departement der Ost-Pyrenäen und in der Gegend um Conegliano in Lombardo-Venetianischen Königreiche (Ann. des Min. Bine Sër., T. IF, p. 515). Zwischen Perpignan und Thuir wurde in 42 Meter Tiefe eine Springquelle von vorzüglicher Güte aufgeschlossen. Luf dem rechten Tech-Ufer, an der Mceresküste, versuchte man, jedoch ohne Erfolg, in einem aus Tuff und Mceressand bestehenden Boden, d. h. im Bette des Mittellündischen Meeres, ein Bohrloch abzuteufen. Dagegen wurde eine sehr erfolgreiche Arbeit im Bassin von Bayes verführt. Die durchbrochenen Lagen waren: 
Dammerde

$0^{\mathrm{m}}, 65$

Sand von einem vormaligen See-Bette . $\quad 2^{\mathrm{m}}, 60$

Gelber Thon mit mergeligen Nieren $\quad 21^{\mathrm{m}, 50}$

Dichter schwärzlicher Thon . . . $0^{\mathrm{m}, 65}$

Kieseliger Sand . . . . . $0^{\mathrm{m}, 50}$

Dunkelgefärbter Thon mit zahlreichen kleinen Lagen von weissen Mergel-Nieren $\quad 9 \mathrm{~m}, 75$

Sehr trockener kieseliger Sand • . $1 \mathrm{~m}, 60$

Schwarzer fettiger Thon in dünne Lagen abgetheilt

Schwarzer Thon, in welchem die, mit Hef-

$9 \mathrm{~m}, 7 \mathrm{~s}$ tigkeit zu 1m,60 emporsteigende Quelle aufgeschlossen worden; sie gibt 2880 Kubik-Meter Wasser in 24 Stunden . $1 \mathrm{~m}, 60$

$$
\text { Gesammt - Tiefe }=\overline{48^{\mathrm{m}}, 60}
$$

Die bei Gajarine durchbohrten Lagen sind folgende:

Dammerde, Sand und Gruss . . . $1 \mathrm{~m}, 58$

Thonmasse, durch Schichten thonigen Sandes in mehrere Lagen abgetheilt o $5 \mathrm{~m}, 06$

Sand- und Gruss-Bänke, geschieden durch kleine Thonlagen

$13^{\mathrm{m}}, 50$

Lagen von Rollstüsisen und von Gruss, gebunden durch ein sehr festes kieseliges Zäment . . . .

Sandiger Thon . . . . . . $1 \mathrm{~m}, 82$

Thon mit sandigen Lagen $\quad . \quad$. $\quad 5^{\mathrm{m}}, 73$

Dergl. mit Sand- und Gruss-Lagen ․ $10^{\mathrm{m}}, 00$

Als man diese Tiefe, $=38 \mathrm{M}$., erreicht hatte und an 23. Mai 1833 Abends das Gestänge aus dem Bohrloche nehmen wollte, vernahm nahn ein ungewöhnliches sehr heftiges Getöse in der Röhre, in dem uämlichen Augenblicke wurde eine Masse sandigen Schlammes ergosssen und es verbreitete sich ein unangenehmer schwefeliger Geruch. Diese Erscheinung dauerte einige Minuten, nachher sank das Wasser wieder zu seinem gewöhnlichen Niveau, einige Meter unter dem Boden. Das Getöse hielt noch kurze Zeit an, wurde jedoch nach und nach schwächer. In der Nacht setzte man das Bohren in der von Sand- und Gruss - Lagen durchzogenen thonigen Masse fort; so oft das Gestänge herausgenommen wurde, liess sich auch das nämliche Getöse mehr und weniger stark wieder vernehmen, und zwar immer, wenn man mit dem emporzuhebenden Gestänge ungefähr die Höhe von 23 Metern erreicht hatte. Mit Tages - Anbruch war eine Tiefe von $41^{\mathrm{m}}, 25$ erreicht wordcn. Man brachte ein Licht an die Mündung der Röhre, und sogleich entzündete sich das mit einer gewissen Gewalt herausströmende Gas und es bildete sich eine Flamme von mehr als 2 Metern Höhe über der 
Röhre. Dic Flamıne brannte mit Lebhaftigkeit während einigen Minuten, sie nahm nach und nach ab, erlosch endlich, und nun bürte auch das Getöse in der Röhre auf. An demselben Tage erfolgte um die Mittagszeit ein neuer Erguss von Wasser und von thonigem Sand, oder vielmehr von fiüssigen Schlamm. Die Erscheinung trat sehr plötzlich ein und mit ungewohnter Stärke, so dass die flüssige Mlasse zu einer Höhe von neehr als 5 Meteru über die Oberfläche des Bodens emporgetrieben wurde; allmählich nahm die Ausschleuderung ab und erreichte nach wenigen Minuten ihr Ende. Bei der vorgenommenen Untersuchung fand man das Bohrloch in der Tiefe von 23 bis 24 Metern mit Erde, Sand und Gruss verstopft. Nur mit grosser Schwierigkeit gelang die Aufräumung, und so oft man den Bohrer herausnahm, erfolgte, aus der Tiefe von 23-24 M., ein neuer Erguss von schlammigem Wasser unter Entwickelung. von geschwefeltem Wasserstoff-Gas. Am 27. Mai Abends hatte man den Bohrer bis zu einer Tiefe von 46 M. gebracht; als derselbe herausgenommen wurde, erhob sich sehr plötzlich eine Flamme von $2 \mathrm{M}$. Breite und $10 \mathrm{M}$. Höbe; zugleich hatten schlammige Auswürfe Statt. In der erwähnten Höhe von 10 Metern erhielt sich die Flammen-Säule, nahm sodann nach und nách ab, stand jedoch noch mit lebhaftern Glanze zwei Stunden lang mehr als 2 M. hoch. - Ähnliche Ausbrüche von geschwefeltem Wasserstoff-Gas hatten auch bei andern artesischen Bohr-Arbeiten Statt. Bei Cormeille en Parisis, unfern Argenteuil, entwich gekohltes Schwefel-Wasserstoff-Gas aus 45 M. Tiefe mit grosser Heftigkeit. In dieser Tiefe hatte man die grau oder schwarz gefärbten stinkenden und schwefeligen Mergel angebohrt. Sie enthalten, ausser dem Schwefel, auch verkohlte Pflanzentheile. Bei Cormeille nahm man ausserdem in 65 M. Tiefe einen unterirdischen Bach wahr, der seinen Lauf in einer Höhle hat, in welche der Bohrer plötzlich 4-5 II. tief hinabfiel. Nach den beobachteten Aszillationen floss die Wassermasse aus $N$. nach $S$. Ihr Strömen war so heftig, dass kein Löffeln möglich war, und man die Bohr-Arbeit aufgeben musste. Die in der Runde um deu Teich von Hontmorency zum Behufe der Wässerung abgesenkten Bohrlöcher zeigten fast alle mehr und weniger häufige Entweichungen von Wasserstoffgas. Der ganze Boden ist selbst in dem Grade damit gesättigt, dass die Mineral-Quellen von Enghien und der Cocquenard - Bach (in der Volks - Sprache Ruisseau puant) überreich an geschwefeltem Wasserstoff-Gas, auf dem Gestein und auf andern Gegenständen, über welche sie ihren Lauf nehmen, in grosser Menge Schwefel absetzen. Die artesischen Brunnen um Saint-Deuze, Pierrefite, Saint-Ouen, Pontin lieferten ohne Ausnahme geschwefeltes Wasserstoffgas, als die kalkig-thonigen Mergel des Süsswasser - Gebildes durchbrochen wurden, oder als man die braunen und schwarzen bitumisen Mergel des unteren Theiles der Gyps-Masse aufschloss. In mebreren Bohr-Löchern hatte die Gas - Entwicklung unter stärkerem oder greringerem Geräusche Statt. - Im Allgemeinen ereignen sich die GasEntwcichungeri sicts, wenn die Wasser-führende Sand. oder Gruss. 
Schicht kavernös ist; die Fluktuation der Wasser bediugt durch die Bewegung des Bohrers das Entweichen des Gases aus den kleinern und grössern Höhlungen *). - Allein nicht immer ist die dem artesischen Brunnen entströmende Luft Wasserstoff-Gas; weit öfter haben nur Ausströmungen von atmosphärischer Luft Statt. Diess ist namentlich sehr häufig der, Fall bei den in der grossen Masse von Kieselkalk im 0 . und S.O. von Paris gebohrten Brunnen. Der denkwürdigste unter denselben ist der zu Nangis unfern Melun. Hier ging man mehr als $60 \mathbf{M}$. nieder in kieselige Kalke, ohne Auzeichen von Quell-Wassern zu erhalten; aber die heftigsten Luft-Ausströmungen hatten Statt: sie waren einem starken Getöse vergleichbar. Die Strömung liess die Eigenthümlichkeit wahruehmen, dass sie gleichsam intermittirte und zu gewissen Tages-Stunden schwächer wurde. - Bei Epinay, niclit weit von SaintDeuze, hat man mit Erfolg eine, tiefer als das geschwefcltes WasserstoffGas haltige Wasser befindliche, Quelle reinen Wassers aufgeschiossen und beide Quellen zu Tag gebracht.

Steinkohlen in Russland (Journ. de St. Petersbourg. $\frac{7}{19} m e$ Avril 1834, N. 42). Das Gouvernement von Katherinoslaff ist das einzige, in welchem Kohlen gewonnen werden. Hier nehmen die Ablagerungen derselben einen Raum von ungefähr 300 Quadrat-Wersten ein. Die Kohlen scheinen an und für sich nicht von besonderer Güte, aber für die Holz-arme Gegend werthvoll.

MaIen: geognostische Beschreibung des Wolfsberges bei Cernossin im Pilsner Kreise (Verhandl. der Gesellsch. des vaterländ. Museums in Böhmen, in der XI. allgem. Versamml. am 10. April 1833. Prag; 1833, S. 22 ff.). Das Grund-Gebirge der Gegend ist Thonschiefer, der nach N.O. streicht, und zu Mies steil nach S.O. fällt, bei Cernossin aber in N.W. sich verfächt. - Von IMies bis Cernossin trifft man kein anderes Gestein und keine bedeutende Unebenheit des Bodens, bei letztgenanntem Orte aber erhebt sich das Thonschiefer-Gebirgé zu einem breiten von S.W. in N.O. erstreckten Gewölbe, das, mit Ausuahme des nordöstlichen Abhanges, nach allen Seiten unter $20-50^{\circ}$ fällt, und mit dem angrenzenden Terrain, über das es emporgehoben, in Rinnen zusammenstösst, in welchen die Wasser der Gegend ablaufen. Auf der Mitte dieses Gebirgs-Gewölbes erhebt sich nit steilern Winkeln eine Kuppe, deren Äusseres schon von Ferne eine Verschiedenheit des Gesteins und dem geübten Auge den Basalt verräth, aus dem dieselbe

*) In diesen Lagen verlieren sich die Spring-Quellen sehr leicht, wenn beim Einsetzen der Röhre ins Bolırloch nicht die gehörige Vorsicht angewendet worden. 


\section{$-614$}

besteht. Auf der N.- und W.- Seite der Kuppe steigt die Basaltmasse in grotesken Felsen schnell gegen den Gipfel; länger gezogen, jedoch immer stark, fällt sie gegen S. ab und, indem sie sich dann in zwei Zungen, gegen S.O. und S.W. theilt, bildet sie in letzter Richtung eine Art Terrasse, die nicht über 25 bis 30 Klafter hoch, breit und eben, allein $^{\overline{7}}$ steril ist und aus dichtem Basalt besteht. Hinter der Terrasse überrascht die ockerrothe Farbe des Bodens, und die in wogendem Weizenfelde darüber ausgebreitete Vegetation desselben. Man ist begierig, die Ursache der auffallenden Verschiedenheit $z u$ erfahren. Bald löst sich das Räthsel in einer Menge ausgeworfener und aufgehäufter Blöcke schwarzen und braunrothen blasigen Basaltes. Die schwarzen sind sehr aufgebläht und schwammig, an vielen die Blasenräume ohne sichtbare Auskleidung bloss bleigrau angelaufen und fettartig übertüncht, wie zu Schlacken geflossene Mineralmassen diess gewöhnlich auf ihrer Oberfläche zeigen. An andern aber trifft man kleinnierige HyalithÜberzüge in den grössern Öffnungen der Masse. Auch Trümmchen von Bergseife sind in solchen eingewachsen. Die rothbraunen Basalte sind porös oder blasig, gelb, die Blasenräume mit Zeolith ausgekleidet. Da die porösen Partieen in die blasigen übergehen, und man beim Zerschlagen gar wohl vom Zusammenhange der Poren mit den grösseren Blasen-Räume sich überzeugt, so wäre diese Erscheinung unerklärbar, wenn man das Daseyn der Zeolithe in den blasigen und das Nicht-Daseyn derselben in den porösen Basalt - Partieen durch Infiltration aufgelöster Zeolith-Masse erfolgt annehmen wollte. Besonderes Interesse erregen ferner die eingescblossenen Hornblende-Krystalle und Trümmer, und zwar nicht nur wegen ihrer verschiedenen Formen, sondern vorzüglich um der sekundären Veränderungen willen, die sie an Form und Sub. stanz erlitten. Die Krystalle sind nämlich oft abgerundet an den Kanten, auch an ihren Seitenflächen löcherig. Sie erscheinen als länglicho Sphäroide, die kleinen wie Pignolen in die gleichförmig in dic Länge gezogenen Blasen auf einer oder der andern Seite derselben eingekittet, und diese wie jene mit einer zarten graulichweissen Rinde, wahrscheinlich von Zeolith-Natur, überzogen *). An Substanz erlitt die Hornblende manchmal die Metamorphose in rothen Jaspis, gewöhnlich beginnend an den Theilungs- oder auch an den End. Flächen der Krystalle, wie man sieht, wenn diese von bedeutender Grösse sind. Auch Körner von gelbem Jaspis findet man in dem Basalt cingeschlossen, die, nach einigen unveränderten Stellen zu schliessen, auch als Metamorphosen des Augits betrachtet werden müssen. - So haben alle im blasigen Basalt eingeschlossenen Körper wesentliche Veränderungen erlitten; auch die QuarzStücke, welche ziemlich unverändert in dem dichten Basalt sich zeigen,

*) Letzteres Vorkommen erinnert an die Leuzit-Lava von Monte Sommu bei Neapel, in der die Höhlungen, ebenfalls nach der Gestalt der eingeschlossemen LeuzitKrystalle gezogen und letztere nur mit einer Seite darin angewachsen gefunden werden. 
erscheinen geröstet, selbst gefrittet im blasigen. Daraus muss man schliessen, dass auch die Abrundungen der Hornblende - Krystalle durch anfangende Schmelzung verursacht worden seyen.

Über dem rothen, durch keinen vorhandenen Felsen unterbrochenen Abhang sicht man lose Hornblende-Krystalle, oder Trümmer derselben allenthalben auf der lockern Ackerkrume herumliegen. Unter der Kuppe erheben sich die blasigen rothen Massen, deren Fortdauer über den ganzen Abhang aus den herumliegenden Trümmern und aus der rothen fruchtbairen Erde, zu welcher sic verwittern, sich vermuthen lässt, in Felsen und verbinden sich dem dichten Basalt, der steil zum Gipfel ansteigt. Beim Hinabgehen vom Gipfel gegen N.W. kömmt man von dichtem Basalt auf grauen, porösen, trifft abermals dichten, dann den blasigen rothen, und endlich wieder den dichten, aus welchem der ganze westliche und nordwestliche steile Absturz des Wolfsberges besteht, an dessen Rande im Triebler Thal der rothe blasige Basalt deutlich als Ausfüllung einer Kluft im dichten vorkommt. Die Kluft hat keine Saalbänder, sonderu die Blasen werden an deren Statt kleiner, die rothe Masse grau, und diese schliesst mit kleinkörnig abgesonderten Stücken an den dichten Basalt der Hauptmasse an. Eine deutliche Vorstellung vom Lagerungs-Verhältnisse des blasigen Basaltes zum dichten erlangt man beim Verfolgen dieser Abänderungen gegen $W$. Obwohl sie hier theils von Vegetation bedeckt sind, so überzeugt man sich dennoch, dass beide äussere Grenzen des blasigen Basaltes zusammenlaufen und sich zwischen dem dichten an dem Rande verlieren, wo dieser schon an den Thonschiefer des Grundgebirges grenzt. Jenseits der Terrasse gegen N.O. ist ein Absturz innerhalb zweier mit Wald bewachsener Bergflügel; diese Stelle gehört zu den lehrreichsten am Wolfsberg. Beide Bergflügel bestehen aus dichtem, und der zwischenliegende Absturz auf 220 Klafter Breite aus blasigem und schlackigem Basalt. An dem kahlen Felsen auf der Nordseite sieht man den dichten Basalt regelmässig zerklüftet in seigern Richtungen, welche mit der Schlackenkluft parallel zu streichen scheinen. Auch zeigt sich sehr deutlich die Verbindung des dichten Basaltes mit dem blasigen durch Auflockerung der derben Masse und deren Trennung iu körnig abgesonderte Stücke, durch höhere $0 x y$ dation ihres Eisenentheils und durch poröse und schwammige Aufblähung der braunrothen Paste. Die Poren und Blasen sind vertikal in die Länge gezogren, welches, so wie die seigere Zerklüftung des dichten Basaltes, das senkrechte Einfallen dieser mächtigen Kluft beweisst. Mehr gegen die Mitte trifft man blasige und schlackige Materien zu TrümmesGesteinen zusammengewachsen, welche grössere oder kleinere sphäroidische Ballen von demselben porösen braunrothen Basalte enthalten, die im Innern zerborsten und mehr oder minder hohl sind. Am linken Flügel des Absturzes lassen herumliegende Gestein-Blöcke dieselbe Erscheinung vermuthen, allein wegen stärkerer Vegetation nicht so deutlich wahrnehmen. Er bietet jedoch zwei andere Beobachtungen dar. Es liegt nämlich aın Fusse des Absturzes weisser, oder von Eisenoxyd braun. 


\section{6}

gefärbter, sandiger Thon, wie man ihn oft am Fusse von Basaltbergen findet, und beim Ansteigen längs der östlichen Kluftscheidung trifft man gelblich grauen Wackenthon mit vielen kleinen Hornblende-Prismen und grössere oder kleinere Stücke zu leichtem Schwamm aufgeblähten schwarzen Basaltes. Nur die Kanten sind wenig abgerundet, übrigens die äussre Form des Bruchstückes unverändert, so dass zu vermuthen, der Wackenthon liege in einer noch später geborstenen Kluft, in welche Bruchstücke bereits erstarrten Basaltes hineingefallen sind. Aus Allem erkaunte man deutlich, dass die blasige Basaltmasse auch hier eine mächtige Kluft zwischen der dichten erfülle, wie die vorher erwähnte Schaale; dass aber diese Füllung der Bildung des dichten bald gefolgt seyn müsse, weil sich beide Basalt-Abänderungen mit einander innig. verbinden. - Das Ende dieser Kluft gegen N.O. kann man nicht sehen, denn das Terrain zwischen beiden Bergflügeln ist mit Basaltblöcken und Vegetation bedeckt. Die Scheidungen konvergiren jedoch sehr stark. - Weiter in nordöstlicher Richtung näher der Strasse, wo ein Hohlweg aus dem Triebler Thal herauf das Terrain einschnitt, trifft man Nichts als Thonschiefer, mithin den Beweiss, dass die Kluft, in welcher der blasige Basalt liegt, schon weiter oberhalb geschlossen sey. - - Der Verf. wendet sich nun zur Untersuchung der südwestlich sich abziehenden Gebirgszunge. Den Rücken derselben bildet der nänliche dichte Basalt, welcher die Terrasse konstituirt. Am südlichen Berg-Fusse gräbt man weissen Thon, gemengt mit Glimmer-Blättchen und sparsamen Quarzkörnchen. Hier zeigt sich daher abermals dieselbe sonderbare Erscheinung, die bei melreren Basaltbergen beobachtet und sehr verschieden gedeutet ward. Da diess Gebilde stets auf einer oder der andern Seite des Basalt-Berges angelehnt, und also auf erhabenem Boden, nicht in Gründen zusammengeschwemmt gefunden wird: da ausser diesen einzelnen Partieen an dem Basaltberge keine Spur solcher Ablagerung in der Gegend zu sehen ist, wovon es als getrenuter Theil betrachtet werden könnte: so nuss man schliessen, dass es mit der Formation des Basaltberges zusammenhänge, und dass dieser PorzellanErde-artige Thon, der an andern Orten, wie z. B. in der Umgegend von Karlsbad und Engelhaus viel sandiger, mitunter selbst Konglomeratartig gefunden wird, beim Aufbrechen der Gebirgs - Spalte, durch die der Basalt emporquoll, vorans hervorgeschoben ward. - - Indem der Verf. ferner den Berg nach S.W., d. i. gegen das Thal, untersuchte, fand er hin und wieder, wo der Basalt an den Thonschiefer grenzt, oder am Fusse des erstern, sehr viele mehr oder weniger abgerundete Quarzstücke und Körner, nitunter von mehr als einem Kubikfuss Grösse. Über die Lagerung des Basaltes gegen den Thonschiefer, ob derselbe aufliege oder eine durchsetzende Kluft erfülle, war nichts zu ermitteln; man trifft nur reinen und niclit eiumal quarzigen Thonsehiefer mit demselben Fallen in N.W., wie in der ganzen Umgegend des Wolfsberges: keinen Basalt - Gang, keinen Quarz - Gang, nichts was mit den Erscheinungen in der Nachbarschaft über dem Thonschiefer im Zusammenhange 
stände. - Um die Untersuchung des Wolfsberges zu beenden, beging ihn der Verf. noch auf der Westseite; allein auch hier zeigt sich nichts, als auf der Höhe dichter Basalt; längs seinem Fusse das Kieselgerölle und Thonschiefer bis ins Triebler Thal; so rings umher bis zur Schlackenkluft, in welcher Gegend die steilen Basaltfelsen des Wolfsberges mit einem Wall grosser und kleiner solcher Felsen-Trünmer umgeben sind; hier trifft man auch Stücke, wo Fragmente von Quarz in grosser Zahl, seltener von Thonschiefer in eine braune etwas erdige Basaltmasse eingewickelt sind. Aus den vorgetragenen geognostischen Thatsaclien lassen sich folgende geologische Schlüsse ziehen:

a) Indem auf dem Gewölbe : zu welchem das Thonschiefer-Gebirge an Wolfsbery sich gestaltet, eine Kuppe von Basalt abgesetzt ist, so darf man schliessen, dass die unterirdischen Gasarten, welche den Basalt aus dem Innern der Erde nach oben pressten, auch das darüber liegende Thonschiefer - Terrain zu einem Gewölbe aufgetrieben haben.

b) $\mathrm{Da}$ die Oberfläche eines Kugel-Abschnittes grösser ist, als desseu Grund-Fläche, so musste bei dieser Auftreibung des Terrains an der Kuppel ein Sprung entstelien, der enger oder weiter auseinanderklafft im Verhältniss der Erhebung. Durch diese Kluft ward auch dem Basalt der Weg eröffnet emporzuquellen, und indem, wie physisch nicht unwahrscheinlich, die zuerst hervorgetretene Basalt-Masse zähflüssiger, als die darunter gelegene weniger abgekühlte war, so blähte sich erstere zu dem steilen westlichen und nördlichen Theil der Kuppe des Wol/sberges auf, während der nachfolgende Basalt-Strom sich in 2 wei $\mathrm{Z}$ weigen gegen S.O. und S.W. ergoss.

c) Schon die zwischen S.W. und N.O. in die Länge gezogene Form des Gebirgs - Gewölbes lässt schliessen, dass die auftreibende Kraft in dieser Richtung wirkte. Da ferner dasselbe nur gegen N.O. in einen breiten Rücken ausläuft, ausserdem ringsum abfällt, so wird diese Vermuthung bestätigt, und darin noch näher angedeutet, dass die Wirkung von N.O. und nicht von S.W. Statt gefunden habe.

Bei der aufmerksamsten Untersuchung des Thonschiefer-Gebirges sowohl in S.W. im Thale, als in N.O. am Hohlwege längs der Landstrasse ist durchaus keine Spur eines in diesen vom Wolfsberg fortsetzenden BasaltGanges zu beobachten; wohl aber liegt die mit blasigem Basalt erfüllte Kluft in der Richtung des gegen N.O. laufenden Rückens des GebirgsGewölbes. Das auffallende Vorkommen isolirter Basalt-Berge in grosser Entfernung von ausgedehnten Basalt - Ablagerungen enträthselt sich daher ain Wolfsbery auf cine seltene Weise. İmmer sah der Verf. derlei Basalt - Kuppen auf einem Gebirgs - Gewölbe stehen, so z. B. auch die berühmten Basaltberge bei Scheibenberg, Annaberg, bei Bärenstein im Sächsischen Erzyebirge. Gewöhnlich bildet aber der dichte Basalt nur eine Kuppe auf dem Gewölhe, und man kann dicse mit Nagelköpfen vergleichen, deren Stift bis in den Schoos der Erde reichend gedacht wird. An Wolfsberge wird aber dieser vernuthete Weg des Hervortretens 
der Basaltmasse an diesem Orte durch die Biasen. und Schlacken. Kluft - man darf sagen - zur positiven Gewissheit. - - Das Vorkommen blasigen und schlackigen Basaltes in dieser Stellung scheint noch nirgends so ausgezeichuet deutlich beobachtet worden zu seyn, als es der Wolfsberg gestattet *). An Wolfsberye füllen die blasigen Basaltmassen eine mächtige seigere Kluft im dichten Basalte aus. LEoNHARD bemerkt: „dass bei mehr senkrecht aufgestiegenen Basalt-Gebilden die Blasenräume zuweilen alle der Richtung aus der Tiefe nach oben folgen". Am Wolfsberg sind zwar auch die Blasenräume vertikal in die Länge gezogen, wie die Begrenzung des dichten mit dem blasigen Basalte vertikal ist, allein dieser ist völlig unbedeckt.

Zum Schlusse versucht der Verf. die besondere Erscheinung am Wolfsberge zu erklären, die keine isolirte ist, sondern im Zusammenhange mit dem mächtigen Hervortreten des Basaltes im nordwestlichen - Böhmen zu stehen scheint. - Indem er vom Wolfsberg die Richtung in N.O. weiter verfolgte, wurde er zu dem 2 kleine Stunden entfernten Basaltberg bei Radisch geleitet. Dieser hat die ähnlichste Konstitution nit dem Wolfsberg. Sein nordwestlicher Theil ist aus dichtem, sein südöstlicher aus Kugel-Basalt gebildet; die Kugeln, von einigen Zoll bis zu mehreren Kubikfussen Grösse, bestehen aus Basalt mit vielen eingeschlossenen Krystallen und Stücken von Hornblende und Olivin. Beide sind durch eine Kluft blasigen Basalts getrennt, welche ebenfalls in der Richtung von S.W. in N.O. liegt, jedoch lange nicht so märhtig, wie jene am Wolfsberg ist. - Der Schwamberg und Schafberg, zwei aus dichtem Basalt konstituirte Berge, liegen dem Radischer Berge nahe, allein ausser der Linie in N.O. In derselben Linie, wie der Wolfsbery und der Radischer Berg, und noch weiter-in N.O. kommen jedoch die Basaltberge bei Merschin und Breitenstein, so wie unweit Augezd und Chlum bei Manetin vor. - Es ist wohl möglich, dass nur die GranitFormation von Petersbury, und das rothe Sandstein - Gebilde, das in deren Ungebung bis Rocow, Kanotop und Hribz in der Launer Gegend sich erstreckt, die Fortsetzung von Basaltkuppen auf dieser Linie verhinderte, denn die Pssaner Berge und der Hasenberg liegen wieder auf derselben.

Vergleicht man die Lokalitäten aller dieser genannten Basaltberge auf einer Karte, so erscheinen sie als Entladungs-Punkte auf einer Erschütterungs-Linie, welche von N.O. in S.W. streicht; und, merkwürdig genug, liegt mit Ausnahme des vereinzelten Schlaner Berges südöstlich dieser Linie kein Basalt-Berg mehr.'

*) Leoxuard sagt: „Wo gangartige Basalt-Gebilde zu Tage ausgehen, findet man ihre Oberflache häufig verschlackt gleich den beim Luftzutritt geflossenen Massen. Vereinzelte Basalt-Kuppen haben oft verschlackte Gipfel. Im Allgemeinen nelımen die Schlacken die höheren Stellen ein, und verlaufen sich der Tiefe zu in dichte Massen. Allein mitunter erscheinen sie auch wechselnd mit Mandelsteinen, und selbst feste Basalte werden hin und wieder in bedeutender Mlächtigheit über den Schlacken getroffen. 
Wendet man sich rom Wolfsberg rückwärts oder in S.W., so lăsst sich auch in dieser Richtung weder in Böhmen noch in den angrenzen. den Gegenden ein Basaltberg mehr auffinden; und dem entspricht auch die Erscheinung, dass während das Gebirgs-Gewölbe des Wolfsberges gegen N.O. in einen Rücken ausläuft, dasselbe in S.W. gegen das Thal des Michelsberger. Baches abfällt, ohne dass nur eine Spur gegen diese Weltgegend fortsetzender Basait-Formation autgefunden werden kounte.

Der Wolfsberg ist daher der südlichste der Basaltberge in Böhmen: er schliesst sie in diesem Lande gegen S. und S.W., und da in ein paar Stunden südwestlicher Entfernung vom Wolfsberg, nänlich bei Tanne, Ölhütte, St. Martin u. s. w. schon der Granit des Böhmer-Waldes hervortritt und auch da kein Basalt mehr sichtbar ist, während er sonst an der Grenze des Granits mit dem Schiefer oft gefunden und sein Hervortreten, wie es scheint, dadurch erleichtert wird: so möchte man schliessen, dass am Wolfsberg die Basalt-Masse erschöpft worden ist. Die unterirdischen Gasarten, welche den Basalt in die Höhe und das hindernde Thonschiefer-Terrain zum Gewölbe emportrieben, aufbrachen und den Basalt durch die Kluft herausdrängten, gelangten am Ende, mit dessen letztem Theile gemengt, selbst gen Tag und trieben diesen aufgeblasen in die Höhe, wonach sie durch die Blasenräumo entwichen. Daher kein Überfliessen der blasigen Masse, wie an anderu Orten, daher auch die Kennzeichen so sehr vermehrter Hitze in derselben, welche den Quarz frittete, die Hornblende-Krystalle abschmolz und die der Kluft angrenzenden Wände des vorausgegangenen dichten Basalts auflockerte, porös machte und so nit der blasigen Masse verband.

\section{Petrefaktenkunde.}

Nodor: über einige am Telegraphen-Berge bei Sémur (côted'or) g e fundene Säu ge thier-Knochen. (Iém. d. l'Acad. des scienc. de Dijon pour 1834; Part. pliys. .....> l'Instit. 1836, IV, 217.) Diese Knochen, in horizontalen Sandschichten unter Schutt an einem Berge zwischen Vulcin und Chevigny gefunden, bestehen theils noch ganz aus phosphors. Kalk, theils sind sie in Kalk-Karbonat übergegangen. Sie rühren von dem, jetzt aus Frankreich verschwundenen Auer (B os taurus ferus), dem Edelhirsch und dem gemeinen Pferde her. Von erstrem fand man einige Mahlzähne, cin Oberkiefer-Stück, ein Unterkiefer-Stïck, ein linkes Schulterblatt, cinen Atlàs, zwei Halswirbel, zwei Obertheile der Tibia, ein linkes Tibia-Stück und einige Fussknochen, im Ganzen von wenigstens drei Individuen. Der Hirsch hat ein Schädel - und ein Geweih-Stück, einige Backenzähne, einen Brustwirbel und eine Tibia geliefert. Von wenigstens zwei Individuen des Pferdes liat man 
einige Backenzähne, ein Unterkiefer-Stück, einige Stücke der Tibia, das Gelenk-Ende des Scbulterblattes und einige Fussknochen erhalten.

NoDor: hat früher schon eine Notiz über die Knochenhöhle von Contard bekannt gemacht, worauf er sich beruft und wovon das Institut (S. 217-218) einen Auszug liefert. -Sie liegt $1 \frac{1}{2}$ Stunden oberhalb Dijoni m Ouche. Thal, und steht in Oolith. Sie besitzt 3 Eingänge in halber Höhe an der Südseite des Berges; der eine hat bis $3 !^{\prime \prime}$ Breite, der zweite $18^{\prime \prime}$ und der dritte $~_{\prime \prime}{ }^{\prime}-1^{\prime}$; beide ersteren zeigen scharfo Kanten, die des letzten sind wie durch Wasser alggerundet. $36^{\prime}$ vom Eingang erhebt sich der Boden am meisten in Mitten einer weiten und hohen Halle, von deren Decke viel Material herabgestïrzt ist. Steigt man östlich fortschreitend wieder hinab, so gelangt man in eine zweite Halle von etwa $60^{\prime}$ Länge auf $25^{\circ}$ Breite und $30^{\prime}$ Höhe mit sehr unregelmässiger Gestalt und unebenen wellenförmigen und dnrchlöcherten Wänden, welche aber überall mit einer dickern StalaktitenKruste in manchfaltigen Formen überzogen sind; die unzugänglichsten Stellen ihrer Decke sind mit einer solchen Menge von Fledermäusen bevölkert, dass deren Exkremiente am Boden einen $10^{\prime}-12^{\prime}$ hohen und $14^{\prime}-15^{\prime}$ dicken Kegel bilden. Von dieser Halle aus weiterschreitend gelangt man in einen zylindrischen Gang von 15' Länge und $16^{\prime \prime}$ Durch. messer, welcher zu einer dritten noch unregelmässigern Halle mit von Spalten zerrissenen Wänden leitet, deren Boden von herabgefallenen Blöcken bedeckt ist; Stalaktiten überziehen die Wände meistens in Blumenkohl-Form und verkitten die Blöcke untereinander. Ein kurzer, schmaler, etwas ansteigender Durchgang leitet zu einer weiten langgezogenen Halle, deren unter $25^{\circ}-30^{\circ}$ geneigter Boden mit einer dicken Lage von braunem weichem Lehm bedeckt ist. Einige Seitengänge führen aus ihr noch zu andern Erweiterungen, und an ihrem hintersten Theile haben sich Fledermäuse, meistens Vespertilio ferrum e quinum, in solcher Menge zusammengedrängt, dass sie einen schwarzer Überzug und manchmal einen beweglich herabhängenden Vorhang bilden. Die allgemeine Form der Grotte, ihre abgerundeten und ron Tausend Löchern durchbohrten Wände, die vielen Geschiebe, die kleinen allenthalben hervordringenden Quellen, die Längsfurchen in den engen Durchgängen sind eben so viele Unstände, welche an der Entstehung durch die Wirkung des Wassers nicht zu zweifeln gestatten.

Folgende fossile Knochen sind in dieser Höhle gefunden worden: 1) der Unterkiefer einer $\mathrm{K}$ atze, etwas grösser, als der unsrer wilden; 2) ein Obertheil des Humerus eiues Raubthieres, etwas grösser, als beim Wolf, (Hyäne?); 3) Trümmer von Schädel und Ober - und UnterKinnladen von $\mathrm{Hunden}$; 4) zwei Femur-Hälften und eine Tibia, die von einem Wolfe seyn mögen; 5) viele andere Knochenreste, die von irgend welchen grossen $\mathrm{Paubthieren}$ herrühren dürften, 6) ein woblerbaltenes grosses Wadenbein, wobl von einem Pachydermen. 
Einige dieser Reste lagen nahe an der Oberfäche, nur von einer eisenschüssigen rothen Lehmschichte bedeckt; andere kamen tiefer unter einer Lehmschichte vor. Sie waren aber ganz versteinert. Alle waren zertrümmert, verstïmmelt, ohne Ordnung durcheinandergeworfen; die Brüche sind scharfkantig. Alle sind im naturhisiorischen Mluseum von Dijon niedergelegt worden.

Ev. Larter: über einige Knochen-Ablagerungen bei Auch im Gers -Dept. (Bull. géol. 183t, IV, 3+2-3tt). Fossile Knochen sind im Gers-Dept. sehr häufig; meist liegen sie in einem feinen Sande unter gröberem Fluss-Sande. Ausserdem hat der Verf. noch einige besondere Lagerstätten derselben entdeckt. Auf einer Höhe über dem Gers-Thale, 4 Stunden von Auch, sieht man auf einem Ackerlande von 5-6 Hektaren Grösse an der Oberfläche ausgepflügt durcheinanderliegen : Schiefermergel mit Dendriten, — rosenfarbene SüsswasserkalksteinStücke mit Knochen ohne Konchylien, - erdige Kalk-Stücke mit Knochen, Limneen, Planorben u. a. Süsswasser-Konchylien, - beim Anschlagen übelriechende Steine; - viele Hirschgeweih - und KnochenTrümmer mit Kalkspath durchdrungen. Unter dieser Schichte folgt eine von $0,020^{\mathrm{m}}-0,025^{\text {m }}$ Mächtigkeit nur aus zertrümmerten Konchylien-Schaalen und voll Knochen; - darunter eine sehr thonige Mergel-Lage, welche mit voriger noch 2 mal wechsellagern soll. Zahlreiche Nachgrabungen in diesen Schichten haben inzwischen nur wenig Wohlerhaltenes geliefert, worunter a) ein schneidiger Fleischzahı wohl von einer Katze, etwas kleiner als vom Tiger; b) ein Schädel von der Grösse wie bein Fuchs; c) einen Elephanten-Stosszalın; d) ein Backenzahn von Mastodou angustidens und e) einige andere von ?Palaeotherium magnum; - keine Pferde-Zähne; jedoch f) eine Menge von Hirsch-Geweihen und - Zälnnen von manchfaltiger Grösse; - dabei kein einziger Ochsen-Zahn. - - Dieser Stelle gegenüber, jenseits des Flusses in einem Kalkgebirge auf dem Boden der Gemeine Ornézan hat sich neuerlich in einem Wasserrisse eiu Backenzahn entweder von Mastodon giganteum oder von M. Cordillerarum gefunden mit fast quadratischer Krone, welche um $\frac{1}{3}$ breiter, als bei M. angustidens ist; die drei inneren Kronenkegel siud bereits abgenutzt, die drei ã usseren noch kaum angegriffen, fast spitz, all an ihrer Basis schief viereckig, so dass sie bei weiterer Abnutzung rautenförmige Flächen bilden müssen, alle ohne Nebenhöcker; an ihrer inneren Seite hat die Krone einen Halskragen (collet). - - Endlich besitzt die Bibliothek von Auch einen halben Backeuzahn aus dem Sande von Vic-Fezensac, welcher dem des Mast. giganteum noch besser entsprechen würde. Er ist ebenfalls $\frac{1}{3}$ breiter als bei M. angustidens, die Kegel sind spitzer, ihre Basen deutlicher viereckig, als bei vorigem, und mit Nebenkegeln verwachsen. 
A. Comele: über die chemisclue Natur fossiler Schuppen und deren Anwendung zum Unterscheiden der Thiere, welchen sie angehört haben (James. Edinb. n. phil. Journ. 1835, XIX, 300-306.) Натснвт scheint der erste gewesen zu seyn, welcher nachgewiesen, dass die Schuppen lebender Reptilien aus geronnenem Eyweisse bestehen, während die der Fische mehr die Natur der Knochen haben und vielen phosphorsauren Kalk enthalten (Plilos. Trans. $1800,373-374$ ). Chevreure hat in den Schuppen der Knochenfischo einen grossen Gehalt an phosphorsaurem und kohlensaurem Kalke entdeckt und der Verf. in der Schuppe eines Knorpelfisches, Acipenser sturio, 0,5383 Knochen-Erden gefunden. Die Brustschuppe eines $\mathbf{8}^{\prime}$ langen $\mathrm{Nil}$-Krokodils hat $\mathrm{ihm}$ dagegen kaum über 0,01 kohlens. und phosphors. Kalk gegeben; die gekielte Rückenschuppe eines andern 4' langen aber 0,03, weil diese Schuppen eine knöcherne Achse besitzen; bei arossen Krokodilen mögen diese Achse und jener Gehalt noch etwas stärker seyn. Gehen daher Fisch-Schuppen in den fossilen Zustand über, so verlieren sie fast die Hälfte ihrer Bestandtheile, welcho organischer Art ist, und diese wird gewöhnlich in gleichem Verhältnisso durch infiltrirte Kalk - oder Kiesel-Erde ersetzt. Reptilien-Schuppen erhalten sich selten fossil, können aber in diesen Falle gänzlich von diesen Infiltrationen ersetzt werden, da sie fast gar keine ursprünglicho Knochen-Erde euthalten. Löset man die Fisch-Schuppen von Burdiehouse in Säurèn auf, so bleibt ein Schuppen-Skelet als Rückstand, aus infiltrirter Kieselerde bestehend. Die genauern Ergebnisse einzeluer Analysen sind:

\section{II. III. IV.}

\section{nach Cinevreur, " nach Convell bei fossilen}

\section{Schuppen beimle- Megalieh. Schuppe in Schupper.} benden Le p is o- thys, v. Bur. Kohlen v. . Tilgate-Fo.

steus. diehouse. Edinburg. rest.

Phosphors. Kalkerde - . $0,462 \quad 0,5094 \quad 0,5575^{*}$ *) $0,6013^{*}$ )

Kohlens. Kalkerde • . . $0,100 \quad 0,1191 \quad 0,1586 \quad 0,2794$

Phosphors. Talkerde . . 0,022 ... Spur Spur

Koblens. Natron . . . $\left.\left.0,001 \quad \ldots 0,0,0106^{* *}\right) \quad 0,0143^{*}\right)$

Kieselige Materie . . . . . $0,0,3658 \quad 0,1617 \quad 0,0042$

Thonerde . . . . . . . . . . $0,0282 \quad 0,0282$

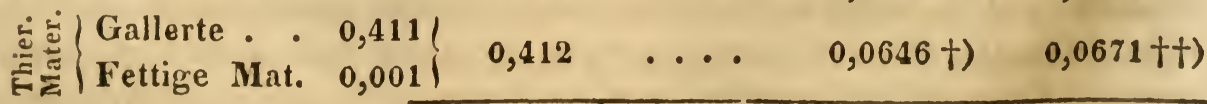

$0,997 \quad 0,9943 \quad 0,9812 \quad 1,0045$

- Bei II ist alle organische Materie im Betrage von 0.36 durch Kicselerde-Hydrat ersetzt worden. Ill scheint auch dem äusseren Ausehen nach von einem mit Megalichthys nur verwaudten Fische

*) Mit etwas Calcium-Fluorid.

*) Mit Kali, zum Theil als Sulphat.

t) Bitumen und Wasser.

††) Wasser, Kohle und Schwefel. 


\section{$-623$}

herzurïhren, ist matter, gelblich, nicht punktirt und, obschon $1 \frac{1}{2}$ "lang und 1" breit, doch nur ein Bruchstück einer grossen Schuppe. Nimmt man an, dass die Hälfte der ursprünglichen thierischen Materie durch Kieselund Kalk-Erde ersetzt worden sey, so wird ihre Zusammessetzung der von II sehr ähnlich ausfallen. - IV hatte $\frac{3^{\prime \prime}}{4}$ in Quadrat, war $\frac{1}{5} "$ bis 10" dick, ohne Rand-Fortsatz, fein punktirt, lag in Kalkgrit, war von MaNTBLL einem Saurier zugeschrieben, wogegen aber der starke Gehalt an phosphorsaurem Kalke streitet. Nimmt man an, dass hier etwas weriger als die Hälfte der ursprünglichen Thiermaterie durch kohlensauren Kalk und nur weuige Kieselerde ersetzt worden, die andere aber unersetzt geblieben sey, so stimnt ihre Zusammensetzung mit der der andern Schuppen ebenfalls überein, und erklärt sich der relative Überschuss an phosphorsaurem Kalke leicht.

Schuppen fossiler Reptilien hat der Verf. nicht untersuchen können. Sie sind selten. In Cuvier's grossem Werke werden derselben nur in 2 Fällen gedacht: beim Gavial von Caen (V, II, 139, pl. VII, fig. 14) und beim Krokodil von Argenton (V, II, 168).

Quenstedt: B eiträge zur Petrefaktenkunde (Wiegr. Arch. 1836; III , 245-250). Gorgonia bacillaris GoLdF. in den Mastrichter Kreideschichten (FAuj. St. Fond. pl. XXXVI, fig. 7; Pariins. II, pl. XII, fig. 4; - Escharites membranaceus und E. cingulatu s v. Schootr. Kollect. und Petrefk., exclus. synon., damn $\mathrm{R}$ babdocrinus Link test. Ehrens.) kann der Analogie nach nicht als unmittelbare Versteinerung, sondern muss als eine Ausfüllung, ein Kern angesehen werden. Von dieser Ansicht ausgehend, erkennt man darin eine Ausfüllung der röhrenartigen 12strahligen Zellen einer Asträa (oder Madrepora Ehr.), wofür der Verf. den Namen A. bacillaris vor. schlägt, mit dem Bemerken jedoch, dass den $\frac{1}{2} " 1$ - $3^{\prime \prime \prime}$ weiten Zellen gemäss, deren Weite aber an jedem Stocke koustant bleibe, darunter noch eine ganze Reihe von Arten begriffen seyn mïsse. Diesc Stäbchen oder Zellen-Ausfüllungen sind eben so, wie die Wände der Höhlen, worin sie liegen, und die Kalkschichten, welche oft noch einen Theil dieser Höhlen ausfüllen, auf eigenthünliche Weise punktirt, der innern und äussern Textur des Polypenstocks entsprechend. Das Ungleichmässige dieser Ausfüllung mag in der grüsseren oder geringeren Menge von organischer Materie seinen Grund haben, welche dem ursprünglichen Korallenstocke noch beigemengt war und die Versteinerung begünstigte. Auch sind in jenen Höhlen nicht selten Überreste [oder viclmehr Kerne] verschiedener Seegeschöpfe angehäuft, die vordem in den Korallenstock eingewachseu gewesen seyu mögen. Diese Anbäufungen zeigen oft feinkörnige und kugelförmige Absonderungen: sie erscheinen dann als Achilleum glomeratum Goudr. -

Sphaerulites Hoeninghausi Des.r. kommt hiermit vor.

Auricula incrassata Sow. pl. CLXIII, fig. 1-3 = Auricula 
ringens Park. III, pl. v, fig. 4 (exclus. synon. Lamarck.) $=\mathrm{C}$ as sis a vella n a Brongr. in Cuv. recherch. II, pl. VI, fig. $10,<\mathrm{Helicites}$ a mpulIaceus v. Schцотн. collect. ist eine Leitnuschel für den Grünsand: in Sussex, zu Blackduun, Ronen, Achen, an der Perte du Rhône, der MIontagne de Fis und nach Dubors an Ufer der Stripa bei Bubulince

- in Ost-Gallizien. Sie hat den stark übergeschlagenen rechten Mundrand von Cussis, aber an der Basis der Spindel statt des Kanals kaum eine Ausbuchtung; von den drei deutlichen Spindelfalten tritt die untere wie ein Zahı über den Grund hervor. Da sie offenbar Meeres-Bewohner gewesen, so wird sie besser zu Pedipes Ad, als zu Auricula (Landbewohner) gestellt werder.

Conus giganteus r. Mürst. vom K̈ressenberg, $=$ Conilites vetustus v. Sснцот. collect., ein bauchiger Kern von 4" Höhe und $3^{\prime \prime}$ Basis, rührt offenbar von einem $S$ trombus her, und zeigt mit dem wohlerhaltenen Str. B on allii-manche Ähnlichkeit; man erkenut daran noch Spuren der Ausbuchtung da, wo der verdickte Flügel-Rand oben an die Windung anschliesst, dann an dessen unterem Ende.

Morrex: über die fossilen Knochen derElephanten in Belgien und insbesondere über die einer neuen Art, E. macronyc h u s (l'Institut, 183t, II, 214-215). D'Onalius, Cauchy und Sauveur erstatteten der Brïsseler Akademie am 7. Juni Bericht über diese Abhandlung, rroraus wir Foigendes entnehmen. Die bisherigen Fundorte fossiler Elephanten-Reste in Bulgien sind die Gegenden un Ostende, Bruges, Antwerpen, Löwen, die Gemarkungen von Tamise, MPlsbroek, Smermaes und Niel (Antwerpen), Cheratte, Chênée und Cholier bei Lüttich. Die beiden geologischen Monographie'n über die Provinz Luxemburg und die von Cauchs über Namur erwähnen keincr E I e ph a nten-Reste in diesen Gegenden. In der Provinz Lüttich kommen sie nur zu Chênée, zu Cheratte und in einigen Hoblen, doch selten vor. Im Hainant werden sie häufiger. In den Provinzen von Brabant, Antwerpen und beiden Flandern sind sie gemein. Eben so in Holland, wie zu Buis le Duc; zu Alblasserwaad, wo 1759 ein Oberschenkelbein und Wirbel ausgeworfen worden; zu Loernen im Over-Betuwe in Geldern, wo ein Deichbruch 1809 cin Jschion u. s. w. ergab: zu Heukelum bei Gorkum u. s. w.

Die Höhe der Ardennen und der höhere Theil ihres Abhanges lie. fern dalier keine Elephanten-Reste. Erst weiter herab, 160 Meter über dem Meere, zu Chukier kommen einige vor, und nit $100 \mathrm{M}$. werden sie häufiger. Vorzüglich im untern Theile der geneigten Ebene zwischen den Küsten von West-Flandern und Seeiand haben sie sich zur Zeit angesammelt, wo dic Thiere in grossen Natur-Ereignissen untergiugen. Damals hatten die Ardennen schon ihre jetzige Höhe (550m Scehöle); sie haben sie zwischen der Zeit der Absetzung der Steiukohlen und des rothen Vogesen-Sandsteins erhalten. Die Fluthen, 
welche die Elephanten - Knochen von den hohen Ardesnen herabgeführt, müssen sich öfters und nach gròsséreu Zeiträumen wiederholt haben. Bemerkenswerth aber ist, dass die reichsten Elephanten - KnochenAblagerungen fast immer (zu Rumpelmonde, Boum, Niel, Tamise, Ostende) über dem Töpferthon des Londonclays vorkommen, als ob solclıer einst die Solıle der Wasserbecken.gebildet hätte, worin diese Knochen zusammengeflösst worden.

W. Buckuand's Notiz über vier fossile Chimaera-Kinnladen, nebst Agassiz' Beschreibung derselben und einer fünften A rt (Geol. Soc. 1835, 7. Nov. = Lond. a. Edinb. philos. Maguz. 1836, VIII, 4-7). Diese Reste waren lange verkaunt, weil die $\mathrm{Ch}$. mären Knorpelfische sind und das Skelett der einzigen lebenden Art bis jetzt vielleicht nur in Leyden zu sehen ist, nach dessen Ansicht B. zuerst die wahre Natur jener fossilen Theile erkannte. Sie gehören verschiedenen Arten an, grösser als die lebende. Die harten hornartigen Platten, welche die Kauflüchen der Kinnladen der lebenden Art bedecken und die Stelle der Zälıne vertreten, mangeln bei den fossilen Exemplaren. Bei der zweiten Art sind die Zwischenkieferbeine selbst so hart, wie Schmelz, und mögen weiter keinen Überzug gehabt haben; aber die Ober- und Unter-Kieferbeine derselben, so wie die UnterkieferBcine der dritten und vierten bieten, rauhe Anhefttlächen für einen solchen dar.

1) Ch. Townsendii B., die grüsste Art; Unterkieferbein sehr gross, kurz, verhältnissmässig viel dicker, die Symphysen - Grube zwischen beiden Ästen seichter, die Kavität des Zähne-Randes breiter, als bei den andern Arten; die äussere Oberfiäche ist konvex, längs gefurcht mit seichten Runzelu. - Zwischenkieferbein sehr gekrümnt. Von Townsend 1832 im Portlandstone zu Great Miltun bei Oxford gefunden.

2) Ch. Egertonii B., das Unterkieferbein kurz und flach; Schnautze abgestutzt und verhältnissmässig sehr gross; Kavität des Zähne-Randes breit; Symphysen-Grube tief; -- Zwischenkieferbein stark gekrümmt; sein Zähne-Rand rechtwinkelig abgestutzt; - das Oberkieferbein unregelmässig dreiseitig, sehr verlängert, gegen den zweitheiligen ZähnePand sich unmerklich zusainmenzichend. Von Egerton im Kimmeridge clay zu Shotuver Hill bei Oxford entdeckt.

3) Ch. Agassizii B. Unterkieferbein regelnässigér, als bei den andern Arten, fast viereckig, sein Zühne - Rand etwas geüffnet; Oberfläche der Symphyse flächer, als bei den andern. Wurde von Mantel. im Kalkmergel von Hamsey aufyefunden; Cuvier latte geglaubt, darin einen hintern Theil vom Unterkiefer eines Sauriers zu erkennen.

4) $\mathrm{Ch}$. Mantelli B. Unterkicfer schmäler und dünser; seine äussere Oberfläcbe glatt und eben; Schnautzentheil schr verläugert und 
spitz; Kavităt des Zühne-Randes breiter, als bei den übrigen. Von Maxtel in der Kreide von Lewes entdeckt.

5) Ch. Greenovii Ag. Unterkiefer viel kürzer, als bei den andern: nicht so lang, als hoch; Synphyse flach; Zähne-Rand abgestumpft und nur an hinteren Theile ausgehöhlt; äussere Fläche glatt, Mitte der inneren Fläche konkav: - Zwischenkieferbein flacher als bei Cl. Egertonii, in eine schmale Spitze ausgehend; Oberkieferbein kürzer als bei der letztgenannten Art. Fundort uubekannt. In der Sammlung Gberovgh's.

Pa. Grex Egerton: über eine, bis jetzt noch nicht beobachtete, Eigenthümlichkeit der Struktur im Genicke der Ichthyos a uren (Geol. Societ. $>$ Lond. a Edinb. philos. Mag. 1835, VII , 414-415). 1) Miss Ansing von Lyme Regis hat in einer dünnen Liasschichte in der Nähe ihres. Wohnortes ein riesenmässiges Skelett einer neuen Ichthyosaurus-Art gefunden, an dessen Hinterhaupts-Bein das Grundstück (basilar element) beständig getrennt erscheint, was nach $O$ wen auf eine äısserst träge Zirkulation in dieser Fanilie hindeutet. 2) Dann besitzt d̦as Genick bei den Ichthyosauren eine Bildung, die dessen Stärke auf Kosten seiner Beweglichkeit begünstiget. Nänlich Atlas und Axis sind mit seltenen Ausnahmen untrennbar mit einander verwachsen, besitzen auf ihren sonst flachen Gelenkflächen korrespondirende Erhöhungen und Vertiefungen, welche deren Drehung aneinander hindern; auch sind sie noch durch ein Beinchen miteinander verbunden, welches wieder bei einigen lebenden Reptilien, doch in anderer Form, vorkommt. Ihre untere Peripherie bildet nämlich zwei unter stumpfem Winkel zusammenstossende seitliche Fortsätze, deren untere Fläche eine dreiechige Vertiefung darstellt, in welche sich jenes Beinchen einfügt, so dass dessen 2 theilige obere Fläche halb auf dem ersten, halb auf dem zweiten Wirbel ruhet, während die untere scheibenförmige in der Mitte eine Buckel-förmige Erhöhung darstellt. - Auch von den nachfolgenden Wirbeln sind noch einige mit ganz ebeneu Gelenkflächen versehen, obne $Z_{\text {wischenwirbelraum. }}$

Croizat meldet die neuerliche Entdeckung vielerFossil-Reste zu Gergovia (Bullet. géol. 1835, $\mathrm{III}, 10 t-106$ ). An der Nordseite des Berges von Gerguria (Oppidum C̈̈sar's) und in $\frac{2}{3}$ seiner Höhe geht ein Thongebilde zu'Tage mit Planorben, Limneen, Melanien und Resten von Schilfen, Gräscrn, Früchten, Krokodilen und Vügeln, worunter zumal lange und spitze Schnäbel, wie von Reihern bemerklich sind. Im S. von Gergovia oberhalb dem Dorfe Merdogne liegt auf Sandstein cin blättriger Lebm voll Pflanzen-Recten, $50^{\prime}$ müchtig uud von tertiärem 
Sand und darauf von Basalt bedeckt; er ist geologisch dem LignitenLehn im Becken von Ménat analog, aber reicher an Abdrücken von Blättern, Früchten und Blüthen aus den Familien der Salicornieen, Ulmaceen, Amentaceen, Myrtaceen, Laurineen, Rosaceen, Plautagineen, Leguminosen, Euphorbiaceen, Caryophylleen, Fahren und Gräser, - in Gesellschaft von Insekten, von Fischen, welche meistens zu Cyprinus gehören, und von Vögeln aus den Familien der Grallen und Palmipeden. Im Osten des Berges, zwischen Gergovia und Bonneval lagen in einem $40^{\prime}$ mächtigen Schuttland Knochen von Carnívoren, Pachydermen und $R$ uminanten, worunter ein $\mathrm{Damhirsch}$ ist mit viel stärkerem Geweihe als die gemeine Art und von abweichender Form. In diesem Schuttlande ist auch eine menschliche Tibia mit dem Wadenbein vorgekommen, welche einem zwar nur $4 \frac{1^{\prime}}{4}$ grossen, aber sehr muskulösen Menschen angehört haben. Die fossilen Pflanzen von Gergovia haben ihre lebenden Analogen theils am Mittelmeere, theils in der Gegend, theils endlich noch weiter nach Norden.

Graf Razovmowsir: über Moos-Ach a te (Bull. géol. 1835, FI, 165-168, Tf. I, Fg. 10). Der Verf. hält es a priori nicht für eine Unmöglichkeit, dass die weiche Kieselmasse vegetabilische Theile ergreifen und beim Erhärten bewahren konnte, und da er selbst einen Moos-Achat mit einem schönen Pflanzen-artigen Einschlusse besitzt, so zweifelt er nicht an der wirklichen Existenz. Derselbe ist ein kugeliger Chalzedon fast 5 " lang und $3 \frac{1}{2}$ " breit, innerlich von Pflanzen - Theilen, welche in allen Richtungen durcheinanderliegen und noch eine grüne Farbe besitzen, erfüllt. Darunter befindet sich dann auch ein vollständigeres Exemplar, 1 $1 \frac{1}{2}$ "lang, mit unterscheidbarer Wurzel, über welcher in einiger Entfermung der Stengel jederseits zwei schwächere Äste abgibt, die sich wieder in eben so dünne wechselständige Zweige unterabtheilen, und Spuren von Gliederung besitzen, wie die Konferven. Wo diese Äste an die polirte Oberfäche gelangen, werden sie braun, wenn sie nicht etwa ganz leere Röhrchen binterlassen, und geben, au eine brennende Kerze gebracht, zwar weder Flamme noch Geruch, erscheinen aber nachher in schwarzen, glänzenden, einer Holzkohle ganz ähnlichen Theilchen. Der Gliederung wegen, welche jedoch auch nur scheinbar und eine Folge mechanischer Verschiebung bei der Versteinerung seyu könnte, möchte sie der Verf. den Konferven vergleichen; den Habitus hat sie von gewissen Fucoiden, insbesondere in hohem Grade von Fucoides intricatus Brgn. und Münsteria flagellaris Str.

v. Sternberg über cinige Fossil-Reste des PragerMuseums (Verhandl. derGesellsch. d. vaterl. Museums in Bölumen, April $1835-36$, S. 23-26, Taf. I. und II) Professor 


\section{$-628$}

Corda hat auf einem fossilen Blatte von Flabellaria borassifolia v. Sterno. maschenförmig verlaufende, missfarbige und der Substanz nach degenerirte und verdichtete Streifen und, längs deren Mitte, feine Gänge als lichtere Streifen entdeckt, in welchen sich Insekten - Larven, wie heutzutage die der Tineen, aufgehalten haben müssen (Tf. I. Fg. 3, 4): ein Anzeigen vom Vorhandenseyu von Thieren, deren kürperliche Überreste selbst man in der Steinkohlen-Formation noch nicht nachzuweisen vernochte, wie das neuerlich mit den Thierfährten der Fall ist. Diese Palmenreste, mit ihrer zarten Oberhaut so deutlich erhalten, sind gewiss nicht durch tropische Meerresströmungen einst nach Böhmen geführt worden. (S. 23 und 34-35).

Dass auch die aufrecht im Gebirg stehenden Baumstämme an Ort und Stelle gewachsen seyen, gelit nicht allein aus ihrer Stellung und ihrem Erhaltenseyn, sondern auch aus dem Umstand hervor, dass sie oft an der Stelle der Rinde sowohl als in ihren Inneren - sie waren daher allmählich hohl geworden - cinen Schieferthon mit vielen zarten Pflanzenresten durchmengt wahrnehmen lassen. Das Museum besitzt solche Stäume von Cycadites Cordai mit 10" - 12" Durchmesser, in welchen andere bis $1^{\prime \prime}$ dicke Theile von Monokotyledonen (Cyc. involutus, Poacites tenuinervis, Fahren-Reste, Karpolithen) eingeschlossen liegen. (Taf. I, Fg. 1, 2, ?S. 24 und 35).

Ferner hat das Museum eine merkwürdige $\mathrm{CaI}$ amopora aus dem körnigen Übergangskalk von Beraun erhalten, die sich durch ihre von Eisenoxyd verschiedenartig gefärbten, regelmässig konzentrischen Lagen, durch die Dornen-artigen in die Zellen hineinstehenden VerbindungsPoren u. a. Merkmale von den übrigen bekanuten Arten unterscheidet (Taf. II, Fg. 1, 5), wesshalb Sterneerg den Namen C. a c a utho po ra dafür verschlägt (S. 26). Corda gibt dazu eine ausführlichere Beschreibung und Diagnose: C. pulvinata, late adnata, zonis concentricis latis ornata; tubulis hexagonis, intus poris lateralibus subuliformibus convergentibus, adscendentibus, acutis; diaphragmatibus convexiusculis 't inter se afproximatis. Die Röhren sind regelmässiger und schärfer sechskantig, aber kleiner, als bei C. polymorpha und C. favosa. Zwischen den einzelnen Röhren ist noch immer ein feimer mit Kalk erfültter Zwischenraum. Hölse $130^{\prime \prime \prime}$, Durchmesser $70^{\prime \prime \prime}$ Paris. (S. 37-38).

Pu. Grex Egentox: über die Knochenlühlen am Harz und in Franken, vorgeles. b. d. Lond. geolog. Soc. 1834, 21. Juni (Lond. a. Edinb. philıs. Magra. 1834; V, 296-2.97). Der Verfasser besuchte mit Lord Cone mehrere der erwälnten Höhlen, und theilt nun ein voll. ständiges Verzeichuiss der viclen dort gesammelten Knochen mit. Die Muggendorfer Höhlen werden jetzt so bewarlit, dass es fast uumöglich ist, etwas von da zu erbalten. Was er 1829 über die Zerstörung des 
Kuhlochs und der Rabensteiner Höhle gemeldnt, wird bestätigt; doch ist sie zu einer Zeit erfolgt, wo der Baron von Rabenstein-von Hause abwesend war. Ausserdem hat er das Zahnloch, die Scharzfelder und die Baumanns-Höhle besehen. Jede der von ihm besuchtén Höblen hat ihm auch neue Gebeine von Ferkeln, Vögeln, Hunden, Füchsen und Wiederkäuern geliefert; die Scharzfelder-, Baumanns- und Gailenreuther-Höhle und das Zahnloch haben auch Trümmer roher Töpferwaare gegeben, die Rabensteiner aber alte Münzen und eisernen Hausrath von sehr alter und unvollendeter Form. Die Knochen der Gailenreuther Höble zeigten keine andern Spuren von Bewegung, als solche schwache, welche sie als Spielzeug junger Bären erhalten haben mögen. Dieselbe Höhle hat ihm 2 Carpus-, 1 Metacarpus-, 1 Metatarsus - Bein und einen Theil des Brustbeins von Bäre n geliefert, welche alle zur Ergänzung von Cuvier's Beschreibung seines Skelettes dienen können; ferner den breiten Schneidezahn der rechten Seite von neunzig verschieden Individuen jedes Alters; keiner der vielen Oberarmknochen von diesen verschiedenen Lokalitäten zeigte die Durchbohrung für die Cubital - Arterie am Condylus; unter 36 eigenen und einer noch grössern Menge von Schädeln in. CoLE's Sammlung ist keiner, woran die mindeste Spur des kleinen vordern Lückenzahnes sichtbar wäre.

Die Gailenreuther Höhle hat Knochen von Felis, Canis, V ulpes, Hya ena und Gulo; das Kuhloch von Hyae na, Canis, Vulpes und Rhinoceros; die Scharzfelder Höhle von Felis und $\mathrm{C}$ a n is und die Baumanns-Höhle von $\mathrm{F}$ elis geliefert.

Voutz: über die Beziehungen der Belemniten mit den übrigen innern Schaalen von Cephalopdoden (l'Institut 1836, Nr. 157). Vergleicht man die eben genannten Theile (derjenigen Arten, welche in des Vfs. grosser Abhandlung über Belemniten noch nicht berührt worden) mit den Belemniten, so kann man sie in folgender Art charakterisiren :

Loligo sagit tat a hat keine Scheide, wohl aber einen Alveoliten, welcher hornartig ist mit ausserordentlich verlängerter RückenGegend, schwach verlïngerten Hyperbolar-Gegenden, sehr verkümmerter Bauchgegend und ebenfalls nur schwach angedeutetem Alveolen - Kegel chne Kammern.

Loligo vulgaris hat auch keine Scheide und nur einen unvollständigen Alveoliten, welcher hornartig, mit ausserordentlich verlängerter Rückell-Gregend, stark entwickelten Hyperbolar-Gegenden versehen, aber ohne Bauch-Gegend, Alveolen-Kegel und Kammern ist.

Teudops is Bolleusis Voltz (三 Ziet. Tf. XXXVII, Fg. 1) hat keine Scheide, und einen hornartigen, nur sehr unvollständigen Alveoliten, dessen Rückengegend ausserordentlich schmal, aber sehr verlängert, dessen Hypèrbolar-Gegenden zumal in ihren unteren oder 


\section{$-630$}

hinteren Theile sehr verläıgert sind und dessen Bauchgegend und Kam mern gänzlich fehleu.

On ychote uthis angusta Mürst. ist nur eine hornartige Leiste, völlig analog der Dorsal-Gegend von Lolig o sagit a t us und den Belemniten, ohne alle Hyperbolar-Gegend, im Gegensatze von Te udopsis. Auch sind die Vorderränder noch in Forn einer abgestutzten Spitze, die den Schwibbogen-Linien der Belemniten entspricht; die Seitenränder sind starke Rippen, wie bei L. sag it tat a.

$0 \mathrm{ctopus}$ hat noch schwache Überreste einer Schaale, welche Ony chote uthis angusta analog ist, nämlich: nur zwei lange zylindrische hornartige Stücke im Rückensack eingeschlossen, in derselben Lage, wie die Seitentheile der Rücken-Gegend bei Loligo, mithin den Asymtoten entsprechend, ohne Hyperbolar - und Bauch - Gegend und ohne Scheide und Kegel.

Bei deu folgenden ist der Alveolit mit Kammern und Siphon stets ganz erhalten.

Bei $0 \mathrm{rth}$ ocera existirt noch allein der hintere Theil der Scheide zunächst der Spitze, der aber selten erhalten und im strasburger Mu. seum nur an einem Exemplar von Lascastel in den Pyrenäen zu beobachten ist, und zwar bloss als eine dichte oder krystallinische Kalkmasse ohne Faser - und Tuten-Gefïge. Die Alveole ist wie bei den Belemniten, aber viel mehr verlängert; der Siphon ist bald zentral, bald am Bauchrande, bald nur einfach exzentrisch, jedoch nie dorsal, und ist im Übrigen wie bei Spirula und Nautilus beschaffen, jedoch im Gegensatze des letztern ununterbrochen und ohne Verbindung mit der Höhle der Kammern, so dass das Thier kein Wasser in diese treiben und aus ihnen ziehen konnte. Die Hyperbolar-Gegend existirt hier nicht; jedoch unterscheidet man auch nicht bestimnt, ob der Alveolit durch die Bauch - oder dic Rücken - Gegend gebildet ist. Da man aber oft auf der dem Siphon entgegengesetzten Seite eine nach vorn gewölbte Queerstreifung wahruimmt, so scheint die Rücken-Gegend die Bildung zu veranlasseu.

\section{Verschiedenes.}

Browne: über einen sonderbareñ Eindruck in Marmor (S1,L1. Americ. Journ. of Scienc. 1831, Jamuar, XIX, 361). Zwölt Meil. N.W. von Philadelphia ist ein, Herrn Henderson gehöriger Marmorbruch in Urkalk, welcher von Philadelplice aus nach Gneiss, Glimmerschiefer, Horublende, Talkschiefer, Urthonschiefer und etwas Eurit folgt. Im November 1829 wurde ein über 30 Kubikfuss grosser Marmorblock aus $60^{\prime}-70^{\prime}$ Tiefe gewonnen und zur Marmor-Sägenühle gebracht. Als man hier eine $3^{\prime}$ breite und $6^{\prime}$ lange Platte davon abgesägt 
hatte, nahm man auf der hiedurch entstandenén Fläche eine $11^{\prime \prime}$ lange und $\frac{5}{8}$ 'hohe vertiefte Stelle wahr, worin sich zwei erhabene Schiffern wie in nebenstehender Figur zeigten. Sogleich wurden einige der angesehensten Gentlemen von Norristown (wo die Mühle war) herbeigerufen, um von dieser sonderbaren Erscheinung Kenntniss zu nehmen und zu bezeugen, dass jene Schiffern nicht erst

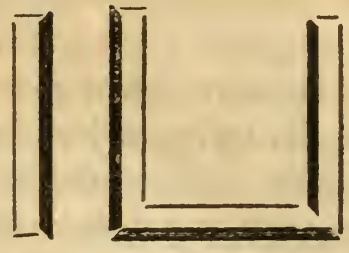
nach den Schnitte ausgehauen worden seyen. [Diese Erscheinung erinnert an den Fuss-Eindruck in Übergangskalk.]

Marcel de Sbrres: Notiz über die artesischen Bruníen im Süden von Frankreich (Mémoir. de la Soc. roy. de Lille pour 1829 - 1830).

Marcel de Serres: Beobachtungen über die artesischen Brunnen, welche neuerlich im Becken von Roussillon oder den Ost-Pyrenäen gebohrt werden ( $>$ Bulletin gévl. 1834, IV, 213-217). In der Ebene von Roussillon liegen unter mehr oder minder beträchtlichen Alluvionen tertiäre Gesteine, unter welche sich die Übergangs - Schichten der benachbarten Gebirge hinabsenken. Viele Quellen kommen darin natürlich zu Tage. Man erhielt im Jahre 1833 in 3 verschiedenen Bohrlöchern nur lauter sehr reines vortreffliches Wasser. Das Wasser stieg über das Bohrloch von

Bages, I, aus $25^{\mathrm{m} 98}$ Tiefe mit $15^{\circ} 80$. C.

- II, - 47"10 - $\quad 17^{\circ} 10$, bis ungefähr $50^{\prime}$.

Rivesaltes, III, $-52^{\mathrm{m} 30}-\quad-17^{\circ} 10,-15^{\prime}$.

Das zwcite Bohrloch ist $4^{\prime \prime}$ weit, lieferte täglich $2880^{\circ} \mathrm{cm}$. und dringt einige Fuss tief in den Übergangs-Thonschiefer ein. Im dritten stürzte das Bohrgestänge bei der angegebenen Tiefe plötzlich um $6^{\prime}-7^{\prime}$ hinab und das Wasser quoll hervor; es gibt ungefähr $1300 \mathrm{Cm}$. täglich, und verursachte nur 380 Francs Kosten. - Der Verf. leitet das Wasser aus dem obern Theile des Bodens von Infiltrationen ab; nimmt aber an, dass jenes in grösserer Tiefe das Wasser der "couches aquiféres" seye, welche in der Reihe der Felsschichten eine genauere Bestimmung verdienten : ihr Wasser war: „der Überrest jener Wasser-Masse, welche die Sedimentär-Gebirge gelöst gehalten hatte" ${ }^{\text {, }}$ und ist daher unversicgbar [!].

Nach Héricart de There (Bull. géol. 1834, IV, 217) hat auch Tours, dessen bisherige Quellen im Sommer oft ganz versiegten, neuerlich vier artesische Brunnen erhalten, wovon der erste 30,000 , der zweite 75,000 , der dritte 173,000 , der vierte $1,500,000$ Litres Wasser in 24 Stunden gibt, so dass 149 Litres auf jeden Einwohner kommen. Im 
letzten Bohrloch steigt das Wasser bis $27_{\mathrm{m}}$ über den Spiegel der Loire und $4-5^{\text {m }}$ über dem Boden.

Lavin: Analyse des Wassers von St. Génis, um dessen Iod-Gehalt zu bestimmen (Memor. Accad. Torin. 1833, XXXVI, 19-32). 'Diese Quelle, seit lange als Heilquelle benutzt, kömmt am Fusse einer Anhöhe, Castagneto genannt, bei Chivasso 4 Stunden öst. lich von Turin zum Vorschein, und bat noch eine andere, quantitativ und qualitativ schwächere neben sich. Ihre Temperatur (im offenen Becken) war $5^{0}$ R., während die Atmosphäre $+9^{\circ}$ zeigte. Mit ihr treten fast periodisch Blasen vou Luft aus dem Felsen hervor, welcho aus hydrosulphursaurem, kohlensaurem und Stick-Gas (ohne SauerstoffGas) besteht und bei ruhigem Stehen des Wassers in ersten Behältnisse die Absetzung eines Häutchens über demselben von sehr weissem Schwefel-Hydrat, am Boden eines zweiten yrösseren Beckens aber und auf dem Wege dahin die eines Schlammes veranlasst, aus welchem zuweilen eine Menge von Hydrosulphur-Gas, wahrscheinlich mit Kohlenwasserstoff-Gas aufsteigt. Übrigens ist das Wasser helle, etwas salzig schmeckend und schr stark nach Schwefelleber riechend. Das in einer geschlossenen Flasche zu medizinischem Gebrauche aufbewahrt gewesene Wasser gab durch Kochen Gas von sich, welches anf 1 Litre Wasser 42 kubische Zentimeter bei $7_{2^{2}}{ }^{\circ} \mathrm{R}$. und unter einem BarometerDruck von $0 \mathrm{~m}, 743$ betrug und aus 19,5 kohlensaurem, 5,0 Schwefelwasserstoff- und 17,5 Stick-Gas zusammengesetzt war. Ein Decalitre Wasser gab durch Ablunsten und Trocknen bei $80^{\circ}$ R. 3,0200 Decagrammes wasserfreies Salz, welches zusammengesetzt ist aus :

\begin{tabular}{|c|c|c|c|c|c|}
\hline Kieselerde & - . & & & & 0,0084 \\
\hline Eisenoxyd & - . & & & & 0,0022 \\
\hline Alaunerde & - $\cdot$ & . & & & 0,0005 \\
\hline Kohiensauren & m Ka & lk & & & 0,0177 \\
\hline Lod-Natroniu & m . & - & & & 0,0045 \\
\hline Schwefels. I & Natro & & & & 0,0050 \\
\hline Unterkohlens & s. $\mathrm{Na}$ & tro & & & 0,0905 \\
\hline Chlor-Natron & aium & & & & 0,6965 \\
\hline Wasser • & & & & & 0,1550 \\
\hline auf Verlust & - & 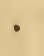 & & & 0,0197 \\
\hline
\end{tabular}

J. KeNrick: über die Griechischen Überlieferungen von der Erdfluth (Lond. a. Edinb. philos. Magaz. 183t, IV, 414-420, und $\boldsymbol{V}, 25-33)$. Bei den ältern Griechischen Schriftstellern findet man nur über die Deukalion'sche und OGxG'sche Fluth ausdruckliche Erwähnung. Von Deuralion ist bei Homer uie die Rede. - Hesiodus crwähnt seiner kaum (I, 136); Sтнаво (VII, 466), Dionxsivs von Halicarnassus 
der Scholiast des Apollonius Rhodivs (IV, 266), Herodotus (I, 56), Constantin Porphyrogenitus und Tuucrdides gedenken seiner nur als eincs Patriarchen oder Fürsten, der mit seinen Nachkommen in Thessalien (oder in Epirus und Macedonien etc.) herrschte, ohne alle Beziehung zu einer Fluth. - Nach Aporrodorus rettete sich Deukalion (der Sohn des Prometheus, welcher die ersten Menschen aus Erde und Wasser gebildet) und Pуrris in eine Arche, wälirend Jupiter Regen vom Hinımel sandte, um das bereits verdorbene Geschlecht zu zerstören, bis auf Wenige, die nach den Hochgebirgen entkamen. Die Arche landete später am Parnass, und das Menschen-Geschlecht wurde theils durch Deukalrov's Kinder. (Helden), theils aus den von ihm und Pyrrha zurückgeworfenen Steinen wieder hergestellt. - Von späteren Dichtern bis zum 5ten Jahrhundert vor Christus gedenken nur noch Hellanicus (IX, 60, ed. В̈̈скн, wornach die Arche am Othrys in Thessalien landete) und Pindar (Ode an Epilarnostus) seiner in dieser Beziehung. Plato (im Trmaeus III, 21) führt ihn in gleicher Absicht an, gedenkt aber auch der Äyyptischen Sage (welche auch die Hindoos haben), dass durch Wasser und Feuer das Menschen-Geschlecht schon öfters bis auf Wenige vertilgt worden, welche Ansicht er auch anderwärts ("Gesetze" III, zu Anfang) anführt. Cuvier hat daher Unrecht zu behaupten (Discours p. 86, Note), dass Plato die Deukalion'sche Fluth als eine einzige und allgemeine angesehén, da er der OGxG'schen nicht erwähne; obschon Aristoteles es zuerst ausdrücklich sagt (Meteorol. I, 14), dass dieselbe nur eine der Regen-Fluthen gewesen, wie sie sich öfters bald da bald dort ereignen, welche dann diessmal Epiras betroffen. - Spätere Schriftsteller, wie Plutarci, Lucian u. s. w. mischen dieser Überlieferung immer mehr Umstände bei, welche sie aus den Sagen Asiatischer Völker entnommen, welche mehr der christlichen Sündfluth entsprechen.

Der Name $0_{G \mathbf{G E S}}$, eines Königs von Attica, kommt in kcinem uns hinterbliebenen Schriftsteller bis zur Zeit des Alexxander vor, und das Meiste von ihm erfahren wir aus christlichen Autoren, wie z. B. Eusebius (Pruep. evang. $X, p .10,119$ et 281 ed. Bonn.) nach Acusilaus. Dem Verf. aber scheint Ogyges und dessen Fluth vielmehr Böotien anzugehören.

Für die Sage von der Deukalios'schen Fluth sind drei Erklärungen müglich. Entweder die Ahnen der Hellenen brachten eine Nachricht von der NoAH'schen Fluth aus Asien mit, und versetzten sie in ihr neues Vaterland Thessalien. Die Nonk'sche Fluth aber soll 2300 oder gar 35,000 (Septuagint.) J. vor Cннгsтus Statt gefunden haben, während man die Sage von der Deukalion'schen erst 5 Jahrhunderte v. Cн. findet; nun aber ist es nicht wahrscheinlich, dass die Griechen diese Sage so lange bewahrt haben sollten, ohne dass ihrer in Schriften erwähnt wurde. Oder es hat wirklich eine solche Fluth in Thessulien Statt gefunden; - wie aber könnte die Arche anf den Parnass gehoben worden seyn, ohne dass ganz Griecheulaml u. s. w. hiedurch überschwemmt wurde, wovon doch (diess musste sich wenigstens 15 Jahrhunderte v. 
Cr. ereignen) sonst keine Nachricht geblieben ist. Endlich diese Fluth könnte eine blosse Überschwemmung durch das Austreten einiger Flüsse gewesen seyn: und dieses ist das wahrscheinlichste. Denn schon die

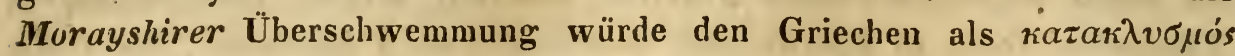
gegolten haben, und zu einer solchen Überschwemmung dürfte das vom Hochgebirge umgebene Thessalien, woraus alle Wasser nur durch Tempe abfliessen können, zur Zeit ehe dieses geöffnet war (denn nach HERoрот VII, 129 war ganz Thessalien vordem ein See), sehr geeignet gewesen seyn, und alle die übertriebenen Nachrichten mögen erst während der allmählichen Überlieferung der Sage hinzu gekommen seyn. Eben so verhält es sich mit der OGyG'schen Fluth in Böotien, dessen Hauptfluss Kephisus sich in den See Kopais ergiesst, der nur einen unterirdischen Abzug in den Eurypus bei Larymna hat. Dieser Abfluss verstopfte sich öfters, und einmal liess ihn Auexander durch Krates von Chalcis wieder öffnen, wodurch ein ganzer Landstrich trocken wurde und Theile überschwemmter Städte wieder hervorkamen.

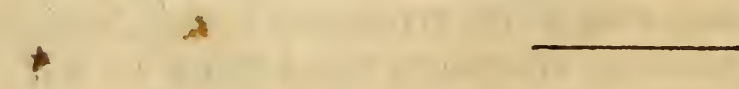

Yates: Magnetismus zu Magnesia (Cambridge Phil. Societ. $>$ Berghaus Annal. 1834 Januar, IX, 351-352). Als die Gesellschaft den Schlossberg von Magnesia, in der Kette des Sipylus, bestieg, hemerkte sie eine östliche Abweichung des Kompasses, welche mit jedem Schritte, bis zu 56 ${ }^{\circ}$, zunahm, vor der Erreichung des Gipfels aber wieder zurückzugehen anfing. Man folgte auf dem Rückwege der Richtung, wohin die Nadel gezogen wurde, und sah dereu Abweichung endlich wieder abnelımen, woraus man folgerte, dass man den anziehenden Gegenstand schon überschritten hatte. Man gewahrte nun hinter sich eine Masse dunkler Felsen. Setzte man den Konpass auf diese Felsen, oder an den Fuss auf dem Boden von ihmen entfernt, so zitterte augenblicklich die Nadel heftig und senkte sich mit der Spitze steil nach unten, ohne - an jener letzteren Stelle - nach dem Felsen hinzuweisen. Der Anziehungs-Punkt muss daher unter dem Boden seyn. (In der That konnte in einem mit nach Hause genommenen Stücke jener Felsen nicht die geringste magnetische Kraft entdeckt werden). Nit jedem weitern Schritte auf dem Heimwege kehrte die Nadel wieder mehr zu ihrer normalen Richtung zurück. - Ein Schiffs-Kompass später nach jener Stelle gebracht, zeigte erst nach verschiedenen Steinen hin, verlor aber bald darauf seine Kraft gänzlich. Die Gesteine der ganzen Gegend enthalten viel Eisen auf allen Oxydations-Stufen. Nach Cirshull (1747) war die Gegend früher wegen des häufigen Vorkommens des Maguetsteins berühmt, obschon derselbe nach Puinius weniger Auziehungs - Kraft als in andern Gegenden besitzen sollte. Von dieser Stadt also hat, wie Lucretrus bemerkt, der Stein wohl seinen Namen erhalten. 


\title{
Monographie des Chabasits, von
}

\author{
Herrn Dr. Fr. TamnaU
}

in Berlin.

Ein älterer Französischer Naturforscher, Bose D’Antıc, war der erste, der den Chabasit als eigenthümliche Spezies des Mineralreichs unterschied und ihm den Namen Chabasie beilegte. Er kannte nur die Krystalle von Oberstein und wählte den Namen auf eine etwas willkürliche Weise nach dem Griechischen Wort $\chi^{\alpha \beta \alpha \sigma \iota \nu v, ~-~ n a c h ~ A n d e r n ~} \chi^{\alpha \lambda \alpha \sigma \iota\llcorner}$, - das in den Gedichten des Orpheus (Lithic. 752) vorkommt und den Namen irgend eines Steines, gewiss aber nicht den unseres heutigen Chabasits bedeutet. Der Name Chabasie, zuerst von den Französischen Mineralogen angenommen, ging schon zu Werner's Zeiten in die Deutsche Nomenklatur über, erlitt jedoch manchfache Veränderungen und Verstümmelungen, und aus Chabasie wurde nach und nach Chabasin, Chabasit, Schabasit, Schabazit. - Ich schreibo Chabasit, weil mir diese Schreibart die jetzt in Deutschland am meisten angenommene zu seyn scheint.

Synon: Würfelzeolith, Kubizit der ältern Deutschen Mineralogen.

Kuboizit. Weiss, Glocker.

Schabasit, Schabazit .Werner, Hofmann.

Chabasin. Karsten, Hausmani, Hauy. 
Synon: Chabasie. v. Leonhard, Hauy, Phillips, Nejker etc. Rhomboedrischer Kuphon-Spath. Mонs:

Trimetrischer Chabasit. Breithaupt.

Rhomboidal-Zeolite von Chabasit. JAMESON.

Rhombohedral Komphone Spar. - Mohs, Haidinger.

Zeolite eubique, - Zeolite en cubes der älteren Franzosen.

Cabasia - der Italiener.

Ausser den verschiedenen Hand- und Lehrbüchern, von denen ich vor allen andern die bekannten Werke von Монs, v. Legnhard und Philuips benutzte, und die ich hier wohl nicht weiter aufzuführen brauche, sind früher oder später verschiedene Aufsätze uad Abhandlungen über den Chabasit erschienen.

Die bemerkenswerthesten darunter wïrden folgende seyn (vgl. v. Leonhard's Handbuch S. 19S, 199):

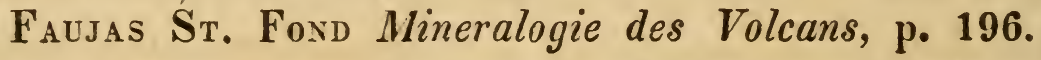

$"$ " Volcans du Vivarais a. m. 0.

Delamétherie . . Théorie de la terre I, 374.

Bosc D'Antic .. Junrnal d'histoire naturelle II, 181.

Bernhardi . . . Schweigger's Journal VI, 343.

Weiss ...... Magazin der Berliner Gesellschaft naturforschender Freunde, VII, 181.

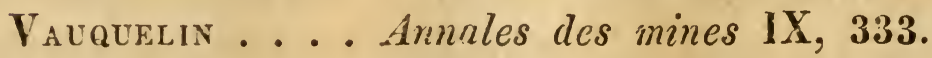

Berzerius .... Afhandlingar $i$ Fysik VI, 193.

$" \quad \ldots$ Zeitschrift für Mineralogie II, 424.

Du Menil . . . Chemische Forschungen, 99.

Arfuedson . . . . Berzelius Ar'sberettelser 1S23, S. 155.

Hofmann . . . Pogeendorff's Annalen XXV, 495.

Zippe . . . . Beiträge zur Kenntniss des Böhmischen Mineralreichs, in Böhmischen Museum.

Conner . . . . . Lond. and. Eddinb. philos. Magaz.

Die Krystallfor'm des Chabasits gehört, wie zur Genïge bekannt ist, demjenigen Krystallsystem an, welches Moнs das rhomboedrische, Weiss das drei- und -dreigliedrige nennt. 


\section{$-633-63 y$}

Die Grundgestalt ist ein Rhomboeder Fig. 1, dessen Winkel nach den verschiedenen Messungen verschieden angegeben werden. Die Axenkante $\alpha$ ist $=$

$93^{\circ} 4 \mathrm{~S}^{\prime}$ nach $\mathrm{H}_{\mathrm{AUY}}$, dem v. Leonhard und Mohs in ihren früheren Werken folgten. Da HAUY's Messungen mit dem Anlege-Goniometer gemacht sind, so dürften sie unfehlbar weniger Genauigkeit besitzen, als die folgenden.

$94^{\circ}$ 40 nach Phillips und Haldinger, deren Angaben Beudant, Necker, Glocker u. s. w. angenommen haben.

$94^{0} 24^{\prime} 40^{\prime}$

$94^{0}$ 24' $^{\prime}$ der von Oberstein nach Breithaurt.

$\mathbf{9 5}^{\circ}$ (annähernd) nach $\mathrm{N}_{\text {aumann. }}$

Der Chabasit erscheint höchst selten oder nie in Krystallen, deren Flächen glatt genug wären, um eine Messung mit dem Reflexions-Gonioneter mit vollkommener Genanigkeit zu gestatten. Ich habe die besten Krystalle, deren ich habhaft werden konnte, mit un so grösserer Sorgfalt gemessen, da die verschiedene chemische Zusammensetzung dieses Fossils es nicht unwahrscheinlich macht, dass auch in den Abmessungen Verschiedenheiten vorkommen dürften. Ich muss indessen gestehen, dass diese mehrfach wiederholten Messungen an ein und denselben Krystall so verschieden ausfielen, dass ich kaum wagen darf, sie auch nur für Annäherungen auszugeben. Nach einem Durchschnitt, von drei verschiedenen Messungen berechnet, fand ich den oben bemerkten Winkel:

$94^{0} 36^{\prime}$ an einem Krystall von Kilmulcolm.

\begin{tabular}{|c|c|c|}
\hline $\begin{array}{lll}4^{0} & 58^{\prime}\end{array}$ & " & \\
\hline $5^{0} \quad 2^{\prime} "$ & » & 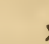 \\
\hline
\end{tabular}

Bei den folgenden Berechnungen habe ich indessen keine dieser Messungen, sondern die Angaben von Phllupz und Haidinger zum Grunde gelegt uud mithin jenen Winkel als : 


\section{$94^{\circ} 46^{\prime}$}

angenommen.

Setzt man nach der Weise von Moнs die Axe des Grund-Rhomboeders $=\mathbf{a}$, die Seite der horizontalen Projection aber $=1$, so ergibt sich aus obigem Winkel:

$$
a=\mathscr{3}, 535 * \text { ). }
$$

Nennt man ferner den Winkel der Axenkante $\alpha$, den Winkel der Rhomboeder-Kante $\beta$, den ebenen Winkel an der Spitze des Rhomboeders $\gamma$, und den ebenen Winkel zwiochen der Rhomboeder-Kante und der Axenkante $\delta$ (s. Fg. 1) und bedient man sich der bekannten von MoHs gegebenen Formeln, wonach

$$
\cos \alpha=\frac{2 a^{2}-9}{4 a^{2}+9}
$$

und

$$
\cos \gamma=\frac{2 a^{2}-9}{2\left(a^{2}+9\right)}
$$

80 erhält man als Abmessungen des Grund-Rhomboeders

$$
\begin{aligned}
& \alpha=94^{\circ} 46^{\prime}, \text { - den gemessenen und zum Grundo } \\
& \gamma=94^{\circ} \text { 24 }^{\prime}
\end{aligned}
$$

und hieraus als Complement-Winkel:

$$
\begin{aligned}
& \beta=85^{\circ} 14^{\prime} \\
& \delta=85^{\circ} 36^{\prime} .
\end{aligned}
$$

Die bisher am Chabasit beobachteten Flächen sind folgendo :

$$
\text { Bezeichnung nach : }
$$

Mon8. Weiss. Naunanin. In den Figuren.
$\mathbf{R}$$$
\left(\begin{array}{c}
c \\
a: a: \infty a
\end{array}\right)
$$
R. P.
$R-1\left(\begin{array}{c}\frac{1}{2} c \\ a: a: \infty a\end{array}\right)-\frac{1}{2} R$.
n. Rhomboeder.
$R+1\left(\begin{array}{c}2 c \\ a: a: \infty a\end{array}\right)$
I.<smiles>CCCCCCCCCCC</smiles>

*) Vergl. Treatise on Mineralogy by Fr. Mons, translated by W. HaIDINGER VOU. II, S. 232. 


\section{$-637$}

$$
\begin{aligned}
& \text { Mons. Weiss. Naumatr. In den Figuren. } \\
& P \quad\left(\begin{array}{c}
\frac{1}{3} \mathbf{c} \\
\mathrm{a}: \frac{1}{2} \mathrm{a}: \mathrm{a}
\end{array}\right) \quad \frac{2}{3} \mathrm{P} .{ }^{2} \text { t. Pyramide. } \\
& (P-2)^{\circ}\left(\begin{array}{c}
\frac{1}{4} \mathrm{c} \\
\mathrm{a}: \frac{1}{3} \mathrm{a}: \frac{1}{2} \mathrm{a}
\end{array}\right) \quad \frac{1}{4} \text { R. } 3 \text { o. Skalenoe- } \\
& \frac{18}{4}(P-2) \frac{5}{4}\left(\begin{array}{c}
\frac{13}{6} \mathrm{c} \\
a: \frac{1}{5} a: \frac{1}{4} a
\end{array}\right) \frac{13}{16} \text { R. } \frac{5}{4} \text { i. } \int^{\text {der. }} \\
& p+\infty\left(\begin{array}{c}
\infty \mathrm{c} \\
2 \mathrm{a}: \mathrm{a}: 2 \mathrm{a}
\end{array}\right) \infty \text { P. } 2 \text { u. Prisma. }
\end{aligned}
$$

Die Fläche $\mathbf{P}$ erschéint an allen $\mathbf{O r t e n} ; \mathbf{n}$ und $\mathbf{r}$ sind häufig, unter vielen andern Fundortẹn kenne ich sie von Rübendürfel, von Oberstein, von Kilmalcolm und von den Fürüern; i erscheint nicht selten, am deutlichsten habe ich sie an Stücken von Kilmulcolm und aus Böhmen beobachtet; $\mathbf{u}$ ist sehr selten und ist mir nur an Zwillings-Krystallen vom Giants Causeway und an einfachen Gestalten aus Island vorgekommen. Die Fläche t habe ich nur an kleinen Zwillingskrystallen aus dem Westerwalde gesehen, hier aber recht deutlich; o endlich erscheint höchst selten an kleinen Krystallen aus Bühmen.

Die oben angegebenën Ausdrücke für die beiden Skalenoeder sind nur als Arnäherungen zu betrachten, da es mir bisher uninöglich war, èinen đóppèltèi Paiallelismus der Kanten wahrzunehmen, die Messúngen aber sich nicht mit unbedingtè Genauigkeit nehmén liessen. - i erscheint in der Regel nur àls eine federartige Streifung des GrundRhomboeder's, s. Fg. 2s; ich habe sie indessen einigemal so deutlich beobachtet, dasš mir über" die Wirklichkeit derselben kein Zweifel géblieben ist. - Phirlups und Haidinger geben die Abinessurigen dièsés Skalenoeder's annäherungsweise zu $173 \frac{1}{2}^{0}$ für die stumpfe, und $103 \frac{1}{2}^{\prime}$ für die scharfe AxenKanté rachi dèn von' ihnen gemachten Messungen. Die Fläche o ist wahrscheinlich ideitisch mit deni von ZIPPE beobachteten Skalenoeder,' von dem mir jedoch nur der allgemeine Ausdruck bekannt geworden ist. 


\section{$-638-$}

Die Fläche $\mathbf{P}$ erscheint theils glatt, theils gestreift.

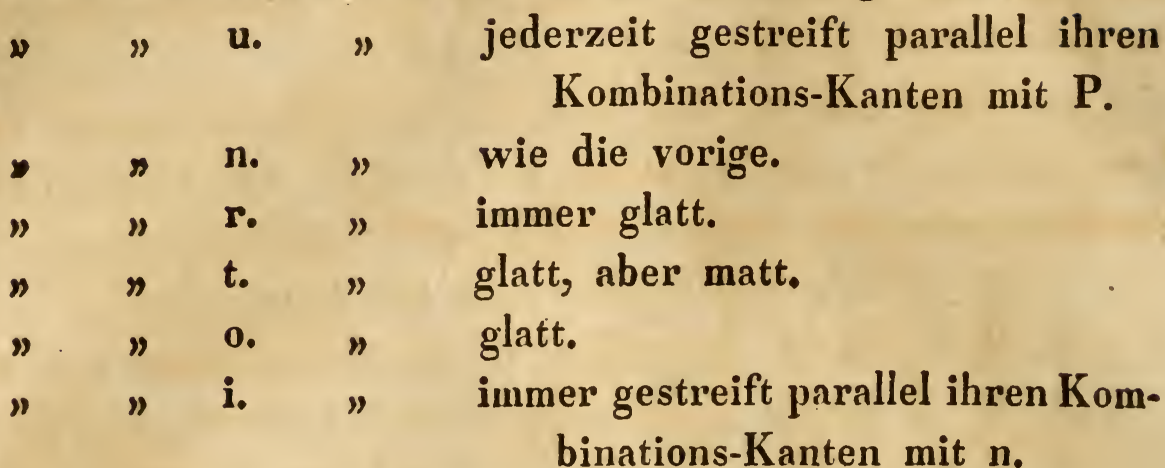

Zwillings-(iestalten finden sich am Chabasit ungemein häufig, und sie erscheinen nach zwei verschiedenen Gesetzen. Es ist nämlich entweder

a) Die Zusammensetzungsfläche parallel einer Fläche des Grund-Rhomboeders R, die Axe der Umdrehung senkrecht auf dieser Fläche, und der Winkel der Umdrehung $=150^{\circ}$,

oder :

b) Die Zusammensetzungsfläche parallel der bisher noch nicht beobachteten Fläche $\mathrm{P}-\infty$ (der gerade angesetzten Endfläche), die Axe der Umdrehung senkrecht auf derselben Fläche und der Winkel der Umdrehung $=150^{\circ}$, oder, was hier dieselbe Erscheinung gibt $=60^{\circ}$.

Im ersten Falle, de $i^{\prime}$ bei Weitem der seltenere ist und mir bisher nur von drei Lokalitäten bekannt wurde, setzen die einfachen Gestalten nicht über die Zusammensetzungsfläche hinaus; im zweiten Fall, der sich ungemein häufig findet, geschieht diess jederzeit.

Das erste dieser Zwillingsgesetze wurde zuerst von Moнs, - das zweite interessantere aber zuerst von $W_{\text {EISS, }}$ - vergleiche dessen oben angeführte Abhandlung, - beobachtet und beschrieben.

Das erste dieser Gesetze bietet ein Beispiel dar von einem - wenn ich mich so ausdrücken darf - Anneinandergewachsenseyn - das zweite von einem Durcheinandergewachsenseyn - zweier Individuen; - eine Verschiedenheit,

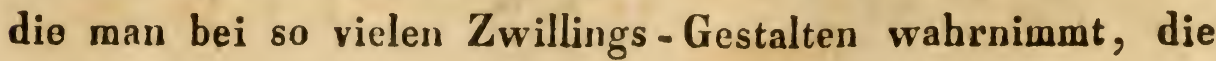


mir aber eine tiefere Bedeutung zu haben scheint, als man ihr gewöhnlich beilegt. -

Es sind mir in den verschiedenen Sammlungen des Kontinents, die ich $\mathrm{zu}$ sehen Gelegenheit hatte, folgende Kombinationen der genannten Flächen vorgekommen:

A. Einfache Gestalten und Kombinationen.

1. R. s. Fg. 1 , überall z. B. Füröer, Böhmen u. s. w. 2. $\frac{13}{4}(\mathbf{P}-2) \frac{5}{4}$. Kilmalcolm in Schottland, s. Fg. 2. 3. R - 1. R. s. Fg. 3. unter anderen Oberstein, Rübendïrfel u. s. w.

4. R. $-\mathbf{R}+$ 1. s. Fg. 4. Schottland.

5. R. $\frac{13}{4}(\mathbf{P}-2) \frac{5}{4}$. s. Fg. 5. Böhmen, Schottland.

6. $\mathbf{R}-1 . \frac{13}{4}(\mathbf{P}-2) \frac{5}{4}$. s. Fg. 6. Böhmen.

7. $\mathbf{R}+1 \cdot \frac{13}{4}(\mathbf{P}-2) \frac{5}{4}$. s. Fg. 7. Kilmalcolm.

S. R. $(\mathrm{P}-2)^{3}$. s. Fg. 8. Böhmen.

9. $\mathbf{R}-$ 1. R. $\mathbf{P}+\infty$ s. Fg. 9. Island.

10. R. $\mathrm{R}+$ 1. $\mathrm{P}+\infty$ s. Fg. 10. Island.

11. R - 1. R. $\frac{13}{4}(\mathbf{P}-2) \frac{5}{4}$. s. Fg. 11. Schottland.

12. $R-1 . R+1 \cdot \frac{13}{4}(P-2) \frac{5}{4}$. s. Fg. 12. Schott land.

13. R - 1. R. $(\mathbf{P}-2)^{3}$. s. Fg. 13. Böhmen.

14. $\mathbf{R}-1$. R. $\mathbf{R}+$ 1. s. Fg. 14. Oberstein.

15. R - 1. R. R. + 1. $\mathbf{P}+\infty$. s. Fg. 15. Giants Causeway, Island.

B. Zwillings - Gestalten :

a) nach dem ersten Gesetz:

16. R; 2 [R] s. Fg. 16. Fassa Thal, Gustavsberg.

b) nach dem zweiten Gesetz:

17. R; 2 [R - $\infty$ ]. s. Fg. 17. Böhmen, Habessinicn etc. 15. $\frac{13}{4}(P .-2) \frac{5}{4} ; 2[R-\infty]$ s. Fg. 1S. Schottland. 19. $\mathbf{R}-1 . \mathbf{R} ; \mathbf{2}[\mathbf{R}-\infty]$ s. Fg. 19. Rübendürfel, Oberstein.

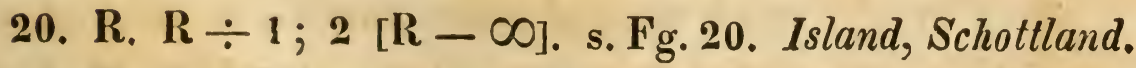
21. R. $\frac{13}{4}(P-2) \frac{5}{4} ; 2[R-\infty]$. s. Fg. 21. Bühmen. 22. $R-1 . \frac{13}{4}(P-2) \frac{5}{4} ; 2[R-\infty]$. s. Fg. 22. 


\section{$-640$}

23. R. $(P-2)^{9} ; 2[R-\infty]$. s. Fg. 23 a und 23 b. Westerwald.

24. $R-1 . R . R+1 ; 2[R-\infty]$. s. Fg. 24 a und 24 b. Böhmen, Island.

25. R. $\mathbf{R}+1 . \mathbf{P}+\infty ; 2[\mathbf{R}-\infty]$. s. $\mathbf{F g} \cdot 25$. Island.

26. $R-1 . R+1 \cdot \frac{13}{4}(P-2) \frac{5}{4} ; 2[R-\infty] .8$. Fg. 26. Schottland.

27. $\mathbf{R}-1$. R. $\mathbf{R}+1 . \mathbf{P}+\infty ; 2[\mathrm{R}-\infty]$. s. Fg. 27. Giants Causeway, Füroer.

Die Zeichnung der Figuren ist nach der Methode von Moнs nach den Winkeln gegeben; vgl. HAlDiNGEn's nieisterhafte Abhandlung: "Treatise of the Method of Drawing Crystals in True Perspective" in den "Memoirs of the Wernerian Natural History Society". - Die Figuren Nr. 14, 17 und 27 sind HAIDINGER's vortrefflichen Zeichnungen éntnom• men. Bei den complicirteren Gestalten habe ich nur die vordere Seite gezeichnet, was übrigens zum Verstehen vollkommen genügend ist. Bei den Zwillings-Krystallen pflege ich das eine Individuum mit gewöhnlichen, das andere aber mit Fraktur-Buchstaben zu bezeichnen, wodurch der Überblick sehr erleichtert wird.

Zur Berechnung der verschiedenen Kanten und Kombinations-Kanten, so wie der verschiedenen ebenen Winkel bediene ich mich theils der bekannten, von Монs gegebenen Gleichungen für die Kombinations-Kanten - (vergl. dessen Abhandlung: „Gleichungen zur Entwicklung und Berechnung zusammengesetzter Krystall-Gestalten etc.", Gilbert's Annalen der Physik, Stück S, Jahrgang 1821), - theils der gcwöhnlichen Formeln der sphärischen Trigonometrie. - (Vgl. Mitscherdich: sur la méthode de calculer les angles des cristaux et le rapport de position de leurs faces).

An den umsteherid gegebenen Kombinationen haben dio vorzüglicheren Winliel folgende Abmessungen:

a. Kanten-Winkel an Flächen desselben Gipfels: 


\section{$-641-$}

n $\| \mathrm{n}=125^{\circ} 18^{\prime} \mathrm{s}$. Fg. 3. $\mathrm{r} \| \mathrm{r}$ (über $\mathrm{P}$ ) $=72^{\circ} 53^{\prime} \mathrm{s} . \mathrm{Fg}$. 4.

n $\| \mathrm{P}=137^{\circ} 23^{\prime} "$ " 3. $\mathrm{r} \| \mathrm{u}=143^{\circ} 3 \frac{1}{2}^{\prime}$ " $" 10$.

" $\| \mathrm{u}=117^{\circ} 23 \frac{1}{2}^{\prime \prime} "$ " . $\mathrm{r} \| \frac{\mathrm{P}}{\mathrm{I}}=143^{\circ} 49^{\prime}$ " " 4 .

n $\|$ u (üb.P) $=90^{\circ} "$ " 9. $0 \|$ o $=155^{\circ} 53^{\prime} " n " 13$.

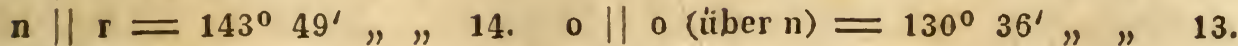

$\mathrm{n}\left\|\mathrm{o}=155^{\circ} 18^{\prime} "\right\|$ 13. $0\left\|\mathrm{P}=162^{\circ} 5^{\prime} "\right\| 13$.

$\mathrm{P}\left\|\mathrm{r}=126^{\circ} 26 \frac{1}{2}^{\prime} "\right\|$ 4. $\mathrm{i} \| \mathrm{i}=172^{\circ} 6^{\prime} ", \quad 6$.

$\mathrm{P}\left\|\mathrm{u}=132^{\circ} 37^{\prime}, " 9 . \quad \mathrm{i}\right\| \mathrm{i}$ (über $\mathrm{n}$ ) $=103^{\circ} 21^{\prime} "$, 6 .

$\mathbf{P} \| \frac{\mathbf{P}}{\mathbf{P}}$ (über dem Gipfel) $=\mathbf{i} \| \mathrm{n}=141^{\circ} 40 \frac{1}{2}^{\prime \prime} "$ " $\quad 6$.

$96^{\circ} 29^{\prime}$ s. Fg. 1. $\mathrm{t} \| \mathrm{t}=145^{\circ} 54^{\prime} "$ " $23 \mathrm{~b}$.

b. Kanten-Winkel an Flächen verschiedener Gipfel:

$\mathbf{P} \| \frac{\mathbf{P}}{\mathbf{P}}=83^{\circ} 31^{\prime}$ s. Fg. 1. r $\| \mathrm{r}$ (über u) $=107^{\circ} \quad 7^{\prime}$ s. Fg. 10.

$\mathrm{P}^{\prime}\left\|\mathrm{r}=119^{\circ} 42^{\prime} "\right\|$ 4. $\| \mathrm{ll}=71^{\circ} 48^{\prime} "$ " $23 \mathrm{~b}$.

$\mathbf{P} \| \mathbf{n}$ (üb. r) $=83^{9} 31^{\prime}$ s. Fg. 15.

n $\|$ n $(u ̈ b . u)=54^{\circ} 47^{\prime}$ s. Fg. 9 .

c. Ebene Winkel:

$\frac{\mathrm{n}}{\mathrm{n}} \| \frac{\mathrm{n}}{\mathrm{n}}=111^{\circ} 27^{\prime}$ s. Fg. 15. $\frac{\mathrm{P}}{\mathrm{i}} \| \frac{\mathrm{P}}{\mathrm{i}}=94^{\circ} 24^{\prime}$ s. Fg. 3.

$\frac{\mathrm{n}}{\mathrm{n}} \| \frac{\mathrm{n}}{\mathrm{P}}=124^{0} 16 \frac{1}{2}^{\prime}$ s. Fg. 15. $\frac{\mathrm{P}}{\mathrm{r}} \| \frac{\mathrm{P}}{\mathrm{r}}=65^{\circ} 22^{\prime}$ s. Fg. 4.

$\frac{\mathbf{n}}{\mathbf{P}} \| \frac{\mathrm{n}}{\mathrm{r}}=90^{\circ} \quad$ s.Fg. 15. $\frac{\mathrm{r}}{\mathbf{P}} \| \frac{\mathrm{r}}{\mathrm{P}}=57^{\circ} 19^{\prime}$ s. Fg. 4.

$\frac{\mathrm{P}}{\mathrm{n}} \| \frac{\mathrm{P}}{\mathrm{n}}=94^{\circ} 24^{\prime} \mathrm{s}$. Fg. 15. $\frac{\mathrm{r}}{\mathrm{n}} \| \frac{\mathrm{r}}{\mathrm{P}}=122^{\circ} 41^{\prime}$ s. Fg. 15.

$\frac{\mathbf{P}}{\mathbf{P}} \| \frac{\mathbf{P}}{\mathbf{r}}=132^{\circ} 48^{\prime}$ s. Fg. 4. $\frac{\mathbf{P}}{\mathrm{n}} \| \frac{\mathrm{P}}{\mathrm{u}}=85^{\circ} 36^{\prime}$ s. Fg. 9.

$\frac{P}{r} \| \frac{P}{u}=132^{\circ} 48^{\prime}$ s. Fg. 15.

$\frac{P}{u} \| \frac{P}{r}=132^{\circ} 48^{\prime}$ s. Fg. 15.

$\frac{\mathrm{P}}{\mathrm{u}} \| \frac{\mathrm{P}}{\mathrm{r}}=137^{\circ} 12^{\prime} \mathrm{s} . \mathrm{Fg} .15$.

d. Zwillings-Winkel.

๔) nach dem ersten Gesetz :

$\mathbf{P} \| \mathbf{P}^{\prime}=171^{\circ} 48^{\prime}$ s. Fg. 16 .

B) nach dem zweiten Gesetz:

$\mathbf{P} \| \mathbf{P}=132^{\circ} 58^{\prime}$ s. Fg. 17. $\mathbf{t} \| \mathbf{t}=180^{\circ} \quad$ s. Fg. $23 \mathrm{~b}$.

$\mathrm{P}^{\prime}\left\|\mathrm{P}^{\prime}=102^{\circ} 51^{\prime}\right\| " 17 . \quad \| \mathrm{t}=71^{\circ} 48^{\prime}$ s. Fg. $23 \mathrm{~b}$.

u $\| \mathrm{u}=180^{\circ} \quad$ " $" 27$.

$u^{\prime} \| u^{\prime}=180^{\circ} \quad " n 27$. 
Ich darf hiebei wohl nicht erst bemerken, dass bei den ebenen Winkeln die mit eiuem ' versehenen Flächen sich auf den untern Gipfel beziehen. - Bei den Zwillingswinkeln bezeichne ich mit $\mathbf{P}^{\prime}\left\|\mathbf{P}^{\prime}, \mathbf{i}^{\prime}\right\| \mathbf{i}^{\prime}$ u. s. w. die ein- oder ausspringenden Winkel, welche in der Ebene des horizontalen Durchschnitts liegen, mit $\mathbf{P}\|\mathbf{P}, \mathbf{i}\| \mathbf{i}$ u. s. f. dagegen diejenigen einspringenden und ausspringenden Winkel, dio gegen die genaunte Ebene geneigt erscheinen.

Die Theilbarkeit des Chabasits ist von geringer Vollkommenheit, parallel den Flächen des Grund-Rhomboeders.

Der Chabasit erscheint fast jederzeit in Krystallen; derbe Massen von sehr geringem Umfange sind wohl nur da erschienen, wo durch Mangel an Raum oder andere äussere Störungen das Krystallisiren verhindert wurde.

Den optischen Untersuchungen Brewster's zufolge besteht das Grund-Rhomboeder aus verschiedenen einzelnen Körpern, die auf eine merkwürdig symmetrische Weise zusammengehäuft sind, und von denen jeder 2 Axen doppelter Brechung besitzt. Sie sind oft um einen Kern vertheilt, der nur eine optische Axe besitzt, die mit der Hauptaxe des Rhomboeders zusammenfällt (vgl. Haidinger, Mineralogy by Moнs, Vol. II, S. 233).

Die Härte des Chabasits ist $=4,0$ bis 4,5 der Skale von Moнs. - Er ritzt Flussspath und wird von Apatit geritzt. - Wie bei den meisten Mineralien, so sind auch hier Härte und spezifisches Gewicht nicht vollkommen konstant, sondern veränderlich nach der grösseren oder geringeren Frische, nach dem höheren oder geringeren Grade des Umgewandeltseyns der verschiedenen Varietäten.

Das spezifische Gewicht wird angegeben zu:

2,100. Krystalle aus Böhmen. Moнs.

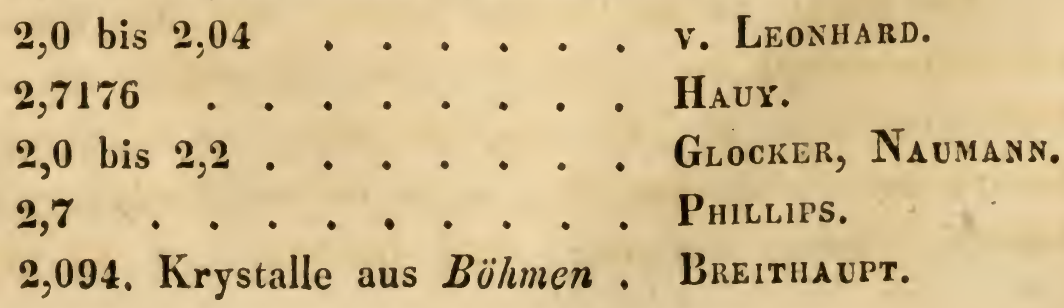


2,0-2,7 •. . . . . Necker.

2,127 bei $7^{0} \boldsymbol{7}^{\prime} \mathrm{R}$, von Rübendürfel

2,112 " S $^{0} 3^{\prime} "$ "Fassa Erast Hofmanv.

$2,075 " 7^{0} 6^{\prime} "$ "Parsborough!

Die Angaben von Hauy und Phillips beruhen unfehlbar auf einem Beobachtungsfehler, und schwerlich dürfte man einen Chabasit finden, dessen Gewicht sich auf 2,7 erhebt.

Die Wägungen, die ich selbst anzustellen Gelegenheit fand, ergeben:

$$
\text { an einem an einem }
$$

einfachen Krystall: Zwilling:

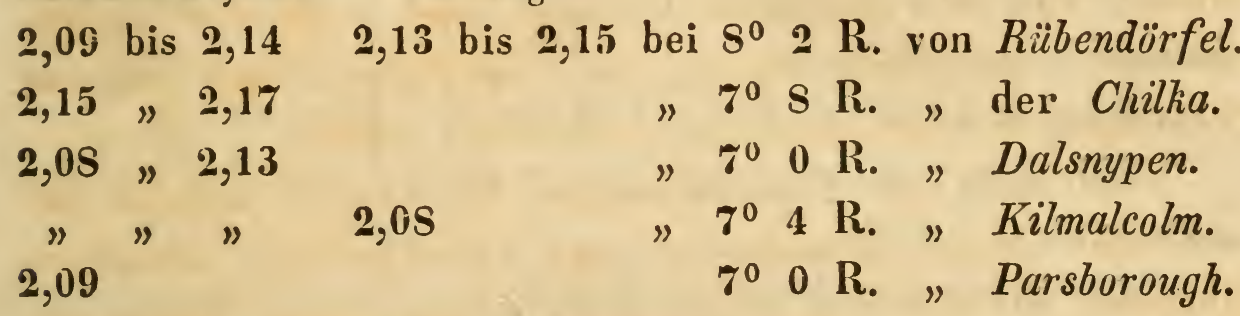

Verschiedene Krystall-Kombinationen scheinen keinen Einfluss auf das spezifische Gewicht zu haben. - Eben so

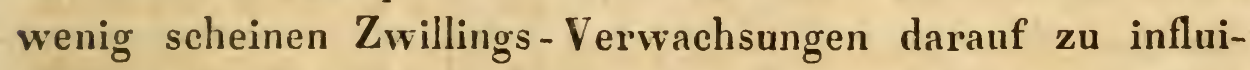
ren, - Dass die Grösse des gewogenen Individuums Einfluss auf das spezifische Gewicht hat, und dass der Grund dieser Erscheinung in der grösseren und geringeren Menge ganz kleiner eingeschlossenen Luftheilchen liegt, ist von BEUDANT nachgewiesen worden.

Der Chabasit ist bei unebenem Bruch sprödle und leicht zersprengbar. - Der Strich ist weiss.

Bei vollkommenem Glasglanz ist der Chabasit mehr oder minder durchscheinend. - Taucht man weisse, wenig durchscheinende Krystalle in ÖI und lässt sie. einige Zeit darin, so vermehrt sich der Grad ihrer Durchscheinendheit.

Die Farbe ist fast immer weiss, nur die Abänderung von Parsborough ist roth, die von Kilmalcolm in seltenen Fällen röthlich, und die von Löwenberg, so wie eine Abänderung aus Nord-Amerika, - in meiner Sammlung - der nähere Fundort ist mir nicht belsannt, - ist gelb. - 
Die erste Varietät ist, wie aus der Analyse von Hofmann hervorgeht, durch Eisenoxyd gefärbt; bei der zweiten und dritten ist der färbende Stoff wahrscheinlich ebenfalls Eisen. - Der Chabasit von Naalsoe erscheint zuweilen grün, und die Varietät aus dem $\mathrm{Val} d i \mathrm{Noto}$ in seltenen Fällen blau. In beiden Fällen ist die Färbung jedloch nur scheinbar. Die kleinen ziemlich klaren Krystalle sitzen in den Höhlungen eines basaltischen Mandelsteins auf einer Unterlage von Grünerde in dem einen, und von Blau-Eisenerde in dem andern Falle, erscheinen jedoch ungefärbt, so bald man sie von dieser Unterlage trennt.

Der Chabasit wird weder durch Reiben noch durch Erwärmung elektrisch.

Säuren äussern keine Wirkung auf denselben.

Vor dem Löthrohr auf blosser Kohle schmilzt er leicht zu weissem Email.

Die erste chemische Zerlegung des Chabasits verdanken wir Vauqurlin. Später analysirte Berzelius die Varietät von Gustarsberg und berechnete nach dem Resultat eine Formel, die später in Folge der Arbeit von Arfvedson verworfen wurde. In neuerer Zeit zerlegte Connel den Chabasit von Kilmalcolm und Ernst Hofmaxn von mehreren anderen Lokalitäten, wodurch er bewiess, dass verschiedene Chabasite verschieden zusammengesetzt sind, und dass für einige Chabasite die alte von Berzelius aufgestellte Formel, für andere aber die neuere den Arbeiten von Arfvedsox entnommene die richtige sey.

Das Ergebniss der bisher gemachten Analysen ist folgendes : 


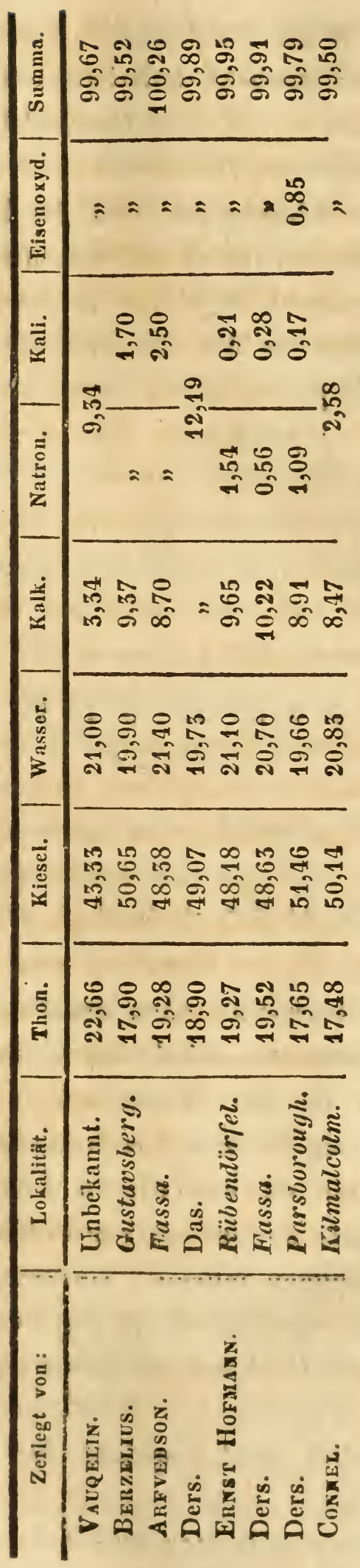




\section{$-646$}

Setzt man bei diesen Analysen die von $V_{\text {Avquelin als }}$ die weniger genaue zurück, und betrachtet man Kalk, Kali und Natron als sich ersetzende Bestandtheile, so verhalten sich die Sauerstoffgehalte:

a) in den weniger Kieselerde enthaltenden Chabasiten:

$$
\begin{aligned}
& \text { der Kieselerde }=8 \quad . \quad . \quad . \quad .=9 . \\
& \text { " Thonerde }=3 \text {. . . }:=3 \text {. } \\
& \text { "Kalkerde }
\end{aligned}
$$

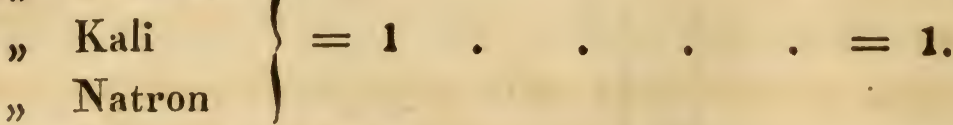

$$
\begin{aligned}
& \text { des Wassers }=6 \cdot{ }^{\prime} \cdot .=6 \text {, }
\end{aligned}
$$

und hieraus ergeben sich die beiden aufgestellten chemischen Formeln :

$$
\begin{aligned}
& \mathbf{C}^{3} \\
& N^{3} \\
& K^{3}
\end{aligned} \mid \dddot{S}_{i^{2}}+3 \dddot{A} l \dddot{S}_{i^{2}}+18 \dot{\mathbf{H}}
$$

und

$$
\begin{array}{c|c}
\dot{C} \\
\dot{N} \\
\dot{K}
\end{array} \dddot{\mathrm{S} i}+\ddot{\mathrm{Al}} \dddot{\mathrm{S}}^{2}+6 \mathrm{H} \text {. }
$$

(Vgl. Ernst Hofmanv's oben erwähnte Abhandlung.)

$\mathrm{Ob}$ nach dieser verschiedenen Zusarnmensetzung auch Verschiedenheiten in den Winkeln sich finden dürften und danach der Chabasit in zwei verschiedene Mineralien zerfallen müsste, oder ob von diesen Analysen nur die eine anzunehmen und die andere zu verwerfen ist, müssen fortgesetzte Untersuchungen lehren. Berzelius entscheidet sich für die erste der von Hormans gegebenen Analysen, und der Umstand, dass G. Rose bei den sorgfältigsten Untersuchungen an der Varietät von Parsborough keine Verschiedenheit der. Winkel fand, spricht für die Annahme von Berzelius.

Nach L. Gmeliv verhalten sich Kali (Natron und Kalk), Thonerde, Kiesel und Wasser $=13,4: 18,9: 47,6: 20,1$ 
(s. v. Leonhard a. a. O.), wobei jedoch nicht die erste, sondern die zweite der obigen Formeln zum Grunde gelegt ist.

Chabasit ist mithin ein Bisilikat von Thon, vorherrschend verbunden mit einem Bisilikat von Kalk, in welchem der Kalk zuweilen durch Natron, Kali oder durch beides ersetzt und überdiess mit Wasser verbunden ist.

Die chemischen Verschiedenheiten scheinen in keinem Zusammenhange mit den geognostischen Verhältnissen zu stehen.

Sollte der grössere oder geringere Gehalt an Kalk wohl davon abhängen, ob die beibrechenden Fossilien Kalkspath oder Zeolith sind Ș Es wäre höchst wünschenswerth, dass die Varietäten von Oberstein und von Andreasberg, die so häufig mit und auf Kalkspath vorkommen, analysirt werden, um jene Frage zu ermitteln.

Die mir bisher bekannt gewordenen Fundorte des Chabasits sind folgende:

1. Giants Causeway in Irland, und zwar hier an mehreren Punkten, namentlich am Port on Spain im Basaltartigen Mandelstein in Drusen mit Zeolith. Die Krystalle bis zur Grösse einer Haselnuss. - Die Formen No. 15, 17.

2. Portrush im nürdlichen Irland. - Vorkommen wahrscheinlich wie bei No. 1; ist mir nicht durch Autopsie bekannt.

3. Kilmalcolm in Renfrewshire in Schottland, mit Stilbit auf den Klüften eines röthlichen Trapp's. - Bis zur Grösse einer Erbe. Die Formen No. 1, 2, 4, 5, 11, 12, 17, 18, 26.

4. Storr an der Westküste von Schottland; - ich habe diese Varietät nie selbst gesehen.

5. Glen Farg in Perthshire, im Trapp mit Stilbit und Analzim.

6. Talisker auf der Insel Sliye, mit Stilbit in den Blasenräumen eines braunen Mandelsteins. Die Gestalten No. 1, 17.

Jahrgang 1836. 


\section{- $648-$}

7. Insel Mull

8. "Canna

9. "Ulva Vorkommen wie bei voriger Varietät.

10. "Gometra

11. "Slaffa

12. Husavic in Island. Kleine durchsichtige Krystalle, die Iöhlungen der fossilen Venus Islandica ausfüllend. Diese von Allan beschricbene Varietät ist mir nicht durch Autopsie bekannt. - Nach andern sollen zwar Kalkspath-, aber nicht Chabasit-Krystalle auf diese Weise vorkommen.

13. in Island. Mit Stilbit in Drusen eines hellbraunen Mandelsteins. Formen 1, 15.

14. in Island. Ohne Stilbit in den Höhlungen eines dunkelbraunen Mandelsteins. Die Formen No. 1, $3,4,9,10,14,17,25$.

14. Dal Dalsnypen $\{$ auf Sandoe.

17. Naalsue.

18. Ridewig auf Osteroe.

19. Füroe.

20. Swinoe.

In den verschiedenen Gestaltungen der bekannten Mandelsteine, mit und ohno Stilbit, A pophyllit, Grünerdo u. s. w. In sehr versehiedenen Gestalten, zuweilen bis zu 1" Grösse.

21. Gustavsberg in Jemtland (Drottning Grufva) mit Stilbit auf Quarz auf den Klüften eines Magneteisensteinlagers. Die Formen 1, 16, 17.

22. Sirgwitz bei Löwenberg in Schlesien. Kleine klare gelbliche Krystalle in den Höhlungen eines höchst porösen verwitterten Basaltes. Formen 1, 17.

23. Dembio bei Oppeln. Kleine Krystalle mit Kreutzstein und Mesotyp (ঙ) im Basalt (n. Glocker).

24. Rïbendörfel bei Aussig in Böhmen. Grosse Drusen in grauem Klingstein-Porphyr. Hier die grössten Krystalle, die mir vorgekonmen sind. Es befinden sich in meiner Samn'ung Krystalle der Formen No. 1, an denen die Axenkanten über einen Zoll lang sind. Die Formen 1, 3, 5, 6, $11,12,14,17,21,22,24$ n, 24 b, 26.

25. Das sogenannte Lettenbiischel zwischen Markersdorf 
und Bümisch Kamnitz. Graulichweisse durchscheinende Krystalle in den Blasenräumen und Klüften des Basalts und einer Basalt - artigen sehr thonigen Wacke. Die Formen 1, $14,17,24 \mathrm{~b}$.

26. Der Pihler Berg in Bülmen. Form No. 1; wie die vorige Varietät im Basalt.

27. Der Mühlberg bei Ober-Kreybitz. Ganz kleine graulichweisse Krystalle der Form No. 1, die Blasenwände eines sehr blasenreichen Basalts überziehend.

28. Der Kaulner Berg bei Böhmisch Leippa. Sehr kleine ungefärbte Krystalle der For'm No. 1 mit Mesotyp (\$̣) im Basalt.

29. Neu P'alia, im nördlichen Böhmen in Mandelstein

30. Lomniz , mit Analzim und Heulandit.

31. Berg Kosakow im Bunzlauer Kreise; anf Amethyst in hohlen Chalzedon-Kugeln. Form No. 14*).

32. Taschow in Bühmen (n. v. LeоNн.) im Basalt.

33. Andreasberg am Harz; mit Kalkspath auf Gängen im Thonschiefer; die Formen 1, 17.

34. Oberstein in Zweibrücken auf Kalkspath-Güngen und in Chalzedon- und Achat-Kugeln im Mandelstein. Von Harmotom, Amethyst, Quarz und Kalkspath begleitet. Dio For'men No. 1, 3, 5, 7, 11, 12, 14, 17, 22, 23 b, 26.

35. Mendenberg bei Linz am Rhein.

36. Unkel am Rhein. Kleine sehr zierliche Krystalle der Formen No. 1, 17, auf Drusen von Stilbit im Basalt.

37. Stenzellerg im Siebengebirge; im Trachyt $\left.{ }^{*}\right)$.

") Die Böhmischen Lokalitäten von No. 25 bis 31 sind nach den Allgaben von ZiPPE a. a. O. gegeben. Es befinden sich in meiner Sammlung noch cine grosse Menge Böhmischer Chabasite, bei denen andere Fundorte als dic oben angeführten angegeben sind, э. B. Tetschen, Rumburg, Leitmeritz, Pichlowitz. - Ich habe indessen nicht gewagt, diese Lokaliäten mit aufzuführen, da ich fiir diesc!ben keine anciere Gewährleistung als jene Etiquetten hatte.

**) Das Fossil von der Wolkenbury in Siebengebirge, in kleinen weissen Rhomboedern, kleine Drusen in 'Trachyt ausfüllend, das ich in verschiedenen Sammlungen als Chabasitgefunden habe, und welches 
38. im Siebengebirge in Basalt. Form, No. 1.

39. Hartlingen am Westerwald. Grosse Drusen im Trachyt mit ausgezeichneten Hornblende-Krystallen. Die sehr komplizirten Zwillings - Krystalle oft so durcheinander gewachsen, dass es schwer ist, die einzelnen Individuen zu unterscheiden. Die Formen 19, 22, 23a, 23 b. - Diese Varietät kam mir unter dem Namen Amalzim zu.

40. Willnsdorf am westlichen Abfall der Kalteiche in Siegen.

41. Eschenrode im Vogelsgebirge; kleine Krystalle kleine 42. Schotten Drusen bildend in grauem Dolerit. 43. Gelnhaar Formen 1, 17.

44. Steinheim bei Hanau. Vorkommen ganz wie bei Eschenrode.

45. Breisach

46. Ihringen am Kaiserstuhl, im Dolerit.

47. Eichsetten

45. Marburg, - der Stempel. - Kleine Krystalle, dem Gmelinit sehr ähnlich, mit Kali-Harmotom in grauem Basalt.

49. Krater von Euben an der Pferdekuppe im RhönGebirge. Im grauen porösen Basalt.

50. Abhang der Pferdekuppe gegen Abtsroth hin, in rothem wackeartigem Gestein.

51. Monzoniberg im Fassa-Thal, auf Klüften des Diorit. Die Formen 1, 16, 17.

52. Puferloch unfern der Seisser Alp in Tyrol mit Faser-Prehnit. Mir nicht durch Autopsie bekannt.

53. Klaussen in Tyrol in Chalzedon-Kugeln (vielleicht mit Datholith zusammen §). Auch diese Varietät habe ich nie gesehen.

54. Berg Le Palle im Fassa-Thal, auf Analzim. Formen $1,3,17$.

auch mir unter diesem Namen zugekommen, und lange als solcher in meiner Sammlung liegen geblieben war, hat sich bei der Untersuchung als kohlensaurer Kalk zu erkennen gegeben. 
55. Val di Noto in Sizilien. Sehr kleine durchscheinende Krystalle in den Poren eines basaltischen Mandelsteins, zum Theil auf einer Unterlage von Blau-Eisenerde. Form No. 1 .

56. Gieshübel bei Schemnitz in Ungarn. Kleine weisse Krystalle der Form No. 1. Drusen im Basalt bildend.

57. Chilka in Sibirien, 180 Werst von Werchnoy Udinsk am Tschikoja-Fluss. Drusen bildend in grauem Mandelstein mit Stilbit und Analzim. Die Krystalle sind zuweilen über $\frac{1}{2} "$ gross, und zeigen die Formen No. 1, 17.

55. Umgegend von Poonah in Ostindien.

59. Ufer des Ataba-Stromes in der Provinz Simen in Habessinien. Weisse Krystalle der Formen 1, 17, in Lava (nach RüPPEL).

60. Umgegend von Gondar in Habessinien. Isolirte Krystalle der Formen 1, 17; bei der Verwitterung einer sehr porösen Lava, in der sie ursprünglich lagen, übrig geblieben *).

61. Insel Bourbon. Im basaltischen Mandelstein; die Form $\mathrm{No}_{\mathrm{s}} 1$.

62. Berg Ounarsorsoak (oder Onartorsoak) bei Godhavn auf Disko-Eiland in Grönland. In schönen einzelnen Krystallen in grauem Mandelstein mit Stilbit. Formen 1, 17.

63. Auckparlartoack in Grönland. Drusen im Diorit. Die kleinen Krystalle zeigen die Formen 1, 4, 17, 20.

64. in Grönland. Höchst ähnlich der Varietät von Kilmalcolm. Auf den Klüften eines röthlichen Trapps mit Stilbit. Die Formen 1, 4, 7, 16, 17.

65. Marmoaze in Canada; ist mir nicht durch Autopsie bekannt.

66. Parsborough in Neu-Schottland. Krystalle von

*) Dic Varietäten No. 58 und 59 sind von RüPPEL mitgebracht und befinden sich im Museum zu Frankfurt, wo Herr H. v. Meyer dio Güte hatte, mich uit denselben bekannt zu machen. 
ziemlich bedeutender Grösse; ausgezeichnet durch ihre rothe Farbe. Drusen bildend in einem rothen Porphyr. Die Formen $1,3,4,14$.

67. Deerfield in Mussachusetts. Diese Varietät habe ich nie geselien. Es befindet sich dagegen in meiner Sammlung ein durch gelbe Farbe und durch sein Vorkommen auf Glimmerschiefer höchst ausgezeichneter Chabasit. Die Krystalle zeigen die Form No. 1 und sind von Stilbit begleitet. Die Etiquette besagt nur: „aus Nord-Amerika“. - Ist diese Varietät die von Deerfield?

Wirft man einen Blick auf das geognostische Verhalten des Chabasits, so sieht man, dass er mit sehr wenigen Ausnahmen ein Produkt plutonischer Erhebungen ist. Fast überall erscheint er auf den Klüften und in den Blasenräumen anerkannt vulkanischer Gebirgsmassen, als: Basalt, Trachyt, Diorit u. s. w. - Um so merkwürdiger ist es, dass er, so wie auch Stilbit, Apophyllit und Harmotom, wenn auch nur in seltenen Fällen, auf Gängen erscheint, wie diess z. B. zu Andreasberg und zu Gustavsberg der Fall ist. Könnte man diess als einen Beweiss der Ausfüllung der Gänge von unten ansehen $\leqq$ - oder könnte man hieraus vielleicht nur schliessen, dass gewisse Spezien der Zeolith-Familie sich eben sowohl auf trockenem als auf nassem Wege erzeugen können؟ - Höchst merkwürdig ist es ferner, dass Chabasit und Mesotyp nicht zusammen vorzukommen scheinen, und dass viele plutonische Gebirgszüge, z. B. die der Auvergne, die reich an Mesotyp sind, keinen Chabasit hervorbringen. Freilich führt dagegen Glocker im Basalt von Dembiu Chabasit und Mesotyp als zusammenvorkommend auf, und eben so $\mathrm{Z}_{\mathrm{IPPE}}$ bei der Varietät von Böhmisch Leippa. - Ob aber jene kleinen haarförmigen Krystalle, an denen wohl schwerlich eine Messung möglich war, mit Bestimmtheit als zum Mesotyp gehörig erkannt werden konnten, - dürfte dahin gestellt bleiben. 
Ich kann diese Zeilen nicht schliessen, ohne die Frage aufzuwerfen, ob es nicht möglich sey, Levyn, Gmelinit, und den neuerdings von BREITHAupt - nach einer gefälligen brieflichen Mittheilung - als eigenthümliche Spezies aufgestellten Phakolith mit dem Chabasit zu einer und derselben Spezies zu vereinigen@ Die Untersuchungen, die ich darüber anzustellen Gelegenheit hatte, und bei denen mein hochgeehrter Freund, Herr Prof. G. Rose, die Güte hatte, mich auf das Freundlichste zu unterstützen, haben zwar aus Mangel an vollkummen messbaren Krystallen zu keinem entschiedenen Resultat geführt; allein sie haben die Möglichkeit jener Vereinigung wenigstens sehr, wahrscheinlich gemacht. Härte und spezifisches Gewicht weichen bei den genannten Spezies nicht mehr von einander ab, als unter einzelıen Varietäten des Chabasits. selbst.

Härte.

$$
\begin{aligned}
& \text { Levyn . } 4,0 \text { (HAld.) 2,1 (Breith.); 2,19S (ConneL). } \\
& \text { Gmelinit } \quad 4,5 \text { (d.) } \quad 2,0-2,1 \text { (d.) } \\
& \text { Phakolith • @ 2,135-2,144 (d.) } \\
& \text { Chabasit s. 0. 4,0-4,5 (d.) 2,05-2,11 (ders.) }
\end{aligned}
$$

Von chemischen Analysen besitzen wir zwei des Levyn, die eine von Berzeluus, die andere von Connel, und zwei des Gmelinit, die erste von Vauquelin, die zweite von Thomsov. Diese Zerlegungen ergaben :

Kiesel. Thon. Kalk. Kali und Wasser. Manganei- Súmma.

$$
\text { Natron. senoxyd. }
$$

Levyn von Füroe nach Berzruius:
48,00
20,00
8,35
3,16
19,30
9S,81

Levyn von Shye nach Connel:
46,30
22,47
9,72
2,81
$19,51 \quad 0,96$
101,77

Gmelinit von Montecchio Maggiore (§) nach Vavevisin : $50,00 \quad 20,00 \quad 4,50 \quad 4,50 \quad 21,00$
Gmelinit von Glenarm nach Thomson:

Eisenoxydul.

$39,896 \quad 12,968$

$9,527 \quad 29,566 \quad 7,443$

100,00 


\section{$-654$}

Von diesen Analysen stimmt die erste ganz vollkommen mit denen des Chabasits überein, wesshalb auch Berzelius schon vor langer Zeit die Identität zwischen Levyn und Chabasit behauptete, trotz der scheinbaren Verschiedenheit der Form. Connel ist zwar der Meinung, Berzelius habe gar nicht den Levyn, sondern ein Gemenge dieses Minerals mit dem Chabasit analysirt; Berzelius hat indessen diese schon früher von Brewster aufgestellte Behauptung so entschieden von der Hand gewiesen, dass bei der bekannten Genauigkeit dieses Chemikers wohl nicht füglich an jenen Irrthum zu glauben ist. Die Analyse von Coxrel weicht durch Verschiedenheit im Kiesel - und Thon-Gehalt von der von Berzelius ab, wenn auch nur unbedeutend, und CosNEL gab darauf für den Levyn die vom Chabasit abweichende Formel:

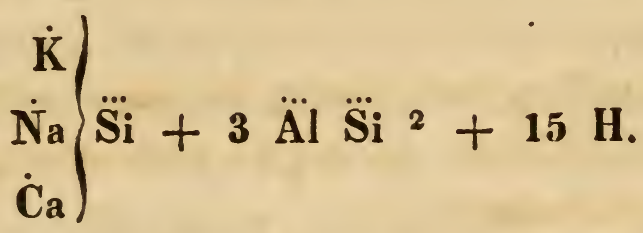

Berzelius hat indessen gezeigt (s. Jahresbericht etc., 15. Jahrg., S. 221-222), dass diese Formel eine chemische Unmöglichkeit enthält, und wenn man erwägt, dass die Analyșe nur mit 10,2S Gran angestellt ist und überdiess einen Überschuss von 1,77 Prozent gegeben hat, so kann man wohl nicht auf eine sehr grosse Genauigkeit schliessen.

Yon den beiden Analysen des Gmelinits stimmt die von Vavauelin wieder genau mit denen des Chabasits überein. Dagegen weicht die von Tномол durch sehr geringen Kieselgehalt und grossen Überschuss an Wasser sehr von der vorigen $a b$, was um so auffallender ist, da THомsом gerade die kleinen rothen Krystalle von Glenarm untersucht hat, an denen die Winkel sehr übereinstimmend mit denen des Chabasits sind s. v. u. Wie überaus wenig Vertrauen jedoch diese Analyse verdient, und aus welchen Gründen, das hat Berzelius - vergl. dessen Jahresbericht, 14. Jahrg. S. 189 - zur Genüge dargethan, und es wäre um so mehr 


\section{$-655$}

2u wünschen, dass diese Analyse recht bald wiederholt würde, da, wenn sie sich bestätigt, sie unfehlbar eine Trennung von dem Gmelinite Vauquelis's hervorbringen müsste.

Die Formen gehören sämmtlich dem rhomboedrischen System an. - Die Abmessungen aber scheinen kommensurabel zu seyn, und in einem sehr einfachen Verhältniss zu einander zu stehen.

Bei dem Levyn gibt Haidinger 3 Rhomboeder an, deren Axenkanten Winkel von:

$$
106^{\circ} 4^{\prime} \quad 79^{\circ} 29^{\prime} \quad \text { und } 70^{\circ} 73^{\prime}\left(70^{\circ} 7^{\prime}\right)
$$

bilden. - Berechnet man hieraus die Neigung der Rhomboederiläche gegen die Axe des Rhomboeders, so erhält man:

$$
46^{\circ} 1^{\prime} \quad 27^{\circ} 24^{\prime} \text { und } 19^{\circ} 13^{\prime}
$$

Beim Chabasit ist die Neigung der Fläche $\mathbf{P}(t)$ gegen die Axe

\section{$54^{0} 6^{\prime}$}

Vergleicht man die Tangente dieses Winkels mit den Tangenten der obigen 3 Winkel, so ergibt sich sehr genau das höchst einfache Verhältniss:

$$
1: \frac{3}{4}: \frac{3}{8}: \frac{1}{4} \text {. }
$$

Es befinden sich in meiner Sammlung einige Stücke Levyn, angeblich aus Schottland, ohne nähere Angabe des Fundortes. Die kleinen weissen Krystalle füllen die Höhlungen eines grauen basaltartigen Gesteins aus. - Merkwürdig ist es an diesen Stücken, dass einige jener Höhlungen mit ganz ähnlichen weissen Krystallen ausgefüllt sind, die ganz den gewöhnlichen Typus des Chabasits tragen, dass aber in keiner jener Höhlungen beide Bildungen zu gleicher Zeit vorkommen.

Zum. Gmelinit rechnet man gegenwärtig hauptsächlich den früher von Vavquelin sogenannten Sarcolith, - ( $\mathbf{H y}_{\mathbf{H}}$ drolith - DE DRÉE) von Montecchio Maggiore, ferner kleine weisse Krystalle im Mandelstein von Glenarm in Irland, und endlich die neuerdings aufgefundenen schönen Krystalle von gelblichrother Farbe ebenfalls von Glenarm. Die Form dieser Krystalle ist belsanntlich eine gleichschenkelige 6seitige 
Pyramide, die wahrscheinlich durch $Z$ willingsverwachsung eben so entstanden ist, wie die am Chabasit vom Westerwald, s. Fg. 23 a und 23 b, und mit welcher die nächste stumpfe 6seitige Pyramide, die gerade angesetzte Endfläche und das erste 6seitige Prisma in Kombination auftreten. Die RandKanten der ersten Pyramide sollen nach einer Messung von Brewster S3 ${ }^{\circ} 3^{\prime}$ betragen.

Ich weiss nicht, welche Varietät diesen Messungen zum Grunde gelegen ist. Die genanuten röthlichgelben Krystalle indessen ergaben nach Messungen, die Herr Professor G. Rose die Güte hatte, auf das Genaueste zu kontrolliren, den genannten Winkel nur zu $\mathrm{S0}^{\circ} \mathbf{5 4}^{\prime}$ in Mittel aus 3 Messungen. Der Randkanten-Winkel der ersten stumpferen Pyramide fand sich ebenfalls im Mittel von 3 Messungen zu 720 34'. Beide Messungen stimmen nach der Berechnung sehr wohl mit einander überein, wenn man die Streifungen und andere Unvollkommenheiten dieser Krystalle mit in Anschlag bringt.

Die Flächen der zuletzt erwähnten stumpfer’n Pyramide scheinen mir ganz identisch zu seyn mit der an Chabasit vom Westerwald vorkommenden Fläche $\mathbf{P}(\mathrm{t})$. Die Beręchnung der Neigung dieser Flächen gegen einander gibt freilich $71^{\circ} 45^{\prime}$ am Chabasit, während sie sich durch Messung am Gmelinit zu $\mathbf{7 2}^{\circ} \mathbf{3 4}^{\prime}$ fand; - erwägt man aber, wie abweichend die verschiedenen Messungen des Chabasits sind, und wie auch der Gmelinit nur unvollkommene Bestimmungen gestattet, so ist eine Differenz von $46^{\prime}$ wohl als unwesentlich zu betrachten, wie gross sie auch immer bei guten Krystallen wäre.

Die Formen des Gmelinits wären also zu betrachten als Zwillinge zweier Rhomboeder. Die Zwillingskante lauft in der Mitte der stumpferen Pyramide, parallel mit ihren Kombinations - Kanten mit der schärferen, was man bei mehreren Krystallen recht deutlich beobachten kann. Die Flächen beider Pyramiden sind gestreift parallel ihren Kombinations-Kanten, und da diese Streifungen in der Mitte 
der Flächen der schärferen Pyramide zusammentreffen, so geben sie-dadurch den Flächen den Anschein, als gingen die Zwillings-Kanten durch diese Flächen, wie sie auch Haidinger genommen und gezeichnet hat. - Die schärfere Pyramide des Gmelinits würde nach dieser Ansicht ein Rhomboeder am Chabasit, welches man bisher nicht beobachtete, nämlich $\underset{3}{2} \mathbf{R}$.

Merkwürdig ist es, und es scheint gegen meine Meinung einer Vereinigung dieser Mineralien zu sprechen, dass unan an den eigentlichén Chabasiten niemals die gerade angesetzte Endfläche beobachtet hat, während dieselbe am Levyn und Grnelinit jederzeit erscheint. Man kann aber auch den Satz unkehren und sagen, dass man diejenigen Varietäten, bei denen jene Fläche erschien, zum Levyn und Gmelinit gezogen, die andere aber bei dem Chabasit gelassen habe. Beobachtet man übrigens diese gerade angesetzte Endfläche genauer, so bemerkt man, dass es eigentlich keine wirkliche glatte Krystall-Fläche ist, sondern dass sie scheinbar dadurch entsteht, dass die Spitzen sehr vieler kleiner Rhomboeder genau in derselben Ebene aufhören. - Die Natur scheint hier, wenn ich mich so ausdrücken darf, mit sich selbst im Streite zu seyn, indem sie einerseits offenbar jene Fläche. bilden will, andererseits aber doch nicht dazu gelangen kamn.

Was nun endlich den Phakolith anbetrifft, so hat $\mathrm{Hr}_{\mathbf{r}}$. Professor Breithaupt nach einer gütigen brieflichen Mittheilung den Winkel des Grund-Rhomboeders $=94^{\circ}$ gefunden. Am Chabasit war derselhe $94^{0} .46^{\prime}$ nach Phillips, $93^{\circ} 48^{\prime}$ nach $H_{A U X}, 94^{0} 2^{\prime}$ nach Breithaupt selbst, s. 0. Die Phakolith-Krystalle sind höchst undeutlich, und die Messungen davon sind schwerlich, und gewiss nicht mit Sicherheit, auf $\frac{1}{2}^{0}$ zu machen, so dass ich überzeugt bin, dass der gefundene Winkel - Unterschied nicht hinreichend ist, um beide Fossilien von einander zu trennen. - Die Formen, in denen der Phakolith erscheint, sind ganz ähnlich denen Fg. 23 a und $23 \mathrm{~b}$; - nach einer gefälligen brieflichen Mittheilung von Brbixhaupr erschoinen am Phalsolith auch 


\section{- $658-$}

die Individuen einzeln, die ich am Chabasit vom Westerwald nur als Zwillinge beobachtete.

Ich glaube daher der Meinung seyn zu können, dass Levyn, Gmelinit und Phakolit nur als Zwillings-Verwachsungen des Chabasit zu betrachten sind, und mit demselben zu einer und derselben Spezies vereinigt werden müssen, - was übrigens Berzelius schon vor langer Zeit aus der übereinstimmenden Analyse für den Levyn gefolgert hat. 


\section{Geognostische Bemerkungen}

über

den Jura der nordwestlichen Schweit:, besonders des Kantons Solothurn und der Grenz-Partie'n der Kantone Bern, Aargaı und Basel,

von

Herin Amand Gressly, Med. Stud.

Durch die trefflichen Arbeiten der Herren Thirria, Thurmans und des Grafen von Mandelsloh kennen wir nun den Französischen und Berner- und den Wïttembergischen Jura: dagegen hat bis jetzt, so viel mir bekannt, noch Niemand die innige Verbindung dieser sonst so verschiedenen jurassischen Regionen studirt und dargethan. Ich werde daher versuchen, einigermassen diese Lücke durch folgende kurze Darstellung der wichtigsten Abweichungen zu ergänzen, die der Jura des Kantons Solothurn und seiner Nachbarschaften unter den beiden Beziehungen der Petround Oro-graphie darbietet. -

$$
\text { Petrographischer Theil. }
$$

Im Jura der nordwestlichen Schweitz bricht die ganze sekundäre Reihe zwischen dem Portlandstone und dem bunten Sandstein zu Tage. - Hier die kurze Übersicht ihrer Haupt-Charaktere. 


\section{A. Jura-Formation.}

(Begreift die drei oolithischen Gruppen und den Lias.)

$$
\text { I. Obere Oolith-Grupe. }
$$

Nichts ist wohl schwieriger, als das Studium dieser jüngsten und auch verwickeltesten Gruppe. Die Portlandsund Corallien-Gebilde, die dieselbe ausmachen, wechselı so häufig, so unvermuthet schnell und so ausserordentlich ihre Charaktere, dass in sehr vielen Fällen eine genaue Bestimmung höchst schwierig, wo nicht unmöglich wird und immer sehr gewagt erscheinen muss. Darum haben auch die ersten jurassischen Geologen - z. B. Meriav, Rengger; Hug1 - diese ganze Gruppe in keine weitern Unterabtheilungen gebracht und sie mit den allgemeiner'n Namen: jüngerer Roggenstein, jüngerer Jurakalk etc. bezeichnet. Herr Thurmarx hat nun jüngst in seinem Berishte über die Abhandlungen der "Société géologique des Monts-Jura" dieselbe Meinung geäussert, die mir keineswegs fremd war, und die ich zu Besançọn ebenfalls mit vielen Beispielen unterstützte. - Bis weiters muss ich aber noch immer diese Ansicht für zu gewagt halten, da doch immer, wie es meine seitherigen genauern Beobachtungen zu erweisen scheinen, sobald die Charaktere deutlich ausgesprochen sind, der Portlandien über und nie unter dem Korallien sich befindet,

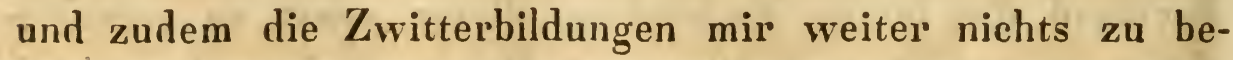
weisen scheinen, als dass man nicht zu strenge irgend eine allgemeine Regel aufstellen und sie überall bis ins Kleinliche zu befolgen suchen müsse: Niemand wird dabei den Einfluss örtlicher Verhältnisse auf die Entwickelung der Gebilde läugnen wollen. -

1. Portland-Gebilde (terrain portlandien: Portlandstone und Kimmeridgeclay).

Dieses Gebilde, so wie es von den Herren Turria und Thurmans beschrieben und charakterisirt worden ist, habe ich nirgends in dem nordwestlichen Theile des Schweitzerischen Juras mehr angetroffen. Unter tausend ver'schiedenen, 
üusserst schwankenden Formen versteckt es seine von jenen Geologen angegebenen Charaktere, so dass, wie ich schon bemerkte, die Geologen des Landes dasselbe gänzlich mit dem Rest der Gruppe verwechselten, dass Herr Thurmans und ich während mehreren Jahren seine Gegenwart, oder doch wenigstens seine gleichzeitige Emporhebung mit den übrigen Gebilden in Zweifel zogen, bis endlich bei genauerer Beobachtung sich Beides deutlich erwiesen. -

Seine so unähnlichen, so eigenen und höchst veränderlichen Charaktere schliessen sich gewöhnlich, besonders die paläontologischen *), auf eine $\mathrm{W}$ eise aus, die ziemlich natïrlich nehrere verschiedene Facies unter'scheiden lässt, deren wichtigsten die beiden folgenden seyn dürften, während die übrigen mehr wie Übergänge, denn als eigenthümliche Formen erscheinen.

\section{a. Korall-Facics mit Apiocrinites rotundus}

mit Charakteren, die bald Ablagerungen in Untiefen, bald vielleicht auch Tiefwasser-Niederschläge bezeichnen.

$\mathrm{Portlandstone.} \mathrm{Die} \mathrm{Ablagerungen} \mathrm{in} \mathrm{Untiefen} \mathrm{zeigen}$ einen mehr oder weniger reinen, oft mergeligen, mehr oder minder oolithischen Kalk, in mehr oder weniger-mächtigen Bänken. Seine hellen Farben bieten alle Nüançen des Weissgelben dar, das ins Grauliche, Blauliche und selbst Braunliche fällt. Accidenzien mancher Art fehlen nicht; so Adern und Drusen von Kalkspath, Ockerflecken; Stylolithen, Queerrisse und wie von Säuren angefressene Stellen. Überhaupt sind diese und die übrigen geognostischen Charaktere sehr schwankend.

*) Besouders merliwürdige Resultate dürften sich von Studium der paläontologischen Veigesellschaftungen erwarten lasser. Eine jede organische Gesammtheit schliesst oft strenge die andere aus, vorzüglich jene Fossilien, die für eine oder dic andere als bezeichnend gelten: so habe ich noch nie den Pterocerus Oceani mit A piocr. rotundus zusamnengefunden. Grehen einzelne Arten auch über, so sind sie doch stets verkümmert, missbildet und nieist selten. 


\section{$-662$}

Der Kimmeridien (Kimmeridge-Clay) zeigt am häufigsten einen sehr mergeligen brüchigen Kalk, reich an groben Oolithen und organischen Bruchstücken, oder auch graulich und blaulich gelbe Mergel; erdig und blättrig, manchmal reich an Fossilien.

Die Gesammtheit der Fossilien zeichnet sich durch viele Lammellen-Koralliten aus: Lithodendron $R$ a uracorum, Asträa in mehreren wahrscheinlich neuen Arten; Cyathophyllum und Anthophyllum, ferner durch manche Radiarien: Clypeaster, Cidarites, Spatangus, Apiocrinites rotundus, Pentacrinites (selten) und endlich durch eine ziemliche Anzahl von Zweiund Einschaálern, wovon mehrere dem Kimmeridge-Clay von Bruntrult eigen, wie Ostrea Kunkeli, O. solitaria! (verkümmert), Exogyra Bruntrutana, Gervillia, Perna plana Thurmann, lsocardia inflata@ - manche neue und eigenthümliche, wie gewisse Pholadomyen, Nerinea, Natica, Ostrea eduliformis s etc. Das Ganze weist überall Wesen auf, die weniger tiefe Wasser oder das Littoral bewohnen. -

Häufig ist das ganze Gebilde durch einen sehr reinen blendendweissen, oder gelblichen sehr festen, einförmigen undeutlich oder gar nicht stratifizirten, massigen, höchst versteinerungsarmen Kalk ersetzt, der Tiefwasser-Erreugniss zu seyn scheint, wenn er nicht etwa seinen Ursprung uns bisher noch unbekannten geologischen Einflüssen zu danken hat.

Diese Facies ist besonders in der Nachbarschaft von Bruntrult: so im Laufenthale und den Umgebungen Räderstorfs (Oberrhein) verbreitet. Sie behauptet mehr oder weniger dieselbe Mächtigkeit, wie der Portlandien im Bruntruttischen.

\section{b. Facies des Schildkröten-Kalks Hugr's}

mit archipelischen und subpelagischen Formen. Hier unterscheiden sich die Unterordnungen Portlandstone und 
Kimmeridge-Clay noch weniger, als in der Korall-Facies; sie sind vielmehr in einander verschmolzen, und der Kimmeridien erscheint nur noch in Form einiger schwachen MergelAblagerungen.

Die archipelischen Formen zeigen in ihren Charakteren sehr veränderliche Kalke, in häufig mächtigen Bänken, die durch leichte grünliche oder bunte Mergel-Einschaltungen oft mit Pyriten, Asphalt und andern Accidenzien verunreinigt, von einander geschieden sind, besonders in den tiefern Theilen des Gebildes. Diese Form enthält eine Menge Portlandische Fossilien und wieder andere, die ihr eigenthümlich sind. Thre Gesammtheit zeichnet sich folgendermaasen aus: Nerinea depressa Voltz, Exogyra Bruntrutana Terebratula biplicata, Tellina incertas Thurm., Pteroceros Oceani Brongn., mehr noch durch Fisehreste: Astracanthus ornatissimus Aasss., Gyrodus, Sphaerodus, Pyenodus, Psammodus reticulatus, durch Sauroïden und Saurier (Megalosaurus, I chtysaurus@ und Plesiosauruṣ̣, das Krokodil von Caen; durch Süsswasser Chelonier (Emys Cuv.), dureh Pterodactylus und Säugethiere aus der Klasse der Dickhäuter, wie Pa la e o the ri u m c ras s u m Cuv. et Douvernoy; Anoplotherium gracile Cuv. und noch einen andere kleine Dickhäuter oder Wiederkäuer, einen I gels, was Alles auf eine urweltliche niedrige Inselwelt mit Süsswassern, dem Aufenthalte der genannten verschiedenen Thiere, hinzuweisen scheint. *) -

*) Wir verdanken diese höchst wichtigen Thatsachen dem unermüdlichen Forschungseifer des rühmlichst bekannten Herrn Professor F. J. Hugr in Soluthurn. Statt weiterer eigener Umstäıdlichkeiten über diese Entdeckungen und ihre Örtlichkeit verweise ich einestheils auf das, was davon in Cuviers "Recherches sur les ossemens fossiles" steht, andererseits füge ich hier einen Brief des Herrn Hugr bei, worin er mir jede erwünschbare Nachricht mitzutheilen die Güte hatte. -

„In unsern Steinbrüchen wurden sonst 9 Schichten, scit 2 Jahren aber noch eine tiefere ausgebcutet: unter diesen 10 wird der Kalk mäch. 


\section{$-664$}

Der Kimmeridge-Clay ist wenig oder gar niclit ausgesprochen, wenn ihn nicht die zumal nach unten häufigern

tig und grob (Coralline?). Jene 10 Schichten treten in allen Gruben unter gleichen Verhältnissen auf. Sie breiten sich ununterbrochen über die ganze Gegend aus; unter der Riese (am Weissenstein) leinen sie sich an den Fuss der Riesefluh, welche den tiefern Schichten von der Steingrube identisch ist. Nur sparsam sind unsere Steinbrüche durch senkrechte Spalten, doch ohne Zer. werfung, getrennt. Sie gehen durch alle Schichten, setzen aber nicht weit fort, nach unbestinmten Richtungen, sind klein und scheinen durch Trockunug entstanden. - Oft sind die Wände derselben mit Asphalt ïberzogen, oft mit Kalkspath, der Raum nur mit Thon oder sinteriger Kalkmasse ausgefüllt, nie durch Anderes, Fremdartiges! - Zwischen den Schichten selbst liegt meist eine zarte Thon-Lamelle, die zwischen der 4 ten und 6ten Schichte mit Sand sich mischt und zu einer Mergelschichte wird, in welcher bei st. Niklaus, wo sie mächtig wird, die best erhaltenen Schildkröten sich finden. - - Die oberste Schichte nun ist östlich nur einige Zoll mächtig, in den westlichen Gruben dagegen über 6 F. dick und dann in 2 Schichten auftretend. Diese Schicht ist matt weiss, nach allen Richtungen leicht zerspiengbar und zu Bauwerken untauglich. In ihr ist die Fanilic der Nerineen vorherrschend; diese sind wach allen Richtungen in die Masse gewirkt, meist als Fragnente und so mit dem Gesteine verschuolzen, dass sie schwer zu erkemnen sind; das lnuere der Schaale ist mit Kalkspath gefiilt. Andere Konchylien fand ich in dieser Schichte nicht, ausser einem Ammoniten. Nur hier kommen vor die Rückenstacheln von Astracanthus ornatissimus, dann manche Vögel-Kuochen (diese hier ausschliesslich), ferner finden sich einzelne Fragmente von Schildkröten, einzelne Zälıe von Gyrodus, Sphacro. dus, Pycnodus. Hier fanden sich zwei Zähne vou Paläotherien: Alles in festem Gestein. Zwischen dieser und der folgenden Schichte Iage 2 Wir be I (einer wahrscheinlich einer gigantischen Frosch-Art nach Duverior, der andere einem Igel, Duvernoy zugehörig) und 2 Astragalus (der eine kleinere wurde von Cuvier als von Anoplotherium gracile erklät)nicht inspalten, sondernzwischenden Schichten. In der $z$ weiten Schichte erscheinen die Nerineen nur noch als Einzelnheiten, dagrgen hier zuerst Zweischaaler: unförmliche Austern und einzelue Terebrateln. Die Schildkröten-Fragmente werden hier häufiger; es zeigen sich Spuren von Cidarite n (C. crenularis etc.). - Zu obigen Fischzähnen erscheinen hier die von Psammodus reticulatus. Auch aus dieser Schicht ein dritter Mahlzahn aus dem Unterkiefer von Palaeothe. rium crassum Cuv. et Duvern. Auch erscheinen sparsam einzelne 
Mergellagen oder ein oolithischer, kreidiger Kalk mit vielen Fossilien aus dem Bruntrutter Kinmeridge-Clay vorstellen sollen.

Die subpelagische Form zeigt mehr oder minder mergelige, schiefrige Kalke und gelbgraue blättrige mehr oder weniger entwickelte Mergel, die bald oben bald unten liegen und vielleicht den Kimmeridge-Clay vorstellen. Unter den je nach dẹ Lokalitäten mehr oder weniger zahlreichen Fossilien kommen viele Tiefwasser-Organismen vor: Ostrea eduliformis, mehrere Ammoniten, die dem biplex und triplex ähneln, Belemniten; ausserdem mehrere Pecten, einige Radiarien und einige Portland-Fossilien. - Diese Form macht den Übergang von den Schweitzerischen zu den Württembergischen Formen.

Diese Facies herrscht in den Ketten, die das Schweitzerische Becken begrenzen, vor; die archipelische Form in den Ungebungen Solothurns, die subpelagische um Olten, gegen Aarau.

Saurier-Zähne. - Die dritte Bank ist durch eine Mengc Terebrate In charakterisirt, die Austern der zweiten Bank bleiben, und die Nerineen der ersten Schichte erscheinen hier wieder. Hier Megalosaurus, das Krokodil von Cren, andere K rokodil-Wirbel (Cuvier) und Sa urier-Zähue. Die oben angeführten Fischzähne werden sparsamer, ebenso die Schildkröten. Die 4te Schicht verhält sich wie die 3 te, und ist schwer von ihr zu unterscheiden. Die 5te ist jene Mergelschicht, in der die ganzen Schildkröte n (auf dem Bauche liegend) sich fauden, in allen übrigen nur Fragmente. Nur hier der Pteroceros O ce a $\mathrm{n}$; ; einzelne Nerineen, Echiniten und Zahnschuppen, die Cuviar so bestimmte ,peutêtre une portion de l'émail d'une grosse dent de paléotherion", die aber uun Agssiz als Fischähne erklärt. Die 4 tiefern Bänke sind von einander durch nichts ausgezeichnet. In ihnen erscheinen einzelne Fragmente von $\mathrm{S} c h$ ildkröte n, eimzelne Saurier, Psam modus, Gyrodus, Pycnodus, einzelne TerebrateIn, Austern, Nerineen. In der 3ten und 4ten Bank 2 oder 3 Koralliten (Asträen)".

So weit Herr Hvar. - Zur Bekräftigung dürfte es nicht ungeJegen sey", zu bemerken, dass ich selbst letzten Herbst das Glück hatte, dem Funde eines $P$ a $I$ a e o the ri um-Zahns, in dem jurassischen Schildkrötenkalke cingeschlossen; beizuwohneu.

Der Verfasser. 


\section{$-666$}

Oft ist diese Facies ebenfalls durch den einförmigen Kalkstein ersetzt, der für die Korallfacies als wahrscheinliche Hochsee- oder besser Tiefwasser-For'm angegeben wurde.

2. Korallien'-Gebilde. (Terrain corallien Thirr. et Thrrm.)

Dieses Gebilde, wenn gleich eben so veränderlich wie das vorige, bietet nur ein untergeordnetes Interesse dar, indem seine Modifikationen keine so deutlichen und bestimmten Bildungsur'sachen anzeigen, als die Abänderungen des Portlandiens.

\section{a. Astartenkalk (calcaire à astartes).}

Die Unterordnung verbindet sich mehr oder weniger mit dem Portlandien oder gehört vielmehr häufig zu demselben. Das bezeichnende Fossil, die Astarte minima, scheint im Bruntruttischen besondere Formen der Korall-Facies mit A p. rotundus anzudeuten, welche eher mit dem KinmeridgeClay zusammenfallen als ein eigenes Glied des Gebildes ausmachen. Übrigens habe ich vom Bruntruttischen an bis nach Aarau die Astarte minima nur noch in einer einzigen Lokalität angetroffen, und diese gehört ganz gewiss zur portlandischen Korall-Facies mit A p. rotundus. Ich beobachtete übrigens häufig von oben nach unten folgende Lagerungsweise:

1. Ein mehr oder weniger bräunlicher, rauchgrauer, nicht sehr fester Kalk, fast ohne Fossilien, und eher unregelmässige, durch einander geworrene, mehr oder weniger verflossene Nieren, als gut-geordnete dicke Bänke bildend. Wenig entwickelt.

2. Ein bräunlicher, fester, etwas krystallinisch-spathiger Kalk, nicht unähnlich gewissen Gebirgs-Arten des untern Ooliths. Ebenfalls nur wenig entwickelt.

Diese beiden Kalke sind nicht sehr verbreitet und folgen der Facies ınit Ap. rotundus. Am gewöhnlichsten ersetzt sie ein sehr reiner mattweisser oder weissgelber mehr oder minder deutlich oolithischer Kalkstein, den unbedeutende Mergel-Einschaltungen in Bänke von ungefär 2 bis 3 Fuss 
Dicke trennen, und der oft eine Mächtigkeit,von 20 und mehr Metern erreicht. - Die Fossilien sind selten und wenig bezeichnend (Nerineen, Natica, Diceras), gewöhnlich in den Mergeln zerstreut. Dieser Kalk trägt oft täuschend die Karaktere des Hochsee- (besser: noch Tiefwasser-) Portlandstones. - Dann fehlen die folgenden Unterordnungen vielleicht durchgängig. -

b. Nerineen-Kalk (calc. à nériuées).

Diese mehr oder minder entwickelte Unterordnung ist oft dureh einen mit dem so eben beschriebenen identischen Kalk ersetzt, oder mit der folgenden Uuterordnung verflossen.

Sie charakterisirt sich sonst durch einen sehr reinen, blendendweissen, mehr oder minder kreidigen Kalk ohne besondere Festigkeit, der Steinkerne und spathige Bruchstücke von Fossilien einschliesst. Diese und besonder's Stückchen von ästigen Korallen, z. B. Lithodendron, sind oft durch die Reibung in mehr oder weniger vollkommene Oolithe verwandelt *). Die kalkigen Fossilien sind freilich zahlreich, doch zerbrochen und verschliffen. - Lamellen - Koralliten, Nerinea Bruntrutana, Melania sind vorherrschend.

c. Korall-Kalk (calc. corallien, coralrag. Tirrr. et Thurm.)

(Anmerk. Der darüberliegende, nach Einigen eine besondere Abtheilung bildende Korallien-Oolith ist nur selten entwickelt und dann immer mit dem Nerineen-Kalk oder dem Coralrag zusammenfallend.)

Der mehr oder minder siliziöse Korall-Kalk ist etwas oolithisch; oft, besonder's wenn Polypenstöcke vorhanden, Zucker-ähnlich krystallinisch; von Farbe graulich oder

*) Scharfsinnige Beobachter haben auf die Verschiedenartigkeit der Oolithe aufmerksam gemacht, und die durch Reibung entstandenen: "Oolithe", die schaalig-konzentrischen durch Niederschläge entstandenen "Pisolithe" zu nennen vorgeschlagen. Zum innigeren Studium der Gebirgsarten ist diese Unterscheidung gewiss von hoher Wichtigkeit. 


\section{$-668$}

schmutzig gelb; häufig mit weiten runden, eckigen oder verzogenen tief-blaugrauen oder braunen Flecken versehen.

Die Fossilien zahlreich, siliziös, mit der umgebenden Gebirgsart innig verschmolzen, gehören beinahe ausschliesslich den Lamellen-Koralliten an. Dieser Kalk bildet gewöhnlich den Übergang des obern Ooliths auf das Chailles-Gebilde der Oxford-Gruppe. Ist das Chailles-Gebilde nicht entwickelt, so pflegt er verschiedenartig ersetzt zu werden.

Je weiter man sich von Bruntrutt aus gegen Norden, zunal etwas östlich durch die Solothurner Ketten gegen den Aargau wendet, um so mehr verliert der Korallien allmählich seine bedeutsamsten Merkmalc, die wie jene des Portlandiens immer ungewisser werden. $E r$ ist in der Nachbarschaft des Bruntruttischen, z. B. im Laufenthale noch ziemlich gut charakterisirt, sehr undeutlich hingegen in den meisten nördlichen Theilen des Solothurner- und AargauerJuras.

Ich muss noch bemerken, dass die ganze obere OolithGruppe, zumal wieder im Norden, sehr häufig durch jenen ausgezeichnet reinen, kompaliten, spröden, weissgelben Kalkstein zusammengesetzt wird, der durch die Einförmigkeit seiner Charaktere, durch seine mächtigen, massigen Bänke und den beinahe gänzlichen Mangel an Versteinerungen dem Beobachter schnell auffällt, und den ich.schon mehrere Male als den Stellvertreter der einen oder der andern. Unterabtheilung anzugeben Gelegenheit hatte. Gegen den Norden des Kantons Solothurn wird er ziemlich häufig mergelig und zeigt ein Verhalten, das, sonderbar genug, ausnehmend an den Portlandien erinnert. - Auf diese Weise bietet er sehr auffallende Analogie'n mit dem Kalke der Wïrtlemberger Alb.

\section{Oxfordgruppe.}

Hier zeigen sich die Modifikationen nur allmählich und diese mittlere Juragruppe bildet zwei Abtheilungen, die deutlich geschieden und gut charakterisirt sind, doch nur 
in den Gegenden, die das Bruntruttische begrenzen: so im Laufenthale. In ihrem Verliafe durch den Kanton Solothurn hingegen verlieren sie nach und nach die von $\mathrm{H}_{\mathrm{rn}}$. Thurmans angegebenen Charaktere, um sich innig mit der Württemberger Osford-Fazies zu verbinden.

1. Chailles-Gebilde.

Es bildet wiederum zwei Unterordnungen, eine obere von nicht gar festen Mergelkalken gebildet, und eine untere, die aus den Sphäriten-Mergeln besteht.

Die erste Unterordnung zeichnet sich durch die Gegenwart stark siliziöser Mergelkalke aus, die in vielen Lokalitäten besonder's des Laufenthals und seiner Nachbarschaft eine Menge der charakteristischen Fossilien des Bruntruttischen einschliessen. Nur sind die Chailles (siliziöse Konkretionen) gänzlich verschwunden, die in der Haute-Scone, den Französischen Jura und auch im Bruntruttischen diese Abtheilung bezeichnen. Eben so verlieren sich nach und nach in fernern Fortschreiten nach Norden auch der Kieselgehalt der Gebirgsarten und die siliziösen Fossilien; die mergeligen und kalkigen Gebirgsarten beginnen sehr vorzuherrschen, bis endlich keine Kieselspur mehr übrig bleibt und ein schiefriger, mehr oder weniger fester, bräunlicher oder rauchgrauer, gefleckter, gut geschichteter Mergelkalk auftritt, der sirh durch Mergel-Lamellen in Lagen tremnt, die selten die Mächtigkeit einiger Zolle überschreitet. Dieser sogenannte Lettstein vertritt dann die obere Unterordnung. - Der Kieselgehalt zeigt hier vielmehr einen Übergang des Korallkalkes auf das Chailles- und Sphäriten-Gebilde, als das eigentliche "Terrain à Chailles" der Haute-Saone etc. an, oder deuteu es nur schwach an.

Die Gesammtheit der Fossilien ist die gleiche, wie im Bruntruttischen, was die kieseligen Gebirgsarten betrifft: je mehr aber der Lettstein überhand nimmit, um so mehr verschwinden die siliziösen charakteristischen Fossilien des Bruntrutter Juras, und fehlen endlich durchaus. Sie sind damn 
nach und nach durch Versteinerungen ersetzt, die sonst dem Oxford-Clay angehören, oder besser noch durch eine neue Vergesellschaftung, die dem geschichteten Kalke der Oxfordgruppe der Wïttemberger Alb eigen ist, und die sich durch mehrere Ammoniten (A.biplex, triplex, cordatus, flexuosus@) und Pentacrinus pentagonalis auszeichnet. Man findet ferner noch ziemlich häufig die Cnemidien und Scyphien der Alb, die nach Herrn Grafen vos 'Mandelsloh sich schon im Koralrag vorfinden. Alles ist auf die gleiche Art, wie am Randenberg versteinert.

\section{b. Untere Unterordnung. Sphäriten-Mergel.}

Gleichzeitig und auf dieselbe Weise, wie die obere Unterordnung ändert sich auch der Charakter der unteren (Sphäriten-Mergel). Die im Bruntruttischen vereinzelten Sphäriten nähern sich und verfliessen in mehr oder weniger fortgesetzte Lager eines Kalkes, der sich durch seine Kennzeichen an den Lettstein schliesst. Die etwas seltenen Fossilien beschränken sich auf einige Pholad om ye n (Pholadomya bucardina D'orb.), Pleurotomarien und die Ammoniten des Lettsteins. -

2. Oxiord-Mergel (Oxford-Clay, marnes oxfordiennes).

Auf weite Strecken sind diese Mergel ganz wie im Bruntruttischen gebildet. $\mathbf{A b e r}$ auch sie ändern nach und nach, indem sie allmählich ihren Asphalt-Gehalt, ihre Pyrite und die pyritösen Fossilien verlieren. Sie werden blättrig, schiefrig, mehr oder minder fest, graublaulich, mengen sich mit dünnen glïnzenden Kalkspathschiefern, - und gewinnen ïberhaupt an Kalkgehalt. - Dann ist die Gesammtheit der übrigens wenig zahlreichen Fossilien mit der des Lettsteins identisch. -

Wir sehen durch diese allgemeine Entwickelung des Lettsteins sich das Chailles-Gebilde mit dem Oxford-Clay so innig vereinigen, dass jede Unterordnung der ganzen OxfordGruppe verschwindet. 
Diese Lettstein-Facies herrscht in dem grössten Theile der Solothurner und Aargauer.Ketten, besonders in jenen, die das Becken der Schweitz begrenzen und die den Schweitzerischen Jura mit dem Würtlembergischen verbinden. Die dem Bruntruttischen eigenen Formen finden sich nur hie und da auf immer seltenern Punkten vereinzelt.

\section{Untere Oolith-Gruppe (groupe oolithique inférieur).}

In dieser Gruppe sind die Abweichungen weit weniger bedeutend, als in den beiden vorigen. Überhaupt bewahrt sie die vorzüglichen Charaktere, die sie im Bruntruttischen aufweist. Ich werde mich also auf die folgenden Bemerkungen beschränken.

a. Die Dalles nacrées (Perlschiefer) und der GreatOolith sind bei Weitem nicht mehr so gut charakterisirt als im Bruntruttischen: oft scheinen sie, besonders letztere, gar zu fehlen. Die Mergel mit Ostrea acuminata scheinen häufig nur eine mergelige Ab:inderung der Dalles nacrées zu seyn, indem sie, so bald letztere vorhanden, bald über, bald unter denselben liegen. Beide sind oft durch einen eisenschüssigen Kalk ersetzt, von Farbe rothbraun und von veränderlicher Festigkeit. Er enthält eine grosse Anzahl Fossilien, besonders Ammoniten, die für den untern Oolith bezeichnend sind. Überall aber zeichnen diese ganze Serie die unzälligen Exemplare von Ostrea acuminata und O. costata (O. Knorrii) aus.

b. Sehr feste, etwas krystallinische mehr oder weniger deutlich oolithische Kalke, bräunlich oder auch dunkler gefärbt, dann sublompakte, graubraune, oolithische, oft tief blaugrau gefleckte Gebirgsarten machen die Hauptmasse der Gruppe aus und gehen auf den Rothsand-Kalkstein und den Eisenrogenstein (calcaire-roux-sableux et oolite-ferrugineuse) über. -

c. Endlich beschliesst der oft sehr entwickelte röthliche, gelbliche, oft bunte Marlysandstone die ganze oolithische 
Reihe. Er enthält sehr häufig unkenntliche Pflanzen-, besonders Fucoiden - Reste. Oft ist er hingegen sehr wenig entwickelt und schliesst sich an den

\section{Li a s.}

Das Lias-Gebilde, aus den obern Lias-Mergeln und den Gryphiten - Kalken bestehend, weist keine etwas bedeutenden Abweichungen mehr auf, und besitzt alle Haupt-Kennzeichen, die es anderwärts unterscheiden.

a. Die Lias-Mergel sind gleich jenen des Bruntruttischen und des Französischen Juras, nur schliessen sie keine Fossilien eil. Gegen den Deutschen Jura hin werden sie mächtiger, als in der Nachbarschaft Bruntrutts. Man sieht platte, blaue, sehr zähe und feste Eisen-Karbonat-Nieren immer häufiger werden. Sie sind sehr rissig, wie zerquetscht: die Risse selbst sind mit Cölestin (sulfate de Strontiane), Baryt $९$ und Sehwefelkies auskrystallisirt. Sie korrespondiren vermuthlich den an Ammoniten so reichen Sphäriten von Gundershoffen (Niederrhein), nur fehlen auch hier Versteinerungen.

b. Die Gryphiten-Kalke weisen hier wie überall durchaus dieselben Charaktere auf. Die sehr verschiedenartige Gesammtheit der Fossilien enthält alle eharakteristischen Arten. Ihre Zahl vergrössert sich, wie man dem Schwarzwalde und der Alb näher kömmt. Besonders fällt dem Beobachter die Menge fossilen Holzes (C yс as \$) am den Schwarzwald auf. -

\section{B. Trias-Formation Alber'ris.}

Sie begreift den Keuper, Muschel-Kalk und den bunten Sandstein. Alle diese Gebilde sind im Norden gut entwiekelt. In den Kantonen Solothurn und Aargau der Keuper und Muschel-Kalk, im Kanton Basellandschaft kömmt noch der bunte Sandstein meist längs dem Rheine hin dazu. - Was diese Gebilde anderwärts bezeichnet, gilt auch für diese Gegenden. - 


\section{Orographischer Theil.}

Die orographischen Erscheinungen des Solothurner und Aargauer Juras bestätigen völlig die theoretischen Ansichten der Hebung, die Hr. Thurmans mit so vielem Erfolg auf die Ketten des Berner Juras angewendet. Nichts desto weniger werde ich im Falle seyn, auf mehrere sehr: interessante orographische Abweichungen aufmerksain zu machen, die sich am Natürlichsten nach ihren Ursachen klassifiziren lassen.

1. Abweichungen, die ihr Daseyn den Modifikationen der Gebilde selbst verdanken.

Wiewohl sich diese Abweichungen auch im Bruntruttischen beobachten lassen, sind sie vielleicht doch noch deutlicher im Solothurner und Aargauer Jura ausgesprochen. -

Wenn ein Gebilde oder eine ganze Gruppe von Gebilden in seiner ganzen Mächtigkeit aus kompakten Gebirgsarten besteht, so wurde jede Beugung und Wendung unmöglich und hatte so $B$ rüche zur Folge, von denen sich starkhervorspringende orographische Zufälligkeiten herleiten, wie z. B. steile Kämme, vereinzelte Stöcke, was wirklich auch die meist feste obere und untere Oolith-Gruppe und den Muschel-Kalk sehr häufig auszeichnet. -

Wenn hingegen die Gebilde aus Mergeln bestehen, oder

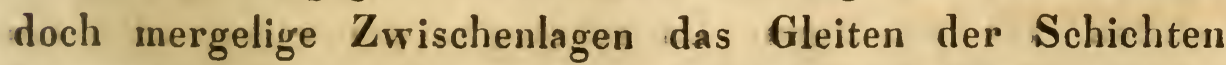
begünstigen, so sprechen sich Kämme und Stöcke selten aus, sondern die Formen sind wehr abgerundet, weniger kühn. Dieses findet für die Oxford-Gruppe in normalen Zustande, fül den Lias, Keuper und den obern Oolith im anormalen Zustande durchgehends Statt, so bald sie jene angegebenen Bedingungen in sich vereinigen. -

Besonder's für die Oxford-Grappe ist der Einfluss der Dichtigkeits-Verhältnisse auf die orographische For'm bemerkenswerth. Wenn nämlich die Gebilde aus verhärteten 
Mergeln oder gar aus Kalksteinen bestehen, die dem Wegwaschen Widerstand zu leisten vermögen; so sind die Komben (combes Provinzialism, der im Französischen Jura etc. schmale, weitlaufende Thalvertiefungen bezeichnet, die dem Jura eigenthümlich sind) nur schwach angedeutet und, anstatt enge und tief ausgefressen zu seyn, wie meist im Bruntruttischen, bilden sie breite, mehr oder minder geneigte Flächen, oft von den Queerrissen ( $r u z$, ein für diese $\mathbf{Z u}$ fälligkeiten eigener Ausdruck der Französischen Jura-Bewohner, gleichbedeutend vielleicht mit Tobel), die den obern und untern Oolith durchsetzen, unterbrochen. Dieses leitet sich einerseits vom Gleiten der dünnen, getrennten Lettstein-Schichten her, was diesen gestattete, sich bis an den Gipfel der Unteroolith-Gewölbe (voûte, Dom@) festzuhalten; andererseits liessen dieselben Gebilde kein bedeutendes Auswaschen zu. Hie und da bemerkt man für die OrfordGruppe die Zufälligkeiten von Kämmen, Hebungsspalten, wie im festen obern und untern Oolith, was Alles denselben Ursachen, die hier wie dort das Gleiten verhinderten, zugeschrieben werden muss. - Vgl. Tf. VIII, Fg. 2.

\section{Abweichungen, durch Modifikationen des Hebungs-Aktes entstanden.}

Diese sehr interessanten Abweichungen erscheinen vorziiglich da, wo der Muschellalk zu Tage bricht. Sie bestehen aus mächtigen Umstürzungen der einen oder der andern "Seite der Ketten, was verschiedene Zufälle der orographischen Verhältnisse veranlasst, wie z. B. zu chaotisch durch einander gestürzten, verworrenen Schichten, zu Trümmerbildungen und zur Zerwerfung von Gebilden susser ihrer normalen Lage. -

Im Norden des Kantons Solothurn und im Aargau bemerkt man wieder eine andere Abweichung, die Kreutzung und die Vereinigung zweier oder mehrerer Ketten in eine einzige. Dieses gibt wiederum Anlass zu manchfachen 
Zufällen, zu grössern oder kleinern losgerissenen Stücken von Gebilden (lambeaux) und auch zu einem unerklärlichen Gewirre von Ketten und unregelmässigen Massen. Je mehr überhaupt die ältern Gebirge auftreten, um so verwickelter wird der Hebungsplan der Ketten. Diese nehmen zugleich eine grössere Basis ein, die jüngern Gebilde zeigen sich nur noch in einzelnen Bruchstücken und schinalen Bändern, und die untere Oolith-Gruppe, der Lias, der Keuper und Muschel-Kalk bedecken die grössere Fläche, was Alles sich besonder's im Aargau und der Basellandschaft beobachten lässt. - Vgl. Taf. VIII, Fg. 1, die Balmberge.

3. Abweichungen, durch geologische Einflüsseverursacht, die erst nach der Hebung stattfanden.

Sie bestehen aus Zufälligkeiten, die ihr Daseyn dem Wegschwemmen von mehr oder minder bedeutenden Gebirgsmassen und dem Ausfüllen durch nenerzeugte Gebilde zu danken haben. Beides geschah wärend der tertiären und quartären Epoche. So sind im Kanton Basellandschaft Molasse - und Süsswasser-Kalksteine auf den Entblössungen des untern Ooliths abgesetzt worden. Diese Ablagerungen wurden dann wieder während der quartären Epoche zerstört; vorzüglich durch die Wassermasse des SchweilzerBeckens, welche den jurassischen Damm zwischen dern Schwarswald und dem Jura von Rheinfelden bis gegen Basel hin durchbrach.

Alle diese Erscheinungen mussten verschiedenartige Breccien, aufgeschwemmtes Land zur natürlichen Folge haben und überdiess noch sehr zur Unregelmässigkeit der vielfach zerstörten Ketten mitwirken, abgerundete und längliche Stöcke und Ilügel und Auswaschungs - Thäler bilden. Alles dieses ist in Basellandschaft besonders längs dem Rhein-Kanal hin gewöhnlich. 


\section{Nachtrag}

zu den

\section{Beobachtungen über Kiesel-Gebilde und Silizifikation der organischen Reste,}

von

\section{Herrn Ober-Bergrath v. Volth.}

Im Verlaufe des jüngst verflossenen Märzes erhielt ich die Nachricht, dass auf dem nordöstlichen Gehänge der auf dem rechten Ufer der Donau unweit Regensburg vorbeiziehenden Jurakalk - Hügelreihe der Grund zu einem Keller ausgegraben und ein Brunnen abgesunken werde. Die in den letzten Tagen dieses Monats endlich eingetretene freundliche Witterung beeilte ich mich mit Freuden zur Untersuchung jener Punkte zu benutzen. Der Keller bot wenig Belehriung dar. Zu oberst lag Ackerkrume mit Grünsand-Schotter; ihm folgte der magere Ziegellehm, welcher die Ebene zwischen der Donau und der Hügelreihe und das nordüstliche Gehänge derșelben entlang bedeckt; zuletzt kam man auf den Grünsand selbst, welcher aus verschiedenen meistens sehr leicht verwitternden Lagern mit den gewöhnlichen Petrefaliten besteht. Eben diese Schichten traf man in der ober'n Tiefe auch mit dem etwa 25 bis 30 Schritte entfernten Brunnen. Der Grünsand hielt mit der nämlichen Abwechselung der Lagen gegen 48 bis 50 Fuss wieder an und 


\section{- 677}

ruhte auf einer 10 bis $12^{\prime}$ mächtig wechsellagernden Sandund Sandstein-Schicht. Das eine wie das andere Gemenge besteht aus abgerundeten Körnern von der Grösse des MohnSamens bis zu der der gemeinen Erbse, an Menge und Grösse bei Weitem vorherrschend aus röthlichgrauem bis graulich - fleischrothem fast durchsichtigem Quarz und gelblich - oder röthlich - weissen, öfters, besonders im feuchten Zustande, ziemlich lebhaft opalisirendem, stets mehr oder weniger verwittertem Feldspathe, und aus einem ockergelben sehr zähen Thone, welcher hin und wieder in Streifen ausgeschieden ist, und so sehr erhärtet, dass er dem Stahle mehr als jeder Feldstein wiedersteht. Im losen Sande waren mit dem Sandstein ganz identische Konglomerate von manchfacher Grösse, Gestalt und Härte unregelnässig zerstreut. Die oberste Sandstein - Schicht zwischenlagert eine 3 bis 4 " mächtige Lage Eisensandsteines von dem gleichen Korne und Gemenge, und überzieht auf den Spaltklüften bandförmig farbenwechselndes Eisen-0xyd.

Der lose Sand, seine Konglomerate und der Sandstein enthalten eine nicht unbedeutende Menge Petrifikate, aber, wenigstens innerhalb des aufgeschlossenen Raumes fast ausschliesslich*) nur Gryphites spiratus Sснцотн., nun Exogyra columba. Die kalkige Schaalenmasse der in den SandsteinSchichten und Konglomeraten eingeschlossenen Individuen ist auf der äussern und innern Fläche in, manchmal in die geschlosseu-dicht-faserige kalkige Mittellage unregelmässig eindringende, Chalzedon-artige, oberflächlich glatte Rinden allmählich übergegangen, und über diese von dem nämlichen Thone (zum Theil mit dem Kalke der Schaale gemengt) bedeckt, welcher das Bindemittel dieser Gesteine bildet. Quarz- und Feldspath - Körner haben sich stellenweise in denselben verschieden tief eingesenkt - jene der in losen Sande liegenden von einem bald in den einen, bald in den

*) Nur kleine Terebratelu der Grüusand - Formation habe ich hic und da ausserdem bemerkt. 


\section{$-678$}

andern ühergehenden Mittelgebilde zwischen Chalzedon und gemeinem Quarze ersetzt, wie es im Hornsteine des Tripels um Bodenwöhr und Amberg häufig gefunden wird, und die bei Bodenwöhr im $\mathbf{T} \mathbf{r}$ i p e l vorkommenden Muscheln silizifizirt.

Ich besitze nun aus dem gedachten Brunnen über 100 mehr oder. weniger vollkommene Bruchstücke (nicht aber e in einziges vollständiges Exemplar)*) von auf diese Art verkieselten Unterklappen und Deckeln der letztern Exogyra. Beim ersten Anblicke ähneln sie von Aussen, nach dem Ausdrucke eines Arztes, kariösen Knochen; im Innern zeigt sich, dass sich von ihrer gesammten Masse nur die äussersten Wände in sehr dünnen (von $\frac{1}{10}$ bis höchstens $\frac{1}{4}$ "' dicken) kieseligen Rinden erhalten haben. Den Raum zwischen denselben erfüllen theilweise oder ganz bald in Gestalt und Gesteinsart manchfaltige kieselige Stalaktiten, bald ein sehr zartes lockeres, in der That Knochen - ähinliches, solches Gewebe. Nur äusserst selten finden sich zwischen den ersten kleine Büschelchen und noch seltener von denselben nach ihrer Ausbreitung hin verschieden unterbrochene Lagen der ursprünglichen faserigen Textur, welche durch ihre lichte-gelblichweise Farbe sogleich in die Augen springen und, laut der Wirkung der Salpetersäure auf sie, ihre natürliche kalkige Beschaffenheit unverändert und unvermischt beibehalten haben.

Jene kieseligen Wände oder Rinden bestehen aus 2 sehr leicht trennbaren Lagen; wesswegen die äussere, kaum Spinnengewebe dicke, schon beim Funde gewöhnlich fehlte. Sie erscheint bald ununterbrochen zusammenhängend und rundlich durchlöchert mit in die Löcherchen eingesenkten Quarz - Körnchen - bald aus scheibènförmigen kreisrunden Theilen, im Mittelpunkt meistens durchbohrt - zusanmengesetzt. Sie ist mehr oder weniger ockergelb und in beiden

*) Es sind alle Anzeichen da, dass diese Zertrümmerung der Schaalen unmittelbare Wirkung des Silizifikations-Prozesses seyen. 
Fällen mit gelblichweissen kreisrunden oder schneckenfürmig gewundenen [§], etwas erhabenen und in der Mitte vertieften oder durchbohrten kieseligen Körner'n dicht oder weitläufiger bestreut. Seltener haben sie sich zu einem Systeme konzentrischer Ringelchen von geringer Anzahl ausgebildet.

Unter der Oberhaut erblickt man eine Manchfaltigkeit und ein Gewirre solcher Ring - Systeme, die zu beschreiben beinahe ans Unmügliche grenzt. Ich hebe daher nur das Wichtigste aus. Sie bedecken die Schaale dicht nicht nur auf der konvexen und konkaven Oberfläche, sondern auch längs und queerüber den Layen des dickern Randes der Unterklappe und des Deckels. Die Systeme bestehen aus 2 bis 10 Ringen und ähneln flachgedrückten, oben abgeschnit-

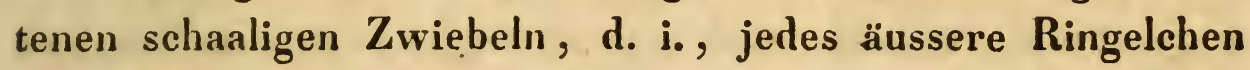
biegt sich über das gegen Innen nächst anliegende dicht angeschlossen ein. Ganze Ring - Systeme weichen verschieden von der Gestalt des Kreises an. Wenn auch jedes von zweien oder mehreren Ring-Systemen sich Anfangs für sich ausbildet, so schliessen doch endlich die äussern Ringelchen alle jene Systeme ohne Unterbrechung oder Verwirrung ein; höchstens beinerkt man beim Zusammenstossen zuerst einen krummlinigen Winkel, welcher sich allmählich vernindert und zuweilen endlich ganz verliert. Das innerste Ringelchen ist fast inmer vertieft, oft durchbohrt; die äusersten scheinen verschieden geborsten. Nicht nach allen Richtungen haben sie gleiche Dicke; ja sie wechseln stellenweise hierin in kurzen Abständen. Ihre oberen Ränder sind uneben und gerundet, wohl auch abgesondert körnig. Beim Zusammenstosse verbundener oder nicht ver'undener Systeme bilden sich die Ringelchen nur nach der freien Seite hin, und im ersten Falle so lange nur dahin aus, bis sie das benachbarte einzuschliessen geräumig genug werden. Von Verdrückung der Ringelchen bei Berührung eines andern Systems konnte ich nichts gewalıren, wohl aber, dass sie übereinunder aufsteigen und mit den Enden ineinander verschmelzen und zwischen sie tretende fremde Gebilde ausweichend 
umzuschliessen. Zwischen den Systemen sind verschieden gestaltige Gruppen rundlicher Körner angehäuft; der Durchmesser derselben wechselt zwischen 1-3 Linien. Terebratel-u. a. Konchylien-Stücke aus dem losen Sande der Königswiesen bei Regensburg (mit deın Galgenberg zusammenhängend) zeigen Rings-Systeme von 4"' Durchmesser und $\frac{1}{4}$ "' Höhe. Die Schaalen - Lagen sind getrennt, und jede ist auf beiden Flächen dicht mit solehen Kieselringehen besetzt.

Hier glaubte ich die Reihe meiner Beobachtungen über diesen Gegenstand in dem mir offen stehenden Gebiete geschlossen und meine Abhandlung darüber beendigt. Bloss un mich zu ergehen und etwa noch einige Petrefakten zu sammeln, besuchte ich einige Tage später die freundliche Gegend noch einmal, und war nicht, wenig bétroffen, als ich im Grünsande selbst eine in der Nähe ihres Schlosses, also an ihrer dicksten Stelle frisch durchbrochene Oberschaale und gleich darauf einen solchen Deckel der nämliehen Exogyra bemerkte, welche in Ansehen des Bruches ganz den in den Sandsteinlagen und Konglomeraten eingewachsenen glich. Bei weiterer Forschung fand ich den Bruch aller in dieser Gesteinsart vorkommenden Exemplare dieser Muschel mehr oder weniger von derselben Beschaffenheit. Ich kounte mich nicht bereden, dass die den faserigen Kern belileidenden Rinden und durchsetzenden Lagen und stalaktitischen Gebilde ebenfalls Kiesel seyen, und legte, um mir davon Gewissheit zu verschaffen, ein Bruchstüek in verdiunte Salpetersäure. Nach geendeter, stets gleich heftiger Efferveszenz blieb ein Körper im Rückstande, der seiner Gestalt nach, zwischen den beiden Rinden, mit den in losen Sande dieser Formation liegenden Exogyren ganz identisch ist, und in den äussern Kennzeichen seiner Masse nach mit denen des Chalzedons genau übereinstimmt, sogar demselben auch darin ähnelt, dass auf den äussern Flächen der beiden Chalzedon-artigen Rinden, wiewohl nur selten und stellenweise und in höchst zarten, zuweilen kaum angedeuteten Zeichnungen, die nämlichen Ring - Systeme 
erscheinen. Von den in den Sandsteinlagen und Konglomeraten eingeschlossenen Schaalen unterscheiden sich die Ring-Systeme hinsichtlich der Art und des Prozesses der Verkieselung dadurch, dass ihre äussere und innere Fläche hart und glatt ist, und der Teig des Grünsandes, - im Verhältniss der Annäherung zu selbem, im Wasser sich allmählich weniger erweicht, überhaupt an Härte zunimmt, und den Schaalen so innig anklebt, dass er, um diese rein zu bekommen, durch Säuren weggeäzt werden muss, oder, wenn man ihn mit Gewalt absprengt, öfter von den obern Lagen der Kieselrinde ansehnliche Stücke lossreisst.

Da der Chalzedon der letztern Muscheln ziemlich satt blaulich-grau gefärbt ist, dadurch gegen die gelblich-weissen Partie'n des kalkig - faserigen Gewebes deutlich absticht, in seinem Gefüge weniger geschlossen zu seyn scheint, daher eine genauere Beobachtung der wechselseitigen LagerungsVerhältnisse gestattet - und da vorzugsweisé diese Beobachtungen zur Aufklärung des Geheimnisses führen können, so will ich sie etwas umständlicher beschreiben.

Der Chalzedon erscheint theils als eine die beiden Flächen der Schaale bekleidende Rinde, theils in Lagen zwischen dem faserig-kalkigen Gewebe, theils als dieses Gewebe verschiedenartig durchsetzender Stalaktit. Ich will die letzte Gestalt zuer'st, und zwar mit allen den Abänderungen, in welchen sie durch die ganze Formation auftritt, vortragen.

Wenn der Chalzedon in freien selbstständigen StalaktitGebilden vorkommt, so sitzen diese, in einer und derselben Schaale, auf den Innentlächen sowohl der äussern als deı innern (ebenfalls in Chalzedon verwandelten) Schaalenwand, bald dort bald da häufiger fest, und ahmen im Kleinen alle Formen und Gruppirungen nach, welche man im Grossen bei andern Gesteinsarten und selbst dem Chalzedon unter andern Umständen findet. Die konischen, Zapfen - förınigen oder wie immer verlängerten sind gewöhulich von einem unstäten Punkt aus gegen die Spitze hin verschieden und nach verschiedenen Richtungen gebogen. Eben so ungleich 


\section{$-682$}

ist ihre Dicke und Länge. Reichen sie von einer Schaalenwand bis zur andern, so wächst ihre Dicke oft bis zu einem beträchtlichen Umfange an. Zahlreicher sind alle diese Ersiheinungen in jenen Schaalen, aus welchen das kalkig-faserige Gewebo zum grössten Theile oder ganz verschwunden ist. Besondérs in letzten Falle erfüllt nicht selten den ganzen Raum zwischen den beiden Schaalenwänden auch ein verworrenes, dem ïber Moosen $n$. dgl. abgesetzten zarten Kallituffe ähnliches, Chalzedon-artiges Stalaktit-Geflechte, welches den Schaalen das kariöse Ansehen gitt, und in den Höhlungen manchmal mit manchfaltigen, wohl auch spiralförmig gewundenen, gelblich-oder blaulich-weissèn, stark-glänzenden Chalzedon-artigen Übersinterungen belileidet ist. Dasselbe erscheint aber auch neben jenen freien selbstständigen Stalaktiten, so dass der Übergang nicht verkannt werden kann.

Als Lage zwischen dem kalkig-faserigen Gewebe ist der Chalzedon nur in den Exemplaren des Grünsandes deutlich zu unterscheiden. In kur'zen Abständen wechselt zuweilen in der nämlichen Schaale die Anzahl, Stelle, Dicke und Entfernung manchfaltig; bald wird die eine, bald die andere, bald werden alle Lagen voin jeniem Gewebe verdrängt; bald verlieren sie sich darin von selbst; bald fliessen die-einen oder alle zusammen, und hin und wieder erfülen sie dadurch den ganzen Raum zwischen den Schaalenwänden. Sie setzen aber auch eben so oft in unverrïckter Erstreckung durch die ganze Kurve der Schaale fort. Übrigens konnte ich auf diesen $Z$ wischenlagen weder der in Grïnsand noch der in Sandstein liegenden Schaalen eine Spur von Ring-Systemen entrlecken.

An den im Grünsande vorkommenden Schaalen zeigt sich unwidersprechlich, dass sowohl die Chalzedon-artigen Zwischenlagen als die beiden Schaalenwände aus mehreren äusserst zarten Blättern bestelen. Ieh komnte an den dünnsten Stellen derselben bis 9 zählen, obwohl noch ein ziemlich dicker Theil unentwickelt war. Auch zwischen und auf diesen komute ich irgend eine Andeutung von Ring-Systemen 
nicht gewahren, so sehr der weisse Zentralpunkt ihre Aufsuchung erleichtert. - Die Dicke der Chalzedon-artigen Rinde der Schaalenwände ist zwar weniger veränderlich, als die der Zwischenlagen, doch fliessen beide stellenweise und vorzüglich gegen die Ränder 'hin so ineinander, dass die gesammte Masse der Schaale aus Chalzedon besteht.

Wie überall, so enthält der Grünsand auch hier ausser den Exogyren und Terebrateln eine Menge ein - und zweischaaliger Molluskenschaalen, und zwar ganz unter den nämlichen Lagerungs-Verhältnissen *). Alle diese sind entweder kalzifizirt, oder völlig aufgelöst und zerstört. Zudem ist die Silizifizirung jener, und die Kalzifizirung dieser durch die ganze Formation in meinem Vaterlande standhaft $*$ ). - Ist es möglich, dass solche auffallende und dennoch von der Natur so konsequent durehgeführte Anomalie'n lediglich in Daseyn oder Nicht-Daseyn des thierischen Stoffes ihren Grund haben s

*) Man vergleiche damit das Verhalten der jungen Grünsand-Formation im nördlichen Gehänge der Alpen (bei Bergen).

*) Die Exogyren (und Terebrateln) sind zu Alten-(Schloss-) Kíreuth bei Roding am äussersten südüstlichen, zu Bodemuöhr, und zu Atzelpicht bei Amberg am äussersten nordwestlichen Ende auf gleiche Art silizifizirt, die übrigen Petrefakten kalzifizirt. 


\title{
Über \\ Monotis decussata von Münster's \\ von
}

\author{
Hrn. Amts-Assessor Römer.
}

Mit Abbildung auf Taf. VIII, Fg. 4 1, 2, 3.

Auf einer letzthin unternommenen Exkursion nach dem Osterwalde, Deister, Stemmer- und Tünnies-Berge, auf welcher ich nicht nur in den schwarzen Asburnham-Mergeln mehrere, anscheinend marine Versteinerungen, sondern auch z.wischen der Portland-Bildung und dem Hastings - Sandsteine eine, wohl ebenfalls zu den Asburnham-Schichten gehörende, mächtige Kalkbildung auffand, war ich auch so glücklich, in den Steinbrüchen des Tönniesberges und zwar unmittelbar bei Wettbergen unfern Hannover einzelne Schaalen der Avicula tegulata GoLdr. und Monotis decussata v. Münst, vom Gesteine befreit, zu sammeln. Da fast alle Exemplare so vollständig und rein erhalten sind, wie sie nur in den jüngsten Gebilden erwartet werden können, so bin ich dadurch in den Stand gesetzt, beiliegende Abbildung und nachfolgende Beschreibung des bisher unbekannten Schlosses dieser von Goldruss so schön abgebildeten Monotis-Art zu liefern *).

Die rechte Schanle - Fig. 1 - zeigt einen ziemlich

$\Rightarrow$ ) Vergleiche jedoch Quensted im Jahrbuch 1836, S. 242.

D. $\mathbf{R}$. 
breiten, ganz geraden, nach aussen gerichtetén, seiner Länge nach gestreiften, hinten etwas verschmälertén Schlossrand, und auf ihm hinter dem kaum darïber hervorragenden Buckel eine breite, dreieckige, oben etwas abgestutzte, im Grunde flache, zur Aufnahme des halb äusserlichen Bandes bestimmte Grube, deren vorderer Schenkel mit der Basis des Schlossrandes einen etwas spitzen, fast rechten Winkel macht, während der hintere Schenkel sehr schräg nach hinten gerichtet ist. Unter dem sehr kleinen vorderen Flägel befindet sich ein starker, durch eine tiefe, äussere Falte hervorgebrachter, zur Aufnahme eines Byssus bestimmter Ausschnitt. Der Muskular - Eindruck scheint rundlich zu seyu und liegt in der Mitte der Höhe, dem Hinterrande genähert.

Die rechte Schaale - Fig. 2 - hat ebenfalls einen geraden, in der Jugend bisweilen etwas gebogenen, breiten, weniger nach aussen klaffenden Schlossiand. Man sieht darauf hinter dem, wenig hervorstehenden Buckel eine dreieckige Bandgrube, deren vorderer Schenkel mit der Basis ebenfalls einen etwas spitzen, fast rechten Winkel bildet, während der schräge hintere Rand allmählich flacher wird, sich gegen den äussern Rand des Flügels ganz verliert und oberhalb durch eine linear-lanzettliche, etwas schwielige Fläche begränzt wird. Die Fläche des Schlosses vor jener Grube trägt oben ein niedriges, dreieckiges, etwas stumpfwinkeliges Grübchen; darunter liegt eine nach unten abgerundete, schwielige Fläche; an beide stossen hinten die blättrigen Anwachsungs-Streifen des abgerundeten vorderen Ohres. Der Muskular-Eindruck ist breit herzförmig und liegt in der Niihe des hinteren Randes.

Nach dieser Beschaffenheit scheint mir die Monotis decussata zur Gattung Avicula zu gehören; ihr Schloss macht der Übergang von den meisten übrigen AviculaArten zur Avicula tegulata Goldr, deren dreieckiges Schlossgrübchen bei unsern schönen Exemplaren - Fig. 3 in der Mitte durch keine Erhöhtung, wio die Abbildung bei 
Gordruss sie darstellt, getheilt wird, und deren Schenkel mit der Basis beide sehr spitze Winkel bilden. MuskularEindruck und vordere Abrundung des Ohres, so wie die übrige Beschaffenheit des Schlossrandes sind fast gleich. Eine rechte Schaale der A. tegulata habe ich bisher vergeblich gesucht.

Den obigen Fundort beider Versteinerungen habe ich früher für unteren Coralrag angesehen, da aber die Avicula tegulata von Goldruss aus dem Great oolite angegeben wird, unsere Monotis auch im Bradford-Thone vorkommt und keine damit bei $W e t t b e r g e$ vorkommende Versteinerung ( - kleine glatte, spitzschnabelige Austern [A. acuminata \$], eine glatte $\mathrm{Kammmuschel}$ und ein am Grunde nicht gefurchter Belemnit -) mehr östlich im wirklichen untern Coral-rag angetroffen wird, so möchte diese Bildung, so wie der am Slemmerberge im Liegenden der Wälderthon-Bildung vorkommende, Kalk, in welchem wir nur die Monotis decussata gesehen, ebenfalls dem Great oolite, oder diese der älteren Abtheilung der Jurabildung angehören. Das Gestein ist ein sandiger, bald fester bald mergeliger Kalkstein mit vielen Eisennieren und Sphäroiden. 


\section{Briefwechsel.}

\section{Nittheilungen, an den Geheimenrath v. LEONHARD gerichtet.}

Alexandria, 19. April 1836.

In der Richtung aus Nord-West in Süd-Ost, von der Lybischen Wüste bis zum rothen Meere, wird ganz Ägypten durch einen Grebirgszug durchsetzt, dessen Abfall gegen Nord-Ost bei Weitem sanfter als der gegen S.W. ist. Dieser Gebirgszug zeigt auf seinem Rücken bedeutende Plateau's, und in Nordost sowohl als Südwest reicht die Wüste bis an seinen Fuss. Mitten durch ihn hat sich der Nil sein Bett gebrochen und das Thal an seinen beiden Ufern mit seinem ihm eigenthümlichen Schlamm erfüllt, so dass, im wahren Sinne des Wortes, zwischen Wüste und Wüste ein Streifen eines der fruchtbarsten Länder der Erde sich befindet: Die örtliche Ausdehnung dieses Gebirgszuges von El Thuareh am rothen Meere bis in die Gegend des Thurns der Araber am Mittelländischen Meere beträgt bei 162,500 Toisen oder bei. nahe 32 Miriameters, bei einer mittlen Breite des Zentral - Rückens von ungefähr 12,000 Toisen. Die mittle geographische Lage dieses Gebirgszuges ist 290 Länge von Paris und $30020^{\prime}$ nördl. Breite. Der ostwärts des Nils liegende Theil dieses Gebirges, der Gebel Attakka am Rothen Meere und die Gebel Mokattam und Gebel Giouchi (oder Ahfrak) bei Kairo und der Gebel Torrah und Bahar-Bela-Ma südöstlich von Kairo gehören zu der sogenannten Arabischen Bergkette, die Berge hingegen westlich des Nils in der Gegend des Bahr el Bala Ma und der Natronsee'n bis zum Thurm der Araber gehören zur Lybischen Bergkette. Im Norden wie in Süden hat diese Bergkette viele Abläufer, die aber von keiner besondern Bedeutung und von derselben Beschaffenheit sind, wie der Hauptrücken, der sowohl in Ost als West mit seinen Zweigen das Gebirge der Wüsten bildet. Das äussere Ansehen ist ganz das jüngerer Gebirge: nicht hoch, die Schichtung terrassenförmig bemerkbar. Auf der Höhe grosser Plateau's verlieren sich die Berge 
in Nord mit sanftem Abfalle, während sie in Süd meist steile Abhänge bilden. Wir wollen hier nur die Berge in der Ungebung von Kairo betrachten, nämlich den Gebel Mukattam und den Gebel Alafrak oder Giouchi. Viel bedeutender durch Höhe und Ausdehnung ist der erste dieser beiden, der Mokattam. Er liegt südöstlich der Starlt und dicht an den Mauern derselben, indem die Zitadelle an seinem südwestlichen Abhange erbaut ist. Gegen Nordost steht er mit dem Gebel Ah/rali, gegen S.W. durch den Bahar-Bela-Ma mit dem Gebel Turrah in Verbindung. Überall sonst begrenzt ihn die Wüste. Sein liüchster Gipfel in der Nähe der Zitadelle von Kairo hat eine Höhe von 420 Par. Fuss über dem Mittelländischen Meere, 390 P. Fuss über dem Ruthen Meere und $404 P$. F. über dem niedersten Stand des Nils. Der Mukuttum ist ein durch die heftige Hitze und die Einwirkung der heissen und stürmischen Wüstenwinde, so wie durch gänzlichen Wassernangel, ganz kahles, beinahe vegetationsloses Gebirge. In den einzelnen Scliluchteu jedoch, wo es der Dammerde möglich ist, sich etwas anzusammelu, fand der mich begleitende Botaniker Котsсн Anfangs April ausser zwei Arten von Fettgewächsen noch Turritis pubescens, Brassica crassifolia, Senecio verrucosus und triflorus, Geranium asphodeloides und reflexum, Diotis candidissima, Plantago recurvatı, Egyptiacu und argentea, Inula undulata und crispa u. a. m. Die Felsbildung erhellt aus beiliegendem Durchschnitte (Tf. VIII, Fg. 3). Zu unterst, gleich hinter der Zitadelle, wo am Fusse des Berges bedeutende Steinbrüche betrieben werden, steht dichter Kalkstein, von gelblichweisser und bräunlichweisser Farbe an, der einc Menge von Versteinerungen, vorzüglich aber Nummuliten führt. Er ist deutlich geschichtet, seine Schichten streichen mit dem Gebirge aus N.W. in S.O. und verflächen unter sehr kleinem Winkel, höchstens vou $2^{0}$ gegen Nordost. Nach diesem Schichitungs-System richtet sich das des ganzen Moknttums. Stellenweise nimmt dieser Kalkstein, besonders nach unten $<$ e ein etwas crdiges Gefüge an. Die Versteinerungen sind nesterweise ausgeschieden und in ihrer Lage lässt sich keine bestimmte Anorduung erkennen. Sie gehören alle Seethieren an, und ihre nähere Bestimmung werde ich bei meiner Rückkelır nach Europa vornehmen. Die Schichten dicses untern NummulitenKalkes siud öfter wellenförmig gebogen, welche Erscheinung aber auf das Schichten-System der obern Felsbildungen keinen Eiufluss zu haben scheint. Der untere Nummuliten-Kaik ist es vorzüglich, der Nester von Feuerstein, Horustein, Jaspis, Karniol, von Basalt -ähalichen Gesteinen und vou Selenit - Spath führt. Alle diese nesterförmigeu Einlagerungen scheinen nichts anders, als chemische Ausscheidungen aus der IIasse des Kieselerde-haltenden Kalkes zu seyn, und nur die basaltischen Gesteine dürten Geschieb-artig in die Masse des Kalkes eingehüllt seyn, weil in dieser die integrirenden Bestandtheile derselben mangeln mögen. Der Selenit-Spath kümmt besonders häufig vor und ist n:itunter in Kopf-grossen Knollen ausgeschieden. Auch funden wir vicle lose Trümmer fossilen Holzes, an dem die eigentlümliche Textur 
ausgezeichnet zu bemerken war, dessen Masse hingegen ganz in ein Hornstein-artiges Gestein, manchmal einen viclen kohlensaurcn Kalk haltenden Kern führend, verwandelt war, und welches offenbar als Versteinerung dem Nummuliten-Kalk angehört. Auf dem untern NummulitenKalk liegt Kreide: ein erdiger, schneeweisser Kalkstein, sehr zerreiblich und Knollen von Feuerstein etc. führend. Er enthält auch kleine Nester cines eigenthümlichen Eisen-Sandsteins, welcher viele Ähnlichkeit hat mit dem, der in den Tertiär-Gebilden am Saume der Alpen und der Baierischen Ebeve den linsenförmigen Thoneisenstein führt. Die Kreide theilt sich in zwei Hauptstraten: die eine führt sehr viele Versteinerungen, die dieser Felsart eigenthünlich sind, besonders aber Nummuliten; die andere, die auf dieser liegt, ist sehr arm an Versteinerungen und mitunter ganz frei davon. Sic führt auch Knollen von Feuerstein, Hornstein etc., aber ebenfalls nur sparsam und enthält gegen die Grenze der sie bedeckenden Felsbildung zu: Nieren von ockrigem Brauneisenstein. Die Kreide zeigt eine Mächtigkeits-Entwicklung von 26 und mehr Fuss. Auf diese Kreide-Bildung folgt eine mächtige Ablagerung eines dichten quarzigen Kalksteins, der hie und da seinem Habitus nach sich dem Hornstein ähnlich zeigt. Dieser Kalkstein fübrt Versteinerungen, theils beigemengt, theils kommen in ihm ganze mehrere Zoll mächtige Bänke vor, die nur aus Meeres-Konchylien, $\mathrm{Numulus,} \mathrm{Terebratula,}$ Venericardia, Mytilus, Cytherea, Lingula u. s. w. bestehen. Der Kalkstein wechselt mit diesen Muschelbänken, so wie mit Lagen eines gelben und grauen versteinerungslosen Thons. Es ist diese Kalk. bildung, welche ich mit dem Namen oberer Nummuliten-Kalk bezeichnete und der Mächtigkeit von 18 bis 20 Fuss besitzt.

Eine $3^{\prime}$ mächtige, viel Eisenperoxyd haltende Thonschicht, sehr sandig und mitunter einen thonigen Sandstein darstellend, bedeckt diese Kalk- und Thon-Bildung in ihrer ganzen Ausdehnung, und darauf liegt ein bei $40^{\prime}$ mächtiger, Kalkstein von dichtem, ins Körnige übergehendem Gefüge. Dieser Kalkstein ist sehr quarzhaltig und zeigt ganz das äussere Ansehen mancher Hornstein-Gebilde, gibt auch am Stahle Funken. Er führt Versteinerungen, die aber bei Weitem nicht so gut erhalten sind, als die der unter ihm liegenden Straten. Charakteristisch für ihn sind Lagen von ockrigem Brauneisenstein mit vielen Selenit-Krystallen, an welchem Fossil er überhaupt sehr reich ist. Besonders ausgezeichnet ist ein solches Lager, das auf dem Gippel des Mokattam zu Tage geht und eine Mächtigkeit von $6^{\prime \prime}$ bis $10^{\prime \prime}$ hat, sich auch auf eine bedeutende Strecke verfolgen lässt. Der Kieselkalk zeigt sich auf seiner Oberfläche durch Verwitterung sehr zerfressen und, wahrscheinlich durch vulkanischen Einfluss, in tié́e Spalten zerrissen.

Die ganze Gruppe dieser Nummulitenkalke mit ihren Thonstraten, ihreu Muschelbänken und Eisensteinlagern gehört, meiner Ansicht nach, dem Gebiete der Kreide an, und dieses Felsgebilde ist es, welches den grössten Theil des nordöstlichen Afrika bedrckt; es ist ohne Zweifel das Gestein, welches die Grundlage der durch ganz Afrika und weit nach 
Asien reichenden Wüsten bildet. Diese Nummuliten-Kalke führen, wie gesagt, häufig Knollen von Feuerstein, Karniol, Jaspis, Hornstein u. s. w. und enthalten auch fossiles in Hornstein umgewandeltes Holz, wahrscheinlich Reste von $\mathrm{Palmen}$ und Sikomore n-Stämmen, auf die Weise, wie sie andere Versteinerungen führen. Berücksichtigt man die grosse Verwitterbarkeit der Nummuliten-Kalke und nimmt dagegen, wie sehr Jaspis, Hornstein, Feuerstein, das erwähnte fossile Holz etc. der Verwitterung widerstehen, so wird das Vorkommen der geschiebartigen Knollen dieser Gesteine und des fossilen Holzes in und auf dem Sande der Wüsten, wo diese Gesteine ganz frei am Tage liegen, nicht mehr befremden. Der Nummulitenkalk, die Kreide nämlich, das Gestcin der Wüste, verwittert zu losem Staub und Sand, während seine grösstentheils aus Kieselerde bestehenden Einschlüsse nicht verwittern, sondern an Ort und Stelle unverändert liegen bleiben, während die heftigen Wüstenwinde den Staub und Sand hier wegführen, dort anhäufen, damit manche Gegenden weit und breit berum bedecken, an manchen Stellen aber wieder das Gestein entblössen, so dass die Verwitterung aufs Neue beginnt. So können diese Feuersteine, Karniole, das fosssile Holz u. dogl. durch Jahrtausende liegen bleiben und vermehren sich zum Theil ihrer Anzahl nach durch die fortschreitende Verwitterung.

Nordöstlich des Mukattams sieht man am Saume der Wüste schwarze, scharf begrenzte Berge kegelförmig der Ebene entsteigen: es ist der Gebel Ahfrak, vom Mokuttam durch ein breites Thal geschieden, mit

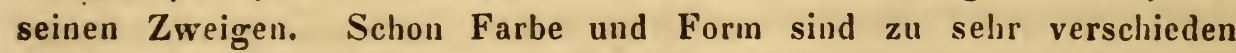
von denen des Mukuttams, als dass man nicht auf eine besondere, von diesen ganz gitrennte Gebirgs - Formation schliessen sollte. Man sieht auf den ersten Blick, dass man sich auf einem vulkanischen Terrain befindet, was auch die nähere Beschauung bestätigt. Angelangt am Fusse des Gebel Ahfrak erstaunt man über die sonderbaren Felsgebilde, die man plötzlich zu seben bekönnt. Sie sind offenbar vulkanischen Ursprungs und docl keine Laven, auch keine sogenannten plutonischen Gebilde, keine Basalte, keine Trachyte, keine Porphyre; denn findet man deren auch welche, so bilden sie doch bei Weitem nicht das eigentliche Gestein des Berges. Dieser ist ein grosser Eruptions - Kegel von 4000 bis 5000 Toisen im Unfang. Auf seinem Gipfel angelangt, steht man am Rande eines grossen Kraters. In diesem bemerkt man viele trich. terförmige Vertiefungen und darunter zwei von sehr bedeutender Grösse, eine Reihe kegelförmiger Erhöhungen umschliesst sie alle und bildet den Hauptkrater. Vom Gipfel des Gebel Allfrak erblickt man mehrere solche Eruptions-Kegel in der den Mokattam begränzenden Ebene, jedoch keinen von solcher Bedeutung. Das durch die Emporliebung dieses Berges hervorgetretene Gestein bedeckt die Felsgebilde des Mukattam an dessen Fusse und man sieht in dem Thale qwischen den Mokattam und den Gebel Ahfrak die Nummulitenkalke und vorzüglich den thonigen Sandstein zwischen dem obern Nummuliten - Kalk und dem Kiesel. kalk deutlich unter die vulkanischen Gebilde des lezztern cinschiessen. 
Der Gebel Ah/ruk ist grösstentheils ganz kahl und auch in scinen Schluchten findet man nur wenige, aber seltene Pflanzen, so z. B. fand Kотsсн in April: Atriplex pruinosa, Calendula Aegyptiaca und sanctr, Bunias Aegypt. und Syriaca, Anastatica hierochuntica, Rumex Aegypt., multiflorus und aculeatus, C'ntaurea pullata, glastifolia und squarrosa, Convolvulus lamuginosus und hastatus u. s. w. Sehr merkwürdig ist das Gestein des Gebel Afruk. Das Haupt:Gestein des Kegels nämlich ist das des Mokattams, nur durch vulkanische Einwirkung theils geschmolzen, theils wenigstens bedeutend verändert. So selıen wir daselbst den Sand der Wüste theils nur zusammengefrittet, theils geschmolzen, den thonigen Sandstein und obern Nummuliten-Kalk gebrannt und geschnolzen; ferner verglasten und geschmolzenen Kicselkalk, geschmolzene Kreide und zu fürmlichem Trachyt geschmolzenen NummulitenKalk mit allen seinen Einschlüssen und durch Feuer veränderten Versteinerungen. In dem gebrannten thonigen Sandstein findet man grosse Stücke des fossilen Holzes, dessen Masse ganz in Hornstein verwandelt ist. Sehr vorherrsciend ist auch ein körniges Quarzgestein, dessen Körner durch Schmelzung ganz zusammengefrittet sind, wahrscheinlich ein tiefer liegendes Gestein, vielleicht eine Art Sandstein oder Quarz-Konglomerat, welches durch dic Eruption emporgchoben wurde, und welches man in der Tiefe des grossen Kraters anstehen sieht. Wan findet teruer schr viele lose Quarzö̈ner, die durch Krystallform, Farbe und Glanz sich ganz jener Art von Bergkrystallen ähulich zeigen, die unter dem Namen Marmaroscher-Diamanten bekannt sind. Die Eruption, durch die der Gebel Alfrak und die übrigen EruptionsKegel am Notiattan entstanden, muss erst geschehen seyn, als bereits Wüste diese Punkte bedeckte; denn man findet den Sand der Wüste von Zustande einer leichten Zusammenfrittung der Körner an bis zur vollendeten Lava, und in den mannigfachsten Nüanzen der Schnelzung. Manche dieser vulkanischen Gesteine sind allerdings porphyrähnlich und zeigen sich durch Aufnahme von glasigem Feldspathe als wirkliche Trachyte, doch zeigen diese Bildungen sich nur noch lokal, haben keine Ausdehnung und scheinen vielmehr nur Modifikationen der allgemeinen Unwandlung der Gesteine durch das Einwirken eines Vulkans zu seyn. Der Gebel Ahfrak gibt uns den liöchst seltenen Anblick eines Vulkans von der Art, wie sie noch heut zu Tage thätig sind und der doch von den gewöhnlichen Gesteinen der Vulkane gauz verschiedene enthält. Die Lava des Ahfrak ist eine andere, als sie die übrigen Vulkane liefern, und in allen seinen Produkten lässt sich das Grund-Gcstein, aus dem sie entstanden sind, nicht verkennen.

RussegGer. 
Rouen, 12. Julius 1836.

Die chloritische Kreide in unserer Nähe, so ausgezeichnet durch ihre Lagerungs-Verhältnisse und durch die von ihr umschlossenen Petrefakten, lässt meist nur sehr wenige grüne Punkte wahruebmen, und oft fehlen diese auch ganz. Die Ihneu übersendeten Handstücke stammen von Fécamp, einen kleinen Seehaven zwischen Dieqpe und le Hâvre. Hier treten mchrere sehr ausgezeichnete Bänke chloritischer Kreide auf. Eine derselben, welche vortreffliche Bausteine liefert, ist beinahe gänzlich weggebrochen worden. Man kann sich wohl erhaltene Versteine. rungen, wie solche unsere Kreide häufig führt, ihrer Zerbrechlichkeit wegen, nur mit einiger Schwierigkeit verschaffen.

\section{DE St. Leger.}

Prag, 2. Sept. 1836.

Bei den Nachgrabungen am Kammerbihl ist nicht viel Arbeit mehr nothwendig, um die Eruptions-Spalte des Basaltes in Glimmerschiefer vollständig bloss zu legen. Diese Spalte ist mit Basalt und mit Schlacke ausgefüllt. Künftiges Jahr gedenke ich die Beschreibung zu liefern; es konmt auch eine Karte dazu. Wahrscheinlich hatte der Ausbruch unter Wasser Statt. Die grösste Menge des Basaltes ist in Schlacken zersprungen. Sehr viele Bomben wurden gefunden, ähnlich jenen, die der Vesuv auswirft. Sie schliessen Glimmerschiefer- und Quarz-Trümmer ein. In der 11 ten Klafter Seigerteufe hat man überall Wasser angefahren.

Kaspar Graf von Sternberf.

Lyon in Sept. 1836.

Ich theile Ihnen einige Nachrichten mit über meinen Ausflug nach Villebois an der Rhone, Dept. de l'Ain.

Vou Lyon aus stromaufwärts, am rechten Ufer gehend, hat man stets das Diluvium zur Seite, in welchem Überbleibsel vorweltlicher Elephanten vorkommen. Auf hohen und steilen Diluvial-Gehängen ruht das Thon-Plateau de la Bresse. Am entgegengesetzten Ufer, in Dauphine, erstrecken sich unermessliche Alluvionen, man sieht die Balmes vieunoises, das ursprüngliche Rhone-Ufer, auf dem sich noch einige alterthünliche Tumuli erheben. Diese Formation verfolgt man bis zum Ufer des Ain, wo zwischen Laguieu und st. Surlin GryphitenKalk (Lias) auftritt, der auch Belmniten und Plagiostomen führt. Von st. Surlin bis zum Rhone-Fall erstrecken sich die steilen Gehänge eines gelblichen, etwas körnigen, ziemlich Muscheln-reichen Kalksteins. Wenig Örtlichkeiten dürften so geeignet seyn zum Studium der Schichten, ihrer Neigungen und Biegungen, ihres Zerissenseyns und der dadurch 


\section{$-693$}

cutstandencn kleiuen Thäler. Eines der letzten zeigt ganz deutlich den Bruch und die Emporhebung der korrespondirenden Schichten. Alle aufgerichteten Schichten lassen gegen die Rhone-Seite ihre wagerechten Euden wahruchmen und senken sich allmählich gegen das Berg-Innere. Der berühmte Rhone-Fall ist kein eigentlicher Sturz, soudern nur eine geringe Henumung durch Felsmassen, so dass der Strom bewegter und reissender wird. Gegen die Stelle hin sind die Kalksteine gelblich und fülıren hin und wieder Muscheln. Man verfolgt dieselben bis Villebuis, wo die ungeheuren Steinbrüche sich befinden, welches die festesten und grössten Massen liefern ( 30 bis 40 Fuss), die in Lyon verarbeitet werden. Alle diese Kalke dürften dem Jura-Oolith angehören. Ostwärts vom Dorfe, an Fusse der Gehänge, geht Bohnerz zu Tag, das meist in sehr regelloser Weise gewonnen wird. Die Mächtigkeit der Lagen beträgt $6-8$ Fuss. Sie ruht auf zerreiblichem, viele Ammoniten eiuschliessendem Mergel. Auch das Erz führt Aımoniten, Belemniten, Pectiniten in Menge, und ausserdem Bruclsstücke verschiedener Bivalven. Auch fand ich einen Wirbel, der muthmasslich von einem Ichthyosaurus abstammt. Über dem Bohnerz liegt eine Bank Muschehn-reichen Kalksteins mit vielen Krinoideen-Fragmenten. Noch höher sicht man Lagen mergeligen Kalks mit Terebrateln, Ammoniten, Pectiniten und Plagiostomen. Das Eisenerz-Lager zeigt dieselben Biegungen, wie die Kalk-Schichten. Es senkt sich dem Giunde des Thales zu, in weichem dus Flüsschen von Villebvis seinen Laut hat. Hier scheint dasselbe unmittelbar auf blaulichem Gryphitenkalk zu ruhen. In der nämlichen Mächtigkeit ist-das Eisenerz-Lager auf einer Erstreckung von $3-4$ Stunden zu sehen und die Gewinnung wäre überall sehr leicht, nur .er Mangel an Brenn-Material ist hinderlich; man muss das Erz bis Vienne und St. Chamond transportiren, welche Orte den SteinkohlenGebilden näher liegen.

In dem 'Theile von Dauphiné, durch welchen ich meinen Rückweg nahm, zeigt der Kalk die nämlichen Merkmale, welihe er am RhoneFali hat. In diesem Gestein ist auch die berühmte Grotte de la Bulm', eines der s i e b e w w n d e r des Danphine und so ausführlich von Bournt béschrieben. Der Eingang ist ein Grwölbe-artiger Bogan vou 100 F. Höhe und 80 F. Breite. - Der Rückweg nach Lyon führte mich fünf Stunden lang über eine mit Rollsteinen bedeckte Ebene.

LorTET.

Durmstadt im Dezember 1836.

Vie!leicht dass Sie einer kurzen Mittheilung über die von mir fortgesetztgn Nachigrabungen zu Eppelsheim gerne cine Stelle in Ihrem Jahrbuche vergönnen. Dieselben wurden in vorigem Monat von Neuem begonnen und ununterbrochen mit einer zahlreichen Mannschaft fortgesetzt. Wie sehr diese Arbeiten Geduld und Ausdauer in Anspruch 
nehmen, davon bin ich durch eigene Erfahrung hinlänglich überzeugt. Neben dem Mühsamen derselben ist zugleich die grösste Behutsankeit anzuwenden und bein Durcharbeiten der eigentlichen Knochen führenden Schichten eine kaum glaubliche Sorgfalt den aufgefundenen Resten $\mathrm{zu}$ widmen.

Nicht selten hat man über $30^{\prime}$ niederzugehen bis zur unteren Knochen - führenden Lage, welche die meiste Hoffnung bietet. Die Arbeit kann dann nur Terrassen - förmig nach unten vorschreiten, indem wegen der Lockerheit der Lagen in gewöhnlichen schachtförmigen Vertiefungen die Seitenwände jeden Augenblick einzustürzen drohen. An einem unterirdischen Bau nach bergmännischen Grundsätzen ist nicht wohl zu denken, indem derselbe nicht allein in Folge eines dauerhaften Streckenausbauens mit fast doppeltem Aufwande, sondern auch mit einer beträchtlichen Gefahr verbunden wäre. In der kleinen Arbeit, die ich über das geognostische Verhalten der knochenführenden TertiärGebilde des Mittelrheins Kaups geologischer Beschreibung des D in otherium-Kopfes beifügte und die ich hoffe lhnen recht bald übersenden zu können, verbreitete ich mich auch über das eigenthümliche Vorkommen der Knochenreste. Sie werden daraus ersehen, wie selten ausgezeichnete Stücke vorkommen und welchen Zeit - und Arbeits-Aufwand es erfordert, einmal etwas von besonderem zoologischem Werthe zu erhalten. Als ein besonderes Glück rechne ich es mir daher an, bei den von Neuem begonnenen Nachgrabungen wieder zwei werthvolle Stücke aufgefunden zu haben, nämlich den Schädel oder Oberkopf von T apirus priscus bis auf den Hintertheil des Kopfes (der fast ganz fehit) vortrefflich erhalten, und den vollständigen Kopf vou Kaup's Dorcatherium Naui, ein der Gattung Cervus nahe verwandtes Thier. Ein so vollständig erhaltenes Exemplar, bei welchem der Unterkiefer noch ganz mit dem Oberkopf zusammenhängt und sogar noch ein Theil der Halswirbel daran sitzt, wurde nach Kaup's Ausspruch bei Eppels: heim noch nicht aufgefunden. Aber ausser diesen beiden Stücken und einem stark zertrümmerten kolossalen Humerus von M a stodon $10 \mathrm{n}$ girostris fand sich auch auf einer Fläche von beinahe 5 Morgen, die zum Theil ganz durchgearbeitet, theils nur versuchsweise nachgesehen wurde, nichts Erwähnenswerthes.

Dem verdienstvollen Bearbeiter unserer vorweltlichen QuadrupedenFauna sind diese neuen Bereicherungen derselben zur Beschreibung und Abbildung übergeben, und es werden dieselben der erwähnten Arbeit über das Dinotherium noch beigegeben werden können.

\section{A. V. Klipstein.}

Bern, 22. Sept. 1836.

Die Versammlung in Solvthurn wird, wenn meine Hoffnung mich nicht betrügt, für unsere Wissenschaft nicht ohne Erfolg bleiben. Man 
hat beschlossen, die Denkschriften der Gesellschaft, die seit der Erscheinung des 2 ten Bandes ins Stocken gerathen sind, weil kein Verleger in die Bedingungen der Gesellschaft eingehen wollte, nun aus eigeneu Fonds und nach einem 'abgeänderten Plane herauszugeben. Die Abhandlungen sollen nämlich einzeln erscheinen und besonders verkauft werden, so dass sich der Druck nicht verzögert, bis man einen Band füllen kann, und Jeder nur davon zu kaufen braucht, was ihn zunächst interessirt. Ein Komité, bestehend aus den Herren Agassiz, Brunner, Decan dolle, Merian, Mousson und RahN, unter dem Vorsitz von Coulon in Neuchâtel soll die Auswahl der zu druckenden Abhandlungen treffen. Unter den ersten Arbeiten disser Sammlung werden erscheinen: ein Anfang zu einer Schweizerisch-Alpinischen Paläontologie von Agsssiz, und meine und Eschers Beschreibung eines Theiles der GraubündtnerGebirge mit Karten und Profilen. - Die Versanmlung hát ferner den Beschluss genommen, ihre Kräfte mit denjenigen des Eidgenössischen Quartiermeisterstabs' zu vereinigen, um in möglichst kurzer Zeit eine genaue Karte der Alpen herausgeben zu können. Die ganze Unternehmung, die seit mehreren Jahren in unserer Gesellschaft besprochen worden war, aber zu keinem Resultat geführt hatte, ist nun der thätigen und einsichtsvollen Leitung der obersten Schweitzerischen Militär. Behörden überlassen worden. - Die Versammlung war zahlireich besucht, und in uaserer Sektion hatten wir das Vergnügen, nebst den Schweitzern Agassiz, Charpentier, Coulon, Escher, Hugi, Lardy, Thurmann, Du. bois, Morsson, Gressly etc. auch die-Hrn. Elie de Beaumont und Durrénox zu besitzen. Das nächste Jahr gehen wir nach Neuchâtel, wo uns, sofern Krieg und Cholera uns in Ruhe lassen, gewiss eine eben so freundschaftliche Aufnahme erwartet, als wir in Sulothurn gefunden haben.

Escher und ich reisten sogleich nach der Versammlung in die Alpen ab. Die Cholera-Quarantaine an der Bündtner-Grenze hatte uns zu einer Abänderung des anfänglichen Reiseplanes gezwungen, der uns nach dem Veltlin und nach Bergamo hinführen sollte; wir verweilten daher mehrere Wochen im Berner-Oberlund, theils um die Fortsetzung der in meinem Buche beschriebenen Kalkgebirge gegen das Reussthal hin genauer zu untersuchen, theils um unsere Beobachtungen über die Verhältnisse des Kalks zu dem sogenannten 'Urgebirge zu vervollständigen und diejenigen, die das Berner-Oberland darbietet, mit den Verhältnissen in Graubündten zu vergleichen. Hierauf erst zogen wir nach Bündten und waren. glücklich genug den ganzen Plan, den wir uns entworfen hatten, noch vor dem Eintritt der scit molreren Wochen herrschenden Regen und Schneestïrme auszuführen. Die Zeit, während welcher in diesem Jahr oberhalb der Baumgrenze in den Alpen geologisirt werden knnnte, wenn man das Wort brauchen darf, hat nicht länger als 5-6 Wocluen gedauert. - Über die Formationsfolge in unseren Berner-Alpen sind wir un bedeutend mehr ins Klare gekommen, doch bleiben stets noch, wegen der Seltenheit organischer 


\section{$-696$}

Überreste, genug Dunkelheiten. Es scheint nämlich, wo nicht, was häufig der Fall ist, Störungen durch Umbiegung ganzer Schichtensysteme, Eindingen fremdartiger Massen, Rücken und Verschiebungen Statt finden, folgende Altersreihe in uuseru Kalkalpen zu bestehen, weun wir nur jenen Theil derselben berïcksichtigen, der zwischen dem Aarthal und dem Rheinthal liegt, oder östlich von den in meinen westlichen Alpen beschriebenen Gegenden.

a) Zwischenbildungen (STudek's): dolomitischer Kalk, Quarzit, bunter Schiefer, Eisenoolith. Hüufige Belemniten und Ammoniten, selten Pholadomyen, Trochen, Terebrateln, theils dem Lias, theils dem untern Oolithe angehörend. Niederschläge 1. Art von Lusser.

b) Hochgebirgs - Kalk von Escher, untere Kalk- und -Schiefermasse Stud. Niederschläge 2. Art, Lusser. Schwarzgrauer schieferiger Kalk, sehr arm an Petrefakten: Belemniten, Anmoniten, Po. sidonien. Dem Lias beizuorduen.

c) Spatangenschiefer. Obere Kalk- und -Schiefermasse Stud. z. Th. Niederschläge 4. Art d Lusser. Terrain néocomien ThurMann, Montmollix, Agassiz. - Schwarze Kalk- und Mergelschiefer, sandig. Niit $S p$ a $t$ ang us ret us us, Gr y pha a Couloni, als Seltenheit Nummuliten. - Bildet die unterste erst in den letzten Jahren zu Neuchâtel erkannte Stufe der Kreide - Bildungen.

d) Hippuriten-Kalk, Schrattenkalk Srud. (Profil der Luzerner-Alpen). Niederschläge 4. Art g Lusser. Dickgeschichteter Kalk, meist nackt, mit sehr vielen aber selten deutlichen Pctrefakten, vorzüglich Hipariten und Diceras.

Gegen die Huchalpen zu. scheinen die zwei letzten Bildungen c und d oft ganz zu fehlen und der Hochgebirgs - Kalk unmittelbar vou e bedeckt zu werden.

e) Nummuliten-Kalk und Sandstein. Hochgant-Sandstein Stud. (Profi! der Li:zerner - Alper). Niedersihläge 4. Art h-1 Lusser. Ausgezeichnet durch die Menge von grüsen Körnern in einigen Schichten. Sehr viele Nummuliten, Petrefalten des Greensandes, 'Turriliten, Inoceramen, Exogyren, Terebratelu, C I y pe a s t e r; stellenweise mit tertiär scheinenden Pctrefakten wie an den Diablerets.

f) Fucoiden-Schiefer, Flysch Stud. Mergelschiefer und Sandstcin unit Fucus intricatus, F. Targioni u. a. Iu der östlichen schueitz Init mächtigen Kalkmassen in Verbindung, die zum Theil aufgelügert scheinen.

Ich erinnere übrigens noch einmal, dass dieses Profil ein ganz ideales ist und nirgends in den Alpen in dieser Einfachheit vorkommt. Es soll nur die Altersfolge der Bildungen, nicht aber die Struktur der Alpen anzergen. Die konstante Verschiedenheit des dem Gueiss aufliegenden Schenkels der Lias- und Kreide-Bildungen von dem der Molasse zugekehrten scheint anzudeuten, dass bereits während des Niederschlages 
dieser Bildungen dic Verhältnisse des Meergrundes in der Nähe der Alpen verschieden von denjenigen in der Nähe des Jura gewesen, dass also die Alpen älter wenigstens als die Kreide seyen.

Wir haben auch die Gebirge von Gadmen und Meiringen, woher wir in Sommer 1835 theils Lias-, theils Kreide-Petrefakten erhalten hatten, nun genauer untersucht und sehr wichtige Aufschlüsse über die geognostische Vertheilung der Formationen im östlichen Theil des Berner Oberlandes und in den Urkantonen gewonnen.

Das Vorkommen von Diablerets - Petrefakten, nämlich Numnúliten, Cerithien, Ampullarien, Cardium etc. unmittelbar auf dem Hochgebirgs. Kalk, während auf der andern Thalseite, in einem ganz ähnlichen schwarzen Schiefer Lias-Ammoniten und Belemniten und mächtige Lager von Rotheisenstein auftreten, ist sehr auffallend. Noch sonderbarer zeigen sich aber die Verhältnisse an oberen Auslauf des Gentel. Thales, auf Engstlen und Joch, indem hier die Diablerets-Schichten unter die Lias-Schiefer der andern Thalseite einzufallen scheinen.

In Hinsicht der Verhältnisse zwischen dem Kalk und dem GranitGneiss sind wir nun, nach Vergleichung unserer Beobachtungen im Bündtner mit denjenigen im Berner Oberland, zu der vollen Überzeugung gelangt, dass sich die Auflagerung des Granits auf den Kalk und die gegenseitige Einkeilung dieser Gesteine durchaus nicht durch ein plutonisches Aufsteigen von flüssigem Granit, Überfliessen und Eindringen desselben in die aufgebrochene Kalkmasse erklären lasse. Diese aufgelagerten oder in den Kalk eindringenden krystallinischen Gesteine sind grösstentheils deutlich geschichtet, es ist Gneiss und Glimmerschiefer, nicht wahrer Granit, obgleich in diesen Übergänge bildend; zunächst auf dem Kalk liegt meist Glimmerschiefer, der sich oft sehr dem Thonschiefer nähert, und Quarzit oder Quarz-Sandstein; erst in grösserer Entfernung von dem Kalk entwickelt sich auch Feldspath und der Quarzit geht in wahren Gueiss über' in der Nähe des Kalkes ist die Schichtung der aufgelagerten Gesteine derjenigen des Kalkes parallel, und wechseln sogar dünne Kalklagen mit Quarzit und Glimmerschicfer, und erst dam, wemn das Gestein in deutlichen Gneiss übergegangen ist, stellt sich steil südlichfallende Schichtung ein. H. Lyell hatte mir geschrieben, bei seinem Besuche des Urbach-Thales hätte ihn sein Führer versichert, auf dem Gipfel des Gstellihorns liege auf dem Kalk wieder Granit. Escher hat noch spät Abends, als wir die Alphütten erreicht hatten, diesén Gipfel bestiegen und die Aussage der Älpler vollkommen bestätigt gefunden: der Gipfel des Gstellihurns ist Granit-Gneiss, der durch den Urbach-Sattel von demjenigen des Tossenhorns ganz getrennt ist und cine isolirte Masse bildet. In dem Kalk des Gstellihorns, unter dem Granit-Gneiss kommen Eisensteinlager vor mit Belemniten, Lias - Ammoniten, Pholadomyen, Terebrateln etć., ganz wie auf Stufistein an der Jungfrau.

Über unsere Beobachtungen in Groubündten cin andernal. - Für die nachsichtige Anzeige meines Buches von Freund Kefensters in den 
Berliner Jahrbüchern bin ich sehr dankbar. Nur wer sich selbst auch, wie mein Recensent, so viele Jahre mit den Alpen beschäftigt hat, keunt die grossen Schwierigkeiten, welche die Geologie dieses Gebirges allen unsern Anstrengungen entgegenstellt, und wird die Versuche anderer mit Billigkeit beurtheilen. Den Folgerungen von Kefersters könnte ich übrigens unmöglich beistimmen. Die Molasse ist, nicht nur durch ihre Meeres -, sondern auch durch ihre Süsswasser- und LandPetrefakten zu gut als ein Produkt der jüngeren Tertiär-Zeit charakterisirt, als dass man je daran denken dürfte, sie den Weald. Bildungen zu parallelisiren. Weit eher möchte ich ELIE de Beaumont beitreten, der den Wealdclay für eine lokale Süsswasser- und Land-Bildung in der marinen Bildung des terrain néocomien hält. Auch die Entstehung der Nagelfluh auf chemischem Wege wird gewiss kein Schweitzer-Geognost unter seine Glaubens-Artikel aufnehmen. Es haben sich überdiess in die Anzeige mehrere Missverständnisse eingeschlichen, die ich nicht gern Wurzel fassen sehen würde. S. 198 wird von Taviglianaz-Sandstein an Gurnigel gesprochen, während es Ralliger-Sandstein beissen sollte; S. 199 wird mir die Ansicht zugeschrieben, dass die ganze Masse der Kalkalpen der Jura-Formation angehöre, eine Ansicht, von der ich weit entfernt bin, und die ich im Gegentheil in allen meinen Arbeiten be. kämpfe; ich sage zwar, dass in Savoyen und Frankreich das Alpenund Jura-Gebirge, in topographischem Sinn, sich innig verschmelzen, dass auch die Gesteine daselbst noch jurassische Charaktere tragen, dass in der Schweitz dann beide Gebirge sich scheiden und die Alpen sich eigenthümlich ausbilden; daraus folgt aber jener Satz keineswegs; die vorherrschenden Gesteine der Kalkalpen, Lias und Kreide, lassen sich bis nach Sïd-Frankreich verfolgen und bleiben immer Lias und Kreide, und die eigentliche Jura-Formation finde ich nur zum Theil und mit alpinischem Charakter in den Gebirgsmassen der Simme und Saone, des Stockhorns und der Bera wieder, die alle drei von West her nur bis an den Thu. nersee fortsetzen und daselbst abgeschnittten werden. S. 202 wird gesàgt, ich zeige, dass der Nummuliten-Kalk ganz untrenubar sey von den Gliedern der Stockhorn-Kette; die angeführten Stellen führen aber keineswegs zu diesem Schluss, indem darin von der Stockhorn-Kette gar nicht die Rede ist. Der Kalk der Stockhorn-Kette, den ich für mittleu Jurakalk anerkannt habe, tritt nirgends in Berührung mit Num. mulitenkalk.

Um das Lesen meines Buches zu erleichtern und seine Resultate in Betreff der alpinischen Sediment-Bildung an. schaulich zu machen, habe ich dreiProfile meines Atlasses von Neuem lithographiren und, mit Aufopferung einiger topographischer Details, die Lagerungs-Verhältuisse darin deutlicher hervorbeben lassen; zugleich sind zu den LokalBenenungen der Formationen auch die systematischen, Lias, Kreide etc. beigefügt. Das Blatt ist hier bei Buchhändler Dalp zu haben, und wird, wennich nicht irre, für 


\section{$-609-$}

$24 \mathrm{kr}$, verkauft, unter dem Titel: "Ideale Profile zurErläuterung der Geologie der westlichen Schweitzer-Alpen."

Bald hätte ich vergessen, Ihnen über den Lungernsee zu schreiben, den wir in den ersten Tagen unserer Reise besucht haben. Escher hätte weit gründlichere Auskunft darüber geben können, da er bei der Ausleerung selbst thätig und seither mehrmal dort gewesen ist. An dem westlichen Ufer des Seebeckens ergiessen sich nehrere Gebirgsbäche in dasselbe, deren früherer Absturz nun zum Theil trocken gelegt ist. Hier nun sieht man von den oberen Bachgrund gegen den See zu die Schichten, aus feinerem und gröberem Kies bestehend, sich nach dem Abfall zu krümmen und unter einem Winkel von $35^{\circ}$ gegen den Seegrund einsinken. Die Höhe des Absturzes, von dem oberen Bachgrunde bis auf den horizontalen, ebenfalls nun trocken gelegten Seegrund mag $40 \mathrm{~F}$. betragen. Die geneigten Kies - Schichten sind in der Tiefe nicht merklich dicker als in der Höhe; ihre Mächtigkeit, z. B. eine Lage feineren Kieses zwischen gröberem Geschiebe, beträgt oft nur $1 \mathrm{Z}$ oll; flache Geschiebe von 6 Zoll Durchnesser folgen mit ihrer breitern Fläche der Schichtung, eben so Blätter und Holzfasern; auf dem rechten Ufer des Baches sieht man zwischen den stark geneigten Geschieb-Schichten ein Lager von bituminösem Holz, bei 6 Zoll nächtig , die Stämme ganz platt gedrückt. Aưf diesen Kies-Bänken, die sichtbar vou den Anschwellungen des Baches herstammen, hat sich der feinere Schlamm des See's, unter einem Fallwinkel von etwa $25^{\circ}$, abgesetzt; seine Schichten nun, die in dor Höhe etwa 4-8 Zoll Dicke haben, wachsen allerdings nach der Tiefe zu bis auf 3 Fuss Mächtigkeit und zugleich biegen sie sich allmählich ins Horizontale un und bilden dem früheren Sceboden. Sie sehen aus dieser Darstellung, dass die Verhältnisse dieser Gegend keinerlei Schwierigkeiten darbieten, dass sie die Hebungstheorie eher unterstützen, als gefährden, und nur gegen allenfallsige Übertreibungen derselben eine Warnung seyn können. DE LA Весне hat in einer sciner Schriften die Verhältnisse der Delta-Bildung ganz so auseinandergesetzt, wie wir sie hier wiederfinden. - Etwas verlegen bin ich um die Erklärung eines Durchschnittes im neueren Schuttland oberhalb Chur, der durch die neue Strassenanlage in diesem Sommer bloss gelegt worden ist. Mitten in den horizontalen GeschiebLagern zeigt sich eine Vertiefung von 30 Fuss horizontaler und 20 Fuss vertikaler Ausdehnung. Die Wände sind beinahe senkrecht, oder übergebogen; denselben parallel hat sich abwechselnd Schlamm und Kies abgesetzt und die Vertiefung aufgefüllt, so dass die überall gleich dicken Schichten der Ausfüllungs - Masse theils senkrecht stehen, theils Krümnungen bilden, die ganz das Ansehen gewundener Schichten gewinnen. Die Zeit und Gelegenheit zu einer genauen Untersuchung fehlte mir, als ich letzthin in Chur war. Vielleicht dass dennoch, ungeachtet der Neulseit der Bildung, ein Seitendruck angenommen werden darf, da die Rabinsa und Plessur, an deren Ausfluss sich die 
Stelle befindet, noch jetzt oft so gross, Massen von Wasser und Gebirgsschutt herbringen, dass eine Bewegung in den älteren Schuttmassen durch das Anstossen der angeschwollenen Gewässer nicht ausser den Grenzen der Möglichkeit liegt.

\section{B. Studer.}

Wien, 25. Sept. 1836.

Sie wissen wahrscheinlich, dass ich die Türkei in Gesellschaft der Herren von Montalenibert und Vip̧uenel, Geognosten, von Friedrichsthal, Botaniker, und Adorph Schwab, Entomolog, bereiste. Wir haben die mittle Türkei ziemlich gut kennen gelernt und manche Gegenden, die man für ganz unwirthbar hält, berührt, namentlich Serbien, einen Theil Bosniens und Albaniens, dann gauz Macedonien und einen Theil von Rumiliens. Später durchstreifte ich sodann allein noch einen Theil von Rumilien, das westliche Bulgarien und das östliche Serbien. Nirgend fanden wir irgend ein Hinderniss, in Gegentheil oft sehr gute Aufnahme; in Serbien ist die Sicherheit vollkommen und in der Türkei ist es auch jetzt in den meisten Gegenden sebr sicher. Ich bin mit Grossherrlichem Firman versehen, mit einem Tartaren und auch ohne letzteren, gereisst, nur mit einem einfachen Türk. Pass, und habe keinen Unterschied gefunden, ausser für die Beherbergung, die in ersten Falle manchmal besser ausfällt. - Ich gedenke im künftigen April mit neuem Muthe und frischen Kräften meine geognostische Aufnahme in der Türkei fortzusetzen, und die Küsten des Bosporus zu bereisen; möchte ich nur so glïcklich seyn, einige junge Physiker und Naturforscher als Reisegefährten zu haben, damit auf einmal mehr Licht über diesen so interessanten Theil Europa's verbreitet wird. Als erstes Resultat unserer Forschungen muss ich die Unrichtigkeiten aller Karten, selbst der besten (wie z. B. der СоттA'schen u. a.) rügen, vicht nur viele Ortschaften sind ausgelassen, oder nicht am gehörigen Orte bemerkt, sondern auch Flüsse und Berge sind ausgelassen, oder auf eine so sonderbare Art dargestellt, dass man leider nur zu oft die Terrain-Formen als ein wahres Werk der Phantasie anzusehen hat.

Ein zweites merkwürdiges Resultat ist die wahre Gestalt der sogenannten Zentral-Kette der Türkei. Den mittlen Theil schildert die Geographie (seit dem Mittelalter) als den höchsten, und er ist gerade der niedrigste, und der westliche, der sogenannte Rhodope oder Despotodagh scheint fast die Höhe der böchsten Gipfel der sogenannten ZentralKette zu erreichen. Die geognostische Beschaffenheit der Türkischen Kette dürfte selbst der Art seyn, dass'eine vollständige Trennung der Zentral - Kette und des Rhodope nicht wohl möglich ist. Wenn die Alpen aus mehreren Ketten bestehen, so sind sie doch fast alle und fast immer in einer gewissen Ordnung; die Türkischen Alpen erscheinen im Gegentheil durch ungeheure Natur-Phänomene getrennt, mehr als 
isolirte Gebirgs-Ketten, denn als ein cinziger Kamm. Der westliche Theil der Zentral - Kette, oder Tschardagh (Scordus älterer Schriftsteller) ist der böchste Theil des Kammes, und erstreckt sich von Uscub oder Kacsunik (ausgesprochen: Katschianili) bis gegen Alessio oder Scutari. Es ist ein Talk- und Glimmerschiefer-Gebirge mit Lagern von körnigem und dichtern Kalk und Partieen von Feldspath-reichen, sogenannten Ur-Gesteinen. Der östliche Balkan - grosser und kleiner Balkan (Bulgarisch: Velico Balkun, malo Balkan; Türkisch: beuk Balkan, Kutschuk Balkan) bildet eine vollständige, jedoch nur kleine Mauer von Sophia bis zum Schwarzen Meere; der Hämus wird immẹ niedriger, je weiter er sich gegen Osten ausdehnt; dieses Gebirge scheint meistens aus Ủbergangs - Schiefer und Kalk mit krystailinischem Schiefer zu bestehen; letzterer findet sich jeduch nur auf der südlichen Seite. Der mittle Theil der Zentral-Kette zwischen Kacsanik und Sophia ist nichts weiter, als ein hügeliges Plateau mit aufgesetzten, ziemlich niedrigen Bergen. Übergangs - Schiefer und Kalk herrschen daselbst vor; bisweilen gesellen sich auch Gneiss und Granit-Partieen, so wie grosse Ablagerungen trachytischer und doleritischer Gesteine dazu. Der Orbelus der Römischen Schriftsteller wird wohl von diesem letzteren Gestein gebildet seyn, und fände sich daun zwischen Kostendil oder Ghiıstendil und Egri Palankil, nördlich von der Hauptstrasse. Der Orbelus ist die höchste Kuppe im mittlen Theil der Zentral-Kette. Höchst merkwürdig war es uns, dass man diesen mittlen Theil an mehreren Punkten überschreiten kann, ohne dass man über ein eigentliches Gebirge oder durch einen hohen Gebirgs-Pass kommt. Südlich von der Ebene von Kossuva oder Pristince ist die Wasser-Scheide auf einem sehr kleinen, höchstens $50-90$ Fuss hohen Plateau, mitten im Thale; und das Durchbruch - Thal der Popentz führt den Reisenden allmälılich ins tertiäre Becken des Vardar herunter. Auf der andern Seite gelangt man in der Ebene von Radomir oder im obersten Strymon - (Türkisch Karasu-) Thal in das der sukowa oder nach scharkoe durch Spalten; nur über cine einzige unbedeutende Erhöhung N.O. von Gerlo oder Grlo hat man zu steigen. Selbst die Wege von Komanova nach Vrana und vorzüglich von Pristince nach Vrance fülsren kaum über Erhöhungen, die man Gebirge nennen könnte. Einige 1000 bis 3000 F. wird wohl das Maxinum der Höhe der erhabensten Gipfel, des Hämüs sowohl als der grössten Erhabenheiten des mittlen Zentral-Gebirges seyn, während der Tschardagh wenigstens 7000 , ja vielleicht 'selbst 8000 Fuss Höhe erreichen mag. Eine Tagereise reicht zu, um über dic breitesten Theile der Zentral-Kette zu steizen. Die grössteu und höchsten andern Ketten der Türkei sind gegen Osten der westliche Theil des sogenannten Rhodope oder Despotodagh, der im Lande die Nameu von Rilsplanina, Staninatiplanina und Perindagle führt. E3 ist cin märhtiges Gebirge, breiter als die Zentral. Kette und gewiss tiber 6000 Fuss hoch. Die ganze Kette von Dubniczl an bis zum Mecre von Murmara, scheint aus krystallinischen Schiefer - Geşteinen zu bestehen; 
sie enthalten schöne Gneiss-Arten, Hornblende- und Granat-Gesteine, so wie auch Granit-Gänge, Kuppen und Lagen körnigen Kalkes, hie und da neben Granit mit den schönsten krystallisirten Mineralien, wie Granat, Idokras, Tremolith, Augit, Epidot u. s. w. Bei dem Rilo.Kloster findet man ähnliche Phänomene, wie bei Glentilt, bei Bervig und Auerbach. Es ist schon bekannt, dass die Taurus - Kette in Klein-Asien nur als eine Verlängerung des.Despotodagh anzusehen ist. Die etwas niedrigere und nicht so mächtige Kette des Pindus und Olymp (Türkisch Skele) scheinen auch aus krystallinischem Schiefer zu bestehen; jedoch die erstere Kette mit grossen kalkigen Neben-Gebirgen. Zwischen Novibazar, Ipek, Herzegowina und dem südlichen Bosnien liegt ein gewaltiger Gebirgs-Stock, der als ein selbstständiges Gebirge anzusehen ist; mehrere Flüsse nehmen da ihren Ursprung. Es ist ein ungeheures Gebirge, das wohl zur Flötz-Zeit gehören wird, und über 6000 Fuss Höhe hat. Es gibt da auch eine alpinische Trias. In Bosnien finden sich noch sehr hohe Übergangs - und Flötzkalk - Gebirge, vorzüglich südlich von Mostar.

Serbien ist meistens ein hohes Hügelland; tertiäre Molasse und Thon-Schichten umlagern ganz die kleinen Übergangsschiefer-oder Grauwacken-Gebirge. Im südlichen Serbien gibt es aber bedeutende Übergangs- und Urschiefer-Höhen, wie das Kopaunik und Jaztrebitzer Gebirge. Das westliche Serbien ist sehr gebirgig. Im östlichen. Serbien und in der westlichen Bulgarei findet man eine interessante rothe Flötz-Sandstein-Formation, ungefähr derjenigen der Alpen ähnlich; dieses Gebilde lässt sich bis in das Bannat verfolgen, wo ich die Freude hatte, sie wirklich in Verbindung mit Quarz-haltigem Porphyr, mit Porphyr-Breccie, Todtliegenden ähnlichen Sandsteinen und vortrefflichen Kohlen-Gebilden beobachten zu künnen. Jedoch der grösste Theil der Kette zwischen dem Donau-Durchbruch und Sophia, oder dem Hämus, besteht aus dichtem Kalk und ǵanz besonders aus dichtem Jura-Kalk, in welchen der so merkwürdige Urkanal oder das Thal von Nissa bis Sophia sich befindet. Gegen die Donau-Abdachung findet man sehr viele Fossilien in jenem obersten Jura-Kalke. Im südwestlichen Macedonien, so wie in Bosnien und Albanien, ist auch derselbe Kalk vorhanden. Die grosse Nummuliten- und Hippuriten-Kreidekalk-Formation Dalmatiens erstreckt sich, wie bekannt, durcn Bosnien und durch den grössten Theil Albaniens. Hippuriten-Kalk wurde auch von uns neben Belgrad bei Novibazar und im südlichen Macedonien beobachtet. Tertiäre Becken, dem Ungarischen gleich, sind in der Türkei häufig; nicht nur der grösste Theil Serbiens und der Walachei ist tertiär, sondern auch das ganze südliche Ufer der Donau in Bulgarien, die grosse Ebene von Sophia, südlich vom Hämus das Maritza - Becken, das Becken des obern Strymon, oder von Dubnicza, Kostendil und Djumava, das obere Vardar- oder Uskub-Becken, das untere Vardar-Becken am Meere, das weisse Drina-Becken in Albanien, das Scutari-Becken. $\mathrm{Zu}$ diesen Molasse-, Thon- und Sand-Ablagerungen gesellen sich noch mehrere kleine Becken nit Süsswasser-Kalkgebilden, wie bei Istip? 
Gafadartzi, Vodena in Macedonien, im Rachina-Becken in Serbien, in den Ebenen von Kossova, Radomir u. s. w. Trachyte baben, oft mitten in der Molasse, sich gezeigt: so fanden wir grosse Trachyt- und TrachytKonglonerat-Gebirge zwischen Komanova und Straczin, zwischen Straczin und Karalova, zwischen Egri-Palanka und Kostendil. Diese Trachyte haben alle Thäler förmlich in mehrere Theile getrennt. Auch bei Novibazar in Bosnien überrascbte uns Trachyt; eine ähnliche grosse Ablagerung findet sich in den Gebirgen südlich von Gafadartzi, und bei Vodena in Macedonien, wo das Bimsstein - Konglomerat sich einem jüngeren Travertino anschliesst. Dolerit-Kuppen kommen bei Nagoritsch im nördlichen Macedonien, so wie auch bei Gerlo und Scharköe in Mösia und in der Bulgarei vor; der Dolerit hat deutlich die Molasse gehoben und verworfen. Eine Art Syenit-Porphyr mit Augit-haltigem Porphyr herrscht in der ganzen Ungegend von Karatova in Macedonien; dieses Gebilde führt, wie in Ungarn, reiche Partie'n oder Streifen, die mit silberhaltigen Bleiglanz-Putzen und -Schnüren gefïllt sind. Wie bei Schemnitz ist das Gebirge von Trachyt, Trachyt-Konglomerat, und sogenauntem trachytischem Mühlenstein-Porphyr umgeben. Herr v. HerDER hat bereits bekannt gemacht, dass die metallischen Syenit - und Übergangskalk-Streifen des Bannats sich im östlichen Serbien bis gegen Maidanpek und Tanda wenigstens erstrecken. Auch im Zentral- und im westlichen Serbien ist diess Gebilde zu finden, jedoch nicht so reichhaltig; es setzt nach Bosnien über. Serpentin ist im Übergangs-Gebilde des zentralen und westlichen Serbiens, bei Pristina, so wie auch in Bosnien, und in südlichen und westlichen Macedonien zu finden. Schöne porphyrartige Protogine bilden grosse Gebirge östlich vom Castoria-See, und Granit sehen wir schon im Rilo-Gebirge, in Perindagh, so wie westlich von Kostendil; bedeutende Massen fanden wir in Greiss. Gebirge von Perlepe, die neben einer Kette von Glimmer-reichem Gneiss, mit Glimmerschiefer, Thonschiefer, körnigem Dolomit (wie "am St. Gotthardt) und dichtem Kalk ziemlich plötzlich aufsteigen. Auch im mittlen Serbien findet sich Granit in der Grauwacke.

Die Phänomene der zerstreuten Blöcke (blocs erratiques) sclieinen der Türkei fremd zu seyn; Löss gibt es viel, vorzüglich gegen die Donau hin. Die Übergangs-Gegenden Serbiens und Bosniens sind, wie das Nassauische, reich an Mineral-Quellen, an Sauerwasser und an salzigen Schwefel-Wasserstoff-Gas enthaltend. Quellen finden sich? häufig, sowohl im östlichen Serbien, Banya, Nissa, Novibazar u. s. iv. als südlich der Zentral-Kette (Banya an Vardar, Kostendil, Banya bei Kostaniz, Banya zwischen Kezlanik unả Philippopolis, Aidos); bei Nissa und in Banya unfern Alexinitza ist gar kein Schwefel-Wasserstoff-Gas vorhanden. Alle diese Wasser kommen unfern der Trachyte, Dolerite oder der syenitischen Porphyre vor.

A. BouÉ. 


\title{
Neueste Literatur.
}

\author{
A. Bü ch er.
}

1835.

Razzoñ: dell' antichissima condizione geologica e politica dell' alta Lombardia. Miluno. $16^{\circ}$ [45 $\mathrm{kr}$.].

1836.

Aвгсн: vues illustratives de quelques phénomènes géologiques, prises sur lc Vesuve et l'Etna pendant les anées 1833 et 183t, in fol. avec $10 \mathrm{pll}$.

J. Lindley and W. Hutton: the fossil Flora of Great Britain, London 1836, Januar [ $5 \mathrm{sh} .6$ d.] enthält: Sphaenopteris Hibberti, Sph. latifolia, Pecopteris lobifolia, Asterophyllites tuberculata, Sphaenopteris furcata, Pinus Canariensis, Neuropteris heterophylla.

Fr. Ad. Römer : die Versteinerungen des Nord-Deutschen OolithenGebirges. Zweite und dritte (letzte) Abtheilung, enthaltend neuen Titel, Text von S. $65-68$ und $75-218$, und Taf. I-XVI. Hannover, in $4^{\circ}$ [ $14 \mathrm{f} .24 \mathrm{kr}$.].

Puscr: Polens Paläontologie, oder Abbildung und Beschreibung der vorzüglichsten und der noch unbeschriebenen Petrefakten aus den Gebirgs-Formationen in Polen, Volhynien und den Karpathen. I. Lief. Bogen 1-10, Taf. I $-\mathrm{X}$, Stuttg. $4^{0}$. [ Die II, Lief. wird noch etwa 20 Bog. Text und 6 Tafeln enthalten.] 


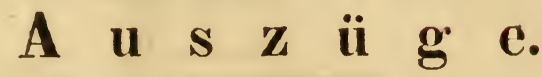

\section{Mineralogie, Krystallographie, Mineralchemie.}

Berzeluus: über den Olivin (XV. Jahresbericht, S. 217). Bei einer Untersuchung zweier Olivine, wovon einer von Boskowich unfern Aussig in Böhmen, der andere aus Auvergne war, ergab sich, dass das Mineral nicht allein die Eigenschaft hat, sehr' leicht von Salzsäure zersetzt zu werden und damit zu gelatiniren, sondern dass es auch Kupferund Zinn-Oxyd enthält, die jedoch zusammen nicht mehr als $\frac{1}{5}$ Prozent betragen. Beide Olivine hielten Nickel, wie Stromeyer längst gezeigt hat.

Aus Lychnele's Analyse mehrerer Arten von' Speckstein scheint sich zu ergeben, dass das Mineral $M g \mathrm{~S}^{\overline{3}}$ ist, wiewohl sich in einigen Varietäteu ein Überschuss an Talkerde zeigt (A. a. O.).

A. Connel hat ein Mineral von den Faröern analysirt, welches mit dem von v. KoBELr zerlegten Okenit vollkommen übereinstimmt (A. a. O. S. 221).

Derselbe Chemiker zerlegte den sogenannten Levyn von Irlund. Seine Analyse gab, gleich der früheren Berzesıus'schen, die Formel der Chabasic (A. a. O.). 


\section{$-706-$}

M. L. Frankenheim: chemische und krystallinische Beob. achtungen (Poggend. Ann. d. Phys. XXXVII, 637 ff.). Der Verf. schildert eine Vorrichtung, um unter dem Mikroskope Winkel zu messen, handelt vom Hydrat des salzsauren Natrons und von der Kieselerde. Aus der letzten Mittheilung entlehnen wir Folgendes: der Opal ist wahrscheinlich eine aus Hydrat gebildete Kieselerde, die daher noch sehr porös ist, und auch noch mehr oder weniger Hydrat enthält. In hohen Temperaturen sintert Opal, wie alle poröse Körper, zusammen, und wird dichter und weniger auflöslich. Vielleicht besteht der oft schön krystallisirte Seesand aus zersetzten Hydratlagern.

L. P. Lychneln: Analyse des Specksteins und des Seifensteins (K. Vet. Acad. Handl. f. 1834, $p .97$ und Poggend. Annal. XXXVIII, 147).

Speckstein :

\begin{tabular}{|c|c|c|c|}
\hline $\begin{array}{l}\text { Vom Mont Cnunegou; } \\
\text { hellgelb; in dünnen } \\
\text { Splittern durchsichtig; } \\
\text { im Bruche splittrig und } \\
\end{array}$ & $\begin{array}{c}\text { Von Salı; unge- } \\
\text { fähr gleiche Merk- } \\
\text { male. }\end{array}$ & 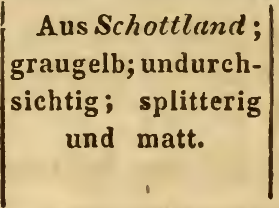 & $\begin{array}{l}\text { Aus China; hell } \\
\text { graulichgelb; } \\
\text { schwach durch- } \\
\text { scheinend; fett. } \\
\text { glänzend. }\end{array}$ \\
\hline 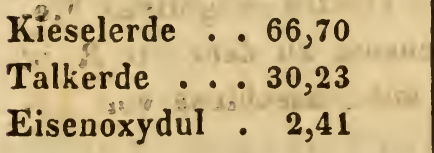 & $\begin{array}{r}63,13 \\
34,30 \\
2,27\end{array}$ & $\begin{array}{r}64,53 \\
27,70 \\
6,85\end{array}$ & $\begin{array}{l}66,53 \\
33,42 \\
\text { Spur. }\end{array}$ \\
\hline 9,634 & 99,70 & 99,08 & 99,95 \\
\hline
\end{tabular}

Der Scifenstein von Bayreuth gab:

$$
\begin{aligned}
& \text { Kieselerde . . . . } 65,64 \\
& \text { Talkerde . . . . } 30,80 \\
& \text { Eisenoxydul •. . } 3,61 \\
& 100,05
\end{aligned}
$$

Derselbe: Analyse des Agalmatholithes (K.Vet. Acad.Handl. f. 1834; p. 101, und Poggend. Ann. XXXVIII, 149). Das Mineral, hellgelb, im Bruche splittrig, schwach fettglänzend, hattc eine Eigenschwere von 2,73 und bestand aus: 


\section{$-707$}

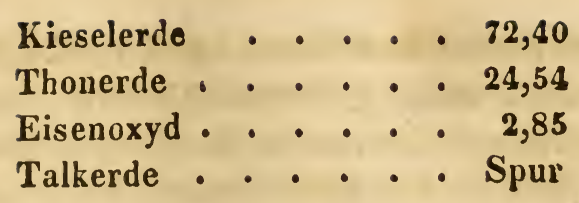

Hienach wird die Formel : $\dddot{\mathrm{A}} \dddot{\mathrm{S}} \mathrm{i}^{3}$.

J. Kudernatsch: über die chemische Zusammensetzung des Pennantits (Poggend. Ann. XXXVIII, $397 \mathrm{ff}$.). Das Ergebniss der Untersuchung war:

$$
\begin{aligned}
& \text { Schivefel . . . } 27,76 \\
& \text { Arsenik . . . . 19,10 } \\
& \text { Kupfer • . • . . . 48,94 } \\
& \text { Eisen . . . . 3,57 } \\
& \text { Silber . . . . Spur } \\
& \text { Quarz . . . . } \\
& 99,45
\end{aligned}
$$

Die Formel für den Tennantit wäre demnach:

$$
\left.\begin{array}{l}
\dot{\mathrm{Fe}} \mathrm{e}^{4} \\
\dot{\mathrm{C} \mathrm{u}^{4}}
\end{array}\right\} \stackrel{\text { Äs }}{-}+2 \dot{\mathrm{Cu}}^{*} \stackrel{\text { Äs. }}{ }
$$

Als Fahlerz ist das Mineral in mehrfacher Beziehung interessant: es ist das erste Beispiel eines Fahlerzes, das als elektro-negatives Metall ausschliesslich nur Arsenik enthält, im Gegensatz zu dem von RosB untersuchten Fahlerze von Klausthal, welches, mit Ausschluss von Arsenik, nur Antimon enthält.

G. Suckow: über den Bitterspath aus der Gegend von Jena (Erdman und Schweiggr - SeIdeL's Journ. f. prakt. Chem. VIII, 408). Vorkommen rhomboedrischer Krystalle in Sandstein, meist kleine Drusenräume füllend.

Karsten: über die chemische Verbindung der Körper Abhandl. d. K. Akad. d. Wissenschaften in Berlin aus dem Jahre 1834. Berlin 1836, S. 1 ff.). Zu einem umfassenden Auszuge fehlt der Raum, wir müssen uns begnügen, des'Resultates zú gedenken, zu welchem der Vf. namentlich in dieser vierten Abhandlung, die chemischen WablVerwandschaften betreffend, gelangte. Er sagt am Schlusse: so weisen denn alle Erscheinungen bei Bildung der Arten aus den neutralen sowohl, als aus den nicht neutralen Mischungen darauf bin, dass den 
unorganischen Körpern keine absolute’, jedem derselben eigenthümliche Verwandtschafts - Kraft beigelegt werden kann, sondern dass es zwei, minder entgegen wirkende Kräfte, die Mischungskraft und die Bildungskraft sind, deren sich die Natur bedient, un in stetem Kampfe die vorhandenen Arten zu vernichten und neue zu erzeugen.

\section{Geologie und Geognosie.}

G. Bellas Grennovgh: B emerkungen über Elie de Beaumont's Hebungs-Theorie, aus seinem Vortrag an die geologische Sozietät in Lundun, bei ihrer Jahres-Versammlung von 1834 ausgehoben (JAMES. Edinb. n. philos. Journ. 834, XVII, 205-227).

1. Hebung der Kontinente. Wenn man diejenigen, diese Benennung nicht eigentlich verdienenden Hebungen ausschliesset, welche bewirkt werden durch Auffüllung von den Flüssen, durch Auswürfe von den Vulkanen, durch untermeerische Aufbauung von den Korallen, durch Aufrichtung einseitig unterwaschener Felsschichten, durch Anschwemmungen von dem Meere, so beruhen dic Beweise wirklich Statt gefundever Hebungen nach a) auf Beobachtung, b) auf Induktion. - a) Nach vos Horf wären 1771 auf Java einige Landstriche gehoben worden und eine neue Bank vor der Mündung des Batavia-Flusses erschienen, worüber sich derselbe auf Sir Stamford Raffles, auf John Prior's Reise im Indischen Meere, und auf die „allgemeine Geschichte der Reisen' II , 401" berufet; auch Lyell führt die erstere Quelle an. Aber RÁFLEs crzählt in keiner Ausgabe seines Werkes etwas der Art. Die andern zwei Quellen konnte G. zwar nicht nachschlagen, aber nach dem Appendix zu den Batavian Transactions, welcher eine scheinbar amtliche Aufzählung aller Erdbeben in Java während anderthalb Jahrhunderten liefert, scheint i. J. 1771 dort gar kein Erdbeben Statt gefunden zu haben. - Viel ist auch das Erdbeben von 1822 in Chili angeführt worden, wodurch die ganze Küste auf 100 Meilen Länge nit einè Fläche von 100,000 Quadrat - Meilen gehoben worden und Austern noch an Steinen ansitzend aufs Trockne gerathen seyn sollten. Die nittle Hébủng dieser Fläche soll 1', die der Küste von Valparaiso $3^{\prime}$, bei Quintero $4^{\prime}$ betragen haben, wie Mrs. Graham in den Geological Transactions und ein Ungenannter im Journal of Science angeben. Doch gaben beide nicht das Mindeste an über die Mittel, wie man diese Höhen-Änderung gemessen, oder über die Art und Zeit, in der sie eingetreten sey; auch Kapitain KIvg, welcher später an Ort und Stelle war, meldet nichts von diesem Ereigniss. Endlich enthält Mourn's Beschreibung von Chili nichts von solchen Ereignissen in früherer Zeit. Zwar findet sich eine Nachricht über obirges Erdbeben von Don Camillo Enzipuez im Mercurio Chileno, die aber der Verf. nicht nachschlagen 
kounte, und eine andere sehr zu empfehlende steht in der Abeija Argentina, wo aber von jener angeblichen Hebung durchaus nicht die Rede ist, sondern nur lokaler Verschüttungen und eines vorübergehenden wiederholten, aber nicht bleibenden Niveau-Wechsels des Meeresspiegels gedacht wird, bei welchem aber die Küste nicht gelitten. Mrs. Graram sagt auch nicht, ob die gehobenen Gesteirie, woran noch die Austern an der Seeküste ansassen, lose oder anstehende gewesen. - Der Vesuv ist gewiss am fleissigsten und längsten unter allen Vulkanen beobachtet worden, aber Niemand hat uoch gesehen, dass der Apenninen-Kalkstein von ihm enporgehoben worden wäre. Wiederholte Untersuchungen der Schwedischen Küste, deren Niveau's - Wechsel zuerst Swedenborg zur Sprache brachte, haben einen solchen von der Mitte des XVIll. Jahrhunderts an bis zum J. 1820, wo Bruncrona und Halström über die früher angebrachten Wasser-Marken Bericht erstatteten, jedoch in geringem Grade und in der Weise bestätigt, dass das Land im Ganzen sich etwas gehoben habe, an einigen Stellen jedoch im Verhältniss zum Meeresspiegel tiefer eingesunken sey, so dass die Erscheinung aus einem Wechsel des letztern nicht erklärbar sey. Die an der Brittischen Küste begonnenen Arbeiten werden wohl für die Zukunft noch mehr Mittel zu Entscheidung dieser Frage darbieten. - b) Die Beweise durch Induktion beruhen auf folgenden Erscheinungen: 1) auf den Ablagerungen meerischer Niederschläge und Thierkörper hoch über dem jetzigen Seespiegel, 2) der Hölıe Gestade-ähulicher Terrassen und der Höhe der Wellen-Spuren; 4) der Aufrichtung von Gesteins-Schichten in der Nähe ungeschichteter Gesteine; 5) der ungleichen Höhe, in welcher dieselben Felsschichten in ihrer Erstreckung vorkommen; 6) der antiklinalen Richtung der Schichten hauptsächlich in Bergketten; 7) der Bogen-oder. Dom-förmigen Gestalt einiger Schichten: 8) dem Vorkommen anscheinend neuer Korallen hoch über dem Meere; 9) der Lage mancher Bauwerke wie des Serapis-Tempels zu Pozzuoli. Jedoch lassen sich einige dieser. Erscheinungen auch durch die Annahme eines Sinkens des Meeres erklären, andere deuten nur auf ganz lokale Erscheinungen, und fast alle sind übertrieben dargestellt. Die Ursachen derselben sollen bald Erdbeben seyn, bald unterirdische Feuer, bald Wasserdämpfe, bald Berührung des Wassers mit Erd- und Alkali-Grundlagen, Gase nach Heine, Expansiv-Kraft nach Playfarr, Magnetismus nach Necker de Saussure, allmälliche Änderung der Erdachse nach WREDE, eine Schichte unter dem Ozean verdichteter atmosphärischer Luft nach LEsLie. Das Vorhandenseyn thătiger Explosiv-Kräfte in der Erde will der Verf. nicht läugnen: die Vulkane liefern einen Beweiss davon, aber sie sind in Mass, Zeit und Raum beschränkt, heben Bergkegel, aber keine Kontinente, schmeizen das Leicht-Schmelzbare, werfen das Strengflüssige aus und bilden hin und wieder einen Lavenstrom. Schwierig ist auch die Annahme des Einsinkens grosser Strecken der Erdoberfläche, weil sie Höhlungen, oder rasch kontrahirende Abkühlungen ganzer Kontinente u. dgl. voraussetze: Doch wissen wir aus den Vulkanen und warmen Quellen 
das feste, tropfbare und gasartige Stoffe unter der Oberfläche der Erde vorhanden sind, in Gesellschaft grosser Wärme, durch welche sie alle ausgedéhnt werden.

Zentral-Wärme. Diese Wärme leitet Daubery von der Berührung des Wassers mit den Alkali-Metallen ab, zweifelsohne mit mehr Grund, als andere deren Quelle in einem flüssigen Erdkerne erblicken : eine eingebildete Annahme, für welche die Temperatur-Zunahme in den uns zugänglichen Räumen der oberflächlichsten Erdrinde noch keinen Beweiss liefert, zumal diese Zunahme nicht mit der Nähe jedes Punkts beim Zentrum, sondern mit dessen Abstande von der Oberfläche in Verhältniss steht; denn sonst müsste man an dèm abgeplatteten Theile-des Erd-Sphäroides die Temperatur viel schneller wachsen sehen. Und wäre diese Zentral-Wärme je vorhanden gewesen: sollte sie nicht während der zahllosen Weltalter der Huttonianer Zeit gefundén haben zu entweichen? So wenig daher das Vorhandenseyn einer grossen Wärme in gewissen Stellen der Erd-Rinde geläugnet werden kann, so wenig ist erweislich, dass sie allgenein, oder zentral seye. Mit jener so schlecht begründeten Theorie steht aber noch die der allmählichen Abkühlung in Verbiudung. Die fossilen Thier- und Pflanzen-Reste sollen beweisen, dass die nördliche Hemisphäre einst ein viel wärmeres und gleichförmigeres Klima und selbst eine tropische Menge und Vertheilung des Lichtes genossen bis zum Beginne der langen tertiären Zeit, während welcher jedoch die Abkühlung noch immer fortgewährt habe. Die Erscheinung ist wohl nicht zu läugnen, aber jener Grund sehr zu bezweifeln. Denn durch Fortleitung kann die Erdoberfläche ihre Wärme nicht verloren haben, da sie von einem leeren Raume umgeben ist; durch Strahlung auch nicht, da diese bei geringeren Temperaturen, selbst noch bei $40^{\circ} \mathrm{C}$. fast unbemerkbar ist, was doch noch das Doppelte von unserer jetzigen mittlen Erd-Temperatur nusmacht. Nach LAPLACE hat sich unser Planet seit 2000 Jahren nicht zusammengezogen und nach Fovrier sich seine Schnelligkeit und seine Bahn nicht geändert, mithin sich derselbe nicht abgekühlt. Was die plutonischen Felsarten anbelangt, so sind die einen, die vulkanischen und TrappGesteine schon durch die mässigen Grade lokal vertheilter Hitze zu fliessen fähig, und unter den Urgesteinen kennen. wir von manchen den Schmelzpunkt nicht einmal. Lavorsier konnte kohlensauren Kalk in der grössten Hitze eines Brennspiegels nicht schmelzen; Quarz bedarf hiezu nach Saussure $4043^{\circ}$ des Wedgewood'schen Pyrometers, während Glas nur $30^{\circ}$ desselben nöthig hat. Wie also will man die Schmelzung dieser oberflächlichen Gesteine von zentraler Hitze ableiten [der Verf. gesteht selbst keine eigene Erklärung dieser Erscheinung geben zu köunen] und sie dadurch bis zu den ungeheuersten Höhen emportreiben lassen? Hat aber die Erde sich nicht durch Wärme-Verlust abkühleu können, so lassen Andere es durch verminderten Wärne-Zufluss von aussen geschehen (Lиввоск); jedoch sind die möglichen astronomischen Einflüsse nach HerscheL's Berechnung: nicht genügend gross, um den 
um den Grund des Ozeans, nach Lyel..'s Ansicht, in die höchsten Bergspitzen emporzuheben. - Man hat die Pflanzen-Reste der Steinkohlen. Formation auf Melville Island als Beweis angeführt, dass jene Breite einst nicht nur viei wärmer, sondern auch viel heller gewesen seyn müsse, als jetzt, und hat dieses zu erklären bald zum Vorrücken der Nachtgleichen, bald zur Annahme einer Änderung der Richtung der Erdachse seine Zuflucht genomnen; aber erstere kann in keinem Falle einen hinreichenden Erfolg haben, und letztere ist nur eine völlig unerwiesene und selbst sehr unwahrscheinliche Möglichkeit. Eine wiederholte Prüfung der im Brittischen Museum niedergelegten Pflanzenreste von Melville Island hat aber auch $Z_{w}$ eifel erregt, ob sich obiger Schluss wirklich darauf gründen lasse?

Innere Höhlen. Höhlen, Klüfte, Spalteu sind im manchfaltigsten Gesteine vorhanden, oft von sehr grosser Ausdehnung. An der Stello der ausgeworfenen vulkanischen Massen müssen Räume im Innern entstehen, worin nicht diese allein, sondern auch noch das enthalten war, was verbrannt und als Wasser, Dampf, Gas entwichen ist.- Auch die Anordnung der Vulkane selbst, die Ausdelsnung der von ihnen erschütterten Landflächen, die offenbaren Beziehungen in den Ausbrüchen öfters sehr entfernter Vulkane deuten darauf hin. Denkt man sich nun unter der Skandinavischen Küste eine Anzahl solcher Höhlen in Verbindung stehend mit Öffnungen auf der Höhe der Gebirge, durch welche Wasser eindringt und keinen Ausweg mehr findet, so gelangt man ohne Zentral-Hitze und sekundäre Abkühlung durch den hydrostatischen Druck allein zur Erkiärung der lokalen und ungleichgrossen Hebungen in jenen Gegenden.

Hebungen durch den Einbruch feuriger Gesteine in die geschichteten. Dieser Gesteine werden bald mehr bald weniger bezeichnet. Jedenfalls sind sie sehr verschiedenartig und daher nicht zu. gleicher Zeit aus demselben Tiegel, sondern aus vielen lokalen Tiegeln hervorgegangen. Die Laven selbst sind wohl nicht ursprünglich feuriger Entstehung, sondern nur umgeschmolzene Gesteine. Warum man aber den Granit und dessen Verwandte als vorzügliches Hebungs-Element ansehe, weiss der Verf. nicht anzugeben. Er trägt kein besonderes Prinzip der Bewegung in sich; die Granit-Gänge in andern Gesteinen sind zu unbedeutend, als dass sie hätten eine Hebung derselben bewirken können, und selbst dessen Kontakts - Wirkungen auf andere Gesteine lassen sich wohl anders als aus einem feurigen Zustande erklären. Er geht in eine Menge anderer Gesteine über. Die tertiären Schichten von Castrogionanni in Sizilien in $3000^{\prime}$ Seehühe abgelagert, sagt man, seyen, nachdem sie unter dem Meeresspiegel entstanden, von und mit einer Granit-Masse von gleicher Mächtigkeit in diese Höhe emporgehoben worden. Aber die Erscheinung lässt sich noch anders erklären. Der nahe Ätna hat mit der Zeit wohl mächtige Höhlen unter seinen Fusse bilden müssen, auf deren einer die Bildung von Castrogiovanni ruhet und sie wasserdicht geschlossen hat, mit Ansuahme der. 


\section{$-\quad 712$}

Seite gegen den Ätna hin, mit dessen Höhen sie zusammenhängt und von ihnen beständige Wasserzuflüsse durch das Schmelzen des Schnee's erlıält, deren hydrostatischer Druck aus 10,000' Höhe jene jugendlichen Schichten so hoch emporgchoben hat und noch höher heben kann; und so mag es sich auch mit andern Punkten in Fal di Noto verhalten.

Schliesslich nimmt der Vf. seine vor 14 Jahren aufgestellte Theorie einer allgemeineu doch vorübergehenden Weltfuth am Schlussc der Tertiär - Epoche zurück.

F. Kries: über den Zusammenhang zwischen den Erdbeben und vulkanischen A usbrüchen mit dem Zustand der At. mos phäre (Acta Soc. Jablonorianae nova 1832, I, IV, 186).

Boussingault : über die Erdbeben in den Anden (Ann. chim. phys. 183.5, LVIII, 81-88). Es ist Thatsache, dass die heftigsten Erdbeben in den Anden, diejenigen welche ganze Städte und Provinzen (Lutacunga, Rio-Bamba, Honda, Caraccas, Laguayra, Barquisimento) verwüsteten, nicht mit yulkanischen Ausbrüchen zusammenfallen; - diejenigen, welche in diesen Falle sind, sind weit beschränkter, lokaler. Auch sind in Amerikı überhaupt die Erdbeben mehr den Gelrigsgegenden eigen und erstrecken sich hauptsächlich in der Richtung der Gebirge und'zwar in solcher Menge, dass, wenn man sie alle aufzeichnen wollte, man finden würde, dass dic Erde dort, an irgend eiser Stelle, fast ohue Unterbrechung bebe. Die Erdbeben scheinen daher mit den Gebirgen, aber nicht mit den vulkanischen Kräften in Beziehung zu stehen, und zwar nach des Verfs. Ansicht in folgender Art:

Die Anden sind emporgehoben und dadurch grosse Höhlen unter denselben entstanden, deren Gewölbe ein oft ziemlich loses Haufwerk von Stcin-Schichten bildet: denn ihre Hebung fand im trockenen, starren, durchaus nirgends im teigigen Zustande hat. Die Anden setzen sich daher fortwährend nieder, und wo irgend jene Gewölbe dabei zusammenstürzen, da entstehen Erdbeben. Das unterirdische Getöse dabei (bramido, Brüllen) ist völlig jenem ähnlich, welches die Bergleute beim Zusammenstürzen eines unterirdischen Paumes vernehmen: sie bezeichnen beiderlei Getose mit gleichem Namen. Dieses Niedersetzen eincs in Masse gehobenen Gebirges findet daher natürlich auch am meisten unmittelbar nach dessen Hebung Statt: je neuer ein Gebirge gehoben ist, desto mehr muss solches vorkommen. Wie Нимвосdт glaubt, dass der Vesuv sich von 1804 bis 1823 um 30 Meter gesetzt habe, so findet man ähuliche Auzeigen auch in den Arden. An der Stelle des CapacUrcu (Haupt-Berges) bei Rio-Bumbu, der der Chimborasso einer Tıadition zufolge ibberragt haben soll, findet sich jetzt nur ein mäsig hoher Hunfen weit umher liegender Traclıyt-Blöcke; sein Setzen hätte 


\section{- $113-$}

vor der Entleckung von Amerika Statt gefunden. Auf der Station Gıngıapichincha bei Quito wurden vor 100 Jabren die Französischen Akademiker in ihren Messungen sehr durch Schnee gehindert, der dort jetzt nicht mehr vorkommt. Der Vulkan Puracé bei Popayan ist minder hoch, als ihn CALDAs 30 Jahre früher gefunden, und nach Angabe der Eiuwohner ist die untere Schneegrenze an ihm jetzt höher oben, als damals, obschon die mittle Temperatur noch dieselbe ist. Auch Quito, Popayan, Santa Fé de Bogota und die Meyerei von Antisana liegen jetzt weniger hoch, als CALDas und Humbordr gefunden, dagegen kein Ort höher, als damals.

Freyer: über die Emporhebung des Landes an der Westk ï ste S'üd-Amerika's i. J. 1822 (Lond. a. Edinb. philos. Junrn. 1835, VII, 318). Dieser und die 5 folgenden Auszüge sind aus den Verhandlungen der geologischen Sozietät in London entnommen. - Nördlich von der Stadt Arica, welche in $18^{\circ} 26^{\prime}$ südl. Br. liegt, sind sandige Ebenen ohne zu Tag stehendes Gebirge, wo Konchylien noch lebender Arten 10'-12' über Hochwasser-Grenze abgelagert sind. Südlich gehen Wechsellager von Sandstein und Gyps zu Tage; am Vorgebirge Morro von Arica sind sie durch eine Masse vou Basalt, Porphyr und Pechstein, welche ineinander übergehen, verrückt und zu $400^{\prime}$ Höhe enporgehoben; und nächst der Spitze desselben nimmt der Sandstein Lager eines Salzes auf, das aus 0,316 Chlorine, 0,316 Sodium, 0,140 Schwefelsåure, 0,915 Kalk, 0,090 Pottasche und Magnesia; und 0,040 Kieselerde besteht. Südlich vom Morro haben diese Schichten ein südliches Einfallen und bilden ausgezeichnete Terrassen übereinander längs der Küste. Wo immer auf diesen Terrassen Stein zu Tage steht, finden sich ansitzende $\mathrm{Bal}$ a nen und überrindende Milleporen, welche in $20-30^{\prime}$ Seehöhe sehr häufig und wohlerhalten sind, aber auch bis zu $50^{\prime}$ Höhe und darüber vorkommen. -

Auf der Insel San Lurenzo in der Bai von Callao fand Fr. in anselınlicher Höhe Coucholepas, Pecten purpureus, Sigaretus concavus u. a. Konchylien in Menge, welche ihre Farben meist so frisch erhalten haben, wie die noch im Meere lebenden.

In Osten von Valparaiso fand' Fr. Konchylien - Ablagerungen weit über dem Bereich der Fluth, und Felsen, welche ihn zur Überzeugung führten, dass sie vor dem Erdbeben von 1822 unter Wasser gewesen.

Capt. Bezcher konnte aus der Zeit vom 22. Sept. in den NotizenBüchern der an der Chile'schen Küste stationirten Englischen Kriegs:schiffe keine Nachricht über die Ereignisse in Haven von Valparaiso findeı (ih. 1836, VIII, 159). 
Lieutn. Bower kam erst im Februar 1823 von England nach Vulparaiso und fand Alles gerade so, wie er es vor 12 Monaten verlassen hatte. Seitdem aber sind Gebäude da aufgeführt worden, wo während des Erdbebens die See fluthete (ibid.).

Cuming: über das Erdbeben z u Valparaiso i. J. 1822 (ebendas. VIII, S. 159-160). Cuming kam in Jänner 1822 zu Valparaiso an und lebte dort, mit Naturgeschichte und insbesondere Konchyliologie beschäftigt, bis 1827 ohne, und dann bis 1831 nit öfterer Unterbrechung. Zur Zeit des Erdbebens bewohnte or ein Haus bei dem Landungsplatze zum Arsenal, welches Haus bei den ersten Stössen zerstört wurde. In der Nacht kam er zwar nicht ans Ufer, hörte jedoch, dass das Meer sich weit zurückgezogen und mit grosser Heftigkeit wiedergekehrt seye. Am 20. Morgens nahm er die Wirkungen in Augenschein, fand aber nur die Folgen einer hohen Fluth und ahnte mit seinen Freunden nichts von einer Hebung oder Senkung des Landes bis zum Erscheinen von Mrs. Grahax's Schrift, deren Angaben sie nicht bestätigen können.

Zwar waren die Felsen in der Bucht von Tange $\mathbf{T}, \mathbf{P}$ a telle $\mathbf{n}$, Chit one n und B a la ne n bedeckt, in deren Ansehen aber während seines 8jährigen Aufenthaltes daselbst nicht die mindeste Veränderung vor sich gegangen; auch fand er solche durchaus nur an solchen Orten, welche von der Fluth bedeckt werden: so an den Punkten Caleta, Quebrada de Dios und Cruz de Reyes genannt. Nach dem Erdbeben bewohnte C. ein Haus in Arsenal, wo die Springfluthen nachher dieselben Höbenzeichen erreichten, wie vorher. Den Estanco gegenüber, halbwegs zwischen dem Lagerhause und dem Marktplatze, etwa 50 Y. vom Mittelwasser, lag ein kleiner loser Felsblock, von welchem er vorher oft $\mathrm{C}$ o n chole pas abgenommen, und welcher auch nachher an derselben Stelle geblicben war. Die Schiffe nehmen in der Bai denselben Ankerplatz ein, wie früher. Doch gibt es Land-Anschwemmungen an Stellen, wo vor dem Erdbeben die Fluth stund und worauf maır seitdem Häuser längs kleiner Strassen erbaut; sie mögen schon seit 50-80 Jahren begonnen haben, waren aber bis zum Juni 1827 nur klein geblieben, wo heftige Regen eine Menge losen Granit-Grundes in dic Bai schwemmten, welchen die Fluth wieder an Ufer in die Höhe trieb, wodurch sich ein freier Platz von $250^{\prime}$ Breite bildete. Das hatte aber auf den Anker-Grund keinen Einfluss, und 200 Yards von der untern Wasser-Grenze entfernt kann man auch nicht ein Granit-Körnchen mehr vom Meeresboden heraufholen. - Im N. und S. von Valparaisu, wo die Küste offen ist, wie zu Lagunilla, Vina del Mar, Con-Con und Quintero, hat das Meer holse Sandhügel viele Fuss hoch über seinen Spiegel und 1000-2000 Fuss weit und zu Quintero noch weiter landeinwärts getrieben, welche an letzterem Orte Lager von Konchylien in 
einem halbfossilen Zustande enthalten: Alles aber noch in Bereiche der Fluth.

Vor etwa 70 Jahren fand zu Valparaiso ebenfalls ein Erdbeben Statt, wie zu Conception: das Meer zog sich weit zurück und kehrte dann nit einer solchen Heftigkeit wieder, dass es alle Häuser zer. störte und die Boote bis zur Kirche San Francisco fübrte, bis zu welcher der Boden vom gewöhnlichen Meeresrande an $\frac{1}{4}$ Meile weit allmählich ansteigt.

Am 25. April 1833, Morgens um 6 Uhr zerstörte eine Erderschütterung eine grosse Anzahl Häuser in Juasco, eime See- und Berg-Stadt in Cuquimbo, und beschädigte viele andre, Ein späterer Stoss soll die Stadt ganz zusammengestürzt habeu. Vermuthlich hat er sich bis Copiopo erstreckt (N. Annal. d. voyag. 1833, Oct. XXX, 128).

J. ReIL: Notiz über das Erdbeben z u Saena in Peru (Janrs. Edinb. n. plilos. Journ. 183亡, July; XVII, 174-178). Der Bericht kommt aus Morra de Sama, jener unfruchtbaren Gegend an der Küste Peru's, welche alles Regens fast gänzlich ermangelt, 40 Engl. Meilen N.N.W. vom Haven Arica und 25 M. einwärts von der Spitze der Bucht gleichen Namens. Doch längs eines von der nur 20 M. entferuten Cordillere, die sich dort in den Tacora und drei andere mit ewigem Schnee bedeckte Gipfel erhebt, herabrinnenden Baches erhebt sich eine üppige Vegetation, und die mittle Temperatur von-Tag und Nacht ist nach 7 jährigen Beobachtungen $17^{\circ} 2 \mathrm{C}$.

Am 8. Oktober 1831, um $9 \frac{1}{4}$ Uhr Abends erfolgte seit fast einem Jahrhundert das erste grosse Erdbeben, vorher verkündet von einem unterirdischen, fernem Donner ähnlichen, doch lauterem Rollen, welches 10 Sekunden lang währte und dann einen heftigen senkrechten Erdstoss von 70 Sekunden Dauer zur Folge hatte, und wodurch eine Menge Häuser zusammenstürzte und Arica gänzlich zerstört wurde. Man fühlte dieses Erdbeben auf 100 Meil. Entfernung von Arica, und bis Chuguisaca 400 Meil. landeinwärts; nicht allein die unermesslich breite mittle Cordillere, auch die Seitenkette von Portosi und das östliche Ende, worauf Chuquisuca liegt, wurden in ihrem Innern erschüttert. Dem grossen Stosse folgten in der Nacht noch 2 andere um 11 und um 5 Uhr; und die Erde fuhr 14 Tage später noch bis zum 17. Februar 1832 fort zu zittern. Der Berichterstatter zählte noch 97 einzelıe Stösse, denen jedoch kein Geräusch mehr vorherging. -

Am 18. Sept. 1833 um 6 Uhr erfolgte cine neue Erd-Erschütterung, wodurch daselbst 1000 von 1200 Häusern gänzlich zerstört, und der völlige Ruin Aricas und aller kleineren Orte der Provinz volfendet ward. Die Erschütterungr erfolgte plötzlich, ohne vorhergehendes Getöse, 
währte 43 Sekunden in horizontaler Richtung, jedoch mit $2-3$ wellenförmigen Bewegungen, welche von allen die zerstörendsten waren; auf jede Sekunde schienen 3 Erschütterungen zu kommen, und das damit verbundene Getöse war weit stärker und fürchterlicher, als der Verf. je einen Donner gehört hat.

An dem, dem Erdbeben vorangehenden Abende bemerkte man manche auffallende Erscheinungen: die Atmosphäre war dick, elektrisch, nur zuweilen von einem Luftzuge ohne bestimmte Richtung bewegt, den man innerhalb der Thüren so gut als auf der Strasse enpfand; die Hunde heulten, die Esel schrie'n, so dass durch alle diese Anzeigen das Volk bereits beängstigt war. Nach jedem Erdstosse selbst, schwach oder stark, liefen sänmtliche Hunde nach Wasser, um zu saufen. Aus mehreren pingegrabenen grossen Gefässen ward viel Wasser herausgetrieben, obschon sie nur bis $3-4$ Fuss rom Rande gefullt gewesen. Von vielen leeren Glasflachen fand man am folgenden Tage die Propfen in allen Richungen umhergetrieben, keine von ihnen war umgefallen; einige volle aber fielen vou dem Simse.

Erdbeben in süd-Amerika. Die Stadt $\boldsymbol{S t}$. Jago in Chili wurde gänzlich vernichtet. Sie war auf einem verborgenen Vulkan gebaut, der an 20. Januar 1834 um 8 Uhr Morgens, als der erste Erdstoss gefühlt wurde, zerbarst. Die Erde bebte heftig; eiue waldbedeckte Strecke, ungefähr 3 Stunden lang und 2 breit, versúnk mit dem Walde, und die zurückbleibende Oberfläche glich einer Savanna mit Steinen und Sand bedeckt. Obgleich die Bäume in dem Walde Menschengeschlechter überlebt hatten, so'blieb doch keine Wurzel übrig, kein Laub war zu sehen an der Stelle, da sie gestanden. Vierundzwanzig Stunden lang zitterte die Erde unaufhörlich, und die ganze Stadt mit ihren Umgebungen wurde in einen Trümmerhaufen verwandelt. Die Hütten der Landleute wurden verschlungen von den sich ôffnenden Klüften, die überall entgegen gähnten. Die Wogen, welche die Erde bildete, rollten in wahren Sinne des Wortes, wie die einer sturmbewegten See und stiegen zu einer grossen. Höhe auf. Achtzig Einwohner von st. Jago wurden verschlungen; die übrige Bevölkerung rettete sich auf einen benachbarten Hügel, der zwar auch wankte, aber nicht versank. Die ganze Scene gewährte ein Bild der Zerstörung, und nichts erblickte man ringum, als Elend.

(Zeitungs-Nachricht.)

Über das Erdbeben zu Pasto am 22. - 24. Jänner 1834 hat man nun amtliche Berichte (James. Edinb. n. philos. Journ. 1834, Juli, XVII, II, 202-203). Is Pasto wurden 2 Kirchen beschädigt, die uibrigen sammt ihren Klïștern gänzlicb zerstört. Die Häuser sind his auf 3-4 zusammengestürt, so dass meistens kaum die Fundamente geblieben. 


\section{$-717-$}

Das Erdbeben begann an 20. Jänner um 7 Uhr Morgens und hielt 4 Stunden lang an. Die Stösse wiederholten sich am 22., und vollendeten die Zerstörung. Alle Ortschaften der Ungegend: Laguna, Niocondino, Buesquillo, Pejimdino, Puerres, C'unehalla, Tumondino, Tongovito, Gualnutan, Pandraco und Tescuel sind sehr beschädigt und alle ihre Kirchen in Trümmerhaufen verwandelt worden. In den Bezirken von Malatiny, Vacuanguir, Tambo, Bucaco, Funds und den benachbarten Sprengeln ist grosser Schaden angerichtet worden. Pechts von dem grossen See in Bezirke von Sibundoy wurde cine kleine Aıhöhe bemerkt, welche grosse Felsstücke aus ihrem Schoosse ausstiess; Höhlen bildeten sich in der Nähe, die öde Ungegend von Bondionella wurde zur Hälfte hinabgeschlungen, zur Hälfte aber zu einem ansehnlich hohen Berge emporgehoben, ähnlich der Höhe zwisehen Sibundoy und Ajuadrico, welche bei ihrer Bildung einen grossen Theil des ursprünglichen Bo. dens überschüttete. Dieser Berg hat bei fernereñ Erdstössen die Hochstrasse zerrissen und bedeckt, und unermessliche Sümpfe haben sich in der Näle gebildet; grosse Erdmassen wurden in den BaldayacoFluss gestürzt und so sein Lauf gehemmt, dass sein plötzliches Austreten Land und Häuser von Santiago zerstörte, indem sein Wasser ungehcuer anwuchs, da er in seinem Lauf 90 Nebenflüsse aufnimmt: Die ganze Gegend ist mit grossen Erdspalten durchzogen.

Wooprine Parisr : über die Wirkung der Wogen bei den Erdbeben an den Küsten des stillen Ozeans (Lond. a. Edinb. philos. Journ. 183.5, VIII, S. 181-186).

In einem Jahre, dessen sich Acosta *) nicht genau erinnerte, war an der Küste von Chili ein so furchtbares Erdbeben, dass es Berge umstürzte, den Lauf der Flüsse verstopfte, dass Seen daraus entstunden, Städte zerfielen, und vicle Leute umkamen; die See erhob sich einige Meilen weit ins Land und trieb Schiffe aufs Trockne.

Im J. 158:2, einige Jahre später, ward Arequipa zerstört.

1586 am 9. Juli fand ein Erdbeben zu Lima Statt, welches uach des Vize-Königs Bericht darüber 170 Stunden weit läıgs der Küste gespürt wurde, und nach Acosta drang das Meer 2 Stunden weit landeinwärts über die Küste und riss viele Bäume aus.

1605, an 26. Nov, fluthete das Meer in Folge eines Erdbebcus über Arica her und zerstörte es grösstentheils so, dass die Ruinen der Strassen noch über 100 Jahre später zu sehen waren ${ }^{*}$ ).

1687, am 20. Oktober um 4 Uhr Morgens begann ein Erdbeben die öffentlichen Gebäude und Häuser zu Lima zu zerstören, so dass

*) Historirs nulurul, y moirul de lus Indins, 1590.

*) Frezier, Reise in die Sïdsee, i. J. 1712-1714. 
viele Personen ums Leben kamen. Bei einer darauf folgenden zweiten Erschütterung aber zog sich das Meer weit von der Küste zurück, um in berghohen Wogen wiederzukehren, welche ganz Callao und die übrige Umgegend mit allen Einwohnern gänzlich überflutheten *). Nach WAFER's Bericht spürte man auf einem Schiffe in $12^{\circ} 30^{\prime} \mathrm{S}$. Br. und 150 Stunden weit von der Küste einen solchen Stoss, dass Alles durcheinanderfiel und man glaubte auf einen Felsen gerathen zu seyn; das grüne Meerwasser war weisslich geworden und mit Sand gemengt. Später hörte er von den Ereignissen zu Callau, wo sich das Meer erst so weit zurückgezogen hatte, dass man es einige Augenblicke lang gar nicht mehr sah, dann aber berghoch über das Land hereinstürzte, zu Callao und auf 50 Stunden weit längs der Küste Menschen und Vieh ersäufte und die Schiffe eine Stunde weit ins Land warf.

Ähnliche Ereignisse hatten zu Santa, 3 Grade nördlich von Callao, neun Jahre früher (1678) Statt gefunden. Der Ort liegt 3 Engt. Meil. von der Küste hinter einem kleinen Berge. Das Meer zog sich auf Gesichtsweite von der offenen Bai zurück und kehrte nach 24 Stunden mit solcher Heftigkeit wieder, dass es drei Schiffe von 60-100 Tonnen jedes, über den Berg und den Ort, der damals noch auf dem Berge selbst stund, hinwegtruy und in einem Thale stehen liess, wo WAFER und seine Begleiter die Wracks nach 9 Jahren noch sahen.

In den Jahren 1697, 1699, 1716, 1725, 1732, 1734, 1745 und 1746 wurde Lima durch Erdbeben heimgesucht, wovon Ullos jedoch kein weiteres Detail mittheilt, das letzte ausgenommen, über welches der Bericht des damaligen Vize-Königs sagt, dass nachdem das Erdbeben schon einen grossen Theil der Städte Lima und Callao verschüttet und die in letzterer an Leben gebliebenen Einwohner sich von ihrem ersten Schrecken zu erholen begonnen, plötzlich das Meer in solcher Höhe und Heftigkeit über Callao hereinbrach, dass die ganze auf einer Anhöhe gelegene Stadt mit allen ihren Gebäuden bis auf die zwei grossen Thore und einige Trümmer der Mauer von Grund aus zerstört, ihre fast 5000 Einwohner sämmtlich ertränkt, und die im Haven ankernden 23 Schiffe zu Grunde gerichtet wurden, von welchen nämlich 4 stärkere in die Stadt selbst oder noch weit über sie hinweg ans Laud geworfen wurden, die übrigen aber versanken. Nicht einmal die ehema. lige Form und Ausdehnung der Stadt war noch kenntlich; grosse Massen von Sand und Schutt bedeckten die Küste weithin. Uluos fügt bei, dass diese schreckliche Überschwemmung sich weit lüngs dem MeeresUfer ausdehnte und die Haven Cavallos und Guanape, die Städte Chancay und Guara und die Thäler della Barranca, Sape und Patevilca das Loos von Lima theilten.

Im Jahre 1751 am 26. Mai zerstörte eine Überschwenmung des Meeres die Stadt Conception - Indianisch Penco genannt - gänzlich, so dass die Einwohner sie darnach von der Küste entfernt an ihrer

\#) UlloA Reise in Siid-Amerika. 
jetzigen Stelle 'wieder aufbauten. Schon 1730 hatte sich einmal das Meer erst weit zurückgezogen, dánn aber diese Stadt dermaasen überschwemmt, dass sämmtliche Einwohner auf den benachbarten Bergen Rettung suchten. Das Erdbeben von 1751 und die darauf folgende Seefluth hatten auch die Spanische Niederlassung auf der Insel Juan Fernandez heimgesucht, die Wohnungen längs der Küsté zerstört und 35 Personen das Leben gekostet.

Von der Katastrophe von 1822 erzählt die Mrs. Graham, dass am 19. Nov, während des ersten starken Erdstosses die See in der Bai von Valparaiso plötzlich anstieg und sich plötzlich wieder zurückzog; insbesondere berichtet sie von den Offizieren auf Lord Cochrane's Schiff gehört zu haben, dass sie von der ansteigendeu Woge getragen mit ihrem Boote an einer Stelle landeten, höber als je ein Boot ans Land gekommen, und dass nach deren Rückzuge viele kleinere Schiffe auf dem Strande blieben.

In Jahre 1835 endlich am 20. Februar zerstörte ein Erdbeben die Stadt Conception von Neuem mit ihrem Haven Talcahuano und allen Wohnorten auf der Küste Chile's vom $35^{\circ}$ bis zum $38^{\circ} \mathrm{S}$. Br. Dreimal stieg in der Bai von Talcahuano die See über diesen Ort in die Höhe, seine Trümmer mit sich forttreibend, und genau zur selben Zeit erhielt ein Schiff "the Glemalier" auf dem hohen Meere, 95 Meilen von der Küste, einen Stoss, dass es im Laufe stille stund und man glaubte, es sey auf den Grund gerathen, wie Warer's Fahrzeug im Jahre 1687.

R. E. Alison schreibt über das Erdbeben an der Clilesischen K üste an 20. Febr. 1835 (ebendas. VIII, 74-75). Es begann $\frac{1}{4}$ nach 11 Mittags mit schwacher Wellen-Bewegung des Bodens, welche aber in wenigén Sekunden so zunahm, dass Niemand mehr aufrecht stehen konnte. Es zerstörte die Städte Conception und Chillan mit den Häven Talcahuano und Maule und noch 20 kleinere Orte nebst einer unermesslichen Menge von Landhäusern. Man spürte es südwärts an der Küste bis zur Insel Chiloe gegenüber, nördlich bis jenseits Copiago, zu Mendoza östlich von den Andes, auf einem Schiffe 100 Engl. Meilen westlich von der Küste, und auf der Insel Juan Fernandez 300 Meilen von ihr. Zu Talcahuano zog sich 40 Minuten nach dem ersten Stosse das Meer plötzlich so zurück, dass in dem kleineren südlichen Eingang in dié Bai man den Meeresboden erblickte, und kehrte nachher durch denselben Kanal mit solcher Macht zurück, dass es $20^{\prime}$ hoch über die Stadt wegging und Alles mit sich fortriss. Diess wiederholte sich dreimal. Das Land soll sich $2^{\prime}$ bis $3^{\prime}$ gehoben, oder der Seegrund, wie man durch die Sonde fand, sich um so viel gesenkt haben. Ein Fels, den man darin vorher nicht gesehen, erschien unter der Oberfläche. Grosse Risse sollen in der Erde entstanden scyn und Wasser ausgestossen habeu; die Erde soll sich geöffnet und geschlossen und bei los Augeles 
sollen mehrere Berge verschwunden seyv. Andere öfueten sich und haben Dampf und schwarzen Rauch ausgestossen. Der Haven der Insel Santa Maria wurde zerstört, die See zog sich 300-400 Yards zurück, während die Riffe um deu grössten Theil der Insel her gänzlich verschwanden. - Eine Stunde von der Insel Juan Fernandez schien die See zu kochen, und hohe $\mathrm{W}$ assersäulen wurden in die Luft emporgetrieben, worauf sich das Meer so weit zurückzog, dass eine Anzahl alter Anker und metallener Geschütze sichtbar wurde; dann aber kebrte es wieder und riss alle Straf-Häuser mit sich fort. An der Stelle, wo das Meer zuerst in Bewegung gewesen, brach ein Vulkan aus. Die Brig Glunmalin spürte um diese Zeit 100 Meilen W. von Talcahuano einen Stoss, als ob sie auf den Grund gerathen seye. - - Zu Valparaiso kommen $1400^{\prime}$ über dem Meeresspiegel Konchylien lebender Arten vor, und bei Conuco finden sich dergleichen in solcher Menge, dass man Kalk daraus brennt. In der Bai ist ein Felseu, über den man 1817 mit einem Boot fabren konnte; jetzt licgt er trocken, ausser bei Spring-Fluth.

\section{Petrefaktenkunde.}

Croizet: über die fossilen Reste der Auvergne (Auszug = Bull. géol. 1833, IV, 22-26).

I. Die Gebirge der gegenwärtigen Epoche enthalten in Allgemeinen nur Reste von noch jetzt lebenden Pflanzen- und Thier-Arten; doch lässt sich nicht läugnen, dass in der Auvergne wie anderwärts seit der Erscheinung des Menschen einige Arten verschwunden sind. Die ThierGebeine der Knochenhöhlen sind ohne Zweifel durch mehrfältige Ursåchen dahin geführt worden. II. Die Diluvial-Gebirge einschliesslich der alten Alluvioneu, welche der Vurf. unter dem Namen der quater$\mathrm{n}$ ären Gebilde (nicht in Dessorers' Sinue) zusammenfusst, haben in Auvergne geliefert: Pflanzen von meist noch lebenden Arten zu Dorat bei Thiers; - Konchylien, - Vögel, - aber insbesondere Säugethiere, welche den Arten nach verschieden sind von jenen, welche Cuvier beschrieben. In den vulkanischen Alluvionen hat man bisher unterschieden a) Pachydermen : 8-9 Arten aus den Geschlechtern Elephas, Rhinoceros, Mastodon, Sus, Tapir, Equus, Hippopotanus; - b) Wiederküuer: 28 Arten: nämlich 22 Hirsche, 40 chsen und 2 Steneodonten (ausgestorbenes Geschlecht); - c) Raubthiere: 9 Arten, worunter 3 Hyänen, 2 Bä-ren, 2 Hunde, 1 Marder oder Herpestes, 1 Otter; - d) Nager: 4 Arten, wobei 1 Biber, 1 Aguti, 1 Haase, 1 Erdmaus, - endlich e) ein Dasypus-artiges Thier und f) Vügel. - III. Die tertiären Süsswasser-Gebilde der Limagne zerfallen dem Alter nach in drei Abtheilungen. 1) Lu 
Mcrgelkalke mit feinen 'Travertinen und bituminösen Schiefern fiıdet man viele ausgestorbene Arten fortbestehender Geschlechter, - 2) im Gypse meist schon ausgestorbene Genera, denen des Seine-Beckens entsprechend, - 3) zu unterst endlich in den rothen und grünen Tho. nen und der Arkose nur wenige organische Reste überhaupt. 1) Die oberste dieser drei Abtheilungen enthält auch einige Braunkohlenlagen, deren Pflanzen-Abdrücke noch ihre analogen Arten im Becken von Ménat haben, und mehrere Arten von Weiden, Linden, Zitterpappeln, Kastanien - Bäumen, Rosaceen, Gräser, F u ca ce en, endlich Spuren in Europa nicht lebender Baumarten unterscheiden lassen. Von ihnen haben sich die-Wiederkäuer und grossen Pachydermen dieser Epoche genährt. Ausser Theilen von Stämmen, Blättern und Früchten kommen daselbst auch Insekten und viele Fische vor, welche bald auf einem Schieferblatte liegen, bald in länglichen, platten Massen von Schwefeleisen eingeschlossen sind. Lecon hatte diese Fische zu Cyprinus papyraceus bezogen; Crorzer unterscheidet jedoch eine Ait, welche den C. leuciscus analog ist, und eine andere, welche mit der fossilen Cobitis von Öningen ain Bodensee übereinstimmt; - jedoch haben auch viele dieser Fische 2 Rückenflossen mit Stachelstrahlen, und die grössten unter ihnen auch zurückgekrümmte Zähne in den Kinnladen, welche ausgestorbenen Arten der Percoiden angehören nö̈gen *). Die Pflanzenreste aus dieser Periode kommen zu Ravel in einem oberen Sandsteine mit Kalk-Züment vor: Gramineen, Binsen, Kastanien-, Wallnuss- und Hainbuchen-Blätter mit $\mathrm{Z}$ apfen-Früchten und Wallnüssen, deren Kern ganz versteinert ist, und welche weit mehr mit den Früchten einer Nord-Amerikanischen Art übereinstimmen, als mit unserer aus Persien gekommenen Inglans regia. Auch PhryganenGesäuse (Indusia tubulata), Cypris faba, Gyrogoniten, Potamiden, Bulimen und Cyelostomen kommen in Menge in dieser oberen Formation vor in Gesellschaft mit einer grossen Anzahl Wirbel: thiere noch lebender Geschlechter; aber meist ausgestorbener Arten. Dahin gebören 3 Rhinozeros-Arten, welche mehr mit den noch in Indien lebenden Spezies, als mit denen jüngerer Formationen übereinstimmen, - zwei dem Moschus-Geschlechte nahe stehende Wiederkäuer, - Nager, welche den Geschlechtern Mus, Hydrochoerus und Castor entsprechen, wovon die letzteren aber sehr klein sind; Insektivoren, welche zu den Spitzmäusen gehören und die Grösse von Sorex giganteus besitzen; - Raubthiere, worunter sich żwei Hunde und eine Katze von der Grösse des Panthers befinden. 2) Die gypsigen Lagen haben Paläotherien, Anoplotherien und Anthracotherien und einen kleinen Pachydermen mit Zitzen-förmigen

*) Jener Cyprinus ist Aspius Brongniarti Ag.; dieser Percoide Perca elongata Ag., aber verschieden von der Oeninger Art. Vergl. Jahrb. 1834, S. 383. 
Zähnen, alle von ausgestorbenen Geschlechtern geliefert; - ferner Krokodile, Schildkröten u. a. kleine Reptilien; - Vögel den Enten analog, und Eier, wovon manche ganz wohl erhalten siud. Auch Phryganen, Cypris, Schnecken kommen hier wieder vor, so wie Muscheln, welche aber von den Mon odonten verschieden sind. - 3) In der untersten Abtheilung, in den Thonen und Arkosen, hat man bisher nur Reste eines kleinen Quadrupeden, kleiner. Reptilien und Dikotyledonen-Abdrücke entdeckt. - IV. Der Kohlensandstein von Langeac (Haute Loire) bietet viele Pflanzen-Abdrücke, worunter einige noch nicht beschrieben sind.

Peghoux fügt den vorigen einige Bemerkungen bei:

A. Die Arkosen (III, 3), werigstens die granitischen, müssen zu den sekundären Formationen gerechnet werden; sie sind keineswegs, wie die tertiären Schichten, söhlig geschichtet, sondern, hauptsächlich an Rande des Primordial-Beckens, aufgerichtet, oft senkrecht, und stellenweise un $200^{\prime}$ höher als an andern benachbarten Punkten gehoben (doch behauptet Croizet, dass sie mit III 2 und 1 wechsellagern). Eine grosse Menge von Punkten bieten hiezu Belerge; während die eigentlichen Tertiär-Schichten uur in der unmittelbaren Nähe basaltischer Ausbrüche (Gergovia) Störungen zeigen.

B. Die übrigen tertiären Gesteine (III, 1, 2) zerfallen demungeachtet noch in drei Alters-Gruppen, nämlich :

a) den Gyps (III, 2), der, wie es scheint, feuriger Entstehung, häufig von Mineral-Aushauchungen in seinem Bestande geändert und von Thermal-Quellen durchzogen ist;

b) den Mergelkalk der Limagne, der homogen ist, sich in sphäroidale Massen sondert und nur wenige Konchylien enthält;

c) den obern Kalk mit Indusia, Cypris und kleinen Paludinen.

A. ZвоRzewsin: mikroskopische Untersuchungen über einige seltene Fossil-Reste Podoliens und Volhyniens (N. Mém. Acad. nat. Mosc. 183t, III, 299-312). Der Verf. (jètzt an das neue Gymnasium zu Luck berufen) hat seit 11 Jahren begonnen eine Mineralien - und Petrefakten-Sammlung aus den Gegenden zwischen dem Dniester und dem Dniepr nach einem geologischen Systeme auf seine Kosten anzulegen, welche er nach ihrer Vollendung einem nationalen Institute anbieten will, und wird ferner die Resultate seiner Forschungen über die Versteinerungen den Geologen und Kosmologen bekannt machen.

Seine Fossilien-Sammlung enthält jetzt $\mathbf{\$ 0 0 0}$ Arten. Unter den einfachen nicht metallischen Mineralien (Litha) ist die Zirkon-Gruppe am ärmsten; doch hat er Smaragde, Saphire und Pyrope aus den verschiedensten Formationen. Von Metallen gibt es nur wenig gediegene (Kiriometalla) und Erze (Mixometalla), aber vicle Metalloxyde 
(Oxydometalla); Spuren ron Zinn in den Primär-, und von Gold in den Sekundär - Formationen. Die Gebirgsarten - Sammlung enthält über 200 Arten gemengter (Granite, Phylladite, Traumatite, Koniolite, Psephite etc.) aber keine vulkanische (Basalte, Trachyte). Die zahlreichen Versteinerungen rühren aus den Übergangs-, Flötz- und Tertiär-Formationen her. Phytolithen jedoch sind nur etwa 40 Arten darunter, Akotyledonen, Monokotyledonen und Dikotylodonen: Algaziten aus den Traumaten, Fucoiden aus dem Kreide - Pudding und Sand, Karpolithen und Phytolithen aus Kreide-Geschieben und Craie tufeau. Von Zoophyten besitzt der Verf. allein an Radiarien [in einem weiten und ungewöhnlichen Sinne des Worts] über 1000 Arten: Alcyoneen, Spongieen, Koralloiden, Milleporeen, Tubiporeen Harmoliten (n. g.), Diskepasmoporen (n. g.) u. s. w.; ferner, über $20 \mathrm{Enkrinen,}$, worunter viele mikroskopische (Mikrakanthozoen). - Von Mollusken ebenfalls über 1000 Arten, worunter fast alle mikroskopischen Genera D'Orbigny's und manche neue (Baculina, Raphanulina, Apiopterina, Lyrina u. s. w.), so wie Oscabrion Fischeri etc. Von Haemakrymen hat der Vf. Schuppen, Kiemen. deckel und viele Zähne von $F$ ischen und Reptilien aus der Kreide, und von $\mathrm{Ha}$ a a therme viele $M a m u t h-, R h i n o z e r o s$ und Pferde-Zähne aus den tertiären Gebilden. Diese Versteinerungen stimmen am meisten mit denjenigen Arten überein, welche um Moskwa, Paris, Passy, Nanterne, Caen (E un mia?, Microsolena, Diastopora, Intricaria etc.), in Thiuringen, um Piacenza und lebend im Mittelmeere so wie bei den Antillen (Oscabrion Fischeri und Odontin a) vorkommen.

Der Verf. beschreibt nunmehr einige seiner neuen mikroskopischen Geschlechter und theilt Abbildungen derselben mit, um diese sonderbaren Formen zu beleuchten [welche uns durchaus verdächtig scheinen].

\section{A. Microphytozo a.}

I. Ceriolina Z. (?Ceriopora GoldF.) Polypenstock steinartig, schneckenförmig, symmetrisch, mit scheibenförniger oder an Ende gerade verlängerter Windung; innerlich in konzentrischen Lagen zusammengesetzt aus der Länge nach gehenden Haar-Röhrchen, äusserlich aus gröberen Röhrchen, welche radiale Reiben an der Oberfläche bilden. Neben A u l o p o r a GoLdp.

1) C. Fischeri (Tf. XXV, Fg. 1 a, b, c). Ammoniten-förnig, Nabel ganz durchbohrt, die Röhrchen der Oberfläche in radialen, etwas gebogenen und wenig vorstehenden Queerreihen, ihre Mündungen demnach eben so geordnet. Sehr selten; in tertiären Sande Volhyniens und Podoliens [ist Cellepora Ammonis Erchw.].

2) C. Jarockii (XXV, 2 a, b, c) fast Lituit en-förmig gerade verlängert, an dem mit Seiten - Röhrchen bedeckten Anfauge mit 2 grossen runden Seiten - Öffnungen, gegen deren eine grössere die Spitze der undeutlichen Windung sich einkrümmt; die kleinere 
steht ihr gegenüber, etwas tiefer. Am Eude münden viele kleine Röhrchen aus.

II. C c II u l in a Z. Polypenstock kalkig, eyförmig, zusammengedrückt, mehr oder weniger verlängèrt, gerade oder wenig gekrümmt, zusammengesetzt aus kugelförmigen Zellen, deren Mündungen an der Oberfläche liegen, und welche durch je ein sehr feines Röhrchen im Innern kommuniziren. Ähnlich den Sepieneyer-Trauben. Aus der Ordnung von Lamouroux's Milleporeen, zwischen 0 rbulites und Discolithes.

1) C. Eichwaldi i (XXVI, 1 a, b, c). Fast dreikantig, gerade, Kugeln etwas Napf-förmig. Im tertiären Sand Volhyniens schr seiten.

2) C. B e s s c ri (VXVI, 2 a, b, c). Fast eyförmig, etwas gebogen, Kugeln Bienenzellen-artig. Vorkommen wie bei voriger.

3) C. Pus c hi i (XXVI, 3 a, b, c). Keulen-förmig, gerade oder gebogen, Kugeln sehr klein und schwer erkennbar. Selten in den Tertiär-Gebilden Podoliens.

\section{B. Micracanthozoen.}

III. Phylloc rina Z. Parasitisch, hornartig-kalkig, durchscheinend, trichterförmig, der Rand in (4) regelmässige un den Mittelpunkt geordnete Blätter getheilt. Etwas ähnlich Acetabul um und Pedi c ellaria Cuv. Aus der Ordnung der E chinodermen?

1) P. St eveni (XXVII, 1 a, b). Stiel lang, Trichter 4blättrig. Aufsitzend auf Kreide-Polyparien oder lose in Feuerstcin eingeschlossen.

2) P. Krinicki (XXVII, 2 a, b). Stiel sehr kurz, Trichter 4 blätterig. Wie vorige, selten.

IV. A c tini na Z. Parasitisches Echinoderm, hornartig-kalkig, röhrenartig, Stiel walzig, am Ende mit rundem Munde, am andern in 3 (horizontale) pfriemenförmige Äste auseinandertretend.

1) A. Jarockii (XXVII, 3 a, b). Krone in 3 Äste getheilt, die sich wieder in stumpfem Winkel spalten. In chloritischer Kreide Podoliens und in Fenerstein Volhyniens sehr selten.

2) A. A ndrzejowski (XXVII, 4 a, b). Eben so, doch die 3 Äste einfach. Mit voriger [Junges?].

3) A. Pallasii: stalt der Krone nur 4 fast halbkugelige Höcker. Mit obigem.

\section{Micrepizoa.}

V. O do n tin a Z. Annelide? oder Pteropode?. Dentalien-förmig, etwas gुekrümmt, kalkig, dicht, am dünneren Ende mit einem Deckel verschlossen, am dicken Ende offen, jedoch stark verengt. Mit Crese is und Cuvieria verwandt?

1) 0. annulata (XXVII, 5, a). Geringelt. In Volhynien und

Podolien; lebend bei den Antillen. 
2) 0. striata (XXVII, $5, \beta$ ). Nach der Länge gestreift. Mit obiger.

3) 0. I a e vis (XXVII, 5, み), glatt, das dickere Ende etwas angeschwollen. Nit vorigen.

D. Micropolythalama.

(Foraminifera.)

VI. Raphanulin a Z. Enallostegier, vielmundig, in Gestalt eines kleinen Eyes, das mit den spitzern Ende auf einem Becher steht, durchscheinend, anhängend oder frei, hohl, an beiden Endeu offen, ohne eigentlichen Mund.

1) R. $\mathrm{H} \mathrm{umb}$ old ti (XXVIII, $1 \mathrm{c}$ ). Einzige Art. In Podoliens tertiärem Saude, selten.

VII. A piop teri n a Z. Enallostegier, vielmundig, Birn- oder Phiolenförnig, der eigentliche Mund am Ende des Stieles. Das dünnere Ende ist in 2 sich entgegengesetzte unregelmässige Flügel ausgebreitet. - Montfort's Lag enula, welche D'Orgigny zu den Polype n verweiset, scheint neben dieses Genus zu gehören.

a) A. d'O r big ny (XXVIII, 2 a?, b). Einzige Art. In Volhyniens Tertiär-Gebirgen sehr selteu.

VIII. Ly rin a Z. Polystegier, sehr zusammengedrückt, gleichsam aus 2 an Grösse ungleichen in einer Fläche aneinanderstehenden runden Scheiben zusammengesetıt. Kugelige undeutliche Zellen stehen in S-förmiger Spirale oder in Form eines 8 auf den Seiten, je 8 bis 16 in einem Umgange.

1) L. F is cheri (XXVIII, 3 a, b, c). Einzige Art, in tertiärem Sande Dachonowas in Podolien.

Garluapor Sohn, Bemerkungen über die Fossil-Reste des M us chelkalkes der Lorraine (Ann. d. sc. nat. 1835, III, 46-50). Der Verf., im Besitze der schon durch Cuvier's, so wie durch dessen eigene Arbeiten bekannt gewordenen Sammlungen seines Vaters aus dem Muschelkalk von Luneville beabsichtiget dieselben zu erweitern und die wesentlichsten Bestandtheile derselben, so wie anderer dortiger Sammler allmählich bekannt zu machen. Hier eine Übersicht derselben:

1) Säu get hi er - und Vögel-Reste mangeln gänzlich.

2) Von Reptilien hat man daselbst, und zwar A. von Sa urieru: a) eine Unterkinnlade mit ihren Zälınen, vorn mit eiuer Ey - fürmigen Erweiterung, wie beim Krokodile (Movgeot's Sammlung); - b) das Gelenk - Ende eines andern Unterkiefers, ganz wic das bei Cuvier (oss. foss. $V, I I)$ beschriebene; - c) mehrere ziemlich vollständige Schädel von ctwa 1' Länge auf $6 "-8^{\prime \prime}$ Breite; - d) viele einzelne Zähne von ungleicher Grösse; - e) eben so viele Wirbel und Rippen, deren grösste 22" Länge hat; die Ripṇen ähneln denen des Monitors: Cuvier hat eine beschrieben; - f) Rabenschnabel-, Oberarm- und 
Oberschenkel-Beine eines mit Ichthyosaurus und Plesiosaurus verwandten Geschlechtes; ein os $\mathrm{pub}$ is ist dem des Plesios a u rus bei Conyeenre ähnlich; - g) viele andere einzelne Knochen, auch Schuppen denen des Krokodils von Caen ähnlich. - B. Von S childkröten insbesondere von Trion yx: Panzerstücke; und von einem neuen mit Chelonia verwandten Geschlechte Knochen der Extremitäten. - C. Viele Koprolithen.

2) Fische. Nach Agassiz's Bestimmungen a) Kiefer- und SchlundZähne von Acrodus Gaillardoti; - b) ein unpaariger Vorderzahn, Eck - und Backenzähne von Hybodus plicatilis oder Iongiconus; - c) Vorderstacheln aus der Rückenflosse dieser und einer andern $\mathrm{Hy}$ bodus - Art, wovon die Zähnelungen längs des Vorder-Randes in zwei Linien mit einander abwechseln; - d) Gaumenzähne eines neuen Geschlechtes aus der Familie der Pycnodonten; - e) Schlund-und Kiefer-Zähne des Placodus gigas; - f) Schuppen des Ptycholepis Alberti und des P. maximus.

3) Ausser den bereits bekannten Konchylien etwa 12 neue Arten; - mit Rhyncholithus Gaillardoti und Rh. hirundo.

4) Von Gliederthieren: Palinurus Sueurii und Gonoplax Latreillii Desm.

5) Neuropteris Gaillardoti.

J. Phillips: über den alten und theilweise verschütteten Forst von Holderness, Yorkshire (Lond. a. Edinb. phil. Mag. 1834, April, IV , 282-288). Der Humber und andere mit jeder Fluth ansteigende Flüsse gehen zu einem Meeresarme durch eine ebene, niedrige und nur mittelst zusammenhängender Dämme gegen die Überschwemmungen der Fluth geschützte Landschaft, deren Boden theils ein Niederschlag aus meist oft wiederholten Überfluthungen, theils Torfmoor ist. Diese Gegend (Holderness) bildet ein Dreieck, welches auf seinen drei Seiten vom Deutschen Meere, vom Humber-Arme und von eiver ansteigenden Kreidefläche, 5 - ist etwas wellenförmig mit einzelnen Bergen und Höhenzügen, welche bis zu $130^{\prime}$ ansteigen; - die Vertiefungen dazwischen sind mit Fluth-Niederschlägen angefüllt, welche sich, wenn das Meer nicht abgedämmt wäre, noch um $5^{\prime}-10^{\prime}$ und mehr erhöhen würden; mehrere dieser Stellen waren vordem mit See'n bedeckt, und alte Schriftsteller gedenken der Gegend unter dem Namen „Inseln von Holderness". Ein brauner oder blauer Thon bildet die allgemeine Basis dieses Bezirkes; er ist voll Kalkstein-, Sandstein-, Schiefer-, Porphyrund Granit-Geschieben aus N.- und N.W.-Yorkshire, Cumberland und Westmoreland; cine Menge Kreide - and Feuerstein - Stücke von den nahen Anhöhen liegen im Thone oder wechsellagern nit ihm; unregelmässig vorkommende Lager von Kies und Sand enthalten Konchylien, wie sie im nahen Meere vorkommen. Diese Ablagerungen sind es, 
welche alle Hügel bilden, in alle Vertiefungen sich hinabsenken, auch einzelne Elephanten-u. a. Wirbelthier-Reste enthalten. Die vegetabilische Materie aber ist nur in den ehemaligen Wasserbehältern angehäuft, wo sie entweder unter Sumpf-Niederschlägen unter oder über dem Tiefwasserstand, oder unter Fluth-Absetzungen, oder endlich unmittelbar an der Oberfläche liegen. Nur auf beide letztere Arten des Vorkommens bezieht sich die weitere Beschreibung.

Bei Anlegung eines Abzugs-Kauales von einigen Meilen Länge fand man, dass die Obertläche des Bodens vom Humber an nordwärts einfalle (ein Verhalten wie in den Marschländern bei Lynn)., so dass sie hier $4-5$, dort landein- und nord-wärts $10^{\prime}-13^{\prime}$ unter. Fluthböhe liegt. Tellina tenuis u. e. a. See-Konchylien liegen stellenweise in einem Seeschlamme von ungleicher Dicke, welcher an höheren Orten unmittelbar auf jenem Thone ruhet, zwischen welche beide in den Mulden die vegetabilische Materie eingelagert ist. An einer Stelle liegen HaselZweige, Eichen- und Kiefern-Stücke zusammengehäuft in einem alten schmalen Fluth-Gerinne, und lose Haselnüsse, Eichel-Näpfchen und Laud-Schnecken zeigen, dass die ganze Masse hier zusammengeschwemmt worden ist, während auch von in dem unterlagernden Thone eingedrungenen Baumwurzeln in ganzen Durchschnitte keine Spur vorkommt. Die Stämnse liegen zertrümmert und ohne Ordnung durcheinander an nur wenigen Stellen; die Zweige, verweseten Blätter u. s. w. sind mehr allgemein verbreitet; phosphorsaures Eisen ist häufig; Knochen hat der Verf. nicht gesehen. - Hier also kann nicht eigentlich von einem unterirdischen, an Ort und Stelle verschütteten Walde, sondern nur von Anschwemmungen die Rede seyn, und es ist von Wichtigkeit zu sehen, wie die Menge von Stämmen und Torfmasse, da wo keine alten Fluss. gerinue vorhanden, überall gegen die Kies - reichen Hügel hin zunimmt. An einer Stelle zwischen den Dörfern Swine und Waghen oder Wawn ist ein niederer Moorgrund von etwa 100 Acres Fläche, von GeschiebHïgeln umgeben, vorhanden, der Wawn Turf Car genannt, an dessen N.W.-Rande eine Menge von Baum-Stumpfen 1-2 Fuss über die RasenFläche hervorstehen, alle von gleicher Grösse, mit abwärts ausgebreiteten Wurzeln und in der Entfernung von einander, in welcher die Natur grosse Bäume zu pflanzen pflegt; - alle stammen von der Schottischen Kiefer; von Feuer oder Axt ist keine Spur mehr daran bemerkbar: ohne $Z$ weifel sind die Stämme von Stürmen abgebrochen worden; geschwärzt ist nur das $\mathrm{Holz}$ der Wurzeln, welche in ein $6^{\prime}-8^{\prime}$ dickes Lager von Torf und Holz eindringen, das viele nach allen Richtungen übereinander liegende Stämme enthält, deren Ast - und WurzelEnden abgebrochen und deren Holz geschwärzt, die aber oft noch zur Verarbeitung brauchbar sind. Sie stammen von Eichen, Eiben, Birken, Erlen, Hascln und Kiêfern, sind meistens durch ihre Grösse ausgezeichnet: einige Eichen und Kiefern noch lang und fehlerfrei vom Stamm. Die Eiben liegen als die schwersten zu unterst, Jarauf die Eichen, die Kiefern nehmen die oberste Stelle ein und sind daher durch Moor-Brändo 
theilweise beschädigt. Einige Kiefern-Zapfen und wenige EichelNäpfchen kommen dazwischen vor, aber keine Konchylien. Der oben erwähnte blaue Thon liegt auch unter diesem Torfe, aber Baumwurzeln sieht man nicht in ersteren eindringen, noch Erde - Theile an den darüber liegenden Wurzeln anhängen. Die ganze Lager-Masse scheint durch Anschweminung aus der Nähe zusammengehäuft worden zu seyn, nachdem Äste und Wurzeln der schon zuvor ungestürzten Stänme abgebrochen und letztere noch vollends, von der anhängenden Erde befreit waren. Jetzt sieht man auf den benachbarteu Anhöhen nur Eschen und Eichen wachsen; vergeblich würde man sich in ganz $\mathrm{Hol}$ derne'ss un Eiben-, Kiffern-, oder Birken-Wälder umsehen, und selbst einzelue Stämme würde man nur init Mühe in dieser den Ostwinden so sehr ausgesetzten Landschaft aufbringen, was mithin auch eine seitherige Änderung des Klima's dieser Gegend anzudeuten scheint. Bemerkenswerth ist aber insbesondere das erwälnte Wachsthum einer späteren Gencration Schottischer Kiefern über diesem Torf-Lager auf einer Fläche, welche 10-12' unter den Hochwasserstand im Humber ist, in welchem die Fluth bis zu 24' (über die Ebbe) ansteigt. Man würde veranlasst seyn, aus dieser Erscheinung auf eine Niveau's - Änderung zwischen Land und Neer zu schliessen, da ursprünglich (vor Anlegung der Dämme) die Kiefern hier nicht aufkommen konnten; wenn man sich aber erinnert, dass die ganze Bodenfläehe nit oft rechtwinkelig auseinanderlaufenden Vertiefungen nach allen Richtungen durchzogen ist, welche zu durchströmen die Fluth-Wasser lange Zeit bedürfen, so ergiht sich, dass diese Stelle nicht nothwendig von der Fluth überschwemmt werden musste, wie denn an der Küste von Yarmouth die Fluth auf ähnlichen Stellen un mehrere Fuss an Höhe landeinwärts abnimmt. Diese Ansicht wird wahrscheinlicher, wenn man'berücksichtigt, dass die ganze Küste von Holderness seit langer Zeit jührlich grosser Abnahme durch das vorrückende Meer unterworfen ist, dass sie demnach einst weiter von der Stel!e dieses Waldes entfernt gewesen, dass mithin die Fluth längerer Zeit als jetzt bedurfte, um dieselbe zu erreichen, und dass, wenn sie etwa nur durch die Mündung des Humbers eindringen konute, die eingedrungene Wassermasse sich über eine hundertmal grössere Fläche (300 Quadr. Nieil.) als jetzt verbreiten musste. Dazu kommt endlich noch, dass $4^{\prime}-6^{\prime}$ dicke Torflager, wenn sie trocken gelegt, um die Hälfte ihrer Dicke, wenn sie aber noch wie hier mit Nirderschlägen beladen werden, sogar bis auf einige Zoll Mächtigkeit abnehmen können. Schon darum muss die Oberfläche jenes Waldgıundes cinst beträchtlich höher gelegen seyn. So vernag dieser einzelue Fall belehrende Aufschlüsse über manche andere der Art zu geben.

W. Chiff: Nachricht über die Megatherium-Reste, welche durch Woodine Parisi von Buenos Ayres nach England geschickt 
wo rden (Lond. geol. Trans. N. N. 1835, III, III, $437-450, \%$ 43-46). Diese Reste [Jahrb. 1834, S. 112 , und 1833, S. 607-608] sind dem Museum des Collegiums der Wundärzte in London übergeben worden. Im Salado-Bette, südlich von Buenos Ayres, ist das fast vollständige Skelett, und unweit davon zu Las Averias im Norden und zu Villamueva in Süden des Salado sind'andere Reste mit Trünmern eines mächtigen Panzers gefunden worden, von dem eine Abbildung hier mitgetheilt ist, indem der Panzer grossentheils selbst, gleich den andern Trümmern der letzten zwci Fundorte, bei Einwirkung der Luft gänzlich zerfallen war. Später, als diese Gegenstände in England angekommen waren, übersandte $\mathrm{D}_{\mathrm{AR}}$ wiN noch andere aus den vom Salado durchströnten Pampas stammende Theile, die aber mit Kalk und Geschieben noch fest verkittet gewesen. Eine der Abhandlung beigegebene Karte zeigt die Stellen genauer an, wo nicht nur die dreierlei zuerst bezeichneten Reste, sondern auch das in Madrid aufgestellte Skelett gefunden worden.

Das Skelett vom Saludo ist minder vollständig, als das zu Madrid befindliche. Es enthält den Vordertheil des Schädels, 9 nnvollständige Zühne, - ein Stück des Os hyoides, - einen ganzen Atlas und einen anderen Halswirbel, -2 gamze Brust- und 13 andere unvollständige ächte Wirbel, worunter 3 ? Lendenwirbel, - Sacrum und Becken bis auf das rechte llium vollständig, $\mathrm{Pubis}$ und Ischion vorzüglich erhalten; 12 Schwanzwirbel mit 10 abgesonderten untern Doruenfortsätzen versehen, wonach etwa 18 Schwanzwirbel im Ganzen vorhanden gewesen seyn mögen, -12 linke und 11 rechte Rippen und Trümmer von andern, $-2 \mathrm{Stücke,} \mathrm{welche} \mathrm{diese} \mathrm{mit} \mathrm{dem}$ Brustbeine verbinden, - drei Stücke des Brustbeins; von den Vorder - Extremitäten beide Schulterblätter, wovon das reclite vollständig, danu das linke Schlüsselbein, den rechten Radius, 6 Mittelland-Beine, einen mittlen Phalanx und viẹ Klauen-Phalangen; - von den lintern Extremitäten beide Oberschenkelbeine, wovon den linken vollständig, die linke Tibia mit einem Stück Fibula, 8 Fussbeine (worunter die mit gesperrter Schrift gedruckten Gegenstände das Mudrider Skelett ergänzen, so wie die Abbildung des Skeletts auf Taf. 44 die Theile andeutet, welche an jedem von beiden Skeletten vorkommen). Beide Nasenhöhlen sind durch eine knöcherne Scheidewand getrennt. Jede Kinnlade enthält jederseits 4 dicht aneinanderstehende Backenzähne, von vierkantiger Gestalt, die der Vorderseite etwas konvex, die Reihen nach vorn konvergirend. Jedoch bchauptet Cuvier mit Unrecht, dass die Backenzähne, in Gegensatze derjenigen bei andern Edentaten, 2 Wurzeln haben: sie sind wurzellos und an der Basis hohl, mit einer pyranidalen Höhle versehen, was auf rin ununterbrochentss Fortwachsen dieser Zïhne ohne Wechsel hindeutet. Sie bestehen ans Elfenbein, welches von einer nur liniendicken Schmelzscheide ungeben ist, an dic sich vorn und hinten noch Züment-Substanz so dick ansetzt, dass sie $\frac{1}{3}$ von der läuge des Zahnes ausmacht. Auf der Kaufläche bilden 
queerziehende Schmelzbänder zwei Queerjoche, von welchen sich 2 abschüssige Flächen gegen die Mitte hin über die Elfenbeinmasse, und 2 nach vorn und hinten über die Zümentmasse herabsenken.

Der vordere Knochen des Brustbeins hat nur 3 Gelenkflächen für 2 Rippen und den zweiten Knochen; die Schlüsselbeine mògen durch Bänder an die kleinen Höhlen inner und über den ersteren befestigt gewesen seyn; - der zweite Knochen hat 10 Gelenkflächen für die 2 vorn und hinten angrenzenden Brustbein-Knochen und für 8 RippenPaare; - der letzte (?vierte) hat nur vorn und jederseits oben eine gedoppelte und unten zwei Gelenkflächen für Rippen. Die Ossa ilia besitzen eine gegen die anderen Edentaten genommen, sehr beträchtliche Ausbreitung, obschon die übrigen Theile mit den analogen in dieser Thier-Ordnung ziemlich übereinstimmen, wie denn auch die ossa pubis an der Symphyse vollkommen verwachsen sind und das Becken vorn schliessen.

Von dem Madrider Skelette ist die absolute Grösse der einzelnen Theile nirgend vollständig angegeben; doch haben PANDER und D'ALTON es in 0,1 der natürlichen Grösse abgebildet, wornach das Londoner in einzelnen Stücken kleiner, in den meisten aber etwas stärker ist. Erstres soll einer handschriftlichen Note zufolge am Sacrum $6^{\prime} 5^{\prime \prime}$ hoch und $13^{\prime} 7^{\prime \prime}$ lang seyn; das Londoner ist etwas grösser und stärker. Vergleicht man es aber mit dem Skelette eines $11^{\prime}$ hohen Elephanten, so ist auffallend, wie einige Theile hinten am Körper sich so mächtig entwickeln konnten, dass die analogen des Elephanten ganz unbedeutend dagegen erscheinen.

So beträgt

beim - beim

Elephanten, Megatherium.

die Ausbreitung der ossa ilia . . . $3^{\prime} 8^{\prime \prime}$. . . $5^{\prime} 1^{\prime \prime}$

die Breite des breitesten Schwanzwirbels $7 "$. . . $1^{\prime \prime} 9^{\prime \prime}$ mittler Unfang des Femur .. . . $1^{\prime} 0^{\prime \prime}$. . . $2^{\prime} 2^{\prime \prime}$

Länge des Os calcis . . . . . $7^{\prime \prime} 5$. . . 1' $5^{\prime \prime}$

Dèr übrige Text der Abhandlung ist den Ausmessungen der cinzelnen Theile gewidmet, derentwegen wir auf das Original selbst verweisen.

W. Buckland: über die Entdeckung fossiler Iguanodon-K nochen im Eisensand der Wealden-Formation auf den Inseln Wight und Purbeck (Geol. Trans. N. S. 1835, III, III, 424-4.32, gelesen am 4. Dez. 1829). Das Vorkommen dieses RiesenThieres "), dessen ganze Länge Mantele aus 7 Knochen nach den Proportionen von Iguana auf $70^{\prime}$, die Länge des Schwanzes auf $52^{\prime}, 5$, den

*) Vgl. Maxtell in Philos. Truns. 1825, S. 179, und Illust. Geol. Sussex, 1827, S. 71 ; - und Murcussos in Gienl. Truns. II, 104. 
Umfang auf 14',5 herechnete, schien auf den Hastings - Sand oder die Wealden-Fornation des Tilgate Forest beschränkt zu seyn, bis B. dessen Reste in Sommer 1829 in 3 anderen Lokalitäten nachwies, nämlich 1) auf Wight im Eisensande, welcher die Südküste bildet, etwas östlich von Sandown Fort zwischen Hoch - und Tief - Wasserstand. Der bedeutendste der hier gefundenen Knochen ist ein Mittelhandbein der linken Seite (vielleicht ein Mittelfussbein des linken grossen Zehens), 6" lang, 5" breit und hinten mit 16" Umfang, fast 6 Pf. scluwer und einem andern in Mantel.'s Sammlung sehr älnnlich. Es ist wohl der grösste aller bisher bekannten Metacarpul-Knochen, viel grösser als die durch Mantel bekannt gewordenen Metatarsal-und Metacarpal-Beine dieses Thieres, verhältnissmässig dicker und kürzer als bei irgend einer lebenden Eydechse, wie das dem schwerfälligeren Körper eines Herbivoren angemessen ist. Der Vf. gibt die Abbildung (Tf. XLI, Fg. 1, 2) und die Gründe, warum er diesem Knochen die oben angedeutete Stelle am Skelette zuweiset, und theilt die Zeichnung von einem 13" langen Metacarpal-Knochen des Megalosaurus und einem Metatarsalbeine des Krokodils aus dem Stonesfielder Schiefer mit um zu zeigen, wie viel schlanker diese Theile bei Karnivoren sind. Damit fanden sich einige Wirbel u. a. Knochen-Reste kleinerer Saurier vor, wie Gerand SmIтн daselbst vor einigen Jahren auch ein grosses Knochenstück vom Pabenschiabel oder vom Becken gefunden hatte (Ox/ord Museum). 2) Kürzlich hat James Vine noch einige andere grosse Kuochen, vorzüglich Wirbel, von I gu an od on in Kirrhspicle Brook am S.W. - Ende der Eisensand-Formation auf Wight (vỏrzüglich bei Brook Point) mit Baumstämmen entdeckt. Diese Wirbel sind grösser als vom Elephanten, kleiner als beim Wale, und von fast viereckiger Form, wie solche MANTELL als charakteristisch angibt. - - 3) Auf Purbeck hat Bafte.ett zu Swanwich viele fossile Knochen gesammelt, welche bei der Zcrstörung des dort als Hochgestade anstehenden, bis $500^{\prime}$ mïchtigen, zwischen Purbeck-Kalk ") und Grünsand gelagerten Eisensand-Gebildes durch Brandung in der Swanwich-Bai entblösst worden. Darunter sind auch vicle I g u a n o d o n- Wirbel, fast so gross wie die des Elephinten, aber fast rechteckig von den Seiten zusammengedrückt; - ferner mehrere Mittelhand- und Klauen-Beine. Die Ablagerungs-Strecke der Iguanodon-Reste, die man als ein ehemaliges Gestade anzusehen geneigt ist, geht daher vom Wald von Sussex durch Wight und Purbeck.

B. Z us a $\mathrm{z}$ vom Ma i 1835. Vielleicht jedoch ist $\mathrm{I} \mathrm{g} u$ anodon als Onnivore anzusehen. Denn einige in Enyland unterhaltene Iguanen (I. t u berculat a u. a.) konnten nur mit Pflanzen-Theilen genälirt werden, während jene, welche die Insel Isabella im Golfe von Californien bewohnen, nach BeLcher's Versicherung sich 'mit Eyern von

«) Nach Coxybeare und Maxteıt, ein Äquivalent der Muschelu-führeuden Kalkschichten von Asburmhım und der oberea Süsswasserkalk-Schichten der PurbeckReihe. 
Seevögelı, (jungen?) Vögeln und Insekten nähren, auch sich gegeụseitig selbst angreifen und nit Hühner-Gedärmen gefüttert werden können.

C. Eine fernere Entdeckung von Iguanodon-Resten zu Yaverland östlich von Sundown Fort auf Wight fand in Juli 1829 durch J. Snith Statt, welche dem Oxford Museum i. J. 1834 einverleibt wurden. Darunter befinden sich ebenfalls mehrere Wirbel, ein grosses Stïck eines zerdrückten Femurs, ein schönes Unterende eines zweiten u. s. w.; jedoch auch viele Gebeine kleinerer Reptilien. - Auch hat Smitн kleine Zapfen von $\mathrm{Z}$ a mia crassa (Linde. a. Hutr. Fuss. Flur. pl. 136) nit Lignit in einem grauen Sandsteine an derselben Stelle aufgefunden.

D. Dazu kommt endlich die Entdeckung eines I $\mathrm{g}$ u a $\mathrm{nod}$ onSkelettes zu Muidstone in Kent (Jahrb. 1834, S. 729), wodurch die früheren Deutungen über einzeln gefundene Knochen bestätigt werden. Es lag in einem Mecreskalksteiu der untern Grünsand-Formation, wohin es durch eine sekundäre Ablagerung aus der Wealden - Formation gelangt seyn mag.

Morton: Synopsis of the Organic Remains of the Cretacous Group of the United States (88 $\mathrm{mp} .80$, with 19 plates, Philadelylia 1834). Dieses Werk ist eine Zusammenstellung der vom Verf. in dem 17., 18., 22., 23. und 24. Bande von Siluman's Journal eingerückten Abhandlungen mit Zusätzen und Verbesserungen im Texte und vollständigerer Ausführung der Abbildungen, deren Anzahl sich auf 160 beläuft. CoNRAD hat auch einige neuere Beobarhtungen über die ältere KreideGruppe in Alabama mitgetheilt, wornach in den Grafsrhaften Pickens, Bibb, Greene, Perry, Dallas, Marengo, Wilcox, Lownes, Montgomery und in einem Theile von Clarke, Monroe und Conecuth der Boden fast ganz von dieser Furmation zusammengesetzt wird; doch herrschen in Clurke die neueren Kreide.Gesteine vor. Das ältere Kreide-Gebirge bildet die lange senkrechte Felsmasse (bluff) zu Demopolis, wo es nach Bohrrersuchen $500^{\prime}$ nächtig ist. Auch der höhere Fels-Haufen zu Erie besteht daraus, durch Pecten quinquecostatus und Exo. gyra costata wohl bezeichnet. Folgt man dem schuarzen Warrior: Flusse, so hören die Kreide-Gesteine etwas vördlich von Erie auf und zu Tuscaloosa schneidet das Flussbette in rothen Sandstein und in bituminüse Kohle ein. Der Tombeckbe und die meisten seiner Zuflüsse durchziehen die Kreide-Formation, obschon ihre Quellen in einem Kohlenkalk-Gebirge im nordöstlichen Theile des Mississippi-Staate' liegen mögen. Die Grafschaften der Chickasaus und Choktaws und der grösste Theil des ganzen Mississippi-Staates dürfte zu dieser Formation gehören. Alle Prairie'n von Alabuma und Mississippi haben eine Unterlage von älterem Kreide-Gebirge; das jüngere herrscht wur im nördlichen Alabama vor, und ist nicht weiter von Prairie-Boden bedeckt. - 
Nummuliten-Kalkstein bildet die Berge um Saggsville, so wie mit Unterbrechung von Claiborne bis Jackson am Tombeckbe, und bei Bassetts creek hat einer dieser Berge $300^{\prime}$ Höhe. Der Kalk ist porös und enthält kugelige Räume durch Zerstörung organischer Reste entstanden: Myriaden von Nummulites Mantelli sind über die Oberfläche dieses in Zersetzung begriffenen Gesteines gestreut.

Seit dem ersten Abdrucke der Arbeiten M's. in erwähnten Journale hat derselbe, noch folgende fossile Arten theils neu erhalten, theils näher bestimmt :

Scolop.ax - Tibia, in zerreiblichen grünen Mergel bei Arneytoun, N.-J.

S e p i e n-Schnäbel.

Nautilus Alabamensis, bei Claiborne in Alabama.

Ammonites Couradi, äusser. lich einer Argonauta ähulich; Prairie-bluff, Alabama.

Am. syrtalis; Greene Co. Ala. A m. vespertinus: Arkansaw. Baculites columna; Prairie Bluff.

Bac. ca a in atus, desgl.

Bac. labyrinthicus, desgl.

$\mathrm{H}$ amites arculus; Greene Co. - torquatus, desgl. - trabeatus; Prairie

bluff.

Bull a, gross, bauchig, Ala.

Trochus leprosus; Pr. $h$.

Delphinula lapidosa; desgl.

Turritellavertebroides; N.-J. und Ala.

Tur. encrinoides.

Scalaria Sillimani; Plairie bluff.

$\mathrm{Sc}$ al. a n n $\mathrm{I}$ a $\mathrm{ta}$; Gloucester, New-Jersey.

Rostellaria pennata; Pr.bl.

$\mathrm{N}$ atica petrosa; ebendas.

- abyssina; ebendas.

Cirrus crotaloides; Erie, Ala.

Conus gyratus; South Carolina.
Ostra cretacea; ebendas. und Erie.

Pecten craticula; N.-J.

Poulsoni; Claiborne.

Plagiostoma dumosum; st. Stephens, Ala.

Placuna scabra.

Plicatula urticosa; N.-J. u. Ala.

Inoceramus Barabini; Greene Co.

Inoc. alveatus.

Avicula laripes, Delaware.

Pinna, ähnlich P. tetragona.

Pectunculus hamula, Pr.bl.

Arca rostellata; $A l a$.

Cucullaea antrosa.

Trigonia thoracica; Pr. bl.

Crassatellavadosa; $A l a$, N.-J.

Pholadomya oc cidentalis Chesapeake- und Deluware-Kanal. Clavagella armata; Pr. bl. Terebratula Floridana; Prairie bl.

H a mu lus : röhrenförmig, regel. mässig gewunden, Windungen getrennt, Mundöffnung kreisrund.

Ham. onyx; Lynch's Creek in s.-Carol.

Astacus; Delaware.

Cassidulus a equoreus; Pairie bl.

Scutella Rogersi; Monroe Co. Ala. 
Ananchytes cinctus; N..J. fimbriatus.

Flustra Sagena; N.-J.

Escharadigitata.

Alveolites cepularis.

Vermetus rotula; $N$-J.
Scaphites Cuvieri Mort. fällt mit Sc. hippocrepis DE KAY (die ältere Benennung) zusanmen.

An der Ost - und West-Küste des Atzantischen Ozeans konmen gemeinsam vor:

a) In der Kreide.

Pecten quinquecostatus.

b) In der eocenen Formation, Londonclay.

Corbis lamellos a LaMr.

Cardita planicost a Blainv.

Fistularia elongat a Desh.
Bulimus terebellatus Lank. Solarium canaliculatum LАMK.

c) In der obern Meeres-, oder älteren pliocenen Formation.

Lucina divaricata Lamr.

Ostrea Virginiana Gmel.

Pectunculus subovatus SAY.
Panopae F a ujasi.

Cerithium melanoides Sow. Bulla acuminata Sow. ?Venus rustica Sow.

\section{d) Noch lebend.}

Purpura lapillus,

Natica canrena,

Fusus Isiandicus,

Cyprina Islandica,

Saxicava rugosa,

Lucina divaricata,

Pholas crispata,

Pholas costata,

Solenensis,

Mya arenaria,

Buccinum undatum.

Mytilus edulis,
Modiola papuana,

Mactra deaurata,

Spirorbis nautiloides,

Thracia convexa,

Solecurtus fragilis,

Glycimeris siliqua,

Cardium Groenlandicum,

Cardium Islandicum,

Strigilla carnaria,

Tellina punicea,

Pecten Is landicus,

Balanus ovularis.

Woraus erhellet, dass die Anzahl identischer Arten an beiderlei Küsten des Atlantischen Ozeans, wenigstens absolut genommen, von der Kreide an bis daher zugenommen habe. (Was wir bezweifeln: denn auch Belemnites paxillosus, Ostrea resicularis u. a. kommen in der Kreide beider Kontinente vor. Br.) 
Duvernoy: Note über ein Becken-Fragment, wahrscheinlich von Hippotherium (Vortrag bei der Strasburger Sozietät 1836, 20. April > l'Institut 1836, IV , 268-269). Zu Châtillon im Bezirke von Montbéliard unweit dem Doubs-Thale sieht man eine KnochenBreccie im Jurakalke, aus welcher der Verf. bereits einige Knochenreste von $\mathrm{H} \ddot{\mathrm{h}} \mathrm{l} \mathrm{e} \mathrm{n} \mathrm{b} \ddot{\mathrm{a}} \mathrm{r} \mathrm{n}$ herstammend an Cuvier eingesendet hatte (oss. foss. t. V, Supplém. p. 515) zur Zeit, wo der Höhlenbär in Frankreich noch nicht gefunden worden, da die Grotte von Osselles im Doubs-Dept. durch Buckland, später durch Fargesu (Ann. sc. nat. II, 236), und die Grotten an der obern Saone duroh Thurris und Fallot noch nicht untersucht worden waren.

Jene Breccie ist sebr hart; die in ihr eingeschlossenen Knochen können nur zerbrochen aus ihr gesondert werden: sie sind etwas versteinert, und grösstentheils schon zertrümmert in die Breccie eingeschlossen worden.

Daraus erhielt nun der Verf. in April 1835 einen etwas grössern und besser erhaltenen Knochen, ein Becken-Stück durch das Darmbein kenntlich, an welchem man den innern oder Spinal-Winkel und den äusseren Winkel wahrnimmt mit einem grossen $\mathrm{Z}$ wischenraum zwischen beiden. Nun sagt Cuvrer (Iv, 20), am Becken der Wiederkäuer ist der innere oder Spinal-Winkel des Inselbeins breiter und weiter nach hinten, als der äussere, und an diesem ist die Abstumpfung schief und fast an den Vorderrand des Knochens angrenzend; während am Becken des Pferdes der Spinal-Winkel spitz, so weit vorn als der äussere befindlich und dieser rechtwinkelig abgeschnitten ist. An dem fossilen Becken aber ist der Spinal-Winkel etwas spitzer als der äussere, aber nicht so weit vorn, als am Pferde. Der vordere Lenden-Rand desselben oder der Zwischenraum zwischen den beiden Winkeln ist etwas konvex statt (beim Pferde) konkav. Der untere äussere Rand zwischen dem äussern Winkel und der Cotyloid-Höhle ist S-förmig statt (bein Pferde) elliptisch. Obschon sich daher dieses Beckenstück dem des Pferdes am meisten nähert, so weicht es doch in einigen wesentlichen Punkten davon ab, und es dürfte somit vielleicht zu Genus Hippotherium gehören, welches Kavp in den Akten der Leopoldiner Akademie XVII, 179 ff. beschrieben hat.

R. I. Murchison: über die neuliche Entdeckung von Palaeoniscus cat opterus im New. red Sandstone von Tyrone in Irland (Geol. Soc. 1835, 7. Nov. > Lond. a. Edinb. philos. Magaz. 1836, VIII, 72-73). An Rhone Hill im Kirchspicle Killyman, 3 M. 0. von Dungannon ungibt dieser Sandstein, aus Antrim herübersetzend, ein kleines Kohlenfeld, ruhet grösstentheils auf Bergkalk und wird im Osten von Thon mit Ligniten bedeckt; die Schichten fallen im Bruche 150 N.N.O., bestehen oben aus rothen und grünen Mergeln, tiefer aus 


\section{$-736$}

rothem kieseligem Sandstein, in welchem allein, in den untersten Lagen, die da zu Tage gehen, die Fische vorkommen, aber so häufig, dass man auf einer Platte von $2^{\prime}$ in Quadrat 250 Fische zählen konnte.

Agassiz hat in England 400 deutliche Arten Fische untersucht, wovon 300 neu. 1) Das Silurische System bietet nur 5-6 Arten dar als erste Repräsentanten der Wirbelthiere; -2 ) der Old red Sandstone mit den Schiefern von Caitlıess und den Gebilden von Gamrie haben 20 Arten geliefert; - 3) die Kohlen-Formation 54 und der Magnesiankalk 16 ; - 4) die Oolith. Reihe von Lias bis zur Wealden-Formation einschliesslich 150 Arten; - 5) Grünsand und Kreide 50;-6) der Londonthon 50, wird aber noch viel mehr liefern köpnen; -7 ) der Crag 5--6 Arten aus Geschlechtern, die in den nördlichen Meeren nicht vorkommen. - Ausser dem merkwürdigen Squalo-raja von Lyme Regis hat man daselbst so wie zu Whitby Reste (Kiemenbogen, Wirbel, Flossenstacheln) eines Fisches gefunden, der wohl der grösste unter allen bekannten seyn dürfte, des Gyrostris mirabilis AG.

G. Mantelr: über das Vorkommen von Vögelknochen in den Schichten des Tilgate Forest in Sussex (Geolog. Soc. 1835, 10. Juni $>$ Lond. a. Edinb. philos. Magaz. 183.5, VII, 518). M. hatte dergleichen Knochen schon frühe in der Wealden-Formation gefunden, aber nach dem Bekanntwerden der Pte rodactylus - Reste war ihre Ächtheit wieder bezweifelt worden, ungeachtet Currer selbst sie für Vogelreste angesprochen. Neuerlich hat der Verf. mehr dergleichen Reste entdeckt und Owes daraus einen Sumpf- und einen mehr mit Reptilien verwandten Vogel, als jetzt vorkommt, crkannt. Der Verf. beschreibt nun ausführlich diese Reste. Es sind 1) ein Theil des linken Tarsometatarsal-Beines mit der Gelenkfläche für die Hinterzehe, von einem Reiher-artigen Vogel; 2) eine ? Tibia; 3) ein MetatarsalBein ; 4) ein Humerus : 5) eine Ulna.

L. v. Вucн: explication de deux planches de Spirifer et d'Orthis (nicht in Buchhandel). Die zwei lithographirten Tafeln gehören zu der, vom Verf. bei der Berliner Akademie gelesenen Abhandlung (vgl. Jahrb. 1836 , S. 174 ff.). Der Text gibt eine Unterscheidung der Geschlechter Terebratula und Spirifer, eine Übersicht der Arteu und eine Erläuterung der Abbildungen theils der inneren Beschaffenheit, theils minder bekannter Arten; - da die Abhandlung selbst in den Schriften der Akademie noch nicht sobald gedruckt erscheinen wird. 


\section{$-737$}

Freiesleben: über das Vorkomm e n fos siler Kuochen und Zähne von Säugethierén und Ampbibieu in Siachsen (in dessen "Magazin für die Oryktographie von Sachsen", lreiberg, 80, VII, 1836, S. 276-287)"). Alle nachstehend verzeichneten Reste scheinen aus Diluvial-Bildungen zu stammen.

In Meissen: Gebeine und Hirnschädel (ALbiv S. 172); - bei Schieritz 1753 , bei Seilitz und anderwärts dgl., mit Narwal-Stangen (Schultze in Hamburger Magaz. 1753, X111, 300-302, und im Dres(lener Magaz. 1762, II , 227); - bei Zschochuu unweit Ostrau vor $30-40$ Jahren Zähne und Knochen, insbesondere einer der schönsten Rhinozeros-Zähue des Werner'schen Nuseums; - bei Pasckkowitz, ausser Nuss-ähnlichen Früchten in Tuffstein, auch Zähne angeblich von Bäre n im Abraume über Flötzkalkstein. - Bei Leisting Knochen, welche in Dresdener Kabinet liegen (Leipzig. Zeit. 1832, S. 234). Im Leipziger Stadtgraben eine fossile Rippe (Museum Linkian. 1786, II, 174); ebendaselbst am Hallischen Thore i. J. 1734-1735 eine Platte mit dem Stück einer versteinerten Schildkröte, in die churfürstl. Petrefakten-Sammlung in Dresden abgegeben (Scniör. Litholog. Lexikon VI, 220); in cinem Flusse bei Leipzig cin Elephanten-Backenzahn (MLus. Link. l. c.) - (vgl. nach Schultze in Titius gemeinnütz. Abhandl. I, 294, und WALch's Naturgesch. d. Verstein. 1783, I, 189). Bei Lohmen Knochen - Trümmer kolossaler Wallfisch-artiger Seethiere durch Hofr. Peichenbach (Leipz. Zeit. 1835, 613). - Zu Zellendorf bei Wittenberg i. J. 1809 Knochen und Zälne denen des Afrikanischen Elephanten äbulich (Langguth und Nitzsch im Wittenb. Wochenbl. 1809, Nro. 25, woraus in Cuv. oss. foss. I, 132; B BER in Mém. de l'Acad. de St. Petersb. 1830; v. MeYer Palueolog. 1832, 69, 139 bei Elephas priscus GowDF.). - Bei Jüterbogk Kinnladen mit Zähnen eines ungeheuren Thieres (Wittenb. Wochenbl. 1780, 280 ; und Zeuns in der National-Zeitung 1810, 637-641). - Bei Baruth ein Geweihe, wahrscheinlich von Cervus primordialis, in v. Bons's Sammlung (Lithophyl. Born. 1792, II, 1; Mus. Link. II, 176 ; KL ̈̈DEN Verstein. Brandenb. 1834, 79). - In der Niederluusitz bei Pieskow in Torfmooren unzählige Reste von Hirsch - Geweihen sehr zersetzt (KLöDEN 1. c. p. 79); auf den Jährischen Bergen und den Feldern bei Luckau Stïcke von H i s c h-Geweihen u. a. Knochen. (v. CArosi Britr. z. Naturgesch. d. Niederlansitz 1790 , S. 31, 32); bei Cottbus cin Hirsch-Geweihe (KLöD. I. c. p. 80); - bei Sorau vor 150 Jahren die 7' lange Rippe wahrscheinlich eines $\mathrm{Meg}$ a the rium; und neuerlich

*) Die Versteinerungen des Kupferschiefers werden S. 256-262 aufgezählt : die Fische nach Branvir.te und Agassiz, die Krustazeen nach Germar und v. Schlotheim, die Pflanzen nach v. Straxrerg. Da keine eigenen Untersuchungen und neue Beschreibungen mit zuverlässigen Bestimmungen dabei vorkommen, so ist es unuöthig, etwas daraus mitzutheilen. Ähnlich verhált es sich mit einem bei Wildełzfels in einem Flötz gefundenen Stücke eines versteinerten Baunstammes (S. 306-308). Übrigens ist die alte und älteste Literatur über die Versteinerungen der Kupferschiefer S. 264-267 aufs Vollständigste zusammengetragen.

D. $R$. 
in dortigen Kalkbrüchen zu Billendorf allerlei Knochen und das viel besprochene Menschenbein (KIRciner de petrefactis etc., und dessen Verstein. u. Fossil. bei Sorru, 1834; Leipz. Zeit. 1835, Nr. 37; Nünזberger in Morgenbl. 183.5, 443; HAupt's neues Lausitz. Magaz. 1835, XIII, 53-61; Gutachten der Oberlausitzer Gesellsch, etc. 1835 Jahrb. 1835, 497; Kirchner dagegen im Lausitz. Magaz. XIII, 145 bis 164). - In der Oberlausitz zu Bellermanisdorf in 'Torf fossile Schädel und Geweihe des Ele n n (Horl Petrefaktenk. 1829, 46); - bei Oberrengesdorf, Kunersdorf u. s, w. H öh l e n b i r -Knochen (Troner in Naumans's Neu. Lausitz. Magaz. 1822, I, 568-572). - In Mans. feldiscken zu Oberwiederstädt und Hettstädt Hirschgeweihe u. a. Zahnund Schädel-Stücke grosser Vierfüsser (geognost. Arbeit. IV , 135); zu Arnstedt grosse Knochen und $8^{\prime \prime}$ dicke und über 18" lange Hörner, wahrscheinlich von Ochsen; bei Eisleben, Wimmelburg Knochen, Hör. ner, Backenzähne, insbesondere neuerlich ein M a mu uth - Backenzahn, in der Bergschule zu Eisleben (Bieringes's histor. Beschireib. d. Mansfeld. Bergwerks 1734, 138; Hoffmans Sendschreib. in Grundio's neuen Versuchen 1749, VI, 482; Liebenroth im Haml. Magaz. 1750, V, 420; Sснгёт. litholog. Lexikon VII , 350; Geognost. Arbeit. IV , 135); zu Obersdurf im Schlottenleimen 1818 ein Schädel wabrscheinlich von C e rvu $s$ giganteus (Freiest. in Isis XX, 434-437, Bütrs. S. 105) und 1825 ein $6^{\prime} 8^{\prime \prime}$ Rhein. langer Elephanten-Stosszahn, in der königl. Mineralien-Sammlung zu Berlin (Werss in Karst. Arch. 1829, I, 395); bei Sangerhausen vor wenigen Jahren Bruchstücke von ElephantenZähnen und Knochen; bei Wendelstein Elepha nte n-Knochen in Gypsschlotten > Bullet. scienc. nat. 1828, VI, 191. Dann bei Querfurth, Eichstädt und Umgegend seit langer Zeit viele Schälel, Hörner, Skelette, angeblich von Elephanten, Meerpferden u. s. w. (Bütriner Zeichen u. Zeug. d. Sündfl. 1710, 219-223 und W Verstein. 1769 - 1771, II, II, 169, 173, 198, 236, III, 207, 208); - bei Landsberg grosse Thierknochen, wobei ein $2 \frac{1}{2}$ Ell. langes Horn (MyLII Mus. 1716, nro. 1459; Lerche oryctogr. Halens. 41); - zu Grana bei Zeitz einige $\mathrm{M} \mathrm{amm} \mathrm{uth-Backenzähne} \mathrm{(Leipz.} \mathrm{Zeit.} \mathrm{1832,} \mathrm{234)} \mathrm{und}$ zu Böhlitz (bci Weissenfels?) Kinnladen und Zähne von Equus Adamiticus und Rhinoceros antiquitatis (Holr Petrefk. S. 43, 55). - Zu Rossback bei Dürrenberg in Sand über Braunkohlen viele kalzinirte Knochen und Backenzähne von ? Elephanten, ? Bärcn u. s. w.; - im Abraume beim Stollen des Braunkohlen-Werkes zn Skortleben Geweilistücke von Hirschen und Eckzähne junger Elephanten, wovon einige in die Universitäts - Sammlung zu Halle gekommen seyn sollen.

W. Williamsox jun.: über die Verbre it ung organ is che $\mathbf{r}^{\circ}$ Reste in der Lias. Reihe von Yorkshire, zu Erleichteruug 
ihres Wiedererkennens aus dem Vorkommen der ersten (Lond. a. Edinb. philos. Mag. 1834, V, 222-223). Die mitgetheilten Beobachtungen sind entnommen aus dem Bezirke vom Peak Hill bei Robin Hoods Bay bis zum Flecken Saltiurn bei Redcar. Die hier verbreiteten Lias-Gesteine sind von oben nach unten

1) Alaunschiefer: a) weicher zerreiblicher Schiefer, $130^{\prime}$ mächtig, a) zu oberst mit Ammonites striatulus, A. communis, A. crassus; Trigonia literata; $\beta$ ) in der Mitte, aus welcher der Alaun gewonnen wird, mit Am. Walcottii, A. heterophyllus, Nautilus astacoides; $\gamma$ ) zu unterst mit Am. exaratus, A. elegans, Nucula ovum und Saurier-Resten. - b) Harter Schiefer, in grossen blättrigen Blöcken brechend, im Ganzen 30' dick: mit A m. elegans; Belemnites compressus, B. tubularis, lnoceramus dubius. - c) Weicher sandiger Schiefer von 15'-20' Mächtigkeit: voll Am. annulatus.

2) Mergelstein, reich an Versteiuerungen, als Am. Hawkerensis, A. Clevelandicus, A. Stockesii, Belemnites conicus, B. elongatus, Turbo undulatus, Dentalium giganteum, Isocardia lineata, Cardium multicostatum, C. truncatum; Corbula cardioides; Amphidesmarecurvum; Mya V-scripta, II. literata; Plagiostoma laeviusculum; Pecten aequival. vis; P. sublaevis; Avicula inaequivalvis; A. cygnipes; Plicatula spinosa; Modiola scalprum, M. Hillana; Terebratula bidens, T. subrotunda, T. tetraedra, T. triplicata.

3) Der untere Liasfels ist ausgezeichnet durch Ammonites planicosta; Plicatula spinosa; Hippopodium ponderosum; Lutraria ambigua; Pinna folium; Gryphaeadepressa, Gr. Maccullochij, Gr. incurva; Pentacrinites Briareus und $\mathbf{P}$. vulgaris.

In diesem Verzeichnisse sind die ganz selten vorkommenden, so wie diejenigen Arten übergangen worden, deren Vorkommen der Verf. nicht selbst beobachtet hat. Das Vorkommen jeder Art in derselben Schichte scheint ihm sehr beständig zu seyn.

Broderip: Beschreibung einiger fossilen Krustazeen und Radiarien (Geol. Soc. 1835, 10. Juni > Lond. a. Edinb. phil. Mag. 183.5, VII, 517). Core und Egerton haben voriges Jahr verschiedene Reste genannter Thiere zu Lyme Regis in Lias gesammelt, von welchen Broderip folgende für neu hält: 1) Vordertheil eines Macrouren aus einem Geschlechte zwischen Palinurus und der Garnelen-Familie stehend: Coleia antiqua. Das Genus ist in den Proceedings charakterisirt. - 2) Ein Postabdomen eines Macrouren, eingekerbt wie bei Palinurus und so gross, wie beim H ummer; - dann zwei andere Theile, woran man die Eindrücke von vier grösseren und vier kleineren 
Kiemen in ihrem Verlaufe gegen das Herz gewahrt, zunächst wie bei den S c yll aru s - artigen beschaffen.

3) Ophiura E'gertonii, der noch lebenden O. texturata nahe verwandt, und von 0 . Milleri PuLc. unter andern dadurch verschieden, dass bei letzterer der Körper lappig ist. Aufgefunden $\frac{1}{2}$ Meil. westlich vom Haven Bridport, in Massen von glimmerigem Sandstein, welche von der Höhe der Uferklippen herabgefällen sind. 4) Cidaris Bechei.

Palä ontologische Notizen aus Normandie (l'Institut, 1836, IV, 313). Luard hat eine grosse Tibia, wahrscheinlich von einem

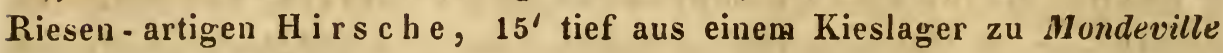
in Normandie erhalten.

Ferner einige Knochen-Platten von unregelmässiger Rauten-Forn, auf einer Seite zum Theil mit Schmelz bedeckt, welches wahrscheinlich Schlundknochen eines Fisches sind, aus dem "Calcaire de Caen" in Normandie.

Nach De Caunont sind neuerlich viele fossile Knochen in Argile de Dives zu Villers-sur-mer in Normandie gefunden worden.

Nach Eudès Descongchamp viele Teleos a urus-Reste beim Dorfe Allemagne daselbst.

Derselbe hat aus den Kalk-Platten, welche im Thon über dem oberen Lias in den Brüchen von La Quaine liegen, zwei Exemplare seines Teudopsis Agassizii bekommen, wovon eines die hornartige Schaale ganz erhalten hatte und mit einer dicken, weisslichen und nach verschiedener Richtung faserigen Hülle versehen war, welche faserigen Theile nach ihrem gesammten Verhalten weicher und muskulöser Art gewesen seyn müssen. Sie lassen die Form der Kalmars und die zwei nach hinten befindlichen Seitenflossen derselben wohl erkenuen.

Huot : über B ele mniten (vorgetr. b. d. Société des scienc. nat. de France ain 25. Juli $1834>$ l'Institut, 1835, III , 261). Huor hat in den faserigen Belenuiten-Scheiden aus der Kreide a) noch animalische Materie gefunden und b) bei ihrer Durchsichtigkeit in deren Innerem kleine, nicht in Spath verwandelte Polypenstöcke entdeckt, woraus denn hervorzugehen scheint, dass a) die Struktur dieser Scheiden - gegen Buainville's Ausicht, der sie erst in der Kreide in Spath verwandeln lässt, - schon in Leben dieselbe war, wie jetzt in ihrem Fossil-Zustande; dass sicli solche aber b) lebend in einem weichen $\mathrm{Zu}$ stande befunden, so dass die Polypen in sie eindringen konnten. [Sie könnten doeh auch-auf der Oberfläche angesessen und von der zuwachsenden Scheide unischlossen worden' seyn]. Wären sie aber erst später 
in Spath verwandelt worden, so hätten die von Natur kalkigen Polypenstöcke es gewiss auch werden müssen.

Farines: über ein e n fos sile $\mathrm{n} Z \mathrm{Z}$ a h n von Bages (l'Institut, 1834, II, 395). Dieser Zahn wurde 1831 bei einem Durchstiche für dic Strasse zwischen Truillas und Bages, in einer $2^{\mathrm{m}}{ }_{5}$ tiefen Thonschichte mit andern Fossil. Knochen gefunden, und von Chapsal in Truillas an die Akademie von Perpignan eingesendet. Farines beschreibt ihn nun hier ausführlich, glaubt darin einen $R$ hin oceros-eher, als einen P a l a e o the ri u m-Backenzahn zu erkennen, und bedauert, dass die übrigen Knorhen verloren gegangen, welche zur näberen Bestimmung hätten dienen können.

Deshayes: über B e l e m n i t e n (Bull. géol. 1835, VII, 51-62). Der Verf. zeigt die Verwandschaft derselben mit $S$ e $p i$ a durch sein fossiles Genus Beloptera, und macht einige andere Bemerkungen, welche mit demjenigen übereinstinmen, was Agassiz, Voutz, Müsster schon früher nachgewiesen, oder Voctz etwa gleichzeitig mit ihm der strasburger Gesellschaft vorgetragen hat.

LA Joye: über einen Ele phan te n - Un te rkief er (Bull. géol. 1834, IV , 428). LA Joye legte der geologischen Gesellschaft zu Paris den Theil eines Unterkiefers eines Elephanten aus den jugendlichen Gebilden des Rhein-Ufers bei Mannheim vor, welcher sehr wohl erhalten ist, und nach seiner Kleinbeit $z u$ schliessen einer neuen Art nur von der Grösse des Rindes angehört haben musste; denn, sagt L., das Thier war bereits ausgewachsen, da [?!] schon ein Ersatzzahn in diesem Kieferstücke vorhanden ist, woruach C. PRÉvost beifügt, dass er bei Fairholme mehrere auf der Küste von Norfolk gesammelte Reste gesehen, welche Elephanten nur von der Grösse des $B$ ü $f$ e Is angehört, dergleichen in Indien noch jetzt (nach FaIRHOLMB), mit dichtem Haar bedeckt, vorkommen sollen (S. 429). 


\title{
Mineralien- HandeI.
}

Lehrreiche Suiten der Mineral-Produkte des meikwürdi. gen Kammerbühls bei Eyer liefert, un billige Preise,

\author{
Procksch, \\ in Franzesbad *).
}

*) Wir können, aus Erfahrung, diese Suiten den Freunden der Geologie recht drill• gend empfehlen; sie entsprechen, in jeder Hinsicht, dem damit verbundenen Zwecke, d. h. instruktive Belegstücke zu H. Coтts's Schrift "der Kummerbïhl nach wiederholten Untersuchungen geschildert (1833)" zu geben, und zu dem wich. tigen Berichte, welchen wir über die Nachgrabungen $z u$ hoffen haben, die drei liöchst achtbare Naturforscher (die Hrn. Gr. V.Stersaerg, Gr. v. Holzexdory und Uberforstrath (OTтA) seit etlichen Jahren unternommen haben, und welche neuerdings von dem Herrn Grafen vor Sterxberg eifrigst fortgesetzt werden. Schon sieht man den Durchbruch basal ischer Lava deutlich vor Augen gelegt. $\mathrm{Zu}$ den interessantesten Stücken unter den Suiten des Hrn. РRоскscr möchten wir die gefritteten und verglasten Glimmerschiefer und Quarze zählen, so wie die Schlacken-Kugeln (Bomben) mit ihren Einschlïssen, und die Lapilli. Nun hören wir, nicht ohne Befremden, dass einige "Unullaubige" sich einbilden, die Verglasungen, welche am Kammerbiihl vorkommen - und die Jeder, der den merkwürdigen Hügel besucht, selbst leicht aufnehmen kann - würden von Hrn. Procksch künstlich bereitet (!!), und die Lapilli seyen keine Lapilli u. s. w. In H. CortA's

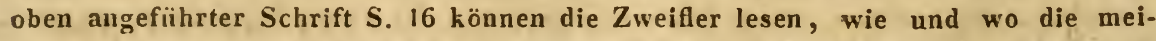
sten Verglasungen am Kummerbiihl gefunden werden. Um unter zahllosen ähnlichen Erscheínungen, deren hier gedacht werden könnte, nur einiger zu erwähnen, erinnern wir an die oberfächlich verglasten Girauwa cken-Stücke vom Rodderberge auf dem linken Rhein-Ufer und vom Mosenberge in der Eifel. Wie am Kammerbiihl der basaltische Durchbruch durch Glimmerschiefer erfolgte, hatte er am Rodderberge und am Mosenberge durch Grauwacke Statt; an letzterer Stelle wurde Grauwack c verglast, an ersterer Glimmerschiefer. Lapilli trifft man in der Auvergne stellenweise in nicht geringerer Menge, als am Vesice und am ätna.

D. R. 


\section{I n h a I t.}

\section{A blh andlungen.}

C. Naumañ : einige Bemerkungen zu Herrn T. E. Gumphecht's Schrift „Beiträge zur geognostischen Kenntniss einiger Theile sachsens und Böhmens" . . . . . . 3-13

B. Cotrs: Aufforderung an das geognostische Publikum, die Erforschung der Alters-Beziehungen zwischen Granit und Kreide in Suchsen betreffend .

B. Cotra: über Lepidodendron punct a t u mon Grossenhain. $30-35$

W. BuскцаND: Bemerkungen über das Genus Belemu-Sepia und über den fossilen Dintensack in dem vorderen Kegel der Belemniten . . . . . . . . . 36-40

Fr. TAMnaU jun.: über die geognostischen Verbältnisse der Gegend um Radau in Siebenbürgen . . . . . 41-49

Breithaupt: über einen als Hüttenprodukt entdeckten Felsit $47-49$ VAN DER WycK: über die Rheinischen und Eifeler erloschenen Vulkane, vorzüglich in Beziehung auf Dr. Hizвers's Geschiclite der ersteren . . . . . . . . . 129-165 Vorgt : weitere Nachrichten über die Hessberger Thierfährten 165-174 L. v. Bucr: über das Genus Delthyris . . . . 175-181 Voltz: Betrachtungen über die Cephalopoden-Schaalen 185-187 Ezquerra del Bayo: das Becken des Duera . . . 188-19j

v. KLIpsterv: Versuch einer geographisch-geognostischen Eintheilung des westlichen Deutschlands, nebst generellen Andeutungen zur geognostischen Konstitution der verschiedene'n Gebirys-Abtheilungen desselben . • . • . 255-289

v. Vorтн: Beobachtungen über Kiesel-Gebilde im Allgemeinen und Silizifikation der organischen Reste insbesondere, gesammelt in den sekundären Gebirgs - Formationen des Regen - Kreises in Königreich Baiern . • . • . . . 290-516 AлсккR: Bemerkungen über einige Abweichungen der Krystall- 
Formen durch Vergrösserung einzelner Flächen, und Hin. deutung auf ein Flächen-Krystal!-System . • • 317-322 Voltz: über 0 nychoteuthis prisca v. Münster, eine Vor-

lesung bei der Strusburger uaturhistorischen Gesellschaft an 17. Nov. $18 j 5$ gehalten . . . . . . 52j-527 B. Studer: über das geologische Alter der Kalkalpen von Uri $328-538$ G. zu Müsster: über einige neue Pflanzen in der Keuper-Formation bei Bayreuth

v. Vorth : die Phosphate des Erzberges bei Amberg . 518-557 Voutz: über das fossile Genus Neriuea . . . . 558-543 Brons: Übersicht und Abbildungen der bis jetzt bekannten Nerinea-Arten . . . . . . . . 544-546

Fr. Tamau: Monographic des Chabasits . . . . 65j-658

A. Gressix: geognostische Bemerkungen über den Jura der nordwestlichen Schweitz, besonder's des Kantons Sulothurn und der Grenzpartie'n der Kantone Bern, Aaryau und Basel 659-675 v. Vorti : Nachtrag zu den Beobachtungen über Kiesel-Gebilde und Silizifikation der organischen Reste • • • 676-68j Röner: über Monotis decussata von Münster . 684-686

\section{B r i f f w e chsel.}

\section{Mittheilungen, an den Geh. Rath von Leonhard} gerichtet, vou den Herren:

v. Gunppenberg: über die Rinne r, besondere Erz-Lagerstätten $50-51$

B. Studer: Grognosie von Bündten und Veltelin; Kreide-Ver-

steinerungen • • • • • • • • • $51-54$

C. Namann: Porphyre bei Tharand; Schiebenberger Basalt $54-55$

Russegger: Verschiebung kontemporärer Gänge in Rauris 194-195

P. Merjan: Rhein-Stand bei Basel • • • • . 195

Lortet: Grundeis; Geschiebe in Nagelfluh mit Eindrücken 195-197

Puscr: Kupfer- und Zinnerz-Bau am Ladoga-See; Geognosie Finn-

lands und von Petersburg . . . • • • • 197-199

C. Gemmelano: Oolith-Gebilde von Tauromina in Sizilien $\quad 200$

Kapp: Salniak-Bildung durch Steinsalz unter Steinkohlen 200-201

Lontet: I c h thyosaurus in Lias; Pflanze u in Oolith bei

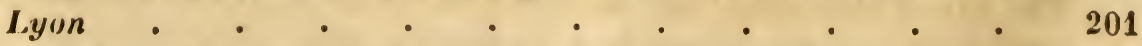

Lortet: Nagelfluh war einst weich; Erzgänge bei Vienne $\quad 359$

Schnemer: sekundïres Weissbleierz auf dem Gang von Holz-

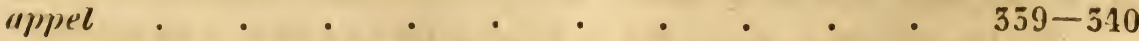

Zevscuner: Krakauer Muschelkalk, scine Erzführung und Kuo-

cheureste $\quad . \quad$.

Rugbeggen: Reise von Wien nach Triest und Patras . $515-517$ 
L. Pilla: geognostische Reise in Sizilien und Kalabrien; Emporsteigen des Granites

Pegroux: Gang von körnigen Kalk in Gneiss in Cantal . 348 Russegger: geognostische Erscheinungen an der Griechischen

Küste • • • • • • • • • • $348-350$

Wanger: neues Mineral in NAger's Sammlung . . . 550

v. Klipstein: Versteinerungen in Molasse und Grauwacke der

Wetterau; Zinnobererz-Lagerung bei Giudenbach . 350-551

Heнt: tiefes Bohrloch und Portlandstone in der Alp . . . 351

B. Cotrs: Weitere Subskribenten zur Untersuchung der Auflage.

rung von Granit auf Kreide in Sachsen . • • 351-352

B. Studer's und Escher's geogn. Arbeiten; Wanger's Tod 552-553

Zeuschner: geognostische Reise in den Karpathen; Fucoiden-

Sandstein; Salzthon : Bergöl-Quellen . . . . 353-359

Troost : geognost. Beschäftigungen ; Goldfuss' Übersetzung - 567

v. Vortн: zur Geognosie von Karlsbad; Arragonit-Tropfstein in der Oberpfalz . . . . . . . . . 567-570.

Schnemer: Erzgänge im Schaalstein bei Holzuppel . . 570-571

B. Cotra: Üntersuchungen über die Lagerung von Kreide, Jura-

kalk und Granit in Sachsen; Subskribenten . . 571-572

v. Kurpstein: Dinotheri um-Schädel bei Eppjelsheim; Braunkohle

im Maynzer Becken und bei Giesen . . . . 572-573

KapP: über die Emporhebung Skandinaviens u. Spitzbergens $\quad 573-577$

B. Corta: weitere Forschungen über die Lagerung von Granit

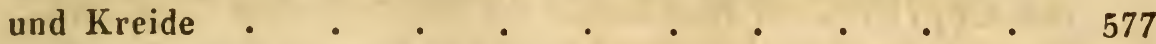

LoRtet : geognostische Bemerkungen um Lyon : . . 578-579

Nïggerath : Schwefelkies-Bildung in Moor-Erde bei Bonn - 580

Russegarr: geognostische Beschaffenheit un Kairo • 687-691

DE ST. Leger: chloritische Kreide um Rouen • • • • 692

v. Sternerg: Eruption des Basaltes an Kammerbiul . • : 692

LORTET: geognostisclser Ausflug von Lyon nach Villebois 692-69j

v. Kuipstern: Dinothe rium-Schädel u. a. fossile Kuochen bei

Eppelsheim . . . . . . . . . 695-691

B. Studer: Schweitzer Naturforscher-Versammlung in Solothurn;

Sekundär-Gebirge in Bern und Bündten; zu seiner Schrift

über die westlichen Schweitzer-Alpen . • • 695-700

BovÉ: geognostische Ergebnisse in der Türkei . . . . 700-705

II. Mittheilungen, an den Prof. Brovn gerichtet, von den Herren:

H. v. Meyer: fossile Sepien; Leptoteuthis; sechsstrahliger

Galerit; Glyphea; Prosopon; Iscerinites; fossile

Wirbelthiere von Öningen, Hohenhöven; fossile Knochen im

Torf von Enkheim bei Frankfurt 
Voltz: Nerineen; Mantellia cylindrica nicht in Muschel-

kalk; Ophiura in Keuper .
FischrR von Watdherm: "Oryctographie de Moscou"; Oolithen. kalk am Moskwa; neues fossiles Schnecken-Genus Paranom a • • • • • . . . . . 201-202

Römen: Werk über die Versteinerungen der Weser-Oolithe; Gliederung der letztern; tertiäre Mollusken von Sternberg 202-203 Ezquerra del Bayo: Erzreichthum in Spanien; Basalt der Mancha .

v. Mandelszoh: Terebrateln u. Portlandstone in der Alp 203

Voltz: Säugethier-Reste in Portlandstone von Sulothurn . . 204

Römrr gibt neue Tafeln zu seinem Werke; Pollicipes im Oolith

L. v. Buch: Dubors fand alten Grobkalk mit Versteinerungen in der Ukraine • • • • • • • • • • $\mathbf{3 5 9 - \mathbf { 3 6 0 }}$

BraUN : Lieferungen von Gebirgsarten und Versteinerungen aus

Bayreuth; Schneide-Zähne in Placodus-Kiefer . . . 360

Göppert : fossile Blüthen in Braunkohle der Wetterau . • 361

Hisinger: "Lethaea Suecica"; NiLson's, Fries' und Wright's Arbeiten

v. Münster: Capitosaurus in Keupersandstein; Pterodactylus longipes von Solenhofen; Gyrodus multidens in Jurakalk; Aellopus elongata daselbst; achte Belonostomus-Art; Fische und Caulerpit zu Seefeld; Lebias und Cyprinus in Braunkohle im Fichtelgebirge; vollstän. diger Placodus gigas; Lumbricarien; Verwechslung sekundärer und tertiärer Schichten zu Solenhofen; Loligo subsagittate; Onychoteuthis speciosa; neues Seestern-Geschlecht von Solenhofen (sonst Phalangites); Squilla antiqua vom Bolca; Insekten von Solenhofen 580-58z Schmid: Cyathocrinit in Kieselschiefer; Posidonia im Alaun-

schiefer von Brilon . . . . . . . . 584

B. Сотт : über die Wealden-Schichten von Niederschöna 584-588

Mathxr: geognostische Aufnahmen in New York • • . 588

\section{Neueste Literatur.}

\section{A. Bücher $(1830-1836)$.}

v. Mandbleseor; L. Pilla; - De la Beche; Al. Bertrand; v. Bregt; Le Buasc et Walter; Dreves u. Wiggers; Elif de Beaumont ; Fourket ; Gras; Gumprecht; Jäger; Lindley a. Huttox; dB Maxdelsloir; de Montlosier; Nyst; Römer; RozeT; - Hartahas 
Pander; - Mawe; Patrix; Saucerotti ; Conversations; FreyesLebet; Kayser; Kayser; Kirchner; v. Kobell; Mantell; Moore; Morton; Petzold; Prese; Reich; Savi; Wackenroder; Young a. Bird; - English, id.; id.; id.; Le Branc et WALTER . . . . • . • • . 205-206

v. Hisinger; - Botd; Dufrénoy; Giuli; Hogard; Hutot; de Laplace; Lindley a. Hutton: Maravigna; Morin; MullingerHiggins; Murchison; d'Omalius d'Hallox; Phillites; Reboul; Riviére; Salacroux; Savi: Shepard; Thomson; De ta Beche; id.; A. Bouź; Brose Karte des Harzes; Burkart; de Byrandt Palstercamp; B. Cotta; Hartanan ; v. Humboldt, Ehrenterg und Rose; Krüger ; Lyele; Mohs; NaUmann; Nilsson; Pusch; Saull; v. Weissenbach; van der Wrck; the fossil Fuel; Brons; Römer.

Laurance; Rose; Ure; - Breithaupt; Dufrénoy et Elie de Beaumont ; Hochstetter ; Kessler ; Kühin; Laurance; Leblanc et Walter; v. Leoniard; Phillips; Rozet; Schmerling; Silvertop; Unger.

Razzoni; Авich; Lindley a. Hutton; Römer; Pusch.

\section{B. Zeitschriften.}

E. Cassola e-L. Pilla: lo spettatore del Vesuvio e de' Campi Flegrei (Napoli 80) F'uscic. I-III, 1832 - 1834 (vergl. 1835 , S. viI)

Karsten's Archiv für Mineralogie, Geognosie, Bergbau und Hüttenkunde (Berlin 80) VIII, II, 1835 (vergl. S. 1855, S. viI) .

Journal of the Geological Society of Dublin (Dublin $\left.8^{0}\right)$ I, Ir, $183+$ (vgl. 1855, S. viI) . . . . . • •

Bulletin de la Suciété géologique de France (Paris, $8^{0}$ ) vergl. 1855 , S. vili).

$1835, I V, V, 65-320$ und $\mathrm{I}-\mathrm{LXI}$. . . . . 207-309 1836, VII, 1-112 . . . . . . . . 265-266

The London and Edinourgh Philosophical Magazine and Journal of Science contain. the Pruceedings of the Geological Suciety of London (Lond. 80 ), 1855, VI, nro. 2-6; VII, nro. 1-5 (vgl. 1835, S. viI) 209-211 1835, VII, nro. 4-7 und Index, S. 1-60 - . . 590-592 1836, VIII, nro. 1-4 • . . . . . . 592-593

H' English: the (quarterly) Mining Review or Journal of Geology, Mineralogy and Metallurgy, London, Nro. I-VII,

Glockвr: Mineralogische Jahireshefte (Nürnb. 80) Band I $=$ Heft $\mathrm{I}-\mathrm{v}, 1831-1835$. 
Transactions of the Geological Society of London (London 40) IV, , 1835 (vgl. 1835, S. viII) • • • • • . 366

(De Carle Sowhray) the London Geological Journal (London 80)

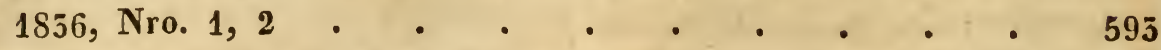

Transactions of the Geological Society of Pennsylvania (Philad. $\left.8^{0}\right)$ I, II, 1835 (vgl. 1855, S. viil)

\section{A u sz üge.}

I. Mineralogie, Krystallographie, Mineral-Chemie.

Fuchs: Analyse der schwarzen Kreide - • • • $\quad 66$

Shrpard: der Microlith, eine neue Mineral-Gattung . . . 66

0. Linné Erdmann: Analyse des sog. Chloritspathes . • . 66

Berzelivs: über Kalkspath mit kohlensaurem Kupfer-0xydul • 67

Kohlensaurer Strontian zu Shoharie in New-York • • $\quad 67$

Blex: Analyse einer Porzellanerde bei Halle • • . $\quad 67$

Fuchs: über Triphyllin u. Triplit von Rabenstein $\quad . \quad$. $\quad . \quad 67$

Forсниямав: Zerlegung des Oerstedits von Arendal • . 68

LAPPE: Analyse eines Asbestes von Koruk in Grönland . . 68

Greenough: Idokras auf dem Eilande Skye • • • $\quad 69$

Dufrénoy: über den Dreelit von Beaujeu . . . . . 212

v. KовELL: über den Nickelwismuthglanz von Sayn . . . 212

Glocker: Amianth, Bergkork u. Asbest bei Straschkan in Mähren 213

Hermans: Analyse eines Dolomites aus der Gegend von Véréia 213

Quenstedt : Afterkrystalle des Serpentins von Snarum . . 213

Меквасн: chemische Zusammensetzung Sächsischer Kalksteine 215

Kuternatzsch : Analyse des weissen Zinnsteins von Altenberg 215

Kerster: Analyse der grünen Kobaltblüthe von Schneeberg • 216

MiLlen: Gestalten des geschwefelten Nickels u. a. Substanzen 216

Durrénoy: Analyse des Bleigummis von Beaujeı • • $\quad 216$

Glocker: Magneteisen, Augit u. Granat bei Reschitz in Mähren 216

" über das Steinmark von Lettowitz bei Brünn . • 217

Brongniart: Metalle im oberen Sandsteine von Paris • . 217

v. Bonsdorff: Analyse des Figuren.Labradors von Finnland . 218

Brooke: mineralogische Notizen • . . . • . . 218

v. KoвELL: über Epidot-Gabbro bei Salzburg • • • • 367

Lavrent: Analyse des Spodumens aus der Arriege . • $\quad 368$

" Zerlegung eines neuen Minerals „Wichtyn" aus Finnland 368

Tronce- WAchtmeister: blaues arseniksaures Kupfer-Oxyd aus

Cornwall . . . . . . . . . 568

Mitscherlich : Untersuchung verschiedener Thonarten : $\quad 369$

Trolle-Wachtmeister: Analyse weissen Granats aus Norwegen, 369

Frск: 'die chemische Zusammensetzung des Thonschiefers • 369 
Laurent und Holms : Labrador-Feldspath in Laven des Vesuv's

GEBHARD: mineralog. und geolog. Bemerkungen über Shoharie

DANA: neues System krystallographischer Zeichen . . . 371

SHEPARD: Uranglimmer in Chesterfield . . . . . $\mathbf{5 7 2}$

Laurent und Hozms: künstliches Magneteisen von Châtillon • 372

Berzelus : Ouro poudre aus Porpez in Süd-Amerika . $\quad 594$

Svanberg: Analyse eines für Osmium-Iridium ausgegebenen Mi-

nerals . • . . . . . . • . . 594

GLocker: über Graphit und Allophan von Petrow in Mähren - 594

Laurent und Holms: Albit von Chesterfield . . . . 595

Connert: Zerlegung des Gadolinits • • • • • • 595

Forchнаmmer: Oerstedtin von Arendal . . . . . 595

Shepard : über den Mikrolith . . . . . . • 596

Kudernatscr: chemische Untersuchung einiger Abänderungen des

Augits und der Hornblende . . . . . . . 596

Berzerius: Untersuchung der Meteorsteine • • • • 599

KöHLER: zur Naturgeschichte des Harmotoms . • . . 604

ZIPPE: Analyse des Comptonits vom Seeberge . . . . 604

Fucus : über Isomerismus und Amorphorismus . . . . 604

" über Graphit und verwandte Gegenstände . . . 604

Kudernatsch : über den Plagionit . . • . . 605

WEIss: über eine eigene Art von Krümmung an Bergkrystallen 605

KоввLL: über Krystall-System und Krystall-Reihe . • $\quad 606$

Kleine mineralogische Notizen aus Sirurmass Journal • $\quad 606$

Richardson: Analyse des Wolframs • • • • • • 607

Thomson und Steel: Zusammensetzung des Gadolinits • • 607

Stevenson: natürliches schwefels. Eisen von Behar bei Patna 607

" natürliche schwefelsaure Alaunerde in Alaunschiefer

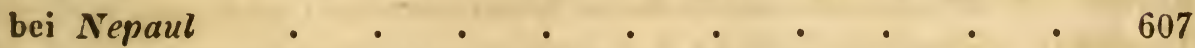

Alluavd: Gediegen Quecksilber in Granit der Haute-Vienne • 608

Brooke's Thulit ist Strömit • . . • • • . 608

Berzelius: über den Olivin . . . . . . . . 705

Lychisel: Analyse des Specksteins . • . • • . 705

Connell: Analyse eines Minerals von den Faröern • . $\quad 705$

" Analyse des Levyn von Irland . . . . . 706

Frankenheim: chemische und krystallinische Beobachtungen • 706

Lycheln: Analyse des Specksteins und des Seifensteins • • 706

Analyse des Agalmatholithes . . . . . 706

Kudernatzoc : über die chemische Zusammensetzung des Pennartits . . . . . . . . 707

Suckow: über den Bitterspath aus der Gegend von Jena . . 707

Karsten: über die chemische Verbindung der Körper . . 707 


\section{Geologie und Geognosie.}

Muнснгson: Klassifikation der Übergangsgesteine in Shropshire und Umgegend, und deren Störungen . . . . . 70

Rofs: Geologie der Gegend von Reading . . . . . 72

TANtscher: Kobalterze in den Kamsdor/er Revieren . . 74

Mille: tertiäre Ablagerung zu Puinte-i-Pêtre auf Guadelonıe. $\quad 74$

Boussingault: Versuch einer Ersteigung des Chimburazo, 1831

HEINE: über künstliche Feldspath-Bildung . . • . . 76

Reiches: Analyse des Mineral-Wassers von Hohenstein • . 79

Sтоскеs: über kugelige Bildungen mineralischer Substanzen $\quad 79$

Horner: über die Menge des im Rheine enthaltenen Schlammes 81

Schneider: geognost. Bemerkungen in Litthauen u. Volhynien 82

Staring: Beiträge zur Geologie des Königr. der Niederlande • 84

v. Mexer: brennender Berg in Dazien . . . . 84

Fournet: Zersetzung der Mineralien feurigen Ursprungs und ihre Verwandlung in Kaolin . • • . • • • 85

Catullo: Supra alcune conchiglie fossili del calcare jurese nel territurio di Belluno . . . . . . . . 88

Pinlr.ips : über unterirdische Temperatur . . . . $\quad . \quad 88$

Arago: über Quellen, Bohr- und Spring-Brunnen . . $\quad 90$

VAN BREDA: tertiäre thonige Formation bei Zutphen in Geldern 97

Matreuccr: über die Bildung von Schwefel-u. Gyps-Schichten 97

JAMEsoN: Ablagerungen von Konchylien noch lebender Arten - 98

v. Raumer: über Basalt-Bildung • • • • • • . 219

Cirr. Kapp: Sterblichkeit der Erde . . . . . . 220

Kліgнт: Geologie von Erris in der Grafschaft Mayo • • 221

Cнr. Kapp: über die Goodwin-Sands . • . • • • 222

Mrrian: über eine natürliche Eishöhle im Kanton Basel . 222

Chr. KApp: über die Bildung der Erde und Meteorsteine . 223

Laurens: Analyse des Wassers aus dem Mittelländischen Meere 224

ВЕск: geognostische Bemerkungen über das Münsterland . • 224

Burnes: Geologie des Indis, Indischen Kaukasus und der Tartarischen Ebenen . . . . . . . . . 224

Dovclas: über die Vulkane von Woahu in den Sandwich-Inseln 226

Fournet: Bildung der Gänge von Pont Gibaud . • • • 227

Murchison: über das Silurische Felsarten-System . • . 229

Puillips: geologische Veränderungen der Oberfläche und Temperatur der Erde . . . . . . . . . . 250

Dissen: Entstehen der losen Steine auf der Drente'schen Heide 250

Desmongchanps: geologische und paläontologische Bemerkungen über ein Kalkflötz auf Polypitenkalk im Calvados . • 251

Lill von Libienbach: Beschreibung des Beckens ron Gallizien und Podolien . . . . . . . . . . 253

Сиableswortu: die Crag-Formation und ihre organischen Reste 256 
Elib de Beaumont: zur Geschichte der Berge in Oisans.

Nöggerath: über das Vorkommen des Goldes io der Eder

DREves : über den frühern Gold-Bergbau im Waldeckischen

Boblaye u. Virlet: Emporhebung d. Bergketten in Griechenland

D'Orbignx: geologische Notizen über Patagonien, Buenos-Ayres,

Chili und Hoch-Pure

Fabian: über das Verhalten der Soolquellen bei Salze

Gregory: über das Petrol von Rangoon . . .

Ausbruch des Vesuv's, 1835

583

Phinsep: Vorkommen des Platins in Ava . . . .

Pleische : Nachweisung von Kali u. Ind im Karlsbader Wasser

Rose : über Grünstein und Grünstein-Porphyr . • • • 585

Merian: über die in Basel wahrgenommenen Erdbeben . $\quad 388$

KenLhav : geognostische Karte von Jemtland und Trondlijen • $\quad 389$

Sinken des Meeres zu Muntevideo . . . . . . 389

Hocman: Notiz über Isle de France und Bourbon . • . 389

Sturmfluth zu Kiel . . . . . . . . 390

Bergsturz in Graubündten zu besorgen . . . • $\quad 590$

Krug von NidDa: geognostische Darstellung der Insel Island . 391

Hilchouse: artesischer Brunnen zu st. George bei Demerara . 400

BRYCE : über Diluvial-Wirkungen im nördlichen Irland . . $\$ 00$

Boussingault: nachträgliche Notiz über seine Ersteigung des Chimburazo . . . . . . . . . . . 402

Fastherstonehaugh: Gegend zwischen Missouti und Red River 403

L. v. Bucir : über Erhebungs-Kratere und Vulkane . . . 405

Escher von der Linta: Beiträge z. Gebirgskunde in d. Schweitz 404

VAN DER Wуск: die Rheinischen u. Eifeler erloschenen Vulkane 404

Murchison: über den Old red Sandstone in Hereford, Brecknock etc.

Murchison: Überblick über die New-red-Sandstone-Reihe in den Grafschaften Salop, Stafford, Worcester und Gloucester .

Postels : über die Vulkane der Halbinsel Kamtschatka • . 408

Bové: Bericht über die Geognosie Hindostans . . . . 412

Trever.yaN : Granaten in Millstonegrit von Newcustle . . 413

Mrrchison: Folge der obern Grauwacken-Reihe in England und Wales

Hugr : vulkanische Umbildungen in Calabrien . .

Tournat : über die vulkanischen Felsarten der Corbieres . . 416

Desgenevez: vulkanische Bildungen des Cantul, der Monts Dore etc. 418

Bove: : über Beavnont's Theorie d. Emporhebung d. Gebirgsketten 426

EAton: über geologisehe Äquivalente . . . . . . 436

Reboul: Abhandlung ủber die tertiären Ausfüllungs-Gebirge • $\quad \mathbf{4 5 8}$

HARDre: Gcologie des Oodipoor - Thales (Schluss) . . . 447

Fincrr: mineralogische und geognostische Nachrichten über die

Grafschaft St. Laurence in New-York 
Burkart : geogn. Verhältnisse d. Silberbergwerke v. Veta grande

De Villeneuve: Ausgrabung des Marseiller Schiffs-Werftes •

HÉricart de Thury: Phänomene beim Bohren artesisch. Brunnen

Steinkohlen in Russland.

MaIER: geogn. Beschreibung des Wolfsberges im Pilsner-Kreise

Bellas-Greenough: über Elie de Beaumont's Hebungs - Theorie

Kriss : über den Zusammenhang zwischen den Erdbeben und vul-

kanischen Ausbrüchen mit dem Zustand der Atmosphäre

Boussingautt : über die Erdbeben in den Anden . . .

Freyer: Emporhebung des Landes an der Westküste S.-Amerikas

BRLCHER : |

Bower: Uüber das Erdbeben zu Valparaiso 1822 . . 713-714

Cuming:

Erdbeben in Coquimbo

ReIL: Notiz über das Erdbeben zu Saena in Peru . . . 715

Erdbeben in Sïd-Amerika . . • . . . . • 716

Uber das Erdbeben zu Pasto an 22.-24. Januar 1854 • • 716

Woodise Parish: über die Wirkung der Wogen bei den Erdbe-

ben an den Küsten des stillen Ozeans . • . • 717

Arison : über des Erdbeben an der Chilesischen Küste.$\quad$. 719

\section{Petrefaktenkunde.}

HARLAN: in Nord-Amerika gefundene organische Überbleibsel,

Wirbelthiere . • • . • . • . . . 99

Ls. Joye: üher den Portunus Hericartii . . . • 110

Evans : über die Koprolithen Buckland's . . . . . . 110

WAGENER: der Sonne Kinder, eine Hypothese . •. • . 110

Wiegmans: üb. d. Thierfährten im Sandstein v. Hildburghausen 111

Conad: Fossil Shells of the tertiary formation of N.Amerika 112

Partscr: die sg. versteinerten Ziegenklauen aus dem Plattensee

in Ungarn, und das Muschelgeschlecht Congeria . . 118

[v. MünstrR:] Verzeichniss der Versteinerungen zu Bayreuth . 121

W. Nrcol: Struktur fossiler Hölzer von Mull . • . . 121 .

R. HaRLan: fossile Knochen von Megalonyx . .. . . 123

Roberton: Ornitho-Koprolithe n bei Valognes . . . 123

Prinsep: Elephanten-u. Büffel-Reste in Ostindien gefunden 125

Quenstedt: Petrifikate des Thüringischen und Englischen Zech-

steines . . . . . . . . . . . 259

Löw: Thierknochen mit Kunstprodukten im Sand des Kreuzber-

ges bei Berlin . . . . . . . . . 211

Catullo: conchiglie fossili del calcare jurese di Belluno . • 245

Nyst : Recherches sur les coquilles fussiles d'Anvers • • 246

Nrcos: über die Struktur der horizontalen Äste der Koniferen . 249

Mackar und Wutra: fossile Equiseten in Irland . . . 249 
Descongchanps: über die Teudopsiden, den Kalnars verwandt

L. v. Buch: Note über die Austern, Gryphäen und Exogyren .

W. GREGory und R. WALKER: Koprolith-Analysen • • • 251

Connelu: zur Analyse der Thier-Reste von Burdiehouse • : 252

Webster : über den Pech-See auf Trinidad • • • • 253

Untermeerischer Wald zu Dieppe ‘ . . • . . 254

Ch. Morren: Biber der Torfmoore in Flandern mit Menschen-

Resten . . . . . . . . . • . 254

GreEv: a monograph of the Trilobites of North-Amerika . 451

GreEn: Beschreibung einiger neuen N.-Amerikan. Trilobiten • 461

Beschreibung einer neuen Trilobiten-Art von Nova Scotia 462

SARS : über einige neue oder unvollständig bekannte Trilobiten $46 \tilde{3}$

Нитснкоск: Fussspuren von Vügeln im New-red-Sandstone von Massachusetts

HaUssmañ über R. Bunsexs im Kalktuff von Göttingen entdeckte

Kunstprodukte und Thierfährten . • • • • • 472

Eudès Descongchamps: fossile Krustazeen • • . • . 476

Göppert: Arbeit über fossile Pflanzen . . . . . 477

Cortesi: sulla scoperta del scheletro di un quadrupede colossale 477

v. Sternierg: über verschiedene Fucoiden . • • . 478

Steininger: äber Halocrinites und Helix . . . . 478

DE Serres : über die Skelette d. Hunds, d. Wolfs u. d. Fuchses 478

Rathie: fossile Knochen aus den Höhlen bei Smeinogursk $\quad 479$

Fischer von Watdhein: über die fossilen Knochen in Russland 481

Farises : Notiz über das Vorkommen von Lignit zu Paziols : 486

$\mathrm{H}_{\mathrm{ART}}$ : Betrachtungen über den fossilen Hirsch von Irland • 487

Grant : über einen Zahn im rothen Sandstein von Berwickshire 488

EICHWALD: vorweltliche [Wirbel-] Thiere der Polnisch-Russischen

Provinzen . . . . . . . . . . 488

DE Serres: Bemerkungen über die grossen Höhlenbär-Arten . 489

Thоmpson: Lebensdauer der Kröten von festem Material ein.

geschlossen . . . . . . . . . . 494

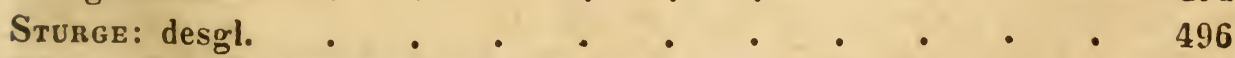

Nodot : Säugethier-Knochen lei Sémur . . . . $\quad$. 619

" über die Knochenböhle bei Contard • • • • 620

LARTEL: Knochen-Ablagerungen bei Auch, Gers • • 621

Connela: chemische Natur fossiler Sćhuppen . • . 622

Quenstedt: Beiträge zur Petrefaktenkunde . • . . 624

Morren : fossile Elephauten-Knochen in Belgien, Elephas

macronychus . . . . . . . . . 626

Buckund's Notiz über vier fossile Chimaera-Kinnladen .' 626

Grey EGerton: Struktur des Genickes des Ichthyosaurus . $\quad 626$

Crorzet: Entdeckung vieler Fossil-Reste zu Gergovia - $\quad 626$

Graf Razumowsкı : über Moos-Achate . . . . . . 627 
v. Starkberg: Fossil-Reste des Prager Museums

Grey Egrrtor: die Knochenhöhlen an Har: und in Franken

Voltz: Beziehungen der Belemniten zu andern Cephalopoden.

Croizet: über die fossilen Reste der Auvergne.

ZвоRzEWsнI: mikroskopische Untersuchungen über einige seltene

Fossil-Reste Podoliens und Volhyniens.

Gaimlardot Sohn: Fossil-Reste des Muschelkalkes der Lorraine

Phiclips : verschütteter Wald von Holderness . . . . 725

Chifft: drei Megatherien von Buenos Ayres • . $\quad 728$

Buckeasd: Iguanodon in Eisensand von Wight und Purbeck 750

Monton: organic Remains of the cretaceous grup . . . 732

Duvernoy: Becken von ? Hippotherium . . . . 755

Mrrchison: Palae oniscus catopterus in New red . . 735

Mastell: Vögelknochen in der Wealden-Formation . . . 736

v. Вuсн: deux planches de Spririfer et d'Orthis . . . 737

Freibsteben: fossile Säugethiere und Reptilien in Sachsen $\quad 738$

Williamson: organische Reste in der Lias-Reihe Yorkshires . 758

Broderip : fossile Krustazeen und Radiarien ' . . . 759

Paläontologische Notizen aus der Normandie: Hirsch, Fische,

Teleosaurus, Teudopsis . . . . . . 740

Hrot: Belemiten . . . . . . . . 740

Farines: Pal a o otherium- oder Rhinoceros-Zahn von

Bages . . . . . . . . . . . 741

Deshayes: über Belemniten . • . . . . . 741

LA Joye: Elephanten-Zahn vom Rhein, kleine Art $\ddots \quad 741$

\section{Verschiedenes.}

Boussingaunt: Besteigung des Chimborazo am 16. Dez. 1831 • 125

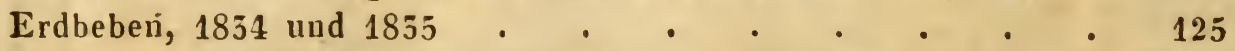

G. Bischoff: zur Kenntniss der Aachener Thermen . • . 126

Bavp: Analyse des Mineral-Wassers von Lavey . • • 127

Einführung von Fröschen und Schlangen in Irland . . • 128

FARINes: Statistik der Bohrarbeiten in den Ost-Pyrenäen . . 128

Mantell und Lyell empfingen Medaillen . • • • . 128

Reichenbacu: über den Meteorsteinfall zu Stannern bei Blansko 496

v. Holger: Analyse des Meteorsteins von Stannern, i. J. 1808497

zu Berzelius Analyse des Meteoreisens von Bohumiliz 497

v. Schreibers: bei Magdeburg gefundene problemat. Metall-Masse $\mathbf{4 9 7}$

Merian : über die Gestalt der Hagel-Körner . • • . 498

Grosse Kälte zu Roeraas in Norwegen . . . . . 499

Berthelot : über das Ungewitter auf Teneriffa im Nov. 1820 • 500

HEBer : über klimatische Veränderungen . . . . . 501

AdIE: Dehubarkeit verschiedener Steinarten in der Wärme . 501

Mineralogische Verhandlungen in Dublin im August 1835 . . 502 


\section{XV}

Geolorische Vorträ Seite

Mineralogische Verhandlung in Luzern im Juli 1834 . • . 507

Mineralien-Handel • . . . . . . . . 508

BRowne : über einen sonderbaren Eindruck in Marmor . . 630

MARcel ue Serres: artesische Brunnen in Süd-Frankreich • 631

" " über die artes. Brunnen bei Roussillon • 631

Héricart de Thury : artesische Brunnen zu Tours . • . 631

Lavini : Iod-Gehalt des Wassers von St. Genis . • • . 651

KeNrick: über die Griechischen Überlieferungen von der Erdfluth 632

YATE8: Magnetismus zu Magnesia . • . . . . 651

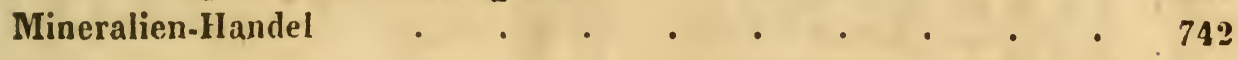




\section{Verbesserungen.}

\section{Seite Zeile}

5, 11 v. u. statt "vom"

28,13 "u. st. "Zusammkunft"

51, 14 , o. st. "im"

5j, 13 " o. st. "wahrscheinlich"

63,2 "4. st. "Hartmens"

67,4 " u. st. "Albil"

$69,9,0$. st. vor "Jahrs."

82,14 "u. st. "solieden"

85,27 " o. \&t. "quatärer"

84,2 " o. st. "Iaevirostris"

122,6 " o. st. "Innen"

123,22 " o. st. "Bulimea"

155,16 "u. st. Brücken"

140,17 " o. st. "Yon S. 23 bis S. $160 "$

245,1 "u. st. "nerengert"

148, 16 "0. st. "Gewalt"

- 16 " o. st. "mopr er"

151,10 v. 0. st. "Oopostone Guaries"

157, 14 " o. st. "Ursprung der"

161,4 " u. st. „Kesset

" u. st. "belebt, utperfliegt"
229, 14 "u. st. "1855, S. Xo"
216, 16 "u. st. "Anzahl"
- 12 "u. st. "mir"
254, 8 "u. st. "welchem"
332, 11 "0. st. "Ariates"
539, 5 " o. st. "Nich"
344, 2 " ist. "(Tf. V, Fig. b)" zu streichen.
1. "1836, S. 70 und $414^{\prime \prime}$.
1. "Anzahl von Arten".
1. "wir".
1. "welchen".
1. "Arietes".
I. "Nicht.

5j1, 10 und 18 st. "Mandegrloh"

467,16 "u. st. "थixvos"

726, 13 " u. nach "Kreidefläche"

Auf Taf. II, bei Fg. 5 fehlt die Buchstaben-Bezeichnung, nämlich $b$ und $d$ an den Enden der aufrechten, - und a an denen der gebrochenen Horizontal - Linie, - $d$ und $c$ an den Stellen derselben, wo die Reihe von Ringchen von deren oberer Seite huf die untere übergeht.

lies "von".

1. "Zusammenkunft".

1. "in".

1. "unwahrscheinlich".

1. "Hartiani".

1. "Albit".

1. "XIVr".

1. "soliden".

1. "quartärer".

1. "latirostris".

1. „innen".

1. "Bulimen".

1. "Brüchen".

„S. 160.

1. "verringert".

1. "mehr Gewalt".

1. ner".

1. "Ovenstone Quaries".

1. „Ursprung aus einer vórausgesetzten".

1. „Kessel im überschwemmten Zustande".

1. "belegt gewesen".

1. "Mandelshoh".

1. "ixvos".

f "umgeben ist". 


\section{An Die Gebildeten 7 Butschlands!}

(5inlabung zur $\Xi_{\mathfrak{b}}$ ficription

auf bas in (E. Schweigerbart' $\mathfrak{B}$ ' Berlaghhandlung in

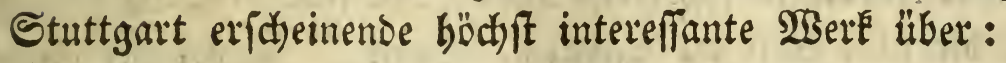

\section{bio $\mathfrak{x} \log \mathfrak{i} \mathfrak{e}$ \\ oder}

\section{Ilaturgelebichte oer Gerde} auf allgemein fä̧lidje Sieife abgebandelt

von

\section{R. C, v. Rconbars,}

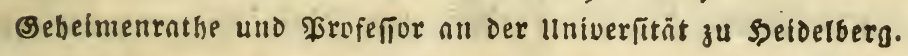

Mit Stahlstichen, 'Lithographieen' und Holzschnitten.

\section{PROSPECTUS.}

Die SBeichaffenlyeit ber Sberflähthe unferer Errde bedingt nidt

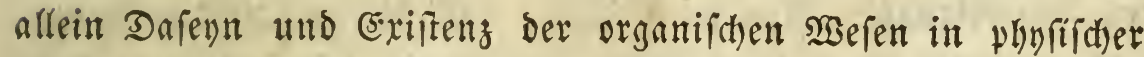
Beziefung, Den Nenficten mit einbegriffen, fie bebingt aud bie

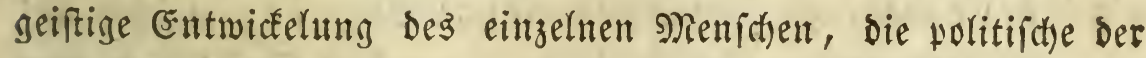

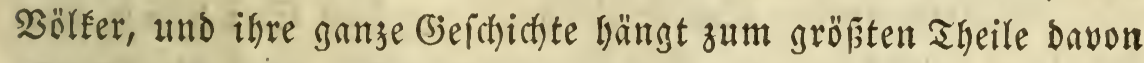
ab; daz Studium ber Geologie kann fonad) nur böd)ît widttig und interefiant penn. - Dem erften Blicke ericheint zwar bie હૈ: forichung der lebenden Natur um Bielez anziehender, alz baz Studium ber unbelebten. Sebez lebende Sisejen ift ein Sild man= nigfaltiger אiräfte, mit jebem gehen zalllloje 2(enberungen vor; fein Seitabidnitt feines Dajenns, ber nid)t burd) eigene überra f(hende Sluftritte beseid)uet würbe. Esine ber unfrigen näber bes 


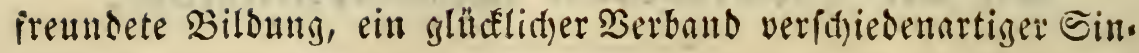

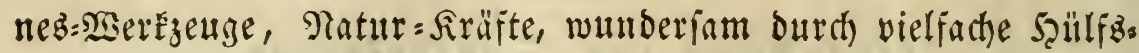
quellen, erwedfen für bie Sliere unjere ganze Sišberierde. Daz ans mutbigite Paturgemälde, einen S(nblicé von feltener Sdjönheit, ges währt bie ftille sillt ber Pflangen. Durd) fie wirb unfer (jefühl

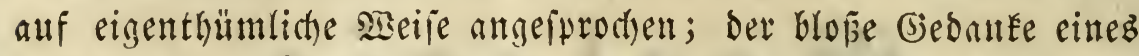

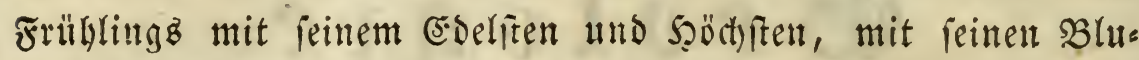
men und Blüthen, reicht hin, um die Luft $_{\text {zur }}$ Planzenfunde mäd)tig alzuregen. - Nicht io ift ez mit bell fiörpern, wo mir

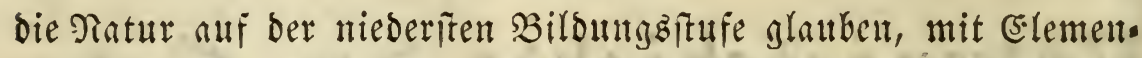
ten und Mineralien. Der Sdauplats bleibt hier fheinbar immer

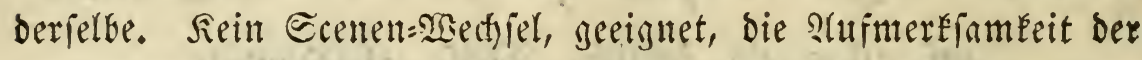
3ufithauer zu fefleln. Srllez lebloz und todt, nidft eine Spur der

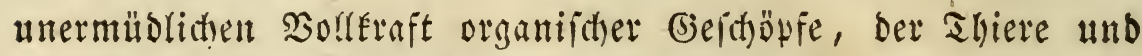

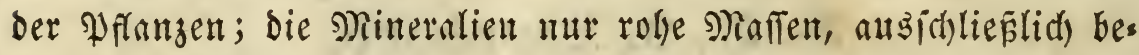
ftimmt, um vermendet zu werben zur Sefriebigung unferer ses, dïrinifie. Sinum vermag man dem Gedanfen Raum zu geben,

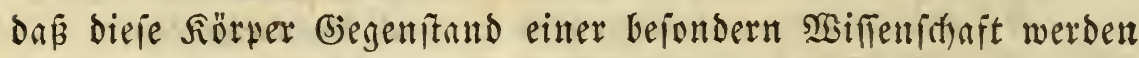

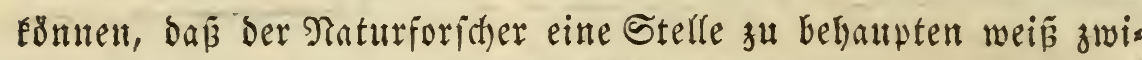
亿九en bem fördernden Sergmann und bem arbeitenden Sïnftler. - Serweilen wir aber nitht beim eriten flithtigen Sd)eine, fres ben wir nad) näberer fientutin, fo wird bald eine befiere lleber: zeugung erlangt. Snan mird fehen, Daj bie gelimmten Naturs (Eritheinungen in gleichem (jrade 2lufmerffamkeit verbienen, bar̃,

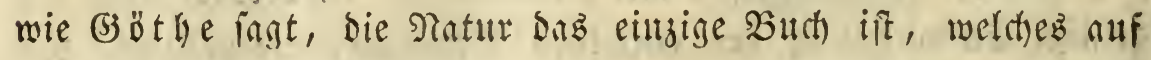
allen slättern groben Gehalt bietet. - Daz Stubium $b e r$

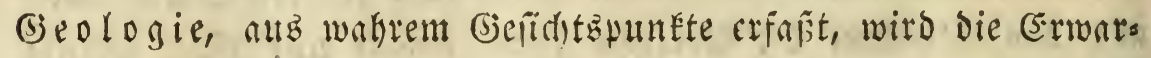
tungen Derer überbieten, welthe fich i⿹n wiomen. (E) ift bie

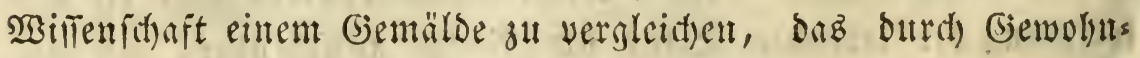
heit dez Cekens und dez Foridens gewinut; wie bent, bem na=

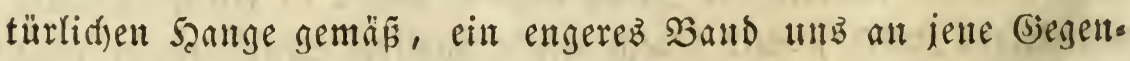
ftänbe fellelt, bie melyr gewälren, als ber erfte flüt)tige slicé ers warten liés. Wäre die wiffenj(jaft nidht eine ber netejten, fo 


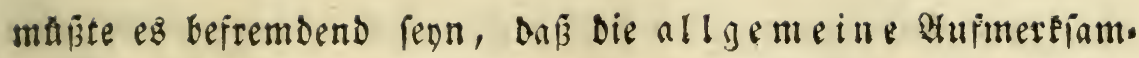
Eeit ilgr nid)t längft zugewendet worben. S(ber nod) lief kein

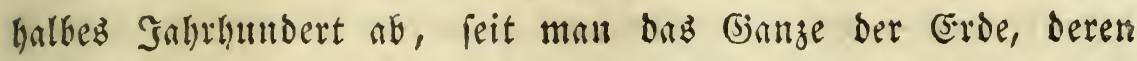
Dberfäthe bie Menfithen bewolnen, nitht mebr als rohes (biewirre, als (5haos, betiachtet, fonbern als ein nath beftimmten (jefeken 2ngeorbnetez und Gieregeltes, in befien Theilen eine ges milfe Alltersfolge mit Sidherheit nad)gewiejen werben Enn. So Siele leben inmitten einer geologija) reiden Natur; forten fie fith nifft begeiftert füblen ourch bie gropartigen Erfitheinungen

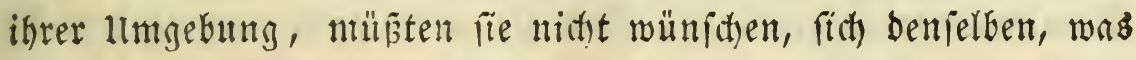
il)re (Errelärung betrift, näher gebracht, und fo mandhe Räthied gelözt za Fehen, weldhe ber täglidten Betrachtung offen liegen, und bie, ftrebt man ma(t) einer vertratern Befanntidaft, fids nicht felten als ganz einfarthe Whänomene barftellen? Taujende befuchen in jebem Sabre, ihrez Bergnügens wegen, Sorte, die fo febr geeignet find, um lebhafte vielieitige Sheilnahme zu erwecken für geologifhe Erricheinungen. Reijen in Stalien, in ber Sd)weiz, in Sntol, Salzburg, in ben Rheingegenden müten Reugierde uno Jnterefle ber sandernben mädytig anregen; es müffen fith ignen zahllofe Shatfachen von eindringlidsitem Sieize barbieten, und jols hen, benen geologifdse Senntnifie nicht fremb find, angenelnme

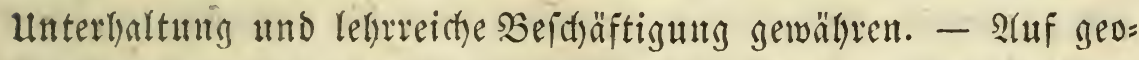

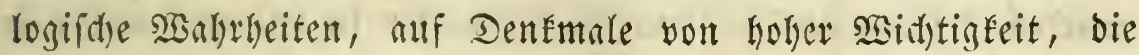

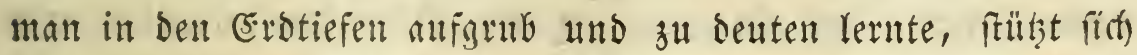
einer ber interellanteften Theile ber Gejothishte, jener, weldyer bie Sehre von ber entmidfelung unjeres Planeten und feiner Bemoh= ner abhandelt. - Ituberiedigend, fdwankend blicben alle Giengo= uien - bie Sehren vou ber serb= Entitehung - éhe man zu einer gemillen 3abl geologifiter Erfabrungen gelangt war. Das Gtu: bium der Gedogie beftärtet ben Menfit)en in feinem Gilauben an heilige Sangrheiten. Das (jomüth wird tief ergriffen werden, es

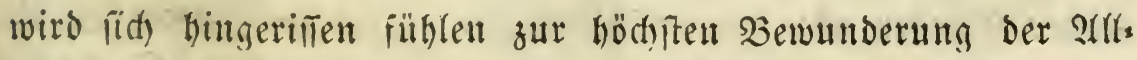
madht von zahlloien Shatinchen, welche zeigen, wie butch bie wobl= 


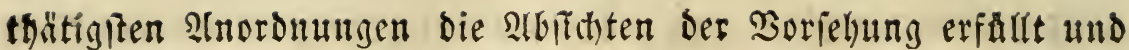

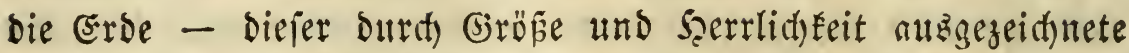
sosuderbau - za einer fïr unz gecigneten Siohnfätte gemad) murbe. Für benende $\mathfrak{I}$ heologen mú bern Reiz baben, mit ber natürlidjen Gefitidite ber Eroe vers

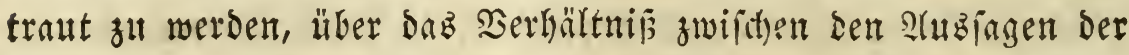

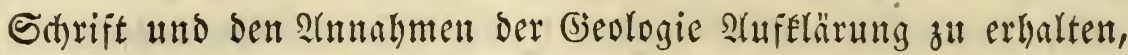

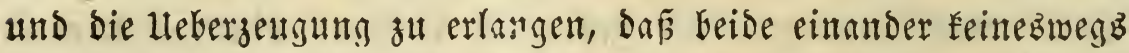
wiberitreiten. Şie viele Sornththeile vermögen Sheologen und S(b) Imänner zu vertilgen, fitto fie nicht ganz unberwandert im Gebiete ber Geologie, wie viele nühtilithe fienntnifie fömnen Durd fie verbreitet merber. - Şiforifer uno હieograylen münen,

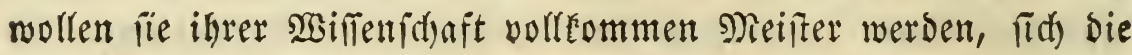
unjerige berieunden; denn mit ber (jefthichte, wie mit ber Gieo= graphie, zumal mit ber reinen (5rb=ßeictreibung, mit ber Dar= ftellumg ber Wlaneten = Dberfläd)e und ibrer Beidaffenleit, ftelst bie Gieologie im engiten, natürlit)iten $\mathfrak{S e r b a n d e . ~ D a z ~ g e a d t ) t e t i ̂ t e ~}$

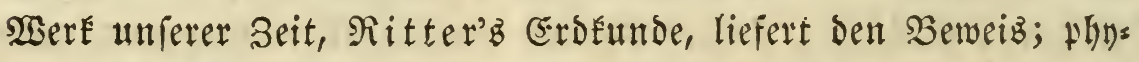

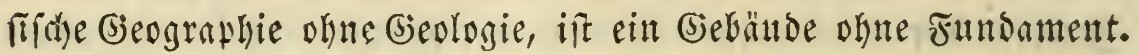

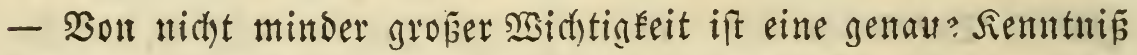

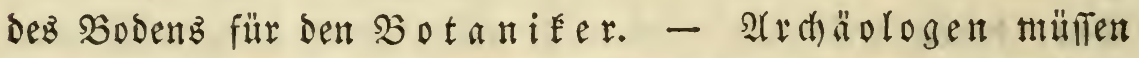
(it) allgemeine Erfabrungen erwerben über sie sagerifẗtten, auz

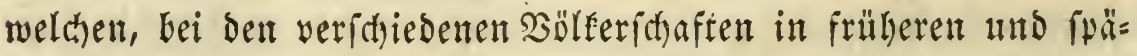
teren Seiten, bas Material zu Funit= Dentmalen entnommen

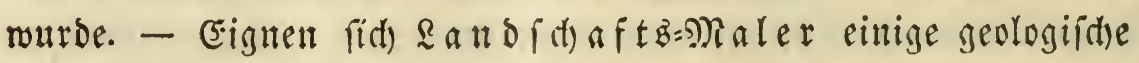
Senntniffe an, fo werben ihre Sfizzen von Felien = \artieen, von ben vielartigen Gieftalten und Umriffen ber Şügel, ber Serge,

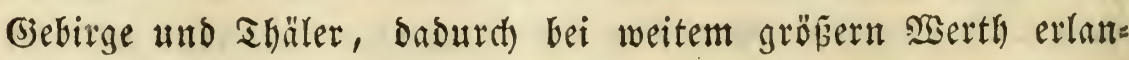
sen, das fie foldhe Erfideinungen, mit allen mannigfaltigen હinzelnheiten, volleommen tren darzuftellen vermögen; benn fei= ner jener ä̈ge ift blopez Spiel bez 3ufallz, er bängt yon whys

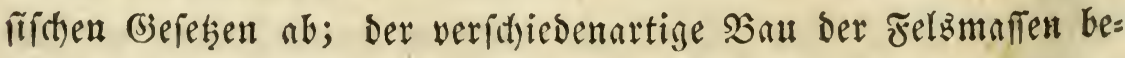

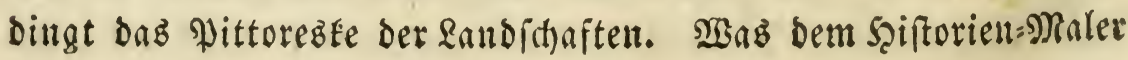


baz Stubium der menidbliden Antutomie, bas ift ith ben kands

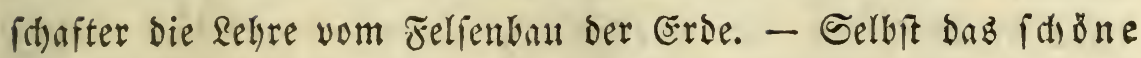

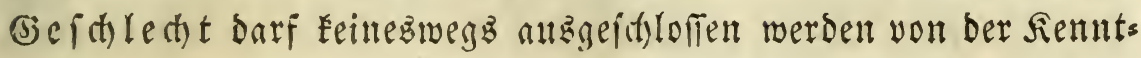

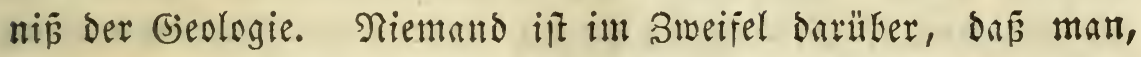
um ber böbern unb forgfältigern stusbiloung willen, fith in ber (jes

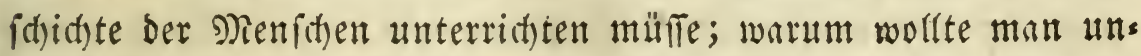

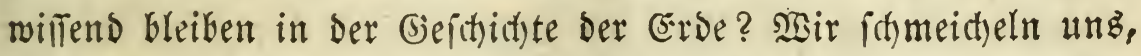

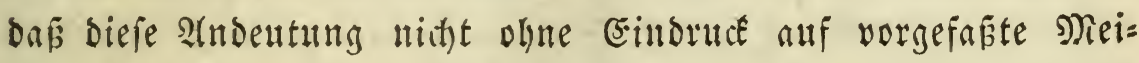
nungen bleiben merbe, wïnithen jebo(t) zugleich, bns man fie niths irrig aแţegen möge.

arber biefes find nicht bie einzigen Ridhtfeiten bes geologiichen

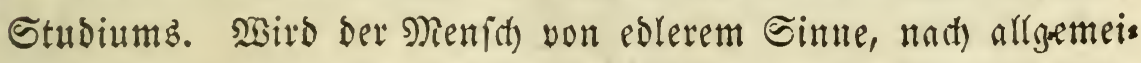
ner Bildung frrebend, fith ergriffen fïhlen ourth Brforftung ber

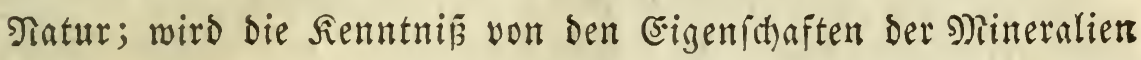
und von ihren Derbältnilien für ben פeritand felgr befriebigend fenn, fo bietet biejelbe zugleith, yon einer anderen Geite, Rittel bar, um bie erlangte esinficht in bem, was man alz pratis

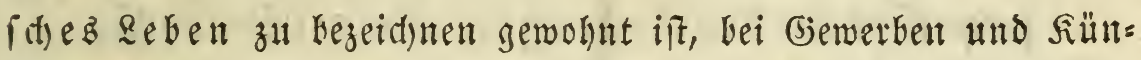

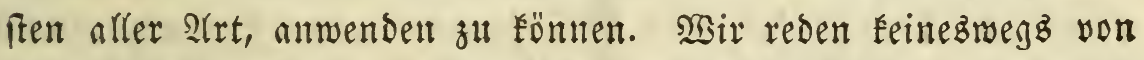
Şergleuten allein, benen geologifthe Fenntuifie unentbelurlich

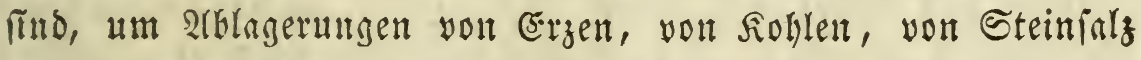
aufaluchen, und mit ihren unterirdifthen Bauen zu veriolgen. Forfteute, \&andwirthe, (5)ätner büren nidyt unerfahen fenn in ber Geologie. Sie mülien bie Sefthaffenheit bes Sodenz fennen, ber yon igmen bepfanzt und bearbeitet wird; biefer So. ben aber, bie Frühth und Bäume tragende (ำbe, geht aus ber allmäligen ummandelung fehr veriftededer Felbarten hervor, fein

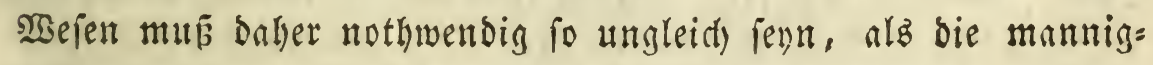
faltigen (jefteine. - Dem wiffenidhaftiden $\mathfrak{A r}_{\mathfrak{r}}$ te, wie bem

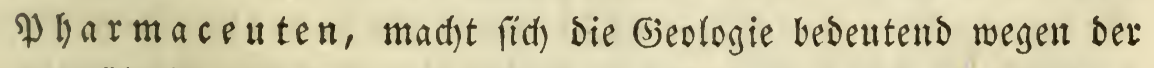
Derbältuife zwiichen Segetation unb Soden nifft nur, fondern vorgüglich audh in mébicinif(t)=topographifher Bezielung. - Dem Sold a ten Darf uniere Sififenibait um bez Ierrain-Studiumb 
willen, nitht iremb ienn. - $\mathfrak{B}$ a umeifter Eönnen nidts belteben

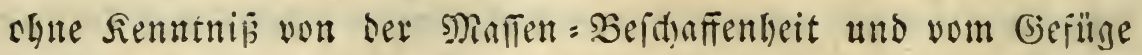

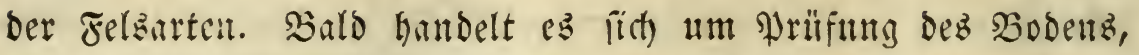
oer beftimmt ift (jebünde zut tragen, anf weld)em Junbamente mit Eifferbeit aufgeïhrt zu werden vermögen; bald ift bie Rede von

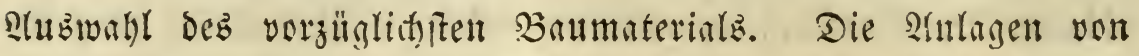

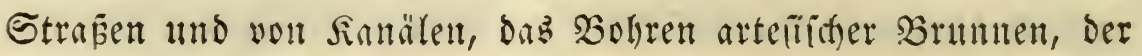
fünitlithen Spring = Duellen, ieşt gewille geologilithe Erwägungen vornas, mälyend bieje in andern Fällen nothwendig find, um grope Shegrabungen zu verantalten, ober um dem Borichreiten

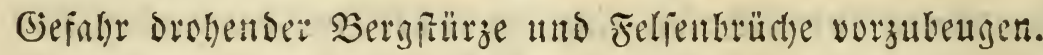

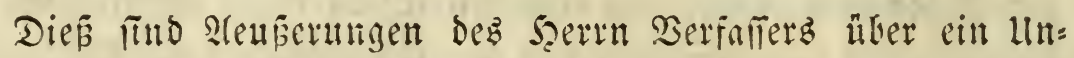
ternelmen, bas vielartige Swede vereinigen, atto einem wabren

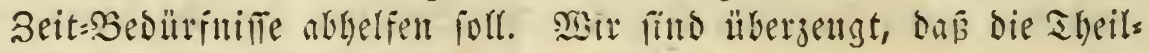

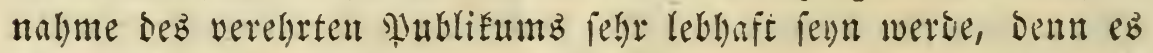
eignen lith) Dieje

\section{populärent sovlejungent ïber Geologie}

für gebildete Refer un seferimen jeden Standeb un

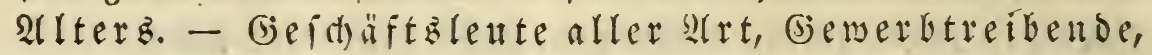
welde ber beologie inte shätigete nitht beionders

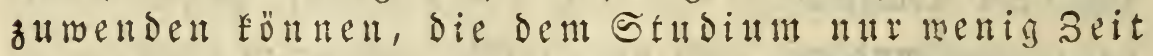
zu wibmen vermïgen, erhalten ermünide (jelegen= beit, fich volfeommen genügend zu unterrititen. Rely= rera un selderinten an böbera, wie an nieberen

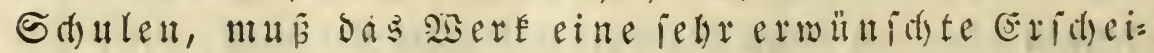
unug feyn. Der Ingend beider bejditedter emplehlen

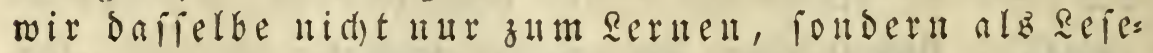

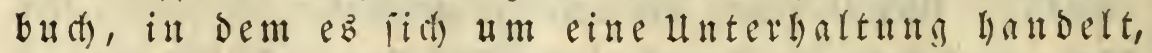

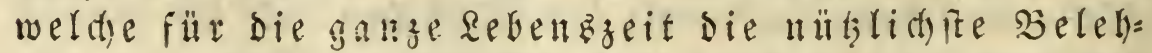
rung gewährt. - - Die yoyuläre Dartellan der (jeologie foll, midt fowohl um bem herrithenden (b)

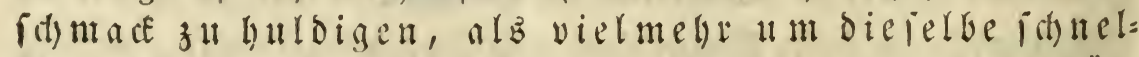
ler und zu möglidit billigem preife lieferm zu fön= men, in 2tbtheilunge zu 6 Sogen ericheinen, wovon in 3 wiftcuräumen vou 2 bis 5 Romaten eite a

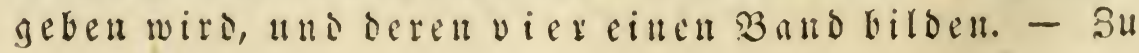




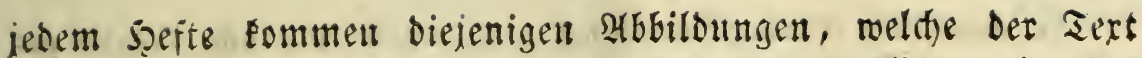
notbwendig mad)t. So erbält baz verehrliche \$ablifum eine Sus gabe von ganz eigenthümlichem Snterelle; Denn ber Serr Derfajs fer, ber feit mehreren Jahrzehenden, zum Seguf feiner geologi. fiten Sorträge, einen Sltlaz zuiammenitellte, wäblte anz diejer

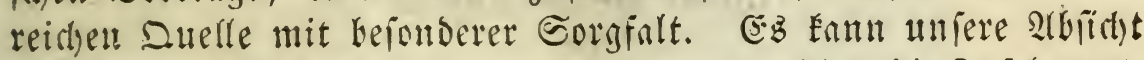

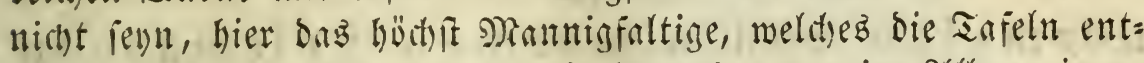
balten werben, aujuzeidyen, wir bemerken mur im arlgemeinen,

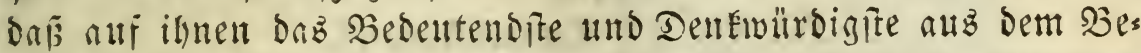
reidse ber Geologie bilslid bargeftellt werden foll: Struftur=2ers

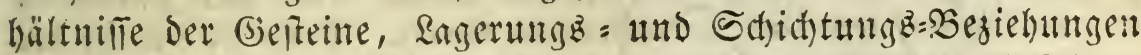

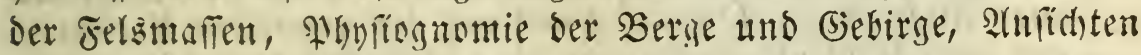
einzeluer, bejonderz wid)tiger Berge und Bebirgb = \$artieen, Ihăs ler, Felienthore, Grotten, verifeinerte organifite lleberreite, Cies

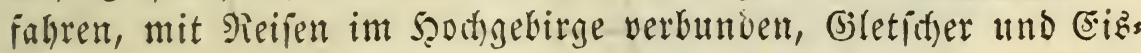
meere, Seen, Errflagerfintten, Phänomene der Ströme, bes ग)iess

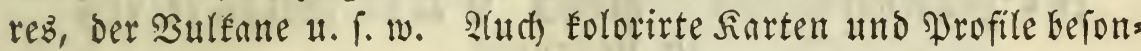
bers widttiger Gebirge und einzelner sanditriche follen bas begleiten. - Den Dreiz jür eine arbtheilung haben wir ali

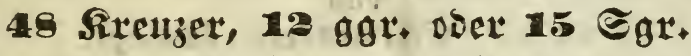

feitgeiest. Bon Jormat, \$lapier und Schrift bienen als \$robe bie 1te

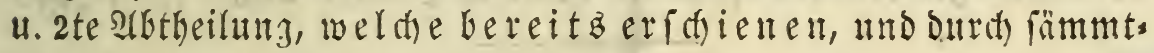

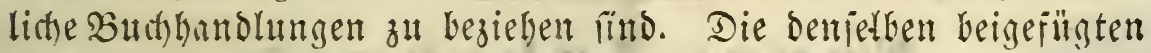
Stahlitiche, aus bem Bergman

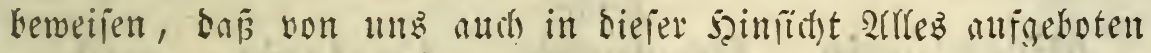
worben. Lm bie 2(mithafturg ju erleithtern, fo wie um bie gröbts

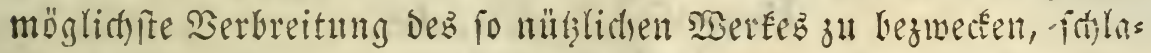
gen wir den sieg ber Subicript iou eill, weldte mit Errityeis

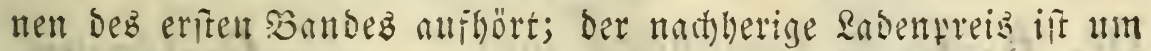
ein Drittheit Göber.

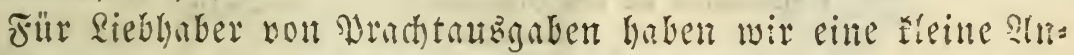

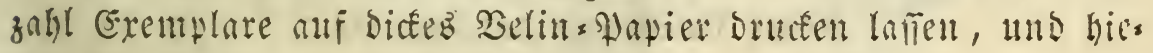
von den glecis auf fl. 1.12 kr. doer 18 ggr. fefrgefezt.

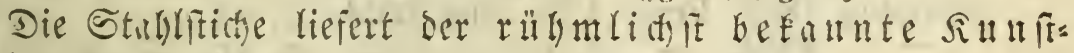

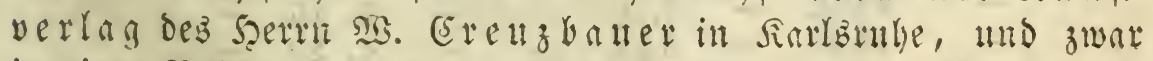

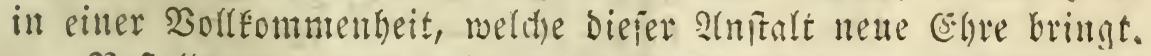
Beftellungen werden in allen 2 udb)holungen Deutidyland uno der Gitweiz nugenommen.

Stutgart.im Suli 1856.

(5. Echwcizcrbart's Berlagibandlung. 
In derselben Verlagshandlung sind auch folgende Werke crschienen und durch jede gute Buchhandlung zu beziehen :

\section{DIE BASACT-GEIBIIDE in \\ ihren Beziehungen \\ zu}

normalen und abnormen Felsmassen von

\section{Ir. C. v. Teomhard.}

2 Theile. gr. 8. Velinpapier. Nebst einem Atlas mit Ansichten und kolorirten Durchschnitten in Quart. Preis fl. 14. $24 \mathrm{kr}$. oder Rthlr. 9. - Für die Abnehmer der populären Vorlesungen iiber Geologie lassen wir bis 1. Juli den ersten Subscriptionspreis von fl. 10. $48 \mathrm{kr}$. oder RthIr. 6. 18 ggr. nochmals eintreteu.

\section{Neptunismus und Vulkanismus} in Beziehung auf v. Le o n hard's Basa!t-Gebilde Prof. Dr. Christian rapp.

14 Bogen gr. 8. Velinpapier. Preis fl. 2. oder Rhlr. 1. $6 \mathrm{ggr}$.

\section{Neues Jaln rouch}

\section{für}

Mineralogie, Geognosie, Geologie, und Petrefaktenkunde,

herausgegeben

Dr. K. C. v. Leonhard und Dr. H. G. Bromn, Professoren an der Universität zu Heidelberg.

Nebst Tafeln mit Abbildungen.

Jahrgang 1833. Preis fl. 6. oder Rthlr. 3. 16 ggr.
- 1834. -
fl. 6 .
3. $16-$
- 1836. -
fl. 8 . - -
4. $20-$
fl. $8 .=-$
4. 20 -

Jeder Jahrgang ist 48 Bogen stark in gr. 8. auf Velinpapier. 


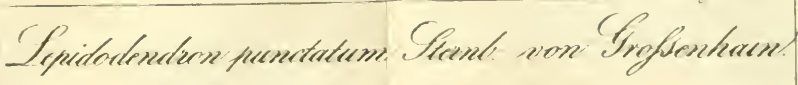
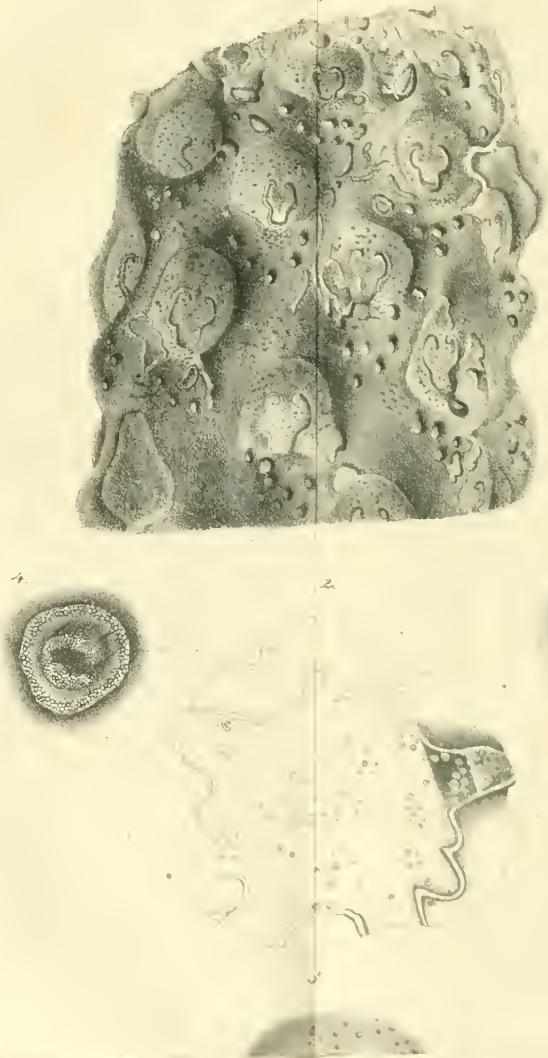


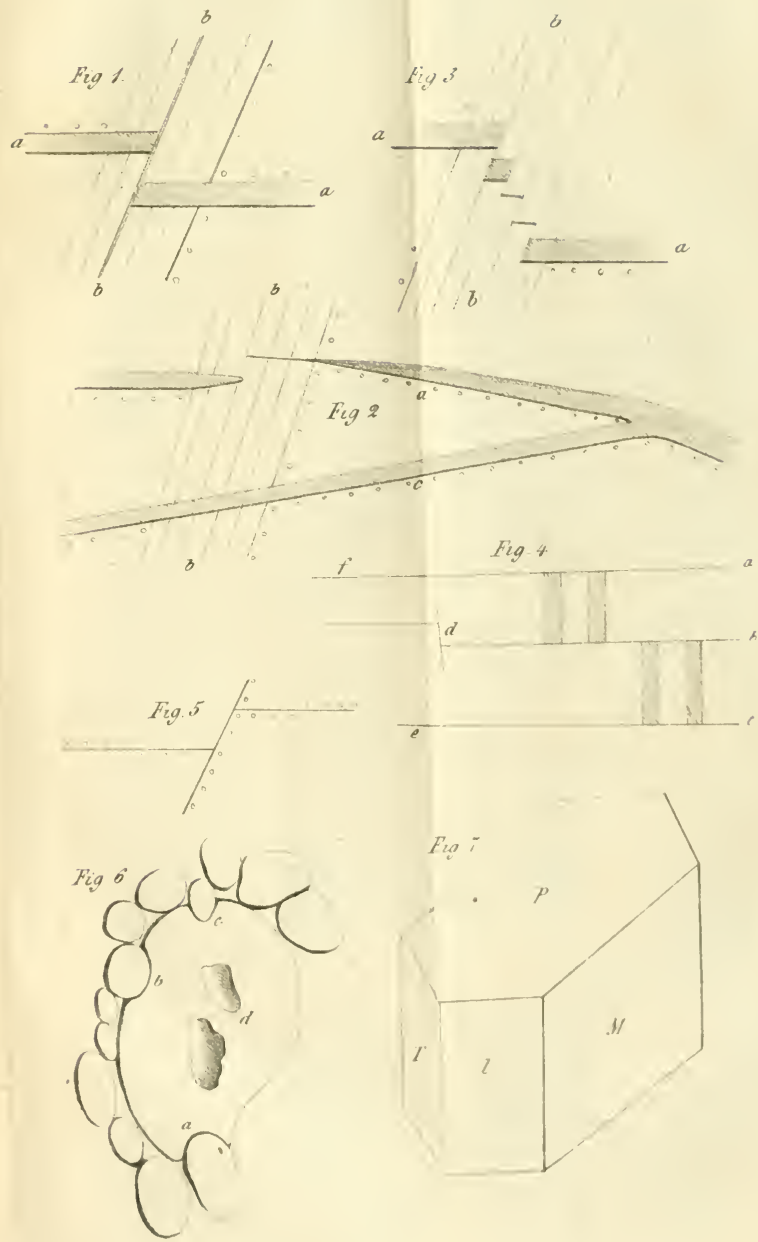


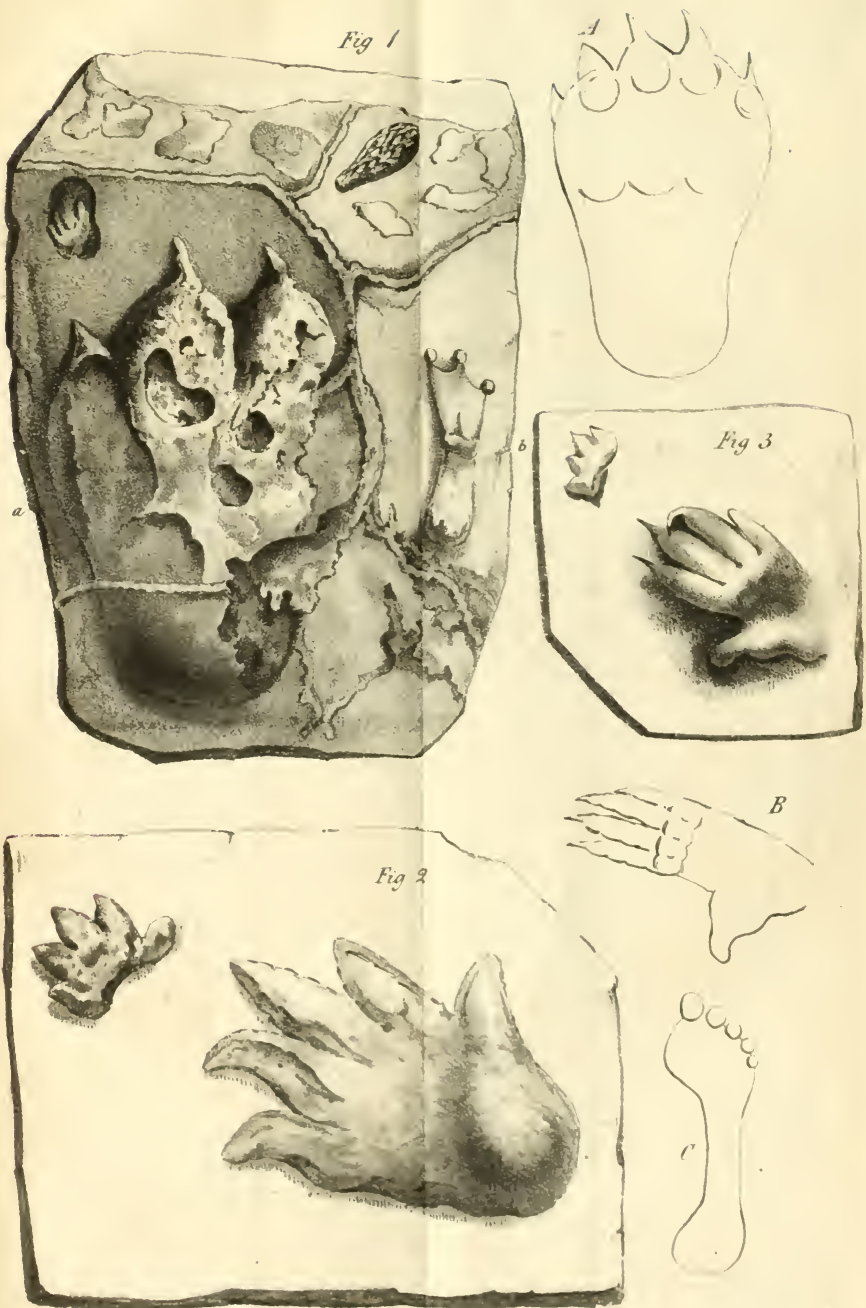
$1+2=0$ .

78

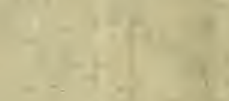

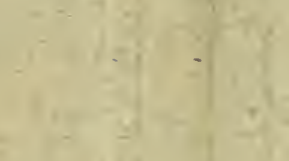

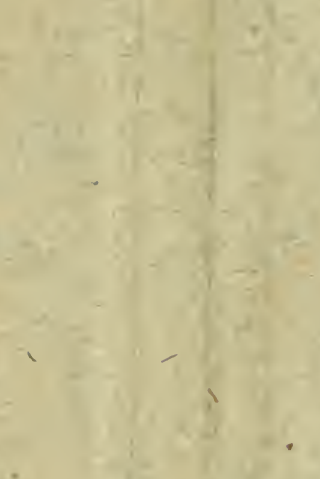

$\frac{15}{5}+\left.\right|^{2}+15=$

$x^{3}-1,4$

$x+\frac{5}{2}+4$

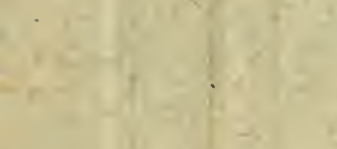

4

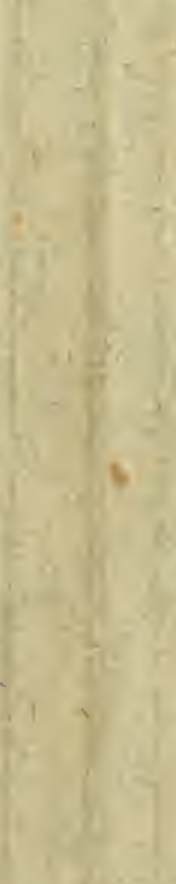




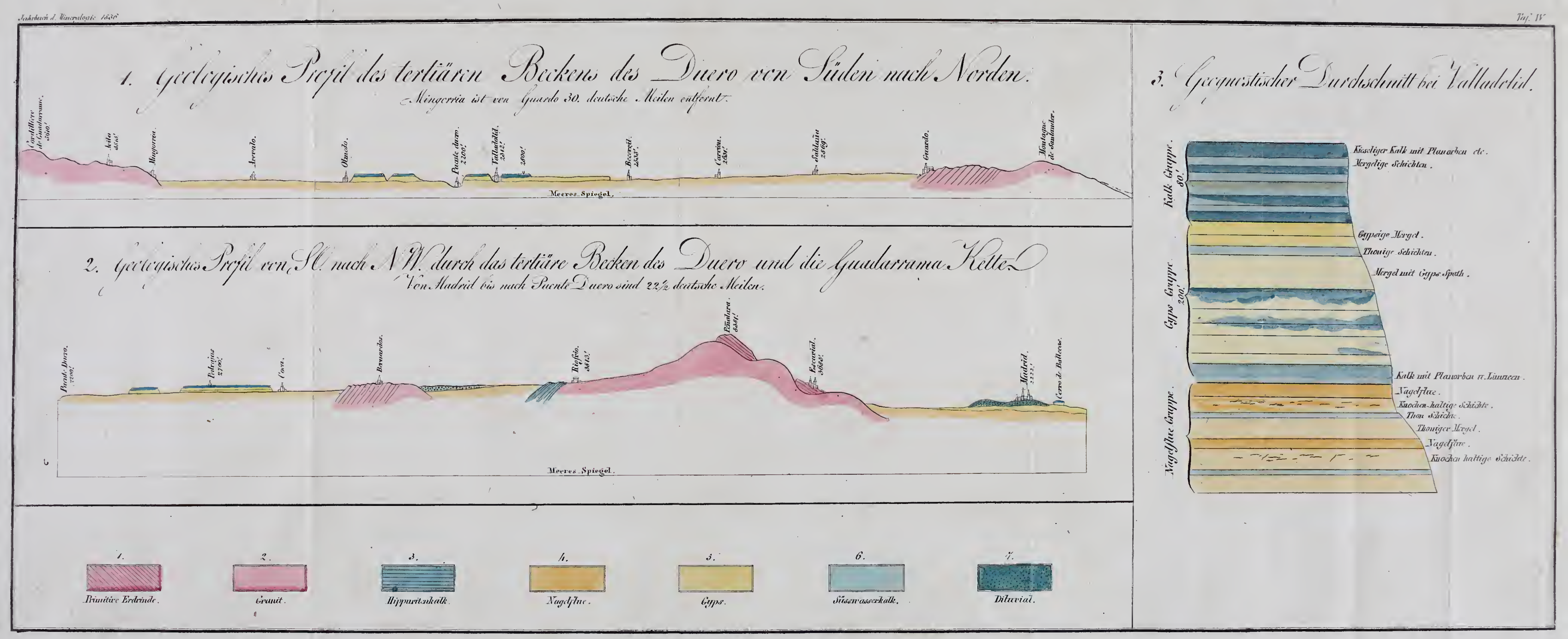




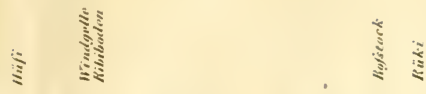

$\frac{5}{3}$

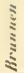
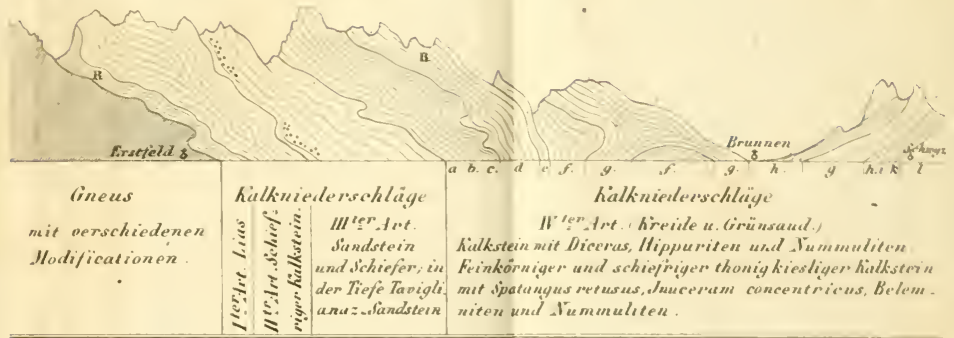

\section{halkniesleseschlinge}

II'per. Art, hirevile u. (irrünsaud.)

Kialkstein mit Dicerus, Ilippuriten urd. Tummuliken

Feinkörniger und schiejiriger thonig kiesliquer hilksterin

mit ipatungus retusus, douceram concentricus, Belesu miten und liumunuliten.
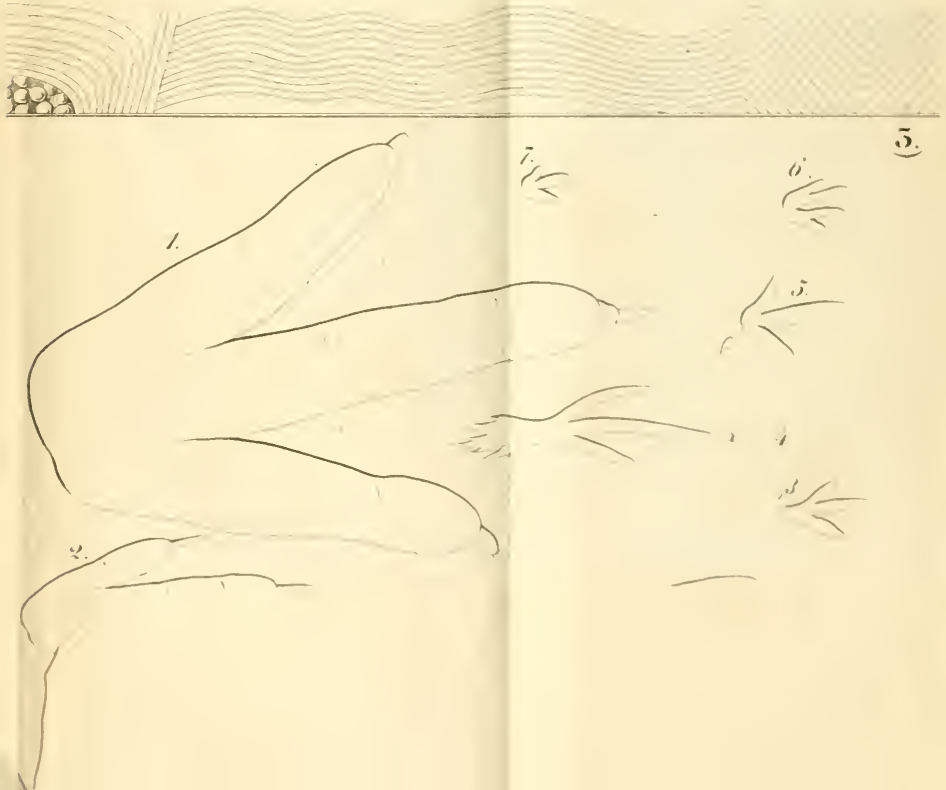



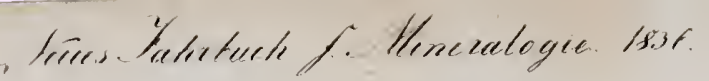

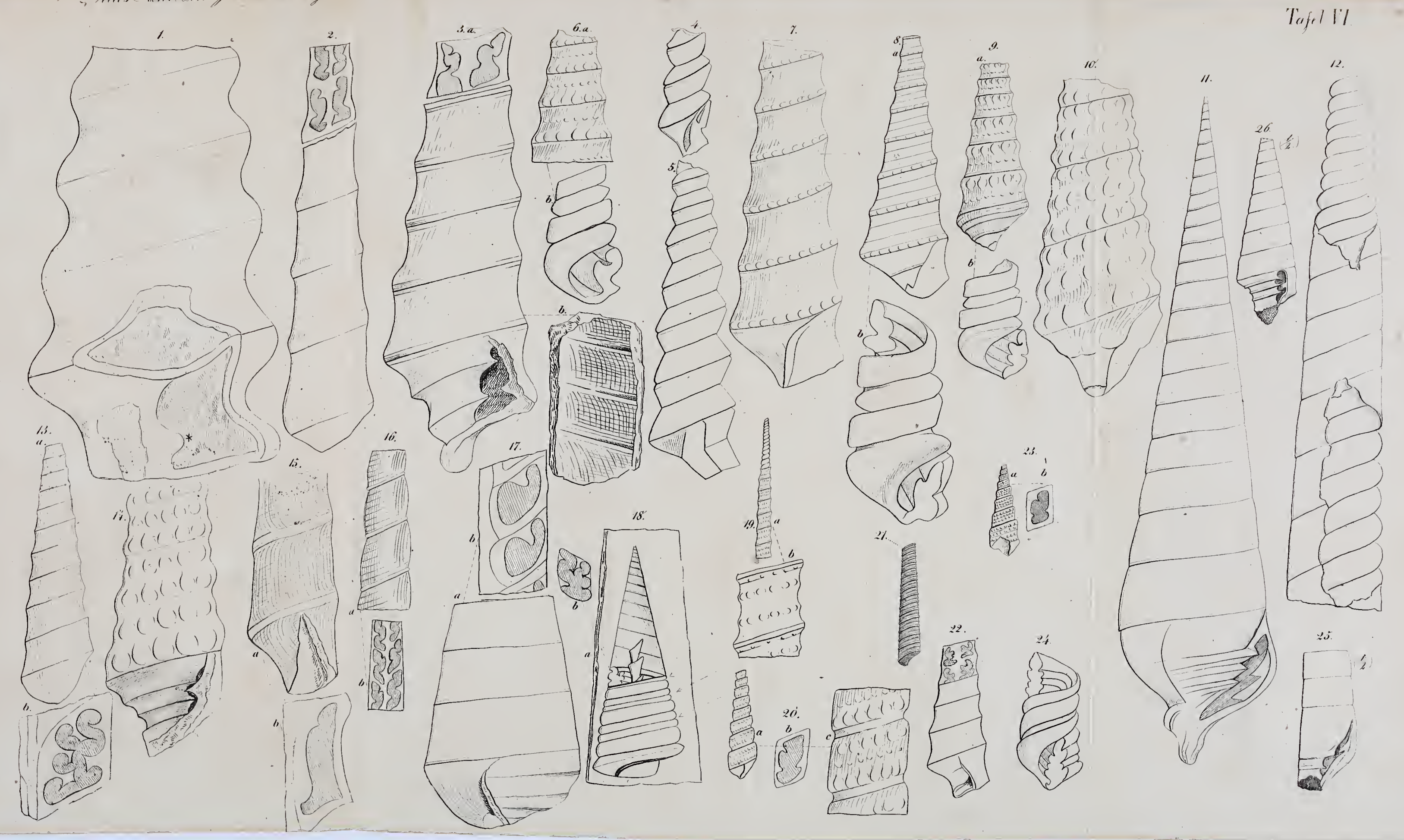



Veues Juhrbuch f. Hineral: 1836:

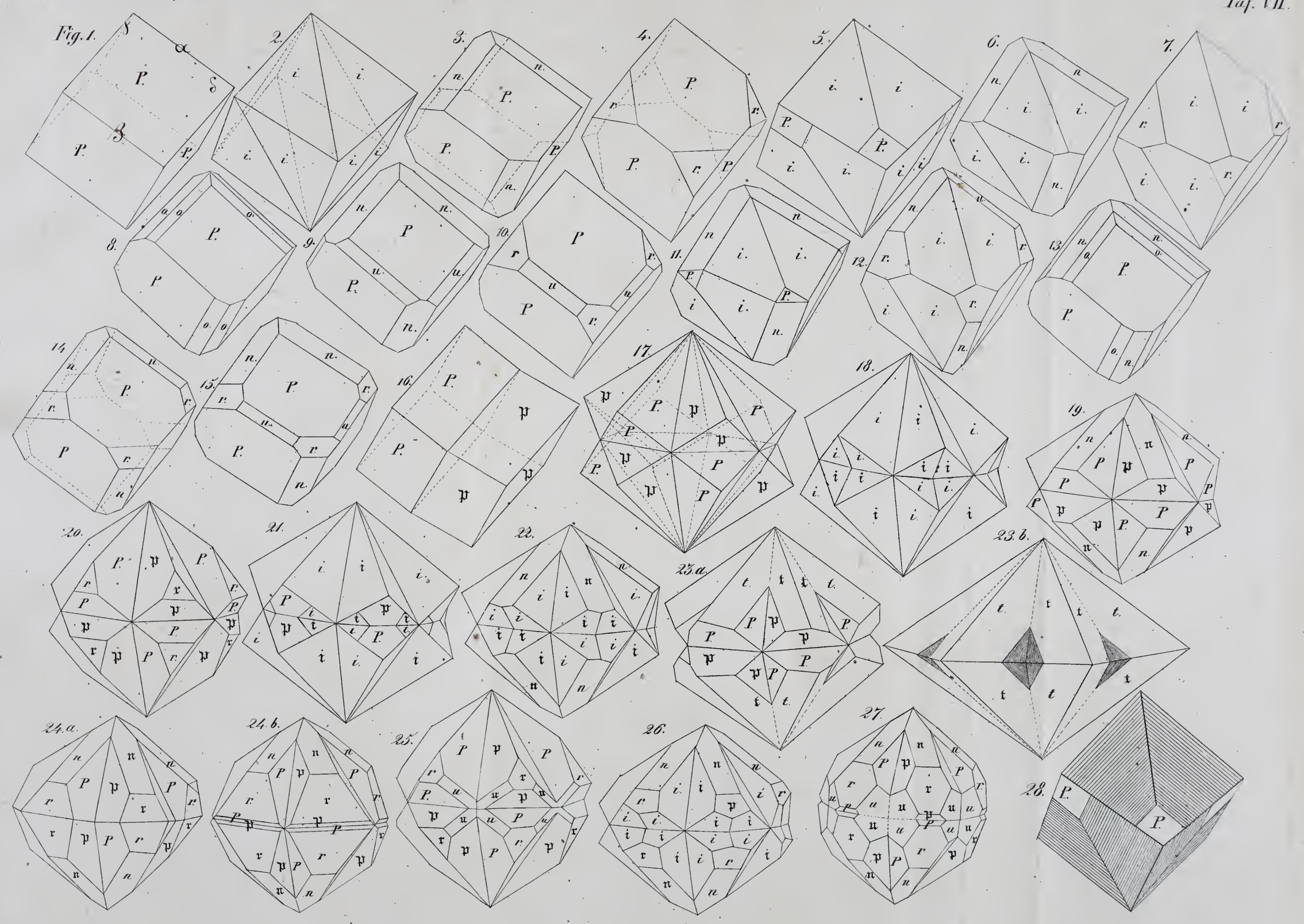




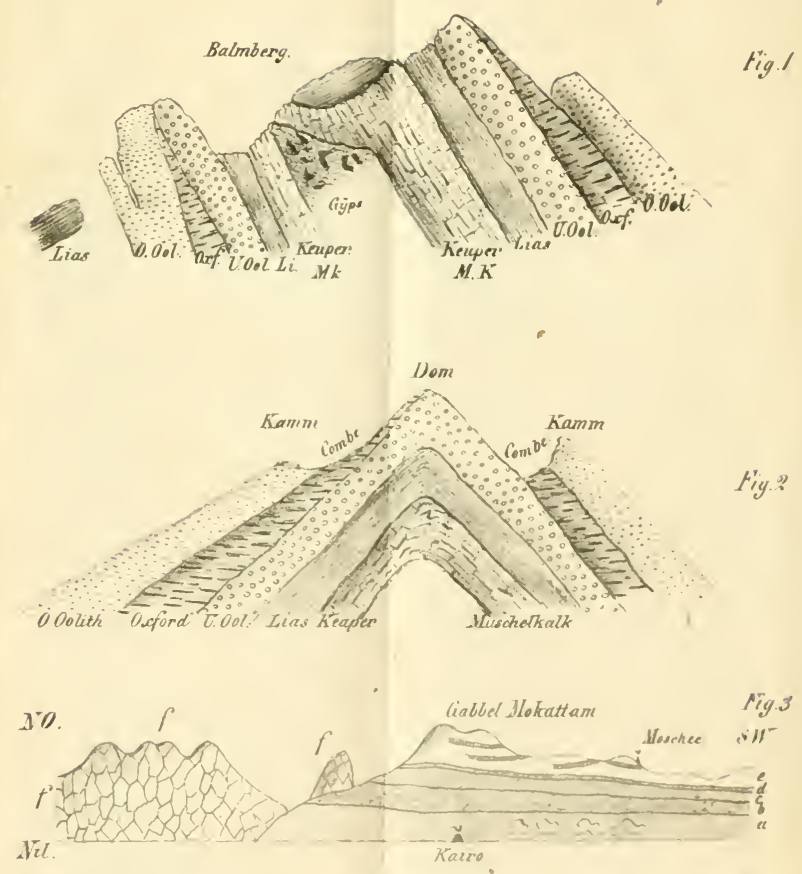

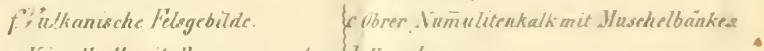
e. Kuiselkalkmit Braurcesenstein b. Kireede 1. Sandigen Thon
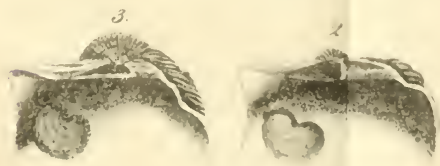

Fig. l. 




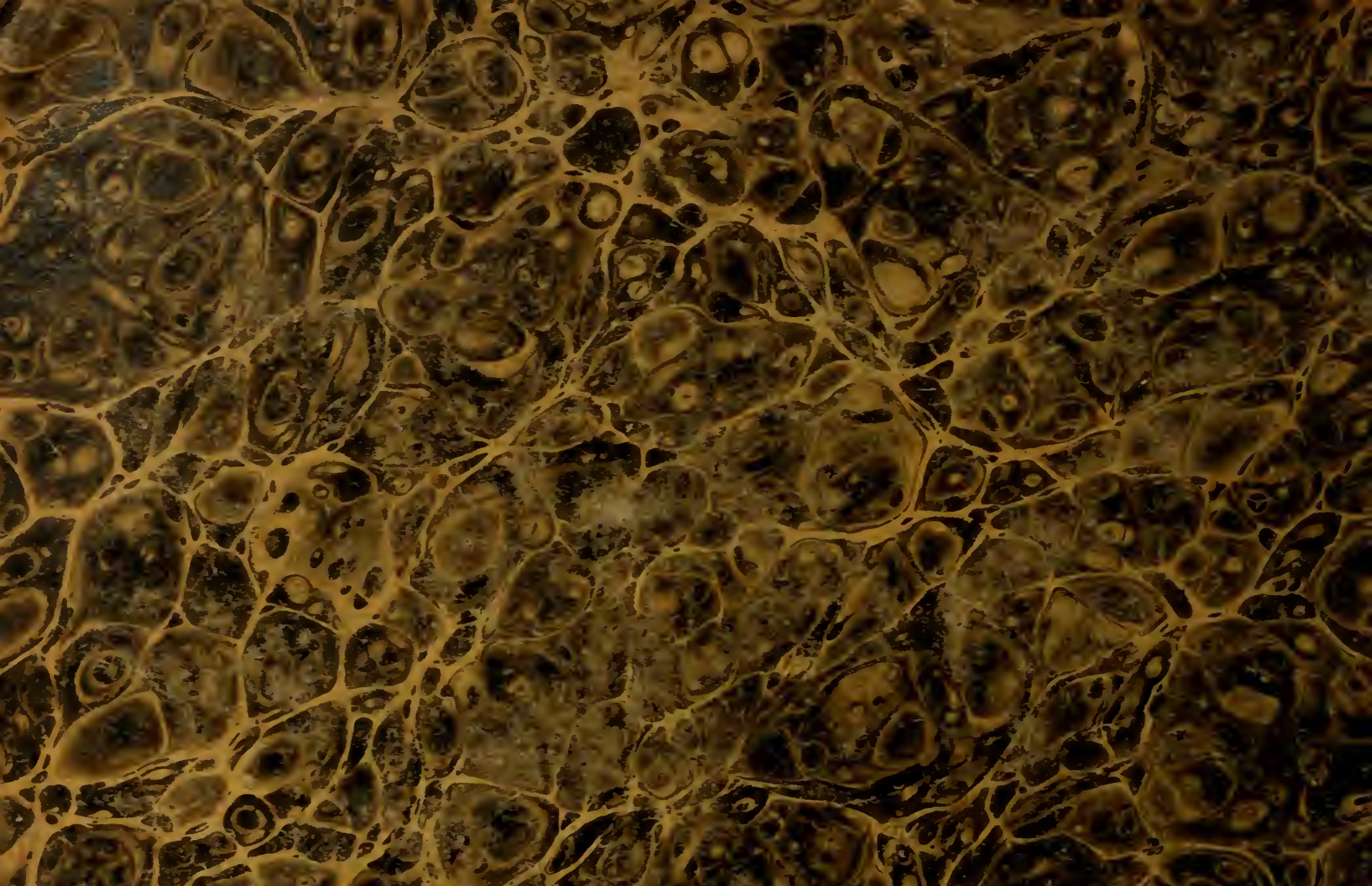

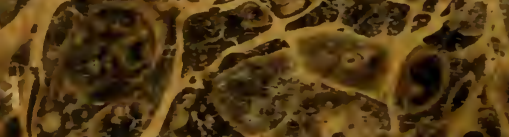

1. 1202

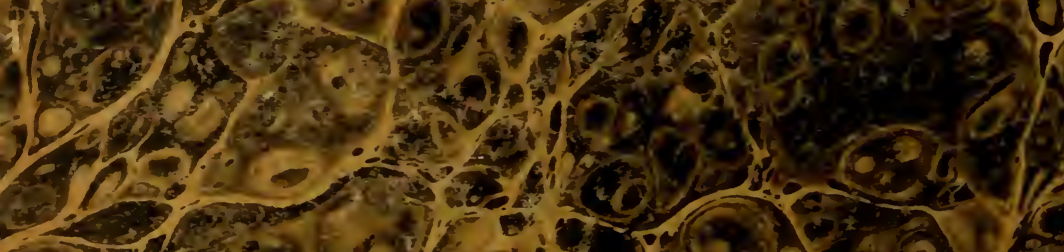

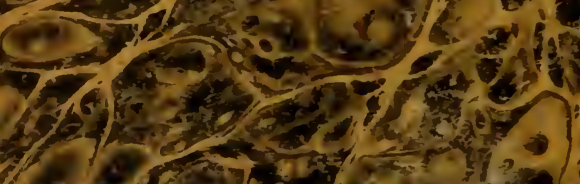

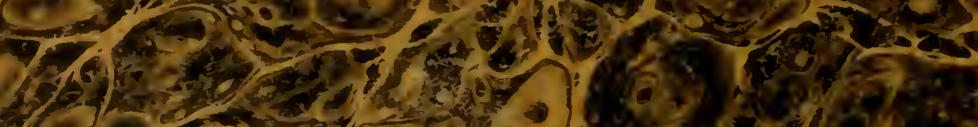

(3)

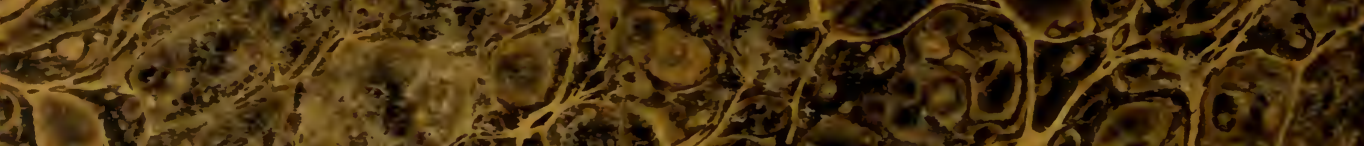

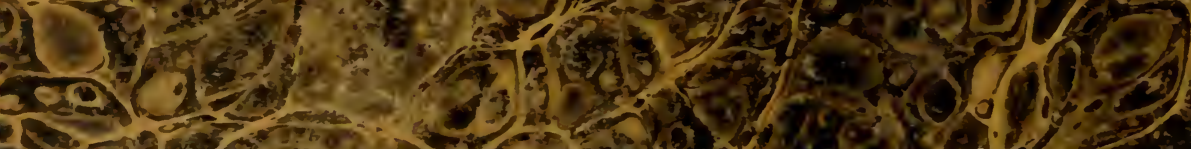

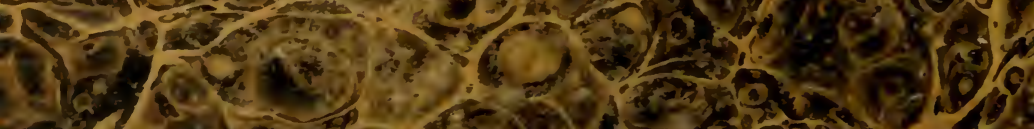

(3)

10
1

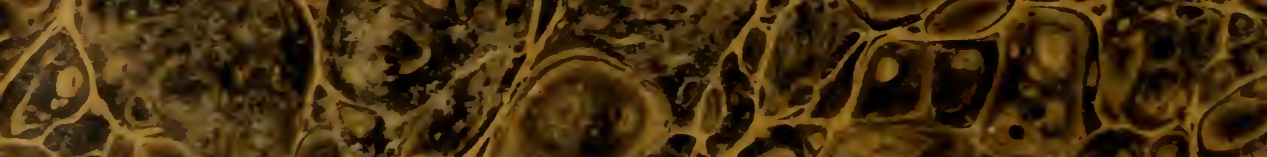

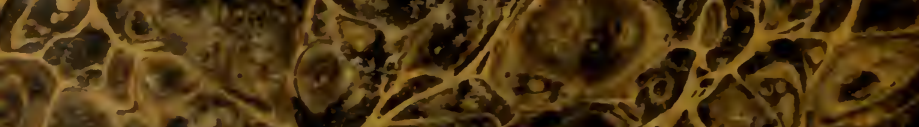

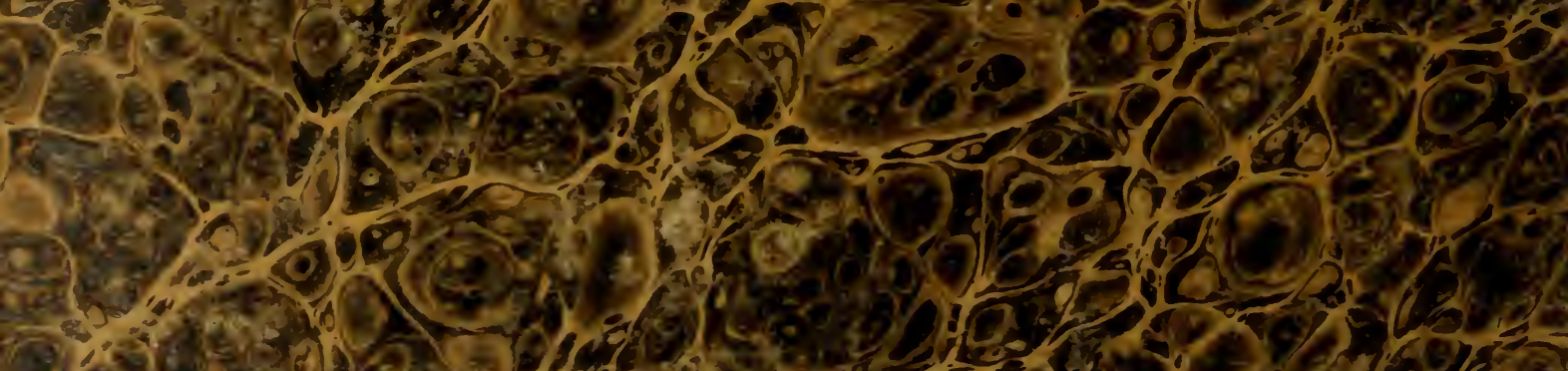

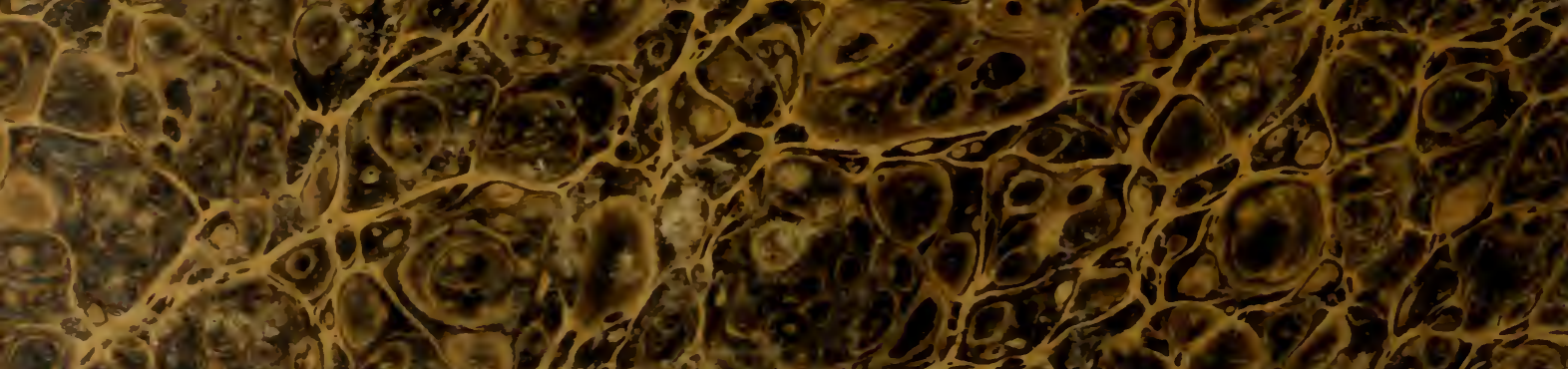

3.10 (6) 